
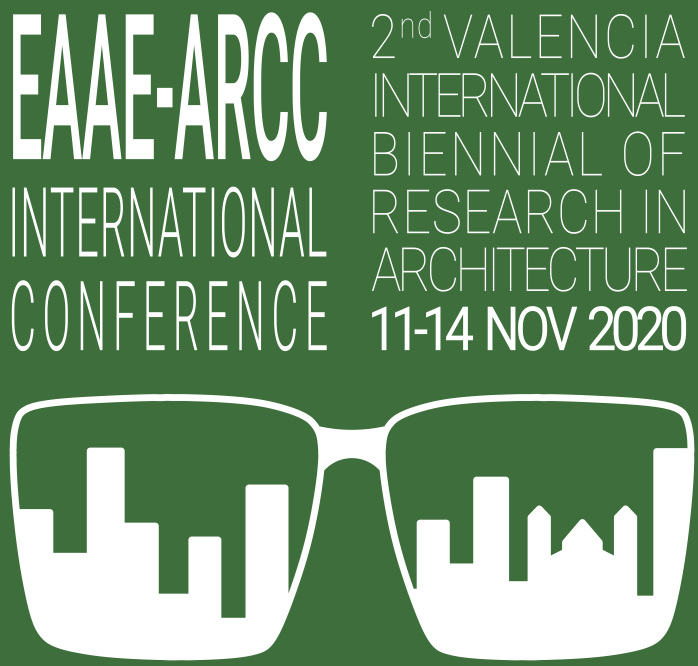

THE ARCHITECT AND THE CITY

VOLUME 1 


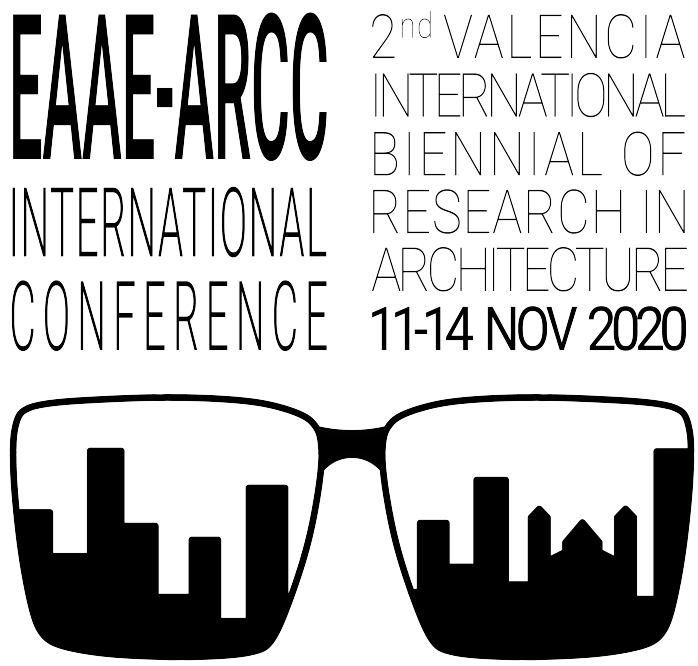

THE ARCHITECT AND THE CITY

VOLUME 1 


\section{Publisher:}

Editorial Universitat Politècnica de València, 2020 http://www.lalibreria.upv.es ISBN 978-84-9048-842-3 (Set of two volumes)

978-84-9048-981-9 (Volume 1) 978-84-9048-982-6 (Volume 2)

DL: V-748-2021

DOl: https://doi.org/10.4995/EAAE-ARCC-IC.2020.13831

Ref. 6568_01_01_01

\section{All rights reserved:}

(c) of the images, their authors

(C) of the drawings, their authors

(c) of the texts, their authors

(c) of this edition

\section{Editorial Committee:}

Ivan Cabrera i Fausto

Ernesto Fenollosa Forner

Ángeles Mas Tomás

José Manuel Barrera Puigdollers

Lluís Bosch Roig

José Luis Higón Calvet

Alicia Llorca Ponce

María Teresa Palomares Figueres

Ana Portalés Mañanós

Juan María Songel González

\section{Coordination and design:}

Júlia Martínez Villaronga

Mariví Monfort Marí

Maria Piqueras Blasco

Diego Sanz Almela

\section{(C)()}

EAAE-ARCC International Conference \& 2nd VIBRArch: The architect and the city. / Editorial Universitat Politècnica de València

Se permite la reutilización de los contenidos mediante la copia, distribución, exhibición y representación de la obra, así como la generación de obras derivadas siempre que se reconozca la autoría y se cite con la información bibliográfica completa. No se permite el uso comercial y las obras derivadas deberán distribuirse con la misma licencia que regula la obra original. 
Conference Chair:

Ivan Cabrera i Fausto

\section{Steering Committee:}

Oya Atalay Franck

Hazem Rashed-Ali

Ilaria Valente

Ivan Cabrera i Fausto

\section{Organizing Committee:}

Ernesto Fenollosa Forner

Ángeles Mas Tomás

José Manuel Barrera Puigdollers

Lluís Bosch Roig

José Luis Higón Calvet

Alicia Llorca Ponce

Maite Palomares Figueres

Ana Portalés Mañanós

Juan María Songel González

Ma Mercedes Cerdá Mengod

Design and Logistics:

Mariví Monfort Marí

Marcos Lizondo Chardí

Maria Piqueras Blasco 
Scientific Committee:

\section{Doreen Adengo}

Adengo Architecture, Kampala

Fernando Agrasar Quiroga

Universidade da Coruña

Naime Esra Akin

Beykent University

Ajla Aksamija

University of Massachusetts Amherst

Ahmed K. Ali

Texas A\&M University

Ana Almerich Chuliá

Universitat Politècnica de València

Miguel Alonso del Val

Universidad de Navarra

Adolfo Alonso Durá

Universitat Politècnica de València

Eva Álvarez Isidro

Universitat Politècnica de València

Cecilie Andersson

Bergen School of Architecture

Isabelle Anguelovski

Universitat Autònoma de Barcelona

Craig K. Anz

Southern Illinois University

César Aquino Insfrán

Universidad Autónoma de Encarnación

\section{Eugenio Arbizzani}

Sapienza Università di Roma

Maziar Asefi

Ryerson University
Izaskun Aseguinolaza Braga

Euskal Herriko Unibertsitatea

Oya Atalay Franck

Zurich University of Applied Sciences and Arts

Pnina Avidar

Fontys Hogescholen Tilburg

Rahman Azari

Illinois Institute of Technology

Marilda Azulay Tapiero

Universitat Politècnica de València

Ángela Baldellou Plaza

Observatorio del CSCAE

Berta Bardí i Milà

Universitat Politècnica de Catalunya

César Bargues Ballester

The Getty Conservation Institute

Michela Barosio

Politecnico di Torino

José Manuel Barrera Puigdollers

Universitat Politècnica de València

Luisa Basset Salom

Universitat Politècnica de València

Genevieve Baudoin

Kansas State University

Liliana O. Beltrán

Texas A\&M University

Julio Bermúdez

The Catholic University of America

Henriette Bier

Technische Universiteit Delft

Manuel Blanco Lage

Universidad Politécnica de Madrid 
María del Carmen Blasco Sánchez

Universitat Politècnica de València

Ana Bonet Miró

The University of Edinburgh

Victoria E. Bonet Solves

Universitat Politècnica de València

Mary Ben Bonham

Miami University

Lluís Bosch Roig

Universitat Politècnica de València

Dag Boutsen

KU Leuven

Anne Mette Boye

Arkitektskolen Aarhus

Ewan Branda

Woodbury University

Danelle Briscoe

The University of Texas at Austin

Óscar Brito González

University of the Arts London

Sigita Bugeniené

Kaunas City Municipal Administration

Ivan Cabrera i Fausto

Universitat Politècnica de València

Romina Canna

IE University

Roberto Vicente Cañete Ferreira

Universidad Autónoma de Encarnación

Miguel Ángel Carrión Carmona

Universitat Politècnica de València

María Emilia Casar Furió

Universitat Politècnica de València
Pepa Cassinello

Universidad Politécnica de Madrid

Nuria Castilla Cabanes

Universitat Politècnica de València

Roberto Cavallo

Technische Universiteit Delft

M. Rosa Cervera Sardá

Universidad de Alcalá

Pilar Chías Navarro

Universidad de Alcalá

Carola Clemente

Sapienza Università di Roma

Helena Coch Roura

Universitat Politècnica de Catalunya

Beatriz Colomina

Princeton University

Edoarda Corradi Dell'Acqua

Illinois Institute of Technology

Manuel Couceiro da Costa

Universidade de Lisboa

Catherine Croft

Twentieth Century Society

Nur Çaglar

TOBB University of Economics and

Technology at Ankara

Ana-Maria Dabija

Universitatea de Arhitectura si Urbanism

"Ion Mincu"

Pau de Solà-Morales Serra

Universitat Rovira i Virgili

Johan de Walsche

Universiteit Antwerpen 
Lynne Marie Dearborn

University of Illinois at Urbana-Champaign

Adalberto Del Bo

Politecnico di Milano

Matt Demers

Barker/Nestor Architects

Miguel Ángel Díaz Camacho

Universidad Camilo José Cela

Carmen Díez Medina

Universidad de Zaragoza

Victoria Domínguez Ruiz

Universidad de Sevilla

Neslihan Dostoğlu

İstanbul Kültür University

Laurent Duport

Ecole Nationale Supérieure d'Architecture de Montpellier

Ihab Elzeyadi

University of Oregon

Inmaculada Esteban Maluenda

Universidad Complutense de Madrid

Maria Faraone

Oxford Brookes University

Emilio Faroldi

Politecnico di Milano

Ernesto Fenollosa Forner

Universitat Politècnica de València

Laura Fernández Durán

Universidad CEU Cardenal Herrera

\section{J. Kent Fitzsimons}

Ecole Nationale Supérieure d'Architecture et de

Paysage de Bordeaux
Teresa Fonseca

Universidade do Porto

Giovanna Franco

Università degli studi di Genova

Jordi Franquesa Sánchez

Universitat Politècnica de Catalunya

Mercedes Galiana Agulló

Universidad Católica de Murcia

Inés García Clariana

Universidad Europea de Valencia

Ángela García Codoñer

Universitat Politècnica de València

Ángela García de Paredes

Universidad Politécnica de Madrid

Daniel García-Escudero

Universitat Politècnica de Catalunya

Carolina B. García-Estévez

Universitat Politècnica de Catalunya

Lidia García Soriano

Universitat Politècnica de València

Queralt Garriga Gimeno

Universitat Politècnica de Catalunya

Mariona Genís Vinyals

BAU, Centre Universitari de Disseny de

Barcelona

Saul Golden

Ulster University

Carlos Gómez Alfonso

Universitat Politècnica de València

Enkarni Gómez Genua

Euskal Herriko Unibertsitatea

M. Esther Gómez-Martín

Universitat Politècnica de València 
Walter Grondzik

Ball State University

Arianna Guardiola Víllora

Universitat Politècnica de València

Ignacio Guillén Guillamón

Universitat Politècnica de València

Elsa Gutiérrez Labory

Universidad de Las Palmas de Gran Canaria

Mary Guzowski

University of Minnesota

Bruce Haglund

University of Idaho

J. Brooke Harrington

Temple University

Harriet Harriss

Pratt Institute

Richard Lee Hayes

Central Michigan University

Deirdre L.C. Hennebury

University of Michigan

José Luis Higón Calvet

Universitat Politècnica de València

Dalibor Hlaváček

Czech Technical University in Prague

Roberta Ingaramo

Politecnico di Torino

Susana Iñarra Abad

Universitat Politècnica de València

Edurne Izagirre Elizaran

Universidad Autónoma de Encarnación

Eva Jiménez Gómez

Universitat Politècnica de Catalunya
Carmen Jordá Such

Universitat Politècnica de València

Ignacio Juan Ferruses

Universidad CEU Cardenal Herrera

Francisco Juan Vidal

Universitat Politècnica de València

Susanne Komossa

Technische Universiteit Delft

Robert J. Krawczyk

Illinois Institute of Technology

Pablo La Roche

California Polytechnic State University Pomona

Vincenzina La Spina

Universidad Politécnica de Cartagena

Carlos Lameiro

Universidade de Lisboa

Susana Landrove

Fundación DOCOMOMO Ibérico

Riva Lava

National Technical University Athens

Laura Lizondo Sevilla

Universitat Politècnica de València

Blanca Lleó Fernández

Universidad Politécnica de Madrid

Jaime Llinares Millán

Universitat Politècnica de València

Maria Carmen Llinares Millán

Universitat Politècnica de València

Verónica Llopis Pulido

Universitat Politècnica de València

Alicia Llorca Ponce

Universitat Politècnica de València 
Angela Lombardi

The University of Texas at San Antonio

Emma López Bahut

Universidade da Coruña

Concha López González

Universitat Politècnica de València

Mar Loren Méndez

Universidad de Sevilla

Antonio Maciá Mateu

Universitat d'Alacant

Khaled Mansy

Oklahoma State University

Polyxeni Mantzou

Democritus University of Thrace

Frederick Marks

Salk Institute for Biological Studies

Kat Martindale

Architecture + Urbanism Research Office

Arturo Martínez Boquera

Universitat Politècnica de València

Raquel Martínez Gutiérrez

Universidad Rey Juan Carlos

Antonio Martinez-Molina

University of Texas at San Antonio

Roser Martínez Ramos e Iruela

Universidad de Granada

Ángeles Mas Tomás

Universitat Politècnica de València

Marta Masdéu Bernat

Universitat de Girona

Nuria Matarredona Desantes

Conselleria d'Habitatge i Arquitectura

Bioclimàtica
Thomas McQuillan

Arkitektur- og designhøgskolen i Oslo

Laura Liliana Medina Valenzuela

Universidad Autónoma de Encarnación

Clara Mejía Vallejo

Universitat Politècnica de València

Camilla Mileto

Universitat Politècnica de València

José Luis Miralles i García

Universitat Politècnica de València

Valerian Miranda

Texas A\&M University

Alex Mitxelena Etxeberria

Euskal Herriko Unibertsitatea

Eugenia Moliner

Roosevelt University

Javier Monclús Fraga

Universidad de Zaragoza

Francisco Javier Montero Fernández

Universidad de Sevilla

Jésica Moreno Puchalt

Universitat Politècnica de València

Sofia Morgado

Universidade de Lisboa

Michel Mounayar

Ball State University

Brook Muller

University of Oregon

Daniela Müller-Eie

Universitetet i Stavanger

Stefano Musso

Università degli studi di Genova 
Zaida Muxi

Universitat Politècnica de Catalunya

Marc Neveu

Arizona State University

Rashida Ng

Temple University

Lucyna Nyka

Gdańsk University of Technology

Derya Oktay

Ondokuz Mayıs University

Leticia Ortega Madrigal

Institut Valencià de l'Edificació

Dolores Otero Chans

Universidade da Coruña

María Teresa Palomares Figueres

Universitat Politècnica de València

Cristina Pardo García

Universitat de València

Ulrike Passe

lowa State University

Luz Paz Agras

Universidade da Coruña

José Manuel Pelegrín Santacruz

Universidad Central del Ecuador

Víctor Pérez Escolano

Universidad de Sevilla

Javier Pérez Igualada

Universitat Politècnica de València

Marta Pérez Rodríguez

Universitat Politècnica de València

Alfred Peris Manguillot

Universitat Politècnica de València
Troy Peters

Wentworth Institute of Technology

Marios C. Phocas

University of Cyprus

Àngel Pitarch Roig

Universitat Jaume I

Philip Plowright

Lawrence Technological University

Ute Poerschke

The Pennsylvania State University

Çiğdem Polatoğlu

Yıldız Teknik Üniversitesi

Ana Portalés Mañanós

Universitat Politècnica de València

Javier Poyatos Sebastián

Universitat Politècnica de València

Sonia Puente Landazuri

Comunica:Ciudad

Núria Ramon Marqués

Universitat de Lleida

Ana Ramos Sanz

Fundació Mies van der Rohe

Hazem Rashed-Ali

The University of Texas at San Antonio

Traci Rose Rider

North Carolina State University

Fatih A. Rifki

Montana State University

Michelle Rinehart

Georgia Institute of Technology

Carmen Ripollés

Portland State University 
Clare Robinson

The University of Arizona

Julia W Robinson

University of Minnesota

David Rockwood

University of Hawaii at Manoa

Krešimir Rogina

University American College Skopje

Pilar Roig Picazo

Universitat Politècnica de València

Marcos Ros Sempere

Universidad Politécnica de Cartagena

Mia Roth-Čerina

Sveučilište u Zagrebu

Alberto Rubio Garrido

Institut Valencià de l'Edificació

Felipe Samarán Saló

Universidad Francisco de Vitoria

João Rafael Santos

Universidade de Lisboa

Marja Sarvimaki

Bond University

Paola Sassi

Oxford Brookes University

Meredith Sattler

California Polytechnic State University

Thomas Schroepfer

Singapore University of Technology and Design

Veronika Schröpfer

Architects' Council of Europe

Marina Sender Contell

Universitat Politècnica de València
Carla Sentieri Omarrementeria

Universitat Politècnica de València

Begoña Serrano Lanzarote

Universitat Politècnica de València

Adil Sharag-Eldin

Kent State University

Lamila Simisic Pasic

International University of Sarajevo

Madlen Simon

University of Maryland

Brian Robert Sinclair

University of Calgary

Félix Solaguren-Beascoa de Corral

Universitat Politècnica de Catalunya

Enrique Solana Suárez

Universidad de Las Palmas de Gran Canaria

Juan María Songel González

Universitat Politècnica de València

Cristina Soriano Cuesta

Universidad de Sevilla

Asenet Sosa Espinosa

Universitat Politècnica de València

Laura Soto Francés

Conselleria d'Habitatge i Arquitectura

Bioclimàtica

Constantin Spiridonidis

Aristotle University of Thessaloniki

John C. Stallmeyer

University of Illinois at Urbana-Champaign

Alexandra Staub

The Pennsylvania State University 
Sally Stewart

Mackintosh School of Architecture, Glasgow

School of Art

Jae Yong Suk

The University of Texas at San Antonio

Judit Taberna Torres

Universitat Politècnica de Catalunya

Beatriz Tarazona Vento

Universidad Central del Ecuador

Rafael Temes Córdovez

Universitat Politècnica de València

Aron Temkin

Norwich University

Ana Torres Barchino

Universitat Politècnica de València

Vasilia Trova

University of Thessaly

Macarena Trujillo Guillén

Universitat Politècnica de València

Marci Uihlein

University of Illinois at Urbana-Champaign

Judith Urbano

Universitat Internacional de Catalunya

Mónica Val Fiel

Universitat Politècnica de València

Ilaria Valente

Politecnico di Milano

Koenraad Van Cleempoel

Universiteit Hasselt

Sara Van Rompaey

E2ARC
José Antonio Vázquez Rodríguez

Universidade da Coruña

Fernando Vegas López-Manzanares

Universitat Politècnica de València

Anna Verges Parisi

Observatori Metropolità de l'Habitatge de

Barcelona

Maria Pilar Vettori

Politecnico di Milano

Marisol Vidal

Graz University of Technology

Blanca Vila Cortell

Universidad Anáhuac Puebla

María José Viñals Blasco

Universitat Politècnica de València

Maria Voyatzaki

Aristotle University of Thessaloniki

Kate Wingert-Playdon

Temple University

João Pedro Xavier

Universidade do Porto

Dongwoo Jason Yeom

Lawrence Technological University

Shai Yeshayahu

Ryerson University

Shao Yong

Tongji University

Zdenek Zavrel

Czech Technical University

Tadeja Zupančič

Univerza v Ljubljani 

INDEX

\section{VOLUME 1}

\section{1_0. THE ARCHITECT AND THE CITY}

Ivan Cabrera i Fausto

\section{1_BLOCK 1: DEVISING, REPRESENTING AND NARRATING THE CITY}

0042_Paper \#1.01: The City in the Landscape : Alfred Caldwell's broader perspective on urban design

Kristin Jones, Zaida Garcia-Requejo

0052_Paper \#1.02: The face of the city

Nuria Casais, Ferran Grau

0064_Paper \#1.03: Co-Drawing: Collaborative Representations of the City Antje Steinmuller, Christopher Falliers

0076_Paper \#1.04: Graphic narratives for reading Indian cities in constant motion Alisia Tognon, Mariana Felix Paisana

0088_Paper \#1.05: The current image of the city of Yerevan (Armenia) through the study of urban spaces

Anna Sanasaryan, María José Viñals 
0098_Paper \#1.06: Toward a Sustainable Urban Development (SUD): A Case Study on Ancient City of Kazerun, Iran Mohammad Akbari Riyabi, Farzaneh Soflaei

0112_Paper \#1.07: And with a pinch of nostalgia: Traces of the past in Nicosia's present and future

Christakis Chatzjichristou, Kyriakos Miltiadous

0126_Paper \#1.08: Many cities in one. Enclaves and microcosms in the general structure of the city: the case of Prague's Ghetto

Domenico Chizzoniti, Yuliia Batkova

0136_Paper \#1.09: From the grid to the layer: post-industrial city as city in (morphological) transition

Michela Barosio

0148_Paper \#1.10: Grid geometry and core structure: Space Syntax analysis of small and medium 'grid-like' US Cities

Saif Haq

0160_Paper \#1.11: The Politics of the Illusion / The Image as a Rejection of Typological Tyranny Jonathan Scelsa

0172_Paper \#1.12: The architecture of Chandigarh Capitol

Maite Palomares Figueres, Ivo Vidal Climent, Ciro Vidal Climent

0184_Paper \#1.13: The new cities of the thirteenth century - a new urban paradigm in the Iberian Peninsula

Filipe Brandão do Carmo

0194_Paper \#1.14: The performance of gender and ethnic identity in the diaspora mosque Irem Oz, Alexandra Staub

0206_Paper \#1.15: Architectural and graphic expression of the Route 66 from Chicago to Los Angeles

Sigrun Prahl

0214_Paper \#1.16: Seeing beyond cities

Ray Kinoshita Mann

0224_Paper \#1.17: Corporeal Polis

Paul Holmquist

0234_Paper \#1.18: The diffuse museum. Toward a new model for interpreting architecture Queralt Garriga Gimeno

0242_Paper \#1.19: Urban Meta Museum

Polyxeni Mantzou, Xenofon Bitsikas, Anastasis Floros 
0252_Paper \#1.20: The skyway as an inhabitable mode of urban representation Mike Christenson, Erin Kindell

0262_Paper \#1.21: FABRIC[ATED]: Fabric Innovation in Architecture + Education Tolya Syril Stonorov

0274_Paper \#1.22: Visual spaces of change: the use of Image for rendering visible dynamics of urban change in contemporary cities

Pedro Leão Neto

0288_Paper \#1.23: Drawing water: The making of fluid graphics Brook Muller, Matt Tierney

0300_Paper \#1.24: Energy Visualization in the Architectural Design Process Giovanna Togo, Marina Maurin

0312_Paper \#1.25: Thin architecture: energy, economy and the all-glass archetype Elizabeth L McCormick, Waleed AlGhamdi

0322_Paper \#1.26: VR, photogrammetry and drawing over: envisioning the city of the future Olivier Chamel, Laurent Lescop

\section{3_BLOCK 2: LIVING IN URBAN LANDSCAPES}

0334_Paper \#2.01: Getting a grip on fiction: graphic narratives as study sites for urban design Carmina Sánchez-del-Valle, V.M. Price

0344_Paper \#2.02: Transescalarity, an instrument for the sustainable territorial development Celia Izamar Vidal-Elguera, Claudia Bengoa-Alvarez, Cinthya Butron-Revilla

0356_Paper \#2.03: Top down planning approaches and urban reality: The case of Delhi, India Sana Ahrar, Alexandra Staub

0364_Paper \#2.04: An inquiry on the architecture of the open cities in the age of planetary urbanization

Esin Komez Daglioglu

0374_Paper \#2.05: Green infrastructure as urban planning regulation of public residential neighborhoods

Andrea lacomoni

0384_Paper \#2.06: Artificially unnatural: Nature 2.0 Gayatri Tawari, Alka Tawari

0394_Paper \#2.07: Mapping the Passive Natural Surveillance The Bilbao Metropolitan Area Iñigo Galdeano Pérez 
0406_Paper \#2.08: Reconnecting with nature: identifying new models of urbanisation Steffen Lehmann

0420_Paper \#2.09: Considering Ladakhi self-sufficiency under climate change, COVID-19 and beyond

Carey Clouse

0430_Paper \#2.10: Sense of absence: place keeping of the intangible Elena Rocchi

0442_Paper \#2.11: Contact and impact (influence). Timeless events in the contemporary city landscape

Salvatore Rugino

0450_Paper \#2.12: Architecture beyond permanence: temporariness in 21st century urban architecture

Marco Enia, Flavio Martella

0460_Paper \#2.13: Public squares, social interactions, and urban sustainability: lessons learned from Middle Eastern Maidans

Shima Molavi Sanzighi, Farzaneh Soflaei

0474_Paper \#2.14: Urban landscape living lab. Base Camp : Vadozner Huus (BC : VH), Liechtenstein

Clarissa Rhomberg, Anne Brandl, Johannes Herburger, Luis Hilti

0486_Paper \#2.15: Sevilla 1910, the motion of censure against the architectural style Art Noveau. Perpetuating and controlling the narrative of the symbolic city in the modern era

Reyes Abad Flores

0496_Paper \#2.16: Urban landscapes in Berlin shaped through cultural diversity Sigrun Prahl

0508_Paper \#2.17: Was Le Corbusier a utopian thinker or a realistic visionary? An analysis of two diverging views

Cihan Yusufoglu, Alexandra Staub

0518_Paper \#2.18: University is city. The infrastructure of education and research as an engine of urban regeneration

Emilio Faroldi, Maria Pilar Vettori

0530_Paper \#2.19: The Mediterranean Peri-urban Historical Huertas (Murcia-Alicante-ValenciaZaragoza). Transversal research

Juan José Tuset, Rafael Temes, Ana Ruiz-Varona, Fernando García-Martín, Clara García-Mayor, Marcos Ros-Sempere 
0542_Paper \#2.20: Employing the industrial landscape. Insights on the use of collective spaces of industrialization in Ethiopia

Arnout De Schryvera

0554_Paper \#2.21: The "second life" of a building. Hidden flexibility possibilities on appropriation of architectural space

Caio R. Castro, Amílcar Gil Pires, João Mascarenhas Mateus

0566_Paper \#2.22: Shopping center and contemporary city: Discussion of appropriation forms Pedro Bento

0578_Paper \#2.23: Intersections with the ground in the contemporary city Luigi Savio Margagliottai

0590_Paper \#2.24: The domestic city: Expansion of the domesticity in the contemporary city Flavio Martella, Marco Enia

0598_Paper \#2.25: The sustainable house: psychology vs technology Olivia Longo

0606_Poster \#2.26: Comfortable parks Anastasiya Volkova, Madlen Simon

\section{1_BLOCK 3: THE NEW FACES THE OLD}

0612_Paper \#3.01: From Dismissal to Development: the Challenge of Architecture Roberta Ingaramo

0622_Paper \#3.02: The hidden designer: rethinking urban rules in city making Caterina Barioglio, Daniele Campobenedetto, Marianna Nigra, Lucia Baima

0632_Paper \#3.03: Designed to change: The future of architecture is Agile Salah Imam, Brian R. Sinclair

0644_Paper \#3.04: Performance: The Fantastical Dichotomies of City-Making. Shai Yeshayahu, Maria del C. Vera

0654_Paper \#3.05: Infrastructure for collectivity: built heritage and service planning in the city Francesca Daprà

0664_Paper \#3.06: Circular economy and recycle of architectural heritage in fragile territories Marco Bovati, Alisia Tognon

0676_Paper \#3.07: Binckhorst: A palimpsest of architectural lives Angeliki Sioli, Willemijn Wilm Floet, Pierre Jennen 
0688_Paper \#3.08: Pursuing potential arising from collision: The Islamic city considering Western hegemony

Sabeen bin Zayyad, Brian Robert Sinclair

0702_Paper \#3.09: New VS Old: Understanding Architectural Tensions in the Design of Public Spaces

Giulia Setti

0712_Paper \#3.10: (sub)URBAN; Merging Suburban Home Qualities with Urban Housing Craig S. Griffen

0724_Paper \#3.11: Changing the Currency of Manufactured Lakes in the Great Plains David Karle

0736_Paper \#3.12: Scarpa in light of croce: the post-lyrical city Frank Harrison Weiner

0746_Paper \#3.13: What Does A Single Building Tell About A City? Burcin Basyazici, Birsen Sterler, Safak Cudi Ince

0760_Paper \#3.14: The Urban Church: Repurposing a Community Detail William O'Neil Bourke

0772_Paper \#3.15: New old cities. The rebirth of German historical centers Michele Giovanni Caja

0784_Paper \#3.16: Adaptive reuse \& regeneration as potential for industrial sites in the metropolitan cities of Pakistan

Naveed Iqbal, Koenraad Van Cleempoel

0796_Paper \#3.17: Metamorphoses in Paris: the fate of Samaritaine among preservation and innovation

Antonella Versaci, Alessio Cardaci

0808_Paper \#3.18: Building a Modern Asuncion: Contributions of the Hotel Guarani in the Configuration of a New Urban Space

Julio Diarte, Elena Vazquez

0818_Paper \#3.19: The architectural Spanish imprint in China. Why an "Alhambra-style" mansion in Shanghai?

Álvaro Leonardo Pérez

0830_Paper \#3.20: Transformation of a historical area in Elche through an apparently invisible architecture

Antonio Maciá Mateu, Ana Mora Vitoria 
0840_Paper \#3.21: Recuperation of the staircase space of Arma Christi San Jerónimo of Cotalba José Manuel Barrera Puigdollers

0852_Paper \#3.22: Workspaces evolution, towards the new coworking spaces Alicia Llorca Ponce, Franca Cracogna

\section{3_BLOCK 4: SMART CITIES VS. TECH CITIES}

0864_Paper \#4.01: Is Dubai a New Paradigm for Smart Cities?

Sabeen bin Zayyad, Thomas Patrick Keenan

0876_Paper \#4.02: Performing and Measuring smartness Giving ground to urban intelligence by an alternative metric

Julien Lafontaine Carboni, Dario Negueruela del Castillo

0888_Paper \#4.03: Smart Design for Bicycle Parking Stations. A proposal for the Historical Center of Arequipa, Peru

Gabriela Manchego, Cinthya Butrón Revilla

0898_Paper \#4.04: A biomimetic research on how cities can mimic forests to become sustainable and smart

Aliye Rahşan Karabetça

0908_Paper \#4.05: Aggregated data management and business model in designing Positive Energy Districts

Paolo Civiero, Jaume Salom, Jordi Pascual

0918_Paper \#4.06: Purposeful Play: Bridging the energy-efficiency gap in Cities Malini Srivastava

0928_Paper \#4.07: Optimal Operation Strategies of Three Different HVAC Systems Installed in a Building Yeo Beom Yoon, Byeongmo Seoa Suwon Song, Soolyeon Cho 



\section{VOLUME 2}

\section{9_BLOCK 5: A FUTURE BASED ON TECHNOLOGY}

0970_Paper \#5.01: Mapping the city: datascape as a tool for representing the invisible Başak Uçar

0980_Paper \#5.02: Integral Design for Urban Transformation to a Smart City Core Marios .C. Phocas, Maria Matheou

0990_Paper \#5.03: Architectural Robots: Rethinking the Machine for Living In Rachel Dickey

1002_Paper \#5.04: The cutting (rounded) edge of 3D-printed architecture Rodrigo García-Alvarado, Alejandro Martínez-Rocamora

1014_Paper \#5.05: The city after the catastrophe. diligent structures Raquel Martínez Cuenca, Ricardo Perelló Roso

1022_Paper \#5.06: Constructability criterion for structural optimization in BIM and Hybrid Digital Twins

Víctor Fernández-Mora; Víctor Yepes 
1034_Paper \#5.07: The sustainable white city

Paolo De Marco

1046_Paper \#5.08: Macrocriteria for compiling data on $\mathrm{CO} 2$ emissions in building materials under EPD, EN, ISO; catalog -IVE

Begoña Serrano Lanzarote, César Emmanuel Arguedas Garro

1060_Paper \#5.09: Mass timber construction for multi-family urban housing: Carbon12 and The Canyons

Edward Becker, Kevin Lee

1074_Paper \#5.10: A Parametric Study of Daylighting in High-rise Residential Buildings in Dhaka, Bangladesh

Sumaiya Mehjabeen, Ute Poerschke, Lisa Domenica Iulo

1086_Paper \#5.11: Application of artificial neural network in solar radiation prediction for realtime simulation

Hany Gaballa, Yeo Beom Yoon, Byeongmo Seo, and Soolyeon Cho

1098_Paper \#5.12: The spatial block: Natural ventilation as an architectural instrument Ezgi Bay

1108_Paper \#5.13: Tuning the masses: climate specific energy optimization guidelines Alexander Mitchell, Tom Collins

1118_Paper \#5.14: Thermal performance of a novel masonry block made from recycled gypsum drywall waste

David Drake, Taiji Miyasaka

1128_Paper \#5.15: Indoor environmental analysis of a LEED gold-certified office building in ASHRAE climate Zone 6

Antonio Martinez-Molina, Jae Yong Suk, Hazem Rashed-Ali

1140_Paper \#5.16: Analysis of energy performance in a residential block in the Ensanche of Valencia and proposals for improvement

Vicente Blanca-Giménez, Natalia Cardona Guerra

1148_Paper \#5.17: Comparative study of sustainable thermal insulating materials in architecture Jose Vercher, Joaquin Segura, Enrique Gil, Angeles Mas, Carlos Lerma, Carlos Silvestre

\section{9_BLOCK 6: RESTORATION, CONSERVATION AND RENOVATION}

1160_Paper \#6.01: Researches and projects between conservation and renovation for the future of the cities

Stefano Francesco Musso, Giovanna Franco 
1170_Paper \#6.02: A Bibliometric Review of Life Cycle Research of the Built Environment Ming $\mathrm{Hu}$

1182_Paper \#6.03: Community preservation of districts: the Brownstoners. The case of BedfordStuyvesant

Ana García Sánchez

1194_Paper \#6.04: Defrosted Architecture: Debussy's Cathédrale Engloutie case study José L. Baró Zarzo, Pedro Verdejo Gimeno, Gracia López Patiño, Verónica Llopis Pulido

1204_Paper \#6.05: Interventions in Spanish monumental heritage: A holistic view of Burgos Cathedral

Elisa Baillieta

1214_Paper \#6.06: The role of knowledge transfer in masonry bridge construction from Spain to Guatemala

Sandra Hernandez, Ahmed K. Ali

1226_Paper \#6.07: ARTs as Catalyst: Strategy for Urban Regeneration - Case of Benesse Art Site: Naoshima, Inujima \& Teshima-

Koichiro Aitani

1238_Paper \#6.08: Spaces and places of culture for the renewal of contemporary city Antonino Margagliotta

1250_Paper \#6.09: The new challenges for conservation and management of HUWI, Ahmedabad, India

Mehrnaz Rajabi, Stefano Della Torre

1262_Paper \#6.10: An incessant research exercise on the historical context of Fiorenzuola d'Arda city

Michele Ugolini, Rossana Gabaglio, Stefania Varvaro

1274_Paper \#6.11: Urban Design Strategies for a Problematic, Southern Mid-Size American City Thomas C. Sammons

1288_Paper \#6.12: Green Book in Arizona: intersecting urban history, heritage, and planning Clare Robinson, Arlie Adkins

1298_Paper \#6.13: The evolution of the Spanish Building Codes: an overview from the seismic design perspective

Luisa Basset-Salom, Arianna Guardiola-Víllora

1310_Paper \#6.14: The Special Protection Plan for the Historic 'Ciutat Vella' District (Valencia, Spain). A new tool to approach heritage enhancement and management María Emilia Casar Furió 
1320_Paper \#6.15: Over-elevation as a measure of urban renewal Maria Piqueras Blasco, Ernesto Fenollosa Forner

1330_Paper \#6.16: Adaptive reuse in fragile contexts. Combining affordable housing solutions, new job opportunities and regeneration of urban peripheries

Elena Fontanella, Fabio Lepratto

1342_Paper \#6.17: Single-wall timber granaries box construction in Turkish and Spanish rural architecture contexts

Ahmed K. Ali

\section{5_BLOCK 7: NEW PROFESSIONAL PRACTICES AND RESEARCH PRACTICES}

1356_Paper \#7.01: Design fiction and architecture Philip D. Plowright

1368_Paper \#7.02: What do we talk about when we research the city? Academic publishing in urban studies

Débora Domingo-Calabuig

1378_Paper \#7.03: A Model for Community and Criticality: The University Urban Design and Research Center

Courtney Crosson

1388_Paper \#7.04: Peer-review or popularity-contest: the erosion + implosion of internal assessment in higher education

Brian Robert Sinclair

1402_Paper \#7.05: Architectural experienced machines: the activation of time José Manuel Barrera Puigdollers

1414_Paper \#7.06: AWOL: psychology, business + research in contemporary architectural education

Brian Robert Sinclair

1426_Paper \#7.07: Design research and a shift in architectural education and practice Ayşe Zeynep Aydemir, Sam Jacoby

1438_Paper \#7.08: Renewing design practice via a diachronic study of Tekton and Arkitekton practitioners

David N. Benjamin, Jonas Holst

1446_Paper \#7.09: Platform, container, environment. 2019 Shenzhen Biennale as innovation in practice

Edoardo Bruno, Valeria Federighi, Camilla Forina, Monica Naso, Michele Bonino 
1456_Paper \#7.10: Glocal architecture against climate change: Rice straw in Valencia

A. Quintana, Joan Romero, I. Guillén-Guillamón, F. A. Mendiguchia

1466_Paper \#7.11: Transferring visual methods from design to social science to advance built environment research

Caryn Brause

1478_Paper \#7.12: Social rental housing siting \& maintenance: Considering the architect's critical role

Chika Daniels-Akunekwe, Dr. Brian R. Sinclair

1494_Paper \#7.13: Youth decarceration: Using sketch models to explore non-punitive attitudes Julia Williams Robinson

1506_Paper \#7.14: Heritage as a resource, memory as a project. Responsible network-based design strategies

Emilia Corradi, Alessando Raffa

1516_Paper \#7.15: Daylighting and Electric Lighting POE Study of a LEED Gold Certified Office Building

Jae Yong Suk, Antonio Martinez-Molina, Hazem Rashed-Al

1528_Paper \#7.16: New synergies between research, practice, and education for health and wellbeing outcomes in the built environment

Altaf Engineer

1538_Paper \#7.17: Rethinking sustainable development in European regions by using circular economy business models

Begoña Serrano-Lanzarote, Nuria Matarredona-Desantes, Vera Valero-Escribano, Cristina Jareño-Escudero

1552_Paper \#7.18: Nexus between sustainable buildings and human health: a neuroscience approach

Madlen Simon, Ming Hu, Edward Bernat

1568_Paper \#7.19: How Much Does Zero Energy Building Cost?

Ming $\mathrm{Hu}$

1580_Paper \#7.20: Between research and teaching: identifying new competencies for Healthy Cities

Francesca Giofrè, Mohamed Edeisy

1592_Paper \#7.21: Natural ventilation in the traditional countryside constructions in Valencia. CFD \& PPD analysis.

F. Mendiguchia, A. Quintana, I. Guillén-Guillamón

1602_Paper \#7.22: Ecomimetics: The maximum power principle for rethinking urban sustainability

Mercedes Garcia-Holguera 
1614_Paper \#7.23: RSM adjustment in absorption coefficient determination of materials in room acoustics

Blanca Pérez-Aguilar, Ignacio Guillén-Guillamón, Alberto Quintana-Gallardo, José L. Gasent-Blesa, Ana Llopis- Reyna

1626_Paper \#7.24: Parallelisms between architecture and painting; the reuniting of subjectivity and objectivity

José Manuel Barrera Puigdollers

1638_Paper \#7.25: Virtual architects: Analysis of dystopian environments in video games Luis Miguel Ramada Peiró, José Manuel Barrera Puigdollers

\section{9_BLOCK 8: PARTICIPATION PROCESSES, DIVERISTY AND INCLUSIVENESS}

1650_Paper \#8.01: Designing a Better World Together: global interuniversity. Partnership addressing UN 2030 SDG

Madlen Simon, Shaimaa Hameed Hussein, Gregory Weaver

1662_Paper \#8.02: The Invented Other: Of the "Stranger-guest," Noise, and the City Isben Önen

1668_Paper \#8.03: Deconstruction in architecture; a history of complete misunderstanding José Manuel Barrera Puigdollers

1682_Paper \#8.04: Public Participation and Citizen Participation in Current Valencian Urbanism María Emilia Casar Furió, Asenet Sosa Espinosa

1692_Paper \#8.05: Social participation through experiences in public spaces in the city of Guadalajara, Mexico Isamar Anicia Herrera Piñuelas, Adolfo Vigil de Insausti, Alfred Esteller Agustí

1702_Paper \#8.06: The Citizen-Architect: Evaluating an Interactive Game for Collaborative Urban Solutions and Green Infrastructure Success

Courtney Crosson, Sandra Bernal

1714_Paper \#8.07: Spaces of difference and association: Islamist politics and urban encounters among heterodox minorities in Turkey

Bülent Batuman

1724_Paper \#8.08: Horizontal exchanges as a design method. Africa urbanisation as a case study

Rossella Gugliotta

1736_Paper \#8.09: Understanding built (ine)quality in peripheries through Bourdieu's distinction: the case of Porto's urban area (Portugal)

David Pereira-Martínez,Virgílio Borges Pereira, Plácido Lizancos, Isabel Raposo 
1748_Paper \#8.10: University-community partnership to address flood resilience and community vitality

Lisa D. Iulo

1758_Paper \#8.11: Building Independence

Scott Gerald Shall

1770_Paper \#8.12: The issue with inclusivity: the promotion of equality and diversity within architectural education

Isabel Deakin

1780_Paper \#8.13: Design guidelines for community spaces in housing Alex Mitxelena, Ramon Barrena, Beatriz Moral, Enkarni Gomez

1790_Paper \#8.14: Disentangling Relational space: adding insights of the everyday life of children to the process of urban renewal

Johannus van Hoof, Erik Van Daele, Bruno Notteboom

1802_Paper \#8.15: The new forms of residentiality for the senior 'inclusive' housing Martina Nobili

1814_Paper \#8.16: Re-Viewing Refugee Spaces: The Case of Mardin, Turkey Neslihan Dostoglu, Merve Güleryüz Çohadar

1831_9. A RESTLESS, NON-CONFORMIST AND ADAPTIVE DISCIPLINE 



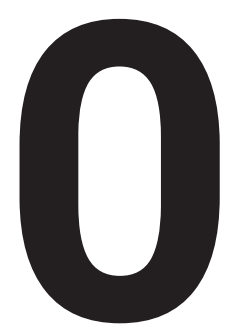

INTRODUCTION 


\section{THE ARCHITECT AND THE CITY}

\section{Ivan Cabrera i Fausto}

Conference Chair

Higher Technical School of Architecure of the Polytecnnic University of Valencia, Spain

Contemporary thinking regarding architecture is nowadays rather dispersed. It is unquestionable that over the course of centuries, human life has become more and more complex. And, as its unmistakable reflection, architecture has also developed into a much more intricate discipline encompassing a vast range of specialized fields. However, most authors totally agree in the characteristics of the modern subject who inhabits the fascinating world of the art and science which designs and materializes the human habitat. This subject is nowadays rational, employs several logics and language resources, has articulated complex societies and organizational structures and has created cities to meet and grow. This anthropological relation between architecture and city has gone through different stages in recent times.

In the first half of the twentieth century, cities took the initiative by means of their experts as a direct extension of a society which was questioning many aspects of obedience. Architects played a fundamental role in these elites and had assumed a meaningful leadership and accepted the responsibilities which it entailed. The number of practitioners was reduced; the profession was prestigious; fees allowed offices with many employees and a comfortable life; the production rate make periods of reflection possible; and economic elites, with benefits as tremendous as nowadays, felt the civic obligation of reverting to society part of this welfare by means of patronage. These conditions, unconceivable currently, lie beneath many remarkable initiatives and projects showing the aforementioned leadership of architects in the design of cities and their future, such as the Plan of Chicago (fig. 1) co-authored by Daniel Burnham and Edward H. Benett in 1909.

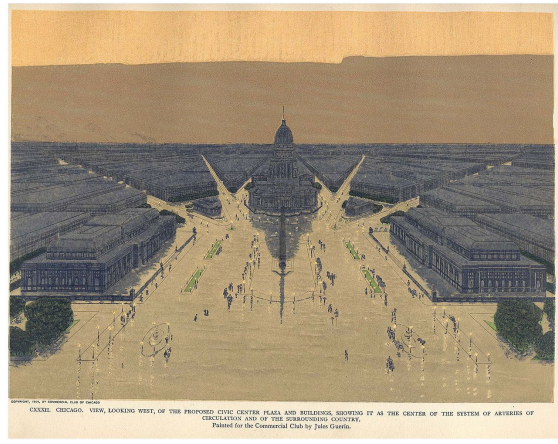

Figure 1. View looking west of the new Chicagoan civic center proposed by D. Burnham and E. Bennett in 1909

However, the second half of the twentieth century was marked by a more acquiescent temper, with profitability and productivity in the foreground. Many factors forged slowly this new scenario. The end of World War II and the need to reconstruct all countries affected, and the necessary and gradual popularization of university studies in order to provide the market with all the required practitioners, gradually weakened the previously extreme convenient boundary conditions of architectural practice. Architects faced an increasing amount of commissions, with decreasing fees and consequently waning office staff. Time for critical thinking on citizenry and its physical scenario started to vanish and other actors, mainly economists mostly focused on economic efficiency and continuous growing entered the scene. Events such as the 1973 oil crisis (fig. 2) accelerated this transition and the theoretical merit of its overcoming surprisingly legitimized the economic forces' position in the control bridge with no questioning if these forces themselves and their priorities had led to the crisis. 


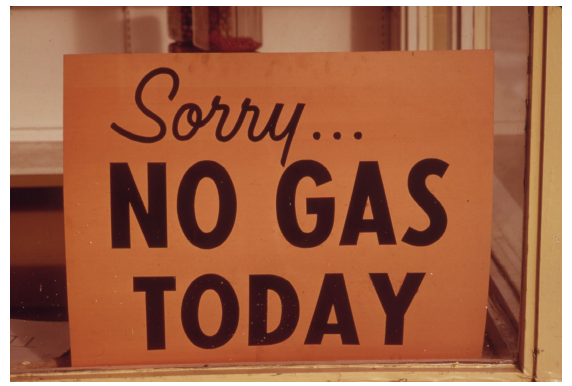

Figure 2. Board at a gas station in Oregon (USA) in 1973

As a result, the remarkable growing of cities often blurred them. Habitational products were not connected with social subjects and development initiative was still taken by productive sectors. While this the number of students graduated in architecture skyrocketed, the number of practitioners increased much faster than commissions did and consequently fees began reducing or even collapsed in many countries. The prestige of the profession was surprisingly still quite undamaged but glimpses of recovering tasks and roles previously undertaken by architects were scarce. But something was about to change. The excesses of a world ruled without architects in leading roles would give them back in a dramatic and unexpected manner.

The excessive risk-taking assumed by financial entities along with the breaking of the United States housing bubble wonderfully described by Adam McKay in his movie "The Big Short" (fig. 3), led to the drop of the values of securities tied to American real states with an increasing damage of financial institutions all over the world and producing what is nowadays known as the 2007-2008 global financial crisis. Once again magnificently narrated in another movie, in this case J.C. Chandor's "Margin Call" (fig. 4), the crash took the world by surprise. Financial markets deteriorated substantially and a huge crisis in the construction industry settled down almost globally with special affection in Southern European countries.

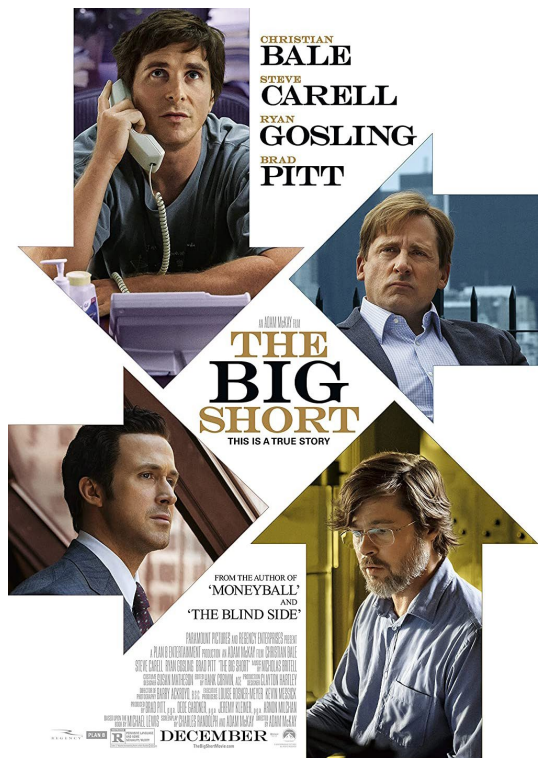

Figure 3. Theatrical release poster for "The Big Short", 2015

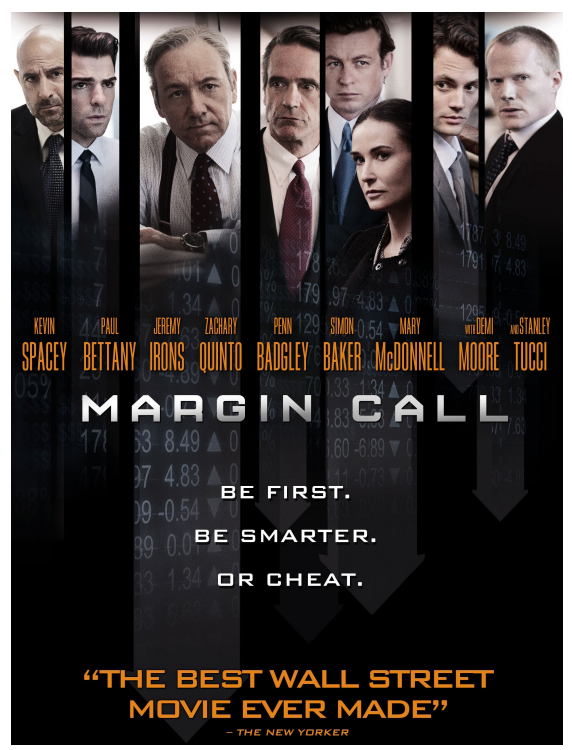

Figure 4. Theatrical release poster for "Margin Call", 2011 
The scarcity of commissions at best, usually completely lack of them, propitiated an unexpected period of reflection for architects. Students and faculty at the schools of architecture, practitioners in their studios and officers in their departments began a slow but solid reconnection with the leadership which architects used to have during the first half of the twentieth century in the development of cities. A third revisionist generation was born and the growing world's population, the noticeable migration to urban areas and the questioning and flaws of capitalism provided the best ecosystem for its growing and establishment. This collective employs different cultural variables such as alterity, applied sociology or social activism. Debates on sustainability, landscape, environment, new documentary frameworks and mapping processes, have set the place for new reflections on: limits, borders, traces, surroundings-city interaction, compact or diffuse cities, and many more. Along with such a themed view new topics such as revisiting the rural, have emerged. This third way has collaterally connected with new parameters derived from committed activism such as cooperation, development, third world, urban overcrowdings, residual fabrics, refugee camps, and others which have incorporated new material and strategic discourses on recycling, crowdfunding or low-cost. The profusion of divisions of the problem has characterized a time of fragmented tests, with a noticeable loss of general perspective and where the architects' responsibility about the cities has again broken through but in a fairly hesitant and slow way.

But against this background an increasing architectural and theoretical production despite disperse has been achieved and an upcoming maturity is now able to draw a first set of general conclusions and to attempt a more global attempt to contemporary issues. A fourth and contemporary and critical generation is plowing its way through. It is characterized by the cohesion of speeches, positions and approaches. With an inclusive, transversal and revisionist nature, incorporates and revisits concepts such as feminism, gender, childhood, shelter, migration, wealth, transversality, glocality, interculturality, multiculturality and many more. Hence, we nowadays face the challenge of refounding the concept of city for the future generations, subjected to the duality of the inherited city and its expansion, to the duality of what is consigned and what is missing.

Within this extremely dynamic, changing and exciting context, the 2020 edition of the International Conference on Research in Architecture organized by the European Association for Architectural Education and the Architectural Research Centers Consortium was presented in June 2020 in Toronto, Canada. The topic chosen ambitioned to tackle simultaneously the changing architectural practice, the newly resumed leadership in the design and management of the cities and the growing importance of urban life: "The architect and the city" (fig. 5). Hosted at the Higher Technical School of Architecture of the Polytechnic University of Valencia, Spain, and originally scheduled on June 10-13, 2020, the event was merged with the second edition of the Valencia International Biennial of Research in Architecture. The logo for the event (fig. 5) included a retro pair of glasses as a tribute to the time when architects shouldn't have eluded their leadership and as an invitation to look to the city through architecture's eyes. 
EAAEAARC

INTENATIONAL
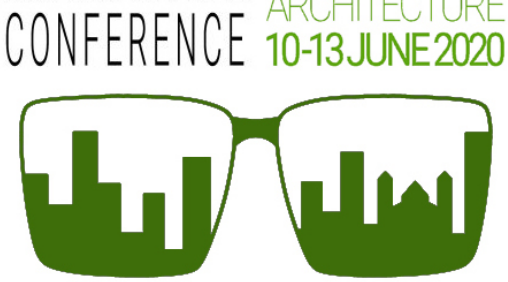

THE ARCHITECT AND THE CITY

Figure 5. Logo of the 2020 EAAE-ARCC International Conference and 2nd VIBRArch designed by Marcos Lizondo before the postponement of the event to November 2020

The stirring committee agreed that the in order to warrant good living conditions for future generations around the planet and to safe the care of the planet itself, research in architecture had to release all its potential. Therefore, the aims of the 2020 EAAE-ARCC International Conference were:

- To focus on the city as the most relevant architectural issue of the twenty-first century.

- To deepen into the historical and modern specificities of the phenomenon of cities.

- To debate about the needs of current cities around the world and to envision an adequate future for them.

- To showcase the city as the scenario of new societal trends, technological advances and professional practices.

- To underline the incipiently recovered leadership of architects in the design and management of cities.

- To place in the spotlight research in architecture as the indispensable mechanism in order to warrant sustainable progress in human habitat.
- To become a meeting point for those who develop their research on the matter of cities, and a platform for presentation and debate about studies, findings, novelties and contributions, encouraging many more to come.

- To highlight architecture's multidisciplinarity as a melting pot of multiple approaches, points of view and expertise.

- To open new perspectives for architectural research on cities by promoting the development of multidisciplinary and interuniversity networks and research groups.

For all that, the 2020 EAAE-ARCC International Conference and 2nd VIBRArch was open not only for architects, but also for any academic, practitioner, professional or student with a determination to develop research in architecture or neighboring fields. The event encouraged the submission of papers concerning up to eight thematic areas aiming to accommodate as many approaches as possible.

"Devising, representing and narrating the city" was the first thematic area or block. Graphic expression has always appeared as a stimulating field for architectural experimentation and research in synergy with many other disciplines within architecture. The way in which cities have been drawn along history and the techniques employed for depicting all their actors and activities play a fundamental role when it comes to understand and apprehend the underlying values that each society prioritized when designing and managing the locations where population would concentrate (fig. 6). Likewise, the actual graphical expression trends are reflections of our interests and inevitable have an influence on our architectural production in the city. This thematic area welcomed papers and posters from different fields of graphic expression which focus on new methods for conceiving and narrating the city, such as new graphic techniques, new modelling and representing methods, and even new ways for depicting urban flows and city dynamics. 


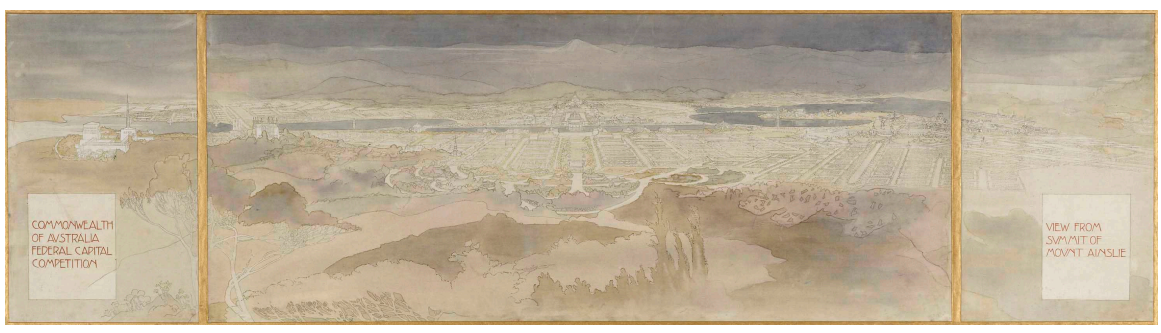

Figure 6. Watercolor from the Canberra Design by Marion Mahony Griffin, between 1911 and 1912

The second thematic area or block was devoted to "Living in urban landscapes". It cannot be denied that people living in the city spend most of their time in anthropised environments. Urban landscape takes center stage and has an undoubted influence on the quality of life. The different scales of urban landscape along with its own internal and external dynamics offer interesting research scenarios to be tackled from multidisciplinary points of view. Among these contexts, urban fabrics and public space constitute a base for research from morphological, functional, social and environmental perspectives. This thematic area encompassed papers and posters on the landscape and urbanistic side of the city, also including those tools for its analysis and interpretation such as cartography. Among many others, topics to be addressed could include human scale, morphology and activity in the city, occupation, sustainability, permanence, transformation, mobility, and obviously landscape as cultural heritage and daily life stage.

"The new faces the old" was the name of the third block or thematic area, considered extremely necessary since cities are living organisms in constant renovation. With the exception of the less and less cases of new neighborhoods developments or occasional brand new cities, isolated replacement of buildings, the renewal of public spaces and their continuous updating and maintenance probably constitute the biggest percentage of any architect job. Therefore, it was considered to be very easy to find cases were a new intervention should meet previous or even historical elements. These encounters shall be designed carefully in order to warrant that the different physical and cultural layers that have built our cities can live together in harmony. This thematic area welcomed papers and posters on theories and examples about the coexistence of old and new actors in the urban context as well as the results of this cohabitation in the quality of the city. Topics might address not only current cases but also how this matter has been addressed during different periods of the history.

The fourth block or thematic area was booked for "Smart cities vs. tech cities". Data have an amazing and increasing importance in today's world. A correct collection and subsequent processing can guarantee a more efficient management of assets and resources. This smart use of the information is providing the inhabitants of smart cities a better and often more sustainable quality of life (fig. 7). But the necessary use of technology for the collecting and processing the data doesn't necessary mean that technology will also be used to implement improvements or that technology has a strong presence in daily life or the employment context. This second step that some cities have already taken, but there are others that might be rather reluctant since their concept or quality of life differs. This 
thematic area encompassed papers and posters which are focused on smart cities, tech cities and the thrilling dichotomy of assuming naturally both roles or consciously and deliberately having chosen one option since some aspects of the refused one are understood as a loss of welfare. Big data influence on urban life as a topic will also be welcome.

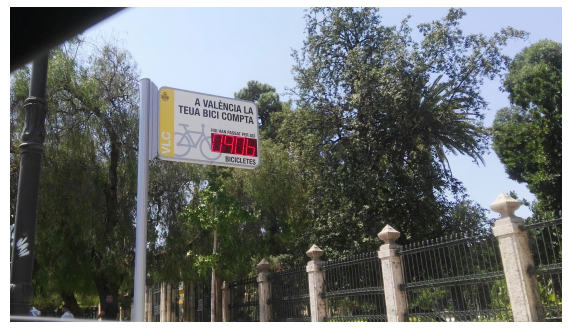

Figure 7. Passing bikes meter in Vivers Gardens in Valencia, Spain

"A future based on technology" was the fifth thematic area or block. City life is increasingly synonym of technology. The quick development experienced by cities during the last centuries cannot be explained without a vast range of technology advances which enabled not only more population in less space but also better living conditions. The desire of accessing this technology benefits is one of the most relevant reasons for more population moving to the city. Innovative building systems and evolved materials are making possible to satisfy the ever more demanding comfort levels and social ambitions. It is absolutely undeniable that the city is being the stage of this continuous evolution and these advances are shaping it. This thematic area welcomed papers on innovative building materials, building techniques for a better building and better living, energy efficiency, renewable energy systems, continuous innovation and improvement in conditioning techniques, and new methods and building techniques in structures for architecture.
The sixth thematic area or block was devoted to "Restoration, conservation and renovation". The interpretation of history has traditionally opened new ways to build the future. That fact is especially undeniable in cities, having been the stage of most of the historical facts that constitute our cultural heritage. The geographical and timescale framework was vast enough to cover stages which comprise from ancient cultures to contemporary times. A transversal and multidisciplinary approach to these issues was undoubtedly an interesting endeavor. Likewise a meaningful percentage of contemporary cities do not expect a meaningful growing, and even those which do have a large number of neighborhoods which are already built but need to be fixed and updated. This thematic area encouraged papers and posters on restoration, conservation and renovation as a matter of research. Architectural heritage and conservation constitute an amazing window of opportunity in modern practice that has induced the development of many fascinating research lines.

"New professional practices and research practices" provided the subject for the seventh block or thematic area. As thoroughly and previously explained, despite this process had already begun much before for many practitioners, the long reflection imposed by the scarcity of commissions produced by the financial crisis of the beginning of the century in many countries led architects massively to look for new professional practices. Curriculums in schools of architecture endow their graduates with knowledge and skills that qualify them for developing much more than the traditional professional practice. Likewise, the importance of research nowadays across disciplines has revealed that most of architecture daily practice is an exercise of research itself since each project constitutes a unique result for solving needs in a specific after a thorough process. This awareness has propitiated the awakening of a new generation of architects which is exclusively focused on research for improving human built environment. Cities 
have been the scenario of these trends and have been substantially influenced by them. This thematic area welcomed papers and posters on new professional practices, research practices and their influence on the city.

Finally, the eighth thematic area meaning the last block was kept for "Participation processes, diversity and inclusiveness". For some years we had been witnessing a process of reflection, reconsideration or even elimination of many traditional concepts and values such as hierarchical governance, adequacy or even normality. Once again having cities as main stage, people are claiming their rights to take command of whatever has a decisive influence on their lives and to be happy and accepted despite their characteristics and circumstances. Participation processes (fig. 8), diversity, inclusiveness and many other neighboring concepts have also arrived to daily architecture practice and are having an incipient but deciding influence on how many nowadays cities are being transformed. This thematic area encompasses papers and posters dealing with new societal dynamics, their irruption in architecture professional practice and their influence on the architectural output. Examples of previous pioneering examples and study cases of any period will also be welcome.

Despite not evenly, all eight thematic areas were successful. Up to one hundred and fiftyfive papers, and even one poster despite the finally online presentations scheduled, made it through the Scientific Committee reviews and judgements. The conference proceedings

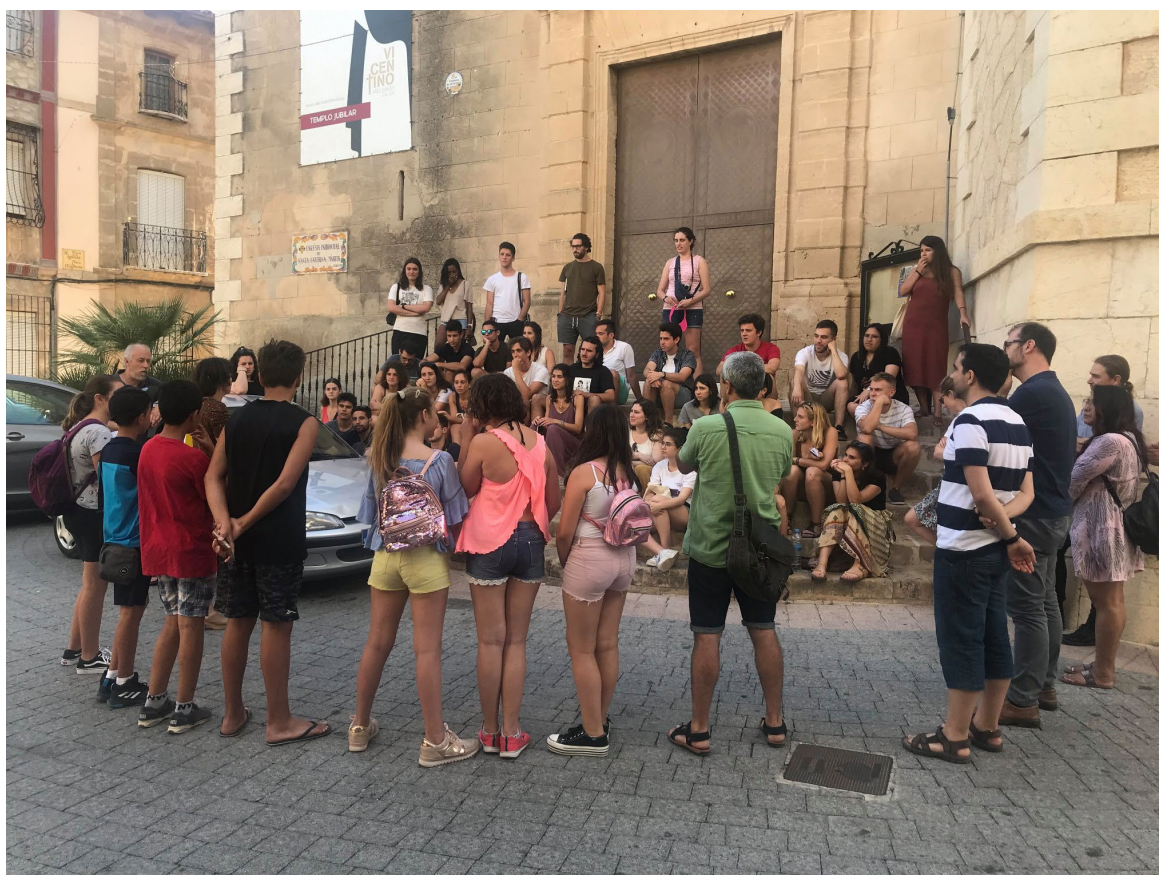

Figure 8. Architecture students and professors meet historic center neighbors in Teulada, Spain 
compile all these works distributed in two volumes, with this brief introduction and the first four thematic areas in the first one, and the next four thematic areas and some brief conclusions in the second one. Therefore, this work constitutes a privileged outlook of the research done by some of the best academics in architecture and neighboring fields in the world. It provides a valuable picture of nowadays state of the art, a fertile source supply for further research and an unbeatable testimony for the future. 

BLOCK 1: DEVISING, REPRESENTING AND NARRATING THE CITY 


\title{
PAPER \#1.01
}

\section{THE CITY IN THE LANDSCAPE : ALFRED CALDWELL'S BROADER PERSPECTIVE ON URBAN DESIGN}

\author{
Kristin Jones ${ }^{a}$, Zaida Garcia-Requejo ${ }^{b}$ \\ allinois Institute of Technology, Chicago, Illinois, USA \\ bUniversity of A Coruña, A Coruña, Spain
}

\section{ABSTRACT}

Alfred Caldwell was among the first full- time American professors Mies van der Rohe hired at the Illinois Institute of Technology (IIT). Many have admired Mies's architecture since the 1920s, and know that his ideas were also transmitted as a professor, first at the Bauhaus in Europe and then as Director of the Department of Architecture at IIT. Caldwell, a practicing landscape architect and protégé of Jens Jensen, is perhaps less widely known, but was a major influence on IIT's program especially in the areas of construction, landscape, and architectural history. Caldwell completed a Master of Science in City Planning with a thesis entitled The City in the Landscape: A Preface for Planning, which can be considered a manifesto of both his professional ideas and IIT's planning pedagogy. In addition to his own works, Caldwell collaborated with Mies and architect Ludwig Hilberseimer, Director of City and Regional Planning at IIT and former Head of Building Theory at the Bauhaus, on the design of built works which left behind artifacts representing the ideal of "the city in the landscape." This communication examines the broader perspective on urban design influenced by the symbiotic disciplines of architecture, city-regional planning and landscape as manifested in the individual and collaborative built work and pedagogy of Caldwell, Hilberseimer, and Mies.

Alfred Caldwell; city planning; landscape; urban design; Illinois Institute of Technology.

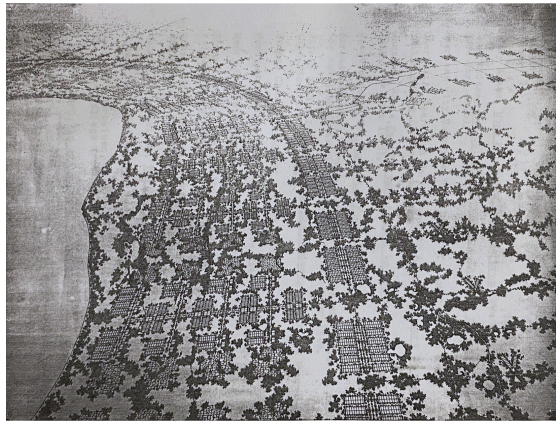

Figure 1. "The City in the Landscape", drawing by Alfred Caldwell, MS thesis 1948. Source: University Archives and Special Collections, Illinois Institute of Technology.

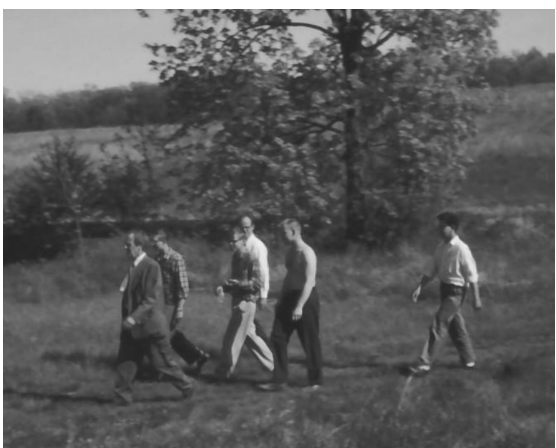

Figure 2. Alfred Caldwell and IIT Students at Bristol Farm, circa 1958, photograph by Jong Soung Kimm. 


\section{INTRODUCTION}

Alfred Caldwell came to IIT in 1944 an awardwinning landscape architect. He had been in practice for 20 years, planning beautiful landscapes for several Chicago public parks and private gardens, and his ideas were beginning to be published (Domer 1997). While assisting Ludwig Hilberseimer, then Director of City and Regional Planning at IIT, with drawings for the book, The New City, Caldwell began to teach undergraduate courses in construction and architectural history. In 1945, Caldwell was awarded a Bachelor of Architecture and earned a Master of Science in City Planning in 1948 with his thesis entitled The City in the Landscape: A Preface for Planning. The City in the Landscape can be considered a manifesto of both Caldwell's professional ideas and IIT's planning pedagogy. After a 22-year hiatus associated with Mies's resignation from IIT, Caldwell returned to teach at IIT until his death in 1996, adding to his teaching repertoire a landscape course. His ideas about human settlement, which advocated a deeper understanding of the connection between humanity and nature, influenced hundreds of students across the U.S. through the end of the 20th century.

\section{DEVELOPMENT OF THE THEORY}

\subsection{Caldwell's Education}

Before establishing himself as a landscape architect working for the Dubuque and Chicago Park Districts, Alfred Caldwell had worked in Jens Jensen's office for five years and spent three weeks with Frank Lloyd Wright at Taliesin East, where in his own words he learnt enormously (Caldwell 1987). While working for the Chicago Park District, Caldwell decided to get his architectural license and enrolled in a refresher course at the Armour Institute of Technology (AIT) to prepare for the state board examination.

Caldwell had a mastery of drawing that opened the door for him to work closely with Hilberseimer helping him prepare the drawings for his book entitled, The New City. Caldwell's skill and collaboration with Hilberseimer preceded the opportunity to be hired as the first full-time American professor by Mies in 1944. Although Caldwell was never officially enrolled in the undergraduate course in Architecture at IIT, the administration accepted his experience related with the subjects, and awarded him a Bachelor's degree in 1945.

As a member of the faculty, Caldwell contributed significantly to the development of the undergraduate program. When Caldwell began teaching at IIT, the undergraduate degree program in Architecture was a fouryear program with an optional fifth year to specialize in Architecture or City and Regional Planning. Mies's program gave students the opportunity to "acquire a basic architectural philosophy and fundamental creative principles which would guide them in their task of creating living architecture" (Achilles 1986, p. 167). The fundamental principles of Mies' architecture program at IIT were structure, space, proportion, materials, painting-and-sculpture, and their integration. In parallel, students were also instructed in general theory and professional training. Caldwell's teaching in the construction studio, with its focus on clear and authentic masonry and timber construction, as well as his special brand of architectural history and landscaping courses were a large part of the program's success.

While Caldwell was working with Hilberseimer on the book, the professor suggested he take a master's degree. Caldwell had been working around the same idea for years: how to have a good life in America, so Hilberseimer encouraged him to put his ideas together. "That is very easy to do. A few words, a few pages..." (Caldwell 1987). 
Under Mies's directorship, a new Master of Science in City Planning was introduced in addition to the existing Master of Science degree in Architecture. To obtain the Master of Science in City Planning it was necessary to study the subjects Theory of Dwellings and Housing, Theory of City Planning, Theory of Regional Planning, Applied City Planning and Applied Regional Planning, all of which were taught by Hilberseimer. Additionally, students attended certain lectures on the history of city planning, art of city planning, social hygiene, national economy, statistics, real estate law and finance, and finally the preparation and acceptance of a thesis. Hilberseimer's ideas about city and regional planning naturally became part of Caldwell's thinking.

\section{2. "The Hilberseimer Plan"}

Hilberseimer's city planning theory represented a new chapter in urban planning that was not based on formal aesthetics and design, but on attempting to align human needs with social and technological conditions in a more sustainable and livable manner. In order to make cities better and healthier places to live, he believed that we first need to conceive of the city as part of a larger whole. Like Caldwell described:

When we began by considering the city just by itself, a multitude of other inter-related maladjustments ... soon revealed themselves. It became apparent that any valid solution of the city must be a whole solution. We must find not only a specific answer to the chaos of the city, but a general answer to the chaos of our time -- of which the city is but a part. (Caldwell 1948).

To discover what is wrong with our cities, Hilberseimer would ask "What is wrong with our world?" defining a broader point of view from which to look at the problem. He would open our eyes to contemporary cities being dominated by commercial industry and ruled by interest, rather than reason and man's needs, as in the Agrarian villages of old (Hilberseimer 1946, p.166). City and regional planning was for Hilberseimer a means to reclaim our individual freedom by rebuilding our cities.

He advocated for planned decentralization which, as opposed to unplanned sprawl, provided an opportunity to integrate modern commerce, industry and agriculture into a healthy and sustainable urban fabric (Hilberseimer 1949, p. 136). Technology of the time also played a significant role in Hilberseimer's specific planning proposals. Greater military defensibility against the atom bomb coupled with available modes of transportation, (i.e. ship, train and automobile), called for and enabled a decentralized model of development. With careful planning, vacant land could be used to adapt and move our cities toward a more sustainable development pattern.

Hilberseimer's plan, taught at IIT into the early 1990s, refers to a planning concept based on the idea of a human settlement "unit". The Settlement Unit (Hilberseimer 1963), as it was called, dealt with and resolved the relationships of contemporary community life (i.e. living, working, and recreation) while also planning for growth. The size of the unit was based on a comfortable walking distance from home to school with a commercial center and industry located a short drive's distance. Other essential features of the unit included houses with Southern exposure to maximize daylighting, a street pattern with cul-desacs separating car and pedestrian modes of travel, (eliminating crossing hazards for children walking to school), and plenty of green space in and around the residential areas and tying together the commercial and industrial areas. Interconnected landscaped areas would be used for gardens and farms, orchards and meadows, forests and parks. 
The settlement unit was conceived as a flexible and responsive concept, adaptable to the unique requirements of any specific community or region over time. It was a theoretical construct. The population of a unit could vary, as individual buildings themselves were conceived to be varied, with apartment buildings and houses, large and small. To accommodate growth, plenty of space was planned around a commercialindustrial corridor and new settlement units could be added indefinitely along a linear traffic artery comprised of local and longdistance streets. Hilberseimer's plan would also be responsive to site, situating airpolluting industry with respect to housing, prevailing winds and topography. Many applications of this concept were developed by Hilberseimer and students at IIT for cities around the world, with many focused on the Midwest region.

\subsection{The City in the Landscape}

Caldwell's affinity for nature and landscape were supported and enriched by Hilberseimer's rational approach to planning. After producing drawings for the book, The New City, Caldwell published a paper collecting many of the ideas shared with Hilberseimer. "The City in the Landscape" published in 1945 in the journal Parks and Recreation, is a brief summary of what years later became his thesis of the same title. The thesis was published in January 1948 under the advisement of Hilberseimer, the year before his next book, The New Regional Pattern was published. A common thread of ideas is shared.

Caldwell's thesis captures the revolutionary spirit of an educational philosophy aimed at quality of life and sustainable practices against the hegemony of industrial capitalism. Of the fourteen chapters, the first twelve are dedicated to an analysis of the city. Chapter thirteen is dedicated to an explanation of Hilberseimer's plan. Chapter fourteen presents an application of the settlement unit concept in Chicago.

Caldwell's "Proposed Plan for Chicago" aimed to remedy five major, interconnected "maladjustments" typical of industrial cities: Smoke, a consequence of the arbitrary location of the industries in the city; Dangerous Streets, as the existing grid pattern of the city is unfit for automobiles; Traffic Congestion and Distance to Work, related to unplanned sprawl; Slums, where buildings have shut out nature and the loss of nature is a prison; and Lack of Parks, or rather, ineffectively located parks (Caldwell 1948, p. 91). To respond to all of these maladjustments at once, the proposal suggested major structural change:

Obviously we must plan the city as a whole. The just and proper solution of parts to a whole we have called order, and it is order which the city lacks. This, it must be finally clear, is the sum and substance of all the defects. The diagram suggests how we might re-plan the city by bringing all the complex parts into some rational order. (Caldwell 1948, p. 92.)

Utilizing Hilberseimer's settlement unit concept, the proposal was to convert the existing constricted city plan to a decentralized, linear pattern which would allow for sustainable development and growth. The diagram of the city (Caldwell 1948, p. 95) shows: located east of a main traffic artery, toward the lake smokeless industries and a commercial strip parallel to the main traffic artery; away from the lake west of the artery, smoke-producing industries with the adjacent communities located such that prevailing wind directions minimize impact of smoke; and heavy industries located along the Des PlainesIllinois River channel. An airport and central railroad are located close to the "center" of the city and minor railroad stations placed on the junction of the main traffic artery and 
the lesser. Additional airports and railroad stations could be added easily in this decentralized city if needed.

We could say it was like a vine, and the parts of the city projecting outward like branches - the residential communities like leaves. We might even say that the closed end streets of the residential areas were like the veins of a leaf. It is possible to point out such comparison, for all nature is the expression of order. So, indeed, our city might be. (Caldwell 1948)

Caldwell's drawing of "The City in the Landscape" (Caldwell 1948, p. 96) shows how planning and interconnecting green spaces into both urban and rural conditions in a decentralized city pattern can provide a way for housing, industry, and transportation to remain connected with nature.

\section{CONNECTIONS BETWEEN THEORY AND BUILT WORK}

\subsection{Gardens and parks}

In his early years as a landscape architect, the influence of the Prairie School comes through. Caldwell came to appreciate the park as a meadow, which symbolized to him the prairies of Illinois -- open spaces bounded by protective forests.

From his earliest works, Caldwell's landscaping palette included the open spaces as much as the rich and varied landforms, materials and plantings. The ground and plantings, the hardscape, water, sound and light all work together to create an environment touched by humans yet reverent of nature. An autodidact understudy of Frank Lloyd Wright, the landscape architecture at Eagle Point Park and Lincoln Park both capture the spirit of the Prairie School so well that they are often mistaken for the senior master's.

In 1933, as superintendent of Dubuque (Iowa) Parks, Caldwell designed the project in Eagle
Point Park he named "The City in a Garden" inspired by the City of Chicago's motto, "Urbs in horto." The 164-acre park is located on a bluff overlooking the Mississippi River with panoramic views of the city. The project was part of an initiative to extend the use of the park into the winter months through the addition of shelters and fireplaces. Caldwell's plan introduced characteristic Prairie School ideas. Structures of splitfaced Niagara limestone laid in irregular horizontal layers suggest the midwest prairie's natural geological stratification and were used alongside timber and stucco in the buildings. The distribution of the buildings in the landscape created a variety of interstitial spaces that were augmented with a variety of plantings, to create an aesthetic quality that was coherent while also rich and varied. The project earned a national W.P.A. design award in 1936, and in 2017 Eagle Point Park was added to the National Register of Historic Places.

During Caldwell's tenure with the Chicago Park District, he created landscape drawings for a number of parks including Montrose Park, Promontory Point at Burnham Park, and Jackson Park. The Lily Pool in Lincoln Park, Chicago is perhaps his best known, and one of his most treasured projects. It is said that he sold his life insurance policy to pay for flowers which he installed. The Lily Pool is a "Prairie garden" of approximately 2.5 acres with an unassuming entrance featuring a lagoon, waterfall, and council ring in stratified limestone. Stone walkways meander through plantings of crab apple, hawthorn, serviceberry, and sumac, underplanted with native viburnum and rose shrubs and woodland perennials. In 2002 the project was named a Chicago Landmark, and a National Historic Landmark in 2006.

This garden is a biographical footnote on the meaning of the Chicago Plain... The trees, shrubs and flowers planted in this garden were native to the Chicago Plain. They 
represented scientifically the ecology of the region. They were those plants which, over thousands of years had achieved perfect adaptation to the environment of climate and soil. Consequently, they were at once the most beautiful and most vigorous and healthy. (Caldwell in Blaser 1984, p. 38)

\subsection{Urban design and landscaping}

The relationship established between Alfred Caldwell and his professors at IIT, Mies and Hilberseimer, extended beyond learning. Mies was engaged by IIT to draw up a plan for the new 30-acre campus whose final version was approved in 1941. The campus plan was based on a 24-foot, 12-foot-high floor module used not only for the planning of each building but also for their location. Mies saw in this decision the solution both for the buildings to harmonize with each other as a whole and in the course of a long construction period which would extend even beyond Mies's retirement from IIT (Blaser 2002, p. 21). The result is a system of pavilions surrounded by nature, a campus in a park. With the plan already approved, Mies invited Caldwell, still a student, to design the campus landscape.

Caldwell never fully developed a landscape master plan, however it is possible to identify in his contributions, the concepts he was working on in the forties and that, at the same time, were a result of his previous experiences. Firstly, as a Jens Jensen's protégé, he shared the idea of using native tree and plant species in order to demonstrate an appreciation of the site. All the trees are placed "naturally" around campus rather than in straight rows, maximizing the idea of freedom of space that can be also connected with Mies's spatial ideas.

According to [Mies's colleague Peter] Carter, Caldwell had found a parallel between 'Jensen's insistence on the integrity of nature and Mies van der Rohe's insistence on the honest expression of a building's structure', so that the 'interaction between this freeflowing landscaping, with its diaphanous honey locusts and substantial hawthorn, and the pristine architecture, contributes a kind of poetry to both exterior and interior milieu'. (Haar 2002, quoting Carter, p. 73)

In the early fifties, after a substantial development of ideas in Caldwell's thesis and Hilbersimer's books, Caldwell and Hilberserimer had the opportunity to work together and with Mies on the urban renewal project, Lafayette Park, in Detroit. Trying to solve the "evils" associated with the industrial city, while bringing out its best, Hilberseimer, Caldwell and Mies approached the problem from different perspectives. Intended for middle class people, Hilberseimer planned Lafayette with three types of residential buildings, a high-rise apartment building, 2-story townhomes and 1-story rowhouses. These buildings, offering different amenities, were arranged on the edges of a clear space that Caldwell imagined as a meadow, or prairie. At one end of the clearing was a school, and on the other, a baseball diamond. Although the development was never completed, the plan comes close to being another application of Hilberseimer's Plan, where at least buildings of different scales are connected by green space and children walk to school in a park. In this project, Caldwell sought to evoke the specific spirit of the Midwestern landscape once again, using native species and integrating buildings and landscape. In the architecture of steel, glass and brick, can be seen Mies's respect for the local industrial materials.

In the hands of Mies and Caldwell, this schema is transformed into a site of lived and sensed interweavings and interrelationships between buildings and landscapes, private and public domains, enclosed and open spaces. (Waldheim 2004, p. 12) 
The Lafayette Park project represents the only built collaborative attempt to solve city problems of today that combines the ideas of Mies, Hilberseimer and Caldwell. Nevertheless, Lafayette Park does not deal with the city as a whole but only a portion of it, a defined site within the city.

\subsection{Caldwell's farm}

In 1948, Caldwell decided to purchase a forty-acre piece of land near Bristol, Wisconsin upon which he started to build his own farm. It was the same year he submitted his thesis and a year before the collaborative Lafayette Park project. Caldwell worked with his wife, family and students on this piece of land for the rest of his life. The project was never completely finished but it should be considered an experiment in living, an attempt to make his ideas come true.

I wanted to buy a piece of land. From the experience I had before I concluded that I have to live on a farm. I have to get my living out of the soil (...) It was consistent with [decentralization], but even more with my experience. (Caldwell 1987)

According to some, the idea of Caldwell's farm traces its origins to Jefferson's idea of an agrarian democracy of land-owning farmers (Waldheim 2004). Caldwell's own actions certainly support the idea of small farms for every American family, though his theoretical ideas also provided space for industry and commerce

In Caldwell's farm, it is possible to identify some influence from each of his mentors. Caldwell had started to think about the city and its current "evils" in relation to nature since he began working with Jensen. Like Jensen, Caldwell used native species of plants and materials as well as materials in their natural state to merge architecture and landscape. The walls of his farmhouse are native stone, whose interior cores are poured with concrete making "solid" stone walls.

This idea of integrating architecture in the landscape could also be associated with Frank Lloyd Wright's conception of Prairie houses. It is necessary to highlight that Caldwell affirmed that he was not particularly influenced by Wright's proposal for Broadacre City, however, like many others Wright defended "a piece of land for everybody" (Caldwell 1987). Wright's impact on Caldwell can be seen more so in the horizontality of architecture and also in the use of materials from the nature that surrounds it. As Wright was known to adapt his buildings to their natural surroundings, making of the two a continuous whole, Caldwell's drawings for the farm too show buildings completely embedded in the landscape.

Mies' influence on Caldwell's architecture can be perceived in the farmhouse both in terms of its clarity of construction and proportion as well as upon closer inspection of the drawings. One of the architectural problems Mies's students at IIT worked on was the development of a Court House, as he had done during his years at Bauhaus. In this kind of plan, the spatial fluidity and connection between interior and exterior is key, and was reflected in many of his projects from the thirties including the German Pavilion in Barcelona. Caldwell's plans for the farmhouse also recall the plans for Mies' unbuilt brick house in the early twenties, with walls extended into the landscape on all sides.

Finally, Hilberseimer's ideas are present in the planning for his farm, from the shared idea of decentralization that Hilberseimer had defended since his European years, to bringing attention to the importance of farms in modern city life. While Hilberseimer is best known for his ideal planning proposals, Caldwell is perhaps better known for his built work and as an activist. Caldwell proudly said: 
When I made my plan for the city of Chicago, I put my farm on this plan-there's a whole series of them, a whole band of these things, so that I always say the city plans never come to anything. Thousands and thousands of city plans have been made in America and they just gather dust on the shelves and are entirely forgotten. Nobody ever initiates any of these plans. Only my city is under construction. (Caldwell 1987)

With his purchase of 40 acres of an 80acre tract, Caldwell began to build the ideal city he proposed. Although the farm was never completed, and his Proposed Plan for Chicago was never fully realized as a whole, he said, "at least it was a try" (Caldwell in Blaser 1984, 50).

\section{CONCLUSION}

The City in the Landscape represented a broadening of the notion of Urbs in Horto at a time when urban planning was broadening from an inwardly looking, functional-aesthetic discipline to one that included social and environmental critique and advocacy, and in which transportation played an increasingly significant part. It was as much a critique of the Industrial Era itself as it was an action plan, a proposed sustainable development pattern for urban renewal. Caldwell's farm, the IIT Campus Masterplan and Lafayette Park each represent the ideal of "the city in the landscape" at different scales, and a greater role for natural landscape in the urban fabric. The landscape is an integral part of the experience of each of these places. Spaces to enjoy nature have been created within and among buildings in such proportions that the buildings inhabit the landscape rather than dominate. His adept and fervent use of native plantings demonstrates Caldwell's deep respect for the natural landscape. The historical status earned by the Mies Townhomes and Lafayette Park testify to the high level of quality that was achieved through the symbiotic relationship formed between disciplines of city planning, architecture and landscape.

The bold ideas and works point to a broadening perspective on urban design. Caldwell looked to the landscape not only for beauty and comfort, but also to secure social welfare and individual freedom against oppressive industrial-capitalistic interests which inhumanely hold profit above quality of life. The role that cities play in this human condition was captured by Hilberseimer in quoting Patrick Geddes:

\begin{abstract}
What we need is constructive peace and constructive peace simply means rebuilding this world, village by village, city by city, region by region, in terms of Geotechnic and of evolutionary ideals. We must go beyond the stone age of predatory economics and its accompaniment of mutual slaughter to the new age of co-operation, of tending our own garden and our nation's, with mutual aid as our ideal. (Hilberseimer 1949, p. 192).
\end{abstract}

The concept of a decentralized linear city embedded in the landscape emerged with respect to human, environmental and technological developments and in contrast to the practice of urban land clearing. Key to the decentralization concept was electricity, which extended previous limitations and promised a new era of great mobility:

Electricity, more and more replacing steam
power, has been an important force toward
decentralization. It has made production
possible anywhere. It has helped greatly to
make it practical, as it is today, to concentrate
or to decentralize at will, both in industry and
in agriculture. (Hilberseimer 1949, p. 185)

The more recent discovery that "the great economic revolutions in history occur when new communication technologies converge with new energy systems" (Rifkin 2011, p.1) 
puts Hilberseimer's and Caldwell's bold ideas into context today. Whereas in the first half of the last century, locomotion became a disruptive planning principle, in this one, Rifkin forecasted that "Internet technology and renewable energies were about to merge to create a powerful new infrastructure for a Third Industrial Revolution that would change the world." He predicted a new disruptor, a new hope, connected with technology, environment and humanity:

In the coming era, hundreds of millions of people will produce their own green energy in their homes, offices, and factories and share it with each other in an "energy Internet,"... The democratization of energy will bring with it a fundamental reordering of human relationships, impacting the very way we conduct business, govern society, educate our children, and engage in civic life. (Rifkin 2011, p. 2.)

The confluence of developments in smart tech, shifting away from reliance on finite fossil fuels, enhanced availability of renewable energy seems to suggest that a new socio-economic order may be on the horizon. Revolutionary ideas from midcentury, like Caldwell's, invite us to ask, What does the growing green-industry ( $\$ 4$ trillion by some accounts) mean for the now globalindustrial-capitalistic order? What of land use, of nature, of decentralization and what of farms and the mixing of agriculture and industry? What does today's city reflecting our new hopes look like?

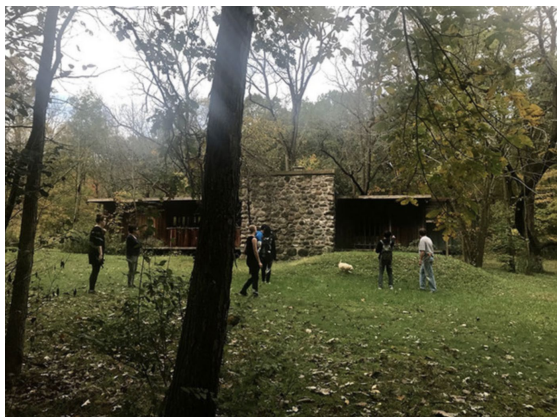

Figure 3. Wandering the Caldwell Landscape, Bristol, Wisconsin, 2018, photograph by Ron Henderson.

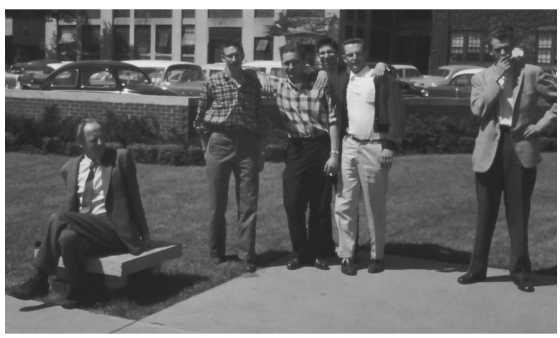

Figure 4. Alfred Caldwell and IIT Students, circa 1958, photograph by Jong Soung Kimm. 


\section{REFERENCES}

Achilles, R., Harrington, K. and Myhrum, Ch. Mies van der Rohe: Architect as Educator. Chicago: Illinois Institute of Technology, University of Chicago Press, 1986.

Blaser, W., ed. 1984. Architecture and Nature: The Work of Alfred Caldwell. Basel; Boston: Birkhäuser Verlag.

Blaser, Werner. Mies van der Rohe: IIT Campus Illinois Institute of Technology. Chicago. Basel, Boston, Berlin: Birkhäuser, 2002.

Caldwell, A. 1948. The City in the Landscape: A Preface for Planning. Chicago: Illinois Institute of Technology.

Caldwell, A. 1987. "Oral history of Alfred Caldwell." Interviewed by Betty J. Blum, February 28, 1987. Compiled under the Chicago Architects Oral History Project, Art Institute of Chicago.

Domer, D. 1997. Alfred Caldwell: The Life and Work of a Prairie School Landscape Architect. U.S.A.: The Johns Hopkins University Press.

Hilberseimer, L. 1944. The New City: Principles of Planning. Chicago: P. Theobald.

Hilberseimer, Ludwig. 1946. "Review of New Architecture and City Planning." College Art Journal, Vol. VI, No. 2, p. 165.

Hilberseimer, L. 1949. The New Regional Pattern: Industries and Gardens, Workshops and Farms. Chicago : P. Theobald.

Rifkin, J. 2011. Third Industrial Revolution: How Lateral Power Is Transforming Energy, the Economy, and the World. New York: St. Martin's Press.

The Cultural Landscape Foundation. n.d. "Alfred Caldwell. Pioneer Information." Accessed February 23, 2020. https://tclf. org/pioneer/alfred-caldwell.

Waldheim, Ch., ed. 2004. Hilberseimer/Mies van Der Rohe: Lafayette Park Detroit. Prestel ; Harvard University Graduate School of Design. 


\section{PAPER \#1.02}

\section{THE FACE OF THE CITY}

\section{Nuria Casais ${ }^{\mathrm{a}}$, Ferran Grau ${ }^{\mathrm{b}}$}

aAarhus School of Architecture, Aarhus, Denmark

bUPC-ETSAB, Barcelona, Spain

\section{ABSTRACT}

The evolution of European cities continues to oscillate between the essence of the "emotional city", and the potential of urbanal scenarios. Historic, newly built and radically transformed urban fragments coexist within a city and seek to fit into an urban structure that tends to redefine itself integrating discontinuities and a changing urbanity. A current review of European transformed cities through specific urban scenes allows a reading of the urban space and the role of architectural languages.

The dialogue between the built environment (ville) and the character of urban life (cité) reveals how cities are inhabited, and how the architectural forms draw a face of the city defined by "cosmetic techniques". Due to architects' trust in the possibilities of architectural language, a display of a cosmetic refinement enhances the subjectivity on the urban readers. Architecture approaches again the old debate between poetry and rationality. In the urban debate, the language and image of the architectural objects are key for the urban identity and centres the debate between cosmetic subjectivity and scientific objectivity. Exterior and interior appearances define the links with the city. Specifically from the outside, architectural objects can choose to be contextual, autonomous or indifferent, to their surroundings. The study of urban scenarios in the European city looking at new or transformed fragments, analysing the use of cosmetic techniques that sheds light on the potential and limitations of each specific context allows to assess the ability of architecture to collectively or individually build the identity of a city.

\section{KEYWORDS}

Urban space; city; identity; cosmetic techniques; architectural image.

\section{INTRODUCTION}

At the end of the 1990s, the political consolidation of the European Union ratified by the signing of the Maastrich Treaty (1992) gave a great boost to public architecture. The optimism of the new community alliances gave rise to new built architectures and others that, in the competition phase, yearned to anticipate the form and function of the architecture of the future. Some of the competitions developed by the Metropolitan Office of Architecture (OMA) acquired this utopian character and would become, without being built, reference architectures in the international debate, both professionally and academically. On the other hand, and within a framework of political and economic development, there were other practices more pragmatic and realistic that explored the limits of the tectonics. The most representative case was embodied by the Herzog \& de Meuron, which in the development of their architecture, sought the "highest ontological state of matter" (Zaera Polo 1993). Their constructive and material refinement was defined by Jeffrey Kipnis as the application of "cosmetic techniques" in which they linked antagonistic terms such as ornament and minimalism (Kipnis 1997). The architecture of Herzog \& de Meuron once again pointed out the role of the spectator's subjectivity and, in a way, bringing architecture closer to the category of art. 
Almost thirty years later, the architectural discipline has had to admit, after a global economic and climatic crisis, other attitudes resulting from a rappel à l'ordre. In the European context, the awarding of the last two Mies van der Rohe Award to interventions in existing residential buildings in the Netherlands and France, has not only valued built architecture, but also the social character that the discipline must take into consideration (Jacobs 1961). ${ }^{1}$

These two reference works have represented many architects who, through projects of a much smaller scale, have approached the architectural pre-existence and the users with care and respect. In this sense, the use of cosmetic techniques has been definitive for managing the architectural language in a personal way. The link between ornament and order, intrinsic to the term cosmetic, has allowed architects to offer the users a personalized response. This personalization of cosmetic techniques has given rise to: ornate architectures, naked architectures (in a way ornamented), technological architectures, brutalist architectures or other almost technically vernacular. Nowadays architecture is defined by artifices, often with layers, and with much or less thickness. This situation reveals the cosmetic character of the construction and the extreme possibilities of the architectural language defining the new based on the syntactic domain of the old. In consequence, the European urban scenarios show more and more the aims of architects for objectifying buildings in a way that highlights the difference between the interior and the exteriors.

This paper studies urban scenarios in the European city looking at new or transformed fragments, analysing the use of cosmetic techniques that sheds light on the potential and limitations of each specific context. In consequence, it assesses the ability of architecture to collectively or individually build the identity of a city, the meaning of homeyness (Caruso 2001), memory, nostalgia, heterogeneity and mistakes and success of urban spaces designed to inhabit.

\section{BARCELONA, ZURICH AND COPENHAGEN. THREE CASE STUDIES}

Barcelona, Zurich and Copenhagen define a European axis (South - North) representative of the cultural, social, urban, geographical and climatic diversity in Mediterranean, Central European and Nordic cities. These three cities have undergone relevant transformations in areas with their own identity and with well-defined physical limits. The diversity of these fragments, situations and contexts, allows establishing conclusive relationships on the architectural and urban appearance, finding points of connection and differences. Barcelona, the compact city (Busquets 2005), has shown that it feels much more comfortable and recognizable in the transformations in the center (El Turó de la Rovira for instance) than, for example, in more "peripheral" ones such as the 22@ or the Forum in which the new identity is characterized by an autonomy with respect to the existing city. Zurich, identity of the central European city, presents growths close to each other, really diverse. The Europaallee operation is a central complex tangent to the train tracks and nearby the Hauptbanhoff. Completely new, it evokes Hans Kollhoff's master plan for Alexander Platz in Berlin (1933) defined by large blocks around a central courtyard and a crown built with volumes at different heights. Architectural tectonics is a clear heritage from Kollhoff's teachings and practice, especially in the mannerism of Caruso St. John's project (who, like Kollhoff, also teach at ETH). Not far away, Zurich West, similar to Barcelona's 22@, has built on the existing industrial fabric, but in this case it has been an excuse for the redefinition of Swiss architectural cosmetics and a truly successful urban atmosphere. Following the train tracks we arrive in Oerlikon,

1 "The need for aged buildings" is the title of one of the chapters of Jane Jacobs' book The Death and Life of Great American Cities. 
an almost new neighbourhood, in which a large number of residential buildings have been built and in which Zurich's urban identity really takes on a new, much more global physiognomy. Copenhagen, to the south of the North, is a dynamic city in which two very interesting transformation zones are worth studying: Nordhaven and Ørestad. The first, the result of the transformation of a port area into an urban fragment, has been subjected to a radical cosmetic process in which the new buildings are, in some cases, prostheses or actions in existing architectures, giving rise to a new urban environment that, by maintaining the original essence, invites its inhabitants to recognize an identity based on pre-existences. Ørestad shows a different situation where the embryo of his growth is not a port, but a metro line and a wetland plain. In this sense, the difficulty of building a new urbanity is greater; here cosmetic techniques are at the service of objects and not so much that of the construction of urban links.

\section{BARCELONA, A BEFORE AND AN AFTER}

At the end of 1985, the Barcelona City Council promoted a communication campaign entitle "Barcelona get pretty" with the aim of advertising the Measures for the Protection and Improvement of the Urban Landscape. ${ }^{2}$ This anthropomorphic message invited citizens to pay more attention to the aspect that "the face of the city" presented. In 1985 the neglect of the architectural heritage in Barcelona was evident and the urban disorder drew an irregular skyline with party walls left exposed. This campaign referred directly to the architectural surfaces of the city, to the epidermis of the buildings, and set "the face of the city" as the starting point of an urban transformation that would end up going far beyond surface treatment. The rehabilitation of the facades was the action that would precede transcendental changes in the urban and infrastructural morphology of Barcelona. These deeper changes were evident globally during the celebration of the Olympic Games in Barcelona (1992), and a few years later, during the celebration of the Forum of Cultures (2004). Both historical milestones were fundamental at the time of internationally projecting a new, much more cosmopolitan, image that would eventually attract numerous global events. Olympic Barcelona was recognized worldwide for its opening to the sea, and last but not least, the optimization of the new infrastructures, as for example the beltway (Les Rondes), today still crucial for the city's mobility. The opening to the sea and the architectural nature of Les Rondes, were complemented with a third new urban proposal addressing the public space, the "hard squares". The so-called "hard squares" (built before the Olympic project) ordered the mobility and prioritized pedestrian rights. Plaza de Sants (1981-83) designed by Viaplana-Piñón with the collaboration of Enric Miralles, was a reference for the design of the Barcelona's public space that relied on geometric systems that created places with a remarkable degree of abstraction ${ }^{3}$. This new abstract public space presented a lack of green areas, especially due to budgetary and maintenance issues. The second public space reference was built ten years later on the occasion of the Olympic Games and it was projected by Eduard Bru in the Vall d'Hebrón. An ambitious Master Plan ordered an area of 37 hectares, attending to a complex topography and integrating sports facilities, green areas and paved areas with outdoor carpets that built a nature with artificial fragments. In Barcelona, in the 1980s and early 1990s, the language and the materiality of public space were more innovative than the building ones (Busquets 2019). ${ }^{4}$

\footnotetext{
2 The technical director of the campaign was the architect Josep Emili Hernández-Cros, architect and professor of the Higher Technical School of Architecture of Barcelona, and author of the Architecture Guide of Barcelona, together with Gabriel Mora and Xavier Pouplana, in 1972

${ }^{3}$ Right now the square is expecting a renovation project that promises to be very polemical.

${ }^{4}$ After 1975, the end of Franco's dictatorship, the city looks to represent the freedom in urban planning through the creation of public space.
} 


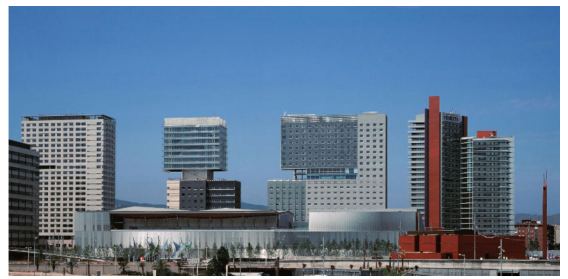

Figure 1. Forum 2004 area. Photographer Duccio Malagamba

"The face of the city" would not undergo a significant change until 2004 as a result of a global urban strategy that aimed to balance the city, both from an urban and economic point of view. The exhibition "Barcelona in progress", organized during the Forum 2004, decoded the meaning of the city's new growth. These new urban guidelines were based on three poles: the Plaza de las Glorias (Cerdà's Eixample centre), the area of the new intermodal station of La Sagrera, and the Forum area complex located at the end of Avenida Diagonal. In addition, the conversion of the former industrial district of Poblenou into an eminently technological district (22@) completed a series of actions in the east of Barcelona. These urban projects did not approach the public space (and the architecture) in an integrated way with the city as the Olympic project did. In this sense, the urban appearance gave rise to public spaces with a more fragmented and no-contextual character and a generic architecture and city (Koolhaas 2006), specially highlighted because of the construction of many hotel buildings very autonomous respect the existing urban identity.

Coinciding with the development of the Forum project (Fig. 1), the construction of new "skyscrapers", mostly concentrated in the final section of the Diagonal and the Forum area, underlined the global character of the city. This less familiar face was partly the result of the difficulty of projecting these buildings in height in contexts not yet consolidated, such as the

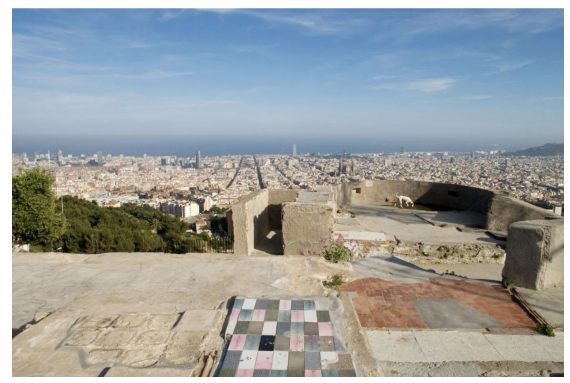

Figure 2. Transformation of the anti-aircraft defence facilities. Turó de la Rovira. Photographer: Lourdes Jansana

Plaza de las Glorias or the new Diagonal (area that goes from Glorias to the Forum). The set built on the occasion of the Forum 2004 integrated large buildings in height and consolidated the architectures with a more global character within a fragment of city built in the blink of an eye. The new skyscrapers in Barcelona were not referenced in those first high-rise buildings built in the late 1970s with a contextual vocation, with textured and three-dimensional facades. These strategically placed buildings would occupy representative corners or islands, and would be designed with a contextual language that managed to integrate them into the existing city, although they would stand out in contrast to the compactness of the urban fabric of no more than six or seven stories. The Torre Colón (1966-1971) or the Torre Urquinaona (1970) are the best examples.

The real estate crisis of world scale suddenly slowed the growth of the city. Barcelona's plans to balance and equalise its growth by promoting actions in the east (Glorias, Sagrera, Forum and 22@) were blocked. The 22@ slowly followed its development based on action units that evidenced economic power through a more no-contextual language and with few points of connection with the city cultural background.

\footnotetext{
${ }^{5}$ Unfinished. Pabellón Español. Biennale Architettura 2016. Ministerio de Fomento y Fundación Arquia. 2016
} 
Currently, the face of the city in Barcelona presents global architectural languages inherited from the era of the real estate boom; but also more affable ones, from the post-crises years, that are the result of the willingness to bring architecture closer to people. These languages were identified by the curators of the Spanish pavilion of the XV Venice Biennale held in 2016, which under the title of "Unfinished"5 gathered a series of projects that evidenced an "unfinished" architecture, in some ways "without make-up", and with a more domestic and iconoclastic character that reacted to a generic architecture or an exuberant architecture that at the beginning of the 21 st Century gave no concessions to the user. This attitude is having, even now, its translation in the design of the city's public space. Examples of public space that developed this attitude were also part of this exhibition. Among them, there was the Jansana, de la Villa, and Paauw's project in Turó de la Rovira (Fig.2). At the top of a promontory, the same place previously was an Iberian settlement, an agricultural settlement, an anti-aircraft defence facility, a barracks neighbourhood, and now a $360^{\circ}$ viewpoint that respects the history that the place has lived and bets on a really unfinished project that seems to be a ruin. This emaciated face of the city contrasts with another project that exemplifies a new line in the treatment of public space. It is the Passeig de Sant Joan, designed by Lola Doménech (2014), which incorporates green areas almost as if they were urban oases offering a friendly and close image, referenced in the hard squares, but also in the nature that was before the existence of the city. This public space project exemplifies how to intervene in existing urban scenarios incorporating new attitudes and promoting alternative urbanities.

\section{ZURICH, FROM THE CENTRE TO THE PERIPHERY}

The urban identity of Zurich remains influenced by the local debate that confronts tradition and modernity. In 1955 the writer Max Frisch (Frisch 1955) openly criticized the conservative character by referring to "homesickness for the day before" while advocating an urbanism that assumed the demands of future evolution and growth. In this sense, the urban identity of the city centre has undergone few apparent changes. Perhaps the most notable ones are the great underground infrastructure performance in the basement of the central Hauptbahnhof railway station, imperceptible from the outside, and the large Europaallee complex, recently built just near the same station, occupying lots next to the train tracks. The two actions are, in regard to appearance, a faithful reflection of the debate that Max Frisch raised, although the dimensions of the underground world under the Hauptbahnhof bravely assume the demands of the future. The appearance of the Europaallee project, with its large blocks with public courtyards inside, picks up a collection of architectural languages that goes from the modern Swiss tradition, sober and of great rationality (E2A), through a more ornate architecture (Caruso St John) to a language of glazed curtain walls (Gigon Guyer) with a more international character.

In the redefinition of Zurich's urban identity, rail infrastructure and old industrial areas have a decisive influence. It is needed to highlight that the great Europaallee project is based on land owned by SBB (Swiss Federal Railways), and that Zurich-West project is based on the conversion of the industrial zone crossed by Hardbrücke Bridge. This old industrial district is now an area that mainly allocates office building and facilities with their own and cosmopolitan identity unknown so far in the city. The success of this operation is the result of having integrated the pre-existence into a new tertiary fabric without renouncing to a new identity. The Gigon Guyer's Prime Tower is 


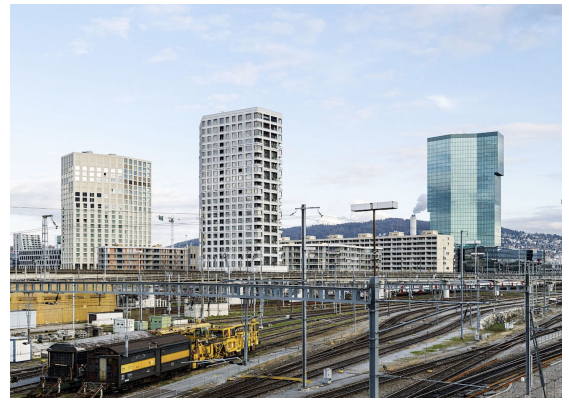

Figure 3. Zurich West. Photographer: Georg Aerni.

leading a modernity that is referenced in some of the downtown Zurich office buildings. The restaurants integrated between the arches of the Viadukt guarantee the life of the district beyond working hours. But the project that best reflects the new identity and a friendly city face is the conversion of the old milk factory (Toni) designed by EM2N studio. Toni Areal is a mixed-use building for education, culture and housing, in an operation that addresses the interior as an internal urbanism (Bideau 2015). Apart from these spaces with an industrial history, there are other areas with a much more noticeable residential character and that also explain the redefinition of the city's urban identity. In this sense, it is necessary to differentiate between those that are the result of an urban re-densification and those that have been completely built from scratch. Among others, these are the metropolitan neighbourhoods of Affoltern, Altstetten, or Albisrieden. In these neighbourhoods, as dictated by Swiss tradition, existing residential projects are always linked to a landscape project. They respond to a desire to be part of the existing urban fabric with a generally austere architecture based on residential buildings with pitched roofs, also identifiable in the first ring of downtown Zurich. In terms of language, the private real state tends to have a global appearance in comparison to the public promotions, which have a more personalized and attentive one, in a way, closer

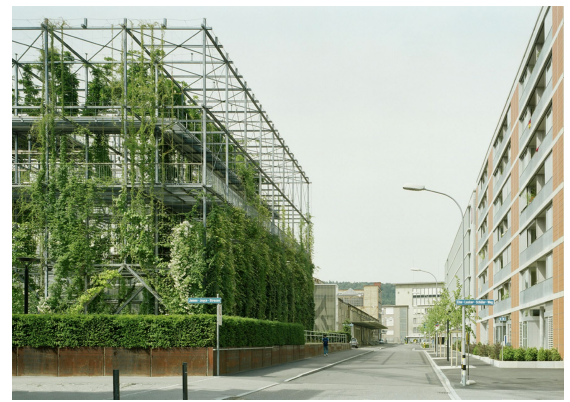

Figure 4. Oerlikon. Photographer: Michael Freisager

to the internationally recognizable Swiss architectural language. Language in collective dwelling projects is especially careful, which, having a long local tradition, collect all the wisdom of local architecture from architects such as Werner Stücheli or Max Bill: a sober architecture, but at the same time very sensitive and full of nuances.

Among the complexes built completely from a tabula rasa, the Oerlikon area stands out. Located in between the centre and the airport, Oerlikon gathers in a single operation a set of residential and commercial blocks with a little referenced character to the Swiss tradition. In this case, architecture is not completely capable of creating an urban context with its own identity, and the public space does not integrate a landscape project able of establishing links with immediate neighbourhoods. In this sense, in this complex, one of the most representative green zones is a metal structure that supports vegetation growth (MFO Park) and can be understood, in a way, as an empty housing block, and as a version away from the Swiss landscape tradition which fulfills the objective of mediating between architecture and the city or the countryside, eliminating any type of physical barrier. The criticisms of the residential project of Oerlikon do not lie on the quality of the housing, which has it and is relevant, but in the urban conception and its link in the general plot of the city. 


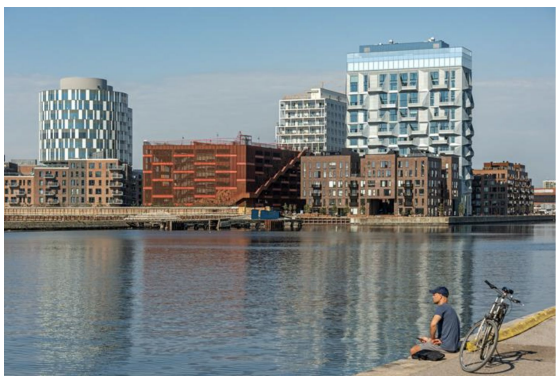

Figure 5. Nordhavn, Copenhagen. Photographer: anonymous

The analysis of the urban identity of Zurich shows that the "apparent disorder of the contemporary city" (Zardini 1997) and the heterogeneity that this disorder implies, is one of the specific characteristics that offers new possibilities for intervention. The commitment to heterogeneity, difference and the value of tradition as a starting point, builds in Zurich the most favourable conditions for the development of urban life.

\section{COPENHAGEN, NEW AND TRANSFORMED COAST}

The coastal border of Copenhagen, as in other cities of Denmark, is in a continuous transformation to allocate new urban fabric. Nordhavn (Fig. 5), the northern port, gives name to the largest metropolitan development in Scandinavia. Located $4 \mathrm{~km}$ from the centre of Copenhagen with exceptional connections by land and sea, its construction began at the end of the 19th Century. Nordhavn extends over the Øresund Strait on land reclaimed from the sea ${ }^{6}$ to house a constructed

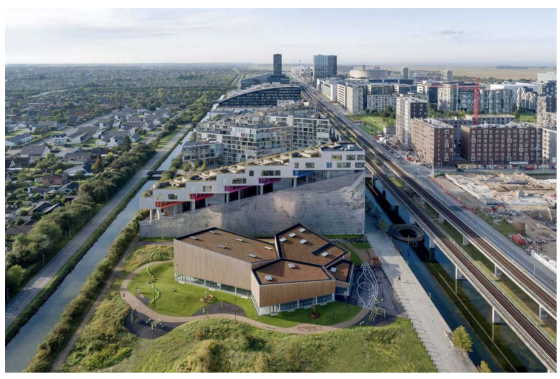

Figure 6. Ørestad, Copenhagen. Photographer: Adam Mørk

area of 4,000,000 square meters, in which 40,000 inhabitants will live and in which 40,000 jobs will be created. With the aim of being a "sustainable city of the future", ${ }^{72}$ the urban project, developed by COBE in 2008, integrates the debate between citizens and developers. The district of Aarhusgade, the first to be developed in Nordhavn, seeks to consolidate itself with the district of Østerbro going forward, despite the infrastructure barriers that separate them. Aarhusgade is the result of the transformation of an industrial sector into an urban residential space, with production and an economy typical of the tertiary sector. ${ }^{8}$

Strolling around Göteborg square we leave behind a stepped waterfront, a sign of a new urbanity, and looking towards the north, we can see an urban space that includes three of the most representative buildings of the old and the new Nordhavn: the Portland Towers (DesignGroup), The Silo (COBE), and Frihavns Tårnet (Praksis). ${ }^{9}$

Different cosmetic techniques define a new architectural identity in which only in the Portland Towers is possible to discern the

\footnotetext{
${ }^{6}$ According to the data provided by By \& Havn, the area reclaimed from the sea in Nordhavn accounts for $1 \%$ of the total area of Copenhagen. The filler material used for the new growth comes from the island of Zealand itself, and approximately 16 percent comes from the excavation of the Copenhagen Circular Metro line.

${ }^{7} \mathrm{CPH}$ City \& Port Development participates in the EnergyLab Nordhavn strategic partnership, which focuses on the development of intelligent energy systems, providing the energy flexibility necessary for the efficient use of renewable energy. A sustainable urban development process is the backbone of a sustainable city with a high degree of habitability. For this reason, the new areas of the city in Nordhavn are certified according to DGNB sustainability standards. Sustainability in Nordhavn can be experienced and measured.

${ }_{8}^{8}$ The new container and cruise port moves to a new extension of the same port (northeast) occupying new land reclaimed from the sea (Ydre Nordhavn).

${ }_{9}^{9}$ The Portland towers are the result of the transformation of two concrete silos built by Aalborg Portland in 1979; The Silo and the Frihavns Tårnet are the result of the adaptation of two silos built by the DLG Company.
} 
existence of a port industrial structure, covered with a volume of cantilevered offices fortified with industrial-style bracing, and finished with an enveloping curtain wall. In Nordhavn, what you do not see is important: in the Frihavns Tårnet building, for example, electricity, light, and heat are controlled by automatic sensors that measure CO2 levels and temperature. This means the temperature and the indoor climate are regulated automatically. On the other hand, what is evident (and visible) in Nordhavn is part of a new style that gives it an identity of its own.

A high-rise red car park (Lüders, JAJA) houses a recreational-public space on its roof covering an area of 2,400 square meters. At 24 meters high, and after climbing 135 steps lined with planters and the history of Nordhavn printed on the metal facade, we recover the view of the centre of Copenhagen, the sea and the dynamic and constantly transformed urban port context.

Approximately eight kilometres south of Nordhavn, the final section of the M1 subway line traces a dramatic straight line. Raised above ground level, it establishes the urban and territorial identity of the district of Ørestad (Fig. 6), located ten minutes from the centre of Copenhagen. The M1 Line circulates on an intermittent concrete bridge just after the Sundby station in the direction of Vestamager, the final stop; in this way, the M1 allows, in a transverse way, the urban connection and the crossing paths of other infrastructures.

Ørestad is an artificial city developed in a wetland area south of the island of Amager, and construction began thanks to the sale of publicly owned land to private interests ${ }^{10}$. Ørestad was conceived in the late 1980s as a strategy to alleviate the main problems of the city of Copenhagen: low growth, unemployment, and indebtedness. Near the two important infrastructures of the airport and the Øresund Bridge, which links Copenhagen and Malmö, it contrasted the tendency of the capital to grow towards the north.

The initial plan included mainly housing and offices, and currently includes educational facilities, a large shopping centre (Field's), an international convention centre (Bella Centre) ${ }^{11}$, and a multipurpose venue (Royal Arena) with global ambitions.

Ørestad is, in itself, a new great axis that divides an urban fabric woven together from single-family homes with gardens, a golf course, and wetlands. The duality between large and small scale coexists in Ørestad, where the architectural organization resulting from the building lots and interests of private development, combines terraced houses with orchards and large housing blocks.

In Ørestad, water is another structural element that participates in a personal way of understanding the urban landscape that connects with the nature of the place. A canal parallels the route of the $M 1$, and a pond defines the southern limit of this promised land that looks out towards the natural area of Vestamager, also known as Kalvebod Fælled ${ }^{12}$. On the southern edge, the architecture of Ørestad is abruptly interrupted by the presence of the horizon. 8 House $(B \mid G)$, on the southern limit of Ørestad, reveres the landscape by tilting its architecture and inviting nature to be part of its dynamic courtyards defined with small mountains, this time, real ones.

\footnotetext{
${ }^{10}$ Together with Ørestad, it was decided to build the subway, which would significantly improve public transport in the capital.

${ }^{11}$ In Ørestad, signs have been installed to announce the identity of this district, and they provide different messages:

- "With roots in Copenhagen architecture and lifestyle, Bellakvarter shows how a local neighbourhood can co-exist beautifully with an international conference centre".

- "A new Copenhagen neighbourhood is in the making right here! The area around Bella Canter is transforming into Bellakvarter - with residents, shops, and visitors from all over the world."

- "Just around the corner, you will find Nordergarden - a new urban space that during the coming summers develops into a hotspot for urban gardens, play, good food, and events for all of Copenhagen. In the middle of Nordgarden the Bella Urban Garden community is growing. Here you will find radishes, apple trees, and flowers and everything in between. During the summer, there are free workshops on urban gardening."

${ }_{12}$ Area reclaimed from the sea in the 1940 s to house military manoeuvres, and which is currently structured as a natural marshland

space.
${ }^{3}$ "La ciudad urbanal es una Ciudad con lugares "urbanales" que explican las consecuencias urbanas de la globalización» [The urbanal city is a city with "urbanal" places that explain the urban consequences of globalization].
} 


\section{CONCLUSION}

With practically no exceptions, the evolution of European cities recognizes two types of contrasting scenarios that make up contemporary urban reality: the essence of the "emotional city" (Caruso 2001), and the confusion and potential of new urbanal (Muñoz 2008) ${ }^{13}$ scenarios. Historic, newly built and radically transformed urban fragments coexist within a city. All of these fragments, succeeding or not, seek to fit into an urban structure that tends to redefine itself integrating discontinuities and an idea of a changing urbanity. The reaffirmation of the urban identity tries to balance local conditions versus global influences, and in some cases strong real estate and market pressures. The diverse socio-economic circumstances and situations experienced in the European context, with moments of prosperity and recession, influence the urban development and the way of making city. The review of the European transformed city through specific urban scenes allows a reading of the production of the urban space (Lefebvre 1974) in the last decades, and the role that the architectural language plays in creating a concrete urban appearance and a specific urbanity (Solà-Morales et al. 2008).

The dialogue between the ville and the cite (Sennett 2018) links the physical and built environment with the abstract nature of the character of urban life. This dialogue reveals how cities are inhabited today, and how architectural forms are designed full of meanings (in their composition and in their envelopes) showing a face of the city defined with different cosmetic techniques (Kipnis 1997) that conditions the perception of urban scenes. In consequence, European architects fully trust in the possibilities of architectural language, and therefore a display of a cosmetic refinement enhances the subjectivity on the urban readers. Architecture, again, approaches the old debate that faces poetry and rationality ${ }^{14}$.

Poetry, today, in the architectural context linked to ornament and the desire to create a much kinder architecture, becomes a tool to bring discipline closer to the user. It could be affirmed that the cosmetic linked to the management of architectural language seeks to create an "initial domesticity"; that is, conditions of comfort and habitability that already exist even before the inhabitant comes to experience architecture. This iconoclastic will is a consequence of the exhaustion of iconic architecture and the demands caused by the real estate crisis.

The habitability of the city is associated with the face, meaning the appearance and the semblance of the city. In Barcelona, El Turó de la Rovira, despite being a deconstructed and naked space, is capable of showing the history of the city and becoming a social meeting place. It is exactly the opposite situation to which one can experience when wandering through the soulless spaces of the Forum area. In Zurich, despite the functional success of the Europaallee blocks and the urban pragmatism of Oerlikon, the essence of the city reappears under the infrastructural bridges or the different viewpoints (Swiss tower or Toni Areal) of Zurich West, and is there where the Swiss socio-cultural identity feels like home, that sense of homeyness that Caruso talks about. In Copenhagen, when strolling around Nordhavn, the marine environment, saltpetre and freedom can be seen in the superimposition of the new on the old without any renunciation of modernity. Meanwhile, in Ørestad the most effective cosmetics are those of each building, such as the 8 by BIG, since the sum of architectural cosmetic techniques dilutes the feeling of belonging to the place.

\footnotetext{
${ }^{14}$ The Triennial of Architecture of Lisbon, that takes place this year 2019 and is title "The poetics of the reason", reaffirms the validity of the debate that raises the application of different cosmetic techniques within the scope of the architectural discipline. «The poetics of reason states that, for all the subjective and non-scientific dimension, architecture does rest on reason, and our aim is to shed light onto he specificity of this reason».
} 
In these urban debates, the language and image (Lynch 1960) of the architectural objects are key for the urban identity. In this sense, the architectural object centres the debate between cosmetic subjectivity and scientific objectivity, and it is confirmed as a meeting point for the meanings of the face of the city and the architectural fragments. In recent decades, the image (Ursprung 2008) and appearance have increasingly played a more important role in the production of urban space, both exterior and interior (Pimlott 2016). In this context, it is necessary to take into account that the order of the visual culture that now prevails, alters and conditions the design processes. The artifice, intrinsic to the architectural act, continues to draw interpretations that regulate the freedom of all those who experience architecture. Exterior and interior appearances define the links with the city and, specifically from the outside, taken into consideration that architectural objects can choose to be contextual, autonomous or indifferent, and therefore, to be friendly, distant or indifferent to their surroundings. 


\section{REFERENCES}

Bideau, André. 2015. 'Two Economies and Myriad Worlds'. In Import Zurich: Cooperative Housing: New Ways of Inhabiting. Barcelona: Cities Connection Project.

Busquets, Joan. 2005. Barcelona: The Urban Evolution of a Compact City. Cambridge: Harvard University Graduate School of Design.

---. 2019. 'Power. Barcelona: Transforming the Compact City'. In Real Urbanism. Decisive Interventions, First, 257-96. Amsterdam: Architecture \& Nature Publishers.

Caruso, Adam. 2001. 'La Ciudad Emocional = The Emotional City'. Quaderns d'Arquitectura i Urbanisme, 2001.

Frisch, Max. 1955. 'Der Laie Und Die Architektur'. MERKUR 9 (3): 261-278.

Jacobs, Jane. 1961. The Death and Life of Great American Cities. New York: Vintage Books.

Kipnis, Jeffrey. 1997. 'The Cunning of Cosmetics'. El Croquis, no. 84: 22-28.

Koolhaas, Rem. 2006. La Ciudad Genérica. Barcelona: Gustavo Gili.

Lefebvre, Henri. 1974. The Production of Space. Oxford: Wiley-Blackwell.

Lynch, Kevin. 1960. The Image of the City. 1st ed. Boston, MA: MIT Press.

Muñoz, Francesc. 2008. Urbanalización. Paisajes Comunes, Lugares Globales. Barcelona: Gustavo Gili.

Pimlott, Mark. 2016. The Public Interior as Idea and Project. Heijningen: Jap Sam Books.

Sennett, Richard. 2018. Building and Dwelling: Ethics for the City. UK: Allen Lane.

Solà-Morales, M., K. Frampton, A. Geuze, and H. Ibelings. 2008. A Matter of Things. NAi Publishers.

Ursprung, Philip. 2008. 'Imágenes'. In Caruso St John. Barcelona: Polígrafa.

Zaera Polo, Alejandro. 1993. 'Continuidades. entrevista con Herzog \& de Meuron'. El Croquis, no. 60.
Zardini, Mirko. 1997. 'The Prevalence of the Landscape'. In Nuevos Paisajes Nuevos Territorios, 203-9. Barcelona: Macba Actar. 



\title{
PAPER \#1.03
}

\section{CO-DRAWING: COLLABORATIVE REPRESENTATIONS OF THE CITY}

\author{
Antje Steinmuller ${ }^{\mathrm{a}}$, Christopher Falliers ${ }^{\mathrm{a}}$ \\ aCalifornia College of the Arts, San Francisco, California, USA
}

\section{ABSTRACT}

Designed as catalytic interventions as part of emerging protocols for public space production, Co-drawing discusses a series of collaborative drawing experiments as platforms for community exchange and dialogue. The form of public space as the domain of architects is increasingly replaced by structuring a process of formation - a forum - that positions architects as collaborators with the public, designing sites, artifacts, and protocols for citizen engagement. Activated in public, the authors' co-drawing artifacts depict latent urban spaces as prompts for citizens to collaborate through drawing, producing collective representations, and fostering dialogue about the city.

Discussing three spheres of design and art practice situate the project: relational aesthetics artworks described as 'catalysts of exchange' or 'producers of an encounter,' (Bourriaud 2002, 15) with outcomes taking the form of lived social environments; the designed engagements within Archigram's Instant City protocols and Raumlabor's temporary activations which position the architect as community advocate and collaborator; and multi-centered representations of cities, ranging from Pieter Bruegel the Elder's The Tower Babylon (commissioned to foster a 16th century convivium) to Atelier Bowwow's 'behaviorology' studies, which describe the multivalent activation of lived urban space.

Producing artifacts and actions in public to be played out by the public, the paper puts forward three design elements central to envisioning the city with the public: an artifact as a platform for public engagement (the drawing within a social form like a community table), a protocol as the structure of public involvement (a prompt to engage and discuss a specific public space issue), and an event, the choreography of public gatherings (an outdoor, communal dinner or public gallery opening). Tested in five cities, these experimental representations/ events have resulted in the production of collaborative urban representations, and, more significantly, initiated community engagement, dialogue, and debate.

\section{KEYWORDS}

Co-drawing; city representations; public space; community engagement; relational aesthetics.

\section{INTRODUCTION}

Within emerging trajectories of practice, the form of public space as the domain of architects is increasingly replaced by structuring a process of formation - a forum - that positions architects as collaborators with the public, designing sites, artifacts, and protocols for citizen engagement. Within this trajectory, traditional architectural and urban design expertise is expanded to include the design of public engagement. Beyond traditional community engagements, such as architect-led community meetings or reports to a community, this type of work stimulates a deeper involvement by the community and two-way interactions between designers and the affected public.

This paper discusses one avenue of this more reciprocal exchange between architectural expertise and community engagement, the exploration of collaborative representations of urban space. It presents a series of collaborative drawing experiments as 
platforms for community exchange and dialogue. Activated in public, the authors' codrawing artifacts depict latent urban spaces as prompts for citizens to collaborate through drawing, producing collective representations and fostering dialogue about the city. Each involves a three-part design methodology: an artifact as a platform for public engagement, a protocol as the structure of public involvement, and an event, the choreography of public gatherings.

Three lines of influence inform the project, the use of multi-focused, multi-authored urban representations, designing and drawing urban engagement, and the use of the object and event in so-called relational aesthetics art practice.

\section{Multi-focused, multi-authored urban representations}

Representations of a city, especially using multi-centered compositions, have initiated critical and/or utopian discussions, and/ or to capture the dynamism of/within urban formation. Pieter Bruegel the Elder's "The Tower of Babel" [1563] represents both the aspirations and critique. As historian Barbara A. Kaminska observes, the painting was "originally displayed in the suburban villa of Antwerp entrepreneur Niclaes Jonghelinck as an image that fostered a convivium (a learned dinner conversation) about the well-being of the city" (Kaminska 2014, 2). The painting is based on the Christian Bible's value ascribed to society identifying itself through its cities, "Then they said, 'Come, let us build ourselves a city, and a tower with its top in the heavens, and let us make a name for ourselves; otherwise we shall be scattered abroad upon the face of the whole earth.' (Genesis 11:4). The urban representation acts here as the stimulant for the convivium's contemplation of 16th century urbanity.

City representations can be simultaneously idealistic and critical. Art historian Hans Belting interprets Hieronymus Bosch's "The
Garden of Earthly Delights" [c. 1480-1505] as utopian and realistic. It reflects "remarkably modern freedom...", "normally guided by compositional structure, here we become lost in an overfilled panorama whose motifs appear like a compendium but cannot be read like one..., revealing the illusory aspect of the way things look in reality" (Belting 2016, 7). Bosch transforms the triptych format so that each panel holds multiple scenes, multiple painterly effects, all within a multi-centered composition. Is the artifact a representation of lived space? Regarding Bosch, architect Jimenez Lai posits that "no single center of gravity to dominate the discourse" (Lai 2015, 10) offers potential for plural visions of constructed space - "an investment in anecdotes: the parts will be more than the sum" (Lai 2015, 10). In Lai's own work, the flattening of urban space is seen through the use of multi-centered compositions and the displacement of the $2 \mathrm{D}$ representation into immersive space. For "insideoutsidebetweenbeyond" [2014], Lai cites Bosch's examination of heterotopian space and a flattening of space and social relations. Lai's "Beachside Lonelyhearts" gallery installation, where an allover drawing on ceiling, floor, and wall surfaces create an immersive environment. This wallpaper effect conflates representational and actual space. Critic John McMorrough argues Lai's own multivalent work continues utopian dialogues addressing "questions of how architecture is represented - its social context, its possibility, and, finally, its continuing resonance - in pocket universes where possibility is unregulated" (McMorrough 2012, 9).

Lai's representational flattening is also disciplinary, as the merging of architectural representation, cartoons, and thought bubbles. This mixing of architectural expertise and popular formats continues the Pop sensibility of Archigram's magazines, a more 'approachable media' open to non-experts. The front cover of "Archigram Nine, Fruitiest yet.... FREE SEED OFFER" [1970], depicts everyday life in mode of representation akin to montage, 
comics, and popular magazine illustrations. These recognizable everyday representations relate personal and common space to urban, social, and ecological topics.

\section{Designing and drawing urban engagement}

Archigram's sequential drawings for "Instant City" [1969] can be seen as precedent for the architect's temporary involvement with the coproduction of urban space. Archigram's series depicts six steps ("Before IC: A Sleeping Town," "Decent," "Event," "Highest Intensification," "Infiltration," "Network Takes Over"). As the Instant City blimp symbolizes the new form of limited duration, event-based urbanism, it also leaves a lasting impact for the citizenry, the seeds of a new self-reliance, and a network to foster external connections. This process both highlights and shows the limits of the architect's role in the co-production of public or common space. Architecture and urban expertise still apply to very specific urban and community conditions, yet necessitates a more egalitarian, temporary engagement with a community, and the initiation of sustained community involvement. Co-drawing can take clues from this analogous approach. Design acts, events, and the input of architectural expertise through a temporary engagement/installation can act as stimuli for community dialogue, an early step in urban space formation and possibly initiate community self-organization.

Contemporary practices examine coproduced urban representations as part of this process. These range from a focus on the understanding of the problems of everyday urbanism to more utopian visions. Atelier Bow-Wow and Manuel Bailo Esteve examine the role of architectural and urban form and urban social behavior. Bow-Wow's quasianthropological work explores the behavior of the public in public, documenting social/spatial configurations within urban contexts. Drawings like Temple of Heaven (from Urban Forest) [2015], architect-designed artifacts, people, and ad-hoc spatial configurations (construct of groups using furniture and props) are rendered with graphic equivalence and precision. They involve students in the construction of large, field-like representations of public space, such as "The Making of a Public Drawing" [2011]. Their multiple eyes and hands lead to rich and multivalent understandings of the spatial configurations and behaviors of the public. Manuel Bailo Esteve's drawings, such as "Public Catalyst (Water Hydrant)" [2017], represent relationships between objects and social behavior of everyday urban life. The use of color highlights these interactions. A colored open hydrant and flowing water are in dialogue with the monochrome playing children documenting the social/spatial catalysts in public space and their use. Both Bow-wow and Estave recognize and reveal the catalytic potential for everyday urban spacedefinitions for citizens' productive use and misuse. This harnesses an understanding of spatial configurations and behaviors of the public as part of a larger ethos of citizens and designers coproducing the city. Atelier Bow-Wow relates these when they state, the "practice of architectural design in accordance with the theory of commonality [...] must adopt an abductive role" (Bow-Wow 2015, 106).

Designing a prompt for urban dialogue, or initiating a community to share messages is a central aspect of the work of urbanist/artist Candy Chang. To initiate the sharing of a citizen's voice, simple designs, well-positioned in public, reveal the unseen community and their unheard voices. In the "Before I Die...___ series [2011- ], a public surface is inscribed with a prompt for individual citizen participation. In this case, a vacant wall is transformed into a community chalkboard, populated with a grid of lines prompting "Before I Die...__ and blank line for individual responses. The format results in a collective archive of individual communication, and reveals some of the identities and stories of a community. These become sites of collective dialogue, merging the graphic broadcasting 
and scale of urban billboards with the kiosk's invitation for interaction.

\section{Influenced by a discussion with Archigram's} Dennis Crompton, Raumlaborberlin's "Architecture Beyond Building, Stick on City" (Venice Biennale) [2008] situated a co-drawing experiment as more of a utopian, aspirational exercise. An imagined, partially completed base drawing of a city sits within a gallery space. A workshop-like table prompts the public to add patches, thus producing a multivalent, multicentered, multi-authored, and 'multi-storied' composition of idealized urban space. Coproducing a representation of the city, the project invited the architects' utopian vision to be overwritten by the public. Working well during the opening days, overriding graffiti-type markings overwhelmed the work near the end of its gallery run.

Representations depicting the potential of a city situated within that same city construct simultaneities of representational and lived urban space. The city and its representation can co-exist, allowing actors changing a part of the city to situate themselves within that context. As a criterion for drawing as community tool, curation and continued engagement become key points to maintain some control of the design act and enhance community/architect dialogue.

\section{Relation to relational aesthetics, use of the object}

In his book Relational Aesthetics [1998], Nicolas Bourriaud identifies art practices that position the artist as the 'catalyst of exchange' or 'production of an encounter', with outcomes that often take the form of lived social environments. Writing about artists working against a cultural situation where social relationships are increasingly predictable and commercialized (Author 2005, 22), Bourriaud highlights artistic production that takes the form of meetings, encounters, events, various types of collaboration between people and places of gathering. The aesthetic 'objects/subjects' on display are the human interactions engender (Author 2005, 22). Rikrit Tiravanja's 1992 Thai dinner inside 303 Gallery in New York imports a kitchen environment and the social protocols of cooking and dinner into the gallery to catalyze/display familial interactions between visitors. Futurefarmers' "Ethnobotanical Station" deploys a mobile cart, map, and information gathering equipment and workshops (joint information gathering and discussion) initiate interactions between people and ecological information to catalyze collective knowledge sharing regarding the relationships between humans and the environment. A mobile artifact allows for flexible engagement and accumulation of knowledge. The unfolded cart attracts, displays and catalyzes, moving beyond a typical gallery experience to situate the work as actor/ catalyst for interaction.

In this type of work, artists are repositioning and transforming familiar artifacts or situations (a dinner, an information cart) within alternative contexts and with additional social content. The relationship between the familiar form and its associated familiar behaviors are the basis for alternative social interactions and form of exchange.

\section{DESCRIPTION OF CASE STUDIES}

\subsection{Drawing Table / Zeichentisch, Berlin Hafenplatz}

"Drawing Table / Zeichentisch", Berlin Hafenplatz (Fig. 1) is an experiment in leveraging architectural expertise to frame and moderate dialogue with citizens by drawing together. The resulting co-drawing builds on a developed base drawing describing Berlin's urban space as an instrument of/for capturing and curating citizen input, as well as the defining a method of participation. The project is produced within an academic travel studio by professors from California College of the Arts, in collaboration 

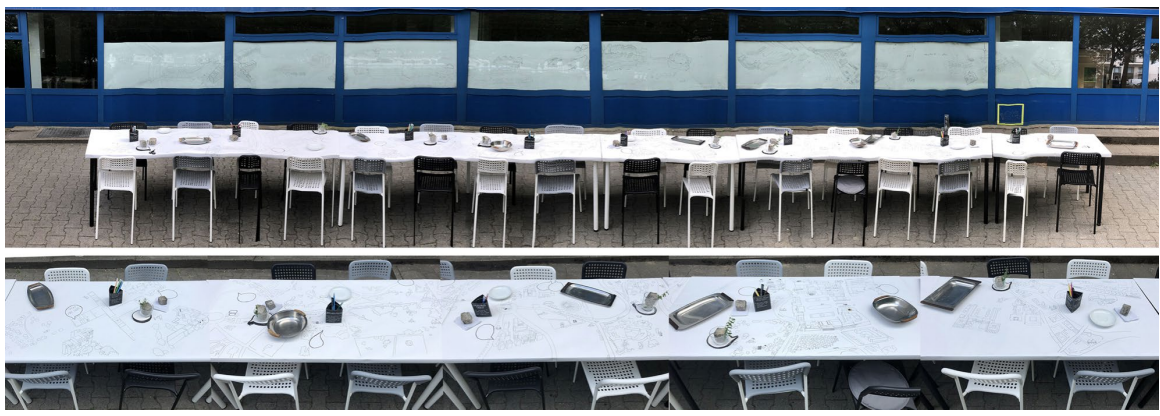

Figure 1. Berlin Drawing Table, Hafenplatz, by CCA Architecture students, Berlin, Germany. Image source: (Steinmuller, 2018)

with CCA students in architecture, industrial design and film, Raumlaborberlin, and the citizens of the Hafenplatz neighborhood in Berlin. Hefenplatz is a complex of 1970's era social housing blocks and series of open spaces. It's inhabitants are a broad range of working-class city dwellers, immigrant families, and students. It sits within a gentrifying district of Berlin.

For three weeks, the travel studio works out of a vacant grocery store within the housing complex. As a way to understand the needs and desires of the neighborhood, a design for engagement is produced by students. A long drawing/dining/meeting table is designed as the site of community engagement (Fig. 2). A base drawing depicts typical and archetypal urban spaces of Berlin (Fig. 1; Fig. 3). Students design a menu of prompts (Fig. 3), questions that play with the meal theme and organize how students engaged with citizens. Finally, students plan, advertise, and organize a 10hour community event. They partner with two local businesspeople, both of whom use vacant storefronts within the complex for temporary uses, one a weekday lunch Thai restaurant and the other a once/week bar. The partnership brings food, clientele, and neighbors together. During the event, students ask neighbors about their neighborhood, the life they come from, and the threats of gentrification. Then, they ask them to draw, or draw with them, on the table to visualize their hopes and visions for Hafenplatz. Students record these drawings and transcribe them on to the grocery storefront windows (Fig. 3, right image). This second drawing becomes an archive of the event in the days after, a form of kiosk allowing the community to see each other's thoughts.
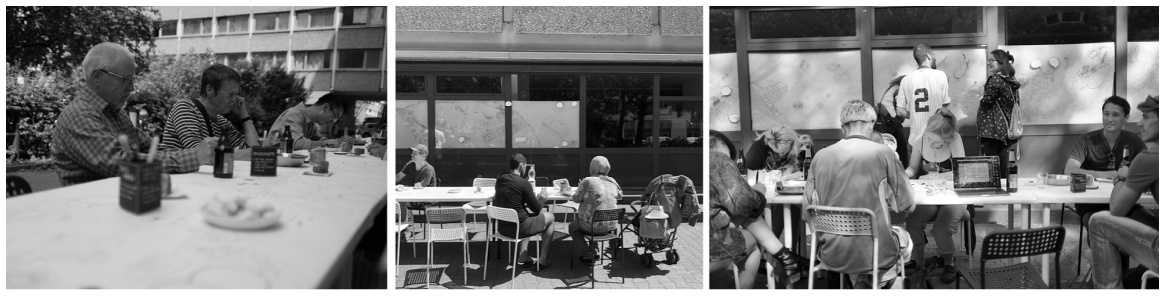

Figure 2. Berlin Drawing Table, Hafenplatz, by CCA Architecture students, Berlin, Germany. Image source: (Zhongwei Wang, 2018) 

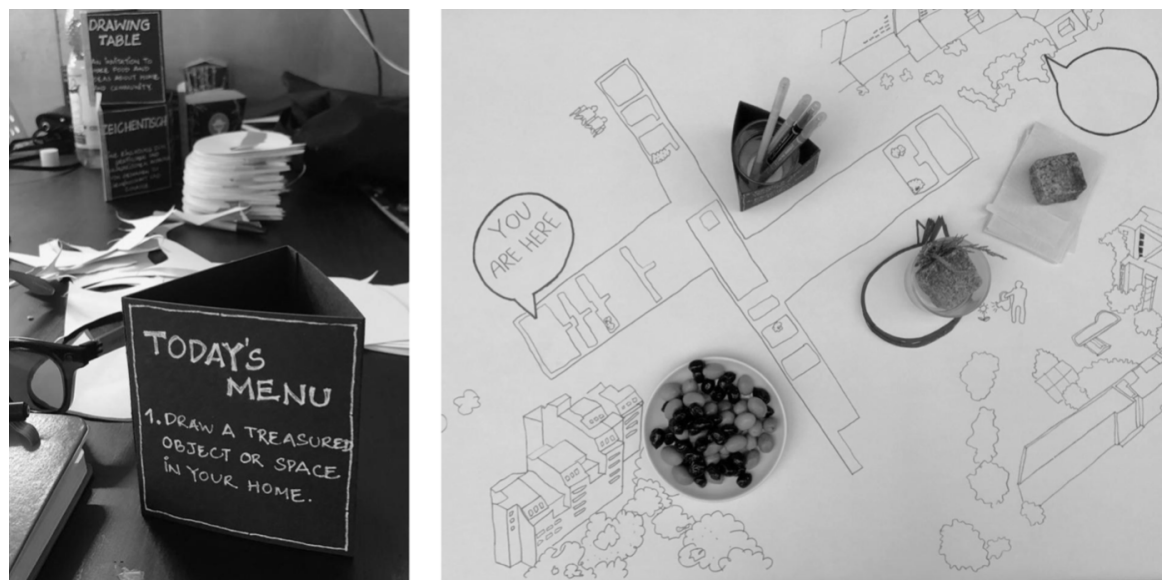

Figure 3. Berlin Drawing Table, Hafenplatz, by CCA Architecture students, Berlin Germany. Image source: (Steinmuller, 2018)

\subsection{All Covered with...}

As part of the Portmanteau Exhibit (a traveling exhibition of suitcases engaging issues of architectural or urban space, social interaction, and/or critique, from 2018-current in multiple venues), all covered with... is a gallery installation which prompts city dwellers to interact with representations of their own city, then co-drawing their visions of, and for, the city. This project has moved cities and has been presented in the Milwaukee Museum of Art (Fig. 4), one of the University of Colorado, Denver's campus galleries, and the Priscilla Fowler Fine Art, a private art gallery in Las Vegas (Fig. 5). The work consists of a pairing of two drawing scrolls over a lightbox, sitting within a suitcase. Drawing instruments and a prompt invite participation. Visitors align, misalign and draw on the paired drawing scrolls, each depicting basic representations of urban places of social interaction, environmental amenities, and vacant sites with latent potential.

For each city (Milwaukee, Denver, Las Vegas, and scheduled for New Orleans, Los Angeles, and San Francisco), simple base drawings depict the authors' observation of one focused theme of a city's latent open spaces. For Milwaukee, the drawing forces on 'junctions', from typical intersections with a the city's grid to transitions between city and river, or city and lake. For Denver, the drawing brought forward the theme of 'linear gaps' or linear open spaces, from the typical neighborhood alley system to the open spaces of and along the creeks and small rivers. The Las Vegas drawing highlighted urban 'islands', ranging from geometric parking lots to beautified figured spaces along the Las Vegas Strip.

The drawing focuses on certain urban characteristics and the prompt asks citizens to envision their vision for these spaces. During gallery openings and normal public hours, the viewer engages the work alone or with companions. This is free of additional influence by the architect, yet conditioned by how other participants left the drawing. Participants drew, sent messages, and responded to each other within the scrolls. An archive of the co-drawing scrolls documents how citizens see and think about the present and future of their city. 

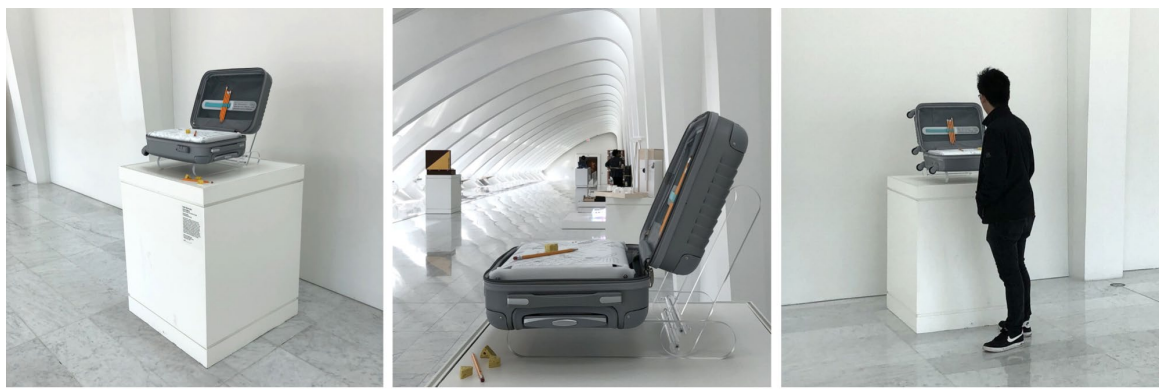

Figure 4. All covered with.., by Ideal X at the Portmanteau Exhibit, Milwaukee Art Museum. Image source: (Steinmuller, 2018

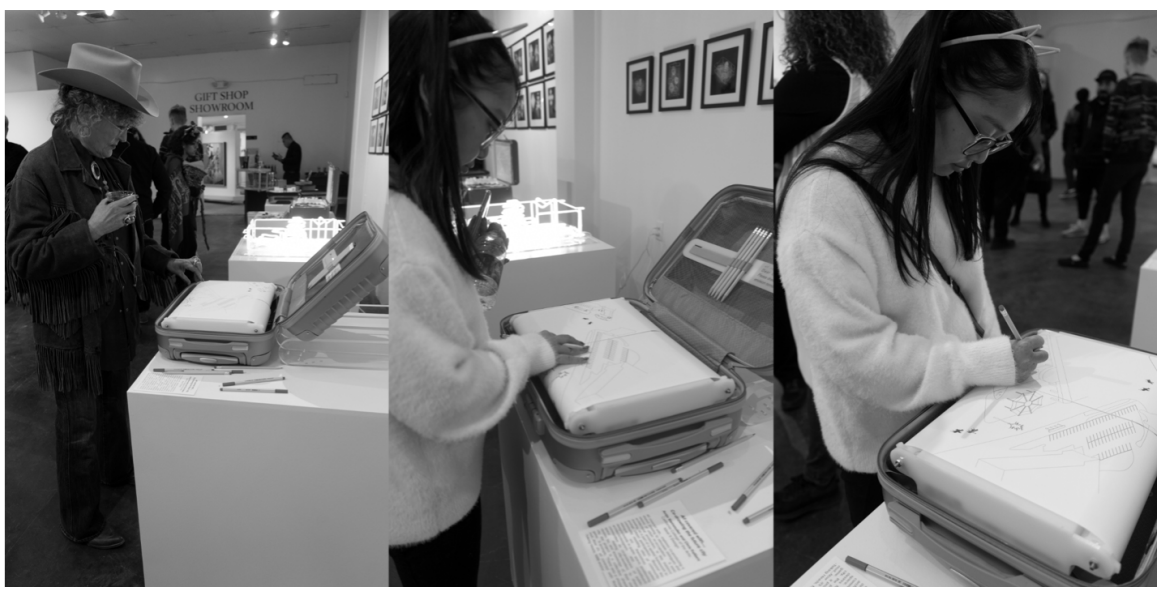

Figure 5. All covered with.., by Ideal X at the Portmanteau Exhibit, Las Vegas. Image source: (Dafne Odette, 2019)

\subsection{The Continuous Campus}

As an experiment in the co-production and sharing of knowledge, The Continuous Campus (Fig. 6), is a drawing [game, engagement, discussion]. The project asks participants to consider the provocation of the title, roll two dice to consider alternative sites and tactics for knowledge exchange. Then participants are asked to draw, collaborate, discuss, and debate the potentials for the exchange of knowledge in alternative and/ or more public spaces. In its initial trial, it situates within a conference for architects and urbanists at Stanford University, with a focus on alternative pedagogy. Quite simply, the project offers participants an alternative to a conference session. Instead of delivering a report within a hierarchical configuration of presenter (expert) and audience (learners), the project attempts to demonstrate a structure for an alternative form of knowledge sharing. Understanding the conference audience includes expertise of varying specializations, conference goers sit with each other at a drawing table. 


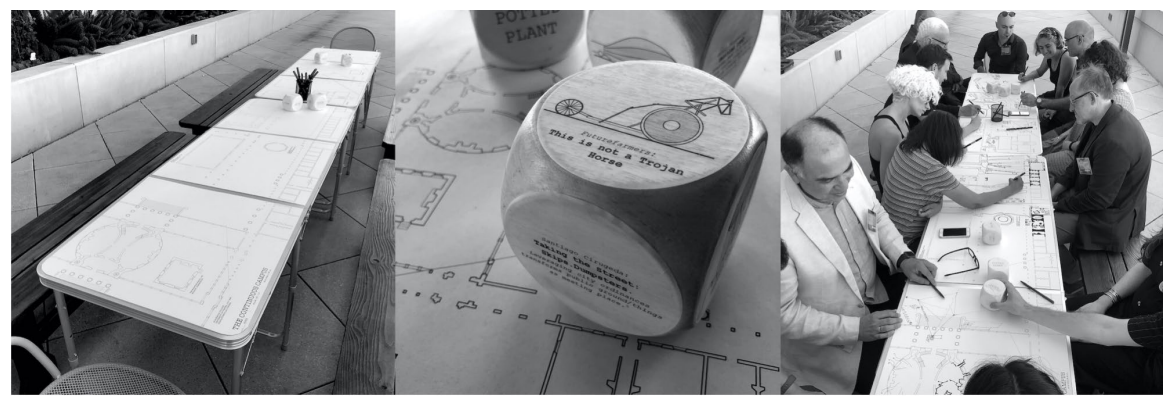

Figure 6. The Continuous Campus, by Ideal X at Stanford University. Image source: (Steinmuller, 2019)

A base plan drawing including a portion of the historic Stanford quad, designed by Frederick Law Olmsted, Charles Allerton Coolidge and colleagues, and by Leland Stanford himself, merges with the plans of other archetypal examples of American education architecture (Fig. 6, left image). This ranges from Thomas Jefferson's plan for the University of Virginia, to one-room rural schoolhouses, to the University of California, Santa Cruz's Kresge College, designed by Charles Moore and William Turnbull of Moore Lyndon Turnbull Whitaker. Instead of one presenter's broadcast of knowledge, participants share expertise and discuss alternatives for the future space of education and knowledge exchange. The act of drawing merges with dialogue, with the architects, urbanists, and educators taking turns to use drawing to make a compelling point or use one hand to document a consensus thought (Fig. 6, right image).

\section{METHODOLOGY}

Producing artifacts and actions in public to be played out by the public, co-drawing experiments put forward three design elements central to envisioning the city with the public: an artifact as a platform for public engagement (the drawing within a social form like a community table), a protocol as the structure of public involvement (a prompt to engage and discuss a specific public space issue), and an event, the choreography of public gatherings (an outdoor, communal dinner or public gallery opening). Tested in five cities, these experimental representations/events have resulted in the production of collaborative urban representations, and initiated community engagement, dialogue, and debate. Each project involved three aspects of design: an artifact as a platform for public engagement, a protocol as the structure of public involvement, and an event, the choreography of public gatherings.

\subsection{Artifact: drawing artifact + spatial artifact}

In each co-drawing experiment, a design artifact included the following.

- $\quad$ An incomplete base drawing, representing urban space for its latent potential and/or archetypal form.

- $\quad$ Adrawing format representing multivalent information (a scroll, a tablecloth, or simply large scale)

- $\quad$ Re-appropriating a familiar form used within public or social engagement, and/ or to provoke initial interest (a dinner table, a storefront window, an everyday suitcase as gallery object)

- $\quad$ The merging of the drawing format and familiar social form 


\subsection{Protocol: prompts to visualize spatial/ social potential}

In each experiment, the design of a prompt included the following.

- An invitation to participate and share thought, geared to specific knowledge (a neighbor asked about her neighborhood, an architect asked about her expertise on a topic)

- A request to consider and respond to the visual information within the drawing (certain types of latent spaces within a specific city, the hierarchical form of a campus or classroom)

- A request to review, act on, and/ or expand the thoughts of fellow participants.

- The form of the prompt ranges from an invitation to engage in the project to a set of dice with which to play a drawing game (Fig. 6, center image).

\subsection{Event: from gathering to dialogue}

The design of, and/or participation in, an event is integral to each project, and ranges in the type of social interaction being leveraged.

- The use and transformation of a familiar social event to be a site of additional interaction (a dinner, a gallery opening, a conference).

- Constructing the event as both social and a time to share knowledge.

Inviting key stakeholder where possible (affected neighbors, additional expertise).

- $\quad$ Constructing partnerships to promote and heighten participation (local food, supporting gallery or institutional format).

- Define the duration to concentrate the time for interaction (a meal, an opening, an meeting).

\section{OUTCOMES}

Although the co-drawing experiments have varied in content, topic, and audience, some initial conclusions can be made regarding co-drawing as a design tool to visualize the patent potential of public space and initiate community engagement and involvement.

\subsection{Limited time, limited engagement}

One of the dilemmas facing participatory design processes and community engagement, the architect's involvement remains temporary as with conventional practice. The depth of engagement that the experiments designed is commensurate with the depth of response. Most successful is exemplified with the Drawing Table, Berlin. As a student and two neighbors sat to discuss the neighborhood, they first talked and listened to each other over a beer and food. This comfort and relatability led to the student drawing with, and for, these particular neighbors for over an hour. This foregrounded the necessity for architectural expertise mixed with engaged listening.

\subsection{Drawing to trigger the imagination}

The base drawing balances a number of issues. It depicts specific characteristics of a city's urban space while remaining open to act upon. The nature of the drawing, whether axonometric, perspectival, or planimetric, and inherent legibility or abstraction must still have enough experiential triggers to spark people's imagination. Conceptually, the drawing must render an incomplete city, one with a future and open to change.

\subsection{Leaving people to draw or build}

Ceding control of a design or representation in these temporary experiments brings all of 
the analogous dangers of unchoreographed urban formations. The experiments should not be understood as an analog for informal urban or architectural formation. The messiness and individual nature of a multihanded representation is more effective as a collector of thoughts and place to see others' thoughts.

\subsection{Drawing as talking}

The majority of the drawing by others consists of visual or written messages. This is less a design or critique and more of a statement of need or desire. The design of the prompt is a key part of this. Asking people 'to envision or comment' leaves the responses fairly neutral at times. This is very different when the prompt asks 'what-if...?' as more of a provocation.

\subsection{Tool for dialogue}

The most pronounced outcome produced is the least visual. The dialogues heard, messages conveyed back to the authors, from conversations among people with very different perspectives, to the revealing of histories, desires, and hidden knowledge was the more significant outcome of the projects thus far. These dialogues and different stories seemed momentary free of the hierarchies of a typical community meeting and increased the authors awareness of how people see and inhabit their own space. The archiving and re-presentation of these messages, stories, and dialogues would be best recorded as an archive of and for the community.

\subsection{Iterations}

The limitation and potential most pertinent is the need for iteration. Tested in only minor ways across the 5 experiments, the time to iterate, curating an initial round of work, revise and re-issue a drawing and prompt, and creating a subsequent, follow-up event would be a next step in the work. This ability to learn from the community, re-interpret and retell the stories back, and have the community engage again is necessary for a deeper use of the tool. This brings expertise back to interpret and narrow the community's story and extends the duration of the engagement.

\section{CONCLUSION}

The use of drawing as an interface supporting the co-production of public space transforms conventional attributes and relationships. As part of the processes to initiate public space production, conventional architectural drawing requires the application of architectural expertise through visualizing latent forms of urban or typological potential. It communicates an analysis of a public space problem. The drawing also is a format to communicate within meetings to solicit and record community input. However, the co-drawing differs from this conventional practice. It necessitates all of the same levels of expertise, but experiments with deeper engagements between architect and community by ceding some of the authorship of an urban representation. This encourages and allows for the visualization of a community's own expertise, initiates community dialogue, and hopefully initiates a deeper involvement by the community. Co-drawing is imagined as a tool for the co-production of public space, where the architect's temporary role expands to design community engagement and deepens their understanding of and engagement with a community. 


\section{REFERENCES}

Atelier Bow-Wow. 2015. Urban Forest. Berlin: Haus der Kulturen der Welt and Spector Books

Belting, Hans. Reprint edition, 2016. Hieronymus Bosch: Garden of Earthly Delights. New York: Prestel.

Bourriaud, Nicolas. 2002. Relational Aesthetics. Dijon: Les Presses de Réel.

Kaminska, Barbara A. Summer 2014. "Come, let us make a city and a tower: Pieter Bruegel the Elder's Tower of Babel and the Creation of a Harmonious Community in Antwerp," Journal of Historians of Netherlandish Art 6:2. Carleton College, Northfield, Minnesota: JHNA.

Lai, Jimenez. 2015. The Politics of Flatness. Chicago: Treatise Publication Series.

McMorrough, John. 2012. "The Architecture of No Place and Eutopia, Infinite Earths and Elsewheres," in Jimenez Lai's Citizen of No Place: An Architectural Graphic Novel. Princeton: Princeton Architectural Press. 



\title{
PAPER \#1.04
}

\section{GRAPHIC NARRATIVES FOR READING INDIAN CITIES IN CONSTANT MOTION}

\author{
Alisia Tognona, Mariana Felix Paisana ${ }^{\mathrm{b}}$ \\ apolitecnico di Milano, Milano, Italy \\ ${ }^{\mathrm{b}} \mathrm{CEPT}$ University, Ahmedabad, India
}

\section{ABSTRACT}

This paper focuses on the definition of a methodological approach to map the territory through a perceptive/phenomenological investigation that represents time, space, and activities in urban space.

The primary research question of the paper is how to determine a methodology of analysis of urban settlement, by mapping spatial dynamics, temporal, and intangible characteristics of a place, and defining appropriate strategies to decode the sense of the "Kinetic City" (Mehrotra 2008) through urban narratives that depict in dialogue the temporality and fluidity of urban spaces.

Indian cities, like many in South Asia, are characterized by physical and visual contradictions, producing landscapes of extreme pluralism. Post-colonial urban spaces are the result of a continuous negotiation between elite and subaltern cultures, resulting in a temporal articulation and occupation of space.

Indian cities are in "constant flux" (Mehrotra et al. 2017), and therefore its mapping requires a study of the temporary occupations of space by people, animals, vehicles, and its different actions, such as vending, celebrating or resting. Mapping Indian territory has to include aspects of informality and temporality because these dynamic processes constitute the base for urbanization. According to Ananya Roy, "informality is inscribed in the ever-shifting relationship between what is legal and illegal, legitimate and illegitimate, authorized and unauthorized" (Roy 2009, 80).

The outcome of this paper is to focus on new methods for conceiving and narrating the dynamics of the city: firstly, pointing out methods to read and record the complex urban reality and secondly, elaborating guidelines and indicators to understand and explain the city and the constant motion of everyday life.

\section{KEYWORDS}

Graphic narratives; Indian city; temporality; informal activities.

\section{INTRODUCTION}

This paper focuses on decoding a methodological approach to mapping, through a 'perceptive/phenomenological' system that can represent not only tridimensionality but also the fourth dimension of urban space claimed by human activities or events. These mapping strategies have the potential to translate and represent the intrinsic meanings of the "Kinetic City" concept (Mehrotra 2008), with narratives that uncover the relation between temporal and spatial structures.

Pioneering studies about the interrelation of urban spaces and social interactions were developed when urban areas started to bring together many cultural strands. In particular, the accelerated processes of urbanization and the effects they had on social sentiments gave rise to studies of Urban sociology, since the beginning of the last century. Sociologists such as Max Weber and Georg Simmel (1903) laid the foundations of urban sociology. Moreover, urban theories of the Everyday Life (Certeau 1984) and Everyday 
Urbanism (Chase, Crawford and Kaliski 2008) developed an understanding of urban design not focused on aesthetics or style but on social structures, user experience, and cocreation of culture. As well as methodological approaches to the study of urban life by William Whyte, Donald Appleyard and Jan Gehl.

The object of this investigation is the urban context in India, which is amid a fundamentally transformative urban awakening. The processes of urbanization and urban growth are embedded in and play constitutive roles in shaping the complex and interactive political, social, demographic and ethno-religious contexts. In 1991, just under 220 million people lived in the country's urban areas. Exponentially, this increased to 380 million in 2011 and is forecast to rise to over 600 million by 2030 (Ahluwalia, Kanbur, Mohanty 2014). As per United Nations estimates, an additional half a billion people will live in Indian cities in the next 35 years, becoming almost 900 million by 2050. The urban modes of living have been long debated in the Indian context, where urbanization comes with its peculiar set of challenges. These are further exacerbated by the phenomena of urban informality (Roy 2005, 147-158), particularly in peri urban expansion or in rapidly growing small and medium towns (Denis \& Marius-Gnanou 2011). The complexities of Indian cities also intensify issues of social, economic and political exclusion: the post-liberalization India has seen an 'invisibilization' of marginalized groups (Fernandes 2004), linked with urban economic modernization.

In this complex environment, the aim is to understand how mapping can be useful for rising appropriate design strategies. Cartographical work can effectively communicate temporal appropriations and particular uses of urban space, and layout methods and strategies for its application. For this reason, it is crucial to understand mapping not as an objective outcome but as a construct and representational device, that is an integral part of the design process, as it is speculative and projective (Desimini \& Waldheim et al. 2016).

This study is part of the ongoing research developed by the authors during the fellowship at CEPT University, Ahmedabad, India (2019). It also includes a comprehensive reflection about how it can be taught for the researchers, as a method for reading the Indian complexity and strategies for mapping urban spaces in constant motion.

\section{THE INDIAN CONTEXT AND THE KINETIC CITY - THE CASE OF AHMEDABAD}

The city of Ahmedabad has been taken as a case study for this research as it embodies all the main characteristics and contradictions of the Indian city. Today, Indian cities comprise two components that occupy the same physical space. The first, which could be called the Static City, is made up of more permanent materials - concrete, steel, and brick. This is the two-dimensional conception that appears on traditional maps, and its presence is monumental. The other is the Kinetic City. Incomprehensible as a two-dimensional entity, it is perceived as a moving city, a three-dimensional construct in progressive development. The Kinetic City has a temporary nature and is often built from recycled materials - plastic sheets, scrap metal, canvas, and scrap timber. It is continuously modified and reinvented. Kinetic City is not perceived in architectural terms, but rather in terms of spaces and occupation patterns. It is indigenous urbanization with its particular 'local' logic (Mehrotra 2008).

In the international world, Ahmedabad is commonly known as an architecture Mecca, where the masterpieces designed by Le Corbusier, Louis Kahn, Charles Correa and Balkrishna Doshi, as well the historical old city submerge in a vibrant kaleidoscope of everyday activities. Moreover, it has become 
the seventh-largest metropolis in India and the largest in the state of Gujarat (Forbe's 2010). In 2017, the historic city of Ahmedabad (Walled City or Old City) became part of the UNESCO World Heritage list, according to criteria II, V (https://whc.unesco.org/en/ list/1551). The motivation was the evident universal significance. The Walled City is not only a tangible testimony of a historical artefact that reflects the succession of eras, but also has a high intangible value of cultural tradition, transliterated in the urban landscape. In the light of these reasons, looking at the city today, Ahmedabad seems to reflect two distinctive souls, with the flow of the Sabarmati river dividing the city in two halves.

Ahmedabad was founded in 1411 AD as a walled city on the eastern bank of the river Sabarmati. It was established as the new capital of the Sultanate of Gujarat in western India by Ahmad Shah, the second sultan of the Muhammadan dynasty (Forrest 1977, 62-86). In those years, the Citadel was built (Bhadra Citadel) and the city was structured with significant trade fair routes in order to transform it into a manufacturing and trade center. Marbles and other precious materials had been imported from afar, to build magnificent mosques, tombs and palaces (Forrest 1977, 64). From this time until the arrival of the Marathas dynasty the city has grown and has consolidated its urban structure - the walls were built, in defense of the pur ${ }^{1}$ (neighborhoods), administratively independent and controlled by the nobility named by the king (Gillion 1968, 26).

Still today, the wallet city has preserved a fairly semi-circular plan, with the core in the center and radiating streets connecting the center to the edge. The site chosen on the eastern banks of the river provided the ideal condition for the growth of the city, due to its location at the crossroads of important subcontinental trade routes and the proximity to water.

For this reason, historically, Ahmedabad has been one of the most important centers of trade and commerce in western India. The city's prosperous and eventful past and present is embodied in its vibrant kaleidoscope of history, art and culture. These conditions and character contributed to enrich the 'old city', which has a great architectural tradition reflected in many exquisite monuments, temples and even modern buildings (e.g. Premabhai Hall, 1976 or Central Bank Of India 1966 - 1967 designed by B.V. Doshi). This peculiar urban fabric is perfectly integrated into a multicultural palimpsest of different eras, in which the monumental landmarks emerge (http://asi. nic.in). In fact, within the walls, there are more than 30 mosques and dargahs, more than 30 Hindu temples, under one hundred Jain temples, and more madrasas, jamaatkhaana, upaashray, dharmashaala. Moreover, the rich domestic architecture in inlaid wood remains in several cases as precious testimony to the minute scale of the urban fabric.

The presence of these architectural landmarks - places and buildings - give a peculiar sense of belonging, continuity and identity. This area of the city is now packed with bazaars, 'pur' with the clustered 'pol' system of dwellings, and numerous places of worship. From a morphological and typological point of view, it is interesting to understand the structure of the urban space, where there is a hierarchization between public and private space still evident today. These are the result of centuries of growth over which newer elements are juxtaposed continuously with older ones. Old buildings

\footnotetext{
${ }^{1}$ Traditionally in the Old city, the pur are composed of pol, groups of houses, with one or two entrances, in which the social unit is based on the link of caste or trade (Vastu Shilpa Foundation, 2002). Therefore, the urban fabric reflects a hierarchical system of movements and social relations: from the level of the city to the settlement ( $p o l)$, from that to the family or community spaces (khancha, khadki). The analysis of the fabric underlines that there are primary roads (bazaars), where traders arrived even from out of town. Secondary roads are linked to these and are characterized by a particular type of products such as jewelry, metal objects and tools and are accessible to residents of the pol. Finally, a third hidden level (alleys) is accessible by the workers for cleaning the streets. (Desai 2019, 39; Yagnik, Sheth 2016, 91-97)
} 
and older areas of the city are assets, as they represent the history of the communities, embodying their tradition, heritage, and culture through architecture and urban form (http://www.intach.org).

Due to high industrial growth and its social and political history, Ahmedabad represents the dynamic two souls in its own physical body. In the eastern part, the original Walled City rooted in the tradition with the outside suburbia dotted with textile mills and chaals, constituted the working and industrial class. On the west bank of Sabarmati, there are new sprawls mainly inhabited by the middle class and characterized by cultural centers, universities and masterpieces of modern architecture (Yagnik, Sheth 2016, 257-258).

Since decades Ahmedabad has been undergoing major transformation in terms of use as well as built form. It is the city where new directions of a new urban future were tried out during the Twentieth Century. It was one of the first cities in India to be industrialized and the second largest manufacturer of textiles after Bombay. For this peculiarity Ahmedabad had earned the title of "Manchester of India" (Spodek 2011). Beyond the textile mills, Spodek has found similarity between Ahmedabad and Manchester. He applied the definition of "shock city" to Ahmedabad, a term coined one year before by British historian Asa Briggs in his book "Victorian Cities" for Manchester. "Every age has its shock city" and the shock cities are a "center of problems, particularly ethnic and social problems, and it provoked sharply differing reactions from visitors" (Briggs 1963, 56). Throughout the Twentieth Century, almost one third of the adult male population was working in the cloth mills (Spodek 2011, 6-7) and in 1920 the first Textile Labour Association was born. Ahmedabad became the headquarters of the freedom movement and also one of the first places where movement against 'untouchability' had been taken up. In 1915 on his return to India, Gandhi decided to establish his ashram in Ahmedabad, until 1930. Gandhi's activities made Ahmedabad a shock city, bringing a sense of unity to the city (Spodek 2011, 167). It had one of the first municipalities, one of the first to have established schools for western education, and the first girls' school came up here in 1849 (Yagnik, Sheth 2016, 119-128).

Today Ahmedabad is a major industrial and financial city, contributing about $14 \%$ of the total investments in all stock exchanges in India and $60 \%$ of the total productivity of the state. Several scientific and educational institutions of national, regional and global importance have been established in the city, attracting a large pool of highly skilled young professionals. At the same time, a significant advancement of the IT sector and a virtuous development of transport infrastructure has been taken up, and in 2016 Ahmedabad has been selected among the first 20 Smart Cities in India (http://www.smartcities.gov. in/).

Moreover, Ahmedabad has had and is having a rapid urbanization. In 1992, the population of its Urban Agglomeration was 12 times that of the Walled City area (AUDA, 1992), but, at the same time, it is registering depopulation phenomena especially in the Old City, where the residents prefer to abandon the traditional pols for moving in the new neighborhoods of the city ${ }^{2}$. The Walled City reveals heavy congested traffic, intricate roads, polluted air, lack of water, weak maintenance of the traditional houses and fragile society. The city has indeed seen several communal riots in the recent past, due mostly to religious conflicts $^{3}$, which created others fragile conditions.

\footnotetext{
${ }^{2}$ Analysis conducted by MCR18 students on Mandvi ni pol during the monsoon semester 2019, Urban regeneration Studio, Cept University. Tutors: Alisia Tognon, Ashna Patel, Jigna Desai.

${ }^{3}$ In 1969 Gujarat saw a riot between Hindus and Muslims during September-October. Unofficial reports claim 2000 deaths and over 48,000 people lost their property. (Gayer, Jaffrelot 2012, 53-60). In 2002 another Gujarat violence called Gujarat pogrom during February - March. Almost 2000 dead and 2,500 injured. (Jaffrelot 2003)
} 
This general situation is creating pressure on the main level of the city, and the definition of public spaces as well. Rapid urbanization is creating an urban complexity and a real estate pressure, which is taking over the open spaces from the future planning of the city.

Reading and understanding these issues is a central question in the study of the Indian context. Urban open spaces (public and private) are the stage for a myriad of activities, such as vending, celebrating or resting, where simultaneously different actors as people, animals or vehicles are living together. At the same time, the sites have a mixture of uses throughout the daytime and the seasons, transformed with different activities. In Ahmedabad, a significant example of this condition is Manek Chowk, in the core of 'old city'. This square contains various events throughout the day, changing functions every day with a similar temporal-spatial succession. Early in the morning, the cows are grazing the leftovers of the night food market and the vegetable vendors. During the day the jewelry market comes up, and the shops extend their selling devices into the open public space, together with the vegetable stalls. In the evening, it is a lively and crowded food market. Many examples, such as this one is representative of a constant and current condition of the Indian city: a city in 'constant flux', where the interchangeable temporary occupation of urban open spaces is perpetual.

\section{MAPPING EVERYDAY LIFE}

When looking at the morphological and typological aspects, as in the western context, the act of mapping focuses on the representation of the more permanent physical conditions: streets, buildings, green areas, and other tangible elements. Differently, in Indian cities it is required to also study the temporary occupations of space. The study of everyday life through maps can be crucial in understanding aspects of temporality and informality, and in designing appropriate solutions that take into account these dynamic processes that constitute the base of urbanization in India.

Referring to the concept of "Everyday Urbanism", as "an approach to Urbanism that finds its meanings in everyday life" (Chase, Crawford and Kaliski 2008), spatial ethnography builds an empirical approach about the sensibility of looking at frequently unnoticed situations and experiences that occur in everyday life. This concept relocates the human body and its social networks in the center of space production. Based on Certeau studies, the physical environment is not deterministic of the humans action in space (Certeau 1984). The users of urban space contest and create new rituals, patterns, and flows that mold the existing territory.

Likewise, Jan Gehl advocates for a methodology to study the 'life between buildings' based on systematic
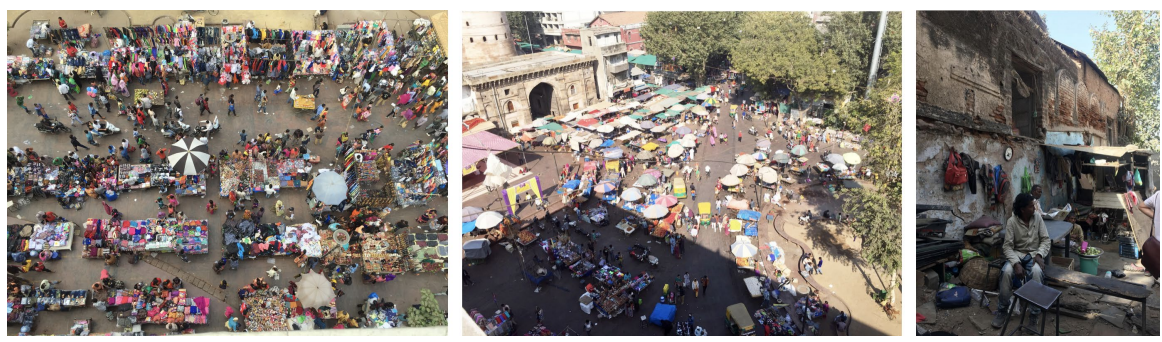

Figure 1. Market at Bhadra Fort, and informal settlements at Raikhad Gate, Ahmedabad (authors 2017-2019) 
documentation, observation, and surveys, to understand how people behave in public open spaces. This is based on the premise that only by understanding how people interact with the physical environment, it is possible to design appropriate urban spaces. Understanding the agency of mapping as "neither reproduction nor imposition but rather in uncovering realities previously unseen or unimagined" (Cosgrove 1999, 213). Mapping is a precious method that can reveal and understand the logic and patterns of the everyday life of urban spaces.

Until the Renaissance, maps were a hybrid representation of spatial relations between objects (houses, people, animals) and fields (settlements, cultivated plots, oceans), and figurative elements, as monsters symbolizing dangerous areas. A map drawn in 1502 by Leonardo da Vinci changed the paradigm of cartography, it represented only streets and buildings (without any figuration) in a parallel projection seen from above (Bosselmann 1998, 13). This became the conventional system of mapping, used in representations such as the Nolli map (1736-38) or the Barcelona Ensanche (1866). This method represented accurately the physical conditions of the city in plan, but, by definition, neglecting many other aspects such as tri-dimensionality, experiential attributes, and social systems. These and other urban qualities were later addressed by urbanists such as Camilo Sitte (The art of building cities, 1889), Gordon Cullen (Townscape, 1961), Kevin Lynch (The image of the city, 1960) or Jan Gehl (Life between buildings, 1971).

Different methods of representation reveal different urban ideologies and distinct conceptualization of the role of the urbanist. Gordon Cullen and, in late 90s, Peter Bosselmann, represented the city through a sequence of images along a path, at a human-eye level, focusing on the experience of walking in the city. Kevin Lynch and Stanley Milgram studied how the city was perceived and remembered by its users, representing those perceptions in maps (mental maps). In the 1960s, Jan Gehl related urban form with social sciences and studied, through maps, the activities of people in public space. This method represented geographical data with parallel projections, along with social data, represented by symbols. A map of Copenhagen done in 1968 shows the plan of a street with human temporal activities people sitting and standing, street vendors, musicians - and the everyday life.

An important aspect of spatial ethnography of 'everyday life' is also its agency to challenge existing power structures. Annette Miae Kim, in her work about the sidewalk life in Ho Chi Minh City, uses the term "critical cartography" to "describe the subset of mapmaking that aims to bring to the fore issues of power' (Kim 2015, 64) This is particularly relevant in the Indian context, where 'everyday life' is intrinsically connected with the 'informal'. Mapping everyday life means to document the informal along with the formal, and to build the bases for a new understanding of this relationship. Also, mapping has the agency to represent informal and formal structures with the same graphical quality, and therefore partially omitting the aesthetics of informality. This can reveal a new imagination, not based on aesthetics or material attributes, but focused on other aspects of these events, such as their metrics or the complexity of their operationality on the use of open space.

With the complexity of temporary occupations of public open space in the Indian context, it becomes relevant to conceptualize mapping as a representation of four-dimensional situations, where time plays an important role. The production of appropriate maps and cartographical work that look at everyday life along with the physical and more permanent environment can be a way to uncover the relations between the static and kinetic city, and to understand them not as binaries but as nuanced and interrelated realities. This 
conceptualization of the Indian city and the traditional use of space is present on the works of Architect B.V. Doshi, the founder of CEPT University, in 1962. In the words of Prof. Neelkanth Chhaya about his work: "not to clean up and isolate an architectural environment into simply an architectural art, but to connect it to life forms, is something which is peculiarly Indian. The weaving in of outdoor spaces and movements across this is something like the way an Indian house or street would work"4.

\section{DEFINITION OF A METHOD TO MAP THE KINETIC CITY}

The first step forward in studying Ahmedabad, as any other Indian city, is to understand how to examine its urban spaces by integrating physical and social information. Therefore, it is important to be able to formulate a method of spatial ethnography that binds together social science and physical spatial analysis. It is crucial to uncover how places are actually used in everyday life, the social process behind them and the meaning of these uses. Only then, design approaches can be appropriate to the complex context of an Indian city, where space is fluid and in flux. Mapping Indian territory means to combine formal and informal aspects. The concept of "informality" represents a state of deregulation, where nothing is fixed, as per ownership or land use, and mapped according to a prescribed set of regulations or laws. Informality is a dynamic process, which is the ground of Indian urbanization (Roy 2009). Comprehending the meaning of 'everyday life' and reading it allows the capacity to generate comprehensive and useful maps, which will include formal and informal, static, and kinetic aspects.

Looking at the European context, the informal components in the urban spaces are rare compared with the static ones. Rarely in
Europe, something is left unregulated, and generally, there is no informal appropriation of public spaces by citizens. Every area is planned, and there is an explicit definition between public and private spaces. These established conditions clarify the modality for reading urban spaces. Commonly, mapping a city in Europe means to map the physical elements: the streets, the functions, the buildings, the water systems, the green area, and not the human activities. On the contrary, mapping the Indian city means to study the movement of humans and animals, the social fabric and the temporal events, as part of the formal and informal occupation of public space.

In the afterword of the book Cartographic Grounds (Desimini \& Waldheim et al. 2016, 251), Antoine Picon states the need for an urgent study of the conventional signs used in maps, since digital tools challenge the 'traditional notions about cartography'. A study of the mapping work developed in the Indian context, where reality is transformed at a fast pace, can bring forward a new nature of signs, that is able to represent the movement of bodies in space and the 'everyday life' in the urban context.

In the research about Kumbh Mela, by Harvard University (Mehrotra, Vera, 2015), we can see the event being mapped by a series of drawings spaced in time. Each map is done on a specific day and it represents a still frame of the construction and organization of semi-permanent shelter structures. This series of maps represents the dynamic process of assembling and disassembling a temporary city. The succession of maps uncovered the logics and patterns of temporary 'urbanization', not visible on one single map, but on the collection of many. In many of the recent academic classes at CEPT University ${ }^{5}$ we can see the centrality of human activities in the process of mapping. When asked to survey a territory, most of the students mapped the physical

${ }^{4}$ https://www.bloomberg.com/news/articles/2018-03-19/pritzker-winner-doshi-put-his-stamp-on-ahmedabad-india 
and social environment, in dialogue. The maps revealed the temporary and informal uses of public space such as squatting, vending, or cow grazing, as well as the more permanent built environment such as dwellings or walls. For this, students created graphic codes for the 'events' happening in the territory, differentiating the temporal conditions of each one of them - mobile (walking, driving, cow grazing), stationary (seating, stadings, vending) or semi-permanent (squatting, vending, celebrating). Other studios experimented with a mapping process that examined the relation between everyday life activities and built form, through graphic narratives. These drawings narrated different events through perspectives or axonometries. Each of these frames presented a story about a place and its use by the movement of the bodies, expressing the activities performed and the relation with the physical environment. Just as a storyboard, these drawings mapped the use of space at a moment in time that is significant for the understanding of the territory. What determines the character of these places is the structure of relationships that materialize primarily on the ground: physical, cognitive, and symbolic connections. The drawings produced in this studio are synthesis, interposed between the tensions that bind permanence, erosions, and poetic resistances.

\subsection{Method to study public spaces in Ahmedabad}

For understanding the complexity of Ahmedabad's public spaces, the challenge is to identify a peculiar methodology for reading the flux and the constant motion of the city. To start, it is necessary to identify and compare different categories of public space that exist in the city of Ahmedabad. To be able to compare different open public spaces, it is essential to select a set of sites with comparable contexts and similar characteristics. The analysis conducted during the research field should be organized in three different steps: exploration (1), restitution of data (2) and interpretation (3).

1 - Referring to the eight principles established by Jan Gehl in his book "How to study public life" the exploration phase sets the indicators of: counting, mapping, tracing, tracking, looking for traces, photographing, keeping a diary, test walk. Each site must be studied at different times of the day, and at two distinct moments of the week (e.g. weekdays and weekend). Generally, the most appropriate time for site visit is: $8 \mathrm{am}$ to $10.00 \mathrm{am}$ and $06.00 \mathrm{pm}$ to $08.00 \mathrm{pm}$. This is necessary because some particular places change drastically during the weekend. The Riverfront Sunday Market is such an example (Fig.3). The market was redesigned in 2012, along with a large area of the Ahmedabad's riverfront, to protect the city from the floods of Sabarmati River. The intrinsic character of the Sunday Market suggested studying the site during the week, while there is no market, and the area is almost empty, and Sunday when the entire area becomes crowded with people, animals, vehicles and vending structures.

2 - The second phase is to develop a way for the restitution of data by synthesizing and analyzing the data collected. The results of this phase are maps - of actors, flows, sounds and lights - that show not only the static elements of the physical space but also the changeable actors of the 'human space'. The aim is to express the tangible and the intangible aspects of the city, as a pillar for the kinetic soul of the Indian city.

3 - In the end, the analysis of the selected spaces is translated into a strategic plan or framework, to be used as tools in the design project. The definition of this framework establishes strategic outcomes for transforming urban spaces. 

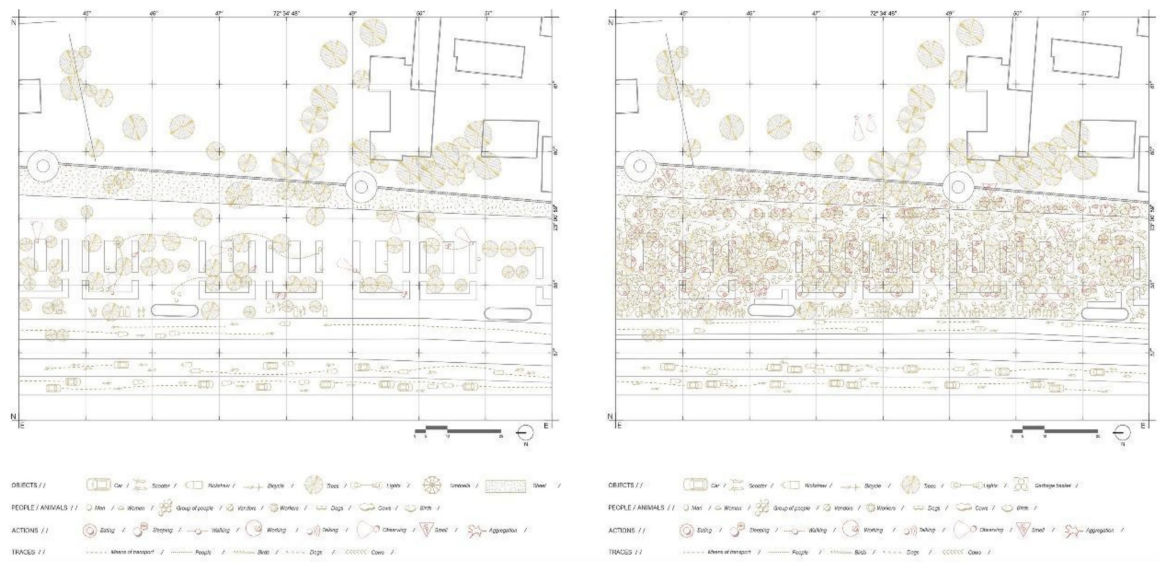

Figure 2. Mapping the Riverfront market Ahmedabad, during the week (left) and on Sunday (right), an Indian case study of everyday urbanism, Master thesis Politecnico di Milano (Sara Rossi, 2019)
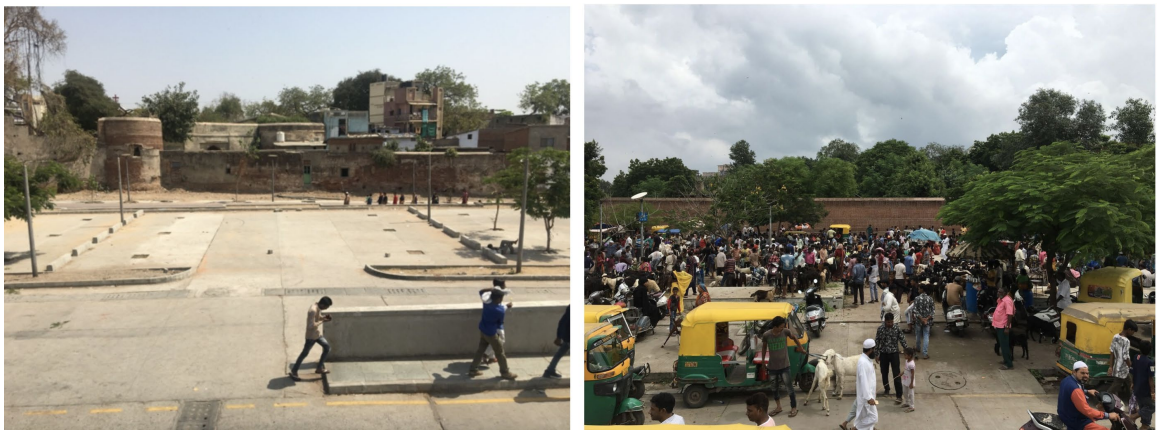

Figure 3. Riverfront market Ahmedabad, during the week (left) and on Sunday (right), Sunday (Authors, 2019)

\section{CONCLUSION}

In a broad definition, we would like to recognize not only the importance of reading the urban spaces through maps but above all, the importance of understanding which types of maps are appropriate for each environment. This is particularly relevant if we acknowledge mapping as an initial component of the design process, where the framework established initially can condition the consequent design decisions.

Drawings that represent not just absolute conditions but fluid realities, have the chance to generate solutions that understand the territory as ephemeral and therefore propose solutions that are also transitory. This is particularly important in a context of rapid urbanization as India, where urban spaces are in constant mutation, and are shared and 
produced by people from different economic, social and religious backgrounds.

As underlined by Kim, urban design has produced disastrous results when it has been informed by ideological ideas that have been generated without ethnographic studies (Kim 2015). Ahmedabad has seen a recent increase of urban development projects that lacked critical knowledge about the local communities and the overall situation. Spatial ethnography is therefore essential for sensible and adequate projects that can explore the relation between pattern and logics of use of space and its physical limitations.

In the work of a student of Politecnico di Milano and exchange at CEPT University (fig.3), we can observe the methodology for mapping the kinetic condition of the Indian city organized in three phases. The first phase is set to explore the location and to rigorously study the site and the events that occur on it. For that it is necessary to examine the territory at different moments of the day, on different days of the week, or the year if there are any festival celebrations on the site. It is common that vacant spaces, for example, have seasonal festivals and are, therefore, occupied during parts of the year with temporary structures and activities, such as wedding parties or other celebrations. The data acquired during the visits is then synthesized and analyzed, looking for patterns and logics of everyday use. The result is a series of maps that represent not just the physical space but the 'choreography' of the bodies in the territory. This series of maps must then be analyzed to recognize logics of relation between physical environment and everyday use, and create new frameworks of understanding, which will inform the design process.

Since temporal and informal conditions of the urban territory constitute the bases of Indian urbanizations, these research offers a perspective on how maps can explore and make visible these phenomena, by mapping the everyday life. 


\section{REFERENCES}

Arnaud, P. 1991. "The History of Cartography", Vol. I: Cartography in Prehistoric, Ancient, and Medieval Europe and the Mediterranean. Edited by J. B. Harley and David Woodward, 1987.

Bosselmann, P. 1998. Representation of Places: Reality and Realism in City Design. Berkeley: University of California Press.

Briggs, A. 1963. Victorian cities. Berkeley \& Los Angeles: University of California Press.

Certeau, De M., Rendall, S. 1984. The Practice of Everyday Life. Berkeley: University of California Press.

Chase, J., Crawford, M., and Kaliski, J. 2008. Everyday Urbanism. New York: Monacelli Press.

Corner J. 1999. "The agency of mapping: speculation, critique and invention" in Cosgrove, D. E. 1999. Mappings. Critical Views. London: Reaktion

Denis, E., Marius-Gnanou, K. 2010. "Toward a Better Appraisal of Urbanization in India." Cybergeo:: European Journal of Geography, Systèmes, Modélisation, Géostatistiques, n. 569, 28-11-2010, http://journals. openedition.org/cybergeo/24798; DOI : https://doi.org/10.4000/cybergeo.24798

Desai, J. 2019. Equity in Heritage Conservation: The Case of Ahmedabad, India. Abingdon \& New York: Routledge.

Fernandes, L. 2004. "The politics of forgetting: Class politics, state power and the restructuring of urban space in India". Urban Studies 41(12): 2415-2430.

Forrest C.I.E., G.W. 1977 "Ahmedabad", in Cities of India. Delhi: Metropolitan Book.

Gayer, L.; Jaffrelot, C. (2012). Muslims in Indian Cities: Trajectories of Marginalisation. Columbia University Press. pp. 53-60

Gillion, K. 1968. Ahmedabad: A study of Indian Urban history. London: University of California Press
Gehl, J. 1971. Life between Buildings: Using Public Space. 6th ed. Copenhagen: Danish Architectural Press,

Hope, T., Biggs, T., \& Fergusson, J. 1866. Architecture at Ahmadabad, the Capital of Goozerat, photographed by Colonel Biggs, With an historical and descriptive sketch by T.C.H., Architectural notes by J. Fergusson. London. De.

Jaffrelot, C. (July 2003). "Communal Riots in Gujarat: The State at Risk?" Heidelberg Papers in South Asian and Comparative Politics.

Kim, A. M. 2015. Sidewalk City: Remapping Public Space in Ho Chi Minh City. ChicagoLondon: University of Chicago Press.

Kotkin, J. 2010. "In pictures The Next Decade's fastest growing cities". Forbes.

Mehrotra, R. 2008. "Negotiating the Static and Kinetic Cities: The Emergent Urbanism of Mumbai". in Huyssen, A. Other Cities, Other Worlds: Urban Imaginaries,. Durham - London: Duke University Press.

Mehrotra, R. Vera, F. 2015. Kumbh Mela: Mapping the Ephemeral Megacity, Harvard University South Asia Institute: Hatje Cantz.

Mehrotra, R., Vera, F., Mayoral, J., Sennett, R., Burdett, R. 2017. Ephemeral Urbanism: Does Permanence Matter?. Santiago: ARQ ediciones.

Mohanty, P. K., Ahluwalia, I.J., Ravi Kanbur, S. M. 2014 Urbanisation in India: Challenges, Opportunities and the Way Forward. New Delhi: SAGE

Waldheim, C., Desimini, J., Mostafavi, M., 2016, Cartographic Grounds: Projecting the Landscape Imaginary. New York: Princeton Architectural Press.

Roy, A. 2005. "Urban Informality: Toward an Epistemology of Planning". Journal of the American Planning Association 71, no. 2

Roy, A. 2009, "Why India Cannot Plan Its Cities: Informality, Insurgence and the Idiom of Urbanization". Planning Theory 8, no. 1 
Spodek, H. 2011. Ahmedabad: Shock City of Twentieth-Century India. New Delhi: Orient Blackswan.

Yagnik, A., Sheth, S. 2016, Ahmedabad: From Royal City to Megacity, Gurgaon: Penguin Books. 


\title{
PAPER \#1.05
}

\section{THE CURRENT IMAGE OF THE CITY OF YEREVAN (ARMENIA) THROUGH THE STUDY OF URBAN SPACES}

\author{
Anna Sanasaryana, María José Viñals ${ }^{a}$ \\ aUniversitat Politècnica de València, València, Spain
}

\section{ABSTRACT}

Yerevan is one of the most important administrative and economic centers of the Republic of Armenia. Carrying the title of the capital city, Yerevan is considered to be the business card of the country. Through the years of prosperity and hardships, the capital has undergone numerous urban changes that altered its image.

Therefore, the objective of this study is the illustration of overall changes in the image of the capital through the study of urban spaces of the central Kentron district of the city, focusing the analysis on the historical center, its evolution and development from the Soviet period. Current research is mainly focused on the spatial pattern related analysis of the city, in particular, on the physical environment.

The methodological approach of the present study was inspired by the analysis conducted by Kevin Lynch (1960). Focusing on the analysis of the image of the city, the author portrayed a comprehensive vision of urban identity in spatial planning and city designing. Following the method, official documents (including master plans, cartographic data, areal images, etc.) were reviewed. Then, combining them with the direct observation of the elements composing the city (paths, edges, nodes, districts, and landmarks) and its historical overview, the analysis of the current urban structure and urbanistic evolution shaping the capital was given.

\section{KEYWORDS}

Yerevan; image of the city; Kevin Lynch; urban layout.

\section{INTRODUCTION}

Being the capital city, Yerevan is by far one of the most analyzed cities of the Republic of Armenia. However, not many works are dedicated to the analysis of its urban layout and spatial environment. Some recent works include the re-imagining the city after the Soviet Rules (Ter-Ghazaryan 2010), evaluation of the urban transformation over the last century (Khatchadourian 2016), studies of its architectural characteristic, as well as the urban and spatial environment (Petrosyan 2017; Kirakosyan and Arshakyan 2019). However, these studies are mostly focused on specific elements within the city rather than on its general urban layout.

Undergoing constant changes, the image of the city and its perception change accordingly. Following questions arise; What are the most evident changes the city experienced? and How did those changes impact on its currentday image?

The current study addresses these questions focusing on the urban analysis of the city, particularly on the evolution of the central administrative district from the implementation of the first Master Plan, created by the chief architect Alexander Tamanian in 1924, to the present days. Therefore, the diachronic data are discussed to indicate major developments in the city center.

\section{METHODOLOGY}

The methodological approach for this paper aims to analyze the setting of urban spaces inspired by the work of Kevin Lynch (1960). Therefore, the study of the city was 
approached by direct observational fieldwork, as well as literature review (including scientific bibliography, official documents, and cartographic data). Data collection was also carried out from official websites.

Lynch's method is based on the imageability and legibility of the city, i.e. the ease of understanding how the city is planned, which can be achieved with the help of two types of maps: physical and mental. The first one is usually drawn by professionals during the fieldwork, with the identification, designation, and localization of the five empirical categories or elements (paths, edges, nodes, districts, and landmarks) on the physical map. While the creation of the second one can be achieved by interviewing the citizens. A mental map is how the individual perceives the city; its image sketched from the perspective of a citizen.

First, it is important to deduce how imageable space is based on the five elements. A city with a high imageability is typically an organized one, containing the five elements in an orderly, coherent manner. Then, after combining mental maps of all interviewed individuals, the public image is created. The analysis of both maps should help with the further development of the city to make it a more sufficient and peaceful place for its citizens.

The present research paper is devoted to the analysis of the physical map. Following the method, first, the contents of the city were classified into the five elements, distinguishing major elements from minor ones. Then, cartographic files were created, and the aforementioned elements were identified and localized. Lastly, the spatial image of the present-day Yerevan was analyzed, as well as comparisons were made with the first urban Master Plan to identify major changes.

The advantage of this method lies in the numerous outcomes that follow. On the one hand, it displays the city as is, and on the other hand, uncovers the way it is perceived by the person living in it. Simplification of the map by categorizing its elements helps visualize the difference between the elements composing the city, detect the concentration of their certain types, identify patterns, detect planning features (that are otherwise not apparent) and provide ideas for future planning modifications.

\section{HISTORICAL AND URBANISTIC OVERVIEW OF THE CITY OF YEREVAN}

The Republic of Armenia is a country of Western Asia. Its capital and the biggest city is Yerevan (fig.1). Yerevan is located in the south of Armenia, in the north-eastern part of Ararat plain, on both banks of the Hrazdan River, at an altitude of 850-1370 $\mathrm{m}$ above sea level (The Cadastre Committee 2008), in a 7-8 magnitude earthquake zone.

The capital occupies $223 \mathrm{~km} 2$, which has a $0.7 \%$ share in the territory of the Republic of Armenia (ARMSTAT 2019). The city stretches in a north-south direction for $19.7 \mathrm{~km}$ and $19.1 \mathrm{~km}$ from east to west. Its appearance is reminiscent of an amphitheater; the city center is located at the bottom, with the bordering districts rising over the surrounding hills (ALARIS 2016).

Yerevan is composed of the following 12 administrative districts (district communities): Achapnyak, Arabkir, Avan, Davtashen, Erebuni, Kanaker-Zeytun, Kentron, Malatia-Sebastia, Nor Nork, Nork-Marash, Nubarashen, Shengavit (fig.1).

It should be noted that administrative borders of some districts as well as the border of the capital itself differ from source to source. For instance, according to some sources the area containing Zvartnots International Airport, as well as the road leading to it, are also considered to be a part of the capital. In order to avoid confusion, the administrative distribution of Yerevan Municipality official website was taken as a basis for current research (https:// www.yerevan.am/en/administrative-districts/). As mentioned before, the capital is located on an unevenly elevated surface. The lowest points are registered in the southern districts of Shengavit and Malatia-Sebastia. The central part, more specifically, the area surrounding the Republic Square (Kentron administrative district), is located in an altitude of $1000 \mathrm{~m}$ 


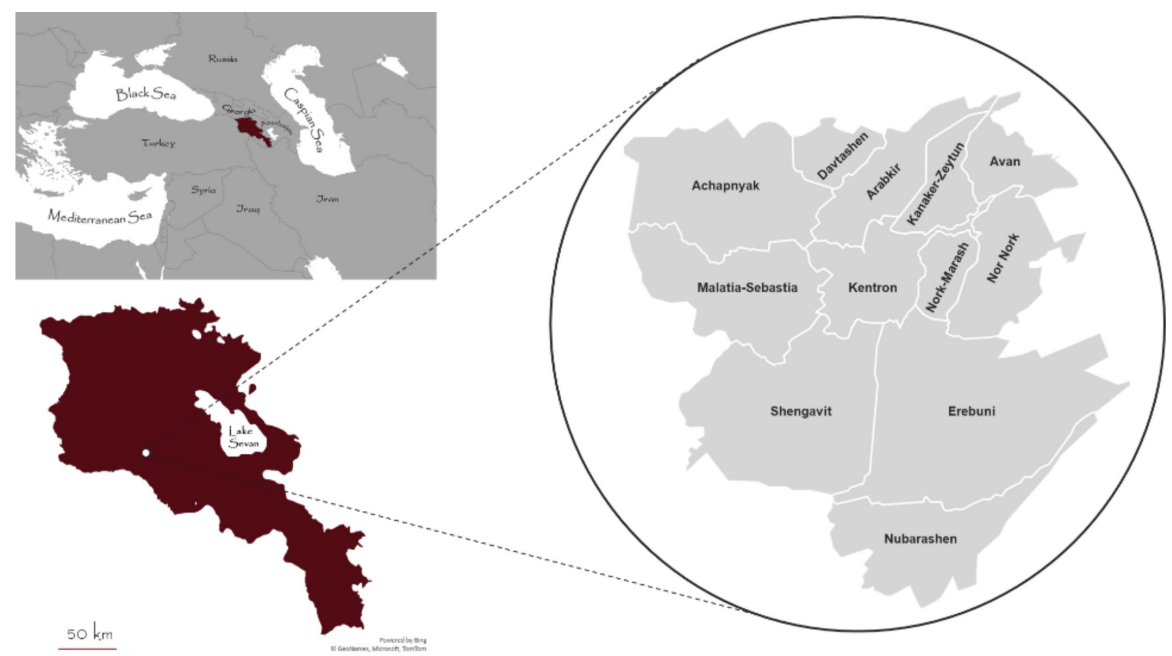

Figure 1. Location map of Armenia, the capital city of Yerevan and its 12 districts.

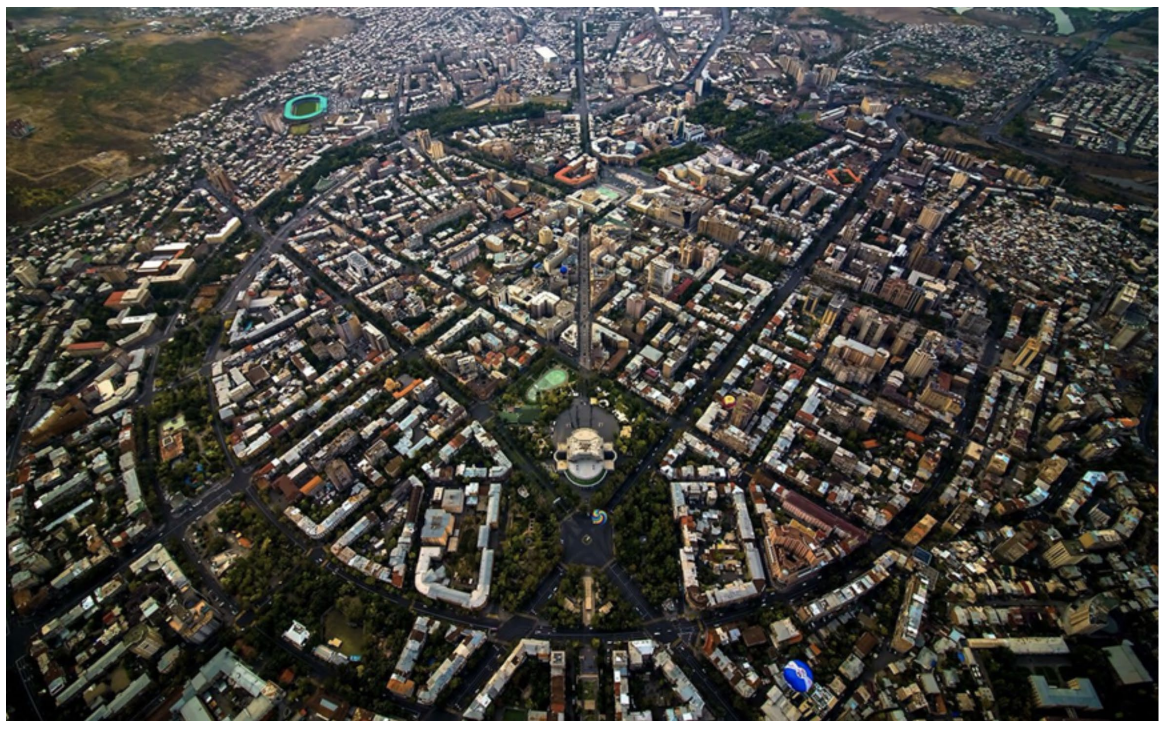

Figure 2. Aerial photo of Kentron administrative district facing south, Yerevan. Source: Skyball-Vardan Petrosyan (n.d.) https://twitter.com/armenia/status/1020570012761972736 
above sea level (ALARIS 2016). While the highest point is registered on the hill adjacent to St Sargis Church of the 5th block of Nor Nork administrative district, with an altitude of more than 1300 m (ALARIS 2009).

The district communities occupying the most territorial share are Erebuni and Shengavit (4749 ha and 4060 ha consecutively); they compose most of the southern part of the capital, whereas the least territory belongs to the community of Nork-Marash (467 ha). The municipal center of the city is Kentron administrative district (fig.2) (in Armenian kentron [Ltiunnnu], means center), which occupies 1335 ha of surface. Davtashen in the north and Nubarashen in the south are the only districts that do not have a direct border with Kentron.

\section{Tamanian's Master Plan.}

Yerevan became the capital city of Armenia in 1918. Several important historical events had a major influence on the development of the image of the city. The one with the most severe impact was the Armenian Genocide in 1915, which led not only to the death of 1.5 million people but also to the major migration of the Armenian nation. Therefore, by 1920s, when the Armenian Socialist Soviet Republic was founded, the overall population of the country decreased. Therefore, when it came to choosing a capital for Soviet Armenia, Yerevan appeared to be the perfect fit for the task, with an already established network of streets on the one hand, and a small number of buildings and small population on the other (Ter-Ghazaryan 2010). Although Yerevan is considered to be a typical Soviet capital city due to the fact that it was given a more distinct definition during the Soviet period, the presence of some preserved historical and cultural monuments inherited from the past serve as a reminder of the origin and antiquity of the city. Before the Soviet rule, the city presented an image with not a clear definition of borders, and with a dispersion of buildings and streets (fig.3).
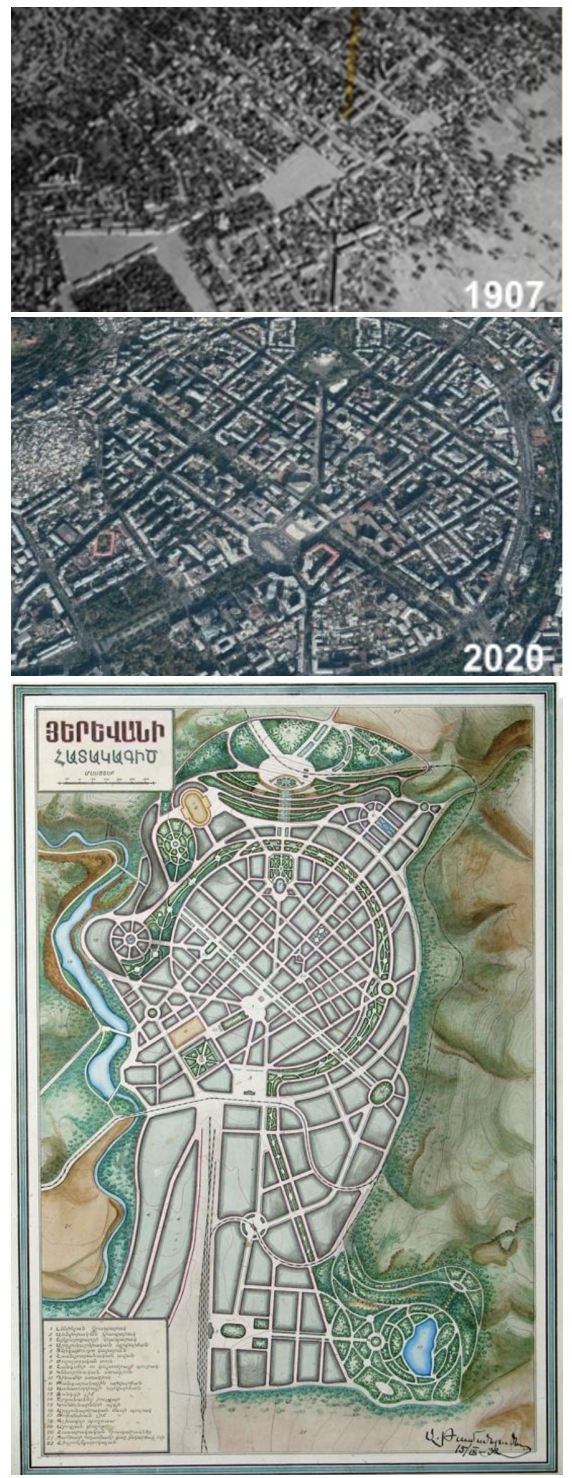

Figure 3. Comparison of urban development of Yerevan in 1907 and 2020. Source: https://www.ribaj.com/ culture/roy-khatchadourian (1907) and Google Earth (2020)

Figure 4. The first Master Plan of Yerevan. (1924) Source: https://upload.wikimedia.org/wikipedia/ commons/0/08 Yerevan_map_by_Tamanyan.jpg 
And so, in 1924 with the leadership of the chief architect Alexander Tamanian, the first Master Plan of the city was created and was put to action. Before that, the total population of Yerevan had been around 60 000 people. Whereas Tamanian's Master Plan was designed to accommodate more than double: up to 150000 people (Schröder 2017).

Adapting to the urban setting of the area, Tamanian's Master Plan (fig.4) was delimited by the bordering hills from the north and the east, as well as by the Hrazdan river from the west, leaving a room for expansion to the south. The core of the plan has a clearly distinguishable circular shape, which is followed by two rings, that surround it almost completely. The first ring is entirely composed of a green corridor, which had to serve as "lungs" for the city (Tamanian 1924). Starting from Kond in the west, the park surrounds the core until the south. Then heading to the south-east, it was planned to come to an end at Lake Vardavar.

Within the core, the road infrastructure is composed of clear, perpendicular lines. Owing to the harmony of the union of these paths, major nodes are instantly apparent on the map; mostly at the intersection of several roads (usually at squares).

Not only was Tamanian dealing with the planning of the city but he was also the author of the main iconic buildings including Opera and Government Houses. He blended architectural elements from Armenian (ecclesial) architecture to the general design of the façade of buildings, which resulted in a unifying combination of the old and the new. According to Ter-Ghazaryan $(2010,64)$, Tamanian's style is considered "an amalgam of Russian neoclassicism, the garden city movement and functional zonation". The buildings were constructed from basalt, granite, marble and especially from pink volcanic tufa, which gave a pink touch to the landscape of the city, as a result of which
Yerevan is also commonly known as "Pink City".

Regarding the types, there were two types of structures planned to be built: residential buildings and community buildings. Residential buildings had to be two-story houses, whereas the number of floors of the community buildings should not have surpassed four (Tamanian 1924). Unfortunately, as time went by, some of those buildings were replaced with new ones, which, with the exceeding number of floors, act as skyscrapers. They are not concentrated in one area, if not constructed in random locations within the city center, which results in a partial loss of homogeneity (fig.2).

\section{Current-day image of Yerevan}

With the growth in population, the expansion of the city borders was inevitable. In addition to that, new districts were built surrounding the center. However, while the historical center was built on a plain surface, the elevation of its urban surroundings fluctuates considerably beyond its circular delimitation. As a result, instead of expanding in a circular form and keeping the ring-shape pattern, Yerevan mutated into a mixed layout, featuring a quadrangular and irregular area (Blasco 2015), so as adapting to the geographical circumstances. Compared to the first Master Plan, Kentron expanded primarily to the west, reducing its southern borders.

From the aerial perspective (fig.5), the core can still be delimited in a circular shape full of green and watershed areas. The first ring surrounding the core is the green corridor called Circular "Oghakadzev" park (in Armenian oghak [onuly] means circle). Unlike the original intent of the Master Plan (fig.4), currently, the park composes only the eastern part of the core surrounding the historical center. And yet, it is still the longest pedestrian path (about $2.5 \mathrm{~km}$ ) of the city. 

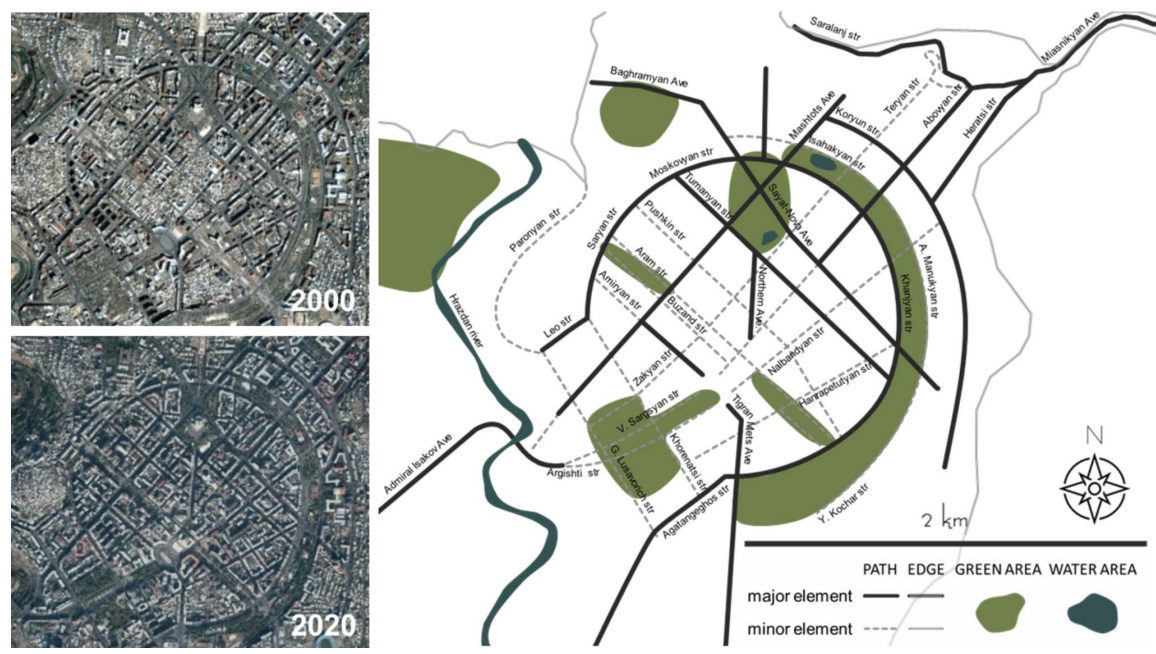

Figure 5. Comparison of satellite views of the historical center in 2000 and 2020 with the current physical elements of Yerevan (paths, edges, green and water areas).

In the physical map of Yerevan presented in Figure 6, three elements were recognized as edges. Firstly, the administrative border of the district. It is designated as a minor element because it is not physically visible or distinguishable. Whereas the Hrazdan river in the west and the northern inclination are detectable from various viewpoints, therefore are considered to be major elements.

Regarding the major paths, the selection criteria were to accomplish one or more of the following points: are relatively wide (20-40 m) dual carriageways; have two or more lanes; are usual routs for vehicular traffic (public transportation); and, in general, are busy streets.

The minor paths are the ones that almost entirely complete the road map of the city. Similar to the major paths, they are carriers of the vehicular traffic. And yet, the minor paths are not so busy as the latter ones. They are usually two-lane, single (sometimes dual) carriageway streets that are mainly parallel to the primary streets.
In general, the complex observation of major paths brings to the conclusion that the "skeleton" of the city, inherited from the first Master Plan, appears to be a combination of simple shapes: circular forms and straight lines. The minor paths are mostly linear streets, that are perpendicular to one another. While the major streets tend to have a curvier structure, on most occasions they are straight lines linked to each other with flexible joints. Owing to their simple composition, the paths stimulate a strong sense of continuity as street channels, and still, are distinguishable due to the major and minor nodes along the way.

As for the differences in the nodes between the Master Plan and the current-day image, the biggest square-shaped node that is adjacent to the core from the south on the Master Plan (fig.4) does not currently exist.

Because of the urban layout, by vehicle, the city does not have direct access from the north, west, and east (fig.6). Coming from other districts the main roads leading to the city are Miasnikyan avenue and Saralanj street in North-East, Baghramyan avenue and Proshyan 


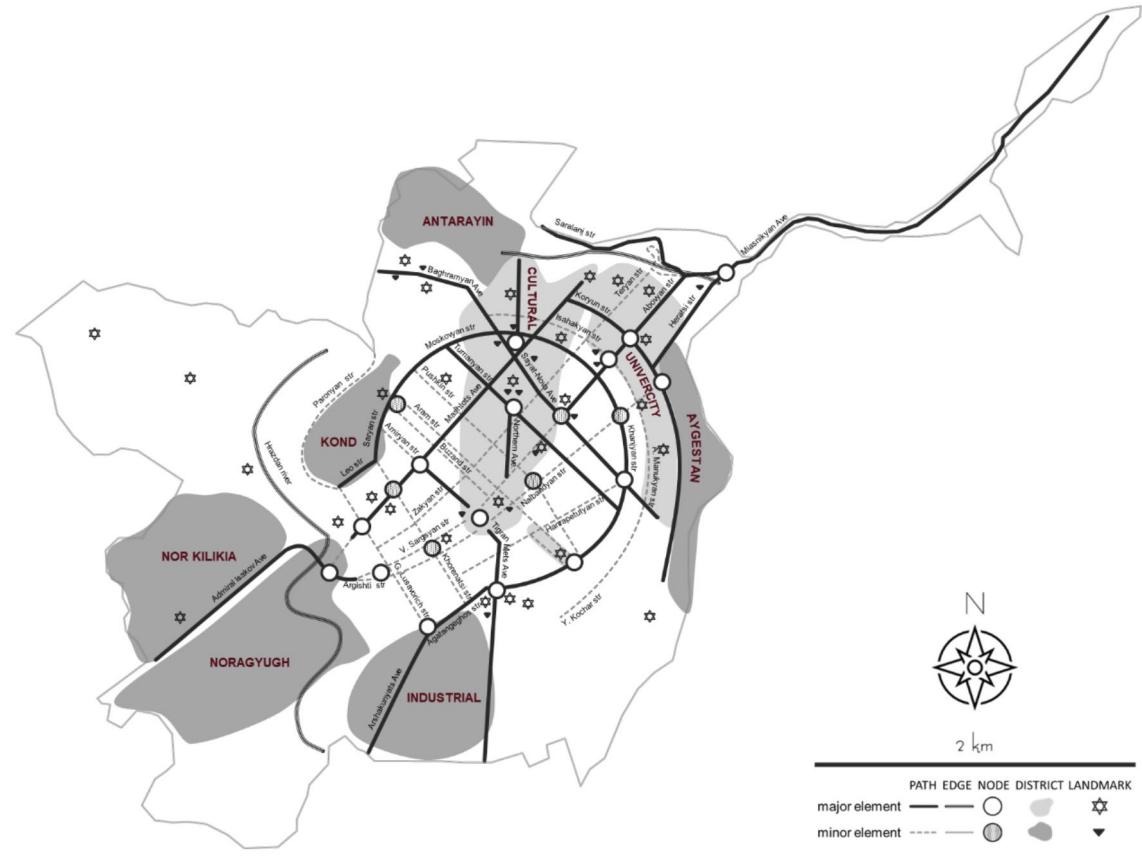

Figure 6. The visual setting of Yerevan (Kentron administrative district) derived from maps, including paths, edges, nodes, districts, and landmarks.

street in the north-west, and Admiral Isakov avenue in the south-west. From the south, the city can be accessed by Arshakunyats and Tigran Mets avenues directly.

One of the most important paths in Kentron district is the M4 interstate road, that is the main connector of the north to the south. It starts with Miasnikyan avenue in the North-East, continues in the Heratsi street. Merging with Khanjyan street it continues by Agatagheghos street and heads to the south by Arshakunyats avenue.

Concerning the road infrastructure within the core, with some alterations, the streets stretching from north-west to south-east remain as planned. While some streets of the opposite direction (from north-east to south-west) were not included in the present urban plan. The most evident example is a street that should have been located between Abovyan and Nalbandyan streets and intended to connect Heratsi street with the Sakharov square indirectly.

The latest and the most significant change in the road infrastructure was the construction of the Northern Avenue (fig.3, 5). Although schemed in the first Master Plan, the concept has come to life only in the last few years. Therefore, Northern Avenue can be considered the youngest segment of the historical center. The Avenue was not built when the Master Plan was being implemented because the area had already been occupied by residential houses, which is noticeable in Figure 5. As those buildings were a part of Armenian history, Tamanian did not want to demolish them. Instead, he suggested to disassemble them, numbering each stone, and assemble in 
another part of the city. However, this project was turned down by the Soviet government due to high rate of expenses. Almost a century later, the Northern Avenue was built by the Yerevan City Council.

Several elements within the city, that have specific classification, can in fact equally be considered as a set of several elements. Four of them are worth mentioning: Cascade, Opera House, Northern Avenue, and Republic Square. Together on the map, they are composing a "J"like path. On the one hand, they are collective elements, that individually are landmarks dominating over their surroundings. On the other hand, being on the intersection of several important roads, they serve as nodes. And finally, collectively they function as a north-tosouth pedestrian path.

Due to its geographical singularity, Cascade is dominating over the rest, as it was built on inclination (on the northern hill). Looking to the horizon, it also has the privilege of having an extensive visual scope/panoramic experience. On the other hand, when looking down at the city, the aforementioned path, is identifiable until the Opera House, which is in this case, a visual barrier.

Out of all avenues, Northern Avenue is a pedestrian street. Even though in the initial plan the maximum number of floors was not to exceed four, current buildings composing the North Avenue are nine-story houses, that not only create a visual barrier from surroundings but also completely block the view for pedestrians walking down the Avenue. Once inside, the spectator can only see the start and the end of the Avenue, all the rest of the scenery is blocked by the buildings. On the positive side, the Avenue gives a sense of direction, which generally manages the pedestrian flow by guiding them either to the north (to the Opera House) or to the south (to the Republic Square).

Implementing the Master Plan, Tamanian segmented the city into several districts/areas; industrial area in the south, university district in the north-eastern area, as well as area devoted to museums in the west (Kond), and labor and commercial areas (Tamanian 1924; Zorian 1978). Some of these areas still serve their designated purpose (fig.6). In particular, the university district has been expended to the south. Concerning Kond, it is now a residential area. There is no specific area dedicated to museums, thus they are spread over the city. Their relatively high concentration is noticeable in the northern area of the city center.

Such segmentation of the city was reasonable at that time, because, for example, the university district was on the outskirts of the city. However, with the expansion of the city, it is now considered to be the area close to the city center, which leads to traffic congestion because of the heavy student flow, especially in the morning hours.

Regarding the landmarks (fig.6), their high concentration is noticeable, especially near the nodes. Considering the fact that the nodes are generally the intersections of roads, the landmarks that are located near play a tactically indicative role, making it accessible for citizens to reach them by transport. The fact that the landmarks are spread rather than concentrated on one area has a positive effect on the congestion of the areas; the landmarks are not too close to each other to create confusion and to be tiring for the eye, and at the same time not too far from one another for the citizens to be unable to navigate themselves.

\section{CONCLUSION}

Comparing the current historical center to the first Master Plan brings us to the conclusion that, having undergone several alterations, the urban layout of the core of the city (the city center) remains unchanged. Overall, the most evident/major change is the expansion of the borders of the capital through the formation of new districts.

The analysis of urban zoning concluded that, similar to the development and the evolution of capital cities of other countries, the further 
urban development of Yerevan (construction and distribution of new districts) was carried out around the historical center. On the other hand, the road infrastructure distinctly differs from the usual 'circular' infrastructure of many capital cities because of the urban layout of the region.

Owing to the spatial sharpness of the paths, tactical zoning, and general homogeneity of the elements, the imageability of Kentron administrative district can be considered medium level. Nonetheless, there is a strong need for the improvement of the physical map (as it was defined by Lynch) by reviewing the transportation system, considering rebuilding some elements and enlarging green areas.

With the historical development of the country, the architectural style and borders of the districts have changed. Over time some older buildings were substituted with new ones, changing the layout of the city. To acquire the complete image of the city, further research must be focused on the mental image, i.e. analyzing how the changes in the main landmarks impacted the emotional perception of several generational groups of the citizens. Together with the spatial analysis, this will help find and define the new identity of the city and create a narrative for it. This can be achieved through the studies of changes in the main landmarks of the city along with the analysis of the emotional impact of the citizens through interviews. Here attention should be paid on the descriptive words the citizens use when referring to the city, more specifically to the status contrast, use contrast, relative age or comparisons of cleanliness or of landscaping as suggested in the book of Lynch $(1960,45)$.

Conclusions made after analyzing both aspects should help with the improvement of the National Planning Policy Framework of the capital city in order to consolidate the pillars of the identity of Yerevan.

\section{ACKNOWLEDGEMENTS}

The authors of this document want to express their gratitude to Yelena Manukyan for providing key information for the current paper, and to Marina Sanasaryan for kind assistance in proofreading. 


\section{REFERENCES}

Armenian Legal Information System (ARLIS). 2009. Enlimin qunquguiur 20102013pд. dnwahn. https://www.arlis.am/ Annexes/3/erit-2_010.pdf

Armenian Legal Information System (ARLIS). 2016. Enlumer punmph

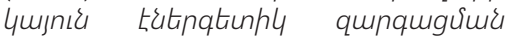
qnnдnnnıpлnıulitnh onmahn. Yerevan. https://www.arlis.am/Annexes/4/ eiatN5_2016N558hav.pdf

Blasco, J.A. 2015. Aproximación al círculo como estructura urbana: Ciudades circulares y otros trazados (parte segunda). https://urban-networks. blogspot.com/2015/04/aproximacional-circulo-como-estructura_25.html (retrieved June 2020)

Khatchadourian, R. 2016. A Juxtaposition of Ideological Expressions: Evaluating the urban transformations of Yerevan (Armenia) during 1915-2015. University of Liverpool UK http://www. presidentsmedals.com/Entry-14960

Kirakosyan, L. and Arshakyan, A. 2019. Spatial environment and symbolic image of Yerevan "Cascade" complex. Bulletin of National University of Architectur and Construction of Armenia. http://www.mathnet.ru/ links/8d70a06f955cfdd62279a7c6bb843 af5/nuaca222.pdf

Lynch, K. 1960. The Image of the City. England. The M.I.T. Press.

Petrosyan, H. 2017. A study of the urban environment and architecture characteristics in the context of visual information inputs: case study of Yerevan city. Bulletin of National University of Architectur and Construction of Armenia. www.mathnet.ru/links/ dddd7b393edcff7c7fae8fef3d3043e4/ nuaca25.pdf

Schröder, P. 2017. Urban Spaces and Lifestyles in Central Asia and Beyond. UK and USA: Routledge.
Statistical Committee of the Republic of Armenia (ARMSTAT) 2019. Marzes and Yerevan city of the Republic of Armenia in figures, 2019. https://www.armstat.am./ file/article/marzer_2019_25.pdf

Tamanian, A. 1924. 2tilnıgniv 3tinluminh furnulymadsimer vimuhr, edited by Azatyan, V. 2014. Cuiunushru nınnunh L

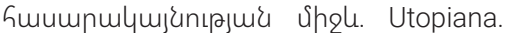
http://www.arteria.am/hy/1429464913

Ter-Ghazaryan, D. 2010. Re-Imagining Yerevan in the Post-Soviet Era: Urban Symbolism and Narratives of the Nation in the Landscape of Armenia's Capital. Florida International University: Electronic Theses and Dissertations. 261.

The Cadastre Committee of the Republic of Armenia. 2008. ¿usjuunuirh

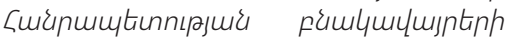
pununur. Yerevan. https://www. cadastre.am/storage/files/pages/ pg_8945925618_pg_907871769_HH_ bnak._bar.pdf

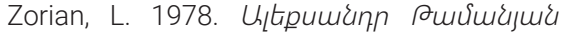
(ठurinjur 100-unjulyh unphu). Historical-Philological Journal. http://hpj. asj-oa.am/3013/ 


\title{
PAPER \#1.06
}

\section{TOWARD A SUSTAINABLE URBAN DEVELOPMENT (SUD): A CASE STUDY ON ANCIENT CITY OF KAZERUN, IRAN}

\author{
Mohammad Akbari Riyabia, Farzaneh Soflaei ${ }^{b}$ \\ aSalman Farsi University, Kazerun, Iran \\ bState University of New York, Oneonta, USA
}

\section{ABSTRACT}

Throughout history, cities have been the main centers of learning, culture and innovation. However, today's cities are facing with an ongoing rapid urbanization that causes many problems exacerbated by the increasing population density and demands of urban environments. This article focuses on the concept of sustainable urban development (SUD), which highlights the need for reform of market mechanisms to achieve environmental goals and the achievement of a balance with social and economic considerations. We selected the ancient city of Kazerun in Iran as a research case, where has always been so noteworthy to the kings and powerful politicians through the whole history of this Iranian city and now it's attracting many visitors counting on it's rare historical, cultural, natural and religious sites to be seen and explored. Our research illustrates how the spatial arrangement and the urban structure of Kazerun has been changed in the passage of time; because of rapid population growth, unorganized urban development, and how it negatively impacts on the connectivity and accessibility of urban facilities and services. We used two research methods: 1) through literature review to identify a research gap in existing strategies that deal with sustainable solutions for urban planning problems in medium-density cities like our case study; and 2) through the survey, we evaluated the existing planning of Kazerun and conducted guided-interviews with stakeholders to understand the urban problems, issues and policies. All data are summarized, integrated and presented in SWOT tables to analyze in

a hierarchy process (AHP) via Expert Choice software. Our findings show that social justice, social welfare, economic prosperity, sustainable transportation methods and intelligent energy management will be the most effective terms to dealing with the future development challenges of Kazerun. As conclusion we propose some sustainable strategies and policies for future development of this beautiful ancient city.

\section{KEYWORDS}

Population growth; urban sprawl; medium dense cities; sustainable urban development (SUD); analytical hierarchy process; ancient Kazerun city.

\section{INTRODUCTION}

The city of Kazerun in southwestern of Iran, is one of the cities of the Islamic East, which dates back to the era of the Sassanid Empire (226-641 AD), as it was its capital, and despite its ancient history that extends to ancient roots, this city remained without any integrated study in its political conditions, social, economic and religious. The Islamic conquests affected Persia in general and the city of Kazerun in particular, as it is from a social point of view that there were groups of society other than what they were before Islam, including Muslims as the local rulers of Persia, in addition to the local population of the Magi and Christians and the few Jews. Today, the city of Kazerun is one of the agricultural cities with fertility in its soil and cultivation 
of various crops, and it has become widely known in the manufacture of linen clothing, and has a commercial significance for its location between the city of Shiraz, which is a base for Persia on the one hand and the Caspian Sea (Bahr al-Khazar) on the other in Islamic times. This city has been distinguished by the emergence of a number of scholars in the villages and its stores affiliated to the city of Kazerun, and they have contributed to enriching intellectual life in the city in particular and the Islamic world in general, such as: Al-Murejani, Kaskani and AlDawani. A number of Muslim scholars who left their impact on the city and from them. Shiraz Al-Alam, the gift of God bin Abd al-Warith alShirazi, and the city of Ruzbeh, the scholar Ibn Hasankwayh, the Persian Muhammad bin Muhammad bin Al-Hassan, and from the city of Nushanjan, the world, Talha bin Ahmed bin Ayoub Al-Muqri AlNushajani, and from Ahwaz Ahmed bin Aqeel bin Rajeh. In addition, the scientific titles obtained by Kazarun scholars have confirmed their diverse scientific product, and the evidence for this is what their scientists have classified in works in the religious, human, mobile, and mental sciences. The city has had a distant lake in its vicinity for several years. The Parishan Lake was the largest freshwater lake in Iran, hosts highly aquatic species, insects and birds, watered down the underground aquifer of the city and moderated the weather conditions of the area. The lake was completely dry since 10 years ago and the surface of aquifers went down by an average of 50 meters. In order to cope with this dehydration crisis, deep and semi-deep wells were drilled whether permissible or unauthorized. On the other hand, trying to make more profit, increasing use of pesticides and fertilizers, seems to be crazy about the environmental resources by. Due to the numerous villages in the strategic area, the influx of villagers from neighboring rural areas threatens the integrity of the social fabric in the city of Kazerun. Increasing water deficit, the agricultural economy has lost its justification, and today most of the city's capitalists are trying to transfer their investments into other neighboring cities such as Shiraz. This has caused the Kazerun's economy to face with serious challenges in recent years.

\section{RESEARCH METHODOLOGY}

This paper is an applied type with a mixed method research. We review theoretical bases in documentary method, and for collecting data in case study, field observation tools, referral to institutions, documentary review and deep interviewing have been used. The SWOT table technique has been used for analyzing and the research strategy has been extracted from this matrix; in order to access the priority list of developmental measures, the AHP technique was used by Expert Choice Version 2 software. The results of the cumulative weighting of each action completed by the Delphi method to compile a downline listing the importance and priority for sustainable urban development strategies.

\section{THEORETICAL BASE (DISCUSSION)}

\subsection{Related concepts}

There is no comprehensive definition universality, since it has been the subject of many definitions of development since its introduction (Elliott 2006). Development is a multidimensional concept that has economic, social, political, and cultural aspects, and if we consider each of these dimensions, we can make the impact both historically and theoretically clear on this concept (Betty and Wheeler 2007). Development is not the same as economic growth, because development is a complex process that involves in the reorganization and the different orientation of the whole socioeconomic system (Maleki 2011). In addition to increasing and improving 
the level of production and income, it includes a fundamental transformation of institutional, social and administrative structures, as well as the public opinion; development in many cases even encompasses people's habits and customs. Some prominent experts, such as Procofield, define development as a basis of moving towards welfare goals such as poverty reduction, unemployment and inequality (Azkia 2005, 27). The origins of the SD approach were launched as part of a cumulative effort from the events of the 1970s and the Stockholm Convention and could be followed up by the World Summit on SD (WSSD) 2002 in Johannesburg (Gouza 2006). In summary, a series of sequential events led to the completion of this theory and the elaboration of its action modes.Peter Hall defines sustainable urban development as a form of continuous development of cities and towns that meet the needs of future generations (Hall 1993).But the most common definition of the SD expressed in Commission on the Environment and Development of the United States in 1987, known as the Bruntland ${ }^{1}$ Commission, said $\mathrm{SD}$ is such a development that addresses the needs of the present without threaten the capabilities and potential of future generations (Henry 2001). The commission tried to communicate between the economic and environmental issues, albeit somewhat ambiguous, but the concept of SD contributes to economic prosperity progress (UNGA 1987, 43). So SD can be considered an important change in understanding the relationship between nature and humans. In general, the policies of SD can be divided into four axes:

- Minimizing the use of nonrenewable natural resources, such as fossil fuels

Sustainable use of renewable resources such as groundwater, soil and vegetation
Keep waste limitations at the local and global absorption capacity, such as greenhouse gases and toxic waste

- $\quad$ Provide basic human and social needs such as access to livelihoods, social participation, and access to a healthy environment with basic services (Hardoy 1992, 4).

\subsection{Objectives and areas of sustainable development:}

Theoretical studies show that economic sustainability, environmental sustainability and social sustainability are three areas of SD. The main objective of SD is to provide basic needs, to improve the standard of living for all, to maintain and manage ecosystems and to have a safer and more prosperous future (Moslem 2006). So eradicate of poverty, eradicating hunger, health and well-being, quality education, gender equality, clean water and sanitation, clean and affordable energy, decent work and economic growth, industry and infrastructure innovation, reducing inequalities, Sustainable cities and communities, responsible production and consumption, climate action, life below water, terrestrial life, peace-justice, and powerful institutions, and ultimately participation in achieving goals are notable goals in the SD approach (UNDP 2000).

\subsection{Sustainability Indicators}

The strong point of the SD theory is the consideration of the relationship, or establishment of relationship between elements of development in a reasonable way that can sustain the development (Reid 1995). Peter Hall noted the foundations of SUD at the Berlin International Conference (2000) in seven Sustainable Urban Economies, Sustainable Urban Sites, Sustainable Urban 
Shelter, Sustainable Ecosystems, mobile Resource Sharing, Living in the City, and empowering citizenship. (Ancient, G. 1998; Sarrafi 2001).

The World Commission on Environment and Development (WCED 1987) also mentions the following principles as essential features of a sustainable city:

- Increasing economic and social opportunities to cover the whole city population

- $\quad$ Reducing the share of energy in urban development

- $\quad$ Optimal use of water, land and other resources needed for urban development

- Minimizing waste and sewage production and maximize waste recycling
- $\quad$ Establishing a management system with the power and efficiency to achieve economic, social and environmental goals

- Driving technologies used by the city towards SUD goals

- $\quad$ Strengthening the capacity of various urban areas in order to prevent or respond to threats and economic, social and environmental objectives. In this regard, a sustainable city have improvement in social justice, diversity and the possibility of life with a desirable quality (Gharokhlu 2006, 160).

Table 1 summarizes some of the indicators considered for SD by different sources.

\begin{tabular}{|l|l|l|l|}
\hline Expert & Year & Document name & Measures introduced \\
\hline $\begin{array}{l}\text { Sheikh-Al-I } \\
\text { slami }\end{array}$ & 2009 & $\begin{array}{l}\text { Article: evaluation Development } \\
\text { stable Urban Macro }\end{array}$ & $\begin{array}{l}\text { Growth, Justice, Efficiency, Integrity, Tolerance, } \\
\text { Biodiversity, Planetary Issues }\end{array}$ \\
\hline UNDP & 2000 & SD Goals & $\begin{array}{l}\text { Poverty and hunger, Health, Quality of education, } \\
\text { Justice, Clean energy, Employment, Economic } \\
\text { growth, Industrial innovation, Sustainable } \\
\text { communities, Production and consumption } \\
\text { management, Climate action, Peace, Participation }\end{array}$ \\
\hline Elliot & 2006 & An Introduction to SD & $\begin{array}{l}\text { Child exploitation, gender inequality, racial } \\
\text { segregation, poverty and hunger, local } \\
\text { communities, land development management }\end{array}$ \\
\hline Pitter Hall & 2000 & Berlin International Conference & $\begin{array}{l}\text { Sustainable Urban Economics, Sustainable Urban } \\
\text { Society, Urban Shelter, Sustainable Ecosystems, } \\
\text { Resource Conservation, Urban Resilience, } \\
\text { Empowering Citizens }\end{array}$ \\
\hline Gharokhlu 2006 & $\begin{array}{l}\text { Article: Index Urban Stable } \\
\text { Development }\end{array}$ & $\begin{array}{l}\text { Economic-social opportunities, energy } \\
\text { consumption, water consumption, sewage and } \\
\text { waste, urban management, new technologies, } \\
\text { urban neighborhoods, social justice, biodiversity, } \\
\text { livelihoods }\end{array}$ \\
\hline
\end{tabular}

Table 1. Indicators on Sustainable Development

\begin{tabular}{|l|l|}
\hline Later & Studied indices \\
\hline social & $\begin{array}{l}\text { Immigration; Population and Culture; Civil Partnership; Urban Management and } \\
\text { Institutions; Settlement }\end{array}$ \\
\hline Economical & $\begin{array}{l}\text { Employment; basic economics; trade exchanges; product diversity; market } \\
\text { economy; functional centers; poverty and income }\end{array}$ \\
\hline environmental & $\begin{array}{l}\text { Animal and plant life; climate; natural hazards; ecological zones; environmental } \\
\text { pollution }\end{array}$ \\
\hline
\end{tabular}

Table 2. The selection criteria of this study on SUD 
Obviously, only a few of these criteria, as shown in Table 2, have been investigated in the case study.

The status of the below indices tested by various interviewing techniques, field observations and documentary studies in the case study area and the collected data will be used to develop the research process.

\section{DATA}

Kazerun city has $4548 \mathrm{~km} 2$ total area. According to the global position, the city of Kazerun has located at $29^{\circ} 35^{\prime}$ to $29^{\circ} 40^{\prime}(\mathrm{N})$ and $51^{\circ} 35^{\prime}$ to $51^{\circ} 41^{\prime}(\mathrm{E}), 154 \mathrm{~km}$ west of Shiraz in the western part of Fars province.

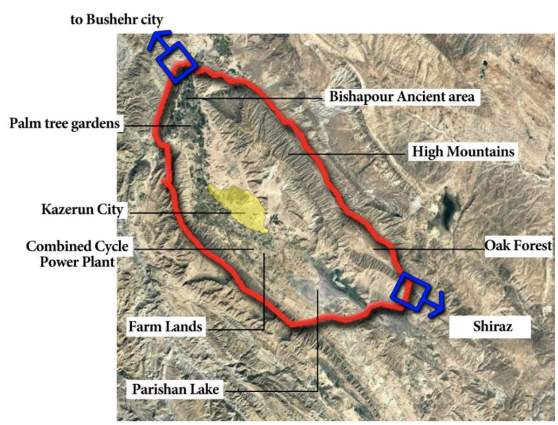

Figure 1. Research Area and Strategic Factors, Source: Author, Processed satellite picture from Land sat/ Copernicus, explored by Google Earth 2018

\subsection{Social studies}

According to this research we survey the present social situation and see several trends and events as you can see in the following sentences. Social crimes raised from 10,950 to 15,331 cases (2006-2016), which represents a 40\% increase (Hosseini 2017).

Civic participation shows a decreasing trend up to $41.7 \%$ in these years.

The level of literacy show that the average level of educated people in the city has increased significantly and in general, the level of literacy gone higher (IAU \& KSFU universities, Department of Education 2017) but many graduates leave the city because they do not find a suitable job or different purposes.

The study of population movements in Kazerun shows that in recent years the rate of migration has been limited to job seekers or villagers who are hoping to live in city and have access to more services. This group of newcomers to the city has not yet properly captured the citizenship culture and these citizens who still pursue their rural culture and are strangers to urban living patterns have much less citizenship accountability (Akbari et.al 2019).

The pressure from population compression in the central parts of the city, including the worn-out texture, along with the weakness of urban infrastructure and services, has caused much multidimensional problems.

\subsection{Environmental studies}

Kazerun city has been expanded to the end of the Zagros mountain range on the KazerunQatar active fault. Statistical surveys show the people of the city every year feel an average of about 38 times the earthquake $(>4)$. The old Zagros folds of the area have become so tired and susceptible to tensile that in the weekly period of 06 Feb. 2018 to 13 Feb. 2018, recorded 23 earthquakes with an intense of 3.1 magnitudes in this town (TUGC 2018).

Kazerun is one of the warmest cities in Iran with up to 302 sunny days per year and an average temperature of 22.4 degrees. The average annual relative humidity of the city is $54 \%$ (Ziari 2005). In such circumstances, when the air temperature reaches more than $50{ }^{\circ} \mathrm{C}$ in summer, about $63 \%$ of the city's buildings use a cooling water cooler system. Each water cooler consumes 70 liters of water per day, and if it's estimated that this water cooler will work only 30 days a year, 3241350 liters of water will be wasted! 
The energy consumption in Kazerun has increased sharply in recent years. On the other hand, the vastness of the city and the centrality of Kazerun have increased the number of journeys that have led to increased fossil fuel consumption. The following can be said about the use of resources and energy in Kazerun. The consumption of electricity for cooling as well as domestic consumption over a wide period of time, consumption of fossil fuels for transportation, agriculture, and so on. Available statistics show that the average daily distribution of fossil fuels (petroleum, diesel, gasoline, etc.) reaches more than 60,000 liters at official fuel supply stations (Petroleum Refining and Distribution Company of Kazerun 2017).

The daily waste production increased from somewhat more than 9 tons (2006) to more than 16 tons of waste in 2016. And in the weakness of any facilities and culture of separation of waste, this is an issue with great concern (Kazerun Municipality 2018). Today, depo's waste sites are rapidly expanding on natural lands, and every day the extent of this destruction is increasing.

Due to the existence of an open surface water collection system, and in some places with a non-fired channel, the existence of multiple wells for each building to dispose of wastewater, the existence of small workshops which sewage enters into the seasonal rivers and the intensity use of pesticides and fertilizers in the agricultural sector, the water and soil resources are threatened with pollution, severely. Soil contamination is mainly related to the agricultural sector and the use of chemical pesticides. The traffic of heavy vehicles and the presence of a lot of workshops in the city that inflict pollution on the natural soil is a further risk of contamination of the region's soil (comprehensive plan and detailed plan approved in 2006). The single-core structure of Kazerun has caused every citizen to travel to the city center (martyrs square) several times daily for access to commercial services, health services, wholesale and etc. Also, the very poor public transport fleet does not service many regions inappropriately, so citizens are forced to use personal vehicles.

There are many villages around the city and many of the villagers every day have to do a village-urban journey, to buy, treat, office, train, and etc. which this volume of traffic will pollute the air. In recent years, that the Khuzestan and Bushehr provinces of Iran have been involved with dusty storms, are entering the area several times a year and Kazerun also is affected. Add to this the burning of garbage and burning of some intrusive plants in the agricultural sector. All of this has led to a serious crisis in the air pollution of Kazerun.

In recent decades, two strategic ecological zones in the city of Kazerun have been heavily challenged, in such a way that the tragic fate of one leads to destruction. According to the Environmental Protection Agency of Fars province (EPAF), in 1986, this basin accommodated more than 353 species of migratory and native bird species, and the biological ecosystem was a highly herbaceous plant (Hatami 2006, 45-52). The lake has been completely dry in recent decades due to the untapped use of groundwater, the unpredictable management of water resources and rivers into the lake, long droughts and etc. in recent decades lead to it was disappeared.

Part of the oak forests is located in our area study. This vast green area and vegetation diversity play an important role in the environmental performance of the region. The size of that part of the forest, which is within our scope, amounts to more than 400 hectares. In recent decades, with the expansion of urban lands and the commissioning of artificial settlements to natural lands, these forests always face the threat of destruction to prepare land for infrastructure. In parts of the jungle, the excessive grazing of livestock, the reduction of rainfall, the drop in groundwater aquifers, as well as the cutting of trees for the use of wood or agricultural land have become a crisis. 


\subsection{Economic studies}

In the economy and trade market, achieving SD is often the ultimate goal of the international trade mechanism. Some articles of the international treaties recognize SD as a primary goal ${ }^{2}$ and emphasizes that promoting $\mathrm{SD}$ is one of the developmental needs to the Clean Development Mechanism (CDM). Smallscale economic development at the local level will contribute to sustainable economic development at the national level (Schneider et al. 2016, 11; OECD, 2001, 9; Maleki 2011).

According to the 2001 census, the population of the city of Kazerun is 127,328 and the town's population is 254,704 . Of the total number of employees in the city of Kazerun, $805(4.2 \%)$ are employed in the agriculture and animal husbandry sector and 4467 (23.2\%) in the industries and mines sector and 13.824 (71.3\%) are employed in the service sector. This pattern of distribution clearly shows the dominant and unquestionable role of service activities in the city's economy. In other words, the economy of Kazerun can be regarded as a service economy with a dominant role in commercial activities.

Economic studies show that the purchasing power of the city has decreased by $12.7 \%$ (Namvar 2017). We can measure the power of purchasing in direct connection with the issue of urban poverty, and declare that the economic poverty of the city has increased.

In recent years, the amount of budget that allocated to urban management has increased, but given the inflation rate and some economic problems, this trend did not influence on the lives of citizens and the understanding of urban management services.

Employment surveys show that unemployment among young people has been rising in recent years, despite the emergence and development of urban services. The unemployment index, according to the Master Plan, is $6 \%$, which in the year 2006 increased to $8 \%$ of the city's population (detailed plan of Kazerun 2006).
Informal studies from interviews and some infield surveys show that despite population growth, the youth unemployment rate has risen to over $15 \%$ in the last five years.

According to this study, it seems that the development of Kazerun will be facing a serious challenge to sustainability, and in the near future, urban management should wait for a response to many problems. Of course, this is a worrying thing that there is no strategic plan for the future development of the city.

The purpose of this study is to achieve such a need for a SUD strategy and to seek a response to the current crisis. The SWOT table technique appears to be a useful tool for providing various inactive strategies, contingency strategies, proactive strategies and adaptive strategies. In the data analysis section, SWOT will identify, assess, and examine the strengths, weaknesses, opportunities and threats of SD of Kazerun. The effort is to have the strategies that are available from the comprehensive table to cover the issues and are so general that they can be interpreted in terms of several policies. By having such strategies, each developmental entity will be able to direct the strategy through several policies towards its intended goals, and then policy will be implemented through design codes.

\section{DATA ANALYSIS}

This article aims to balance the space organization, resource management and other developmental strategies in order to achieve its goals. We use SWOT matrix to have a rational structure for surveying the present conditions. Now, we need to provide relevant strategies for problem management. It seems that the framework provided by Pierce \& Robinson (Pierce \& Robinson 2016) provides the right tool. Table 5 presents some of proposed strategic plans to strengthen SD of Kazerun.

${ }^{2}$ In this regard, paragraph 6 of the Paris Treaty and parts of the Kyoto Protocol can be noted.

104_block 1: devising, representing and narrating the city 


\begin{tabular}{|c|c|c|c|c|}
\hline & Strength & Weakness & Opportunity & Threat \\
\hline social & $\begin{array}{l}\text { - social } \\
\text { interactions } \\
\text { - cultural ethnics } \\
\text {-Historical } \\
\text { background } \\
\text {-Statistical } \\
\text { increase of urban } \\
\text { services }\end{array}$ & $\begin{array}{l}\text {-Weakness of civil } \\
\text { participation } \\
\text {-Increasing crime } \\
\text { and delinquency } \\
\text { - social instability } \\
\text {-Citizenship } \\
\text { Responsibility } \\
\text {-Immigrant Village } \\
\text { Entrance } \\
\text { - Informal } \\
\text { settlements }\end{array}$ & $\begin{array}{l}\text { - promoting } \\
\text { interactions } \\
\text { - attracting the } \\
\text { creative and } \\
\text { educated class } \\
\text {-Strengthening the } \\
\text { collective identity }\end{array}$ & $\begin{array}{l}\text {-The centralized } \\
\text { identity } \\
\text {-Access to services } \\
\text { - distributive } \\
\text { injustice } \\
\text {-Security feeling } \\
\text { - health care }\end{array}$ \\
\hline Economical & $\begin{array}{l}\text { - agricultural } \\
\text { products } \\
\text { - commercial } \\
\text { highways } \\
\text { - target markets } \\
\text { and proximity to } \\
\text { harbor towns }\end{array}$ & $\begin{array}{l}\text {-Monoculture } \\
\text { economy } \\
\text { - lack of clarity in } \\
\text { urban } \\
\text { management } \\
\text {-Loss of financial } \\
\text { resources } \\
\text { - Unemployment }\end{array}$ & $\begin{array}{l}\text {-Population in active } \\
\text { age } \\
\text {-Mines and natural } \\
\text { resources } \\
\text {-Tourism } \\
\text {-Handicraft and } \\
\text { small businesses }\end{array}$ & $\begin{array}{l}\text {-Immigration of } \\
\text { investments } \\
\text { - reducing the need } \\
\text { for human } \\
\text { resources }\end{array}$ \\
\hline environmental & $\begin{array}{l}\text {-Suitable climate - } \\
\text { agricultural lands } \\
\text {-Natural } \\
\text { resources - } \\
\text { Ancient city }\end{array}$ & $\begin{array}{l}\text { - water resources } \\
\text { exploitation } \\
\text { - Energy } \\
\text { consumption } \\
\text {-Natural disasters } \\
\text {-Relying on fossil } \\
\text { fuels } \\
\text {-Environmental } \\
\text { Pollutions } \\
\text {-Destruction of } \\
\text { ecological organs }\end{array}$ & $\begin{array}{l}\text { - Urban Green } \\
\text { Spaces } \\
\text { - solar and wind } \\
\text { energy } \\
\text { - modern irrigation } \\
\text {-Resource } \\
\text { consumption } \\
\text { management }\end{array}$ & $\begin{array}{l}\text {-Drought and water } \\
\text { crisis } \\
\text {-Infiltration of waste } \\
\text { pollution to water } \\
\text { and soil resources } \\
\text {-Air pollution - } \\
\text { natural disasters } \\
\text { - chemical } \\
\text { pesticides }\end{array}$ \\
\hline
\end{tabular}

Table 3. Analysis Matrix 


\begin{tabular}{|l|l|l|l|}
\hline \multicolumn{2}{|c|}{} & Strength & Weakness \\
\hline \multirow{4}{*}{$\begin{array}{l}\text { S o c i a I } \\
\text { dimension }\end{array}$} & Opportunity & $\begin{array}{l}\text { SSO1. Enhancing Civil } \\
\text { Participation } \\
\text { SSO2. Integrated and Intelligent } \\
\text { Management Development }\end{array}$ & $\begin{array}{l}\text { SWO1. Empowering informal } \\
\text { settlements } \\
\text { SWO2. Strengthening Urban } \\
\text { Infrastructure }\end{array}$ \\
\cline { 2 - 4 } & Threat & $\begin{array}{l}\text { SST1. Observe social justice } \\
\text { SST2. Healthy and inclusive city }\end{array}$ & $\begin{array}{l}\text { SWT1. Establishing social } \\
\text { interactions } \\
\text { SWT2. Promoting Public Welfare }\end{array}$ \\
\hline \multirow{2}{*}{$\begin{array}{l}\text { E c o n o m i c } \\
\text { dimension }\end{array}$} & Opportunity & $\begin{array}{l}\text { ESO1. Creative economy and } \\
\text { enjoying the elite class }\end{array}$ & $\begin{array}{l}\text { EWO1. Multidisciplinary and } \\
\text { Resource Economics } \\
\text { EWO2. Emphasis on Urban } \\
\text { Tourism }\end{array}$ \\
\cline { 2 - 5 } & Threat & $\begin{array}{l}\text { EST1. Avoiding the passing of } \\
\text { the city and strengthening the } \\
\text { economic gateways }\end{array}$ & $\begin{array}{l}\text { EWT1. Boosting and removing } \\
\text { economic barriers }\end{array}$ \\
\hline \multirow{2}{*}{$\begin{array}{l}\text { Environmental } \\
\text { dimension }\end{array}$} & $\begin{array}{l}\text { EnSO1. Utilizing new energies } \\
\text { and reducing CO2 emission } \\
\text { EnSO2. Encourage user } \\
\text { interoperability and convertibility }\end{array}$ & $\begin{array}{l}\text { EnWO1. Water management } \\
\text { EnWO2. Encouraging the city } \\
\text { and intensive development } \\
\text { EnWO3. Sustainable transport } \\
\text { practices } \\
\text { EnWO4. Toward the electronic } \\
\text { city }\end{array}$ \\
\cline { 2 - 5 } & Threat & $\begin{array}{l}\text { EnST1. Conservation of } \\
\text { ecological organs and historical } \\
\text { centers } \\
\text { EnST2. Facilitating access to } \\
\text { service centers }\end{array}$ & $\begin{array}{l}\text { EnWT1. Natural Disaster } \\
\text { Management } \\
\text { EnWT2. Intelligent energy } \\
\text { leadership }\end{array}$ \\
\hline
\end{tabular}

Table 4. Proposed Strategies (Development Scenarios)

\section{FINDINGS}

The idea of SD requires a fundamental change in policy making. In the first place, groups may focus on the challenges of poverty- distributive injustice, but not only economic needs, but also a strong demolition of the environment; an issue that will require the participation of local communities, empowerment and localization of solutions will be required (Warburton 1998, 3).

Given the available data and their analysis in the SWOT table, several macro strategies are presented in SD approach. Each strategy can be pursued through one or more policies in further researches.
In the next step, we can test these strategies by considering the development goals with the help of the AHP technique under the Expert Choice software and have a good prioritization for adopting each one in each component.

The results have a desirable validity and reliability, and by verifying the data, now, based on the aggregate score of each of the development scenarios, a priority list of useful and strategic measures for SD of the city of Kazerun can be presented. . Table 7 shows the list of selected scenarios in descending order of importance. 


\begin{tabular}{|c|c|c|c|}
\hline & Major strategy & Development scenario & $\begin{array}{l}\text { Action } \\
\text { priority }\end{array}$ \\
\hline \multirow{8}{*}{ social } & \multirow{3}{*}{$\begin{array}{l}\text { Good urban } \\
\text { governance }\end{array}$} & Observance of Social Justice $(0.500)$ & 1 \\
\hline & & $\begin{array}{l}\text { Integrated and Intelligent Development Manager } \\
(0.250)\end{array}$ & 2 \\
\hline & & Enhancing Civil Participation (0.250) & 3 \\
\hline & \multirow{5}{*}{$\begin{array}{l}\text { Citizens' Communities } \\
\text { Resilience }\end{array}$} & Promoting Public Welfare $(0.463)$ & 1 \\
\hline & & Strengthening Urban Infrastructure $(0.190)$ & 2 \\
\hline & & Healthy and All Inclusive City (0.151) & 3 \\
\hline & & Establishment of social interactions $(0.124)$ & 4 \\
\hline & & Empowerment of informal settlements $(0.072)$ & 5 \\
\hline \multirow{4}{*}{ Economical } & \multirow{4}{*}{$\begin{array}{l}\text { Strengthening the } \\
\text { urban economy }\end{array}$} & $\begin{array}{l}\text { Economic Prosperity and Elimination of } \\
\text { Economic Barriers }(0.469)\end{array}$ & 1 \\
\hline & & Multi-product and Resistant Economy (0.315) & 2 \\
\hline & & $\begin{array}{l}\text { Creative economy and utilization of the elite } \\
\text { class }(0.137)\end{array}$ & 3 \\
\hline & & Emphasis on Tourism (0.079) & 4 \\
\hline \multirow{10}{*}{ environmental } & \multirow{5}{*}{$\begin{array}{l}\text { Spatial organization } \\
\text { and sustainable } \\
\text { access }\end{array}$} & Sustainable transport practices $(0.321)$ & 1 \\
\hline & & $\begin{array}{l}\text { Encouraging User Interface and Conversion } \\
\text { Improvement }(0.253)\end{array}$ & 2 \\
\hline & & $\begin{array}{l}\text { Encouraging Compressed City and Intermediate } \\
\text { Development }(0.160)\end{array}$ & 3 \\
\hline & & Facilitating Access to Service Centers $(0.157)$ & 4 \\
\hline & & Move to Electronic City (0.109) & 5 \\
\hline & \multirow{5}{*}{$\begin{array}{l}\text { Rely on the } \\
\text { environment }\end{array}$} & Smart Energy Leadership (0.304) & 1 \\
\hline & & Water Resources Management (0.244) & 2 \\
\hline & & $\begin{array}{l}\text { Management of natural and abnormal accidents } \\
\text { and disasters }(0.231)\end{array}$ & 3 \\
\hline & & $\begin{array}{l}\text { Preservation of ecological organs and historical } \\
\text { centers }(0.149)\end{array}$ & 4 \\
\hline & & $\begin{array}{l}\text { Utilizing modern energies and } \mathrm{CO} 2 \text { emission } \\
\text { reduction }(0.072)\end{array}$ & 5 \\
\hline
\end{tabular}

Table 5. Prioritize SD strategies of the city of Kazerun 


\section{SUMMARY AND CONCLUSION}

The present study showed that although concepts related to SD can be categorized in three social, environmental and economic dimensions, but because of the multitude of proposed criteria and the inherent complexity of the concept, there are no comprehensive indexes for the indicators discussed in each comprehensive index. The present research, in each component, explains only some of the more elaborate and accessible indicators as an example of the circumstances of the situation under study in that component.

As Elliott believes, it is necessary to correctly identify the flow of change in the process and to improve it. Assessing the financial needs for SD in developing countries is a matter of urgency, despite the difficulty. There are many evidence that many SD patterns can be implemented without large financial costs and also there are many barriers and limitations that do not directly relate to income; in fact, there is no need for fundamental changes or massive costs for start-ups this intellectual trend, but simply by improving the way of looking at it, the attitude towards developmental issues and the responsible management of the budgets, we can run sustainability in development (Elliott 2006).

To wrap up, as we have seen, there is no sense in terms of SD as an intelligent and necessary approach to future development. If the current route is responsive, but there is no guarantee for the future, it is in conflict with the spirit of SD, and undoubtedly it needs to be reformed so that future generations will benefit from this accountability. The city of Kazerun, with its specific social, economic, environmental, cultural, climatic and etc. conditions, now has many qualities of a livable city, whose examination of these qualities was not the subject of this research, but as evidence suggests, If development continues in the same way, there will be concerns for the future and multiple threats in different sectors may reduce the city's viability for future generations, so if we want to face this, the SD approach an appropriate response will be that authorities and people involved in development can take on the future of this city. Many cases, although nowadays act as a strong point, but with limited resources available in the future, will become a weak point, and the need to respond to it is inevitable. As it is evident, the necessity of preparing and drafting City Development Strategy plans is binding.

Proper policy-making in partnering local communities as well as the exploitation of Non-Governmental Organizations will lead to microeconomic flows within the framework of the macroeconomic goals and will provide the necessary cost for the improvement of environmentally friendly programs. In fact, the relationship between the economy, the community and the environment is so tightly intertwined, that, despite the difficult appearance, they will easily interact in the course of sustainability for development, and the clever stimulation of development in each sector stimulates the development of other sectors and the overall system will move toward the goals. Therefore, as some scholars believe, we will achieve big successes with small beginnings (Reid 1995).

Citizens' Permanent Educational Programs to Promote and Strengthen Citizenship Culture, along with the development of life cycle assessment programs, efforts to branding and strengthening urban identity, transparency of information, management of urban marginalization issues and similar policies, provide an appropriate corrective role in improving the social development of the country.

According to the second priority of the economic sector, in the findings of this study, it seems that moving towards greenhouse crops, modern and high-yielding irrigation 
practices, cultivating crops consistent with climate and organic, developing industries and small manufacturing workshops, Innovative businesses and knowledge base, taking advantage of the city's high education potential and doing so, will be a good policy for SD. In the present situation, considering the importance of tourism in the world economy and the place of cultural tourism in which the most important elements are the ancient works of each land, it is necessary to identify restoration and preserve the historical works of Kazerun. What is noteworthy is that most of the historical areas related to ancient Iran, are located outside its legal boundary of the detailed plan of Kazerun. The cases that are now seen in the city of Kazerun are related to Iran after Islam, which in their current condition is a total of 18 works. Of these, only three have been recorded, seven of the other recorded Kazerun's are outside the legal boundaries of the city. Historical works of the current city of Kazerun are more like the monuments and elders' homes. Thus, by adopting clever strategies or implementing separate plans, or incorporating historical monuments into an integrated range of detailed plans, and so on, efforts have been made to maintain and enhance the historic capital of the city and to pave the way for activating the potential of tourism development.

Planning for the management of wastewater and waste management, turning the structure of the city into a multi-core one, strengthening public transportation, Focusing on resource management to reduce fossil fuel consumption, and increasing the use of renewable fuels in a climatefriendly location and similar measures, Environmental policies will be reformed. Ultimately, the effort to maintain SD in the city of Kazerun is a continuous movement, and this vision necessarily overshadow the people's and people's worldviews in managing and using existing resources. SD will be a step that will require the cooperation of all development stakeholders, and the improvement of cultural, managerial, economic, environmental, developmental and political activities of each one will contribute to the achievement of the goal. 


\section{REFERENCES}

Akbari, M., Eslami Afrooz A. and Amirazodi, $\mathrm{H}$. "Measuring the status of residents' responsility in the old and new fabric of the Kazerun city." Not published.

Ancient, G. 1998. Indicator of Sustainable Development: Economic Development and National Accounts in Green. Commercial Publishing Company.

Azkia, M. 2005. Sociology of Development. Tehran: Kayhan Publishing House.

Betty, T. And Wheeler 2007. Writings on Sustainable Urban Development. Translator Kianoush Zakhooraghi, Ministry of Housing and Urban Development, Center for Urban and Architectural Studies.

Elliott A. Jennifer, 2006. An Introduction to Sustainable Development. Third Edition, Routledge.

Gouza, Jenifer S. 2006. Sustainable Development, Assignment for Course Module: Introduction to Sustainable Development. Lecturer: Prof. Mark Swilling. Available in https://www. sustainabilityinstitute.net/consulting

Gharlakh, M., Hosseini, S.H. "Indicators of Sustainable Urban Development." Geography and Regional Development 4, No. 8 (Spring and Summer 2007): 157177.

Hall, P. 1993. Toward sustainable livable and innvatitve cities for 21 century. The third conference of the world capitals, Tokyo.

Hardoy, J., Mitlin, D. and Sattherthwaite, D., 1992, 'Sustainable development and cities', Environmental Problems in Third World Cities, London: Earthscan.

Hatami, H. 2006. Natural Geography of Kazerun. Shiraz: Nashr.

Henry, J. 2001. Creativity and perception in management. Walton Hall Publication.

Hosseini, A. 2017. Interview with the Deputy Director of the Department for the Prevention of Crimes in the Provincial Police Command. Kazerun.
Maleki, S. 2011. Income on Sustainable Urban Development. Ahvaz: Shahid Chamran University Press.

Mehrazan-Fars Consulting Engineers (2006), Detailed Design of Kazerun City, Housing and Urban Development Organization of Fars Province.

Moslem, A. "Sustainable Rural Development with Emphasis on the Human and Environment System." Journal of Jihad, No. 270 (2006) 149-126.

Namvar, M. 2017. Investigating the dependence of purchasing power on household income in cities of Fars province. Master's thesis, Islamic Azad University, Gonabad Branch.

Organization for Economic Co-operation and Development (OECD), 2001. Sustainable Development. Policies to enhance Sustainable development. www.oecd.org

Pierce and Robinson 2016. Strategic Planning and Management. Sohrab Khalili Shourini Translation, Tehran: Book Release Publisher.

Reid, D. 1995. Sustainable Development: An Introductory Guide, Earthscan, London.

Sarrafi, M. 2001. Foundations of Sustainable Development of Tehran Metropolis. Conference on Development and AntiSocial Development, Tehran.

Schneider Lambert, et.al. October 2016. Market Mechanisms in the Paris AgreementDifferences and Commonalities with Kyoto Mechanisms. Discussion Paper. German Emissions Trading Authority (DEHSt). Available in: www.dehst.de/EN

Sheikholeslami, A., Karimi, B. and Iqbali, R. "Evaluation of Sustainable Urban Development of Shiraz Municipality." Zagros Landscape Geographic Quarterly Journal 1, No. 2 (Winter 2009): 31-53.

Tehran University, Department of Geophysics (TUGC), 2018, website, available at http:// irsc.ut.ac.ir

The Kazerun Municipality 2018. July, Interview with Deputy Director of Urban Services.

United Nations Development Program (UNDP), 2000. Sustainable Development Goals. 
United Nations General Assembly (UNGA), 1987

Warburton, Diane, 1998. Community and Sustainable Development Participation in the Future. Earthscan. London.

World Commission for Environment and Development WCED, 'Our Common Future' ,Oxford: Oxford University Press, 1987

Ziyari, K. 2005. Urbanization and Urban Planning in Kazerun. Tehran: Arts Treasure Publishing. 


\title{
AND WITH A PINCH OF NOSTALGIA: TRACES OF THE PAST IN NICOSIA'S PRESENT AND FUTURE
}

\author{
Christakis Chatzjichristou ${ }^{a}$, Kyriakos Miltiadous ${ }^{a}$ \\ aUniversity of Cyprus, Nicosia, Cyprus
}

\section{ABSTRACT}

With all the hype around the latest developments in technology and how these affect the way cities are experienced, lived and planned, any mention of nostalgia as an important ingredient in the making of a vibrant urban environment may seem anachronistic, useless if not outright dangerous. Such a reaction could perhaps be valid if nostalgia is understood as a fixation on an imaginary past with the purpose of reinstalling it as part of the present, what has been referred to as restorative nostalgia. There is yet another way the past is used in order to think of the present and the future, what has been described as reflective nostalgia. The paper examines the many and different forms of nostalgia found in the "making" of a contemporary city, taking the half of Nicosia administered by Greek Cypriots as its case study. The term "making" is here used to include any factor which contributes in or influences the way a city is lived. This includes planning strategies, built projects as well as any media through which aspects of the city are offered to its dwellers and visitors. Statues and memorials, museums and archives, historic centres and restored vernacular neighbourhoods are only the obvious and perhaps less powerful forms nostalgia may take. The analysis attempts to widen the spectrum by looking at how the latest technological developments on the one end, and the most basic conceptual apparatus used in the most pragmatic of planning on the other, may indeed both contain a pinch of nostalgia of one form or other.

\section{KEYWORDS}

Nostalgia; city; representation; city-making.

\section{INTRODUCTION}

Nostalgia and the city are terms characterized by an ambiguous yet intimate relationship that is discussed by researchers from different academic fields such as urban studies (AlRagam 2015), cultural geographies (Legg 2004) and social sciences (Boym 2001). Contested sites such as cities marked by crises or war but also post-war communities, provide a fertile terrain for the growth of nostalgic sentiments. Trauma, displacement and loss are frequently seen to play an important role in the emergence of the phenomenon we call nostalgia (Davis 1979, Boym 2001, Legg 2004). In the case of Nicosia, the capital of Cyprus (Fig. 1), the violent enforcement in 1974 of a de facto boundary known as the Green Line, becomes an important physical manifestation of a disturbed era between Turkish and Greek Cypriot communities, a spatial symbol of an unresolved socio-political conflict. As a result, thousands of Greek and Turkish Cypriots were forced to abandon their homes and move to the other side of this new boundary, becoming refugees in their own city. The population on the south half of Nicosia is now 341,700 (Statistical service of the Republic of Cyprus, 2019).

The imposition of the Green Line is recognized by many scholars as an event, which has triggered nostalgia (Papadakis 2006, Bryant 2008). In fact, the violent disruption of space and time caused by the enforcement of the 
boundary has had a real emotional effect on people and has thereby left an indelible mark on their perspective and consciousness. Nostalgia may appear in the present but what it actually does is allow the victims of the situation to "mourn for the violent loss of a past place and time" (Zembylas 2014, 7).

Nostalgia over time appears as an uncanny term, as the word itself receives a wave of different and yet contradictory interpretations. In most recent studies, nostalgia is defined as,

a backward glance to a place and time that no longer exists or has never existed (Boym 2001, 7).

For a long period of time, nostalgia was seen in a negative context: a notion opposite of progress, associated with sentimental or melancholic attachments with the past. Such restorative nostalgia as it is defined by scholar Svetlana Boym strives to fulfil an impossible desire for authenticity and overall return to an idealized past. This form of nostalgia puts emphasis on the word nostos and what it attempts is a historical reconstruction of the lost home through figurative and literal means. The word "restoration" has Latin roots; it derives from the word re-staure (re-establishment), meaning the complete return to an initial state. As many scholars argue, restorative nostalgia dwells at the core of nationalism which engages in

the anti-modern myth-making of history by means of a return to national symbols and myths, and occasionally through swapping conspiracy theories (Boym 2001, 41).

Nationalists utilize nostalgia as a political instrument to achieve their ideological goals, such as appeals to a glorious monumental past. According to Boym, restorative nostalgia and the "imagined homeland" is the leading cause of a host of catastrophes that occurred during the 20th century, ranging from the Nazi Regime, the Soviet Terror, to more recent nationalist revivals such as the case of former Yugoslavia. Furthering this statement, Boym writes:

Outbreaks of nostalgia often follow revolutions; the French Revolution of 1789, the Russian Revolution, and the "Velvet" revolutions in Eastern Europe were accompanied by political and cultural manifestations of longing. (Boym 2001, xvi)

Restorative nostalgia is clearly not what Michel Foucault proposes regarding the "historicization of memory". Foucault rejects the return to the origins and the existence of history as a "pretended continuity" (Foucault 1977). In respond to homogenous historical narratives he proposes the concept of "countermemory": fragments of memories that challenge the monolithic tradition of heritage.

More recent literature and research on nostalgia shed light on an alternative meaning of the term, by paying attention to its complex, heterogeneous nature. Nostalgia is not necessarily seen as the expression of a conservative impulse, but rather as a vehicle for critical thought that is capable of approaching the past in productive ways. This reflective nostalgia as it is called by Boym, dwells on the word "algia" and addresses the past in a way that is "ironic, inclusive and fragmentary" (Boym 2001, 50). In reflective nostalgia, the past appears in the form of fragments of memories produced by individuals, not necessarily accepted in the officially written history of a place, event or period. Thereby, this type of nostalgia calls into question the hegemonic narratives of memory and loss. The word "reflection" has also Latin roots; it derives from the "re" meaning "back", and the word "flectere" meaning "to bend"; for Boym, "re-flection suggests a new flexibility, not the reestablishment of stasis" (Boym 2001, xiv). In the context of Nicosia, despite some mentions of the word nostalgia in discussions about the intertwined relation between memory and the city (Bakshi 2012), and the 
role of nostalgia in representations of the city (Hatay and Bryant 2008), little has been done towards an investigation into the role of nostalgia in the processes of making, representing and reconstructing the city of Nicosia. In the present piece of research we see Nicosia as a battlefield of different attitudes regarding the past, the present and their relationship to the future, thus rendering the city as an excellent case study to explore the dynamics of the phenomenon referred to as nostalgia. Our hypothesis is that nostalgia is a dynamic multi-layered force that can act at different scales and levels in the making of the contemporary city. Through our exploration of nostalgia we aim at capturing and revealing the different types of nostalgia embodied in the city, or half of the city to be more accurate, drawing material from three kinds of primary sources: textual, digital, and material sources. The word "making" refers not only to physical constructions such as museums, statues and memorials, but it also includes everyday practices of inhabiting the city, planning strategies and official policies, myths of urban identity and more hidden stories of everyday life. What follows could be seen as a collection of snapshots of what is happening in and with the city, starting with those related more with conflict and trauma and continuing with those that talk more about the city's culture.

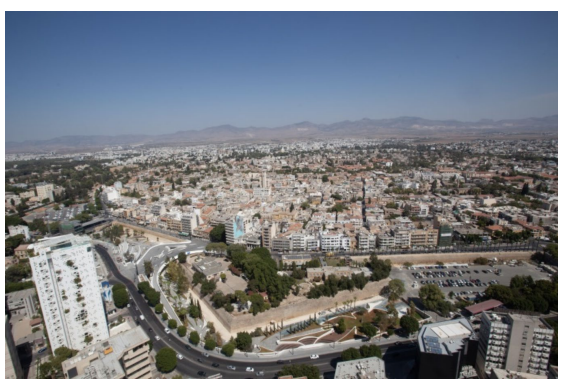

Figure 1. The Venetian city of Nicosia. Source: (Authors 2020)

\section{EMBODIMENTS OF NOSTALGIA}

\subsection{The Nicosia Master Plan}

An increasing number of various bicommunal reconciliation projects strive to construct common visions for the future of the dwellers of Nicosia. Such practices aim to carve alternative trajectories to the oppressive official narratives. The main ancestor of such synergies can be traced back in 1977 when a joint project between the two communities has emerged, driven initially by the need to coordinate and establish a shared sewerage system for the whole city. The project was envisioned by the mayors of the two communities of Nicosia, Greek Cypriot Lellos Demetriades and Turkish Cypriot Mustafa Akinci (Demetriades 1998). The successful installation of the sewerage system set the foundations for the creation of a Nicosia Master Plan (NMP) in 1981, a project supported by the United Nations Development Programme and the United Nations Centre for Human Settlements as an attempt to revitalize the historic centre of Nicosia. The bi-communal urban planning team constituted of architects, planners, and sociologists collaborating with the aim of developing a holistic master planning strategy through a unified vision for the city. The project was divided into three phases. The first phase which lasted between 1981 and 1983 concentrated on the conduction of an analytical report for the condition the city was in at the time. The main objective of the second phase which lasted between 1984 and 1986 was the composition of an operational plan for the central city of Nicosia, focusing on both the Turkish and Greek Cypriot areas within the walls. The third phase which began in 1986 focused on the implementation of projects for specific urban quarters, such as the areas of Chrysalliniotissa within the Greek Cypriot side and the Arab Ahmet within the Turkish Cypriot side (Bakshi 2015). 
Despite the fact that some of its attempts were successful, the NMP is considered with scepticism in some of the literature on the subject; the subdivision of the project into a "dual approach", which allowed for separate developments on each side is seen as a failure to embrace the possibility for a common vision for the city (Bakshi 2015).

A look at such political, administrative and planning strategies developed for Nicosia sets an interesting point of departure for discussing how nostalgia is engaged with city-making in both productive as well as counter-productive ways. To begin with, the existence of different, and in some occasions contradictory practices indicates the very fact that there are different constructions of the past, different future aspirations and thus different nostalgic recollections not necessarily only regarding traumatic past experiences or events but also about previous periods in the life of a community in general. If this is the case, then the concept of a masterplan may not be the most appropriate conceptual model to use when dealing with the multifaceted and multilayered nature of nostalgic phenomena. The observed contradiction between these two terms may be spotted from the very birth of the project, the insistence to have a common sewage system for an already divided city. The effort of having a common infrastructure for practical and other reasons is not here criticized. What is seen as remarkable though is the strong doze of nostalgia in a project as pragmatic as the construction of a sewage system for a city that has long been functioning as two cities despite the sense of wholeness given to it by its circular Venetian walls.

\subsection{Use of slogans (I do not forget)}

In the aftermath of the 1974 Turkish invasion, the dominant ideology supported by the Greek Cypriot political discourse was not to forget the lost territories and thereby maintain the past as it was before the war, in its supposedly perfect and pure form. Within this framework the utilization of nostalgia became a highly political weapon. As Papadakis notes,

The cultivation of nostalgia for their old homes and villages became a significant part of the official policy. These Greek Cypriots, and their children, should always feel like refugees (Papadakis 2006, 11).

The "Myth of Return", a concept developed by Roger Zetter seems to provide a useful framework when discussing the strategies and processes adopted by both communities after the 1974 war. Such a myth evokes "a familiar, idealized past and sustain[s] the memory of collective loss" by maintaining the "concreteness of a familiar home or point fixed in space" (Zetter 1999, 4). The goals of the state policy mentioned above are also found behind spatial practices with a more physical dimension within and around the walled city of Nicosia. The old core of the city provides the ground for the construction of monuments, statues, museums, street naming and other strategies in order to construct and celebrate a glorious, monolithic image of the past.

\subsection{The statue of Liberty}

Commemorative structures such as museums, monuments, statues and memorials hold a prominent position within the old city of Nicosia. One of the most indicative examples of such structures is the Liberty Monument that is sited at the Podocataro Bastion of the Venetian walls (Fig. 2). It consists of seventeen bronze human figures - men and women of different ages which are seen against a pyramidal base with a white marble veneer. The figures are shown as they come out of the dark prison and look up to the sky. At the top, a centralized statue symbolizing Liberty, stares at two fighters removing the chains that held the prison gate locked, allowing the Greek Cypriot prisoners walk out into freedom. And while the monument was erected in 1973 to pay tribute to the Greek-Cypriot guerrilla 
fighters of the 1955-1959 EOKA struggle against the British, the Turkish invasion in 1974 resulted in a broadening of the initial narrative with the notion of freedom being transformed into a future vision "when [this land] is resurrected from the tomb of Cypriot slavery" (Loizidou 2010, 96). The monument thus simultaneously embodies two different aspirations through its post-1974 presence: first, it celebrates a glorious past with direct references to the armed struggle against the British Rule; second, it represents the longing for a future when the island is freed from Turkish occupation.

The Museum of National Struggle is another important place of memory within the walled city and close to the buffer zone. The Imprisoned Tombs (Filakismena Mnimata), the graves of some of the heroes of the guerrilla war against the British are found within the premises. Here, as before, what lies at the core of such projects is the longing for an "imagined community" of pure origins.

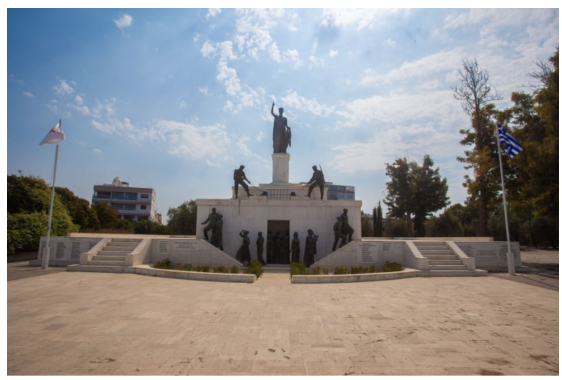

Figure 2. The statue of Liberty. Source: (Authors 2020)

\subsection{Naming of streets}

Street naming for commemorative purposes is recognized as a vital act contributing in a powerful manner to the transformation of the urban network into "a political social setting" (Azaryahu 1996, 311). The word "setting" is used here, to mention any active arrangement that seeks to evoke social interaction. Therefore, "the ability to control the meanings of such settings is an important expression of power" (Giddens 1979, 207). Moreover, as scholar Karaiskou argues, streets define "home" and in this way are bounded up with personal experiences and may thus have a strong sentimental impact (Karaiskou 2019). In Nicosia the process of commemoration through the names of streets becomes an obvious political gesture. Key places of social interaction bear a name that develops direct connections to the officially acknowledged history of the ethnos or race. More than half of the existing roads as well as small squares bear names of historical events and heroic personalities, both real as well as mythological. In particular, three essential categories of names are identified (Karaiskou 2019). The first category consists of names from iconic figures from ancient Greek history such as Hippocrates, Pericles and Sophocles. The second category bears names that reflect on the ancient Greek mythology, such as Hermes and Athena. The third category bears names that echo the Byzantine Period such as Constantinos Palaiologos. Only a few cases diverge from references to the Greek homeland, thus misinterpreting the multicultural past as well as the present of the country. An example of such an exception is Ouzounian Street, dedicated to the Armenian family of Ntikran and Touma Ouzounian.

\subsection{Ledra / Locmaci checkpoint}

In April 2008 the passage through the buffer zone connecting Ledra Street in the south with Locmaci Street in the north opened again after 34 years, allowing people to cross to the other side. Panels depicting young children holding colourful balloons were positioned along the sides of the passage (Fig. 3). The purpose of the corridor thus formed was to obstruct any views of the buffer zone which looks like a jungle with ruins. The innocence associated with children and the playfulness and lightness associated with holding a balloon have been here combined to camouflage the grave 
nature of the situation. The theme selected to accompany the people crossing to the other side takes a role similar to a chat about the weather that takes place between strangers or people feeling uncomfortable with each other. It is an attempt for neutrality through the avoidance, or better erasure in this case, of any reference to a heavily troubled common past. Such spatial practices mentioned above could be characterized as anti-nostalgic as they challenge the blind rhetoric that argues for an absolute return to a glorified past. Here, the key words are normalization and erasure, not commemoration. Yet, in a paradoxical and ambiguous manner the discussed practices could also be characterized as nostalgic. They express an unspoken longing for a potentially different future, "a nostalgia for the future that expands the possibilities of what might be" (Stephanides 2007, 10). Even though nostalgia has traditionally been defined as yearning for a lost home, this does not imply that the "home" should be real. As Stewart argues, nostalgia is a longing for an object that does not exist, a utopian dwelling. After all, "nostalgia is the desire for desire" (Stewart 1984, 23). In fact, this form of nostalgia is dialectically linked with forgetting that is considered as necessary for the forging of a new identity. However, this form of longing problematic, as is the case with restorative nostalgia, in the sense that it displays only visions for a common future without directions, without any references to the past, and therefore without movement.

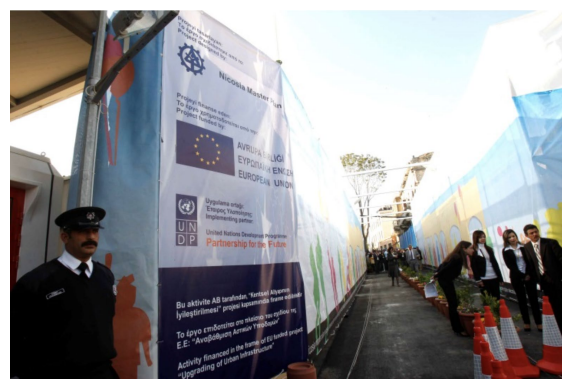

Figure 3. The Ledra/Locmaci street opening. Source: (Manoli 2008)

\subsection{Archbishop Makarios III monument}

One of the most striking examples that reveal the ways in which the two different nostalgic tendencies collide on the fabric of the city is illustrated by an incident involving the statue of the first president of the Republic of Cyprus, Archbishop Makarios III. It was located in a prominent spot within the courtyard of the Archbishop's Palace in the eastern part of the old city. On the morning of the second day of September 2008 the monument was found desecrated and vandalized by being splashed using balloons filled with yellow and red paint and by writing the following short yet strong phrase on its base: "For Sale: Down With Idols" (Fig. 4), (Leonidou 2008). At first glance, this event could be read as a resistance to the political discourse, an attempt that seeks to deconstruct the hegemonic narrative by using irony and disrespect. Yet, at the same time it becomes a battleground of clashing nostalgias and future aspirations. Such an act reveals the double edged nature of nostalgia since it can be "an emotional antidote to politics and... the best political tool" (Boym 2001, 58). After all, as scholars Hatay and Bryant claim, the words nostalgia and revolution are characterized by a shared desire to reinterpret the political condition as a decline or loss (Hatay and Bryant 2008).

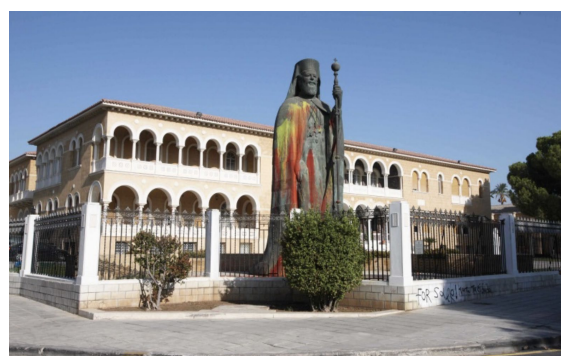

Figure 4. Archbishop Makarios III monument. Source: (Manoli 2008) 


\subsection{The Home for Co-operation}

Along one of the main crossings between the two sides of the divided city, one finds the "Home for Co-operation" (Fig. 5), a building that houses a bi-communal nonprofit network that was envisioned by the Association for Historical Dialogue and Research back in 2008 (Akbil and Psaltis 2016). Its aim is "to transform what is currently referred to as the buffer zone...into a zone of cooperation" (Epaminondas 2011, 6). Following the guidelines provided by the authorities, the façade has been faithfully restored to its original state, while the interior was renovated in a way to encourage communication between the communities. Beyond the signs of natural decay, the building was marked by "bullet holes", by barbed wire scratches and by other traces left on it by the war it survived in 1974. An important element in the initial proposal of the design team, a concept referred to as the healing wounds process,

\section{suggested symbolically the passage from wound to scar, from concave to convex through the installation of crystal semi- spheres and tiny historic images in 3-4 bullet sign (Akbil and Psaltis 2016, 205).}

This project could be seen as an interesting example of reflective nostalgia in the sense that it enters into a dialogue between different elements or entities at different levels: the location chosen is within the buffer zone that divides the two communities; the choice to have the exterior reveal the troubled past while using the interior to practically deal with the challenges of the present; and the choice not to erase the scars on the exterior but to use them as a reminder of what went wrong in the past.

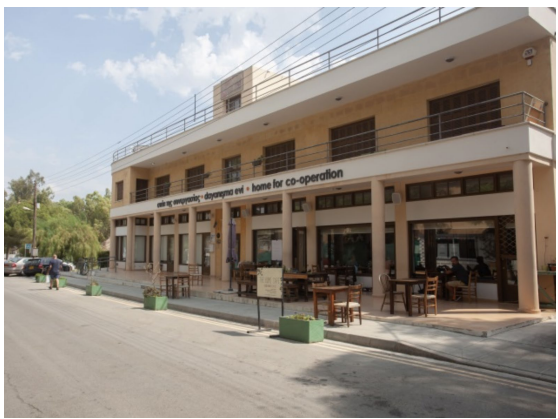

Figure 5. The Home for Co-operation. Source: (Authors 2020)

\subsection{The "Green Line Project"}

The "Green Line Project" is a virtual platform that documents spaces in the buffer zone, which remain inaccessible to people, Greek and Turkish Cypriots alike, since 1964. According to the authors, their aim was "to turn the buffer zone into a memorial of the catastrophic consequences of divisive politics" (Bekiaris and Mavros n.d.). Demonstrated as a digital memorial, the project preserves traces of the buffer zone as they exist today through the effective medium of virtual reality. But these virtual constructs represent something more than literal reconstructions of the actual spatio-temporal condition within the buffer zone. The virtualized Green Line affects the way in which this traumatic space is perceived from an aesthetic and ethical perspective. As Warren-Crow puts it, the digital image is "full of endless morphological potential" (Warren-Crow 2014, 2). A sense of distance is developed between the subject (viewer) and the object (virtual image) allowing multiple layers of communication between the "now" and the "then", the "here" and the "there". The project thus offers the viewer the ability to virtually visit the Green Line and oscillate between the past and the future, the haptic and the optic, the dynamic and the static. 


\subsection{The traditional neighbourhood}

A popular tourist destination within the walled city is an area referred to as the Laiki Geitonia or traditional neighbourhood. It is a restored area where buildings that used to be mainly houses have been converted into restaurants and souvenir shops. Apart from the shell of the buildings, nothing else informs the visitor on how life was in the days this area was indeed a neighbourhood. Such a project cannot comfortably be referred to as an example of restorative nor reflective nostalgia since it may be mainly catering to the need of the tourist visitor rather than the local, to get a glimpse of what used to be the authentically local, an identity gained not only by being different from the local contemporary but also by being different from the authentic local in the visitor's own culture. More of a theme park, it could be considered as satisfying a unique yet quite popular form of nostalgia; the desire to be safely exposed to a manageable doze and for a short time to something not necessarily old but different.

\subsection{City heart transplant}

As in many cities, the old city center of Nicosia is mainly inhabited by foreign workers who find apartments in old and badly maintained buildings affordable. And while a large percentage of the population employs a foreign worker as house-help or for taking care of the elderly, many are appalled by the predominance of non-Cypriots in the heart of the city, a phenomenon which is made even more noticeable by the tendency of the locals to use their car for even the shortest of trips and the fact that foreigners walk and make more use of the public spaces, not necessarily by choice. Could the xenophobia expressed by many locals related in any way to nostalgia? Could it be that nostalgia is actually a form of xenophobia if the term "xenos" is not taken to mean only strange people but strangeness in an expanded form?

\subsection{Yesterday Years of Nicosia}

"Yesterday Years of Nicosia" is a digital network that shares old photos of the district of Nicosia, taken in the 1980's and prior; it aims at celebrating and commemorating the past of the city through the creation and coordination of a digital archive composed of snapshots such as postcards, clipping from newspapers, pieces of magazines and maps. According to the creator of the platform:

The ultimate goal of the team is for the Nicosians, through the nostalgia triggered by the old photos and through the strong sense of identity that is created by the study of the history of the city to believe in Nicosia one more time. (Xenou 2019)

These visual fragments are characterized by an intimate and bittersweet aura; they indicate a sense of nostalgia for a past which is seen as perfect compared to a troubled present. The inclusion of visual fragments from a specific chronological period aims at restoring a distinct vision of Nicosia. In this way history is fixed in its place and the perceived image of the city is not allowed to evolve.

\subsection{Archaeological sites within the urban fabric}

Archaeological remains have, in recent years created headaches, dilemmas and heated discussions, and caused costs to skyrocket, since they seem to appear every time the municipality starts a new major project within or around the walled city. The construction of the new Municipal Hall (Fig. 6), Eleftheria Square and the new House of Parliament have all been delayed considerably because the excavations for the foundations of these projects brought to the surface archaeologies that were considered by the Department of Antiquities to be worth preserving. The heated debates that followed reveal the existence of different views regarding the desired 
relationship between the remains of the past with the present as well as the future of the city. Such a situation could be seen as a fight for space between the past and the present. The question that could here be posed is: is space unable to accommodate more than one era, ideology, or vision, making it necessary to fight over?

Looking at such situations through a different lens, it could be argued that, if, as it was the case in all three projects mentioned above, the findings were of some foundations and no more, why should they be part of our present day experience? Are they valuable and worthy of preservation because: they inform us of the way things used to be; because they add meaningfully to our experience of the place; or because, like any other relic, they deserve our respect? To what degree is our attitude influenced by curiosity, nostalgia or ethics?

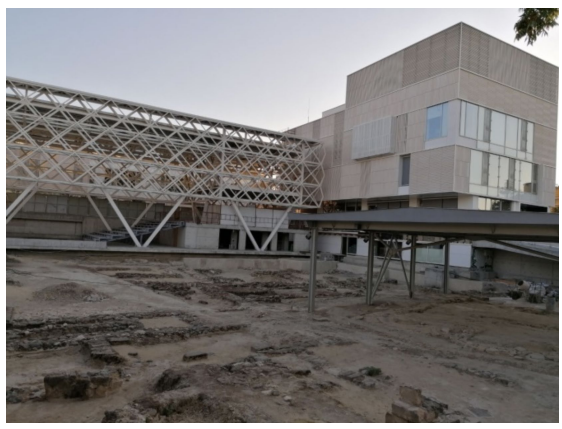

Figure 6. The new Municipal Hall. Source: (Authors 2020)

\subsection{Transfunctional buildings}

The archbishop of Cyprus has recently announced that he is planning to convert some buildings owned by the church into museums of ecclesiastical history. Such a building is the house of Hadjigeorgakis Kornesios who was a dragoman, a local Christian who, during the Ottoman Rule, was appointed as the official interpreter for the
Divan (Council) of the Sultan. Kornesios, envied by the local population because of the power and wealth he gathered, was finally beheaded in Istanbul.

The building currently functions as a museum for the period it was inhabited (late 18th century). As expected there was a strong protest regarding the archbishop's intentions who, feeling offended, finally published an announcement where he states that he, as well as his collaborators, are not lacking in sensitivity regarding the history of the city. What will happen remains to be seen but what is relevant to our topic is the interest the public is taking in such issues.

So, what is the main cause of the expressed disagreement with the Archbishop's intentions? The material currently exhibited in the museum indeed refers to the life in the house itself as well as the culture and politics of the period. The change proposed would shift the focus on the history of the church in that same period. Clearly the proposal seems like a mistake but is it such a big mistake to account for such a strong and widespread protest? Could the specific issue partly serve as the battlefield in which other issues are dealt with? In this specific case, the main protest may actually be about the archbishop's attitude and not about the intended change. It could therefore be that the protest is not caused by a respect for the authenticity of the old but by a disrespect of a present person, event or situation. As is perhaps the case in all exhibitions of nostalgia, what really matters is not in the past or even in the future but in the present. Transporting the issue into either the past or the future may make it easier to deal with in the present.

\subsection{A bridge, not a square}

One of the most controversial projects in Nicosia is clearly the redesigning of Eleftheria Square, the most centrally located public space in the city (Fig. 7). The project 
was given to the office of Zaha Hadid after an international architectural competition that was carried out in 2005. The public expressed strong negative feelings after the competition drawings were publicized. Some felt that the aesthetic qualities of the proposal were not suited for the context while others focused on the absence of any measures to deal with the hot climate of Cyprus. Yet others were outraged because according to them, the proposal replaced the existing entity, which they saw as a bridge, with a square. As in the previous case discussed, the situation may involve more than the eye can see. Could the anger felt by many citizens who, other than such occasions are completely indifferent to public issues, be due to the fact that the strange aesthetic was, subconsciously or not, associated with another doubly strange element in the setup? Could it be that at least some of the protests were actually against the architect Zaha Hadid, an Arab and a woman? In many impromptu conversations this was clearly the case. The question is, what was the main trigger: the strangeness in the aesthetic expression of the project or the strangeness of the author? We would say it was the first that triggered the second.

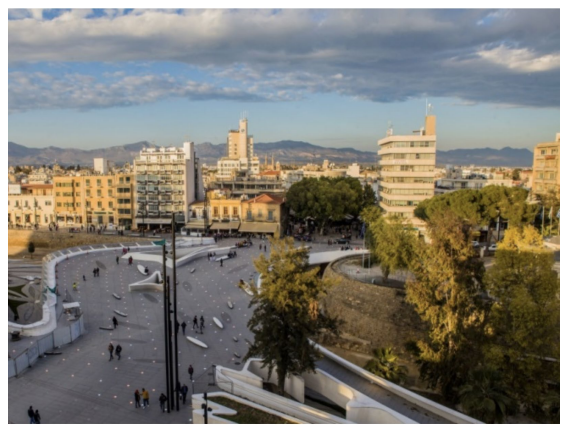

Figure 7. Eleftheria Square. Source: (Authors 2020)

\section{CONCLUSION}

A number of points can now be made regarding the different shades nostalgia can take in the making, representing and reconstructing the city:

- Boym's distinction between restorative and reflective nostalgia is quite important and helpful. What the analysis above may suggest though is that, even though one type may predominate, there is always a doze of the other in most cases examined. This could be seen as the case with the Nicosia Master Plan for example where the effort is to work on pilot projects on each side of the divided city separately and yet keep a vision of a united city as well.

- Anti-nostalgic practices and attitudes express a special form of nostalgia where the longing is for a future free from a burdened past. The Ledra/Locmaci checkpoint is such an example. The lining of the sides of the crossing with neutral and totally irrelevant imagery could be paralleled to the kind of stitching where the thread used does not have any common elements with either of the sides it connects so that it will not be rejected as foreign by the other. Whether this move will indeed allow for a new common ground between the sides remains to be seen.

- Expressions of nostalgia about specific elements of the perceived past, say traditional architecture, may actually have more to do with a dissatisfaction with quite different elements in the perceived present. The displacement or rather transference of elements from one reference system to another may be seen as what Colin Rowe and Robert Slutzky have described as phenomenal transparency (Rowe and Slutzky 1963). This may be the case with the strong reaction of an otherwise disinterested public regarding the plan of the archbishop to create an ecclesiastical museum. The negative feelings were actually about what is perceived as an authoritarian church leader and not about the function to be accommodated in the specific building. 
- Nostalgia may be a longing for a perceived past but it may also be about a fear for a strange present or an uncertain future. Its strong relationship to such concepts as identity, history, and time, may thus be influenced or even conditioned by a deeper connection to the concept of change and death. The xenophobic attitude of the Nicosians regarding the overwhelming presence of foreigners in the city center is probably such an example.

-In many nostalgic visions for a present or future, what already existed in the past may be given a privileged position over the new, a phenomenon similar to the one identified by Derrida and logocentrism where presence is privileged over absence. The freezing of large and important projects for the present life of the city due to archaeologies found during excavations is indeed a good example of this attitude. This is indeed a problem in a country like Cyprus where the chances of hitting on an ancient foundation or grave while digging are high. This competing of space between the old and the new is quite an interesting topic for further investigation due to what it implies.

In closing, a more general observation regarding the topics associated with nostalgia is that there seems to be a degree of fluidity and transparency between them. A hydraulic system in which the element traveling through it may not only change locations but, perhaps more importantly, change states as well may reflect the dynamics of the phenomenon of nostalgia and the many shades or versions it may take. Its sleepery nature may indeed be a source of problems but it may, at the same time, be a source of potential. The more we understand the processes and mechanisms through which nostalgia mutates from one form into another, the more we, as designers, will be able to contribute in using this strong and important ingredient of any community or society constructively rather than destructively. 


\section{REFERENCES}

Al-Ragam, A. 2015. Critical nostalgia: Kuwait urban modernity and Alison and Peter Smithson's Kuwait urban study and matbuilding. The Journal of Architecture, 20, 1, 1-20.

Azaryahu, M. 1996. The power of commemortive street names. Environment and Planning D: Society and Space, 14, 311-330.

Bakshi, A. 2012. A shell of memory: The Cyprus conflict and Nicosia's walled city. Memory Studies, 5, 479-494.

Bakshi, A. 2015. Nicosia Master Plan. Planning across the divide. In: Björkdahl A. and Strömbom L. (Ed.), Divided Cities: Governing Diversity, 197-215. Lund: Nordic Academic Press.

Bekiaris, I. and Mavros, A. n.d. The Green Line. Available at: http://www.greenlineproject. com.cy/. Accessed on 28 January 2020.

Boym, S. 2001. The Future of Nostalgia. New York: City Press.

Bryant, R. 2008. Writing the catastrophe: Nostalgia and its histories in Cyprus. Journal of Modern Greek Studies, 26, 2, 399-422.

Davis, F. 1979. Yearning for yesterday: A sociology of nostalgia. New York: Free Press.

Demetriades, L. 1998. The Nicosia Master Plan. Journal of Mediterranean Studies, 8, 169-176.

Epaminondas, M. 2011. Home for Cooperation. Nicosia: K\&L Lithofit Ltd.

Foucault, M. 1977. Nietzsche, genealogy, history. In D.F. Bouchard (Ed.), Language, counter-memory, practice: Selected essays and interviews by Michel Foucault, 139-164. Ithaca NY: Cornell University Press.

Giddens, A. 1979. Central Problems in Social Theory. Berkeley: University of California Press.
Hatay, M. and Bryant, R. 2008. The jasmine scent of Nicosia: of returns, revolutions, and the longing for forbidden pasts. Journal of Modern Greek Studies, 26, 2, 423-449.

Karaiskou, V. 2019. Deep in Memory: Urban Space and Visuality in Cyprus. In Fouseki, K., Guttormsen, T. and Swensen, G. (Ed.), Heritage and Sustainable Urban Transformations: Deep Cities, 67-88. UK: Routledge.

Legg, S. 2004. Memory and nostalgia. Cultural Geographies, 11, 99-107.

Leonidou, L. 2008. The Ultimate Indignity: Vandals Deface Makarios Statue. Available at [http://www.cyprus-mail.com/ news $/$ main . php? id=41154\&archive $=1]$, accessed on 17 January 2020.

Loizidou, C. 2010. On the Liberty Monument of Nicosia. In Loizos, P., Philippou, N., Stylianou-Lambert, Re-Envisioning Cyprus, 89-101. Nicosia: University of Nicosia Press.

Papadakis, Y. 2006. Nicosia after 1960: A River, A Bridge and a Dead Zone. GMJ: Mediterranean Edition, 1, 1-16.

Psaltis, G. and Akbil, E. 2016. From Conflict to Reconciliation: Heritage Conservation in the Cyprus UN Buffer Zone. In Schneider P. (Ed.), Catastrophe and challenge - Cultural heritage in post-conflict recovery. 199-208, Cottbus: Brandenburgische Technische Universität.

Rowe, C. and Slutzky R. 1963. Transparency: Literal and Phenomenal. Perspecta, 8, 4554.

Statistical Service of the Republic of Cyprus. 2019. Population: Summary data at the end of the year Available at: https:// www.mof.gov.cy/mof/cystat/statistics. nsf/populationcondition_21main_ en/populationcondition_21main_ en?OpenForm\&sub=1\&sel=2, Accessed on 11 September 2020. 
Stephanides, S. 2007. Cultures of Memory, Memories of Culture. Nicosia: University of Nicosia Press.

Stewart, S. 1984. On longing: Narratives of the miniature, the gigantic, the souvenir, the collection. Baltimore: Johns Hopkins University Press.

Walder, D. 2009. Writing, representation and postcolonial nostalgia. Textual Practice, 23, 935-946.

Warren-Crow, H. 2014. Girlhood and the Plastic Image. Hanover: Dartmouth College Press.

Xenou, E. 2019. How to believe in our city? Available at https://www.kathimerini.com. cy/gr/apopseis/arthrografia/eleni-xenoy/ pws-na-pistepsoyme-stin-poli-mas. Accessed on 23 January 2020.

Zembylas, M. 2014. Nostalgia, Postmemories, and the Lost Homeland: Exploring Different Modalities of Nostalgia in Teacher Narratives. The Review of Education, Pedagogy,and Cultural Studies, 36, 7-21.

Zetter, R. 1999. Reconceptualizing the Myth of Return: Continuity and Transition Amongstthe Greek-Cypriot Refugees of 1974. Journal of Refugee Studies, 12, $1-22$. 



\title{
PAPER \#1.08
}

\section{MANY CITIES IN ONE. ENCLAVES AND MICROCOSMS IN THE GENERAL STRUCTURE OF THE CITY: THE CASE OF PRAGUE'S GHETTO}

\author{
Domenico Chizzonitia, Yuliia Batkova ${ }^{\mathrm{a}}$ \\ aPolitecnico di Milano, Milan, Italy
}

\section{ABSTRACT}

The design of autonomous urban areas concerning the urban environment that surrounds them is an increasingly widespread practice in urban transformation. The model promoted by this practice of recognizing autonomous microcosms in the city confirms the operational intent of defining portions of comprehensible and identifiable cities. The paper investigates the case of Prague as an urban phenomenon due to the fact of its urban complexity made by parts of different origins. Highlighting connections between the origins of the city development and its transformations is a crucial point in understanding the laws of its construction. It leads to a reasonable investigation of urban recovery processes within the context of the city. Firstly, the work is based on the analysis of the city and its essential facts, highlighting the principle of "autonomous settlements development" throughout the history of Prague presented as the primary settlements. This examination becomes operational as a tool of knowledge capable of enriching the potential of choices through accurate elements of judgment in the project options. Secondly, the opinion tries to experience the character of the Prague ghetto and the reasons for its formation and further transformation, the relationship between the Prague Ghetto and the city itself. Finally, the paper investigates the difference between the concept of an urban island, as presented by primary settlements distinguished in the urban tissue nowadays, and the enclave of the ghetto as a culturally distinct part. Nowadays the historical character and the identity of the transformed Jewish ghetto represents by singular architectural facts. Our intention is not to reproduce, but to transform the site into a living matter. The identification of the importance of the historical sites makes clear the role of preservation that holds the nature of the site with its structures, architecture and all of the components that belong to it.

\section{KEYWORDS}

Urban analysis; urban morphology; jewish culture; urban transformation; the city by parts.

\section{INTRODUCTION}

Architecture as an urban phenomenon should have been taken into a fundamental consideration of the study of the city. The city and its construction are the ultimate goals. In fact, research on architecture acquires relevance, as it is considered the most incisive tool in the construction and transformation of the city. One of the most important characters of the architecture is the urban quality of the city: the ability to dialogue with the context; ability to place itself in relation to other existing architectures, to a given landscape, to an infrastructure system, etc.; the ability to become a complete part of an on-going process. In this perspective, the identification of the relationships between figuration and urban form and their changes throughout history is a decisive element in understanding the formative and transformative laws of the physical (but also political and economic) constitution of cities.

This approach has two purposes:

1) knowledge (by comparison of individual urban phenomena) of cultural processes 
and material conditions associated with the physical construction of cities in the various historical periods and, therefore, of a specific contribution by the architect to a more general history of the culture of cities in urban construction processes;

2) knowledge (for a diachronic reading of the historical events of a city) of the stratification and transformation processes of the urban structures of a single city and, therefore, of a contribution by the architect to an urban history related to specific contextual conditions.

Above mentioned ideas are fundamental for the design background of each operator involved in urban recovery or transformation processes. From these studies emerges the desire to become aware in each transformative process of the "conformative" results on the city that the architectural intervention produces. Also, to have a control over it. This paradigm is linked to the belief that architecture always has a profound role of impact on the urban form.

Further methodological acquisition of this research concerns the question of the formally completed part of the city, as an autonomous, physically recognizable element. "The completed form is the achieved unity, in a given historical period, of the formalization process: it is therefore found both in a single building, as a refinement of its constituent elements (the Parthenon, compared to previous temples) and in a part of the city (the complex of the Vatican Palaces, S.Pietro, Borghi and Castel S.Angelo in Rome) and finally in an entire city "(Aymonino 1975). The formally completed part of the city is therefore fully proposed as an urban fact. So, the architectural dimension tends in many cases to coincide with the part itself. This process gives the absolute unity achieved by the part itself, which effectively cancels the formative value in the city of its individual constituent elements, as in a kind of chemical process of irreversible composition of the elements towards the creation of complex particles with their own identity distinct from that of the individual component elements. This approach is thus applied to both new and existing parts. Therefore, it makes the possibility of breaking down the existing city into completed or to be completed parts in a critical-planning context.

\section{THE CASE OF PRAGUE}

The city of Prague saw many urban transformations. The urban tissue is fragmented; thus the relation of its parts represents the city. It is derived from the complexity of social, political, geographic and environmental issues affecting the city during its history. Therefore, shedding the light on the origin of a complex structure of Prague implies an interdisciplinary approach. The perception of the Prague transformation and development process implies the necessity to study the history of its parts. The complexity of such a study initially leads to understanding the reality of urban organism through geographic perception.

The Czech historic geography has a multidisciplinary character. It examines the causes and consequences of transformations, so it goes out of the rigid limits of environmental changes. It tends to highlight the essence of the environmental changes through the meaning of it to the individuals. The historiographic boundaries and composition of contradictive, at time, urban forms perceived through their ideological social meaning (Semotanová, Eva and Chromý 2012, 13).

The first information on the urban development on the banks of VItava River imprinted on maps dating back to 1200. On the hill of Hradčany on the western bank of the river emerged the first fortified structure of Prague Castle. The natural conditions of narrow, stretched slope within the rock were compensated by its strategic location in the basin. The chrome terrain structure was a prerequisite for the fortified development. As a result, the architectural configuration of the establishment is subjugated to the natural 
configuration of the environment. Later on, in 1257 the residential district of Malá Strana arose to the south of Hradčany.

In the middle 10th century another fortified castle Vyšehrad has emerged on the east bank. Based on the hill, the development was dedicated to being a fort.

Where the east bank's slope forms a natural amphitheater with terrains, emerged settlement dedicated to being the historic core of the future city (Staré Město). Grownup along the river since the 10th century it was intensively developed in the 14th century.

Later on, New Town (Nove Mesto) district emerged on the southwest of the city core. It was established and settled in the 14th century and closed the medieval development of Prague.

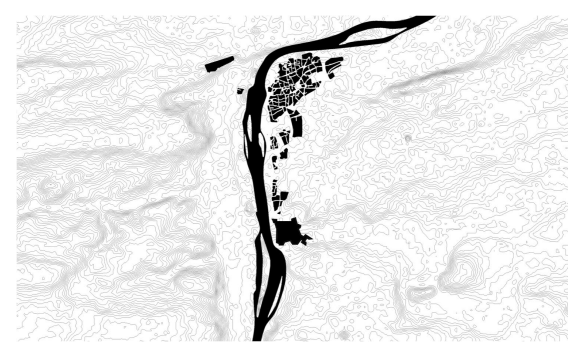

Figure 1. Early settlements of Prague. Source: (Author 2020)

In the baroque period, new fortifications were built around Malá Strana and Nové Město. Until the industrial revolution of 19th-century city development was contained within the medieval pattern of the basic street layout. It was limited by the fortification system.

The year 1784 is remarkable by a new phase of development of Prague, as it is the year of the unification of its parts. At the turn of the century, the technological and social changes provided particular conditions for city growth. Urban fabric expanded behind the fortification walls and formed a neighborhood of new residential and manufacture buildings - Karlin. Later on, the external boundary of the city was demarcated by areas of high-rise residential districts (Chizzoniti et al 2017, 282-285).

\section{MANY CITIES IN ONE}

According to the study of topography and the history of urban evolution, the first developments on the Vltava river formed on the need for defense and commerce and the fundamental prerequisite for this was a geographic factor. They have qualities unlike those of the development types that were to come later. Each town was cut off from the surrounding countryside and compactly built within distinct limits, caused by security. It is typical for the European urban formations of medieval times (Sert 1994, 394). The development itself was separated in its independence and local autonomy. Each part had its character determined by certain geographic location and organization of lifestyle. Hence, in contrast to the rural settlements, each part was dependent on a certain function.

Unlike castles that had a defensive character, the Staré Město transformed into the large trade center. Its diverse population was engaged in variable activities. This was fundamental for the formation of social groups affecting each other. This aspect reflected through the urban tissue and resulted in its transformations. On the other hand, Vyšehrad castle stopped on the face of the fortification fort as it was located in an unproductive area incapable of generating any significant trade.

Primary towns were closely spaced between each other, thus the unification of those after time seems logical. Their evolution generated further development that was already determined by social-political and economic issues. 


\section{NATURE OF ISLAND}

The principle of "autonomous settlements development" is present throughout the history of Prague as the primary municipalities of the city are clearly distinguished in the texture of the city nowadays. Thus, here can be applied the concept of the urban islands (microcosms) and insularity. As claimed by the "geographers of insularity", it is not only the physical data that defines the structure of an insular territory, but rather human activities. Geographers insist on the notion of "insularity" understood as a "range of possibilities" of a territory, or a settlement to be constantly compared to something other than itself (Chizzoniti et al 2017, 282-284).

"It is no longer the island that is separated from the continent, it is humans who find themselves separated from the world when on an island. It is no longer the island that is created from the bowels of the earth through the liquid depths, it is humans who create the world anew from the island and on the waters...An island doesn't stop being deserted simply because it is inhabited. ... some people can occupy the island-it is still deserted, all the more so, provided they are sufficiently, that is, absolutely separate, and provided they are sufficient, absolute creators... we need only extrapolate in imagination the movement they bring with them to the island. Only in appearance does such a movement put an end to the island's desertedness." (Deleuze $2004,10)$

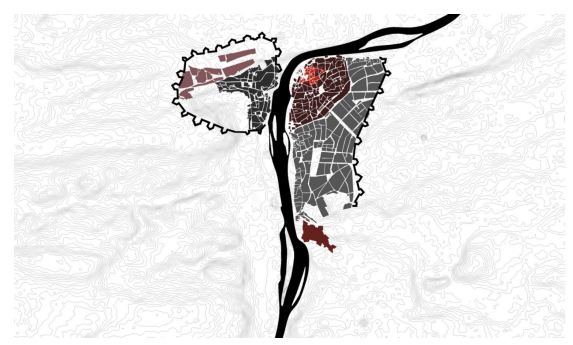

Figure 2. Districts of Prague in 18- century. Source: (Author 2020)
In the city context, the boundaries of metaphoric islands are less explicit, than in the case of a distinct division between the sea and the land of the material coastline. However, this meaning can be applied to the primary urban cores of Prague city, as they remain contextually isolated and well defined within the "sea" of surrounding territories. However, the concept of "island" improbably can be used to describe any part of a big entity, referring exclusively to its location within a wider spatial context. Conversely, this conclusion can derive from its internal spatial configuration itself and its particular characteristics.

\section{GHETTO}

It's difficult to say when Jews reached Bohemia and when did they settle in Prague. However, Spanish Jewish traveller Ibrahim Ibn Yakub proposes the story referred for the second half of the 10th century (Kieval $1991,23)$. Half of them were allowed to cross to the other bank of the river Vltava, where they occupied a large area in the core of Staré Město. During Medieval time the settlement grew in all directions until it was fenced and thus separated from its Christian surroundings. With this transformation, the area of the Jewish quarter was distinguished and fixed. The Medieval Ghetto was an area with its configuration composed of its main streets and its side routes.

At the end of the 16th century, city authorities started numerous attempts of forced evictions of Jews from Prague. The uncertainty surrounded the life of the community. Caused by those migrations the property in the ghetto was frequently purchased and sold, thus started to be owned both by Christian and Jewish inhabitants. Fragmented timber housing had insufficient hygienic conditions. It resulted in serious damage after conflagrations in 1561, 1567, 1603 and 1689 successively (Vilimkova 1993, 31). 
The middle of the eighteen-century was marked by radical measures towards the Jewish population in Prague. It is difficult to distinguish all reasons for upcoming in the 1745 year another expulsion of the Jewish population from Prague and the kingdom of Bohemia, but the effect of it on the further life in the ghetto was significant. For the first time, the decision meets the stability of the city authorities so for the first time Jews illuminated from the town and returned to Prague just by the year 1748 (Rybar, 1991, 58). Jewish community was ruined. In 1754 the Ghetto again went up in flames. More than two-thirds of the dwellings were burned down. Only buildings made from stone and brick survived around Old cemetery and by the river. In 1849 Jewish Town of Prague became one of the city quarters called Josefov and the surrounding rampart had to be destroyed.

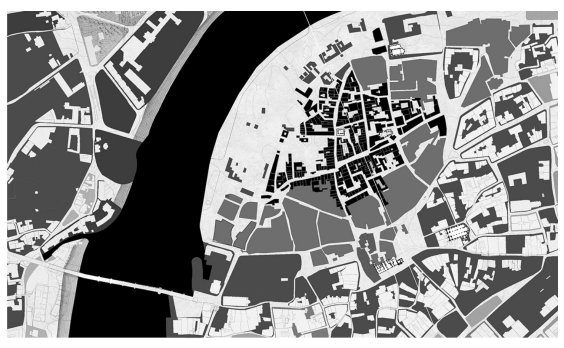

Figure 3. Prague Ghetto in 18-th century. Source: (Author 2005)

Before the fenced zone of the ghetto provided an opportunity for the formation of a separate Jewish community. It supported and covered the necessary needs of its inhabitants. After its collapse and equating the Jewish population to the rest of the inhabitants of Prague, there was no hope for any help. This gradually created conditions when changes were demanding. In 1897 started clearance of the city that covered Josefov quarter and New Town. The Prague ghetto and its neighborhood were demolished, and a new residential quarter was built (Vilimkova 1993, 43).

\section{ENCLAVE}

Speaking globally, three types of ghetto can be distinguished. Firstly, open ghettos had no fences or walls around their perimeter. Despite this, there were still restrictions against who could enter or leave, when, and how often. Secondly, closed ghettos were separated from the surrounding by fences or walls. Leaving or entering the ghettos was prohibited. These circumstances made conditions inside extremely unsanitary, with huge shortages in food and water leading to high death rates. Then the last type is characterized as certain spaces in towns and cities that were sealed for short periods of time, typically around two weeks, before their inhabitants were deported to extermination camps and murdered.

Prague ghetto doesn't fully correspond to any of those types. Its inhabitants were isolated due to their beliefs and desire, need of isolation and protection. Moreover, that partially resulted from the wish of the surrounding Christian population, the will of which was translated by the city authorities. It is literally a city within the city with its own infrastructure, rules and regulations. There was no considerable amount of restrictions that were respected stably. Those were occurring rather from extreme to extreme according to political issues. In other ghettos there usually was no mixture between inhabitants. Dwellings in Prague ghetto, on the contrary, were hosting both Jewish and Christian inhabitants during long time. Therefore, the Prague ghetto is a unique one as it is perfectly integrated into the city.

The Josefov ghetto is clearly distinguished between other districts of Prague. It is caused by the conditions of its formation. While primary urban islands were determined by a geographic organization and dedicated the territorial geometric principles for the future development, political and social factors caused inner further division of the city. Thus, Josefov Ghetto was generated as an enclave within the city core. 
The Oxford dictionary defines urban enclave as: "a portion of territory surrounded by a larger territory whose inhabitants are culturally or ethnically distinct" or "a place or group that is different in character from those surrounding it". Thus, it is characterized by forming the place within the city where the community can be part of a larger whole.

The city is a human creation. Moreover, it is deeply connected with the society and gives a unique form to it. This is the basis for an empirical study of the city as it was evolved from the earliest settlements (Rossi 2007,20). Following this idea, enclaved Jewish quarter kept the characteristics of separated social group living there. Conversely, what we call island in Prague doesn't represent the specific characteristics of a place inhabited by differing social group. It rather keeps the idea of insularity and characterizing features of the time of its establishment. That is why those terms have to be clearly distinct.

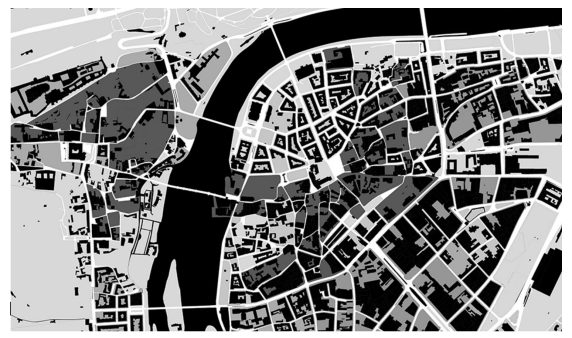

Figure 4. Prague center after the transformation. Source: (Author 2019)

The character of Prague ghetto as an enclave and its relationship with the city can be studied through the essence of its boundary. The line of territorial division provides possibilities for relationship development. On the other hand, it is a critical zone where the different ideologies are distinguished at their most. Thus, the character of the border is determined by the nature of the dialectic relations of adjoined territories.
It's difficult to certainly define the character of the Ghettos boundary. Time to time it was translating the characterizing desire of the Jewish community - that to be separated. That comes from the traditional and religious perception of place in Jewish culture (Loubser 2011, 227). Their use of space and way of living often provoked discontent and contention in the Christian neighborhoods. Thus, the enclave of the ghetto, having risen in the structure of the city, provoked critical manipulations from the side of city authorities. Spatial division can be taken both contextually and literally. This is due to political and economic factors and it happened also in metropolitan cities (Low and Smith 2006, 5).

The approach towards the Prague ghetto covered the issue of territorial divisions and regulations to distinguish spatial areas, including coercive measures, the building of physical boundaries. Rules prescribing certain spatial principles were introduced. Thus, in this case, the fenced boundary of Prague ghetto constituted as the symbol of authority power on different faces of its history. Prague Ghetto always had characteristics of autonomy within the city even after becoming an official district. It kept its identity within its boundaries. The quarter's transformations were determined by events that had an influence exclusively on the territory inside the boundaries while they did not have a major influence on the outer city. Thus, it is perceived as an enclave within the wide urban formation.

Josefor was significantly transformed after the ghetto's demolition and further reorganization of the urban pattern to match the criteria of growing city of industrialization era. The story of events that took place within walls of the ghetto is defined now solely by the presence of singular architectural facts. They form a skeleton of pure elements of historic origin. 


\section{THE CITY BY PARTS}

The urban analysis gives an idea of the relationships, potentially established between an area susceptible to intervention and its surroundings - between the project and the place - in the mutual interference between context and project. That would lead to the measure of effect within scientific practice or research, which is used to assess both positive and negative consequences of an urban intervention or treatment. Such measures can often be quantified using effect sizes. So that, the more parameters will be investigated in urban analysis, the more it will be possible to trace the relationships that intervene in the design even in conditions of partial or total disappearance of the surroundings. Here perhaps one of the contact points between the analysis and the intervention can be identified. The analysis of urban structures intervenes in the design. Through the analysis is generated a judgment, which consequently becomes a design parameter: not of the single building but of the surroundings that are directly involved in the transformation process. It is a position of disillusioned autonomy of judgment towards the history of the city, however based on a conscientious and documented acknowledgement of the values of history: this does not exclude the desire to give up making value judgments and expressing its own subjective contribution in an interpretative sense - therefore also innovative and transformative if necessary.

This approach potentially leads to two different types of outcomes: internal and external deliverables generated in the methodological relationship between the setting of urban analysis and the experimental architectural prototypes.

-The internal deliverables of the project that we can define as goals, focused on the object of the investigation. In this case it is concerning the specific solution given to the single problem of the relationship of the Prague Ghetto and its transformed surroundings.
-The external deliverables - we would like to highlight here - which are the potential results of the process which describe the methodological path that can be generalized starting from the project outcomes.

The assumption of the "architectural dimension" as a sort of reading tool that can be used not only for individual buildings but also and above all for urban forms with a wider range. As a result, rather than reading the city as the sum of buildings (aggregation of building types) such approach proposes a complex perception of unitary architectural systems, which, depending on the case, may have a building scale or an urban scale. Importantly, synthesis of "an architectural unity" opens a possibility to evaluate a specific role of complexity in the context of urban relations, while the identity of each element still can be grasped.

The critical evaluation applied to the case of Prague reveals and helps to systemize the complexity of its organization and underlying forces that shaped the city in this way. Further reading of the city as a system of separable bodies and organisms (with its autonomous physiognomy), on which design controls, helps to observe how the particular experience of each historic part finds its expression. Thus, it is possible to contextualize an architectural dimension (of autonomous designated monuments or further possible interventions) within the defined unity as parts of the contemporary reality of clear and legible meaning.

The project of the city (by parts) takes place through the project of identification and fulfilment of these parts and through their mutual relation. The specific design response, therefore, tends at first - having ascertained the complexity of the city to make the architecture even complex, reaching the theorization of the cancellation of the relationship between building typology and urban morphology in a "city like all architecture". It is resolved entirely with basic typological tools as founding elements not 
by volume or by summation of geometric elements, but through an experimental compositional way also extended to the urban scale.

\section{THE CITY BY ABSENCES}

In the event that the process relies on something that has disappeared, no longer exists, dispersed, as in the case of many Jewish settlements in the historic city, what approach to adopt? In identifying the construction of absence, we draw attention from one side what has been built and then demolished or transformed; from another side what is necessary to create new conditions according to the idea of enhancement of architecture, building or historical site. In this idea of vacancy, of "non-appearance", the problem of critical conservation, such as rehabilitation by reconstruction, is widely regarded as insoluble. This apparent insolubility is often taken as a sufficient reason for completely abandoning this critical approach to the conservation. To preserve the appearance, the history and project can represent a frame of reference of which one is more aware today than at any other historical time. In order to discover and to save the memory of historical architecture, site, context, is necessary to bring their teaching up to date and make them valid again. Although many factors have changed, and much is that is unknown, ineffable about the said architectures, we know that it is quite impossible to reproduce the initial conditions that give rise to them, but we can preserve their appearance. Following this idea, it is clear now that our aim is not to reproduce a copy of those historical aspects, elements or figures, rather our objective is to transform them into live matter, making them be of use by a new project, by drawing them to the present through what is still today the common heritage of architecture, coming down through the history. To identify the importance of historical sites the act of acknowledgment the cultural resources is linked to the prefiguration of the pretense of preservation, that carries the meaning of the site, the character of structure, the authenticity and the values of all the components of the architectural space and finally the significance of figuration (tangible like iconographic value and intangible like iconological value). In that case the role of architectural design is to preserve the appearance, through a project of conservation (see N.Goodman, The structure of Appearance, 1951) and pre-figure a conceiving of absence, so as to create new conditions for the building or site, working on new figures and new architectural structures.

\section{CONCLUSION}

The extensive control over all urban construction is desirable even if it consists of divided parts with a much more elastic and articulated notion of autonomous settlement. So that the architectural coherence of the parts is understood to be achieved through more gradual procedural operations, aimed at a result with its own recognizable unity, and where therefore the piece, the architectural unit, becomes a complementary tool to perform the part. However, from the point of conscientious and documented acknowledgment of the values of history, this judgment towards the history of the city is disenchanted. This excludes the renunciation of making value judgments and expressing one's own subjective contribution in sense of interpretation - therefore also innovative and transformative when necessary. What is more interesting than this approach is the assumption of the "architectural dimension" as a sort of reading tool? It can be used not only for individual buildings but also for urban forms with a wider range. This process made the reading of the city as the sum of buildings (aggregation of building types). The reading of the city considered as the sum of unitary architectural systems, which depending on 
the scale (building scale or an urban scale). However, the identity of these systems should be recognizable, or should be an "architectural unity" and a specific factor in the context of urban relations. In conclusion, it is a matter of reading the city as a complex system of separable bodies and organisms (with their own autonomous physiognomy), on which a design control can be exercised, deriving from conceptualizations and tools that are exquisitely architectural. The project of the city, assumed by parts, takes place through the identification and transformation of these parts and with their mutual relation. Taking into consideration the complexity of the city, the specific design response emerged of making the architecture more complex by reaching the theorization of the cancellation of the relationship between building typology and urban morphology in the city. It is "fully resolved" with the basic typological tools as founding elements being not already a quantitative volumetric typology, but a compositional opportunity in urban function. 


\section{REFERENCES}

Aymonino, Carlo. 1975. II Significato Delle Città. Bari: Editori Laterza.

Chizzoniti, Domenico, Gaia Preta, Luca Preis, Letizia Cattani, and Monica Moscatelli. "The Ancient Josefov Jewish Quarter in Prague: An Example of Urban Island." Journal of Civil Engineering and Architecture 11, no. 3 (April): 282-294.

Deleuze, Gilles. 2004. "Desert Islands." In Desert Islands and Other Texts: 1953-1974, edited by David Lapoujade. Translated by Michael Taormina. 9-14. Los Angeles, CA: Semiotext(e).

Goodman, Nelson. 1977. The Structure of Appearance. Dordrecht: D.Reidel Publishing Company.

Hillel J. Kieval. 1990. "The Lands Between: The Jews of Bohemia, Moravia and Slovakia to 1918." In Where Cultures Meet: the Story of the Jews of Czechoslovakia, edited by Natalia Berger. 23-52. Tel Aviv: Beth Hatefutsoth.

Loubser, Johannes. 2011. "Jewish Topographies: Visions of Space, Traditions of Place." Review of Jewish Topographies: Visions of Space, Traditions of Place, by Julia Brauch, Anna Lipphardt, and Alexandra Nocke. Time and Mind: The Journal of Archeology, Conciseness and Culture 4, no. 2 (July): 227-232.

Low, Setha and Smith, Neil. 2006. The Politics of Public Space. New York: Routledge.

Rossi, Aldo. 2007. The Architecture of the City. Cambridge, Mass: MIT Press.

Rybár, Ctibor. 1991. Praga Ebraica: Glosse Ad Una Storia e Ad Una Cult: La Guida Attraverso i Monumenti. Praha: TV Spektrum.

Semotanová, Eva and Pavel Chromý. 2012. "Development and current trends of the Czech historical geography." Historical geography 38(1): 9-34. The Institute of History, Academy of Sciences of the Czech Republic, v. v. i., Prague.
Sert, Josep Lluis. 1944. "The Human Scale In The City Planning." In New Architecture and City Planning: A Symposium, edited by Paul Zucker, 394-412. Minneapolis: Graywolf Press.

Vilimkova, Milada. 1993. The Prague Ghetto. Prague: Aventinum. 


\title{
PAPER \#1.09
}

\section{FROM THE GRID TO THE LAYER: POST-INDUSTRIAL CITY AS CITY IN (MORPHOLOGICAL) TRANSITION}

\author{
Michela Barosio \\ aDAD Department of Architecture and Design, Politecnico di Torino, Torino, Italy
}

\section{ABSTRACT}

Starting from the assumption that industrial settlements have different roles in urban fabric, depending on their location, on their typology, on their size and their age of settlement, as well as on the pattern and the structure of the city considered, the paper will examine productive areas through six methodologies of urban analysis methods, ranging from urban morphology approach to perceptive approach. The different methods are employed to understand a different formal role of productive plants and they are applied to several cases studies from all over the world illustrating historical productive settlements already regenerated or still waiting for reconversion and a contemporary productive sites.

The paper will analyze the way in which urban analysis methods can engender different visions of the city, and specifically different approaches in the regeneration design of industrial dismantled areas to tackle the common misconception that post-industrial cities are places where no clear urban form is recognizable anymore, suffering of a lack of global urban vision, looking for new city's identity and vocation. Depending on the capability of recognizing their urban role, industrial dismantled areas, can be either considered as brown fields that prevent urban renewal or as strategical elements to regenerate the city, providing new opportunities.

The final goal is to set a methodology of morphological analysis able to grasp the transitional character of urban phenomenon, reading the post-industrial city as a stage of a continuous transition in urban form and not as a final step. In this perspective urban regeneration processes of urban industrial dismantled areas can be conceived as impermanent configurations originating from the historical traces and types but also anticipating future morphologies.

\section{KEYWORDS}

Urban morphology; transition; industrial settlements; layers.

\section{INTRODUCTION}

Starting from the assumption that industrial settlements have different roles in urban fabric, depending on their location, on their typology, on their size and their age of settlement, as well as on the pattern and the structure of the city considered, the paper will examine productive areas through six methodologies of urban analysis methods, ranging from urban morphology approach to perceptive approach. The different methods are employed to understand a different formal role of productive plants and they are applied to several cases studies from all over the world illustrating historical productive settlements already regenerated or still waiting for reconversion and a contemporary productive sites.

The paper will analyze the way in which urban analysis methods can engender different visions of the city, and specifically different approaches in the regeneration design of industrial dismantled areas to tackle the common misconception that post-industrial cities are places where no clear urban form is recognizable anymore, suffering of a lack of global urban vision, looking for new city's identity and vocation. Depending on the capability 
of recognizing their urban role, industrial dismantled areas, can be either considered as brown fields that prevent urban renewal or as strategical elements to regenerate the city, providing new opportunities.

The final goal is to set a methodology of morphological analysis able to grasp the transitional character of urban phenomenon, reading the post-industrial city as a stage of a continuous transition in urban form and not as a final step. In this perspective urban regeneration processes of urban industrial dismantled areas can be conceived as impermanent configuration originating from the historical traces and types but also anticipating future morphologies.

\section{POST-INDUSTRIAL CITIES ARE CITIES IN TRANSITION}

\subsection{From the industry to the city}

The concept of city itself is strongly related to industrial revolution as the real change in population distribution and urban living patterns occurred with the industrial revolution in the nineteenth century. The development of industrial capitalism has shifted the balance between urban and rural. The proportion of people living in urban areas fluctuated between 4 per cent and 7 per cent throughout history, until about 1850 (Lowry, 1991). After the industrial revolution this proportion raised up to $30 \%$ in the Fifties of the XX century, but still growing even after the industrial crisis and during the deindustrialization process in Europe. Today more than 55\% of population is living in urban context and UN estimate the urbanized population to raise $70 \%$ of the overall population by 2051 . This continuous and endless urban growth might be one of the reasons why during the industrial age we thought that the industrial endless growing paradigm, and the urban endless development related to it, was the only possible paradigm. In the same perspective the deindustrialization process has often been perceived as a phenomenon to counteract, wishing an industrial come back, driven by a new type of industry free from pollution and workers exploitation, to bring back wealth and incomes to our cities. This paper proposes a reverse perspective, considering, from the morphological point of view, the industrial age as a transitional age between pre-industrial settlement, proto-industrial city and postindustrial urbanization. In a more general way, in any age city's morphology ought to be considered a transitional configuration always hosting simultaneously morphological elements heritage from the previous era and other formal characteristics already anticipating the future stage.

Trying to focus on the post-industrial city we can assume that the morphological characteristics of industrial city related with the productive functions and the connected urbanizing phenomenon, such as transportation and mass workers housing, are quite evident while the formal consequences of the post industrial age are not that clear. This is also due to the fact that the concept of postindustrial cities should not be understood as a mere chronological or functional definition.

\subsection{Post-industrial City. Possible definitions}

A first possible acceptation of post-industrial city is a city which has been characterized by a strong presence of industry which has then left the specific urban environment to move away. In this sense it is important to understand how and when the industry has left the city. Following Marcel Smet deindustrialization taxonomy (Smet 1990), it is evident that the shape and the transformation potential of the urban settlement is directly linked to the kind of production settlement that was there before and also to the elapsed time from the industrial dismantling. In this sense we can observe several different cities from the industrialization

\footnotetext{
${ }^{1}$ United Nations World Urbanization Prospects 2018 https://population.un.org/wup/
} 
phase till nowadays. Considering that in the European context the deindustrialization process starts from the beginning of the $X X$ century in some regions, while in some others areas production sites still active till the end of the XX century, western cities become postindustrial cities in very different periods of the last century. For the same reasons, we might observe that the cities that have faced the deindustrialization process in the early years of the XX century, have then been dealing with a variety of urban phenomena leaving a multitude of physical traces characterizing a long transition from the industrial city, through the non-industrial city, toward a not-better defined contemporary city. According to this perspective the post-industrial city could be considered more a transitional phase of the city artifact, than a specific and final configuration. In a second, broader, acceptation, a postindustrial city is any urban agglomeration developing in a socio-economic context in which industry, industrial production, are no longer the main driver for economic development and social behavior. In this frame most of the European cities are post-industrial cities and it is difficult to envision a common urban morphology, for their historical cores as well as for their new developments.

A third possible, but restrictive acceptation, to address the post - Fordist city is to consider it as a city where industrial production is still settled but with a different spatial and social organization from the Fordist age. This case is still rare in Europe, but more and more firms are looking to relocate their productive site in urban context in western countries. As W. F. Lever explains very well in his text The post Fordist city (Lever 2011), if in urban terms, Fordism could be equated with the success of large cities and large urban systems, it's because the predominant modes of production required locations in large cities, not just as the homes of large industrial workforces but as the providers of the most advantageous sets of externalities. Nowadays, the growth of the small enterprises sector, requires less labor employed, more flexibly, and the transition from employment in manufacturing to employment in services. In this sense Lever observes the 'uncongeniality' of the standardized towns, whose spaces differentiated according to function are no more suitable for the flourishing of small enterprises looking for the benefits of urban livability.

\subsection{Urban industrialization as cycling process}

Looking at these three possible definitions of post-industrial city, we realize that most of the European and western cities can correspond, in different proportions and in different parts of the urban territory, to all of them. In fact, despite the generalized de-industrialization process in Europe and north America, the urbanization process is still growing (Champion 2011). Transition from Urbanization to Suburbanization to Disurbanization, to Reurbanization (not forgetting Counterurbanization) is still going on, that's why we might assume that this is a cycle, not a linear process. Noticing that different countries and regions are at different stages of the de-industrialization process in a given period (Champion 2011), as well as different cities in the same region and different parts of the same cities are in different stage of the cycle, it becomes interesting to identify the different stages of this cycling phenomenon considering the different kind of city we are facing: are they inner cities, fringe belts, touristic cities, successful cities, shrinking cities? The only evident thing is that they all are cities in transition.

Speaking about cities in transition in literature, often means to speak about cities that are living transition phenomenon in their social, political or economic dimension. The urban built environment is often perceived as the final outcome of transition process which mainly concern other dimensions than the urban form itself. The Handbook of urban studies (Paddison 2011), identifies four types of cities coexisting dimensions at the same time in 
the same Urbis: the city as environment, the city as people, the city as economy and the city as organized polity. Those "cities" have different but simultaneous evolutions that engender physical outcomes on the urban form. Therefore the second part of the paper proposes to use different analytical tools in order to catch the several layers of physical outcomes related to the various dimensions of the city. Industrial settlements are here used as index fossils to establish the relationship between the urban morphogenesis and possible urban regeneration design approaches.

In this frame it might be possible, aiming to set up new tools for urban morphological regeneration, to define post-industrial city through the identification and analysis of formal elements, or morphological characteristics, able to distinguish it from other types of cities. As a matter of fact the morphogenesis of the industrial cities has been broadly discussed and should now be considered as a departure point to investigate the post-industrial city in his multiple variations in order to trigger and to design regeneration processes. Its main characteristics are well known ranging from their growing size, to the territorial spread phenomenon related to the new ways of transport, the zooning technique separating housing from production areas and from social housing through multiple enclosures. Arguably the most important single topic to which geographical urban morphologists have devoted their attention is the process whereby urban areas have grown physically (Whitehand 2011). But if the paradigm in which industrial city has flourished was an endless growth paradigm, the post-industrial city is dealing with a de-growth, or sustainable growth, paradigm in the frame of which we have to look for new generative models able to implement multiple social instances but also able to reconnect heterogeneous part of the city as heritage from the Fordist city.

\section{URBAN ANALYSIS AND CITIES' MORPHOGENESIS: POSSIBLE LINK}

Attempting to propose a first step towards a systematic understanding of generative models of the urban form, at a large scale, Raimbault and Perret, define urban form as "geometrical properties of building layouts at the scale of a district" and they underline the lack of quantitative indicators to measure urban form, which is mostly analyzed only in relation to visual impression. The proposal of Raimbault an Perret is to focus on the coevolution of building layout and road network through a set of indicators considered relevant at a district scale. Those indicators are set on a square grid that allows to compare different generative models able to capture both bottom-up-self organizing processes and top-down-planning processes. The grid can be adapted to the scale of the analysis as well as to the specific thematic focus on urban analysis. This kind of approach highlights how much urban analysis is a pair of glasses through which different phenomena and different characteristics of the urban fabric can be highlighted depending on the lens that we choose.

Urban industrial settlements are taken as case study to understand the possible link between the urban analysis method and the morphogenesis of the city for several reasons. First they often have driven, in the last two centuries, important city's expansion becoming the main catalysators for entire new neighborhoods structured by the industrial patterns and landmarks. As those cities have grown, the originally peripheric industrial suburbs have become central parts of the city and are nowadays strategic locations close to core city's center. Besides, those settlements are frequently characterized by bigger plots than the average of the urban fabric, allowing strategical urban transformation facilitated by the concentration of the real estate ownership. For all these reasons, urban industrial areas, even more when they are already dismantled areas, represent strategical factor for 
morphogenesis or morpho-regeneration process of the city's fabric. The contemporary challenge is to understand the specific role that industrial settlement have played in the original morphogenesis of the city as well as the role they can play in contemporary regeneration of urban fabric.

The methodology proposed in this paper consists in defining six types of morphological relationships between industrial settlements and the city. Those six possible role performed by the industry in the urban context are infer from a broader observation of European main - former or present - industrial cities. For each type of relationship, a couple of urban analysis methods are suggested to foreground the specific formal role of the productive settlement analyzed. The hypothesis is that each method enables the understanding of peculiar interactions between the elements that generate urban form that are directly related to the morphogenesis of the city. The six types of interactions, the six different roles, mentioned depend on the type of industry, on the stage of urban development and on the preexisting morphological structure of the city. In this frame, productive sites can be considered as a new pattern in the city, a landmark on the urban landscape, a focus for new directions of development, a rift in the urban fabric, an urban scenery or a real city into the city itself.

\subsection{Industrial settlements as pattern matrix}

Some industrial settlements have been able to generate new patterns of the city, and therefore to trigger a brand new urban fabric based on the industrial building typologies, on the logistic principles and on the specific needs of the production. Because those settlements are characterized by building types and the streets and plot network, the best way to analyze their pattern is to merge the two traditional urban morphology analysis. The Muratori approach (Muratori 1960) operates a systematic building survey specifically focusing on the ground floors survey to highlight the relationship between private and public space. Building a sequence of historical buildings survey of the settlements, Muratori's analysis reveals the "hidden structure" of urban phenomena, the morphogenesis process. Applied to the Michelin Area (fig. 1) developed in the second part of the XIX century in the northern part of Torino (Italy), this type of analysis unveils the original connection between the contemporary urban fabric and the pattern enclosure inside the dismantled factories' wall. The other school related to morphological approach, the Conzenian approach (Conzen 1960), can usefully complete the Muratori' s analysis. Actually Conzen focus more on the arrangement of street and plots and therefore allows to understand how the industrial needs, in term of movement and circulation, engender the urban pattern of street and how the plot's characteristics of the industry is able to deal and/or to influence residential surrounding patterns. The regeneration of the industrial Docks on the riverside of Marseille well illustrates urban design centered on the reconversion of the industrial pattern driven by the conzenian approach.

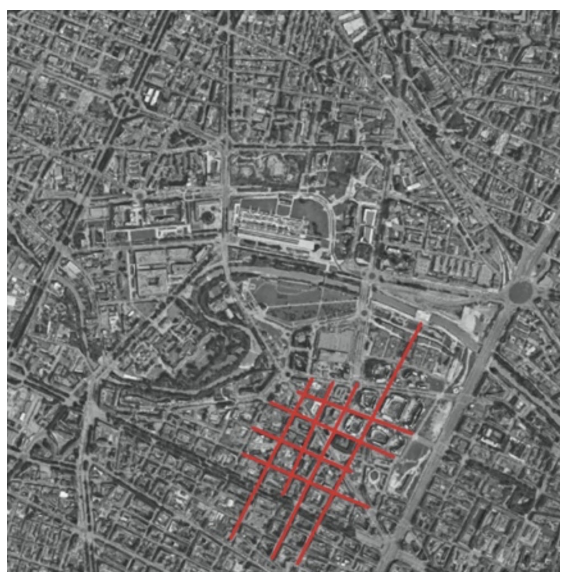

Figure 1. Industrial settlements as a pattern matrix (author 2020) 


\subsection{Industrial settlements as new expansion directions' drivers}

Other productive sites don't properly structure new patterns, but determine the directions for urban expansions. The modern city has then grow in a fragmented and discontinuous way along those axes as shown in the early $X X$ century by the south development of the city of Torino toward the new settled FIAT Factory of Lingotto (fig. 2) or as it is happening by now in Maranello with the brand new Ferrari's Factory designed by Jean Nouvel in the outskirt of the city. Therefore to analyze these heterogeneous new parts of the city we attempt to disassembly complexity, trying to break up the urban fabric into elementary urban entities as suggested by Paola Viganò (Viganò 1999). This helps in understanding the new characters of the contemporary city where buildings are no more space definers, like in the traditional compact city, but have become space occupiers. In this frame the definition of the contemporary urban elements and their relationships enable to read the city as an overlapping of layers no more ordinated through a general plan but generating an urban fabric apparently chaotic, characterized by the intersections and the conflicts of the multiple layers. In this context a non-built element of the city turns to be essential to better understand the morphogenesis of the city: the study of the flows. Pioneered in the Seventies by Bill Hillier (Hillier 1982,) together with his colleagues at UCL, Space syntax analysis aims to analyze and represents the spatial accessibility in the city at different scales. This type of analysis makes the invisible visible describing how urban morphology can have deep impact flows' circulation and attempting to design new urban masterplan able to ensure, through the location, the position and the spatial layout of building elements, a more accessible, and therefore livable, cities' expansions. The reconversion of the La Villette productive site in the far suburbs of Paris by Bernard Tschumi is completely based on a layer's rationale which is able to organize the people fluxes, as it is now a scientific public park, but also to keep memory of the industrial past traces.

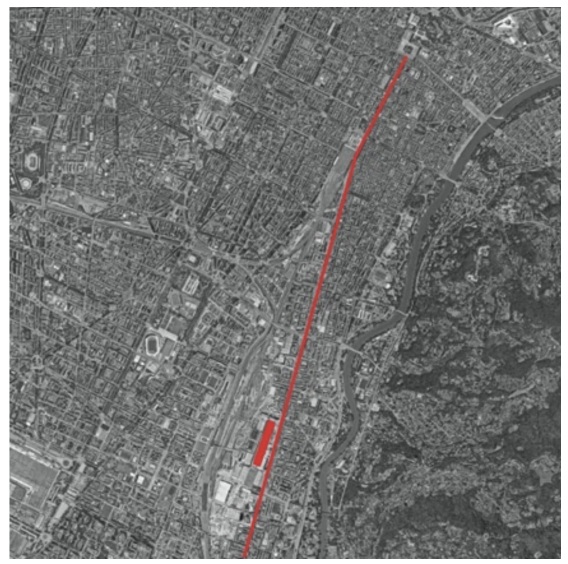

Figure 2. Industrial settlements as new expansion directions' drivers (author 2020)

\subsection{Industrial settlements as a city in the city}

In some cases, the industrial settlements are so big and so complex that they can be considered as "city in the city" in the sense that they are made by several buildings, a network of internal streets and open collective spaces, together with representative buildings, just like a real, traditional city. Very often those kind of settlements, raised from a small nucleus far from the city, has grown so much that when they came close to the city, or the city has grown up around the industrial settlements, they begun to need a precinct, a wall, to preserve the safety both of the citizen and of the workers. To understand the mutual relationships between the enclose pattern of the industrial site and the urban pattern of the neighborhood surrounding the industry precinct, the reading of basic 
buildings types set up by the Muratori's follower, Gianfranco Caniggia seems to be a very useful tool (Caniggia 1979). The three steps of this urban analysis methods - to understand the historical reasons for urban form, to overcome them and to recognize the continuity in the morphogenesis of the city - enable to highlight the aggregation systems of buildings types and how urban tissues are generated through time in mutual relationships. The observation of the evolution phases of the urban structure shows as cities are made by continuous aggregation of unitarian, often originally homogeneous, nucleus or settlements. To investigate not only the topographical dimension of urban fabric, but to inquire also the aesthetical dimension of urban settlements, another Italian scholar, Cavallari Murat (Cavallari 1968) employ a conjectural survey to describe successive stages of the development of baroque cities in Italy detecting window's position, roofs' protrusions, entrances, porches and courtyards to describe the aesthetic evolution of the urban form. These elements specifically enhance how industrial buildings, for their types and for their formal elements, are, depending on the different phases of the urban evolution, part of the whole city, as in the case of the "White meat city" in Copenhagen (fig. 3) or a totally separate settlement, as in the case of the Matadero in Madrid. This character fundamentally impacts on the regeneration physical outcomes: if in the first case the district of White meat has been slowly and gradually reconverted by private investments into a restauration and shopping district completely embedded in the urban fabric of Copenhagen, in the second case the Matadero complex still enclosed in its protective walls and its regeneration and transformation in cultural district has been financed mainly by the municipali.

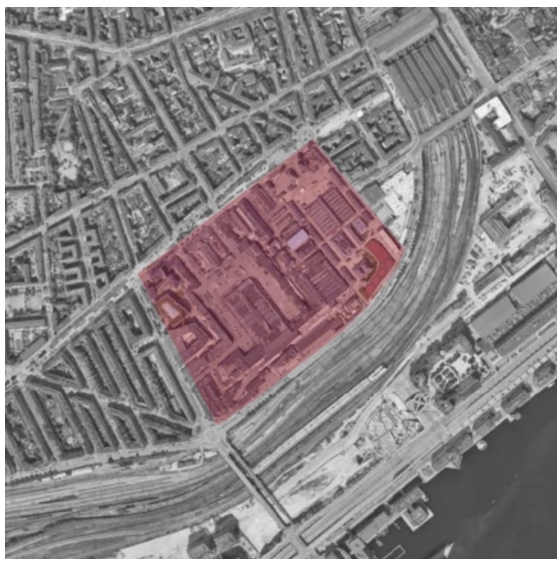

Figure 3. Industrial settlements as a city in the city (author 2020)

\subsection{Industrial settlements as landmarks}

For their scale, and for their iconic and symbolic values, part of the industrial settlements often represent urban landmarks and strongly contribute to the "image of the city" as Kevin Lynch described it in his masterpiece in 1960 (Lynch 1960). Therefore it is fundamental, to understand in depth their role in generating urban form, to use perceptive approach to analyze those settlements comprising built elements with strong visual impact at the city scale. Industrial architectonic elements such as chimneys, monumental façades, entrance gates or wall strongly contribute in building the urban image and to improve its "imageability". The industrial sites that have contribute, from the beginning of their development, to build this strong and vivid urban image, able to give identity, structure and meaning to the city, are nowadays not preserved as whole. Only elements recognized as landmarks are kept and protect by law, completely forgetting that their contribute to the urban image was not only made from those preserved exceptional buildings, but even from the relationships 
that all the different parts of the site have built with the surrounding city. To catch these complex visual relationship the Gestalt theory is much helpful. Considering that "the whole is other than the sum of the parts", the Gestalt scholar identify several "laws" able to explain how the human mind subjectively perceive the relation between the different part of an organism. Arnheim applies these laws to architecture (Arnheim 1977) explaining how urban space is made from interplaying forces generated by built objects and how the perception of the space become dynamic arising from couples of antithetic values such as verticality/horizontality, empty and forlorn and so on. The perceptive approach seems to be antithetical to morphological approach because it counterpoises subjective approach to objective approach, tridimensional point of view to bi-dimensional vision, and nonexpert vision to expert analysis. But aiming to understand morphogenesis' process of the city, in order to set un design guideline to regenerate urban industrial dismantled areas, the two approaches seem to complete each other adding a democratic dimension to the historical established tradition, explicating collective feeling to foster cultural identity, and being, both, pre-operational tools for the transformation of the city. This integrated approach is the key factor of the successful masterplan for the regeneration of the Van Nelle plant in Rotterdam (fig. 4) designed by Wessel de Jonge. In this project the new masterplan recognize the plant as an organic complex, a city in the city, and the buildings to be kept are decided according to their role as landmark for the industrial settlement and for the city. For the same, as the continuous glazed façade constitutes a real landmark for the urban landscape, the glass envelope it rebuild to look exactly as the original despite to the energetic issues: this important value is recognizable only through a perceptive analysis.

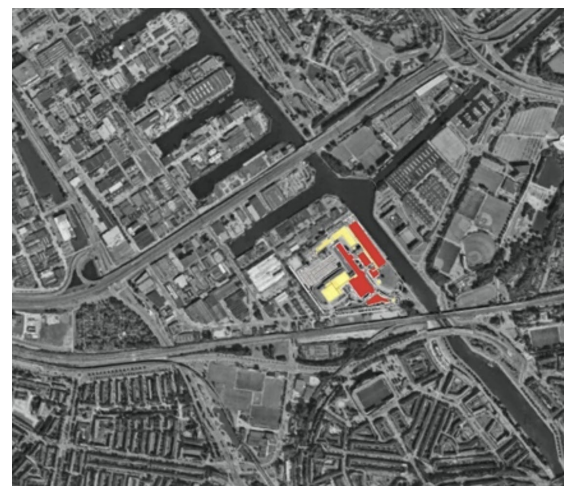

Figure 4. Industrial settlements as landmarks (author 2020)

\subsection{Industrial settlements as a scenery}

A different case is when the industrial sites become, for their dimension and for their location, a sort of scenery, a background for entire neighborhoods or land pieces. The idea that a building, or a group of buildings, can constitute an urban scene in the frame of which other urban elements are located and perceived is not new. From the History of architecture of Auguste Choisy (Choisy 1877) to The art of building Cities (Sitte 1902) many scholars have lighted the role of perception in the urban design, but it is only with the Handbook to design urban landscape of Gordon Cullen (Cullen 1961), that the role of the movement is explicated. Analyzing the urban scene through the Serial visions tool, Cullen explains that when wandering through the city we perceive two different elements: the existing view and the emerging view. As human mind reacts to contrasts, the contrast between these two views generates the image of the city as a coherent drama that, in this perspective, can be designed. Being the starting point of several urban expansions from the end of the XVIIIth century on, industrial settlements often become a scenery for the successive developments growing all around them. In 
this sense workers housing, public services and infrastructures but also new activities connected with the new suburb, organize their location and their pattern considering the industry as a given background dominating the urban landscape. This phenomenon is well illustrate by one of the more representative buildings of FIAT, the renown Italian car factory, the Mirafiori plant (fig. 5). The first building dates back to the thirties, when I was located in the countryside, but the site kept growing till the eighties. Around the industrial plant housing, commerce and a big planted boulevard axed on the offices' building were built using the productive complex as a foreground, as a monumental scenery.

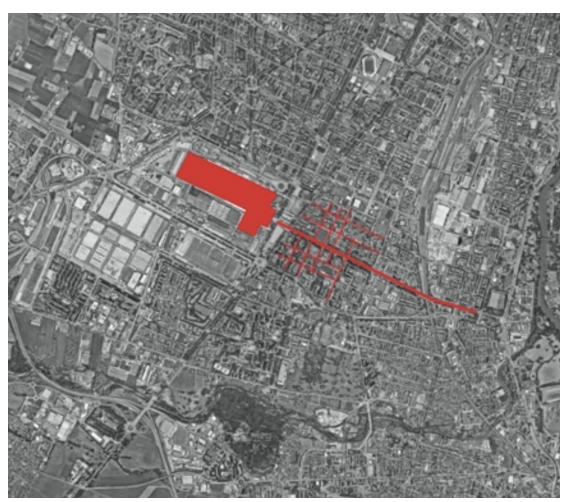

Figure 5. Industrial settlements as scenery (author 2020)

\subsection{Industrial settlements as a rift}

The multiplicity of roles that Industrial settlements can assume in the city analyzed in the previous paragraphs are all based on a specific type of interrelation between the productive site and the urban organism. The last role that we can observe is when no relationship is established between the city and the industry because the industry constitutes a sort of rift, of scarf in the urban fabric. Considering the land, and the city as well, as a palimpsest, André Corboz (Corboz 2001) suggests to read them as layered structured where traces from the past have been erased but still recognizable here and there by emerging fragments. To recognize the meaning of those emerging elements they have to be read as a part of a same layer. The palimpsest metaphor allows to consider the urban fabric as a parchment sheet full of inscriptions and traces left behind by society and construction not always taken into consideration when a new layer, like the productive layer, is added to the city. Therefore, following specific functional and logistical needs, sometimes industries are built up without any consideration to the previous rural or urban traces. The result is that the layout of the built elements as well as their pattern and their boundaries cut the city without any consideration for the existing urban pattern or connections. This is the case of the Ebbinge industrial suburb of Groningen in the Netherlands (fig. 6), where the industrial development of the early XX century consists in a series of productive pavilions built regardless to the previous urban pattern or to the surrounding plots. The regeneration operation called open Lab Ebbinge, assumed the rationale of the industrial original settlements, and promote a temporary settlement made of contemporary pavilions deliberately in contrast with the surrounding urban fabric, belonging to the pavilion layer of the historical factories.

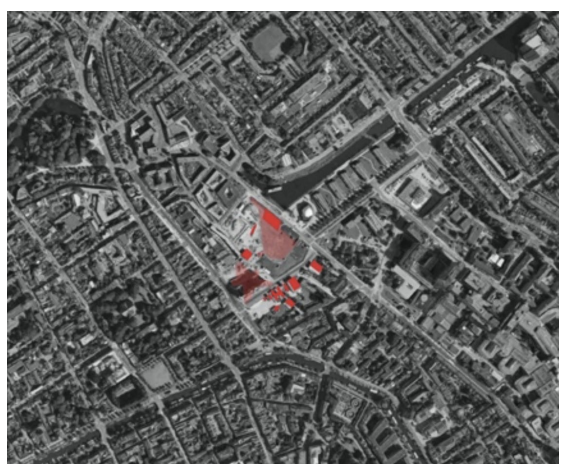

Figure 6. Industrial settlements as rift (author 2020) 


\section{CITIES' MORPHOGENESIS: TRANSITION AND HYBRIDIZATION}

Attempting to set a methodology of morphological analysis able to grasp the transitional character of urban phenomenon, reading the post-industrial city as a stage of a continuous transition in urban form and not as a final step, this paper describes a possible classification of the role played by industrial settlements in the city. It essential to remark that this taxonomy does not aim to establish fixed urban types or unambiguous relationships between industrial settlements and urban context. This sort of Atlas of industrial settlements' roles is set up through the induction method, from the observation of a multiplicity of case studies, general types are defined. The final goal of this methodology is to analyze urban dismantled areas in order to improve the outcomes of their regeneration process and of the redesign of consist parts of the city. As the taxonomy is based on the observation of multiple cases studies, it can be considered as an abduction operation. The abduction process proceeds from a single case study, or an innovative proposal, to formulate a new hypothesis, which is not yet a law or a rule, but just a possible principle to be further investigated, validated or finetuned. In this sense the industrial settlements can be firstly considered as playing one of the six roles identified and therefore analyzed through the urban analysis methods associated to each urban role. This first analysis is likely to highlight the non-matching elements, suggesting that all urban context are complex system non reducible to a single type of relationship between productive sites and city's pattern. Therefore the methodology forecasts to apply successively more than one urban analysis method to reflect the complexity of the urban palimpsest. Following the more commonly accepted conception of complex system as a system which is linked to the unpredictability of its evolution in time, the contemporary complex city is evolving in a vertical way, by transition in time, and in an horizontal way, by hybridization in space. To look at the city assuming those two actions, transition and hybridization, as the two main morphogenetic processes, might be effective in overcoming the fixity of urban types and in unveiling the relationships between urban elements often considered as inconsistent or corrupted while there just evidences of a city in transition.

Assuming the industrial age as a transition phase means to conceive the urban regeneration techniques not aimed to design a definitive urban design configuration, but rather to outline a flexible grid able to give consistency and meaning to the next steps of urban development. Urban regeneration projects should then plan the different urban functions as temporary and organized by layers, conceived as overlappable with a certain autonomy towards the grid that ensure their assemblage with an internal consistency. The final goal of the whole urban regeneration process, from a morphological point of view, is to improve the sense of urbanity. But what is "urbanity"? Irrespective to ages and geographical context, the essence of the city deals with mixité instead of zoning, with walkability, flexibility of spaces and infrastructures, with gathering spaces. The combined approach proposed, mixing urban analysis methods and bridging urban analysis with design, envisions urban regeneration as the process of repairing the urban grid, reconnecting the existing fragments, not searching for urban growth, but adding temporary, consistent and meaningful layers to this grid. 


\section{REFERENCES}

Arnheim, R. 1977. The dynamic of architectural Form. Berkeley: University of California Press.

Batty, M. 2013. The new science of Cities. Cambridge: MIT Press.

Bertuglia, C.S., Vaio, F. 2019. II fenomeno urbano e la complessità. Torino: Bollati Boringhieri.

Caniggia, G. 1979. Lettura dell'edilizia di base. Venezia: Marsilio.

Cavallari Murat, A. 1968. Forma urbana e architettura nella Torino barocca. Dalle premesse classiche alle conclusioni neoclassiche. Torino: UTET.

Champion, T. 2011. Urbanization, Suburbanization, Counterurbanization and Reurbanization. In Paddison, R. (ed) 2011. Handbook of urban studies. London: Sage publication.

Choisy, A. 1899, Histoire de l'architecture. Paris.

Conzen, M.R.G. 1970. Alnwick, Northumberland: A Study in Town Plan Analysis. London: Institute of British Geographers.

Corboz, A. 2001. Le territoire comme palimpseste et autres essais. Paris: Les éditions de l'Imprimeur.

Cullen, G. 1962. Townscape. London: Architectural Press.

Hillier, B. 1999. Space is the machine: a configurational theory of Architecture. Cambridge: Cambridge University Press.

Lever, W. F. 2011. The Post-Fordist City. In Paddison, R. (ed) 2011. Handbook of urban studies. London: Sage publication.

Lynch, K. 1960. The image of the city. Cambridge: MIT Press

Muratori, S. 1960. Studi per una operante storia urbana di Venezia. Roma: Istituto Poligrafico dello Stato.

Olmo, C. 1980. La città industriale. Protagonisti e scenari. Torino: Einaudi.
Paddison, R. (ed) 2011. Handbook of urban studies. London: Sage publication.

Raimbault, J., Perret, J. 2019. Generating urban morphologies at large scale. ALIFE 2019: Proceedings of the Artificial Life Conference 2019. Cambridge: MIT Press.

Sitte, C. 1889. Der Städtebau nach seinen künstlerischen Grundsätzen. Wien.

Smet, M. 1990. A Taxonomy of Deindustrialization in 42 Rassegna - The abandoned Areas. Milan: CIPIA

Tang, M., Yang, D. 2008. Urban paleontology, evolution of urban forms. Irvine: Universal Publishers.

Viganò, P. 1999. La città elementare. Milano: Skira.

Whitehand, J.W.R. 2011, The Physical Form of Cities: A Historico-Geographical Approach. In Paddison, R. (ed) 2011. Handbook of urban studies. London: Sage publication. 



\title{
PAPER \#1.10
}

\section{GRID GEOMETRY AND CORE STRUCTURE: SPACE SYNTAX ANALYSIS OF SMALL AND MEDIUM ‘GRID-LIKE' US CITIES}

\author{
Saif $\mathrm{Haq}^{\mathrm{a}}$ \\ aCollege of Architecture, Texas Tech University, Lubbock, TX, USA
}

\section{ABSTRACT}

The theory and techniques of Space Syntax originally based on topological assumptions and tested on organic layouts have been developing since the 1970's. After countless publications, and software of different kinds, this is a well-established field - respected and used by design-researchers. Unfortunately, one aspect not entirely resolved is the paradox that seems to exist between the mathematical modelling and geometric conditions of grid or grid-like layouts (Ratti 2004b, 2004a). While this challenge was quickly responded to by Hillier and Penn (2004), we now have at our disposal much more sophisticated analytical technology, namely angular and metric analysis of segmented streets that allow fine grained explorations. Haq and Berhie (2018) have used them to investigate a grid-like medium sized American city, and has demonstrated that 'Angular Choice' and 'Metric Mean Depth' is a useful tool.

This paper extends the earlier study in four grid-like towns/cities in West Texas, USA and includes 'normalized angular choice (NACH)' to compare them. Results indicate that while some of the most recent theories apply equally to grid-like and organic conditions; some special aspects apply to grid-like cases. These are (1) a background structure derived from metric analysis and a foreground structure from 'angular choice' post-dict the functions of grid-like West Texas cities at both levels, (2) such cities cannot generate center to edge connections, but create periphery to periphery links, (3) city size is a factor in the formation of a center, but the rim is highlighted in all cities regardless of size and (4) in numerical calculations of mean and maximum $\mathrm{NACH}$ values the grid-like city samples used here produced comparable values of much larger world cities.

\section{KEYWORDS}

Space syntax; morphology; grid cities; urban design; US Cities.

\section{INTRODUCTION}

Space Syntax theory and application methods have always been a bit unresolved when it came to grid-like cities. As its theory sharpened and methods became sophisticated, it seemed that the more contemporary ideas might be equally applicable to both organic and gridlike cities. Granted, isotropic gridded cities are not found in real instances, yet some cities are more 'grid-like' than others. Such city types have developed west of the river Mississippi, in the Unites States of America, perhaps being influenced by the planning concepts of Thomas Jefferson that was adopted by congress in 1785 (Rayner and Schmidt 1955). Driven by top-down policies, these cities were designed as a grid layout of roads for vehicle friendliness to which functions were added later. They are opposite of the idea that "the process of aggregating buildings ... create[s] the physical city" (Hillier 2012)

In West Texas we find such grid-like cities/ towns of various sizes. We have selected four of them as specimens to critically examine the most recent ideas of Space Syntax. This 
paper starts with an abridged history of Space Syntax and suggests three distinct periods of development, and the most recent and significant one happened during the last decade of Prof Bill Hillier. Some of the recent ideas are tested in this paper by applying them to the selected grid-like cities of different sizes.

\section{SPACE SYNTAX BASICS}

Space Syntax is both a theory and a method for analyzing and understanding spaces in layouts through their configurational properties. Since beginning in the nineteen seventies, its theory and method advanced in tandem, and in the process, responded to new challenges with more robust ideas. In the early days, Space Syntax methodology considered simple topological 'connections' between spaces - not simply as immediate connections to adjacent spaces (understood as connections at level one), but also connections to other spaces 'through' the immediate neighbors (connections at level two), to others that were connected to those 'neighbor of the neighbors' (connections at level three) and so on, until connections of all spaces to all other spaces (through a set of direct or in-between spaces) had been taken into account. In this manner of considering each space's connections to all other spaces, Space Syntax calculated unit values for each space. Two of these values were called 'integration' and 'choice' (Hillier and Hanson 1984). Integration value of a unit area or space is a function of the mean number of spaces in the system and the changes needed in order to reach all other spaces in that system of spaces 'Choice' calculates how likely a unit space is to be passed through in shortest routes from all spaces to all other spaces in the system (Hillier et al. 1987).

Unit spaces were carefully defined. In urban analysis 'axial lines' were mostly used. This is the longest uninterrupted visibility line that can be drawn in a plan of a city or settlement. A collection of such lines covering the entire study area is called an 'axial map' (Hillier and Hanson 1984). This method called for identifying the fewest and longest number of possible lines through the open space system. One must also realize that computers were not advanced and not easily available during the beginning days. Their use in this field probably stated in the nineteen nineties. Perhaps that is why experimental investigations only considered axial lines as units and one variable - topological 'integration'. Computers also made it easy to visually represent the analyses by overlapping on the axial map a set of colored lines to represent their numerical values of 'integration'. Typically, they are displayed from warm to cool colors, with warmer colors indicating higher values. Occasionally, a map of the lines having the highest values (usually $5 \%$ or $10 \%$ ) would be produced. This illustrated the syntactic structure of the analysis area and was called the 'core'.

A good number of observational studies in many cities across the world have found generally positive correlations between topological 'integration' and both pedestrian and vehicular movement patterns (Hillier et al. 1987; Hillier, Penn, Julienne Hanson, et al. 1993; Peponis et al. 1989; Penn et al. 1998; Read 1999). From these, it has been estimated that about 60 to $80 \%$ of movement could be predicted by the spatial configuration of the city layout itself (Stonor 2011).

Such discoveries led to proposals of a set of related theories such as 'natural movement' (Hillier, Penn, Hanson, et al. 1993; Hillier 1999b), 'movement economies' (Hillier 1996, 1999b) 'live centrality' (Hillier 1999a) and 'orderstructure' (Hillier 1999c). Visual studies of 'core maps' of organic cities coupled with a general understanding of their functional distribution, and comparison to ideal cities led to a distinction between 'order' and 'structure' (Hillier 1999c). While 'order' is geometric and visible in a synchronic condition (like looking at a map or a diagram), 'structure' may be considered diachronic, and is revealed over time by locational aspects and cognitive developments 
of its peripatetic visitors (Haq 1999; Penn 2001; Haq 2003; Haq and Zimring 2003). Space Syntax maps are special because they illustrate diachronic experiences synchronically, and in doing so reveal the underlying 'structure'. Hiller (1997) had argued that this 'structure' takes the shape of a 'deformed' wheel where a small central area is highlighted (hub of the wheel) with longer connections to peripheral areas (spokes). This paper will address the contemporary development of this idea with special relevance to 'grid-like' cities.

\section{A SIGNIFICANT CHALLENGE}

While topological considerations in Space Syntax seemed to work quite well for organic cities, Carlo Ratti (2004b) challenged that while a 'deformed wheel structure' was reported in many organic cities, it could not be the case for isotropic grids, because all the lines attained the same integration values. Thus, geometry or 'order' will prevail over underlying 'structure'. From this, one can infer that the thesis regarding a relationship between syntactic patterns to structure or movement and associated city functions in such cities would also be unrealistic. Later research on movement patterns and Space Syntax variables reflected this point. For example, Mora (2003) noted weak correlations between land use and syntactic values in the gridded center of Barcelona (a grid inclusive city). Later, he and a colleague (Mora and Dahany 2005) reported $\mathrm{r} 2$ values of 0.403 and 0.555 for correlations of global integration with pedestrians and vehicles respectively in a small semi-gridded part of Toronto (grid inclusive, but not isotropic). Previously, Peponis, Ross and Rashid (1997) had reported that in the colliding grid of downtown Atlanta, correlations between vehicular traffic and integration ( $r 2)$ was 0.58. Another researcher (Paul 2013) studied 'grid-like' Lubbock and found very poor correlations $(r 2=0.18)$
The challenge posed by Ratti (2004b) was responded to in different ways. Making the case that real cities are far different than ideal grids, Hillier and Penn (2004) highlighted two aspects of reality. First, a few streets invariably connect to areas outside the city and so attain different relationships creating unequal distribution of values across the city roads. Second, realities of geology and function inside the city cause interruptions of the intended grid (Hillier 1996). Later, Major (1997) demonstrated that in many cases natural elements also influence edge conditions and contribute to the breakup of the grid creating a non-regular situation. He also demonstrated that, in some American cities, individual isotropic gridded sections were sometimes connected to one another in a non-geometrical manner (colliding grids). In sum, it was generally accepted that these 'deformations' of the grid layout was enough to produce a configurational 'structure' different from its geometric shape (order). As such, theories developed in organic cities were expected to be reproduced in grid-like ones too. Unfortunately, this matter remained at the level of discourse.

\section{THE SECOND WAVE OF DEVELOPMENT IN SPACE SYNTAX}

Meanwhile to produce evidence-based explanations of observed relationships between Syntax values and movement patterns, a subsequent set of Space Syntax studies in the late 1990's and early 2000's undertook experimental work. One set of such studies explored wayfinding behavior (Peponis, Zimring, and Choi 1990) and cognitive dimensions of axial lines (Haq 2003; Penn 2001). These demonstrated that highly Integrated axial lines were used more often by exploring and wayfinding adults and were also featured in their cognitive maps. On this basis both Peponis et. al. (1990) and Haq and Zimring (2003) identified intersections 
of axial lines as places of decision making and therefore a natural spatial-unit for Space Syntax analyses. Haq (2003) went further and proposed segmenting the longer lines at their intersections to create nodes. At about the same time, another significant experiment studied path patterns of moving people and highlighted the role of angles between street connections by demonstrating that moving individuals preferred least angles while travelling (Dalton 2003).

These experiments led to substantial developments of Space Syntax theory and methodologies. First, segmented lines i.e. lines broken at their intersections, were accepted as new Space Syntax units, and second, two new concepts of 'distances' between unit spaces -- angles between lines and metric distances between their center points (Turner 2001; Dalton 2003) were added. Simultaneously, computational software became sophisticated -- the paramount one being 'DepthmapX'. This remarkable software can analyze both axial and segmented line maps and can calculate 'integration' and 'choice' values at various radii by considering either connections (topology), angles between them (geometry) or distances between their center points (metrics). Furthermore, it can restrict radii of calculation in distance metrics while doing angular analyses. Of special note is an enhanced understanding of the variables 'integration' and 'choice'. At this time 'integration' was re-considered as akin to 'closeness' and so was expected to have more destinations and indicate 'tomovements' within the spatial system. 'Choice' was associated with 'betweenness' and was expected to measure 'through-movements'. Table 1 indicates the many combinations of unit spaces, variables, and analytical techniques that are available today.

\section{SHARPENED THEORIES - ADVANCED METHODS}

The third and most recent development wave of Space Syntax was led by Professor Bill Hillier in a series of papers published from 2000 to the time of his passing in 2019. Through this final set of publications, he was successful in transforming his beginning ideas into a complete theory of spatial analysis and formal descriptions of settlements. These papers take into account segmented axial lines as units, angular and metric distance concepts, many radii of analyses, case studies of more than 50 cities across the globe (Hillier, Yang, and Turner 2012; Hillier 2019), cognitive concepts (Hillier and lida 2005; Hillier 2009) and existing pedestrian and vehicular movement data from four areas of London collected many years ago (Hillier and lida 2005). Working from all these arguably with an inductive mindset, Professor Hillier and his colleagues put forth a series of developed theories and suggested specific analytical techniques and representation standards.

With regards to the challenge reported in section 3 of this paper about difficulties of dealing with grid like cities, this set of papers implied that the distinction had been bridged with the new concepts and theories. The fifty cases in his database included both 'organic' and 'geometric' cities. Although the authors did not make categorical distinctions between them, they have discussed some of them separately when appropriate (Hillier, Yang, and Turner 2012). In this paper we plan to investigate some ideas by looking at one medium and three very small American cities/ towns located in West Texas, USA. These cities/towns are Lubbock, Slaton, Idalou and Abernathy. (See table 1 for their comparisons). However, before that, let us quickly review the new ideas that were proposed. 
CONCEPTS FOR ANALYSIS

VARIABLES

OF UNIT SPACES

CALCULATED BY

SPACE SYNTAX

\begin{tabular}{|c|c|c|c|c|c|c|}
\hline UNIT SPACES & $\begin{array}{l}\text { DISTANCE BETWEEN } \\
\text { UNIT SPACES: } \\
\text { - Topological } \\
\text {-Angular } \\
\text {-Metric }\end{array}$ & $\begin{array}{l}\text { RADIUS OF ANALYSIS. } \\
\text { Also } \\
\text { - Turns } \\
\text { - Angles } \\
\text { - Distance }\end{array}$ & 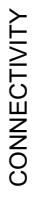 & 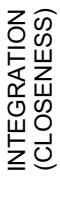 & 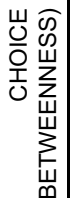 & $\begin{array}{l}\text { ㅁ } \\
\text { r } \\
\text { Z } \\
\text { Oे }\end{array}$ \\
\hline Axial Lines & & & $\sqrt{ }$ & $\sqrt{ }$ & $\sqrt{ }$ & \\
\hline Segmented Lines & & & $x$ & $\sqrt{ }$ & $\sqrt{ }$ & \\
\hline Unit of a Grid & & & $x$ & $\sqrt{ }$ & $\sqrt{ }$ & \\
\hline
\end{tabular}

Table 1. Different unit spaces, analytical techniques, radii of analysis and calculated variables that are used today.

\begin{tabular}{|c|c|c|c|c|c|c|c|c|}
\hline $\begin{array}{l}z \\
\vdots \\
0 \\
\vdots \\
\vdots \\
0\end{array}$ & 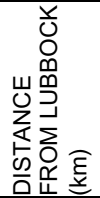 & 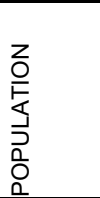 & 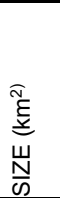 & 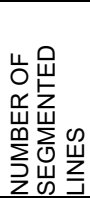 & 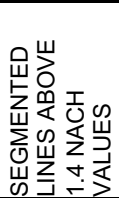 & $\begin{array}{l}0 \\
0 \\
\frac{\pi}{0} \\
0 \\
\stackrel{0}{0} \\
\frac{1}{1} \\
0 \\
\frac{1}{Z}\end{array}$ & 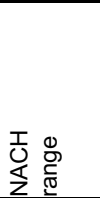 & 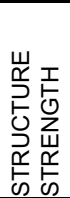 \\
\hline Lubbock & & 255885 & 319 & 14023 & 1050 & 0.945 & $0-1.59$ & 13.36 \\
\hline $\begin{array}{l}\text { Lubbock } \\
\text { inside existing ring }\end{array}$ & & & & 7617 & 686 & 1.018 & $0-1.61$ & 11.10 \\
\hline $\begin{array}{l}\text { Lubbock } \\
4 \text { square blocks }\end{array}$ & & & & 994 & 95 & 1.139 & $0-1.57$ & 10.46 \\
\hline $\begin{array}{l}\text { Lubbock with } \\
\text { speculative ring road }\end{array}$ & & & & 13946 & 1181 & .956 & $0-1.58$ & 11.81 \\
\hline Slaton & 27.26 & 6121 & 14.2 & 942 & 62 & 1.101 & $0-1.57$ & 15.21 \\
\hline Idalou & 19.63 & 2250 & 2.59 & 227 & 15 & 0.943 & $0-1.5$ & 15.2 \\
\hline Abernathy & 30.58 & 2805 & 3.1 & 461 & 29 & 1.051 & $0-1.58$ & 15.96 \\
\hline
\end{tabular}

Table 2. Information about the four cities/towns and speculative conditions used

\subsection{The generic city and its dual structure}

After almost fifty years of contemplating cities, Professor Bill Hillier never lost his conviction that "...at a deep enough level cities seem to be the same kind of thing" (Hillier 2016, pp. 200). He believed that despite differences in 'order', all cities have a common 'structure'. He called this 'generic city' (Hillier 2012, 2014), which includes the 'order-structure' idea. In this newer version he proposed it at two coexisting levels. The first is a 'foreground structure' that reflects microeconomic activities of the city. Since these are more or less general to all cities and benefit from maximum movement, co-presence and reach, they tend to link public center with edges and interconnects smaller centers (Hillier 2001). The shape of this structure generally follows the 'deformed wheel' idea. As such, they are expected to have a 'rim', a 'hub' and some 'spokes'. In the new 'dual structure' proposal, Hillier also added internal 'lateral' structures to link sectors of the city to 
each other and away from the center (Hillier, Yang, and Turner 2012, pp.181). The second is a 'background structure'. It is conservative because it restrains movement according to the culture and requirements of a locality. It is structured by distances and it identifies discontinuities of the urban grid, usually looking like a patchwork (Hillier 2016, 2014) So how are these structures unveiled? Hillier and Vaughan (2007, pp. 01-02) says, "In terms of understanding structure function relations, urban space seems to be globally topo geometric but locally metric. Recall that 'choice' is a measure of 'betweenness' and so indicates the potential for through movements (Hillier et al. 1987). Also, cognitive science had indicated that urban network is generally understood in geometrical and topological terms rather than metric (Hillier and lida 2005). Armed with these two ideas they proceeded to test four sub areas in London using existing movement datasets. These indicated that "...geometric, or least angle weighting yields the strongest movement prediction, with an average of around 0.7 for vehicular movement and 0.6 for pedestrian..." (Hillier and lida 2005, pp. 23). As such, 'choice' values derived by angular analyses of segments restricted by maximum metric radius was proposed to model the 'foreground' structure of cities (T1024 choice radius-n in Depthmap terminology). This is reproduced in figures 1 and 2 as the 'foreground' structure (in color) of the four case studies. And what about the background structure? Again, going back to Space Syntax foundations and theoretical arguments over time, the residential processes are explained as culturally biased and restrictive. It can be modelled through 'metric-integration' analysis at an appropriately low metric radius. Figure 1 and 2 show the background structure in grey tones. They were calculated at a 1600-meter radius (about one mile).

\subsection{Normalization and comparison between cities}

A significant aspect of Space Syntax in the beginning years was the process of 'normalization' in 'integration' calculations. This was necessary to control for physical sizes and allow comparison between them. The process compared 'integration' values of individual spaces to an ideal 'diamond shaped' graph (Hillier and Hanson 1984). It was very successful. Unfortunately, no 'normalization' was available for 'choice' values.

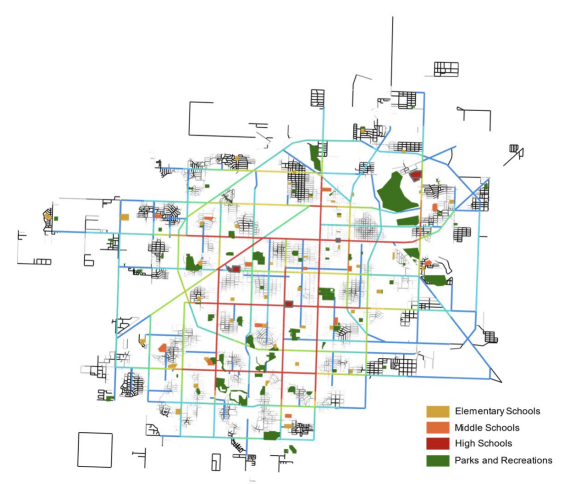

Figure 1. Dual structure of Lubbock showing the relationship to neighborhood amenities.

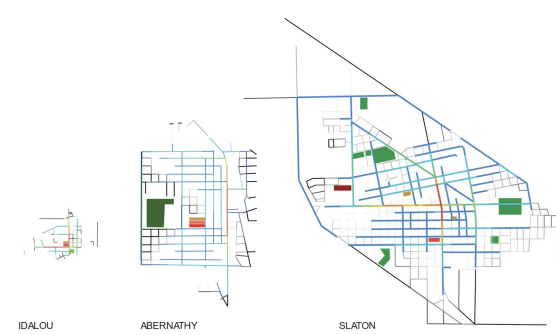

Figure 2. Dual structure of three towns showing the relationship to neighborhood amenities 
As segmented lines became more useful and the importance of 'through-movement' were systematically understood, normalization of 'choice' became necessary for interlayout comparisons and so the equation for 'normalized angular choice (NACH)' was developed (Hillier, Yang, and Turner 2012). Depthmap allows $\mathrm{NACH}$ to be calculated at any radii, with any concept of distance (see Table 1 for these). The most useful concept of distance to restrict radius in angular analysis was metric. Hillier and his colleagues systematically examined a data set of 50 cities (and some hypothetical layouts) and concluded that a range from 0.8 to 1.4 (blue to red) produced the most telling representation. Figures 3 and 4 show the NACH of our four case study towns/cities calculated at the maximum metric distance $(n)$ and displayed in the color palette to match the .08 to 1.4 scheme.

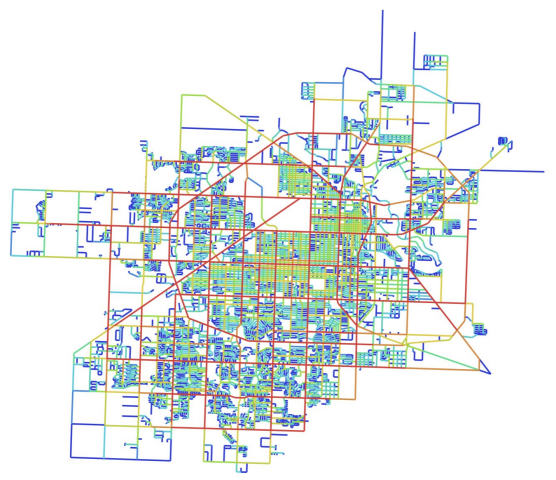

Figure 3. NACNn (0.8 - 1.4) structure of Lubbock

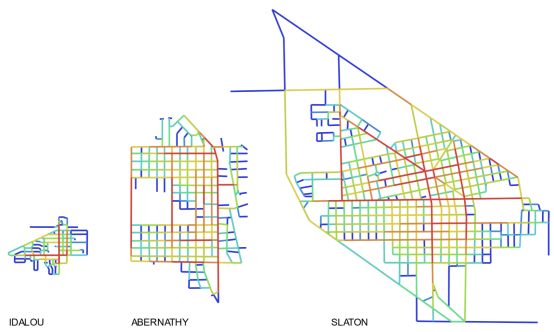

Figure 4. NACNn (0.8 - 1.4) structure of three towns

\section{WHAT CAN WE LEARN FROM OUR CASE STUDIES?}

It might be useful to reiterate here that metric analysis for background, and angular analysis (at a set metric distance) for foreground is a useful concept to study the functioning of individual cities, especially regarding their function at local and global levels. On the other hand, to compare cities of different sizes we should consider 'normalized angular choice values (NACH)'.

\subsection{Local-global structure of grid like cities}

Our four sample cities vary quite a bit in size but are similar in their general grid-like conditions. Among them Lubbock is the largest, at about 22.5 times the next town. The other three are quite small. Figure 1 shows the local and the global structures superimposed for Lubbock, and figure 2 shows the same for Idalou, Abernathy and Slaton. The global structure is given by the higher 'choice' values calculated at the maximum metric radius (n), and the local structure is indicated with the patchwork that was created with metric analysis at the radius of one mile. These diagrams unveil some interesting characteristics.

In Lubbock, the patches highlight a central area of every subdivision located somewhere inside its one-mile grid divisions. Second, in all the central areas identified (patches) there is a neighborhood amenity, either an elementary school or a park. Third, a colored line representing the global core is connected to the amenity of each center/ patch. Taken together, they indicate that the identified central patches are not only the vibrant centers of neighborhoods (living centers), they are also well connected to the city's (global) structure. Thus, the patches seem to act as thresholds between the public and private domains of the city. The other three cities are too small to have clear neighborhoods defined, but the phenomenon 
observed in Lubbock is also discerned. In small cities, where neighborhoods are few, the school buildings usually act as a public amenity. In all the cases shown here, the schools are located in the global structure, but also close to neighborhood patches.

This method of analysis, it seems, has postdicted the planning of grid-like cities. This is an important finding and shows that even in grid like conditions the logic between local and global structures and the logic of placing local amenities endures.

\subsection{Rims and edges}

Since NACH values do not depend on the size of a system, we can use it to compare cities. A visual survey of the three small towns in our sample (figure 2 and 4 ) reveals that the edges or the 'rim' is highlighted as predicted by Hillier. In many of the cities that have been described through $\mathrm{NACH}$ in the literature, specifically those with an outer ring, the rim had become highlighted. For example, when London inside the circular M-25 is modelled, the rim becomes quite significant (Hillier, Yang, and Turner 2012). It is the same case for Tokyo, Santiago, Barcelona, Beijing (Hillier, Yang, and Turner 2012), Apt (Hillier 2019), Nicosia (Hillier and Vaughan 2007) and other circular shaped cities. Lubbock does not have a well-defined edge (figure 1). It has a 'ring-road' but has grown out of this circular boundary. Even then, the analysis depicts this ring as significant (figure 1 and 3). Two interesting questions pop up: does the shape of the edge influence the 'rim' being highlighted, and do the city size matter? We investigated this question with three theoretical maps created by extending or reducing Lubbock. They are, Lubbock modelled inside the loop road only (figure 5a), a four-quarter section of Lubbock bound by its arterial roads (figure $5 b$ ), and Lubbock with a speculative larger loop around it with the gridded arterial roads extended to meet it (figure 5c). In all the cases we find that the exterior roads, either circular or not, when continuous, become highlighted. From this small experiment we can answer the two questions: (1) when exterior roads are continuous, an outer rim will be identified by $\mathrm{NACH}$ analysis, supporting Hillier's assertion, and (2) size of the city do not play a role in the formation of this highlighted edge (rim).

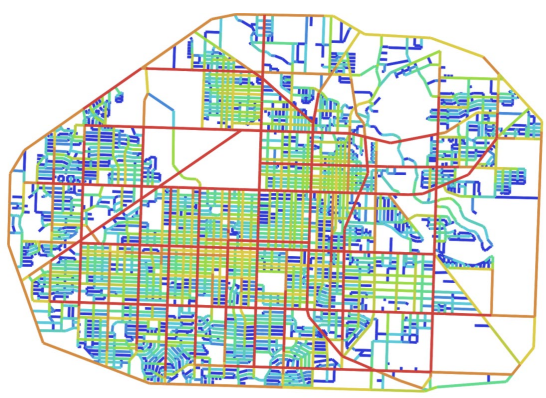

Figure 5a. $\mathrm{NACH}(0.8$ - 1.4) Lubbock inside ring road

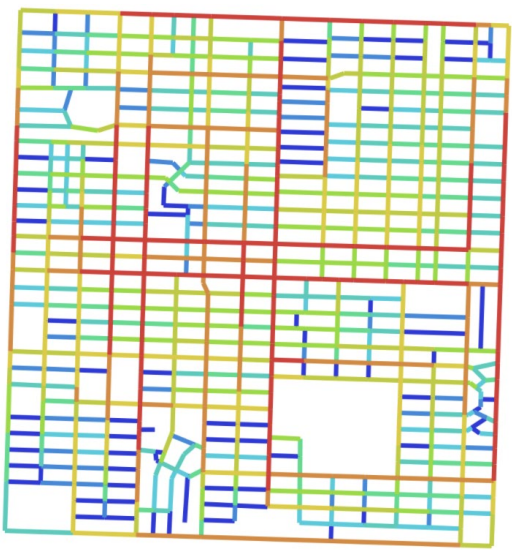

Figure 5b. NACH (0.8 - 1.4) Lubbock four arterial roads 


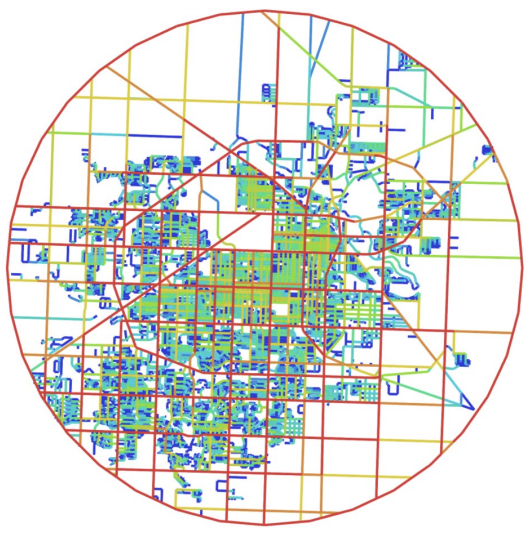

Figure 5c. NACH (0.8 - 1.4) Lubbock speculative ring road

\subsection{Spokes or edge to edge connections?}

In terms of creating the 'spokes' however, we do not see a clear pattern. Obviously, the gridlike layout does not provide opportunities for radial streets, but we do notice in the three small towns that some roads connecting edge to edge (of the rim) is highlighted. This is curious, because the streets seem to have connected one part of the edge to another without meeting at a significant center, since it may not exist. So, we may extend the original idea with this: in the case of a missing city center for very small grid-like towns, the foreground structure of the city will connect edge to edge, serving the global requirements of a 'bypass'. This becomes especially important for grid like conditions because, as mentioned by Ratti (2004b), the geometry also has a strong influence. Once identified, we also notice some 'edge-toedge' roads in Lubbock,

\subsection{Center formation}

Theoretically, the geometry of a grid works against the creation of a center. As cities grow, settlement processes, economic factors, policy, legislation, natural terrain etc. interact and make changes to the ubiquitous grid. The smaller towns studied here has not been developed enough or are not large enough to attain a configurational center. We can discern the semblance of a center in Slaton, the largest of the three small towns (figure 3), and certainly in Lubbock where a clear central area can be identified. From these we can infer that, unlike the edge, city size has a role in the creation of a 'center'.

\subsection{Numerical comparisons}

Hillier, Yang, and Turner (2012) studied a data set of 50 cities, where the smallest city had less than 1000 line segments, and the largest one had more than 250,000. Among them, some are discussed as 'geometric' - perhaps the closest approximation of a grid-like city, although not clarified. They also studied hypothetical structures of three grid like layouts - (1) a 60 segment by 60 segment orthogonal grid, (2) the same grid with a single pair of crossed diagonals at the center grid, and (3) the same grid with two continuous diagonals. Their analysis revealed that mean $\mathrm{NACHn}$ values were higher in the grid-like conditions (1.25) than any actual city they studied. In our four towns and three theoretical layouts the mean $\mathrm{NACHn}$ value was not very high (0.93-1.139). From this we can say that our sample cities behave less like isotropic grids, and more like actual working cities. Second, in the Hillier et.al study above, hypothetical gridded conditions displayed lower values of maximum $\mathrm{NACHn}$ when compared to their sample cities (more than 1.36 as compared to 1.6+). In all our cases the maximum $\mathrm{NACHn}$ values were 1.5 -1.61 , which is approximately the same range as the previous study. So, in this comparison also, the four grid-like cities of West Texas functions similarly to the other cities reported in the literature. Thus our studies support the statement "...Cities in effect seem to sacrifice 
$\mathrm{NACH}$ to create the pattern of high values that we call the structure of the system." (Hillier, Yang, and Turner 2012, pp 163)

\section{CONCLUDING REMARKS}

Our sample had one medium and three quite small grid-like cities and three speculative conditions from a mid-sized city. They were investigated with the most advanced Space Syntax technology available - 'segmented angular analyses' for the foreground structure and 'segmented metric analyses' for the background structure. Additionally, 'normalized angular choice' was used to compare between them and to published values of world cities from literature.

This study demonstrated that in general, theories developed with predominant illustrations of organic layouts also work for grid like city conditions. For example, all the layouts explored here produced very comparable maximum and mean $\mathrm{NACH}$ values. Some specific findings are that city center formation in the foreground structure is a factor of city size, but the outer rim is a ubiquitous phenomenon. Also, in gridlike conditions instead of center to edge connections, wefind edgeto edge connections. Overall, this paper suggests that advanced theories and methodologies developed by Prof Bill Hillier (and his colleagues) in the last decade of his productivity is indeed applicable to both grid like and organic cities and the theory can be considered (almost) complete. 


\section{REFERENCES}

Dalton, Ruth Conroy. 2003. "The Secret is to Follow Your Nose: Route Path Selection and Angularity." Environment and Behavior 35 (1): 107-131.

Haq, Saif. 1999. "Can Space Syntax Predict Environmental Cognition?" 2nd International Space Syntax Symposium, Brazilia.

---. 2003. "Investigating the Syntax Line: Configurational Properties and Cognitive Correlates." Environment and Planning B: Planning and Design, Pion Publications, London 30 (6): 841-863.

Haq, Saif, and Girmay Berhie. 2018. "Space syntax investigation of Lubbock, a gridlike American city and some insights into isotropic layouts." Journal of Urban Design 23 (1): 5-22. https://doi.org/10.1080/1357 4809.2017.1369872.

Haq, Saif, and Craig Zimring. 2003. "Just down the road a piece: The development of topological knowledge of Building Layouts." Environment and Behavior 35 (1): 132-160.

Hillier, Bill. 1996. Space is the Machine. Cambridge: Cambridge University Press.

---. 1997. "The Hidden Geometry of Deformed Grids or, why space syntax works when it looks as though it shouldn't." Space Syntax First International Symposium, London.

--- 1999a. "Centrality as a Process: accounting for attraction inequalities in deformed grids." Space Syntax Second Internationa Symposium, Brasilia, Brazil.

--- 1999b. "The Common Language of Space: a way of looking at the social, economic and environmental functioning of cities on a common basis." [web page]. http://urbandesign.ir/wp-content/ uploads/2017/11/Urban_space-syntaxhillier.pdf.
---. 1999c. "The hidden geometry of deformed grids: or, why space syntax works, when it looks as though it should'nt." Environment and Planning B 26: 169-191.

---. 2001. "A Theory of the City as Object Or, how spatial laws mediate the social construction of urban space." 3rd International Space syntax Symposium, Atlanta.

--- 2009. "Spatial Sustainability in Cities Organic Patterns and Sustainable Forms." 7th International Space Syntax Symposium, Stockholm, Sweden.

---. 2012. "The City as a Socio-technical System: A Spatial Reformulation in the Light of the Levels Problem and the Parallel Problem." In Digital Urban Planning and Modelling edited by Stefan Müller Arisona, Gideon Aschwanden, Jan Halatsch and Peter Wonka, In Communications in Computer and Information Science, 24-48. Berlin Heidelberg Springer-Verlag.

--- 2014. "The Generic City and its Origins." Architectural Design 84 (5): 100-105.

---. 2016. "What are cities for? And how does this relate to their spatial form?" Journal of Space Syntax 6 (2): 199-212.

---. 2019. "Structure or: Does Space Syntax Need to Radically Extend Its Theory of Spatial Configuration?" 12th International Space Syntax Symposium, Beijing JiaoTong University: Beijing, China.

Hillier, Bill, Richard Burdett, John Peponis, and Alan Penn. 1987. "Creating life: Or, Does Architecture Determine Anything?" Architecture and Behavior/Architecture et Comportment 3, No 3: 233-250.

Hillier, Bill, and Julienne Hanson. 1984. The Social Logic of Space. Paperback Edition 1988 ed. Cambridge, UK: Cambridge University Press.

Hillier, Bill, and Shinichi lida. 2005. "Network and Psychological effects: A Theory of Urban Movement." 5th International Space Syntax Symposium, Delft, The Netherlands. 
Hillier, Bill, and Alan Penn. 2004. "Rejoinder to Carlo Ratti." Environment and Planning B 31: 501-511.

Hillier, Bill, Alan Penn, Julienne Hanson, T Grajewski, and J Xu. 1993. "Natural movement: or, configuration and attraction in urban pedestrian movement." Environment and planning B 20 (1): 29-66.

Hillier, Bill, Alan Penn, Julienne Hanson, T. Grajewski, and J. Xu. 1993. "Natural movement: or configuration and attraction in urban pedestrian movement." Environment and Planning 20 (B): 29-66.

Hillier, Bill, and Laura Vaughan. 2007. "The City as One thing." Progress in Planning 67 (3): 205-230.

Hillier, Bill, Tao Yang, and Alasdair Turner. 2012. "Normalising least angle choice in Depthmap and how it opens up new perspectives on the global and local analysis of city space." The Journal of Space Syntax 3 (2): 155-193.

Major, Mark. 1997. "Are American cities Different? If so how do they differ." Space Syntax First International Symposium, London.

Mora, Rodrigo. 2003. "Land uses in the context of a perfect grid: the case of Barcelona." 4th International Space Syntax Symposium.

Mora, Rodrigo, and John Dahany. 2005. "Mechanisms of differentiation in a regular grid: the case of Toronto." Fifth International Space Syntax Symposium, Delft.

Paul, Abhijit. 2013. "Reviewing the axial-line approach to capturing vehicular tripmakers' route-choice decisions with ground reality." Transportation 40 (3): 697711.

Penn, Alan. 2001. "Space Syntax and Spatial Cognition Or, why the axial line." Space Syntax 3rd International Symposium, GeorgiaTech, Atlanta.
Penn, Alan, Bill Hillier, D Banister, and J Xu. 1998. "Configurational Modelling of Urban Movement Networks." Environment and Planning B 25: 59-84.

Peponis, John, E. Hadjinikolaou, C. Livieratos, and D.A. Fatouros. 1989. "The Spatial Core of Urban Culture." Ekistics 334, 335 Jan-Feb, Mar-Apr: 43-55.

Peponis, John, Catherine Ross, and Mahbub Rashid. 1997. "The Structure of Urban Space, Movement and Co-Presence: The Case of Atlanta." Geoforum 28 (3-4): 341358.

Peponis, John, Craig Zimring, and Yoon Kyung Choi. 1990. "Finding the Building in Wayfinding." Environment and Behavior 22 (5): 555-590.

Ratti, Carlo. 2004a. "Rejoinder to Hillier and Penn." Environment and Planning B 31: 513-516.

--. 2004b. Space Syntax: Some Inconsistencies. In Environment and Planning B.31; 487-499

Rayner, Willam Horace, and Milton O Schmidt. 1955. Elementary Surveying. Philadelphia:

D. Van Nostrand Co.

Read, Stephan. 1999. "Space syntax and the Dutch city." Environment and Planning B: Planning and Design 26: 251-264.

Stonor, Tim. 2011. "Spatial Layout Efficiency" presentation made to National Capital Planning Commission, Washington DC, 15 June 2011. Washington DC.

Turner, Alasdair. 2001. "Angular analysis." Space Syntax 3rd International symposium, Altanta, GA, USA. 
PAPER \#1.11

\section{THE POLITICS OF THE ILLUSION / THE IMAGE AS A REJECTION OF TYPOLOGICAL TYRANNY}

Jonathan Scelsa ${ }^{a}$

apratt Institute, New York, NY USA

\section{ABSTRACT}

The architectural academy's new exploration between the complex relationship of image and geometry has come under scrutiny of late as a rejection of the multiplied interest in form wrought by the prowess of the digital generation. This burgeoning trope - wherein images, graphics and low depth decoration are implemented for their ability to overpower, undermine and push geometry into the realm of false or readings - has a rich history for its use in the political rejection of authority, despite its oft contemporary implementation as a neutral post-digital affect of ambiguity. Throughout several times in western history, the realm of the decorative architectural image illusion has been utilized as a sharp criticism of the totalizing and absolute authority of the architectural type that had been forcibly instituted by a larger regime, political force or faith. Through critical manipulation of the prevailing drawing practice of the time period, architects would be able to implement a criticism of the spatial practices insidiously inserted within an opulent construction of the stylistic whole. This essay will examine four situationally specific drawing practices, the Second-Style of Antiquity, Mannerist Quadratura, PostEnlightenment Anamorphosis, the Supergraphic of Post-Modernity. This paper will use new representational methods of Point Cloud Photogrammetric scanning to reconstruct the image oriented space of illusionary wall situation drawings, establishing the political critique embedded in this practice as a means of contemporary critique.

\section{KEYWORDS}

Illusion; quadratura; anamorphosis; photogrammetry.

\section{INTRODUCTION}

The architectural academy's new exploration between the complex relationship of image and geometry has come under scrutiny as of late as a rejection of the multiplied interest in form wrought by the prowess of the digital generation. This burgeoning trope - wherein images, graphics and low depth decoration are implemented for their ability to overpower, undermine and push geometry into the realm of false or readings - has a rich history for its use in the political rejection of authority, despite its oft contemporary implementation as a neutral post-digital affect of ambiguity. Throughout several times in western history, the realm of the decorative architectural image illusion has been utilized as a sharp criticism of the totalizing and absolute authority of the architectural type that had been forcibly instituted by a larger regime, political force or faith. Through critical manipulation of the prevailing drawing practice of the time period, using precise optic strategies of Spherical Antique perspective, Quadratura, and Anamorphposis architects would be able to implement a criticism of the spatial practices insidiously inserted within an opulent construction of the stylistic whole.

While, the digital turn has seen a change in our visual studies syllabi to conflate projective drawing procedures in both digital and 
analogous hand drawn procedures, imageoriented procedures continue to be shunned to a different time and place of the curricula invested in Photoshop filters or photorealist rendering procedures. This peculiarity may be most linked to Giorgio Vasari's original separation of Disegno, meaning drawing or design, from colore, that which concerns decorative painting. The former taking root in design and perspective as a manipulation of points and lines in space as cut and cast through picture planes. While historically, this segregation was underscore by the division of labor for those who were technically constructing an architectural mural today's technology no longer creates such a differentiation. Contemporary means of photogrammetry, blends the two color and geometry into a singular piece of image data containing 6 numerical values, $x, y, z$, and r,g,b. ( Figure 1).

Further when we examine the larger idea of the image-window, rather than the picture plane for merely geometry, it is apparent these are all a part of the same rigorous procedure and lineage of thinking.
'From the mid-fifteenth century writings of Leon Battista Alberti to the late twentiethcentury computer software trademarked by Microsoft as Windows, the window has a deep cultural history as an architectural and figurative trope for the framing of the pictorial image. An opening in architectural space the window supplies a common metaphor for the various frames that form its virtual analogs - the frame of the painting or photograph, the screen of the movie, television and computers. Alberti's Renaissance metaphor drew upon the window as an analog for the perspectival frame of the painting; since then the window and its common metaphysical corollary perspective have remained central figures in theorization of the space of vision (Friedberg 2009).

In her book, The Virtual Window, Friedberg describes the evolution of the thinking of Albertian projective mechanics over time through a vast array of media, that arguably have been in effect far earlier than even the fifteenth century master himself in one form or another. When we consider a pixel to be a

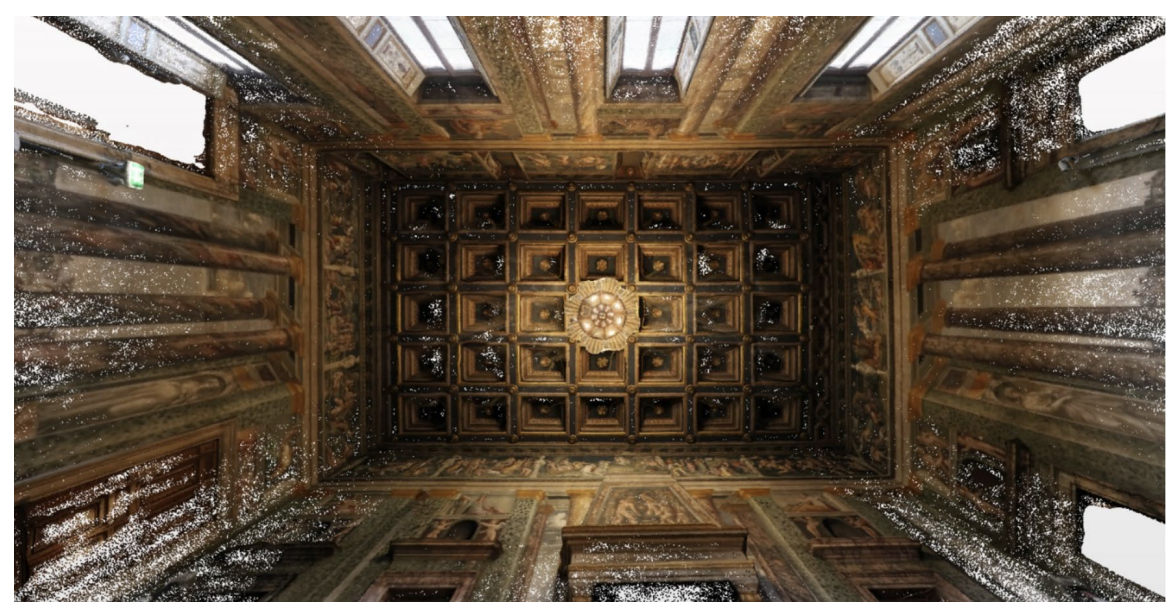

Figure 1. An illustration of a scan of the Piano Nobile Prospettivo Room designed and painted by the architect Baldassari Peruzzi in the Villa Farnesina in Rome by the Author. 
point of colored light rendering an infinitesimal moment, we can also understand its ability to travel in space towards the eye creating a set of colorful lines that are in turn capable of being protectively cut by the picture plane, the window or the screen as can be described in the authors (figure 2).

In this way image too is a projective procedure, and throughout history we can see its technique has been rigorously used for its ability to calculate and create distortions on the surfaces of architecture. It is also clear that image and geometry have a complex relationship, as often the internal high contrast within image can visually overpower the effects of shadow and light thereby undermining our ability to detect the folds and curves of the surface geometry on which the images are at play. While this fact may have just gained attention and traction within the contemporary community as a direct rejection of the import and digital turn's obsession with geometry and form, it has been a known practice throughout western and eastern architectural tradition as a means of utilizing projective mechanics to create a sense of false space, virtually constructed and over-riding the spatial typology whence it is deployed.

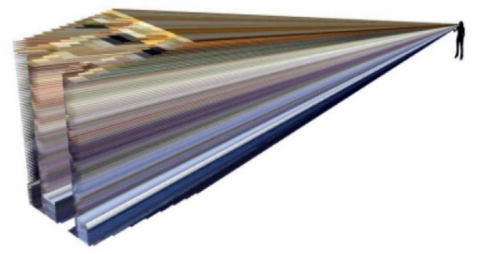

Figure 2. An illustration of the way that contemporary technology has the capability to move image data through the perspectival lens in the same manner as lineaments and projection of geometric lines by the Author.

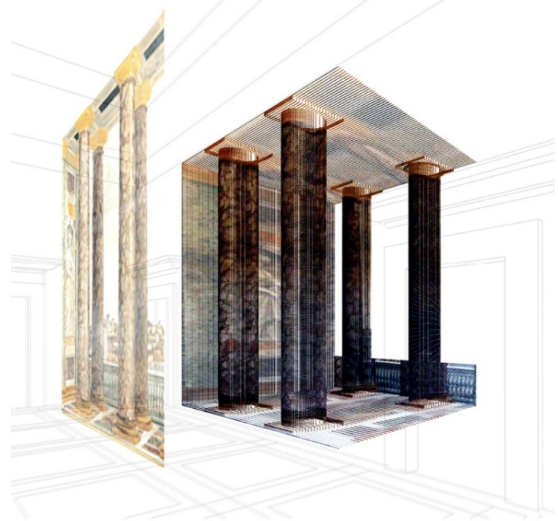

Figure 3. The decomposed point cloud of the Prospetivo painted by Baldasarri Peruzzi projected onto its virtualized geometry by the Author.

Further, the contemporary presents several new technologies that are embedded in the historical techniques discussed above, including most notably photogrammetry. A system that relies on the camera as a perspectival machine de-coupling color and space into a form of architectural colored points, each embedded with spatial coordinates and an RGB value to aid in the production of a robust digital environment.

\section{The Second Style in the Domus}

One of the most analyzed and celebrated Architectural aspects of Roman Antiquity would be the Atrium House or Domus as described and illuminated by Vitruvius in his Ten Books on Architecture. While, it is most often discussed for its environmental merit or typological persistence, this essay will argue that the image oriented decorative principles of the Atrium, at the time of the Roman Republic, demonstrate a political act of subversion as rendered through spatial illusion. During the Roman Republic, 
between the fourth and first century before the common era, atria existed as defined spaces, albeit often with gray borders at two scales of implementation, both at shared scale of the city as well as at the scale of the individual domestic within houses of state and mercantile leadership. Notably in both cases the atrium was formed as a quasi indoor - outdoor space with some overhead framed view of the sky, within a semi-enclosed environment that maintained open-access. The concept of access should be qualified in this case as both view-shed access and physical and tangible ability to move within and in between the various programs of the surrounding architecture. It is notable that in antiquity there was a radical different notion of public - private space (Russell 2016).

One of the natures of the roman republic was a scattered work-force where artisans, and senators each maintained their own practice within their homes. As a result, during republican rule, two centers, the atrium and the peristylium, were employed within the home. The atrium was an extension of the roman market and road, axially bleeding into the home as a space of connection and commerce (Sewell 2002). These atrium, elastically varying in size from domus to domus, would be employed in families of merchant class, senatorial class as well as in the smaller scale houses of the poor, albeit scaled down with similar planometric rules. These atria informed the center of the roman public life within the home and the space of salutatio, a practice wherein the merchant owner or governmental patrician would be available each morning by law to greet petitioners from the street. For the ancient world, it could be maintained that the atrium acted as an urban juridical device, both in its ability to bring individuals in, allowing them to become witness observers, but also in the way it endemically presents a symbolic space of the republic's principles of representation.
Herein we see that many rooms of dining and the alae were directly accessible to the public as they moved into house during salutatio, extending the visual watch of political praxis. This spatial typology, regulated by the government.

The image frescoes of the domus, provide a further example of the efficacy of the spatial type for public oversight in their attempt to subvert that spatial typology by providing illusionistic privacy. It is notable that the atrium was written about as public, in the way it should be adorned; Cicero, Sallust and Pliny were notorious for attacking the use of high decoration except in places where all could enjoy, an example of which described in Cicero's De Officiis being the house of a public official as a space of salutation (Russell 2016). The Second-Style of the Ancient Roman republic, utilized what has now been described by authors such as Erwin Panofsky, as Antique Perspective, or spherical perspective, wherein the pictureplane described an understanding of the world based on our view through the ocular sphere. This technique deployed that understanding of perspective for the purposes of confusion and opulent camouflage de-materializing the physicality of the wall through references to exterior garden spaces of the peristylium. Though often dismissed by Roman Historians such as Andrew-Wallace Hadrill as an opulent parlor trick, an alternative argument can be constructed these frescoes were commissioned to present an illusionary affect to the solicitor entering the atrium during salutation, in order to create a sense of false-privacy spatial distortion of the legally mandated typology. 


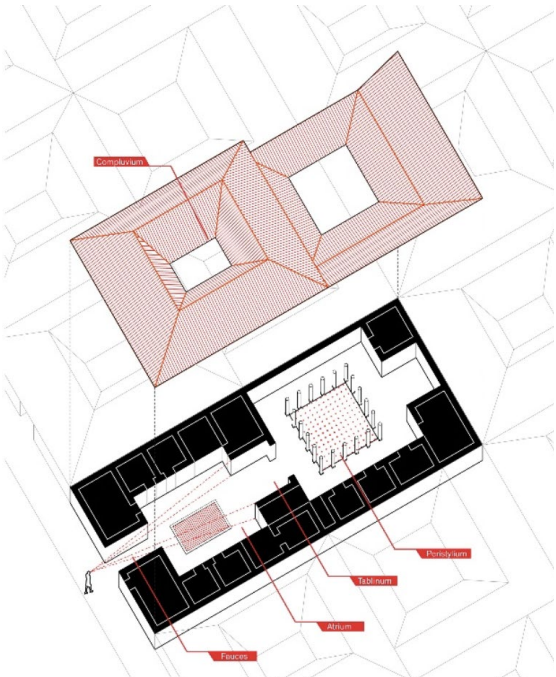

Figure 4. The space of illusion during the second style was encased within the quasi public open area of the house which provided a senses of false privacy for the public officials who lived in governmental regulated typology. Drawn by the Author.

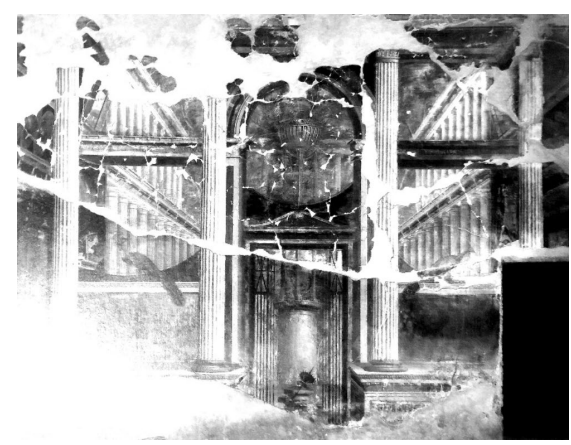

Figure 5. Photo taken by the author of the Villa Poppea visitation space which figured a false depth courtyard as a typological separation tool.
The Roman practice first stipulated the painting a plaster coat called the intonachino, in which the scheme of the planned spatial depiction was rapidly scratched as a series of Lineaments, we can see an example of this idea as depicted within the archaeological space of Villa Opplontis. The Pictor Parietarius, literally meaning of "painter of the walls," would enter the scene first drawing the columns, aediculae, bases, pediments, for the background and frame, employing equipment such as plumb-lines, leaving space for the Pictor Imaginarius, to paint the individual figural moments and scenes of landscape within and beyond. Beyond technique, several spatial ideas were also cemented in the Ancients. Firstly, choreographed station points as Scenografia, were used to impress visitors of the mercantile and political homes within the atria of the domus. The frescoes were placed in view corridors that would be coincident with the visitor, extending the space. Secondly, the frescoes did not operate alone, but rather their subject matter, such as fictional columns would correspond in plan to the ring of columns surrounding the adjacent courtyard.

Support for this might be witnessed within the subject matter of the actual canvas by example of the Villa Poppea of Opplontis. Herein the wall-image references the very room upon which it is painted though it is pushed backwards in space, and surrounded by a fictional garden. Thus the space of the meeting is objectified by creating a walledprivacy perimeter. Several art historians have noted the visual and cultural change to Rome following the Republic under the Imperial Rule of Augustus, whom pushed for "the moral turn-around" during which "the illusion of breaking through the wall is no longer sought - rather its integrity is emphasized - and the viewer is meant to focus on the meaning of just a few images that dominate 
the room. (Zanker 2002)" This break from the interest in speculative unreal or hedonistic fantastic practice, could also be argued to an imperialistic return to the physical architecture of a surveilled reigning in the act of confusion. With the neutered power of the senate and the mercantile class under imperial regime there was decided less need for privacy, particularly within the change of state-hood.

\section{Quadratura in the Villa}

This new illusionary practice, was more formalized into painting and decorative practice within the Cinque Cento, known as the Quadraturista. The mannerist century brought forth several new inventions to the trompe - loiel practice while seeing it popularized, in noble houses. Within the last century, there has been intense architectural scholarship on the typology of the Italian villa during the mannerist era of the sixteenth century. Figures such as Rudolf Wittkower and Colin Rowe analyzed and pronounced the work of Andrea Palladio as an individual who developed formal and proportional rules, a game which was of high interest for the late Modernist academy, whom was currently under the its own tyranny of modernist technologic rules of construction. Even today the analysis of the Palladio's Magnum opus has retained an emphasis on architectural form and geometry over the embedded imagery that was often planned simultaneously with the architecture and painted coincident with construction. The suggestion has been always that the villa is one of the most radically ideological architecture's because it hides its economic dependency on the city by claiming selfsufficiency within the countryside (Aureli 2011). The time period of the sixteenth century would underscore this analysis due to a called switchover of regional economics in the Veneto from the mercantile Venetian dominance to an agrarian base and a call by such nobleman like Alvise Cornaro that the country-side economics should be of dominance politically. Later historians have called attention to their earlier colleague's omission of the situational elements of the Palladian architecture including the Barchese Barns. Interestingly, the imagery of the walls planned by architectural illustrator Paolo Veronese, whom often painted trompe' loiel architectural image alterations to the Palladian typology, with false doors and elongated passageways that would serve to link.

Baldassari Peruzzi at the turn of the sixteenth century introduced asymmetrical standpoint and thus proto- anamorphosis in his master-work for the Farnese family in the prospettivo room of the Villa Farnesina. This asymmetry began to make noticeable the prospect of the illusion. The prospettivo room is situated on the piano nobile of the Villa which at the time was on the outskirts of Rome on the south bank of the Tiber surrounded by agrarian fields of which the room in fact is only able to view to the south. Peruzzi creates false imagery of the room to depict an outer balcony wrapping around the piano nobile, a decisive typological anomaly within the villa that typologically always demonstrates a sidedness of front and back. Even more peculiar and perhaps subversive is the content of the horizon depicted in the omnidirectional balcony. The horizon depicts the full-relationship of the villa to both the country-side and the city of Rome itself, sprawling around it on multiple axes. Though the regional economics of Lazio were different from that of the Veneto, and the Farnese family may not have been as openly oppositional to the city, this can be seen as an open criticism of the prevailing ideology to separate the type into the nature of the countryside. 


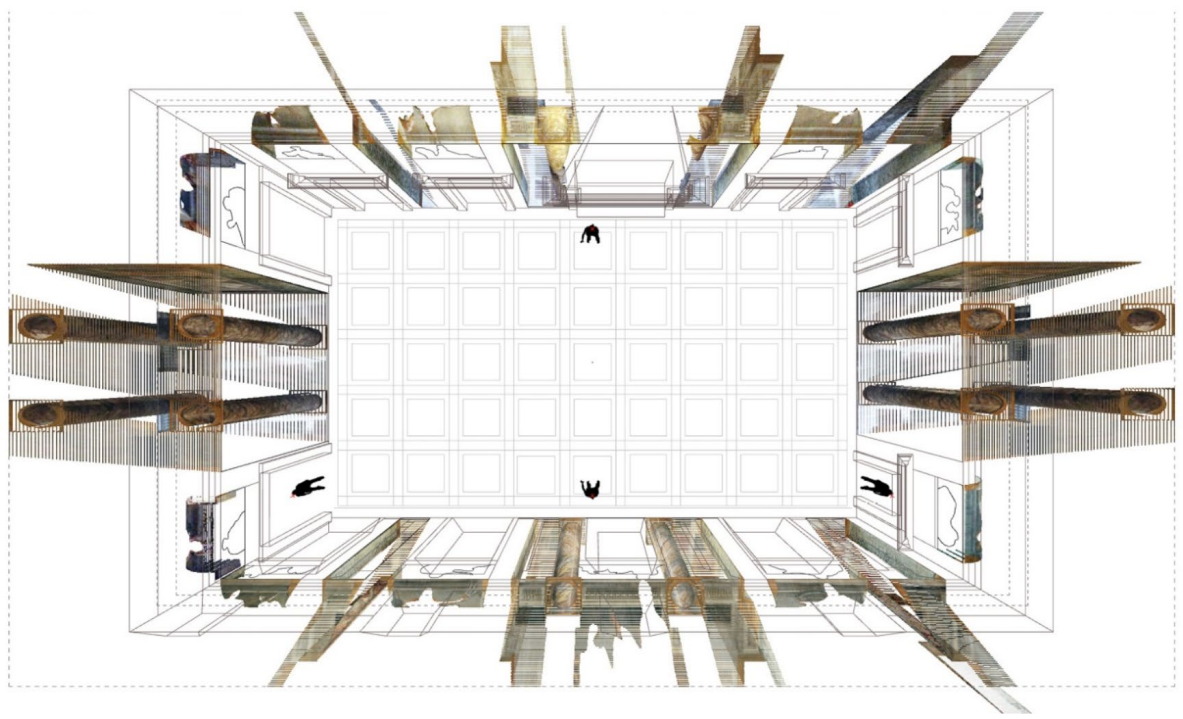

Figure 6. The overlay of the two typological spaces provide a form of contradictory critical collage, which was suggestive of a means of alteration against a prevailing structural, organization and typological configuration in the above case the Villa by the Author.

\section{Anamorphosis and the Mother Church}

The post-enlightenment period saw, another example of architectural illusion in the form of Anamorphosis Perspective, as a means of countering the propaganda of a specific sect of the Church. The period of the enlightenment within Italy, developed much specific research on the properties geometric distortion as developed through the optic capability of mirrors, lenses and warped picture planes. The Church of the Santissima Trinità dei Monti, became a sanctuary for exploration surrounding drawing, a place where later the Jesuits would commission Pozzo to create a room. Here two French monks Emmanuel Maignan and Francois Niceron in an academy like setting began exploring the principles of Anamorphosis, a little known technique that was minimally explored by Hans Holbein in his work of the Ambassadors a century earlier. The Monks developed this technique as the drawing an image through an oblique or non-perpendicular picture plane such that the individual would understand this from a specific angle. It is notable that one of the monks, Niceron began to explore this through processes of mirror reflectivity and the distortion of the image through conical reflection, while the other Emmanuel Maignan explored the ways the technique to be used to hide images from specific vantage points and expand space. 


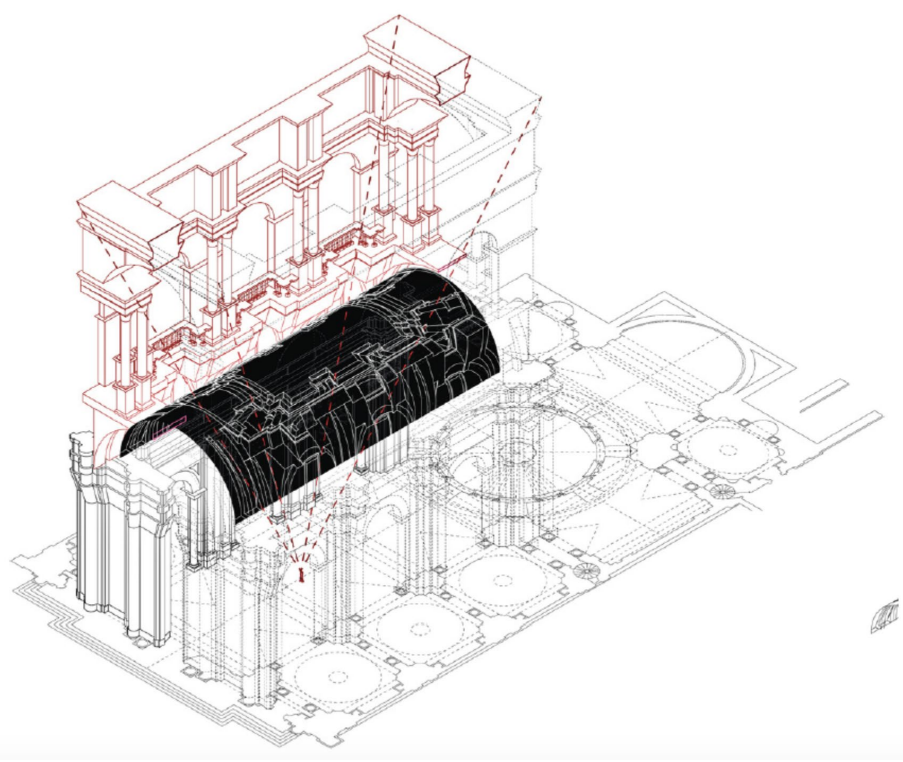

Figure 7. The Optical criticism of The Mother Church typology as rendered by Andrea Pozzo in St. Ignatius in Rome.

The society of the Jesuits was a newly formed sect of the Christian church during the 15th century, and one which was backed by the Farnese family during the Cinquecento in Rome and eager to gain a foot-hold. As written about retroactively "The Nineteenth-century notion of a Jesuit Style designated architecture as a system of persuasion, treating built forms as evidence of the manipulative methods of the Jesuits (Levy 2004)." Its home church, II Gesu, earned its fame by for the first true Baroque Façade was built in Rome by the Farnese family Architect Giacomo Barozzi di Vignola. The plan-type is famous for a limited to non-existent narthex, the typical interior exterior transition zone, and a singular nave without aisles derived in a fashion to create full attention to the main altar. Very quickly the design of the church set forth a typological plan for Jesuit churches around the world that lasted into the twentieth century arguably as a form of propaganda in an aesthetic agenda.
The later instantiation of the Mother Church's plan at St. Ignazio also in Rome, provides a case-study in the use of Anamorphosis as a subversion of the type through the dematerialization of the ceiling. The decorative designers, architect and brother Andrea Pozzo, utilized the recently discovered new techniques such as Anamorphosis for spatial criticism of the unyielding type, through the activation of a vantage point in the central stage that removed the gaze from the central liturgy and focused on individuals ascending to a heaven above with signs and emblems of science, such as the mirror. Pozzo went on to use this technique in several other Jesuit churches through Italy and Austria, and more closely in the chambers of the original II Gesu to convert the barrel vault of a room into a more classically minded enfilade picture gallery chamber, flattening the cylindrical ceiling and false situational geometry of the site into an elongated and flat cellularized room, for contemplation and change of speed. 


\section{The Super-graphic in Housing}

The 1970's, gave birth to another countercultural image - space project. Sponsored by research at Yale under Charles Moore and C. Ray Smith the project began under the labels of Campo-pop, and the Super Mannerism the project combining the current practices of Camp, pop and op art. The Supergraphic was defined as giant - two dimensional graphics applied to architectural surfaces, with the forms being so large that "no design is to be held within a given architectural plane" (Mcmorrough 2007). The activation of the graphic over multiple planes de-stabilizes the optical perspective, due to the high contrast reading of flatness. This disfiguring of the geometric sensibility of the perspective was most often used as a point of specific cultural insertion into the white box of Modernism wherein the post-war generation found themselves. Otherwise the condition has been used as a method of Optical Dissociation from space and time, Op-Art as seen as a means of "breaking the rationalization of space we call scientific perspective (Gombrich 1985)." The image of the supergraphic both undermines the geometry through flattening but also serves to unify a disparate set of designed spaces under a singular whole, Norma Skurka and Oberto Gill go further to define the social capability of this where, 'In modern buildings there is none of the inherent charm of earlier times... The cost of decorating these boxes to give them some of the atmosphere that they can lack can be outrageous, but paint is cheap and colorful.( McMorrough 2007).' Herein the McMorrough underscore one of the inherent dichotomys of the image project and why it has been eschewed from the architectural realm, as a part of the lack of intrinsic, or tectonic, while establishing its power in changing and altering the perception of Geometry. Throughout the latter half of the twentieth century, architects such as Hugh Hardy and Barabra Stauffacher Solomon pushed for a new paradigm between image and geometry in their house and apartment projects establishing expansion and subtraction of the reality of the white box enclosure. Today perhaps a new order of gradient between image and geometry needs to be established rather than the initial dichotomy put forth by Vasari where the technology and criticality of the author can be established in a spectrum ( Figure 8 ).

\section{CONCLUSION}

The schism of image and projective drawing in today's schools marks the continuation of thought that suggest the colore practice is not able to be complicit in the disgeno or formal generation. This hard-graphic line has maintained a separation between architect and his/her ability consider the realm of interior design and decoration as integral to the architectural practice. The irony is that these architect / painters of the past have demonstrated that colore or manipulation of image is also a procedure of projective geometry and truly a spatial practice. This is evident both in its procedure of pixels and paint being manipulated in a virtual projective model, but also in its ability to over-ride and subvert the spatial typology informed by the geometry of the architect. The second outcome is to demonstrate the possibility of illusion within the realm of architecture as a critical agent beyond its mere opulent effect. The work will be situated in narrative within its context and time-frame, to show the micro-political changes that the image - geometry relationship participated in. Further, the project will serve not to emphasize image overly in the generic, but architectural images which are spatially keyed to specific vantage points activating a spatial organizational problem. Our courses that fall under visual representation need to move beyond drawing as exclusively the province of disegno and into the all-encompassing ideology of the Architectural Image in both pixel and vector. 


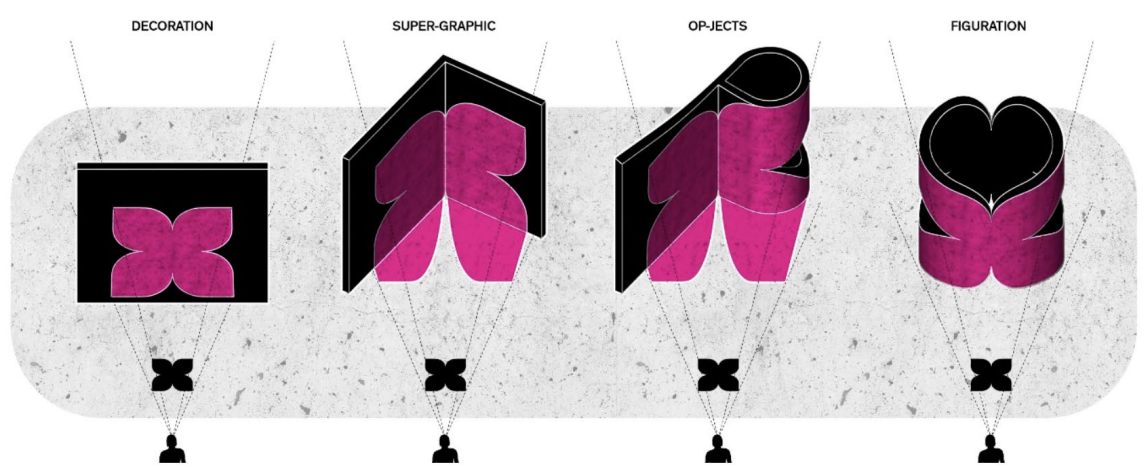

Figure 8. Rather than segregating pictorial image color content into two strands perhaps a more apropos spectrum allows for the understanding on whether these provide a critical redressing of the geometric typology as in the hybrid examples in the center. Drawn by the author. 


\section{REFERENCES}

Aureli, Pier Vittorio. The possibility of an Absolute Architecture: Massachusetts Institute of Technology. 2011.

Friedberg, Anne. The Virtual Window: from Alberti to Microsoft, MIT Press, 2009, pp. 5 Russell, Amy. The Politics of Public Space in Republican Rome. Cambridge: Cambridge University Press, 2016, p8.

IBID. p 12

Sewell, Jamie. The Formation of Roman Urbanism, 338-200 B.C.: Between Contemporary Foreign Influence and Roman Tradition. Portsmouth, RI: Journal of Roman Archaeology, 2010.

Zanker, Paul. The Power of Images in the Age of Augustus. Ann Arbor: University of Michigan Press, 2002.

Levy, Evonne. Propaganda and the Jesuit Baroque. University of California Press; First edition, 2004.

MacMorrough, John. "Breaking the Lid off of Paint' in Hunch: Rethinking Representation Vol 11. The Berlage Institute. Episode Publishers. 2007

Gombrich, EH. Meditations on a Hobby-Horse. Phaidon Press; 1985 



\title{
PAPER \#1.12
}

\section{THE ARCHITECTURE OF CHANDIGARH CAPITOL}

\author{
Maite Palomares Figueres ${ }^{\mathrm{a}}$, Ivo Vidal Climent ${ }^{\mathrm{a}}$, Ciro Vidal Climent ${ }^{\mathrm{a}}$ \\ aUniversitat Politècnica de València, Valencia, Spain
}

\section{ABSTRACT}

From ancient Babylonian and Egyptian civilizations man has found in the architectural enclosure the response to a feeling of protection and presence that nature itself already offered in certain places. Its trail takes us from the funerary temple of Djoser, built by Imhotep, where a first mastaba defines a funeral enclosure which assumes, given the need for horizontal growth, the construction of a stepped pyramid that gives an answer to the visual call as a monument. Or the Athenian Acropolis itself, which dominates as an island on the Attic plain, in which architecture has emphasized the landscape of nature transforming the hill of the Acropolis in a sacred enclosure. This enclosed platform is called a Temenus and it establishes the relationship of unity amongst the gorgeous buildings that make up the sanctuary, allowing us to perceive the Parthenon as a great territorial monument. This same system of spatial boundedness is behind the generation of the capitoline enclosure of the city of Chandigarh and gives the naturalness of its limits to the different buildings that are placed on it. That is why we understand the capitol complex as a unity in which every building, every monument, has a relationship with the others, despite its vast but neat extension of about four hundred meters. The importance of this work by Le Corbusier lies in its founding will to affirm the new impetus of Indian civilization, and it does so by accepting that both the enclosure and its content belong to a millenary architectural code. The architectural limits once again become the key that allow us to incorporate the abstract and emotional thought that nests hidden in a collective memory that connects the different civilizations with each other.

\section{KEYWORDS}

Civilization; landscape; territory; enclosure; monument; Chandigarh.

\section{INTRODUCTION}

The objective of this writing is to show the correspondence between the material reality that architecture produces as a human contribution and the physical reality of the site that the territory offers. In this sense, the choice of the enclave is essential to participate in the production of the material witnesses that every civilization bequeaths to the future as testimony of its existence. Impressed by the Indian landscape of Punjab, Le Corbusier realizes that the feeling of perenniality that permeates the territory has to be maintained within the new city created from the political will of an emerging state in order to become an act of affirmation of Indian civilization.

Site awareness is a subjective experience that human beings perceive when stimulated by the surrounding landscape. What gets disturbing for an architect is not the fact of knowing that the landscape can become the threshold that calls us to a transcendental understanding of the earth as a human site, but knowing that other previous architectures have been able to convey that experience, because from the cultivation of its memory as consciousness, the enclosure is understood as a place, and therefore a negation of that non-place (Marc Augé's non-lieu) that envelops and engulfs a banal civilization.

When, at the end of December 1949, Le Corbusier was commissioned for the 
Chandigarh project, he was already a mature architect, and, although his time on earth was shortening, he knew that each work generates an emotional threshold that permanently haunts strong architects. Le Corbusier, moved by the territorial beauty of the enclave where the Capitol was to be built, took note of the background landscape that the Siwalik mountain range offered to the Capitol settlement. Faced with an offering such as the plain with the open furrows and the bottom of the hills prior to the Siwalik mountain range, Le Corbusier's epiphanies transport him from the Athenian acropolis (Fig. 1), the Roman fields or the Algerian coasts to his immersion in the Mughal civilization. Everything is an unrepeatable reference that architecture assumes and adopts as a dialectical means to increase and complement the cultural value on which civilizations rely to stabilize.

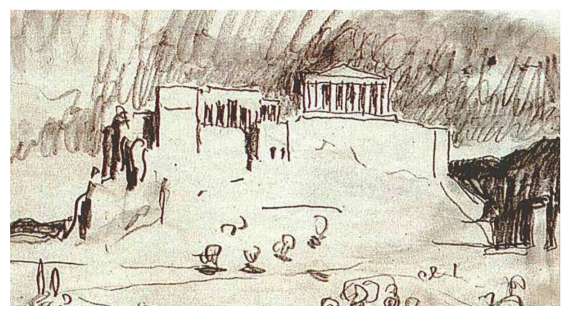

Figure 1. Le Corbusier's sketch of the Acropolis of Athens. (AV Monografías 2015)

\section{Lansdcape}

The term landscape has a multiplicity of meanings. It appears in the most diverse disciplines and is used both to designate a more or less humanized physical space or a metaphor. However, the notion of the landscape that we can use, from the architectural point of view, is more linked to the sensitive and emotional aspects and to the way of limiting the enclosure and accepting the place, rather than to the totally remote rational concepts typical of the disciplines of the geographer, ecologist or sociologist. We speak of landscape as an extension of land whose locus consciousness is defined by certain spatial stimuli.

\section{Territory}

The territory (from the Latin Territorium) is a portion of the earth's surface, a physical extension where the landscape is located. If we analyze the term territory, in some way, we discover that although the limits that define it are mentally very complex, they are threedimensionally linked to the finite vision and the spatial continuum.

\section{Enclosure}

The enclosure (from Latin re and cinctus, enclosed, surrounded), is understood as the space comprised within certain limits, the enclosed, possessed, marked or limited space.

The immeasurable space takes, through the tangible object, the opposite notion of measurable space. In this way, both space and object become a tangible volume that has three-dimensional quality and is scientifically measurable. These two entities as duality are sufficient to form, through their almost unlimited possibilities of variation, the objects and space of common architecture. But not every object-space duality configures a place. Enclosure awareness has a subjective connotation that is linked to a deeper intuition of space, but whose measurability is linked to the limits that configure it. If we analyze these limits, we will discover the relationship between the territorial enclosure configured by natural elements and the enclosure constructed artificially by the human being. The similarity between the vertical wall or the horizontal platform, and the tangible elements that configure the measurable boundaries of the territory, render the enclosure a dimensionless architectural operator and, 
occasionally, difficult to distinguish in the landscape in which it is territorially implanted. Although enclosures can be different in scale and disposition, they are not dissimilar in primeval organization because they serve the same function of providing scale and measure to space in order to form the most precious and evanescent value of architecture, the consciousness of the formation of a place.

The architectonic operator of the enclosure, so common in the natural world, arises simultaneously in distant places and from different starting points, because its relationship with the environment can be authoritarian or subtly sensitive and therefore its attitude can vary between the domination of the territory and the simple differentiation. In Chandigarh Capitol Le Corbusier links the enclosure, as a spatial operator, with the monument, as destiny. The first is legitimated through its limits, however the second is only constituted as a corporeal element having the previous configuration of the enclosure.

\section{Monument}

The term monument (from Latin monumentum, moneo mentum), is an expression originally derived from the concept of memory. The meaning that interests us is that of a natural or artistic element which, due to its exceptional nature, is worthy of attention, of showing itself and even of being saved.

Territorially, the monument is linked to the theatrical figure of the protagonist and, due to its exceptional nature, it must be shown alone since its excessive repetition can transform it into a background. Thus, a small hill can be a large monument inserted in a plain, while an abrupt and irregular mountain range becomes an unquestionable territorial limit.

The search for visual domination of the territory is a characteristic of architectures that aspire to an impressive figuration and therefore are associated with the concept of monument. The predominant disposition of the monument must be subtly sensitive to the environment, since its formal expression, that aspires to impress, must occur as an event, as a special ingredient, in order not to generate confusion. In this interaction with the environment, architecture grows gradually from a conceptual structure that sets the boundaries between the geometric and the natural world, organizing its level of relationship and overlap.

\section{ENCLOSURE AND MONUMENT IN LE CORBUSIER}

The study of nature does not imply imitating its appearance, since the existential laws of whose complexity we feed reside in its diversity, strength and unlimited subtlety. Visiting a place like Chandigarh, which hides a balanced harmony under an apparently random order, allows you to discover the relationship between the distant landscape and your own place. This natural dialogue implies equality and mutual subordination. This balanced dialectic is particularly sought after in Le Corbusier's projects, and it is in his later works such as Ronchamp or Chandigarh, that we can experience his architecture feeling the effect of the combination of visual patterns typical of the monument, together with the topographic patterns typical of the enclosure.

\subsection{Voyage d'Orient}

In his "Journey to the East" he uses six travel "cards", as a tool not to forget, in which he prints some 300 drawings that reveal, along with the writings he outlines on some pages, the inquiries that he would apply throughout his career using basic, simple principles. The way of working of some of his later projects is clearly expressed in these notebooks. Le Corbusier's urban proposals are characterized by accentuating the characteristics of the territory in which they are projected, in such a way that they seek to preserve, given the necessary urbanization, the landscape 
sensation that the environment already housed.

On his early trip to Athens, Le Corbusier visits the Acropolis site and the monumental Parthenon, which is located in the highest area of the city's sacred temenus. The architecture that is located on the temenus fascinates him since it emphasizes the natural elevated enclosure, transforming the former hill into a founding enclosure.

\subsection{The lesson of Rome}

In the drawings in which he traces the profile of the Vatican with Bramante's Belvedere as the protagonist, we can recognize the importance for him to discover the magnitude of the horizontal line that marks the limits of the Renaissance enclosure, since he even added a note that clarifies the intention of the drawing "it never extends enough". This reflection, together with the imaginary views of Rome in which he draws horizontal lines and vertical volumes, are the printed expression of a most important inquiry, in which the historic city becomes the master teaching a promising young apprentice. How else to understand the chapel on Ronchamp hill where he evokes, in the east portico, the ancient pagan rite of the external sacrificial ara visually dominating the orderly Roman fields (champ romain) that give their name to the location.

\section{CHANDIGARH}

When India became independent from the British in 1947, the country was divided into two, with Muslim Pakistan to the northwest and Hindu India to the northeast. The most traumatic part of this division was the fracture of the Indian province of Punjab, whose capital Lahore, was ceded to Pakistani territory. This motivated the decision of Prime Minister Nehru in 1947, three years after the partition of the former English colony, to create a new capital for the provinces of Punjab and Haryana. This new city was called Chandigarh (चंडीगढ़), which means "Fort Chandi", in honor of a templefortress dedicated to the goddess Chandi located nearby.

The lack of Indian professionals with the ability to plan a new city made it necessary to call a Western professional. The first proposal, in the form of a fan based on the garden-city of Ebenezer Howard, was drawn by the American architects Matthew Nowicki and Albert Mayer but, after Nowicki's death in a plane crash, and given Mayer's resignation, the comission was given to the Swiss architect Le Corbusier.

Charles-Édouard Jeanneret-Gris (Le Corbusier) had not had the opportunity, despite the influential ideas on urban planning discussed mainly through the CIAM (International Congress of Modern Architecture), to develop on large-scale the architectural concepts already put into practice in various smaller projects. He did not hesitate to assume the role of "Spiritual Director" of the project and organized a team formed by his cousin Pierre Jeanneret, the English Maxwell Fry with his wife Jane Drew and a score of enthusiastic young Indian architects, to develop a new project and dismiss the one made by Mayer. Chandigarh was thus, the only urban project executed by Le Corbusier, in which he put all his efforts from 1951 until his death in 1965, generating a city of wide roads, gardens and parks, with a very different architectural value, away from the traditional intertwined labyrinth that the cities of the neighboring provinces had become.

\subsection{Territotial location}

Le Corbusier and Pierre Jeanneret took contact with the vast plain where Chandigarh would be located on February 23, 1951. The visual limit of the Siwalik mountain range to the northeast, the two tributaries of the Cho Sukhna river to the east and west, as well as a plain with a slight slope that descended towards the southwest and a wavy valley formed by the seasonal erosion of the monsoon rain in the 
plain, established the natural conditions by which the urban project should be allowed to be promoted. The capture of the distant limits that make up the backdrop of the Siwalik mountain range (or External Himalayas), the last of the mountain ranges located south of the Himalayan mountain range, generated a natural setting that allowed to restore the quiet territorially inherited monumentality. The regular and orthogonal plot of the plowed fields, with its spontaneous linear organization justified revising the wavy lines of Mayer's previous project for Chandigarh. About twenty years before he had given the solution to the urban problems of the American cities, after a systematic observation of all the variables. On February 23 Le Corbusier found, in the hollow that strategically crossed the agricultural plain and was oriented towards the mountains, the direct path to the new planning (Fig. 2), as it became the metaphorical axis of the new city: a linear park, crossed by winding roads and small forest areas that, following the course of the water, would link the city center with the Capitol complex. The moment in which the new capital establishes the natural conditions of the territory is when the grid of streets takes the territorial direction marked by this valley.

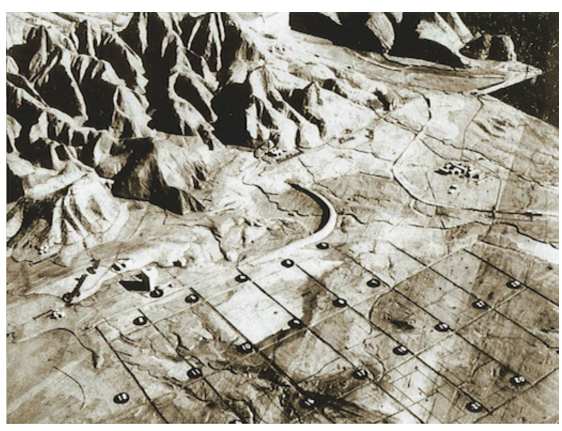

Figure 2. Model of Chandigarh (1951-65). (AV Monografías 2015)

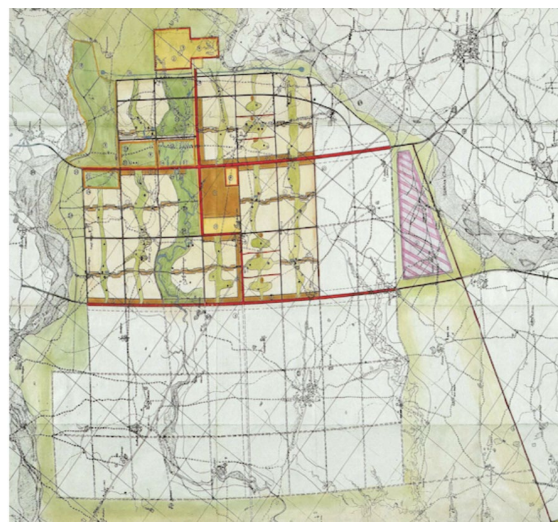

Figure 3. Urban plan of Chandigarh (AV Monografías 2015)

\subsection{Communication grid}

The response to the specific characteristics of the territory was an orthogonal grid unfolding on the plain, as previously the old roads that crossed the plowed fields had done. In this way the timeless country landscape merged with the urban design to offer a perfect combination between the awareness of the natural environment and the planning of the city.

The city of Chandigarh, with half a million inhabitants, is based on a geometry of a rectangular grid of streets called "Vs" that adapts to the topography of the land (Fig. 3). The basic unit of this orthogonal grid proposal is the "Sector", conceived as self-sufficient and introverted, subdivided into neighborhood units of around 150 families. Each sector, measuring $1200 \times 800 \mathrm{~m}$, is circumscribed by high-speed roads called $V 2$ if they go to special public services or $\mathrm{V} 3$ if they are high-speed avenues that cross the city. Crossed in turn, from east to west, a commercial street $\mathrm{V} 4$ connects to other adjacent sectors and leads to local facilities, and a V5 neighborhood road from north to south allows it to connect with domestic access roads $\mathrm{V} 6$, while pedestrian roads $\mathrm{V} 7$ and $V 8$ bikeways are linked to the fringes of parks and green areas. 
Le Corbusier's ability to capture the significance of the eastern heritage allowed him to discover the immense possibilities of historical documents such as the Mansara Shilpa Sastras, a set of old architectural treaties over 3,000 years old, to solve the question of the relationship between contemporary and historical urbanism. The unprejudiced gaze of a master of architecture is able to see with yearning eyes beyond the line where others already lack clarity. With that mixture of intuition and historical rigor he found a new way of relating to an ancestral culture, although also very different from the historical treatise that gave account of that culture. Regarding city planning the Mansara Shilpa Sastras talks about the division of the city into "sectors", the basic units that Le Corbusier reinterprets in the twentieth century, in which the fast roads will end up giving them a new meaning.

When a site is selected for constructing a village, town or building there on the ground is divided into different numbers of squares. Thirty-two kinds of such schemes are distinguished by as many different names according to the number of squares into which the whole area is partitioned out. The whole scheme has been arranged in such a manner that in each case the number of partitions, represents the square of the serial number. The eighth plot, for instance, which is called Chaudita, comprises a division into sixty-four squares, while by the ninth plot, which bears the technical name of Paramagadhika, the ground is divided into eighty-one squares. (Kumar Acharya, 1934, 3738)

As happens with travel drawings, historical treaty research and descriptions of trips to the East such as those of François Bernier to Hindustan and Kashmir, memory suddenly comes out of its long hibernation to participate in an architectural reflection. In the planning process of Chandigarh, "memories" took an active part and, in the countless meetings and information exchange that are always behind a project, Le Corbusier clearly made use of his abundant collection of resources.

\subsection{Chandigarh Capitol}

The capitol is located under the protection of the Siwalik Range (or Outer Himalayas), which is the last mountain range south of the Himalayas, so that, in the plain where the new city grid is built, the view adresses naturally to the north.

On February 24, $1951^{1}$ (Casciato, 2015), one day after he had his first contact with the plain where Chandigarh would be located, Le Corbusier had checked the suggestions of the territory, but he had not yet decided in which direction the grid of the new city should be positioned. The next day he crossed the mountains located to the north of the site and visited the garden of the Maharaja of Patiala, the garden of Pinjore (Fig. 4), and in the drawing that he makes we can first recognize these same mountains as a backdrop as well as a succession of horizontal planes at different levels arranged along an axis perpendicular to the mountain range. The timeless lesson of this garden allows him to connect the project of the city with the territory, since the main axis that provides the geometry to the garden coincides almost exactly with the direction of the axes of the new city of Chandigarh. Great Indian gardens were designed around a central axis that related them to landmarks in the landscape and to figures that stood out majestically over the geometric structure of gardens and terraces inherited from Mughal architecture. The Mughal civilization, which began in the early sixteenth century, provided refined spatial sequences of horizontal planes akin to eastern Indian expressiveness, and paths where volumetric figures were related through a unitary conception of the outdoor space. 


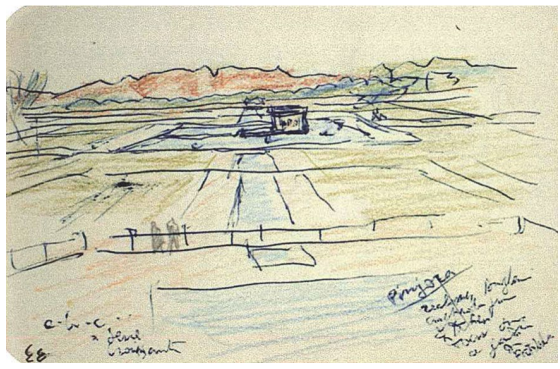

Figure 4. Sketch of Pinjore garden (1951)

(AV Monografías 2015)

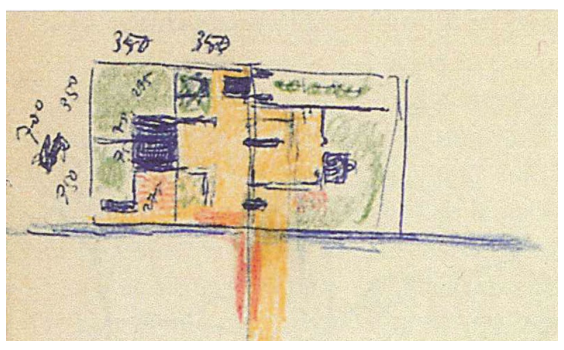

Figure 5. First sketches for the Capitol

(AV Monografías 2015)

Two days after contact with the plain and the inheritance of the Mughal tradition, on February 26 Le Corbusier drew the first traces of the Capitol of the city of Chandigarh (Fig. 5) arranging its buildings on a large horizontal plane in the classic way used for the design of the sacred and foundational precincts both by the East and the West. In this scheme it is clear the intention of not understanding the Capitol as a set of fractions, but as a unit in which the space that is found bounded amongst the three main buildings will be the central area of the enclosure. Thus he aligns the building of the courts (judiciary) on one side of the symbolic axis, while on the opposite side he gathers the Assembly (legislative power) and the Secretariat (executive power). The long void between the Palace of Justice and the Assembly creates the central motif of the enclosure, which is the weight of space in the absence of a building. This great vacuum sustained by the tension between the two representative buildings is projected towards the city through the wide landscaped axis that forms the backbone of the urban grid and which is located perpendicular to the mountain range to offer it to the distant vision of the passersby who are heading towards northwest or to the Capitol.

Arranged at the northern end on the edge of Lake Sukhna, the Capitol is located in sector 1 separated from the rest of the city by parks and highways. In this enclosure Le Corbusier accentuates the mass of concrete buildings by relating them to the distant landscape, but where he shows his deep vision is by arranging the buildings, not as a dispersed series of volumes seated on the plain, but as a set of volumes related by a refined spatial sequence of horizontal planes that reaffirm its unitary conception as a governmental center of a region. This characteristic sense of unity transmitted by the Capitol relates it to the spatial development of Fathpur Sikri (Hoag, 1976) (Fig. 6), a palace complex built $42 \mathrm{~km}$ from Agra in 1573 with a massive red brick that has nothing to do with Chandigarh tectonics, but whose spatial sequence of gardens, ponds and terraces at different levels create a unity that provides the awareness of the enclosure (Bottero, 1966).

The Assembly (Fig. 7) is made up of three elements: the base formed by seven openings bounded by eight concrete walls, the lintel that crowns the openings and that reproduces again the horizontal line on which the third element appears, which is the emergence of two related silhouettes by a small void, an issue that is not strange to Indian sensibility because Mughal architecture already incorporated elements of distant silhouette, such as the iwan, the towers and domes in the Taj Mahal. The advantage of working with elements that have a familiar morphology is that modernity can deal with them without violence. 


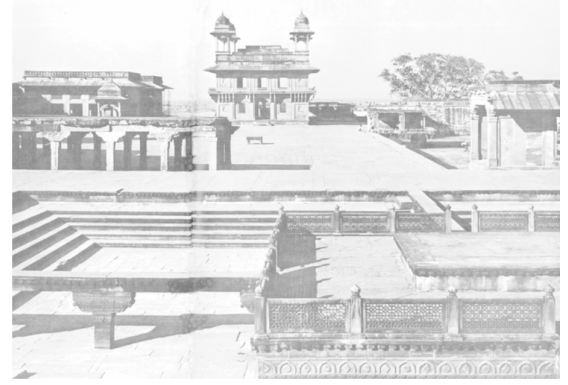

Figure 6. North view of Fathpur Sikri (Hoag, 1976)

In the Palace of Justice a similar decantation process occurs, since the first element that is perceived from the distance is the large roof that can be read supported by the transparency of the distant arcades, an architectural resource that is perceived by Le Corbusier as a defense against the heat through the shade and the breeze. However, in the short distance, this roof has been transformed, thanks to the geometric shape of the conoid, into a large horizontal line where, in addition, the location of the access has shifted to the left, renouncing to central symmetry (Fig. 8). The scale of this access reminds us of the iwan, the main access building of Mughal architecture, which is characterized by its axial position, the curved envelope of the arch, the depth of the opening and the generous height of three floors.

Le Corbusier uses those elements that are recognizable within Indian civilization, gives them dimension and depth, but displaces them in favor of a totally modern asymmetry. This condition of modernity also leads him to transform the upper openings visible as arches into a completely horizontal front or eave. In addition, just as the large horizontal roof unifies and gives modernity to the deep archway visible along the route to the building, also from a distance the brise soleil façade transforms into a fine openwork that filters the sun's rays as if it was a delicate filter or

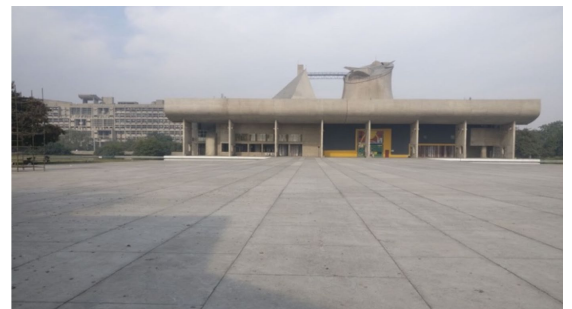

Figure 7. Front view of the Assembly and Secretariat

brocade. That is, the elements of architecture are already elements that were in India and are collected to form a modern language that is legible, accepted and emotional.

The two confronted buildings dialogue as autonomous figures arranged on the horizontal plane and envelop us in a first range of plastic experiences that is enriched as we walk through the governmental platform, as we find a complete and built system of horizontal planes at different levels that preserve spatial continuity. This visual link between the different planes produces unity and allows extreme flexibility in the organization of the internal elements that characterize the governmental complex, which are the Geometric Hill, the Martyrs Memorial, the Tower of Shadows and the Open Hand.

The sculpture of the Open Hand (Fig. 9) occupies a lateral place about 150 meters away from the main platform. It is a depressed enclosure with approximate dimensions $25 \times 40$ meters. In this level four meters below

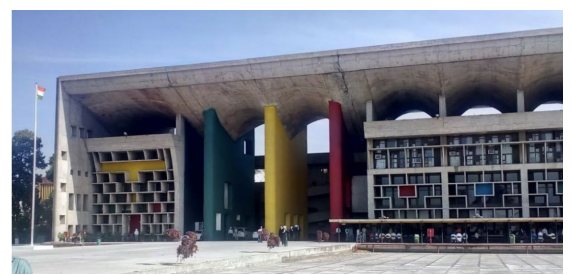

Figure 8. Palace of Justice. Main access. 
the main platform, the sculpture's silhouette emerges weightless up to 25 meters in height and, by spinning on its axis, it once again claims our attention on its formal autonomy. Le Corbusier pays special attention to the dependence on shade as a way to overcome the high temperatures that the climate imposes regularly for more than half a year. This reason leads him to elaborate the Tower of Shadows (Fig 10) as an open construction whose shape is subject to obtaining shade, ventilation and volume. This enigmatic piece interspersed in the path of the Capitol platform invites visitors with the promise of a certain freshness and its strong visual presence. Next to it are the stairs that lead to the lower plane where the Geometric Hill is positioned, whose inclined front paved with local stone is characterized by having the drawing of a wave or sinusoidal curve, mathematical truth and clairvoyant allegory of the current era, dominated for the rights on frequency bands. In front of the massive presence of the Hill is the Martyrs' Memorial, an elevation perceived as a gentle ramp that provides the highest point of view from the main platform.

These three pieces act in a choral way, constituting a landmark in the central and narrower area of the platform. But they are not only perceived as figures, but the limits that configure the enclosure where they are installed, as well as the horizontal planes to which they obey, form a sequence that complements the great paved extension of the main platform. This integration of the various planes allows us to think of the governmental complex as a Greek initiatory temenus that offers a unifying order to the different constructions and which, in addition, is accompanied by smooth sheets of water that duplicate the presence of architecture and produce a reverberation that contributes to the perception of the unique atmosphere of this founding place.

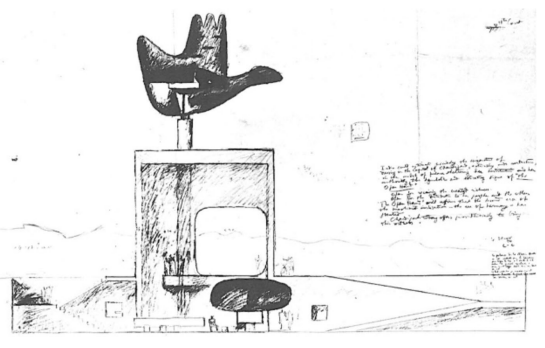

Figure 9. Sketch of the Open hand enclosure (AV Monografías 2015)

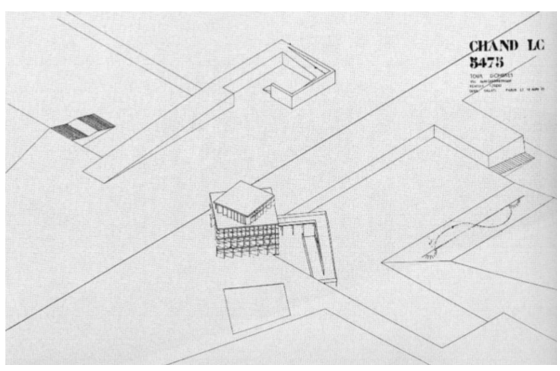

Figure 10. Axonometric of the Tower of Shadows Geometric hill and Martyrs' Memorial

\section{CONCLUSIONS}

The experience gathered by Le Corbusier regarding his reflections and drawings throughout his various journeys can be extrapolated to the historical investigation of the treatises and also to the descriptions of the travelers of the seventeenth century. In this sense, the memory hibernated for years emerges renewed to settle in the present and offer an updated interpretation of the limits between the natural environment and that manufactured by man. The hidden keys to the Capitoline precinct consist in recognizing the richness of the preceding civilization in a way that it is still readable by a population whose cultural roots are to be revitalized. 
Le Corbusier uses extension as an isotropic principle without directional property that finds in the enclosure the key to maintaining its unity and its apparent immensity. The spatial complexity of the Capitoline complex implies working with opposites such as axiality-asymmetry, vertical-horizontal, emptyfull, to be able to generate an identification with the place that is perceived distractedly when moving through the pedestrian bridges and paved surfaces, or when surrounding the artificial hill and water ponds or simply sharing on the platform of the Capitol an atmosphere that multiplies the value of the whole and makes it representative of our time.

The modernity of this work lies in accepting the site as an abstract operator that has its roots in the perceptual memory of every architect, and not in the tectonic imitation that leads to a shallow iconography. To understand the contributions of modern civilization it is necessary to recognize the codes of past times and to update their potential translating them with different means of production. By incorporating certain ancient architectural codes into a founding work like the Capitol Le Corbusier renewed their destiny in the Indian civilization.

Against the widespread belief that Le Corbusier is a mere inventor of forms, the appreciation of his great intellectual capacity must prevail as he was able to establish a link between the architecture of the past and contemporary architecture. In Chandigarh Le Corbusier produced a modern architecture conducting a multitude of dispersed voices that belonged to different fractions of a codified architectural material and he did so in a way that maintained a continuity with the territorial and cultural context of India. 


\section{REFERENCES}

Bernier, François. Viaje al Gran Mogol, Indostán y Cachemira. Espasa Calpe S.A. Madrid 1940

Bottero, Maria. Viaggio in India: da Le Corbusier a Kahn. In Zodiac No 16. Le Corbusier. July 1966, Milano, Edizione de Comunità. Pp. 120-136.

Casciato, Maristella. Chandigarh: el paisaje de una nueva capital. In AV Monografías. "Le Corbusier. An Atlas of Landscapes". 2015, N0176, Madrid, Arquitectura Viva SL. Pp. 86-93.

Hoag, John D. Arquitectura Islámica. Aguilar S.A. de ediciones. Madrid 1976. Pp. 371.

Kumar Acharya, Prasanna. Indian Architecture according to Manasara-Silpasastra, Oriental Books Reprint Corporation. New Delhi. Originally published by Oxford University Press, London 1934. Pp. 37-38

Martienssen, Rex D. La Idea de Espacio en la Arquitectura Griega. Ediciones Nueva Visión. Buenos Aires 1972.

Nitschke, Günter. Ma, El sentido japonés del lugar. Cuadernos Summa-nueva visión No 26/27. Japón una nueva perspectiva. Junio 1969, Buenos aires. Ediciones Nueva Visión SAIC. Pp. 14-15

\section{IMAGES}

Figures 1, 2, 3, 4, 5.- AV Monografías No176. Le Corbusier. An Atlas of Landscapes, Madrid 2015, Arquitectura Viva SL. Pp. 11. Pp. 15. Pp. 89. Pp. 93. Pp. 92.

Figure 6.- Hoag, John D. Arquitectura Islámica. Aguilar S.A. de ediciones. Madrid 1976. Pp 368-369.

Figures 7, 8. Google images.

Figures 9, 10 Le Corbusier Volume 8 des Euvres Completes, Les Dernieres Euvres, Zurich, Les Editions d Architecture Artemis, 1973, pp 67, pp 74. 

PAPER \#1.13

THE NEW CITIES OF THE THIRTEENTH CENTURY A NEW URBAN PARADIGM IN THE IBERIAN PENINSULA

\author{
Filipe Brandão do Carmo ${ }^{a}$
}

aLisbon School of Architecture, Universidade de Lisboa, Lisbon, Portugal

\section{ABSTRACT}

In the thirteenth century, in the wake of the Reconquista and the Hundred Years War, a need came to the reigning monarchs of the Iberian Peninsula and Southern France to consolidate newly conquered territory.

If the paradigm of the Iberian city is to be discussed, we must first trace its origin in history. When, in the thirteenth century, Alfonso $X$ of Castile is urged with the need of consolidating his territory, he produces a new code of laws: Las Siete Partidas, a true instrument for the creation of new cities, much like its successor the Law of the Indies would be for the new territories of America. This necessity to consolidate territory was shared with other monarchs including Afonso III of Portugal and his son (Alfonso $X$ grandson), Jaime I of Aragon and the Count of Toulouse and the English and French kings. Through this need several new cities came to existence in the region of the Iberian Peninsula and Southern France.

What was a need to expand claims of territory gave rise to a rethinking of the city and of its morphology. The new cities of the thirteenth century will bring forth a new urban paradigm, incorporating traditional street patterns but also establishing new urban elements.

The following paper will try to identify a common elements present in the Iberian city by the comparison and study of representative cities of the previously stated kingdoms. The underlying principles and urban morphologies of this period will set the tone not only for the continental cities but also for the new cities to be founded all over the world.

\section{KEYWORDS}

Iberoamerican history; city history; urban morphology; iberian cities.

\section{PRELIMINARIES}

\subsection{Historical Premises}

Following the occupation of the Iberian Peninsula by Moors in the eighth century, a military force of Asturians, having won a set of important battles led a military effort to reconquer the lost territory in what would become known as the Reconquista. If most of the peninsula was reconquered by the twelfth century, the progression was not steady and only in 1249 AD, for Portugal and $1492 \mathrm{AD}$ for Spain was all the territory free from Moorish dominion. Although the conquering progressed quickly for the first centuries, most of the land was inhabited and a need for the consolidation and setting of urban networks was necessary. The effort to establish new towns was noteworthy in the thirteenth century following the expansion of territory within frontiers.

Spain did not start as a unified country and was composed of several smaller reigns. The military conflict between these powers also potentiated the establishment of new cities that better symbolized the power and administrative capacity of the rulers. Portugal, Navarra, Castile, Aragon and the islands of Majorca and Menorca were all competing for a strong centralized control where their power would be unchallenged internally and externally. 
Near the northern border of the Peninsula, the kingdoms of England and France fought a dispute of territory that would lead to the progressive entrenchment in solid fortified cities on either side. This region also had a communitarian tendency avoidant of centralized powers. The phenomenon of free cities also led the ambitious rulers of this zone to repress several cities and the power that they started to amass. The Albigenses crusade was the epitome of this suppression, aided by the ever-centralizing power of the catholic church. After this incursion several cities were repopulated as others were built to increase the dominance of the ruling class. After the cessation of the Mediterranean commerce in mid tenth century, a new surge arises from the victories of the maritime nations over the Moorish kingdoms. The development of the economy arose with the increased trust of merchants that would incentivize the growth of the cities, adding to their already defensive function an economical one.

Alfonso $X$, the Wise, finishes in 1265 AD the gathering of laws that would be called "Las Siete Partidas". This book inspired greatly by roman law, was not only a repository of laws but a means to the administration of the land. Much like the modern regional urbanistic instruments, these set of laws also established a procedure to resolve the management of territory. Set in the same tone as the Fueros, a set of laws applied locally, the code set by Alfonso $X$ was more universal in its scope intending to encompass the whole kingdom under one centralized rule and law.

This set of laws established the precedent of centralized ordinances in what would become the state of Spain. In later years the Law of Indies established by Phillip II would resort to a similar will to institute a common law to the newfound lands.
A similar code of law, the Ordinacions is set by Jaime II, King of Majorca and Lord of Montpellier. More focused on the social economic development of the new cities conquered in the island of Majorca, this set of rules not only informed the urban fabric to be applied to existing or to be founded cities but set an ordinance instrument to the whole region.

All these codes of laws were not only a gathering of judicial procedures and laws to be enforced but, extending from the doctrinal scope, they were instruments of establishing power through the control of the land, boosting the dominance exerted by these rulers. Trade which was booming once again with the securing of land and sea, guaranteed the safe workings of the new merchants. Under the increasing power of the rulers, the relationship was two-directional benefiting both state and commerce.

Although most cities founded in the reign of Afonso III of Portugal (and later his son Dinis $^{1}$ ) were based on the instrument of the Foral (same logic as the Spanish Fuero), a similar desire to centralize the power of the ruler against an increasing power of the aristocracy resulted in the Inquisições Gerais in 1258, an instrument to restrict economic corruption and to restrain the aristocratic power, equalizing the difference between the rising bourgeois class and the military and religious classes. Several new cities only under the King, with no Lord, were established under more universal laws that would thwart the domination of the aristocracy and incentivize commerce and its respective class. Special laws were applied to the city - a walled precinct, this construction built only under the order of the monarch - which favored those living inside the walls. ${ }^{2}$

The influence of the French thinking on Afonso III is well documented as well,

\footnotetext{
1 The influence of Alfonso $X$ in the reign of Portugal was ever present. It should be noticed that Dinis was grandson of the Castille and Leon ruler by his mother, Beatriz de Castella. The influence of his grandfather can be noted on the continuation of his father policies of city founding and rigorous state control and management.

${ }^{2}$ Luísa Trindade, "Urbanismo na Composição de Portugal", 146
} 
his aunt being the mother of Alphonse of Poitiers. The future king of Portugal spent a vast time on the French court, coincident with the foundation of several Bastides.

On the theoretical realm, Eiximenis, a Catalan writer gathered in his Lo Crestià, specifically in his Dotzè del Crestià, the knowledge that the rulers needed for the good governance of kingdoms. Dealing with government and politics in general, a part of this work is dedicated to the correct arrangement of the City. The idea that the City was the physical representation of the Spiritual City was not new having the Franciscan writer drawn inspiration from Saint Augustine's City of God, where the concept of a heavenly city had already been exposed. Still the divulgation of his work throughout the Iberian courts was decisive in the emergence of a new urban spirit.

One of the objectives of this theorization was also a religious one: the new urban landscape, now conquered back to Christianity needed to be set apart from the Islamic one. The Christian city needed to conform to rules prescribed by a Christian god, explained through ideal precepts, and imposed by Christian kings. Thusly, the new cities, based on Christian ideals, would not only inaugurate a new city, fully Christian, but also assert a new type of king with a power ever more centralized.

\subsection{Methodology and Objectives}

The adopted method for the following analysis is based on the morphological study of cities, in what concerns to its form. Through the urban design manifest in the city form, we will identify the main elements of the city, namely its buildings, axis and limit, and the relation existent between them. This analysis will enable the cross analysis of all cities proposed for this study, considered to represent the different urban universes in the Iberian Peninsula. We consider this analysis, that clears all other social aspects and restricts the analysis to the urban form, the only way to compare different cities, albeit a possible simplification.

The analysis will be limited to the following aspects: date of foundation - being that in some cities the date is either not set or the date given corresponds to a time in which the urban intervention was more conspicuous; Limit - divided into three types, the Limit is the physical ending of the City in the form of a wall or fence, or even the last road of the City; Axis - corresponding to the main streets linked to the main points of access to the city, which in turn connect to other cities; Top of Axis - stemming from the previous one, this element evinces the most important function of the given city; Main Square - the function assigned to the main square of the city is also indicative of the main concern in the foundation of the city; Blocks - the gathering of the masses of buildings, in this case we considered all the space that was not public, allowing for the identification of the morphological devices. The different plans have represented the Limit represented in dashed lines, the main axis in black lines, the blocks shaded in gray and the churches in yellow. The plans are oriented to North and are not represented in scale as this is not a factor for our analysis.

From this analysis we have as an objective to identify similar morphological elements and configurations, and to understand which ones prevail most and which will prevail for the following centuries in the kingdoms of Portugal and Spain. Thusly we will propose the main configurations and morphological devices in use when founding new settlements in the ending of the thirteenth century and beginning of fourteenth century in the Iberian Peninsula. For this we have chosen two groups of cities: defensive cities established along the border - the cases of Portugal are spread from North to South and in Spain, the region of Navarre gave two examples that are important not only for their function as defensive bastions but 
also as entrepôts on the Santiago pilgrimage; and cities for the consolidation of the territory - with an interior and continental example and one insular example, showing how the logic applied is very similar in very different circumstances. Finally, the French Bastides will have a mentioning due to their importance as a model for defensive cities. Although small in number the examples here offered give a wide but discrete overview of what was a city in the thirteenth century and fourteenth century.

\section{CASE STUDIES}

\subsection{Portugal}

Of the three cities under analysis - Arronches, Monsaraz and Chaves - certain elements are common. The main street defined by a central axis is common between all. This axis connects the main gate and the castle for quick access to the defensive system of the city. This castle located in one extreme of the city was a defensive necessity and so is present in all cities

In Chaves is present a morphological pattern of "espinha-de-peixe" (fish bone) ${ }^{3}$, that is, a main street crossed perpendicularly by less important roads, constituting thin elongated blocks.

In Monsaraz the axis is broken right in the beginning- This axis has adjacent to it the main square of the church, main gathering place of this city. The regular form of this square hints to a more geometrical urban planning.

In Arronches, a double axis leads from the main gate to the castle as well from the church to the castle. The blocks further to the North are part of an extension of the city. Although not strictly geometrical, these new blocks obey a rectangular outline and parallel streets, constituting an innovative urban design, that complemented the long blocks already existing in the city.

In all three cities the main streets finish in the castle. In the length of this main street, it is always present a church with an open space linked to it. In smaller or larger dimensions this space is the essence of all these cities.

The blocks are constituted by thin and long plots with short façades, creating a morphological device stretched and elongated, not favoring crossings and the division of blocks.
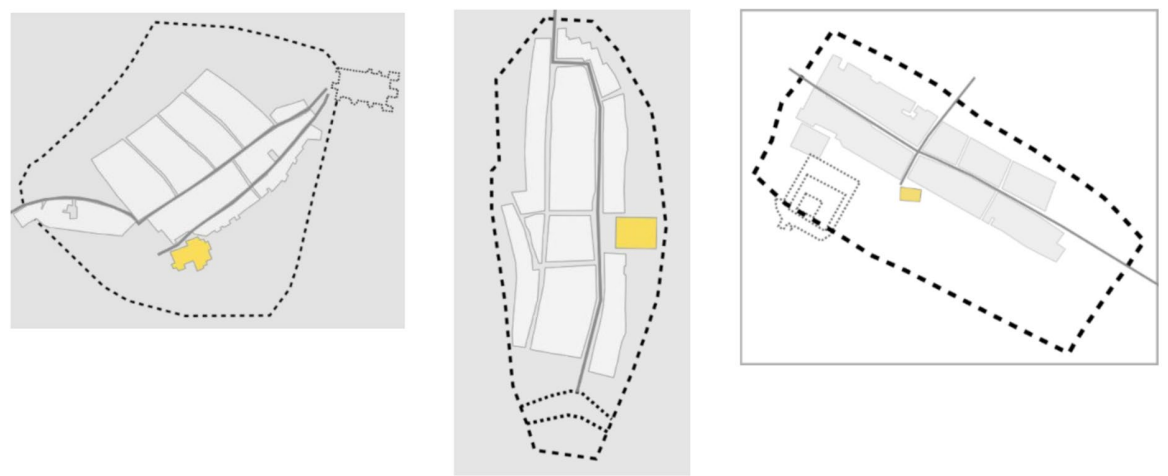

Figure 1. From left to right: Arronches, Monsaraz and Chaves.

${ }^{3}$ This pattern is quite recurrent in the Portuguese city normally appearing in association with a street called Rua Direita (Straight Street). Examples of this urban organization can be later seen in XV century Lisbon in several new interventions on the urban fabric. 


\subsection{Spain - Basque region}

The origin of the two cities analyzed is different, being Huarte-Araquil a defensive city, planned to fortify the frontier and establishing a presence near the border; and Sanguesa a pilgrimage city.

Still the presence of a main axis crossing the city is common to both cities. In the case of Huarte-Araquil and Sanguesa this street crosses the whole city, being the main square or main buildings adjacent to it.

In Sanguesa the phenomenon identified in Chaves, "espinha-de-peixe" is evident again with long elongated blocks perpendicular to the main street.
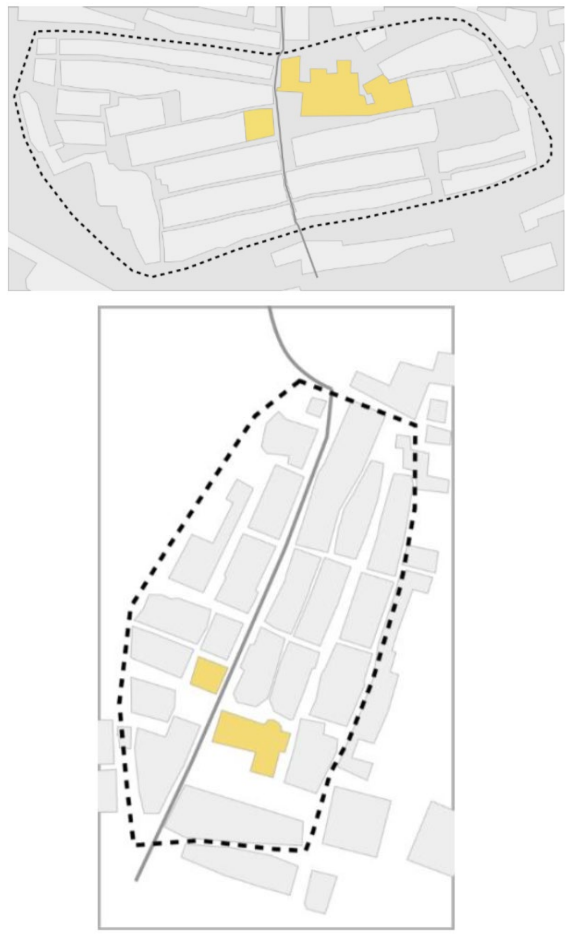

Figure 2. From left to right: Sanguesa and HuarteAraquil.
In Huarte-Araquil the blocks align with the main axis and are parallel to it. As in Arronches a second street runs parallel to the main street finishing in the church.

The limit of both cities is irregular adapting to the terrain, a common feature in the cities established in the mountainous region of the Basque region. Common to both cities is the presence of a small yard next to the church. This yard is, in both cases, the main square of the city. Thus, it is possible to notice the strong connection between State and Church in the urban fabric of both cities.

\subsection{Spain - Castile}

Even though these cities are situated in a different kingdom - Castile - the same morphological patterns are manifest. The two cities in study - Briviesca and Foncea - as was the case with Sanguesa were set along the pilgrimage path of Santiago, explaining the motion of influence between the two kingdoms.

The Laws of Las Siete Partidas are clearly manifest in the design of both cities shown - Briviesca and Foncea - as they dictated a single road crossing the whole city in elongated cities. ${ }^{4}$

In Briviesca, a main axis runs adjacent to a main square. The church with its own yard, does not share the center of the city, being located near a gate.

The urban fabric is divided this time in a grid accusing more and more the pattern of the grid imposed in later years in the American possessions. The blocks, rectangular still (with some in square form), are not as long in this case being cut through in more occasions by perpendicular streets

In Foncea, the model is much closer to the previously analyzed cities, exhibiting elongated blocks. The urban fabric is much denser and the phenomenon of "espinha-depeixe" is once again present. 

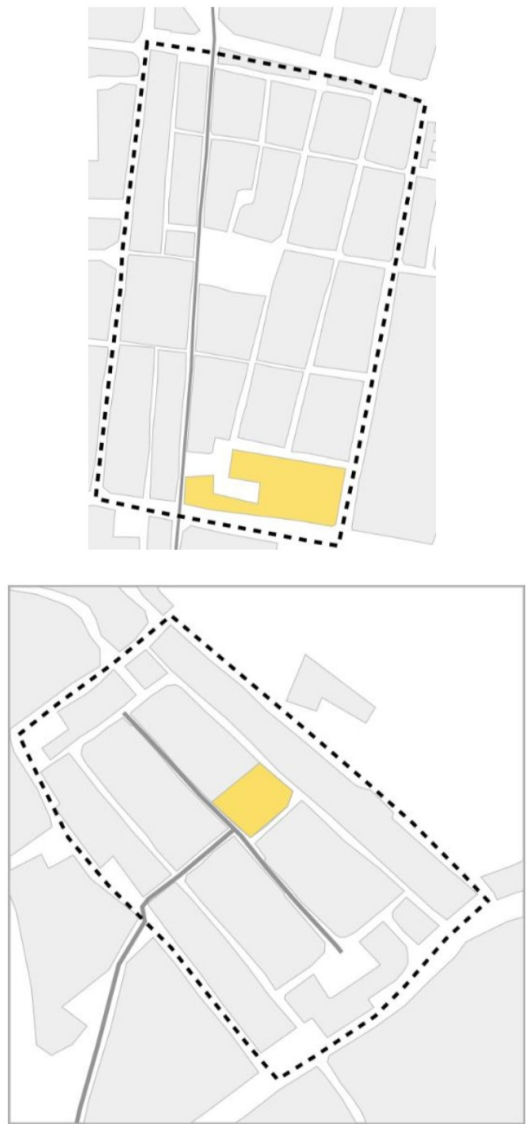

Figure 3. From up to down: Briviesca and Foncea.

Only the main street holds a significant difference, since it gets cut by a perpendicular street, having the church at its end.

It is evident as in the thirteenth and beginnings of the fourteenth century the models are still diverging, being adopted different configurations for the cities to be founded.

\subsection{Spain - Majorca}

In a truly urbanistic fashion Jaime II of Mallorca regulated the territory of Maiorca, trough the Laws known as Ordinacions. After the peace made with his brother from Aragon, it was possible to establish the administration of the land inherited from his father. The establishment of zones to be served, the maximum of population by city, including concepts of self-sustainment and dynamics between industrial and commercial sectors were all applied by this monarch. ${ }^{5}$

Although the influence of the Bastides is clearly established ${ }^{6}$, the pueblas of Mallorca were created to populate the islands and not for military purposes as the former. As such both cities were not walled. The influence of Las Siete Partidas is still observed as it established that in square cities two or more main streets should be built parallel and perpendicular to each other. ${ }^{7}$

In the case of Petra this relation exists, with a main axis being crossed by two others. In Sa Pobla there are two main streets, the one further south already existing before the implementation of the new city. A new axis parallel to this one is completely established with the expansion of the city to North.

Different from the Bastide's model is the removal of the Church from the main square reserved for secular purposes.

The urban model of Jaime II established square blocks in groups of 16 or 25 blocks. Surrounding these central blocks, rectangular blocks were set around them adjacent to the city perimeter. If in Petra the model was strictly followed, the pre-existing buildings in Sa Pobla forced the adaptation of the model. Still the northern half of the city still exhibits an adherence to the model.

\footnotetext{
${ }^{5}$ Alomar, Gabriel. Urbanismo Regional en la Edad Media: las «Ordinacions» de Jaime II (1300) en el Reino de Mallorca. Barcelona: Gustavo Gili, 1976... p. 52

6 The geographical proximity of Montpeller, a city in the dominion of Jaime II, to Aigues Mortes is a very strong indicator of the influence of the Bastide's design in Jaime II. Goitia, Fernando Chueca. Breve História do Urbanismo. Translated by Emílio Campos Lima. Lisboa: Editorial Presença, 1996. Alomar, Gabriel. Urbanismo Regional en la Edad Media: las «Ordinacions» de Jaime II (1300) en el Reino de Mallorca. Barcelona: Gustavo Gili, 1976. p. 56.

${ }^{7}$ Alomar, Gabriel. Urbanismo Regional en la Edad Media: las «Ordinacions» de Jaime Il (1300) en el Reino de Mallorca. Barcelona: Gustavo Gili, 1976. p. 60.
} 

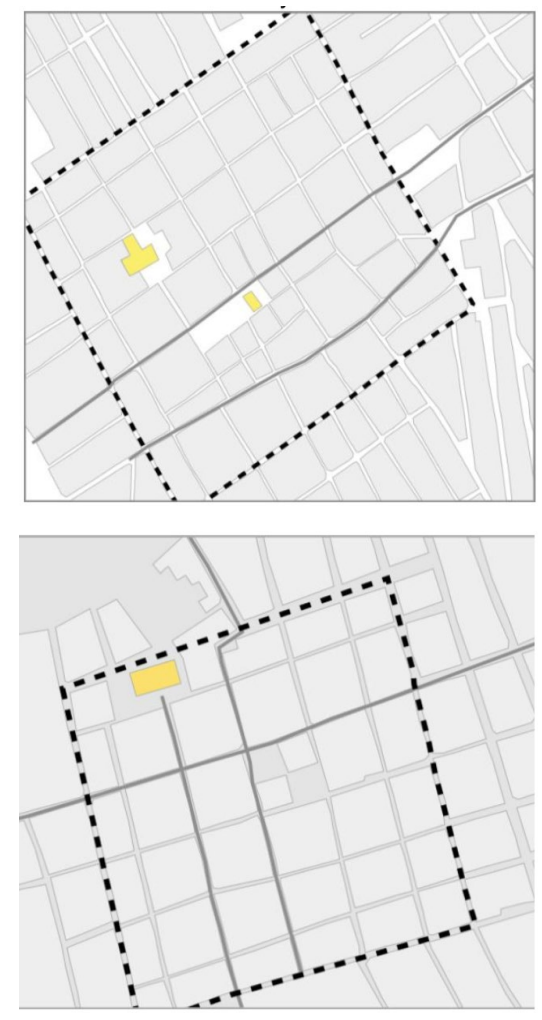

Figure 4. From up to down: Sa Pobla and Petra.

\subsection{Bastides}

Being much larger than similar fortified cities in the Iberian Peninsula, the Bastides - from the verb bastir, to build - these walled precincts were the main urban model for the South of France. In this region war between France and England potentiated the emergence of these walled cities. The symbolic representation of the power of the ruler dictated a strictly geometric shape of the walls, that is the limit, of some bastides.
In analysis we have two cases: Aigues-Mortes, founded in 1240 and Mirande in $1282 .{ }^{\circ}$ Founded both with defensive walls the differences in the street configuration are notable. While the blocks in Mirande are square and a regular square is present, the two main axis form a cross. As in the case of Petra, the church of Mirande is not adjacent to the main city square, serving this space for secular functions.

Aigues-Mortes on the other hand has perfect geometric design regarding its walls, but the blocks are rectangular and elongated. The two mains axis of this city run parallel to each other and a main square is also present. The church in Aigues-Mortes is established on the main square and forms the main spot of one of the city's axis.
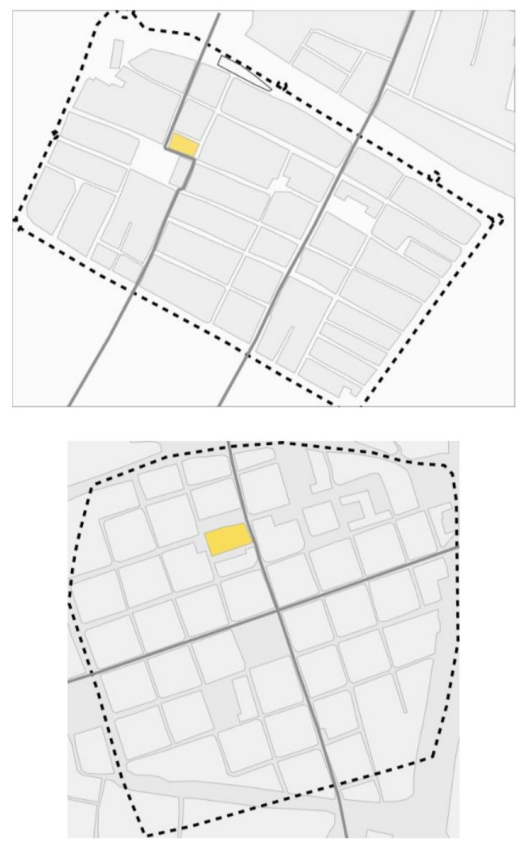

Figure 5. From up to down: Aigues-Mortes and Mirande. 
The Bastides, although not always applying it, are based on a grid design. The walls normally follow a rectangular form and a central square is always present. This new design is very characteristic and would influence decisively the urban model to be applied by Spain in its colonies in America being the Law of Indies the culmination of this influence. ${ }^{9}$

Still, as is the case of all the previous cities, the main squares of both cities are adjacent to one of the main axis, being this a characteristic common to all the cities in study.

\section{CONCLUSIONS}

The cities analyzed previously all share one influence: Las Siete Partidas. This set of laws, almost a treaty of urbanism, through several ways found its way to the several kingdoms and leaders of the Iberian Peninsula. The Roman influence is also present in all cities ranging its influence from previous settlements in which the new cities were rebuilt upon, to the influence in theoretical urban design as is the case for the Bastides. These, along with the treaty of Eiximenis, were also the main influence for the cities founded by Jaime II in Mallorca.

As for the main conclusions to be taken from the previous analysis and to what refers to the Limit, the main factor of differentiation seems to be the terrain. Cities with a more elongated pattern are present in mountainous regions, like Sanguesa, Huarte-Araquil and Monsaraz, resting on the ridges. Flat regions allow for more geometrical limits, still considering that there are variations such as Arronches and Mirande. The main axes vary according to terrain and shape of the limit. The more mountainous regions again are constricted by the availability of space and thus have only one main axis. The other factor is the direct influence of Las Siete Partidas and its article that defined that in square cities the axes should cross perpendicular and in rectangular cities the axes if more than one should be in the same direction. The Bastides not sharing this influence do not have a clear alignment for its axes.

\begin{tabular}{|c|c|c|c|c|c|c|c|}
\hline City & $\begin{array}{l}\text { Date of } \\
\text { Foundation }\end{array}$ & Limit & Axis & $\begin{array}{l}\text { Top of } \\
\text { Axis }\end{array}$ & $\begin{array}{l}\text { Main } \\
\text { Square }\end{array}$ & $\begin{array}{l}\text { Church } \\
\text { Yard }\end{array}$ & Blocks \\
\hline Arronches & $\begin{array}{l}1235 \\
\text { (reconquered) }\end{array}$ & Irregular & $\begin{array}{l}2 \\
\text { (parallel) }\end{array}$ & Castle & Religious & $x$ & Elongated \\
\hline Monsaraz & 1276 (foral) & Elongated & 1 & Castle & Religious & $\mathrm{x}$ & Elongated \\
\hline Chaves & $\begin{array}{l}1258 \\
\text { (repopulated) }\end{array}$ & Rectangular & 2 (Cross) & $\begin{array}{l}\text { Castle/ } \\
\text { Church }\end{array}$ & Religious & $x$ & $\begin{array}{l}\text { Espinha-de- } \\
\text { Peixe }\end{array}$ \\
\hline Huarte-Araquil & XIV century & Elongated & 1 & - & Religious & $\mathrm{x}$ & Elongated \\
\hline Sanguesa & - & Elongated & 1 & - & Religious & $x$ & Elongated \\
\hline Briviesca & 1305 & Rectangular & 1 & - & Secular & $\mathrm{x}$ & Rectangular \\
\hline Foncea & - & Rectangular & 2 (Cross) & Church & - & $x$ & $\begin{array}{l}\text { Espinha-de- } \\
\text { Peixe }\end{array}$ \\
\hline Sa Pobla & 1300 & Square & $\begin{array}{l}2 \\
\text { (Parallel) }\end{array}$ & - & Secular & $\mathrm{x}$ & Square \\
\hline Petra & 1300 & Square & 3 (Cross) & - & Secular & $\mathrm{x}$ & Square \\
\hline Aigues-Mortes & 1240 & Rectangular & $\begin{array}{l}2 \\
\text { (Parallel) }\end{array}$ & Church & Religious & $x$ & Rectangular \\
\hline Mirande & 1282 & Irregular & 2 (Cross) & - & Secular & $\mathrm{x}$ & Square \\
\hline
\end{tabular}

Table 1. Comparison of the analyzed cities.

${ }^{9}$ Goff, Jaques Le. La Ville Mediévale: des Carolingiens à la Renaissance. In Histoire de la France urbaine. edited by George Duby. Vol.2. Paris: Éditions du Seuil, 1980. p. 196. 
A common feature (we believe of every European Christian city) of all the analyzed cities is the yard adjacent to the church, in several cases being later expanded to form the city square. In tight urban fabrics, like Foncea, the yard was the only opening of a dense city. The main square might not always be adjacent to the church serving other functions in some of the cases studied. The more religious cities had the church in the main square such as Sanguesa, Huarte Araquil and the Portuguese cities. The Bastides vary too much, having, some, a more religious function such as Aigues-Mortes contrasting with Mirande and its commercial and administrative square. The top of the axis in more religious cities has the church present, being that in cities for defensive functions such as Monsaraz and Arronches the Castle occupies this place.

The main square is not always a presence in the Spanish cities, making its regular appearance with the cities of Jaime II. The Portuguese cities on the other hand already displayed squares and, in some cases, as in Monsaraz, the square is regular, albeit not being formed by the suppression of a block. Thus, we cannot consider that the square is an obligatory, much less characteristic, element of either Portuguese or Spanish cities.

It is curious to note that the Portuguese will, in the fifteenth century, continue the configuration of espinha- de-peixe in the expansions done to several cities and a common model for the foundation of cities in their colonies. Still the grid and blocks closer to the quadrangular proportion will be present. Perpendicular intersections of two main axis are as well present, even regular squares.

As for the Spanish, even though the elongated blocks will still be in use, the grid experimented firstly in the Bastides and in Majorca and Menorca by Jaime II, will be the prevalent model being widely applied. The main square of the size of a block will also be commonly present in the Spanish-American cities. There is an evolution from the elongated less planned block to a rectangular and then to square ones, the ones to be mainly used. Still we consider that the elongated block will still be observed in the Americas. From this analysis we put forth the hypothesis that the model devised by Jaime II would be the main influence of the plans for Americas in Spanish settlements. In the case of the Portuguese, the models even if not so strictly, would still be regular, but incorporating such devices as the Espinha-de-peixe.

What we propose is that both models and the different configurations have, since the foundation of the modern states of Portugal and Spain, been present in both states and are applied through its urban history. The ignorance, purposeful or not, of this fact leads to erroneous readings of the cities, their foundation and development, leading to a poor intervention in historic cities. 


\section{REFERENCES}

Alomar, Gabriel. Urbanismo Regional en la Edad Media: las «Ordinacions» de Jaime II (1300) en el Reino de Mallorca. Barcelona: Gustavo Gili, 1976.

Carita, Hélder. Lisboa Manuelina e a formação de modelos urbanísticos da Época Moderna (1495-1521).

Lisboa: Livros Horizonte, 1999.

Goff, Jaques Le. La Ville Mediévale: des Carolingiens à la Renaissance. In Histoire de la France urbaine. edited by George Duby. Vol.2. Paris: Éditions du Seuil, 1980. Goitia, Fernando Chueca. Breve História do Urbanismo. Translated by Emílio Campos Lima. Lisboa: Editorial Presença, 1996.

Trindade, Luísa. "Urbanismo na Composição de Portugal". PhD diss., Coimbra University, 2009. 


\title{
PAPER \#1.14
}

\section{THE PERFORMANCE OF GENDER AND ETHNIC IDENTITY IN THE DIASPORA MOSQUE}

\author{
Irem Oza, Alexandra Stauba
}

aThe Pennsylvania State University, University Park, Pennsylvania, USA

\section{ABSTRACT}

Judith Butler uses performativity to investigate the unconscious, unintentional and situational performances of gender through discourse. I argue that the built environment as a part of this discourse has the ability to transform and (re)produce identities. I focus on the diaspora mosque as the performative unit where ethnoreligious identity is performed as an everyday, embodied practice.

Using a feminist lens to analyze how gender, religion and space intersect, I examine the Marxloh Merkez Mosque in Duisburg, Germany as a cultural case study. Informed by ethnographic fieldwork conducted over a period of nine months, I analyze how the performative character of the Marxloh mosque has come to shape TurkishMuslim women's gender relations through separation and surveillance and question how relations translate to the greater sphere of neighborhood space, influencing TurkishMuslim women's sense of identity and integration into current-day Germany.

Using Butler's performativity both as a theoretical lens and part of my methodology, I examine how gender relations are inscribed in the mosque space through processes of repetition and reiteration. Drawing from my interviews from 24 women that use the mosque regularly and are residents of the neighborhood, I argue that the normative standards in terms of gender relations are performed through acts of separation and surveillance. The discourse created in and around the mosque, which focuses on the reproduction of Turkish-Muslim identities and poses Turkish-Muslim women as the moral subjects.

\section{KEYWORDS}

Gender; performativity; space; mosque; diaspora.

\section{INTRODUCTION}

Turkish women in Germany are a group that holds particular place in public discourse and imagination of the 'others'. The topic TurkishMuslim women is one of the main subjects that is used to create difference and justify the disparity between a German collectivity and the Turkish other. This can be seen from the number of social studies research on Turkish-Muslim women that far exceeds the number of studies on other immigrant nationalities (Lutz and Huth-Hildebrand 1998), transforming the debate on foreign women into a debate on Turkish-Muslim women. While mainstream research tends to cast the existence of Turkish-Muslim women as the main reason of their problematic integration (Raetzhel 1994), it also fails to consider the point of view of the women they categorize. The agency of Turkish-Muslim women is usually neglected by posing them vis-à-vis of German women and framing them as an oppressed group in a patriarchal setting - a group without a voice.

My motivation in this study was to understand the process of integration (or lack thereof) and the how it relates to the reproduction of gender from the perspective of TurkishMuslim women. An approach that uses Butler's framework to examine gender and how it manifests individually and collectively is useful when researching women's experiences in largely patriarchal settings. An 
appropriation of Butler's theory emphasizing the mosque in a diaspora setting allows for a dual examination of the performativity of female congregants of the mosque in terms of rules and norms defined by the dominant culture and gender conceptions that in turns shape the behavior and interaction of TurkishGerman women.

This article begins with the introduction of the concept of performativity and explores the possibilities of its use within a spatial framework. In this research, Butler's performativity was used both as a theoretical lens and a tool for analysis. Addressing space as a part of the performative discourse allows me to analyze how spatial performances that take place in the architectural space of the mosque create gendered norms play out in the neighborhood by navigating between different scales. Using ethnographic interviews and participant observation, I analyze how performative acts of separation and surveillance are experienced by TurkishMuslim women living in Marxloh and their accounts of resistance against those acts within the architectural space of the diaspora mosque and how does this translate to their performances of gender and identity in the neighborhood space.

\section{THEORETCAL FRAMEWORK}

\subsection{Performativity}

The term performativity has come a long way since J.L. Austin coined the term in the 1950s. Austin conceptualized the term in the field of linguistics to refer to the multiple functions of the spoken language. According to him, spoken language, is not only used to describe the world outside but it is in fact an active agent that shapes and transforms the world (Snickare 2012). He uses formal and ritual utterances as examples, such as 'I name the ship the Queen Elizabeth' or an everyday phrase like 'I bet you sixpence it will rain tomorrow'. However, he also emphasizes that the performativity of an utterance still highly depends on the context of the utterance. He illustrates this with the example of a judge, who is only able to utter performative speech in specific contexts and attire - the judge's bench and robe (Austin 1962). In other words, an utterance must be said under the right circumstances, by the right speakers with the right intentions would be able to transform the circumstance. Miller builds upon this and suggests that for the successful outcome of performative acts, the gestures, movements, dresses, precious objects and the architectural setting are essential (2001).

With the performative turn, the concept has moved away from the field of linguistics and has been taken up and developed further within the fields of deconstruction, aesthetic theory and gender theory (Burke 2005). Jacques Derrida builds upon the concept to include all kinds of language and cultural phenomena, from scholarly writing to utterance itself (1982). He also explains the relative relationship between the effect and the intention: an utterance which is performative produces meaning and continues to produce new meaning, even after the 'death of the author. In the 1990s, the concept became firmly established within the humanities with the writings of Judith Butler. She uses the concept to illustrate through repeated acts and gestures within specific cultural contexts, (gender) identities are produced and inscribed (Snickare 2012).

Butler argued that gender is not internal but in fact, a continuous, unstable and socially constructed process, which is enforced through a series of repetitive and performative acts. Performativity, simply, is the formation of the subjects, which creates what it tries to describe/categorize through embodied social practices (Cavanaugh 2015). For Butler, the 'script' of gender performance is passed on from generation to generation through socially established meanings. As humans are social beings, most actions are witnessed, 
reproduced and internalized, eventually taking on a performative quality (1988). In the acts of convention through repetition, we end up making them 'real' to some extent - the enactment of gender norms has real consequences. Gender is instituted through the stylization of body; the enactment of the gender norms in the most mundane ways (our gestures, movements, the way we dress, with whom we socialize, how we talk, etc.) are accumulated, eventually becoming the normative standards and through their continuous repetition they maintain power and hegemony. According to her, as those actions become internalized, the concept of gender (binary) is legitimized and eventually is seen as natural (Butler 1993).

Following these discussions, if gender is instituted through internal acts, the appearances of the subjects are nothing more than their constructed identities performative accomplishments which are accepted by the mundane social audience and even by the subjects themselves. If the gender identity is grounded on these stylized repetition of acts, this also brings the possibility of a different sort of repeating that breaks or troubles the established style (1988). These nonnormative performances are punished along with the identities that do not conform into the normative standards (heteronormativity in Butler's conceptual framework). On the other hand, these alternative performative acts bring the possibility of resistance against the normative standards as they do not have any claim to justice and are historical and rely on their continuous citation and repetition by subjects to preserve their status-quo (Butler 1990).

Butler anticipated the application of these concepts outside of reach of gender identity and their redeployment in "urgent and expanding political purposes" (1993, 228). Feldman discusses that Butler's explanation of gender being the "reiterative power of discourse to produce the phenomena that it regulates and constraints" $(1993,2)$ can also be used to analyze different power relations. He argues that essentialized subjects - nation, state, immigrant, minority, man, woman, etc. - is socially constructed through repetitive acts and by means of opposing positions in reference to each other. The viability of one identity requires the inscription of threat in its putative opposite. The narrative around the identity of Turkish women living in Germany can be given as an example of this opposing claims. Performativity then, does not only mean the construction of subjects through social practices, but rather it is about the construction of separation and boundaries between subjects through discursivelyregulated practices (2005).

\subsection{Performativity and space}

But how does space operate in Butler's work? Butler uses a spatial rhetoric to describe how a subject is materialized and that the discourse has material effects in terms of boundaries and enclosures. Her argument is based on Foucault's model, where our actions and bodies are measured against the norms of architectural space but space is not articulated in her theorization of performativity. Smitheram argues that space is already inherent in Butler's theorization and proposes a "spatialized performativity" that it would expand the language and scope of performativity. Following Foucault's model, he frames the spatialized performativity as the "reiteration of pre-existing bodily norms that function to form the subject, which occurs in relation to architecture". His model suggests that when subjectivity is tied to the spatial axis, it in turn generates further performative utterances (2011, 59-60).

The concept of performativity has become a part of the vocabulary of architecture to explore the relationship between subjectivity and space/architecture; how space/ architecture participates in the construction of norms through performativity (Smitheram 2011). Mark Wigley argues that women 
are contained within architecture by a law that positions women in the emotional and personalized space of the home rather than the structured and impersonalized public sphere (1992). This act of positioning feminine within the home is inscribed through the citation of the law, where space is used to secure one's gender and the norms of space. Kuhlmann illustrates this with Adolf Loos's designs for his own house, in which it is easy to see which spaces are designed for men and women. While his wife's room was provided with a very light wool rug, in the libraries - or the 'gentlemen's rooms' - he used a lot of dark colors and hard material (2013).

Lisa Henry Benham draws from Butler's notion and suggests that "the enacting of identities/ spaces in fact brings those identities/spaces into being, rather than expressing some predetermined essence" $(2003,91)$. In other words, gender and space are realized through their enactment, through the materialization of the body and space. She also mentions the repetition of these enactments consolidate the regulatory frames and norms that emphasize the social standing of different groups and establishing their identities (2003). Kuhlmann identifies two models of regulatory frames that form most prevalent and effective methods: separation and surveillance. While spatial separation of individuals and groups can be used to disrupt and prevent communication or any contact, surveillance - especially visual surveillance - can be used to control and change power relationships between individuals. With such strategies, architecture is used as a tool to create physical spaces that enforce social distinctions between the sexes, races, classes, etc. (2013).

Drawing from this argument, I argue that the diaspora mosque within the context of Marxloh, not only becomes the stage of the performance but also acts as an active agent during the performative acts. Gendered sociospatial processes that repeatedly take place in architectural space of diaspora mosque define a set of norms and standards for the mosque going Turkish-Muslim women within the context of Marxloh. These norms define both the group and gender identities and present a set of rules to be performed for the mentioned identities in order to belong to the group. I theorize that these norms and standards that are defined in relation to the diaspora mosque translate to the greater sphere of the neighborhood and in turn have an effect on the integration of the TurkishMuslim women living in Marxloh. In this paper, I examine how separation and surveillance are enacted and resisted in the mosque and in turn how they affect women's behavior in the neighborhood context.

\section{CASE STUDY AND METHODOLOGY}

This research takes the case of Turkish commissioned mosques in Marxloh, a northern neighborhood in the city of Duisburg. While Marxloh, with its high percentage of ethnic Turks, stands as an excellent example of an ethnic enclave, the area is also unique in that it hosts three mosques (one of which is the first and the largest purpose-built Turkish mosque in Germany) belonging to the three major Turkish-Islamic organizations. Another unique characteristic of the neighborhood is the fact that it hosts Marxloh Merkez Mosque, commissioned by DITIB organization, which is usually referred as "the miracle of Marxloh" due to the lack of controversies at the time of its construction and opening ( $\mathrm{Oz}$ and Staub 2018). Although the DITIB religious association has active in the area since its establishment in 1984, using a make-shift prayer area found within an unused cafeteria space, they became much more visible with the construction and opening of the purpose-built mosque in 2008 (Oz and Staub 2019). My research focuses on this Marxloh Merkez Mosque and examines how mosque spaces in non-Islamic contexts contributes to the reproduction of Turkish-Muslim group identities and how Turkish-German women 
interact with and appropriate this maledominated space of the diaspora mosque.

As this study is concerned with an immigrant community which is socially and spatially segregated from the rest of the city and shaped around the religious field as a mechanism of negotiating identity and gender, I use a qualitative research design to access to the individuals' constructed reality and interpretation of their own experience. Interviews and participant observation are the major sources of data in this project and were conducted during an ethnographic fieldwork, over a 9-month period between October 2018 and June 2019. During this time, I lived in Marxloh and was able to both fully participate in the neighborhood life as a resident and became a member of the mosque congregation. The 24 interviews that were conducted with the Turkish-Muslim women that are among the congregants of the Marxloh Merkez Mosque, had a very biographical, narrative nature and were conducted in Turkish. The interviewees were also asked to draw sketches of their mental maps of the neighborhood and other spaces that they frequently visit. The interviews were supplemented by go-along outings and expert interviews with local administrations and representatives of the social service providers.

\section{DISCUSSION OF THE RESULTS}

\subsection{Separation}

Foucault provided a theoretical assumption that each society is based on exclusion and spatial practices are used to marginalize people who are different - the ones that remain in disadvantaged positions within the sphere of uneven power relations. He claims that groups that occupy more advantageous positions use the space to create and consolidate a distinction between the self and the other by inscribing a set of rules that are deemed appropriate and inappropriate
(1977). While spatial separation can be used to control and limit communication between genders, this regulatory framework can also be applied to any two groups that are in an uneven power relationship. In the context of this paper, the groups that are effected by the uneven power relations are identified as: Turkish-Muslim women vs. Turkish-Muslim men, Turkish-Muslim women vs. German women.

Sex segregation in the mosque has been a controversial subject, remaining central in discussions of gender in Islam. This segregation is usually based on different interpretations of Islamic law however, the spatial organization of gender usually follows cultural and historical traditions (Aryanti 2012). Turkey, being a country caught up in tensions between its secular character and Muslim population, especially in the last decade with the rise of Islamism. In 2011, Kadriye AvcI Erdemli, Istanbul's deputy müftü (highest ranking religious officer) conducted a research reporting the conditions of the facilities used by women in Istanbul's mosques. The results were shocking as many of the mosques did not have facilities for women. Some mosques included spaces for women but most of those spaces were used as storage places and when they had appropriate spaces they were most of the time dirty/freezing cold in winter (Jones 2011).

The same conditions applied to the women's spaces in the Marxloh Merkez Mosque before the construction of the purpose-built mosque. One of my interviewees explains the old situation and how it improved with the construction of the mosque:

We used to use this cafeteria space back in the day. The main cafeteria space was used by men. There was a structure, almost like a shed, that was given to the women. We did not even see the men, we were placed in a separate room. We would listen to the prayer from a speaker. Men would enter the mosque from the front street and we used to use the 
back entrance. I don't even know what the men's section looks like. There was no contact - visual or physical - between men and women at the time. When the mosque was planned, there were a lot of meetings. I really liked that what we thought also mattered. When they [the planning committee] came up with the proposal that there would be no separate entrances for men and women, people - mostly men - didn't like it. They didn't even want a women's section to be constructed anyways. They thought it was not right, they had to bring the müftü of Istanbul to explain them. Even then they wanted to surround upstairs [women's section] with a curtain so that they would not see us. I like that we use the same entrance now, it gives a feeling that our congregation is more connected to each other. (Ayşe, 45)

The mosque in the context of Marxloh is not only used as a religious center but is also used as a community center. The mosque structure includes spaces to provide for these communal activities, such as conference rooms, cafeterias, libraries and classrooms. I observed that many of these spaces are used only by men, women can use these spaces under conditional circumstances - like when there are no men around or when they are accompanied by their husbands or fathers (Fig. 1). The only space that was defined for women's use is the kitchen area that is located in one of the apartments surrounding the mosque however; even this space occasionally is used by men when they need it. Although there is no formal assignment of spaces based on gender (except for the prayer hall), most of these communal activity spaces are used by men, a rule that was not enforced by anybody but enacted through many reiterative performances. Nazlı explains this as:

There are so many places in the mosque men can use, I think the women were not considered that much when they were planning. I wish they included more spaces for us. Women have their kitchen area, they have a place there to sit all together, but that place is not always available. They meet there on Friday mornings to bake and sell goods after the Friday prayer. It is like a socialization activity. But I don't see them using that space in their free time - the mosque administration does not like us using there if no baking activity is taking place. After the Quran course or Friday prayers women like to chat a little bit, but they do not have a space to do so, like men do. (Nazlı, 33)

From Nazlı's comment, it can be understood that women can use the kitchen area conditionally, as long as they are preparing food, contributing to the mosque. On some occasions, men use this space to socialize, when they want to eat or grill together. Within the very limited social space that are defined for the women within the context of this mosque, women can only exist conditionally

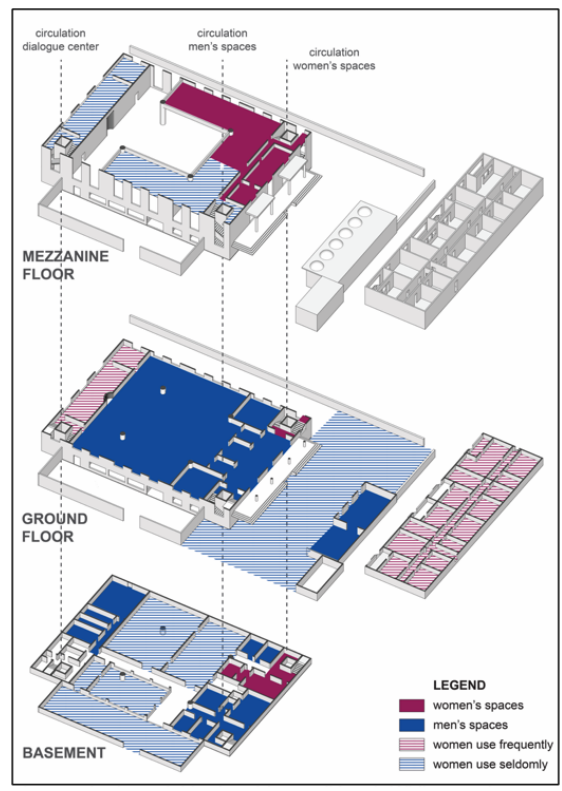

Figure 1. Men's (blue), women's (pink) and mixed spaces in the Marxloh Merkez Mosque. Source: Author 
as long as they conform into the rules enforced by men that are more advantageous to them with respect to the power relations. Even then, this dominant group can invade women's very limited space when they deem necessary.

How does this conditional existence within the mosque transfer to neighborhood space? The rules established through gender relationships in the mosque creates and sustains performances of women in the neighborhood space: women ignore certain areas or women go to some areas only when accompanied by men. Nur and Elif's explanations of their use of neighborhood space shows this clearly:

I think Marxloh is misrepresented in the media. We do socialize here with my friends. We like to go to the cafes and look at the shops. For the most part, I feel pretty safe and comfortable here. But yes, there are places that I ignore, I ignore coffee houses. Going into one of that coffee houses is out of question but I would even ignore the street that they are on. I change my route sometimes to ignore passing in front of those places. It makes my walk longer but I feel safer this way. I also would not dare to go out alone after $9 \mathrm{pm}$. I am scared to do so without my brother or my father. (Elif, 31)

With my husband, we like to take long walks. As you know there are a lot of small parks surrounding this neighborhood, so we go for walks every day. I would not go to those parks alone though, I feel nervous going to those parks alone or with my daughter, there are all kinds of people. With my daughter, we prefer to stay in the main street, window shopping or going to a café. With other women, we usually visit each other in our home. (Nur, 48)

Despite her protective feelings towards her neighborhood, Elif expresses that she does not feel safe in some places. From both Elif's and Nur's accounts, it can clearly be seen that Turkish-Muslim women's existence in the neighborhood is conditional. While men have some established spaces that they can socialize, women's socialization always come along with a condition. They can only use the public space during the day, the nocturnal public space belongs to men. They either use certain spaces while ignoring others or use them only with the company of a male chaperone (Fig. 2).

As most women expressed feelings of conditional security and comfort socializing in the neighborhood, I asked them about their socialization outside of Marxloh. The influence of 'the appropriate way to socialize' that is enforced both in the mosque and in neighborhood space also effects their performances in the city:

I don't go to the city center. My son tells me that there are some very nice cafes in the city center. But we have everything here, we have our shops where we can find appropriate [Islamic] clothing, we have our restaurants where we can find halal meat and our cafes where no alcohol is served. I think I would feel uncomfortable being in a place where they serve alcohol where women and men be inappropriately close. I also feel uncomfortable because there are a lot of Germans there who think I am weird because I wear a headscarf. I feel comfortable here where I can be who I am. (Rabia, 59)

We actually like hanging out in the city center. The cafes are much nicer. As long as people mind their own business and do not harass me, I don't care who drinks/eats what or who socializes with who. I think as Turks we are being very close-minded. In my experience, if you are accepting of them, they [Germans] tend to accept you more. (Aslı, 21).

These conflicting accounts show different performances. Rabia, a first-generation immigrant, who came to Germany from a little town in Turkey when she was 24 after getting married, continues to conditionally exist in the city as well; her performance in the city is informed by her understanding of what is (in) appropriate, inscribed through the countless performative acts in the mosque. Reacting 
to the treatment she receives from Germans, she unintentionally deems their performance inappropriate and choses to stay in the category she creates. On the other hand, her daughter Asli, a second-generation immigrant born and raised in Germany, has a much different performance of the city center. While this can be explained through Asll, having been socialized in German culture, therefore knows the cultural codes to conduct herself in a German context, this can also be interpreted as an act of resistance. As Butler explains, through

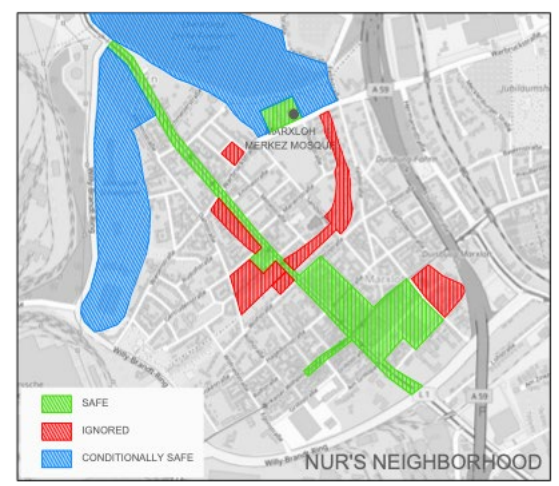

Figure 2. Nur and Elif's neighborhoods. Source: Author

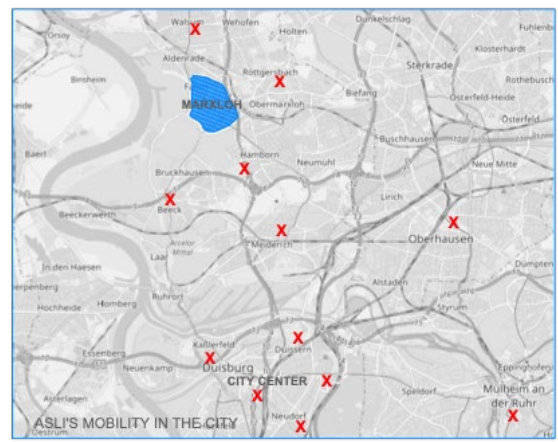

repetitive acts, behaviors and desires that challenge the existing gender assumptions, subjects can reinforce new approaches on doing gender (1990). Among other younger women's accounts, Asli's performance of socialization in the city center defines a new set of norms of gender performance. The spatial implications of these transformed performances can also be seen from the comparison of maps in which my interviewees marked the areas that they use within the city (Fig. 3).
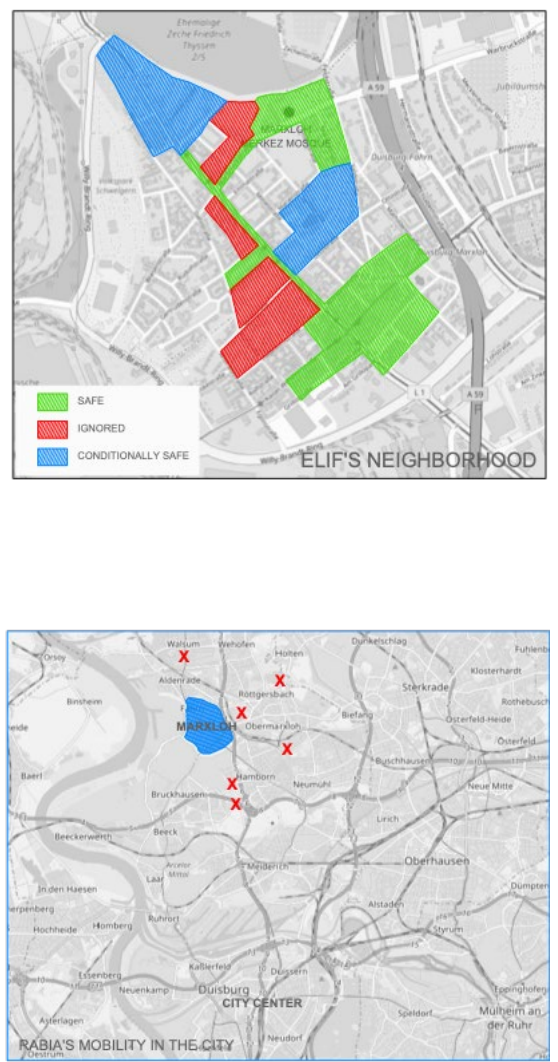

Figure 3. Aslı and Rabia's mobility in the city Source: Author 


\subsection{Surveillance}

According to Butler, "gender is always doing" (1990, 34); gender identity is performed simultaneously by the expressions that it produces as a result, thereby concealing its origins and inscribing the fictitious categories of gender on space that appear as innate and static (1995). The mosque separated into binary gendered spaces produces the same fiction. Although space has no gender, dual categories of gender is inscribed to the space through the repeated stylization of the body within a highly regulatory frame. Kuhlmann identifies surveillance is one of the regulatory frames to control subjectivities that take place in space (2013). According to Foucault, power operates within a field of visibility; the subjects that are made visible can be observed and kept under surveillance (1977).

In Marxloh Merkez Mosque, women's prayer space is located on the second floor, in a mezzanine-like area overlooking men's prayer space. While women can see men's prayer area, women stay outside of men's field of visibility (Fig. 4). The quote from Ayşe's interview in the previous section mentioned that during the planning phase of the mosque men wanted to surround the area with curtains to prevent any possibility of women becoming visible in the mosque. While the architecture of the mosque prevents women's surveillance by men when they are in the prayer space, in this case the surveillance comes from within the group. From Büşra's account, it can be seen that surveillance that comes within the group, or self-surveillance regulates the gendered performativity. When women do not adhere to the rules, the punishment comes from within the group in terms of peer pressure.

I sometimes get very frustrated with teyzeler [aunties - older women]. When there is a prayer or when we are trying to listen to the sermons, they talk so much. They use that time for socialization but it is not a time to do

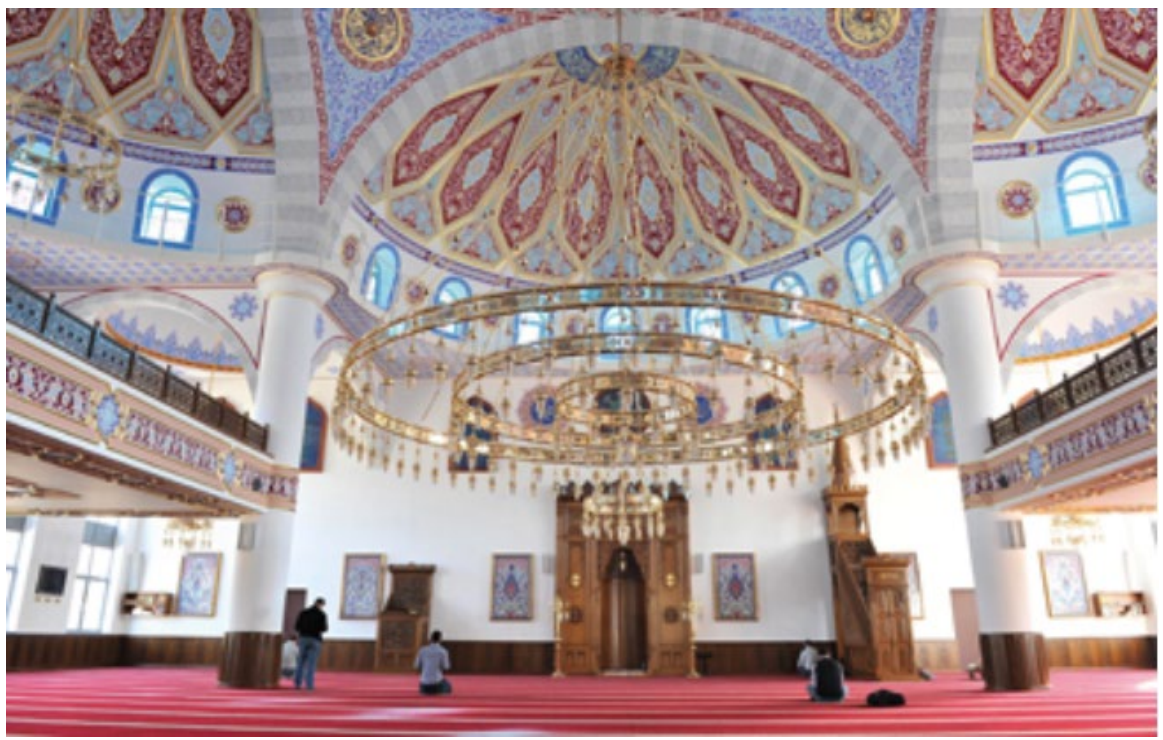

Figure 4. Men's and women's prayer spaces (Source: Mosque in Duisburg Marxloh 2012) 
so. It is disrespectful. But even worse, men can hear them. What is the point of being segregated, if they can hear us? I try to warn them or give them dirty looks but to be honest they don't care that much. (Büşra, 27).

Outside of the women's prayer space, in the public space of the mosque, the surveillance comes from men. Marxloh Merkez Mosque has a sizeable courtyard bordered by a teahouse belonging to the mosque (Fig. 5). Woman leave the mosque from the doors opening to this courtyard, where there exists a constant male gaze. This constant surveillance (or fear of surveillance) prevents women from spending a lot of time in courtyard. Beyza explains this as:

I spend a lot of time in the mosque, I come here 4-5 times a week. Sometimes when the weather is nice, I would like to sit outside. But amcalar [uncles - older men] are always there. They come here in the morning and stay there until evening. When I sit outside with my friends, if we laugh too loud or sit close to them, they warn us. When they don't I can feel their looks. They also gossip a lot. They report everything to each other. My father does not come to this mosque but if he did, I am sure he would know every single thing that I do here. Mosque administration says that the tea-house is for everybody but I feel pressured not to use it. I feel like no matter what I do I will never be a member of the mosque like a man is. (Beyza, 22).

Beyza's account makes it clear that she tries to resist the normative standards of the mosque. The normative standard, created and repeated over time until it becomes instinctive, is that the tea-house can be used by men. In this case, Beyza's subjectivity not confirming into the norms of the community, causes her to suffer anxiety and being punished for her transgression. Women end up existing in the mosque as long as they perform the rules administered by men causes temporary disassociations from the mosque. "I feel like a passerby, while men are there to stay" as put by Leman. On the other hand, this control of the docile body extends outside of the reach of the mosque. Burçin, who lives in one of the apartments surrounding the mosque, explains that she feels pressured to dress a certain way. Leman also explains how this constant surveillance translates to the neighborhood space and she resists against it.

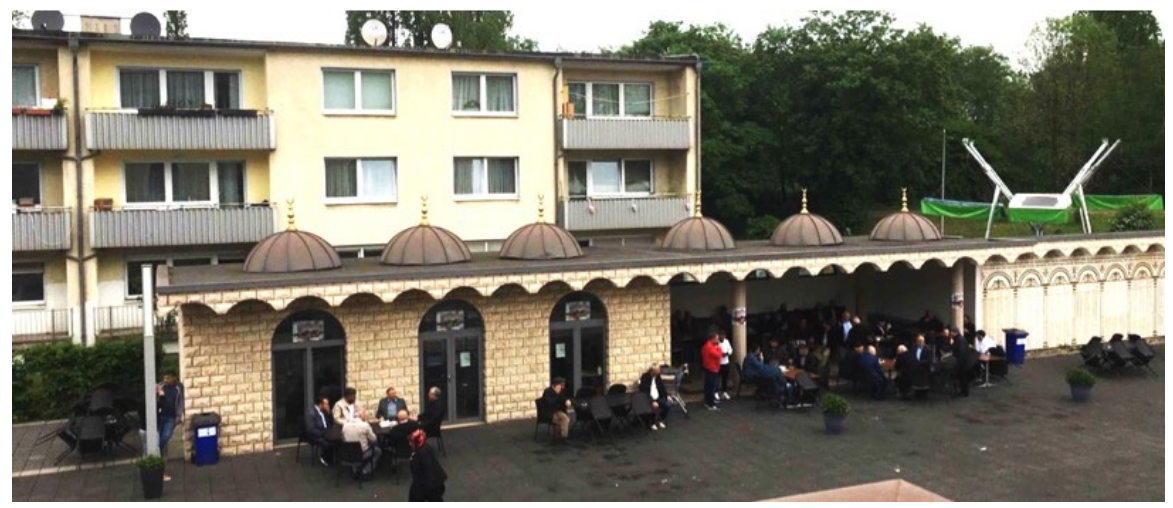

Figure 5. The courtyard of the mosque (Source: Author) 
I would never go out wearing shorts here [in Marxloh]. My family does not really say anything about how I dress, but I never feel comfortable going out wearing a dress or shorts. I feel like everybody is looking at me and disapproving me. There is like a neighborhood pressure. Whenever we go to Turkey for our summer holidays, I dress however the way I want there. Nobody knows me there... (Burçin, 18).

You know the coffee houses, right? At any given time, there are 15-20 men hanging in front of those places. They do nothing, they are no different than a pole. Just stand there all day and watch who goes where, who wears what. I usually change my direction so that I wouldn't have to pass in front of them. My father has a martial arts studio and I am one of the instructors there, so most of those guys know me. I usually keep my distance with them I heard from others that they started to gossip about me, because I passed by the coffee house twice. My friends told me that they defended me saying that I was not like other girls, that I am manlike. I am a masculine woman, you see, but you know what bothers me; the only thing that provided me protection was that I was behaving masculine and they stopped harassing me because I was like one of them. (Leman, 32).

Burçin experiences control by the advantageous group in the light of the idea of appropriate clothing and refrains from dressing however she wants to avoid the male gaze and pressure that comes with surveillance. While Leman also experiences the same pressure, and stays away from using certain streets in the neighborhood, her alternative performance of gender allows her to resist not only the norms defined for her gender but also the male gaze and surveillance that comes with it. She makes space for herself in the areas where most women avoid through her masculine mannerisms and martial arts skills, which in turn make her a non-normative and non-docile subjectivity.

\section{CONCLUSION}

In this paper, the aim was to present how incorporating space into Butler's notion of performativity would provide theoretical and methodological opportunities. By using Butler's performativity both as a theoretical lens and a methodology, I have discussed that the mechanism of power works through performative acts that enforce categories through definition of normative standards. Through repetition and reiterative performances, these stand ${ }^{00} \mathrm{rds}$ are performed to the point that they are perceived as natural.

For the context of the diaspora mosque, Marxloh Merkez Mosque, the spatial techniques of separation and surveillance are enforced to reproduce gender(ed) identities. Separation of the women in the mosque from men, imposed the idea that women can only exist conditionally in the mosque. In the neighborhood level, this norm is reproduced again through acts of conditional existence. While some women adhere to the standard norms having limited mobility, the gender conflict comes into play and women among younger generation find alternative ways to perform their gendered identities, leading to greater exposure and mobility within the German sphere. On the other hand, surveillance of women (that comes either from in or out of the group) create a sense of control, preventing them from fully experiencing the mosque and the neighborhood like men do, which in turn causes feeling of not completely belonging. The resistance to the norms comes from subverting the gender roles in this case. To sum up, the normative standards that are defined in the mosque and translated to the neighborhood confirm women in such a small space in the city, limiting their mobility and preventing them from being exposed to the German context, effecting their integration. 


\section{REFERENCES}

Aryanti, Tutin. 2012. "Women's Prayer Space: Body and Boundary." The International Journal of the Constructed Environment 2 (3): 177-90.

Austin, John L. 1962. How to Do Things with Words. New York: Oxford University Press.

Burke, Peter. 2005. "Performing History: The Importance of Occasions." Rethinking History 9 (1): 35-52.

Butler, Judith. 1988a. "Performative Acts and Gender Constitution: An Essay in Phenomenology and Feminist Theory." Theatre Journal 40 (4): 519-31.

---. 1990. Gender Trouble: Feminism and the Subversion of Identity. New York: Routledge.

---. 1993. Bodies That Matter: On the Discursive Limits of "Sex." London: Routledge.

Cavanaugh, Jillian, R. 2015. Performativity. Oxford: Oxford University Press.

Derrida, Jacques. 1962. Magins of Philosophy. Chicago: Chicago Press.

Feldman, Gregory. 2005. "Development in Theory: Essential Crises: A Performative Approach to Migrants, Minorities, and European Nation-State." Anthropological Quarterly 78 (1): 213-46.

Foucault, Michel. 1977. Foucault, Michel, Discipline And Punish: The Birth of the Prison. New York: Pantheon Books.

Henry Benham, Lisa. 2003. "Diversity in Architectural Process: Identity and Performance of Place." In 20 on 20/20 Vision, Linda Kiisk, 90-97. Boston: AIA Diversity Committee.

Jones, Dorian. 2011. "Can Turkey Make Its Mosques Feminist." The Atlantic, 2011.

Kuhlmann, Dörte. 2013. Gender Studies in Architecture. New York: Routledge.

Lutz, Helma, and Christine Hutz-Hildebrandt. 1998. "Geschlecht Im Migrationsdiskurs: Neue Gedanken Über Altes Thema." Das Arguement 1 (2): 159-73.
Miller, Tim. 2000. "Suck, Spit, Chew, Swallow: A Performative Exploration of Men's Bodies." In Masculinity: Bodies, Movies, Culture, P. Lehman, 279-99. New York: Routledge.

Oz, Irem, and Alexandra Staub. 2018. "The Tale of Two Mosques." ARCC Conference Repository 2018.

- - 2019. "Fieldwork In-between Architecture and Anthropology." ARCC Conference Repository.

Räthzel, Nora. "Harmonious 'Heimat' Disturbing 'Ausländer."' Feminism and Psychology 4(1): 81-98.

Smitheram, 2011. "Spatial Performativity/ Spatial Performance." Architectural Theory Revew 16(1): 55-69.

Snickare, Mårten. 2012. "How to Do Things with the Piazza San Pietro: Performativity and Baroque Architecture." In Performativity and Performance in Baroque Rome, Gillgren and Snickare, 6583. Surrey: Ashgate Publishing.

Wigley, Mark. 1992. "Untitled: The Housing of Gender." In Sexuality and Space, Colomina and Bloomer, 327-289. New York: Princeton Architectural Press. 


\section{PAPER \#1.15}

\section{ARCHITECTURAL AND GRAPHIC EXPRESSION OF THE ROUTE 66 FROM CHICAGO TO LOS ANGELES}

\section{Sigrun Prahla}

anniversity of Applied Science, Krefeld, Germany

\section{ABSTRACT}

At its inception in 1926, Route 66 was intended to include the main streets of rural America. It was an optimistic road, full of hope, that introduced an access to the west, and was known as "The Mother Road" and "The Main Street of America."

Food, gas, and lodging were the most important features on the route, but the added attractions made the adventure of the route feasible and also interesting and exciting.

Along Route 66 often the signs were visually more attractive and more important than the buildings. The characteristic style of large size, bright colors, and flashy lights of the signs along Route 66 responded directly to the moving automobile and nomadic lifestyle.

Now, Route 66 can no longer be traveled exclusively from beginning to end. It is intertwined with a series of interstate super highways, a system that has taken over the traffic, the gas, food and lodging services. Route 66 has become a fragmented road, yet remains complete in memories and paraphernalia preserved in museums and souvenir shops. Its legacy has been continued in pop-culture, television shows, music and iconography.

Today towns capitalize on the tourism industry that draws people to see the old sites of the route. Therefore traveling Route 66 in itself has become a destination, a place that has many aspects of a theme park.

\section{KEYWORDS}

Route 66; roadside architecture; main street; Americana; traveling.

\section{INTRODUCTION}

At its inception in 1926, Route 66 was intended to include the main streets of rural America. The paving began in late 1926 in Chicago, Illinois and by 1937 Route 66 had meandered across the United States ending in Santa Monica, California. When it was finally paved from end-to-end one would travel through eight states (Illinois, Missouri, Kansas, Oklahoma, Texas, New Mexico, Arizona, California) and three time zones.

In the beginning, it was an optimistic road, well traveled, well praised about and full of hope. It introduced an access to the west and was known as "The Mother Road" and "The Main Street of America." The appeal of Route 66 was first and foremost the experience of being on the open road. One was set free on Route 66 but there were just enough sights, diners, gas stations, and other assorted oddities to make one feel at home on the road. The song Get Your Kicks on Route 66 popularized by Nat King Cole brought more interest to it.

Route 66 also symbolized the renewed spirit of optimism that went through the country after economic catastrophe and global war. "The Main Street of America" linked remote and under-populated regions, providing small towns with vehicular access to larger cities. An estimated 210,000 people migrated on it to California to escape the despair of the Dust Bowl to whom Route 66 symbolized the road to opportunity. It also grew popular through the trucking industry.

Route 66 was officially decommissioned in 1985 although its uses had long ago been replaced by the interstate system. Now, Route 66 can no longer be traveled solely throughout the long distance. In its span from Illinois to 
California, Route 66 is intertwined by a series of interstates and super highways like US 40, a system that has also in large parts taken over the traffic, the gas, food and lodging services. Route 66 has become a fragmented road, yet remains complete in memories and paraphernalia preserved in museums and souvenir shops. Its legacy has been continued in pop-culture, television shows, music and iconography. Today towns capitalize on the tourism industry that draws people to see the old sites of the route.

\section{SIGNS AND ROADSIDE ARCHITECTURE}

The life manifested on the old route was seen visually along its path. The signs and architecture along the highway attracted the traveler to pull over to the businesses and the owners with their hospitality brought the people inside.

When Route 66 was at its prime it carried a certain feeling of romance along its path. People had used the highway to travel west in search of having a good time or sometimes a better life out west. The spirit possessed by the route was important to many people and showed the freedom and ability of people to just go. Moreover, for the residents along the path, it supported the American Dream of being self-employed and owning your own business, which the majority of motels, shops, and diners inhabiting it were.

Along Route 66 there are still signs and architecture that are as adventurous visually as the road was to travel. Signage was the most important aspect in leading perspective customers off Route 66 and into the trading posts, entertainment, gas, food, and lodging areas. These businesses that were encountered throughout the 'Mother Road' were small, and needed to use unique signs to make their business seem more desirable than the next. The Route is still infested with signs of various shape, size, and style, whether it is a huge painted board or a small neon sign.
Road signs often not only act as physical markers but also as cultural, political, economic or patriotic statements. They hold value in capturing ideas held by their creators and an understanding of the cultural climate in which they were built.

Main street signage traditionally has simple rectilinear compositions suspended outside a business in a downtown district. The automobile changed this downtown layout and size. Due to congestion and the lack of parking many businesses were forced to out-lying highway strips. This freed business owners from the spatial confines of the main street and allowed for free standing signs not attached to buildings. This type of signage tends to be large in scale, close to the roadside, and angled to be viewed by automotive traffic traveling at high speeds. The sign heralds to travelers from as far down the highway as possible, and signals the driver to slow down.

Buildings or paintings on them can also act as a form of signage. The signs along the Route 66 became an integral part of America's vernacular through their material, form, structure, typography, naming conventions, color, symbolism, and three-dimensional composition in space. The signs featured being on Route 66 as a trademark but always tried to be designed individually.

The original roadside architecture along Route 66 also remains the most visual reflection of each region's landscape, weather, and history. Building materials came from the resources of each state. Whether wood or clay or concrete, the buildings were built simply and usefully (a characteristic of the time) by local miners, farmers, and townspeople. These locals slowly emerged as small entrepreneurs taking pride in their small stores, gas stations, cafes, and motels. By maintaining the attitudes, customs, and history of their respective lands, they celebrated their local culture. Thus, Route 66, by winding through the deserts, the mountains, and small metropolises, brought people to the local architecture. 


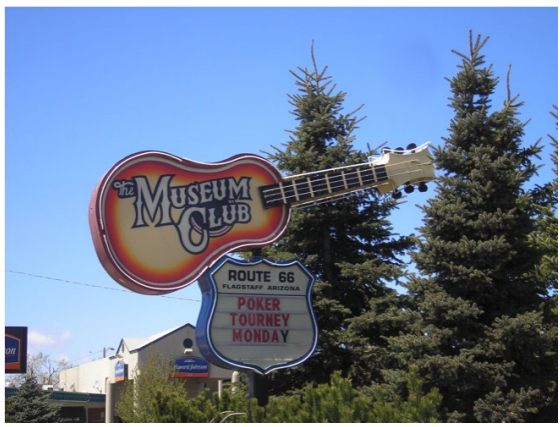

Figure 1. Neon sign.

Onthe contrary, the interstate is very impersonal, it seems to be a lonesome road that sets up non descript stations where you can stop when you are hungry, tired, or need to re-fuel. There is no special attraction drawn to these stops. The signs along the interstate system are generic. They want to be recognized as parts of a chain and unlike the various and expressive ones that had once been so common on Route 66 they are identical in all states. In addition, along interstates the buildings are set back from the road, making the driver leave the road totally to get there, therefore making the road and the building seem separated from each other. However, on Route 66 the businesses were located along side the road in parts, letting the road and the architecture be used together to create a common space and a personal feeling.

\section{GAS}

Another important factor of Route 66 was that the first simply constructed automobiles needed gasoline. On a road that stretched for a couple of thousand miles, gas stations became a necessity. New drivers first purchased gasoline at liveries, repair shops, or general stores. They arduously poured the gas in buckets and then funneled it into their gas tanks. This primitive method would soon become obsolete. By the 1920's with the growth of the automobile and the construction of roads, the now thriving oil industries began developing more consumer-friendly distribution systems. This move inevitably led to the modern gas station.

The gas station buildings originally told a lot about a region's climate and available materials. Where houses were mainly brick or wood, the gas stations of Illinois had a wooden or brick structure covered by clapboard or shingles. In Missouri, the material was sandstone. In the more Western regions of Route 66, the arid desert and sub humid plains catered to the large canopy design to protect customers from the sun. These canopies also had to be tall enough to let in light and allow for larger trucks. By the 1930's, Pure Oil, Phillip's Petroleum, and Texaco were all standardizing their gas station and designed a basic "Streamline Moderne" building. This design could be used all over the country with any materials available porcelain-enameled steel, brick, concrete block, or frame and stucco. Moreover, Texaco's universal simplistic design (a white building with 3 green stripes) became a recognizable icon for gasoline.

Today, the filling stations that accentuated Route 66 are long gone. Their tanks below ground are rusted out and pumps are outdated, if not looking skeleton-like. The interstate provides gas stations with easy on and off access to it, making the traveler's journey faster and more efficient. Participants of the travel

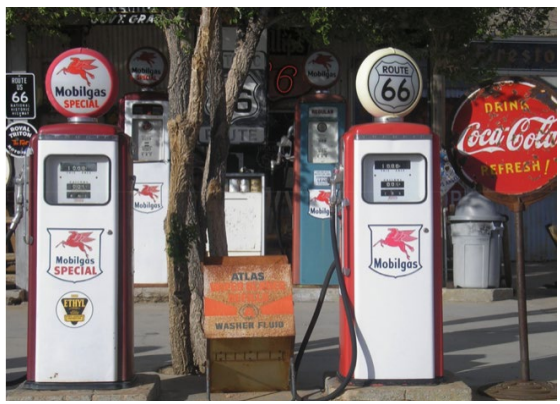

Figure 2. Gas filling station. 
way no longer purchase gasoline from liveries or general stores, but from big business oil companies who run a monopoly with stations set up along the freeway. By strategically setting up stations along a certain length, corporate companies took over the function of general stores and liveries.

\section{FOOD}

Along the historic Route 66 a wide variety of restaurants, cafes, diners, bars still tend to maintain their original look and their old style signs in front of their place from old days. Every state has its own top spots where people can enjoy the food and drink while traveling across the Route 66 and taste the original old recipes from the time when the Route 66 was the main road. They once served the people who traveled the long way from the state of Illinois to the state of California, and today they serve tourists who want to taste the old ways when Route 66 was celebrated as the main road and not as the historical path as it is today.

Moreover fast-food restaurants evolved from the eateries spawned by the car culture. Drive-Ins with food delivered to waiting cars, "Walk-Ups" where customers queued in multiple lines to speed food purchase and ultimately the Drive-Through, where food was handed to motorists in waiting cars, were introduced. Reflecting on the industrial age assembly lines, food preparation, and delivery were engineered to fully rationalize time and motion. With the widespread adoption of the automobile for personal transportation

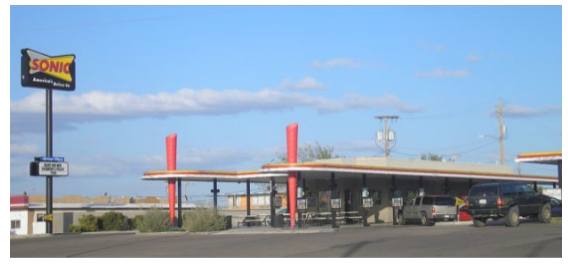

Figure 3. Drive through food stop.
Americans took on automobile-convenient food as a logical extension of their mania for the on the go lifestyle. This also changed the use of public and private space. The boundary between inside and outside of a restaurant is not crossed when ordering from the car. Today this type is mainly represented by generic hamburger chains along the interstate.

\section{LODGING}

Route 66 and traveling by car has diminished the role of the hotel. Hotels are often located in the urban core of a city or town. They are directly adjacent to the street, and they have no or limited parking because they were originally geared towards visitors arriving by train. They are usually designed as a destination, not a passage, that means to accommodate multinight stays, and their guests are usually there for the purpose of business or vacation in the local area. They often include additional amenities like function rooms, dining facilities,

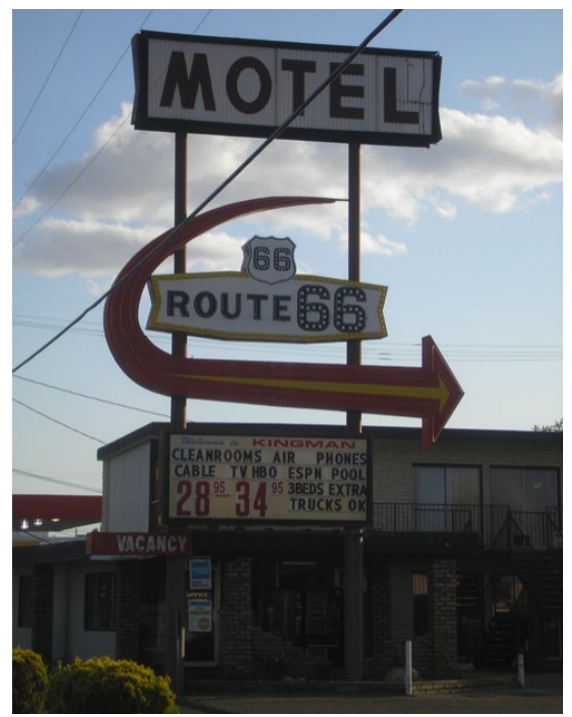

Figure 4. Motel lodging. 
and a welcoming entry lobby. The motel, on the other hand, is well suited for one-night stays. The building is separated from the street to accommodate the cars. Easy parking drops guests off in front of their room, built with only one or two floors, room access is direct on the outside of the building, that is arranged around a parking lot or an open air swimming pool. The accessibility makes the motel the ideal system for transient travelers.

Many of the motels were built in the early 20th century and carried a local character. In Kellyville, OK, for example, the motel appears like an old farming village made of stone. This style of motel is unique to Oklahoma, and could not be seen anywhere else. In Flagstaff, Arizona, a great neon sign shows the Flamingo Motor Hotel, with its slate roofs to sustain the desert heat. This type of roof differs greatly from roofs elsewhere, and would stick out in a person's memory of their travel along Route 66. The Wigwam Motel in Rialto, California is also different in that the rooms are actually a series of tepees resembling a Native American tribe settling alongside the road. All of these motels can be seen right along the side of the street, and are not advertised on monotonous green, red or blue signs of a motel chain.

Therefore many motels along the road were attractions as well, and some old and historical motels still stand and are visited along the main road today. Often the signs of the motels are visually more attractive and more important that the building itself. The characteristic style of large size, bright colors, and flashy lights of the motel signs along Route 66 respond directly to the moving automobile and nomadic lifestyle.

Today the motels along the interstates are much different from the old motels on Route 66 . The only way you know when to stop for a motel would be to look for a generic sign to tell you. When you do find a hotel, you notice that it looks the same as the one you have seen in the previous state. Motels have become a chain, and have lost their originality and specific qualities.

\section{ROADSIDE ATTRACTIONS, ART AND MUSIC}

The explorers of Route 66 originally followed a dream, their wheels brought them to new lands. Their path rolled, rose and fell, it pitched and heaved around every hairpin turn, what would they find around the next bend? Would it be something intriguing or scary? Would it be a giant boy carrying a hamburger, a big blue whale, a stretch of painted Cadillacs buried in the ground, a giant dinosaur in front of a cavern, a giant rabbit wearing a saddle, a spaceman carrying a rocket, a big neon pig dancing on a sign, or would it just be a stretch of Camelback Road, empty enough to travel along quickly and give one the sense of a roller coaster ride?

The Cadillac Ranch, for example, located on the outskirts of Amarillo, consists of ten Cadillac automobiles from 1949 to 1963 that are partially submerged head first in a wheat field. The art installation, created by installation artists and architects collectively known as Ant Farm, was a combination of commemorating the glory of Route 66 with the freedom it engendered allowing for the flow and movement of Americans westward. Though the actual vehicles are placed at the exact angel of the Pyramids of Giza, the designers want to commemorate a concept closer to the American people - that of the fascination with a sense of place, the concept of roadside attractions and the mobility and freedom of the automobile.

Other attractions were trading posts, racing on the road, natural wonders, and drive-in movie theaters. The purpose for the human-made attractions were to welcome, accommodate, and entertain travelers. Food, gas, and lodging were the most important, but by adding attractions, it made the adventure of the route not only feasible but also interesting and exciting. The tourist trade increased and a unique way of marketing one's product developed. Whatever was built or electrified was always large and often strange. Phrases 
such as, world's largest, longest, tallest, and others may still be seen along Route 66 today. Bobby Troup's "(Get your Kicks On) Route 66" is, without question, the most recognized, and the most covered, ode to old 66. Written in 1946, it characterizes the legendary highway as the only way to truly travel west. There is no wonder over 76 artists, including The Cramps, Anita Bryant, Louis Jordan, The Rolling Stones, Sammy Davis Jr., the Replacements, Chuck Wagon and the Wheels, Nat King Cole, and Depeche Mode, have remade the tune. They all knew the real Route 66, and they had one message: "Get your kicks on Route 66!"

\section{ROUTE 66 VERSUS INTERSTATE}

When the interstate system came along and neighbored Route 66, travelers mainly used this instead. The interstate was a faster and a more efficient way of traveling if someone just needed to get from a to $b$. Along this path there aren't usually any exciting visual aspects incorporated, just a long, paved, and boring highway. The interstate took a lot of the life out of the old route and caused many businesses to shut down. In many respects, the physical remains of Route 66 mirror the evolution of highway development in the United States from primitive country roads to a federally subsidized complex of uniform interstate expressways.

Route 66 now has become more like a theme park or an attraction rather than a common traveling experience. It seems like the days of enjoying traveling across the country in the car are almost over, or they are a luxury, and getting to the destination as quickly as possible now becomes more essential. On the other hand one thing that makes Route 66 so unique is the way the road in itself has become a destination. This is almost ironic in that traveling a highway has become a vacation destination for some people rather than having a place as a final location with the journey being the destination.

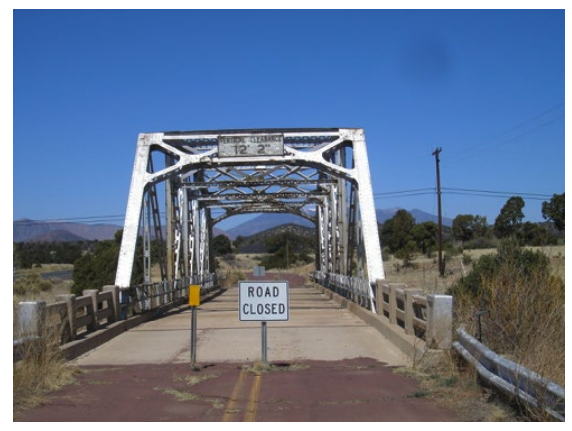

Figure 5. Route 66 - not a through street.

Shops and antique stores are popular on Route 66 today. Most restaurants, motels, and other places along the way have memorabilia of Route 66 . The cafes are old fashioned, the restaurants still serve the greasy hamburgers that travelers loved in the old days, and the attitudes are still friendly and inviting.

Looking a Route 66 also provides the opportunity to reflect on an early and mid-20th century urban and rural transportation system and its influence on urban development. Formerly the villages had mostly been self-sustained through agriculture or manufacturing. Getting connected through the main street of America changed that narrative - it actually got it started. Experiencing locally built environments, different landscapes, local food and drink and different climates

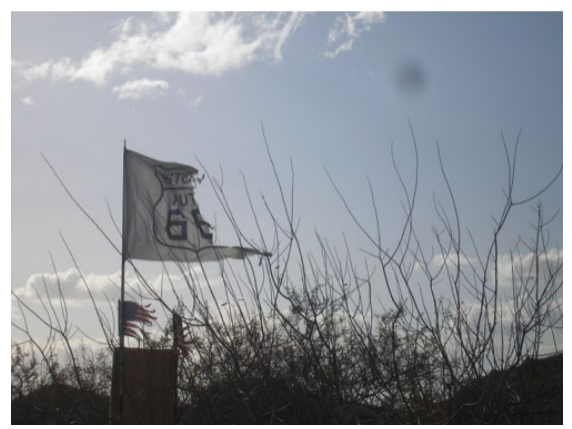

Figure 6. Route 66 - flag. 
provided the travelers, who came by private car, public bus or commercial truck, with new experiences.

Chain stores and chain motels settling besides the road or next to the interstate can be called harbingers of globalization at a time, when the word was not really existing yet. This development can be transfered to many different areas, villages and cities in numerous countries. In that case the identity of a place is not rooted in the origin of a place anymore, it lacks individuality and looks almost the same in different countries, landscapes and settings. Along the Route 66, the old fashioned ways are being showcased rather than the chain stores. That is one reason why Route 66 is still deeply rooted in the collective memory, and its myth is still being celebrated. Therefore although it is rundown in some parts, Route 66 still retains that down home feel. So if you want a taste of a slower pace, get off the interstate, take the byway and see the country and its people. Find your own kicks on any route, but, just even for day, try a piece of Route 66! 


\section{REFERENCES}

Bernard, J., Brown, P., 2003. American Route 66 Home on the Road. Santa Fe: Museum of New Mexico Press.

Clark, M., 1993. The Route 66 Cookbook. Tulsa: Council Oak Books.

Freedth, N., 2001. Traveling Route 66. London: Salamander Books Ltd.

Hess, A., 1985. Googie: Fifties coffee shop architecture. San Francisco.

Kaszynski, W., Route 66: Images of America's Main Street. Jefferson: McFarland \&Company.

Kittel, G., Route 66. New York: Thames \& Hudson.

Repp, T. A., 2002. Route 66: The Romance of the West. Lynwood: Mock Turtle Press.

Scott, Q., 2000. Along Route 66. Norman: University of Oklahoma Press.

Snyder, T., 2000. Route 66 Traveler's Guide and Roadside Companion. New York: St. Martin's Griffin.

Venturi R., Scott Brown D., and Izenour S., 1977. Learning From Las Vegas: The Forgotten Symbolism of Architectural Form. Cambridge: The MIT Press.

All pictures by Sigrun Prahl 


\section{PAPER \#1.16}

\section{SEEING BEYOND CITIES}

\section{Ray Kinoshita Mann ${ }^{a}$}

aUniversity of Massachusetts Amherst, Amherst, Massachusetts, USA

\section{ABSTRACT}

The notion of the "city as the most relevant architectural issue of the twenty-first century" is a problematic mode of thought. It implies that going forward, the city should monopolize our attention to the exclusion of the vast and complex systems, human and non-human, of which dense urban settlements are merely a part. Many current literatures have come to belie the alleged superiority of the city as more efficient, more innovative and productive, more livable, or more sustainable-some cities may be, others may not. In terms of per capita total resource (greenhouse gas) consumption, cities are coming out at best a break-even proposition relative to every sector-rural, ex-urban, suburban (with the wealthy consuming far more wherever they are). Urbanization has also been coupled with the increasing corporatization of agricultural land and natural resources-a troubling trend not necessarily more efficient, desirable or inevitable. Equally worrying are signs of cities' accelerating inequality and the acute vulnerability particularly of coastal cities to the impacts of Climate Change. Oddly enough, all this debunking is good news: By jettisoning the valorization of one form of human existence over others, we can take a serious look at how we can (and must) do better across the board in all aspects of habitation and production. We can discard antiquated notions of the city slicker versus the country rube, of sprawl as the ugly stepchild of the city, of cities as objects not systems-to harness the full gradient of possible sustainable productivities and resiliencies from the seas and hinterlands to the urban core. For this paper I propose a Literature Review drawn from a broad range of disciplines, and through logical argumentation articulate the critical importance of recasting our focus beyond the confines of the city, even when working on the city.

\section{KEYWORDS}

Urban; suburban; rural; consumption; sprawl.

\section{INTRODUCTION}

The city vs. the country as a subject of centuries-long debate has taken on new urgency in the last few decades as we face critical decisions about the future. The current near-obsessive focus on the city-particularly by designers and planners-may not be entirely well-grounded, and has troubling implications if left unchallenged. The literature is voluminous and complex, so this paper tries to frame the core arguments in a deliberately reductive way, bringing together findings of planners, economists, sociologists, environmental scientists and others. I propose to examine three different part-towhole problems that are roughly analogous to successive delineations of the urban core, the metropolitan area, and the region.

\section{THREE PART/WHOLE PROBLEMS}

For at least a decade, two narratives have shaped the pro-city movement in both the minds of the public and the professions: The first narrative is most easily represented by 
Harvard economist Edward Glaeser's 2011 book, Triumph of the City that declared cities as both "greener" and more productive than the hinterlands. His argument for "green" was rooted in the greater walkability, decreased automobile dependence and the reduced energy/resource and infrastructure costs of density, while productivity was evinced by the significantly higher average urban per capita GNP purportedly spawned by the greater "creative capital" of urban agglomerations (Glaeser 2011). Urban planner and pro-urban threorist Richard Florida also touted these ideas in The Rise of The Creative Class in 2014, and cities all over the world embraced his thinking. Almost concurrently, physicists/ systems theorists Luis Bettencourt and Geoffrey West pioneered the idea of applying allometry to cities-a biological concept where larger animals are shown to be more efficient in terms of energy use than smaller animals, providing mathematical justification to the argument that density in settlements-much like volume in animals-provides the best from and for humans: On average, as city size increases, per capita socio-economic quantities such as wages, GDP, number of patents produced and number of educational and research institutions all increase by approximately $15 \%$ more than the expected linear growth (Bettencourt and West 2010). Based on this theory, the bigger and denser the city, the better at infinitum-seeming to point to megacities of populations of 20 millions-plus as the way of the future, with a correspondingly emptied countryside "left to nature" or farmed with minimal human involvement.

The second narrative is that "sprawl" and extensive infrastructures beyond a city's central boundaries is not only objectionable but unsustainable--a "growth Ponzi scheme" in the words of Strong Towns founder Charles Marohn, that was sold to post-WWII America (and ultimately around the world) and is headed for collapse as it ages out (Marohn 2011). These declarations had critics even at the time they were introduced-but they have had remarkable staying power, not least in the imagination of planners and designers who would love to realize dense built environments "done right." The most optimistic declare that cities can even feed themselves and process their waste via urban permaculture, making connections to the ex-urban and rural even less necessary. More recently, however, skeptics are making their voices heard, including that of Richard Florida himself. In Urban Crisis from 2017, Florida sounds the alarm on the extreme inequities and social tensions that are clearly on the rise from the pro-urban boom. Florida's copious arguments are worth analyzing because they embody many of the complexities, contradictions and dilemmas of the urban equation-though without ever conceding to any demerits in his original pro-density ideas.

\section{CITY VS. CITY}

Let's assume for a minute that a city can be defined as primarily its high-density core, the dense "walkable" commercial/residential/ cultural urban fabric that most people picture in their minds as "city." The relationship of the core to what surrounds it will be discussed later in the paper, but here I focus on the first part-to-whole consideration of the urban core itself-in that the tendency to focus primarily on residential and vehicular fuel consumption or Greenhouse Gas Emissions (GHG) as the metric for establishing that urban living is more "green" is in itself an incomplete standard of measure.

Based on transportation alone, studies confirm that annual transportation fuel consumption can be a factor of two or more lower for urban core households than their suburban and rural counterparts (Newman and Kenworthy 1999). 
Likewise, while less dramatic, the operational and embodied emissions of higher density housing types are found to be somewhat lower than their low-density counterparts (Fuller and Crawford 2011, Stephan et al 2013, Brown et al 2017). If all other consumption factors between household types were equal, the stark difference based primarily on the transportation difference would stand (at least until EV vehicles become the norm), but it turns out that when the total consumption of households are assessed, a different picture emerges. This is most clearly articulated by the concept of "parallel consumption" introduced in a series of Finnish studies that hypothesize that "lifestyle" and its associated energy consumption turns out to be shaped or "situated" by the settlement forms in which one lives (Heinonen et al 2013).

Heinonen et al explain that in higher-density urban areas, "the reduced living spaces... are actually a trade-off between living space possessed and high proximity to various service spaces that can be used to "extend" the living space." As such, urban dwellers avail themselves at a higher rate to restaurants, health clubs, and the like that provide "consumption opportunities...which lead their residents (to) having the highest carbon footprints" (Heinonen et al 2013). Each such facility contributes to the consumption of a household, often in redundant ways (food preparation, equipment space, etc.)-hence the "parallel" nature of the consumption. While recognizing that such facilities are neither exclusively used by their immediate urban residents nor are exclusive to urban areas, the study's data nonetheless indicate a distinctly elevated pattern of use among urban dwellers. In addition, even at similar income levels urban dwellers had higher expenditures on household goods and more frequent travel to second homes or cottages. Even daily transportation emission differences between non-urban and urban dwindle thanks to more time spent in stop-and-start traffic in spite of shorter distances traveled (Heinonen et al 2013). A similar though less exhaustive 2010 study from the U.S. context using overall consumption critieria finds that ex-urban "sprawl living" is only $17-19 \%$ more energy intensive than living in the core (Shammin et al, 2010). Ultimately, it should come as no surprise that the higher productivity of urban areas touted by proponents such as Edward Glaezer should result in higher household consumption, but it does somewhat pull the plug on the notion that dense settlements are achieving more with less than their less dense counterparts.

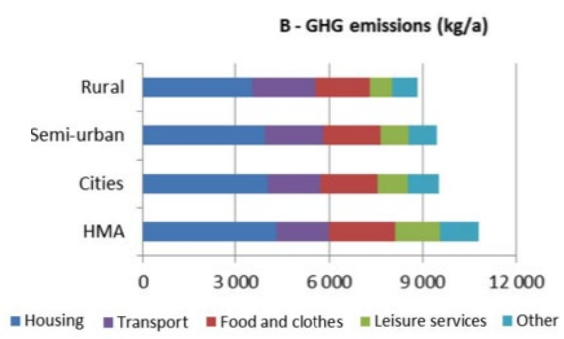

Figure 1. GHG emissions including consumption (HMA $=$ Helsinki Metropolitan Area) (Heinonen at al 2013)

Infrastructure cost and material considerations remain outside the findings outlined above, but need to be addressed as a facet of the pro-density argument. Do substantial infrastructure efficiencies of emanate from a large number of users per area served? How to properly answer this question turns out to be very difficult; the best effort I could find was a working paper from the Brookings institute (Brooks and Liscow 2020). The authors seek to tease out which particular factors contribute to the high cost of infrastructure repair and construction, particularly in the U.S. where costs have multiplied well ahead of inflation, and which can be 2-3x that of comparable work elsewhere in the world. After due consideration of planning, land acquisition, material and labor 
costs, project complexity, litgation, price-fixing, regulations and environmental factors just to name a few, the only consistent correlation the authors could pinpoint was affluencethe relative wealth of the populations directly impacted by a project. Affluence appears to serve as a proxy measure of the extent to which citizens feel empowered to litigate against projects, as well as demand higher quality infrastructure, particularly subsequent to the passing of the National Environmental Policy Act of 1969 (Brooks and Liscow 2020). The study evaluates costs on a per mile as opposed to a per capita basis. While greater density suggests lower costs per capita, the greater affluence of urban areas suggest the potential for elevated costs, particularly in cities that are wealthy but aging out of their infrastructure.

\section{CITY VS. SPRAWL}

From the beginning, sprawl has been one of those words more useful in suggesting an attitude than in indicating any actual conditions. The attitude has almost always been negative. (Bruegmann 2006, 17)

An equally vehement issue for many, though not all pro-urbanists is a distaste for "sprawl," the ugly stepchild of the city that typically spreads every which-way around the periphery of the perceived boundaries of city-ness. While in the tradition of Glaeser, we can try to excise the suburbs and other "sprawl" from what we define as the city, it is clear historically that sprawl IS part of the city (Glaeser 2011). Of the 80-plus percent "urbanized" population of the continental U.S., $52 \%$ is in suburban zones (the census does not have a category of "suburban" so only identifies urban vs. rural) (Breugmann 2006). While each country has its characteristic version, "sprawl" is worldwide. Robert Breugmann, Joel Garreau, libertarian Joel Kotkin, and even Richard Florida have long made the argument that sprawl is a natural outgrowth of cities, as an "edge" condition where space is cheaper and less regulated that is as critical to urban vitality and productivity as is the core.

In terms of emissions, sprawl is the fly in the ointment for cities if one accepts them as an inherent part of the urban whole. Just as a more thorough tabulation of emissions in the urban core have increased its numbers, actual carbon emission measurement data via the Arizona State University's 2013 Vulcan Project, brought together with the population distribution data of the Global Rural-Urban Mapping Project (GRUMPv1) were able to demonstrate that metropolitan agglomerations tend towards higher per capita GHG, not lower (Oliveira et al 2014). The NASA/Doe-funded Vulcan Project was able to break out each energy sector such that transportation is separate from both residential and commercial activity-laying bare the contributions from each. Identifying super-linear behavior in allometric terms (as per Bettencourt and West), the research concluded that:

Doubling the city population results in an average increment of $146 \%$ in $\mathrm{CO} 2$ emissions, rather than the expected isometric $100 \%$. This ...suggests that the high productivity found in larger cities is done at the expense of a disproportionately larger amount of emissions compared to smaller cities (Oliveira et al 2014).

That doubling population more than doubles emissions is cause for concern, particularly for mega-city advocates.

There is no doubt that sprawl can be "done" better, but rushing to densify it in the name of emission reduction can have its own perils, especially if by the time the full range of urban household consumption is taken into consideration, it is a wash: "As a 

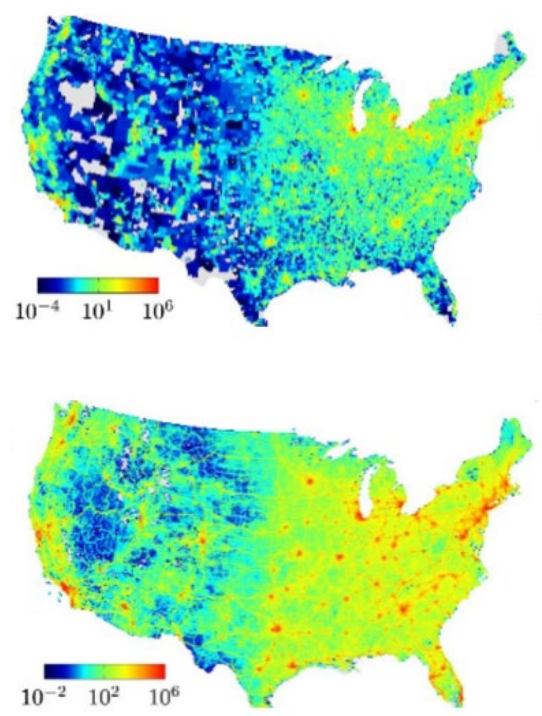

Figure 2. Carbon emissions for U.S. Residential and On-road CO2 mappings (Oliveira et al 2014)

policy measure to reduce GHG emissions, increasing population density appears to have severe limitations and unexpected trade-offs" (Oliveira et al 2014,1) And as Richard Breugmann reminds us:

Strident efforts to reverse the course of urban history and push these places back into the mold of dense 19th c. cities heavily dependent on public transportation risk destroying the very things that have made them such magnets for population and economic growth in the first place (Breugmann 2005).

\section{CITY VS. COUNTRY}

A prevailing truism is that the urban condition is economically and culturally superior to the rural-that no country can substantively grow its GNP without big cities, and that traditionally ex-urban activities such as agricultural production and resource extraction are not the best use of human capital. Rural areas are assumed to be too dispersed to incentivize concentrated job creation or access to services and knowledge sharing, and so on. Many pro-urbanists furthermore promote the separation of the built environment from "nature," with each serving as an antidote to the other. Resource economists John Day and Charles Hall, however, have long argued that cities draw deeply from their regions, more than people generally recognize (Day and Hall 2016). Primary resources are often the actual source of a city's wealth even in the present day, both in terms of commodities and production. Pulling people off the land to place it into fewer and fewer (corporate) hands should also be concerning-farms are getting bought up throughout the Midwest by venture capitaloften foreign in origin-that take little interest in local or regional affairs (Ashwood et al 2020). Statistics on agricultural land ownership indicate substantial corporatization-Nonoperating landlords own 31 percent of farmland in the U.S. (USDA 2014).

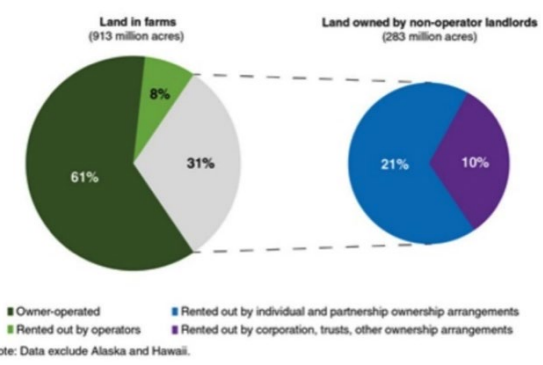

Figure 3. Acres owned by non-operator landlords (USDA 2014) 
Moreover, agriculture is about to get more important, not less-especially if we want to get serious about greater urbanization, not to mention the production of things like biomaterials at an industrial scale. Advanced knowledge and skills, not only about agriculture but the environment more broadly are critical, and many of the jobs that are emerging require higher education. Agricultural innovation requires partnerships with institutions and research capital. Even Richard Florida has noted that innovation as measured by patents is surpassed by rural and ex-urban zones over urban (Florida 2018). In other words, "creative capital" isn't exclusively urban-and there is no reason that knowledge can't be flowing freely through the rural-suburban-urban space. "Smart Cities" tout IT infrastructure-but these technologies should equally be able to serve dispersed populations and activities. Digital technology makes it much more possible outside cities than before-communicating with markets, etc. so theoretically, people are not isolated by living outside the city. Energy researcher and author Oscar Serpell urges us not to base future drivers for urbanization/ de-urbanization on past drivers: For example, if off-grid storage becomes cost-effective, or transportation becomes primarily electric and driverless-suddenly transportation CO2 drops and productive commuting time can enhance connectivity between multiple geographies and livelihoods.

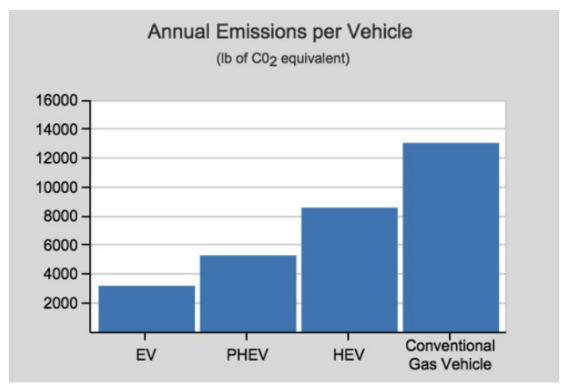

Figure 4. Annual Emissions per Vehicle, New York (Tesla 2015)

\section{DISCUSSION}

As a topic outside of my core area of expertise as an academic and practicing architect/developer, this preliminary Literature Review is more broad and less systematic than ideal. Piecing together findings from associated but distinct disciplines rife with unsettled debates, has its challenges. For every argument one can also find its opposite, making it critical to wade through the data and metrics with a grain of skepticism and common sense in equal measure. Ultimately I seek a straightforward but sufficiently nuanced framework that will bring greater clarity to how we make decisions as planners and designers. On the hunch that residential transportation and housing emissions are an inadequate metric, I sought out studies on additional measures of consumption. I sought out $\mathrm{CO}_{2}$ measurement data to further reinforce or refute these findings. However, the source of emission in one study is doesn't entirely overlap with what is measured in the other, either in type of emission, place or time-and it assumes that typical behaviors observed in Finland are approximately similar to those in the United States on any given year in the last decade. Nonetheless I am cautiously satisfied that these findings can expand a common understanding.

\section{CONCLUSION}

Rather than rushing to density, by leveling the playing field between multiple scenarios of productive existence both in terms of societal and ecological impact, we can make more considered choices. The reason for caution is that while agglomeration offers clear economic growth advantages by amassing knowledge, labor and resources to create a competitive productivity, it also tends to exacerbate inequity. Researchers such as economist Jordan Rapaport have noted that, "density generates diseconomies like traffic 
congestion or expensive housing costs, which limit growth," and that "Dis-amenities begin to outweigh advantages, managerial complexities become too vast, and happiness is found to be greater in less dense settlements (Rapaport 2018)." (Rapaport's sweet spot for city population is from just under 500,000 to 3 million). "Climate-friendly" higherdensity housing, however, has been found to be an accelerating factor in neighborhood gentrification and displacement of existing residents (Rice et al 2019). Moreover, the heightened dependence of cities on manmade systems and centralized control are also likely to make cities-especially traditional coastal/trade more vulnerable than less to Climate Change. The arrival of the pandemic has further exposed the extent to which high settlement population and density can backfire on multiple levels.

So what is the free-market solution, assuming that is what we want? More choices, right? Putting all your eggs in the star-city baskets, where they become de-facto monopolies on job creation and real estate value is neither necessary or a given. Recognize that wealth creation can be more geographically diversified and focus on the infrastructures that can support them. John Day and Charles Hall urge us not to make the mistake of looking at urbanism as a setting (form) rather than the manifestation of a portion of a system (Day and Hall 2016). Human settlement objectives can be considered regionally, linking urban, exurban, country, with movement and knowledge-sharing back and forth to seek solutions for reducing GHG while improving life tailored to localities. Our data suggest that an entirely new approach of highly tailored, community-scale carbon management is urgently needed" (Day and Hall 2016). 


\section{REFERENCES}

Editor's Pick 2015, \#4:

Non-Operating Landlords Own 31 Percent of U.S. Farmland.", accessed Sep 21, 2020

"How Tesla Will Change the World." Wait But Why., last modified -0602T09:47:44+00:00, accessed Sep 22, 2020

"The Faster Growth of Larger, Less Crowded Locations.", accessed Sep 22, 2020

"The Growth Ponzi Scheme." Strong Towns., accessed Sep 21, 2020.

"Yes, there's a Rural Creative Class, Too." 2018. Bloomberg.Com.

Ashwood, Loka, John Canfield, Madeleine Fairbairn, and Kathryn De Master. 2020. "What Owns the Land: The Corporate Organization of Farmland Investment." The Journal of Peasant Studies 0 (0): 1-30.

Brooks, Leah and Zachary D. Liscow. 2019. Infrastructure Costs. Rochester, NY.

Brown, Marilyn A., Frank Southworth, and Andrea Sarzynski. 2009. "The Geography of Metropolitan Carbon Footprints." Policy and Society 27 (4): 285-304.

Bruegmann, Robert. 2005. Sprawl : A Compact History University of Chicago Press.

C40 Cities, University of Leeds, University of New South Wales, and Arup. 2018. Consumption-Based GHG Emissions of C40 Cities: C40 Cities.

Day, John W. and Charles Hall. 2016. America's most Sustainable Cities and Regions. [Electronic Resource] : Surviving the 21st Century Megatrends. 1st ed. 2016. ed. Springer New York.

Florida, Richard L. 2017. The New Urban Crisis : How our Cities are Increasing Inequality, Deepening Segregation, and Failing the Middle Class-- and what we can do about It Basic Books.

Glaeser, Edward L. 2011. Triumph of the City : How our Greatest Invention Makes Us Richer, Smarter, Greener, Healthier, and Happier Penguin Press.
Heinonen, Jukka, Mikko Jalas, Jouni K. Juntunen, Sanna Ala-Mantila, and Seppo Junnila. 2013a. "Situated Lifestyles: I. how Lifestyles Change Along with the Level of Urbanization and what the Greenhouse Gas Implications Are-a Study of Finland." Environmental Research Letters 8 (2): 25003.

"Situated Lifestyles: II. the Impacts of Urban Density, Housing Type and Motorization on the Greenhouse Gas Emissions of the Middle-Income Consumers in Finland." Environmental Research Letters 8 (3): 35050.

McDonogh, Gary, Cindy Isenhour, and Melissa Checker. 2011. "Introduction: Sustainability in the City: Ethnographic Approaches." City \& Society 23 (2): 113116.

Newman, Peter and Jeffrey Kenworthy. 1999. Sustainability and Cities: Overcoming Automobile Dependence Island Press.

Oliveira, Erneson A., Jr Andrade José S, and Hernán A. Makse. 2014. "Large Cities are Less Green." Scientific Reports 4 (1): 4235.

Pichler, Peter-Paul, Timm Zwickel, Abel Chavez, Tino Kretschmer, Jessica Seddon, and Helga Weisz. 2017. "Reducing Urban Greenhouse Gas Footprints." Scientific Reports 7 (1): 14659-11.

R. J. Fuller and R. H. Crawford. 2011. "Impact of Past and Future Residential Housing Development Patterns on Energy Demand and Related Emissions." Journal of Housing and the Built Environment 26 (2): 165-183.

Rice, Jennifer L., Daniel Aldana Cohen, Joshua Long, and Jason R. Jurjevich. 2019. "Contradictions of the ClimateFriendly City: New Perspectives on EcoGentrification and Housing Justice." International Journal of Urban and Regional Research 44 (1): 145-165. 
Roberts, David. "Cities are Beginning to Own Up to the Climate Impacts of what they Consume." Vox., last modified -0701T11:30:00-04:00, accessed Feb 23, 2020.

Shammin, Md R., Robert A. Herendeen, Michelle J. Hanson, and Eric J. H. Wilson. 2010. "A Multivariate Analysis of the Energy Intensity of Sprawl Versus Compact Living in the U.S. for 2003." Ecological Economics 69 (12): 2363-2373. Stephan, André, Robert H. Crawford, and Kristel de Myttenaere. 2013. "MultiScale Life Cycle Energy Analysis of a Low-Density Suburban Neighbourhood in Melbourne, Australia." Building and Environment 68: 35-49.

West, Geoffrey and Luis Bettencourt. 2010. "A Unified Theory of Urban Living." Nature 467 (7318): 912-913. 



\section{PAPER \#1.17}

\section{CORPOREAL POLIS}

Paul Holmquist ${ }^{\mathrm{a}}$

aLouisiana State University, USA

\section{ABSTRACT}

What relation do architects have to the political dimension of the city as polis? What is the relation between urban protest movements and the city spaces they take place within? How can architecture learn from protest, and particularly from what happens to spaces and places in protest in order to anticipate, support, and even sustain the possibility for the political dimension of the city to emerge in urban experience? In this essay I attempt to outline a response to these questions through a discussion of the differing roles of place in urban protests such as Occupy Wall Street in 2011 in New York, the 2011 Egyptian Revolution, the ongoing pro-democracy protests in Hong Kong, and the Gezi Park protest of 2013 in Istanbul. I examine the interrelation of place and the political in these cases with respect to the political philosophy of Hannah Arendt, and to her conception of action and appearance in relation to the irreducible corporeality of political actors and of the spaces produced in action. I argue that the bodily presence, acting and speaking of political actors implicate the shared corporeality of urban places as part of the common world, and opens a political and actionable sense of reality within the otherwise predominant instrumental and operative reality undergirding apparatuses of power. I conclude that in prioritizing this actionable reality and the corporeality of the acting body, architecture and urbanism as design practices can begin to articulate places that may potentially reinforce and resonate with the political dimension of human action and being-in-common, and in so doing, materially recollect and reconstitute the city as a corporeal polis.

\section{KEYWORDS}

Urban protest; public space; the political; corporeality; Hannah Arendt.

\section{INTRODUCTION}

In the last decade the question of the political nature and viability of public, urban space has been brought to the fore around the world by repeated protests and uprisings against the exclusion, inequality and injustice of oppressive structures of power. According to theorist and geographer Erik Swyngedouw, the protesters who take to urban spaces to reclaim them politically from the governmental apparatuses of neoliberal capitalism and authoritarian state regimes are "insurgent architects," whose actions remake cities as properly political sites of contest, dispute and dissensus where alternate forms of beingin-common can be envisioned, prefigured and enacted.(Swyngedouw 2018) In these insurgent "urban designs," wherein urban spaces are reappropriated and repoliticized in dissent, political actors and their intentions take priority over those of the professional designers of architecture and urbanism. In their actions, and through their bodies and voices, protesters themselves are responsible for opening spaces in which the political, as such, can appear and be experienced in the city. As urban spaces are taken back, if only momentarily, from their erstwhile designers and the regimes of power that structure, organize and police the city, the question arises of what relation architects have to the political dimension of the city as polis. What role do architects and other designers play, or can possibly play, in the emergence of the political 
as such in protest? Can architects address the potentiality of urban places to become sites for the political? Can they cede priority to political actors while still enabling conditions for protest and other political action? How can architecture learn from protest, and particularly from what happens to spaces and places in protest? What lessons can be drawn from them so that architecture may be able to anticipate, support, and even sustain the possibility for the political dimension of urban experience to emerge out of action, wherever and whenever it may occur? I will attempt to outline a response to these questions through a discussion the interrelation of action, place and the political in protest events with respect to the political philosophy of Hannah Arendt, and to her conception of action and appearance in relation to the irreducible corporeality of political actors and how it directly implicates the 'corporeality' of spaces and places that are the sites of action. I argue that for Arendt, an objective, actionable sense of reality emerges out of the bodily co-presence of heterogenous actors that is integral to place and opens up within and as an exception to the predominantly instrumental and operative sense of reality that apparatuses of power are predicated upon. Drawing as well upon Judith Butler's work on the body and performative assembly and Jean-Luc Nancy's on community and the common, I furthermore argue that the bodily presence, acting and speaking of political actors potentially implicate the shared corporeality of urban places as the common world such that the political - the potentiality of being-in-common - manifests immanently within it. Through a discussion of protest movements such as Occupy Wall Street in New York and the Egyptian Revolution, both of 2011; the Gezi Park Protests of 2013 in Istanbul; and the ongoing Hong Kong prodemocracy protests; and how they effectively and communicatively 'corporealize' the urban spaces they take place within, I hope to further understand the potential capacity of urban places to materially undergird the emergence of the political, and point to ways that architectural and urban design practices may be able to reassert the priority of actionable reality to recover the city as a corporeal polis.

\section{PROTEST AND POLITICS}

While the scientific literature on urban protests is vast and multi-dimensional, including much critical work on the spatiality of urban protest, critical examination of their specifically architectural dimensions, broadly speaking, has not been widely undertaken. Architecture as practice and artifact is generally associated with the operation of power that protest movements struggle against, and it must collectively be reappropriated, reprogrammed, redeployed and recreated in order for it to enable more equitable, just and inclusive agendas. An exception to this view can be found in Beyond Zuccotti Park: Freedom of Assembly and the Occupation of Public Space (2012), edited by Ron Shiffman, et al, a multi-disciplinary collection of essays on the mutual implications of political protest, public space, the commons, architecture and urbanism that was compiled shortly after the 2011 Occupy Wall Street protests in New York.(Shiffman et al 2012) On the other hand, there is a burgeoning literature on the political agency of architecture and urbanism themselves as capable of empowering social and political actors and critically engaging spatial structures of oppression, exploitation and exclusion, including the appeal to socalled "spatial agency," "tactical urbanism," and "insurgent" and "guerilla urbanism."(Awan, Schneider, and Till 2011; Gadanho et al 2014; Hou et al 2010) Much of this work follows in some way from that of sociologist and philosopher Henri Lefebvre who, drawing upon Marx's reduction of human reality to the social conditions of production, extends it to the space and fabric of the city as a collective "work" whose potential to accommodate the 
fulfillment of a properly authentic human life proceeds directly from the equitable, inclusive nature of those social conditions. In this view, the production of space and architectural artifacts likewise proceeds directly from the corporeality of labor production within the social relationships that entangle bodies, entraining them reciprocally within the spaces and artifacts they produce. Urban protest can thus be understood by theorists and commentators such as Erik Swyngedouw and Mustafa Dikeç in terms of reappropriating and reproducing urban space through spontaneously reconfiguring the relations of production through the collective action of equal and inclusive actors.(Swyngedouw 2018; Dikeç 2015) Drawing upon a wider range of thought from figures such as Hannah Arendt, Jean-Luc Nancy, Jacques Rancière, Slavoj Žižek and Chantal Mouffe, these and other theorists attempt to articulate how the properly political dimension of cities and space in general an arise through contesting the control and meaning of urban places, and staging prefigurations of alternative forms of being-in-common that are more equitable and inclusive in occupying them. Swyngedouw goes so far as to characterize these protesters are "insurgent architects" and urban "designers," who effectively reshape the city materially and symbolically to collaboratively envision and enact it as polis. (Swyngedouw 2018)

While this body of critical work on space and protest is powerful and incisive, the assumption of an operative reality of production common to both oppressive power and emancipatory resistance is highly problematic in that it renders political action as effective or not according largely to an instrumental framework of ends and means. Architecture and urban spaces become subject to an instrumental reality that renders them either as tools of repression or emancipation, and effectively subsumes them within the domain of force, even if only in principle. It is furthermore difficult to ascribe what freely and undeniably appears, or comes to light, in protest - the prefiguration of alternate modes of being-in-common and the appearance of dignity, beauty, equality, inclusivity - to the same processes of direct resistance and contest of authority and power. Many commentators, including those noted above, turn to Arendt and her performative theory of political action to account for this phenomenon of political appearance, even within agonistic contest, in order to recognize the priority of non-instrumental action taken solely out of a common concern for the just. Yet even a cursory reading of Arendt's work shows the fundamental incompatibility of her thought with any emancipatory politics, and especially with rendering the political realm subject to instrumentality in any way. For Arendt, the very freedom at stake in political action and appearance is destroyed by constraining it within the framework of ends and means, which entrains action within the necessity of causes and intended effects.(Arendt 1998) While much criticism of Arendt's thought centers on her distinction between work, labor and political action as interrelated but essentially different realms of human activity, her strict exemption of action - as exclusively political and concerning the possibility of human freedom - from all instrumentality is very often ignored. In this paper I attempt to outline how the political dimension of urban protest in relation to urban places can be rethought through Arendt's political theory, in such a way that the expressly political, non-instrumental dimension of protest action can be seen in the likewise non-instrumental reciprocity of bodies, spaces and places in the city.

\section{CORPOREALITY, APPEARANCE AND PLACE}

Arendt's political theory is, like that of Lefebvre, a powerful and incisive means of conceptualizing the interrelationship of protest action, space and urban places 
so as to preserve the possibility of human freedom in political action. As with Lefebvre, the acting body is the originary site of the political, but only insofar as action is taken for the sake of manifesting the particularity of human freedom, and for establishing, sustaining and preserving a public realm of human affairs - the realm of our concern for being-in-common - wherein human freedom can be enacted in action and speech.(Arendt 1998; 2006) For Arendt, the public realm is a space of appearance in which actors disclose themselves as human in freely acting for the sake of common concern.(Arendt 1998) The public realm is a formalization of the space that arises between acting bodies, and as such depends on the co-presence of actors and their bodies in space, and the ability of all actors to see and hear everyone else.(Arendt 1998) The public realm as a sphere of appearance furthermore inheres in the tangible common world in which bodies coexist and, as Judith Butler writes, coconstitute location and place in permeating the physical world with their own spatiality. (Butler 2015) The co-constitution of the common world as a place is contingent on the unique bodily location and perspective of heterogeneous actors, by virtue of which both the objectivity and reality of the world are provisionally established among them. This reality, born out of the co-presence and irreducible difference of plural acting bodies, is an actionable, rather than operative, sense of reality. It is the sense of reality in which action in its fullest political sense gives rise to human appearance and freedom, which for Arendt is the very essence and meaning of the political.(Arendt 1998; 2006) Furthermore, it is only in this actionable and freeing reality that the political as the horizon of possibility for being-in-common, following Jean-Luc Nancy, can open, or be exposed. In this opening the very question of the common - of beingwith-others - can come into light, be grasped, take orientation, and be engaged.(Nancy and Fynsk 1991)
The political dimension of protest action then, when seen through an Arendtian lens, arises first out of the gathering and co-presence of bodies in places wherein the corporeality of location and action constitute the world as a co-corporeal, actionable place. This corporealized sense of place is coincident with the opening and actualization of a sphere of common concern through bodily copresence and co-action, and, as Butler argues, this place is thus materially transformed to manifest the corporeal qualities of plurality, difference and equality of the bodies that co-produced it.(Butler 2015) Here Butler follows more directly from Lefebvre, but her point recalls the fitness for appearance that Arendt requires of the common world - that it manifest the beauty and tragic dignity of the human that resonates with and orients the qualities of human action taking place within it.(Arendt 1998; Curtis 1999) As I have argued elsewhere, the fitness of the common world for human appearance can be understood as its capacity to manifest the common - to allow the common, as such, to appear within it.(Holmquist 2020) Whereas for Arendt the common in terms of human qualities and ideals was traditionally embodied in monuments as the traces of past action, nowadays we must look to the ephemeral and contingent qualities of place as it emerges in co-corporeality with acting bodies during the event of protest. Some of the ways that this co-appearance of the common takes place with actors in urban protests will be discussed below. For now, it is enough to recognize this potential capacity and how, in principle, it constitutes the proper political dimension of many urban protests through action for the sake of opening the common, and the possibility of orientation and engagement. This view is again in contrast to the instrumental contestation of control of action or places in order to achieve discrete ends, however principled, although the difference between these actions is not always clear. Following Arendt, protest action 
appears ambivalent in that instrumental action is taken for the sake of opening a properly political space of free disclosure and orientation, and actionable reality must often arise within operative reality, and be subject to the force that can be implemented through it. Place likewise appears concretely as both an instrumental and expressively resonant extension of the body.

\section{OCCUPY WALL STREET 2011}

There is no doubt that the experience of urban protest is intensely corporeal, wherein action, bodies and places fuse within the space and time of the event, especially when bodies are subject to violence and endangered. Yet the co-corporeality of bodies and places in protest, and the actionable reality they constitute through their co-corporeality, may well be most clearly seen in cases such as the Occupy Wall Street protest in New York's Zuccotti Park in the fall of 2011, where protests were on the whole non-violent and the police response was generally not life-threatening. The Occupy Movement, of course, takes its name from the traditional tactic of contesting power through mass assembly in a prohibited or otherwise controlled place. Occupy Wall Street protesters, however, strategically chose Zuccotti Park for occupation because as a so-called 'privately-owned public space' it was not subject to municipal ordinances governing assembly and opening hours as were city-owned parks and was required to be accessible to the public twenty-four hours a day.(Kayden 2000) Zuccotti Park thus served the protesters' immediate objective to gather together as many people as possible proximate to Wall Street without breaking the law or contesting control of the space, and to maintain their constant presence and action through encampment. Within this suspension of place-time in the neoliberal capitalist governance of the city a radically plural, egalitarian and democratic space opened up wherein a new model of being-incommon was enacted through new forms of interaction and communication. As is well known, the Occupy Wall Street protest had no leaders, or specific goals or demands other than to register outrage at the injustice of neoliberal economic order, and to enact in the space of protest an alternative to it. The struggles with police were almost incidental to the intent and meaning of the protest even after the park was forcibly cleared of tents, signs and other belongings, as seen in the protesters' immediate return with only their own bodies and voices.

In refusing to tie their action to instrumental objectives, Occupy Wall Street protesters actualized the actionable reality of Arendt within the space of Zuccotti Park for the sake of appearance, out of a common concern for the just. Through their active bodily occupation, they re-corporealized the empty corporate plaza used primarily for access to the nearby subway station by enfolding it within their collective space of appearance as a material co-constituent. From participant accounts in media at the time and afterwards, the park appeared to be materially transformed by the action taking place within it, as Butler argues for, but in a way that could not be reified or iconicized in any form or image. This was the case in spite of large, prominent works of public sculpture within the park, including Mark di Suvero's monumental Joie de Vivre, which protesters referred to only as 'the big red thing.'(Schneider and Solnit 2013) Likewise, the aspects of the park that come through most strongly in writing and images are not the forms of the park itself or of the buildings surrounding it, but the colors and qualities of the materials they were made of: the grove of honey locust trees and the brilliant yellow glow of their canopies; the gray granite of the park paving and seating areas; the blue of the plastic tarps covering protesters' tents; the red of di Suvero's sculpture, and another by Isamu Noguchi.(Schneider and Solnit 2013) These qualities and facts of materiality come 
forward in contemporary images as mutually imbricated within the assembly of actors and their bodies, not merely as their setting or accoutrements, but as resonant extensions of their corporeality. I have suggested elsewhere that Zuccotti Park can be understood as having been effectively compelled to become fit for the appearance of the political taking place within it, following Arendt, and to comanifest the beauty and tragic dignity of human action.(Holmquist 2020) In so doing, I argue that the resonant corporeality of the park recollected an originary potential for being-with at the basis of human being-incommon that, according to Jean-Luc Nancy, is shared by all being, human and non-human. (Nancy 2000) It is therefore by virtue of this originary relation of human and nonhuman potentiality of being-in-common that urban places can be understood to embody something of the transcendence of mere corporeal facticity that is the essence of human political experience. It is furthermore this potentiality of being-in-common with the world that is at stake in the re-corporealization of place in urban protest, and that links action and place within an ambivalent operativeactionable reality.

\section{TAHRIR SQUARE 2011}

The re-corporealization of urban place to open an actionable political sense of reality seen in the Occupy Wall Street protest can be understood as a general phenomenon of urban protest, and particularly in how, as John Berger observed, protesters' bodies are implicitly and explicitly offered as targets for state violence.(Berger 2001) In the 2011 Egyptian Revolution, the corporeal interrelation between protest action, place and violence came to light most clearly in the epicenter of the uprising in Cairo's Tahrir Square. Modeled in form during the 19th century after Haussmann's depoliticizing of Parisian public squares, Tahrir Square had developed over time into an important public space identified with the nation, in spite of having been transformed into a major traffic circle. Flanked by important public buildings and including a monument to nationalist hero Umar Makram, the square evokes the sense of an Arendtian public space that is ostensibly common, invested in meaning, and clearly bounded. Yet as a place, the square implicitly embodied the repressive state apparatus in giving priority to the monumental urban form as object and icon, rather than the bodily space of potential assembly and action. The occupation of Tahrir Square in the first months of 2011 by up to 250,000 protesters represented the literal re-corporealization of the square by encompassing it wholly within the actionable political space of appearance in non-violent protest. As with the Occupy Wall Street protests later that year, the enduring bodily co-presence of protesters served to explicitly contest and deny the prevailing operative reality of signification and repression, and gave lived, corporeal presence, weight and urgency to the political question of the common at stake. Unlike Occupy Wall Street, however, this re-corporealization of the square was met with brutal and violent force directed against protester's lives and bodies, and their potential for co-presence and co-action, which was, following Arendt, the basis of the collective power that they possessed.(Arendt 1998) The persistence of the protesters to fully inhabit the square through encampment in the face of violent reprisal effectively identified their own bodily endangerment with that of the square as a public place, and of the nation in question and envisioned anew. The square in turn became the living, struggling figure, as it were, of the protest, and the corporeal frame and stage for the space of appearance opened within it in which the powerful demand for political change could become effective. 


\section{HONG KONG 2014}

In the Occupy Wall Street protest and Egyptian Revolution, actionable reality opened up in spite of the predominant operative reality, and in exception to it, through the co-corporeality of protesters and places. In the Hong Kong prodemocracy protest movements of 2014 and 2019 which continue today, actionable reality has opened up through the transformation of operative reality itself through bodily performances of instrumentality that deny its apparent priority and hegemony. Similar to Occupy Wall Street and the Egyptian Revolution, the protests in Hong Kong began peacefully and utilized concerted bodily assembly and encampments, but quickly shifted to staging actions and events widely across the city and territory and directly confronting, even violently, repressive police action. In many instances, protesters countered aggressive police tactics with their own, throwing Molotov cocktails and bricks, breaking storefronts, setting fires and commandeering police equipment and implements. Yet perhaps more significantly, protesters also responded directly to police action by deploying and repurposing everyday objects such as umbrellas for shields; sports and industrial equipment such as hard hats, goggles, body pads and respirators for helmets, face shields, body armor and gas masks; phone lights for flares; and plywood panels for shields. Infused with a simultaneously functional, performative and communicative irony, the 'do-it-yourself' ethic of improvisation and the emphasis on the 'gearing-up' of protester's bodies parodically transforms the violent operative reality of repression by reappropriating it for the ends of protest on its own terms. Artists and curators Carlotta Werner and Johanna Sunder-Plassmann have framed these repurposed implements as "hacked protest objects" which are "designed" through crowdsourcing in response to overwhelming police force, and whose practical and symbolic meaning can shift and change.(Werner and Sunder-Plassman 2014) Yet in diverting their determined intentionalities, these implements can be read in light of the Lettrist and Situationist tactic of détournement as hijacking operative, instrumental reality itself and folding it within a larger actionable reality of appearance. The effectiveness of these tactics stems first from their communicative performativity, and second from their actual effectiveness, as evident in the flood of media images showing masses of protesters and police advancing towards each other, respectively behind extended umbrellas and bullet-proof shields. In their gear, protesters' bodies are re-articulated as instrumental extensions capable of acting, in an Arendtian sense, within the operative reality that subsumes the space of the city. Their bricolage of gear allows protesters to become mutually imbricated within the physicality and objectness of the city, and to project performative, 'detourned' instrumentality into the controlled spaces of commerce, transportation, and public institutions. Here the spaces of the city as the common world are called upon to be perceived as the stages for performative action, and I would argue that like Zuccotti Park, they are compelled to 'appear' in a way that is fit for political appearance as spaces in which the hegemony of instrumental operative reality is not only suspended, but suspendable. The instrumentalized bodies of the protesters thus open up an actionable reality of communication and concern for being-in-common within an alternate sense of reality, and thus of possibility, in which the common as the horizon of potentiality can be discerned. While such protest action has no hope of overwhelming police action through force, it is imbued with the power that arises out of co-presence and co-action of bodies for Arendt and sustains the capacity of the question of just and equitable beingin-common to appear in the protests. (Arendt 1998) 


\section{GEZI PARK 2013}

The Gezi Park protests in Istanbul of 2013 likewise featured the denial of the hegemony of the instrumental, operative reality that enables the ongoing capitalist transformation of the lived city, as well as the brutal police response to the protesters themselves. Similar to the protests in Tahrir Square, many thousands of protesters peaceably occupied Gezi Park and the adjacent Taksim Square out of similar political concerns, and in the face of violent reprisal. The park is one of the last public green spaces in Istanbul and had been threatened with redevelopment into a commercial and residential complex under President Erdogan's so-called 'crazy' program of nationalist, capital-driven transformation of the city. The protest occupation of the park was launched by activists out of ecological and environmental concerns and occasioned a proliferation of communal and collective practices in the space involving not only protest, but education, recreation and everyday activities that were given heightened visibility and significance within the protest space of appearance. As with Tahrir Square, the Erdogan regime responded by attempting to disrupt and disperse the concentration of acting bodies by force and expel protesters physically from the park. The formerly peaceful occupation turned into a fierce struggle between protesters and police in the park and in other areas of Istanbul and across Turkey, in which a number of people were killed. While the corporeality of protesters' acting bodies can here be understood similarly to the Egyptian protest as the basis of the properly political dimension of the protest, a particular tactic taken which garnered global attention was the celebrated inaction of a particular protester, the so-called 'Standing Man.' In the midst of the struggle to maintain the occupation of the park, protester and performance artist Erdem Gunduz prominently refused to act further, and began to stand still in Taksim Square facing the
Ataturk cultural center.(Seymour 2013) He maintained his stillness and silence for eight hours and was joined by other protesters in the square and across Turkey. Gunduz's bodily performance of inaction has been interpreted widely in the tradition of passive resistance in the face of overwhelming physical repression, and as a poignant affront to the regime through aesthetic tactics. Yet Gunduz's 'inaction' can also be understood as a particular realization of actionable reality in performing the denial of the operative reality of the governmental regime that endangered protesters' lives and bodies, as well as the viability of Gezi Park as a natural, living place. By identifying his inactive body with the threat posed to natural life and actual lives within both the park and the city, Gunduz performed a corporeal solidarity with the essential non-instrumentality of living things, and the being-with-others that human being shares with the non-human world. In corporeally denying operativity, the park and square were effectively re-corporealized by invoking the shared being-with of all being as the origin of the human experience of the political, and implicitly calling for the non-human to be recognized, in its own sheer corporeality, as included within the city as polis. While the political dimension of the Gezi Park protests encompassed a much wider set of concerns for the question of being-in-common, the ecological concern highlights the expansive political dimension implicit in the interrelation of place and protest.

\section{CONCLUSION}

This essay is but a preliminary outline of an inquiry that requires much further research and reflection. Yet it has attempted to show how the corporeality of protesters becomes imbricated within the spatiality and materiality of urban spaces in ways that reveal the significance of the body to political action, and to the city as an inherently political 
place. In each of the cases discussed, protest entailed the massive, bodily assembly of plural, diverse and in principle, equal actors united less by specific demands or objectives than a more universal demand for a just and equitable society. Within these protests, an actionable reality arose out of the co-action of corporeal actors to sustain a powerful space of appearance, simultaneously within, and subject to, the operative reality of repression and violent reprisal. Within this actionable reality, alternative modes of being-with and being-in-common emerge to prefigure and enact possibilities of the political, albeit ephemerally and contingently. In light of the acting body's fundamental role, in its essential corporeality, to materially coconstitute the space and place of the political with other bodies, what can architects and other designers learn from the "insurgent architects" who "re-design" urban spaces to reassert the political in protest? A key lesson, first and foremost, is the priority of the actors in their corporeality, and correspondingly that of the political, objective sense of actionable reality that actors co-constitute out of their plurality and heterogeneity. From protests such as Occupy Wall Street and the Egyptian Revolution we can discern our shared embodiment with places and their resonance and identity with our experience of the political. In particular, we can consider the capacity of the world to speak to perception of a common, pre-reflective potentiality of beingin-common, in some ways similar to the tacit resistance to techno-scientific hegemony that Kenneth Frampton recognized in the tactility and materiality of Alvaar Aalto's Säynätsalo Town Hall.(Frampton 2002) From the Hong Kong and Gezi Park protests, we can see how instrumental, operative reality can be performatively and corporeally 'detourned', co-opted and denied to open the question of the common within an exceptional, actionable reality. The question for architecture may perhaps first be how these priorities and realities can be recognized in design; how they can be articulated and structured within the fabric and texture of the common world; and how they may remain susceptible to being actualized by political action, whether extraordinary or in everyday life. Although design is necessarily predicated in part upon an operative and technical reality, Arendt writes that architecture, as a public art, depends on the political wisdom of phronesis in order to grasp and negotiate actionable human reality, so that architecture and the common world might be made fit for the public realm of human affairs, including protest. (Arendt 1998) In conclusion I would suggest that by prudently attending to the priority of corporeal actors and of actionable reality can architecture begin to articulate places that may potentially undergird, reinforce and resonate with the political dimension of human action and being-in-common, and in so doing, materially recollect and reconstitute the city as a corporeal polis.

\section{ACKNOWLEDGEMENTS}

The author hereby acknowledges the support of the School of Architecture at Louisiana State University for this research, and for its presentation at the 2020 EAAE-ARCC International Conference. 


\section{REFERENCES}

Arendt, Hannah. 1998. The Human Condition. 2nd ed. Chicago: University of Chicago Press.

---. 2006. "What Is Freedom?" In Between Past and Future: Eight Exercises in Political Thought, by Hannah Arendt, 142-69. New York: Penguin Books.

Awan, Nishat, Tatjana Schneider, and Jeremy Till. 2011. Spatial Agency: Other Ways of Doing Architecture. Abingdon, Oxon: Routledge.

Berger, John. 2001. "The Nature of Mass Demonstrations." In Selected Essays, Kindle edition. New York: Vintage Books.

Butler, Judith. 2015. Notes Toward a Performative Theory of Assembly. Kindle edition. Cambridge, M.A: Harvard University Press.

Curtis, Kimberley. 1999. Our Sense of the Real: Aesthetic Experience and Arendtian Politics. Ithaca, N.Y: Cornell University Press.

Dikeç, Mustafa. 2015. Taking on the Political: Space, Politics and Aesthetics. Kindle edition. Edinburgh: Edinburgh University Press.

Frampton, Kenneth. 2002. "Towards a Critical Regionalism: Six Points for an Architecture of Resistance." In Labour, Work and Architecture: Collected Essays on Architecture and Design, 77-89. London: Phaidon Press.

Gadanho, Pedro, ed. 2014. Uneven Growth: Tactical Urbanisms for Expanding Megacities. New York: Museum of Modern Art.

Holmquist, Paul. 2020. "Designing Dissensus: Exposing the Common." Contour (6). http://contourjournal.org/index. php/contour/article/view/designingdissensus."
Hou, Jeffrey, ed. 2010. Insurgent Public Space: Guerilla Urbanism and the Remaking of Contemporary Cities. Abingdon, Oxon: Routledge.

Kayden, Jerold S. 2000. Privately Owned Public Space: The New York City Experience. New York: John Wiley.

Nancy, Jean-Luc. 2000. Being Singular Plural. Stanford, CA: Stanford University Press.

Nancy, Jean-Luc, and Christopher Fynsk. 1991. The Inoperative Community. Edited by Peter Connor. Minneapolis, M.N: University of Minnesota Press.

Schneider, Nathan, and Rebecca Solnit. 2013. Thank You, Anarchy: Notes from the Occupy Apocalypse. Ebook. Berkeley, C.A: University of California Press. www.jstor. org/stable/10.1525/j.ctt3fh39s.

Seymour, Richard. 2013. "Turkey's 'standing Man' Shows How Passive Resistance Can Shake a State." The Guardian, June 18, 2013, Online edition. https://www. theguardian.com/commentisfree/2013/ jun/18/turkey-standing-man.

Shiffman, Ron, ed. 2012. Beyond Zuccotti Park: Freedom of Assembly and the Occupation of Public Space. Oakland, CA: New Village Press.

Swyngedouw, Erik. 2018. Promises of the Political: Insurgent Cities in a Post-Political Environment. Cambridge, M.A: MIT Press.

Werner, Carlotta, and Johanna SunderPlassman. 2014. "Hacked Protest Objects (Anon)." Design and Violence (blog). May 28, 2014. https://www.moma. org/interactives/exhibitions/2013/ designandviolence/hacked-protestobjects-anon/. 
PAPER \#1.18

\section{THE DIFFUSE MUSEUM. TOWARD A NEW MODEL FOR INTERPRETING ARCHITECTURE}

\section{Queralt Garriga Gimeno ${ }^{a}$}

aUniversitat Politècnica de Catalunya, Barcelona, Spain

\section{ABSTRACT}

Architecture, the most approachable artistic discipline, and yet paradoxically, the least known. If we want to communicate the values of architecture as a discipline and its qualities as an artform, we must offer a new model for interpreting built space. Not a model based on abstract or conceptual knowledge, but one that understands how architecture structures, orders and articulates individual, concrete and perceptible spatial experiences. The best way to acquire architectural knowledge is through direct experience in the building itself, helping the visitor to be more aware of what is happening directly before him. The diffuse museum is a new way of understanding what an architectural museum can be. It is a museum dispersed throughout the territory, not circumscribed within an enclosure. Its collection consists of the best spaces and buildings in our cities, waiting for someone to help them become visible, recognizable, interpretable and communicable.

\section{KEYWORDS}

Museum; architecture; communication; museology; interpretation; heritage.

\section{ARCHITECTURE AND SOCIETY, AN ABSENT CONVERSATION}

We all move through, inside and around architecture. Architecture is the backdrop to our everyday lives, and yet paradoxically, it is the least known artistic discipline. The commonplace landscape that surrounds us, the city and its most significant elements, are invisible to most of society. Despite the apparent architectural media fevers of recent decades and the proliferation of international architectural events, there persists a lack of knowledge among the general public concerning architectural fundamentals and values. This lack of familiarity translates into less empathy towards architecture as compared to other arts. In order to improve our cities, we must disseminate architectural knowledge among the general public. To achieve this, the following study proposes a new method for interpreting architecture.

Seventy years ago, Bruno Zevi (1951) stated that one reason for this situation was architects' own lack of interest in being understood. Traditionally architects have been more interested in the building of architecture than in its communication, and this task has been relegated to other disciplines.

Today, more than ever, citizens are directly involved in the process of defining the city. However, this empowerment in public debate has not been accompanied by the wide dissemination of necessary architectural and urban concepts.

In addition, institutions responsible for the diffusion of architectural culture use cryptic museological concepts and museographic tools that in general are far removed from the reality of the architectural discipline. Centres for the interpretation of architecture should stop merely exhibiting documentation -objects and elements-, and instead investigate forms of communication that are more didactic. Their main objective should be to transmit architectural values and concepts, so that architecture can be valued, enjoyed and respected. Because architecture is, like all artistic disciplines, meant to be communicated. The question is: what needs 
to be explained and how. Citizens urgently need new interpretive instruments to learn to see and appreciate architecture. It Is urgent because the city is built by all of us, not just architects. We are all co-responsible of the city. Citizens must be supplied with methods and instruments so that together we can create a better debate and dialogue.

\section{EDUCATING THE GAZE: TEACH LOOKING, IN ORDER TO SEE}

Typically, architectural discourse, like that of other art forms, is distant and intimidating. This is because, in general, art education values the memorization of answers given by others more than the stimulus of spontaneous conversation spawned by direct interaction with the artistic reality. When looking at artworks, the intellectualization of what we see prevails over the conscious perception of what we apprehend -the experience of art-. And, as explained by Eulàlia Bosch (1998),

In doing so, we convey the idea that understanding a work of art is knowing how to classify it, so that when a student stands before a work of art (...) he searches at top speed what terms are pertinent and begins to speak before starting to look.

Our gaze is the filter of our memory, that which is prior to the acquisition of knowledge. Learning to look is necessary to enable the construction of criteria and the formation of judgments. All visions are valid. All perceptions are genuine and unique.

Although expert knowledge is required to thoroughly analyse a building's characteristics, proportions and effects, anyone can grasp the sensations that are directly transmitted by a space, by taking note of their own reactions and trusting their own perceptions. However, for this to happen we must give the building an opportunity to present itself, we must be willing to linger and listen to the experience.
As John Berger stated, we only see what we look at (Berger, 2015). And looking requires time, curiosity and the careful, slow, sustained observation of reality. It requires a gaze capable of looking at recognizable objects as if it were seeing them for the first time, trying to discover their essence. A gaze that rests on its subject, but doesn't impose; that listens, but doesn't demand. A gaze that isn't trying to understand reality rationally, but to appreciate it perceptually.

Albert Viaplana claimed that making architecture is simply recovering architectural experiences (1994), assuming we have all experienced them. And so, it is. We have all observed the world while crouching under the protection of a table or hidden behind the halfopen door of a cupboard; we've all built a space with four huge cushions or designed a castle with mountains of sand. However, for want of practice, we have forgotten. As adults we do not recognize the architecture in the diminutive and innumerable phenomena we experience every day.

Because architecture's reality lies beyond built architecture. Navarro Baldeweg (2009) claims that the built object is like a resonance chamber, the instrument that allows music to sound, and music -the phenomenon- is, of course, what really matters. This experience can be found in countless places and is produced by an infinite variety of instruments. The challenge is to know how to listen.

The interpretation of our built heritage has not traditionally been a task of architects and therefore seldom addresses the experience of space through movement and time. Architectural phenomena -that result from the conjunction of these variables- are not part of the script. Today, architecture still needs its own specific, comprehensible museographic interpretation, which speaks exclusively about the experience of space: an interpretation based on the assumption that architecture structures, orders and articulates individual, concrete and perceptible spatial experiences. 


\section{ARCHITECTURE AND EXPERIENCE, NARRATIVES OF SPACE}

The direct experience of space is the best way of acquiring new architectural knowledge. Actual space has an emotional capacity that none of its representations possess -in the same way that it is not possible to substitute hearing a melody to the visualization of its musical score-. Knowledge is remembered when it is experienced in person. However, as pedagogy proved long ago, new knowledge is not acquired by receiving information, but through dialogue and interaction between the individual and reality (Dewey, 2008).

Space is not apprehended through intellect alone, but by all senses simultaneously, and therefore becomes irrevocably part of our memory. The most vivid architectural memories of childhood have to do with perceptible atmospheres rather than with data or concepts. We remember and appreciate the essence of the space, the aspects related to our sensory experience of them.

Our daily experience of architecture doesn't consist so much in geometries or measurable dimensions, but in what we might call architectural events ${ }^{1}$. Architecture is built up of phenomena linked to our inhabiting the world. Pallasmaa (2006) agrees with this position in his definition of what an authentic architectural experience consists of:

for instance, of approaching or confronting a building, rather than (in) the formal apprehension of a façade; of the act of entering and not simply the visual design of the door; of looking in or out through a window, rather than the window itself as a material object; or of occupying the sphere of warmth, rather than the fireplace as an object of visual design.

The experience of a work of architecture is constituted by the sum, contrast and articulation (Pallasmaa, 2010) of the multiple architectural events of which it is configured, more than by the rational understanding of its form. Touring a building forms a sequence of partial perceptual experiences that, when added up, determine our narrative of the space. The events or episodes of this narrative are the relationships between the different elements perceived as we move: the openings frame, the light bathes, the space is prolonged, the wall turns and the sounds envelope. The perception of a static image from a fixed viewpoint disappears and becomes a kinetic, continuous and uninterrupted spatial experience. Displacement also suppresses the sharp and focused vision (Pallasmaa, 2006) that is transformed into the blurry and the diluted, broadening the peripheral vision and multiplying stimuli.

On the other hand, -as explained by Michel de Certeau (1990) - people describe space mostly by movements, actions and verbs. Which is to say, we understand architectural space as a place of human activity. The everyday experience of architecture consists of specific activities: working, eating, sleeping, etc. The remembered architectural experience is the one that is actively carried out: reading by the window, rocking in front of the fireplace or playing on the wooden floor. Space exists because it houses an activity that develops over time. For the individual, a space which has been appropriated is an engaged space, a space in which the events of life occur, from "the rooms so small in which you cannot do anything, to the forgotten loft that serves for everything" (Bachelard, 2010).

In ordinary language it is common to say that things 'take place' meaning that they happen, that they are done. In a work of architecture, we can say that a space becomes a place when it can be experienced. In this sense, the important thing about architecture is not its appearance, its conceptualization or its description but what it provokes. Architectural spaces are promises of action or they do 
not exist. As the philosopher John Dewey said (2008), the real nature of the work -in this case an architectural space- and that which is characteristic of it, is not its physical manifestation; it cannot be found in the work, but it emerges from it, it is the experience it generates. And it is not something outside of us, but something which happens within us.

There is, therefore, no single way to experience a built space. There are as many ways as there are individuals, all unique and all valid. The architectural event is thus inseparable from the individual who experiences it. And there cannot be transmission of the architectural fact without this experimentation.

\section{INTERPRETING ARCHITECTURE, A NEW MODEL}

The experience of an architectural work is a singular phenomenon and has very little to do with stylistic or identifying classifications, which give us limited artistic interpretations that only refer to an aseptic and distanced vision of the architectural events that occur in space. It could be said that, until today, the interpretation of architecture has been based on the accumulation of many data, but very little actually looking. This often ends up making what we have before our eyes become invisible. One tends to think that the works need to be explained, when it is not so. We don't enter Mies van der Rohe's Barcelona Pavilion to receive information, we enter to live a spatial experience that will be untransferable and probably unrepeatable (depending as it does on the time of day, the day of the year, if we are accompanied, who accompanies us, how we feel, etc.). We must advocate for an interpretation of architecture focused on the visitor and their reception of its message.

In tours of buildings or monuments, it is not a question of transmitting descriptive information or abstract knowledge according to a unidirectional communicative scheme (from 'one who knows' to 'one who does not know'), but to provoke the acquisition of new knowledge from the existing reality and its direct relationship to the user.

The visitor must be placed at the centre of a pedagogical process based on a dialogue and informed by the direct experience of space. This approach relegates all other kinds of notions or information (relating to history, the rationale on which the work is based, the necessities it satisfies, the technical complexity, etc.) to a secondary, important but subsidiary role to the individual experience of space.

Interpretation should be encouraged above all through stimulus and questioning, in the spirit of provoking a more space-conscious experience. It should promote that the visitors experience directly, without previous data, that which is presented to them. So that they are called to initiate an intimate and genuine conversation with the artistic reality. The story is not unique, but it is individual. It is based on the architectural element (the object) and in its relation to a person (the subject). The bonds are built anew with each visitor, with every new perception.

In addition, this is an accessible interpretation, recognizable by the visitor because it refers to phenomena from his daily life or to his memory; it's about revealing architecture not as untouchable scenarios, but as livedin places. This approach is about activating a new consciousness of place, revealing its architectural potential and making the space tangible by letting visitors use their perceptual capacities and exponentially increase their ability to see. It tries to create a new relationship between the subject and the object. The intention is not that people understand what architecture is, but that they experience it in a conscious way that leads them to reflect on it. 


\section{COMMUNICATE ARCHITECTURAL KNOWLEDGE, TOWARDS A DIDACTIC OF SPACE}

In the architectural interpretation of a building, around what elements should the script revolve?

Rem Koolhaas, as curator of the 2014 Venice Architecture Biennial, organized the exhibition into 11 architectural elements. According to him, these elements were the "fundamentals" of architecture: stair, door, bathroom, wall, hallway, etc. According to the exhibition, what is essential to architecture are its components, used by different architects over time. The objects on display were not the works of architects, but elements of architecture, its history, evolution and case studies. The exemplified architectural elements were isolated, without any concession to the surrounding space or the people who use them. Is architecture really defined by the material elements of which it is composed or does the architectural experience reside in the relationships that we establish with the elements and with the environment, thanks to them? Is the shape, dimensions or materials of a window more characteristic of the architecture or -as Alison and Peter Smithson appreciated ${ }^{2}$ the world of experiential possibilities and the relation with the environment that the former does offer?

to work or write at a creeper bordered window; to see the sunlight spread across the floor; to stand and look out without glare; to see the view/ vegetation/ trees/ the ground while sitting; to see out form the bathroom/ or perhaps be doubly enclosed; to have easy access to possessions without sensing their presence all the time; to sit comfortably and read or talk of an evening; to close wooden shutters in winter, etc. (Simthson, 1994)
What are the real components of a house? What does it mean to inhabit? Paradoxically, coming out of the Biennale you could pick up a brief booklet where the curator, who had just impressed us with historical and typological analysis of the elements, narrated in the first person his memories of the different spaces he inhabited during his childhood, through sensory experiences linked to the activities carried out in each space.

Like Dewey's interpretation of aesthetic experience, an appropriate interpretation of architecture would try to analyse the architectural experience and define its parts, what makes it, how it develops and what keeps it in our memory. According to Dewey, the individual becomes aware of art through physically experiencing it, and it is at that point when reflection can occur. Dewey understood that the artist basically deals with perceptual instead of conceptual material, and that, in perception, spatial and temporal experience go hand in hand. His approach always poses a parallel with the architectural experience.

The important thing then, for the transcription of the architectural experience, is to be able to configure the relationship between the body and the space, procure that an individual can sense the difference between being in a space and not being in it. Make explicit the characteristics of the architectural event and its time. That is, to proceed in a participative way, from the visitor and achieving a conscious experimentation. As the artist Olafur Eliasson (2009) explains with regards to his works, it is "to put in relation the thought and the action. (...) between thought and action, I would say that there is the experience".

It is a question of proposing an interpretation that recognizes the aesthetic events caused by the architecture. Not to explain it, but to demonstrate its qualities and make them present. The architectural interpretation of a building should be a tour constructed for the concrete and conscious experimentation of

\footnotetext{
${ }^{2}$ Alison and Peter Smithson, Small pleasure of life (from: Smithson, A. and P. 1994. Changing the Art of Inhabitation. London: Artemis
} 
certain spatial phenomena, those that occur in the space through which one is passing. It is to pave the way, to accompany the person, according to a sensory and sequential narrative that speaks exclusively of what you see and what happens in the spaces through which you are travelling.

Space is not a stage set that is seen passively, but a scene that is experienced, a place where the architectural event is lived in first person. Unlike the usual interpretations that tend to analyse, document, quantify or date the different elements that make up the building, it should be their effects on the space, as well as the relationships they establish among themselves, which are the main focus of attention. Rather than 'documenting' elements and spaces, the visitor can gain direct knowledge of their architectural value by physically moving through them and observing other people's interactions with them.

\section{THE DIFFUSE MUSEUM, A NEW CONCEPTION OF THE MUSEUM OF ARCHITECTURE}

This research proposes a new understanding of the traditional architectural museum that we define as a diffuse museum ${ }^{3}$. This is not an alternative, but an essential complement to the traditional museum.

It is a museum of architecture that understands that the best possible collection -including its most outstanding pieces- already exists; the city itself and its best buildings are waiting for someone to help them become visible, recognizable, interpretable and transmissible. It is a museum which is not confined within the walls of a building -where the real museum objects, the works of architecture, can never reside-, but exists in the interpretation of the existing parts of the city, which are outdoors, permanently on display and not exclusively in the collection documents used to represent them.

A museum that, in addition to preserving, focuses on communicating knowledge in the street and in the city.

The diffuse museum is a museum scattered throughout the territory, a museum that understands that it is in real architecture where this new knowledge can best be acquired. The diffuse museum refers to the "originals" whose value compared to their reproductions is precisely their authenticity.

The diffuse museum is an opportunity to contribute to recovering architecture as one of a citizen's rights, understanding it as a common good. This implies a change of model: the communication of architecture should stop referring exclusively to architects and instead communicate with all citizens. Architecture is a public service for people, not for architects. And even though architectural knowledge is generally held by architects, architectural opinion corresponds equally to all citizens.

The point is not to turn citizens into architects, but to provide them with instruments that strengthen their position in the dialogue between architecture and society, facilitating conditions that permit citizens to shift from being consumers of architecture to being active and committed users. The goal is to create a critical society that contributes to a better built environment and a better landscape.

Implementation of these ideas in cities would mean that those responsible for local, national and regional cultural policy would have to take responsibility directly for the development, promotion and interpretation of that other collection, the original, which is outdoors. The means, methods and instruments -at least some of the possible ones- are proposed in this essay. 


\section{REFERENCES}

Bachelard, G. 2010. La poétique de l'espace. Paris: Presses Universitaires de France.

Berger, J. 2015. Modos de ver. Barcelona: Gustavo Gili.

Bosch, E. 1998. El plaer de mirar. El museu del visitant. Barcelona: Actar.

Bloomer, K. and Moore, C. 1982: Body, Memory and Architecture: Introduction to Architectural design. Madrid: Blume.

Certeau M. 1990. The invention of everyday life, V.I., arts to do. Paris: Gallimard.

Dewey, J. 2008. El arte como experiencia. Barcelona: Paidós.

Eliasson, 0. 2009. Playing with space and light. TED2009, http://www.ted.com/

Garriga, Q. 2015. Arquitectura en exposición. Trascendiendo el paradigma clásico. Barcelona: UPC.

Navarro Baldeweg, J. 2009. "La activación de los signos" in: Grigor, M. 2009. Sir John Soane. Arquitecto inglés, legado americano. Barcelona: Fundación Caja de Arquitectos.

Pallasmaa, J. 2010. Una arquitectura de la humildad. Barcelona, Fundación Caja de Arquitectos.

Pallasmaa, J. 2006. Los ojos de la piel: la arquitectura y los sentidos. Barcelona: Gustavo Gili.

Smithson, A. and Smithson, P. 1994, Changing the Art of Inhabitation. London: Artemis.

Viaplana, A., 1994, ETSAB's inaugural design course speech, unpublished. Barcelona.

Zevi, B. 1981 [1951]. Saber ver la arquitectura. Barcelona: Poseidón. 



\title{
PAPER \#1.19
}

\section{URBAN META MUSEUM}

\author{
Polyxeni Mantzou ${ }^{a}$, Xenofon Bitsikas ${ }^{b}$, Anastasis Floros ${ }^{a}$ \\ aDemocritus University of Thrace, Komotiní, Greece \\ b University of Ioannina, Ioannina, Greece
}

\section{ABSTRACT}

Urban public spaces are an ideal field for investigation on how digital and physical can coexist concur, interact, intermingle and co-generate a new hybrid and augmented reality. Digital spheres mixed with the physical, material surroundings, create association, amplification, multiplicity and diversification, alongside with the possibility of constant reinterpretation and meta-production.

The city historically has been an open laboratory of meta-production and overlapping layering that sometimes cover and perhaps erase previous layers, or in other cases leave them in a pending state constructing a palimpsest that reveals the vertical time organization of the city in different, successive layers.

PALIMPSEST is a program funded by GRIT INTERREG, Priority Axis 2 - Integrated Environmental Management that works on the concept of the city's palimpsest and the potential that digital technologies provide to recuperate lost or forgotten layers of the city. PALIMPSEST rethinks concepts such as the Archive and the Museum that are transformed by the post-alphabetic era and redesigns their novel, fluid, participatory and interconnected version. The main aim is to revitalize the city's palimpsest by incorporating forgotten events and stories that took place in the city's urban web. This way, PALIMPSEST will activate an open and editable archive in the form of an app and an open, immaterial museum that embeds art installations and organizes an extra stratification in the city.

Content for the PALIMPSEST museum is cocreated by the public involved in the collection of narratives from the city's past and artists responsible for the mise en scène of the narratives in the public urban space. This interrelation of experts and public, of traditional emitters and receivers, of authors and audience for the co-creation and the common authorship of the content is an issue of great significance. Architects are re-positioned as mediators that inter-relate people, stories, art and the city.

\section{KEYWORDS}

Urban, museum, meta-production, palimpsest, art-installations

\section{INTRODUCTION}

The proliferation of digital technologies introduces the post-alphabetic era, an era of fusion and hybrids, where categories and typologies succumb to the fluidity and indefiniteness of a rapidly changing and uncertain world. Hybrids thrive in different aspects of contemporary life, while the digital and physical tend to merge and define augmented, mixed, hybrid realities. The postalphabetic era, defined by the use of electronic media, comes after the alphabetic, defined by the predominance of the alphabet and vision and actually, doesn't seem to be closer to the pre-alphabetic, defined by orality and hearing, in contrast with what McLuhan had foreseen. The post-alphabetic era is a mixture of both the previous two phases and endorses hybrids. (Mantzou 2017)

In architecture the change is occurring in a rather vague and abstruse way, not as a result of a planned variation in prerequisites and criteria but rather as an intrinsic and bottom 
up transformation. Traditional architectural typologies gradually become obsolete as digital media merge time and space use. Public and private spaces are mingled; working and home time is fused; commerce, entertainment, education and work are becoming impossible to distinguish.

Specifically, there are two typologies of interest for the present analysis. On one hand a concrete and regularized architectural typology, the museum, and on the other a rather fluid and difficult to capture but still distinct and clear category, the public space.

The museum typology is the ideal typology of the alphabetic world; a typology of taxonomy, hierarchy, surveillance and control. In the post-alphabetic word surveillance is traded for immersion and thus, the museum is being transformed by the urge to be appealing, allencompassing and inclusive, to offer more and find new ways to engage the over-stimulated visitors. To do so the museum has to involve visitors and invite them to be more active and ideally to even post-produce and participate (Bourriaud 2006). Museums are adapting to change in a rather unsettled and spasmodic way by including commerce, entertainment and gaming in order to preserve and attract a more demanding and more saturated public. The past typology of the museum, a mechanism of surveillance, is now becoming an undetermined hybrid.

Public space is also under transformation; it is infiltrating previously considered private spheres and at the same time in its traditional form, that is as open, urban public space, it is being infiltrated by private spheres. Therefore, its borders are becoming indiscernible. Moreover, the public urban space of the city is compelled to offer more in order to compete with the digital public spheres and preserve its attractiveness in everyday life. In addition to its traditional fusion of uses, public space is now required to become more playful, engaging, interactive and interesting, in order to appeal to its digitally-awaken and maybe even spoiled users. The current public of public spaces demands an active role as central features and post-producers, constantly manipulating and interchanging information.

The case study presented is an ongoing GRIT Interreg EU program, PALIMPSEST, where Museumand Urban Public space are coalesced; where past and present coexist; where actors and public are interchangeable; where fiction and reality are fused. PALIMPSEST offers a test-bed for rethinking and reshaping from an architectural point of view previously distinct typologies, categories and organizations, such as the Museum and the Public space. At the same time, PALIMPSEST introduces practices where scientific, social, economic and marketing factors are integrated in order to create a holistic strategic approach. PALIMPSEST's midway results are presented as a temporary assessment of open-ended and inconclusive but yet indicative and suggestive outcomes that can be sufficient for further analysis and tactical suppositions.

\section{DESCRIPTION}

PALIMPSEST, is a program, funded by GRIT INTERREG, Priority Axis 2 - Integrated Environmental Management, which works upon cultural heritage and reshapes it for the digital age, by applying the concept and metaphor of the city as a palimpsest. Cultural Heritage constitutes one of the city's most valuable elements and assets, as it provides the subject with the opportunity to relate to the urban space and reactivate and reinforce its sense of historical, spatial and temporal continuity as well as the feeling of community and belonging. Digital technologies open a whole new field of actions for reintroducing cultural heritage into urban public space with their immense potential for archiving, processing, circulating and transforming /postproducing cultural heritage assets.

PALIMPSEST reconsiders concepts such as the Archive and the Museum with the intention of reconsidering them, by embracing their fluid, 
participatory and bottom-up, contemporary version. The intention is to reactivate and revitalize the city's palimpsest by incorporating forgotten events, stories and legends that allegedly took place in the city's urban web.

The narratives are retrieved as part of an oral history and tradition and transformed into an open, common and editable archive and a public, interactive, multisensorial and immaterial museum. The Museum and its archive are both post-productions that constitute an extra stratification in the city's public space, augmenting and hybridizing it.

The project's first stage involves an initial archive, created with the participation of schools and trans-generational collaboration. Students seek stories and memories related to the urban fabric of the city, from elder people in their familiar environment. They transcribe them, guiding the narrators to points that interest them and they tag, categorize and archive them. Tags used related to content are partly defined freely by the students and partly by the selection from a given tank of tags; while at the same time chronological and locative tags are also requested. Media used to record the stories are chosen by the students but must include text.

Subsequently the collected material is uploaded on a digital application open for the public. The users can search for stories and events using filters; can add stories following a similar procedure; can add comments to stories that already exist; and can suggest links among stories. This archive has all the features of a post-alphabetic archive, that is, a hybrid archive, which combines top-down rules and pre-existing structure with bottomup, unrestricted and unforeseen development. On one hand, it is configured with predetermined tags and temporal periods that users apply in order to categorize the stories that they upload or search the archive; on the other hand the stories that are presented are interpreted by the users who may add relevant audiovisual material, tag and also connect stories to other stories. Moderators, whose role is to check the posted material and its relevance, are, at first, members of the PALIMPSEST team and will gradually be substituted by active groups of the community that are already organizing similar collections of digital material. PALIMPSEST expects to create a community of involved moderators through the active engagement and participation of the public with the project. This community will act as guardians and trustees guaranteeing the proper functioning of the APP and its content, taking into consideration the reports and suggestions from the APP's users.

During the next stage, PALIMPSEST focuses on the creation of art installations in the urban space of the city. At first, the artists will select stories from the archive and then they will reinsert them as art installations in the city's public space appending them to their original location. The art installations will not significantly affect the physical condition of the city at its present condition. These settings, activated by visitors, will be interactive and multi-sensory, with no visible footprint in the urban area.

\section{INNOVATION}

PALIMPSEST proposes an open-air, constantly changing, evanescent, dreamlike, and yet, personalized, museistic experience that questions and defies traditional organizations of museums. As a Museum, PALIMPSEST is quite different than traditional museums in various levels, because it changes 1) the way content is provided 2), the fixed ubication in a building 3) the passive experience of the exhibits 4) the traditional bisection between curators and spectators 5) the detachment between exhibit and context.

Content is a novelty in PALIMPSEST. The PALIMPSEST's museum is co-created by both, the public involved in the collection of narratives from the city's past and also, artists responsible for the mise-en-scène of the narratives in the public urban space. The 
traditional, top-down, hierarchical structure of the conventional museum is reshaped as PALIMPSEST proposes a bottom up, participatory approximation through the interrelation of experts/actors and public, of traditional emitters and receivers, of authors and audience for the co-creation and common authorship of the content.

PALIMPSEST adopts the way information is produced in our current condition. In the post-alphabetic era receiving, producing, post-producing and emitting information becomes feasible for all those who use digital media. In our alphabetic past, information and knowledge were produced by certain centers and was distributed to the public that was usually a passive receiver. Authority was defined in advance and authorship remained indisputable. History, in the alphabetic world, was rendered as objective and could difficultly be perceived as an interpretative and biased understanding of the past. It claimed the right to be unique and impartial; the unbigoted and uncontestable knowledge of the past.

In this circumstance the museum enters a crisis as an authoritative and trustworthy institution for the objective and established representation of the world (Marotta 2012); as a hierarchical structure that separates authors and public. This is the theoretical context upon which PALIMPSEST aims to work. One of its main objectives is to re-engage the inhabitants of the city, who are asked to collect, organize and associate, and therefore interpret information and narratives about the city's past. It is centered in the non-institutional history of the city, which is gathered through individual implication in the form of particular descriptions and subjective storytelling. The representation of the city in the MAP and APP format recreates the layered representation of the actual palimpsest, which every city has as a base, although it is often ignored and forgotten. The Museum is not only dissolved as a topdown institution but also as an institution instituted in a separate, detached place. It becomes an open, overlapping and infiltrating structure that inhabits the context of its exhibits instead of isolating and disconnecting them from their milieu. The proposed model is one of a Museum without walls and limits; without predefined and fixed routes; without detachment, distance and disconnection. A hybrid condition of public urban space and museum that interact and infiltrate each other. Consequently, the reactivation of the city's palimpsest changes the inhabitants' mental representation of the urban public space. Collected stories are elaborated and a number of them are selected by the artists as a basis for the construction of art installations in the city. The art installations take one-step further the interpretation of the collected stories. Their apparently random activation by visitors and the personalized perception of the museum that this creates, is an additional filter that distorts any possibility of an objective and hierarchical reading of the museum's content. PALIMPSEST rethinks the traditional classifications of authors and public without dissolving them. Oral history and collective cultural production which comes from our distant pre-alphabetic past coexist with the necessity of the artist as a distinct and established figure allowing both ends to explore and exploit the possibilities that arise from their interconnection.

PALIMPSEST regards the city's public open space as a canvas that is restored and recuperated and at the same time augmented and activated. It creates a hybrid approximation between the situationists' views for a city animated by its inhabitants and a more commercial, thematic approach, where the city is transformed in a spectacle structure (Debord 1967). Public space in this animated, augmented version offers possibilities for encounters and concurrences and engages passive and indifferent people to act and to experience vivid reinterpretations of past events instituted in their original place and transported in the present. 


\section{METHODOLOGY}

PALIMPSEST, is a test-bed for theories and concepts with diverse origins, joined and blended together. It draws concepts and approaches from urban studies, museology, art and art theory, archiving, history cultural and media studies, informatics and digital cultural heritage, performance and staging and it is based on combinations and interactions. Methodologically PALIMPSEST is a hybrid; of different fields, of distinct categories, of diverse typologies. Therefore, although its methodology is constantly being elaborated and reconsidered it is arduous and impractical to present as is habitually done in predefined, hierarchical, controlled projects. The project is also a hybrid of topdown traditional organization and bottom-up, participatory approaches. Therefore, during its implementation and because of the genuine and profound interaction with agents and actors exterior to the project, the methodology is continuously reviewed and re-adapted.

Still, the PALIMPSEST stands for PostAlphabetic, Interactive Museum using Participatory, Space-Embedded Story-Telling; these concepts are the principal basis for the PALIMPSEST's approach.

\subsection{Post-Alphabetic}

Post-alphabetic is the term McLuhan used to define the change that digital media would bring to our understanding, interrelation and mental construction of the world (McLuhan 1962). Decades after McLuhan's prophetic writings the post-alphabetic era is presented as an era where definitions, limits, categories, taxonomies, typologies and hierarchies succumb to the proliferation of mixtures, combinations, fluidity and hybrids. PALIMPSEST is post-alphabetic because it opts for mixing rather than separating, it prefers merging rather than detaching; it is post-alphabetic because it acknowledges subjective and multiple truths as more powerful and reasonable than a unique and objective truth; it is post-alphabetic because it engages experts from multiple fields with the general public in the co-creation of a common, shared construction.

\subsection{Space-Embedded}

PALIMPSEST will not be strictly limited within an exhibition space. On the contrary it's content will be scattered all over the involved cities' historical centers and embedded in public spaces. The artworks and installations will be inspired by urban legends and old stories, so each and every artwork's identity will be inseparable from its physical location and surroundings. PALIMPSEST aims to re-install local lore into real-world environments, and by that old stories reclaim their rightful spaces.

When the project is fully developed, the art installations will be embedded in public spaces and will only become visible if the user activates them. This will give the ability to the public to experience urban legends where they originally took place. The merging of past and present worlds will redefine the urban experience and have both visitors and inhabitants look at mundane and common places differently. These artworks and installations may be digital and intangible, but they are embedded in physical, material spaces. The stories may have happened in the distant past, but they are restored to their former glory in the present. This hybrid museum experience opens up new possibilities that are yet to be explored. Dull places are now transformed into immersive, interactive encounters.

\subsection{Augmented}

Augmenting the public urban space of the city with interactive art installations, allows many levels of augmentations to occur. Past is added to the present as past stories return to their original location without affecting or altering it. Multisensorial art installations augment the perception of public space 
by creating a theatrical but still transient atmosphere that involves a holistic, somatic experience. The visitor is surrounded and not placed before the installations and becomes the center of the story told instead of a simple spectator. Everyday urban life is augmented by art installations that intensify and enhance our relation to it. The overwhelmed by digital media subject is satisfied by the multi-layering and the augmentation of the public space and becomes engaged and activated.

\subsection{Participatory}

PALIMPSEST introduces a groundbreaking, participatory museum experience, where the public can actively participate and shape the content exhibited. Users will be encouraged to download the app and upload forgotten tales, tag them and illustrate them with photos of family heirlooms, $3 \mathrm{~d}$ models of historical objects, etc. Users will be able not just to share his/hers content, but also to shape the preexisting by creating connections and therefore, add another layer of history in the city's palimpsest. The tags that the user will select for each story will be based upon the repository of tags proposed by the students for the initial stories, used as a basis when launching the APP to the public. This repository of tags proposed by the students was further processed and analyzed by the PALIMPSEST Team in order to summarize and cover as much as possible of the vast range of the stories' thematics. The public's involvement is crucial for the project; the project is not about passive consumption, but active participation and the public, supported by experts, becomes the project's curator and trustee.

PALIMPSEST creates a spectacle that everyone can enjoy and, at the same time, it creates a situation where the visitor is not just a passive recipient but an inter-active participant. As a result, when it comes to our relationship with the city, the project's museum experience is a hybrid between spectacle/ theme entertainment practices and art-driven/ situationist approaches.

\subsection{Interactive}

Interaction is designed in different levels. On one hand, the APP that is being developed generates interactive content - an APP designed to involve the user and invite his/ hers input but also respond to his/hers actions, capturing attention right from the start. When PALIMPSEST is fully developed, everyone will be able to download the APP and immerse oneself in art installations that will be waiting in public areas. These installations will also be interactive. They will only be activated by active human agents that will engage with them, explore their content and they will respond to their presence accordingly. Users will not be able to activate the installations repeatedly because this would deconstruct the efforts to create an atmospheric dreamlike condition. Installations will interact intelligently with the public and will prioritize responses in different conditions following their programming.

\subsection{Storytelling}

PALIMPSEST is not concerned about historic truths - it is intrigued by orality and aims to preserve urban legends and stories. Local lore should be passed on and shared, because stories create a sense of community. PALIMPSEST helps people come together in a creative context while they delve into storytelling, a craft that is as old as time. The project aims to re-engage urban inhabitants and encourage them to collect and organize - or, in other words, interpret - information about the involved cities' past. At the same time, visitors can listen to other people's stories and uncover lost layers of the cities' past. This offers a possibility to strengthen the connection among past and future generations through sharing common experiences. 


\subsection{Museum}

Museums are institutions that belong to the previous paradigm; the alphabetic, supervised, ordered and categorised world. In our days, the rapid information flows and the proliferation of channels that distribute it, leave no time to check it and assimilate it and therefore the reception becomes more passive. Supervision, classifications and categories soon became a thing of the past as we became accustomed to sometimes absurd, vivid collages and medleys with no hierarchical or taxonomical organization. Television ages gave the first stroke to the alphabetic hierarchical organization of facts that the printed book and the press had established (Debray 1992) and later on, the post-alphabetic media made each receiver a potential transmitter; leading us now to the point where information is produced and transmitted by all. This democratization process with the subsequent elimination of any truth-factor, previously idealized by the alphabetic, modern condition, is a dealbreaker for every authoritative and top-down construction. Instituted knowledge becomes disputed; sources are overwhelmingly multiplied and mostly uncontrollable; authorship is no longer a privileged condition of the few; selection, categorization, ordering and hierarchies appear in multiple versions, subjective and subjected to their transmitters. The Museum is transformed in this postalphabetical phase into an open basis, where each visitor can interact to create personal interpretations, interactions, narratives, in a digitally enhanced spatial context. The curator's authority as a specialist who oversees and controls the Museum cannot resist the pressure exerted by the digital sphere, as is the case with the creator's authority. The Museum becomes less hierarchical and rigorous, more anarchic and open but at the same time more spectacular and commercial. Digital reproduction as well as continuous post-production introduce new questions to the visitor-exhibit relationship that obviously affect the context of this relationship, namely the Museum. However, not everything is so transparent and clear. Similarly to what happens with the archive, in the museum too there are mechanisms that are often obscure and affect what is accessible and what remains missing. (Mantzou 2017)

\section{OPEN CHALLENGES}

PALIMPSEST as an ongoing project faces various open challenges that demand constant awareness and the ability to re-adjust and reapproach planning, without losing focus or lowering the quality of the final outcome.

First of all, one of the main challenges that PALIMPSEST has to deal with is the fruitful collaboration and effective cooperation of the project's multidisciplinary team, formed with members from different fields of study. Installation artists, architects, computer engineers and educators have to work closely together, go beyond their area of expertise and, at the same time, bring along their particular vision in the project. This multidisciplinary group has to combine those who have the know-how and those who know-what and have to apply this know-how in order to realize it, exchange methodologies and working procedures, thus giving the opportunity to rethink and re-invent processes, optimizing the final outcome. As a result, the configuration of an open-ended, authentically hybrid approach, where collaboration is not based neither in entirely discretizing tasks and responsibilities nor in totally mingling them, but rather in finding ways to create perversion without dissolution was of vital importance. Collaborating closely as a group and organizing weekly meetings and periodical workshops has enabled satisfactory communication and complementary work.

Another challenge is the bottom-up, participatory character of the project because open access in the APP may also present issues of content control, which cannot be tackled easily and may undermine the accessibility 
and the openness of the database. The engagement of students and schools that have worked enthusiastically with the PALIMPSEST team has provided the project with many local agents willing to undertake a significant role as moderators of the APP.

At the same time, as the project is getting completed, maintenance issues arise and have to be tackled in order to assure the project's future. In order to address maintenance not just as repair and continuance of the project's function but also as a process of evolving and further developing, it is important to involve the local government but also other local public institutions and the local private sector. As a Museum PALIMPSEST aims to constantly renew its collection; and as a common, participatory project it intends to do so with the collaboration of different forms of local actors that share the same interest for the public urban common space of the city. 


\section{REFERENCES}

Bourriaud, N. 2006 Postproduction. Berlin: Sternberg Press

Debord, G.1967. La Société du Spectacle. Paris: Buchet-Chastel

Debray, R.1992. Vie et mort de l'image. Une histoire du regard en Occident. Paris: Gallimard Education

Mantzou, P. 2017. Aporia in Architecture: What now? Athens: Epikentron Publishers

Marotta, A. 2012. Typology: Museums in The Architectural Review, December 2012

McLuhan, M. 1962. The Gutenberg Galaxy:The Making of Typographic Man. Toronto: University of Toronto Press 

PAPER \#1.20

\section{THE SKYWAY AS AN INHABITABLE MODE OF URBAN REPRESENTATION}

Mike Christenson ${ }^{a}$, Erin Kindella

aUniversity of Minnesota, Minneapolis, Minnesota, USA

\section{ABSTRACT}

This paper sets out the possibility of treating the skyway as an inhabitable mode of urban representation. It reviews the historical context of the skyway, considering different critiques of the system, and proposes representational strategies for analyzing the skyway.

\section{KEYWORDS}

Architecture; representation; skyway.

\section{INTRODUCTION}

In the context of this work, the word skyway refers to a grade-separated, internalized system enabling pedestrian movement within an urban context, an "immense, labyrinthine building at the second story," as Minneapolis architect Bernard Jacob has described it (Jacob 1985). For people experiencing the city from its streets, the most visible manifestation of the skyway is the ubiquitous elevated, enclosed, pedestrian bridge (Fig. 1).

While grade-separated systems can be found globally, and examples drawn from throughout history, we are particularly interested in the systems of the kind found in cities throughout the United States and Canada, including Fort Worth, Cincinnati, Calgary, Atlanta, Des Moines, and others; they are designed to efficiently connect nodes within the city (e. g., parking ramps and department stores) while providing some protection from weather.

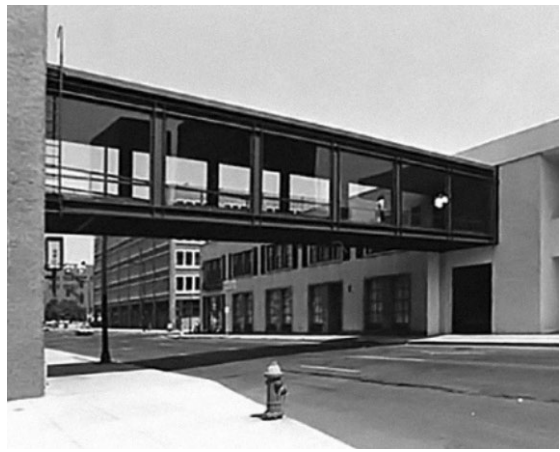

Figure 1. Skyway connecting Twin City Federal and American National Bank, Sixth Street, St. Paul (MN). Source: Minnesota Historical Society. 01243-15a (Negative Number); MR2.9 SP2.1 p168 (Copy Locator Number).

\section{THE SKYWAY AS AN ARCHITECTURAL INTERFACE}

The academic study of skyways exists ambiguously within conventional disciplinary fields, intersecting questions and methods from architecture, planning, sociology, ethnography, and anthropology. What makes the study of the skyway interesting architecturally is that it exemplifies the concept of architectural interface (Christenson 2019). Unlike a software interface, the architectural interface is a device that problematizes its own presence, operating through a kind of frictional resistance: the architectural interface is translucent rather than transparent, both affecting and being affected by what passes through it. Colomina's discussion of the fenêtre en longueur (i. e., the long or horizontal window) condenses an issue central to the definition of architectural interface, i. e., representation as 
the reproduction of objective reality (Colomina 1992). De Certeau's invocation of the viewing platform at the World Trade Center similarly situates the architectural interface as a device able to distinguish between distinct patterns of human behavior and thought (De Certeau 1984). But while built works of architecture necessarily constitute architectural interfaces, so do drawings, models, and other modes of architectural representation, insofar as these modes include specific acts of omission and highlighting and are never fully transparent. Thus, architectural interfaces, whether built or drawn, embody Derridean différance to the extent that they make differences visible without permitting closure or settlement (Derrida 1982).

Supposing that the skyway is an architectural interface, what then is it capable of making visible? What are the ways in which it problematizes its own presence? What are the binary distinctions to which it gives rise, only to see their final settlement endlessly deferred? This work develops these questions with a focus on the skyway system in St. Paul, Minnesota.

\section{CRITIQUES AS REFLECTIVE OF CONTEXT}

The pitfalls of grade-separated systems such as skyways are amply addressed in the literature. A commonly addressed critique is that skyways adversely impact the vivacity of street activity since people are moving either above or below grade, in consequence creating downtown cores that appear desolate and idle. For Robertson, "[t]he moment that we abandon the street for an enclosed, controlled, second level, we have furthered ... privatization and have removed the citizen farther from his [sic] city" (Robertson 2004). Robertson's views coincide with a larger critique that the skyway removes economic activity from street-facing, ground-floor units to inside building cores, often invisible from street level.

\subsection{Social critique: the analogous city}

An essential critical position with respect to the skyway (and grade-separated systems generally) is that they operate to segregate occupants by race and class, and in particular that they cater heavily to mostly white, middleand upper-class, commuting, suburbanites, just as they fail to serve people of color or those who walk, bike, or use transit. This critical position emerges from the development context of skyway systems within the United States and Canada in the 1950s and 1960s, a period characterized by the expansion of suburban areas and associated demographic changes involving movement either in or out of urban cores. Urban Renewal and associated struggles on the basis of class and race existed alongside the rise of retail shopping malls, and as cities considered as wholes became increasingly segregated, interventions like Detroit's Renaissance Center provided fortress-like enclaves for urban expatriates. Skyways, as envisioned by Gruen (1956) and others, fit within this approach: they result in a peculiar construct that Boddy has described as an "analogous city" simultaneously capable of filtering and substituting for what he considers to be a genuine urban experience (Boddy 1992). For Boddy, the "analogous city" is evidence of a contemporary preference for simulation over reality. In a similar vein, Willensky identifies the skyway as "a second city," one positioned to avoid the "first city"s problems, even as it introduces its own problematic (Willensky 1985). Augés well-known critique of "nonplaces" is relevant in the same context, as is Jameson's discussion of John Portman's Westin Bonaventure (it "ought not to have entrances at all") and Blauvelt's suggestion that the skyway "displaces street life to a world hovering just above the 'real city"' (Augé 1995; Jameson 1991, 40; Blauvelt 2016, 12). Yet, the broad history of city-making is characterized by just the kind of insertions, impositions, and layering critiqued by Boddy, 
Willensky, and others. In acknowledging that Parisian arcades, over time, evolved from exclusionary spaces into something more inclusive, Boddy implicitly holds out the possibility that the "analogous city" is not static; it may provoke change. The idea that the skyway segregates people on the basis of constructs such as race and social class, or that the skyway enables and enforces a kind of social homogeneity, or that the skyway accelerates the privatization of public space, are at once familiar and serious critiques with real impact on contemporary urbanity. But how, and in what ways, do we understand these critiques in ways that are disciplinarily specific to architecture?

We should ask, then, not does the insertion of an 'analogous city' create new problems, as it inevitably will, but rather how does the 'analogous city' transform the way the 'real city' is understood? And furthermore, how does the mechanism of transformation make new opportunities possible? Rather than analogize city and skyway to the skyway's detriment, a possibly more productive analogy is between the skyway and architectural representation. Architectural situations that emerge, for example, from the study of a floor plan, may not obviously succumb to resolution until we decide to draw a section. The act of drawing the section should, of course, be expected to introduce its own set of intractable issues, but in so doing it necessarily transforms the situation that emerged from the plan. Drawing sections is not guaranteed to result in resolution, but the act must necessarily transform the context in which issues are seen and understood.

So it is with the skyway. To introduce skyways within the city is not to assert that all extant problems will be solved, nor is it to ignore problems, any more than the act of drawing a section ignores problems that are specific to the plan. Instead, the value of inserting the skyway (or of drawing the section) is that it transforms the context in which questions can be framed and in which responses can be developed. In this way, the skyway exemplifies the concept of architectural interface.

\subsection{Historicist critique}

Another form of critique considers the skyway from the aesthetic and particularly the historicist viewpoint. A skyway bridge, especially one designed to adhere to a uniform set of guidelines (as is the case in St. Paul), seemingly ignores the buildings which it connects, creating an amalgam of materials and styles that don't necessarily coordinate. Andersen (1988) places the skyway somewhere between "bland modernist modules" and violent, headlong-smashing devices capable of obliterating historical facades (e. g., the Scandinavian Bank Building on Marquette Avenue in Minneapolis).

Consistent with this approach, Minneapolis architect Bernard Jacob posits skyways as a form of violence to which citizens have become desensitized (Jacob 1985). Jacob's critical approach reveals an understanding of the city as composed of integral, independent, and above all apprehensible object-buildings. For Jacob, buildings are objects and the street grid is responsible for "[holding] the buildings apart and in place." In this view, any skyway bridge which fails to architecturally "suggest a crossing [or] a leap from building to building" is necessarily suspect. Jacob's critique is broadly consistent with Burns's well-known distinction between cleared sites and constructed sites, two apparently opposed conceptions, with the cleared site representing a design approach that assumes pre-existing sites to be devoid of any meaningful content or significant prior construction, and the constructed site accounting for sites' multilayered and contingent pre-existing qualities (Burns 1991). What is important in the present context is the relationships between these critiques and the forms of architectural representation implicated in the skyway system. If we accept (following Burns) that the cleared site assumes the grid, the plan, and the map as 
primary tools in the mathematicization of the site, then it may be productive to think of the skyway system as an ideal network of connectivity between nodes that follows and reinforces the city grid. If, again as Burns suggests, the constructed site privileges the section, then it may be productive to address the skyway as a "parallel city" lifted off of the ground plane but responsive to its topography. And while it seems that Jacob fails to acknowledge that skyway bridges are less like objects but something more like parasites or viruses, attaching onto and infiltrating existing context, it is essential to remember that the skyway is not reducible to bridges between object-building, but rather consists of an embedded system of which only certain parts are visible from the street. Jacob correctly acknowledges that "[d] owntown St. Paul appears as one immense, labyrinthine building at the second story, a building that is occasionally disguised to match the buildings above and below it." It is precisely this labyrinth that we seek to make visible in the discussion that follows.

\section{UNIQUELY ENABLED ARTIFACTS}

What the critiques of the skyway tend to miss is the serious consideration of how the skyway system uniquely operates as an architectural interface, which is to say, how the system enables and constrains perception of the city in unique ways; and related to this, how the tools of representation are mutually implicated in this question. In short, what is missing is the notion of the system as a device for reading local particularities.

Once we are able to identify the social, political, and topological contexts of the skyway, the question becomes how to address its ability to enable architectural representation in specific ways. This could acknowledge its unique vantage position deriving from being alternately suspended over the street and buried deep within buildings, or from the characteristic movement it enables through the facade. Such a pursuit is broadly consistent with Venturi, Scott Brown, and Izenour's approach in Learning From Las Vegas, in which the authors seek to develop and promote forms of architectural representation uniquely enabled by the analysis of the Las Vegas strip (Venturi, Scott Brown, \& Izenour 1972). Their work resituates perception from its historically understood pedestrian perspective to that of the car. Similarly, Appleyard, Lynch, and Myer (1964) develop forms of representation firmly centered in the car within the context of the grade-separated roadway (i. e., freeways). Critical approaches of this kind are important not only because they respond uniquely to observed conditions, but because the representational artifacts they produce operate as architectural interfaces: they propose to overlap multiple and contingent forces. For Venturi, Scott Brown, and Izenour, these forces might include the casino economy and the advent of the automobile; for Appleyard, Lynch, and Myer, they might include the need to navigate the city via high-speed freeway and the need to minimize distraction.

\section{AN INHABITABLE MODE OF URBAN REPRESENTATION}

\subsection{As a hypothesized iteration of an idealized form}

Like the urban freeway, the skyway is designed to eliminate obstacles - for skyways, those include streets, but also private areas within buildings - and to promote something like a smooth flow of movement through a pre-existing, rough terrain. Also like the freeway, the skyway concretizes (or makes specific, in built form) the concatenation of forces and pre-existing obstacles within the city. One way in which this can be seen is to understand the city-skyway relation as capable of assuming an idealized form, 

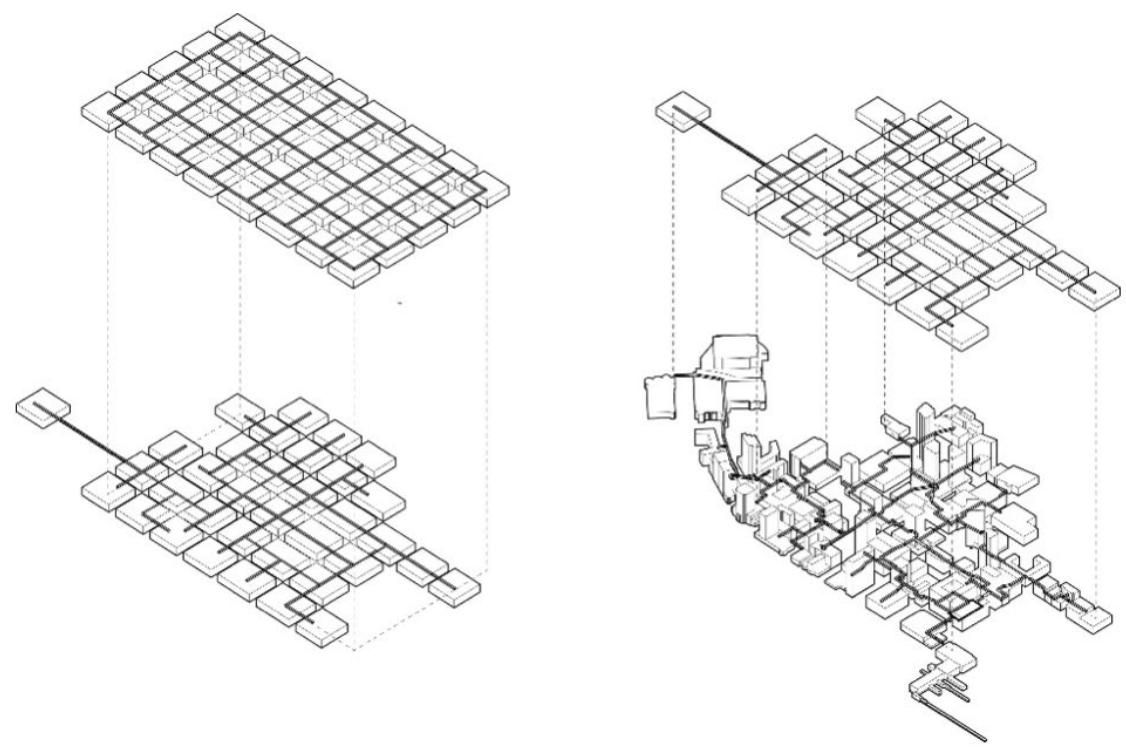

Figure 2. Transformation of the St. Paul skyway system from an idealized form (upper left) to the built condition (lower right). Source: By authors.

and then developing iterations as a series of coherent deformations of this initial condition aimed at arriving at a representation of the existing city. The approach is suited to St. Paul, a mid-sized American city with a central core consisting of a regular rectangular grid (rotated with respect to the cardinal directions). Moreover, the St. Paul skyway is characterized by skyway bridges designed to a consistent set of guidelines. Together, these observations suggest a hypothesized originating condition: a rectangular grid of city blocks, each block populated by a building mass, each building mass connected to its neighbor across the street by a mid-block skyway bridge (Fig. 2, upper left).

When the built form of the city is compared with the idealized form, and particularly if the skyway system is extracted from the context of streets and building masses, two questions arise. First, how does the skyway system register the forces compelling it to deform from its idealized condition? A second, related question is, if we are given the form of the skyway system - extracted from its context - can we infer the city's form? The two questions both assume that we can make a reasonable speculation about the forces that have deformed the skyway system from its idealized condition: acknowledging that this may be the case is to allow that the skyway system is, in effect, an inhabitable mode of urban representation. More particularly, it is an indexical trace that represents simply by responding to what it encounters.

\subsection{As capable of revealing unique conditions}

The skyway can be seen to result from a hypothesized act of extrusion, as if the system takes its form by means of extruding a rectangular cross-sectional shape through the city, along lines of travel. As it finds its way through the city, this extrusion twists and 
turns subject to constraints embodied in the building code and in accessibility guidelines, as well in as the physical fabric of historic buildings. These conditions can surprisingly manifest themselves, forming a kind of especially resistant terrain which the system is obligated to address. If understood in this way, the skyway can be understood as a device for measuring or reading local particularities. To state this idea differently, the skyway operates as a disturbable, neutral form extruded through the environment; we might think of it as an inflectable probe inserted into a city, by means of which certain resistances can be measured and made visible - disturbances of the idealized form. The exceptions from the idealized form constitute a reading of local particularities. It is precisely through the skyway's capacity to admit exceptions to its idealized form that persistent local forces (e. g., topography, or the political will of a resistant entrenched population) become manifest, and it is when the system enters into buildings that this dimension is most obvious.

Speaking generally, the skyway encounters five different kinds of conditions on its journey through the city. The first of these is the condition where the system encounters predefined, pre-existing, public or quasi-public spaces, and appropriates these spaces within itself. The archetypal example in St. Paul occurs within the Railroad and Bank Building, designed by Charles S. Frost and built from 1914-1916 (Fig. 3).

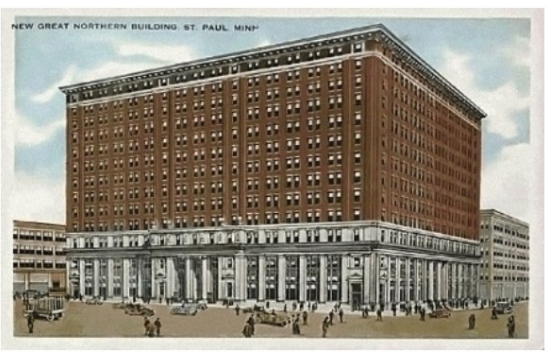

Figure 3. Railroad and Bank Building. Source: City of Saint Paul and the Saint Paul Heritage Preservation Commission (1988).
The Railroad and Bank Building incorporates a multi-story interior light well, at the base of which is an ornate atrium currently operating as an event venue. An isometric drawing of the atrium within the context of the building's second floor indicates its appropriation by the skyway system (Fig. 4).

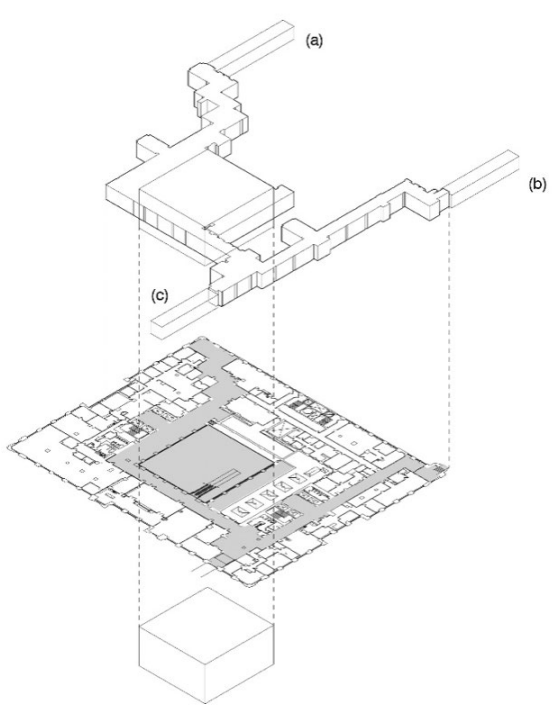

Figure 4. Skyway within the Railroad and Bank Building. Source: By authors.

Skyway bridges (marked a, b, and c) connect the Railroad and Bank Building to neighboring buildings. In the condition illustrated by the Railroad and Bank Building, the discovered condition of the historic atrium, a space originally designed as an internally focused, internally-lit core, is revealed through the possibility of a new approach, i. e., via the building's second floor: an approach not contemplated by the building's original designers. As the skyway system finds its way from the perimeter of the Railroad and Bank Building to the atrium's arcades, it appropriates original corridor spaces (e. g., the segment 
between bridges $\mathrm{b}$ and $\mathrm{c}$ ) as well as repurposed, previously marketable, office spaces (e. g., the segment near bridge a).

The second condition encountered by the skyway is the quasi-public internal space designed in anticipation of connection to the skyway system. An excellent example of this condition - directly connected to the Railroad and Bank Building by skyway - is the atrium inside Cray Plaza, designed by Miller, Hanson, Westerbeck \& Bell, and built 1986 (Fig. 5).

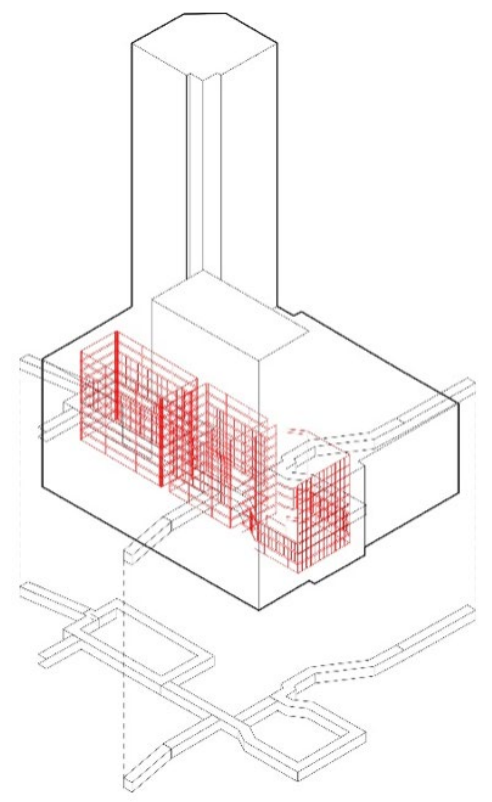

Figure 5. Atrium and skyway system within Cray Plaza. Source: By authors.

Anticipatory spaces of this kind are wellpositioned to engage the skyway in a way closely approaching its original vision, i. e., as a system providing efficient connections between nodes such as parking ramps and retail. Although retail has largely disappeared from Cray Plaza since its construction, the atrium and its integration of the skyway system still reveal the commercially-driven priorities of its architectural design.

The third condition encountered by the skyway is the conversion of formerly private or quasiprivate space deep within buildings into the system. The best example within the entire St. Paul skyway system is Park Square Court, a collection of nineteenth-century wholesale buildings adjacent to Mears Park, designed by J. Walter Stevens and built between 1886 and 1906 (Fig. 6).

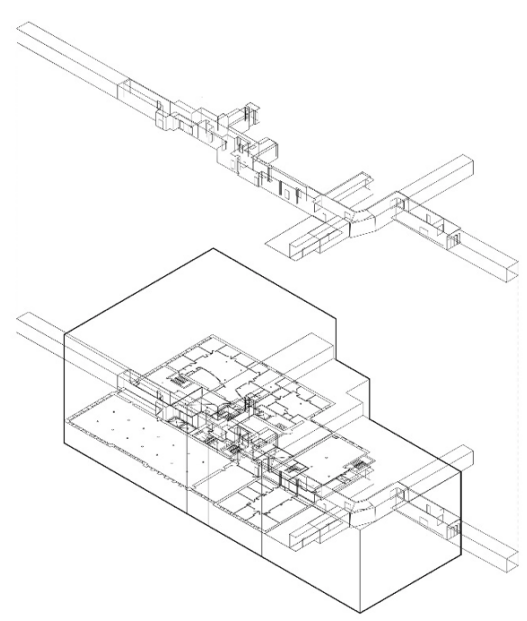

Figure 6. Atrium and skyway system within Park Square Court. Source: By authors.

This is a found condition of entirely different quality than that in the Railroad and Bank Building: at Park Square Court, the discovered spaces within the building result from a process akin to excavation: walls and floors being selectively removed so as to admit passage, light, and view. To occupy the discovered territory within Park Square Court is to experience these buildings in ways that were quite inconceivable until the arrival of the skyway system.

The fourth condition - the underground tunnel - exists rarely in St. Paul, although it 
plays a prominent position in other gradeseparated systems such as Toronto's PATH system. Finally, the only condition clearly visible and apprehensible to the broader public from the perspective of the street is the bridge, freely spanning from one building to the next. It is here, and here alone, that the skyway most closely approximates its idealized form.

\section{CONCLUSION}

As a system, the skyway structures experience in a way which encourages focus on distant goals rather than immediate detail, promoting a kind of "tunnel vision" unlike anything else in the contemporary North American city. In this sense it is a lens or prism, structuring perception, action, memory, and movement in unique ways, obscuring and enabling behaviors, views and perceptions, and ways of moving within the city. As an architectural interface, the skyway is a device for generating architectural and urban knowledge. More specifically, it generates knowledge of architecture and of the city - precisely by idiosyncratically limiting and structuring visibility and movement. It enables processes, exchanges, and negotiations, and in so doing makes local particularities visible in specific ways. In this essay, rather than emphasizing possible numbing effects of the skyway on perception, or critiquing its effects from a social or political perspective, we have proposed that its physical form - its departures from a hypothesized idealized form - record and make visible and memorable local particularities. Along the way, the skyway becomes something which isn't quite a built work of architecture, and isn't quite a drawn representation of architecture: it exists as an oscillation between building and drawing, an inhabitable mode of urban representation.

\section{ACKNOWLEDGEMENTS}

The authors acknowledge and thank the University of Minnesota School of Architecture for providing funding to support the graduate research making this work possible. 


\section{REFERENCES}

Andersen, K. 1988. "Fast Life Along the Skywalks: By Going Indoors, City Dwellers Escape the City." Time, August 1, 1988.

Appleyard, D., K. Lynch, J. R. Myer. 1964. The View from the Road. Cambridge, MA: MIT Press.

Augé, M. 1995. Non-places: Introduction to an Anthropology of Supermodernity. London: verso.

Blauvelt, A. 2016. "Preface." In Parallel Cities: The Multilevel Metropolis, Jennifer Yoos and Vincent James. Minneapolis: Walker Art Center.

Boddy, T. "Underground and Overhead: Building the Analogous City." In Variations on a Theme Park: The New American City and the End of Public Space, edited by Michael Sorkin, 123-125, 141-144. New York: Hill \& Wang.

Burns, C. "On Site: Architectural Preoccupations." In Drawing, Building, Text, edited by Andrea Kahn, 146-167. New York: Princeton Architectural Press.

Christenson, M. 2019. Theories and Practices of Architectural Representation. New York: Routledge.

City of Saint Paul and the Saint Paul Heritage Preservation Commission. 1988. "Railroad and Bank Building." https:// saintpaulhistorical.com/items/show/201.

Colomina, B. 1992. "The Split Wall: Domestic Voyeurism." In Sexuality and Space, edited by Beatriz Colomina. New York: Princeton Architectural Press.

De Certeau, M. 1984. The Practice of Everyday Life. Los Angeles, CA: University of California Press.

Derrida, J. 1982. "Différance." In Margins of Philosophy. Translated by Alan Bass. Chicago: The University of Chicago Press. Gruen, V. 1956. A Greater Fort Worth Tomorrow. Fort Worth, TX: Greater Fort Worth Planning Committee.
Jacob, B. 1985. "Architectural Form in the Urban Setting." Design Quarterly 129, 2931.

Jameson, F. 1991. Postmodernism, Or, The Cultural Logic of Late Capitalism. Durham, NC: Duke University Press.

Robertson, S. 2004. "Visions of Urban Mobility." In Urban Infrastructure in Transition: What Can we Learn from History? edited by Peter Wilding. Graz, Austria: IFF/IFZ.

Venturi, R., D. Scott Brown, and S. Izenour. 1972. Learning from Las Vegas. Cambridge, MA: MIT Press.

Willensky, E. 1985. [Untitled]. Design Quarterly 129, 14-15. 



\title{
PAPER \#1.21
}

\section{FABRIC[ATED]: \\ FABRIC INNOVATION IN ARCHITECTURE + EDUCATION}

\author{
Tolya Syril Stonorova \\ aNorwich University School of Architecture + Art, Northfield, Vermont USA
}

\section{ABSTRACT}

Fabric has long been a catalyst for innovation, reflection, change and transformation in architecture. This paper explores how the research and testing of fabric innovation and material responsibility can influence architecture and design. Part of a larger future book, (expected publishing date 2023), this study will explore the ways in which fabric can and historically has revolutionized architecture, teaching and design. This analysis will uncover fabric's multidimensional and multifaceted role in architecture and design and its influence on social justice: architecture and design that aids humanity and the environment, creating an inclusive, diverse, and altruistic environment for all. This inquiry examines fabric in architecture through a multilayered approach and is divided into sections, beginning with an analysis of precedents, using both written and built work. The study then turns to an examination of educational case studies: community-driven projects that exemplify dynamic and groundbreaking models for national and international projects that make the connection between fabric and the built environment. The chosen case study projects focus on how these approaches are being incorporated into academic architectural and design studios. Finally, the paper examines one case study in depth, looking at the relationship of gender and garments to architecture and skin. The paper highlights how fabric, in its broad definition, continues to be an important and innovative material in the development of socially conscious architecture.

\section{KEYWORDS}

Fabric; innovation; tensile; pedagogy; gender.

\section{INTRODUCTION}

This paper examines Fabric as a catalyst for innovation, reflection, change and transformation in architecture, and how the research and testing of this thesis can influence architecture and design education. This study, which is part of a larger future book project, FABRIC[ated], (publication expected 2023), explores the ways in which fabric can and historically has revolutionized architecture, teaching and design. From the relationship of gendered vernacular garments to architectural space, to the sustainability of tensile structures, ${ }^{1}$ this paper uncovers fabric's multidimensional and multifaceted role in architecture and design and its influence on social justice. Social justice is defined here under a broad definition of architecture and design as a force that aids humanity and the environment, while creating an inclusive, diverse, and altruistic environment for all. Through a multilayered approach, the paper will study this topic with sections on the use of fabric in tensile structures, concrete fabric, refugee tent structures, fabric as a gendered translation from the traditional female garment to buildings, smart/responsive fabrics, such as the innovative research conducted by Kennedy Violich Architecture, and the groundbreaking fabric-focused work of others. Through an examination of

${ }^{1}$ Tensile Structures: "A tensile structure is a construction of elements carrying only tension and no compression or bending... Tensile structures are the most common type of thin-shell structures." https://en.wikipedia.org/wiki/Tensile_structure 


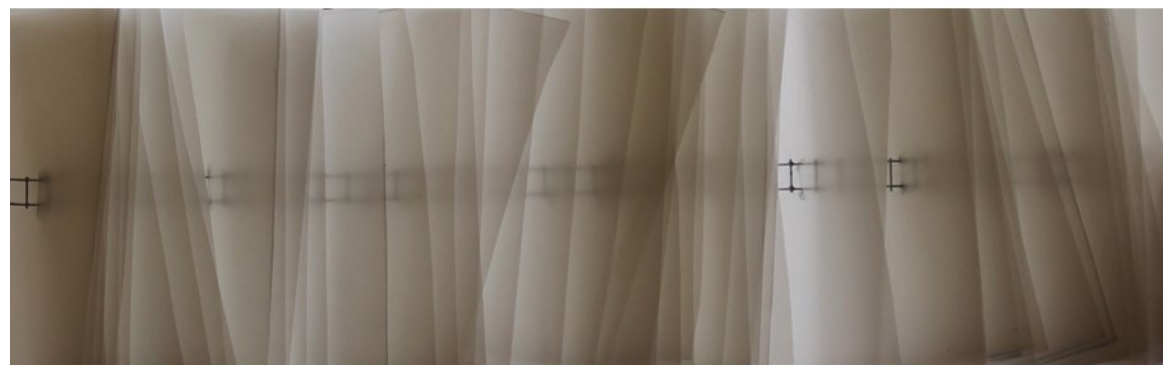

Figure 1. Urban Water Body Studio, Stonorov, Norwich University

case study community-driven projects, the paper offers readers pedagogical models for national and international projects that illuminate various aspects of this issue. The chosen case study projects will focus on how these methods are being incorporated into academic architectural and design studios. Specifically, the paper documents 6 case study learning environments, that deal with the different aspects of the book's thesis.

FABRIC[ATED] brings current research about the relationship between fabric and architecture and design innovation and social justice together under the larger focus of academic learning and how academia can work to incorporate these ideas into the future of architecture. Radical designers like Hella Jongerius have pushed the relationship between the body and design and revolutionary engineers and architects like Frei Otto, Peter Rice and Herzog and De Meuron have explored how we can re-envision the skin of the built environment - architecture's relationship to structure and material. It is noteworthy that leading architects, such as Thom Mayne of Morphosis, have discussed the relationship of skin, (it too a tensile fabric), and the body to architecture and thus have established the context for this paper: "The space between the surface of the body and the surface of the skin -- the interstitial territory bounding interior and exterior -- allows each face of the building to alter as the light conditions change with the movements of the sun across the sky and of pedestrians along the street."2 This paper will take an inclusive approach to these studies and weave these interrelated subjects together under the umbrella of the sustainability of social justice. I.e. each topic will be examined in a holistic way and evaluated in relation to its impact towards human and environmental good.

\section{PRECEDENT: LITERATURE REVIEW}

There is exciting and significant research published about fabric in relation to sustainability, garments and architecture; architecture for the underserved; tensile structures and innovation. Yet, existing publications tend to be highly focused in their approach, or have been published decades ago. This paper attempts to present this body of research in a broad, current and integrated fashion. In Architecture in Fashion, Singley and Fausch state, "This...cleavage between durable edifice and ephemeral textile motivates not only advertising's use of architecture as a sign for resistance to change, but also fashion's desire to acquire an aura of classic timelessness through a metonymical relationship with the edifice." ${ }^{3}$ In this text, the editor and chapter authors

\footnotetext{
${ }^{2}$ Quote from Thom Mayne in Lupton, Ellen. Tobias, Jennifer. Imperiale, Alicial. Jeffers, Grace. 2002. Skin: Surface, Substance, and Design. New York, NY. Princeton Architectural Press.

${ }^{3}$ Fausch, Deborah, Paulette Singley. 1996. Architecture in Fashion. New York, NY. Princeton Architectural Press. (page 7).
} 
examine the relationship between fashion and architecture, drawing conclusions and comparisons between the movements and trends in the two related industries. This work provides important context for the work in this book, in that it deals with the garment/ fashion/building relationship and speaks to appropriation and manipulation, both physical and in thoughts.

In Ellen Lupton's Skin: Surface, Substance, and Design, the study of skin in relation to the building envelope is eloquently written about: "Skin is a multilayered, multipurpose organ that shifts from thick to thin, tight to loose, lubricated to dry, across the landscape of the body." ${ }^{4}$ In this text she knits complex responses to the idea of skin through an exploration of precedent projects. Lupton discusses the relationship between interior and exterior space relative to the body, "Skin, a knowledge-gathering device, responds to heat and cold, pleasure and pain. It lacks definitive boundaries, flowing continuously from the exposed surfaces of the body to its internal cavities." 5

The study of the relationship between fabric and the built environment demands new approaches to the way we teach. In relation to the pedagogy of teaching methods, Hella Jongerius has been a leader in boundary pushing processes, working with fluid forms and fabric innovation, for decades. Her lab, currently located in Berlin, Germany, explores state-of-the-art weaving techniques and other textile innovations. Jongerious writes "The unfinished, the provisional, the possible - they hide in the attention for imperfections, traces of the creation process, and the revealed potential of materials and techniques...This working method...not only celebrates the value of the process, but also engages the viewer, the user, in her investigation." Jongerius' highly experimental methods point to potential in the products of studio exploration. As FABRIC[ATED] explores pedagogy and how these concepts can affect student learning, work like Jongerius' with Droog Design is essential for pushing the idea of process and product.

Architecture is an art that exists in space. It encompasses the built world and requires experiential understanding. When examining the existing work in the field, precedents may be looked at using two methods. The first involves research and analysis of texts written on the topic, outlined above. The second, of equal importance, involves an investigation of built work precedents, and how the theories and practices of the relationships between fabric and design are incorporated into the built environment.

\section{PRECEDENT: BUILT WORK}

\section{Frei Otto}

Frei Otto is one of the leading architects on tensile and lightweight structures. Otto is widely considered to be one of the most important architects of the $21^{\text {st }}$ century, and in 2018, Otto received the Pritzker Prize, a highly prestigious architecture award. Though his work was clearly pushing innovative boundaries in terms of materials and engineering, Otto was also deeply concerned with social justice. In an interview with the Pritzker Prize committee he stated "I've never done anything to gain this prize...Prizewinning is not the goal of my life. I try to help poor people..." His work was a rooted in sustainability at its core, though it may not be immediately apparent. The choice to examine how structure might be envisioned as something light and minimalist, as opposed

\footnotetext{
${ }^{4}$ Lupton, Ellen. Tobias, Jennifer. Imperiale, Alicial. Jeffers, Grace. 2002. Skin: Surface, Substance, and Design. New York, NY. Princeton Architectural Press.

${ }^{5}$ Lupton, Ellen. Tobias, Jennifer. Imperiale, Alicial. Jeffers, Grace. 2002. Skin: Surface, Substance, and Design. New York, NY. Princeton Architectural Press.

${ }^{6} \mathrm{http}: / /$ www.jongeriuslab.com/information

${ }^{7}$ https://www.nytimes.com/2015/03/11/arts/design/frei-otto-german-architect-wins-pritzker-prize-posthumously.html

Last accessed 11.14.19
} 
to the heavy, material abundant traditional forms of wood and steel framing methods, was a political statement as well as a design manifesto. Otto questioned need and excess in his work through rethinking how buildings could be made. "Otto's work was lightweight, democratic, low-cost and sometimes

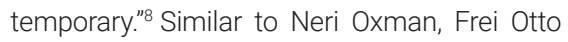
was inspired and fascinated by examples of lightweight minimalist structures in nature. Otto was fundamentally committed to learning by doing and was known to construct complex physical models to test the tensile structures he envisioned. These examples of social justice, doing more with less, and physical making, are key themes that point to how fabric innovation has contributed to goals of social justice. "The advantage of cable net structures is that load transfer can be achieved with an enormous saving in material."9 This material frugality represents a pressing issue in architecture fabrication today. In minimizing the sheer amount of material used in construction, the design embraces sustainability at its core, creating a greater focus on resource scarcity.

The relevance of Frei Otto's empirical model aesthetic lies in identifying the enormous potential of object knowledge and its materialcultural dimension - on the one hand to continue to anchor the perception of the resource between nature and technology, and on the other to allow better investigation of the complex interrelations between digital and analog. So what does it mean for architects and engineers to design in a society that seeks a balance between growing digitalization and increasingly important resource awareness? ${ }^{10}$

\section{Kennedy Violich Architects}

Kennedy Violich Architects, KVA, has spearheaded research and implementation of innovative fabric and material studies for decades. KVA's work with the Soft House, in Hamburg Germany, explores how soft surfaces throughout the house may be used to absorb and provide solar energy. Exterior 'twisters', flexible photovoltaics, are used to capture energy throughout the day. The innovative use of flexible and moving structure results in a higher energy yield.

Flexible photovoltaics in textile 'twisters' are
attached to flexible fiber composite board on
the roof, offering shape adaptation for daily
and annual seasonal sun tracking - creating
the first 2-axis soft solar tracking system. ${ }^{11}$

The Soft House further uses high tech fabric curtains embedded with lights to divide spaces within the dwelling. This highly customizable flexible infrastructure provides the user with enhanced agency to define their experience. Coupled with large expanses of glass, the curtains allow the user to meld and screen their public and private inhabitation of the space. The LED lit fabric divisions both veil the interior from bright sunlight and create a gentle and luminous wall in non-lit times of the day. KVA brings this research to their teaching at Harvard through architecture design studios.

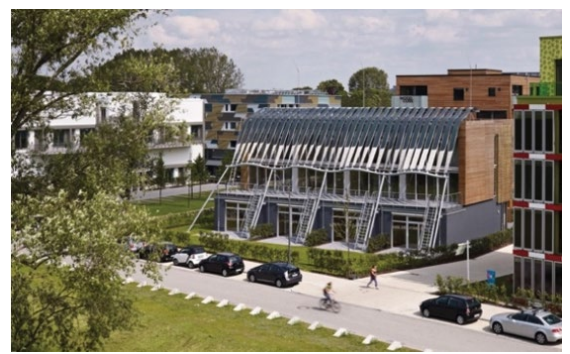

Figure 2 Soft House, http://www.kvarch.net/ projects/87

\footnotetext{
${ }^{8} \mathrm{https}$ ://www.pritzkerprize.com/laureates/frei-otto Last accessed 11.14.19

${ }^{9}$ Meissner, Irene; Moller, Eberhard. 2017. Frei Otto, A life of research construction and inspiration. Munich, Germany. Detail, Second Edition.

${ }_{10}$ Meissner, Irene; Moller, Eberhard. 2017. Frei Otto, A life of research construction and inspiration. Munich, Germany. Detail, Second Edition.

${ }^{11}$ http://www.kvarch.net/projects/87, last visited 1.22.2020
} 


\section{CASE STUDIES}

The following Case Studies examine fabric, gender, material responsibility and inclusive sustainability. They were specifically chosen for their community-based attention to issues of holistic social justice and their innovative exploration of fabric.

\section{KESWA: AN UNCOVERING}

At a recent Design Build Xchange Conference in 2017, Emily Baker, architecture professor at Tulane School of Architecture discussed her project titled KESWA: AN UNCOVERING. Through working with Muslim female students at Tulane, Baker developed a project that examined the veil, the abaya, in Arabic culture today. Female students digitally fabricated a steel enclosure that abstracted the abaya and encouraged the community to inhabit this enclosure. "Keswa invites the public to enter the space of the abaya, simultaneously venerating the garment and subverting its power to subordinate."12 This reinterpretation of the traditional female garment starts to dissolve gender-imposed boundaries and barriers and encourages users/viewers to question their own perception and preconceptions. This research points to the Gender Space Architecture essay by Beatriz Colominia:

[Silverman] points to the role of the object in forming both its own image and that of the spectator. Moreover, by stressing the notion that seeing and being seen are reciprocal positions in the same operation, she returns us to the dual nature of representation: at once inscribing the image of the thing represented and revealing its own culturally constituted structure. ${ }^{13}$

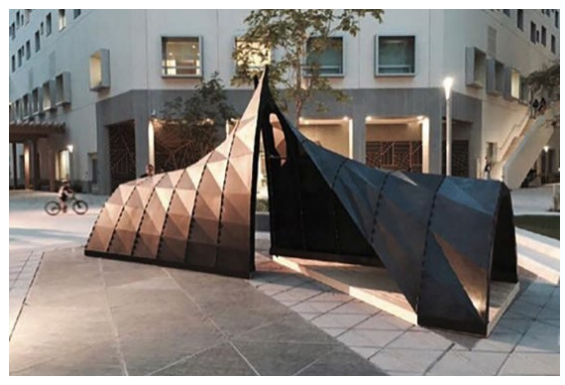

Figure 3. KESWA, Copyright Emily Baker

\section{Fabrik}

At the University College of London Bartlett School of Architecture, Daniel Widrig, Stefan Bassing and Soomeen Hahm worked with students, I-Ting Tsai, Somdatta Majumdar, Xixi Zheng and Yiru Yun, to create a dynamic and fascinating body of research-based studio work: Fabrik. By using a single sheet of felt, students formed and stitched complex volumes that resulted in furniture designs. After an extensive period of experimentation, students discovered a workable resin mixture, which caused the felt to become rigid where needed and remain soft as required for comfort. Unlike the traditional use of fabric as a drape or vessel for cushioning, Fabrik relies entirely on the felt composite to create the form of the piece. The felt and resin combination creates a concrete like result, with a soft tactile quality.

\section{Airdraft}

Thomas Randall-Page and Benedetta Rogers', AirDraft, pushes the boundaries of definable space. With clear inspiration from the 1960's Antfarm, AirDraft is an inflatable cultural space that inverts the previous life of an industrial barge and transforms it into a mobile performance/gallery space. Airdraft

\footnotetext{
${ }^{12}$ Emily Baker, http://architecture.tulane.edu/news/2016/03/article-1909

${ }^{13}$ Rendell, Jane. Penner, Barbara. Borden, lain. 2000. Gender Space Architecture. London. Routledge. Essay 34, Beatriz Colominia. 1992. Excerpts from 'The Split Wall: Domestic Voyeurism', from Beatriz Colomina (ed.) Sexuality and Space.

${ }^{14} \mathrm{http}: / /$ superarchitects.world/portfolio/fabrik/

${ }^{15} \mathrm{http}: / /$ thomasrandallpage.com/AirDraft
} 
shines light on the shift that the canal system has undergone from that of industry and utilitarian meaning to conduits of leisure and pockets of cultural experimentation. The form itself references counter culture testing of decades earlier radical designers. Yet, the inflatable nature of Airdraft is born out of a necessity to create space with some permanence, while also being able to dissolve that same space based on the physical constraints of the canal system. The inflatable model provided a solution to this need, allowing the space to be constructed and deconstructed as needed. The use of fabric in this experimental form of cultural space, provided a flexible and innovative material answer to the issue and opportunity.

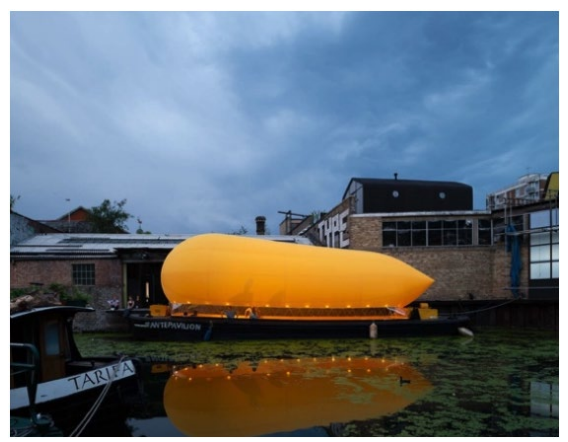

Figure 4. http://thomasrandallpage.com/AirDraft

\section{Shade-Water Pavilion, New Orleans, Louisiana}

The Tulane Small Center for Collaboration and Design + The Carrollton-Hollygrove Community Development Corporation (CHCDC) came together to produce Hollygrove Greenline Shade-Water Pavilion in New Orleans, Louisiana. This shade/water pavilion is an insertion of protest in a blighted area. The pavilion and the surrounding water gardens seek to transform a derelict area into an educational beacon that provides for the community. Founded on the simple idea of an inverted series of tents, the ShadeWater Pavilion gathers rainwater that would otherwise contribute to the city's storm water system, collects it and distributes the water to nearby urban farming gardens.

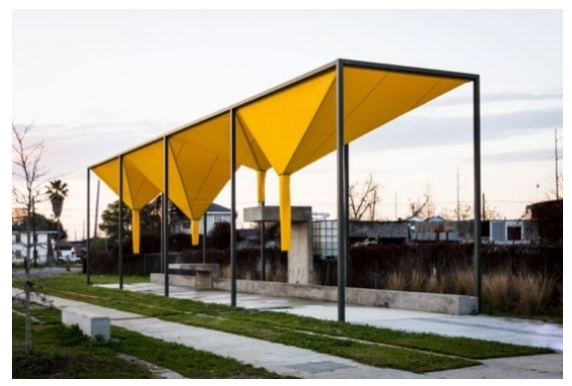

Figure 5. Shade-Water Pavilion

\section{Spacer Fabric}

Claudia Luling is a leading professor currently conducting research into fabric innovation in relation to the architectural envelope. Luling's architecture studios have researched how fabric can provide skin and structure through methods of folding and layering with a foam centered structure. Her work is questioning the typical wood or metal framed building system and suggesting that a digitally produced, 3D printed fabric and foam envelope can provide a streamlined product that will produce significantly less waste than traditional building processes.

Luling's SpacerFabric_HOME (ZeltHAUS) uses an innovative folding technique of a double layered fabric to provide temporary housing to refugees. These structures attempt to answer a very current need for provisional shelter in our growing refugee crisis.

"Three dimensional, double layered textile structures are used as structural elements, which once foamed serve as lost formwork for the fabrication of stable and insulated 
lightweight structural elements. Integrated into this system are hingeless folding mechanisms that enable fast building and dismantling."16

It is precisely this sort of innovation that is specifically allowed by fabric's material qualities. The lightweight, transportable design provides a bright and dynamic solution to a basic human need that it currently in crisis.

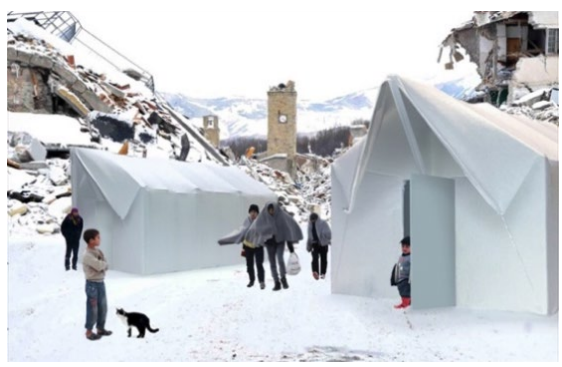

Figure 6. Copyright Frankfurt University, Claudia Luling

\section{Urban Water Body Studio}

In my own, Urban Water Body Studio, an upper level architecture studio at Norwich University, School of Architecture + Art, I taught a studio on the relationship of the garment to the body and the translation of the garment to the building. This work was born out of my thesis work at the University of California, Berkeley where I examined how the act of dressing or housing, the layered relationship between public and private space, can be reviewed by looking at the correlation between the female garment and architecture. Architecture may be envisioned as our third skin and the garment as our most immediate second skin. Like the garment, our edifices at once shield and expose. Building and garment share a parallel language, both affording refuge to the body. The focus of each is concurrently external and internal and what is divulged is selected by choices of spatial immediacy, permeability and layering. The passage towards private space in built form is analogous to the movement towards the body through the layers of a garment. In researching this topic, it is useful to examine this relationship through a historical analysis. This analogy can be examined through the relationship of the kimono and the veil to the traditional Japanese and Islamic house. From this study, lessons can be extracted, abstracted and applied to built form.

The construction of the kimono shares with its architectural counterpart a true economy of means. Both space and fabric are intricately thought out, rejecting wastefulness. The kimono is based on a bolt of cloth that is typically 14 inches by twelve and a half yards. Its construction follows this standard fabric size and uses a minimal amount of cutting to achieve the final garment. The main body of the garment is two lengths of the bolt sewn together in the back and left open in the front. An additional length is divided in two and sewn to each open length in the front, providing overlap. The entire pattern for the kimono is laid out on a single bolt, perfectly divided to ensure no wastage of material. The obi, a belt like attachment that keeps the kimono closed, is the one part of the kimono that is separate from this concise pattern; it is also the component of the kimono that most transforms over the centuries.

The garment is modified from person to person, but instead of excess material being cut and discarded, it is folded into the seams, allowing for change. The kimono is the antithesis of a pair of American jeans that are discarded yearly or with a change in weight; it is a garment for the life of the person and accordingly can transform to fit the current form of that person. This flexibility implies a certain generosity and lack of rigidity of the kimono that may be misleading. Different styles of the kimono throughout history have 


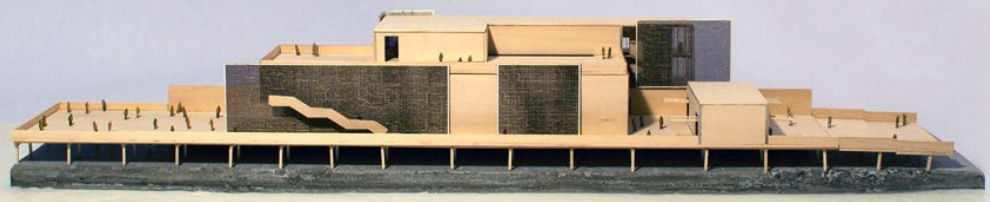

inhibited women's movement. In the Edo period during the late 18th century, the length of the kimono was several inches longer than the height of the woman (a style that continues today) and the obi was widened to 12 inches; both made walking difficult. At this point the obi covered most of the midsection, from the pelvic bone to their chest. It transformed from a simple and functional rope meant to fasten the garment, to an elaborate and wide mechanism that could not be tied by the person wearing the garment. To get in or out of this kimono, a woman had to be assisted. This points to a built-in dependence that the garment itself imparted on women.

The Japanese house embodies the characteristics of the kimono. The house, as with the garment, has an economy of space and materiality. Corresponding to the kimono standard bolt of the fabric that is derived from the basic width of the human form, the Japanese house is based around the tatami mat whose dimensions stem from the shape of the human form, 90 centimeters wide and 180 centimeters long. The tatami was originally conceived of as a floor covering that could be used to sleep on, but was also used to cover the entire floor. "When the designer of a traditional Japanese house first begins drawing up plans for the building, she first determines how many tatami mats will be needed to cover the floor. By designing different layouts, the final configuration of the mats will determine the shape and size of the house. In this way the architecture employs a unit of measurement that is standardized and columns, street frontages and room sizes were made. The idea of the human scaled module translated to how spaces within the house could be used. Instead of delineating exact placement of walls and doors, the house is constructed around sliding screens that move in response to season or mood. The use of the shoji screen further emphasizes the subtlety of the space. Light is softened as is enters through the paper screens, creating complex shadows that bring a specific emotion to the room. The house responds to the changing conditions as the kimono responds to its changing user. The subtle complexity of the kimono and Japanese house, embodied in the concept of 'iki', creates a sensuous interaction between body and form. Shelter, in both garment and built form, is seen as something that can be opened or closed depending on the degree of privacy and warmth desired to respond to the exact needs and desires of the users.

In the Middle East, the relationship between the veil and the traditional Islamic house is highly complex. The veil by nature creates duality. It determines two things as different. $A$ is made aware of $B$ because of $X$, the veil. Depending on this $X, A$ and $B$ can be separated or united. $X$ becomes the interface between $A$ and $B$, the public and private spaces of house, and body. The degree of privacy required determines the nature of the veil. In Indonesia the veil is 
a simple white cloth, mandil, that is draped over the head, leaving the face exposed. In Somalia the veil covers the entire body, but leaves an opening for the eyes, where in Saudi Arabia, even the eyes are covered by a dark mesh, hijab, that is impossible to penetrate. In 1999, I spent several months in Northern India, where, during my time in Pushkar, Rajasthan, I saw that women donned the veil only in certain occasions. I spent a day with an Indian man and his family, where I noticed his wife putting on and removing her veil (a thin piece of colorful cloth), depending on who was in the room. I was told that his wife only wore her veil around his older brothers and father. Around his younger brothers, she did not wear the veil, shedding light on the relationship of the veil to the hierarchy within a family and society.

The veil itself is donned for two main reasons, firstly it allows the woman to display her religious piety and secondly because of

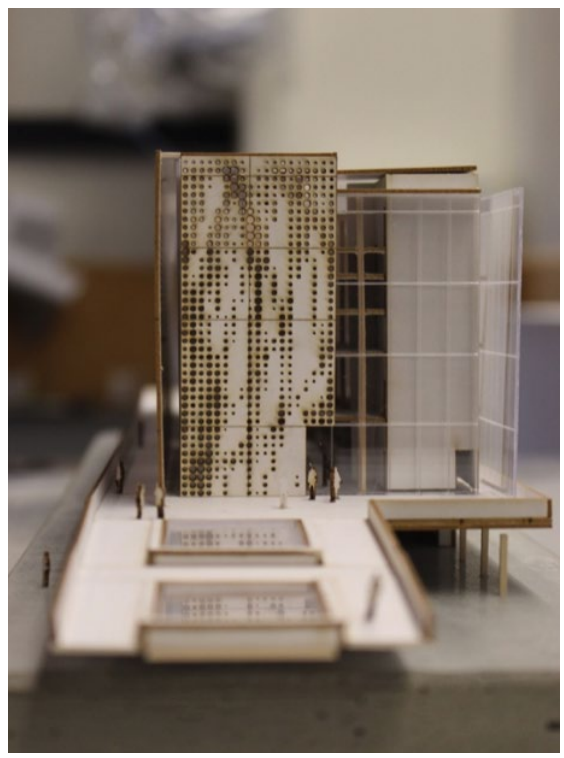

Figure 8 Urban Water Body Studio, Norwich University male assertion. The juxtaposition of these two reasons makes the veil so fascinating. From a Western view point, the veil echoes with ideas of subservience and chauvinism, a garment that forces women into confinement and prevents self-expression. Yet, to many women who wear them, the veil is a sign of solidarity with other women, religious piety and freedom. The role of the veil, to the women who chose to wear it, is not one of confinement, but rather a garment that allows them to exert their religious beliefs and frees them from voyeurism in the public world. Sherifa Zuhur notes in her book Revealing, Reveiling, that "the majority of the younger veiled women saw the hijab as a symbol of change. This change was not only a personal and moral, but represented a social sisterhood to them."17 On this level, by taking the veil, the woman has the ultimate power over voyeurism, as she decides when and by whom she will be perceived.

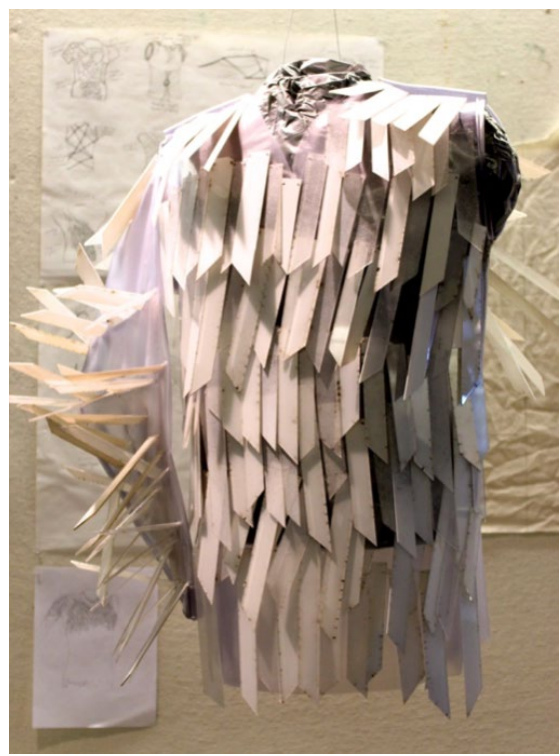

${ }^{17}$ https://www.frankfurt-university.de/en/about-us/faculty-1-architecture-civil-engineering-geomatics/contact/professors/ architecture/prof-dipl-ing-claudia-lueling/tab-designbuild-e/spacerfabric-home/ Last viewed 1.22.2020 
Similarly, the traditional Middle Eastern house also provides an inward facing space. Like the mesh that covers women's eyes in Saudi Arabia, the intricately carved facades of the Islamic house create a screen through which the public street or courtyard is viewed. "The veil performs many of the functions of seclusion and introversion as expressed in Islamic domestic architecture... In house architecture, the screened balcony allows the female occupants to view the outside world without being seen." ${ }^{18}$ The house then directly mirrors the garment, articulating the edge between public from private. Furthermore, it delineates the importance of this interface and highlights the need for controlling when and where women are seen. The veil is a topic so complex, that this investigation inevitably provides only a small glimpse into the political and social issues present. What the exploration does offer is a window into an intricacy of the veil that may serve to heighten curiosity and interest. This study then, is itself only a preview for a larger study of the complexities of the veil, one that provides a rich entry point into the design of built form.

This research into the relationship between female garments and architecture provides an entry point from which one can define a design proposal, a test case on which we can examine the ideas embedded within the investigation. Bringing this research into the studio setting allowed complex conversations around the ideas of layering, permeability, voyeurism and public and private space. After an initial examination of an organic skin, students extracted the lessons they had learned a fabricated a garment related to that skin. These garments were constructed at full scale and represented the first housing of the body. From this point, the studio moved into a secondary exploration by conceptually examining the third skin, the building. As a conceptual jumping off point, the students constructed a 'building' out of layers of mylar films, that when built up, can provide privacy and comfort to differing degrees, much like a garment. This study allowed the physical, although often metaphorical, garments to find a more traditional built form, while maintaining abstraction. The richness of ideas presented from the skin/garment/body/ building research allowed for a more nuanced and complex development of a building. It further allowed students to examine their own cultural constructs and question how they clothe themselves may be related to a building's envelope. Further it highlighted how the female garment can be influenced and influence in return, the built environment.

\section{OUTCOMES + CONCLUSION}

From each of the case studies examined, we may glean exciting possibilities of how fabric has architecture material potentials. These innovative methods and case studies provide fresh ways of looking at architecture, culture and social justice. In each we see novel techniques for addressing space, culture and need. In Otto's dynamic and groundbreaking work, ideas of heavy structure are replaced by light and malleable forms that use dramatically less material, while also creating delight. In the work of KVA, fabric provides a more responsive and interactive solar collection system, while heightening the interior possibilities of the user experience. Like the traditional Japanese house, the user in the Soft House can adjust their interior space through the use of fabric walls, similar to the vernacular Japanese sliding screens. Through the qualities of these translucent materials, daily experience finds richness in the previously mundane. Similarly, the inverting of the veil experience by Baker's dynamic studio, turns the user experience into one of introspection and discovery. By inhabiting the veil, Baker subverts the typical power dynamic of the garment, highlighting the complex relationships. Airdraft's playful

\footnotetext{
${ }^{18}$ Edwards, Brian, Sibley, Magda. Land, Peter. Hakmi, Mohamad. 2006. Courtyard Housing: Past, Present and Future. Taylor and Francis.
} 
and interactive cultural space emphasizes real social shifts in the London canal system. Its ethereal and temporal nature draws attention to the shifting landscape of cultural space on this everchanging waterway. Luling's work with fabric is pushing the boundaries of how we think about temporary refuge. Her studio's work is simultaneously acutely innovative and expressly political. Like Otto, Luling is rethinking structure and how it relates to the building envelope. This shift in material and intention provides a more socially minded outcome and a goal of architecture for all. Culturally, it is important to recognize how women have influenced and continue to influence the built environment. Through an examination of the traditional female garment in relation to vernacular architecture, we can garner a deeper understanding of a dynamic cultural relationship. Fabric, in its broad definition, continues to be an important and innovative material in the development of socially conscious architecture.

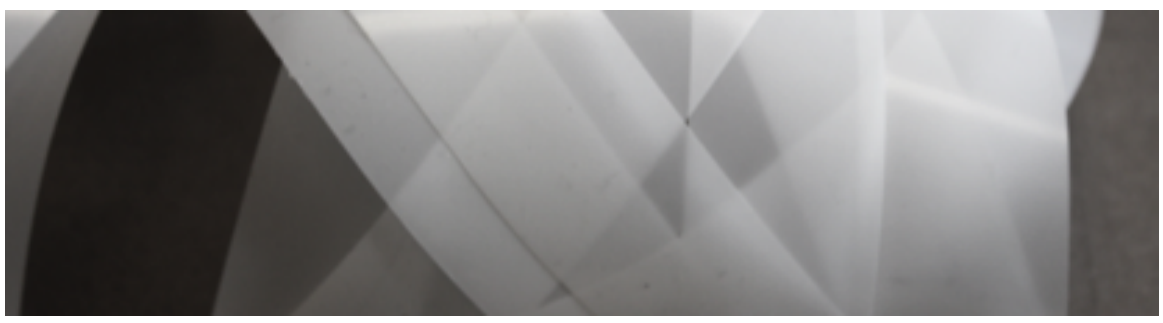




\section{REFERENCES}

Accad, Evelyne. 1978. Veil of Shame: the role of women in the contemporary fiction of North Africa and the Arab world. Quebec, Canada. Sherbrooke.

Lüling, Claudia; Richter, Iva. 2017. Architecture Fully Fashioned - Exploration of foamed spacer fabrics for textile based building skins. Journal of Façade Design and Engineering. Vol 5 No1. TU Delft Open

Black, Alexander. 2000. The Japanese house. Boston. Tuttle Publishing.

Balmond, Cecil. 2002. Informal. London, United Kingdom. Prestel.

Crawford, Matthew B. 2009. Shop Class as Soulcraft, An Inquiry into the Value of Work. London, England: Penguin Press.

Darabi, Parvin. 1999. Rage Against the Veil: the courageous life and death of an Islamic dissident; Amherst, New York. Prometheus Books.

Fathy, Hassan, 1986. Natural Energy and Vernacular Architecture, Principles and Examples with Reference to Hot Arid Climates. Chicago and London. The United Nations University by The University of Chicago Press.

Fausch, Deborah. 1996. Architecture in Fashion. New York, NY: Princeton Architectural Press.

Fletcher, Kate. 2008, 2014. Sustainable Fashion and Textiles, Design Journeys. Oxon. Earthscan. Routledge.

Goodwin, Jan, 1994. Price of Honor: Muslim Women lift the veil of silence on the Islamic world. Boston. Little Brown.

Hillenbrand, Robert, $1994 . \quad$ Islamic architecture. Columbia University Press. New York.

Hoag, John D., Nervi, Pier Luigi. General Editor; Abrams, Harry N. 1977. Islamic Architecture, Inc., New York. Publishers.
Iwamoto, Lisa. 2009. Digital Fabrications, Architectural and Material Techniques. New York, NY. Princeton Architectural Press.

Kinney, Leila. 1999. Fashion and Fabrication in Modern Architecture. Cambridge, Mas.: MIT press, Journal of the Society of Architectural Historians, Vol. 58 No. 3. (pp. 472-481).

Kinoshita, Masao. 1964. Japanese Architecture; Shokukusha Publishing Co. Tokyo, Japan.

Miodownik, Mark. 2013. Stuff Matters, Exploring the Marvelous Materials that Shape Our Man-Made World. United Kingdom. Penguin Books Ltd.

Michell, George. 1978. Architecture of the Islamic World, New York. William Morrow and Company, Inc.

Musterberg, Hugo, 1996. The Japanese Kimono. New York. Oxford University Press.

Pfeffer, Richard M. 1979. Working for Capitalism. New York. Columbia University Press.

Rice, Peter. 2017. An Engineer Imagines. England. Batsford, an Imprint of Pavilion Books Co.

Rudofsky, Bernard, 1965. The Kimono Mind, An Informal Guide to Japan and the Japanese. New York, NY. Van Nostrand Reinhold Company.

Schittich (Ed.), Christian. 2001. Building Skins, Concepts, Layers, Materials. Basel, Germany. Birkhauser Edition Detail.

Schouwenberg, Louise. 2003. Hella Jongerius. London, England. Phaidon Press.

Tsutoma, Ema. 1950. Kimono: one hundred masterpieces of Japanese Costumes. Tokyo, Japan. Meiji-Shobu. 


\title{
VISUAL SPACES OF CHANGE: THE USE OF IMAGE FOR RENDERING VISIBLE DYNAMICS OF URBAN CHANGE IN CONTEMPORARY CITIES
}

\author{
Pedro Leão Netoa \\ aFaculdade de Arquitectura da Universidade do Porto, Porto, Portugal
}

\section{ABSTRACT}

This paper presents the results of the first case study implemented within the research project Visual Spaces of Change. It particularly focuses on the use of Image for rendering visible dynamics of urban change in contemporary cities, exploring the potential of photography for suggesting different readings of past, present and future architectures and places. By discussing the main methodological aspects of implementation of this practical experiment, an innovative process of investigation is proposed for engaging researchers and authors in the fields of Architecture, Art and Image on the creation of visual narratives in public spaces. The use of different representation methods and approaches to photography as a research instrument, and different techniques for communicating different issues related with architecture and public space are discussed. Potentialities and shortcomings of different representation methods and imagery for communicating the identity and transformation of architectures and public spaces are analysed, pinpointing the challenges for a more comprehensive use of visual research and visual data for (i) linking the appearance of the built environment with its identity, meaning and history, (ii) positing interpretative, speculative, symbolic and artistic visual discourses about the city and its architecture, as important elements for reflecting about societal values and understanding different layers of meaning embedded in the built space. The paper concludes by drawing a number of preliminary findings of the ongoing research that is being developed within the project Visual Spaces of Change.

\section{THEORETICAL ASPECTS OF PHOTOGRAPHY RELATED TO ARCHITECTURE, CITY AND TERRITORY}

The use of photography as a research instrument is grounded in the idea that valid scientific insight into culture and society can be acquired by observing, analyzing and theorizing its visual manifestations (Luc Pauwels 2015, i). From this perspective, the use of visual research methods in the fields of architecture, city and territory can contribute to the creation of a knowledgeenabling environment that allows for a more specific study of architectural forms and urban realities, as well as its transformations and appropriations, thus rendering visible aspects of spaces where people socialize and interact, which are difficult to perceive without the use of image and photography an idea sustained by the argument presented by Tim Davis on the article Photography and Landscape Studies that photography can:

\section{(...) shed new light, supply new metaphors, and suggest new directions for the notion of places and for ways in which they may be perceived and used $(1989,8)$.}

In this sense, the universe of photography has been theoretically revised as a practice that translates into an approximation of culture, society, and politics, that uses different strategies to build a critical discourse of what surrounds us, helping to understand architecture and landscape also as cultural constructions and physical expressions which are encoded with 
meanings that can be read and interpreted. An extensive overview of the state of the art on the distinct possibilities and photographic discourses about the fields of Architecture, City and Territory has already been made and published in book format. It can be found in Um outro olhar sobre Obras de Álvaro Siza Vieira: Fotografia Documental e Artística: Um Olhar Contemporâneo sobre a Arquitectura Portuguesa (Pedro Leão Neto 2018, 179-239) a publication released prior to the beginning of the VSC research project that contains its theoretical foundation, due to the extent of the scope of investigation, which includes an extensive and informed review of a significant number of authors and works that showcase contemporary and critical photographic vision of architecture based on a postmodern documentary approach towards public space transformations and how people live and appropriate these places. From the standpoint of art, David Campany (2014) makes a case in point for the idea that photographic essays produced in artistic contexts can be useful in providing us new readings about critical issues - and particularly in the fields of Architecture, City and Territory - in the article Architecture as Photography: document, publicity, commentary when he defends that critical and independent photographic discourse about architecture are vital, an observation that's also in line with the arguments presented by Pedro Gadanho in the article Image-Making After Photoshop: Architecture, Public Space and their Visual Discontents, where he defends the value of the independent photographic discourse:

We should tackle the fictional and narrative approaches that have defined authorship within contemporary art, potentially as independent vehicles for critically observing architectural culture, and also the evolution of urban space representations $(2019,102)$.
Moreover, the use of visual methods such as photography, film and drawings as tools for research have proven to open the door to a deeper understanding and interpretation of social realities, which is important for our research that understands architecture in a comprehensive manner as a practice and discipline able to both give formal expression and integrate social - economics, politics, historical and technical - realities. This broad integrative notion also supports the idea of architecture as socially constructive idealization, close to what Gerard Bast wrote about the work and thoughts of Frederick Kiesler "(...) architecture has to be understood as an engagement with all facets of life (...)" $(2015,7-8)$. Further methodologies are also presented by Luc Pauwels:

(...) visual social research ranges from the study of existing visual data of a variety of sources ('found' visual materials) to the production of visual data - often photographs and film/video records, but also drawings by the research team ('researcher-produced materials') or by the field ('respondentgenerated production, photovoice), and to using visual materials in interview situations to trigger partly unanticipated factual information and projective comments (visual elicitation, photo elicitation) $(2015,3)$.

The use of photography as a visual research method can prove to be a valuable resource in terms of an investigation. However, as Marcus Banks (2007, 9-10) noted in the book Using Visual Data in Qualitative Research, the development of such a critical thinking requires the researcher to firstly formulate an intellectual problem, and then consider the most appropriate subject or empirical context to investigate, which in turn will inform decisions regarding the methods that are most likely to be effective in a particular context, including the data to be collected related to the problem being analyzed. 
That is to say that every photograph that a researcher produces in the context of his investigation has to serve a higher purpose that to accomplish the fulfillment of his or her desire to take a picture and it cannot be merely illustrative. As Gillian Rose has argued in the article Visual Culture, Photography and the Urban: An Interpretive Framework:

Simply saying 'our culture is visual now, so we need to take photographs' is not an adequate methodology (...) $(2014,7)$

Important theoretical and methodical advancement in the field of visual analysis can also be ascribed to a related line of thought, on which photography is progressively combined with other materials and various forms of visual expressions, introducing and admittedly subjective view that uses the theme and subject matter of architecture and urban spaces to communicate something more than is common in architectural photographs. Through these interdisciplinary approaches, the articulation of photography with other analogue and digital image formats may be explored, sometimes incorporating texts, personal stories, drawings and other images in addition to photographic images. The combined use of these resources address aspects particularly useful in the study of Architectural objects and Urban Landscapes, providing the researcher with essential research tools and communication strategies. A significant example of this practice can be found in the work of Mies van der Rohe, who could produce drawings and photomontages in the context of the same architectural project, in order to further amplify the scope of architectural representation. To quote Martino Stierli on the practice of this particular architect from the book Montage and the Metropolis: Architecture, Modernity, and the Representation of Space:
The large format, the forme tableau, the use of perspective, and the reality effect produced by photography all serve to simulate an urban experience within the gallery space, and the figures depicted in the foreground take on the role of identification figures for the viewer. The photomontages are more than a means to an end; they are themselves the bearers of a striking architectural idea $(2018,145-146)$.

Given all the above considerations, it is important to acknowledge that it is possible to find a great heterogeneity of perspectives and visual strategies with which the researcher must be familiar with in order to be capable to build a knowing photographic discourse. Within this context, it is important to be able to explore photography as an object of thought and production of meaning, creating fictional and symbolic worlds that act as autonomous territories, as is theoretically explained and can be seen in the work of many authors who present diverse critical and poetic perspectives about the real to explore architecture and city spaces with a special interest about the people who live and use those spaces. Jeff Wall's Mimic (1982), Overpass (2001) explore urbanity and the tensions of life in the city. By staging the space, other of Wall's Morning Cleaning, Mies van der Rohe Foundation, Barcelona (1999) deals with a very strong social component and can refer to our own experience of the spaces and city environments and to make us rethink the cultural values of those environments. In Paul Graham's work, we can see the tension among the apparently traditional documentary objectives - focused on the issue of the British presence in Northern Ireland or the social divide in America and the questioning and exploration of the medium of photography itself, breaking his own rules, as was the case with his strategy of uniting at the time the practice of colour with the "documentary" style in Troubled Land (1984-1985) and with the over- exposed images in American Night (2003). Thomas 
Ruff's critical re-interpretation of Mies van der Rohe's work in the series I.m.v.d.r (19992004) makes the digital manipulation clear and reinterprets imaginatively the work of this land mark architect of modernity, and in doing so, questions architectural representation and makes possible the critical reinterpretation of Mies van der Rohe's work coming from the appropriation of archive material, rejecting the factual documental traditional of photography and embracing the idealization and making of new images from that important legacy of modernism.

The above discussion on the theoretical weight and intentionality contained in the act of photographing shows how photography can be an instrument of communication, representation and ideation (creatively processing, developing, and communicating new ideas - taking place inside the practice and discipline of architecture and urban thinking, demanding on the one hand a comprehensive understanding of visual culture capable of integrating and giving shape and meaning to various dimensions: technical, social, economic, historical, political and artistic. On the other hand, the capability it has of communicating the features considered relevant by the researcher in the process of cultural production. This means, among other things, to perceive the photographic image beyond a constructive or technical representation, as an instrument of thought, and therefore a medium of conceptualization in the universe of architecture, city and territory practice and theory.

\section{METHODOLOGY ADOPTED WITHIN THE VISUAL SPACES OF CHANGE RESEARCH PROJECT}

The first case study of the Visual Spaces of Change (VSC) research project promoted a series of open talks, public presentations and exhibitions of contemporary photography projects related to the subjects of Architecture,
City and Territory during the 2019th edition of Ci.CLO Bienal Fotografia do Porto. These initiatives intended to broaden the discussion about how architecture transforms and is transformed by trends and ways of living, using as its subject of study Porto's Metropolitan Area.

The methodology developed in this pedagogical experiment builds up on previous research combining blended learning and e-learning (Neto, 2008) with visual research methods and photographic techniques (Neto e Neto, 2016a; 2016b) that enable students to manage the whole process of conception, development and implementation of photography projects in a collaborative learning environment. The use of these different components have been thought in order to enhance the articulation of activities between teaching staff, researchers and students, enabling the exchange of knowledge and explore scientific and technological capabilities of each of the participants. The learning activities of the VSC project have been structured in two main technical and artistic components which enable the researchers to develop individual photographic projects inserted in a collective pedagogical strategy containing various communication tools, representation methods, visualization techniques, and involving multiple interaction levels and new ways for the researcher to understand and relate with various aspects of the public space.

The methodological framework has been designed with special attention to the multidisciplinary character of this project, complementing each other and putting in relation the various aspects covered within this integrative approach regarding Architecture, City and Territory. Within this general approach, the researchers involved in the VSC project developed empirical investigations in concrete case studies of selected urban spaces, confronting the present reality of specific places with 
documentary photographs and original photographs taken from chosen viewpoints of the study objects. Practical exercises of image manipulation and diachronic reconstitutions of certain landscapes organized in temporal layers, allowed to visualize changes in the configuration of public spaces - these diachronic reconstitutions were not only based in the research of historical records, but were also combined with other techniques of photo montage and the overlap of temporal sequences, among other techniques of image manipulation from existing urban spaces.

The identification of the VSC public spaces that in this first case study was restricted to a set of Metro Stations located not so far apart from each other - because of technical and administrative reasons - will in the following case study be enlarged with a selection of locations with different relational scales along the Metro do Porto infrastructure network, in order to maximize the experimental potential of this case study within the Porto Metropolitan Area (AMP). The collection and systematization of visual information about the selected places constitutes the working database of the research, which is an ongoing process organized in three main information blocks: cartography (maps and satellite images), photography (document and artistic registries of selected locations), and historiography (monographs and previous research). These elements have been used in order to characterize the main features of each photographic project, providing the means to create a comprehensive analysis of the territory under study. The contextualization of the collected material focused on the evolution of architecture and public spaces and the modes of appropriation of the cultural and symbolic meaning of particular places. Informed by the material collected for each architecture selected in the first stage of data collection within the VSC project, empirical investigations in the field have been held in order to compare the present reality of each specific place, producing original current records of the same viewpoints found in the data collection surveyed. In this context, a set of critical visual narratives have been constructed about architecture, public space and their experiences, through the art and technique of photography, it was necessary to adopt a photography teaching strategy that integrated, from the outset technical and aesthetic aspects. This meant, first, to convey the idea that photography is a unique form (art and technique) of visual language and as such is based on a specific visual grammar.

The visual narratives developed in each selected location have been designed in order to communicate an open, critical and profound reading of the architecture and territory, representing different public spaces in an interpretive, artistic, even fictional, aspect, seeking to give visibility to specific spatial and temporal aspects that are difficult to perceive without the purposeful use of image and photography. In the physical installation of each photographic project, contrasting views of architectures and places have been placed in relation to each other, in order to create a dynamic of interaction between various public and collective spaces, forming an urban network conceived as itineraries for experimental exhibition. The proximity between these visual narratives (VSC Public Spaces) connected by metro stations and urban pathways, have been intended to suggest an urban network, conceived as an "Open Museum" within the metropolitan area of Porto, in which pilot experimental curatorial and cultural actions involved a wide range of artistic and cultural institutions, extending their reach to a larger public audience for collectively transform imaginings of the city. 


\section{CONTEMPORARY PHOTOGRAPHY PROJECTS USED IN PILOT STUDY}

The collaboration between VSC and Ci.CLO 2019 materialized through the operationalization of a curatorial project associated with a set of activities that cross the universes of photography and editorial in two complementary strands: (i) The exhibition of Contemporary Photography Projects in several public spaces of collective use located in Porto's Metropolitan Area and (ii) an Exhibition of alternative publications for the dissemination of authors and photographic works with a particular focus on Architecture, City and Territory. This program lasted from the 16th of May until the 2nd of July of 2019 and was implemented in various public spaces and collective use, seeking to generate a dynamic of interaction with exhibitions in cultural organizations, professional associations, universities and other alternative spaces of artistic production.

During Ci.CLO 2019, the highlights were the exhibitions at São Bento Metro and Aliados Metro Stations, as well as the exhibition at the Ordem dos Arquitectos Secção Regional Norte and Biblioteca Municipal Almeida Garrett. The material brought to the public through the contemporary photography projects exhibited in these spaces constitute 'visual narratives' that intentionally interfere with the territory, provoking real and virtual encounters between contrasting landscapes of Porto's Metropolitan Area, offering angles and perspectives on this territory that raise a new look at its cultural, environmental and architectural heritage. A total of seven photography projects were exhibited, plus one video project. The seven photographic projects are: Fendas Intemporais by Jiôn Kiim and Artur Leão; Clareira by Ana Miriam; Ode by Edu Silva; Piscina das Marés by Marta Ferreira; Contínuo by Sérgio Rolando; Casa de Chá da Boa Nova by Hélder Sousa; Momento. Perceção - Representação by Sofia F. Augusto. The exhibited video project is called Déjà Vu - Uma Lembrança do Presente, a work by Leonardo Motta Campos (AoLeo).

During the exhibitions, a series of public presentations of the projects with the presence of the authors was organized, in order to promote the debate about the multiple representations of the public space as well as its own process of change. The activities proposed under this partnership were oriented towards an understanding of the processes of interrelations between Architecture, Art and Image, identifying the points of articulation of the ethical and aesthetic dimensions of these universes. The photographic projects that were installed in several public and collective spaces for
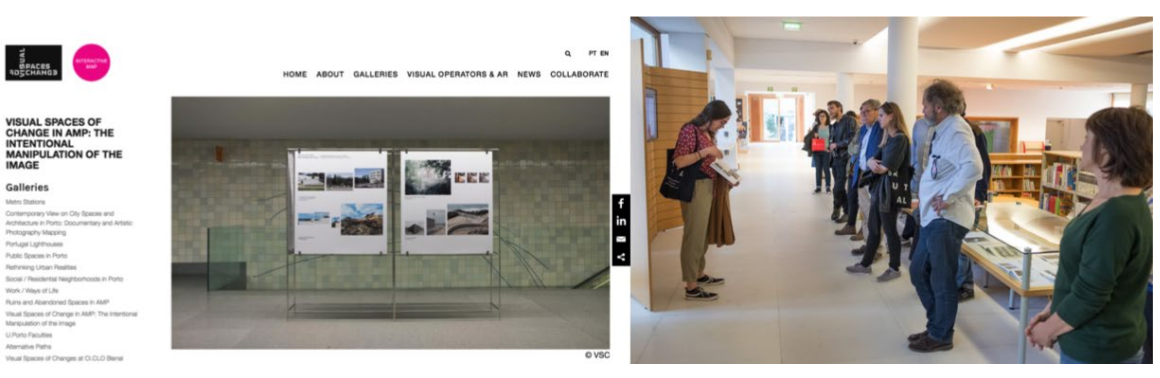

Figure 1. On the left, The Visual Spaces of Change online platform (Source: VSC); On the right, a presentation that occurred during Ci.CLO 2019 (Source: Edu Silva). 
temporary exhibitions are the copyright objects through which the aim was to broaden the debate around the cross-cutting themes of the VSC and Ci.CLO 2019 themes. VSC aims to explore how photography is a medium that can align artistic practice and academic research, while at the same time positioning itself critically before these universes. The strategy proposed to promote this approach intends to explore the potential of the photographic image as a critical and inquisitive instrument used to reinforce and expand communication and interaction capacities among agents involved in creative, cultural and artistic processes.

\section{THE QUESTIONNAIRES AND ITS METHODOLOGY}

A questionnaire was created specifically for this first case study for which the author and the researchers that were at the time in VSC research, namely Eduardo Silva and José Barbed, collaborated actively along with its making, field implementation and the processing of the data collection that is here discussed.

The questionnaires applied in the context of each exhibition held within the VSC project adopted an on-site approach. It was explained to the respondents that the data provided would only serve for qualitative purposes in the specific context of the scope of the project Visual Spaces of Change, and subject privacy has been guaranteed. Surveys were made face-to-face and individually, and wherever possible the conversation has been recorded, making sure that the area where the surveys were conducted was sufficiently isolated from noises that would impede this recording. Two publicly announced exhibitions of contemporary photographic projects took place. In result of the interest in having the respondents' qualitative evaluation of the exhibition of photographic projects and the questionnaires, several open-ended questions were included in the questionnaires. To test both the exhibition of photographic projects and the content of the questionnaire before conducting the public presentations, some adjustments were made to the content of the questionnaire given to the public in order to facilitate the respondents' answers. For example, the respondents were asked to classify several aspects within a five-point scale, placing the corresponding number in a box. This was a way of collecting data more quickly, saving time to the respondents in answering to this questionnaire. Ordinal scales were also used in order to obtain the respondents' opinion on several aspects of the photographic projects.

\section{RESULTS}

At the time of this ongoing project, the main results of the research were obtained through interviews and questionnaires used for collecting quantitative and qualitative information about people's perceptions towards specific public spaces of Porto's Metropolitan Area. A broad set of issues have been addressed, directing the questions to aspects related with spatial experiences and subjective perceptions of urban transformation. The key aspect addressed in the questionnaires was the impact of each photographic project in individuals' perceptions regarding the transformations of the physical spaces selected as objects of study within the VSC project, reflecting questions about the processes of change that occurred over time, driving the conversation towards individual memories of these places by the respondents. A remarkable result of the questionnaires concerns the choice of place and/or theme suggested by the respondents to be integrated in the VSC project, and through our questionnaires, we found that the elder respondents were more 


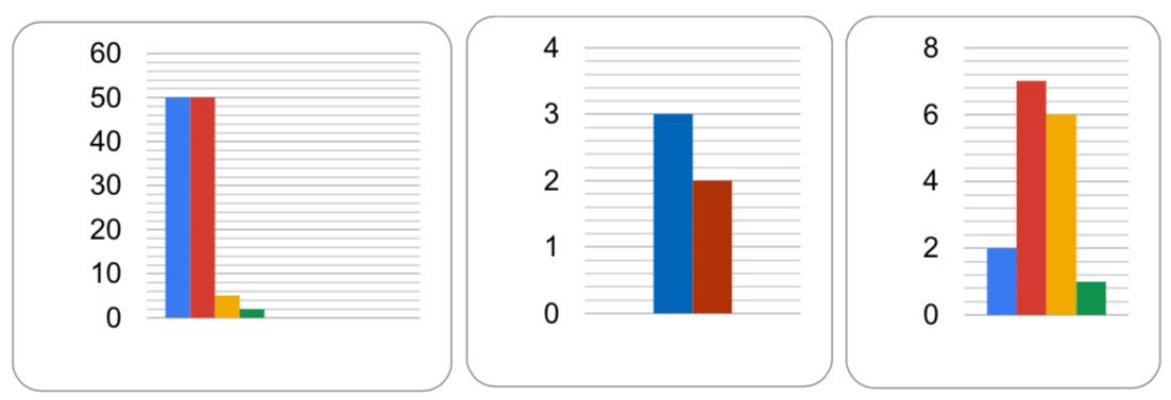

Figure 2. These charts display the data obtained from the following question: "What other theme or place would you like to see represented and discussed within this project?" (Source: VSC).

prone to relate specific places and themes of debate, choosing related themes and places in one third of these contributions. Below, we present three charts: The first chart from the left illustrates the global sample; The second chart, the number of respondents that were under twenty-two years old; The third chart, all respondents that were over sixty-fixe years old. A qualitative aspect we were able to retain from these questionnaires is related to the place and/or theme suggested by each respondent: The color blue relates to a suggested theme, the color red relates to a suggested place, the color yellow suggestes the combination of both, and the color green signifies that no suggestions were made.

While it is not possible within the limits of this paper to present a exhaustive list of the places and themes suggested, the contributions made by the respondents resulted in the incorporation of a wide range of topics that were not initially covered by the VSC project, as well as the inclusion of a number of places and architectures to be object of study in subsequent phases of development of the research process. We will, however, briefly mention the most voted place and issue. In total, out of one hundred and nine respondents, eleven of them positioned the issue of gentrification in Porto as a theme that most needed to be debated. In terms of places, Foz do Douro was the place that most respondents voted - seven out of one hundred and nine - as the one that they would like to see portrayed in the future. Given these results, we'll further focus on projects related not only specifically to the territory of Foz do Douro but also other coastal areas of Porto's Metropolitan Area, as well as investigate and discuss the process of gentrification and how it transforms the urban landscape - focusing specifically in the case of Porto. Another question we've posed to our respondents was: "To what extent your perception about the spaces portrayed has changed?". The answers we've obtained for this question clearly show that a large majority of the respondents recognized that the photographic projects had an impact on their perception about the architectures and places portrayed: 4,6 $\%$ responded that their perception about the spaces portrayed has totally changed (depicted with the color yellow in the charts below); $24,1 \%$ stated significant change in their perception (depicted with the color grey in the charts below); $44,4 \%$ recognized that their perception changed to some extent (depicted with the color red in the charts below); $26,9 \%$ of the respondents approximately one quarter - said no change in their perception occurred (depicted with 


\section{To what extent your perception about the spaces portrayed has changed?}

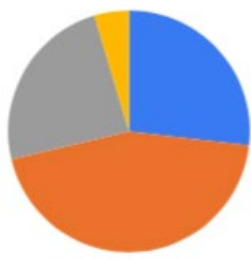

No changes

"Some changes

- Significant

\section{Total}

Figure 3. Global sample (Source: VSC).

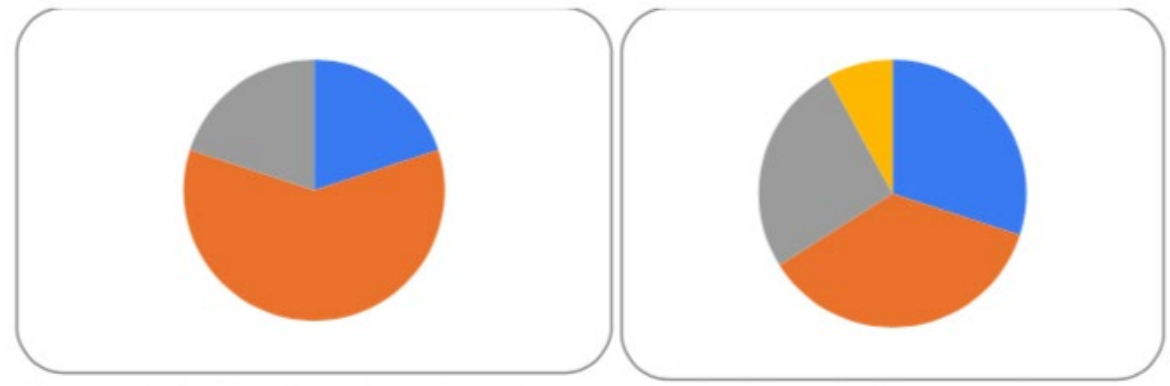

Figure 3.1. Depicted on the chart on the left hand side are the respondents with ages between fifteen and twentyone years old; Depicted on the chart on the right hand side are the respondents with ages between twenty-two and forty nine years old (Source: VSC).

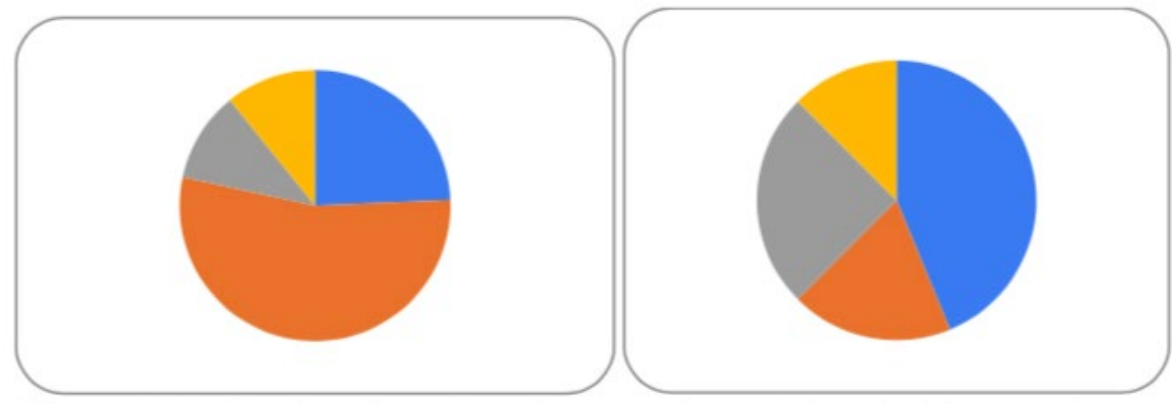

Figure 3.2. Depicted on the chart on the left hand side are the respondents with ages between fifty and sixty fixe years old; Depicted on the chart on the right hand side are the respondents with ages over sixty fixe years old (Source: VSC). 
the color blue in the charts below). Based on the overall results of the queries, we can affirm that these initiatives were successful in promoting the debate on the current dynamics of use and appropriation of certain spaces in Porto's Metropolitan Area. Not only that, we were able to deduct pertinent issues and places to be further explored in future investigations, based on the responses of the questionnaires. In this sense, the results of the questionnaires not only validated our initial premise, but also brought to light possible paths for further investigation.

Looking at disaggregated data for each age segment, the respondents with twenty-one years or less were the group that recognized a major impact of the photographic projects exhibited in their perception about the places and architectures portrayed: 20\% declared that their perception has changed very much and $60 \%$ reported considerable impact, against 20\% that said little change occurred in their perception. In the group between twenty-two and forty nine years old, there was a more expressive number of respondents declaring little change in their perception and even no change at all (8\%). However, two-thirds within this age group recognized considerable changes (36\%) or significant changes (30\%). Within the elder groups, more than half of the respondents between fifty and sixty fixe years old reported considerable change in their perception, $(54,1 \%)$ and approximately one quarter $(24,3 \%)$ said that their perception changed very much. 10,8\% said little change occurred and the same value has been registered with no change in their perception. Finally, 43,8\% of the respondents with more than sixty fixe years old said their perception changed very much and $18,8 \%$ recognized that considerable change occurred after looking at the contemporary photographic projects. It was within the elder that a larger number of respondents declared no change at all $(12,5 \%)$ or little change (25\%).

Observing the results to the question "To what extent do you think this exhibition enriches the debate about architecture, public space and urban transformation?", these also confirms the general impact of the photographic projects: $29,6 \%$ of the

\section{To what extent do you think this exhibition enriches the debate about architecture, public space and urban transformation?}

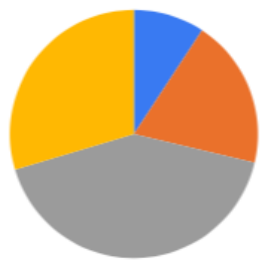

- Nothing

Little

- Considerable

Very much

Figure 4. Global sample (Source: VSC). 


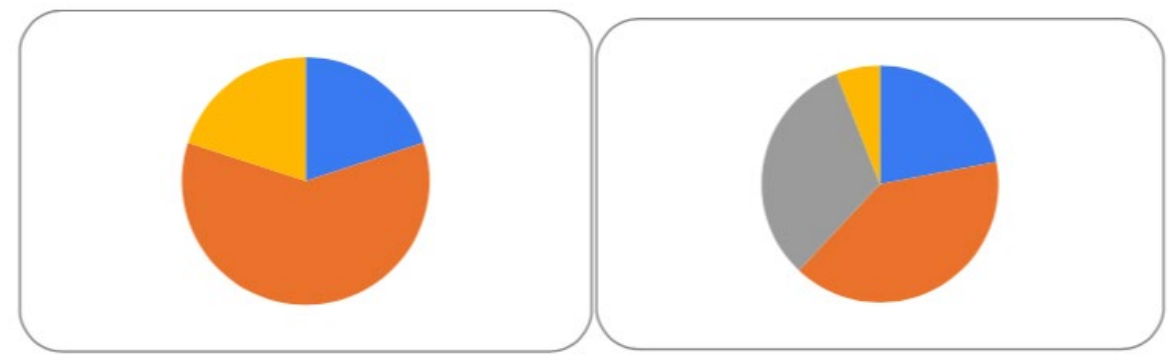

Figure 4.1. Depicted on the chart on the left hand side are the respondents with ages between fifteen and twentyone years old; Depicted on the chart on the right hand side are the respondents with ages between twenty-two and forty nine years old (Source: VSC).

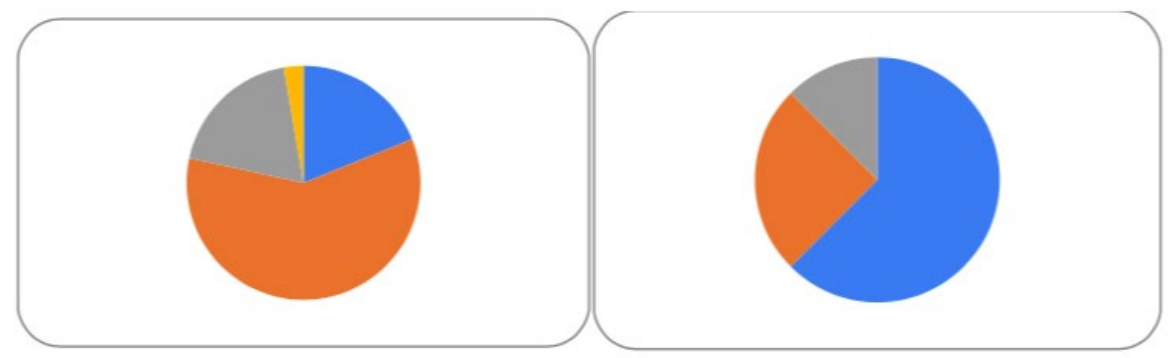

Figure 4.2. Depicted on the chart on the left hand side are the respondents with ages between fifty and sixty fixe years old; Depicted on the chart on the right hand side are the respondents with ages over sixty fixe years old (Source: VSC).

respondents stated that the photographic projects contributed very much to related debates on architecture, public space and/ or urban space transformation (depicted with the color yellow in the charts below); $41,7 \%$ recognized that the exhibition of these projects considerably enriched such debates (depicted with the color grey in the charts below); $19,4 \%$ stated that there was little impact (depicted with the color red in the charts below); $9.3 \%$ said these projects didn't enrich the debate on these matters (depicted with the color blue in the charts below).

While it is still difficult at the present stage of the project development to clearly find a pattern regarding the opinions of the public about the impact of the VSC project in the debate on architecture, public space and urban transformation, since opinions vary widely among different age groups. However, it seems to be a tendency for a more positive opinion about the extent to which the exhibited photographic projects enrich related debates among the younger generations, especially within the respondents bellow twenty-two years old (20\% total impact and $60 \%$ some impact against 20\% reporting no impact). These results are in stark contrast with the age group over sixty five years old, where $62 \%$ of the respondents didn't recognized any impact and $25 \%$ said little impact occurred, while just $12,5 \%$ recognized that the images 
portrayed significantly enriched the debate on architecture, public space and urban transformation. Mixed results in this regard have also been found in the intermediary groups, but the referred tendency of better reception of the project by the younger groups is also confirmed, with $40 \%$ of the respondents between twenty-two and forty nine years old recognizing total (6\%) or significant (32\%) impact, and another 40\% declaring some positive impact in the debate on architecture, public space and urban transformation.

\section{CONCLUSION}

The self-replicating potential of this open public and pedagogical experiment will allow to expand communication and interaction capacities between the public, students, researchers and institutions, namely opening academia to society and allowing the creation of synergies between them. It is expected that the VSC platform will potentiate interaction, feedback, and networking among the participants in a pedagogical process designed to structure, represent and expose individual and/or collective interpretations of their social reality, stimulating the capacity of the public and academic community to understand and to critically think and act over its transformation. If and when the capabilities of this case study are used in its fullness, these may prove the potential of image for broadening horizons both for academic teaching, learning and research, making citizens in general as well as the academic community more conducive to the construction of new spaces of political discussion and social intervention.

As a general conclusion, we have enough elements to confirm that the choice of the communication strategy adopted for each photographic project should depend on a number of variables to be taken into account, namely the possibility of the authors to be present in live sessions explaining their visual narratives to the public. The research conducted so far confirms that the photographic projects developed by the researchers and students involved in the VSC project made a useful contribution to make the general public more conscious and to participate in problems of common concern regarding the transformation of concrete public spaces, engaging to the general public in specific issues. The present study certainly confirms this potential while exposing some shortcomings regarding its impacts on urban change. However, it is remarkable that the potential of bringing about real change in urban matters is significantly potentiated by making the research products of the VSC project available online, which will be happening in the near future with more force, allowing a more dynamic interaction between the locations where photographic projects are being developed, and the general public, as well as enabling to communicate diverse aspects of these spaces from various perspectives and disciplinary backgrounds. This research was funded by Fundação para a Ciência e Tecnologia and co-financed by the Operational Programme for Competitiveness and Internationalisation (POCI) through Portugal 2020 and the European Fund for Regional Development (FEDER). 


\section{REFERENCES}

Banks, Marcus. Using Visual Data in Qualitative Research. London: SAGE Publications Ltd, 2007 Bast, Gerard. "The More Complexity, the More Kiesler: Foreword by Gerald Bast." In Endless Kiesler, edited by Klaus Bollinger, Florian Medicus and Kiesler Privatstiftung Wien, 7-8. Basel: Birkhäuser Verlag, 2015.

Campany, David. "'Architecture as Photography: document, publicity, commentary, art'. An essay written for the book accompanying the exhibition Constructing Worlds: Photography and Architecture in the Modern Age, Barbican Gallery London, 25 September 2014 - 11 January 2015; ArkDes Stockholm, 20. February - 17 May 2015; Museo ICO Madrid, 3 June - 6 September." David Campany, 2014. https://davidcampany. com/architecture-as-photographydocument-publicity-commentary/.

Davis, Tim. "Photography and Landscape Studies." Landscape Journal 8, no. 1 (Spring 1989): 1-12. https://doi. org/10.3368/lj.8.1.1.

Gadanho, Pedro. "Image-Making After Photoshop: Architecture, Public Space and their Visual Discontents." Sophia Journal 4, no.1 (December 2019): 100109.

Neto, Pedro, Andrea Vieira, Luís Pereira and Lígia Ribeiro. 2008. " CCRE digital platform for collaborative learning, public participation, architecture and arts." In Proceedings of the 4th International Conference on Digital Arts Technology in Art Design and Communication, Porto, 2008, 274-283. Porto: Escola das Artes, Universidade Católica Portuguesa.
Neto, Pedro and Maria Neto. "(Re)descobrir os espaços de cidade: a fotografia como um dispositivo mental que pode levar a uma nova percepção sobre o espaço e a sua arquitectura." Branca - Revista de Arquitectura da Universidade da Beira Interior 1, no. 1 (December 2016): 30-37. Neto, Pedro and Maria Neto. 2016. "The Use of Photography and Media for idealising and exploring new Spatial Forms." In Proceedings of the 17th International Conference of the Utopian Society Studies, Lisboa, 2016. Lisboa: Universidade Nova de Lisboa, Faculdade de Ciências Sociais e Humanas Pauwels, Luc. Reframing Visual Social Science: Towards a More Visual Sociology and Anthropology. Cambridge: Cambridge University, 2015

Rose, Gillian. "Visual Culture, Photography and the Urban: An Interpretive Framework" Space and Culture, India 2, no. 3 (December 2014): 4-13. https://doi.org/10.20896/ saci.v2i3.92.

Stierli, Martino. Montage and the Metropolis: Architecture, Modernity, and the Representation of Space. 



\title{
PAPER \#1.23
}

\section{DRAWING WATER: THE MAKING OF FLUID GRAPHICS}

\author{
Brook Muller ${ }^{\mathrm{a}}$, Matt Tierney \\ aUniversity of North Carolina, Charlotte, USA \\ bSnow Kreilich Architects, Minneapolis, MN, USA
}

\section{ABSTRACT}

Given pressing need to address the multiple water-related stressors confronting cities including climate change, scarcity, contamination, and downstream ecological impacts, among other challenges, architects are called upon to engage water as driver of sustainable regional, urban and architectural design processes. Given the 2020 EAAE/ARCC conference thematic area "Devising, Representing and Narrating the City" that makes mention of "devising, representing and narrating the city," and the benefits of "depicting actors and activities to understand underlying values," we examine water as a highly potent and yet tremendously underrepresented actant as reflected in graphic conventions architects and their collaborators deploy currently. To this end, we seek to augment emerging graphic approaches by speculating as to new and hybridized representational strategies revealing fluid relations along a scalar continuum. To begin to consider such strategies that bring water more centrally into the designer's creative ambit, we consider examples of effective "hydrographics" from a diverse range of sources. At one end, we look to graphic artifcats that frame broader landscape-scale, regional and urban water conditions and dynamics. At the other, we consider representations of microurban interventions within the context of the watershed. Between and with respect to these two scales, we consider how rendering visible water as an actant in urban and architectural design can prompt interventions that link the immediacy of civic experience with the larger

hydrological reality and flows within which urban dwellers live. No matter the scale of attention, latent in a process of redrawing water is recognition of the incompleteness of any one artifact and therefore the value of indicating through representational devices the larger flows extending beyond any one design intervention. Such an expansive, water-centric design process and graphic procedure, it is hoped, becomes a means of anticipating architectural works that deliver net positive watershed impact.

\section{KEYWORDS}

Water; Cities; Hydro-social; Graphics; Hybridization.

\section{FLUIDS IN FRAGMENTS}

How might more effective graphic representations of water in design prompt more ecologically and culturally responsive and resourceful urban architectures and environments? What representational strategies might designers borrow from other sources in order to develop graphics that render visible a proactive stance toward the multiple water challenges confronting cities including climate change, scarcity, contaminants of emerging concern, and downstream ecological impacts? How might new representational devices, re-drawings of water that marry the technical and aesthetic, the spatial and temporal, anticipate architectural and urban design projects that positively enmesh with larger hydrological flows?

\footnotetext{
1 Jessica Barnes. 2014. Cultivating the Nile: The Everyday Politics of Water in Egypt. Durham, NC: Duke University Press: 77
} 
The geographer Jessica Barnes claims of water that "the fluidity of the resource confounds the process of forming a community around it." Perhaps this offers one explanation for the fact that "water" never once appears in the National Architectural Accrediting Board 2014 Student Performance Criteria. Unlike space or tectonics, architects do not view water as a synergizing force helping set other systems in patterned alignment. Representative of its marginalization and fragmentation are the representations themselves. Graphic conventions focused on water and the built environment exhibit tremendous variety as a function of scales of attention, points of use, where water exists in a sequence of flows, and who assumes responsibility for its conveyance and quality. That architects and those in related disciplines draw and draw upon water differently thwarts synergies and dissolves water's potency to wield significant design influence.

This paper speculates as to graphic approaches that cast water as a design protagonist, with the conviction that such a hydrologically attuned process can lead to design interventions that are more holistic and integrative. We proceed from a perspective that a gap in effective representations of water might perhaps be best filled by culling and hybridizing various resources. To that end, we begin in Section 2 by using the case study method focused on representations of water across a range of scales and that reveal different dimensions of water. We interrogate charts, hydrographs, diagrams ("riser" and other), maps, and details typically overlooked by architects as a means to speculate hybrids where water's graphic variety is a driver of holistic design decision making. We ask in each instance: what actors and activities are given value through a particular manner of water's representation, and what does this suggest for a "hydro-logical" approach to design? We the use the lessons learned from the case studies to explore hybridizations and aggregates of water graphics in Section 3 that attempt to account for water's confounding fluidity and complexity (one great challenge with this undertaking, as will become clear, involves striking a balance between clarity and effectively contending with this very complexity). In this process, we endeavor to move across scales and emphasize the "interscaler" in acknowledging flows from city to building.

Embracing a more integrated, watercentric approach, designers might borrow productively from geographers' notion of the "hydro-social cycle," that is, "a socio-natural process by which water and society make and remake each other in space and time."2 From this perspective, hardlines between natural processes and human constructs blur, water assumes the role of creative actant within the city, and new spaces of co-production surface. ${ }^{3}$ Seeing design interventions as what Brent Bucknum, principal of Hyphae Design Laboratory, describes as "nodes along networks," a hydro-social architecture holds promise of design interventions becoming functional components of urban watersheds. ${ }^{3}$ Such a goal, and a related aspiration of forming more intentional design communities around water, is advanced through an examination of and evolution in water-based graphics. In order to proceed, let us now examine sources from the continental to that of the fixture, representations that offer different framings of water's many natures.

\section{DRAWING OUT REPRESENTATIONAL WATER SOURCES}

Bioregional Thinking Before "Bioregionalism" Existed - In the aftermath of his storied explorations of the American West in the late 1800's, geologist and explorer John Wesley Powell produced his remarkable bio-

\footnotetext{
2 Jamie Linton and Jessica Budds, 2014. "The Hydrosocial Cycle: Defining and Mobilizing a Relational-Dialectical Approach to Water," Geoforum, 57: 175

${ }^{3}$ Personal correspondence, July 19, 2019
} 
regionalist 1869 map of the "Arid Region of the United States". ${ }^{4}$ This map illustrates Powell's argument that insufficient precipitation west of the 100th Meridian calls for a different manner of water management, agriculture and settlement than what characterizes the relatively rain-plenty regions to the east. His arguments and speculations within these studies unfortunately did not lead to more hydrologically sensitive geographic boundaries (consider "The Four Corners" - the ultimate geographic indifference), and yet his cartographic observations hold great relevance to this day: Powell's map suggests the value of aligning jurisdictions and watersheds. They give precedent to the logic of forming polities with respect to the more sinuous lines which define freshwater resources in a water-scarce region.

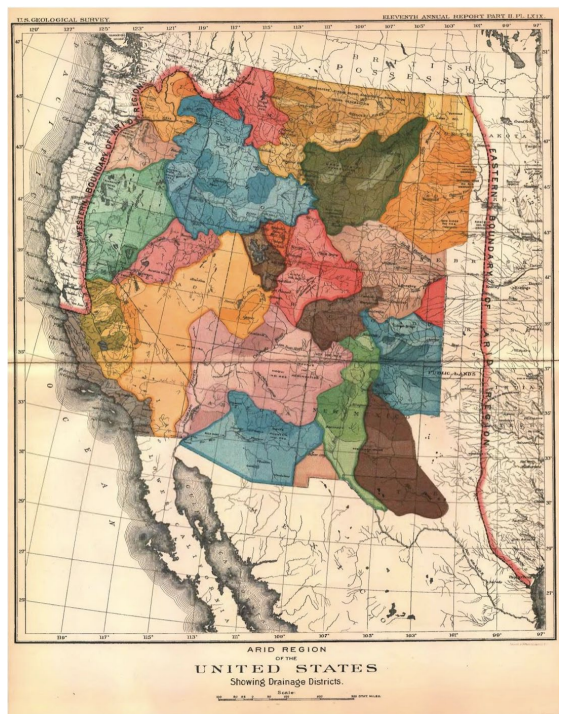

Figure 1. Source: John W. Powell 1889-1891. Title: Map of Arid Region of the USA 11th Annual Report - U.S. Geological Survey

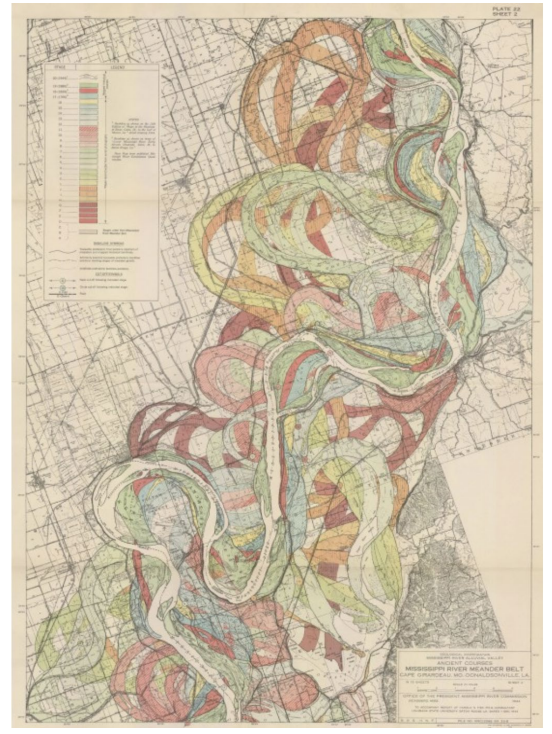

Figure 2. Source: Harold Fisk - 1944. Title: The Alluvial Valley of the Lower Mississippi River. Plate 22 - US Army Corps of Engineers

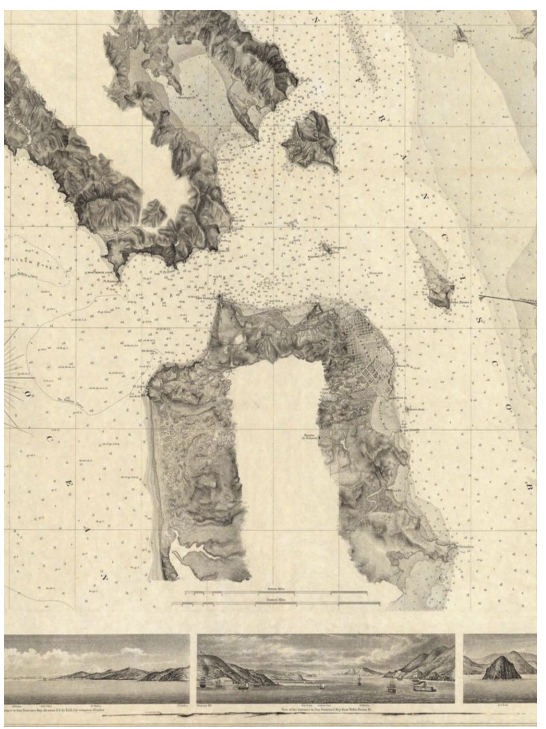

Figure 3. Bache, Cutts, Rodgers, Harrison. 1859. Title: Entrance to San Francisco Bay, California. United States Coast Survey 
Painting Sinuosity - Produced alongside Army Corps of Engineers maps documenting the Mississippi River and its flood potential, Harold Fisk's stunning 1944 map of the river's historical meanders delights in its palimpsest-like visual complexity. ${ }^{5}$ With its intense spatial specificity (documented using the Mississippi River Commissions Quadrangles as a basemap) and robust variety of coloration and hatchure (28 color/hatches), Fisk's map offers value in its representation of the aesthetics of hydraulic patterning and the shaping of the landscape by water over time.

Revealing What Water Hides - Humans develop conventions to comprehend what lies beneath or beyond our vision or immediate comprehension. Nautical sounding or bathymetric contour maps, such as Bach's chart of San Francisco Bay, are exemplar in this regard. ${ }^{6}$ Both bathymetric and sounding maps use contour and spot elevation to reveal a veiled topography "visible" and therefore make more safely navigable a dangerous waterscape. Those plying waterways have relied on this convention for centuries, and before that, on less scientific, but evolving oral and written histories and rough documentation of underwater hazards testifying to the wildness of riverways. Bach's nautical chart offers value by indicating depths of features one cannot see and by marking the profile of a liquid body through delineation of edges.

Water as Catchment - Responding to the thirteen year "Millennium" drought in the 2000's, the City of Melbourne, Australia, embarked upon an ambitious plan to dramatically reduce water use. " "City as Catchment" allows a reconceptualization of water and the city by representing relationships in a manner understandable to all. Icons depicting factors impacting water management such as "over consumption" and "salinity" are superimposed on a catchment-scale systems diagram depicting flows from reservoirs upstream

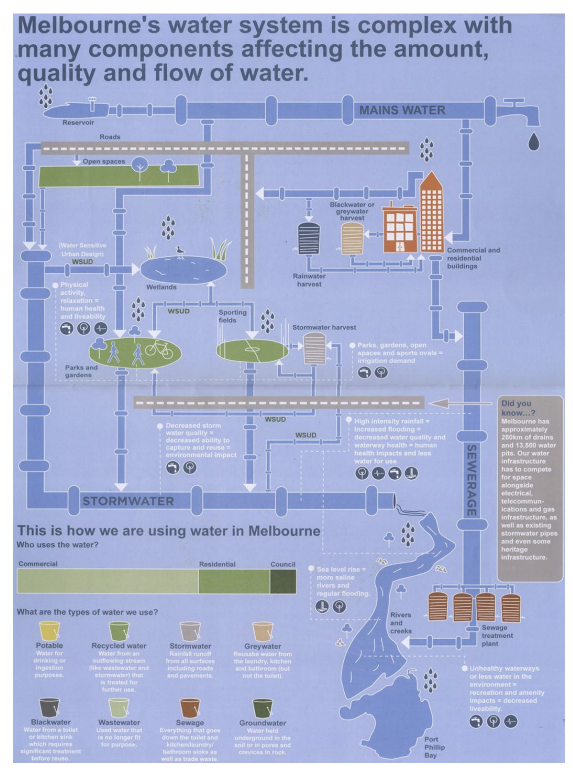

Figure 4. Source: City of Melbourne, Title: Total Watermark - City as a Catchment. Online Digital Image. Accessed: June, 2019.

through the city to Port Phillip Bay. ${ }^{8}$ The diagram aligns the human, infrastructural, and ecological and identifies convergences and needed separations of sources in the journey of water through the urban landscape. Not unlike a subway map, the diagram acquires legibility by abstracting scales and distances. By linking graphically systems, flows and physical features in the urban landscape, the diagram delivers value in allowing people to visualize localized hydrological events as interconnected. Peaks and Trickles - A hydrograph is an important tool for understanding the variety of flow conditions that a river exhibits before, during, and after a rain event. ${ }^{9}$ Distinct points along a hydrograph's bell-like curve indicate dynamic instances like peak discharge, lag time, rising limb, falling limb, and base flow. The hydrograph depicts the dynamism of water

\footnotetext{
5 Jason Kottke, Jun 20, 2019. The Marvelous Mississippi Meander Maps, Online Article, https://kottke.org

${ }^{6}$ Bache, Cutts, Rodgers, \& Harrison. 1859. Entrance to San Francisco Bay, California. United States Coast Survey.

${ }^{7}$ Melbourne, City of. 2014. Total Watermark - City as Catchment: Creating a Healthy City in a Healthy Catchment: 2

${ }^{8}$ Melbourne, City of. 2014. Total Watermark - City as Catchment: Creating a Healthy City in a Healthy Catchment: 7

${ }_{9}^{9}$ BBC. Jun 2019. Intermediate Geography, Rivers. Website. http://www.bbc.co.uk/scotland/education/int/geog/rivers
} 
over time and shows the aggregate effects of multiple water conditions (precipitation, transpiration/infiltration, transport, sewer outfalls, temperature/dew point, etc.) in a single view. By removing graphic references to shape, character and size of the urban environment that orchestrates peaks, limbs, and flows, the hydrograph offers value by simplifying water's changing temporal flow so as to be useful to multiple disciplines both prospectively and retrospectively.

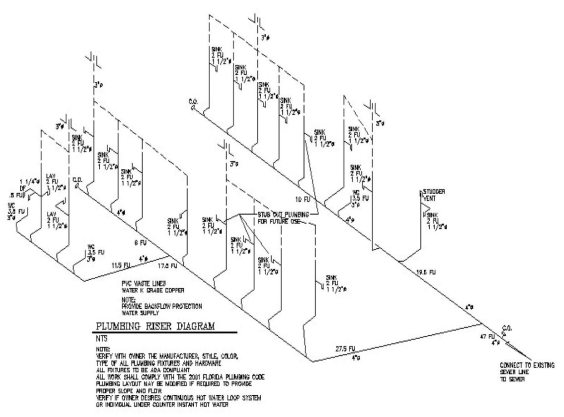

Figure 5. Source: CAD Offshore. Title: Plumbing Riser Diagram. Online Digital Image Accessed: June, 2019

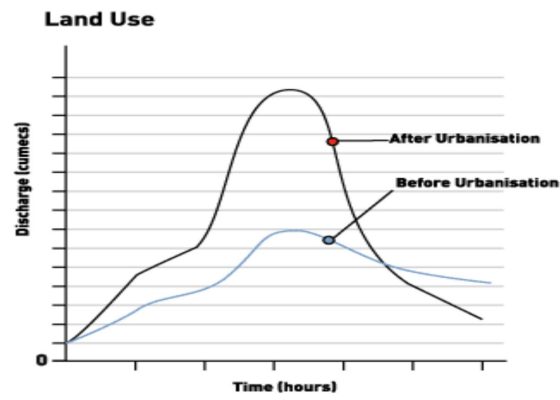

Figure 6. Source: BBC. Title: Hydrograph - Land Use Online Digital Image Accessed: June, 2019
Regulating the Flow of Urban Water Innovation - Recode, a Portland, Oregon nonprofit with a mission to "ensure access to and accelerate adoption of equitable and sustainable business practices," has created a diagram convention not dissimilar to a plumbing riser diagram (see the section on riser diagrams to follow) but extends it further in linking potential sources (condensate, rainwater, stormwater, surface water, shallow groundwater) to end uses (kitchen sink, fire-suppression, other). ${ }^{10} \mathrm{~A}$ diagram for the city of Bellingham, Washington, indicates allowable connections between source and use, where permits are not required, and where pathways are blocked by current policies. While complex, the diagram uses convention and symbol to depict regulatory impediments to innovation in water systems design. By linking use, reuse, disposal and transfer systems in the urban environment to the rules governing which systems are allowed to be implemented, the Recode diagram offers value in highlighting instances where policy change can foster new design opportunity in a context where higher levels of resourcefulness are demanded.

Mapping Project-Environment Flows - A hydrosocial architectural act makes visible flows well beyond the boundaries of any one site that impact its condition. The work of Hyphae Design Laboratory gives indication of the tremendous potential of harnessing these flows such as stormwater and rainwater for improved project performance. The "Sankeystyle" diagram for the Harmony project in Louisville, Kentucky is a study in how sites and buildings can mesh with broader hydrological realities. ${ }^{11}$ With this simple conflation of graphic types - section, isometric, and diagram Hyphae's diagram delivers value by situating any one project in a larger urban hydrological condition, a prerequisite to realizing a building that delivers benefits to the parent ecosystem (in the case of Harmony, treated water is returned to the aquifer).

\footnotetext{
${ }^{10}$ Recode Now. Accessed November 2019. Recoding Solutions for Sustainability. Website. http://www.recodenow.org.

${ }^{11}$ Provided to authors by Brent Bucknum, founding principal of Hyphae Design Laboratory
} 

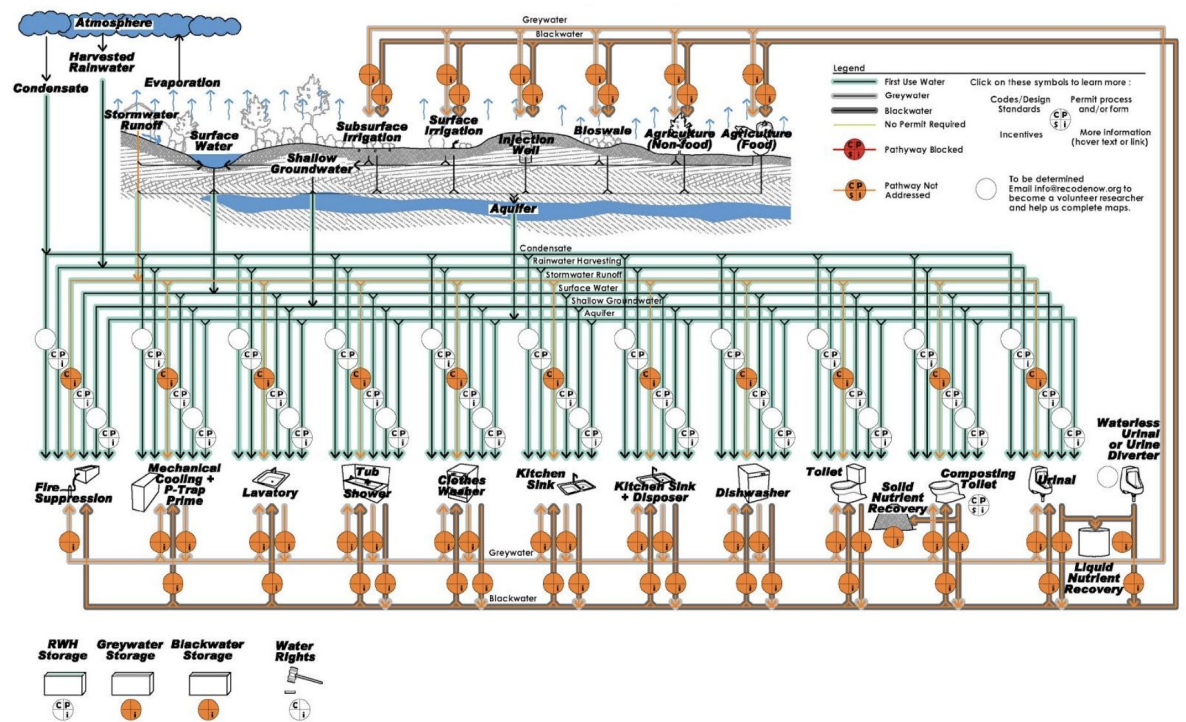

Figure 7. Source: Recode. Title: Onsite Water Reuse Permit Pathways for Bellingham/Whatcom Counties, WA Online Digital Image Accessed: June, 2019

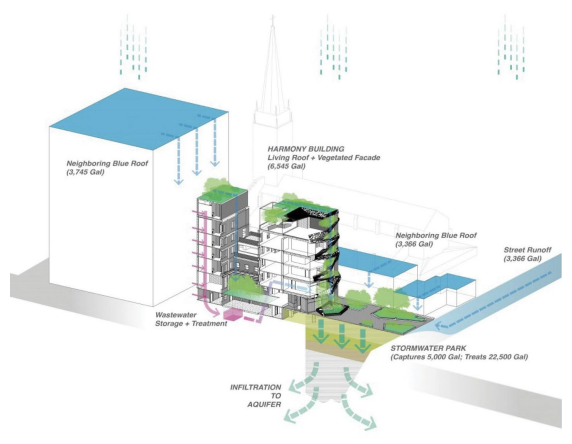

Figure 8. Source: Hyphae Design Laboratory Title: Harmony Building Water Section, Louisville, KY Online Digital Image 2016. Accessed June, 2019

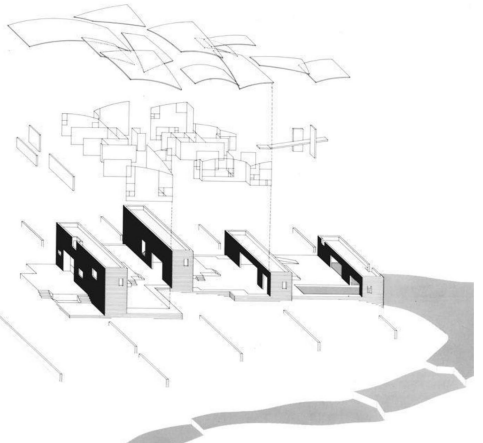

Figure 9. Source: Steven Holl Architect Title: Stretto House Axonometric Online Digital Image Accessed: June, 2019 
Co-Constitutive Constructions - Steven Holl's isometric for the Stretto House in Dallas (1989-1991) illustrates a conceptual logic in which water directly influences the patterning of rectilinear site foundation elements and anticipates the location of pools that establish a rhythmic alternation of landscape rooms and interior spaces. ${ }^{12}$ Sail-like roof elements and gauze-like interstitial façades hover in the top of the drawing, ready to collapse into place to complete the water-sensitive, architectural ordering. While Holl abstracted from another medium (the composition "Music for Strings, Percussion and Celeste" by Bela Bartok), what offers value for our purposes is the manner in which the exploded axonometric indicates a design process that places emphasis on the coconstitution of water, architecture, landscape construction and sitework.

Developing Conventions for Ease - A plumbing riser diagram maps water's transport, pointof-use, and waste streams through a building in either two-dimensional vertical position or planimetric view. The complex routing and configuration of pipes and fixtures of a system is depicted using a basic palette: solid lines, dashed lines and callouts. The abstraction and graphic neutralization that inheres in the convention allow for more efficient handling of the complex tangle of building water systems elements in acts of design, estimating and construction. Used in other engineering trades such as electrical and mechanical, the riser diagram delivers value by isolating a subsystem out of a larger one. That said, given contemporary water challenges and the necessary move by many cities to a "portfolio" (multiple source) approach to meeting demand - as well as the dramatic changes in water and wastewater technology including viable onssite treatment in dense urban settings - there would be value in evolving this convention and extending its reach.

\section{SPECULATIONS ON INTER-SCALAR HYBRID WATER GRAPHICS}

How might these diverse examples influence our thinking about representing the city, watershed, urban landscape, district and building and their relations? How might we actively reimagine through the act of drawing ways of more effectively programming and structuring urban water systems where multiple benefits are be derived in response to climatic, ecological and other contemporary pressures? How can we build from the many values of depiction described previously in developing suitably integrative graphics? What follows are descriptions and depictions of three hybrid "hydro-graphic" artifacts at a range of scales from the situating of projects and events within the urban sub-watershed to hydro-socially interconnected urban districts to the groundwork and sky-work of buildings and their interstitial landscape.

Situating Projects and Events within the Urban Sub-Watershed - An urban environment can be recognized a made up of urban sub-watersheds consisting of new hard surfaces and morphologies and relics of pre-development conditions. An evolving nomenclature corresponds to this understanding and anticipates new ways of drawing water and the city. Kevan Moffett, Ph.D., who runs the Moffett Research Lab with the Washington State University EcoHydrology Group, speaks of "streets as streams and street trees as BMP's" (best management practices): "Each urban street acts like an ephemeral headwater stream, and the street trees serve as that stream's riparian zone. ${ }^{13}$ Roy Iwai calls the urban environment "the pipe-shed." ${ }^{14} \mathrm{~A}$ rooftop constitutes a boundary and beginning of a tributary within the urban sub-watershed. How can we make these boundary states and catchments perform in a more ecologically

\footnotetext{
12 Steven Holl, Juhani Pallasmaa, and Alberto Perez-Gomez. 1994. Questions of Perception: Phenomenology of Architecture. Architecture and Urbanism Special Issue: 146

${ }^{13}$ Excerpt from Oregon Association of Clean Water Agencies Annual Summit, May 9, 2018: "Streets as Streams and Street Trees as BMP's" was the title of Moffett's talk.

${ }_{14}$ Personal Correspondence, May 16, 2018; Iwai is Multnomah County (Oregon) Department of Community Services Water Resources Specialist
} 
and functionally attuned manner, and what are the graphic consequences?

Proceeding from this conceptualization, it might be possible to borrow from Powell's delineation of watersheds and map the city as a series of water catchment districts based on topography, urban interventions, stormwater infrastructure, etc. To draw this is to help shape design inquiry for undertakings at a smaller (district or site) scale that is cognizant and anticipatory of the larger hydro-social condition. It would next be possible to overlay a current and a desired hydrograph as water courses its way through the city as a means of revealing problematic and potential flows that architectural and ecological elements deployed in the urban landscape govern. While the city has been configured to remove water quickly to reduce flooding, with consequent downstream peaks and ecological impacts, to draw a reduced peak condition is to anticipate the introduction of green infrastructure and a greatly reduced coefficient of friction.

A next step in an ascension of value involves borrowing the catchment notion from the City of Melbourne, diagramming urban water flows and showing links between human, infrastructural, and ecological systems and the various forces acting upon them. Hyphae Design Laboratory's work on the Waterman Gardens residential project, a response to the pressure to ensure higher levels of resilience and functionality in increasingly limited urban space, anticipates this. That downtown San Bernardino sits atop a floodplain has resulted in multiple hydrological problems. By drawing a section extending miles past the project site, from the foothills to the Santa Ana River, by representing an area much larger than the scope of the project, Hyphae demonstrates the advantages of an urban design strategy which aggregates effects of efficient water management of individual sites like Waterman Gardens as opposed to vastly more expensive, singular and "engineered" solutions.

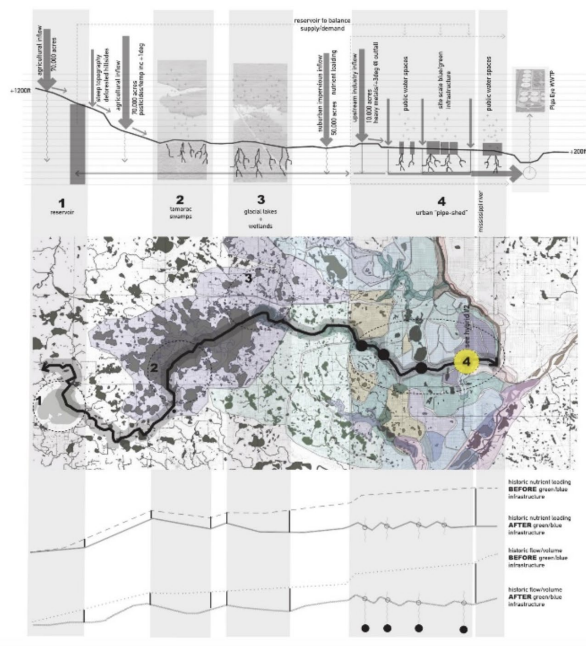

Figure 10. Situating Projects and Events within the Urban Sub-Watershed. M Tierney + B Muller. 2020

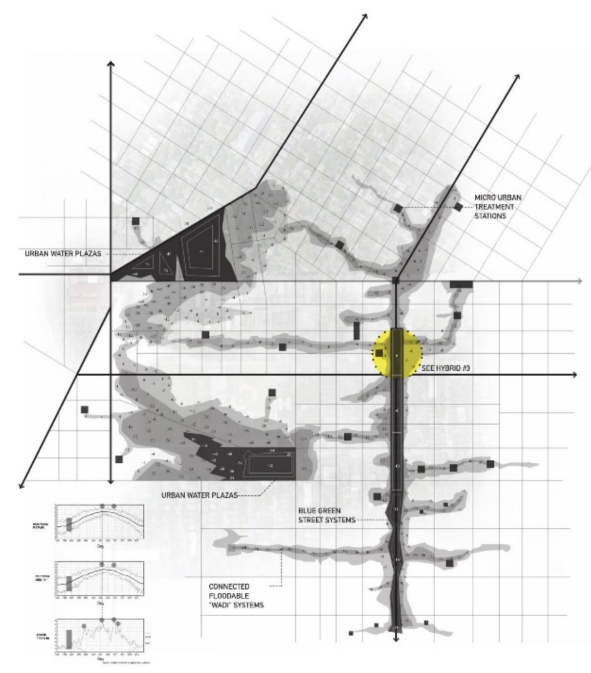

Figure 11. Hydro-Socially Interconnected Urban Districts

M Tierney + B Muller. 2020 
Hydro-Socially Interconnected Urban Districts - Rotterdam-based De Urbanisten's water squares demonstrate the value of water infrastructure as not invisible and instead a forethought in the urban design imaginary, where both human experience and hydrological performance capturing water's changing moods across the day and seasons are elevated. Basketball courts and other sunken features in civic spaces double as places to gather water during major rain events. In a similar manner, GBD Architects' Hassalo on Eighth mixed-use development project in Portland, Oregon, introduces stormwater features integral to the formal expression of the urban design proposition (these elements shape spaces in what was a vehicular dominated street converted to one more favorable to pedestrians).

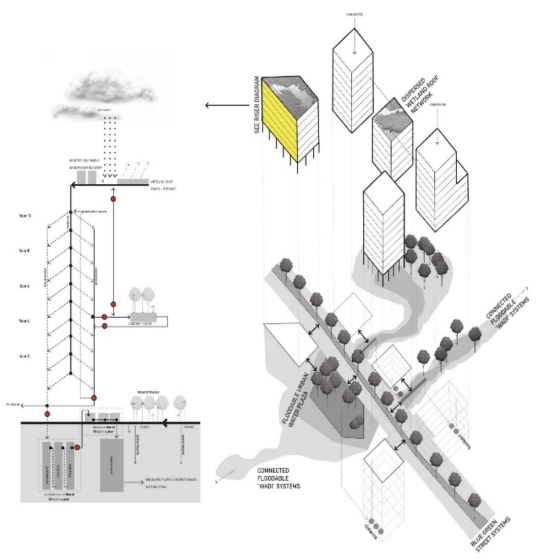

Figure 12. Groundwork and Sky-Work of Buildings and the Interstitial Landscape, M Tierney + B Muller. 2020

Could we imagine the drawing of urban squares that assume different identities and capacities during major rain events? That they swell, expand and assume new forms that combine the hard-edged and the sinuous, the latter akin to Fisk's illustration of the dynamic meanderings of the Mississippi? That this IS a contemporary urban spatial aesthetic, where identities change dramatically as a function of severity of event, and where human, ecological, and systematic "stocks" within a place are rendered visible? And as with plaques on buildings of Rome commemorating peak flood levels of historical events, might we develop graphic proposals that encourage the marking of depths of former floods akin to readings from nautical charts? A rendering that makes visible a past event that exists only in the recesses of our consciousness, one drawn from the flow of water across the specific peaks, valleys, eddys and confluences, might in turn prompt the making of urban spaces and architectures that accept, divert, filter, store, or slow water, that are markers enabling a higher level of awareness of the hydro-social forces we are immersed within.

Groundwork and Sky-Work of Buildings and their Interstitial Landscape - The Stretto House exploded isometric inspires graphics that convey the importance of groundwork as the organizational patterning of a hydrosocial urban site. A drawing as a composition of interrelated wetland gardens, akin to the aforementioned Hassalo on 8th project, storage features, foundations of buildings, civic spaces and streets is treated as one aesthetic and technical act, a new form of expressive grounding akin to Holl's pools and cores. A simultaneous "sky-work," in the manner of Hyphae Design Laboratory, follows the journey of rainfall and intercepted stormwater from neighboring roofs, streets and landscapes. Such a graphic viewshed reveals the manner by which architecture, landscape structure, and highly visible and ecologically responsive water features are co-constitutive, where boundaries of constructed and natural systems blur into compelling new hydro-social urban ecotones. It speaks to the value of designing in systems, where what is designed and 
built pairs and reacts with elemental forces and built constructs in the surrounding environment.

A riser diagram set adjacent to the isometric links building water systems to a larger systems, captures the movement of flows, describes differing pressures acting on the system, and also indicates, borrowing from Recode, the regulatory pathways and pinch points where regulatory innovation is required and where to deepen conversations across domains of design, policy and law. Lastly, by studying building occupancies and behaviors over time, not unlike a hydrograph with its peak flows, designers can represent usage, waste, space, and proximity and thereby program more effectively across buildings and within the landscape.

\section{ATTENDING TO GRAPHIC FLOWS}

Through design thinking we have pulled dimensions of water's many properties and manners of representation apart to understand their potentials; by design thinking we shall knit them back together. And designers would be well served to embrace graphic processes focused on water that attend to factors in addition to - and perhaps of far greater consequence than - proper flashing details, grading plans, and ensuring adequate space for plumbing and mechanical equipment in wall sections. Water holds potential to shape and interact with building and landscape systems if we can free it from the limitations that govern conventional representations and design procedures. Thrust into a protagonist's role and lent new graphic identities, water forms new design communities and serves as the designer's connective tissue at the scale of the room, building, city or region in a manner providing great value to ecological, economic, political, and hydrological metabolisms alike. A hydro-social process begins by attending to water and its representation as a pervasive actant on urban and regional stages and as a basis for synergistic design innovation. The process holds tremendous promise both within allied professions concerned with water and as part of innovative curricula integrated in seminar and studio formats. May the impacts ripple outward: by making water more explicit in our design consciousness, we can better represent and actualize hydro-social connections so critical at this moment in our profession's changing present. 


\section{REFERENCES}

Jessica Barnes. 2014. Cultivating the Nile: The Everyday Politics of Water in Egypt. Durham, NC: Duke University Press: 77

Jamie Linton and Jessica Budds, 2014. "The Hydrosocial Cycle: Defining and Mobilizing a Relational-Dialectical Approach to Water," Geoforum, 57: 175

John Wesley Powell, 1889-1891. Map of the Arid Region of the USA. US Geological Survey; 11th Annual Report

Jason Kottke, Jun 20, 2019. The Marvelous Mississippi Meander Maps, Online Article, https://kottke.org

Bache, Cutts, Rodgers, \& Harrison. 1859. Entrance to San Francisco Bay, California. United States Coast Survey.

Melbourne, City of. 2014. Total Watermark City as Catchment: Creating a Healthy City in a Healthy Catchment: 2

Melbourne, City of. 2014. Total Watermark City as Catchment: Creating a Healthy City in a Healthy Catchment: 7

BBC. Jun 2019. Intermediate Geography, Rivers. Website. http://www.bbc.co.uk/ scotland/education/int/geog/rivers

Recode Now. Accessed November 2019. Recoding Solutions for Sustainability. Website. http://www.recodenow.org.

Steven Holl, Juhani Pallasmaa, and Alberto Perez-Gomez. 1994. Questions of Perception: Phenomenology of Architecture. Architecture and Urbanism Special Issue: 146

Excerpt from Oregon Association of Clean Water Agencies Annual Summit, May 9, 2018: "Streets as Streams and Street Trees as BMP's" was the title of Moffett's talk. 



\title{
PAPER \#1.24
}

\section{ENERGY VISUALIZATION IN THE ARCHITECTURAL DESIGN PROCESS}

\author{
Giovanna Togo ${ }^{a}$, Marina Maurin ${ }^{a}$ \\ aEfficacity, Champs-sur-Marne, France
}

\section{ABSTRACT}

In the context of architectural design process, where environmental and energy questions are increasingly emerging, key data and parameters to be taken into account in all project phases are multiplying too. These new challenges and new design tools (such as BIM and parametric tools) have been reorganizing traditional construction's sequential steps by leaving room for non-linear sequences. This new complexity requires multidisciplinary methods and unprecedented collaborations between actors.

This increasingly complex nature of the design process (actors, parameters, data) requires decrypting. One way such clarification can be achieved is through new instruments and methods of visual representation. Graphic expression has always existed as a stimulating field for architectural experimentation. And within the current growing complexity, graphic expression proves an exciting opportunity for research and experimentation with the aim of developing a shared, visual culture on energy and environmental subjects. The proliferation of incoming and outgoing data, due to the digital environment, leads us to wonder how interacting with them and how creating new visuals are taking shape to organize information and to explore it in a new way. A visual representation can thus contribute to making fast, good decisions shared among all the actors involved in the processes.

\section{KEYWORDS}

Energy visualization; digital environment; technical data; energy performance; process.

\section{INTRODUCTION}

Awareness of the planetary environmental emergency has been spreading throughout the world. This implies noteworthy metamorphosis in procedures and policies affecting all fields. The construction industry is notably concerned in a massive way due to the magnitude of its impact on energy consumption and on its $\mathrm{CO}^{2}$ emissions. According to France's Ministry of Accessible Ecological Transition [Ministère de la Transition écologique et solidaire], the field of construction is responsible for $44 \%$ of the final energy national consumption and $25 \%$ of its greenhouse gas emissions. It is possible to reduce these impacts through the choices of materials and/or construction processes. However, the approach to significantly reducing energy consumption and to aligning with environmentally-sensitive posturing, reveals a complexity that is inherent to urban and architectural projects, and which goes beyond reflection on just materials.

Indeed, as of the very first design phases, the initial decisions will already have an impact on the ultimate environmental report of a project. Twenty percent of the decisions made during the first steps of a project will influence eighty percent of the subsequent decisions (Attia, 2013). As, for example, the decisions made concerning the parameters linked to the shape and orientation of buildings; they will strongly affect their exposure to sunlight and, thus, both their energy requirements, and potential for energy production (Nault, 2016) (e.g. Figure 1). The early design stage is also the moment in the process when designers possess the greatest decisional freedom (Zeiler, et al., 2007). Decisions are made at each level, successively more detailed and specific than the previous, as we go from the early to the advanced design stages. 


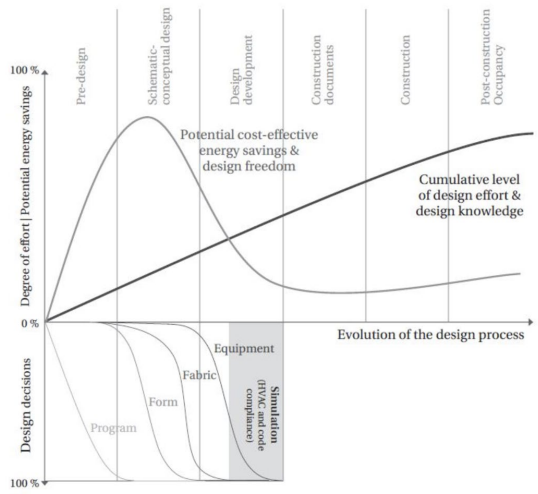

Figure 1. There is great freedom in early design decisions, which hold the most effective energy savings potential. BPS typically occurs at the advanced design stage. Source: (Quoted by Nault, 2016 : 8)

Such decisions are dependent on the data given in the project description. While if previously, such descriptions included mainly the program and building code constraints, today they now show new types of information and new needs regarding environmental demands (Attia, 2013). A new way of designing is being born. One that is more interactive, interdisciplinary that leads to tighter collaboration between professionals from different fields who all intervene in the project. According to Baraud-Sarfaty and Jacquot, we are being confronted with key shifts in the classic scenario of intervention, towards a broadening of the perimeter of intervention in the "urban factory" (I. BaraudSarfaty, C. Jacquot, 2016 : 1). This constitutes a less-fragmented, less-linear process and involves the interaction of various project actors during the same project phases.

In the context of a multiplication and heterogeneity of givens, coupled with a multiplication of available design tools, the question of finding a "common language" arises. As Nathan Brown and Caitilin Mueller affirm, despite advances in the speed and accuracy of predictive simulations, current technological and organizational barriers often prevent practitioners from fully integrating simulation data, which has traditionally come from engineers or other specialists, into their design workflows. In many cases, building-design projects have already moved into design development or are otherwise frozen in terms of massing or geometry before all relevant performance simulations have been conducted (Brown, Mueller, 2017 : 155).

The need to work more closely, and to work together in order to improve projects from an environmental point of view, becomes clear, as does the need to facilitate such exchange through the creation of a common language.

Thus, this study seeks to work towards the development of a new visual language dedicated to energy issues. This visual language becomes a simplifying tool that is accessible to a broad number of users. In addition, for designers, it plays a key role in design mechanisms. "visual tools are considered as more important than verbal ones. In other areas, like engineering, the use of verbal tools including numerical datasets, are prevalent. Therefore,

the visualisation of numerical data is a powerful tool to communicate with and assist architects (Miyamoto, et al., 2015:3).

\section{COMPLEXITY AND DECISION MAKING}

The subject of energy today is still quite exclusive to fields in engineering, yet the first design decisions regarding energy efficiency are actually based on the experience or intuition of architects (Miyamoto, A, et al, 2015). Architects and urban designers are rarely experts on these issues and can often perceive energy consumption and greenhouse emission reduction objectives as yet further constraints to their designs. After reviewing the 
design process through various case studies, Weytjens and Verbeeck noted that,

energy related issues are often more seen as 'add-on' components, which can be fixed in a later stage of the design (Weytjens L., Verdonck E. and Verbeeck G., 2009).

What's more, in parallel, the number of simulation tools has also multiplied. This increase requires gathering and treating a large amount of input data and generating a large quantity of output data. The latter must be filtered for results that are pertinent to the initial design phases. According to Shadi Attia, the integration of BPS tools (Building Performance Simulation) can contribute to improving the way energy issues are taken into consideration in the initial design phases (Attia 2013). There are many tools available (e.g. Fig 2), but using them accurately and getting pertinent results turns out to be at times difficult due to the high volume of data which is often hard to interpret and put into use in an operational project. Attia also highlights the fact that a recent study has shown that " architects' most important selection criteria for BPS tools is its intelligence and ability of guidance to inform the decisionmaking tools » (Attia, $2013: 1$ ).

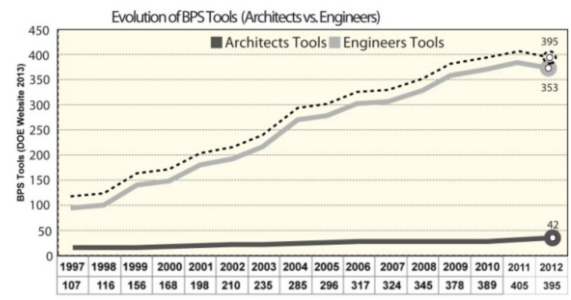

Figure 2: Evolution of BPS tools over the last 10 years. Source: (Attia, 2013: 1)

Decision making, thus, appears to be a crucial point in the design process. S. Attia demonstrates, in the case of a study on the design of zero-energy residential buildings, the existing barriers to decision making, illustrated in the following figure (e.g. Fig. 3).

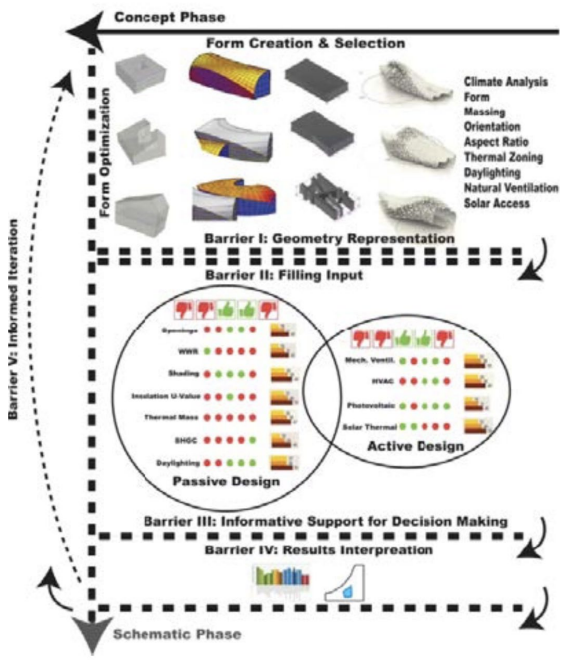

Figure 3. Barriers to decision making during early design stages. Source: (Attia, 2013: 2)

Attia identifies the absence of aids in interpreting the results of simulations as an obstacle to their accurate usage. And yet I.T. tools could significantly guide choices and highlight key elements among a multitude of results. (Attia, 2013)

In addition to an overview of the state of the art on the science of visualization, a series of interviews were done at the Efficacity Institute of $R \& D$ for Urban Energy Transitioning in the framework of the development of the software tool xMUSE. These semistructured interviews, given to architecture and urbanism design professionals, were mainly centered on digital tools and their usage in architecture, urban design, and environmental engineering firms.

The interviews allowed to go far beyond the initial questions and brought to light numerous points regarding the design process and the interaction among the different actors. The splits and conflicts among the participants became clear, but the 
interviews also revealed potential solutions for overcoming them.

Two points seem very interesting from our point of view: on the one hand, the at times difficult relationship between architects and engineers with the recurring division between the two worlds, and on the other hand, the little consideration taken for environmental stakes in the early design stages, in part due to the cost of extensive studies, and the risk involved for the engineering offices. This latter point leads to just cursory studies being done at this stage with development of a strategy passed on simply orally with few or no specific studies being undertaken.

Our approach strives, notably, to position itself as one possible way to deal with the first aspect, the division, even if we are aware that the roots of this difficult collaboration go way beyond a mere question of dialogue. Other factors, such as economic or regulatory ones, play an important role. Concerning the second point, we feel a method of "translating" the technical data could contribute to greater agility in the transmission of information at all phases of the design, and consequently fulfill the need for a simplifying element, right from the start of the very initial design phases, to heighten the involvement of the engineering office.

This complexity which is inherent to the development of new practices, the proliferation of tools, and the access to huge volumes of heterogeneous data should not become obstacles to the design process. This complexity entails a source of potential innovation. It involves offering the keys to enable the full use of this treasure house of technical information to design better. We can identify two significant challenges. The first involves responding to the need for "decrypting" linked to the development of I.T. means, the available tools, and the multiplication and diversification of the data. The second corresponds more to a need to make the language more understandable to non-specialists, which could contribute to improving exchange among the actors intervening in the process. That is, the previously mentioned complexity and the vast amount of data that will nourish the operational process of the project, need to be usable by all the actors. This vulgarization of information aims to streamline exchanges among actors in order to enable to come to an informed decision and, ultimately, design better.

Our research offers a response to the second challenge. That is, our objective is to find methodological solutions to improve the exchanges among the operational professionals of the architectural and urbanism design worlds, concerning the themes of energy and the environment. It involves striving for the elaboration of a method and of a trans-disciplinary visualization tool for environmental questions applied to architectural and urban design projects.

The culture and usual practices of designers leads them to think about and conceive their projects graphically. Thus, developing a shared trans-disciplinary visual culture on energy and environmental questions seems an obvious contribution to improving the process.

Feedback in the scientific literature on the subject (Attia, 2013), allows to affirm that the representation of information and of data constitute an essential aid for dialogue and an important instrument in the decisionmaking process. Several researchers have demonstrated how the capacity to visualize a grouping of complex results can contribute to streamlining this decision-making process in an architectural project (e.g. Fig. 4).

For example, G. Halin (2007) refers to the construction of reasoning mechanisms " through images » that are the designer's own. Their specific visual approach is defined as "visual-spatial intelligence" (Gardner, 1992), the image is at the same time raw material for creation, but also a way of seeing and perceiving a problem. 


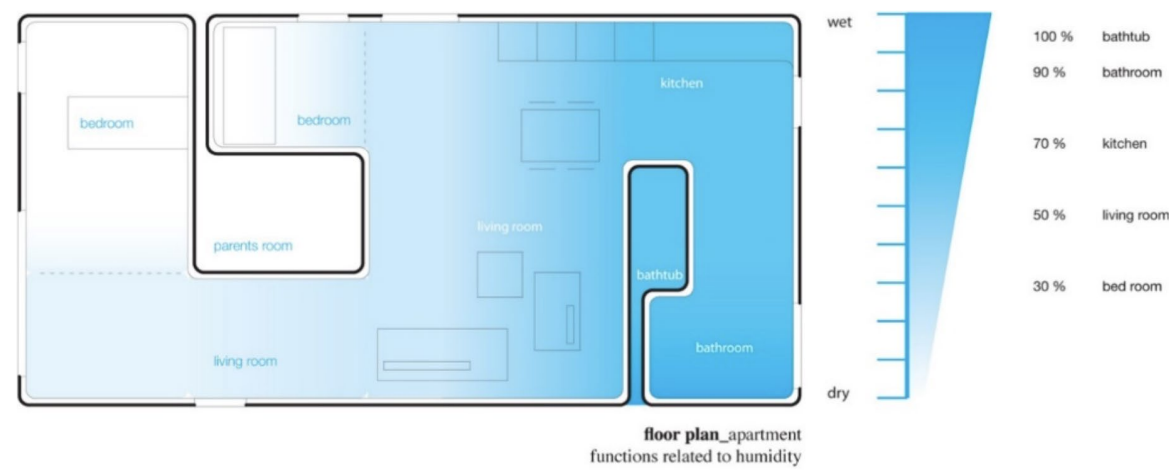

Figure 4. Plan of an apartment conveying the distribution of dampness. An example of how the constraint can turn into a project parameter and how the image portrays both the spatial information and technical data. Source: (P. Ram, vapor apartements, 2009)

Morpho 1_102 Morpho 2_M Morpho 3_101 Morpho 4_P

$\begin{array}{rr}1,764458 & 1,305668 \\ 1,517734 & 1,069254 \\ 1,794852 & 1,701493 \\ 1,48381 & 1,054254 \\ 1,85528 & 1,270392 \\ 4,323983 & 4,291698 \\ & \\ 14,38197 & 10,645651 \\ 12,370938 & 8,718072 \\ 14,629702 & 13,872975 \\ 12,094425 & 8,595769 \\ 15,122253 & 10,358035 \\ 35,244463 & 34,991998 \\ & \\ 8,610293 & 6,321012 \\ 7,406315 & 5,176484 \\ 8,758607 & 8,237283 \\ 7,24077 & 5,103865 \\ 9,05349 & 6,150236 \\ 21,100388 & 20,777015\end{array}$

$1,8538761.947894$

$1,2960431.643221$

1.885812 .167103

$1,5590051.664142$

$1,727882.240065$

$4,3479574,426128$

$15,12847515.871854$

$10,57630313.389316$

$15,38905617.658016$

$12,72219413.559784$

$14,10029218.252524$

$35,48131436.065025$

$\begin{array}{cl}9,122788 & 9.747005 \\ 6,377732 & 8.222463 \\ 9,279929 & 10.843898 \\ 7,67175 & 8.327149 \\ 8,502771 & 11.208989 \\ 21,395976 & 22.147758\end{array}$

5,67924927

8,64314524

18,560133

8,47894385

5,72776111

9,43313343

\section{Morpho ref}

1,67596173

1,13215818

1,86456844

1,12256919

1,70841805

3,66862573

13,7445859

9,28484812

15,2913523

9,20620894

14,0107611

30,0864525

\section{Cooling $\left(\mathrm{kWh} / \mathrm{m}^{2}\right)$}

Heating $\left(\mathrm{kWh} / \mathrm{m}^{2}\right)$

\author{
Lighting $\left(\mathrm{kWh} / \mathrm{m}^{2}\right)$
}

Figure 5. Example of raw data, pertaining to energy consumption. Source: (G.Togo, 2019) 
In the framework of new complexity, linked today to the integrated administration of new constraints, the development of a new visualization method adapted to new themes would enable to bring to light information that appears complex and at times hard to follow in a table of figures or a long written report (e.g.Fig.5).

Putting in place this methodology relies on tools developed at the Efficacity Institute of R\&D for Urban Energy Transitioning. The approach is focused, firstly, on a tool allowing to modify the design parameters of a project to improve its energy and environmental performance. In this light, the idea is to put in place a tool to visualize in a simple and intuitive way, the results of cross simulations and the effects of the variation of certain input parameters on the energy demands and the well-being of the end-users at the very outset of design phases. Conceiving new graphic forms to visually organize and explore a large amount of incoming and outgoing data due to the digital environment is one of our aims and has been experimented through case studies.

\section{ENERGIES VISUALIZATION}

What do we mean by the visualization of energies? The meaning of the term "energy" deserves to be clarified. Of course, a precise definition of the word "energy" exists, yet here for this document we broaden its significance. In our research, this term includes, and identifies energy consumption, renewable and fossil-sourced resources, and also climate phenomena (wind, rain,...) or sunshine elements. We, thus, focus, in a very general way, on the graphic representation of energy and environmental matters concerning the city and buildings.

From a methodology point of view, we firstly relied on an overview of current usage and, secondly, followed with hands-on practical workshops. This work showed the existence of numerous graphic elements which enable to illustrate technical and energy data. These graphic elements stem from design professionals' know-how, however they have not been codified in France yet as they have been abroad. They involve an experimental language which has been tested in practice by designers and includes broadly recognized symbols and graphic representations, such as: - $\quad$ The association of certain colors with states and sensations : red/heat/heating, blue/coolness/air-conditioning, yellow/light/ electricity

- The association of symbols: an arrow indicates a direction, an orientation (airflow, for example) several arrows can indicate the movement of an entity in a given direction.

- $\quad$ Color gradients: variation in an item

Are the existing codes recognized and commonly used in all the concerned fields? Are they adapted to more and more complex design projects?

The existing elements revealed by the overview of the field, and already partially integrated into professional practice, constitute an initial starting point for further potential development. According to Deshayes,

the act of architectural design, a communicated act where graphic and verbal conveyance is favored [...] Graphic representation, the materialization of a mental space for creation, is considered as a system of manifestation allowing to catch part of the immanence of the creation and to reach possible meaning, a communicability (Deshayes, 2012).

But how can we structure the existing into a grouping that is intelligible to a large number of people of different backgrounds and expertise so that they can work together better?

One way would be to put together a guide or catalogue of possible visualizations for design professionals which would certainly help simplify decision making processes. Developing such a guide would bring up more questions, for example: 
What kind of impact on the energy and environmental performance of selected projects would there be?

How can visualizations focused on energy impact architectural and urban design, and, more concretely, the development of the projects and their impacts on the environment?

To continue our exploration of the issue, hands-on workshops were organized at Efficacity. They took place in two steps. Firstly, we dealt with an audience of design actors (architects, engineers, contractors, urban designers, sociologists) faced with the exercise of representation. Secondly, a similar workshop was done with the researchers of the Efficacity Institute of R\&D making up the participants.

The aim of the workshops was to test the initial hypotheses of our research, and to work in an interdisciplinary way on the question of the visualization of energies by obtaining contributions from a variety of professional profiles. The workshops, within a short, one-hour format, were based on practical exercises. The participants played an active role: starting with a game using imposed data (Figure 6), along with given a receiver and representation objective they were asked to do a hand drawing of their own visualization.
Represent the following sunshine data for Toulouse

\begin{tabular}{|c|c|c|c|}
\hline & Irradistion & $\begin{array}{c}\text { Hours of } \\
\text { Sunshine }\end{array}$ & Inclinstion \\
\hline January & $2,55 \mathrm{kWh} / \mathrm{m}^{2}$ & $90 \mathrm{~h}$ & $63^{\circ}$ \\
\hline February & $3,80 \mathrm{kWh} / \mathrm{m}^{2}$ & $115 \mathrm{~h}$ & $57^{\circ}$ \\
\hline March & $5,25 \mathrm{kWh} / \mathrm{m}^{2}$ & $175 \mathrm{~h}$ & $45^{\circ}$ \\
\hline April & $5,45 \mathrm{kWh} / \mathrm{m}^{2}$ & $185 \mathrm{~h}$ & $30^{\circ}$ \\
\hline May & $5,50 \mathrm{kWh} / \mathrm{m}^{2}$ & $210 \mathrm{~h}$ & $16^{\circ}$ \\
\hline June & $5,90 \mathrm{kWWh} / \mathrm{m}^{3}$ & $230 \mathrm{~h}$ & $10^{\circ}$ \\
\hline July & $5,15 \mathrm{kWh} / \mathrm{m}^{2}$ & $250 \mathrm{~h}$ & $14^{\circ}$ \\
\hline August & $5,00 \mathrm{kWh} / \mathrm{m}^{2}$ & $240 \mathrm{~h}$ & $25^{\circ}$ \\
\hline September & $5,60 \mathrm{kWh} / \mathrm{m}^{2}$ & $205 \mathrm{~h}$ & $41^{\circ}$ \\
\hline October & $4,40 \mathrm{kWh} / \mathrm{m}^{2}$ & $150 \mathrm{~h}$ & $54^{\circ}$ \\
\hline November & $2,80 \mathrm{kWh} / \mathrm{m}^{2}$ & $100 \mathrm{~h}$ & $62^{\circ}$ \\
\hline December & $2,50 \mathrm{kWh} / \mathrm{m}^{2}$ & $85 \mathrm{~h}$ & $67^{\circ}$ \\
\hline Yearly & $4,65 \mathrm{kWWh} / \mathrm{m}^{2}$ & $170 \mathrm{~h}$ & $36^{\circ}$ \\
\hline
\end{tabular}

Represent the energy needs report on the following buildings

\begin{tabular}{|c|c|c|c|}
\hline & Heating \& DHW & Cooling & Electricity \\
\hline B 1 & $435 \mathrm{MWh} / \mathrm{an}$ & $100 \mathrm{MWh} / \mathrm{an}$ & $3440 \mathrm{MWh} / \mathrm{an}$ \\
\hline B 2 & $90 \mathrm{MWh} / \mathrm{an}$ & $170 \mathrm{MWh} / \mathrm{an}$ & $540 \mathrm{MWh} / \mathrm{an}$ \\
\hline B 3 & $535 \mathrm{MWh} / \mathrm{an}$ & $710 \mathrm{MWh} / \mathrm{an}$ & $1150 \mathrm{MWh} / \mathrm{an}$ \\
\hline B 4 & $4110 \mathrm{MWh} / \mathrm{an}$ & & $1370 \mathrm{MWh} / \mathrm{sn}$ \\
\hline B 5 & $780 \mathrm{MWh} / \mathrm{an}$ & - & $110 \mathrm{MWh} / \mathrm{an}$ \\
\hline B 6 & $110 \mathrm{MWh} / \mathrm{an}$ & $340 \mathrm{MWh} / \mathrm{an}$ & $1100 \mathrm{MWh} / \mathrm{an}$ \\
\hline
\end{tabular}

Figure 6. Example of exercise files used during the workshops to question the participants on potential visualization solutions. Source: (G. Togo, 2019). 
Several interesting configurations of workshop participant / data / receiver led to significant conclusions, for example:

- $\quad$ Participants of different professions chose the same set of data (whether for the same receiver or not)

- Participants having the same profession each created their own visualization of the same set of data, but with different receivers.

The reading of the ensuing visualizations revealed several interesting points, like, for example:

- The importance of clarity of the data as a starting point, that is, the need to pre-prepare a simplification and harmonization of the data to represent beforehand. This simplifies their conveyance through a visual language.
- $\quad$ The need to identify the receiver of the representation and his or her aim beforehand in order to offer a pertinent visual, as, for example in the following images. The two illustrations correspond to the same set of data (table detailing energy flow) (e.g. Fig. 7) intended for different receivers (decision makers on the top and the general public on the bottom). The two representations use the model of a flow diagram (Sankey diagram). The top right image reports the information in a factual and direct manner, while the second, on the bottom, superimposes the arrows on the image of a house. This type of representation is certainly more attractive to a general public as it links to the image of family, and on top of that, it adds information about expenses by providing an equivalent of energy expenditure in Euros.
Represent the following data concerning energy flow : primary resources to main usage
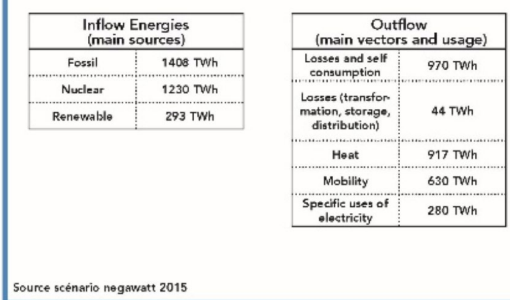

Source scenario negawatt 2015

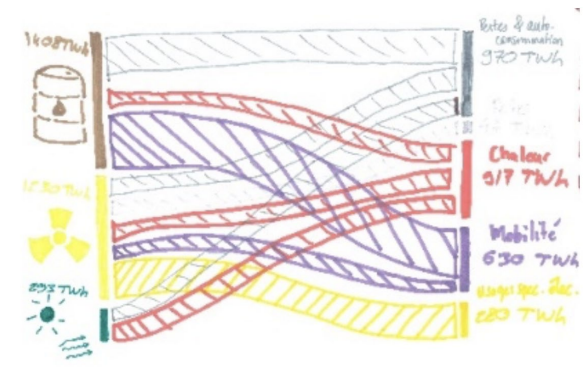

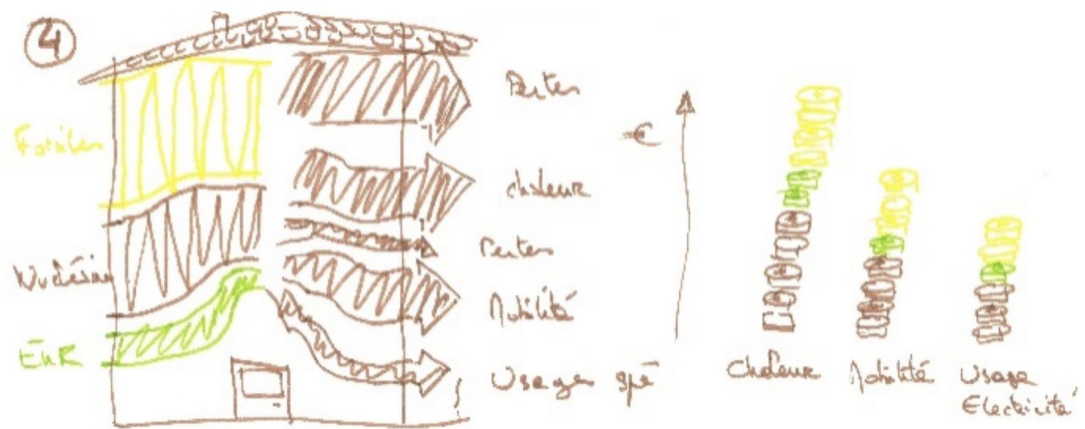

Figure 7. Project file et examples of representations done during the workshops. Source: (G. Togo, 2019). 
Represent the following sunshine data for

Toulouse

\begin{tabular}{|c|c|c|c|}
\hline & Irradiation & $\begin{array}{c}\text { Hours of } \\
\text { Sunshine }\end{array}$ & Inclination \\
\hline January & $2,55 \mathrm{kWh} / \mathrm{m}^{2}$ & $90 \mathrm{~h}$ & $63^{\circ}$ \\
\hline February & $3,80 \mathrm{kWh} / \mathrm{m}^{2}$ & $115 \mathrm{~h}$ & $57^{\circ}$ \\
\hline March & $5,25 \mathrm{kWh} / \mathrm{m}^{2}$ & $175 \mathrm{~h}$ & $45^{\circ}$ \\
\hline April & $5,45 \mathrm{kWh} / \mathrm{m}^{2}$ & $185 \mathrm{~h}$ & $30^{\circ}$ \\
\hline May & $5,50 \mathrm{kWh} / \mathrm{m}^{2}$ & $210 \mathrm{~h}$ & $16^{\circ}$ \\
\hline June & $5,90 \mathrm{kWh} / \mathrm{m}^{2}$ & $230 \mathrm{~h}$ & $10^{\circ}$ \\
\hline July & $6,15 \mathrm{kWh} / \mathrm{m}^{2}$ & $250 \mathrm{~h}$ & $14^{\circ}$ \\
\hline August & $6,00 \mathrm{kWh} / \mathrm{m}^{2}$ & $240 \mathrm{~h}$ & $25^{\circ}$ \\
\hline September & $5,60 \mathrm{kWh} / \mathrm{m}^{2}$ & $205 \mathrm{~h}$ & $41^{\circ}$ \\
\hline October & $4,40 \mathrm{kWh} / \mathrm{m}^{2}$ & $150 \mathrm{~h}$ & $54^{\circ}$ \\
\hline November & $2,80 \mathrm{kWh} / \mathrm{m}^{2}$ & $100 \mathrm{~h}$ & $62^{\circ}$ \\
\hline December & $2,50 \mathrm{kWh} / \mathrm{m}^{2}$ & $85 \mathrm{~h}$ & $67^{\circ}$ \\
\hline Yearly & $4,65 \mathrm{kWh} / \mathrm{m}^{2}$ & $170 \mathrm{~h}$ & $36^{\circ}$ \\
\hline
\end{tabular}

Figure 8. Project file et examples of representations done during the workshops. Source: (G. Togo, 2019).

The profile of the author of the visualization had a reduced impact (if the other parameters were clear) on the intelligibility of the results. Here, the participants of the workshop had to create a graphic representation able to convey a set of data regarding the monthly and annual sunshine in the city of Toulouse. Both visualizations shown in the following image were done by the participants of the workshop coming from two very different fields (e.g.Fig.8). Both illustrations, while different, are pertinent and legible. This observation holds true more generally for all the representations done in these user workshops.
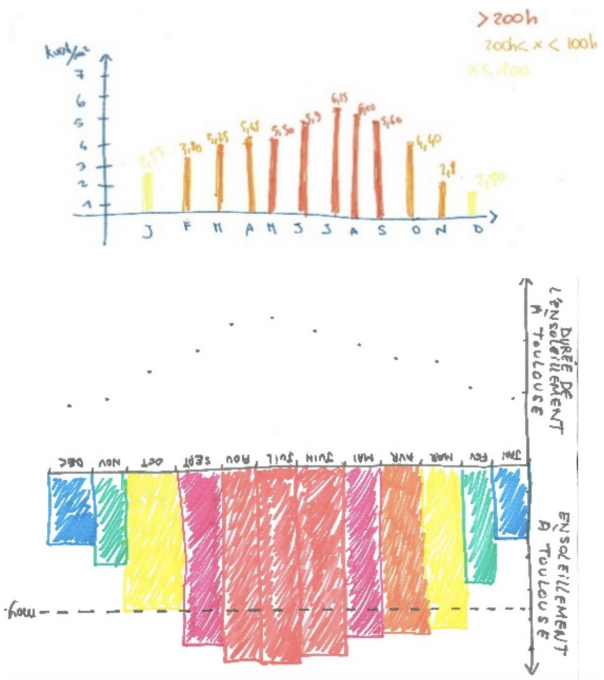

\section{CONCLUSION}

Research on the visualization of energies, the subject of this study, was at first developed within the framework of a specific project at Efficacity, in its application to the architectural and urbanism design processes. In this field, the changes in the processes are obvious at all scales and new practices rely more and more on a hybridization of roles and new professional profiles.

The hybridization of roles and the increasing need for an interdisciplinary approach is also interesting with respect to other contexts consequent to the growing complexity of the world in which we live. The Efficacity Institute of $R \& D$ rises to meet this complexity to further the energy transition for the city and its urban and architectural projects. Efficacity works with researchers from various fields to offer innovative options for the city of 
tomorrow and to design tools and methods for sustainable design and management. Engineers, sociologists, economists, and energy specialists work together and collaborate on ambitious projects. Efficacity is, thus, a fertile ground for research on the visualization of technical data and the issues surrounding interdisciplinary exchange of information.

Visualizing energies appears to be a powerful communication aid in interdisciplinary work. Barriers linked to difficulties in communication can sometimes be simplified by pertinent visuals, as emerged during the previously cited workshops.

To achieve this, we plan to pursue the research through practical applications which enable bringing clear answers, and through contributing to the development of a library of solutions. In parallel, we will apply and adapt the first research results to other Efficacity projects. Doing so will contribute to broadening the reflections in this study to other project scales and to other themes which are currently only marginally addressed as, for example, lifecycle and waste management analysis. 


\section{REFERENCES}

Attia, S., Gratia, E., De Herde, A. and al. 2013. Simulation-based decision support tool for early stages of zero-energy building design. Energy and buildings.

Brown, N. and Mueller, C., 2017. Designing With Data: Moving Beyond The Design Space Catalog. Acadia.

Deshayes, C. 2012. Aspects dialogiques de la conception architecturale. Espagne, in: Proceedings of the 10th World Congress of the International Association for Semiotic Study.

Halin, G., Chaabouni, S. and Bignon J. 2007. Recherche de références par l'image dédiée à l'assistance à la conception architecturale. Hal-00153849

Miyamoto, A., Nguyen Van, T., Trigaux, D. and al. 2015. Visualisation tool to estimate the effect of design parameters on the heating energy demand in the early design phases, In: PLEA2015 Architecture in (R) Evolution. Ass. Building Green Futures.

Nault, E., 2016. Solar potential in early neighborhood design. A decision-support workflow based on predictive models. Thèse $n^{\circ}$ 7058. Ecole Polytechnique fédérale de Lausanne.

Weytjens L., Verdonck E. and Verbeeck G., 2009. Classification and use of design tools: the roles of tools in the architectural design process. Design principles and practices: an international annual review 3. 



\title{
PAPER \#1.25
}

\section{THIN ARCHITECTURE: ENERGY, ECONOMY AND THE ALL-GLASS ARCHETYPE}

\author{
Elizabeth L McCormicka, Waleed AlGhamdib \\ aUniversity of North Carolina at Charlotte, Charlotte, North Carolina, USA

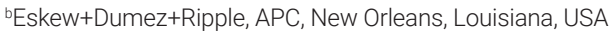

\section{ABSTRACT}

Mechanical conditioning technologies have become a welcome luxury in tropical climates, though not without cultural and environmental implications. Early office towers used operable windows to provide for ventilation, lighting and passive solar gains. However, the adoption of air conditioning as the primary thermal strategy has given way to a ubiquitous placelessness among modern buildings, an overall detachment from nature and expansive ecological degradation well beyond their geopolitical boundaries. In fact, many regions have sacrificed their local identity and age-old construction techniques for the sake of Western building styles as symbols of power and prosperity. With modernism came a desire for thin building enclosure systems and thus the invention of the curtain wall and the all-glass archetype.

As developing regions struggle to keep up with rapid urbanization, they also seek to maintain modern expectations on the global stage. Meanwhile, numerous studies show that tropical economies lag behind cold or temperate regions in several categories: GDP, education, health, technological developments, among others. In this study, the authors compare the relationship between tropical underdevelopment and energy consumption using economic indicators and simple energy modeling. The universal adoption of air conditioning, tall buildings, and curtain wall technology all within the span of a single generation, has created incredible impacts on the urban skyline as well as on global energy consumption. Despite global efforts to mitigate climate change, rapid development of the tropics with northern-latitude building typologies will lead to deleterious environmental challenges as well as continued economic hardship.

\section{KEYWORDS}

Curtain wall; energy use; glass buildings; tropical regions; EUI.

\section{INTRODUCTION}

Mechanical conditioning technologies have become a welcome luxury in tropical climates, though not without cultural, environmental and economic implications. The adoption of air conditioning as the primary thermal strategy has given way to a ubiquitous placelessness among modern buildings and expansive ecological degradation well beyond a city's geopolitical boundaries (Forman and Wu 2016). In fact, many regions have sacrificed their local identity and ageold construction techniques for the sake of thin architecture and the all-glass archetype, developed primarily in northern latitudes as symbols of power and economic prosperity. As development and urbanization trends move increasingly toward the Tropics ${ }^{1}$ (figure 1), lower-latitude regions seek to maintain modern expectations on the global stage

\footnotetext{
${ }^{1}$ Geographically, 'the Tropics' represent the part of the globe located between the Tropic of Cancer $\left(23.5^{\circ} \mathrm{N}\right.$ latitude) and the Tropic of Capricorn $\left(23.5^{\circ} \mathrm{S}\right)$. Though these regions have higher ambient temperatures closer to the equator, there is a significant difference between hot-humid and hot-arid climates in regard to building energy use. As the focus of this paper is on hot-humid climates, the authors use Köppen-Geiger's climate classification zones Af, Am and Aw to describe tropical (equatorial) climates. These climates are shown in figure 1.
} 
while also promoting economic growth in regions that have historically lagged behind (Sachs 2001). Despite efforts to mitigate climate change, rapid development of the tropics using northern-latitude building styles will lead to both environmental and economic challenges in already underdeveloped regions. Using economic indicators and simple energy modeling of the all-glass archetype, this paper seeks to demonstrate that the thin architectural style established by modernism not only challenges the identity of the tropical vernacular, it furthers economic disparities between the tropics and upper-latitude regions.

\section{BACKGROUND}

\subsection{Urbanization Trends}

Within the span of only 100 years, the Earth's population has grown exponentially from 1.5 billion at the beginning of the 20th century to 6 billion in 2009 and is expected to grow to nearly 10 billion by 2050 (Gielen et. al. 2016) with the most significant growth rates occurring in developing nations in Asia and Africa (Hoekstra and Molnar 2010). As the Earth's population swells, people are also moving into cities at unprecedented rates as more people are choosing to live in cities than in rural areas for the first time in history. While there were only sixteen cities with populations beyond one million people at the beginning of the 20th century, there are now over four hundred cities that meet this mark, with over $70 \%$ of them found in the developing world (United Nations Department of Economic and Social Affairs 2016) (Cohen 2006). With land at a premium, more energy intensive, high-rise buildings are being constructed than ever before.

The United Nations has established the top ten urbanizing regions ${ }^{2}$. With the exception of Nepal, all of these economies are found within the geographic tropics - a portion of the world that has historically lagged in wealth and resources (Sachs 2001). In fact, only four major tropical economies Hong Kong, Singapore, Saudi Arabia, and Venezuela - are classified as "high-income" economies as defined by the World Bank (figure 2).

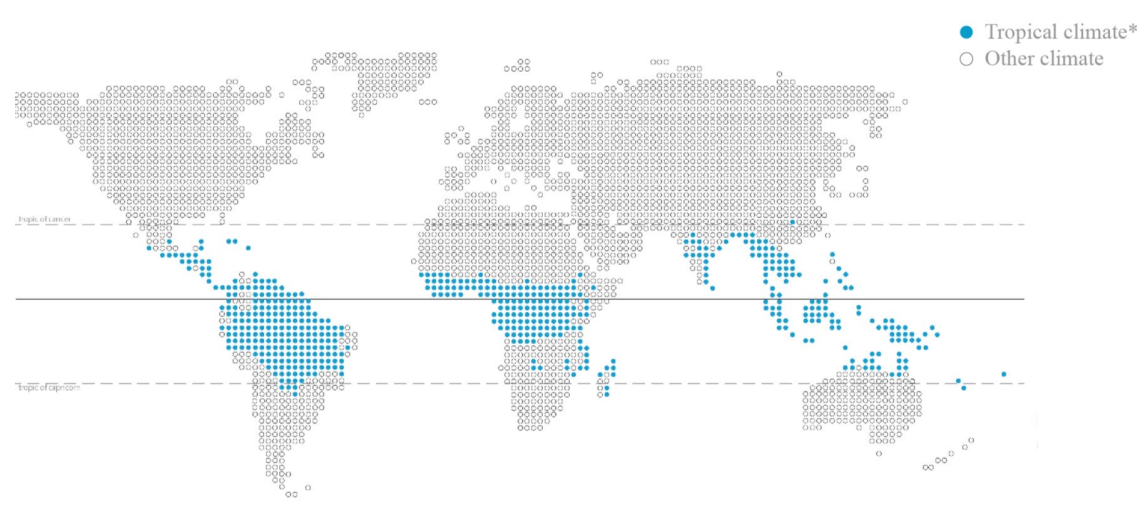

Figure 1. Summary of Tropical* Climates. Data summarized from (Peel et. al. 2007) *defined by Köppen-Geiger's Climate Classification zones Af, Am and Aw.

${ }^{2}$ The top ten urbanizing regions in descending order are: Burundi, Uganda, Ethiopia, Nepal, Niger, Eritrea, Rwanda, Malawi, South Sudan and Burkina Faso (United Nations 2015). 


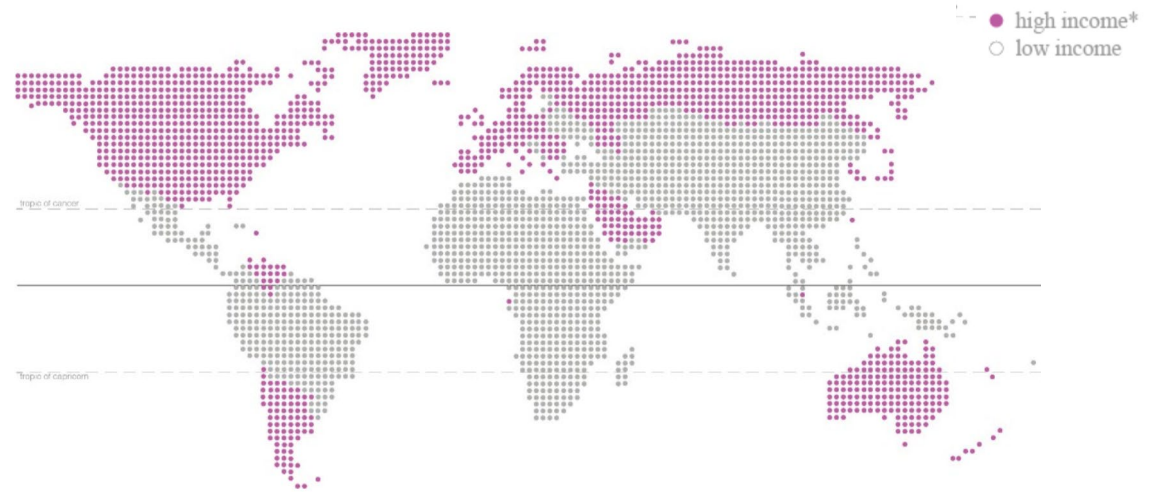

Figure 2. High-Income* Economies (by GDP PPP). Data from the (The World Bank 2013)

*defined as gross national income per capita above US\$12,735

\subsection{Economic disparities across regions}

An emerging body of research is exploring the correlations between geography, climate and economic factors. In fact, one study shows that over three quarters of the global population lives closer to the equator than Japan, but less than a third of the world's gross domestic product (GDP) is located there (Tanzer 2012). Another study shows that the average gross national product (GNP) per capita of the temperate zone is nearly five times higher than that of the tropical zone (Sachs 2001). Nobel Prize-winning economist William Nordhaus found that the optimal ambient temperature correlated with maximum economic output density is $12^{\circ} \mathrm{C}\left(54^{\circ} \mathrm{F}\right)$ (Nordhaus 2006). Tropical regions typically range from $23^{\circ} \mathrm{C}\left(73^{\circ} \mathrm{F}\right)$ to $45^{\circ} \mathrm{C}\left(113^{\circ} \mathrm{F}\right)$. Though it is not a perfectly linear correlation, figure 3 demonstrates the average GDP per capita is higher at the upper latitudes.

Though economic principles assume that poorer countries will have higher economic growth rates, growth has stagnated in the Tropics (Sachs 2001). Even beyond economic indicators, the Tropics lag in health, education, energy, productivity and technology. The burden of disease is also higher in tropical climates, further contributing to economic challenges. Many of these regions still have limited access to reliable and affordable energy services, which is a critical indicator of "global development challenges, including poverty, inequality, climate change, food security, health and education", the major contributors to the creation of wealth and economic development" (Bazilian et al. 2012).

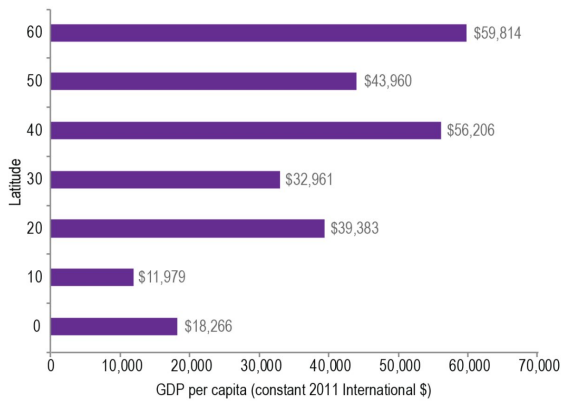

Figure 3. GDP per capita by latitude data from World Bank, International Comparison Program database, world development indicators, 2019 


\subsection{Technological diffusion \& globalization}

Economist and public policy analyst Jeffrey Sachs defines technological diffusion as "the process by which new technologies are adopted for use across individual firms or households in a given market, and across different markets" (2001). Agricultural and health-related technologies, for example, are implicitly linked to climate and ecology (Lybbert and Sumner 2012) and do not diffuse easily across climate zones. In architecture and construction, diffusion is evident in the ubiquitous building styles and materials emerging in urban centers across the globe (Eldemery 2009). Hoping to replicate the heroic structures found in the West (Wong and Hassell 2009), the all-glass tower has emerged in India, the Middle East, Southeast Asia and many other regions, regardless of context and climatic conditions.

Globalization describes the "phenomenon by which the experience of everyday life, as influenced by the diffusion of commodities and ideas, reflects a standardization of cultural expressions around the world" ("Globalization" 2017). The history of the built environment is quite extensive, as building typologies have typically evolved slowly over time. However, the universal adoption of air conditioning, tall buildings, and curtain wall technology all within the span of a single generation, has created incredible impacts on the urban skyline as well as on global energy consumption. As these standards and styles evolve independently of climate, we look to mechanical systems to make up the difference. Compounding this issue, there is an ever-evolving relationship between thermal comfort standards and technological developments. Just as certain building materials and methods became associated with confidence and power, there became an association between climate control and social status, symbolic of man's victory over nature (Brager and de Dear 2008), an idea that was propagated by the modernist movement.
"Architects of the 1950's had little concern for energy conservation. It was left to mechanical engineers to insure occupant comfort" (Kelley and Johnson 2013). The modern aesthetic developed concurrently with affordable airconditioning and mechanical ventilation strategies as architects became increasingly interested in the general aesthetic as opposed to the intrinsic performative qualities of the building enclosure.

\subsection{The all-glass archetype}

Historically, civilizations have established vocabularies of vernacular styles based on cultural antecedents and climatic conditions, creating unique building styles around the world. Cold climate buildings, for example, were bulky and insular while tropical buildings were naturally ventilated and deeply connected to the environment (Fisher 1984). Instead, post-war modernism brought a departure from the regional aesthetic in order to embrace the International Style - an architectural response to industry, technology, mobility and sociopolitical orders (Eldemery 2009). As made famous by architects like Mies van der Rohe, Walter Gropius and others, the International Style emerged in the first half of the 20th century, which represented the "vast colonizing effort by the European nations" (Braham 2000). The styling of the modern archetype was largely influenced by the "machine-made aesthetic with which the early Modernists were captivated" (Kelley and Johnson 2013). Modern and quickly erected, the all-glass archetype, made possible by divorcing the façade from the function of structure (Hitchcock and Johnson 1997), emerged as a symbol of economic growth and prosperity in the West (Oldfield et. al. 2009). In fact, Ian McCallum, the executive editor of Architectural Review, described the curtain wall as "the new vernacular" in 1957 (Yeomans 1998). It was at this juncture in time that the façade became a thin, passive 
recipient of differential conditions between inside and out.

Beyond its visual implications, this new system was appealing as it increased usable floor area, reduced lighting costs, reduced the weight of the wall and facilitated prefabrication. Glass is relatively durable and lightweight, but above all else - it is transparent and immaterial. "Questions of surface and materiality and the relative relationship between skin and structure... opaque or transparent... thick or thin" (Merwood 2001). Developed concurrently with reinforced concrete floors and relatively small, set-back steel columns, curtain wall buildings rejected any "overt expression of structure" (Yeomans 1998), climate or place.

The building and construction sector is responsible for $36 \%$ of final energy and $39 \%$ of global $\mathrm{CO} 2$ emissions from building operations and construction (Global Alliance for Buildings and Construction 2018). Additionally, the direct effects of climate change are expected to be most severe in rapidly developing regions, and regions currently supporting largely rural populations, such as the Tropics (Samson et al. 2011). Aside from the human impacts of climate change, a $2^{\circ}$-temperature rise would reduce world GDP by $1 \%$ globally (Stern 2007), but would cause a $4-5 \%$ decrease in developing tropical countries (Bierbaum and Zoellick 2009).

\section{CASE STUDY - ENERGY USE INTENSITY}

As with many other technologies, building systems and styles are difficult to diffuse across climates, regardless of cultural expectations, due to a wide variety of varying environmental conditions, not limited to solar gain, humidity and ambient temperature. As the modern aesthetic permeates across climate zones and ecological divides, all-glass buildings in tropical, lower-latitude regions are increasingly burdened by excessive energy usage, compared to their northern counterparts, particularly as it relates to cooling and dehumidification. In fact, there is an indirect correlation between energy use (EUI) and economic growth (GDP) across the various latitudes generalized by figure 4 , further perpetuating tropical disparities. To explore this phenomenon, the authors conducted a small-scale energy analysis of a single all-glass building type across a number of cities in order to find an average energy usage by latitude to compare against published economic data.

\subsection{Energy use intensity}

Energy use intensity (EUI) is an energy-use indicator used to compare and manage energy consumption patterns across various building sizes and usage types (Chung et. al.2006). The metric normalizes energy usage by area, measuring consumption in energy-per-areaper-year, or kBTU/ft2/yr (IP) or kWh/m2/yr (SI). Its usefulness can be compared to the miles per gallon (MPG) rating which demonstrates how efficiently a vehicle uses fuel. Likewise, economists use gross domestic product (GDP), in a similar capacity to quantify the economic health and productivity of a region (Callen 2008). In the case of GDP, a higher number represents strong economic growth. However, a higher EUI represents high energy usage and thus a poorly performing building.

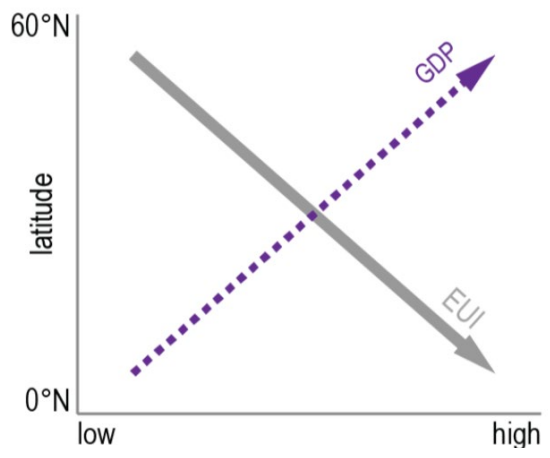

Figure 4. expected results (simplified) 


\subsection{Study parameters}

One uniform building type was modeled across 18 different climates (3 per latitude) to show the resulting EUI. The envelope parameters ${ }^{3}$ were roughly inspired by the material qualities during the boom of the International Style in the 1950's and mechanical inputs are simplified for the sake of this study ${ }^{4}$. In practice, buildings in heating-dominated climates typically rely on burning a carbon-based energy source such as natural gas or oil- for space heating, whereas cooling-dominated climates rely primarily on electricity for cooling. Although the analysis was run using electricity as the single source of energy, utilizing heat pump technology for both heating and cooling to reduce simulation noise due to variation in HVAC system type across climate zones, it is unlikely to rely on a single energy type for space conditioning across all climate types. The analysis was conducted by performing an annual hourly whole building energy simulation using DOE 2.2 eQUEST 3.65, a software developed by the US Department of Energy, and is among the widest used tools in the industry. The model was built

${ }^{3}$ Modeled building parameters:

\begin{tabular}{|l|l|l|}
\hline \multicolumn{3}{|l|}{ BUILDING PARAMETERS } \\
\hline Floor Area & 300,000 & SF \\
\hline Number of Floors & 30 & Floors \\
\hline Floor to Floor Height & 13 & Feet \\
\hline Wall Area & 156,000 & SF \\
\hline Window Area & 124,800 & SF \\
\hline Window-Wall Ratio & 80 & $\%$ \\
\hline ENVELOPE & 0.082 & \\
\hline Wall U-factor & 0.040 & \\
\hline Roof U-factor & 0.521 & \\
\hline Glazing U-factor & 0.500 & \\
\hline Glazing SHGC & \multicolumn{3}{|l|}{} \\
\hline INTERNAL LOADS & 1.0 & W/SF \\
\hline Lighting Power Density & 1.0 & W/SF \\
\hline Plug Loads & 0.3 & CFM/SF \\
\hline Air Infiltration, Envelope & 0.20 &
\end{tabular}

with a simple square floor plan and a simple perimeter and core thermal zone layout. The "Floor Multiplier" feature in eQUEST was utilized to reduce the amount of time each run of simulation takes, which removes interior floors plates that are identical, simulating them once then multiplying them by the total number of identical floors. The thermal zone floor plan layout had one zone per solar exposure at a depth of 15 feet (4.57 $\mathrm{m})$ from the exterior wall and one thermal zone in the core of the building, consistent with the energy modeling protocols laid out in the energy standard ASHRAE 90.1.

\section{RESULTS \& DISCUSSION}

An identical model was simulated several times with only changing the weather file for the simulation. The following figures (table 1 and figure 5) plot the result of these simulations in terms of EUI against the latitude of each building, showing a correlation between weather, represented by latitude, and energy efficiency represented by EUI. Additionally, figure 5 overlays the economic data previously discussed in figure 3 .

${ }^{4}$ Modeled mechanical system parameters:

\begin{tabular}{|l|l|}
\hline \multicolumn{2}{|l|}{ MECHANICAL SYSTEM } \\
\hline \multirow{2}{*}{ HVAC System Type } & $\begin{array}{l}\text { Packaged Variable Volume } \\
\text { Variable Temperature Heat } \\
\text { Pump; Air Cooled }\end{array}$ \\
\hline \multirow{2}{*}{ System Configuration } & $\begin{array}{l}\text { System per zone; } \\
\text { Ducted to Space }\end{array}$ \\
\hline $\begin{array}{l}\text { Temperature } \\
\text { Setpoints }\end{array}$ & Cooling $76^{\circ}\left(82^{\circ}\right.$ unoccupied $)$ \\
\cline { 2 - 2 } Design Temperatures & Heating $70^{\circ}\left(64^{\circ}\right.$ unoccupied $)$ \\
\cline { 2 - 2 } & Cooling $75^{\circ}$ indoor; $55^{\circ}$ supply \\
\hline Cooling Efficiency & $8.2 \mathrm{EER}$ \\
\hline Heating Efficiency & $2.9 \mathrm{COP}$ indoor; $90^{\circ}$ supply \\
\hline System Capacity & Auto sized heating/cooling \\
\hline Humidity Control & Max RH $60^{\circ}$ \\
\hline
\end{tabular}




\begin{tabular}{|c|c|c|c|}
\hline Lat. & City & EUI & Average \\
\hline \multirow{3}{*}{50} & Frankfurt & 29 & \multirow{3}{*}{31} \\
\hline & Kiev & 33 & \\
\hline & Adak & 31 & \\
\hline \multirow{3}{*}{40} & NYC & 33 & \multirow{3}{*}{33} \\
\hline & Tashkent & 34 & \\
\hline & Tianjin & 33 & \\
\hline \multirow{3}{*}{30} & San Antonio & 37 & \multirow{3}{*}{39} \\
\hline & Kuwait City & 47 & \\
\hline & Shanghai & 33 & \\
\hline \multirow{3}{*}{20} & Honolulu & 40 & \multirow{3}{*}{35} \\
\hline & Hanoi & 41 & \\
\hline & Mexico City & 24 & \\
\hline \multirow{3}{*}{10} & Addis Ababa & 25 & \multirow{3}{*}{40} \\
\hline & Batticaloa & 49 & \\
\hline & Managua & 46 & \\
\hline \multirow{3}{*}{0} & Singapore & 47 & \multirow{3}{*}{32} \\
\hline & Nairobi & 28 & \\
\hline & Quito & 21 & \\
\hline
\end{tabular}

Table 1. EUI comparison of the same building by latitude $^{5}$

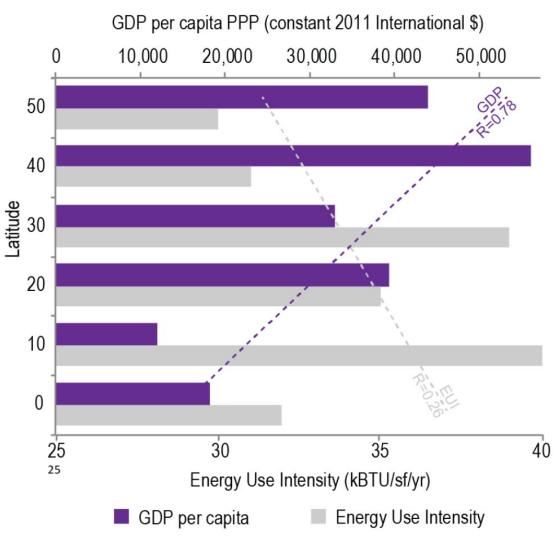

Figure 5. comparison of EUI and GDP by latitude
In this study, the authors sought to compare the relationship between economic indicators and energy consumption of the all-glass archetype to explore the contribution of energy to tropical underdevelopment. Though this limited data set generally trends in accordance with an inverse relationship between energy use and GDP the authors note that additional factors must be included in the study moving forward, due to the complexity of the issue. These factors include air temperature, relative humidity, solar access and elevation above sea level. Although latitude is a major factor in determining these climatic characteristics, other macro and micro climate phenomena will likely have a significant effect on energy consumption of the sample building. For example, where two cities have the same general latitude and air temperature, one city can have higher relative humidity due to its proximity to a large body of water, which results in considerably higher latent cooling loads than the other, which will affect the overall EUI of the building. This can be found when comparing the EUI of Singapore, on the southern end of the South China Sea, which has an annual average relative humidity $(\mathrm{RH})$ of $84 \%$ with Nairobi, roughly 500 kilometers inland from the Indian Ocean coast, which has an annual average $\mathrm{RH}$ of $72 \%$. Another avenue of inquiry might be to instead limit the conversation of energy to only cooling energy or building loads as opposed to total EUI, as cooling energy and cooling systems require more advanced technologies ${ }^{6}$.

\section{CONCLUSION}

This research shows that energy usage and economic health are in direct opposition, provoked by the all- glass building and the International Style. The authors observed that as GDP decreases toward the equator,

\footnotetext{
${ }^{5}$ The EUls in this study are generally lower than those expected of older buildings. This is mainly due to the use of mechanical systems following current energy code minimums. It is expected that the relative EUI relationship between these cities will hold regardless of the mechanical system used, and only the absolute EUI for each individual city will be affected.
} 
and hypothesized that energy use of a model curtain wall building would increase, causing challenges for the rapidly urbanizing tropical climates hoping to maintain the modern aesthetic but with the burden of increased energy usage, particularly as it relates to cooling. Many scholarly works have been published about the impact of local cultures on thermal comfort and conditioning strategies, yet we are now seeing the impact of these technologies on local urban identity through redundant skylines of sealed glass towers. In no place is this phenomenon more evident (and environmentally harmful) than in the rapidly developing tropics.

Advances in mechanical technologies and air conditioning market penetration have supported global trends toward glazingdominated, sealed buildings regardless of climate, culture or local identity. Paired with the rapid influx of people into cities and unsustainable development strategies, tropical regions experience developmental challenges well beyond the burdens of the extreme climatic conditions and economic vulnerability. Partnered with economy and ecology, tropical regions must develop their own modern aesthetic that competes with the all-glass archetype but also supports sustainable tropical development. 


\section{REFERENCES}

Bazilian, Morgan, Patrick Nussbaumer, HansHolger Rogner, Abeeku Brew-Hammond, Vivien Foster, Shonali Pachauri, Eric Williams, et al. 2012. "Energy Access Scenarios to 2030 for the Power Sector in Sub-Saharan Africa." Utilities Policy 20 (1): 1-16. https://doi.org/10.1016/j. jup.2011.11.002.

Bierbaum, Rosina M., and Robert B. Zoellick. 2009. "Development and Climate Change." Science 326 (5954): 771-771. https://doi. org/10.1126/science. 1183876.

Brager, Gail S., and Richard J. de Dear. 2008. "Historical and Cultural Influences on Comfort Expectations." In Buildings, Culture and Environment: Informing Local and Global Practices, edited by Raymond J. Cole and Richard Lorch, 177-201. John Wiley \& Sons.

Braham, William W. 2000. "Erasing the Face: Solar Control and Shading in PostColonial Architecture." Interstices Journal of Architecture and Related Arts.

Callen, Tim. 2008. "What Is Gross Domestic Product?" Finance \& Development, 2.

Chung, William, Y. V. Hui, and Y. Miu Lam. 2006. "Benchmarking the Energy Efficiency of Commercial Buildings." Applied Energy 83 (1): 1-14. https://doi.org/10.1016/j. apenergy.2004.11.003.

Cohen, Barney. 2006. "Urbanization in Developing Countries: Current Trends, Future Projections, and Key Challenges for Sustainability." Technology in Society, Sustainable Cities, 28 (1-2): 63-80.

Eldemery, I.m. 2009. "Globalization Challenges in Architecture." Journal of Architectural and Planning Research 26 (4): 343-54.

Fisher, Thomas. 1984. "The Well-Tempered Tropics: Design for Hot, Humid Climates." Progressive Architecture 65 (4): 98-103.

Forman, Richard T. T., and Jianguo Wu. 2016. "Where to Put the Next Billion People." Nature 537 (September): 608-11.
Gielen, Dolf, Francisco Boshell, and Deger Saygin. 2016. "Climate and Energy Challenges for Materials Science." Nature Materials 15 (2): 117-20. https://doi. org/10.1038/nmat4545.

Global Alliance for Buildings and Construction. 2018. "2018 Global Status Report."

"Globalization." 2017. In Encyclopedia Britannica. https://www.britannica.com/ topic-browse/History/Modern-World/ Globalization.

Hitchcock, Henry Russell, and Philip Johnson. 1997. The International Style. W. W. Norton \& Company.

Hoekstra, Jonathan M, and Jennifer L Molnar. 2010. The Atlas of Global Conservation: Changes, Challenges, and Opportunities to Make a Difference. Berkeley: University of California Press.

Kelley, Stephen J., and Dennis K. Johnson. 2013. "The Metal and Glass Curtain Wall: The History and Diagnostics." In Modern Movement Heritage. Taylor \& Francis.

Lybbert, Travis J., and Daniel A. Sumner. 2012. "Agricultural Technologies for Climate Change in Developing Countries: Policy Options for Innovation and Technology Diffusion." Food Policy 37 (1): 114-23. https://doi.org/10.1016/j. foodpol.2011.11.001.

Merwood, Joanna. 2001. "The Mechanization of Cladding: The Reliance Building and Narratives of Modern Architecture." Grey Room, no. 4: 53-69.

Nordhaus, William D. 2006. "Geography and Macroeconomics: New Data and New Findings." Proceedings of the National Academy of Sciences of the United States of America 103 (10): 3510. https://doi. org/10.1073/pnas.0509842103.

Oldfield, Philip, Dario Trabucco, and Antony Wood. 2009. "Five Energy Generations of Tall Buildings: An Historical Analysis of Energy Consumption in High-Rise Buildings." The Journal of Architecture 14 (5): 591-613. 
Peel, M. C., B. L. Finlayson, and T. A. Mcmahon. 2007. "Updated World Map of the KöppenGeiger Climate Classification." Hydrology and Earth System Sciences Discussions 4 (2): 439-73.

Sachs, Jeffrey D. 2001. "Tropical Underdevelopment." Working Paper 8119. National Bureau of Economic Research. http://www.nber.org/papers/w8119.

Samson, J., D. BerteauX, B. J. McGill, and M. M. Humphries. 2011. "Geographic Disparities and Moral Hazards in the Predicted Impacts of Climate Change on Human Populations." Global Ecology and Biogeography 20 (4): 532-44. https://doi. org/10.1111/j.1466-8238.2010.00632.x.

Stern, Nicholas Herbert. 2007. The Economics of Climate Change: The Stern Review. Cambridge University Press.

Tanzer, Sam. 2012. "Why Is There Such A Strong Correlation Between Geographic Distance From The Equator And Prosperity?" Forbes, 2012. https://www. forbes.com/sites/quora/2012/03/20/ why- is-there-such-a-strong-correlationbetween-geographic-distance-from-theequator-and- prosperity/.

The World Bank. 2013. "Country and Lending Groups." October 22, 2013. http://data. worldbank.org/about/country-andlending-groups\#High_income.

United Nations. 2015. "World Urbanization Prospects, 2014." http://esa.un.org/ unpd/wup/Publications/Files/WUP2014Report.pdf.

United Nations Department of Economic and Social Affairs. 2016. The World's Cities in 2016. Statistical Papers United Nations (Ser. A), Population and Vital Statistics Report. UN. https://doi. org/10.18356/8519891f-en.
Wong, Mun Summ, and Richard Hassell. 2009. "Tall Buildings in Southeast Asia - A Humanist Approach to Tropical HighRise." Council on Tall Buildings and Urban Habitat (CTBUH, no. III. http://global.ctbuh. org/resources/papers/download/414tall-buildings-in-southeast-asia-ahumanist-approach-to-tropical-high-rise. pdf.

Yeomans, David. 1998. "The Pre-History of the Curtain Wall." Construction History 14: 59-82. 


\title{
VR, PHOTOGRAMMETRY AND DRAWING OVER: ENVISIONING THE CITY OF THE FUTURE
}

\author{
Olivier Chamel ${ }^{\mathrm{a}}$ and Laurent Lescop \\ aFAMU, Tallahassee, Floride, USA \\ bENSA Nantes AAU-CRENAU, UMR-CNRS 1563 - Nantes, France
}

\section{ABSTRACT}

This article proposes to discuss a research/ design methodology aimed at developing urban visions based on case study analysis of existing urban environments using Virtual Reality technology and Photogrammetry. In order to visualize possible scenarios for the city of the future the method described here is based on "drawing over" existing urban images whether in a 2D format or a 3D environment. As a preliminary to this creative urban design phase the urban context of a specific street is analyzed both in terms of its physical and material qualities as well as its experiential ones.

\section{KEYWORDS}

VR; photogrammetry; pedagogy.

\section{INTRODUCTION}

Technologies such as virtual reality, though they have been around for a while in various formats have only recently been identified and used as potential design tools in the field of architecture. The initial goal of these technologies was to develop an immersive representational system aimed at creating a realistic and convincing spatial $3 \mathrm{D}$ environment. The obvious benefits to architecture and its related fields lie in the ability for designers to create interactive $3 D$ models of their designs in order to experience moving through spaces and therefore better understand a particular design solution. The first iterations of virtual reality technology presented promising opportunities mostly as an improved and enhanced spatial representation system because of its experiential qualities. The idea of using VR as a design tool in architecture is relatively new and follows recent software developments in that field. When the Cave system was invented at EVL (Electronic Visualization Lab) in 1991 it was designed for industrial needs and did not really make its way to the field of professional practice. For a long time VR tools were understood by architects more as rendering tools than design tools. Though in the naval industry for instance, this difference between designing and visualizing does not exist and VR tools have been embraced since their beginning. Paradoxically some schools of architecture still view 3D tools as "anti-creative" as opposed to other more "traditional" design tools. In the context of the design methodology discussed here, we are using 2D images, photogrammetry and VR both as analytical and design tools.

The ambitious goal of having students aim at developing urban visions stated at the beginning of this paper invites an interesting series of questions. First of them, teaching notions of urban design in architecture programs poses a number of challenges. Aside from the fact that students have to grasp the built environment at a different scale they also have to understand concepts such as phenomenology of perception, positive and negative space and think in terms of spatial sequences as well as how building forms are experienced in motion and context. And in order to understand the many concepts associated with urban design, it is crucial for students to physically experience such environments. That is to 
physically visit urban centers and cities, which display successful examples of urban design solutions. Interestingly the current generation of students, and architecture students are no exception, have developed a significant number of meaningful interactions that are not physical in nature but rather digital and virtual. As the millennium generation uses screens in a widespread fashion (phones, tablets) in order to communicate with one another and access information these tools have played an important part in shaping or reshaping their perception and vision of the world. In fact in the past few years we have observed a generation of students who seem more engaged and seem to place more value at times on a digital world rather than on the physical one. As this current trend poses obvious challenges in education and when it comes to physically engaging students, it also provides new opportunities. Developing a design process based on $2 D$ and $3 D$ images as well as VR environments effectively draws students with tools they are familiar with and may serve as a re-introduction to the real world. Tools such as Google Street view, 3D scanners, photogrammetry and various VR applications have opened new realms of designs by providing large quantities of information about existing urban environments very quickly and accessible anywhere in the world. All that information can then be formatted and analyzed in order to provide valuable input and inform design decisions. For example Google maps and Google Street view can be used effectively to develop reliable 3D urban models most anywhere in the world. This type of access is especially useful for architecture schools where students are geographically isolated from major urban centers.

In addition to being tied two specific tools (i.e. 3D models, immersive technology) the methodology we are describing here is also defined by having teams of students from two different schools, one in Nantes, France and the other in Tallahassee, Florida US complete the work. Each team would develop a case study of an existing street in their urban location using a variety of digital tools and then create a design proposal for urban development and growth. Each school will then share the materials gathered during the case study with the other school so that ultimately each team of students at each school would develop a design proposal for their local site as well as for a remote site. Based on the information provided, i.e. Google Street views, photogrammetry and VR, on a specific environment they are not necessarily familiar with, each team of students would have to apply their own set of analytical tools specific to their pedagogical environment and cultural background. Ultimately the urban design proposal of the offsite teams when compared to the local teams may be influenced by a difference of cultural perspective but also by the fact that they did not have physical access to the site. In our attempt to try to identify the factors driving design decisions, each team would fill out an exhaustive questionnaire (in the form of a table) describing design goals and how they were translated in urban forms. This process would attempt to decipher which design decisions were driven by a particular pedagogical environment, cultural urban context, case study format or other unforeseen factor. Teams at each school would present their design proposals in a similar format composed of mostly graphic materials such as urban maps, street plans, street sections, diagrams, 2D perspectives, and VR immersive environments. Some of the anticipated outcomes would be to identify how trends in urban design proposal, both successful and less successful, are tied to specific curricula and cultural context. These two issues would be especially interesting to investigate as they touch on the place of urban design in architecture education and would provide clues of a European versus American perspective.

European cities have historically been very engaged with the notion of constantly 
improving the urban environment and addressing growth as well as cultural and social issues. Faced with issues of high density, mobility and transportation, low economic growth, inequalities and sustainability, European urban centers have been under pressure to innovate and propose concrete solutions to these ongoing challenges. Current strategies include increases in urban density by means of adding stories to existing buildings, filling empty lots, developing zoning regulations discouraging sprawl and shared vehicles to name a few. On the other hand the US has only seen such ideas of controlled density an urban environment quality gain traction in the past 20 years with such movements as the new urbanism. Similarly to their European counterparts American cities are facing acute challenges. Urban sprawl alone is omnipresent and is responsible for the destruction of valuable natural environments, increased commute time, pollution, loss of productivity, stress and infrastructure cost increase. Structurally the making of most American cities was driven by short-term economical goals and by zoning laws associated with the development of the automobile. Therefore the suburban nature of the American urban landscape and our relationship to space in that context is very different from that of European citizens. Therefore it is interesting to evaluate to what extent urban and spatial environments affect the way we can conceive urban spaces especially for a generation of students immersed in digital media and an imagery full of global references. The identification of potential cultural driving factors for students' urban design would in turn shed some light on the place of education and of a particular curriculum in the urban design process. Aside from the quality of the urban design work itself the benefits of this approach would also inform us on the appropriateness of relatively new visual tools and determine the values of being placed in a drastically different cultural design environment.

\section{METHODOLOGY}

The design methodology of this urban design project is organized in 2 distinct phases. The first phase is analytical in nature and consists in gathering data on the project site, an existing street, using Google Street View as a 2D photographic tool. The second phase involves the use of 3D scanning and photogrammetry to bring streets in a 3D immersive environment for an experiential and phenomenological analysis. Flatten photos of the 3D photogrammetry models will be created to analyze content, typologies, surfaces and determine the level of complexity of the street. Following the information gathering phase, the second phase will consists in developing urban design proposals using the same techniques introduced in the initial phase. Therefore students will first draw over existing 2D street view images in perspective using the Procreate application on an iPad to represent their urban design ideas. They will then sketch in 3D in immersion (Gravity Sketch) and finally draw over on a projected $360^{\circ}$ flatten image. This last step would allow a co-presence from students from both schools in a shared design experience.

\section{CASE STUDY AND ANALYSIS}

\subsection{Google Street View}

The first step of the analytical phase of the project consists in using Google Street View as a 2D photographic tool. This graphic media provides an introductory approach to the spaces and surfaces of an existing street. Students initially create a scaled map of the urban space to be studied in order to get a sense of the context and understand the nature of the urban fabric. The map will also be used to reference the locations of the different perspective views. Though the 2D perspective views extracted from Google Street View are not at eye level and the point of 
view is located on a road, the overall format of the representation system presented is similar to that of a person walking along a Street. The analysis would be composed of two series of Street views in perspective, one in each direction. The photos would then be displayed adjacent to a street map referencing the point of view of all the photographs. This method is consistent with a traditional and sequential photographic analysis of a space. It provides a description of a space along a dynamic axis by means of still photographs to evoque a spatial experience through movement.

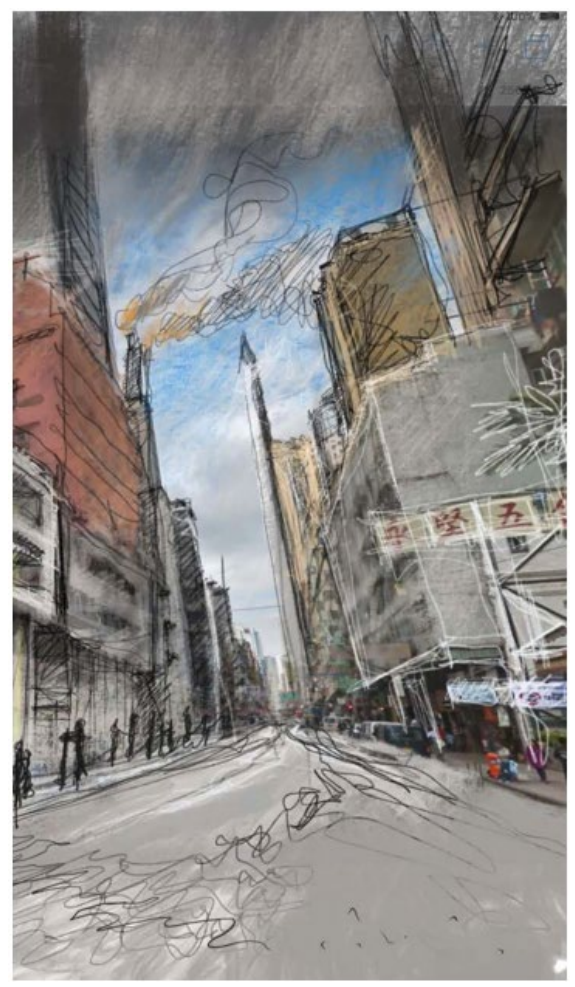

Figure 1. Sketch over Google Street View (Olivier Chamel)
This approach would inform students about the physical characteristics of an urban space, its scale proportions, materials and would also provide clues about the qualities of the overall spatial experience. This would also allow students to observe patterns in terms of building massing, surfaces and façade details and start to identify how these typologies may affect the human experience. Students will ultimately produce a graphic analysis of the street by means of annotated photographs and conceptual diagrams.

Based on the photographs collected during the initial phase of the analytical study, i.e., the Google Street View analysis, students will be given the opportunity to draw over or sketch over the street view photographs. The process is simple and consists in sketching in layers over the original image in order to create new building masses and possibly modify the existing urban fabric. A number of drawing Software or applications are currently adapted to this exercise and we have chosen the Procreate application with an iPad Pro and i-pencil. Typically students would use one layer to create a line drawing in order to delineated new urban patterns and massing while using two or more layers to apply color either as new built surfaces or to cover or modify existing buildings.

One purpose of this exercise is to provide a pre-existing environment, the street view photographs, as a way for students to be mindful of the existing urban context as they are exploring design ideas. This

process involves freehand sketching but because it is digital it allows students to continuously edit their work until they are satisfied. They can create new layers, delete existing one and move layers to the foreground or background of the drawing. We have found this method to be conducive to developing numerous an interesting urban design ideas as it is flexible and provides drawing guidelines, which the current generation of students appreciates as their freehand drawing skills may be limited. 


\subsection{Drawing on a 220 degree screen in co- presence}

Immersive environments have now a long history if we consider panoramas as the first immersive devices. The first panorama was invented by Barker in 1787 and received many improvements associated with technological advances such as photography, electric light, automated machines and even movies. One can find examples of immersive images at a large scale in movies, an early example being the Napoleon feature film from Abel Gance in 1927. More recent applications include theme parks such as Disney World or Universal. Nowadays digital technology has made considerable improvements and it is relatively easy to create convincing immersive environments by using several video projectors (Lescop-2017-2019).

For three or four hundred dollars, it is now possible to buy a fairly good $360^{\circ}$ camera. These types of camera are equipped with two $220^{\circ}$ lens, which instantly create a $360^{\circ}$ image at a resolution of $4 \mathrm{k}$ for the most standard models. Controlled with a smartphone the camera creates an equirectangular image, meaning that the sphere is mapped on a 2.1 rectangle. It is then possible to redraw this image in two different ways. The first one consists in drawing directly on the flat image, though it typically inlvoves geometric deformations from the sphere being flattened on a flat rectangle. Software such as Panopainting, which involves a real 360 VR Painting constitute an improvement from the original set up. The equirectangular image is remapped on a spherified cube that eases the redrawing.

Since 2012 we use panoramic immersive devices to work in co-presence. It means that students together or students and professors can have a $360^{\circ}$ drawing or photo projected around them and work on it. The first immersive device we had is the Naexus. The Neaxus was a $220^{\circ}$ cylinder screen of $15 \mathrm{~m}$ long and $2 \mathrm{~m}$ height. Any software could run on this device and was so very easy to project an image around the student(s) and design with a regular tablet or even a mouse.

The Naexus screen is like a huge computer desktop. Sitting together, students and their
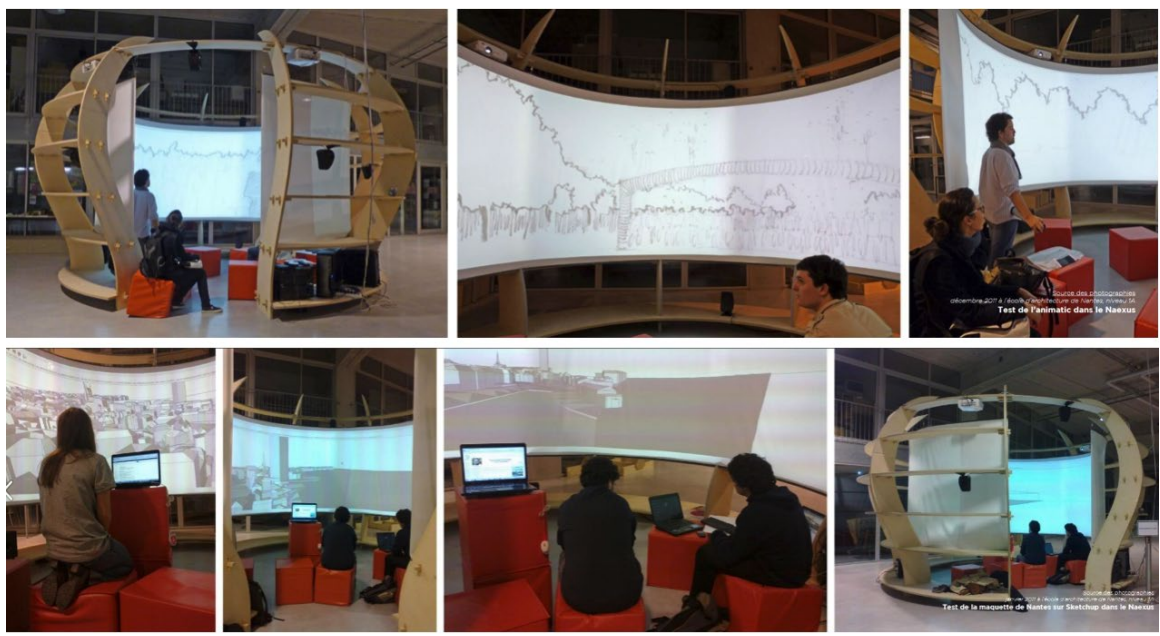

Figure 2. Drawing at $220^{\circ}$ in the Naexus (photos Laurent Lescop) 
tutors can experiment shapes and spaces drawn in 2D but projected on the curved screen with a huge feeling of immersion. The Neaxus is a straight forward device, which does not require extra software to work. Sketchup, AutoCad, Photoshop are naturally used and someone just needs to put a tablet, a mouse and a keyboard in the center of the device. For four years we have been using the Naexus as a very effective collaborative design tool, until we could have a better solution.

\subsection{Photogrammetry: flattened 3D images}

Drawing on a panoramic screen allows designers to create in a real-time interactive environment. The relationship between professor and student is modified because the design work is created side by side as opposed to a pin-up where the work is evaluated after completion. Pedagogical improvements are significant and have been measured by the John Gero research team at UNC Charlotte and by Julie Milovanovic in her PHD defended in 2019. (Milovanovic 2019)
After the Naexus experiments, two major improvement have been possible: on one hand the increasing power of graphic cards create a real "real-time" experience with a complex 3D model and on the other hand the possibility to survey any kind of environment at no cost. This has been made possible with photogrammetry. Photogrammetry consists in using the parallax between two images to retrieve the 3 rd dimension. One of the first statement of the technique can be found in 1893 with the creation of "metric archives". Scheimpfiug (1865-1911) was the first to articulate the grounding rules of photogrammetry: "The identification of three points in a couple of photographs is enough to determine the absolute position of the couple". Photogrammetry has long belonged to the field of land planners and aerial cartography. The development of photogrammetry is strongly linked to advances in computer science and online calculation services brought about by the spread of the Internet. Nowadays photogrammetry is progressively getting integrated to BIM models. According

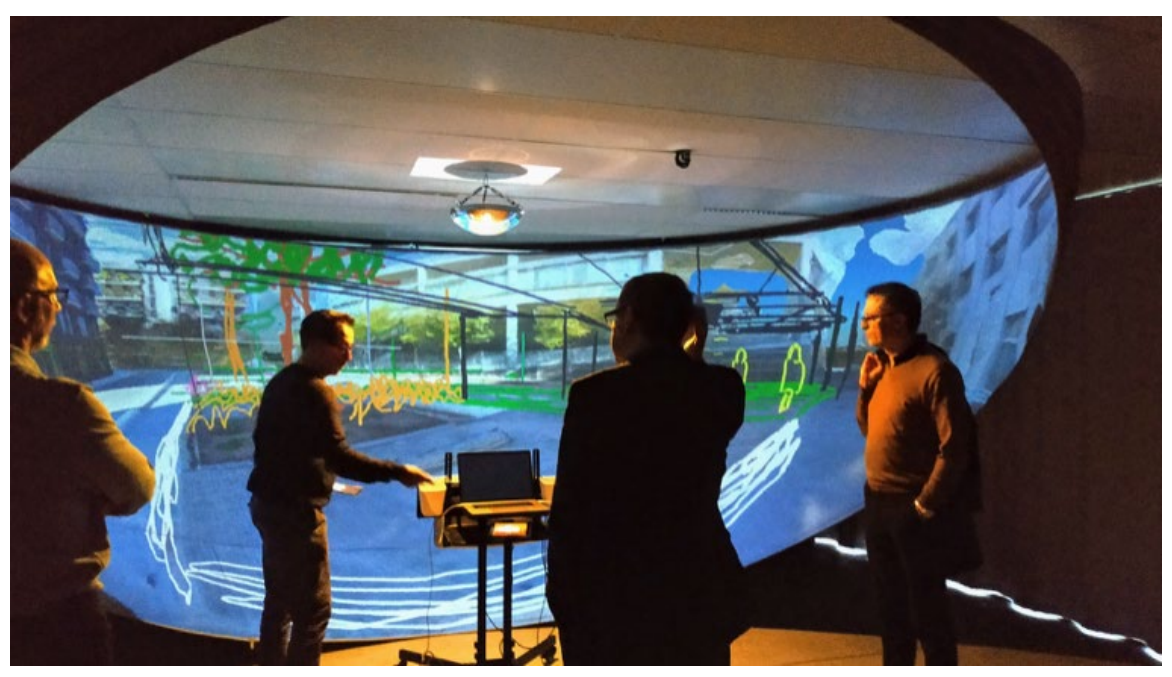

Figure 3. Drawing on a 3D photogrammetry with Tomas Dorta's Hive-3D in Nantes (photo Laurent Lescop) 
to H.Marcher ${ }^{1}$, further scanning systems will involve the fusion of photogrammetry and lasergrammetry. Cloudpoints will be made out of the correlation of thousands of photographs, or from several sensors or from Light Detection and Ranging (LIDARs), a surveying system that measures distance to a target by illuminating the target with laser light and measuring the reflected light with a sensor.

The acquisition process can be described in three steps. Initially the photo shoot is conducted with $60 \%$ overlay and as far as possible perpendicular to the target surface. When photographing a building, it is better to have a pole, as high as possible to take details that might be out of range. Secondly the collection of photographs is aligned in a 3D space, using a specific software such as MetaMesh or Autodesk Recap. The position of each shot is determined by the camera alignment. From these positions every single pixel is located on an xyz axis creating a dense colored cloud point. This cloud point is then transformed into a mesh thus creating a polygonal colored model. The final step consists in extracting the color information to create a texture map. It is then possible to work from this textured model. The mesh is imported into a 3D software like Blender or 3DsMax to be simplified and then to be reworked, transformed and augmented. It is then possible to add some geometries on the existing structure. It is easy to draw shapes and volumes on top of the mesh given by the photogrammetry. This 3D sketching allows to test the first raw ideas before diving in a more precise and complex design.

Drawing over a 3D environment built with photogrammetry requires a specific device to be fully effective. The best one we've been working with is the Hive-3D invented by Tomas Dorta at the Univerty of Montreal - Hybridlab (http://hybridlab.umontreal.ca). The Hive-3D is a $180^{\circ}$ portable screen that allows to sketch in the 3 dimensions. With a single IPad using the tablet's gyroscope correctly oriented in space, the student can perform a freehand drawing, add objects, copy/paste. When finished, the sketch can be exported and reworked. The Hive-3D is able to display in real time very large or complex models such as those we can get from a laser or photogrammetric survey.

\subsection{Immersive VR environment}

The next step we are currently testing is the full immerged sketching experience. In that regards the recently released HTC Vive is offering impressive new capabilities. The HTC Vive is a headset for virtual reality which allows the user to move, walk and twitch. The device is sold with TiltBrush, a software that allows to paint and draw in a 3D space. With TiltBrush the user does not paint on a canvas anymore but literally in the air so it is then possible to walk through the painting. Following TiltBrush came Gravity Sketch which is more dedicated to platonic shapes, 3D models and lights. With Gravity Sketch it is now possible to import a 3D model, (our simplified photogrammetry for instance) and work at full scale to create virtual 3D spaces, additions, shapes and so on. Before Gravity Sketch, building in 3D was made possible with a special addition of the Unreal Engine. A virtual library of shapes and objects was available to create in real time. Gravity Sketch is only one of the softwares capable of doing this. Even Sketchup has a virtual component that can be manipulated in real time either at the scale of a model or by moving inside a building.

We started to experiment two things with our students. First sketching on a 3D model using TiltBrush. With this app it is literally possible to sketch in 3D on an imported model (which shall be light) and have the possibility to walk around, and freely draw details, additions, comments in real time. With Gravity Sketch, the user manipulates real geometry and is able to process a real technical design with shapes, curves, lines, imported models and much more. The very innovative way to work is given by the 


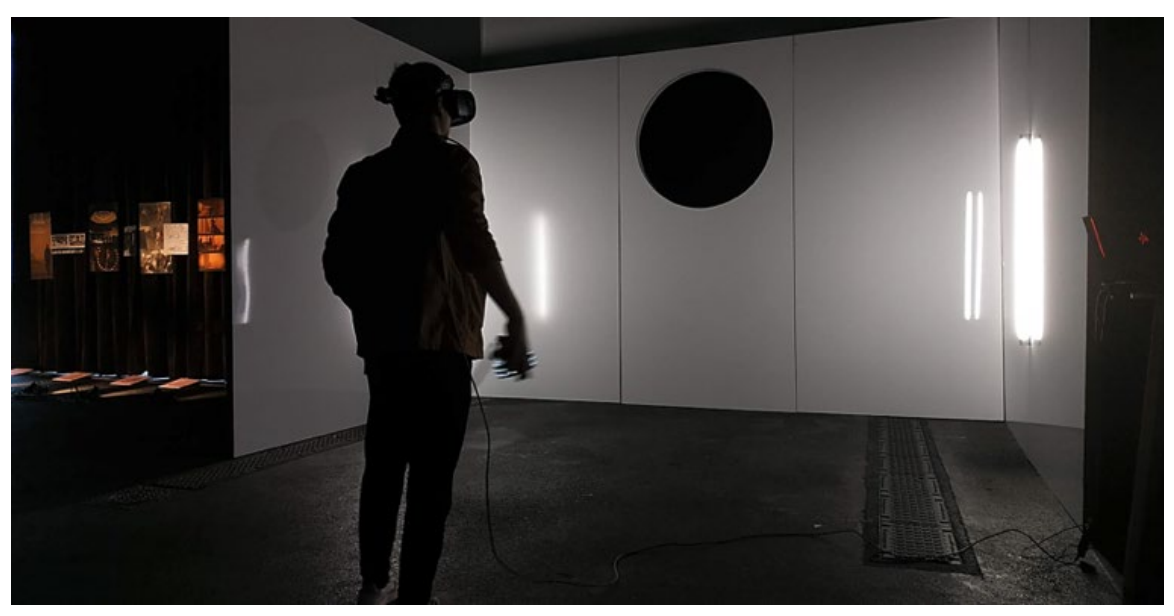

Figure 4. VR design in a real built neutral environment, this neutral environment is than virtually augmented.

possibility to modify the model's scale on the fly and have a scaled model in the hand and then expend it and walk in a real scaled model. We know that we are at the very beginning of VR/AR work and we are just waiting to have more collaborative tools to be in a real process of sharing the design and knowledge.

\section{CONCLUDING THOUGHTS}

Project visualization at full scale and in real time can considerably impact the design process of an architectural project. It is widely accepted that sketching is a quick and efficient exploratory design method because of the direct hand/brain connection and has proven to facilitate creative thoughts. Though sketching does not necessarily have to involve paper as a medium. Some of the latest VR goggles offer sketching tools, which are at least as fast, flexible and accurate than traditional pencils. The paradigm change consists in the fact that sketching does not occur on a 2D surface anymore but rather directly in 3D. Therefore this implies that students have to familiarize themselves with a new form of perspective drawing at full or reduced scale in a real space. Because of our perceptual stereotypes associated with 2D representation, 3D sketching can produce distorted creations, which may take some learning and adapting. One can wonder if we should go beyond the question of parametric design and start to include real world data in the design process. This is especially pertinent as architecture and design is viewed more and more as an integrated process including such notions as sustainability, spatial quality and systems along with the development of meaningful concepts. The ability to move around freely in the virtual space of a full-scale building or in a 3D model under construction should not be perceived as a limitation but rather as an opportunity to empower architects. This would equip them with powerful tools and ultimately help them make meaningful decisions in an increasingly complex design environment. We see value in the tools and processes discussed here because we believe they can positively contribute to the definition of a contemporary design process. 


\section{REFERENCES}

Laurent Lescop. Sep 2017, 360 vision, from panoramas to VR. ENVISIONING ARCHITECTURE: SPACE / TIME / MEANING, Tom Maver, Paul Chapman, Christopher Platt, Victor Portela and David Eaton, Glasgow, United Kingdom. pp.226232.

Laurent Lescop. 2019, Topologies de l'immersion - Études digitales. Etudes digitales, Classiques Garnier, pp.21-52. <10.15122/isbn.978-2-406-09288-9>

Julie Milovanovic. 2019, Exploration de la pédagogie du studio de projet d'architecture : Effet de l'écosystème de représentations du projet sur la situation de la session critique. Education. École centrale de Nantes,

Y. E. Kalay, 2004, Architecture's new media: principles, theories, and methods of computer-aided design. Cambridge, Massachusetts: MIT press.

R. Grover and A. Wright, 2020, "National Design Studio Survey: Initial Results."

D. Oprean, 2014, "Understanding the immersive experience: Examining the influence of visual immersiveness and interactivity on spatial experiences and understanding.", University of Missouri-Columbia.

S. Boudhraa, T. Dorta, J. Milovanovic, and D. Pierini, 2019, "Co-ideation critique unfolded: an exploratory study of a codesign studio 'crit' based on the students' experience," CoDesign, Feb.

T. Dorta, G. Kinayoglu, and S. Boudhraâ, 2016, "A new representational ecosystem for design teaching in the studio," Des. Stud., vol. 47, pp. 164-186.

L. Caldas and M. Keshavarzi, 2019, "Design Immersion and Virtual Presence," Technol. Archit. Des., vol. 3, no. 2, pp. 249-251,

J. Gero and J. Milovanovic, 2019, "The situated function-behavior-structure codesign model," CoDesign, no. August,
G. Goldschmidt, 2014, Linkography: unfolding the design process. Cambridge, Massachusetts: MIT press.

P. Pauwels, T. Strobbe, J. Derboven, and R. De Meyer, 2015, "Conversation and Critique within the Architectural Design Process: A Linkograph Analysis," in Design Computing and Cognition, pp. 135-152.

H. Sopher, D. Fisher-Gewirtzman, and Y. E. Kalay, Jul. 2019, "Going immersive in a community of learners? Assessment of design processes in a multi-setting architecture studio," Br. J. Educ. Technol., vol. 50, no. 5, pp. 2109-2128.

S. Buckingham Shum, R. Ferguson, and R. Martinez-Maldonado, 2019, "HumanCentred Learning Analytics," J. Learn. Anal., vol. 6, no. 2, pp. 1-9,

T. Dorta, G. Kinayoglu, and M. Hoffmann, 2016, "Hyve-3D and the 3D Cursor: Architectural co-design with freedom in virtual reality," Int. J. Archit. Comput., vol. 14, no. 2, pp. 87-102.

"AAU-CRENAU dévoile la maquette virtuelle de la plateforme CORAULIS au salon Innovatives SHS 2019 du CNRS," [Online], 2019, Available: https://aau. archi.fr/actualites/2646-le-saloncnrs-innovatives-shs-a-lille-avec-laparticipation-aau-crenau/.

A. Bouattour, 2019, "L'écrin de Coraulis, morphogenèse et conception de l'enveloppe d'un dispositif immersif Amin," 




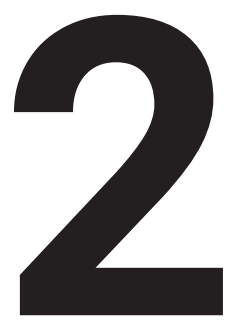

BLOCK 2: LIVING IN URBAN LANDSCAPES 


\title{
PAPER \#2.01
}

\section{GETTING A GRIP ON FICTION: GRAPHIC NARRATIVES AS STUDY SITES FOR URBAN DESIGN}

\author{
Carmina Sánchez-del-Valle ${ }^{a}$, V.M. Price ${ }^{b}$ \\ aHampton University, Hampton, Virginia, USA \\ ${ }^{b}$ Independent Scholar, Missouri, USA
}

\section{ABSTRACT}

This essay argues for the value of examining graphic narratives - comics and graphic novels - in which city spaces have roles affecting the urban lives of the characters. In them, characters make evident how they consider and use urban spaces. Graphic novels point to meanings urban spaces have for a diversity of occupants. They offer wider insights into the public's views of what it means to live in urban spaces, and provide portrayals of its perceived functions and dysfunctions. Because they present perceptions of public attitudes and uses of urban space, graphic novels are a resource for designers on the impact of digital technologies on the non-use, evolving use, and usefulness, if any, of these spaces to satisfy the human need for faceto-face interaction. What do graphic novels indicate the new ways of communicating have done to repurpose that realm? Do they show urban spaces of a new kind or form, with greater purpose and more enabled by smartphones, the Internet of Things (IOT), and social media? And what directions could such views be suggesting the design professionals consider for the coming, or going city?

A selection of graphic novels, published in the last ten years, was searched for clues of urban space use, communication and sensibilities that may be emerging in a digital age. The graphic novels are named and their urban space concerns or criticisms are listed and summarized. These are themes that question whether or not 'urban spaces are designed for people'. Life as presented in these novels appears to counter with the notion that 'human action re-identifies and alters the urban space function(s)'. The themes are: 1) surveillance and freedom; 2) gathering and dispersal; 3) order and disorder; 4) solidarity and confrontation; 5) intersections and encounters; 6) strangers and acquaintances; 7) anonymity and celebrity 6) isolation and fellowship, 7) peace and violence; 8) sensibility conveyed with views in and out; 9) sensibility conveyed with views from above and from below; 10) sense of safety and of unease; 11) digital and remnant analog technologies. Artifacts, interactions, and events discerned are compared with images selected from Frans Masereel's seminal 1925 graphic novel The City.

\section{KEYWORDS}

Digital communication; Frans Masereel; graphic narratives; urban space.

\section{INTRODUCTION}

The graphic novel may seem, to some professionals, a too casual means through which to face criticisms of the urban spaces and urbanscapes designed by them, or created as a by-product of their enveloping structures. The graphic narrative may appear an unscholarly reference or source, anachronistic in its use of media, and superficial. But graphic narratives can be and do serve as the 'visual' mouthpiece of a public unhappy with the dysfunctional, threatening, or obsolete urban spaces they must traverse. 
In these narratives urban space problems are typically highlighted by staging the stories' worst events within them. The images link desired or detested urban spaces to the event(s) that they attract.

Illustrating urban space issues in a fictional story-telling format is not unique to today, but became more widespread with the onset of mass media in the 20th century. Frans Masereel is one of its precursors. He studied in Paris, worked as a newspaper political cartoonist from 1917 to 1920 in Geneva, Switzerland. In this capacity he learned to work fast "creating a drawing related to a daily event." (Berona 2007) In 1925 Masereel published the 'wordless' graphic novel The City. It is not his first graphic novel, or his best known'1. However, it is the one he dedicated explicitly to the city. In an interview he said, an artist "can also be a witness to the age in which he lives [...] For me it cannot be otherwise." (Cohen 1977) Authors of today's graphic novels and comics that are set in the city appear to agree.

In The City the celebrations and criticisms of the urban spaces were visually glaring rendering words unnecessary. His work has been described as "dramas of class struggle, of the degradation and thrill of urban life" (Lanier, 2007) that "expressed his horror of war and capitalism."(Bernière 2018) The novel opens with a veduta of the city as seen from a hill by a man, and closes in the city with a view of a woman looking out of a window into a starry sky - one infers a desire of the novice to venture into urban space, and one expresses the yearning of one of the entrenched to escape it. The city is presented as a series of scenes moving the viewer back and forth from interior to exterior. Building façades delimit the action outside. Inside people concur with their own kind only. Late at night in a street the solitary wander, while somewhere from a tall building's windows, the city is alive with smoke flowing out of tall chimneys. Everyone moves hurriedly crisscrossing the path of the crowd, horses, vehicles, and trains. Masereel's visual commentaries are stark. His work is as insightful and precise as the muckraker journalists of his time, equally blasting the city for contempt-by-negligence of its own denizens. Its impact on urban space design considerations is worthy of further research.

\section{STUDYING THE CITY THROUGH GRAPHIC NARRATIVES}

It would benefit the work of design professionals to appraise and question their own work and agendas for a project in and of the city by considering the perceptions and sensibilities of urban spaces presented in graphic novels. In particular, designers should look at the following three public concerns raised by graphic novels. First, corrections to a designer's point-of-view are offered bringing it down to the users' level. For example, a very open urban plaza shown in a panoramic view from above may end up being rarely used for congregating or socializing, because the people experiencing it below feel way too exposed, vulnerable, and surveilled. Second, the designer sees building projections and columns providing shade to the pedestrian. Yet, the graphic narrative shows them concealing surveillance, or an attacker. Third, the design provides a rhythmic arrangement of benches and sculptures in and around a plaza. The graphic novel shows not a soul in the plaza, but people sitting outside surrounding coffee shops, or standing with their backs to buildings at the street surveilling the plaza. These sequences of images don't "point out the meaning of something", but rather "point in a certain direction that by itself requires interpretation." (Gadamer 1986, 68-69)

The five graphic novels selected for study present criticisms and concerns of urban spaces in today's cities. Most are in the

'Passionate Journey (1918-20) is Masereel's best known work. Germany banned his books in 1933. By this time he had published five. Joris van Parys notes that "up until twenty years ago, Masereel's work remained virtually unknown in the U.S. and U.K." Cohen writes that it inspired contemporary graphic novel artists such as Peter Kuper, Eric Drooker, and Art Spiegelmann. 
Western hemisphere. The criteria for selection was based on the following: a) publication must have been within the last ten years to access the most contemporary views, and to coincide more or less with the introduction of mobile media and pervasive use of social media2; b) the story must be fictional to allow invention; c) urban spaces must play a significant role in the story; d) the places depicted must be recognizable as urban, and be presented in more than one frame; e) objects shown must be at the scale of the frame; f) there must be a direct correspondence between action and space credible in a city, no matter how exaggerated, or fantastic; g) they must be about the present and a near future.

While the graphic novel selection limits this discussion on urban spaces, there remains a growing scholarship on the subject, with work disseminated across national boundaries. Markers ${ }^{3}$ of the start of this expanding body of work are: a) the 2010 exhibition "Archi \& BD, La Ville Desinée" presented in Paris; b) the 2010 collection of essays edited by Ahrens and Meteling Comics and the City: Urban Space in Print, Picture and Sequence; c) Mélanie van der Hoorn 2012 Bricks and Balloons: Architecture in Comic-strip Form; and, d) Enrique Bordes 2017 Cómic, Arquitectura Narrativa.

\subsection{Building common ground}

This exploration assumed graphic novels by the 'others' would regard general city terms the same as design professionals - the city is a dense human settlement where many forces are at play, where exchange, collaboration, and sharing are required in some form for it to exist. A large city that stretches out into the territory surrounding it is a metropolis. Urban is not only used to refer to city, but also to life in town and village. These are all places where there are congregations of people not necessarily related by blood ties, but who live together and share spaces and services. Public space is a type of urban space. In the historicist language of New Urbanism, streets are corridors connecting urban rooms, plazas and squares. Here we use cityspace and urbanspace to refer to amalgams of scenes, activities, buildings, spaces, things, people, and other living beings. Cityscape usually refers to a veduta, a painting or sketch of a scene or panoramic view of a city mostly from a distance.

Ahrens and Meteling contend that from a historical perspective "comics are inseparably tied to the notion of city." $(2010,4)$ It was for the widely read newspapers of the early 20th century that comics came into being. Sociologist James Donald discussing the impact of mass media on the representation of the city of that time, calls newspapers a "pedagogic medium that compensated for the impersonality and overstimulation [of the metropolis]." (2008, 50) Donald reminds us that "mass newspapers packaged a view of the world," and "encouraged and managed the urban state of mind." (49-50) Brian Longhurst offers a contemporary perspective with a quote from Nick Couldry: "the media frame our views of reality, they sustain the frame in which our experiences of the social occur." (2000, 115) Henri Lefebvre argued space is a product of social practices where social space is "a diversity or multiplicity of spaces irreducible to a 'form' imposed upon phenomena, upon things, upon materiality." $(1992,27)$ Comics and graphic novels can offer accurate and rich visual narratives for the study of the concept of the city, both in terms of form and way of life. Because of the multiple formats and perspectives, graphic novels can present multidimensional views with which to construct, or reconstruct life in an urban landscape.

\footnotetext{
2 The World Wide Web was established in 1991, Skype beta version launched in 2003, Facebook started in 2004, iPhone was presented in 2007, and in 2010 the iPad was introduced.

${ }^{3}$ Also of note are the articles that have appeared in Domus, and Abitare. In particular those by Caterina Grimaldi reviewing work from Africa to the Middle East, to Europe and Asia.
} 


\subsection{The city in graphic novels and comics}

The cities in graphic novels ${ }^{4}$ are products of the imagination placed in an invented past, present, or future. Yet, they are contexts for discussing the city as it resides in the very real social imagination, or collective consciousness. Graphic narratives make active participants out of place details and urban spaces that are more subtly portrayed in text.

Berger and Mohr call images arranged to tell a story a montage. Their ordering is not sequential, or necessarily chronological, because "all stories are discontinuous."(1995, 285) However, they can be understood because "the narrator, the audience, and the protagonists of the story have a tacit agreement about what is not said" (285), and can "enter the narration becoming part of its reflecting self."(286) Berger and Mohr look at the story told as a mirror, where the viewer not only sees the characters, the places, and the narrator, but also sees themselves.

The graphic novel combines sensorial and social experience within a visual construction. Its frames act as 'mirrors' on which to observe the city. Henri Lefebvre comments on the concept of the mirror:

In and through the mirror, the traits of other objects in relationship to their spatial environment are brought together [...] Into that space which is produced first by natural and later by social life the mirror introduces a truly dual spatiality: a space which is imaginary with respect to origin and separation, but also concrete and practical with respect to coexistence and differentiation. $(1992,186)$

The graphic novel's ability is to communicate an imagined place in an assembly of images that are not necessarily in sequence. The graphic novel brings to the viewer-reader's attention the larger points by the number of frames provided and images rendered, and by the pivotal spaces detailed therein. It gets the reader/viewer closer to the provisional aspects of a place by showing it has been occupied and recently used; for example, with a frame focused on the cigarette butts or gum marks left on sidewalks, or at block corners ${ }^{5}$. The reflected image requires interpretation, and may raise issues not heretofore considered by the reader/viewer.

Graphic novels are a mapping of their imagined city. The map highlights places of value for the story, be it a location or historical marker that serves as an orientation device, or the setting for an event. The city is shown as skyline, as a perspectival view of a street defined by a variety of objects and people depending on the setting or an elevation, a bird's eye view of the city or vector, a map of the city, a view from a window, or from a roof. Objects presented indicate how the city is perceived. Some graphic novels use the panoramic view, or 'veduta' to quickly express the city's perceived character, then take the reader/viewer to the street to carry that character into the story. Neuroscientist Colin Ellard argues that we don't understand our world geometrically, but rather connect "images of places with stories that link one image to another, [...] as a series of connected nodes." $(2009,11)$ Graphic novels exploit this form of navigation to allow us - the viewer/reader- to occupy the space of reality perceived and imagined.

For example, in the seminal graphic novel City of Glass ${ }^{6}$ set in New York City, walking always has a physical destination. We see the character walking from W 107th Street to E 69th Street and Madison Avenue, and we know this because the street signs are shown. The same kind of sign identification is provided where we see the main character exit a subway station with the numbers 1, 2 or 3 subway shown; and

\footnotetext{
${ }^{4}$ The term comics is used to refer to stories usually published as a series, recounted using graphics and text in a mutually supporting format. The narratives can be short stories, novellas, and novels. The comic strip and the cartoon (single frame/single plate) have not been included in this discussion.

${ }^{5}$ This is one of William H. Whyte's techniques.

${ }^{6}$ City of Glass was authored by Paul Auster as a written novel published in 2005. It was transposed into graphic form by Paul Karasik and David Mazzucchelli.
} 
the narrator has indicated he is going to $\mathrm{W}$ 96th Street. In the next scenes the character follows a person around the neighborhood to go to Riverside Park and back for several days. We see the character's walking drawn in a map to explain where he has been. In these sequences the viewer/reader not only maps the area with the protagonist, but experiences it in different conditions (day or night, rain or sunshine) and from various perspectives. Taken together they give us the image of the district through the eyes of the protagonist. The character wanders through the city stopping at the United Nations' park to write on his notebook about the people he has seen that day. The viewer/reader can recognize the UN Assembly and tower buildings. In this New York there are wide boulevards with trees in the middle, and treeless narrower streets where buildings face the sidewalk with few interruptions, except for stoops marking the entrance to urban villas, and awnings for hotels and other establishments. The protagonist demonstrates that at W 69th Street one can sit in a service entrance for days, and nobody will bother him. The urban furniture are sign and light posts, traffic posts, mail boxes and fire hydrant, phone booths and wire trash cans. Water tanks can be seen on the roofs of some buildings. Buildings are densely packed in blocks, and their façades of different styles and heights. While sitting on a bench in a boulevard park one can see people as they come and go, undisturbed by any of them. The park located within the neighborhood offers a view of a river, has a thick tree canopy and a rocky landscape. Most people move through the park, some on bikes, a few sit on long benches. The park is open to all, and one can feed the pigeons. This is the material that provides a physical impression of the city. The reader/viewer comes to understand they themselves are the surveillance character of the story; seemingly innocuous actions and places are being watched from somewhere by someone in a 'city of glass'.

\subsection{Discussing urban concerns and criticism of the contemporary}

The five graphic novels and comic series selected for discussion are in the order in which they were published: Supermarket: Cash Money Edition (Wood and Donaldson 2009), Iron Man: Ultimate Wars (Ellis and Kurth 2010), Strange Attractors (Soule and Scott 2013), War of Streets and Houses (Yanow 2014), and Estamos Todas Bien (Penyas 2017). All are graphic novels except for Iron Man: Ultimate Wars, a collected comic series. Three are set in New York City, one takes place in a city in Canada, and another in Spain.

These are the urban space concerns and criticisms raised in these novels:

1) Surveillance and freedom;

2) Gathering and dispersal;

3) Order and disorder;

4) Solidarity and confrontation;

5) Intersections and encounters;

6) Strangers and acquaintances;

7) Anonymity and celebrity;

6) Isolation and fellowship;

7) Peace and violence;

8) Sensibility conveyed with views in and out;

9) Sensibility conveyed with views from above and from below,

10) Sense of safety and sense of unease;

11) Digital and remnant analog technologies.

In Supermarket: Cash Money Edition all of the urban space/use concerns listed are raised. The setting is an alternative near future in New York City, or in a place quite akin to it. Two families control all the money in the city, and therefore access into every space. The main character explains: "Everyone calls [the city] the supermarket. It's quite a shock if you aren't used to it" - "Cash rules everything around here." This character is the key to free the city from this tyranny. She lives in an expensive gated neighborhood in a suburb from where the city's skyline can be seen. But the story takes place in the city, which 
is divided into sectors. The tallest buildings and all luxuries are in the city-center district. Somewhat like Times Square, it is framed by skyscrapers and immense lighted signs and billboards. It is crammed with people all dressed in dark gray. Only the wealthiest can go up to the tallest building to view the city. People of different economic strata don't mix. Buses and underground metro connect the lesser districts. Those with means use their own cars, or take taxis. Supermarket is a highly monitored city, where everything has its place. The street is for driving.

In Iron Man: Ultimate Wars the urban space/ use concerns raised are, again, all of the items listed. Manhattan has been flooded "but Iron Man remains vigilant". The dystopic city is a well established character in superhero comics. The first plate is a wide street level view showing the devastation: flooded cars, a twisted light post and looming above a tall building with intact commercial signs and broken windows. There is no life in the streets of Manhattan. The way to check on the damage is through an electronic map and cameras. However, in London demonstrators are out around Trafalgar Square. The viewer/ reader knows it is London because one of the first frames in the sequence is an iconic panoramic view of the Thames framed by the Millennium Wheel. In the center, the Westminster Bridge, and on the edge the Big Ben Clock Tower. The protesters are shown in the screen of a large TV display carrying signs; and, later from above and at close range street level as they are attacked by robots. The city is the stage where Iron Man destroys the robots. Compared to Masereel's city, this one has an invisible and pervasive system for monitoring action on the street.

In Strange Attractors all items noted in the list of urban space/use concerns are also raised. This novel appears to be a reaction to superhero stories. One of the main characters is a mathematician that has spent his life mapping by hand the connection between apparently insignificant events. He recruits another mathematician to help avoid a major disaster that he has predicted will destroy the city. In this novel the main characters move in the city from neighborhood to neighborhood, using the subway or walking. They sit to talk in parks where there are others playing chess, talking, watching. Landmark views are used to locate the action. They produce maps of the city that have no regular grid. In fact, for the story the authors created two maps. One was formed by combining the patterns of "tangled clumps of hair, images of skin diseases, and rat kings." They overlaid "lightning storms, the movement of electricity across nodes, and what that might look like when out of control." For the other map they used patterns of lines as if they were "highways, robot parts, connected nodes, and wiggly lines as if a loose weaving." In this visual narrative there are smartphones and computers but digital media do not provide for the "interface" between social spheres that Martijn de Waal refers to in City as Interface. The more significant exchanges between people happen indoors. Outdoor spaces are mainly transitional, except for parks. Large crowds out and about are absent. Surveillance of the spaces through which they move may be happening, but because the characters' actions are so ordinary, no red flags are shown raised. And apparently, any surveillance is visual only. Listening is not inferred.

War of Streets and Houses is partly autobiographical, and a very brief treatise about the city. It raises all urban space/ use concerns. It contemporizes Thomas Robert Bugeaud's work of the same title, and discusses it in contraposition to David Harvey's Right to the City. It uses line drawings with zones of gray and black. The story is about a student that decides to protest against an increase in tuition costs. In the beginning the main character tells the viewer/reader that in their childhood there were no Google maps, which now give directions to paths that at that time "they knew were impassable." Views move to the character in the street, to 
a demonstration where many have masks on their faces, and hoodies. The public space where the demonstration takes place is surrounded by austere blocks of buildings. In one frame a traffic light, in another a sign on a post. Next the main character reminisces about living in Paris, "the first real city I ever lived in." There is no background for Paris as the character stands alone in the frames that form the sequence. The visual narration continues the exploration of the meaning of city, and of its form commenting on Foucault's 'disciplinary space,' followed by a sequence where demonstrators are confronted by the police. In the next frames the police barricade the demonstrators using chain-linked fences. Later, the character watches the films $\mathrm{La}$ Haine and The Battle of Algiers to muse about knowing "so few of the names of the streets where I grew up." The novel closes with sideby-side plates of windows showing views to the outside. In one, the reader/viewer can see wires hanging from an electric pole. In the other the branches of a tree are shown. The narrator explains they had expected to return to the place of their childhood - to the woods - but they probably would not.

In Estamos Todas Bien all urban space/use concerns are raised except for surveillance and freedom, order and disorder, peace and violence, and safety and unease. Two grandmothers from two different villages move to the cities closest to them. One moves to Madrid, the other to Valencia. Ana Penyas celebrates the lives of her grandmothers from the time of their youth, to their journeys from village to the city, and then finally to when their apartments empty as the children move away to other places. Land and mobile phones are the link to their progeny, who visit on special occasions. Doors leading outdoors play more of a role than windows. The rhythm of life is dictated by the time to go outside and the TV shows. In this narrative the city is occupied by the elderly. Only they stroll the streets of their neighborhood, buy in the shops, eat in the cafes, and sit in the plazas. Looking from the outside one can see in the balconies a person, a bicycle, a potted plant, and an empty chair. Old friends meet outside their apartments. TV personalities become virtual neighbors to gossip, and to worry about. If there is surveillance, surely it is the elders doing the watching. The scenes imply the city environment has become so static, there is nothing of interest to a growing age, so why bother.

\section{CONCLUSION: WHAT EMERGES?}

As noted at the outset, this was an exploration into graphic narratives of urban spaces imagined by others who are not architects or urban design professionals; about how had they presented their views, concerns and attitudes towards inhabiting the public realm through their characters' interactions in city spaces. Masereel showed early on the eyes of others can reflect views on the problems of urban spaces that those who design them should not be ignorant of, nor should they ignore. The intent was to uncover in their articulation of their views of the urban spatial experience, what may be emerging from this digital interfacing age. One expectation was people would be shown continuing their social civic exchanges and meetings in the public realm. Another was that graphic novels would show more action and interaction on the streets that now included characters using social and surveillance devices. Instead, those U.S. graphic novels investigated, including the ones discussed in this writing, envision an abandonment of public life, and rare reference to surveillance or drones. A sense of unease is implied when characters have limited exchange with the strangers they encounter in urban public spaces. Often the interaction shown among strangers is a fight, particularly in graphic novels with superheroes.

Those more insightful graphic novels flagged as exceptions to the sense of public realm abandonment are Supermarket and Strange 
Attractors. However, they infer or openly speculate on other threats waiting for people who venture into a city's future public spaces. Novels examined published by authors from countries other than the U.S. were Metro (El Shafee 2012), Estamos Todas Bien, War of Streets and Houses, The Spectators (Hussenot 2015), and PTSD (Singelin 2019). They imagined other issues of the coming alteration to public life in urban spaces and their consequent different uses. For example, they consider veteran's homelessness, space for children and for young adults, the silver city, opportunities for fellowship, and the privatization of the public realm among others.

What to make out of this? A disconcerting condition raised by many of the graphic novels and comics examined is how increasingly segregated people are in the digital-age urban. This 'fiction' is confirmed in recent studies showing the growth of the socio-economic differences coinciding with increased segregation of the population in the U.S. Does this signal the end of an 'urban public' that used to be forged by the open interaction among dwellers and users in the city's public spaces?? Other questions posed to design professionals in these graphic novels are: Is there anything design can do to counter the 'zombieness' of urban spaces, so devoid of human face-to-face interaction? Should we continue designing to bring back and maintain the active and safe, friendly 'use' of urban spaces that, in today's digital world, no longer attract? Or, should design professionals 'let go' of those 'old' lines and spaces of communication for human use, and leave them to the efficient private and public transport of people and goods. Who walks anymore in most cities anyway? Just service workers? Do they matter?

These are the more unambiguous issues of design raised by the 'others' in graphic novels and comics. T. F. Tierney wondered "how architects can meaningfully engage with change and shape this new world toward humanistic objectives." As we know, before a design problem can be addressed, it must be recognized, examined, and articulated. Do design professionals wait for 'others' to begin new uses of the remnant urban spaces of the city, to jump in with great ideas? The novels are flags waving from the fallow fields of whatever urban is left on the street now. How do we approach them ourselves, and with our clients? 7 In his book De Waal makes reference to Paul Goldberger, who argued that digital modes of communication adversely impact the
life of the street. 


\section{REFERENCES}

Ahrens, Jörn, and Meteling, Arno. 2010. Comics and the city: urban space in print, picture and sequence. New York: Continuum

Berger, John, and Mohr, Jean. 1982. Another Way of Telling. New York: Vintage Books. (1995 edition).

Bernière, Vincent. "Frans Masereel, le Dürer du roman graphique" Beaux Arts Magazine. Issue 42 (October 2018): 34-35.

Berona, David. 2007. Introduction. In Masereel, Frans. Passionate Journey: A Vision in Woodcuts. Mineola, New York: Dover Publications, Inc.

Cohen, Martin S. 1977. "The Novel in Woodcuts: A Handbook." Journal of Modern Literature 6, no.2 (April): 171-195.

De Waal, Martijn. 2014 The city as Interface: How digital media are changing the city. Rotterdam: Nai010 Publishers.

Donald, James. 2008. "The Immaterial City: Representation, Imagination and Media Technologies." In A Companion to the City. New York: Gary Bridge, Sophie Watson, eds. John Wiley \& Sons.

Ellard, Colin. 2009. You are Here: Why We Can Find Our Way to the Moon, but Get Lost in the Mall. New York: Knopf Doubleday Publishing Group.

Ellis, Warren, and Kurth, Steve. 2010. Ultimate Comics Iron Man: Armor Wars. New York: Marvel.

El Shafee, Magdy. 2012. Metro: A story of Cairo. New York: Metropolitan Books, Henry Holt and Company.

Gadamer, Hans-Georg. 1986. The relevance of the beautiful and other essays. Robert Bernasconi, ed. Cambridge, New York: Cambridge University Press. (1988 reprint)

Hussenot, Victor. 2015. The Spectators. London: Nobrow.
Karasik, Paul, Mazzucchelli, David, and Auster, Paul. 2004. City of Glass. New York: Picador/Henry Holt.

Lanier, Chris. 2007. "The 'Woodcut Novel': A Forerunner to the Graphic Novel." World Literature Today. Vol. 81 Issue 2 (MarchApril): 14-15.

Lefebvre, Henri. 1991. The Production of Space. Oxford: Blackwell.

Longhurst, Brian. 2007. Cultural Change and Ordinary Life. Maidenhead, Berkshire; New York: Open University Press, McGraw-Hill.

Masereel, Frans. 2012. La ciudad. Madrid: Nørdica Libros.

Penyas, Ana. 2017. Estamos Todas Bien. Barcelona: Ediciones Salamandra.

Singelin, Guillaume. 2019. PTSD. New York: 1 First Second.

Soule, Charles, and Scott, Greg. 2013. Strange Attractors. California: Arcaia.

Tierney, T. F. 2017. "Public Space Rewired." Architectural Review. Vol. 241 no.1439 (March): 5-12.

van Parys, Joris. 2019. "The 'Silent Novels' of Frans Masereel: Godfather of the American Graphic Novel," The Low Countries: Arts, April 7, 2019. http://www. the-low-countries.com.

Yanow, Sophie. 2014. War of Streets and Houses. Minneapolis: Uncivilized Books.

Wood, Brian, Donaldson, Kristian, and Robbins, Robbie. 2009. Supermarket: Cash Money Edition. San Diego, California: IDW. 



\title{
PAPER \#2.02
}

\section{TRANSESCALARITY, AN INSTRUMENT FOR THE SUSTAINABLE TERRITORIAL DEVELOPMENT}

\author{
Celia Izamar Vidal-Elguera ${ }^{a}$, Claudia Bengoa-Alvarez ${ }^{a}$, Cinthya Butron-Revillab \\ aPolitecnico di Torino, Turin, Italy \\ bUniversidad Nacional de San Agustín, Arequipa, Peru
}

\section{ABSTRACT}

Territorial planning is a component of the government's territory, which is in charge for its management according to political, economic, demographic, social, cultural and ecological criteria of society, (Council of Europe 1983) in this context, planning instruments are established where these criteria are determined from an integral process of activities projection. However, to address this topic widely and therefore understand and represent more accurately the character of the different phenomena that are linked to the interior of a given territory, we see ourselves in the need to consider scales of analysis different to the established geographical scales; therefore the principle of transescalarity is born, which allows to integrate systemically two or more geographical scales as well as the analysis of the relations between them, for example the local/global relationship. (Bonavero 2005) Consequently, this article presents a reflection on the theoretical and methodological approach that implies building common strategies with transescalar contributions from regional planning to urban-architectural planning in order to improve the territory control from its valuation, management and transformation from a sustainable perspective; evidencing its importance as it provides quality of life for this and future generations, as well as a coherent, equitable and geographically balanced social-economic development. As an example of this approach, we presented the case study of the regional planning of Piedmont (Italy), as well as an overview of the situation in territories that lack sustainable planning such as the region of Arequipa (Peru).

\section{KEYWORDS}

Transescalarity; urban-regional planning; sustainability.

\section{INTRODUCTION}

Territorial planning is a field that articulates and mediates the complex system of relations and interests that are established between the various disciplines and multiple factors that influence the development of itself, it is here where planning instruments that allow to manage the territory at different scales are available; also, over the years, territorial planning has been seen in the need to consider a development that protects the environment and guarantees the life quality of the citizens, emerging, in this way, sustainable planning. According to Carmona, the literature states that a fundamentally good design is sustainable, but this involves much more than simply reducing energy use and carbon emissions, instead it implies a much deeper basis where by linking theory with practice, considers how the sustainability principles impact in the range of different spatial scales and their links. Therefore, research has focused its search on the implementation of innovative instruments that allow to effectively relate territorial planning with sustainable design. 
Currently, in many cases the planning instruments are very limited and not very efficient, therefore, in order to understand and represent more accurately the character of the different phenomena that are linked to the interior of a given territory, we see ourselves in the need to consider scales of analysis different to the established geographical scales, since talking about scale it is not just give measure to things. As Folch says, changing scale is much more than enlarging or reducing, when we increase the scale, we don't see the same things to a larger size, but we see different things. This is how the principle of "transescalarity" arises, which allows to integrate systemically two or more geographical scales and the analysis of the relations between them.

Consequently, this article presents a reflection on the theoretical and methodological approach that implies building common strategies with transescalar contributions from regional planning to urban-architectural planning, in order to improve the territory control from its valuation, management and transformation from a sustainable perspective. To develop this approach, we have studied two examples oriented towards sustainability, such as the instruments of regional planning in Piedmont (Italy), and the approach of innovative urban-architectural tools; contrasted with the situational panorama in territories that lack sustainable planning as is the case of the Arequipa region (Peru).

\section{INSTRUMENT FOR THE ANALYSIS AND INTERPRETATION OF SUSTAINABLE TERRITORIAL DEVELOPMENT}

\subsection{Transescalarity}

Geography moves on several scales at once, from a smaller dimension such as a neighborhood, town or city to a larger dimension such as a region, country, continent or planet. To talk about scale, then, is not only to give measure to things, but also to understand and represent more accurately the character of the different phenomena (economic, social, cultural, political, psychological, etc.) that are linked within a given territory. As Folch states, changing scale is much more than enlarging or reducing; when we increase the scale, we do not see the same things at a larger size, but we see different things. (Folch 2003)

The specific contribution that geography can make to social research in a context of interaction and disciplinary integration is achieved by adopting a transescalar research perspective. (Bonavero 2005, 5) Transescalarity can be understood in two ways, the first is in a weak sense or also known as multiescalarity, which refers to the application of concepts and analysis tools at different geographical scales, going from one territorial scale to another; the second is in a strong sense, understood as a joint consideration of two or more geographical scales and the analysis of the relationships between them. (Ibidem)

To understand these two modalities, we presented some examples of conceptual tools that reflect the content of each type of transescalarity. An example of a transescalar tool in the weak sense would be:

$$
\begin{aligned}
& \text { The description and interpretation of spaces } \\
& \text { through the centre-periphery conceptual } \\
& \text { scheme: in this case a concept defined } \\
& \text { from a physical space is used [...] referring } \\
& \text { it to different analytical dimensions such } \\
& \text { as economic development, political power, } \\
& \text { cultural influence, etc. (Ivi., 6) }
\end{aligned}
$$

This conceptual scheme then, is an example of a concept of a multiescalar nature since it lends itself to being applied at different geographical scales. (Ibidem)

The notion of transescalarity in the strong sense can have two meanings: the first understood as: 
The network metaphor, [...] in other words, the joint consideration of different geographical scales, [...] this is generally used to represent a set of physical connections (road network, telecommunications network, electricity network, etc.), (Ivi, 6-7)

In this case it is meant as a set of nodes of different types (depending on the geographical scale that is considered) joined by groups of relations of different types; (Ivi., 7) for example, if we analyze the dynamics of a city, it can be understood as:

A network of nodes, since it is made up of various elements that make up the complex economic and social system (the companies that operate in the different economic sectors, the local entities, the training institutes, the health system, [...] etc.) connected to each other by articulated systems of relations; on the other hand, if we change the scale of analysis and consider, for example, the national or continental or global urban system, the same city can be seen as a node of networks, i.e. as an element of the national/continental/global urban system, made up of the different cities of a country (of a continent, of the world), linked together by a set of relations of various types (between companies, between universities, between research centers, between local entities and national/supranational organizations, etc. (Ivi., 7)

The second meaning refers to the analysis of the existing relations between different geographical scales, (Ibidem) for example, in the analysis of the local/global relation, this is understood as the study of the existing relations between the phenomena (economic, social, cultural, etc.) that occur at a local scale and those that occur at a global scale. (Ibidem) These relations can be of determination, if the phenomena that occur at a global scale determine those that occur at a local scale, in this case the relations between the two scales take a unidirectional form, (Ivi., 9) or they can be of interaction, with impulses and tensions that go not only from the global to the local, but also in the opposite direction, configuring, like this, a bidirectional relation; (Ivi.,10) for this last type of relation to exists it is necessary that innovations take place in the local systems in which the global system is articulated. (Ibidem) As an example of a relationship of interaction, we can quote Fiat:

This presents, on one hand, a dense network of relations within the local system of Turin (with other industrial companies, [...] with tertiary companies, with higher education institutes, with local entities, etc.), and on the other hand, an articulated system of supra-local relations at different geographical scales, from the national level (with the production units located in southern Italy), the continental level (with the production units in Eastern Europe) to the global level (with the production units in South America and the agreements with General Motors. (Ivi.,11)

Having analyzed the theory and examples of transescalarity, we can determine that the most appropriate transescalar tool to achieve sustainable development at various scales is transescalarity in the strongest sense with regard to interaction. If we enter with this concept in the field of planning, we can determine that it is important the existence of a greater innovation through the sustainable urban-architectural design that allows local development and that in turn has an impact at greater scales; in the same way, it is important that planning at a greater scale as that of the region, uses an innovation in terms of better instrumentation in a way that allows regional development and influences at smaller scales. Consequently, the complementarity of innovations at both scales will allow a convergence of actions that are favourable to the territory. (Fig.1) 


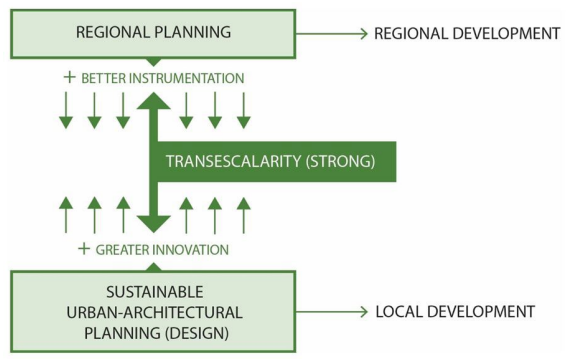

Figure 1. Strong transescalarity scheme in planning. Source: Own elaboration.

\subsection{European and Latin American regional planning}

In order to address the issue of regional planning and understand the importance of sustainable development from the best instrumentation and innovation from a strong transescale perspective, we must first understand the concept of territorial government. This is defined as:

\section{A complex decision-making process of policies through which public authorities regulate - according to the distribution of competences provided in the Constitution - the multiple uses of the territory, combining among them the various relevant interests. (Chiti 2003, 93)}

The system of territorial government of European countries is very diverse among them, for this reason, in order to illustrate the similarities and differences of their approach, the European Commission in 1997, carried out a compendium where 4 types of spatial planning systems were identified, which are shown below: regional economic planning approach (e.g. France), general integrated approach (e.g. Germany), land use management (e.g. United Kingdom) and urbanism (e.g. Italy). (CEC 1997, 36-37)

Regional development planning in Latin America is defined as the strategic stochastic procedure, (Boisier 1979) in other words, of non-deterministic behavior, in which the evaluation of alternatives and the relations of the environment play a determining role. Furthermore, in the span of 20 years of explaining attempts, systematization of theories and plans for the development of the delayed peripheral or underdeveloped regions of Latin America have been dominated by a theoretical body consisting of three main elements: spatial economic theory, regional macroeconomics, and the development hubs theory. (Coraggio 1980) This is the origin of Latin American planning decisions based on the concept of development hubs (Malinowski 1978) with respect to border areas and intraregional territories. In addition to this diversification of theories, the countries of Latin America follow a planning system based on Latin American urbanism, with foreign urbanistic influences through: the contribution of the academic context, the visits of foreign luminaries, the training of Latin American planners in European and North American schools, and the participation in international events. (Cfr. Almandoz 2002; 2007) All this has led to an apparent structuring of the theory and practice of urbanism in Latin America, with a variety of theoretical approaches, giving immediate solutions to social, economic and urbanistic problems, as well as facing a regional problem from a technical and not a theoretical point of view. (Coraggio 1980; Boisier et.al., 1981) Regional planning, then, is a component of territorial government, understood as the management of spatial planning at the regional level according to political, economic, demographic, social, cultural, and ecological criteria of society. It is:

The most appropriate framework for the implementation of spatial planning policy: coordination between the same regional authorities, local and national authorities and between regions in neighbouring countries. (Council of Europe 1983) 
As Petroncelli (2005) states - connecting to Fuccella's (1995) analysis - the purpose of planning is:

Mainly social, since it must be defined in relation to the needs of the community and aim to achieve development. Development can take place only when man has the possibility of carrying out all the physical and intellectual faculties in a coordinated autonomy; this implies that, on one hand, rules are defined, in order to appease conflicts between individual and collective instances and actions, and, on the other hand, he moves in accordance with the environment, in harmony, that is, with the heritage of the resources available in time and space. (Petroncelli 2005, 37)

Regional planning can therefore achieve this aim with the following objectives:

Balanced socio-economic development, improvement of the quality of life, responsible management of natural resources and protection of the environment and rational use of the territory. (Council of Europe 1983)

In this context, it is important to mention that in order to obtain a better control of the territory, regional planning must act in a transescale manner, which will happen if it has better instrumentation. We will mention some examples of this instrumentation later on materials and methods section.

\subsection{Sustainable urban-architectural planning}

The process of planning and modelling of buildings, public spaces, transport systems and services, that does not degrade the environment and provides life quality to citizens, comes from the sustainable urbanarchitectural design approach, which favours a development that allows to satisfy the needs of the present without endangering the capacity of future generations to satisfy their own needs, (WCED 1987) achieving also a coherent, equitable and geographically balanced social-economic development. Likewise, its importance lies in several aspects, such as mitigating pollution and climate change, promoting land conservation and recovery, properly managing resources and waste, as well as planning and improving efficient environmental and transport systems, as well as promoting a well-developed green structure, and encouraging the construction of highquality infrastructure that uses environmentally friendly techniques and systems, all while respecting and building on the basis of heritage and cultural legacy.

Currently the orientation of urban-architectural design towards sustainability is crucial, however in many cities we do not see effective results in practice, this is partly because sustainable development requires a greater vision; for this reason it is important to apply the transescalar view on this approach of urban-architectural planning as it allows a more effective sustainable development; in other words, it is fundamental to apply the strong transescalarity with relation of interaction in sustainable urbanarchitectural design, since the innovation of the interventions proposed at this scale, will be relevant to improve the effectiveness of this type of development at other scales, for example at regional level; and although most urban design interventions are relatively minor, the transescalar interaction of minor strategies can add up to important modifications at the regional, national, continental and global levels, (Carmona 2009) the city in this sense is a complex interconnected system in which any intervention impacts on the sustainability of the whole and vice versa. Sustainable transescalar urban-architectural design is applicable to any place that seeks to adopt effective and synergistic forms of sustainable development. According to Huang et al., $(2015,10-57)$ there are twelve strategies that act in a transescalar manner, aimed at cities with unplanned urbanization processes that seek to obtain effective sustainable development. (i) To establish a limit of urban growth, obtaining 
compact cities that allow the conservation of more green areas and the reduction of air pollution and road congestion. (ii) The city should be structured around its public transport system. (iii) Combine land uses, getting more dynamic sectors. (iv) The blocks should be small, establishing a network of streets with less flow of vehicles. (v) The public green space accessible must occupy between 20 and $40 \%$ of the urbanized surface. (vi) Emphasize the pedestrian environment on a human scale by creating dense networks of footpaths and bike paths. (vii) To work on the consolidation of an efficient public transport system integrated with non-motorized traffic. (viii) Generate strategies to reduce car use. (ix) Restructure or construct buildings that seek to minimize environmental impact by applying various guidelines, such as efficient use of climatic and geographic factors, use of recyclable or low energy content materials, implementation of strategies to reduce and optimize energy and water consumption, also promoting their reuse, as well as the use of green spaces and vegetation as control elements. (x) Analyze and promote district generation of renewable energy. (xi) Achieving sustainable waste management by implementing waste classification systems that must be composted, recycled and reused. (xii) Manage water efficiently.

\section{MATERIALS AND METHODOLOGY}

\subsection{Study case: regional planning instruments in Piedmont (Italy)}

Piedmont region obtained its first regional law Tutela ed uso del suolo - 56/77 in the 70s with the passage of the territorial government of the state to the regions. It is here that the subjects and instruments of planning at different scales are established. This law has been modified in 2013, with the aim of achieving governance, a modality of territorial government where there is a coordination of social, economic and institutional factors in order to achieve sustainable development of the territory. This is achieved through strategic planning, i.e. planning where both short and long term objectives and actions are established and where citizen participation and cooperation of public and private sectors is fundamental. (Font and Rivero 1999) Similarly through the principles of environmental sustainability and energy efficiency, defined as the result of a dynamic balance between the components: environmental (preventing and minimizing environmental impact through environmental prevention or compensation measures), economic (making the benefits produced greater than the costs in the short and long term) and social (determining a positive impact on the entire population involved). (Regione Piemonte n.d. a, art. 30)

These principles of environmental sustainability and energy efficiency are part of the common strategies of the Piano Territoriale Regionale (PTR) and Piano Paesaggistico Regionale (PPR) instruments. The PTR, in this sector, offers an overview of the regional territory, possible development scenarios, as well as the definition of sustainability objectives and guidelines for territorial and sectoral planning/programming at each level, (Ibidem) with particular reference to the elements that constitute essential limits to safeguard the environmental sustainability and the socio-economic development of the territory. (Ibidem) One of the most important novelties that can be found in the Regional law is the adoption of the PPR, a very significant instrument, since it raises awareness of the landscape potential of the region, this plan has the function of:

Defining procedures and rules to ensure that the landscape is adequately known, protected, valued and regulated; in order to promote the safeguarding, management and recovery of the landscape assets and the realization of new coherent and integrated landscape values. (Regione Piemonte n.d. b, art. 1) 
The plan considers the following four components: natural-environmental (mountains, forests, rivers, etc.), historicalcultural (historical centers, areas of archaeological interest, etc.), perceptualidentity (viewpoints, visual relationship between settlements and their context, places and elements of identity, etc.) and morphological-settlements (consolidated urban areas, discontinued suburban fabrics, rural settlements, etc.) (Ivi., part IV)

Another novelty used is the Strategic Environmental Assessment (SEA), which is an:

\begin{abstract}
Instrument to evaluate, a priori, the environmental effects induced by the implementation of a plan or program, thus ensuring the integration of the principle of environmental, social and economic sustainability in the decision-making process from the preparation of these instruments. (Ídem 2011, art. 15)
\end{abstract}

Finally, among other relevant innovations, we have copianificazione understood as an activity of integrated consultation between the institutional subjects that are in charge of the planning of the territory at regional, provincial and district level. (Regione Piemonte 2013, Tit, I) From this we have the principle of subsidiarity in the formation and approval of district and provincial plans, with this principle a certain degree of independence is guaranteed to a lower authority with respect to a higher one, thus distributing the competences among the different levels of power; (Pavy 2020) also this principle establishes that the decisions are taken by the power closest to the citizens, and only in case this one acts in an inefficient way, the higher power will be able to intervene. (Infoleges.it n.d.) Lastly, we have the introduction of territorial agreements and planning conventions, in order to share and coordinate territorial policies, as well as to develop an associated form of urban planning.

\subsection{Overview of Regional Planning in Arequipa}

The Arequipa region is located in southern Peru and is controlled by the instrument Plan de Desarrollo Concertado (PDC), which has been institutionalized from the local economic planning reform system and aim to establish a culture of planning within municipalities and to improve efficiency in the allocation of public funds; (PinedaZumarán 2015, 66-67) for this reasons, the PDC not only links the economics of planning processes with financing mechanisms, but also institutionalizes participatory planning in order to present to the population the list of infrastructure projects that are managed in a given period. In this context it is clear that, traditionally, there is a disconnection between theory and planning practice not only in regional areas but also throughout all Peru.

The limited planning practice is evident for various reasons. First of all, most regional and municipal governments have few resources and, therefore, they lack the professional and economic capacity to prepare and implement the various instruments required by law for the effective operation of urban planning and management. (Remy 2005, 134) Secondly, public administrators who manage urban planning deal almost only with short-term urban affairs, which are the most urgent requirements that are institutionalized in the PDC. Thirdly, given the limited municipal information systems, according to the Ministerio de Vivienda planning does not adequately incorporate urban dynamics: even if local governments have cadastre systems, they are only used for tax collection purposes; in addition, there is almost no evaluation or monitoring of planning processes and interventions. (Pineda-Zumarán 2015,17-18) In the fourth place, it is relevant to keep in mind that planning in Peru lacks specialized technicians, since there are no planning schools: planning studies are only included 
in educational and specialized courses in architecture. Although the Peruvian national government has started a reform in the educational system, it is still necessary to take into account that this reform does not deal with incorporating specialized disciplines that are lacking in the country. (Pineda-Zumarán 2017, 2-3) Finally, the weakness of urban planning is also related to its low financial independence since local governments have limited resources to execute projects and intervene in urban development: this last limitation is evident in the management of the PDC. (Remy 2005, 112)

In this context, the Regional PDC of Arequipa in 2021 incorporates four strategic axes to reach its planned vision; however, for the management of these axes, work structures have been established from the central government which, through national ministries, exercises national policies in regional territories. Although the incorporation of the Municipalities Act of 1984 delegates to the local governments the planning of powers and competences to administer their territories, it gives the governments freedom in decision making but it does not allow them to fully manage their financial resources. Then, Arequipa's regional planning uses a single instrument which, despite having laws that seek to substantially boost and reorient the planning framework, still uses the traditional top-down procedure in its technical management instruments, evidencing inefficient urban management. (Pineda-Zumarán 2016)

\subsection{Urban-architectural examples of sustainable innovation}

There are several examples of sustainable innovation at the urban-architectural scale, however, we will mention only two that will later serve to explain how, when interacting in a strong transescalar way, they generate better instrumentation at the regional level.

- Bioclimatic site matrix: useful tool to determine the vocation of use of internal and external spaces according to the thermal comfort of users. It consists of shadow projections superimposition and the projections of areas without wind currents in the place to be built, determining four possible combinations of the relationship between site, sun and wind; such superimpositions should take as a sample one summer day and a winter day at three specific times; the result will be the projection in situ of a numerical matrix that according to a scale of priorities will define the most appropriate use of each area. This tool can be used at different scales. (Grosso 2011)

- District Renewable Energy: tool that allows reusing of wind, solar and geothermal energy in public and private spaces, through private agents or in consensus between public authorities and private companies; in each project the energy required by the district must be analysed, combining the needs of heat and electricity, its losses and possibilities of reuse. An innovative example that impacts on different scales is the construction of a municipal power plant that captures the waste heat produced by a nearby steel plant, and then uses it for the benefit of the district. (Huang et al. 2015,46 )

\section{DISCUSSION AND RESULTS}

In order to obtain a better control of the territory through its valorization, management and transformation under a sustainable view, a better instrumentation at a Regional Planning level and a greater innovation in the strategies of Urban-Architectural Planning must be achieved. This will be achieved by applying the principle of strong transescaling that works by systematically and cyclically integrating two or more geographical scales and the analysis of the relations between them, thus generating a synergy. (Fig.2)

To demonstrate this from a sustainable perspective, we propose two Regional Planning instruments: the regional landscape plan and the strategic planning, taken under 
the European approaches of the study case, and two innovation strategies for UrbanArchitectural Design: the bioclimatic site matrix and the district renewable energy generation, considering them useful elements for territories with absence or deficiency of sustainable planning as is the case of the Arequipa Region. These proposals are related in a transescalar way (at urban-architectural/ regional level) since the bioclimatic site matrix allows the development of a more precise regional landscape plan in its morphological and environmental dimension, and the district renewable energy generation allows a strengthening of the strategic planning by generating a true cooperation of public and private agents, allowing the proposals not to work in an isolated way but rather synergistically as a whole. Given that transescaling occurs in a cyclical manner, these proposals also function in the inverse manner (regional/urbanarchitectural) and in a parallel manner (urbanarchitectural/urban-architectural and regional/ regional), producing as a result a better control of the territory based on optimal sustainable instruments and guidelines.

\section{CONCLUSION}

A strong transescalarity in relation to interaction is the most appropriate instrument for achieving sustainable development in planning, where innovation between the different scales generates a complementarity and convergence of actions that are favourable to the territory.

The conceptual theoretical framework of this research allows to support that the efficient instrumentation in the regional planning can create a transescalarity development from the territory to smaller scales, in a constant roundtrip improvement phase where: (i) the deep study of the territory, (ii) the incorporation of improvement strategies in the cooperation between citizens and public/private entities, added to (iii) the search for environmental, economic and social sustainability, would allow to value, manage and transform the territory. In addition, this new perspective can begin to challenge the evident limitations in the regional planning - such as the one in Arequipa's region - which lacks appropriate instruments. However, more research with

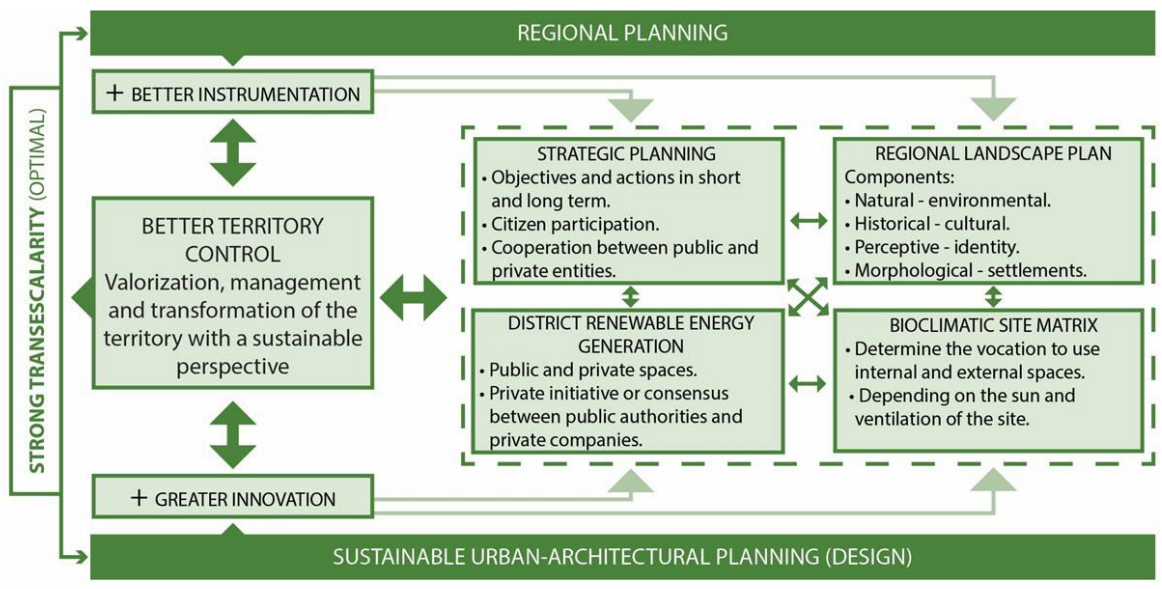

Transescalar relationship

Figure 2. Transescalarity functional system based on some strategies. Source: Own elaboration. 
qualitative and quantitative methods is needed on these issues, both in Latin American and European regional areas, to further validate these initial conclusions.

The implementation of cross-cutting strategic guidelines will make it possible to manage development plans in an integrated manner, with the main objective of achieving a consensus view in the regional territory. Likewise, the establishment of cyclical guidelines - which, through a policy network where all agents intervene, will allow to diminish the problems of corruption and judicial crisis - are elementary to solve the problems of regional planning policies in our country. In this way, all the provinces that integrate the region will develop together. 


\section{REFERENCES}

Almandoz, Arturo. 2002. "Urbanization and Urbanism in Latin America: from Haussmann to CIAM." In Planning Latin America's Capital Cities, 1850-1950, edited by Arturo Almandoz, 13-44. London: Routledge.

Almandoz, Arturo. 2007. "Modernización urbanística en América Latina. Luminarias extranjeras y cambios disciplinares, 19001960." Revista Iberoamericana 7, no. 27 (September): 59-78.

Banini, Tiziana. 2011. "Introduzione alle identità territoriali." In Mosaici identitari. Dagli italiani a Vancouver alla kreppa islandese, edited by Tiziana Banini. Rome: Edizione Nuova Cultura.

Bonavero, Piero. 2005. L'approccio transcalare come prospettiva di analisi. II contributo della geografia alla ricerca economica e sociale. Milan: EDUCatt Università Cattolica.

Boisier, Sergio. 1979. Seminario Internacional sobre Estrategias Nacionales de Desarrollo Regional en América Latina. Bogota: ILBIS y UNIADES.

Boisier, Sergio, Fernando Cepeda, José Hilhorst, Sohel Riffka and Francisco Uribe. 1981. Experiencias de Planificación Regional en América Latina. Una teoría en Busca de una Práctica. Chile: Comisión Económica para América Latina de las Naciones Unidas.

Carmona, Matthew. 2009. "Sustainable urban design: principles to practice." International Journal of Sustainable Development 12, no.1 (July): 48-77.

Chiti, Mario P. 2003. "Il ruolo della Comunità europea nel governo del territorio." Rivista Giuridica dell'Edilizia 3, 91-107.

CEC-Commission of the European Communities. 1997. The EU Compendium of Spatial Planning Systems and Policies, Regional Development Studies, no. 28. Luxembourg: European Communities.
Coraggio, Jose I. 1980. Las Bases Teóricas de la Planificación Regional en América Latina (Un Enfoque Crítico). Mexico: El colegio de México.

Council of Europe. 1983. Carta Europea de Ordenación del territorio. Spain: Torremolinos.

Folch, Ramon. 2003. El territorio como sistema. Conceptos y herramientas de ordenación. Barcelona: Diputació de Barcelona.

Font, Javier, and Cristina Rivero. 1999. "Participación de la sociedad civil en el desarrollo estratégico urbano y territorial." In ¿Existe sociedad civil en España?: Responsabilidades colectivas y valores públicos, edited by Joan Subirats. Madrid: Estudios de la Fundación Encuentro.

Fuccella, Renato. 1995. Elementi di urbanistica. Florence: Alinea.

Grosso, Mario. 2011. II raffrescamento passivo degli edifici in zone a clima temperato. Rimini: Maggioli editore.

Huang, CC, Chris Busch, Dongquan He and Hal Harvey. 2015. 12 Green Guidelines, CDBC'S Green and Smart Urban Development Guidelines. China: China Development Bank Capital.

Infoleges.it.n.d. "Glosario."Accessed February 5, 2020. http://www.infoleges.it/NewsLetter/ Content/?shortName=Glossario

Malinowski, Andrzej. 1978. "Los Problemas de Planificación Regional en la América Latina." Boletín de la sociedad geográfica de Colombia-revista de la Academia de Ciencias Geográficas 31, no.112.

Pavy, Eeva. 2020. "The principle of subsidiarity." Accessed February 8, 2020. https:// www.europarl.europa.eu/factsheets/en/ sheet/7/the-principle-of-subsidiarity

Petroncelli, Elvira. 2005. Pianificazione territoriale, principi e fondamenti. Naples: Liguori editore.

Pineda-Zumarán, Jessica. 2017. “Exploring practitioners' perception of ethical issues in planning: The Peruvian case". Environment and Planning Politics Space 36, no.6 (December): 1109-1132. 
---. 2016. "Spatial Data Usage, Spatial Thinking and Spatial Knowledge Generation: The Case of Planning Practitioners in Arequipa, Peru." Planning Practice \& Research 31, no.3 (March): 270-291.

---.2015. "Learning and Knowledge Generation in Local Decision Making in the South. The Case of Urban Infrastructure Provision in Arequipa, Peru." Journal of Planning Education and Research 36, no.1 (September): 60-75.

Regione Piemonte. 2013. Elementi per un "Codice dell'urbanistica in Piemonte." Turin: Regione Piemonte. Accessed February 7, $2020 . \quad$ https://carteinregola. files.wordpress.com/2013/10/ codiceurbanistica-piemonte.pdf

---n.d. a. "Piano Territoriale Regionale (PTR-2011)." Accessed February 8, 2020. https://www.regione.piemonte.it/web/ temi/ambiente-territorio/territorio/pianoterritoriale-regionale-ptr

- - -n.d. b. "Piano Paesaggistico Regionale (PPR-2017)." Accessed February 8, 2020. https://www.regione.piemonte.it/web/ temi/ambiente-territorio/paesaggio/ piano-paesaggistico-regionale-ppr

Remy, María Isabel. 2005. "Los gobiernos locales en el Perú: entre el entusiasmo democrático y el deterioro de la representación política." In El Estado está de vuelta: desigualdad, diversidad y democracia, edited by Victor Vich, 111136. Lima: Instituto de Estudios Peruanos. WCED-World Commission on Environment and Development. 1987. Our Common Future. London: Oxford University Press. 
TOP DOWN PLANNING APPROACHES AND URBAN REALITY: THE CASE OF DELHI, INDIA

Sana Ahrara, Alexandra Stauba

aPenn State University, University Park, Pennsylvania

\section{ABSTRACT}

In India, a considerable share of the urban population lives in informal developments, while the rate of urbanization in megacities is one of the highest in the world. Indian society is defined by extreme economic disparity, diverse religious practices, and class and caste stratifications, all of which have contributed to spatial segregation. Challenged by widespread informal development, urban planners' response has been to force a "global city" planning model. This model, which focuses on upscale infrastructure, is in stark contrast with the urban poor's idea of an ideal and inclusive city. Through the use of archival data, site observations, and interviews, this paper examines an urban village in Delhi as a case study. This paper analyzes how community members have created their utilitarian environment which, while it does not conform to global city ideals, serves as a well-functioning urban microcosm.

The ingrowth of urban villages is a byproduct of Delhi's rapid urbanization, absence of affordable housing and Delhi's Masterplans. In the absence of affordable housing and employment opportunities, urban villages provide domestic shelter to their residents while offering a low-scale cottage industry market for rural migrants. In the Indian context, where decision-makers and urban planners conflate the "needs of the urban poor" with their own political aspirations for a progressive "global city", this paper puts forth that India's approach toward informally developed settlements must change.

\section{KEYWORDS}

Urbanization; informal development; urban village; planning approach; urban informality.

\section{INTRODUCTION}

The unprecedented growth and expansion in Indian cities cannot be understood from the generalized theorizations of the global urbanization process (Roy 2005, Sassen 2005); rather patterns of urbanization remain contingent on local conditions and their dependency on and interlinkages with the larger regional scale. One consequence of the fast-paced urbanization of India's capital Delhi are the scattered and heterogeneous housing developments that have cropped up in response to housing needs of various sections of Indian society. These often informal developments call for a more comprehensive view into the urbanizing processes taking place in Indian cities.

Urban villages in Delhi are often agrarianbased settlements that have transformed amidst rapid urbanization. Many have grown organically in close proximity to agricultural fields. As the State Development Authority and other developers acquired the agricultural lands surrounding such settlements in order to build further residential developments and infrastructure, these settlements were caught in the development process of a post-colonial city (Chattopadhay et al. 2014). The changes that occurred in these settlements and their increasing density can thus be understood as a byproduct of Delhi's rapid growth, deficiency of affordable housing, and as a consequence of Delhi planners' attitudes towards these settlement types. 
Planning authorities in present-day Delhi recognize 135 urban villages, morphologically divided into seven "not-formal settlement types" (Center for Policy Research 2015). Considering that the 1961 master plan recognized only 47 urban villages, this presents a drastic increase in settlements recognized as transitioned from rural villages. The estimated population residing in this settlement type has increased exponentially in the last two decades.

In order to understand the complexities of Delhi's urbanization process and similar processes of growth and transformation in Asian cities, it is important to investigate smaller developments such as urban villages. This paper examines an urban village in Delhi as a case study, using archival data, site observations, and unstructured interviews conducted during an initial site visit in 2017.

The terms "formal" and "informal" are used here in alignment with nomenclature in official planning documents such as Delhi's master plan. The terms define land zoning, controls and regulations. While settlements planned by the state or developed privately with state approval are described as formally planned settlements, developments in violation of the master plan or developed without official approval are understood as "informal developments".

This paper first discusses organically grown urban villages in Delhi. The second part of the paper examines Chirag Dilli, an urban village in present-day South Delhi. We analyze how these urban villages grew during the pre-1947 colonial period and how they have densified to accommodate a post-colonial population influx. The paper concludes by discussing what we can learn from how India's urban villages function and why it is necessary to rethink India's urban village planning approach.

\section{CASE DESCRIPTION}

Delhi was not developed from a single node or planning form; it has been built and rebuilt from different cores and using different planning ideologies over the years. The problems and needs of the city's diverse demographics vary based on class and caste divides, social and cultural practices, and other constraints and parameters. With the city's increasing population density and the existing formalinformal relationship between planned and informally developed communities, it is essential to focus not only on solving presentday density problems, but also on recognizing and preparing for anticipated growth. In the following section, we examine the conditions, exemptions and planning legislatures that led to the formation of these complex settlement types in the heart of the capital city.

The current "Master Plan 2021" identifies 362 villages in Delhi, of which 135 are considered urban and 227 rural villages. The urban villages in this setting are defined as formerly agrarian villages that were engulfed as Delhi rapidly urbanized in the post-colonial period after 1947. The rapid growth resulted in Delhi's shift from having an agrarian-based economy to one employing the residents of these villages in the tertiary sector. Rapid growth also led to physical changes in the built environment to accommodate the higher non-agricultural population. These spatial and demographic changes were followed by sociocultural changes due to the influx of migrant populations (from India's rural areas) in the ensuing decades.

Today, urban villages have emerged within and in close proximity to the original seven cities of Delhi: historic cores such as tombs, shrines, and Sarai's (resting place for travelers). Under British governance in 1908, the administration demarcated such settlement areas as Abadi, or habitation areas (Pati 2015; Fernandes 2016) and exempted them from land revenue collection (Sheth 2017). The intention behind this nomenclature was to catalog revenue estates, rather than to develop or plan the city. In the post-colonial period, these villages were not integrated into the planning process; instead they were demarcated and received little attention from planning authorities. The 
Delhi master plans have acknowledged these villages and the need to integrate them in the planning process but have never detailed the process (Expert Committee on Lal Dora and Extended Lal Dora, 2007). As the Committee report states:

"Building control regulations were neither prescribed in the Master Plan nor made effective in urban villages (Lal Dora or Extended Lal Dora) under the erroneous but convenient assumption that since such regulations were not applicable in the village 'abadis', the same would also not apply to urbanized villages as well."

\section{CHIRAG DILLI: THE URBAN VILLAGE}

Chirag Dilli dates back to the 14th Century. The settlement emerged to circumscribe the tomb of a venerated Sufi saint during the Delhi Sultanate period (Rewal 2014). The built form of the village is delimited by fortification walls that were constructed around the tomb site during the Mughal period, alongside the 'Barapullah nallah' (drain) which runs along the edge of the settlement (Rewal 2014; Mitchell 2010). Unlike other urban villages in Delhi, Chirag Dilli presents a unique case since the village developed as a walled settlement (Mitchell 2010). Delhi's present master plan identifies it as a heritage complex, alongside five other such zones in Delhi (Delhi Development Authority 2007). Many historic structures were erected during the Delhi Sultanate and Mughal period in this village. The settlement has grown both horizontally and vertically within the village boundaries to accommodate the overlaying demands of affordable housing for the urban poor and migrant populations, as well as associated services and employment opportunities in the form of small-scale cottage industries (Narayanan and Veron 2018).

Urban villages similar to the city's other informally developed settlements have a symbiotic relationship with adjacent formally planned developments (Narayanan and Veron 2018). Chirag Dilli is located next to a planned and plotted development, which explains why migrant populations have chosen to reside in this settlement. The initial agrarian-based communities that

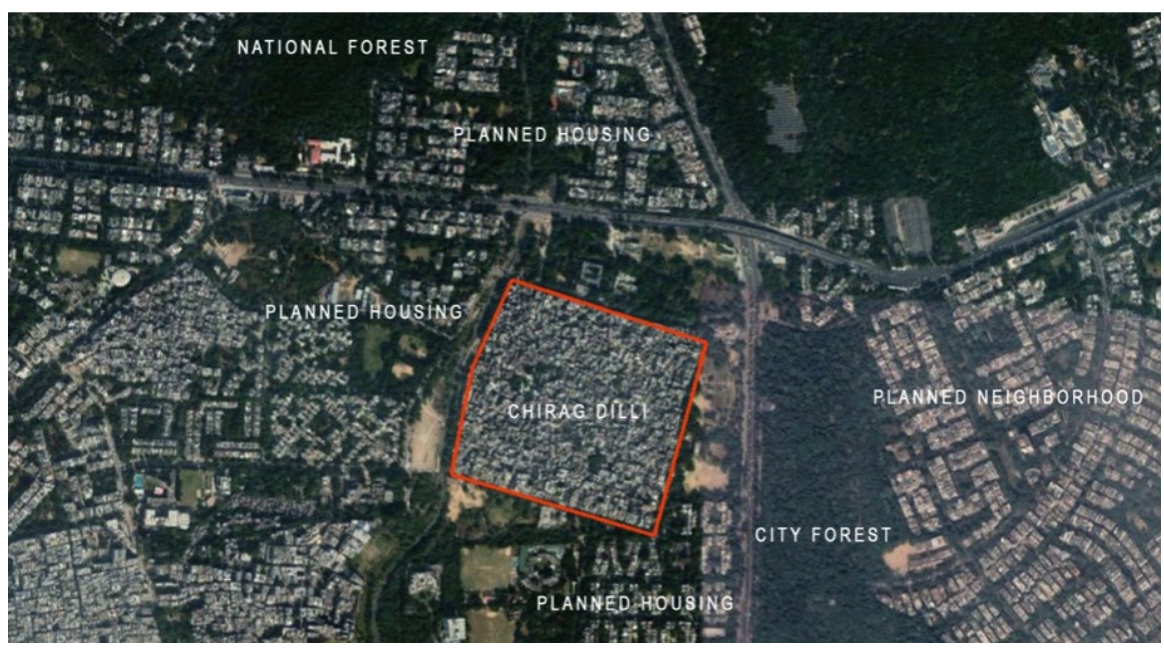

Figure 1. Chirag Dilli. (Source: Google map Accessed 2020) 
settled in these villages lost their primary economic means as farmers when the agricultural fields were acquired by the State Development Authority for development. Paired with market forces and the need for economic sustenance, the property owners in the urban villages rented out portions of their houses to incoming migrants, while the village's periphery became lined with shops catering to the village residents as well as the neighboring, formally planned settlements (Narayanan and Veron 2018). Since land use and settlement morphology changes were impromptu and not based on building codes and regulations, the present-day urban village is a densely packed settlement with a labyrinthine form that includes crumbling historic structures.

The social changes in this formerly agrarianbased community and the influx of migrants with diverse backgrounds are spatially evident in the caste-based segregated settlement (Mitchell 2010). Chirag Dilli still retains many rural characteristics, yet has become "urban" due to its high population density and expected amenities. The settlement's perimeter is lined with shops selling items and services for everyday life, such as hardware, timber, electronics, automobile repair, and fast food. Alleys lead to smaller stores such as beauty salons and other services that cater to the residents and the community's small-scale industries.

\section{THE INFORMAL INDUSTRY AND THE LIVE- WORK RELATIONSHIPS IN THE VILLAGE}

In Chirag Dilli, small-scale cottage industries such as the Momos (Tibetan dumplings) industry became a major economic source for both property owners and tenants (Narayanan and Veron 2018). Tibetan dumplings are a popular street food in Delhi. Migrant laborers from north-eastern states such as West Bengal and Manipur as well as international migrants from Tibet and Nepal have found informal employment in this small-scale cottage industry run by local entrepreneurs in Chirag Dilli. The dumpling's basic ingredients include chicken and vegetables that are procured from the village itself, providing economic benefits to other small-scale establishments in the settlement as well (Narayanan and Veron 2018).

Housing within Chirag Dilli has changed over the years. Traditional housing was built for extended families and had a courtyard layout. New housing is made up of mixed-use buildings with smaller residential units for the owners, rental units for workers, commercial spaces, and spaces for the production of dumplings. This has changed the density of the built fabric and the morphology of the urban village. Furthermore, since the workplace and rental housing are within the settlement, the public squares, or chowks, serve as social network nodes, with ethnic clustering for the workers. (Narayanan and Veron 2018),
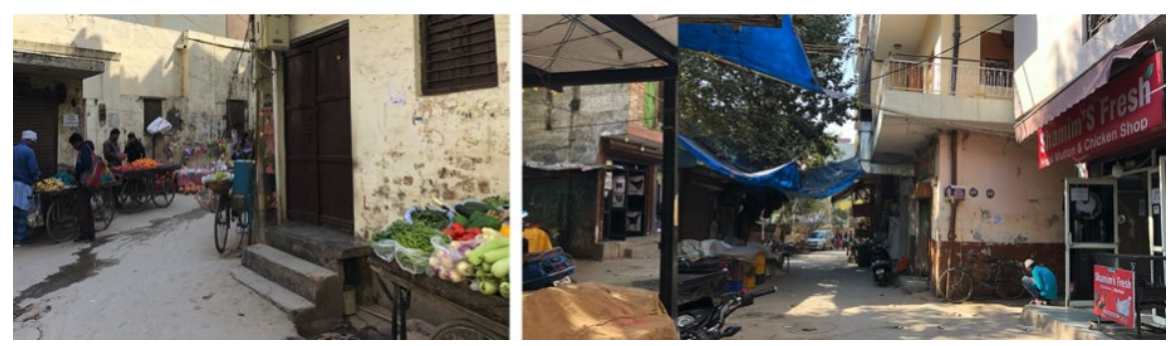

Figure 2. Vegetable and meat vendors within the Chirag Dilli settlement (Source: Author, 2020) 
Informal spaces created to sustain this smallscale industry within the settlement, as well as the informal market practices which are dependent on these productions, are spread across South Delhi. The central location of Chirag Dilli and the lack of control over the developments and changes within the village have allowed Chirag Dilli to become a major supplier of these dumplings to South Delhi neighborhoods and markets. In this case, the means needed for the functioning of this small-scale industry, i.e. the migrant workers and the ingredients, are both available in the settlement itself. Produce supply has been arranged informally through vendors and market stall owners. Some of these merchants live in the settlement itself, while others live in nearby areas where the dumplings are transported for consumption. The absence of rigid land-use guidelines for informal settlements such as Chirag
Dilli has allowed alternative use of spaces based on supply and demand. Migrant populations and urban poor have tapped into the spatial flexibility of the informal village, and we argue that the functional nature of this flexibility can serve as a model for neighborhood planning. The temporality of spaces in the settlement can also be understood as serving the residents' social and economic needs and can be seen as a well-functioning Geddesian (live-work-play) triad. Low-cost housing (live), joins with informal employment opportunities and microeconomies (work) and dynamic social spaces (play) in the village to promote sociocultural bonds between the residents. Since the streets in the village are not designed for vehicles, the compact setting allows for walkable spaces, and cultural activity spills into all available spaces, leading to needbased adaptations.
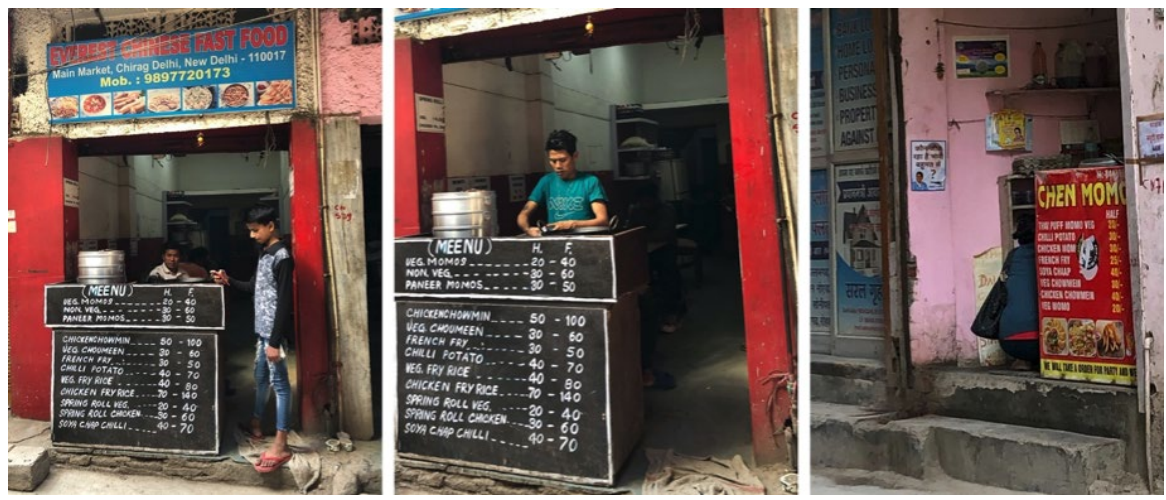

Figure 3. Momo/dumpling shops in Chirag Dilli (Source: Author, 2020) 

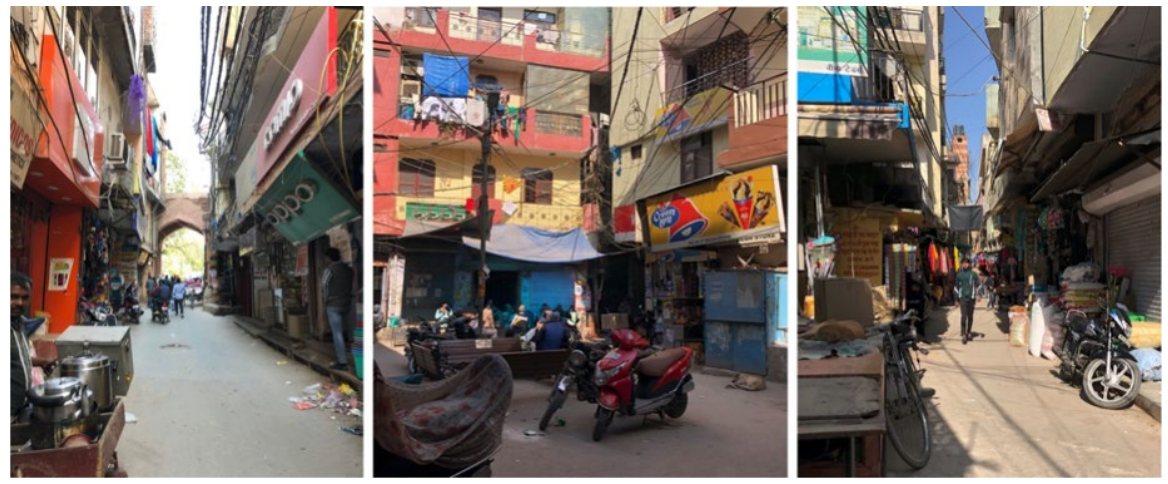

Figure 4. Mixed-use streets within Chirag Dilli (Source: Author, 2020)

\section{CONCLUSION}

Advantages of mixed-use development have long been promoted by urbanists. Such thinking has made its way into Indian cities through mixed-use settlements that are built as formally planned, gated communities, and complexes that bring certain attributes of village life into fast-growing cities. Global scholars' interest in the urbanization process in quickly urbanizing cities, as well as the informal approaches adopted by residents to deal with population growth and the inadequacies of affordable housing, present an intriguing case for studying informal settlement in the Indian context.

The "urban-rural blend" transforming villages in Delhi presents examples of walkable, mixeduse, compact, and organically developed settlements where the urban poor reside in close proximity to their workplaces. The spaces in and around these villages have changed due to informal economic activities and ever-growing demands for housing and employment resulting from increases in Delhi's migrant population. Over the years, informal economic activity has allowed landlords to improve their economic status. It has also allowed for business expansions, where entrepreneurs have created beneficial relationships within the urban village. The informal economy has benefited the village by improving housing conditions and village developments in a bottom-up manner (Narayanan and Veron 2018).

This brings forth the argument that functionality is not confined to formal planning. Noticeably, an informally created microcosm such as can be found in urban villages appears to function well for the urban poor. Informality goes handin-hand with economic benefits to the resident community, as well as more affordable shelter and employment opportunities within and in close proximity to the settlement. Moreover, in such settlements the relationship between informal systems of informal economies, space creation and the flexibility of space and function is undeniable. Community members have created their utilitarian environment while retaining some of the village's rural characteristics. At the same time, accelerating urban population densities help illustrate the urban processes taking place in informal settlements in India's capital.

Roy (2009) notes that the differentiation between "legal" and "paralegal" by planning authorities in India is a "fundamental axis of inequality" (Roy 2009, 80). The inadequacy of the state to provide an affordable housing supply, employment opportunities, and 
infrastructure have led to an uptick in privatized developments. Officials' attitudes towards the "not so formal" developments in the city have led to mismanaged developments and misguided initiatives that tackle problems in ways that are not sustainable. At the same time, state-sanctioned developments for the city seem to focus on infrastructure development and can be perceived as urban aesthetic enhancements (Ghertner, 2015), or as "image-building" exercises (Dupont 2011, 533).

Since the liberalization of economic policies in the early 1990s, the Delhi capital region has surfaced as a major center for foreign investment. The decision to set up Special Economic Zones, with economic reforms for foreign investments and the provision of cheap skilled and unskilled labor, set a precedent for the vision of Delhi as a "worldclass city" (Baviskar, 2014; Ghertner, 2015). The world-class city model has been promoted as a political ambition towards capital city planning that runs counter to the existing order suggested by informal communities.

The scenario of privatized infrastructural development to meet the demands of growing cities suggests a problem-fixing exercise rather than a long-term plan. Informal settlements that have come about in Delhi, while in no way ideal creations, are nevertheless functional entities. While one might claim that informal developments are haphazard and that they don't have the physical resources and infrastructure of formally planned communities, they present examples of functioning live-work relationships. For those interested in how urban systems work, they can broaden our understanding of how the urban poor in India can more effectively meet their needs. 


\section{REFERENCES}

Baviskar, Amita. 2014. "Dreaming Big: Spectacular Events and the 'WorldClass' City: The Commonwealth Games in Delhi." In Leveraging Legacies from Sports Mega-Events: Concepts and Cases, edited by Jonathan Grix, 130-41. London: Palgrave Macmillan UK. https://doi. org/10.1057/9781137371188_12.

Center for Policy Research. 2015. "Categorization of Settlement in Delhi." New Delhi, India: Center for Policy Research. https://www.cprindia. org/sites/default/files/policy-briefs/ Categorisation-of-Settlement-in-Delhi.pdf. Chattopadhay, Subrata, Priyanka Dey, and Joel Michael. 2014. "Dynamics and Growth Dichotomy of Urban Villages: Case Study Delhi." Int. Journal for Housing Science 38 (2): 81-94.

Ghertner, D. Asher. 2015. Rule By Aesthetics: World-Class City Making in Delhi. Oxford, New York: Oxford University Press.

Delhi Development Authority. 2007. "Masterplan for Delhi 2021." Delhi Development Authority. https://dda.org. in/planning/mpd-2021.htm.

Dupont, Véronique D. N. 2011. "The Dream of Delhi as a Global City." International Journal of Urban and Regional Research 35 (3): 533-54. https://doi.org/10.1111/ j.1468-2427.2010.01027.x.

Fernandes, Boniface G. 2016. Fixing Flawed Urban Planning: The Case of Delhi. Copal Publishing Group.

Mitchell, Maurice. 2010. Learning from Delhi: Dispersed Initiatives in Changing Urban Landscapes. edited by Shamoon Patwari and Bo Tang. Routledge.

Narayanan, Nipesh Palat, and René Véron. 2018. "Informal Production of the City: Momos, Migrants, and an Urban Village in Delhi." Environment and Planning D: Society and Space 36(6): 1026-44.https:// doi.org/10.1177/0263775818771695.
Shrivastav, P P. 2007. "Report of the Expert Committee on Lal Dora and Extended Lal Dora in Delhi." Union Ministry of Urban Development. http://delhi-masterplan. com/wp-content/uploads/2009/09/ Expert-comittee-report-on-lal-dora.pdf.

Pati, Sushmita. 2015. "The Regime of Registers: Land Ownership and State Planning in the Urban Villages of Delhi" 1 : 15.

Rewal, Raj. 2014. "City Level Project Report: Chirag Delhi and Its Precincts." Delhi Urban Art Commission.

Roy, Ananya. 2005. "Urban Informality: Toward an Epistemology of Planning." Journal of the American Planning Association 71 (2): 147-58. https://doi. org/10.1080/01944360508976689.

Roy, Ananya. 2009. "Why India Cannot Plan Its Cities: Informality, Insurgence and the Idiom of Urbanization." Planning Theory 8 (1): 76-87. https://doi. org/10.1177/1473095208099299.

Sassen, Saskia. 2005. "The Global City: Introducing a Concept." The Global City XI (2): 18.

Sheth, Sudev. $2017 . \quad$ "Historical Transformations in Boundary and Land Use in New Delhi's Urban Villages." Economic and Political Weekly 52 (5): $1-11$. 


\section{PAPER \#2.04}

\section{AN INQUIRY ON THE ARCHITECTURE OF THE OPEN CITIES IN THE AGE OF PLANETARY URBANIZATION}

\section{Esin Komez Daglioglua}

aMiddle East Technical University, Ankara, Turkey

\section{ABSTRACT}

Urban sociologist Richard Sennett (2017, 2019) has recently introduced the notion of "open city" as a place, which enriches the experience and in which people are more and more skilled in managing complex conditions of life. In this context, Sennett defines complexity as the ability to live and work with people who are different from us and interacting with them without abolishing the boundaries between self and other. This fundamental public dimension and its underlying politics differentiate cities from local communities: individuals have the freedom to remain apart as strangers yet being mutually aware and interactive. Historically, the phenomenon of the city was a political construct - as can be found in the concept of the polis - where different encounters, social conflicts, and their resolution were made possible in its public spaces (Arendt 1958, Aureli 2011). However, the spreading urbanization practices, which have increased enormously since the 19th century in many parts of the world and now reached the planetary scale, have triggered the production of endlessly growing and homogeneous urban spaces by diminishing the distinction between the public and the private, and have become a tool for rationalizing the networks that meet the expectations of globalism and capitalism. Likewise, the urbanization practices in Turkey, which have been effective since the beginning of the 20th century and accelerated in the 21 st century, could not succeed in producing sufficient urban form and public life. The most current and clear example of this can be observed in the new peripheral urban developments in Ankara. This paper argues that in order to achieve open cities, architects should reclaim form as a means to cultivate the social and political conditions of urban life. In this regard, based on the typological, morphological and programmatic analysis of the current peripheral urban landscapes in Ankara, this paper aims to speculate on the possible architecture(s) of the open city.

\section{KEYWORDS}

Open city; planetary urbanization; urban sprawl; architectural form; Ankara.

\section{INTRODUCTION}

Cities evolve and constantly transform in relation to their social, economic and cultural contexts (Geddes 1915). However, the speed of this transformation has increased enormously since the 19th century due to the spreading urbanization practices in many parts of the world. Urbanization has triggered the production of endlessly growing and homogeneous urban spaces by diminishing the distinction between the public and the private, and have become a tool for rationalizing the networks that meet the expectations of globalism and capitalism. Today, urbanization is so expansionist that the concepts of edgeless city, metacity, megalopolis, city-region, etc. were introduced to define the current state of many large 
cities (Lang 2003, MVRDV 1999, McGrath and Shane 2012, Neuman and Hull 2014). Urban theorist Neil Brenner (2014, 185-186) even argues that now we are facing with planetary urbanization by stating:

The emergent process of extended
urbanization is producing a variegated
urban fabric which, rather than being simply
concentrated within nodal points or confined
within bounded regions, is now woven
unevenly and yet ever more densely across
vast stretches of the entire world.

More than half of the world's population lives in cities today and a discussion on the political, social, and formal definition of cities gains outmost significance in the current state of planetary urbanization.

Our contemporary world is immensely urbanized, but do these urbanized areas have the features and potentials of what the idea of the city originally intended? In the light of this question, this paper first discusses the notion of open city, which is recently popularized by urban sociologist Richard Sennett. Following Sennett's depiction of the open cities, this paper dwells on architectural theorist and educator Pier Vittorio Aureli's city versus urbanization distinction to identify the roots and characteristics of these two concepts and relates it with Sennett's comparison of cité and ville. Then, as its methodology, the paper adopts case study analysis by studying the urban sprawl in the city of Ankara with specific reference to the Kanuni Sultan Süleyman Boulevard located at the southwest part of the city. Afterwards, the paper discusses how architects could contribute to the making of cities against the pervasive character of contemporary urbanization by reclaiming form. Finally, the paper concludes with a call for architects to take positions in imagining the contemporary city by giving examples from the discipline's own history.

\section{LITERATURE REVIEW}

The concept of "open city" has become a hot topic in contemporary urban sociology and planning studies (Ash 1969, Friedmann 2002, Ipsen 2005, Rieniets et al. 2009, Porqueddu 2018). Among the multiplicity of the discussions, this paper mainly dwells on Richard Sennett's elaboration of the term. Sennett (2017) defines open city as a place, which enriches the experience and in which people are more and more skilled in managing complex conditions of life. In this context, Sennett (2017) frames complexity as the ability to live and work with people who are different from us and interacting with them without abolishing the boundaries between self and other. This fundamental public dimension and its underlying politics differentiate cities from local communities since in cities individuals have the freedom to remain apart as strangers yet being mutually aware and interactive. Therefore, cities are significant political constructs, which cannot simply be reduced to its economic functioning, and as Sennett (2017) argues, we need to "open the city physically up, so that people's experience in it could be more complex and their ability to manage difficulty and complexity could expand." However, in order to discuss open cities, it is necessary first to differentiate the origins, characteristics and the mechanisms of the two related but distinct concepts: city and urbanization.

In his book The Possibility of an Absolute Architecture, Pier Vittorio Aureli (2011) compares the notions of city with urbanization by tracing their roots in Greek polis and the Roman urbs. Polis was consisted of separate and well-defined public and private realms and politics was possible in its public spaces since the things related with individuals are non-political as argued by Hannah Arendt (1958) in her seminal book The Human Condition. Similar to Arendt, Aureli states 
that historically, the phenomenon of the city was a political construct - as can be found in the concept of the polis - where different encounters, social conflicts, and their resolution were made possible in its public spaces. On the other hand, as Aureli (2011) argues, urbs are organized on the basis of economic efficiency without embodying any political qualification. Aureli (2011) identifies that polis has a distinguished and well-defined boundary while urbs intends to expand endlessly and homogenously to organize its entire territory based on economic functioning. "While the Greek polis was a strictly framed by its walled perimeter, the Roman urbs was not intended to be restricted, and in fact it expanded in the form of a territorial organization, in which roads played a crucial role" (Aureli 2011, 4) Therefore, the concept of urbanization, which was first introduced by the Spanish planner Ildefons Cerdà and theorized in his book Teoría General de la Urbanización in 1867, embodies the character of urbs as its origin.

Similar to Aureli's comparison of polis and urbs, Sennett makes a distinction between the French words cité and ville. In his book Building and Dwelling: Ethics for the City, Sennett (2018) argues that there is a great difference between the lived and the built, place and space, cité and ville. Sennett claims that the great urbanists of the 19th century such as Haussmann, Cerdà and Olmsted aimed to shape the ville without considering the lived experience of the cité and he (Sennett 2018,62) states that in the twentieth century "urbanism became less ambitious about connecting the lived and the built". Therefore, there is a growing gap between the cité and ville, and Sennett introduces here again the concept of open city to bring these two together. There are great resemblances between Aureli's distinction of city versus urbanization and Sennett's differentiation of cité and ville. However, while Aureli aims to resist urbanization in favor of the city, Sennett tries to engage them. In this regard, these two figures offer completely different and even contrasting design strategies to reclaim the idea of the city. Before commenting on these strategies, this paper will first analyze the current state of cities with particular reference to the urban sprawl of the city of Ankara.

\section{METHODOLOGY}

Contemporary trends of urban sprawl in cities can be understood from the perspective of Roman urbs, which lies at the heart of the idea of urbanization as discussed above. Among many cities, the case of Ankara can be given as an example to discuss the distinction between cities versus urbanization. Ankara is the capital and the second largest city of Turkey. Currently it has more than 5,5 million inhabitants, which have increased by 1,5 million after 2000 . Therefore, the city has shown a rapid urban development by expanding its periphery. Originally, the city was designed based on two urban plans developed successively by the German planners Lörcher and Jansen in the 1920s. However, the city has started to expand outside the boundaries of these plans in a very short time due to the unexpected population growth. The control over the overall form of the city and its expansion has started to diminish since the city became uncapable to manage the speed of inmigration. As Batuman $(2013,588)$ states "the urban history of Ankara throughout the 20th century displays a gradual move away from planned and controlled development." This paper will briefly discuss the character of the urbanized periphery by particularly referring to the area located at the southwest part of the city, around the Kanuni Sultan Süleyman Boulevard. This area is selected since it is one of the most recent 
examples of rapid urban expansion in the city and has many shared properties with the newly emerging urbanized territories in the other parts of the city. This area was hosting some small village settlements and a few numbers of low-density gated housing estates prior to the opening of the Kanuni Sultan Süleyman Boulevard in 2006. Two high-rise housing developments were built in the south of the boulevard in 2012; one by a private investor and the other by the Housing Development Administration of Turkey (TOKI), which has become Turkey's major mass-housing developer during the last two decades. Since then many new buildings were constructed around the boulevard and urbanized its vicinity.

Various maps are developed in the scope of this paper to show the speed of the urban expansion the relation of the solids and voids, the type of the housing units, greenery, programmatic and transportation analysis of the site and the visual experience of and around the boulevard. The urban sprawl of the city of Ankara during the last two decades shows that the city has majorly expanded through its west and south-west axis. (Fig. 1) The solid and void relation of the urban texture shows that buildings are detached and freestanding and they do not compose well-defined open spaces along the boulevard. (Fig. 2) The study area has many low and high-rise housing settlements and the high-rises are located mostly along the boulevard while the low rises, most of which are gated communities, are located on the inner parts. (Fig. 3) These houses are mostly very luxurious and address the upper middle class. Parks and public spaces are mostly privatized and there is a lack of programmatic diversity and public facilities (i.e. health and education). (Fig. 4) Public transportation is limited as well since there are only few busses, all of which connects the area to the nearby metro stations only. Therefore, there is no direct access to the city center via public transportation and using private cars is encouraged. (Fig.5) The area has no identifiable texture and density but embodies just an agglomeration of distinct object-buildings. (Fig.6)

The selected example from the city of Ankara illustrates how the newly urbanized periphery of the city do not have a clear form. The area utilizes the high-rise urban block for its territorial expansion without offering any public spaces, mix-use activities, and social integrity and multiplicity. The speed of urbanization was intensified with the addition of the basic infrastructure (i.e. roads and boulevards) without any control on its urban form and texture. Buildings are isolated and self-standing; they do not offer well-defined borders. Open spaces are vast and undefined and they are mostly privatized. The entire land is homogenous, neither the built form nor the open areas have a distinct identity. There is neither clearly defined public spaces nor social diversity. By referring to Louis Wirth's seminal article "Urbanism as a Way of Life" dating 1938, Lévy $(2008,66)$ argues "density and diversity represent a good measure of urbanness, which can be defined as what makes a city a city." Then, the mentioned analyses of the urban sprawl in Ankara brings the question of do we live in cities or in merely urbanized territories? Could architecture have any agency in the making of cities rather than acting merely as a tool serving the pervasive urbanization of the entire territory? 


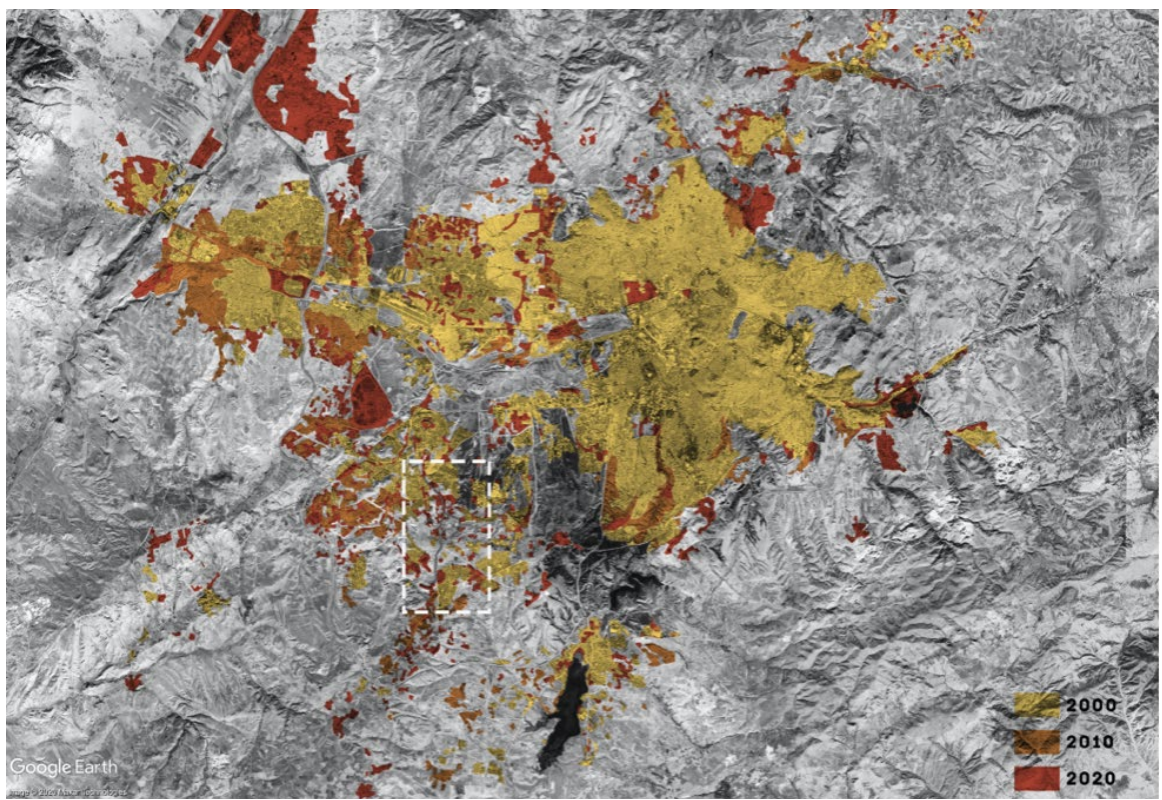

Figure 1. Urban sprawl in Ankara during the last two decades. White dash line indicates the study area. Source: (Komez Daglioglu, Guler and Sahin 2020)

\section{6}

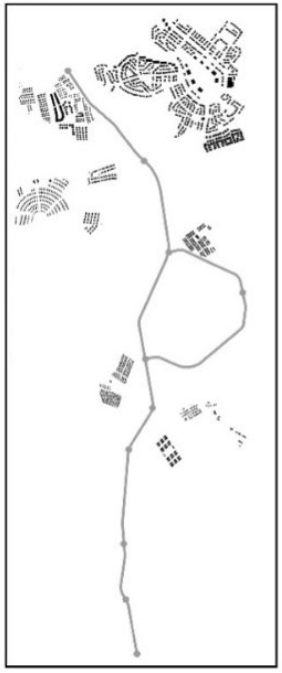

2012

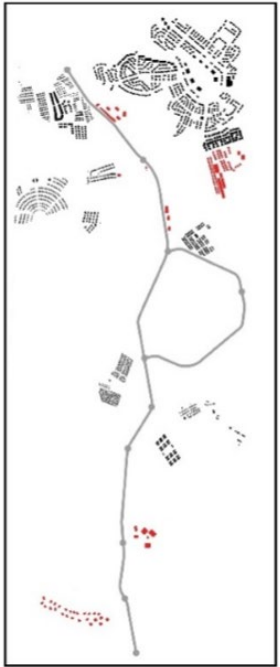

2018

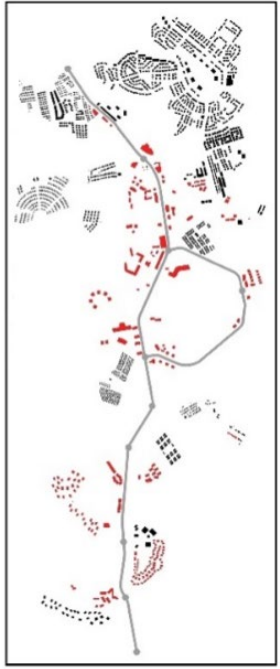

Figure 2. Urban texture and the process of the urbanization around the boulevard since 2006. (Komez Daglioglu, Guler and Sahin 2020) 

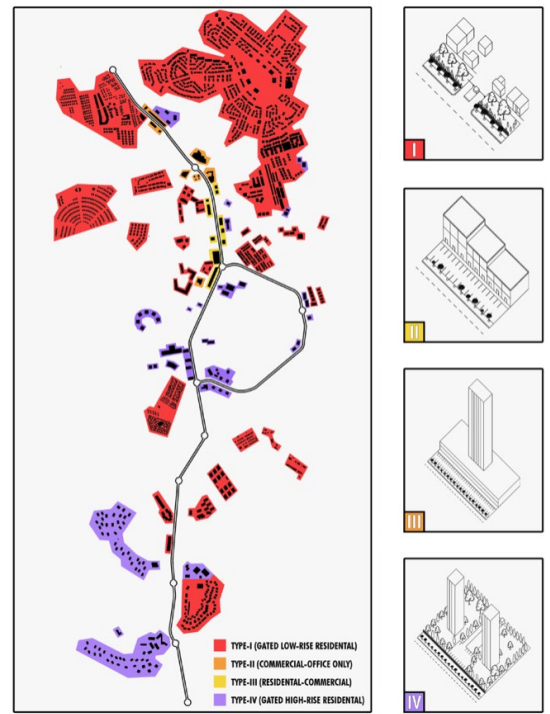

Figure 3. Distribution of the different building typologies around the boulevard. Source: (Komez Daglioglu, Guler and Sahin 2020)
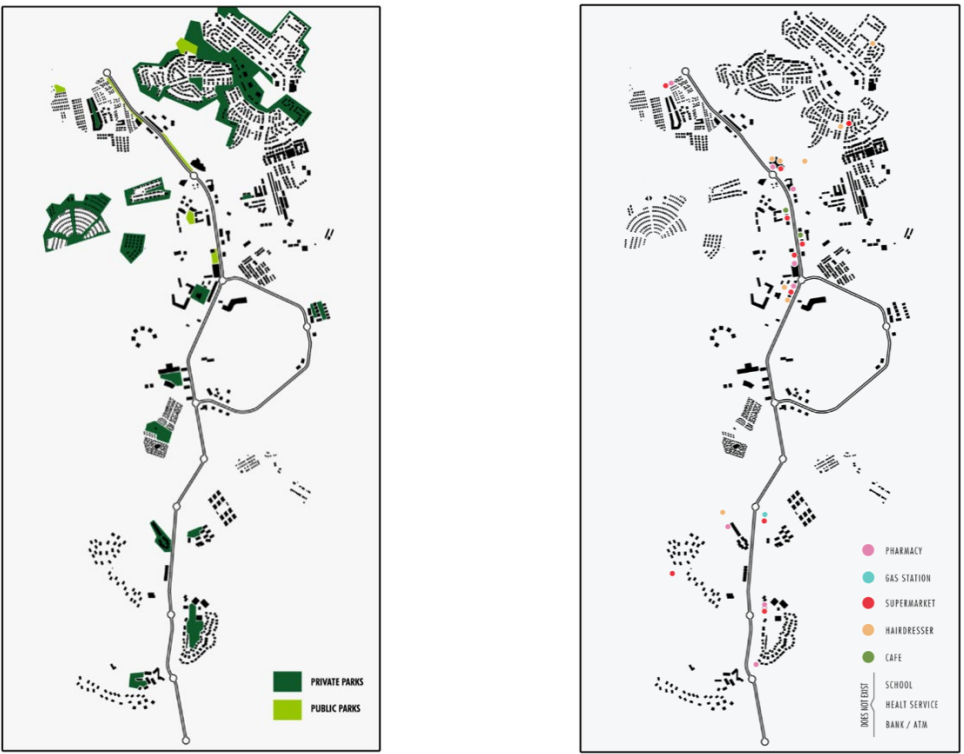

Figure 4. Left: Distribution of the public and private parks around the boulevard. Right: Commercial and public programs around the boulevard. Source: (Komez Daglioglu, Guler and Sahin 2020) 


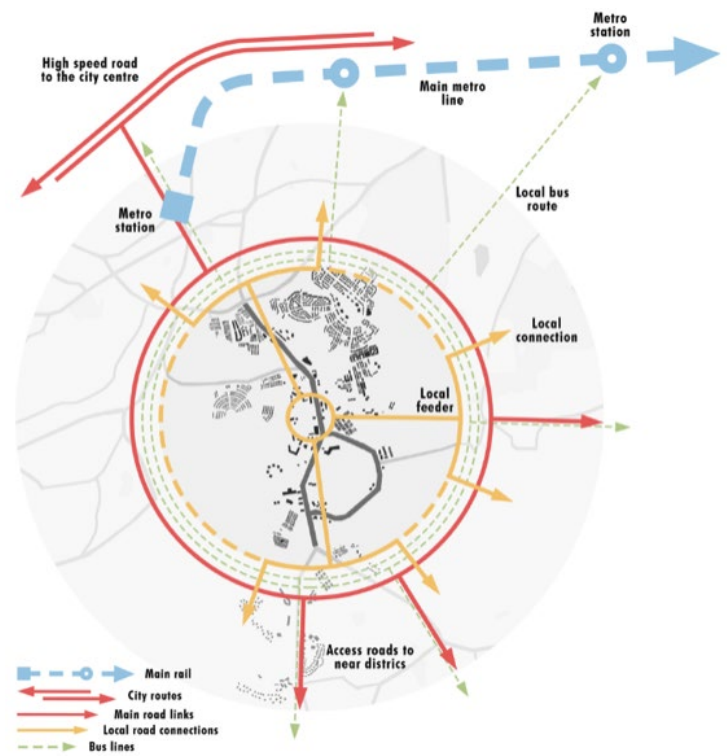

Figure 5. Analysis of the transportation systems in the study area. (Komez Daglioglu, Guler and Sahin 2020)

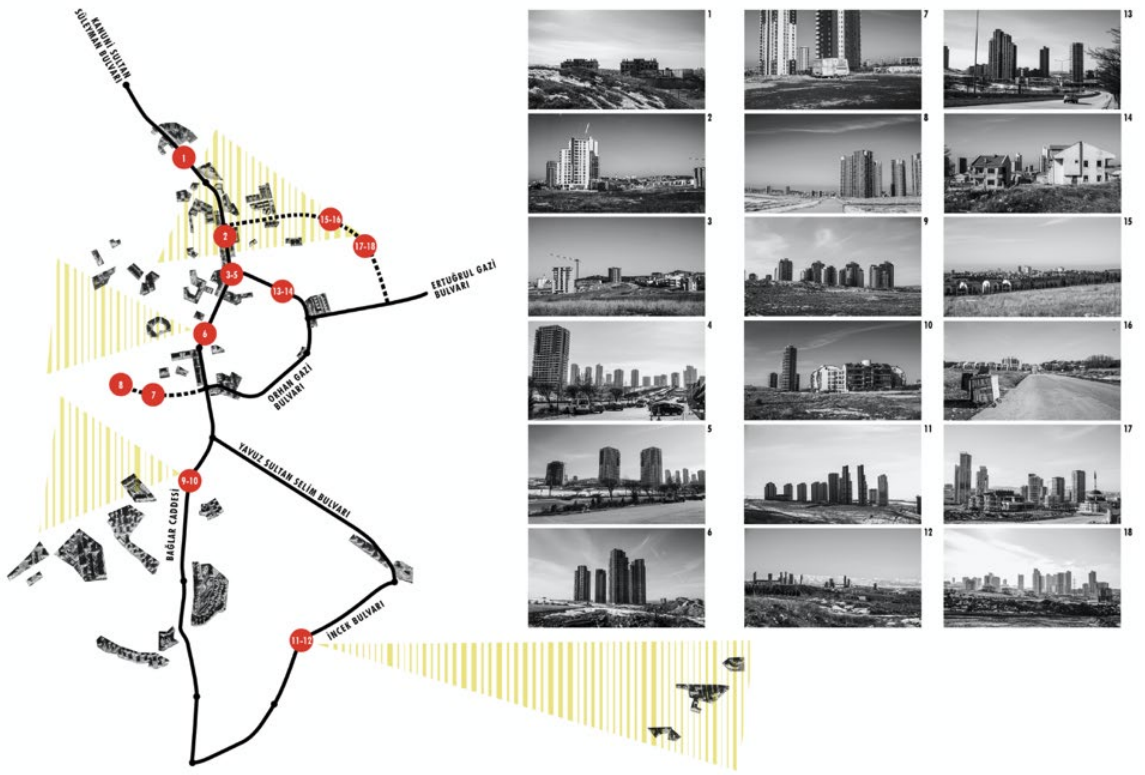

Figure 6. The character and the experience of the built form around the boulevard. (Komez Daglioglu, Guler and Sahin 2020) 


\section{DISCUSSION}

How should we design open cities when the speed of urban sprawl is enormous and reached the planetary scale? If we return back to Sennett, he claims that open cities can be designed through ambiguous edges, incomplete form and unresolved narrative. Firstly, in defining ambiguous edges, Sennett $(2019,127)$ refers to the distinction between boundaries and borders by stating that "the boundary is an edge where things end; the border is an edge where different groups interact." Thus, Sennett (2019) argues, we should design porous borders, which could enable more interaction among different communities, against strictly defined boundaries. In other words, edges of the cities should not be designed as a welldefined boundary but as a permeable border. Secondly, Sennett $(2019,128)$ proposed incomplete form so that a building "can be added to, or more importantly, revised internally in the course of time as the needs of habitation change." Therefore, flexibility and participation are significant aspects of architectural and urban design in achieving open cities. Thirdly, Sennett (2019, 128) states that design starts with a narration but this narrative does not need to be linear and completely clear but it could rather be a discovery of exploring the unforeseen. Therefore, the design should aim for exploration rather than over determination.

Sennett's discussion on open cities is crucial for reminding architects and planners the fundamental aspects of cities. However, the three strategies he proposed for the design of open cities - namely ambiguous edges, incomplete form and unresolved narrative underestimates the potentials of architectural form in enabling the spaces of the public and the political in cities. The analysis of Ankara's urbanized periphery shows that urban sprawl provides closed cities even though there is no total design, clear narrative or the over determination of the urban form. It is clear that open city does not truly mean open form and a well-defined form can truly lead to open cities if "a sharpened formal consciousness in architecture is [understood as] a precondition for political, cultural, and social engagement with the city" (Aureli 2011, back cover). As Sennett $(2019,126)$ argues, "an open city can well be designed". Perhaps not through porosity, incompleteness and ambiguity but through rigorous experimentation on defined, limited and bounded architectural form. Therefore, against Sennett's emphasis on porous borders, incomplete form and lack of clear narratives in design, this paper suggests Aureli's "absolute architecture" as a means to achieve the architecture of the open city.

In defining absolute architecture, Pier Vittorio Aureli (2011, xiii) emphasizes "the autonomy of the project, for the possibility of architectural thought to propose an alternative idea of the city rather than simply confirming its existing conditions." $\mathrm{He}$ proposes absolute architecture as a finite form that resists violent urbanization. In other words, Aureli (2011) introduces form as a precondition for both the autonomy and engagement of works of architecture. In this regard, architecture's critical position towards the city could be achieved through its separation of itself from its other - the space of the city - and in this way separation turns into a political action (Aureli 2011). Aureli's (2011) examples of absolute architecture are various such as Andrea Palladio's ideal villas, Piranesi's map Campo Marzio, ÉtienneLouis Boullée's visionary projects, and Oswald Mathias Ungers and Rem Koolhaas' The City within the City - Belin as a Green Archipelago proposal. All these examples are from different periods and in different scales, but what they share in common is their deliberate elaboration of architectural form, the underlying concern of which is the city at large and its transformation. In short, "architectural form" has to be reclaimed if we wish to reclaim the idea of the (open) city. 


\section{CONCLUSION}

Today, architects, architectural theorists and educators are rather ineffective in discussing the problems of contemporary urbanization and in projecting an alternative idea of the city. In fact, various visions towards the making of cities have been developed throughout the history of the discipline. On the one hand, many architects offered utopian projects in the 1960s and 1970s to criticize the existing conditions of cities and societies and to imagine an alternative future such as Archigram's Walking City and Plug-in City, Superstudio's The Continuous Monument, and Archizoom's No-Stop City. On the other hand, Colin Rowe's (1978) Collage City and Aldo Rossi's (1976) "The Analogous City" could exemplify how architects could offer real or hypothetical models to bring solutions to the problems of the existing urban questions. Today, we need more than examining and analyzing the conditions of the contemporary cities as offered by "learning from" studies, which were epitomized by Robert Venturi and Denise Scott Brown's (1977) Learning from Las Vegas and later reutilized by Rem Koolhaas in his Harvard Design Studio's "Project on the City" series. What architects could offer is to envision alternative images for the city against the fading of cities under the threat of unlimited urbanization. This is not a call for total design or social engineering utopia but rather a proposal for searching the potentials of architectural form, which takes into consideration the city at large. As Aureli $(2011,46)$ argues, "architecture must address the city even when the city has no goal for architecture."

\section{ACKNOWLEDGEMENTS}

This work is supported by Research Fund of the Middle East Technical University. Project Number: 10276. I am thankful to the researchers of the project Ilayda Guler and Umut Bora Sahin for the analysis and their visualization. 


\section{REFERENCES}

Arendt, Hannah. 1958. The Human Condition. Chicago: University of Chicago Press.

Ash, M. 1969. Regions of Tomorrow, Towards the Open City. London: Evelyn, Adams and Mackay.

Aureli, P. V. 2011. The Possibility of an Absolute Architecture. Cambridge, MA: MIT Press.

Batuman, B. 2013. "City Profile: Ankara." Cities 31: $578-590$.

Brenner, N. 2014. "13 Theses on Urbanization." In Implosions/Explosions: Towards a Study of Planetary Urbanization, edited by Neil Brenner, 181-202. Berlin: Jovis.

Friedmann, J. 2002. "City of Fear or Open City?" Journal of the American Planning Association 68: 237-243.

Geddes, P. 1915. Cities in Evolution: An Introduction to the Town Planning Movement and to the Study of Civics. London: Williams \& Norgate.

Ipsen, D. 2005. "The Socio-spatial Conditions of the Open City: A Theoretical Sketch." International Journal of Urban and Regional Research 29: 644-653.

Lang, R. 2003. Edgeless Cities: Exploring the Elusive Metropolis. Washington DC: Brookings Institution Press.

Lévy, J. 2008. "Measuring Urbanness." In The City: Critical Essays in Human Geography, edited by J. Lévy, 65-75. London: Routledge.

McGrath, B. and Shane, G. 2012. "Metropolis, Megalopolis and Metacity." In The SAGE Handbook of Architectural Theory, edited by C. Greig Crysler, Stephen Cairns and Hilde Heynen, 641-655. London: SAGE.

MVRDV. 1999. MetaCity / Datatown. Rotterdam: 010 Publishers.

Neuman, M.and Hull, A. 2014. The Futures of the City Region. London: Routledge.

Porqueddu, E. 2018. "Toward the Open City: Design and Research for Emergent Urban Systems." Urban Design International 23:236-248.
Rieniets, T., Sigler, J. and Christiaanse, K. 2009. Open City: Designing Coexistence. Amsterdam: SUN Publishers.

Rossi, A. 1976. "The Analogous City: Panel." Lotus International 13: 4-9.

Rowe, C. and Koetter, F. 1978. Collage City. Cambridge, MA and London: MIT Press.

Sennett, R. 2019. "The Open City." Lotus International 168 (January): 117-129.

Sennett, R. 2018. Building and Dwelling: Ethics for the City. London: Penguin Books.

Sennett, R. 2017. "The Open City." Filmed October 2017 at Harvard GSD Talks, Cambridge, Massachusetts. Video, 1:33:48. https://www.youtube.com/ watch? $=7$ PoRrVqJ-FQ

Venturi, R., Scott Brown, D. and Izenour, S. 1977. Learning from Las Vegas. Cambridge, MA: MIT Press. 


\title{
PAPER \#2.05
}

\section{GREEN INFRASTRUCTURE AS URBAN PLANNING REGULATION OF PUBLIC RESIDENTIAL NEIGHBORHOODS}

\author{
Andrea lacomoni ${ }^{\mathrm{a}}$ \\ aniversity La Sapienza, Rome, Italy
}

\section{ABSTRACT}

The construction of public city, intended as the set of public components related to public spaces, green areas, equipment, mobility, social residences, invents the structural objective to be placed at the base of any planning strategy, as well as regeneration of the city. Hence the need for new cognitive and design strategies, as well as a rethinking of the reference models, typical of the traditional urban society, starting from an integrated, intercalary approach that recovers significant relationships between theory, practice, physical dimensions, economic and social change.

The objective is to set a reflection on the role of the green axes for the redevelopment of popular neighborhoods in the broader theme of green infrastructure as urban planning. Residential districts, potential green lungs, can constitute a "green network".

It is part of the broader disciplinary sector that involves "resilient cities and green infrastructures" as a natural aspect, but also as a response to the anthropization of mobility. This highlights, within the public space, a decisive role of landscape and infrastructures which, when combined, contribute to the broader regeneration, through a design method in which the contextual analysis is the element on which the hypotheses of metamorphosis, as Grassi (1999) reminds us, of conformation with respect to the place itself of the intervention, wherein this meeting the place, which takes on a new form, is modified as well.

The contribution will reflect on the sustainable development of the city, highlighting useful elements to be disseminated to civil society, valid not only for understanding the places in which we live but for the changes taking place, knowing that

building means collaborating with the earth, impressing the sign of a man on a landscape that will remain forever changed, contributing to that slow transformation that is the very life of cities (Yourcenar, 1951)

\section{KEYWORDS}

Neighborhoods; public space; green infrastructure; urban regeneration; urban project.

\section{INTRODUCTION}

The contribution is part of the debate on the theme of the quality of open spaces in public housing developments (Cicalò, 2009) which has produced over the years in a vast literature, with particular reference to the French experience ${ }^{1}$ (Garano, 1990) In this context, the contribution explores. The theme of the project of collective spaces in 
the neighborhoods of the public city (Di Biagi, 1986), characterized by a general condition of physical, social and economic marginality, as a privileged field of action on which it intervenes through the implementation field of integrated urban regeneration strategies (De Matteis, Marin, 2013), in addition to conferring a renewed identity and quality to components of the spatial relationship systems and guaranteed the possibility of building places of interaction, social cohesion and sharing (Rykwert, 2003).

Starting from the suburbs means recovering a portion of the existing city, linked to modern expansion, because the suburbs have particular identity thicknesses that are linked to the political and economic history of our nations, which in the last century saw a flourishing period of expansion, in detail linked to the residence. For example, in Italy, they arouse a lot of interest in public residential building districts born after the war following various national laws ${ }^{2}$ which led to the construction of significant architectural works, but which did not have the "urban weight". Because the relationship with the other parts of the city was grafted, above all due to the lack of definition of the public space. Thus, following the evolutionary processes of contemporary cities, the problems of public neighborhoods are increasingly accentuated, highlighting a lack of services, connections and general quality of public spaces.

As already mentioned, many studies and projects have highlighted the potential of public residential neighborhoods as complex organisms of the city. Today, however, the condition of recovery must necessarily link to the environmental and natural component of the project, highlighting the potential of "green lungs" in these neighborhoods, where, very often, green standards are very high, but do not have a spatial definition. It is, therefore, necessary to look at the regeneration of these neighborhoods through sustainable models, aware of the values involved such as social equity and respect for local populations, the protection of natural resources and the agricultural use of soils, attention to real performance capabilities of existing territorial systems and their ecological fragility, the uniqueness and unrepeatability of historical, architectural, archaeological and landscape permanences.

The presented work focuses on the issue of building public green networks as a strategy for urban regeneration of residential neighborhoods, which starts from the search for thematic and perspective convergence between the disciplines of Urban Planning and Spatial Planning, of the landscape, environmental technological and design, by making theoretical and methodological approaches interact with the experimental and intervention dimension in the city and in the territory (Iacomoni, Mariano 2019). Urban regeneration interventions require the coordinations of numerous technical, administrative and social cohesion skills, to act in sharing, participating spaces and transformations actions are not only ideas but also by now practices of architecture and urban planning; practices that underlie a different planning as well as a new role of the territory project.

The contribution is divided into three parts: the first linked to the theme of green infrastructure, the second gives an account of the methodological structure adopted for the research and project phases, the third focuses on the results of the experimentation activities conducted on three areas of the city of Pisa, outlining future research prospects in the conclusions.

\section{RESILIENT CITIES AND GREEN INFRASTRUCTURES.}

For the relationship between human beings and the surrounding environment, it is important to have an overview of everything 
that can be considered territory and, at the same time, to have an organized view of the various structural and semantic changes that we indicate with the term "anthropization". It is evident that the main function within the complex man-nature system is carried out by the infrastructures and the most important for their functional value are the green ones, a network of green spaces that provides ecosystem services, at the basis of human well-being and the quality of the life.

The European Commission (2019) describes green infrastructure as

a tool intended to provide ecological, environmental, economic and social benefits through solutions in harmony with nature, to help understand the benefits it offers to human society and to mobilize the investments they support and they enhance these benefits,

acquiring a nuance that strongly connotes them with meanings linked to the ecosystem. Green areas also contribute to the cultural and historical landscape, giving identity to the places and scenery of urban and periurban areas, where people live and work. They can make a significant contribution to achieving the objectives of the European Union's regional and rural development policy, climate change, disaster risk management, agriculture, forestry, and the environment. ${ }^{3}$

The goal of an urban strategy that guides redevelopment through green infrastructures is to direct cities towards resilience to changes that are, the ownership of complex systems to react to stress phenomena, activating response strategies and adaptation to in order to restore the functioning mechanisms therefore able to contrast and mitigate climate change and its consequences. ${ }^{4}$
The "resilient city" is modified by designing innovative social, economic and environmental responses that allow it to resist (changing) in the long term, the stresses of the environment and history. Hence the need for the implementation of new cognitive and design strategies, as well as a rethinking on the reference models, typical of the city and traditional urban society, starting from an interscalar and integrated approach, which recovers significant relationships between theory and practice, understanding and proposal, between physical and economic and social dimensions of change.

\subsection{The role of urban green as a material for the redevelopment of the city.}

Some of the most recent studies ${ }^{5}$ highlight how, due to the strong climate changes, the "geographical" characteristics of the environments in which we live are increasingly changing. To go against the trend, green infrastructures can be an effective planning tool capable of contrasting and mitigating climate change and its consequences in the short and mediumterm. In particular, Greenery in the city is considered fundamental not only from an aesthetic point of view but also from an environmental one, because it combats air and noise pollution; and from the social one, because it is an occasion for conviviality and meeting. In this sense, various cities have developed strategic planning in which political regulation prevails over constructive privatization. It is thus evident that

the main function within the complex man-nature system is carried out by the infrastructures and the most important for the functional value are the green ones,

\footnotetext{
${ }^{3}$ Member States are invited to carry out a mapping and assessment exercise on the state of ecosystems and related services in their national territories: this will contribute to the assessment of the economic value of ecosystem services and promote the integration of these values into accounting systems and reporting at EU and national level by 2020 .

${ }_{4}^{4}$ Resilience does not imply the restoration of an initial state, but the acquisition of a new balance and the maintenance of functionality.

${ }_{5}^{5}$ A 2016 Guardian analysis showed that CO2 concentration has reached levels never seen in 3-5 million years. A recent study, published in the Corriere has highlighted an increase in temperatures in the coming years, which will lead to a "degeographisation" of many cities: that is that climate change will make, by 2050, hundreds of cities that will resemble meteorological, to places that today are closer to the equator.
} 
that is, a network of green spaces that provides ecosystem services, which are the basis of human wellbeing and quality of life ${ }^{6}$ (lacomoni, 2019) which determine action against climate change and to stimulate the development of a "green urban movement".

A strategic planning that has brought interesting results towards the goal of a "Green urbanism", as happened for the Strategic Plan of Barcelona, with the recovery of 200 hectares of urban areas destined for a park; Munich, where urban green and sustainable mobility are the basic axes, ${ }^{7}$ but also demonstrated in the "Urban forestry" strategies of Melbourne or Barcelona, and more generally by the systemic approach to the role of green applied by European green capitals. ${ }^{8}$ In Italy, many strategic plans have green in the center: Turin, a city in which urban quality and public green have grown a lot, in all neighborhoods; Florence, which aims to expand the offer of urban parks, by connecting a large green areas already structured as a park, located along the Arno; Pisa, with the aim of doubling the greenery in the city, plans to re-naturalize the urban environment. Precisely on this city research was carried out for a deepening of the green networks of public residential neighborhoods, in a wider urban system of public green. Research, of a design type, which led to the redevelopment of some public residential neighborhoods located "circularly" in the historic center of the city.

The reflection is supported by the explanation of emblematic projects that have regenerated and revitalized green spaces through "Regreening". Here, the spaces are reinterpreted thanks to the use of "green" as urban planning of the city, focusing on the quality of the cities and on complex strategies to be pursued and implemented continuously over time and respecting the specifics of the contexts.

The goal of an urban strategy that guides redevelopment through green infrastructures is to design social, economic and environmental responses, in which one of the objectives is to bring nature back to the city within a reasonable time interval to make cities resilient and give citizens quality of life.

Therefore, it is also worth dwelling on the green as one of the "good sustainability practices" adopted by Green Capital. This is the case of Lisbon, with the enhancement of its huge natural area just outside the historic center - Parque Forestal De Monsanto, about 1.000 hectares - sectored into equipped areas and internal ecosystems; Ljubljana covered for three quarters by green areas, where the recovery of the ancient barbed wire barrier erected during the Second World War becomes a green path of memory that connects the new large parks around the city built by recovering abandoned areas (a former landfill, a cemetery area, etc.). Still, on disused landscapes we know the interventions in the Ruhr and the most recent the Zollverein in Essen where the project has taken on an important role in managing the balance between conservation and transformation, combining the recovery of the buildings with that of the landscape in its naturalness, seeking to modify the existing green as little as possible. Unlike in Copenhagen, the green project acquires a strong environmental connotation, with the aim of combating the effects of ongoing climate change; so in the large urban park of Norrebro - 85.000 square meters -the hydrological, biological and social circuits are strengthened by creating a basin ${ }^{9}$ in which water will be collected and reused and will also become a place of biodiversity. (Iacomoni, 2019).

\footnotetext{
${ }^{6}$ It is therefore a network of green spaces that provides ecosystem services, which are the basis of human well-being and the quality of life. The green system has an aesthetic, ecological and social function, but it is also the link between the different areas of the city. ${ }^{7}$ The green system has an aesthetic, ecological and social function, but it is also the link between the different areas of the city.

${ }^{8}$ Melbourne - Urban Forest Strategy: Making a great city greener 2012-2032, Barcelona (Plan Estratègic d'Espais Lliure de Barcelona. Defined dels corredors verde urbans), Nantes, Stockholm and in particular the examples of the "Green Capital", cities that have presented a pioneering call to action, to underline the importance of cities in the fight against climate change and other environmental

challenges and to stimulate the development of a green urban movement. (lacomoni 2019)

${ }^{9}$ The concept is that of Rain Gardens, parks with portions at altitudes lower than the context, where water can be conveyed during important weather events.
} 


\section{METHODOLOGICAL APPROACH}

The methodological approach used is based on the notions of the Urbanisme des modes de vie

(Masboungi, Bourdin, 2004), and in particular on the ability to "look" at the place through the lens of the daily use of spaces, bringing back lifestyles "Premises" at the center of the urban project, for the achievement of an objective of urban quality and renewed use of public spaces, essential elements to relaunch a new urban welfare.

In all three projects drawn up, the methodological structure followed saw a first "analytical-evaluation phase", consisting of an in-depth knowledge of the components of the territory that play a structuring role, with particular reference to the landscapeenvironmental system and values historical and cultural, to the settlement and territorial context of belonging, and concerning the principles and elements characterizing the urban morphology of the settlements, the accessibility system and the system of offer of services of collective interest. A phase that is not a mere descriptive collection of analytical data, but an interpretation of the dynamics of the stratification and construction process of the territory and, as such, a fundamental moment in the subsequent organization of the rules that underlie the design choices.

The analysis phase is associated with a subsequent phase of "interpretation and critical evaluation of the territory", explained in diagrams and formulated according to criteria of a functional, ecological, formal, aesthetic-perceptive, economic and social nature, which allows identifying the values and the existing qualities on which to base the project; the potential recognizable in some components and/or the aggregations of components that can represent significant opportunities to "exploit" in the project; the risks and negative situations recognized in some portions of the territory for which the project is called upon to find suitable and adequate solutions. The implementation of territorial actions open to the participation of institutional subjects and inhabitants has prompted some questions on the meanings and forms that the places of interaction between people today can take inside the neighborhoods. Prolonged dialogue with those who daily face the conditions of often difficult living, immersing themselves in the public city to take on the gaze of those who normally live and frequent it, has allowed us to reflect on the role that physical space can play in the activation of new urban regeneration strategies, in which public action is confronted with the needs of its recipients, taking as a priority the reconstruction of a notion of the common good.

The second phase of "Design strategies and explicit objectives" allows to define the design strategies, the general and specific objectives and the degree of transformability of the systemic components, also in relation to the congruence between the forecasts of the urban tools and the design hypotheses, obtaining thus the first indications to guide the actions and the punctual interventions, graphed in the proposal of the Preliminary Structure Scheme.

The third phase is represented by the "Project proposal", with particular reference to some themes, such as integration with the surrounding area, functional mixitè, integration between private and public spaces and the consequent morphologicaltypological choice of the parts built, attention to the construction of connective public spaces of social aggregation, attention to the hierarchical system of mobility and accessibility and the integration of the green design with the settlement system and mobility ensuring the continuity of the components of the ecological network.

Regenerating the city and contemporary territories, giving a renewed centrality to the 
public space project, therefore represents a strategic perspective, a way of taking care of the city, starting from what it is currently and restoring it to its original sense of aggregation center social, because as Grumbach wrote (2003):

The shape of the city is difficult to fix. It escapes. It is precisely for this reason that we must build the base, the evidence, the permanence: the public space.

\section{THE GREEN SYSTEM OF PISA PUBLIC RESIDENTIAL QUARTERS}

The territory can be seen as a "landscape network" or as a flexible structure of "networked landscapes", therefore we face the notion of landscape as a characterized space, but also as a possible infrastructural sub-system "in" and "starting from" Territory. This has a new aggregating function, welcoming spaces of calendared activities that attract the inhabitants, identifying new hierarchies and "urban topographies". Topography originates from tópos, "place", and graphía, "handwriting", it represents the discipline that studies the procedures and systems necessary for the representation in a planimetric and altimetric scale of the terrain. In the configuration of a city, it is determined in relation to the distribution of streets, squares, monuments and the like, that is, from those elements that characterize its use and accessibility. In these topographies, we can identify a new common area in geographical and territorial terms, in which to produce original research on the theme of the intercalar project: from the city to the landscape, to architecture; where infrastructures represent the trait d'union.
Consequently, one of the future objectives may be to increase the role of nature in the city, "making cities more resilient and able to host populations with adequate quality of life levels" (Ghezzi, Daole, and Ottaviani, 2017). We previously highlighted the decisive role of green infrastructures among the strategies of the capitals characterized by very large green areas $^{10}$ and by a network of public parks more than 300 meters away from each other. Starting from 2006, the city of Pisa has undertaken design strategies to increase the well-being of its citizens in the urban area, with a global vision of the ecological infrastructure project that has provided for the interaction of three main actions developed with a finalized landscape vision. to qualitatively increase the pedestrian and cycle connections of the widespread green network of the city in its entirety (Fig. 1).

The in-depth analysis dealt with on the city of Pisa highlighted how the $2018^{11}$ Strategic Plan places green infrastructure as the basis on which to organize the territory with a desire

to indicate the stages for the sustainable and lasting development of the territory by facing changes climatic.

If it is true that green infrastructure is realized at different scales (national, regional, metropolitan, local)

Pisa has built its green infrastructure from a local scale with an over-municipal perspective, where the pillars are vegetation, the water, culture, and sweet transport;

constituting the identity of the place as the city and the architecture.

\footnotetext{
${ }^{10}$ Above all the green network of Hamburg, the Parque Florestal de Monsanto in Lisbon, the Path of Memories and Comradeship in Ljubljana, but also the green spaces of Nijmegen.

${ }_{11}$ The Masterplan, combined with the Strategic Plan approved in 2018, places the green infrastructure as the basis on which to organize the territory (Fig. 15). However, the parks and gardens of the Municipality of Pisa, with the exception of the historical ones, appear as many small particles scattered throughout the territory without connections, a typical expression of the zoning urban culture.
} 


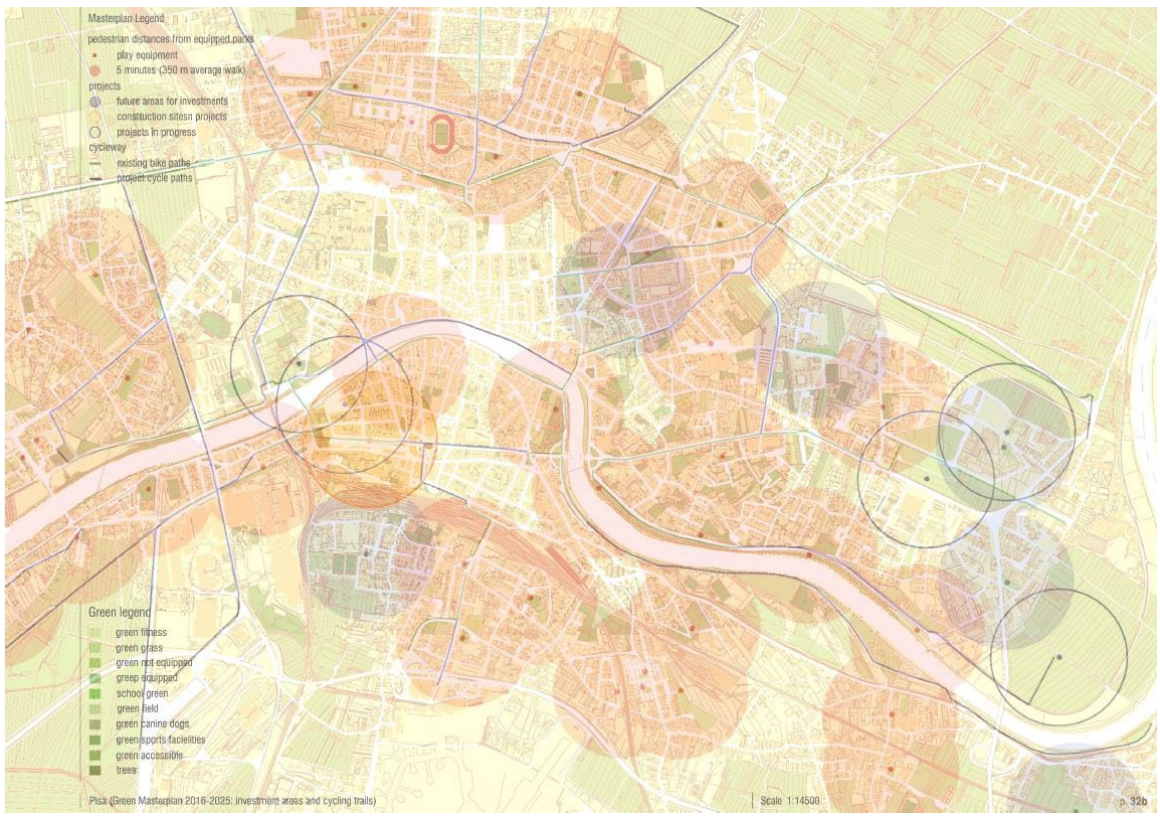

Figure 1. Reworking of the Green Masterplan in Pisa. Source: (Semprepiovi 2019)

The project research activity reported here was intended to provide the theoreticalmethodological and operational tools necessary for the experimentation, according to an integrated and interscaling approach, of a planning and design process, aimed at implementing a regeneration strategy and urban and metropolitan rebalancing, with particular reference to the design of the system of green spaces. ${ }^{12}$

The neighborhoods of public residential buildings, which historically have a good supply of greenery, are part of this green system around the capital. Therefore, it may be useful to investigate the potential of green infrastructure as a city planning regulation, in particular, the role of natural axes for the redevelopment of popular neighborhoods, potentially green lungs in a "green network".
In fact, the reconstruction of the public city (understood as the set of public or public use components relating to public spaces, green areas, equipment, mobility, social housing) is the structural and indispensable objective to be set at the basis of any regeneration strategy of the contemporary city. With this objective, in recent years, the Municipality of Pisa has undertaken a strategy for the redevelopment of public residential neighborhoods, in particular here we mention some interesting examples, partially created, but with different design approaches, such as the INACasa of Gagno neighborhoods (Fig. 2,3), the Passi and San Giusto which through the redesign of public spaces, with a decisive role of interstitial greenery (but also of the larger parks) constitute a "network" within the wider context of "Pisa is a resilient city and its green infrastructures". 
The cases, which we are not going to describe in detail, highlight the fundamental importance of the green design, as an ornamental element, but above all as an object of environmental redevelopment and implementation of spaces for socializing and relaxing.

These projects are designed as part of a larger project to naturalized the capital, in which rural, urban, public and private areas coexist, with the intention of participating in the wider strategy of "Pisa green and the resilient city".
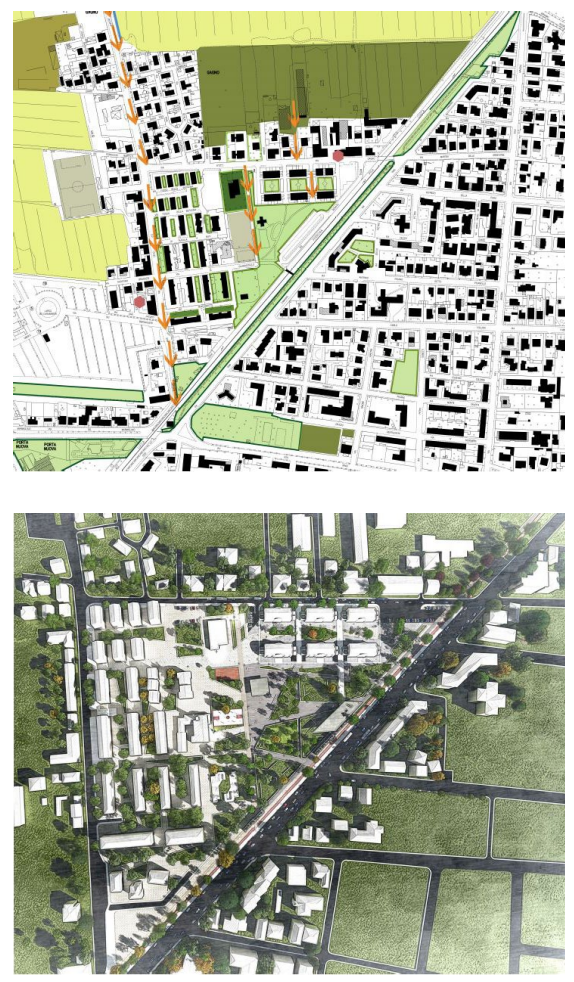

Figure 2,3. Green regeneration project of the Gagno district in Pisa. Source: (Workshop Student lacomoni 2017)
The city and the territory, in their entirety, can no longer be understood as a purely geometric physical space that must be organized and modified to satisfy the needy of the community but must be conceived as relational spaces. The real change is a new way of thinking, planning and managing the fragmentation of green areas as the only large park, through an 'urban mending' operation aimed at improving the quality of life, from primary physical needs to different recreational and social expectations; in essence, it will be necessary to radically rethink the space of the city as a whole. (Fig.4)

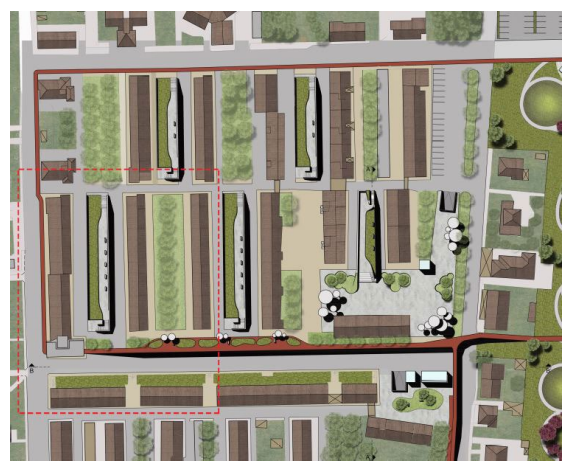

Figure 4. Redevelopment of the I Passi district in Pisa. (Student Urban Laboratory lacomoni 2016)

\section{CONCLUSION}

The public city can play a role in the activation of regeneration processes in larger areas of the contemporary city. This is due to the frequent proximity of the districts to landscape resources, infrastructural networks and nodes, centrality at urban level; the "porosity" and, consequently, the high transformation margins of their spatial structure; of the increasingly pressing demand for social housing that invests them 
today. The contribution aims to highlight a fundamental aspect for the sustainable future of cities: that of the importance of a complex and overall green strategy, both in the preparation of plans and in the individual project; approaching the goal of a green city: building a network of green, natural, manmade, agricultural or urban spaces, which is a small radius, and combined with mobility, determine an increase in the quality of the city and users. Thus, the Pisan context examined, due to its location on the edge, can easily interact with the major infrastructures in the north and south of the city by creating a network system of public housing districts. Here we can highlight the determining role of the landscape and infrastructures which, put in a system, contribute to the wider regeneration, through a design method in which contextual analysis is the element on which the metamorphosis hypotheses are defined. (Fig. 5,6)
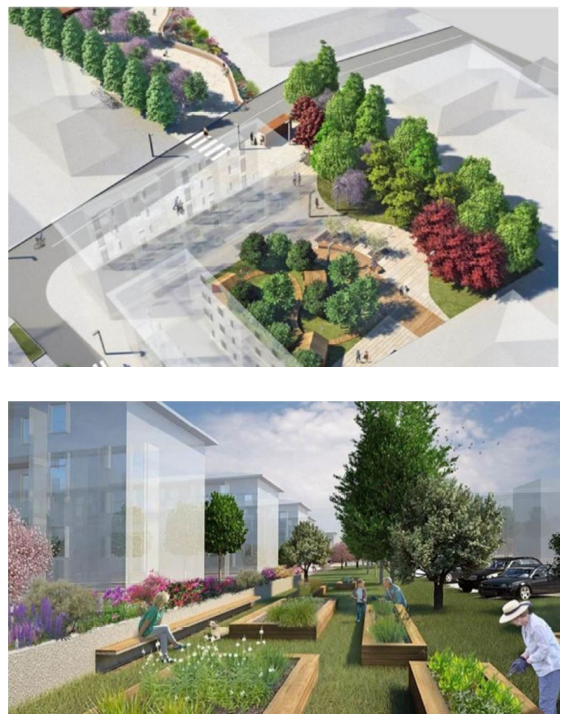

Figure 5,6. Project for the redevelopment of public, mobility and green spaces in San Giusto district in Pisa. Source: (Giraldi lacomoni Architects 2018)
In fact, through the use of a methodology that focuses directly on the knowledge of the context, the structuring systems and the figures of the spaces present in areas under study have been outlined, being able to verify how, between place and project, a relationship of change, but also and above all, as Grassi recalls, of

conformation with respect to the place of the intervention itself, wherein this meeting the place is changed as well, which takes on a new form (Grassi, 1999).

Thus, the products obtained can represent a useful document to be disclosed to civil society, valid not only for understanding the places in which we live but above all for the changes taking place in these territories, with the awareness that

\begin{abstract}
"building means collaborating with the land, imprinting the sign of a man on a landscape that will remain forever modified, contributing to that slow transformation that is the life of cities" (Yourcenar, 1951).
\end{abstract}

\section{ACKNOWLEDGEMENTS}

The projects are developed by the author (figure 5,6) and in courses and workshops held by the author (figure 1,2,3,4). 


\section{REFERENCES}

Cicalò E. 2009. Spazi pubblici. Progettare la dimensione pubblica della città contemporanea, Milano, FrancoAngeli

De Matteis M. e Marin A. 2013. Nuove qualità del vivere in periferia. Percorsi di rigenerazione nei quartieri residenziali pubblici, Gorizia, Edicom Edizioni

Di Biagi P. 1986. "La costruzione della città pubblica”, Urbanistica n. 85

Commissione Europea. 2019. Relazione della Commissione al Parlamento Europeo, al Consiglio, al Comitato Economico e Sociale e al Comitato delle Regioni - Riesame dei progressi compiuti nell'attuazione della strategia dell'UE per le infrastrutture verdi, 184 final

Garano S.. 1990. a cura di, La riqualificazione delle periferie nella città europea, Roma, Edizioni Kappa

Ghezzi, P., Daole, F., Ottaviani, G. 2017. Pisa. Piantare alberi per mettere radici. Città Resilienti, Infrastrutture Verdi, Milano, Paysage

Grassi G. 1999. "Progetti per la città antica. La mediocrità come obbligata”, Casabella n. 666.

Grumbach A. 2003. "La città, processo e linguaggio", Rassegna di Architettura e Urbanistica n.110-111.

lacomoni A. 2019. "European Green Capital. Best practive for sustainable urban development", Agathòn n. 6

lacomoni A., Mariano C. 2019. "An experience of public space regeneration in the social housing district of Gagno in Pisa", Territorio n. 89

Masboungi A., Bourdin A. 2004. Un urbanisme des modes de vie, Parigi, Le Moniteur

Rykwert J. 2003. La seduzione del luogo, Storia e futuro della città, Torino, Biblioteca Einaudi

Yourcenar M. 1951. Mémories d'Hadrien, Parigi, Librairie Plon 


\section{PAPER \#2.06}

\section{ARTIFICIALLY UNNATURAL: NATURE 2.0}

\section{Gayatri Tawari, Alka Tawaria}

aUniversity of Michigan, Ann Arbor, Michigan / CTES College of Architecture, Mumbai, Maharashtra

\section{ABSTRACT}

It is no secret that humans are biophilic species. Environment, climate and geography all play a crucial role in creating our landscape; and as shapers of the built world, we predominantly orchestrate access to it. "Connection to nature" is arguably an overused phrase in our field - in education as well as profession. Yet, it is also one of the most under designed aspects of most designs, for lack of function. We equate artificially curated "green space" or a "cluster of trees" in an otherwise non-functional space as a celebration of nature fitting into our designs; and that is where we have gone terribly wrong. We have brought the superficial openness of nature into our urban fabric, without giving it any underlying purpose or intention. Nature is function, in its entirety. John Muir has said, "In every walk with nature, one receives far more than they seek". As our cities continue growing, we need to respond with innovative and functional places of respite that offer more than just a vista to look at. From beekeeping on rooftops in New York City, USA, to repurposing a warehouse rooftop for greenhouse farming in Montreal, Canada or Prinzessinnengärten in Berlin, Germany where wasteland was converted to a thriving urban farm; there are several precedents for alternate ways of accessing, engaging, and coexisting with nature. At the rate of urbanization, density is an asset to help maximize infrastructure in the most efficient method for most people, but landscape could be our strongest tool to combat and attempt at reversing the damage we cause because of it. It cannot be solely about ornamentation or planting native shrubs anymore; it has to be our way of giving back some of what we take.

\section{KEYWORDS}

Urban landscape; city scape; city design.

\section{INTRODUCTION}

Cities have always been the center of innovation, creativity and ingenuity, ever since the concept of city dwelling came into existence. When people are put together, opportunities, ideas, wealth grow at a more influential and exponential curve, unhindered by our base number. This model has worked time and again, led to the rise, as well as fall of many cities over time. Simply put, cities are nothing but a complex network of information exchange over several different physical as well as metaphysical platforms. The bigger the city, the wider the network and thus a much larger appeal that makes people migrate to that city. The current rate of shift in residence of rural population to urban areas is expected to increase to $68 \%$ by 2050 based on a population projection study conducted by the UN. This, combined with a growing global population, needs a thorough evaluation of the spatial and utilitarian demands placed on these urban areas and the socio-political, environmental and overall wellbeing of its residents. The industrial revolution of $18^{\text {th }}-19^{\text {th }}$ century resulted in cities becoming the center of not only innovation, but also disease and miserable living conditions for its city dwellers. This then led to adoption of landscape architecture as a 
profession to help bring livability back to cities. What started out as expansion of garden designing skills, now helps create thriving and vibrant communities, while helping preserve and protect our natural environment.

An excellent historic example of this would be the ancient Aztec city of Tenochtitlan. Because the city was set at the bottom of a valley, the city would constantly flood during rains. Instead of trying to go against nature, the ancient civilization developed a very unique method of co-existing with nature and the issues that arose because of it. Along with allowing for water canals to become a source of transportation, they also developed the ingenious method of developing chinampas, or arable land created over fresh water to allow for agricultural use even in a region that was constantly flooded.

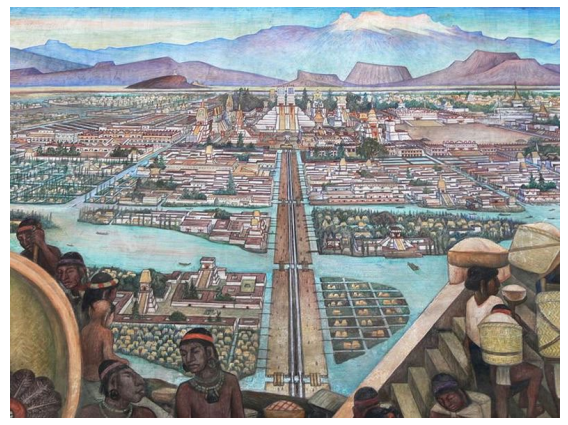

Figure 1. A mural of a market in Tlatelolco in ancient Tenochtitlan, where modern day Mexico City sits. It is currently on display at the Palacio Nacional in Mexico City. Source: (Jen Wilton 2012)

Modernization and development in modern day Mexico City later forgot these ingenious methods, and the chinampas only exist in a small region in Xochimilco at the southern end of the city.

Unfortunately, this field has yet to undergo its final transformation of adding utility to this man-made landform design. Central Park, Manhattan for instance, is one of the largest urban parks in the world, yet on any given day, it is primarily the formal and curated spaces that have the most people, while a majority of the parkland stays underutilized, because people don't know what to do there. As one of the more densely packed metropolises that is fighting for every square inch of space, does Manhattan truly need acres of sculpted and ornamental nature, with vistas of rolling meadows and curated forest patches? Would it not be more prudent to find purposeful use of this limited and invaluable resource?

With all these factors tying into the increasing scarcity of spatial and natural resources, as designers it is imperative that we look past mere ornamentation and take every opportunity to design for a landscape that offers much more than its users can imagine - because that will lead to more innovation. New Yorkers have already innovated the use of their rooftops for beekeeping all across the city. So, isn't it our duty as city designers to offer them even more access an opportunity to find ways to innovate and revolutionize our coexistence with nature?

This paper attempts to answer that question and provide support for the hypothesis that multifunction landscape design is the need of the hour to create an environment where nature is function. Regardless of any calamity in the past, nature has sustained and survived for the future. Nature finds a way, because it has a purpose. Cities will need a first line of defense against several of the effects of global warming, and our built world cannot afford functionless ornamentation any more. Our landscapes will define not only livability but also resiliency against the impending climate change repercussions.

\section{CRITIQUE OF MODERN DAY URBAN LANDSCAPES}

\subsection{Origin of Landscape Architecture}

Historically, landscape architecture originated from the garden design skills of transforming 
landforms with the use of water and vegetation and applying it to man-made spaces. It created an ornamental vista to look at and is comparable to a work of art. These spaces provided a much needed respite from the industrial world and added a certain softness to the cities. These oasis pockets are vital in the social fabric of a city as they offer opportunity for interactions and cultural engagement with the rest of a community.
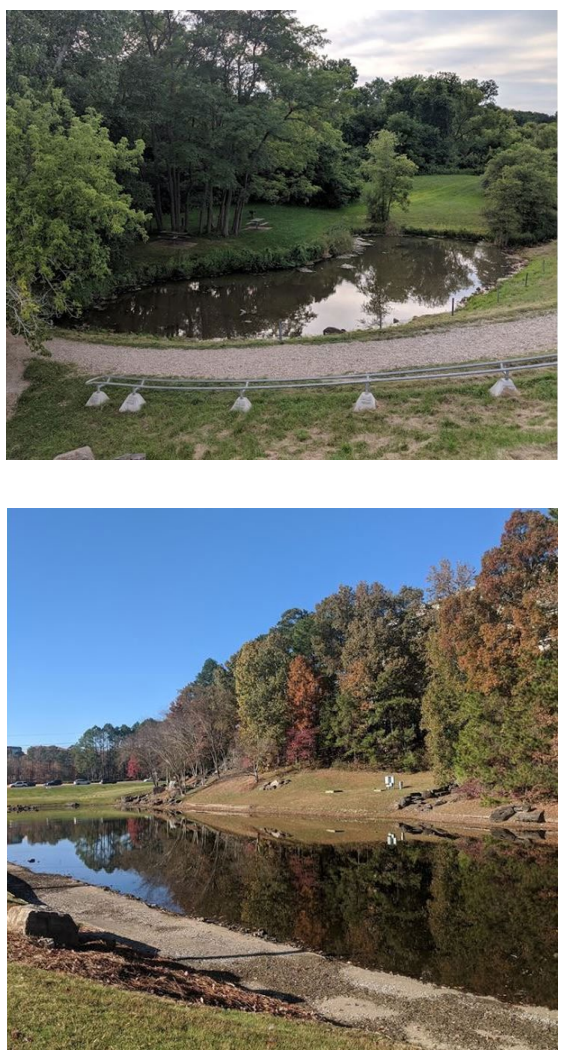

Figure 2. Undefined function in parks often go unused or are underused because people don't know what to do with the space. Up: Ann Arbor, Michigan; Right: Birmingham, Alabama. Source: (Gayatri Tawari 2019)

\subsection{Influence of Landscape Architecture on Cityscapes}

The result of landscape design are beautifully sculpted gardens with minutely curated experiences ranging from a forest trail to a tranquil pond or a bustling fountain in the middle of a plaza and rolling meadows around. Any and all leftover space is then turfed over with grass and adds yet another useless greenspace to our cities. Huge areas of land are just carpeted in green, with wasted potential for resiliency opportunities. Apart from possible urban farming opportunities, these could be used for storm water capturing, or by planting naturally purifying plants these could be used as sites for purifying greywater that could then be distributed for other landscape functions.

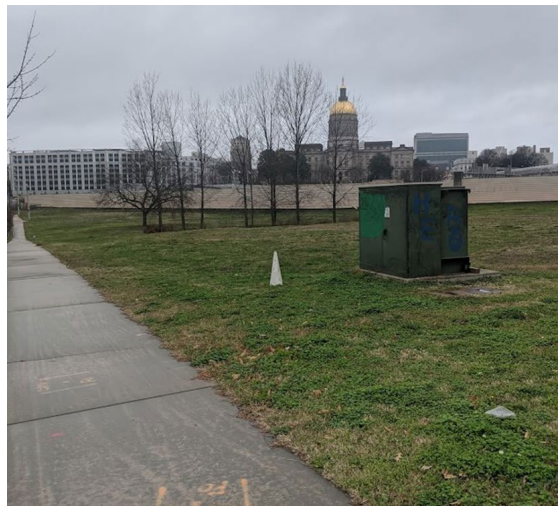

Figure 3. Giant fields of unused and purposeless green space is blocked off from the surrounding neighborhoods in Baltimore, Maryland. Source: (Gayatri Tawari 2020)

\subsection{Influence of Landscape Architecture on Streetscapes}

The modern day street landscape is limited to ornately lined trees, potted shrubs if any, and medians on street covered with turf. That's a lot of real estate in the public domain that has 
absolutely no inherent value - ornamental or resilient. The trees are restricted because of surrounding buildings, and people can barely even use the medians because there's no function associated to it. Just because it is leftover, doesn't mean it should be ignored or left purposeless. The fact that we're not asking questions like, "What could be a more efficient and optimum use of this space?" serves as a reminder, that we treat nature as a leftover entity in our city planning. Anything that is too random a shape, or is a no man's island is converted into a green lawn.

\section{PRECEDENTS}

Humans are very creative and given the right framework find opportunities in the unlikeliest of scenarios. Israel as a country is an excellent example of resiliency and transforming public lifestyle to work towards the collective aspiration of conserving water. Their water usage efficiency, including agriculture and everyday usage, is at $92 \%$. So today, a landlocked nation with no source of fresh water is not only self-sufficient, but is also exporting high quality potable water to its surrounding nations. Is anything truly impossible if we lay the groundwork out for the unknown innovations from the onset? This is the type of ingenuity we need to allow for in our city planning from the onset. How do we create the optimal policies and spaces for our city dwellers to flourish and innovate unhindered? Following are some example of radical land and space usage that outline the benefits of alternative methodologies.

\subsection{Beekeeping in New York City, USA}

Urban beekeeping exploded in the city in around 2010s as more and more residents started maintaining bee farms on the rooftops of their buildings. Once they realized the functionality and ease with which they could adapt their interest to their geographic location, it has caught on more interest. There is an official beekeeping society as well as several certificate programs for amateurs who are interested in pursuing it as well. From setting up local honey farms, to creating a lot of awareness for environmental benefits for the beekeepers as well as the other residents of the building, it has ended up bringing together a community and setting up the situation for creating other creative outlets as well.

In recent times, the bee farms are doing so well that the bees are running out of forage and have to go a further distance for flowers. This creates an interesting opportunity for city planners to come up with a solution to this unforeseen issue and leads to question how the planning laws and regulations need to be written to account for the unknown.

\subsection{Rooftop farming over industrial warehouses in Montreal, Canada}

Lufa Farms is a local company in Montreal that is making tremendous progress in making urban agriculture hyper local and sustainable. Rooftops are a grossly underutilized building surface, especially in large industrial complexes where there can be no other use added on to the structures. By converting that space to introduce vertical farming, hydroponics and other innovative urban agriculture methodologies, they will be able to feed $2 \%$ of the local population with very sustainable, local and fresh produce. This solution does not require more intervention than setting up greenhouses over existing rooftops. Imagine, with the right resources and tools if every community could set up a smaller version for themselves, while relying on these larger farms for a bigger proportion for distribution, it would bring resiliency to every household. If we think if this as a kit of parts, this solution reads as a hyperadaptable one, because in other climate zones, it could be modified to be conducive to the microclimate of any area and only use the 
technology and infrastructure necessary for that particular area.

While their largest farm will be about 15,200 square meters, this could also be accommodated on the smallest of roofs for the basic necessities. The trans-scale applicability of the solution is yet another perk, that will make it relatively easy to plan for it from city design and city planning point of view. From creating jobs to boosting the local market, this method also promotes a healthy lifestyle with very little carbon footprint by reducing transportation, and thus long distance storage requirements.

\subsection{Urban gardening in a decrepit land in Berlin, Germany}

Prinzessinnengärten is a 6,000 square meters site, is an example of a community and neighborhood coming together to create and urban oasis which continues to add on to the city's eco-friendly drive in every aspect. By encouraging the drive to go hyper local and instill a sense of well being, the community came together to turn a desolate area into a lush oasis that provides plentiful produce every season. Staying local also helps appreciate the seasonality of farming, because to grow out of season crops requires that many more resources or it increases transportation costs to have the produce shipped in. Instead of just an urban garden, this space has become the center of the social fabric where residents across multiple groups come together to learn and change their lifestyle.

This, in tandem with social initiatives could serve as a wonderful opportunity to push for urban renewal and revival efforts for a city struggling to do so.

\section{OPPORTUNITIES}

Modern day cities are practically built out, any new construction is a series of negotiations between what is existing and how we can accommodate more. This opens up a lot of scope of innovation, creativity and strategic planning for ensuring we enable our cities to be able to deal with any challenge, instead of disable them to respond to their own needs. Like the electronics industry, this is the perfect opportunity to focus on compact, smaller scale interventions that then go on to create a much larger impact on the built environment. No space can be wasted and if anything, the smaller the space the bigger the challenge to repurpose it with efficiency way beyond its means.

\subsection{Copenhagen's response to climate change}

Copenhagen created a plan to tackle climate change and flooding caused due to rains in the city along with rising sea levels by developing a network of blue-green infrastructure throughout the major arteries with the hope of providing ample functional green space during the dry season while transforming into lakes and areas for the storm water courses to capture large amounts of storm water. This helps create responses for several key parameters that get affected due to flooding on streets, from traffic congestion, to lack of space for pedestrians to safely navigate the area. This blue green infrastructure is also very functional in the sense that it is relatively low tech. By employing highly permeable substructure and vegetation it reduces the need to build complex underground drainage tunnels that take up a lot of cost for maintenance and are unused in the dry season. But this solution is usable at all times and has tremendous storage capacity without heavy infrastructural intervention.

Compare this with the functionless green medians found throughout US streetscapes, which offer absolutely no resiliency to the street network and end up creating danger road conditions for automobiles. The bluegreen infrastructure also allows for park space to be broken down and distributed throughout the city instead of as just one localized point. By creating this blue-green networks in major activity areas also creates an 'eye on the street' 
situation which helps add security and the peace of mind for people to engage with and enjoy this beautiful yet functional amenity.
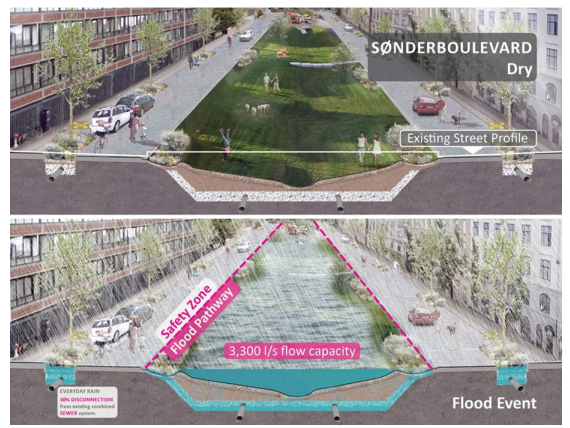

Figure 4. Ramboll Studio's vision for streetscape transformation by building resilient landscape to accommodate flooding situations in Copenhagen. Source: (Atelier Dreiseitl 2015)

\subsection{Mexico City's response to growing urban farming needs}

Mexico City has an ancient tradition of collective farming called ejido lands. In ancient times, a community would develop around a farmland and cultivate crops together by sharing ownership of the land. In 2017, I explored one possibility of bring that tradition to modern times and applying it to the present day space crunch and growing population demand the city faces. Already there is a major initiative underway to transform all the major bridges and public infrastructures like flyovers into a green belt using vertical landscape and other methodologies to help offset the ecological damage and pollution in the city. Continuing that effort further, vertical farming solutions can help solve the issue of the farmlands that no longer exist in a city running out of space. If the shared walls and roofs of buildings are treated as the surface for farming, the collective ownership can instead be found on the perimeter of buildings instead of on flat land along it.
This collective ownership could result in various groups coming together and forming a tighter community when one group runs out of space or ends up having a much higher demand that they can sustain. Mexico City also has a very strong informal economy set up, and this system could aid in the development of processes to formalize some of that system into mainstream economy. Exterior walls and roof tops are highly underutilized blank canvases that present a prime potential to push for hyper local farming and investments in local economy.
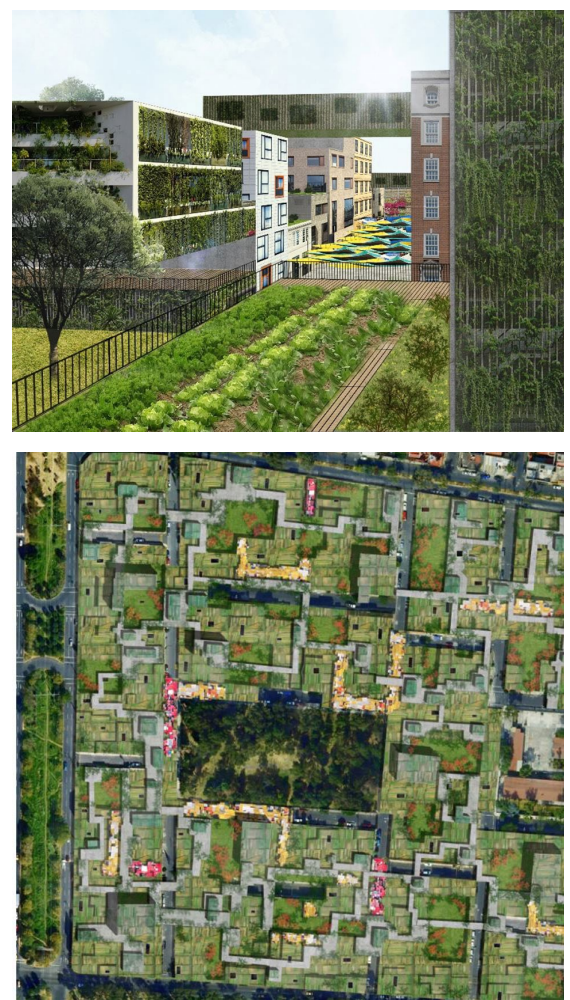

Figure 5. An exploration of using the present day shared ownership surfaces of exterior building walls and roof tops as the ejido land for urban agriculture. Source: (Gayatri Tawari 2017) 


\subsection{Mexico City's response to growing flooding and land sinking crisis}

Mexico City is a city of paradox, in that it has simultaneous land sinking crisis due to underground water table depletion as well as seasonal flooding and severe damage to existing infrastructure in the city. A lot of it has to do with the fact that the city actually sits at the basin of an ancient lake, drained out by the Spanish invaders to establish modern day Mexico City. Due to this, water naturally pools into the streets as it has no where else to go, but none of this water is captured for later use. At the same time, population explosion has resulted in overuse and of the underground aquifer system which has resulted in the overall land sinking by several inches since the depleted water is not replenished.

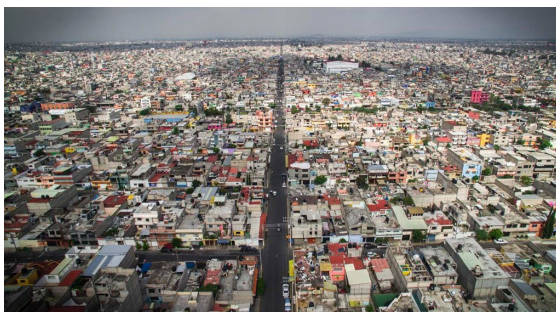

Figure 6. Modern day neighborhood of Nezahualcoyotl, Mexico City. Source: (Johnny Miller, 2016)

As the international airport in Mexico City is going to move to a different area, the current airport site presents a tremendous opportunity to deploy forward thinking urban planning policies as well as for researching some solutions to develop resilient planning in the city. I researched the design implications of integrating a blue-green infrastructure into the neighborhood level breakdown to help capture seasonal flood water, and through naturally permeating and filtering processes help replenish the underground water supply as an effort to stabilize the land sinking - thereby targeting and solving both problems with one relatively low tech solution. Neighborhood level bioswales would transform into small ponds and the bioswales along the major arteries would work as rivers carrying the water away and retaining any surplus water. This water would naturally filter through the permeable streets and pavements, soil and other vegetation, and make its way into the underground water system. Throughout the exploration, conscious effort was made to keep the fundamental ideology of existing social fabric as is, while providing strategic planning at critical points to have the maximum benefit with minimum intervention.
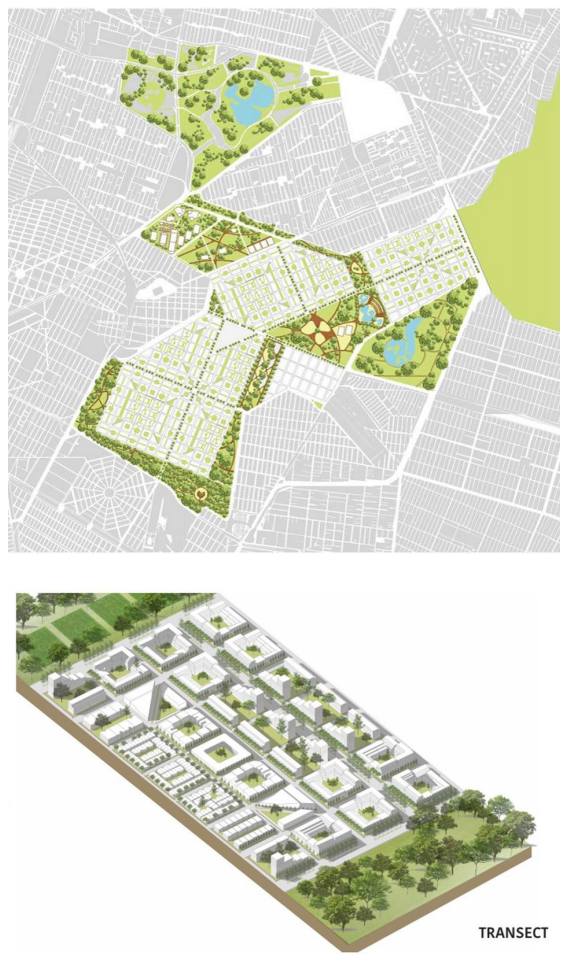

Figure 7. An exploration of blue-green infrastructure broken down by neighborhood level to help offset the seasonal flooding in Mexico City and to help alleviate land sinking issues as a result of underground water depletion. Source: (Gayatri Tawari 2016) 


\section{CONCLUSION}

The reason landscape architecture is so important now and for our future, is because it is not absolute. The public domain that we develop through it is permeable, and fills in the spaces between the heavy infrastructure and building that are crucial to creating a dense urban footprint. Landscape design is our tool not only to provide for immediate needs but to also be prepared for what awaits our fragile environment due to global warming. Our urban landscape will be the one major force that holds the entire fabric of our social construct. Imagine losing access to farm lands that are flooded with water, and having warehouses ready start producing our food through aeroponics or hydroponic farming systems that are built throughout the city. Imagine having entire waterfronts and street networks be prepared to stop and accommodate floods from rising sea water levels, that life doesn't need to come to a standstill.

Urban landscape needs to be ready for rapid transformation because there's only so much space and even that is endangered. We as urban dwellers, need access to nature, but can no longer afford it to be just a visual or sensory experience. Instead of just seeking an experience, we need to learn how to coexist with nature because it will require a lifestyle change from us, and that cannot be an overnight change. The nature around is in constant flux, to expect it to stay the same despite all the damage that over consumption has caused it, is going to be a big disadvantage for the pursuit of solutions. The sooner we realize the problem, the sooner we can start finding better and more meaningful solutions to remedy it. The sooner we remedy it, the better our future generations can flourish and not be left to deal with the mess that our inaction will have created.

Nature is function, in its entirety. Nature is not superficial and nature does not serve one sensory experience alone. Nature doesn't need preservation, because nature is resilient, she will survive. What we need is to learn adaptability, learn to transform. Until we do that, it is a disservice to claim that we emulate nature in our designs.

\section{ACKNOWLEDGEMENTS}

I would like to thank my professors - Maria Arquero De Alarcon and McLain Clutter at University of Michigan, Ann Arbor for always making me to push the boundaries of research and pursuit of solutions for the many problems plaguing our world today. I would also like to thank Prof. Alka Tawari for always providing the most meaningful encouragement and to never stop seeking new problems to solve. Seth Seigel's book "Let There be Water" has played a tremendous role in increasing my curiosity and interest in the State of Israel for developing top down policies that create for some of the most innovative problem solvers and what governments and nations need to do to sustain ingenuity. I hope to further my research and studies into public policy because of it. 


\section{REFERENCES}

Cichanowicz, Lily. "Urban Gardening: A Look at Berlin's Prinzessinnengärten." Culture Trip. The Culture Trip, October 17, 2016. Accessed March 2, 2020. https:// theculturetrip.com/europe/germany/ articles/urban-gardening-a-look-at-berlinsprinzessinnengarten/.

Wilton, Jen. "Diego River mural in the National Palace, Mexico City" Flickr. Yahoo!, November 14, 2012. Accessed August 28, 2020. https://www.flickr.com/photos/ guerillagrrl/8185829539.

Kimmelman, Michael. "Mexico City, Parched and Sinking, Faces a Water Crisis." The New York Times. The New York Times, February 17, 2017. Accessed March 2, 2020. https://www.nytimes.com/ interactive/2017/02/17/world/americas/ mexico-city-sinking.html.

Kunstler, James Howard. The City in Mind: Notes on the Urban Condition. London: Simon \& Schuster, 2003.

Lau, Rachel. "Montreal Company Says New Greenhouse Will Be Largest Rooftop Farm in the World." Montreal, CTV News, November 21, 2019. Accessed March 2, 2020. https://montreal.ctvnews.ca/ montreal-company-says-new-greenhousewill-be-largest-rooftop-farm-in-the-world1.4695825?cache-

Mehta, Samira. Menon, Palliavi. "Mexico City: A City That is Flooding, But is Still Running Out of Water." Water Center. Accessed March 2, 2020. https://watercenter.sas. upenn.edu/mexico-city-a-city-that-isflooding-but-is-still-running-out-of-water/.

Seigel, Seth M. Let There be Water: Israels Solution for a Water-Starved World. New York: Thomas Dunne Books, an imprint of St. Martins Press, 2017.
"Two Years After Legalized Beekeeping, City May Be Running Short on Forage: WNYC: New York Public Radio, Podcasts, Live Streaming Radio, New." WNYC. Accessed March 2, 2020. https://www.wync.org/ story/218358-urban-bees-may-berunning-out-foraging-ground/.

29.06.2016 Climate Change: Copenhagen Declares War on Floods." Drees \& Sommer, February 1, 2019. Accessed March 2, 2020. https:/www.dreso.com/en/press/pressreleases/2016/Copenhagen-declares-warom-floods/ 



\section{PAPER \#2.07}

\section{MAPPING THE PASSIVE NATURAL SURVEILLANCE THE BILBAO METROPOLITAN AREA}

\section{Iñigo Galdeano Pérez ${ }^{a}$}

aUniversity of the Basque Country, Santurtzi, Basque Country

\section{ABSTRACT}

This research focuses ontheparameterization of a generative algorithm that allows the comparative, valid and reliable analysis of the different urban morphologies in terms of security. Specifically, this algorithm is programmed to qualify and map the degree of the passive natural surveillance, a glocal principle of the Crime Prevention Through Environmental Design methodology. Thus, although exclusively architectural and morphological, this study is based on a theoretical framework and on a dialectics formed by the material feminism and the environmental criminology. The analysis, the approach and the scope of application seek the actuality, the suitability and the social relevance in the autonomous community of the Basque Country, because the last revision of its Land Planning Guidelines included for the first time the terms security and gender. In short, the algorithm has been applied on the left bank (Santurtzi, Portugalete, Sestao and Barakaldo) and on the right bank (Getxo, Leioa and Erandio) of the Bilbao Metropolitan Area, mapping the natural surveillance of 8.000 hectares (861.100.000 ft2) by a grid of 40.000 sectors. One grid where each sector represents the number of doors, windows, showcases, etc., (passive or panoptic natural surveillance) which focus on that portion of public space. In conclusion, a new urban and criminological reading of the city, that allows the analysis of the different morphologies. A new urban information source, a new support and help for the participatory detection of the so-called hot spots of fear.

\section{KEYWORDS}

Criminology; security; architecture; urbanism; algorithm.

\section{INTRODUCTION}

This research introduces a new review and parametrization of the eyes on the street of Jane Jacobs (Jacobs, 1961). An investigation from a thesis, in development stage, of the University of the Basque Country within the framework of the SCAHL doctoral programme; the doctoral programme in Scientific Cross Disciplinary Approaches to Heritage and Landscape.

Specifically, the article focuses on the development and results of the parameterization of a generative algorithm programmed to qualify and map the passive natural surveillance; a glocal principle of the Crime Prevention Through Environmental Design methodology, the CPTED methodology. In short, this generative algorithm has been parametrized to allow the comparative, valid and reliable analysis of the different urban morphologies in terms of security. It has been parametrized to create a new urban and criminological reading of the city, a new urban information source, support and help for the participatory detection of the so-called hot spots of fear.

Then, it should be noted that the analysis, the approach and the scope of application seek the actuality, the suitability and the social relevance in the autonomous community of the Basque Country, because the last revision of its Land Planning Guidelines has 
also included for the first time the terms security and gender. They are included in a brief manner, but at least they are included for the first time in the Basque urbanism.

Therefore, although, trial and error, the algorithm was parameterized using the municipality of Bermeo (Biscay) as reference, due to its small size and due to an agreement with the council. It should be noted that the definitive scope of application of this SCAHL thesis has been the left and the right banks of the Bilbao Metropolitan Area (Biscay); the fifth most populated metropolitan area in Spain, almost the $80 \%$ of the population of Biscay, and the $43 \%$ of the Basque Country

\section{SCOPE OF APPLICATION}

Summarizing the scope of application; on the one hand, the left bank of the estuary of Bilbao, the Nervión estuary, is popularly known as the Working Bank, which hereinafter will be called by its official Basque place name Ezkerraldea (Ezker-Left, Aldea-Zone). An estuary bank composed by the municipalities of Santurtzi, Portugalete, Sestao and Barakaldo. Altogether, 4.053 hectares (436.260.000 $\mathrm{ft}^{2}$ ). And, on the other hand, the right bank of the Nervión estuary is popularly known as the Bourgeois Bank, which hereinafter will be called Eskuinaldea (Eskuin-Right, Aldea-Zone). An estuary bank composed by the municipalities of Getxo, Leioa and Erandio. Altogether, 3.898 hectares (419.577.000 ft2). In total, left and right, 7.951 hectares (855.838.000 ft2) that have been mapped by the generative algorithm.

Ezkerraldea, the Working Bank, and Eskuinaldea, the Bourgeois Bank, territorialize the worker and bourgeois class struggle; a struggle that has been extended from the Basque industrialization directly to the present day. If in the heart of the intense Basque industrialization the greater presence of the iron and steel heavy industry, such as the Blast Furnaces, was located at Ezkerraldea, turning it into one of the most important birth places of the state of the labour movement, socialism and communism, at the other bank, at Eskuinaldea, were located the industrialists and the bourgeois-class. And, even today, if the municipalities of Eskuinaldea, such as Getxo, are listed amongst the cities with the highest per capita income levels (23.589€) and with the lowest unemployment rate $(10,6 \%)$ of the Basque Country, the municipalities of Ezkerraldea, such as Santurtzi, are listed amongst the cities whit the lowest per capita income levels (15.117€) and the highest unemployment rate $(16,1 \%)$ (EUSTAT, 2020).

But although that differences are important and should be observed, the main reason why this region conforms the scope of application of the thesis, is that there is not only a political and economical counter position between the banks, but also a morphological and architectonical one. There are two different city model; one on the left workers bank and other one on the right industrialists and bourgeoises bank.

In this way, morphologically, Ezkerraldea is an industrial estuary bank full of workingclass residences and high-density buildings, while Eskuinaldea is a bourgeois estuary bank full of single-family homes, mansions and low-density buildings; a territorial area for the secondary residence of the Biscayan rich bourgeois-class.

Ezkerraldea, apart from host the greater presence of the iron and steel heavy industry, is an area completely linked to the Exterior Port of Santurtzi, to the shipbuilding industry of Bilbao and to the Mining Area (Mehatzaldea); a region composed by the municipalities of Abanto-Zierbana, Muskiz, Ortuella, Trapagaran and Zierbana. So, it can be said that the iron and steel heavy industry cycle was closed at the left bank of the Nervión estuary, because the ore 
was extracted, processed and exported on site. First of all, the ore was extracted in the mining towns of Mehatzaldea; then, it was transported by train to the heavy industry of Ezkerraldea, a region in which the ore was processed; and finally, the shipbuilding industry of Bilbao was responsible for the construction and reparation of the ships which exported the processed ore from the exterior port of Santurtzi to the international markets.

In contrast, if historically Ezkerraldea was a proletarian area, whose inhabitants depended on the port, the mining and the industrial activity, Eskuinaldea was a capitalist area, whose inhabitants depended on the labour exploitation of their neighbours and on the perpetual extraction of their surplus value. At first, in the 19th century, on the right bank there were not an iron, steel or shipbuilding heavy industry, mining activity or a big exterior port; Eskuinaldea was an urban development based on the elite tourism such as the Sands neighbourhood (Areeta) whose urbanism references were searched from the nearby spa cities, such as Donostia or Santander.

But at the beginning of the 20th century, they began to build new residential complexes of immense and luxurious mansions; a new urban development focused on overcome the tourism to generate a not only seasonal stay. So much so that, the Basque bourgeois- class gave advertising names to their new neighbourhoods such as the Winter City (Neguri); "a city for the winter, not only for the summer (not only for the seasonal stay)".

An historical dynamic, that finally generated the greater demographic explosion of Eskuinaldea in the seventies when the middle-class families ditched Ezkerraldea joining the bourgeoisie, in the search of a more comfortable place to live rather than the left bank of the Nervión estuary.

Thus, while the Basque bourgeois-class was creating word games for their luxurious new residential complexes, the workingclass chanted "Alirón, Alirón" in the sports fields, as a victory cry, in reference to the exclaimed cry in the mines when the new high iron content veins were found; All-Iron. An economic, social, political, morphological and architectonical heterogeneity interesting to be studied from an urbanistic and criminological perspective. Furthermore, it is a heterogeneity particularly relevant in view of the industrial navigability of the estuary and the subsequent lack of bridges and communication between the banks; 100 meters (328 feet) of estuary wide and 10 kilometres (32.800 feet) of estuary length that become an insurmountable natural barrier that separates banks, social classes, political ideologies and urban morphologies; a continuous line that separates two different models of city. (Fig. 01)

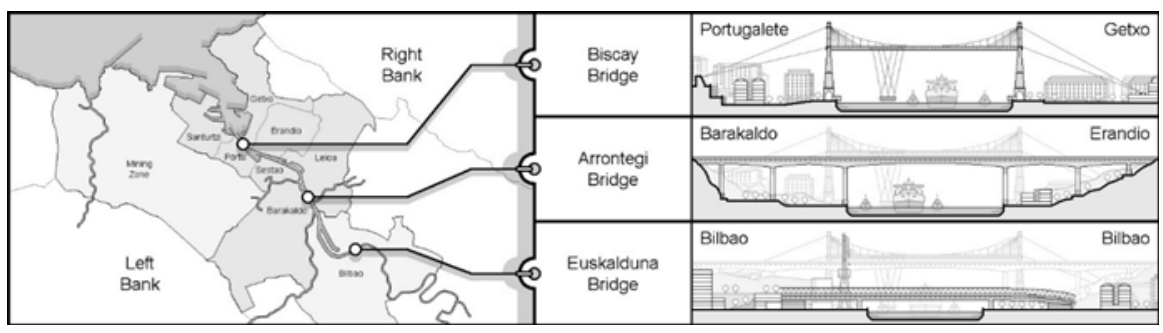

Figure 1. Metropolitan Bilbao bridges. Source: (Own production 2020) 
It was not until 1893 that the banks were connected for first time, when the Biscay Bridge was built at the mouth of the estuary, connecting Portugalete and Getxo; a bridge of 45 metres (147 feet) above the high tide live and 164 meters (538 feet) long, whose pay gondola only has capacity for 6 cars and 200 passengers every 10 minutes.

90 years after and 6 kilometres (20.000 feet) far away from the Biscay Bridge, in 1983, the second bridge, the Arrontegi Bridge, was built connecting Barakaldo and Erandio; a conventional and free of payment bridge only whit traffic access, not pedestrian. That is, abovementioned, nowadays, in 10 kilometres (32.800 feet) there is not a pedestrian communication free of payment between Ezkerraldea and Eskuinaldea, between the Working and Bourgeois Bank. The nearest one is the Euskalduna Bridge of Bilbao; a conventional and pedestrian communication between the left and the right banks; outside the scope of application; 10 kilometres (32.800 feet) far away from the Biscay Bridge and 4 kilometres (13.125 feet) from Arrontegi. A bridge built in 1997 upon the ancient shipyard of Bilbao, which was closed in the late eighties, removing the navigability of the estuary and closuring definitively the steel and iron industrialisation; note that the Guggenheim Museum of Bilbao was inaugurated on the same year, 1997.

Definitively, this scope of application is a curious and small territory that offers a wide range of morphologies in which test the programmed algorithm.

\section{THEORETICAL FRAMEWORK}

Before proceeding with the details and results of the parametric algorithm, it is also appropriate to approach, superficially, the theoretical framework and context of this study; only superficially, because it is not the goal of this article, and because it has already been explained and discussed in other international congresses:
Congresses, where the feminist and materialist perspectives of the thesis have been explained, such as the MoMoWo Symposium; Women's Creativity since the Modern Movement from 1918 to 2018 Toward a New Perception and Reception (Torino, June 2018); the Karl Marx from 1818 to 2018 an International Conference on the 200th Anniversary of His Birth; A Critique of Political Economy (Bilbao, March 2018); and the 3rd MoMoWo International Conference Workshop; Women Designers, Architects and Civil Engineers between 1969 and 1989 (Oviedo, October 2017).

Other congresses, where the architectonical and criminological perspectives of the thesis have been explained, such as the 4th ISUF-H (International Seminar on Urban Form - Hispanic) International Congress; Urban Form and Metropolitan Territories (Barcelona, September 2020); the 4th Research and Doctoral Days of the International Doctoral School of the Catholic University of Murcia (Murcia, June 2020); the 1st Congress of Criminology of the European University of Madrid; The Criminology as a Transforming Agent (Madrid, October 2019); the Arcadia 5; International Conference of Architecture and Cooperation, Architecture and Habitat, and Sovereignty of the People (Donostia, October 2018); and one collective book about quotidian criminology whit Wolters Kluwer editorial Great Criminological Challenges of the XXI Century (Madrid, July 2020).

And congresses for internal promotion of the University of the Basque Country, where the academic research in Basque language is encouraged, such as the 2nd Doctoral Days of the UPV/EHU; Our Research (Bilbao, July 2019); the 3rd IkerGazte Research in Basque; International Conference for Basque Researchers (Baiona, May 2019).

Furthermore, currently they are in process others congresses, such as the organized one by the International CPTED Association in 2021 and the 8th Doctoral Sessions of the G9 (Zaragoza, March 2020) where the doctoral student, representing the field of architecture 
and engineering of the University of the Basque Country, will defend this investigation against the universities of Cantabria, CastileLa Mancha, Extremadura, Balearic Islands, La Rioja, Oviedo, Navarre and Zaragoza.

Consequently, although exclusively architectural and morphological, this study is based on a theoretical framework and on a dialectics formed by the material feminism and the environmental criminology; thus, on the scientific materialism and on a dialectical contrast between the Marxist usage and exchange values of the city; a dialectical contrast studied by Henri Lefebvre in The Right to the City (1968), reviewed by David Harvey in Rebel Cities: From the Right to the City to the Urban Revolution (2012).

A revolutionary school of thought, theoretical and practical, in continuous evolution from The Communist Manifesto (1848) to the last Marxist-Leninist studies; in continuous revolution from The Urban Question (1974) of Manuel Castells to The New Urban Question (2014) of Andy Merrifield; from the French poems of The Flowers of Evil of Charles Baudelaire (1857) to the anonymous nom de plume of The Invisible Committee (2017); and a long et cetera, because in accordance with Hannes Meyer: the more one is aware of the systematic oppressions, the more one is required to report them, architecturally too (Meyer, 1972). In other words, this is a scientific and materialist study, for the class struggle, based on the concrete analysis of a concrete situation. A thesis based on the architectonical material feminism (Hayden, 1981) where the capitalism and the patriarchy are the key aspects to take into account for the urban and criminological study, analysis and project of the city.

Specifically, abovementioned, the investigation is focused on a materialist and feminist review of the eyes on the street of Jane Jacobs, because as she described in The Death and Life of Great American Cities: There must be eyes upon the street, eyes belonging to those we might call the natural proprietors of the street (Jacobs, 1961). That is, according to Jane Jacobs, more eyes upon the street, more people on the street means safer neighbourhoods. As she said: When there are people present in a public space such as city streets, it strengthens the space and inspires social cohesion (Jacobs, 1961).

So, against the growing postwelfarist culture of control described by David Garland in The Culture of Control: Crime and Social Order in Contemporary Society (2001), this study seeks the urban safety, through the culture of care, reviewing the conditions provided by Jane Jacobs for the city diversity, contact and safety: (1) the generators of diversity, (2) the need for primary mixed uses, (3) the need for small blocks, (4) the need for aged buildings, and (5) the need for concentration (Jacobs, 1961).

\subsection{CPTED Crime Prevention Through Environmental Design methodology}

In this case, the eyes on the street match exactly with natural surveillance of the CPTED methodology; a simple and structured methodology adaptable to the Marxist-Leninist perspective in order to gain a revolutionary character that claims the necessary supremacy of the city usage value, theoretically and practically.

In short, the Crime Prevention Through Environmental Design (CPTED) methodology is defined as a multi-disciplinary approach of crime prevention that uses the urban and architectural designs and the management of builds and natural environments not only for reduce the crime, or minimize the fear of it, but also for increase the social cohesion and the sense of community among the inhabitants; the culture of care; the usage value.

Based on the eyes on the street of Jacobs and on the defensible space of Oscar Newman (Newman, 1973) its five glocal principles are: (1) the natural surveillance, (2) the legibility or accessibility, (3) the image or maintenance, (4) the territoriality or ownership, and (5) the community participation (Abbotsford, 2013). (Fig. 02) 


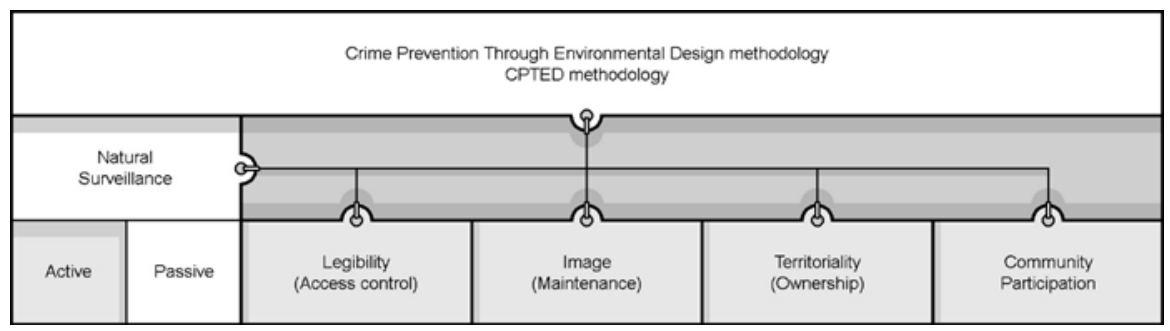

Figure 2. Glocal principles of the CPTED methodology. Source: (Own production 2020)

\subsection{Natural surveillance}

Within this general framework, the natural surveillance is the bidirectional surveillance practiced by the members of the own community at their everyday lives; the eyes on the street; the people present in the public space. A bidirectional surveillance (care) because when you see (care) a neighbour, the neighbour sees (cares) you; you are seeing (caring) and being seen (cared) in a natural way.

A natural surveillance completely different form the artificial, bourgeois, capitalist and unidirectional surveillance practiced by the security guards, public or private police officers, video cameras, algorithms, sensors or any other human or technological systems of control. A unidirectional surveillance (control) because when a police officer sees (care) you, you don't see (care) the police officer; you are being seen (controlled) in an artificial way.

So, unlike this unidirectional and artificial surveillance, the skill and felling of seeing and being seen (natural surveillance) implies the bidirectional co-responsibility for care, and the socialization and redistribution of the reproductive works, turning the neighbours not into mere passive beneficiaries of a security system or into helpless victims of the danger, but into active participants in the drama of the civilization versus the barbarism in the cities (Jacobs, 1961).
Thus, architectonically, the main objective of the natural surveillance is the generation of auditory and visually permeable morphologies that allow the skill and the feeling of seeing and being seen, of hearing and being heard; morphologies that allow neighbours to casually observe activities in their environment; that allow people to create community; morphologies that grant the eyes on the street; the city diversity, contact and safety through the supremacy of the city usage value and the decommercialization of the city.

\subsection{Active and passive surveillances}

Further, there are two different ways or surveillance: active and passive surveillances. To sump up, the active natural surveillance may be represented by a neighbour; the active artificial surveillance by a police officer; the passive natural surveillance by a window; and the passive artificial one by a video camera.

That is, when you are seeing a neighbour (bidirectional care) or a police officer (unidirectional control), you are directly (actively) observing them; you have the skill of seeing and being seen. But when you are in front of a window (bidirectional care) or in front of a video camera (unidirectional control), they provide you a feeling of permanent visual and auditory contact without effective awareness of the presence of another observer; you only have the feeling (passive) of seeing and being seen. 
In that way, the artificial passive surveillance, the one provided by video cameras, algorithms, sensors, ID cards, bank cards, privacy restrictions, and other technological systems (unidirectional control), is the surveillance provides at the non-places of Marc Auge (1992); at the non-cities focused on the perpetual generation of surplus value; the supremacy of the city exchange value.

In contrast, one door, one window, balcony or viewpoint focused on the street provides a natural passive surveillance (bidirectional care); provides eyes on the street. Returning to the quote by jane Jacobs: There must eyes upon the street, eyes belonging to those we might call the natural proprietors of the street. (the quote continues) The buildings on a street equipped to handle strangers and to ensure the safety of both residents and strangers, must be oriented to the street. They cannot turn their backs or blank sides on it and leave it blind (Jacobs, 1961). That is, there must eyes upon the street, eyes belonging to the people (active natural surveillance) and to the buildings (passive natural surveillance); altogether represent the eyes of the city; the heart of the city; the community.

The building façade holes encourage an invisible, mutual and perpetual care (bidirectional care) which increases the tranquillity on both sides of the glass, in the public space and at home; although there is not another observer behind the door, behind the second story window, balcony or viewpoint, the idea of the presence is as effective as the presence; it is a panoptic surveillance, an apparent omnipresence that confers the continuous illusion of observing and being observed.

To conclude, on the other side of all those video cameras, RFID chips and algorithms there is a capitalist state that controls you to get your surplus value (exchange value). But, on the other side of all those windows and doors there is a community that cares you; that you care (usage value).

\section{THE GENERATIVE ALGORITHM}

Abovementioned, this research focuses on the parameterization of a generative algorithm programmed to qualify and map the degree of the passive natural surveillance of different urban morphologies, allowing the comparative, valid and reliable analysis of them in terms of security.

In short, the algorithm draws a colourful grid on the embedded urban morphology; a kind of semaphore (easy to read and understand for any neighbour whatever its age or social condition) which represents the number of building façade holes, doors, windows, balconies and viewpoints that focus on that square of the grid mapping the passive natural surveillance. (Fig. 03)

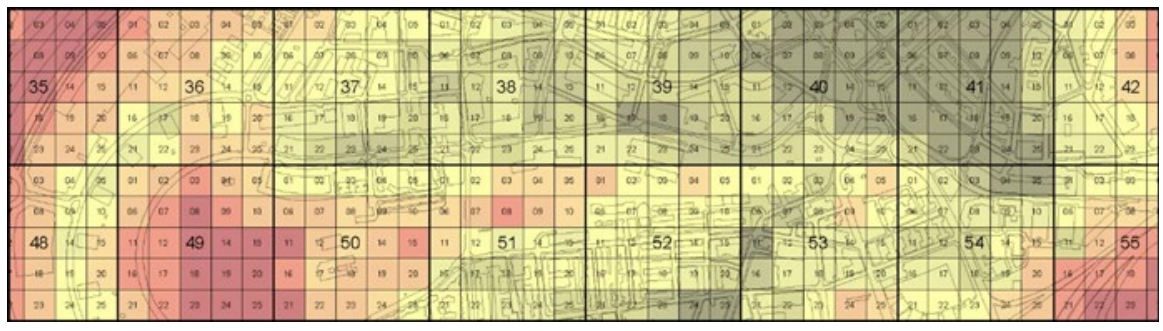

Figure 3. Barakaldo. Passive natural surveillance map. Scale 1:10.000. Source: (Own production 2020) 


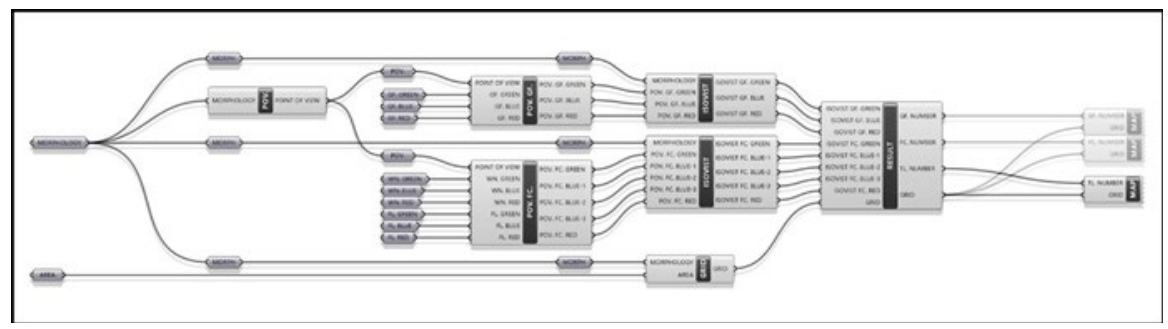

Figure 4. Grasshopper 3D, Generative Algorithm. Source: (Own production 2020)

Regarding to the software, the generative algorithm has been parametrized using Grasshopper 3D; a visual programming plugging of Rhinoceros 3D created by David Rutten in 2007 and normally used to build generative algorithms such as the one of this investigation. And the added urban planes have been drawn in 2D dwg format using AutoCAD from Autodesk.

In this case, the algorithm has been parametrized connecting the outputs and inputs of different and subsequent components which contain mathematical operations and logical propositions; a visual programming, that is properly sorted and grouped into 10 different folders, allowing the easily and intuitively change of the scale of the planes, the dimensions of the grids, the colours or contrast of the semaphore or any other features of this surveillance mapping. (Fig. 04)

Step by step, first, after embedding the urban plane in dwg format, the algorithm generates a grid according to the stipulated dimensions (Grid folder) and a set of points of view located above the facade holes (POV folder); differentiating between the ground floor facade holes (POV. GF folder) and the holes of the rest of the façade (POV. FC folder).

Second, depending on the percentage, situation, dimensions and height of the facade holes, the algorithm generates a set of isovists simulating the visual field observed from each window (Isovist folders).

And finally, the algorithm crosses mathematically the data of the public space area of each grid square and the total number of isovist hosted in them (Result folder) transforming the numerical results of each square into a colour scale; from red to green. A last step that becomes the mathematical results graphically and quickly readables by anyone, whatever its age or social condition (Map folders). (Fig. 05)

The algorithm generates three different maps: (1) the first one corresponding to the passive natural surveillance of the city ground floor, a map that allows the analysis of the small commerce along the city; (2) the second one corresponding to the passive natural surveillance of rest of the facade, a map that allows the analysis of the urban density and concentration; (3) and a third one that is the weighted average of the first and the second one.

Above mentioned, the algorithm was parameterized using the municipality of Bermeo (Biscay) as reference, and then it has been applied on the left bank (Santurtzi, Portugalete, Sestao and Barakaldo) and on the right bank (Getxo, Leioa and Erandio) of the Bilbao Metropolitan Area (Biscay), mapping the natural surveillance of 8.000 hectares (861.100.000 ft2) on a 1:10.000 scale, by a grid of 40.000 sectors. (Fig. 06,07) 


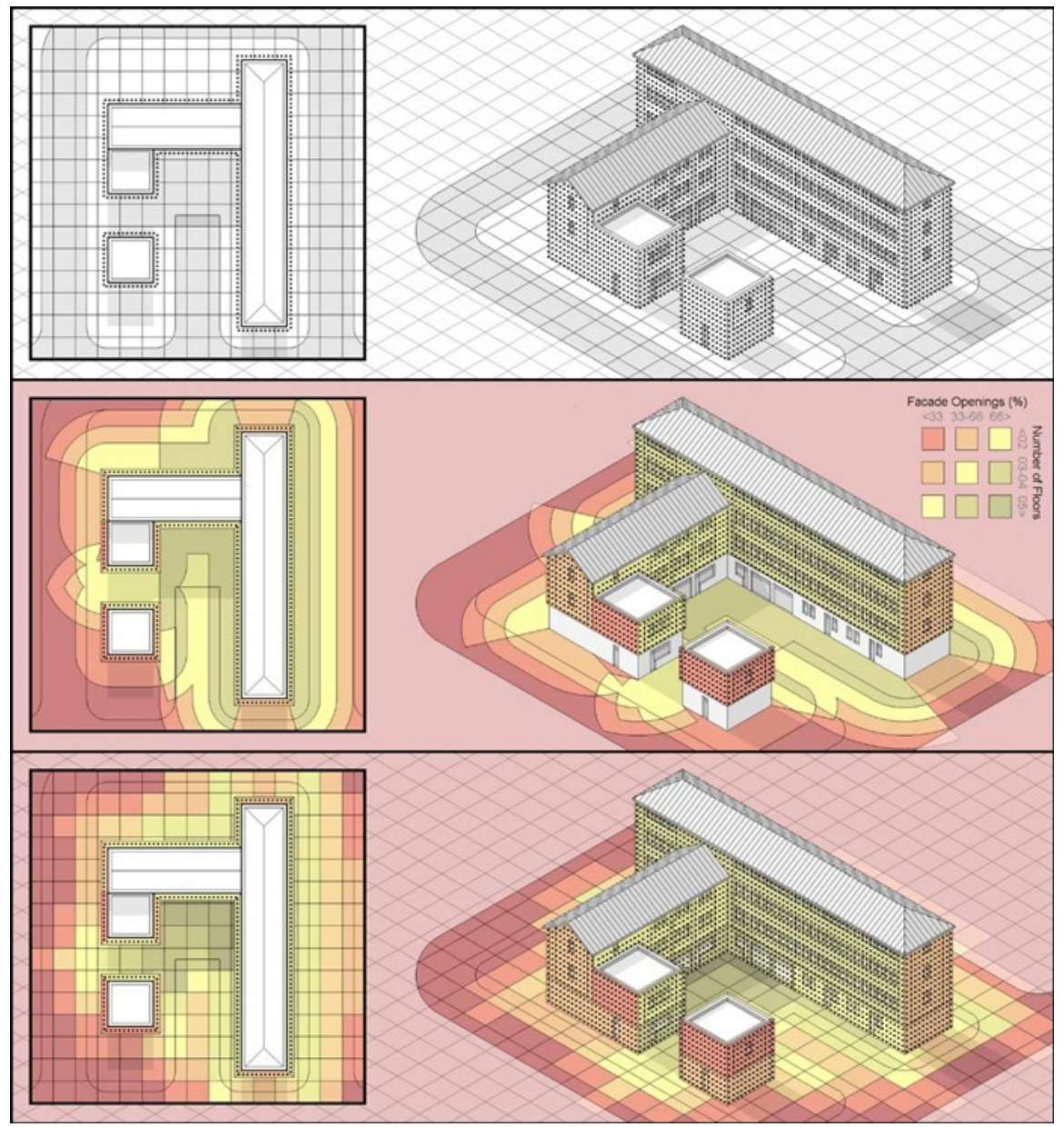

Figure 5. Passive natural surveillance map. Process. Source: (Own production 2020) 


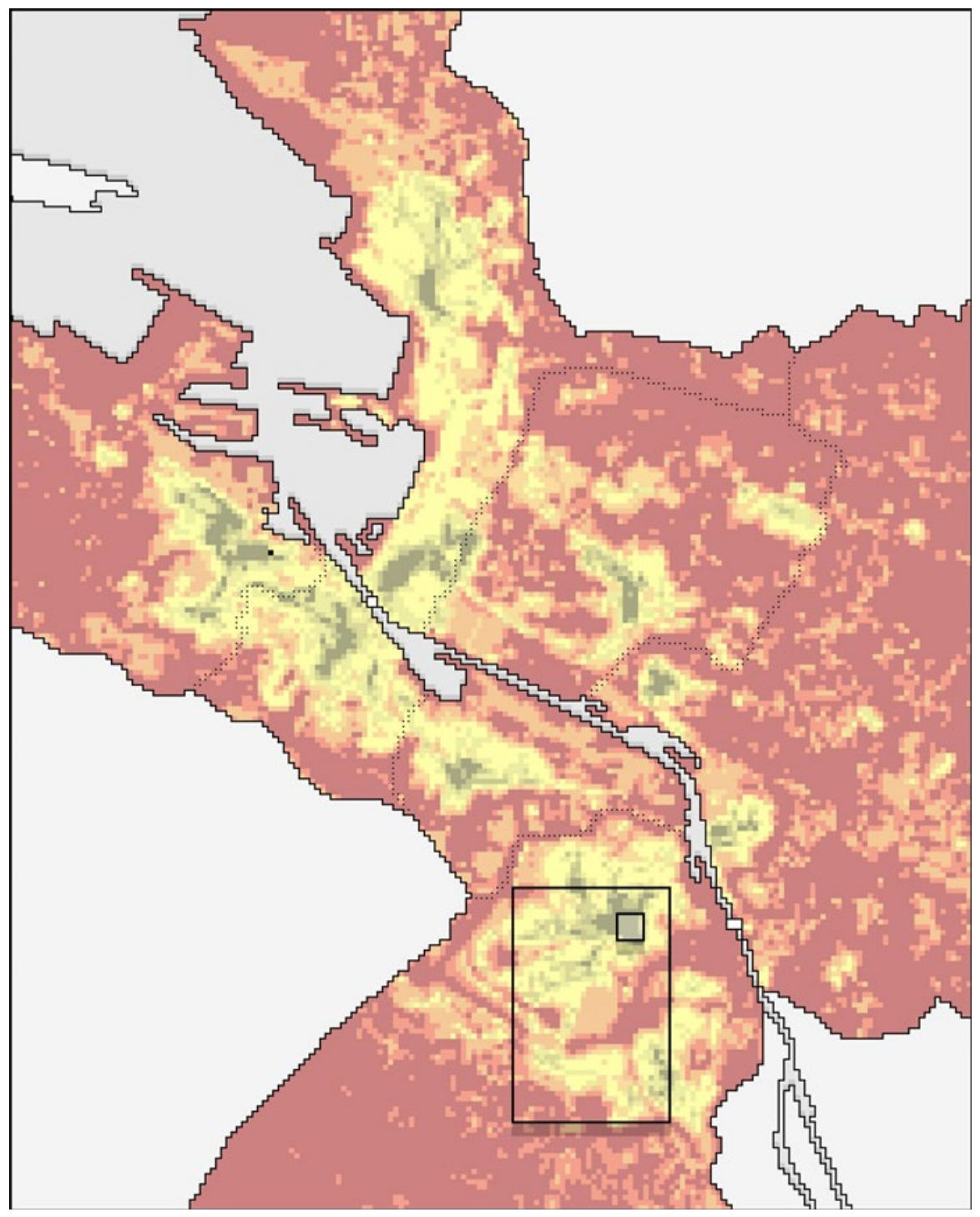

Figure 6. Passive natural surveillance map. Scale 1:50.000. Source: (Own production 2020) 

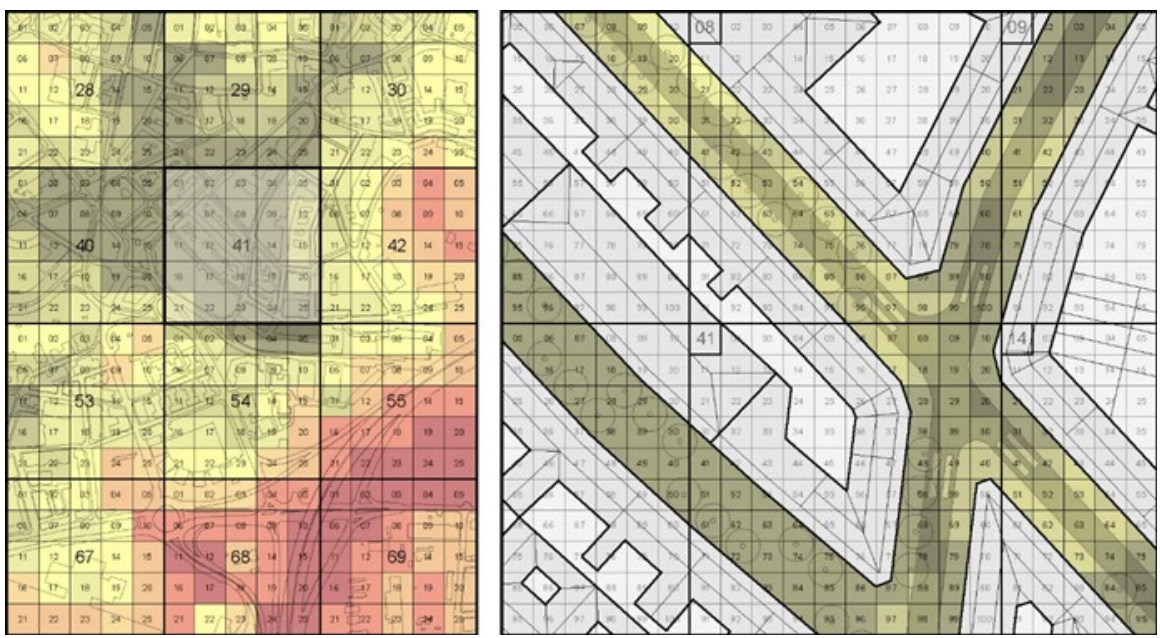

Figure 7. Passive natural surveillance map. Scale 1:10.000 and 1:1.000. Source: (Own production 2020)

Today the generated maps (Fig. 06,07) are being exposed and discussed in the different municipalities; it is being discussed the influence of the different urban infrastructures, services and equipments: the new large supermarkets, the tourism industry, the transport infrastructures, schools or sport centres, etc. It is being analysing the potential for the natural surveillance of the working-class neighbourhoods and of the bourgeois suburbs taking into account their density, concentration, cohesion and commercial network.

In conclusion, without pre-empting the outcome of the stakeholder's discussions (which are under way), such as the noise maps where the decibels are mapped, this is a new urban and criminological reading of the city that allows the analysis of the different morphologies; a new urban information source, a new support and help for the participatory detection of the socalled hot spots of fear.

A tool (not an answer) for the participatory creation of the city, of the community. A step to start rethinking our security system, our care system; a step to vindicate de usage value of the city, the decommercialization of our territories. 


\section{REFERENCES}

Abbotsford, 2013. City of Abbotsford Crime Prevention Through Urban Design (CPTED). Abbotsford: Planning and Development Services.

EUSTAT, 2020. https://www.eustat.eus/ municipal/datos_estadisticos/info_ territorial_c.asp. Accessed, February 2, 2020.

Garland, D. 2001. The Culture of Control: Crime and Social Order in Contemporary Society. New York: Oxford University Press Inc.

Hayden, D. 1981. The Grand Domestic Revolution: A History of Feminist Designs for American Homes, Neighbourhoods and Cities. Massachusetts, Massachusetts Institute of Technology Press.

Jacobs, J. 1961. The Death and Life of Great American Cities. New York: Random House.

Meyer, H. 1972. El arquitecto en la lucha de clases y otros escritos. Barcelona: Gustavo Gili.

Newman, O. 1973. Defensible Space; Crime Prevention Through Urban Design. New York: Macmillan Publishing. 


\title{
PAPER \#2.08
}

\section{RECONNECTING WITH NATURE: IDENTIFYING NEW MODELS OF URBANISATION}

\author{
Steffen Lehmann ${ }^{a}$
}

anniversity of Nevada Las Vegas, Las Vegas, Nevada, USA

\section{ABSTRACT}

Climate change is occurring around us and influencing our daily lives, meaning that we have to plan our cities in a different way. There is increasing awareness of the need for daily contact with green spaces and the natural environment in order to live a happy, productive and meaningful life.

This paper tells the narrative of how our urbanisation models have been disconnecting humans from nature. Living in contact with nature improves a large number of aspects of our life. However, non-sustainable, nonresilient patterns of urbanisation, along with the neglect of inner-city areas, have resulted in fragmentation and urban decline, led to a loss of biodiversity, causing deterioration of ecosystems and their services. Urban regeneration projects allow us to 'repair' and restore some of this damage whilst enhancing urban resilience. Connecting existing and enhanced ecosystems, and re-establishing ecosystems both within cities and at the peri-urban fringe is vital for strengthening ecosystem resilience and building adaptive capacity for coping with the effects of climate change.

Cities worldwide need to look for suitable solutions to increase the resilience of their urban spaces in the face of climate change. The paper addresses this timely question by giving an overview how this could be achieved through the integration of nature-based solutions, re-greening of neighbourhoods and by correctly attributing value to natural capital. Transforming existing neighbourhoods in this way will enable ecosystems to contribute their services towards healthier and more liveable cities (urban metabolism analytical frameworks might support effective management of natural capital contributing towards more "circular" urban resource flows). Revisiting the "wisdom of nature" will inform less resource-intensive and more climateresilient organisational structures.

From Descartes, to Fairchild, to Howard, to McHarg, the author identifies the linkages that exist between a rich palette of seminal literature and different schools of thought about nature within the city.

\section{KEYWORDS}

Overview paper; urbanisation models; resilience; ecosystem deterioration; naturebased solutions; adaptive capacity; living in urban landscapes.

\section{INTRODUCTION}

Every city is unique. Cities not only differ in their size, density and population distribution, but also in their climatic and cultural context, location and in the ways in which they are vulnerable to climate change. When it comes to strategies to increase urban resilience, what works in one city may not work in another. However, urban regeneration projects usually allow to 'repair' and restore some of the damage caused to ecosystems whilst enhancing urban resilience. Even when change is acknowledged as necessary, it can be a daunting prospect.

Facing the need for change on a large scale, it can be helpful to remember that cities are never finished; cities are constantly undergoing transformation. What is needed now is to nudge that transformation in the direction of sustainable and resilient solutions, making the most of opportunities for re-greening and 
re-naturing of cities, using resources efficiently and acknowledging the value of natural capital. Over the centuries, man has become a force that changes the planet. Now it has become so strong that it could finally overturn the Earth system. Our current disconnect from Nature has evolved over the last 300 years with the emergence of science and the subsequent industrial revolution. Within a very short time, humans have experienced transition from a life predominantly spent outside towards a very different life mostly inside buildings. We have changed how we live, and a fundamental change in our relationship with nature has been the result. Over $80 \%$ of the U.S. population currently live in urban areas and a large portion are estranged from nature (Office for National Statistics, 2016). Today 90\% of our lives is spent indoors, in controlled interior environments (ASHRAE, 2010); with increasing 'screen-time' spent alone online.

\section{THE EVOLUTION OF HUMANS DOMINATING THE EARTH}

Everything about how we define our technologies, and ourselves today, our cities, industries have only been on Earth for a relatively short period. The earth began to develop around 4.5 billion years ago. Although Homo sapiens emerged some 200,000 years ago, the human impact only really began with the impact of agriculture; for instance, the Australian aborigines used fire to assist hunting before that (they also avoided burning certain areas to retain food sources in drought years). We are a comparatively young species on this planet, and all the while, we have been constantly pulling back from nature. Although we have seen ourselves increasingly as separate from, and superior to nature, our impact upon nature has been immense. Biodiversity evolves as different species share the same ecosystem where relationships between the species develop. In this balanced system, the planet's biodiversity has grown to include 30 million different species. Each species is necessary for keeping something in balance in the natural world, yet we have not respected or maintained this delicate balance. Since the time of the dinosaurs 65 million years ago, there has not been this level of sustained destruction on our planet. The current rapid loss of biodiversity is quite possibly the biggest disaster ever. The average abundance of native species in most major land-based habitats has fallen by at least $20 \%$, mostly since 1900 (a recent UN Report sates; 2019). Although extinction is a natural phenomenon, it occurs at a natural "background" rate of about one to five species per year. Scientists in the UN Report estimate we are now losing species at up to 1,000 times the background rate, with literally dozens going extinct every day (IPCC, 2018). In the big picture of Earth's evolution, Homo sapiens has only been around for a very short time, and it is likely that the Earth will still be around for a long time even after we have destroyed ourselves as a species (the reason why Martin Seligman argues that we have been misnamed as Homo sapiens, since we are not a 'wise' species at all).

'Touching the earth lightly' means that one only takes from nature what one really needs at that particular moment. Over the last 10,000 years, we have gradually changed our relationship with nature, shifting to agriculture and drawing on an awareness of the cycles and seasons of nature. This has been a process of empowering ourselves, taming the natural world and taking control of our own lives and our own destiny: we are not at the mercy of nature; we can farm the land, build dwellings that resist nature's forces, and we can harness what agriculture offers.

Everything changed with scientific discovery, technology and the Industrial Revolution. Over the last 300 years, we saw that humans could manipulate nature through the emergence of science. Humankind started to believe that it had dominion over the Earth; and that the Earth and nature have to serve us in our own evolution. Just think of the discoveries of philosophers 
and scientists like Copernicus, Galileo, Descartes and Newton. Their understanding was that nature was meaningless and purposeless, and its only function was to "serve humans in their evolution". Descartes for instance, in "Discourse on the method" (1637) believed that animals had no feelings. His belief was: Man is at the top and Earth is here for us to use, to exploit. (See: Figure 1) It took many years to correct our relationship with the Earth. The seminal book "The limits to growth" (Meadows et al., 1972) displayed the limits of finite resources and noted that the whole Industrial Revolution was about taking and extracting minerals and resources, and disposing of waste, with a complete disregard for the environment and natural ecosystems (See: Figure 2).

However, today, a new awareness is emerging that is driving the regeneration and re-greening of our cities aiming to recreate "a place for nature" in our cities. With this new awareness, humans are able to and have a desire to participate in the community of life and in nature, interacting with all of the species on this planet, without necessarily destroying any of it, let alone destroying all of it. This requires new models of urbanization (Lehmann, 2010; Woo et al, 2014; Afanador et al, 2015; UN Habitat, 2016).

For some time now, humankind has been out of touch with nature and has lost its connection to the natural world. There is a need for us to renew our connection with nature since this is key to both good health and resilience. Related to this is the importance of re-greening cities and introducing nature-based solutions through urban regeneration projects (such as the examples shown at Figure 3).

The purpose of this paper is to first analyse our disconnect from nature and the subsequent loss of biodiversity, how we got into the thinking mode that nature could be less relevant than the economy, and the questions addressed by the paper: Could the concept of Biophilia be a valid approach to make our cities more healthy and resilient? (Grinde et al, 2009) How would this alternative urbanization model look like, and what could urban designers do to counteract the degradation of our ecosystem?
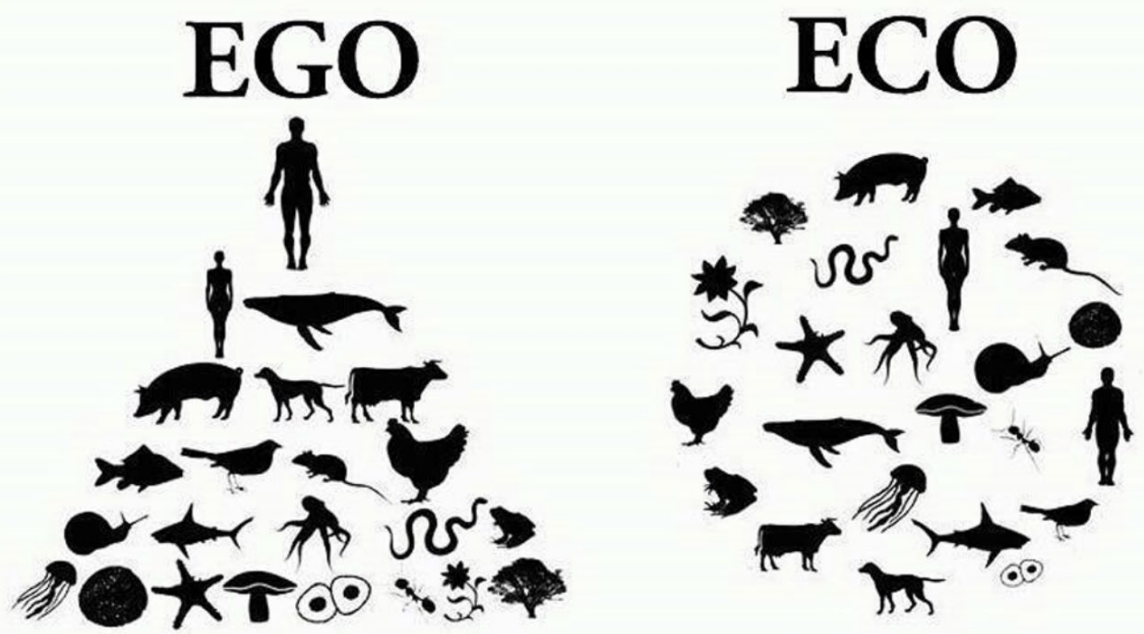

Figure 1. Diagram 'Ego-Eco' - Humankind is part of the ecosystem, not apart from or above it. The left part illustrates Descartes thinking of exploiting the Earth. 

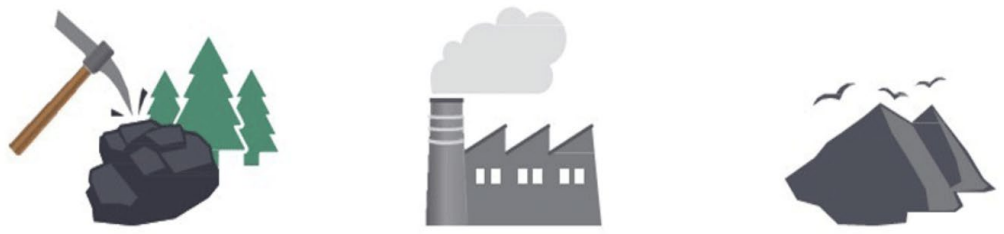

\section{TAKE}

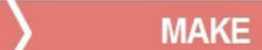

DISPOSE

Figure 2. Diagram: The linear extraction process of resources is unsustainable (S. Lehmann, 2012)
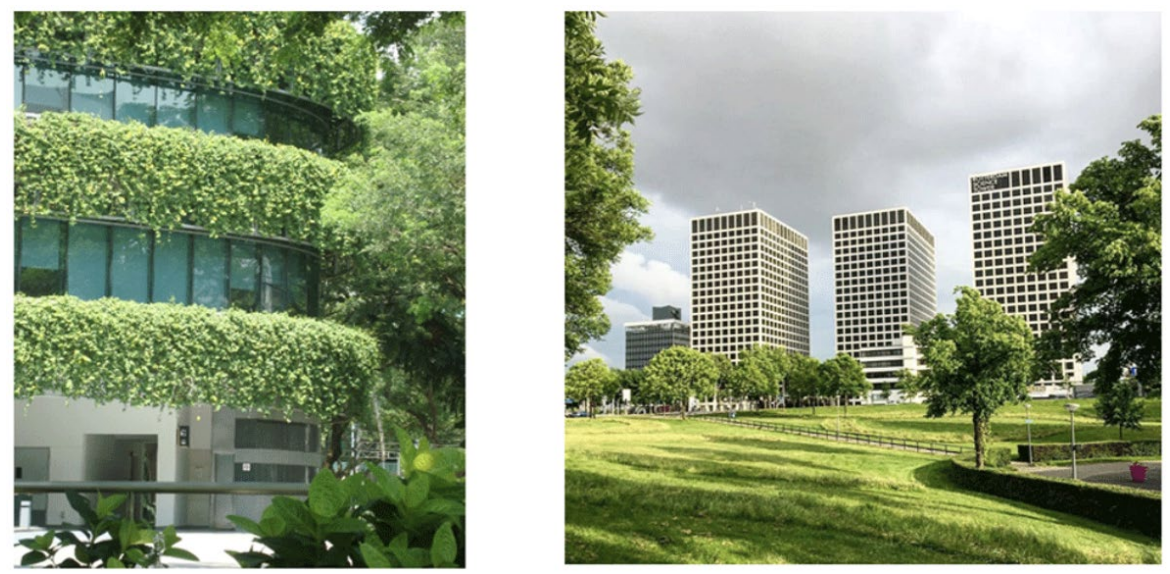

Figure 3. There are numerous ways vegetation can be integrated into the city's structure (S. Lehmann, 2010)

2. LITERATURE REVIEW ON THE NEED FOR A RE-APPRECIATION OF NATURE WITHIN CITIES

The study of ecology allows for an understanding of the Earth as a single living system that is in balance with nature. Within this system, cities evolve as the greatest creation of humankind and yet cities are a source of overload and environmental stress. Cities can possess degrading conditions just think of windowless work environments, over-crowded housing, air pollution and noise. They are not obvious places to connect with the natural environment.Cronon (1995) asserts that urban inhabitants have created a wholly artificial view of what nature and wilderness are, based on ideas of open space and grandeur that rarely correspond to the lived reality of the people who inhabit rural spaces. The view of nature as a pristine and uninhabited space makes it difficult to see nature on a smaller, less imposing scale, and to appreciate for instance that a tree in an urban back garden can equate to a tree growing in a forest; that the two trees are identical despite the different setting. In our mind, the forest tree somehow has a greater 
perceived natural value, and nature is seen as being something that does not belong within the city (Cronon, 1995). Rautio and colleagues (2017) argue that this does not have to be the case. In working with children in Finland they have found that urban inhabitants are not necessarily disconnected from nature; there is plenty of nature present in urban environments for them to explore. To imply that urban children are disconnected is to disregard the ways in which nature is present in and encroaches on their lives. Their focus is on how children's relationships with nature emerge and change based upon the setting, which they are in. The children's understanding of nature in the urban environment is an assemblage. The author argues that nature should not be viewed as something that exists beyond the city, but instead, "environmental education research and practice could and should intensely focus on the everyday materialisations of complex historical, societal, political and cultural conditions that give rise to environmental phenomena, human attitudes and relations included."

Hand and colleagues (2017) explored how children living in urban environments respond to different natural environments. They noted that urban back gardens represented the main source of interaction with biodiversity for these children, and that children were not spending less time in nature due to the lack of natural environments in urban areas; but rather that lifestyle factors, including parental limits and the attraction of electronic media over natural play spaces, were the cause of the children's increasing disconnect with nature. A behavioural shift is needed to reattribute value to the protection of nature within cities and importance to time that is spent outdoors in a biodiverse environment. Although Rautio et al. (2017) argue that the urban population is not necessarily disconnected from nature; it is fair to say that the time spent connecting with nature is decreasing for certain groups within society. The penetration of technology into our everyday lives has led to the development of a 'heads-down' generation who spend more 'screen-time' indoors and less time on outdoor activities, and who do not necessarily place the same value on natural encounters.

However, it has been well established that connecting with nature makes people come alive and nourishes the senses. The author argues that today, we are at a turning point how we think about nature within cities. We understand that cities need to be built on regenerative principles, as we start to grasp how everything in life and the environment is connected (Girardet, 2008). We are revisiting the wisdom of nature to inform our organisational structures (e.g. local food production) and realize that nature has a profound positive influence on our health and well-being. We have arrived at a new understanding, that we are merely participants in the natural world. We rediscover indigenous traditions and the interdependence of all things in nature, things that coexist together. The inter-connectedness of systems - it means that we are not in a privileged position to exploit or destroy the ecosystem. In fact, the opposite is true. We have a position of stewardship, where we must lead in a respectful and responsible relationship to the natural world. We are not 'above' nature.

The quality of our social, professional and ecological relationships is at the core of what makes us feel alive, happy and safe. Part of this are walkable neighbourhoods on a human scale and the ability to enjoy nature within the city in a short distance from our home or workplace. Urban designers' worldwide aim to bring nature back into the city, to compensate for a frequent lack of parks, gardens and green spaces. The concept of 'Urban Metabolism' understands cities as a living organism. Urban metabolism analyses the flows of energy, resources, food, people and materials in cities (as if the city were an ecosystem) and provides a framework for the study of the interactions of natural and human systems, using the metaphor of the city as a living organism. Ecologist Arthur 
George Tansley (1871-1955) expanded the term in 1935 to encompass the material and energetic streams (Tansley, 1935). Seminal texts by different authors offer further ecological wisdom on the architect's relationship with landscapes and their ecosystems (Carson, 1962; Girardet, 2008; McDonough \& Braungart, 2002; McHarg, 1969; Register, 1987).

A new deep understanding of nature has emerged that sees the commonality of all of life as part of the same ecosystem, and it influences our thinking of cities as living organisms (one of these approaches is urban metabolism). The concept that the Earth is a self-correcting organism, the socalled Gaia hypothesis, was developed by James E. Lovelock in 1975 and published in 1979 (Lovelock, 1979). It states that the Earth is a vulnerable system in balance, and that the temperature of the planet and its atmosphere are produced and maintained by the sum of living organisms. The Gaia hypothesis is based on the idea that all life on earth functions as a single system. This system both defines and maintains the conditions necessary for its survival. Lovelock argues that the earth's living matter - including the atmosphere, oceans and land areas - combine to create a complex system with the ability to keep our planet a place fit for life.

The Gaia hypothesis has fundamentally altered the way scientists view evolution and the environment, but not all agree. Contrary to the Gaia hypothesis, which suggests the Earth has a self-righting tendency, Johan Rockstroem, Director of the Stockholm Resilience Centre (2018) and numerous other leading scientists say that the feedbacks of global warming could push the planet to an extreme state. In the face of this scenario what we need are strategies to mitigate the effects of climate change. Greening up cities alone will not make a difference unless there is a sharp reduction in the use of fossil fuels (Steffen et al, 2018).

\section{DISCUSSION: FROM GARDEN CITIES TO BIOMIMICRY AND BIOPHILIA - A WAY TO HEALTHY AND RESILIENT CITIES?}

The 19th century Garden City movement based on the ideas of Ebenezer Howard (expressed in the seminal book "Garden Cities of To-morrow" (1902) was the search for an escape from the polluted cramped conditions of the City of London at this time. Still today, this relatively simple theory of new circular cities in Arcadia have a significant impact on urban theories on urban systems and how to possibly develop new cities from scratch.

One important characteristic of complex urban systems is their resilience. Urban resilience of cities means the ability to maintain human and ecosystem functions simultaneously over the long-term (Alberti \& Marzluff, 2004). Urban resilience, also called adaptive capacity, refers to a city's ability to cope with and recover quickly from hardship or crisis. A resilient city is typically one that is prepared and well equipped to contend with and mitigate the multiple effects of climate change, such as urban heat islands, heatwaves, urban flooding, energy blackouts, and other potential disasters. A resilient city has a robust infrastructural system and can even turn a crisis into a positive development (Meerow et al., 2016; Mitchell \& Harris, 2012).

Redefining cities and identifying a sustainable and healthy model of urbanization in the age of global warming goes right to the core of the ability to adapt, and underpins our complicated relationship with nature, technology and place. A healthy city is conscious of health of its residents and striving to improve it. Thus, a healthy city has a strong commitment to health and wellbeing, and a process to achieve it. The WHO report (2014) refers to the need for sufficient green spaces in all cities and defines what a Healthy City is: "A healthy city is one that continually creates and improves its physical and social environments and expands the community resources that enable people to mutually support each other in performing all the functions of life and developing to their 
maximum potential." This approach puts health high on the political and social agenda of cities and builds a strong movement for public health at the local level, and as driver of all urban design. It strongly emphasizes equity, participatory governance and solidarity, intersectoral collaboration and action to address the determinants of urban health. The concept of Healthy Cities was inspired, supported by the WHO European Health for All strategy and the Health21 targets, and is aligned with the UN's 2030 Agenda for Sustainable Development.

In a similar way, the concept of Biophilia introduced by Edward O. Wilson (1984) suggests that humans possess an innate tendency to seek connections with nature and other forms of life (Kellert, 2011). As predicted by Rachel Carson in 'Silent Spring' in 1962, we are now in the process of redefining our relationship with nature, and how our lives and health depend upon it. This growing understanding is not about giving up technology, but rather developing the most advanced technologies to date, for instance through the biological revolution, digital engineering and nanotechnology. We have to use that rich and available knowledge to find innovative and better solutions, employing ideas of Biomimicry - innovation inspired by natural systems (Benyus, 2002; Neves \& Francke, 2012).

The emulation of nature's genius is a promising path for our urban systems, processing and neighbourhood designs. It goes beyond just emulating natural form, involving systems' thinking and asking: how does it fit into the wider ecosystem? Nature has 3.8 billion years of "R\&D" behind it, which we can learn from. Learning from nature also means that the principles of a Circular Economy have become part of this learning process. The Ellen McArthur Foundation (EMF) argues "a circular economy is one that is restorative and regenerative by design" (Ellen MacArthur Foundation, 2017). Part of the circular economy includes designing out waste and rebuilding natural capital and resilience.

\section{URBAN DESIGN STRATEGIES TO REDUCE THE BIODIVERSITY LOSS, URBAN HEAT ISLAND EFFECT AND ECOSYSTEM DEGRADATION}

It is widely accepted that our cities are facing a wide range of challenges, with unsustainable urbanization (built frequently at too low density) in turn being linked to human health problems, the degradation and loss of natural capital and its corresponding ecosystem services (clean air, soil and water), climate change and a worrying increase in the risk of natural disasters. Urban expansion is always leading to changes in land cover in the countryside, shifting green space to 'artificial surfaces'. An aerial survey of the UK in 2015, for instance, revealed that over 22,000 hectares of green space was converted to artificial built surfaces between 2006 and 2012. Over 7,000 hectares of this land were previously forest, and over 14,000 hectares were previously agricultural areas and farmland. Over 1,000 hectares were changed from wetlands to artificial built surfaces in order to provide more suburban homes. Completion of urban construction sites comprised nearly 3,000 hectares and completed new industrial and commercial developments slightly over 1,000 hectares (University of Leicester, 2015).

More research is needed to clearly define the factors in our current urbanization models that hinder the reconnection with nature in the urban system. These factors are economic, social, technical and environmental. Governments are increasingly trying to quickly fix the issue of housing affordability by boosting supply and approving inacceptable low-density car-dependent housing developments on precious greenfield land. However, far too many homes are being planned and built on greenfield sites that were formerly protected green-belt land (Lehmann, 2019). At the same time, sufficient land for urban infill and regeneration is available. For instance, there 
are sufficient brownfield sites for an extra million homes in England alone, and there is no excuse for further encroaching into precious greenfield land that is necessary for recreation, biodiversity, forestry and food supply (CPRE, 2018). The government, developers and policy makers do still not prioritise the redevelopment of brownfield land and infill densification enough.

As far back as his 1722 book "The City Gardener", the English botanist Thomas Fairchild (1667-1729) noted that city residents feel more relaxed and healthy when they can enjoy gardens and greenery (Fairchild, 1722). He suggested improving air pollution and improving the urban microclimate in London by creating parks and gardens, and he realized that numerous small gardens with trees and bushes are more effective rather than just a large park with a lawn. Almost three hundred years later, the research on the urban heat island (UHI) effect confirms Fairchild's observation (Bowler et al., 2010; Doick et al., 2014).

Obviously, trees and their canopies are a critical piece of the life support system on this planet and are vital for any future project. Urban forest projects, constructed wetlands, and the urban farming movement are all good ways to re-integrate nature into an urban setting (see: Figure 4). Natural elements such as street trees, gardens and planting have been a feature of cities for hundreds of years. The most effective urban green space is not a lawn, but a garden with tree coverage from different types of trees and bushes with large leafs.

The dangerous UHI effect leads to significantly warmer urban areas compared to surrounding rural areas, and this temperature difference is usually larger at night than during the day. The UHI effect occurs because the dense, dark surfaces (such as bitumen on roads or concrete on building roofs) absorb and store heat during the day and then release it at night. Urban greenery can help reduce this heat gain and the impact on human health (Lehmann, 2015; Sailor, 2014). The main cause of the $\mathrm{UHI}$ effect is from the modification of land surfaces and material, for instance concrete roofs that store and trap solar heat during the day. It can best be counteracted by green roofs (and facades) with planting and vegetation, white or light-coloured surfaces (using the Albedo Effect to reflect solar radiation) and the use of materials that absorb less heat (Note: from 2012 to 2014, the author was principal investigator of 'Urban Climate Research', the largest study of the UHI effect in Australian cities). It is only a question of time until green roofs will become mandatory for new buildings in the U.S. and other countries.

Understanding the many benefits of urban greening, municipalities are now looking at how urban areas can adapt their landscapes to better cope with increasing heat stress and the UHI effect. There is growing understanding and appreciation that re-naturing cities can help provide viable solutions for urban engineering, using and exploiting the properties of natural ecosystems and the services that they provide. "Ecosystem services" that city vegetation delivers, through avenues, gardens, parks, wetlands, urban forests, green roofs and living walls are now becoming more appreciated.

The term nature-based solutions (NBS) refers to the use of nature for tackling environmental and societal challenges while increasing biodiversity. A definition offered by the European Union Commission, which has been funding critical research in NBS over the last ten years, states: These solutions are "inspired and supported by nature, which are cost-effective, simultaneously provide environmental, social and economic benefits and help build resilience (...) and bring more, and more diverse, nature and natural features and processes into cities, landscapes and seascapes, through locally adapted, resource-efficient and systemic 
interventions" (Rizvi, 2015; Shanahan, 2015; EU-Commission, 2015 and EU-Commission, 2017; Fields in Trust, 2018).

These NBS provide practical, sustainable, cost-effective and adaptive alternatives for various urban planning objectives; by working with nature, rather than against it, it is possible to take further steps towards a more competitive, resource efficient and greener economy (which is often termed 'green growth'). It can also help to enhance natural capital rather than depleting it. For instance, green roofs or walls can be used to reduce the impact of high temperatures, collect storm water, reduce pollution and fine dust, and act as carbon sinks, all whilst simultaneously enhancing biodiversity. Similarly, the collection and storage of rainwater in constructed wetlands, or the protection of mangrove forests along coastlines utilise a nature-based solution to achieve several objectives, including disaster risk reduction. Urban flood control is regulated in a natural way, with mangroves alleviating the impact of wind and waves on coastal settlements or cities whilst also capturing $\mathrm{CO} 2$. Additionally, the mangrove forests can provide safe nurseries for marine life and help control coastal erosion resulting from a rise in sea-levels, mitigating potentially harmful effects on the environment and on human health and society (Kabisch et al., 2016; Lennon \& Scott, 2014; Maes \& Jacobs, 2017; Rich, 2018; World Forum on Natural Capital, 2018).
New urban design concepts should form an urbanisation model for incorporating and reintroducing greenery and biodiversity into the urban built environment. Maintaining biodiversity in the face of urbanization, habitat loss, environmental deterioration and climate change is one of the extreme challenges of the present day. The inclusion of trees, shrubs and other plant matter into green spaces and gardens within the city is of paramount importance in helping to keep the urban landscape cool, mitigating against buildings and pavements which increase heat absorption and heat storage, leading to the UHI effect (Hawken, 1999; Watts, 2018). Numerous studies have been conducted on the role of green canopies in urban life, with the result that tree coverage differs widely between cities (Pauleit et al., 2005; Schwarz et al., 2015). One of these, the 2018 MIT Senseable City Lab study, established the Green View Index (GVI) that represents the total percentage of a city covered by trees. The study found that Paris has a very high population density but only a GVI of 8.7 percent, compared to London (12.7 percent), Amsterdam (20.6) or Oslo (28.8 percent) (MIT Senseable City Lab, 2018). (See: Figures 4 and 5)

These strategies introducing nature in urban regeneration projects improve numerous aspects of our lives and can be measured by the increasing live expectancy and reduced time residents take sick leave from their workplaces. 


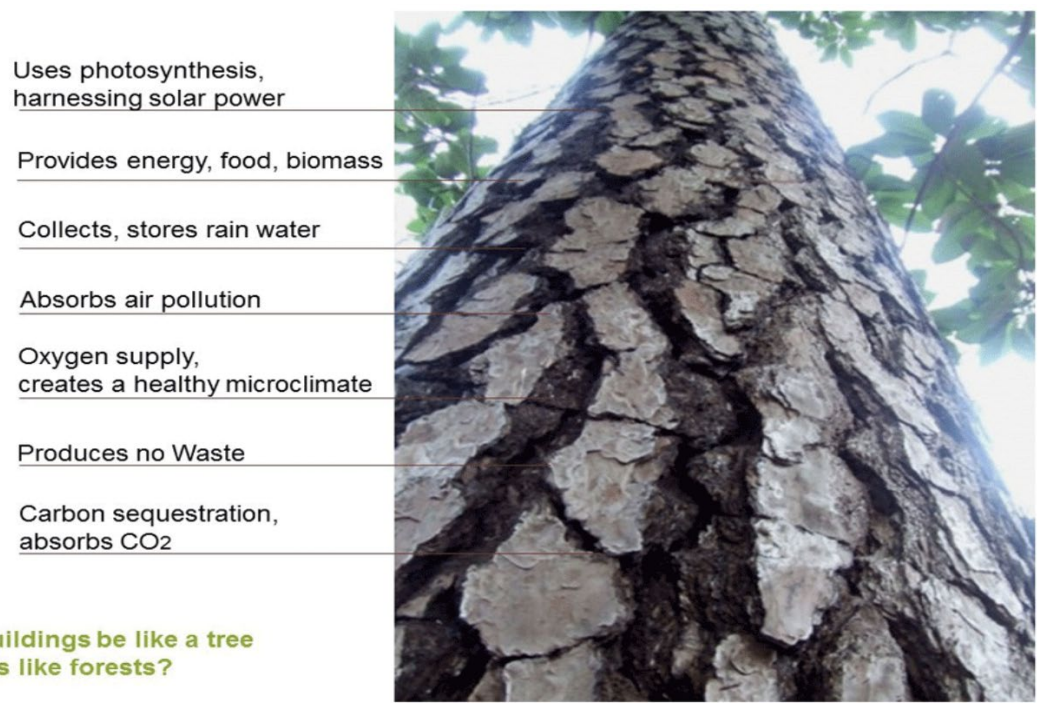

Figure 4. A tree stores carbon and provides a large range of ecosystem services (S. Lehmann, 2010)

Could buildings be like a tree and cities like forests?

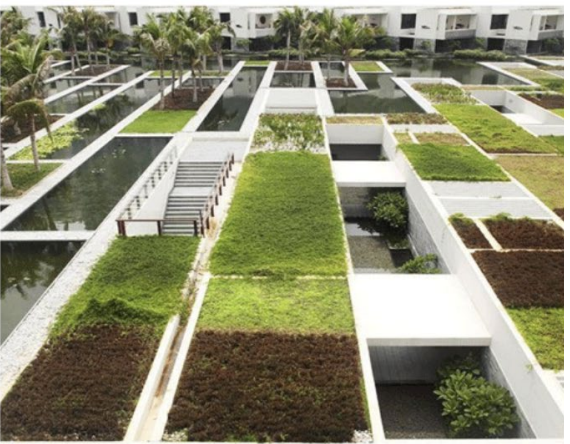

Nature-based solutions

Ecosystem Services
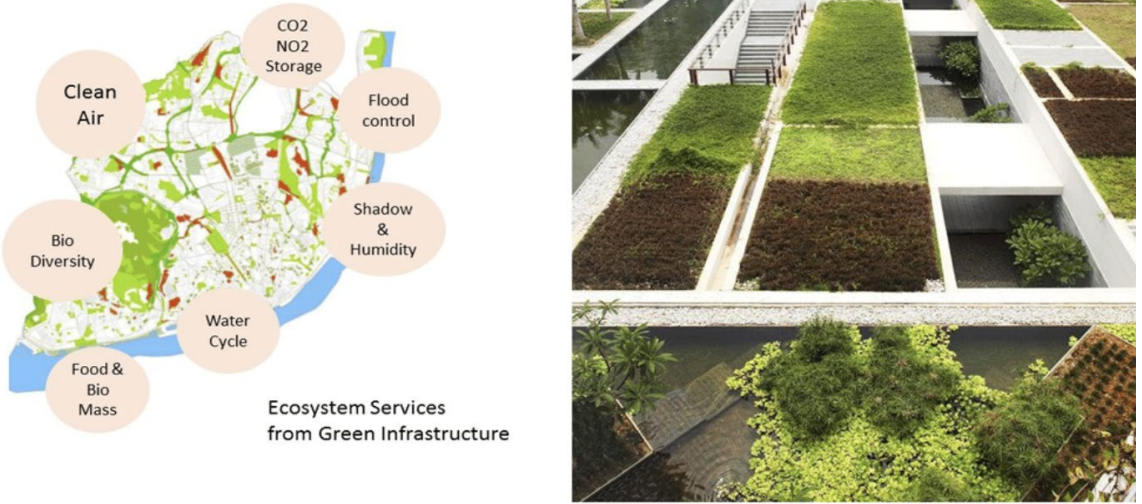

Figure 5. Ecosystem services include essential services provided by nature, such as water management, biomass energy, food, oxygen supply, humidity and flood control, carbon storage and sequestration (S. Lehmann, 2017) 


\section{CONCLUSION}

The urban neighbourhoods of the future will have to offer new forms of green space. These will serve a dual purpose, existing both as areas for recreation whilst acting at the same time to mitigate the warmer urban microclimate. Tomorrow's neighbourhoods will also need to generate at least 50 percent of their own power themselves (Lehmann, 2015). Integrated development, which concentrates on energy and water management, green infrastructure and the urban microclimate, will take a leading role in urban regeneration.

Every city is unique. Cities differ in the ways in which they are vulnerable to climate change. When it comes to strategies to increase resilience, what works in one city may not work in another. Urban regeneration projects allow 'repairing' and restoring some of the damage caused to ecosystems whilst enhancing urban resilience. What is needed now is to nudge that transformation in the direction of sustainable and resilient solutions, making the most of opportunities for re-greening, using resources efficiently and acknowledging the value of natural capital (Lehmann, 2017; Nature Editorial, 2018; Lehmann and Melis, 2021).

A good example for such linkages is the author's international research project "Crunch - the Food-Water-Energy Nexus", which explores these issues in greater depth using integrated methods (see: www.fwenexus.eu).

By beginning to place a value on natural capital, and assessing our vital systems as whole and not as separate parts, we can begin to make efficiency savings that previously would not have been apparent. In doing so, we not only benefit financially through saving valuable resources and mitigating against environmental risks resulting from climate change, but also contribute towards the repair and renewal of our ecosystem, conserving resources that are finite and helping to prevent further global temperature rise. Hence, a final question the paper might raise among its readers is: How can we all set the conditions for the change to happen and reasonably "quickly"? In other words, how can effective local to planetary stewardship strategies for urban ecosystems and the biosphere be "codesigned" within and across communities (of knowledge, practice, and citizenship)?

\section{ACKNOWLEDGMENTS}

The author would like to thank his colleagues at the University of Portsmouth (UK) and the University of Nevada Las Vegas (USA) Urban Futures Lab for providing discussion and input. 


\section{REFERENCES}

Afanador A, Begemann E, Bourgault C, et al. 2015. The potential of scaling up proven low-carbon solutions.

Alberti M, Marzluff J. 2004. Ecological resilience in urban ecosystems: linking urban patterns to human and ecological functions. Urban Ecosyst. 2004; 7(3): 241-265.

ASHRAE 2010. Guideline 10P, Interactions Affecting the Achievement of Acceptable Indoor Environments, Second Public Review. ASHRAE, Atlanta, USA.

Benyus J. 2002. Biomimicry-Innovation inspired by Nature.

Bowler DE, Buyung-Ali L, Knight TM, et al. 2010. Urban greening to cool towns and cities: A systematic review of the empirical evidence. Landsc Urban Plan. 2010; 97(3): 147-155.

Carson R. 1962. Silent Spring. Penguin Modern Classic, London and New York.

CPRE 2018. State of Brownfield: An analysis demonstrating the potential of brownfield land for housing. Campaign to Protect Rural England; London, UK.

Cronon W. 1995. The Trouble with Wilderness; or, Getting Back to the Wrong Nature. In William Cronon, ed., Uncommon Ground: Rethinking the Human Place in Nature, New York: W. W. Norton \& Co., 1995; 69-90.

Descartes, R. 1637. Discourse on Method (original title: Discours de la méthode pour bien conduire sa raison et chercher la verité dans les sciences), Paris.

Doick KJ, Peace A, Hutchings TR. 2014. The role of one large greenspace in mitigating London's nocturnal urban heat island. Sci Total Environ. 2014; 493: 662-671.

Ellen MacArthur Foundation 2017. The Circular Economy. A Wealth of Flows (2nd edn), accessed 10 July 2019.
European Union Commission, DG Research and Innovation 2015. Towards an EU research and innovate policy agenda for nature-based solutions and re-naturing cities. Final report of the Horizon 2020 expert group on 'Nature-based solutions and re-naturing cities', European Commission, Brussels, 2015; 70.

European Union Commission 2017. Naturebased Solutions: Innovating with Nature. European Commission, Brussels, accessed 10 July 2019.

Fairchild T. 1722. The City Gardener. T. Woodward, London.

Fields in Trust 2018. Revaluing Parks and Green Spaces. Study UK; 2018; accessed 10 July 2019.

Girardet H. 2008. Cities, People, Planet: Urban Development and Climate Change (2nd edn). John Wiley \& Sons, London.

Grinde B, Patil GG, 2009. Biophilia: does visual contact with nature impact on health and well-being? Int J Environ Res Public Health. 2009; 6(9): 2332-2343.

Hand KL, Freeman C, Seddon PJ, et al. 2017. The importance of urban gardens in supporting children's biophilia. Proc Natl Acad Sci U S A. 2017; 114(2): 274-279.

Hawken P, Lovins A, Lovins H. 1999. Natural Capitalism. Creating the Next Industrial Revolution. Little Brown and Company, New York.

Howard, E. 1902. Garden Cities of To-morrow: A Peaceful Path to Real Reform, London.

IPCC, 2018. Global warming of $1.5^{\circ} \mathrm{C}$. An IPCC Special Report on the impacts of global warming of $1.5^{\circ} \mathrm{C}$ above pre-industrial levels and related global greenhouse gas emission pathways, in the context of strengthening the global response to the threat of climate change, sustainable development, and efforts to eradicate poverty. 
Kabisch N, Frantzeskaki N, Pauleit S, et al. 2016. Nature-based solutions to climate change mitigation and adaptation in urban areas: perspectives on indicators, knowledge gaps, barriers, and opportunities for action. Ecol Soc. 2016; 21(2): 39.

Kellert SR, 2011. Biophilic Design. The Architecture of Life. Tamarack Media, USA. Movie.

Lehmann S. 2010. The Principles of Green Urbanism. Transforming the City for Sustainability. Earthscan, London (Chinese Edition, 2014).

Lehmann S. 2015. Urban microclimates: mitigating urban heat stress. Lehmann, S. (ed.) Low Carbon Cities: Transforming Urban Systems, Routledge, London, 251.

Lehmann S. 2017. The challenge of transforming a low-density city into a compact city. Bay JHP. and Lehmann, S. (eds) Growing Compact. Urban Form, Density and Sustainability, Routledge, London, 69-93.

Lehmann S. 2019. Urban Regeneration: A manifesto for transforming UK cities in the age of climate change. Palgrave Macmillan, London.

Lehmann, S. and Melis, A. 2021. Resilient Communities. D-Editore and the Venice International Biennale of Architecture, Italy, forthcoming, May 2021.

Lennon M, Scott M. 2014. Delivering ecosystems services via spatial planning: reviewing the possibilities and implications of a green infrastructure approach. Town Plan Rev. 2014; 85(5): 563-587.

Lovelock JE. 1979. Gaia, a new look at life on Earth. Oxford University Press, UK.

Maes J, Jacobs S. 2017. Nature-Based Solutions for Europe's Sustainable Development. Conserv Lett. 2017; 10(1): 121-124.

McDonough W, Braungart M. 2002. Cradle to Cradle: Remaking the Way We Make Things. North Point Press, New York, NY.
McHarg I. 1969. Design with Nature. Doubleday/Natural History Press, New York; Falcon Press, Philadelphia.

Meadows D, Meadows DL, Randers J, et al. 1972. The Limits to Growth: a report for the Club of Rome's Project on the Predicament of Mankind. Universe Books, New York, NY (1971 Report/1972 Book).

Meerow S, Newell JP, Stults M. 2016. Defining urban resilience. A review. Landscape Urban Plan. 2016; 147: 38-49.

MIT Senseable City Lab, Carlo Ratti et al. 2018. Treepedia, developed in collaboration with WEF. Cambridge MA, USA; accessed 5 Aug 2018. 2019.

Mitchell T, Harris K. 2012. Resilience: a risk management approach. Background Note ODI, Overseas Development Institute, UK.

Nature Editorial, 2018. Climate talks are not enough. Nature. 2018; 556: 407-408.

Neves J, Francke I. 2012. Creative product design using biomimetics. Design and Nature VI: Comparing Design in Nature with Science and Engineering, 2012; 4: 149.

Office for National Statistics, 2016. Small Area Population Estimates 2013. Office for National Statistics, London.

Pauleit S, Jones N, Nyhuus S, et al. 2005. Urban Forest Resources in European Cities. In Urban Forests and Trees. ed Cecil Konijnendijk, Kjell Nilsson, Thomas Randrup, Jasper Schipperijn. Springer Verlag; Berlin.

Rautio P, Hohti R, Leinonen RM, et al. 2017. Reconfiguring urban environmental education with 'shitgull' and a 'shop'. Environ Educ Res. 2017; 23(10): 13791390.

Register R. 1987. Eco-City Berkeley: Building Cities for a Healthy Future. North Atlantic Books, Boston. 
Rich N. 2018. Losing Earth: The Decade we almost stopped Climate Change. New York Times, New York; accessed 10 Aug. 2019.

Rizvi AR, Baig S, Verdone M, 2015. Ecosystems Based Adaptation: Knowledge Gaps in Making an Economic Case for Investing in Nature Based Solutions for Climate Change. Gland, Switzerland: IUCN 48.

Sailor DJ. 2014. A Holistic View of the Effects of Urban Heat Island Mitigation. In Low Carbon Cities: Transforming Urban Systems. Routledge, London, Ed. S. Lehmann, 2014; 270-281.

Schwarz K, Fragkias M, Boone CG, et al. 2015. Trees grow on money: urban tree canopy cover and environmental justice. PLOS One. 2015; 10(4): e0122051.

Shanahan DF, Lin BB, Bush R, et al. 2015. Toward improved public health outcomes from urban nature. Am J Public Health. 2015; 105(3): 470-477.

Steffen W, Rockström J, Richardson K, Lenton T, Folke C, Liverman D, Summerhayes C, Barnosky A, Cornell S, Crucifix M, Donges J, Fetzer I, Lade S, Scheffer M, Winkelmann R, Schellnhuber H. 2018. Trajectories of the Earth System in the Anthropocene. Proceedings of the National Academy of Sciences. 2018; 115(33): 8252-8259.

Tansley AG. 1935. The Use and Abuse of Vegetational Concepts and Terms. Ecology. 1935; 16(3): 284-307.

The World Forum on Natural Capital, 2018. What is Natural Capital? Accessed 10 July 2019.

UN-Habitat, 2016. The City We Need 2.0. United Nations Human Settlements Programme (UN-Habitat). Nairobi.

University of Leicester, 2015. State of our countryside: Land-use map of the UK. Accessed 10 Aug. 2019.

Watts J. 2018. Domino-effect of climate events could move Earth into a 'hothouse' state. The Guardian, London; accessed 10 Aug. 2019.
Wilson EO. 1984. The Biophilia Hypothesis. Island Press, New York.

Woo F, Wortmann J, Schurig S, et al. 2014. Regenerative Urban Development: A Roadmap to the City We Need. Hamburg: World Future Council.

World Health Organization (WHO), 2014. Healthy Cities. Promoting Health and Equity. Copenhagen; accessed 10 July 2019. 


\section{PAPER \#2.09}

\section{CONSIDERING LADAKHI SELF-SUFFICIENCY UNDER CLIMATE CHANGE, COVID-19 AND BEYOND}

\section{Carey Clouse ${ }^{a}$}

aniversity of Massachusetts Amherst, Amherst, MA

\section{ABSTRACT}

The long-term self-sufficiency of high-altitude subsistence farmers in Ladakh, north India, is noteworthy, particularly in the context of the pressures of globalization. This paper identifies design attributes that contribute to this extraordinary autonomy, in part due to the architecture, landscape architecture and infrastructural adaptations that have occured under recent climate change challenges. However, the impact of the COVID-19 virus has also tested these measures of Ladakhi independence, and in telling ways. In comparing resilience measures from climate change adaptation and the earliest waves of the outbreak in Ladakh, this paper charts the limitations of planned self-sufficiency, and makes connections between these problem areas and broader planning goals for resilience.

\section{KEYWORDS}

Ladakh; COVID-19; climate change; resilience; adaptation.

\section{INTRODUCTION}

Over time and throughout history, the remote region of Ladakh, in north India, has proven itself to be extraordinarily self-sufficient. This is the ethos that has underscored hundreds of years of ongoing life in highaltitude farming villages, has helped to characterize the strong cultural and social ties of residents, and has enabled the relative autonomy of the area relative to state formation in other parts of India and South Asia. In recent years, climate change has caused extreme environmental changes in the region, and adaptive responses have continually reinforced ideas of selfsufficiency and autonomy. In 2020, however, the COVID-19 pandemic emerged in Ladakh, severely testing Ladakhi resilience. This paper offers a brief overview of the topic of self-sufficiency in Ladakh, charts examples of climate change adaptation in the area, and then offers initial thoughts on the impact of a global virus through the lens of early, initial reports from Ladakh. The goal of this ongoing research is to begin to understand potential correlations between climate change adaptation, notions of resilience and state autonomy, and the early stages of a global pandemic.

\section{BACKGROUND}

The Union Territory of Ladakh is a relatively new designation, as until 2019 the region was a part of the state of Jammu and Kashmir, India's northernmost state. Today Ladakh is made up of two districts, one in Leh and one in Kargil, located in a relatively remote and isolated high-altitude mountain environment. Leh District is the portion of Ladakh considered for this paper, although the two areas of Ladakh have relatively similar attributes. Throughout this paper the term Ladakh is used to designate the portion of land that is officially known as Leh District. Located between the Himalayan and Karakoram mountain ranges, the region of 
Ladakh is characterized by high-altitude mountains, scarce rainfall, and relative isolation from the Indian subcontinent. The region's barren landscapes and extreme seasonal weather patterns have given rise to village lifestyles that exhibit specialized traits for collective survival. Under the pressures of climate change, methods for subsistence farming have been revisited through a wide array of adaptive design interventions. Together, these ancient skills and newfound techniques can be understood as a series of old and new forms of architectural, infrastructural and landscape adaptations for survival in a difficult climate and context. Despite the long history of Ladakhi stability, each new environmental shift can have an extraordinary impact upon social, cultural, religious, economic and environmental foundations in the region. Scholars Marcus Nüsser and Ravi Baghel note that, "Regardless of the specific point of departure, research aims, theoretical foundations, and methodological designs of case studies, it is widely accepted that the livelihoods of most of the Himalayan population are under stress and adversely affected by continuous degradation or depletion of the natural resource base."(Fewkes 2011) This paper briefly discusses some of the adaptive design approaches explored under current climate change challenges, and the broader landscape of self-sufficiency in Ladakhi society.

\subsection{Self-sufficiency}

Ladakhi self-sufficiency has been welldocumented by visitors and scholars, and it is a prized trait that emerges in the stories and daily interactions of residents (NorbergHodge 1991). Notions of independence pervade the majority of basic needs, from food production, to land tenure, to education, religion and healthcare. Ladakhi villages have historically produced most, if not all of the food and material products needed for their own consumption, emerging as self-reliant units within a broader landscape of Ladakhi space (Crook and Osmaston 1994). Indeed, Ladakh was never entirely isolated from the rest of the world, as individuals within these groups also engaged in trans-national trade for additional products such as tea, oil and salt, and animals that provided material, labor or food products (Fewkes 2011). However, even today, Ladakhi villages tend to be agrarian in nature, with fields planted with crops for household consumption and animal fodder.

Self-sufficiency, as a practice and an ethos, is deeply embedded into village space and cultural practices (Norberg-Hodge 1991). The disciplines of architecture, landscape architecture and spatial planning are not widely practiced in this region, and yet these disciplinary domains feature prominently in both historic and current adaptive measures. For instance, the design and planning of water management structures enables high-altitude village agriculture, and so the topic of infrastructure features prominently in the Ladakhi conception of territorial independence. Similarly, sustainable design is a part of agricultural systems and the shape and functions of vernacular and contemporary buildings in this landscape (Prakash 1991).

\subsection{Tourism}

Ladakh has long occupied a geophysical position of international importance, as an outpost on major trade routes such as the Silk Road (Devers 2017; Fewkes 2009), and more recently as a contested borderlands region. But Ladakh still remains somewhat isolated, by some combination of political mandate, geography or weather, in uneven ways, even today. In 1974, the region was opened to outsiders and since then has supported a growing population of visitors who have helped to sustain a growing economy based on tourism. Today tourism accounts 
for a major share of the local economy, affording individuals and households earning opportunities away from family villages (Akhtar and Gondhalekar 2013).

\subsection{State Control}

Today, it is possible to chart the extraordinary resilience of several hundred Ladkahi subsistence farming villages that have been continuously operating for nearly a thousand years, enduring raids, changing political structures, and even efforts at state formation (Moorcroft 1841). Political scientist and anthropologist James C. Scott has written extensively about the autonomy of groups who live at some remove from the working aparatus of the state. Stateless people benefit, according to Scott, by living beyond the jurisdiction of a governing authority, avoiding taxation or conscription, for instance (Scott 2009). In recent years, the physical remove that Ladakhi villages have had from the Indian subcontinent has given the region and its people a special status, as a borderlands region. In this capacity, Ladakh receives financial and infrastructural support, while retaining relative autonomy from the state through self-governing agreements and, for better or worse, narratives of isolation (Demenge 2013).

Scott identifies a number of groups in Southeast Asia who have evaded state control over time, and while north India is not explicitly included in his study, it falls into a similar category based on traits and characteristics. The region of Ladakh is isolated geographically, but also in terms of trade and supervision. While on several major trade routes, including the historic Silk Road, Ladakh is at an elevation that effectively shuts down road access from October through June each year. Even today, this area must be accessed by walking on frozen rivers for days, or by flying - using a helicopter to reach the most extreme outposts. This seasonal separation requires Ladakhis to maintain a practiced regime of self-sufficiency, because although assistance and support is provided by the government of India, it may be literally out of reach (Daultrey and Gergen 2010).

\section{CLIMATE CHANGE ADAPTATION}

Ladakh can be considered a useful region for the study of self-sufficiency and resilience not only because of its uniquely autonomous experience over time, but also because it has made changes to adapt to recent climate change challenges. In both sustained methods for survival over time, and new techniques for physical adaptation, Ladakh offers an example of what it means to make do with fewer resources, and to change behavior to support radical communitarian living (Nüsser et al. 2019). Ladakh is exposed to a variety of challenges, all of which have shaped, in some way or another, its enduring legacy. The region is located in a contested border zone known for its inhospitable climate. It has a landscape defined by high altitude, impassable roads, and steep, rugged terrain. It has been shaped by tourism and recent struggles for sustainable economic development. All of these conditions create the challenging context of contemporary Ladakh, in which adaptive design responses must shore up older notions of selfsufficiency.

\subsection{Characteristics of Adaptive Projects}

Ladakhi villages harbor a variety of types of climate adaptive design projects, typically small in scale, with site-specific, dispersed footprints. These projects range in type from infrastructure interventions to energy systems and development projects. Many have physical, cultural, social, religious, and economic ties to the region. Indeed, the small-scale adaptive projects in Leh District are contextually responsive, using local materials, labor and resources. 


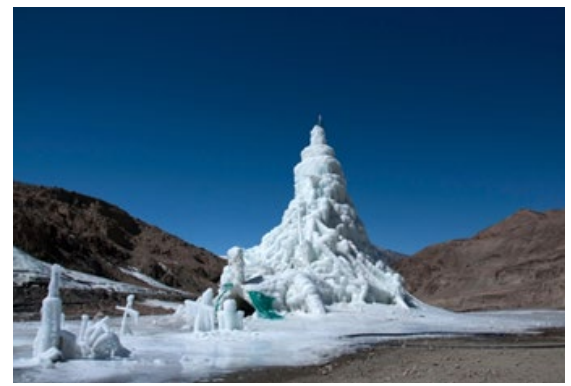

Figure 1. Ice Stupas create freestanding caches of water for irrigation, held in the winter as ice. Source: Carey Clouse

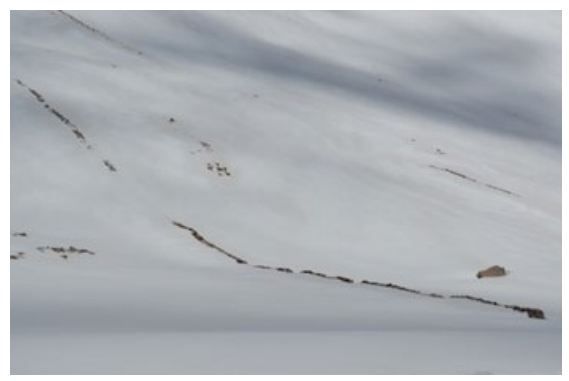

Figure 2. Snow Barrier Bands are built on mountain passes to catch and divert wind-blown snow for irrigation use. Source: Carey Clouse

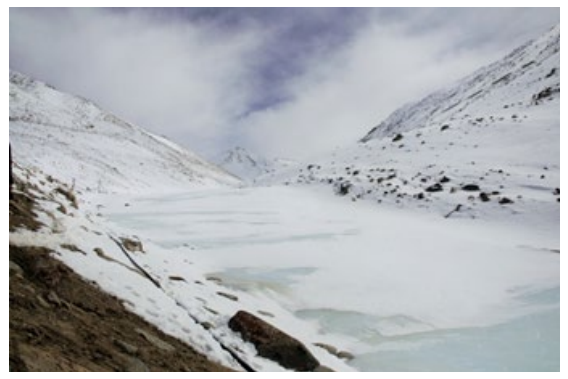

Figure 3. Artificial Glaciers are built to trap and hold meltwater, as ice, for the following agricultural season. Source: Carey Clouse

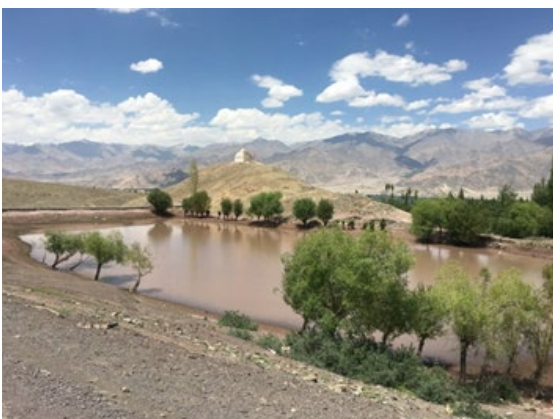

Figure 4. Water reservoirs are built into the landscapes above village farms and below glaciers, to hold irrigation water for equitable shared use, as a form of the commons. Source: Carey Clouse

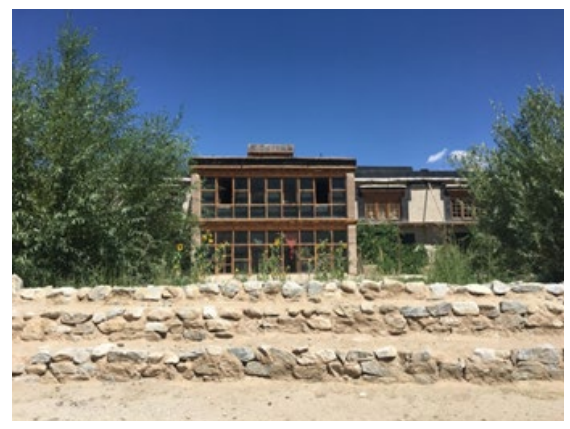

Figure 5. Passive solar architecture strategies have improved energy efficiency and year-round livability in Ladakh. Source: Carey Clouse

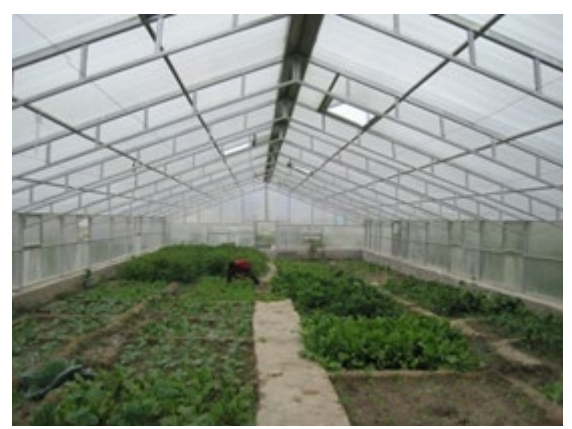

Figure 6. The interior conditions of an improved greenhouse in Ladakh enables a year-round growing season. Source: Carey Clouse 


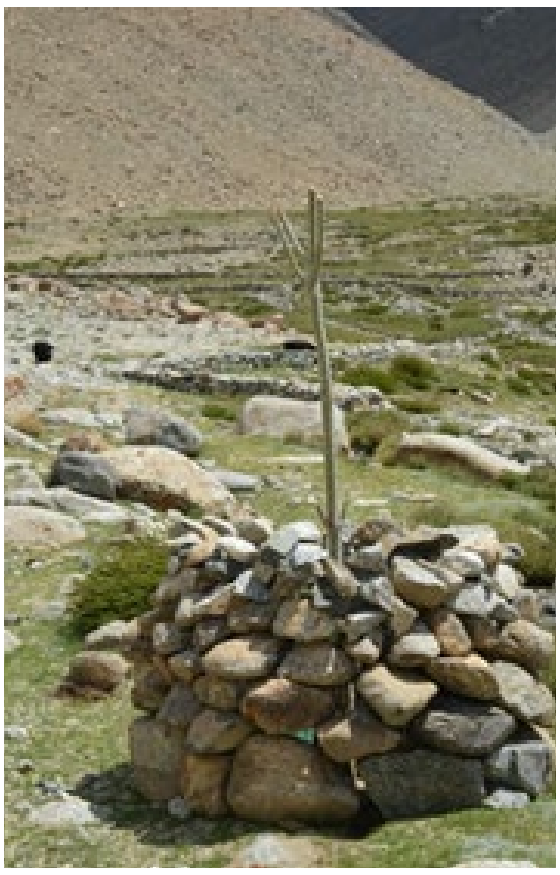

Figure 7. Tree armor helps a newly planted sapling to thrive; as a design strategy it produces local tree resources and all of the benefits trees provide for ecosystem functioning. Source: Carey Clouse

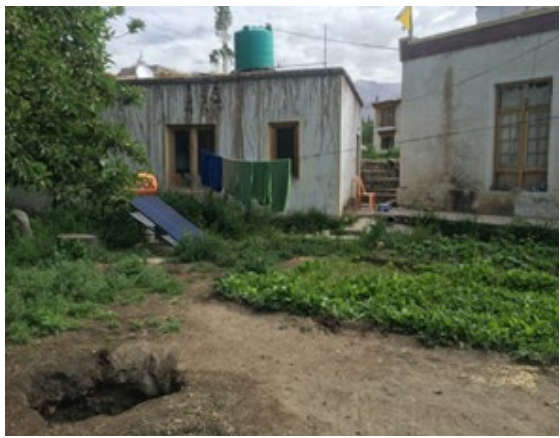

Figure 8. A hole (foreground) dug to store food underground helps to manage food security. Source: Carey Clouse
Four major themes guide current climate adaptive work in Ladakh. Energy efficiency, food security, water stewardship and resource management appear again and again as the driving forces behind individual projects. Climate adaptive strategies include the production of ice stupas, snow barrier bands, artificial glaciers and water reservoirs; the development of solar architecture and greenhouses; the use of tree armor; and food stockpiling and sharing. In each of these examples, extant practices were augmented using new materials, techniques, or design hacks. For instance, the implementation of an artificial glacier simply enhances the functioning of existing meltwater irrigation systems in the area, rather than replacing proven systems of water self-sufficiency.

\subsection{Examples of Climate Change Adaptation in the Region}

The following images of climate adaptive projects help to illustrate the range and type of designs currently implemented in Ladakh. These projects typically operate outside of governmental support or engagement, instead having a local ethos, production effort and system of management. Each of these systems or designs has helped to solidify the region's autonomy, even as various systems have been eroded by destructive forces of climate change. (Figures 1-8).

\section{COVID-19}

When the global pandemic caused by COVID-19 struck travelers in January and February of 2020, Ladakh appeared to be a region that was well-insulated from global tourism, largely because very few travelers typically venture to the region during the winter months. Moreover, Ladakhi people also perform reduced service roles in the winter months, instead working on farms, retreating to ancestral homes and often 
limiting contact with others because movement is hampered by extreme winter weather.

The first COVID-19 cases were identified in March, 2020, affecting a dozen residents who had returned from pilgrimages abroad. These travelers acquired the illness while abroad, thus bringing it into the region. The individuals were hospitalized while the rest of the region moved into a quarantine lockdown. It appeared that this strategy worked: in late-March, Ladakh was declared COVID-free (Sharma 2020).

However, in the ensuing weeks, many hundreds of students returned from schools in other cities and states to shelter in Ladakh with their families. This caused an additional influx of travelers into the region, along with other residents returning home from across India and beyond. In April, additional cases were announced in local and national news sources, and Ladakh again appeared to have active cases. In the weeks up to this writing, government agencies have continuously reported additional COVID-19 cases in both Leh and Kargil districts. Together, the two districts had a combined total of more than 1,000 cases by July 1st, 2020 (Tribune News Service 2020).

\subsection{Impacts from Tourism}

In addition to the essential concerns about human health and wefare, Ladakh has also suffered a major economic loss, in the form of tourism, from the COVID-19 virus in 2020. The region has witnessed explosive growth in recent years, with the number of annual tourists rising steadily since 1974, when the government opened the region to visitors. In the past decade alone, Ladakh has seen an enormous uptick in tourists, who come for a variety of reasons: to trek in the mountains, to see ancient Buddhist relics and spaces, or to witness the special cultural products of Ladakhi society (India 2019).
Tourism is the central driver for Ladakh's contemporary economy, and it has permeated almost all parts of the Ladakhi economy, from the jobs of hotel staff, drivers and tour operators to food produced and prepared for visitors and even the wide array of materials bought and sold in marketplaces. Farming families rely on visitors for homestays or as customers for dried aprocots and knitted hats. Businesses sell gear and experiences to tourists, and the associated travel industry is completely reliant on the influx of summer tourists each year.

With the summer of 2020 appearing to be a lost year for tourism, many hotel, guesthouse and restaurant businesses are projecting a loss of profits. Without an influx of visitors, the enormous structure of Ladakhi tourism falls apart, leaving many individuals without jobs. This is an environment where nearly every Ladakhi has an ancestral home or farm to return to, and the idea of homelessness or destitution is still unprecedented. But several concerns have already emerged, and as the ripple effect from a lost season of tourism plays out, there will undoubtedly be others as well.

Additionally, many individuals have taken out loans in order to build guest living quarters on their land, or to purchase vehicles or other business assets. These small-scale entrepreneurs could be in danger of losing their land, assets, and ultimately their means of employment if they cannot make payments to the banks on their loans this year.

The second major impact will be seen in educational attainment. Ladakhi students pay tuition to attend many secondary schools and colleges, both regionally and nationally. Initally, students will not be able to physically attend classes due to distancing measures, and they will likely struggle with distance learning because of a lack of internet access. In the following years, students whose families can't afford the high cost of tuition may need to remove their students from 
these high schools and colleges. This ongoing loss of education, professional preparation and the overall advancement of the Ladakhi workforce will likely have a lasting imprint on Ladakhi opportunities in the future.

\subsection{Highlighting Gaps in Self-sufficiency}

Across the globe, the areas of impact of the virus on the economy, the environment, and society are far-reaching. But in Ladakh, the pandemic is also illustrative of gaps in the relative independence of a region that is both lauded for radical autonomy and extraordinarily vulnerable to change. It is then perhaps useful to consider how climate adaptive design interventions have fallen short of assisting in ameliorating the problems of the pandemic, and also to acknowledge the region's capacity to pivot to greater resilience, even given current COVID-19 challenges. Climate-adaptive design projects tend to impact and improve environmental, rather than human systems. Increasingly, the concerns of human, social, cultural, religious, political and economic realms may be understood as embedded within, and central to, environmental functioning.

Two striking areas where self-sufficiency is lacking in contemporary Ladakh is in tourism and education. Healthcare access is uneven, as many Ladakhis integrate care from traditional healers and Western medicine, and these two alternatives have varying degrees of access throughout the region. These three weak points might be addressed in future planning efforts, as they could be bolstered with strategic design interventions aimed at increasing self-sufficiency. Just as climate change and environmental health has moved to the forefront of planning efforts in recent years, healthcare, education and tourism might also benefit from new design solutions.

\section{DISCUSSION}

The position that many Ladakhis are in today, under a COVID-19 quarantine, is perhaps no different than the situation that is faced by individuals the world over. The future economic health of the region appears to be in a dire condition, pushed perhaps in one direction or another by the duration of this virus and its long-term impact on tourism. As in many other places, Ladakh has been split- between the individuals who have little to lose- having no prior reliance on tourism for economic benefit or education, and those whose lives will be forever altered by the loss of income, or opportunity, that this pandemic produces.

But this great divide is difficult to accept, given the Ladakhi ethic of self-sufficiency and the sheer number of generations that have successfully operated outside of the state's control. If the economic and intellectual promis of Ladakh is crushed by a single virus, then one must reckon with the awareness that this region is now inextricably linked to global phenomenons, and that it is, no longer, an autonomous and utterly resilient place.

Geographer Neil Brenner's articulation of planetary urbanization is perhaps useful here, as it appears that COVID-19 has only highlighted the ways in which Ladakh is now tethered to the rest of the world (Brenner 2014). This connection is a double-edged sword- one that brings economic prosperity, an influx of ideas and support, crosscultural awareness and sharing, and then, on the other hand, also risk, in increased vulnerability to physical, economic, political and social change. For Ladakhis to remain independent and autonomous they will need to self-isolate, with all of the intertwined opportunities and obstacles that such a measure would represent. 


\section{CONCLUSION}

Ladakh is a high mountain landscape populated by tiny, thousand-year-old villages. Here villagers might be considered to be living on the front lines of climate change, where melting glaciers predominate, and GLOFs, cloudbursts, mudslides, and a decoupling of precipitation from agricultural norms have become commonplace events. Here too are the farmers and engineers who have effectively countered these landscape shifts with their own climate-adaptive design responses.

This paper outlines a few of the climateadaptive design responses found today in Ladakh, and acknowledges the region's deeprooted self-sufficiency. These examples of resilience stand in stark contrast to the impact of the COVID-19 pandemic, which has been, to many in the region, devastating. In comparing Ladakhi notions of autonomy and climate change adaptation with COVID-19 challenges, it is possible to highlight the gaps in overall system resilience. While climate-adaptive design interventions have remained viable during the current pandemic, a loss in the spheres of education and tourism represents severe limitations to the functioning of Ladakhi society.

If there is something to be learned from the case of Ladakh, remoteness, and the self-sufficiency that accompanies this geographic remove can be a considerable benefit in the context of a global pandemic. Individual village households, as subsistence farming units, function well without many external inputs. Climate-adaptive design interventions all contribute to the functioning of households and farms, enabling ongoing agricultural production during quarantine.

But what good is it to operate at a remove? What if you desire education for your children, economic opportunity for your family, or perhaps access to the very healthcare needed in such a pandemic? At this very early stage in the global COVID-19 pandemic,
Ladakhi self-sufficiency and austerity, is very much on stage. Ladakhi society, and norms, have shifted in the five decades since the region opened in 1974, and during that time the expectations, hopes, and interests of its residents have also evolved. Perhaps what is best for limiting virus transmission is also antithetical to these human desiresand the very things that support our ongoing connection to each other. 


\section{REFERENCES}

Akhtar, Adris, and Daphne Gondhalekar. 2013. "Impacts of Tourism on Water Resources in Leh Town." In . Vol. 30. leh-ladakh: International Association for Ladakh Studies.

Brenner, Neil J., ed. 2014. Implosions/ Explosions: Towards a Study of Planetary Urbanization. Berlin: Jovis.

Crook, John, and Henry Osmaston. 1994. Himalayan Buddhist Villages: Environment, Resources, Society and Religious Life in Zangskar, Ladakh. Bristol: University of Bristol.

Daultrey, Sally. 2010. "Adaptation on the Roof of the World." The Center for Design and Geopolitics (blog). December 30, 2010 . http://designgeopolitics.org/ blog/2010/12/adapatation-on-the-roofof-the-world/.

Demenge, Jonathan. 2013. "The Road to Lingshed: Manufactured Isolation and Experienced Mobility in Ladakh." HIMALAYA, the Journal of the Association for Nepal and Himalayan Studies 32 (1): 51-60.

Devers, Quentin. 2017. "Charting Ancient Routes in Ladakh: An Archaeological Documentation." In Interaction in the Himalayas and Central Asia: Processes of Transfer, Translation and Transformation in Art, Archaeology, Religion and Polity, edited by Eva Allinger, Frantz Grenet, Christian Jahoda, Maria-Katharina Lang, and Anne Vergati, 321-38. Vienna: Austrian Academy of Sciences Press. https://www.academia.edu/39101653/ Charting_Ancient_Routes_in_Ladakh_An_ Archaeological_Documentation.

Fewkes, Jacqueline. 2009. Trade and Contemporary Society along the Silk Road: An Ethno-History of Ladakh. New York: Routledge. https://academic.oup.com/ ahr/article/115/2/513/11286.
2011. "Living in the Material World: Cosmopolitanism and Trade in Early Twentieth Century Ladakh." Modern Asian Studies. https://doi.org/10.017/ S0026479X07002058.

India, Press Trust of. 2019. "Leh Emerging Favourite Destination for Foreign Tourists, Nearly 50k Visited in 2018." Business Standard India, January 19, 2019. https:// www.business-standard.com/article/ pti-stories/leh-emerging-favouritedestination-for-foreign-tourists-nearly50k-visited-in-2018-119011900373_1. html.

Moorcroft, William. 1841. Travels in the Himalayan Provinces of Hindustan and the Panjab; in Ladakh and Kashmir; in Peshawar, Kabul, Kunduz, and Bokhara. Vol. 2. London: John Murray. https://www. wdl.org/en/item/17537/.

Norberg-Hodge, Helena. 1991. Ancient Futures: Learning from Ladakh. Sierra Club Books.

Nüsser, Marcus, and Ravi Baghel. 2016. "Local Knowledge and Global Concerns: Artificial Glaciers as a Focus of Environmental Knowledge and Development Interventions." In Ethnic and Cultural Dimensions of Knowledge, edited by Peter Meusburger, Tim Freytag, and Laura Suarsana, 8:191-209. Cham: Springer International Publishing. https://doi. org/10.1007/978-3-319-21900-4_9.

Nüsser, Marcus, Juliane Dame, Benjamin Kraus, Ravi Baghel, and Susanne Schmidt. 2019. "Socio-Hydrology of 'Artificial Glaciers' in Ladakh, India: Assessing Adaptive Strategies in a Changing Cryosphere." Regional Environmental Change 19 (5): 1327-37. https://doi. org/10.1007/s10113-018-1372-0.

Prakash, Sanjay, ed. 1991. Solar Architecture and Earth Construction in the Northwest Himalaya. Sustainable Development Series 5. New Delhi: Har-Anand Publications in association with Vikas Pub. House. 
Scott, James C. 2009. The Art of Not Being Governed: An Anarchist History of Upland Southeast Asia. Yale University Press.

Sharma, Arun. 2020. "Covid-Free Not Long Ago, Ladakh Sees 198 New Cases." The Indian Express, June 14, 2020. https:// indianexpress.com/article/india/covidfree-not-long-ago-ladakh-sees-198-newcases-6457813/.

Tribune News Service. 2020. "With 11 New Patients, Ladakh's Tally 1,002," July 4, 2020. https://www.tribuneindia.com/ news/j-k/with-11-new-patients-ladakhstally-1-002-108196. 
PAPER \#2.10

\section{SENSE OF ABSENCE: PLACE KEEPING OF THE INTANGIBLE}

Elena Rocchia

aArizona State University, Tempe, USA

\section{ABSTRACT}

There are episodes in which the built form of a city can not be discerned. For instance, while driving on freeways. In those moments, a city turns absent in the sense of being receptive to any change of meaning. It becomes a espace propre $^{1}$ as the effect of what it is imagined. This multiple-case design research generally tests how to grasp what is "perceived but not apperceived" (Leibnitz) in architectural education, using a methodological approach that involves an in-depth exploration of perceptions of a city using videos as data collection. The procedure is sequential. Two instrumental bounded case studies follow each other: the outcome of looking at a part of a historical movie informs the selection of the second case study - a design studio. The first case study - the prelude to more extensive research - is the content of the first fourteen minutes of Psycho (1960) as Hitchcock's image of Phoenix. It is an exploratory case study conducted in 2015 before a research question was identified, done following film analysis in terms of mise en scene to investigate a place. The second one is the analysis of a six-year studio's design phases. It involves extensive data collection, including a combination of film analysis and students' observation of situations using movie clips, the method used to look critically at the environment. The research purpose is to develop a more in-depth understanding of how movies shape how cities are seen by observing ways the interaction between students and films infers design narrative. Considering the issue across the studio's processes and outcomes not only extends across the intuition the Hitchcock movie but provides a test of a theory. It informs on ways architectural students can actively perceive a continually changing environment and capture moving images of the city to inform preliminary projects using transmediation introducing programs as situations.

\section{KEYWORDS}

Image; Phoenix; Hitchcock: psycho; espace propre; transmediation.

\section{INTRODUCTION - FADE IN}

The scope of the architectural research's analysis is to observe ways the nature and the function of experiences - the mental image of a city - can inform architectural projects. The knowledge of the mental picture of the city builds upon Kevin Lynch's book, The Image of the City (1960,) and on a premise: if Lynch investigates the city image as the look of its form built "on foot," this study investigates the one made by cameras, not experienced. In the scope of analyzing it, Phoenix is chosen as the context in which the research problem grows. As the built representation of many American metropolia, Phoenix is the epitome of cities "plastic to the perceptual habits of thousands of citizens: open-ended to change of function and meaning, receptive to the formation of new imagery," and representative of environments "well organized but poetic and symbolic as well." Phoenix speaks of cities of complex societies, and generally, "of the complicated functions and movements of the city world." 2 The transitional and transformative space of

\footnotetext{
${ }_{1}^{1}$ According to De Certeau, a subject defines a city in three phases, being the first one the act in which a subject produces a space propre - in a physical, mental, and political sense.

${ }^{2}$ Lynch, K. 1960. The image of the city. The Mit Press: 119
} 
its freeways, constructed to be unoccupied, is a vast area of absence. As the blank area in Piranesi's Pianta di Roma (Plan of Rome, 1756), is the palimpsest of one's interpretive memory fragments as the private visions built while driving, suspended in between the visible and perceived reality, fragmented images as incomplete ruins. Cars not only distort the relations humans have with the city but conform their minds and, in turn, the city becomes their product. I The multiple-case design research procedure is sequential: two instrumental bounded case studies follow each other. The subject of the first case study is the film analysis of the first fourteen minutes of one movie: Psycho (1960). In the film, Phoenix's urban desert is not seen as a built form but as an absent one. The second case study uses fifteen projects of a performance-oriented/ city-theatre studio done in 2017. Students began their projects following positions of speculative realism as a methodology. They used a phenomenological visual study to grasp Phoenix's urban reality as a location architecturally. The design process's steps saw students initially shooting movies using cameras at rest, analyzing them to determine potential narratives, and finally, creating both two-dimensionalimages and three-dimensional projects as Phoenix's duplicate products. I The purpose of the multiple-case design research is to reveal the construction of the city's mental image as the espace propre - the relationship between reality and representation of a city. In examining the beginning of Hitchcock's movie, the cinematic image of Phoenix is revealed not in terms of "imitation" but of Marion's lived experiences (espace propre.) | Results infer that the use of mental images in architectural projects is essential to investigate and crucial in a project setting. Thus, that imagination has a role in architectural design and urban reconstruction. This study advances, on the one hand, new ways for students to understand how to produce projects as their own space, using vivid and memorable images as visual experiences - moving images. On the other hand, it reconsiders the value of "edges" of interrupted cities generally experienced as disturbing: more than representations, cities are theaters of absence as shared visions that highlight what is universally and fundamentally human.

\section{DESCRIPTION OF THE CASE STUDIES}

\subsection{Cut to case study $1:$ Psycho - the absence of Phoenix}

For quite a long time, cinema critics have been reflecting on one of Hitchcock's most popular and successful movies -Psychofocusing on its contributions to modern horror films, on Norman Bates' psychosis, on the manipulation of audience's fear and so on. But the fact the secretary who steals, runs away and dies is from Phoenix goes unseen. In the opening credits, the text "Phoenix - Arizona" appears superimposed on a city. Immediately after, for fourteen minutes, an unprecedented Phoenix is shown not as a city but as a location. From Phoenix, Hitchcock takes only the name - not the setting. Psycho is not "a super production," as he says, but "a very strange film in every sense." ${ }^{3}$ Except for the opening scene, Hitchcock shoots the whole picture in Hollywood's interiors, portraying the city on Marion's car front and rear windows with the same look of his television films Alfred Hitchcock Presents shot in the Revue Studios. I The beginning of Psycho is a visual experience of forty-five seconds. From the helicopter, Hitchcock shows a city at the end of the 50s already widespread. Then, the camera movement goes from the panoramic view of Phoenix down to an interior. Moving from the city surface to its deep interiority, Hitchcock transitions space to void following the "farthest to the nearest" principle (Truffaut, 1985), announcing not only the film as a whole but the image of Phoenix according to

${ }^{3}$ Naremore, J. 1973. Filmguide to Psycho, London: Indiana University Press Filmguide Series, Harry Geduld and Ronald Gottesmann, General Editors: 19. 
Hitchcock: absent. Psycho happens in Phoenix, wholly invisible and absent. I One year after Frank Lloyd Wright's death, Hitchcock flies a camera lower and above a sun-bleached white midtown section of Phoenix. He is seeking out a specific location of an old hotel with large painted letters advertising "Transients-Low Weekly Rates-Radio in Every Room." In the 70s, the film theorist James Naremore's quickly summarized and described the deliberateness, rhythm, and logic of this opening sequence:

Like nearly everything else in the film, bear testimony to careful preplanning. (...) After the credits, there is a dissolve to a view of city rooftops: the sun is bright, and in the distance, we can see a desert landscape half-obscured by haze. The camera is panning slowly, pointed first at a prosperous part of town, where a new building is under construction. As the camera eye roves across a thoroughfare, an almost imperceptible dissolve tales up to a slightly closer view. At the same time, works in small block capitals appear at either side of the screen and converge: PHOENIX, ARIZONA. The camera is still panning slowly to the right, and we begin to see a rather drab clock of buildings on the other side of the town; another set of titles converges at the center - FRIDAY, DECEMBER ELEVENTH - and another dissolve takes us a bit closer. The panning movement continues, but now the camera begins a slow zoom down toward one of the buildings, and a last title appears: TWO FORTY-THREE P.M. Still another dissolve, and the camera stops before an uglylooking wall, peering at a bank of windows. Slowly, it moves toward the single opening, where a set of closed and lowered Venetian blinds has left about sin inches of space. Cut to a closer view of the window (a stage set); the camera slides toward the murky opening under the blinds and enters a room. ${ }^{4}$

After the initial sequence, dissolve after dissolve, Hitchcock depicts a climate of nefariousness, back-door-ness, darkness, shadow, and secrets. Before reaching the shower at the Bates Motel, where she will be murdered, Marion is involved in a drama of precise perception occurring in Phoenix as a transient city. Episodes of three interiors are connected by a car she uses to get away. They are the cheap hotel room where she meets her lover, the interiors without the air-conditioning of the Lowrey Real Estate offices, and the bedroom of a modest conventional home she shares with her sister. While driving on the way between here and there, Marion ignores Phoenix. From "inside" the car, she stares past it to a distant point, with her mouth set. Hitchcock then drives her away from Phoenix, building for ten more minutes a threshold as the evaporated limit of the sprawl, accounting on Marion's flight transitioning between two worlds.

\subsection{Cut to case study 2: assuming Marion's viewpoint}

Inspired by Marion's viewpoint from the interior of the car as well as Hitchcock's depiction of Phoenix as absent, a performance-oriented/ city-theatre studio was conducted in 2017, Spring semester. The studio was part of "The Phoenix Challenge: Desirable Urban Futures research," a collective design initiative that focused on outlining desirable futures for American Cities in the 21st century. It was developed as a research method to study perception using movies to grasp Phoenix as a location. Students were requested to wander in the city as Marion - by car - and to make movies while moving between the school and their home's interiors. While driving on the way between here and there, they were requested to ignore Phoenix by using cameras at rest. The goal was to use the narrative extracted from these clips to design non-anthropomorphic machines as ecological objects to foster enhanced scenarios and renew urban experiences in the metropolitan condition of Phoenix. 


\section{METHODOLOGY}

\subsection{Cut to case study 1}

Film analysis, as a form of rhetorical analysis, provided a strategy for critically analyzing and evaluating the frames' sequence of the beginning of Hitchcock's movie, explained in terms of the mise-en-scene approach. These questions were used to begin the analysis: What effects are created in the fourteen minutes sequence through the alternation of interiors and car? How many times does Hitchcock show Phoenix as the exterior context? How does the cinematic Phoenix look like? How does it change from its reality? What does the Hitchcock setting say about Phoenix? The continuous fourteen-minutes sequence was analyzed in terms of the script's arrangement and watched several times to extract representative still images: two cuts, three dissolves, "from Marion's viewpoint," Marion's car, and the final dissolve. They were listed as the script does -- Ext. Phoenix, Arizona - (Day) - Helicopter Shot; Cut to: Int. The hotel room - (Day); Cut to: Ext. Downtown street (Day); Dissolve to: Ext. Lowery Real Estate Office - (Day); Dissolve: Int. Mary's bedroom (Day); Dissolve to: Ext. Main street in midtown Phoenix - (Day); From Mary's viewpoint - (Day); Mary's car - (Day). Ext. Main street in midtown Phoenix - (Day); Mary's car - (Day); Dissolve to: Ext. Highway - (Day). Then, the still images as the compositional elements of the film were distinctly separated to explain the significance behind this sequence critically. The resulted script's sequence analysis as the graphic representation of deliberate choices on the part of the director and the screenwriter showed Phoenix's image in three ways: from a distant point, in the front windshield, and the rear window.

\subsection{Cut to case study 2}

The design process of the six-year studio started following positions of speculative realism. The projects did not begin with a program but a narrative. Practices involved the use of short-clips as codes. In the preliminary phase of their projects, students acted like archaeologists indexing a temple from the collection of ruins: they post rationalized the video material collected during one week to reconstruct an imaginary part of a city from the fragmentary evidence of the clips. As Marion in Psycho, students glued fragmented interiors of different neighborhoods by driving, creating an espace propre of Phoenix through personal stories. A series of short movie clips served as in-depth interviews without words and as a database to increase the reliability of the research. The group of students designed projects in this way: 1) they shot three clips of fourteen-minutes each as the initial ideas they had of their city, understanding the improvement of their ability to analyze Phoenix's urban reality; 2) they analyzed their movies as extracted on-site experiences; 3) they interpreted them through coding; 4) they translated them into two-dimensional images; 5) they transformed these images into scenographic artifacts.

As conceived between the visible and perceived reality, projects contained the narratives students extracted in the form of movies and reinserted into a context with a need for reactivation. In a sense, the videos
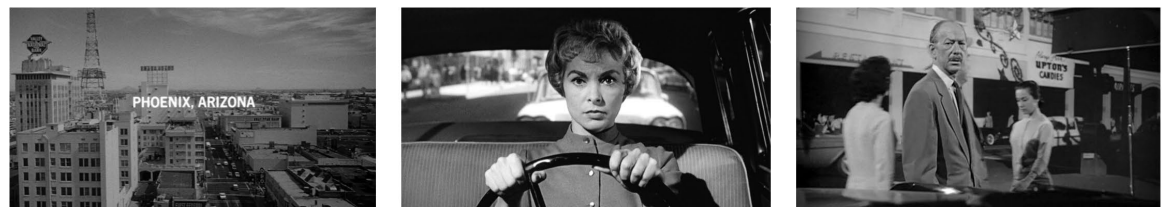

Figure 1. A. Hitchcock, Psycho, still frames 
- not the students - discovered spaces as urban theatrical sets. They were shot to detect the presence of situations during the mentalabsence state of driving that interrupts the city's form. Students individually recorded three fourteen-minutes movies from the car's interior space using the cameras at rest intended as both ideal fix parts of the body (eyes staring off into space) as well as moving parts of the city (moving centers.) The series of videos were watched in class for one day, uninterruptedly, to connect disconnected students' experiences simultaneously. Using qualitative methods, students then analyzed patterns and meanings of content to produce images and projects, post-producing the material according to a contraction of time that reduced the movies from fourteen to five minutes. The edited clips revealed parts of Phoenix plenty of nothingness. As to measure absence in their phenomenological observations, students coded their movies according to a classification of exceptions, degrees of stability, and kind of space. They controlled these elements' positions in the time and the space of the movie. To make valid inferences from the viewing activity, they set up a list of conditions, coding the same categories and in the same way - presence and absence. They transformed these observations of founded types into iconic texts such as twodimensional drawings.

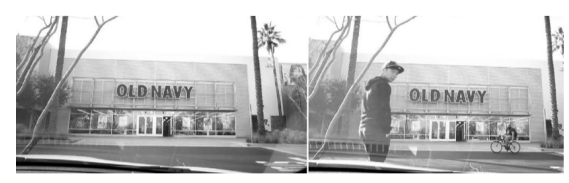

Figure 2. Student's work, 14-minutes video
At the end of the process, some students re-edited the extracted situation as the artifact's narrative. One student, for example, post-produced his first clip with an existing soundtrack. A dialogue between cars in the foreground is the main protagonist. In the background, the desolation of a widespread neighborhood at night where his project was reinserted. The presence of voices takes on an exact symbolic meaning: the rhetorical use of cars prefigures much of how the city is understood, therefore, architecture. It expresses the sense of alienation, and the uncertain status of Phoenix as a model of a contemporary city architecture must address. In another project, a student combined a video showing the car he just parked with another shot previously taken looking oppositely from the vehicle looking at him moving towards the entrance of the supermarket - an empty view of his idealized metaphysical landscape. These two movies are the example of how the succession of individual scenes virtually collided together - like the succession of acts in a theatre - to build a project as the espace propre. As the particular aspects of the students' city and their life, situations were noticed and extracted to inform unique physical locations. A personal itinerary as the own vision recreated from the controlled space of the car revealed them a city in all its dimensions.

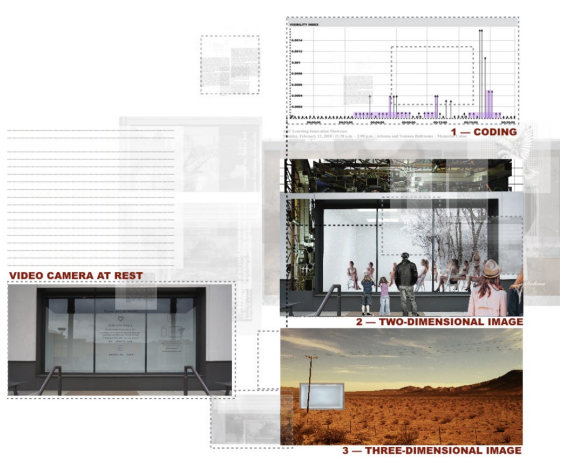

Student's work, process 


\section{DISCUSSION}

\subsection{Marion's car: Post-production of a city}

To discuss how architects extract visual imagery of places that are absent to the senses and Lynch's criterion of imageability ${ }^{5}$ of Phoenix - an interrupted city - I have concentrated on a movie to investigate a place - Psycho, one of Hitchcock representative films - and on a studio's processes and outcomes. The multiple-case design research and its sequence revealed that generalizability (case study 2) enhances a single argument (case study 1 ) to provide a test of a theory. Why is the beginning of Hitchcock's movie so unique to be taken as a reference for starting a project? In the movie, the omission of Phoenix is so explicitly notable that it is hardly seen. In not showing Phoenix, Hitchcock shows the "matter" of the possibility of contemplating cities through the form of cinema as a realm of absence - the crisis of the physical sprawl within American cities one perceives driving. In moving from the farthest to the nearest, he trespasses it, and in reaching the other side, he essentially explores the infra-ordinary of Phoenix as the personal sense of Phoenix. Hitchcock recalls our attention on a fact: if cities are built in terms of the direct presence of figures and bodies in space and time, images as movies are not. If architecture moves through the creation of buildings, images as cinema do it through the nature of perceptions. Shots and frames of a city take on a different significance: they are units that ultimately help to investigate thoughts on a city - architecture. Architecture does not provide the thought-material inherent in cinema. Cinema, in this sense, must be intended not as a medium to reflect on architecture, but the emerging medium of thoughts. By understanding this, we can grasp the significance of Psycho's representation of Phoenix. As an art-form, Phoenix reveals its nature through a movie. Hitchcock's strategy of using separations in between scenes using Marion's car and his omission of reality during fourteen minutes interrupts Phoenix. If Phoenix's relationship with a vast space makes the number of possible Hitchcock's shots of the city almost unlimited, he chooses to obscure it completely. Psycho is, therefore, Hitchcock's montage of Phoenix, disjointed, done using the circumstances of a performance - a movie. It is the post-production of a city with a moving center - Marion's car - shown interacting with its ghosts as its diffuse boundaries. If the machine of a city is scenographic one - in the sense that its scenery starts with a center as the optical mechanism and the stage of the representation - Phoenix is not. In its boundaryless environment, both center and stage are no longer found. In Psycho, Marion wanders endlessly in between disconnected fragments of her life using her car as a "moving bridge" (Ballard, J.G.: 1971.) in Phoenix, she is always inside interiors, and inside the car where all her reflections are gathered. Seated, her gaze is fixed. In her routinely trips in between here and there, Marion shoots stories as fragments of a city that best reveals itself along highways - episodic narrations of images without continuity, time, or space, tales of a city as a cut through. If pedestrians are drawn to some sites of the "scenic" aspects of Florence, Marion, as the driver, builds scenographic experiences in terms of speed as pacing, distance, and time - new mythology of interactions with the supernatural and existential takes place. The car is, therefore, her moving stage as the spectator and the actor of a drama as well as the subject and a symbol in the film. Capable of feeding her fantasies of personal imagination, the car is the metaphor of Marion's existence as the concrete container for her abstract vision, delusional, and irrational. In Hitchcock's movie, the car serves only to explain this change in the perception of reality, not the reality of the environment of Phoenix, since the environment and the vehicle are separated.

\footnotetext{
${ }^{5}$ Image ability: that quality in a physical object which gives it a high probability of evoking a strong image in any given observer." Lynch, Kevin, Idem: 9.
} 
Marion's car is, in fact, a static set design, with no projection forward other than that of thoughts. She is sitting inside, placed between window screens where Hitchcock displays exterior shots of Phoenix. She is trapped in the car as in a camera obscura or as Jeffrey in his apartment in Rear Window (1954). With a courtyard window named as the glass opposite to the vehicle's windshield - rear window - Jeffrey's apartment is like Marion's psychotic space of her car. He sits all the time with his left leg up as if his foot in on the clutch. Marion and Jeffrey both face windows that are rear windows with no view except the one of the espace propre, the support where the internal visual horizon meets with the external environmental one. Rear windows are as cameras at rest - the empty support for random figurations "spacedout" from a distance in absent state. Taken indiscriminately and without commentaries, the series of fourteen-minutes movies shown how the world looks like without people. As Hitchcock's rear windows, they show how a movie looks like in a movie. They are the tools necessary to obtain graphically suitable material to observe without sentimentalism to measure it. In watching their movies, students saw them for what they were: a world of things as things in a world - rather than their world with things in it - studies of absence in spaces in which emotion, imagination, and reflection naturally dwell.

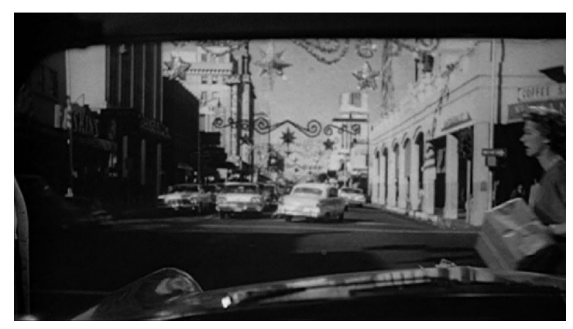

Phoenix, as the American city, can only be found from a personal point of view, in the car - differently than a city like Rome, founded by the relation between people. In the same year when Psycho was released, Federico Fellini portrayed La Dolce Vita (1960) as his feeling for Rome: the space for people - not for cars. He represented a Rome of narrow corridors with a baroque waterfall as the center of an architectural jungle where Marcello wants to hide. "Rome is like a jungle - it's easy to hide..," as it says, Marcello. La Dolce Vita is not a psychotic movie. It is a movie of two people wandering from the center to the edges of its limits, from the nearest to farthest, a theatrical space. Cities are quickly revealed at the moment they turn into theatrical spaces. In this moment, not only light, color, sound, and movement take place, but someone perceives the intuitional space (J. Gurazky, 1980) ${ }^{6}$ as the built space mediated by the presence of someone else in the front. In these cities, citizens are cocreators of the performance of the city by occupying a place defined by the stage and the backstage surrounding them as the audience. In these ideal theaters, there are no edges, no division between the audience and the performance. In these cities, citizens and the city become one.

In immersing Sylvia and Marcello on the central stage of Rome, Fellini shows the image of these cities as ideal theaters,

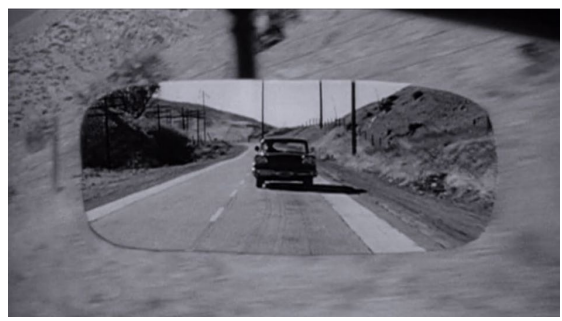

Figure 3. A. Hitchcock. Psycho, still frames of windshield and rear view mirror. 
explaining with the movie why the correspondence between architecture and people is extraordinary here. Any sense of individuality is lost as Fellini identifies architecture as the giver and Marcello and Sylvia as the receivers of sensations. But psychotic Phoenix is a whole other thing, more difficult to grasp as a city. If Marcello's reactions are in response to the intuitional space as what is in front of Sylvia as well as it is invisible to her - Rome - Marion's reactions are all introverted since Hitchcock isolates in the car's interior space - a center in movement on an absent theater and with no audience. If Fellini's La Dolce Vita takes place in the presence of Rome, Hitchcock's Psycho unfolds in the absence of Phoenix. Phoenix is, in this sense, a private foundation. Happening indefinitely at each time and virtually, it is a separated, and synchronous city as the assemblage of heterogeneous, fragmented narratives and subjectivities a giant collage of disconnected segments as the paradigm of modern urban planning in American cities Hitchcock portrays majestically.

\section{CONCLUSION - DISSOLVE TO: EXT. HIGHWAY}

This study has sought to explore ways to build new knowledge about how the mental image of a city informs architectural projects. It focused first on visual mental imagery with the analysis of Alfred Hitchcock's movie as the construction of the mental image of a city as the espace propre, and then analyzing a method of teaching architectural students the delineation of what is intuited. In the scope of analyzing it, Phoenix has been chosen as the context in which the research problem grew, the example of cities of a complex society "open-ended to change of function and meaning, receptive to the formation of new imagery." It provided not only a framework to address the research question but allowed the possibility to explore in detail how people experience the city they live in. The research questions were refined during the process. They are: How do we extract mental images as experiences? How do we move them from a non-representational to a representational way? How do movies shape how cities are seen? How can the interaction between students and films shape the design narrative? What I consider to be the most important findings is A) transmediation between reality, movies, and images is the method for images' extraction students can use for analyzing city; B) the reconsideration of the imageability of interrupted American cities as Phoenix. A) Most of the time, the point of view of users is not taken into consideration in architectural production. In learning about their city through the making of clip movie sequences, students understood how production and reception of architecture cannot be separated and how their reciprocal effects as relationships can inform environments. The assumption of transmediation between reality, movies, and images as the method students can use for analyzing city - from the space of the car - opens up the possibility of using "editing" in architectural education for post-producing moving images of reality as narrative. Editing is not quite making because it is still invisible. While during this process, one is not still aware of the visibility of the design, editing is a little more physical as the assemblage of shots cut off the stage of reality into a sequence effectively "reimagined." "Editing" crafts the first cohesive whole of an idea as narrative. B) By starting this research from Kevin Lynch's criterion of imageability as visual experiences on foot, we found the image of a metropolis founded from the personal point of view of cars, adopting Kevin Lynch as the theoretical framework for this particular study helped to deepen on explanatory power's levels. Giving 
relevance to the imageability of interrupted cities takes into consideration what the city's form means to the people who live there as drivers, as well as to elevate the transitional and transformative space of edges and freeways to one of the visions suspended in between the visible and perceived reality. Revealing and place keeping the intangible as what is essentially human of a place can help understand how to foster renewed urban experiences through alterity, detecting in the specific what the city's form means to the people who live and drive there. The knowledge of the mental image of the city, built upon Kevin Lynch's book The Image of the City, has permitted to transition observed phenomena to projects. To better grasp various aspects, I have built a comparison between Federico Fellini's portrait of Rome and Hitchcock's Phoenix, using Jerzy Gurazky's theory of intuitional space. Although my case study may offer important insights about the research problem, there is likely an additional finding that unexpectedly reveals as the result of my in-depth analysis of the case. The absence of Phoenix from Hitchcock's movies speak of something more, of how we can use movies not as a medium to analyze projects, but as the emerging medium of thought. If cities are built in terms of the direct presence of figures and bodies in space and time, metacities (McGrath, Pickett: 2011) - like movies - are not. As a heterogeneous intricate spatial mosaics of multiple centers, metacities can only be experienced as personal montages of pieces connected by absences, an espace propre in movement, according to circumstances that dynamically turn their built form into absence. Like all art-forms, cities can reveal their nature through movies as a new medium of architectural thought, showing the fundamental difference between a city and the image of a city, between Phoenix and the image of Phoenix, where Psycho stands. If the built environment of highways shapes a city as interrupted, cars shape citizens as the centers in movement on an interrupted map. Architecture should not use movies as recordings but reverse engineering their process to duplicate the structure of their content, to create a design by visually inspecting them. A movie object can be deconstructed to reveal the architecture of the natural phenomenon re-imagined. In 2007, the Hamlet Shakespeare's classic tragedy was re-imagined by The Wooster Group's by repurposing a Richard Burton's 1964 Broadway production. Simultaneous performance of "Theatrofilm" via a precursor to high-definition television, Electronovision, confronted actors on stage with those in the movie. The Wooster Group extracted the architecture of the theatrical performance from the film's evidence. At the moment the actors appeared on the stage, the movie started and became their companions, while the physical theatrical set mirrored the virtual film shot. The audience realized that the narrative was not a neutral background. On the contrary, the movie was connected with what was happening on the stage. It made it three-dimensional as a kind of reflection and introduced programs as situations. As those actors spent the play placed acting against the sequence of the movie, following the film, continually adjusting to fill those positions as the narrative, students can capture dramatic actions and unforeseeable presences to significantly reveal an architecture, using transmediation of moving images, drawing, music, text. The results illustrated in this paper inform paths to quantitively measure in the future how transmediation informs preliminary designs for urban landscapes while exploring the leading role students have in the design of the future of cities. 

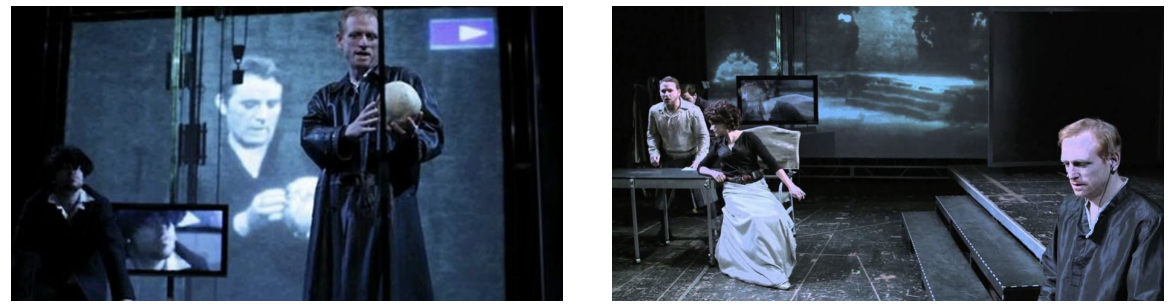

Figure 4. The Wooster Group. Hamlet, still frames. 


\section{REFERENCES}

Augé, M. 1992. Introduction à une anthropologie de la surmodernité, Paris, Seuil; trad. it. Nonluoghi. Introduzione a una antropologia della surmodernità, Milano, Elèuthera, 1993.

Ballard, J. G.1996. A User's Guide to the Millenium. Essays and Reviews, London: Flamingo.

Crash, Cronenberg, D. 1996 Canada/UK.

De Certau, M. 1984. "Walking in the City", in The Practice Of Everyday Life, Translated by Steven Rendall, University Of California Press. Part III Spatial Practices, Chapter VII.

Goebbels, H. 2010. Aesthetics of Absence: Questioning Basic Assumptions in Performing Arts, Cornell Lecture on Contemporary Aesthetics.

Baugh, C. 2016. Play within space: the scenography of Jerzy Gurawski. Journal Theatre and Performance Design, Volume 1, 2015 - Issue 4: 281-297 | Published online.

Lynch, K. 1960. The image of the city. The Mit Press.

Naremore, J. 1973. Filmguide to Psycho, London: Indiana University Press Filmguide Series, Harry Geduld and Ronald Gottesmann, General Editors.

Pernigo, Carolina, "L'uomo e la macchina. La proposta di J.G. Ballard per la contemporaneità", Tecnologia, immaginazione e forme del narrare, Ed. L. Esposito, E. Piga, A. Ruggiero, Between, IV.8 (2014), http://www. betweenjournal. it/ 29

Pernigo, C. 2014. L'uomo e la macchina. La proposta di J.G. Ballard per la contemporaneità. Ed. L. Esposito, E. Piga, A. Ruggiero, Between, IV.8.

Stefano, J. 1959. Psycho's script, based on the novel by Robert Bloch, Retrieved at https://sfy.ru/?script=psycho 

PAPER \#2.11

\title{
CONTACT AND IMPACT (INFLUENCE). TIMELESS EVENTS IN THE CONTEMPORARY CITY LANDSCAPE
}

\author{
Salvatore Rugino \\ aDepartment of Architecture. University of Palermo, Palermo, Italy
}

\section{ABSTRACT}

The places, narrated by the poets of the past, seem to increasingly fade from the collective imagination, replaced by others where new social behaviors and new subjects are expressed. The feeling that one has within these places is of extraneousness from everyday life. From an architectural point of view, these spaces are a copy and simulacrum of the structures of the past. Existential aspects prevail over morphology, in fact, it does not depend only on how space is occupied, but above all on how one lives it.

\section{KEYWORDS}

Architecture; city; influence; shopping; below.

\section{INTRODUCTION}

The contemporary city, today, takes on a different role than in the past, it is a complex landscape formed by different superstructures that make it somewhat fascinating.

The places, narrated by the poets of the past, seem increasingly to vanish from the collective imagination, replaced by others where new social behaviors and new subjects are expressed such as, for example, the citizen of shopping centers and the metropolitan museum, both spaces where it perpetuates itself the ritual of the consumption of goods. In these places everything is simulated to seem real, thus creating contact areas where it is possible to find hybridization phenomena. The events created within this new vision of space can be considered as traumas that refer to anxiety for the rational and for the real, introducing a new era that can be defined as simulation. A new culture of fascination takes shape, a labyrinth of meaningless signs, where the "historical sense" is transformed into an event. The distant, the experience of the past, becomes hazy, leaving room for new flows. History is only a myth, a lost referent that finds refuge in a new collective imagination that generates new places, whether they are real or brilliant simulacra that lack, however, a new gaze, a new vision (Baudrillard 2008, 23). And it is for these reasons that today we feel the need to expand our horizons, exploring and experimenting through the differences and incongruities of cultural systems.

In dealing with these phenomena, we will avoid seeing them as rapid changes, therefore we will not use the term rapid oscillation to describe them, but instead we will use the simpler and more easily understood terms impact (influence), and contact.

The impact occurs, in a previously unknown area, as a recognition of an environment of something else that has become sensitive. Contact takes place when the one who has foreseen its direct and conscious presence has envisaged its theoretical possibility in an influence that conditions the space in an unconscious way. It is more than a simple registration, it develops in a conscious reciprocal action; provides new information; it is of a revealing nature and it can be said that in its initial stages it guarantees, to those who respond to it, the existence of a new field of exploration and adventure (Bailey 1977, 98).

To these phenomena perceived as rapid oscillations, but we have seen not to be, as continuous changes imposed by today's society, all register a response to the 
impressions they cause on people and things. For example, if we make a pendulum swing, and put sand under it, the pendulum will leave traces of its swing, describing clear and precise traces. In this case the response to changes, to transformations is automatic. Today, we feel the need to go beyond the simple response recorded by the fluctuations. There is a need to get in touch with further knowledge that will open up a field of intercommunication.

These transformations, or needs to look beyond, imply conditions that are dictated by the two terms: contact and impact (influence). The experience we live, through this new way of looking and living in space, inexplicably projects us into a world similar to the original, things seem to double compared to their scenario. Thus new places are born, where the game of illusions and daily ghosts becomes an imaginary world: perfect order that simulates a new society.

\section{THE NEW PLACES}

The feeling you get inside these places is one of alienation from everyday life. What happens inside the temples of myth, of consumption, has something emic and phage.

Ultimately, the public space, delimited by fortress buildings without elements of aggregation, almost a desert, is an architectural interpretation of the "emic" strategy, while the spaces of consumption interpret the "phage" one. Bauman identifies as an "emic" space a space of interdiction (for example the outlets outside the cities) where one tries to save the reality principle through a false representation of the same, and as a "phage" space any shopping center (Bauman 2000, 102 ) place, as we have mentioned, where the illusions and ghosts of the already happened are staged.

From the architectural point of view, these spaces of consumption are a copy and simulacrum of the structures of the past. Copy as a formula that respects a basic architectural structure, simulacrum as a simulation of security, where many aspects of the urban community are found.

We have described the city not through urban morphology but through existential aspects. In fact, it does not depend only on how the space is occupied, but above all on how it is lived.

In this regard, taking a leap into the past, in 1951 Ronald Lampitt, who designed landscapes and urban landscapes as real places for real people, tried to draw a map of the ideal city described in the British magazine Illustrated, in the same year, by the journalist and writer John Sleigh Pudney.

The city described, through the brushstrokes, by Lampitt is a paradise located on an undulating terrain built from vaguely familiar monuments. An urban landscape rich in memory, but sterile; there is no shop, no shack, no garbage heap, no advertising billboard, there is no space-time loss, everything is measured.

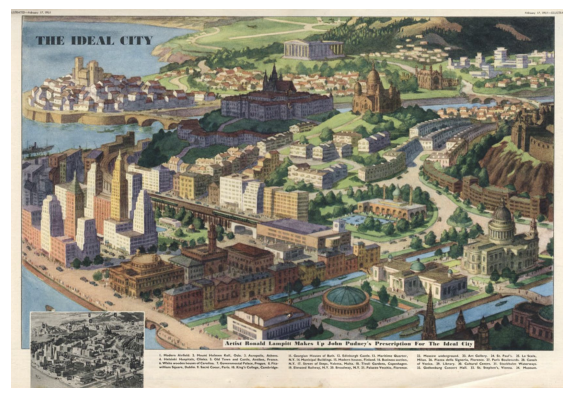

Figure 1. The Ideal City. Illustrated: (Lampitt 1951)

The city described by Pudney and interpreted by Lampitt, through his map, does not have all those elements that instead characterize the contemporary landscape today.

Pudney, in the aforementioned article, does not prefer the ideal humanist city, but his description is that of a controversial city. Because its reality must not be built only for those who thought it up, but for all of humanity. Here the biblical metaphor of the Tower of Babel falls, where the structure of the living space takes on a utopian and ideal charge. According to this 
allegory, the whole of humanity must be united, even in utopian intentions, so that it does not get lost. This ideal has had a catastrophic failure, because the common man no longer recognizes himself in "prison cages", to put it in Pudney's style, consequently there is a strong loss of recognition of the "ideal space".

Throughout its history, man has had the ambition to be able to live in a city that fully reflects socio-political ideals. It is precisely these that structure an ideal city. In the absence of elements that characterize the city, one can end up simply reflecting, reproducing, or perpetuating the relations of power and social assets expressed by society.

This type of structure does not reflect the expectations of the ideal Renaissance city, the place par excellence of representation. Serlio's tragic scene is concentrated on the pedestrian street, the pre-industrial city is concentrated on the side scene of the streets, on the facades of the buildings that characterize it, almost a theatrical scene, all in perspective flight. Space and time are determined by the codes of the Renaissance perspective, by an ordered space measured in time. Everything goes back to the proportions of the human body. The urban street becomes the theater of life, a place for the representation of daily actions.

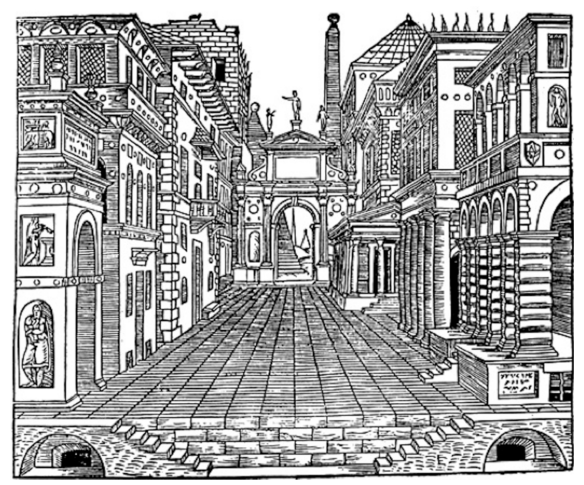

Figure 2. The tragic scene. Second perspective book: (Serlio 1545)
It is symbolic, measured and ordered in space where, however, the presence of man does not exist in the various representations of the city. It is a city that represents itself, the power of ideals.

The city enters a crisis when machines and infrastructures invade the spaces of representation, space is disrupted, in some cases the car does not enter the street, it breaks its harmonic proportions and so does the infrastructure in the territory. The theatrical space, representative of the city, is fragmented, broken by speed everything becomes elusive, dissolves in space. It no longer assumes a role of monumentality but of fading.

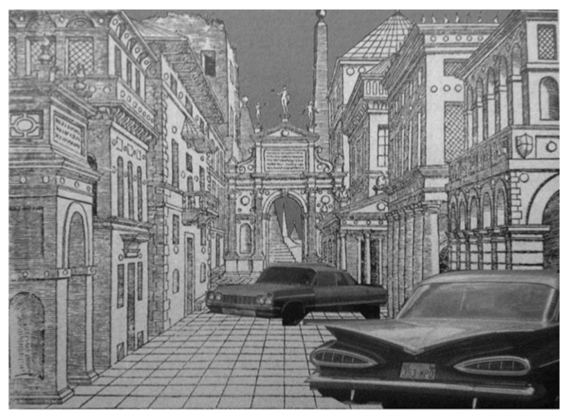

Figure 3. The tragic scene with cars. Sprawltown: Looking for the City on its Edges: (Inghersoll 2006)

In this regard, Wim Wenders, in the film Lisbon story, makes the leading actor walk with a video camera tied to his shoulders to be able to see what all of us, walking, cannot see. This experiment has a main objective: to increase and develop sensitivity to those unexplored areas, where the relationships between phenomena take on new forms within the contemporary landscape. A vision of space that reaches a certain height excluding that part of the genius loci which is the relationship with the sky but favoring the one with the earth. 


\section{THE CITY FROM BELOW}

The adventure begins from the bottom, from the places where phenomena generate dynamics that radically modify the community, in this transition of civilization and above all in this transformation of society that opens up a new possibility for architecture on an urban scale, new architectural typologies, new spatial and formal inventions. This, if the programming takes a right turn, not idealistic, not dominated by rules, not from above, but on the contrary relational, experimental, from below (Costanzo, Ricci 2007).

The city from below, a place where the potential of an open dialogue, between the community and the space, of communication and common action through friction is experienced.

The cities of our time have become so complex that to understand this complexity it is now necessary to resort to new ways of observing. They require new approaches to transformation processes. Within the context of cities in rapid change and scenarios of contraction that are increasingly difficult to govern, the phenomena in progress take on particular importance.

Italo Calvino (Palomar 1983) comes to our aid on how to observe phenomena, where the main character of the text makes philosophical considerations on the world around him, showing us a man on a mission to quantify complex phenomena, in a search for fundamental truths about nature of being. The first section of the book deals mainly with the visual experience, the second with anthropological and cultural themes, the third with speculations on more general issues, such as the cosmos, time and infinity. Calvino points out, but above all he asks himself how an event can be observed without taking into account the complex aspects that contribute to formulating it, and the equally complex ones to which it gives rise. First of all, aspects vary and that is why one phenomenon is always different from another. However, there are forms and sequences that are repeated, albeit irregularly distributed in space and time. We could speak of divergence or convergence but the main difficulties arise in fixing the boundaries of the field of observation, because, by changing the boundaries, the space under consideration is overturned and at the same time compressed.

In this frame of reference, we could build a model or complex system of reading the contemporary project and city, through the search for a balance between the principles and the experience of the phenomena in progress. Secondly, check whether the model, produced by the sum of actions and experiences, which do not resort to fixed models and predictable solutions but, simultaneous and sometimes contradictory, fits the practical cases observable in the experience of completed and unrealized projects. Finally, make the necessary corrections for model and reality to coincide. And it is precisely from reality, from the real city, that we must start. Made in Tokyo, a research project later published by Tsukamoto and Momoyo Kaijima (2001), exalts the virtues of what they call the "real city". They start by describing the current phenomena that involve all the great metropolises. Cities where you get stuck in traffic because they are full of construction sites that modify them and make them attractive to a wider audience: we could say that they are turning into a consumer product. If we look at history anyway, one of the most interesting things about the city is its constant reconstruction of itself.

On the one hand we have the city as a consumer product, made up of skyscrapers, large buildings for consumption (food and cultural) and on the other the real city, built up of small low buildings: we could define it as a low place. The real city continues to fill the empty spaces, continues to prioritize a stubborn architectural honesty in response 
to the environment and programming needs, without insisting on aesthetics and form.

Large projects are quite controversial, says Oshima, a professor at Columbia University, noting that most people are entranced by skyscrapers because they completely change the character of their neighborhoods. Cities are reversing their natural dimension from horizontal, made up of buildings of three or at most four floors, to a vertical one, but whether the land and infrastructure are able to support this density is another question. And whether they make a better city is up for debate. Everything is linked to consumption phenomena. It is precisely these that are determining the complete transformation of the city from below. To understand how this type of development breaks with the typological tradition of the city, we need to look at history.

Our cities, especially the buildings that shape it, derive from the Roman insula, where the tabernae, that is the shops, were located on the ground floor. This typology has been configured, with the necessary modifications, until today as the result of the direct transformation in the site of the type.

Clarifying example of this concept of transformation, it is a singular square with an elliptical shape, closed by medieval houses which is located in the city of Lucca, today called Piazza del Mercato.

This was created for shows and was the amphitheater of Lucca, an imposing structure. In the Middle Ages, this place became a square, where popular assemblies were held.

Over the centuries it was transformed, first into a fortress. Then it became a fundamental space for the layout of the city, until it became the city market.

This example clarifies how the type has undergone transformations: from an amphitheater to a city market. It should be noted that the transformation undergone has changed the function within the city, but has not transformed its type, its shape in the city.

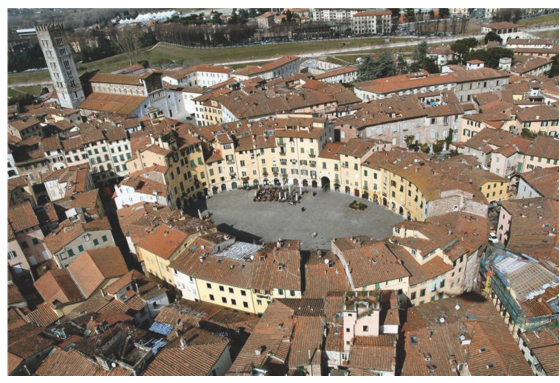

Figure 4. Market square of Lucca. (www.dovealucca.it)

Today, an important fact happens, due to the opening of large shopping centers and shopping villages, these places dedicated to commerce, such as the city market of Lucca, no longer have the function of relational places for sale. This phenomenon tends to move the sale of consumer goods from the city, from its historic sites, to the new centers for commerce in the outskirts of the city.

What was previously separated by functions today is concentrated in a single space, or rather what was scattered in private plots, the insule within the public space, now group together in a new environment that is neither public nor private in the classic way .

It is the ground floors, the tabernae that are losing their social and commercial function. It would seem a little obvious, but the continuous lowering of the shutter is causing the total closure of most of the shops, whether they are in the center or in the suburbs. All this involves phenomena that determine a complete transformation of the city. The security of our cities no longer exists. The city is going through a profound crisis. From neighborhood to neighborhood, from the main arteries to the villages, sealed doors, shop windows with the words "for sale" and "for rent" clearly visible. And the most worrying thing is that many of those signs have been there for months because nobody bets on the small shop anymore.

Because, if it is now an outdated phenomenon that sees the small suburban trade supplanted 
in favor of shopping centers, few would have bet that the crisis would have crept into the most elegant streets of the city. Instead something has changed. In places where years ago there was a competition to open a shop, now there are places with closed shutters. The closure of historic shops often takes over from clothing stores or pizza by the slice and distributors of other fast foods for lunch breaks or even temporary activities of non-EU citizens.

\section{CONCLUSION}

In reality, ours is an era, a culture, which requires constant change; the city cannot be deprived of its liveliest space, more direct to the user. We cannot continue to think about changing the city with large-scale interventions or restyling. Situations of deprivation need to be reinterpreted by recognizing public space as potential, seeking new or lost connections at special and social levels. Rejected spaces are brought back into the field of vision in relation to the user. This is not a need for uniformity of style but something much deeper. It is a question of understanding according to which principles to orient the transformation of something (our space), which is a common good no longer representative, as in the Renaissance but relational.

Ultimately, what we propose is a real and projective frame of reference, which will reveal combinations, configurations and new organizations, which do not come from habits, but from that area of confluence of experiences.

Today, we must free ourselves from patterns and conventions in order to understand the "new", what diverges from what has already happened. It is nothing more than the result of the creative instability and materials, real and virtual, of architecture. We do nothing but describe the new as something "outside" our competences, as something foreign to our way of operating. We must, however, recognize that this "outside" is everywhere, we are surrounded by it, and it is within us, within our imagination. The secret lies in freeing "the view from objects and habits that derive from a vision that is too concentrated on the object" (Kwinter 2002, 38).

We stop describing to clarify. One question, one possible answer. We try to occupy the space, so that the dynamic action dominates the continuity of the predictable paths. In this way, space is generated, and not ordered by movement. A space that is the instant sign of use.

Today, we must focus our attention, not on familiar images, but on those structures that represent a dismembered reality, taking advantage of and at the same time enhancing its fragmentation through the culture of differences. 


\section{REFERENCES}

Bailey, A. 1977. Telepatia e il veicolo eterico. Roma: Editrice Nuova Era.

Baudrillard J. 2008. Simulacri e impostura. Milano: Pgreco edizioni.

Bauman, Z. 2002. Liquid Modernity. Oxford: Blackwell Publishers Ltd.

Calvino, I. 1983. Palomar. Milano: Mondadori.

Costanzo, M. 2007. Leonardo Ricci e il Villaggio Monte degli Ulivi a Riesi, "Metamorfosi n. 64".

Kwinter, S. (edited by). 1996. Rem Koolhaas: Conversations with Students, New York: Princeton Architectural Press.

Inghersoll, R. 2006. Sprawltown: Looking for the City on its Edges. New York: Princeton Architectural Press. 



\title{
PAPER \#2.12
}

\section{ARCHITECTURE BEYOND PERMANENCE: TEMPORARINESS IN 21ST CENTURY URBAN ARCHITECTURE}

\author{
Marco Eniaa, Flavio Martella ${ }^{\mathrm{b}}$ \\ a.D.L.A.P., Puebla, Mexico

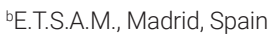

\section{ABSTRACT}

Architecture has always had an obsession with time. Architects from different places and generations have struggled to make buildings able to last for decades, or even centuries; permanence has traditionally been considered the most desirable architectural quality. Even if, throughout history, temporary interventions have played a key role in defining urban spaces, architects have often considered them a minority practice not deserving much attention. Things have changed in recent years. Increasingly, architects understand temporariness as a potential answer to some of the most pressing problems of contemporary cities. Being adaptive and quick to build, temporary interventions can help architecture bring life back to vacant lots; or provide vitality and dynamism to the most distinct urban situations; or restore a sense of home and urbanity in post-disaster camps. In 21 st century architecture, temporary buildings have a special place, for their flexibility and for the formal / spatial possibilities they offer to architects: because of their characteristics, temporary buildings are often pure space, free from the constraints of function and timefighting. The paper aims to analyze strategies and objectives of temporary interventions in the context of 21 st century urban architecture, through case studies from the last two decades.

\section{KEYWORDS}

Pop-up architecture; temporary interventions; city-making.

\section{INTRODUCTION}

Architecture has always had an obsession with time. Architects of different places and generations have struggled to make buildings able to last for decades or even centuries. In a discipline full of different views on virtually every aspect of its theoretical and practical nature, there is instead a general consensus on the idea that time is the enemy. Permanence, that is, the ability to endure over the years, has traditionally been considered the most desirable architectural quality (Ford, 1997). In a way, architecture's relationship with time reflects the way societies deal with the very idea of death: buildings have often been understood as an instrument to make something survive over the years. Where humans cannot go, and neither do civilizations, buildings sometimes can: they thus become a sort of time-capsule, able to transmit to distant futures the intimacy of private events - as is the case with the Taj Majal - or the complexity of an entire cosmovision- such as the Greek temple. It is therefore not surprising that the history books of architecture mainly tell the story of the buildings that stand still. This is something that makes sense in many respects. Only buildings still physically present can provide direct information about the architectural ideas of a civilization and, more generally, about how a society related to the territory and tried to give tangible form to abstract and immaterial concepts. Architecture gives a knowledge that cannot be transmitted with words, images or anything else but architecture. The spaces that societies produce are their most faithful mirror, as Lefebvre commented (Lefebvre, 2009). 
Nonetheless, the idea that permanence should always be the ultimate goal of architecture presents some remarkable problems. The first is that the very notion of permanence is an illusion: every building is temporary (Cairns, Jacobs 2014). Some last less, others more, but in the end, each one of them will have to surrender to time. It is temporariness, not permanence, the truth about architecture. Permanence is a somewhat reassuring concept, which makes us believe that we have real control over time and its effects, over the devastation produced by history and societies. It is a tale we tell ourselves to imagine that our buildings, and with them our civilization, are safe from unpredictable circumstances or simply bad luck: from those unexpected events that can destroy even the most solid and well-built constructions - like the fire that burned down the library of Alexandria, or the earthquake that devastated the Colossus of Rhodes, for example. The other problem is that the paradigm of permanence does not seem capable of effectively addressing some of the most urgent problems of the inhabited landscape. All over the world, societies are undergoing profound transformations that are occurring very quickly. Some challenges are emerging that require quick, short-term responses from architecture and the sciences of the territory. One of these challenges is the increasing flow of people migrating from their homes, whether because of war or the consequences of climate change. In 2018, there were more than 70 million forcibly displaced persons worldwide, increasing at a rate of 25 units per minute (UNHCR, 2018). Displaced persons do not usually settle in a specific place for a long time; they rather often move. In cases like this, permanent, traditional architecture cannot be an adequate response; other solutions must be found, if we are to successfully deal with one of the most dramatic problems of our time. Nor can permanent architecture be the solution to all the pressing problems of contemporary cities. Some of them demand flexible solutions that the usual approach - top-down, permanent interventions - cannot provide. This is even more true in a situation where the economic and financial crisis has taken a lot of resources away from the construction sector, so that the traditional operational model is often no longer practicable.

The question of whether permanence should still be understood as the prominent architectural paradigm becomes even more relevant when one considers that there is an alternative approach, active since the origins of the discipline: that is, ephemeral, temporary architecture. Throughout history, temporary architecture has played a key role in defining the relationship between humans and places. The invention of a temporary typology, such as tents, was one of the oldest architectural gestures, and made possible the transitory way of life of nomadic societies. It is through ephemeral constructions that so many cities have, historically and still today, renewed their image on special occasions, such as festivals or celebrations. Temporary interventions have sometimes also facilitated the construction of permanent buildings: it is well known the case of the Basilica Palladiana in Vicenza, for which the architect had previously had to create a 1:1 scale model of one of the arcades. Despite this, architects have generally regarded temporary interventions as a minority practice, not deserving much attention. Things have changed in recent years. Increasingly, architects understand that some problems that cannot be addressed through permanence, can be more effectively dealt with through temporary interventions; their adaptability and flexibility, in fact, enables them to be useful both in consolidated urban environments and transitional ones, such as camps. Also, they can be developed either as bottom-up, extitutional practices of communities autonomously caring for a place, or as top-down approaches to address complex situations. 


\section{POP-UP NEIGHBORHOODS}

In the last century, cities around the world have undergone profound transformations. As the world's population grew, and the number of people living in urban environments constantly increased, cities began to expand in ways never seen before. In just a few decades, they became something very different from what they had been in the past. Only fifty years ago, cities could be understood, studied and designed as if they were a single piece of architecture, as Aldo Rossi commented (Rossi, 2018). With this, Rossi intended to point out the objectual qualities of cities, which, however large, had a formal, material and spatial coherence that allowed to understand them as unitary and quite homogeneous organisms: exactly as if they were a piece of architecture, designed not by a specific person or firm, but by society over different generations. Nowadays, however, it seems difficult to share this view. Many cities have grown to such dimensions that they cannot be perceived as a giant architectural object, but rather as a territory, where each neighborhood usually has its own formal, socio-cultural and economic characteristics that make it different from the others. The largest cities in the world have expanded to a degree impossible to imagine only a few years ago. The urban area of New York today is approximately 11 thousands $\mathrm{km} 2$, which is more than the entire extension of a country like Lebanon; the Greater Tokyo Area is more than 14 thousands km2 (Demographia 2019).

All of this has already changed the way people relate to their cities. Having become territories impossible to know in their entirety, big cities have lost the human scale. As a result, it is increasing the role of neighborhoods in providing citizens with spaces suited to their needs. This is not only a matter of size, or of the facilities available in a specific context. This is also about whether a neighborhood offers the possibility to strengthen those social bonds without which a city is only a lifeless set of buildings. Neighborhoods have always been the privileged settings in which to cultivate relationships. But today their function of community builder is becoming even more important, precisely to counteract the loss of human scale in the urban environment. In recent years, cities have implemented multiple strategies to strengthen the capacity of neighborhoods to build communities; one of these is urban acupuncture (Solá Morales, 2008). This expression, coined in the context of the Barcelona Olympics but adopted later by planners around the world, refers to those punctual, one-off interventions that have the potential to produce benefits on a larger scale. Architectural interventions are one of the possible instruments of urban acupuncture, but there are others, such as the celebration of events of all kinds taking place in the street. Everything that makes a city pleasant, vibrant, full of life, can be considered as urban acupuncture (Lerner, 2003). In this sense, one instrument of urban acupuncture that is becoming increasingly relevant is temporary, pop-up architecture (St.Hill, 2016). When the objective is to revitalize a neighborhood and its community, temporary interventions have some distinctive qualities that can help reach the goal. While permanent interventions take some time to be carried out, pop up architecture is very quick to build. Permanent interventions remain in place for a long time and therefore block the ability of a lot to change according to the evolving needs of communities. Temporary architecture is instead very flexible: it occupies a site for a short period of time, and disappears after a while leaving the site open to new modifications. While permanent architecture, by its very nature, is static, temporary architecture is very easy to disassemble and assemble in different locations: in fact, it can also be mobile. Flexibility, quick construction and mobility are key factors in the use of popup architecture to revitalize neighborhoods, since they provide spaces with a dynamism and adaptability to the transformations that permanent intervention cannot give. 
In the last years, pop-up architecture has become one of the preferred instruments of tactical urbanism, an approach to the city that aims to improve neighborhoods through small-scale, low-key interventions (García, Lydon 2015). The work carried out in the Central District of Rotterdam by ZUS - Zones Urbaines Sensibles provides a good example of this approach (Koreman, van Boxel 2015). In 2011, after the financial crisis, a planned development in the central district was cancelled. This led to vacancies in many existing office spaces and to a general lack of activity in the neighborhood. Over the years, ZUS revitalized the district through a series of strategic interventions at its most sensitive points. Their first action was to transform an empty office block, the Schieblock, into a civic laboratory housing different collective services - such as stores, bars, workshop spaces and an urban farming roof. They then started to perform tactical operations in outer space, mainly through ephemeral interventions. One of such operations, probably the most relevant, was the construction of a crowdfunded temporary bridge $400 \mathrm{~m}$ long, to provide proper pedestrian access to the area. The other interventions varied in scale and function, ranging from community gardens, to spaces for culture and debate, to a nightclub meant to give vitality to the space 24 hours a day and a series of pop-up shops to give people a reason

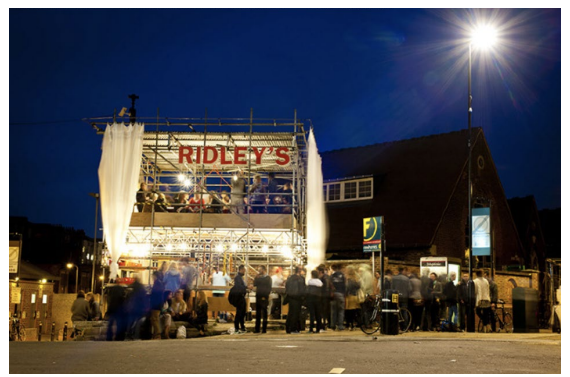

to stick around. In 2018, as a result of the new vitality and improved connection of the district, ZUS could also build public garden on the roof of the former Hofplein station. The Decorators applied a similar approach in the regeneration of different neighborhoods in London. In 2011, together with Atelier Chan Chan, they built a pop-up restaurant in east London's Ridley Road market, with the intention of helping local economy and, at the same time, providing the community with a meeting place (The Decorators, 2011). The architects prepared the brief together with the community, listening to their needs and concerns. Following this interchange of views, they decided to build the temporary restaurant, designed as a place where people could trade raw ingredients bought at the market for cooked meals (Fig.1). In 2013, in a similar situation, they promoted at Poplar's Chrisp Street Market a programme of events to highlight the importance of the market as a civic space. In this case, their intervention relied more on the actions undertaken, than on the construction of buildings. They set up a radio station in an empty unit, where people could share views about the importance of the market and its future. Starting from this feedback, they installed new temporary market stalls to host activities such as boxing, music and cinema, while also providing an infrastructure for outdoor eating.v

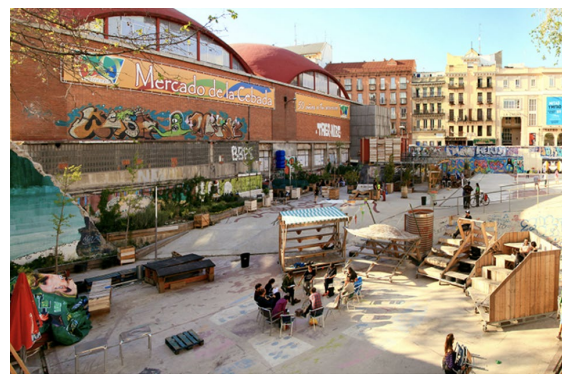

Figure 1, 2. On the left, Ridley's temporary restaurant. Source: (The Decorators, 2001) On the right, Campo de la Cebada. Source: (El Campo de la Cebada, 2011) 


\section{MEANWHILE URBANISM}

Temporary interventions are also an effective strategy in the reclamation of urban voids. Throughout the 20th century, urban voids were mainly seen as spaces to be filled with new buildings, so that the city could keep growing. Today, however, the way in which they are understood has changed; so has their role within the urban environment. Large cities have become hypertrophic organisms where it is more likely to feel the necessity to subtract elements, than to add new ones. Urban voids, previously considered mainly as places where new buildings could emerge, are increasingly understood as structural elements of the city: their relevance lies precisely in being empty (Gunwoo, 2016). In a context where some parts of cities may be perceived as too dense, urban voids become important because they appear as an interval, a pause from an overbuilt fabric. They help the city not to feel too claustrophobic, providing spaces where the air can flow and the gaze is free to move without being interrupted by the walls. Also, they are places where the most diverse activities can be performed, thus fostering social relationships and public life. In this sense, temporary interventions are becoming increasingly important for various reasons. First of all, they make urban voids suitable for collective use through minimal modifications, without changing their nature as empty spaces, which is the very reason for their relevance. A good example of this approach is provided by a project by Cedric Price. In 1999, participating in an architectural competition to reclaim a vacant lot in Manhattan near the Hudson River, Price proposed keeping it empty and implementing only small, temporary modifications (Muschamp, 1999). He was the only participant in the competition who did not propose to fill the void with largescale buildings. As he explained, the reason to do so was that the lot was an important green lung for the whole neighborhood, for its nature of empty space, but also because it allowed the air coming from the river to pass through and enter the city. Another reason for the relevance of temporary interventions is their own flexibility. Being in a lot only for a short time, they allow for future modifications more suited to the changing demands of the city. This approach has been called "meanwhile urbanism", and consists of short-term actions intended to occupy a lot with events and activities until a more lasting intervention can be carried out. In this way, lots are prevented from becoming neglected and forgotten, and can continue to play an active role in the city. Meanwhile urbanism is not an approach of new invention. Aldo van Eyck, for example, employed a similar strategy when working for Amsterdam City Council. From 1946 to 1975 he designed more than 700 urban playgrounds, mostly made of few elements and light structures (De Roode and Lefaivre, 2002). Some of them occupied vacant lots, and aimed to reclaim them while waiting for a permanent intervention. By doing so, he intended to make the city a pleasant place for children, and at the same time ensure that all of its lots could participate in urban life.

Even if meanwhile urbanism is not a new approach, today its importance is increasing. Economical crisis had a huge impact on cities, which do not always have the necessary resources to build some planned development. Sometimes, permanent interventions cannot be carried out simply because of a lack of money, both in the public and private sectors. It is in such circumstances that meanwhile urbanism, whether extitutional or promoted by city councils, becomes a major strategy: for its ability to bring abandoned lots back to life, for being cheap, and for its shortterm nature that allows for its replacement after some time. In many European cities, meanwhile urbanism was the instrument that prevented different areas from becoming derelict. The work of ZUS in the Central District of Rotterdam is a valid example of such a strategy. But in the last years similar approaches can be recognized in a number of 

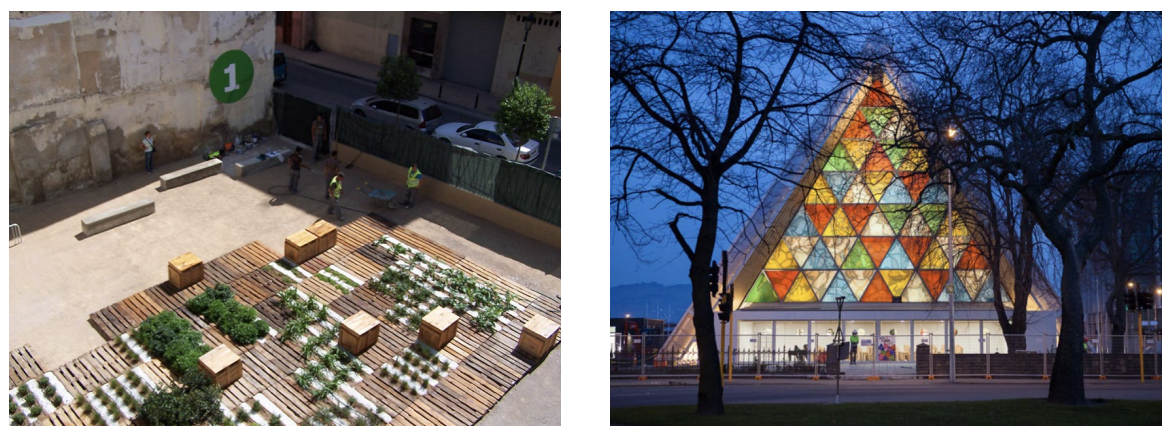

Figure 3, 4. On the left, Estonoesunsolar, Calle San Blas 94. Source: (Di Monte, Grávalos 2009) On the right, Cardboard Cathedral in Christchurch. Source: (Ban, 2013)

cities. This is the case, for example, with the experience of Campo de la Cebada, in Madrid (El Campo de la Cebada, 2011). In 2006, on a lot in the city center, a building was demolished to make way for a new sport complex. After the demolition, however, the planned development had to be stopped due to the financial crisis. As a result, a large, vacant and useless lot was opened in the very heart of the city. Since then, and for many years thereafter, the neighbors autonomously reclaimed the lot through low-key, short-term operations. They filled it with temporary furniture and plants, invited street artist to paint its walls, and, most important of all, constantly organized events that would invite people in (Fig.2). In a few years, the neglected lot became one of the most vibrant and lively places of Madrid. A similar example is provided by Estonoesunsolar, a series of interventions carried out in Zaragoza by Grávalos Di Monte arquitectos from 2009 onwards (Di Monte, Grávalos 2009). Following the same logic of ZUS interventions, but within a program promoted by the city council, Grávalos Di Monte built temporary interventions in several lots in the city. The intention was to occupy the lots while the city council developed a plan for permanent interventions, but also to foster the relationship between the neighbors. For this reason, all interventions were carried out through a participatory process, in which communities were able to share their views and observations. Over the years, estonoesunsolar allowed the rehabilitation of 29 vacant lots. Two of them were located in the San Pablo neighborhood, in the historical center of the city, one on Calle San Blas and the other on Calle de Las Armas. In Calle San Blas, Grávalos Di Monte transformed the lot into an urban garden, mainly through the placement of some wooden pallets full of different botanical species (Fig.3). Similarly, the lot in Calle de Las Armas was turned into a garden by filling it up with plants and placing two pop-up structures formed by containers, intended to serve as rooms where activities related to gardening could take place.

\section{TEMPORARY SETTLEMENTS}

Temporary interventions are not only useful when recovering public spaces in consolidated urban environments. They can also help to reclaim transitional ones, such as refugee or post-disaster camps. Architecture has culpably ignored the situation of these camps for too many years, for the same reasons it overlooked ephemeral interventions in general. This was mainly due to the idea that only through the paradigm 
of permanence can architecture positively contribute to the inhabited landscape, and that only buildings that last can leave a strong mark on a community and a site. For a long time, temporary camps have not been the main interest of architects, since they are necessarily the place of transience and shortterm. They are cities built to disappear - in fact, in the very idea of community, the sooner they disappear, the better. Traditionally, architecture has contributed to post-earthquake recovery mainly through the design of new towns, or the reconstruction of damaged ones. This, of course, is a highly desirable approach, which architecture must continue to pursue even more, finding ways to properly build or rebuild cities that can be as solid and beautiful as ever. Still, it is also crucial that architects do not forget the importance of working in the transitional settlements that people inhabit right after the earthquake. Communities can end up living for months, sometimes even years, in these camps; it is too long to think that architecture should not be concerned. In such cases, the paradigm of temporary architecture is the only one capable of providing an effective solution. Furthermore, developing strategies to intervene in postdisaster settlements could help architecture understand how to deal with similar situations, such as refugee camps, where architects have been almost totally absent so far. In recent years, the commitment of architects to temporary settlements has been increasing (Charlesworth, 2014). Japanese architect Shigeru Ban, for instance, has been working his entire career in post-disaster camps, designing a number of projects aimed at improving the lives of communities facing such a challenging situation (Bruderlain, 2014). Sometimes he designed temporary houses, like the prefabricated wooden complex for the 2016 earthquake in Kumamoto, or the paper log shelters he built in camps around the world. Sometimes he designed instead entire camps, always with the objective of providing communities with an environment as welcoming and pleasant as possible. This is the case, for example, with the temporary settlement of Onagawa, created in response to the 2011 earthquake and tsunami (Ban, 2011). The camp was built using shipping containers, assembled to form multi-storey houses similar in size and typology to a traditional domestic space. Such a settlement, however low-key it may appear, is a real attempt to reproduce the atmosphere of home in a situation where all domesticity seems to be denied. Ban considered that, even if postdisaster camps are temporary, it is important to build a sense of normality and routine as soon as possible, to prevent communities from falling apart. Domestic space, in this sense, plays a key role. A distinctive feature of
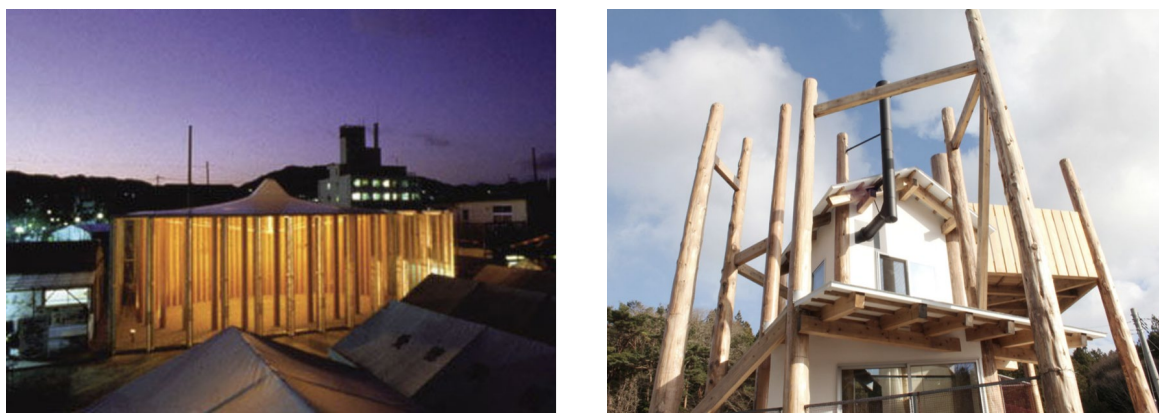

Figure 5, 6. On the left, Paper church in Kobe Source: (Ban, 2005)

On the right, Home for all in Rikuzentakata. Source: https://www.metalocus.es/en/news/home-all-rikuzentakata 
many of Ban's temporary interventions is the use of paper as main material. Paper is cheap, easy to find and, if properly processed, allows for the construction of very solid structures. But it would be a mistake to think that Ban's only concern, in his disaster relief projects, is to build quickly and economically. In fact, in his interventions, especially those made with paper, a clear intention can be recognized to show that post-disaster buildings do not have to be trivial or unattractive. Many of his projects prove him right, such as the paper church in Kobe, built in 1995, or the cardboard cathedral in Christchurch, New Zealand, built in 2013 (Fig. 4). The first project is especially interesting since it shows the intrinsic flexibility of the concepts of temporality and permanence (Fig.5). Designed to be a shortterm intervention, the church actually lasted ten years in its place (Ban, 2005). Later, it was disassembled and sent to the village of Taomi in Taiwan, which had suffered a major earthquake a few years earlier. Rebuilt there, the paper church is now one of the main attractions in the area. The relationship between permanence and temporality is therefore quite ambiguous: no architecture is permanent, as time will eventually prevail. But a temporary intervention, in certain circumstances, can last for a period of time comparable to that of so-called permanent architecture.

A similar example of disaster relief project is provided by the experience of Home for All, a programme started by Toyo Ito as a response to Tōhoku 2011 earthquake and tsunami (Ito, 2013). The objective of Home for all was to address the lack of public facilities in postdisaster camps through the realization of small temporary civic centers. Ito considered that in such camps public life is not a luxury, but a necessity, and that therefore the construction of buildings acting as social condensers could really improve the condition of the communities. Several architects participated in the program - among them Sou Fujimoto, Ryue Nishizawa, and Kazujo Sejima
- which eventually led to the construction of fourteen temporary pavilions in camps all over Tōhoku region. The interventions, however different, followed a similar approach, involving communities in a participatory process. All the pavilions were quite simple and unpretentious, partly because deadlines and resources did not permit otherwise, partly because everything in such situations seems to call for sobriety. In Rikuzentakata, Inui, Fujimoto and Harata, along with Toyo Ito, built an urban kitchen, that is, a place where people could go to cook, share a meal and spend some time together. Their intention was to build a pavilion that, although temporary, would become a landmark for the camp, acquiring social and symbolic values. For this reason, they built it using trunks swept away by the tsunami, as a metaphor for the possibility of not surrendering to the disaster and starting all over again.

\section{CONCLUSION}

Temporary architecture always played a significant role in shaping cities and the territory. From the tents of ancient nomadic societies, to the ephemeral constructions changing the image of cities on special days, to contemporary pop-up interventions, temporary architecture has been around since the beginnings of the discipline. However, for too long architects have overlooked this approach, considering it a minor practice unable to adequately address the problems of the inhabited landscape. This is due to the misconception that temporary interventions cannot present remarkable architectural qualities, due to their quick construction, their relative cheapness and their short-term nature. But this is not true. The reason why temporary interventions have always been present in the history of architecture, in all places and times, is because they provide something that permanent interventions simply cannot. They are adaptable, flexible 
and can be easily replaced and relocated, thus giving communities the chance to shape their place as they see fit. Permanence and temporality are not opposite paradigms, but complementary: each gives architecture something that the other can not give. Both must be taken into consideration when shaping the territory, to see on a case-by-case basis which is the most useful. It seems that recent events, such as the real estate bubble and the resulting crisis in the construction sector, have led architects to rediscover the qualities and potential of temporary interventions. However, it would be a big mistake to assume that such an approach can only be useful in a situation of scarcity. As contemporary experience shows, temporary interventions can be useful in the most diverse circumstances. Cities and territory are facing problems that need urgent and out-ofthe-box responses. Sometimes thinking outthe-box can mean inventing something totally new; sometimes it can mean rediscovering something very old that is strangely suited to the present time. This seems to be the case with temporary interventions, a tool architecture must not do without if it is to properly address contemporary and future challenges. 


\section{REFERENCES}

Ban, S. 2005. "Paper Church" Accessed August 24, 2020 http://www. shigerubanarchitects.com/works/1995_ paper-church/index.html

Ban, S. 211. "Container temporary housing" Accessed August 24, 2020 http://www. shigerubanarchitects.com/works/2011_ onagawa-container-temporary-housing/ index.html

Bruderlain, C. 2014. Shigeru Ban: Humanitarian architecture. New York: Distributed Art Publishers Demographia. "Demographia world urban areas: 15th annual edition". Accessed August 24, 2020. http://www. demographia.com/db-worldua.pdf

Cairns, S. \& Jacobs, J. M.2014. Buildings must die. A perverse view of architecture. Cambridge: Mit Press

Charlesworth E., 2014. Humanitarian architecture. 15 stories of architects working after disasters. Abingdon: Routledge.

De Roode I., Lefaivre L. 2002. Aldo van Eyck: the Playgrounds and the City. Rotterdam: Nai Publishers

Di Monte P., Grávalos, I., 2009. "La alfombra verde de San Blas 94-100". Accessed August 24, 2020. https://estonoesunsolar. wordpress.com/2009/09/10/laalfombra-verde-de-san-blas-94-100/

El Campo de la Cebada, 2011. "El Campo de la Cebada". A+T, 38, 162-167.

Ford E. 1997. "The theory and practice of impermanence", Harvard Design Magazine, 3. Accessed August 24, 2020. http://www.harvarddesignmagazine. org/issues/3/the-theory-and-practice-ofimpermanence

García, A., Lydon, M. 2015. Tactical urbanism short-term action for long-term change. Washington: Island Press

Gunwoo, K. 2016. "The public value of urban vacant land: social responses and ecological value", Sustainability, 8 (5), 486
Ito, T. 2013. "Architecture. possible here? Home for all" Lotus, 152, 10-13

Koreman, K., van Bogel, E. 2015. City of permanent temporality. Rotterdam: Nai publishers

Lefebvre, H. 2009. The production of space (1974). Malden: Blackwell

Lerner, J. 2003. Acupuntura urbana. Rio de Janeiro: Editora record

Muschamp, H. 1999. Critic's notebook; design fantasies for a strip of the West Side. New York Times, October 18, 1999. Accessed August 24, 2020. https://www.nytimes. com/1999/10/18/arts/critic-s-notebookdesign-fantasies-for-a-strip-of-the-westside.html

Rossi, A. 2018. L'architettura della città (1966). Milano: II Saggiatore

Solá Morales, M. 2008. De cosas urbanas. Barcelona: Gustavo Gili

St. Hill, C. 2016. This is temporary: how transient projects are redefining architecture. Riba: Newcastle

The Decorators. "Ridley's temporary restaurant". Accessed August 24, 2020. http://www.the-decorators.net/Ridley-sTemporary-Restaurant

UNHCR. "Global trends-forced displacement in 2018". Accessed August 24, 2020. https:// www.unhcr.org/globaltrends2018/ 


\title{
PAPER \#2.13
}

\section{PUBLIC SQUARES, SOCIAL INTERACTIONS, AND URBAN SUSTAINABILITY: LESSONS LEARNED FROM MIDDLE EASTERN MAIDANS}

\author{
Shima Molavi Sanzighia ${ }^{a}$ Farzaneh Soflaei ${ }^{\mathrm{b}}$ \\ alslamic Azad University, Gonbad Kavoos, Iran \\ 'State University of New York, Oneonta, USA
}

\section{ABSTRACT}

This article highlights the social function of public squares that has been transformed after modernism. Before that, public squares were places for stop, watch, and integrate, while entering modern components like roundabout and junction to the urban structure, have resulted separation of people and public spaces. In fact, the historical pattern of public squares has been also transformed to the traffic nodes to facilitate the traffic flow, where have no longer functions for social interaction as the key issue of the urban social sustainability. This paper focuses on historic public squares in the Middle East, in order to identify their socio- spatial design characteristics that successfully have contributed to the social sustainability of cities. We selected three valuable public squares in Iran from Safavid era (1502-1736) including Naghsh-e-Jahan square (Isfahan), Amir Chakhmaq square (Yazd), and Ganjalikhan square (Kerman) as case studies. While Iran as a Middle Eastern country where these cities are located may not be considered model democratic states, the social interactions these open spaces accommodate has lessons for advancing the 2030 Agenda for Sustainable Development of making "safe, inclusive and accessible, green and public spaces". Our research will show how, despite major urban transformations in the passage of time, these three cases have persisted as historic cultural landscapes. Through a mixed-method analysis of selected Maidans, we 1) Identify

socio-spatial features of case Maidans; 2) decode the role of design in encouraging social interactions. As conclusion, a sociospatial framework will be presented for the design and revitalization of public squares to improve social sustainability in future development. Our goal is to shed fresh light on future research in the field of urban design and can be used to evaluate proposals for new and regeneration of existing public squares in cities for a sustainable future.

\section{KEYWORDS}

Social sustainability; urban social sustainability; social interactions; public squares; socio-spatial framework .

\section{INTRODUCTION}

Sustainability is a holistic approach that integrates various components of coupled human and natural systems across all dimensions to address complex interconnections and identify effective solutions to urban challenges (Liu, et al., 2015). It embraces three equally important aspects (environmental, economic and social) that need to be balance (Soflaei, 2017).although social aspect is the least studied and only has been seriously considered after the year 2000 as an integral part of the sustainability that should be distinctively debated (Figure 1). 


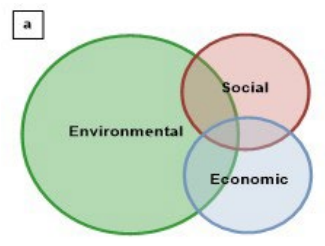

1980-mid 1990s

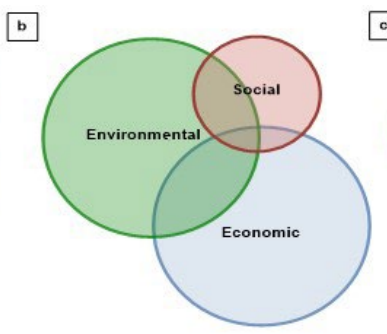

Late 1990s,

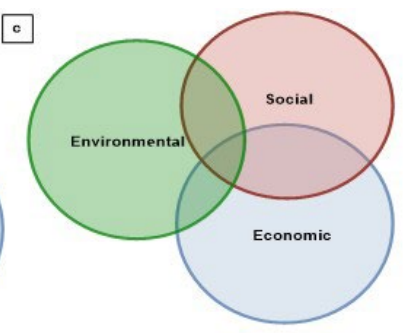

2000 , balance?

Figure 1. Various dimensions of sustainability and their relative importance: a) 1980-mid 1990s, b) Late 1990s, and c) 2000, balance (Colantino, 2010)

This research focuses on the social pillar of sustainability and postulates that future generations should have the same or greater access to shared urban resources for social interaction as inherited by the current generation. The main attention is paid to the impact of public squares, as potential venues for social interaction, on urban social sustainability. Public square is defined as an open space exists among buildings in urban area that place is for urban residents to meet and talk with others also is a multi- functional space it could be a center for political, economic, cultural activities.

Today, Iranian cities are suffering from the dominance of vehicles in their public spaces, and the social function of public squares has been neglected in modern urban development. This study is aimed to analyze the historical public squares in Iran as successful social places, to identify the socio-spatial design characteristics that have contributed to the social sustainability of Iranian cities. To achieve this purpose, a comprehensive literature review was conducted on two key ideas of urban social sustainability, urban transition and evolution process of public squares in Iran. Furthermore, a survey study was also carried out to locally evaluate the socio-spatial features of historical public squares in Safavid era. (Soflaei \& Zhu, 2013). Three valuable historical public squares from three ancient cities of Iran, namely Naghshe-Jahan square in Isfahan, Amir Chakhmaq square in Yazd, and Ganjalikhan square in Kerman, were selected as research cases. As conclusion, all data were integrated to offer a socio-spatial framework for designing, developing, and revitalizing of public squares in Iran, in order to enhance social interaction and urban sustainability in future communities.

\section{LITERATURE REVIEW}

In this research, literature review is characterized by a logical flow of two key ideas including: 1) The concept of urban social sustainability, and 2) Urban transition and evolution process of public squares in Iran.

\subsection{The Concept of Urban Social Sustainability}

Colantino (2010) argued that environmental and economic pillars dominated the sustainability debates since its beginning whilst it is only in the late 1990s that social issues were taken into account within the sustainability agenda (Colantino, 2010).. However, there are few practical resources that directly address the question of "How to create places that are socially sustainable?" 


\section{Research Process}

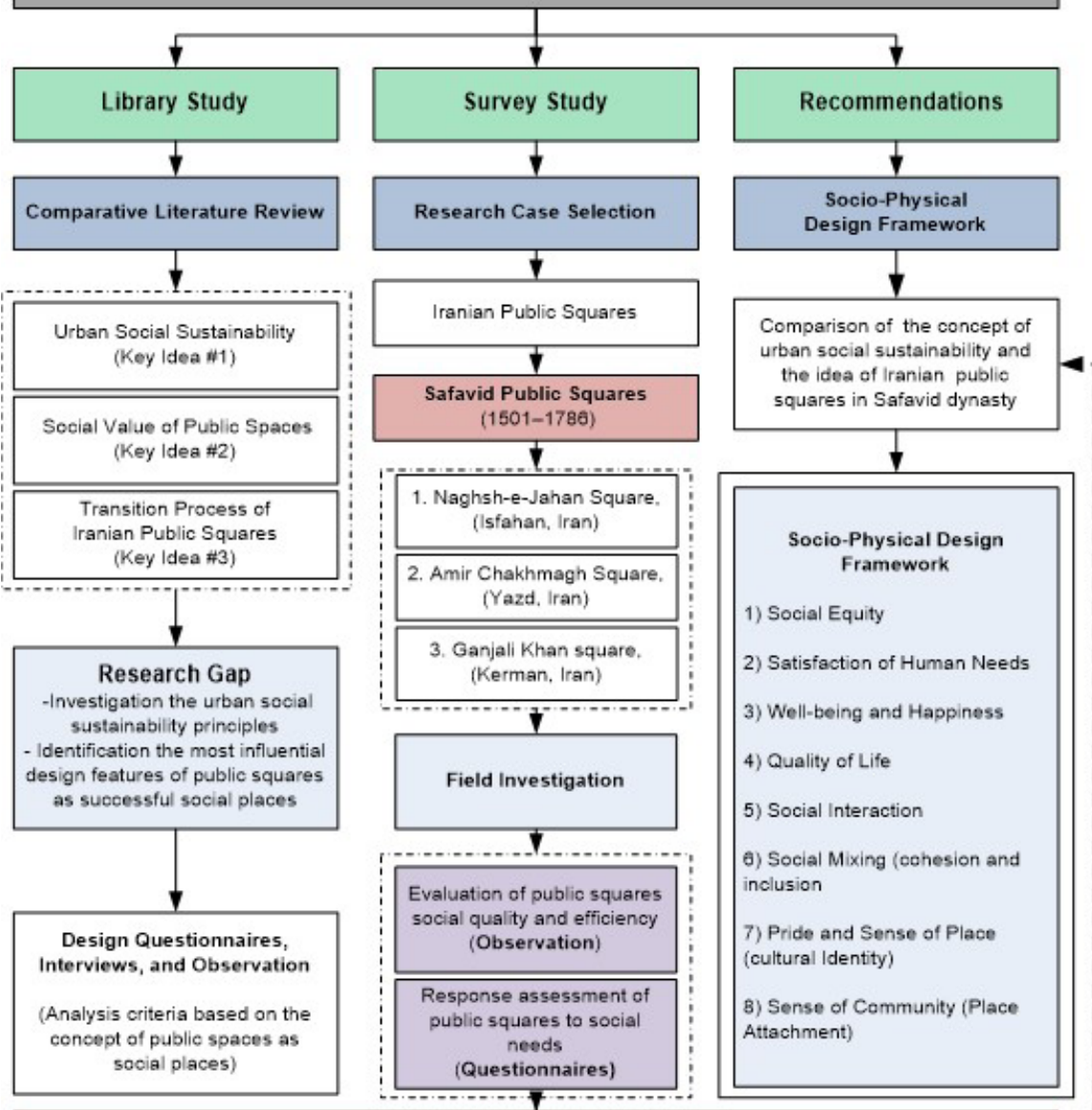

\section{Socio-Physical Design Characteristics of Safavid Public Squares}

1) Spirituality and manifestation of religious ideology (sense of presence in paradise, holy urban orientation, sense of introspection in respect to privacy, and sense of unity)

2) Historical continuity, identity and sense of belongings.

3) Considering the historical precedents

4) Satisfaction of human needs (physically, emotionally, socially and spiritually)

5) Designing based on archetypes

6) Visual and aesthetic considerations

7) Innovation and uniqueness in design

8) Accessibility with a particular attention to the street connectivity concept

g) Multi-functional space to public participation and social interaction.

Figure 2. Research process 
(Woodcraft, 2011). Literature review reveals that definitions of social sustainability in urban context are offered under four theoretical frameworks: 1) Theories that pay more attention to the existing positive conditions of urban life. For instance, Segerstedf and Abrahamsson (2019) mentioned that urban sustainability goals are directly related to social acceptability around shared concerns. 2) The main focus in the second framework is on the "measurement (Segerstedt \& Abrahamsson, 2019)". According Colantino (2010) to social sustainability themes such as employment and poverty alleviation are increasingly being complemented or replaced by the less measurable concepts like "happiness", social interactions and "sense of place" (Colantino, 2010). 3) Scholars have also maintained a "future focus" on the continued improvement of individual "well-being" from the current to the future generations. 4) Theories in the fourth framework offer a functionalist understanding of social sustainability as a process of generating cohesion. According to Mckenzie (2004), social sustainability is a life-enhancing condition within communities arrived through a process (McKenzie, 2004). Examples cited under each of the theoretical frameworks reveal six common characteristics of communities deemed socially sustainable including Social equity 2)Satisfaction of human needs, Well-being and happiness, Social interaction and social mixing (cohesion and inclusion), Sense of place (cultural identity), Sense of community (place attachment), Future focus (Mehan \& Soflaei, 2017)

According to fourth charter, Studies have shown that positive social interaction is an important element of sustainability that can improve and alter people's behavior and attitude (Soflaei \& Aghajani, 2013). This paper therefore explores the impact of public squares as potential venues for democratic participation and interactions, on social sustainability in Iranian cities.

\subsection{Urban Transition and Evolution Process of Public Squares in Iran}

Square is considered as one of the essential features in urban planning that is often adjacent to bazaars, large mosques and other public buildings (Pakzad, 2003).According to Soltanzade(1991), Maidans are basically divided into three main types based on function, urban scale, and form. In addition, they may be subdivided into five categories based on urban scale consisting of suburb, city, region, district, and neighborhood squares (Soltanzade, 1991). In terms of form, they have been identified in the history and subdivided into five types such as irregular organic forms before Islam, regular geometrical forms in Safavid era (rectangular and square), regular geometrical forms in Qajar era (rectangular ellipsoid and circular), regular geometrical forms in Pahlavi era (circular), and irregular forms after Islamic revolution to present (Soflaei, 2012).

The main concept of square was first made in the Persian- Hellenic cites, from 9 BC to 3 AC. Meidan in Sassanid cities that was called Shahr-e-Parti from 3 AC to 7 AC, was multifunctional place.. Gradually, public squares were designed based on regular geometric forms; mostly rectangular and square that were surrounded by urban spaces such as governmental buildings, mosque, religious school, bazaar, and public bath. The most remarkable public squares in the history of Iranian urbanism were built after Islam in Safavid dynasty (17th century), as the concern of this research.

The bazaar and square were the urbanbackbone of the city and other urban spaces were arranged around that. Social interactions still took place mainly in bazaar as the focal point of public life, and a center for social, cultural, recreational, religious and political activities. In the process of urban transition, most of the Iranian public squares lost their identity and were changed to urban nodes 


\begin{tabular}{|c|c|c|c|}
\hline & Dynasty & Time Period & Function \\
\hline \multirow{2}{*}{$\begin{array}{l}\text { Before } \\
\text { Islam }\end{array}$} & $\begin{array}{l}\text { Soluki Dynasty } \\
\text { (Persian-Hellenic city) }\end{array}$ & $9 \mathrm{BC}$ to $3 \mathrm{AC}$ & $\begin{array}{l}\text { Multi-functional center for cultural, official and } \\
\text { commercial purposes like Greek Agora. }\end{array}$ \\
\hline & $\begin{array}{l}\text { Sassanid Dynasty } \\
\text { (Shahr-e-Parti) }\end{array}$ & $3 \mathrm{AC}$ to $7 \mathrm{AC}$ & $\begin{array}{l}\text { Symbol of the government's power like Roman } \\
\text { Forum. }\end{array}$ \\
\hline \multirow{4}{*}{ After Islam } & $\begin{array}{l}\text { Safavid Era } \\
\text { (Isfahani Style) }\end{array}$ & $1501-1736$ & $\begin{array}{l}\text { Multi-functional center and surrounded by various } \\
\text { urban spaces such as governmental buildings, } \\
\text { great mosque, religious school, bazaar, and public } \\
\text { bath. }\end{array}$ \\
\hline & $\begin{array}{l}\text { Qajar Dynasty } \\
\text { (Tehrani Style) }\end{array}$ & $1785-1921$ & $\begin{array}{l}\text { Bazaar and square as the city's backbone, and } \\
\text { other urban spaces were arranged around. }\end{array}$ \\
\hline & $\begin{array}{l}\text { Pahlavi Dynasty } \\
\text { (Industrial Revolution Period) }\end{array}$ & $1921-1978$ & $\begin{array}{l}\text { Inspired by western style and ignorant of historical } \\
\text { architectural elements, unity through continuity in } \\
\text { the form, advent of automobiles, paying attention } \\
\text { to details in façades. }\end{array}$ \\
\hline & $\begin{array}{l}\text { Contemporary Dynasty } \\
\text { (After Islamic Revolution) }\end{array}$ & 1978-present & $\begin{array}{l}\text { The number of cars has been increased, public } \\
\text { squares lost their original concept and converted to } \\
\text { nodes or roundabouts to facilitate the traffic flow. }\end{array}$ \\
\hline
\end{tabular}

Table 1. Urban transition and evolution process of public squares in Iran

to facilitate the traffic flow that were neither multi-functional open spaces as they were traditionally, nor an urban place for social interactions. In Pahlavi rule in 1925, these roundabouts had some greeneries, water fountains, statues or memorial symbol, which could be mainly watched by driver from the streets, contrary to squares as an open urban space that the people could enjoy the safety and serenity of it for resting, sitting and social communications (Habibi, 2013).(Table1)

Today, contemporary Iranian public squares are transformed to urban nodes, as an unknown territory, where people pass their time without any enthusiasm. Even some of old public squares with rich history and imposing monuments also changed to traffic intersections or boring parking lots (Bolouki, 2008; Soflaei, 2014). Nowadays, Iranian citizens live next to each other, but they do not live together because of lack of proper public spaces to stop, discover each other, find freedom, interact, and have a normal social life, although people became more interested in using the public space for entertainment along with their family in cultural non-religious venues, and social interactions (Bahraini, 1998) (Figure 3)
A comprehensive literature review revealed that most of the research describes the Iranian public squares in a historical context, and have left the social aspect as the focus of this article. Therefore, this study goes further to analyze the historical public squares in Safavid era (1502-1736), as research cases, to identify their socio-spatial design characteristics that have contributed to the social sustainability of Iranian cities. The ultimate goal is to present a socio-spatial design framework, as lessons learned from the past, for designing, developing, and revitalizing public squares as a promising approach to enhance the urban social sustainability in future cities.

\subsection{Filed Investigation: Socio-Spatial Analysis of Iranian Public Squares in Safavid Era (1501-1736 AC)}

The concept of Iranian urbanism in Safavid era was formed based on three main factors including power, religious beliefs, and symbolism. These three factors that were influenced by people, were manifested in public squares (Sanianiani, 2013). The goal of this paper is to highlight the morphological, functional, social, and spatial properties of 

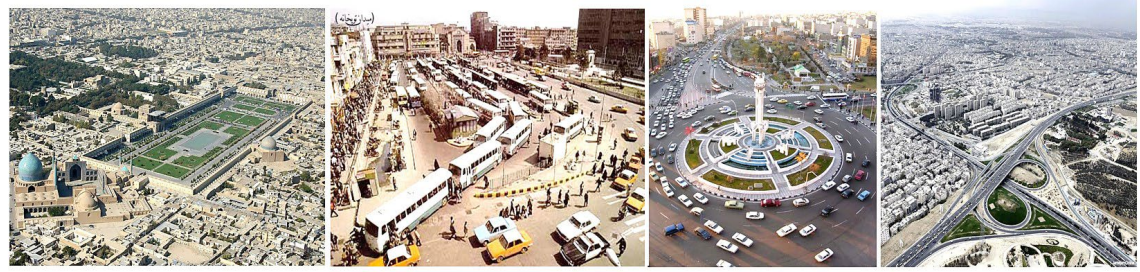

- Naqsh-e Jahan Square, Isfahan

ToopKhāneh Square, Tehran

Sadeghiyeh Square, Tehran 1995 Noor Square, Tehran 2005

\section{$\longleftarrow \quad$ Historical \\ $\longleftarrow$ Historical}

Modern
Public Squares

$\rightarrow$

Contemporary
Public Squares

Future

Public Squares

Figure 3. Urban transition and evolution process of Iranian public squares in the passage of time

public squares in Safavid period that provided a dynamic connection between the royal palace (government), city (public square), and society (people). The Safavid squares not only were the ceremonial places for government, but they also served as multi-purpose spaces for commerce, civic, religious, and political activities. They were designed with regular geometrical forms, based on a careful attention to cultural context to provide a safe and welcoming social place to encourage people for public participation, activities and interactions (Figure 3).

This research is aimed to study the historical public squares as successful social places, to identify their socio-spatial design patterns that have contributed to the social sustainability of Iranian. To that end, a comprehensive survey is carried out to analyze different design characteristics in three valuable historical public squares from Safavid era (1502-1736), as research cases including:

Naqsh-e-Jahan Square is situated at the center of Isfahan. It was constructed between 1598 and 1629, and is one of UNESCO's world heritage sites. It is 160 meters wide by 560 meters long, and is surrounded by the Shah Mosque on the south side, the Ali Qapu Palace on the west side, Sheikh Lotf Allah Mosque on the eastern side, and at the northern side Keisaria gate opens into the Isfahan grand bazaar (figure4).

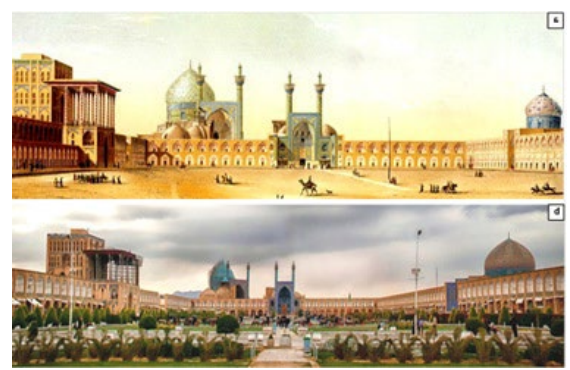

Figure 4. Naghsh-e-Jahan square as successful social place (before and after): a): Naghsh-e-Jahan Square in 1839, a painting by Xavier Pascal Coste (Safavid era), b) Naghshejahan square, Isfahan in 2003 (contemporary era) 
Amir Chakhmaq square is a prominent structure in Yazd heritage city, and was built in the 15th century on the north side. A bazaar and caravanserai were constructed on the other sides of the square in the same year. Many parts of the complex including caravanserai, public bath, caravanserai, confectionary, and water reservoir, were reconstructed in the Safavid period. 3) Ganjali Khan square is located in the historical urban texture of Kerman, with length of 99 meters and width of 54 meters, which is aligned with Vakil Bazaar. It is composed of a school, square, caravanserai, bathhouse, water reservoir, mint, mosque and bazaar.

Naghsh-e-Jahan square was designed in Isfahani style, by two famous traditional architects namely, Mohammadreza Esfahani and Ali Akbar Esfahani that both were the best in that time (Taylor, 1995). The common socio-spatial design patterns in these three cases were identified, and the results are presented as follows:

- Spirituality and manifestation of religious ideology: One of the most distinguished features of Iranian public squares in Safavid era is the consideration of religious spaces such as great mosque and religious schools around the square, to provide a social place for Muslim people to gather for different religious rituals. Manifestation of this religious ideology has affected the following design qualities:

- Sense of introspection: This concept originated from Islamic ideology and has affected Iranian social life in respect to privacy. It has been used in architectural and urban spaces with different functions from traditional courtyard houses, mosques, schools, to public squares. The concept implies that all enclosed spaces are located around a void space, and all are opened to it.

Sense of presence in paradise: The concept of green city was outlined in Safavid era for the first time in the history of Iranian urbanism and was inspired by the idea of paradise in the Islamic culture. This concept has been considered by Iranian Muslim planners as one of the most important basic design patterns of Safavid public squares. The goal is to create a beautiful landscape through natural elements such as water, plant, light and sky, based on Persian garden concept. Sense of unity: Surrounding urban spaces in Safavid public squares, have used various functions to meet different needs of citizens. The goal is to provide opportunity for people to actively participate in the urban spaces and interact with each other, during their daily life. This spatial continuity has caused three dynamic relationship between nature (square), human (main bazaar) and God (mosque) as a philosophical issue.

- Holy urban orientation: According to Islamic beliefs, the most valuable spatial element is Kaaba in Mecca. One of the most notable features of Safavid public squares is the great mosque building that has been built toward the Kaaba, as the manifestation of religious beliefs in this era. The master architects have designed two passageways being different in length on both sides of the square to assimilate the axis of the mosque to the direction of Kaaba which has an angle of 45 degrees, to cover the change of direction without losing the proportions (Figure 5).

- Historical continuity, identity and sense of belongings: Studying the evolutionary process of Iranian public squares in Safavid era has shown that they have experienced many changes in the passage of time. However, the continuity of their use through the time in respect to the socio-cultural values and user satisfaction has led to enhance sense of belongings for citizens.

- Satisfaction of human needs (physically, emotionally, socially and spiritually): Architects and urban designers in Safavid period, focused on the society and citizens' needs regardless of gender, race, ethnicity, age or socio-economic level. 


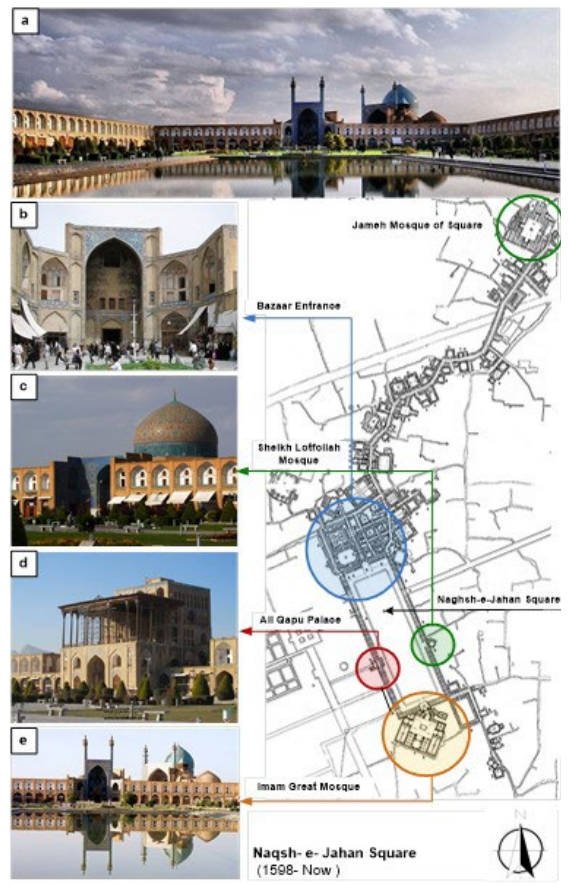

Figure 5. Naghsh-e-Jahan square in Isfahan, as a sample of successful public squares in Savaid dynasty of Iran era, a) Square as multi-functional urban space to encourage people for various social activities, $b$ ) Bazaar entrance in the northern side of square, $b$ ) Sheikh Lotfollah mosque in the eastern side, c) Royal Ali Qapu palace in western side, and d) Imam great mosque in the southern side of square

They considered five significant principles for Iranian Islamic architecture including, humanism and proportionality, abstinence from inanity, structural consideration, self-sufficiency, introversion, purity in the shapes and volumes introspection, and symmetry to fulfill human needs (Hosseini, 2012).

- Considering the historical precedents: The idea of combination of old and new textures in urban development through the great bazaar as an urban backbone, was outlined in Safavid era for the first time in the history of Iranian urbanism. For instance, the main bazaar connects the Naghsh-e-Jahan square as a new urban square in Safavid period to the Atiq square as the oldest urban square in Isfahan city.

- Visual and Aesthetic considerations: Some design patterns like symmetry, rhythm, geometrical proportions, the low-rise surrounding bodies in human scale in respect to the monumental scale of square, visual richness, location of important buildings along the symmetrical axes, all can be considered as aesthetic features of the public squares in Safavid dynasty (Figure 6).

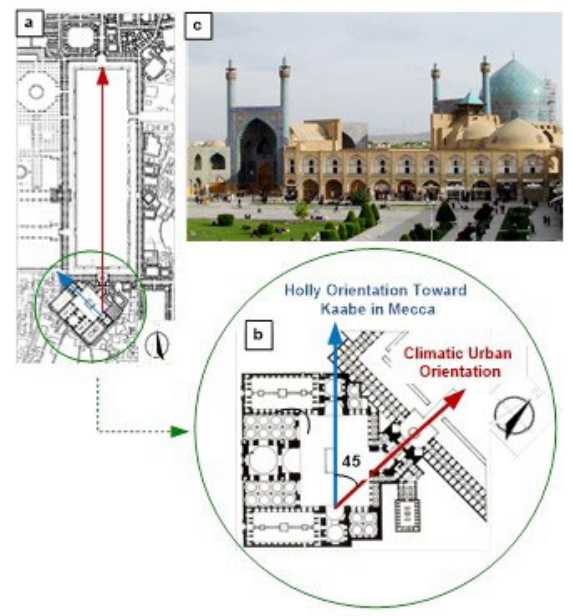

Figure 6. Imam great mosque in the southern side of Naghsh-e-Jahan square, was oriented to the direction of Kaaba which has an angle of 45 degrees with the climatic urban orientation of Isfahan city and Naghshe-Jahan square 
- Designing based on archetypes: Based on old archetypes, broken cross or Chalipa has a special place in the Iranian architecture and urban design. It is the symbol of the connection between the sun and the moon and four fundamental forces of water, wind, fire and soul which keeps the existence and creation of the world and the human beings. Since the Chalipa has four directions and four apexes, the number 4 to be reviewed as the view-point of secretdiscovering as dealt with structure and content issues (Ashrafi \& Habib, 2013). This symbol was used in concept designing of public spaces in Safavid era. For instance four urban spaces including Imam great mosque square, bazaar entrance, royal Ali Qapu palace, and Sheikh Lotfollah mosque, were considered as the members of this broken cross in Naghshe-e-Jahan square.
- Innovation and uniqueness in design: The historical origins of the basic concept of public squares in Safavid era, could be traced back to the ancient Saheb Abad Square in Tabriz, Shah Square in Qazvin, and even Atiq square in Isfahan city. However, Safavid public squares are innovative and unique examples in the history of Iranian urbanism regarding their dimension, scale, proportions, visual richness, location in the focal point of city to provide easy accessibility, and multi-functional spaces to meet various social needs.

- Accessibility: Safavid public squares were designed as social places to stop, integrate and watch. They were adopted to this transition by considering the concept of street connectivity. This concept suggested a system of streets with multiple routes and connections serving the same origins

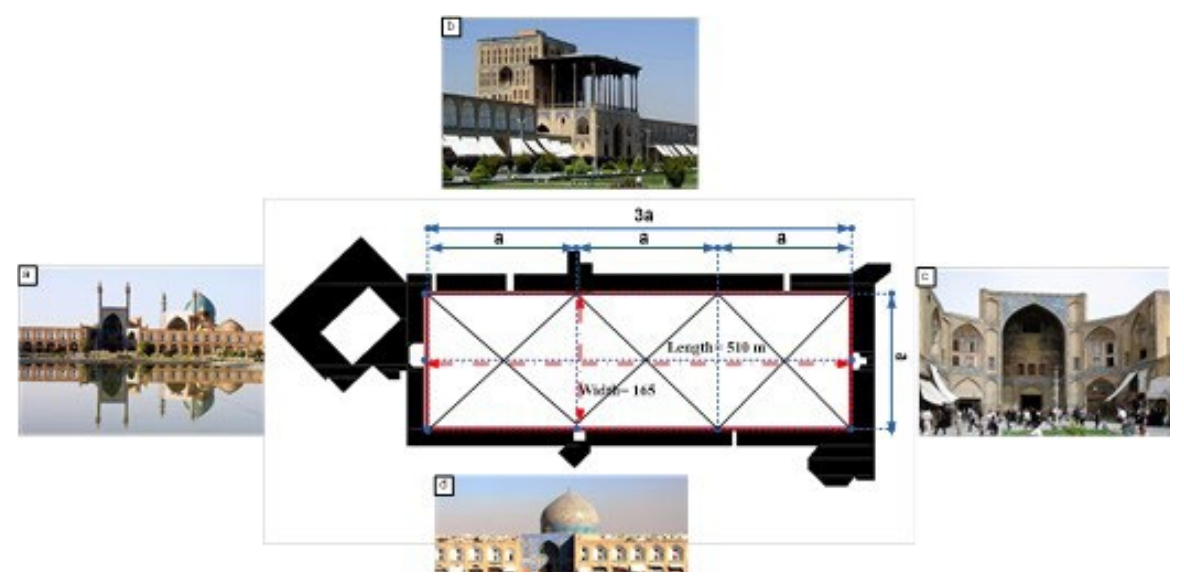

Figure 7. Visual and mathematical aesthetics considerations (geometrical properties and proportion, symmetrical axis, and low-rise surrounding bodies in human scale in respect to the monumental scale of square in Naghsh-eJahan square in Isfahan, as a sample of successful public squares in Savaid dynasty of Iran, a) Imam great mosque in the southern side of square, b) Royal Ali Qapu palace in western side, c) Bazaar entrance in the northern side of square, and d) Sheikh Lotfollah mosque in the eastern side. 
and destinations. Connectivity not only relates to the number of intersections along a segment of street, but how an entire area is connected by the transportation system. This concept by providing a strong connected network of roads and pedestrian facilities can help distribute traffic, reduce travel distances and times, improve routing for transit and reduce walking distances. Good connectivity also provides better routing opportunities for emergency and delivery (solid waste, recycling, mail) vehicles. The concept of street connectivity has been considered for development of Naghsh-e-Jahan square, and the car accessibility has been restricted in only two main streets and the other 15 streets has been designed just for pedestrians.

- Social interactions: Safavid public squares were designed as multi-functional urban spaces in order to invite people for different events and activities (actively and passively) and have never lost their social function in the passage of time. For instance, social function of Naghsh-e-Jahan square in the process of history, from the beginning of Safavid era until present time, is investigated by (Shahabinejad, et al., 2014) and the result is presented in Table 1.
The results of field investigation illustrate that public squares in Safavid era were designed based on a careful attention to the sociospatial factors. Among these factors, political power that was constructed by the king and the royal family, had the most impact on the formation of Safavid public squares. It should be noted that, political power and religious beliefs were both manifested in the concept of public squares in this period of time. As conclusion, a comparative study was conducted between the concept of urban social sustainability, and the idea of Safavid public squares as successful social places (Table 2).

The result of this comparative study shows that there are 8 common features between these two perspectives including 1) Social equity, 2) Satisfaction of human needs, 3) Well-being, happiness, 4) Quality of Life, 5) Social interaction, 6) Social mixing (cohesion and inclusion), 7) Pride, sense of place and culture (identity), 8) Sense of community (place attachment). These common features, as a socio- spatial physical framework can be considered for designing, developing, and revitalizing of contemporary public squares in order to enhance the urban social sustainability in Iranian cities.

\begin{tabular}{c|l}
\hline Historical Period & Social Activities \\
\hline Safavid Era & $\begin{array}{l}\text { Political activities, religious ceremonies, commercial activities, traditional gatherings, } \\
\text { military marches, polo matches, horse riding competitions, national festivals, religious } \\
\text { festivals, fireworks, puppetry, acting, storytelling }\end{array}$ \\
\hline Qajar Era & $\begin{array}{l}\text { Permanent commercial center, temporary Fridays commercial center, military training, } \\
\text { barrack, demolishing the green space in the middle of square }\end{array}$ \\
\hline Pahlavi Era & $\begin{array}{l}\text { Revitalization of square, easing accessibilities by foot and by car, creating fountain and } \\
\text { planting in middle of the square, creating green space for recreational activities, civic } \\
\text { activities }\end{array}$ \\
\hline Contemporary Era & $\begin{array}{l}\text { Restricting the entrance of cars in to square, paving the square, decreasing the air } \\
\text { pollution and visual barriers like traffic lights, bus station, bars and etc. }\end{array}$
\end{tabular}

Table 2. Urban development and social transition in Naghsh-e Jahan square through the time (Shahabinejad, et al., 2014) 


\begin{tabular}{|c|c|c|}
\hline No & $\begin{array}{l}\text { Social Sustainability Concept } \\
\text { In Urban Context }\end{array}$ & $\begin{array}{l}\text { Social Sustainability Concept } \\
\text { in Iranian Public Squares in Safavid Era }\end{array}$ \\
\hline 1 & Social equity & Accessibility (easy and direct accessibility) \\
\hline 2 & Satisfaction of human needs & $\begin{array}{l}\text { Respect for human needs (physically, emotionally, socially and spiritually), } \\
\text { Aesthetic Considerations, Sense of Introspection, Holy urban orientation, } \\
\text { Climatic urban orientation to provide human comfort for citizens. }\end{array}$ \\
\hline 3 & Well-being, Happiness & $\begin{array}{l}\text { Sense of presence in paradise, Sense of introspection and respect for } \\
\text { privacy, Sense of unity, Sense of belonging, Social interactions, }\end{array}$ \\
\hline 4 & Quality of Life & $\begin{array}{l}\text { Innovative and uniqueness, Meet different of social physical, emotional } \\
\text { and spiritual needs, Respect for urban social life: citizens' gathering and } \\
\text { participation in various events and social interactions. }\end{array}$ \\
\hline 5 & $\begin{array}{l}\text { Social interaction, social mixing } \\
\text { (Cohesion and Inclusion) }\end{array}$ & $\begin{array}{l}\text { Multi-functional spaces in order to social engagements, public activities } \\
\text { and social interaction }\end{array}$ \\
\hline 6 & $\begin{array}{l}\text { Pride, Sense of place and culture } \\
\text { (Identity) }\end{array}$ & $\begin{array}{l}\text { Historical continuity, identity and sense of belongings, Considering the } \\
\text { historical precedents, Designing based on archetypes }\end{array}$ \\
\hline 7 & Sense of community & $\begin{array}{l}\text { Historical continuity, identity and sense of belongings, Multi-functional } \\
\text { spaces for public participation and social interaction. }\end{array}$ \\
\hline 8 & Future focus & $\begin{array}{l}\text { Combination with the historical precedents, Accessibility based on the } \\
\text { concept of street connectivity in revitalization, Innovative and uniqueness } \\
\text { in design. }\end{array}$ \\
\hline
\end{tabular}

Table 3. Comparison of the concept of social sustainability in the Iranian public squares of Safavid era

\section{CONCLUSION}

Public spaces by offering opportunities for equal participation irrespective of gender, age, nationality or social-economic status, have a great potential to raise the quality of life and social sustainability in contemporary cities. This paper emphasized on the impact of public squares on urban social sustainability of Iranian cities to investigate urban transition and evolution process of public squares, from before Islam until present time, to identify the most successful public squares. Safavid public squares, as research cases, were selected to identify their socio- spatial design characteristics.

The research findings are listed as below: Different definitions of the concept of social sustainability in urban context were reviewed and seven common key ideas are extracted including: 1) Social equity, 2) Satisfaction of human needs, 3) Well-being and happiness, 4) Social interaction and social mixing (cohesion and inclusion), 5) Sense of place (cultural identity), 6) Sense of community (place attachment), and 7) Future focus. These seven ideas were considered as analysis criteria for social assessment of Safavid public squares. It is identified that the social function of public spaces has been ignored after modernism in Iran, and transformed to roundabouts or urban nodes to facilitate the traffic flow. Consequently they have no longer any function for social interaction. In contrast with the fast urban transition, the contemporary Iranian society has also faced a great social transition. Today, Iranian people like other people in the world have a tendency to visit public squares especially after the current social transition in social values and attitudes which used to limit some characteristics of people's presence and their activities (especially for females) in public squares.

The social concept of three valuable historical public squares in Safavid dynasty as research cases, was investigated, and their common 
socio- spatial design patterns were identified as: 1) Spirituality and manifestation of religious ideology (sense of presence in paradise, holy urban orientation, sense of introspection in respect to privacy, and sense of unity), 2) Historical continuity, identity and sense of belongings, 3) Considering the historical precedents, 4) Satisfaction of human needs (physically, emotionally, socially and spiritually), 5) Designing based on archetypes, 6) Visual and aesthetic considerations, 7) Innovation and uniqueness in design, 8) Accessibility with a particular attention to the street connectivity concept, and 9) Multifunctional space for public participation and social interaction.

A comparative analysis between the concept of urban social sustainability and the idea of Safavid public squares, as successful social places, was conducted and the common features between these two perspectives were presented as socio- spatial framework as following: 1) Social equity, 2) Satisfaction of human needs, 3) Well-being, happiness, 4) Quality of Life, 5) Social interaction, 6) Social mixing (cohesion and inclusion), 7) Pride, sense of place and culture (identity) 8) Sense of community (place attachment). With respect to the current social needs and considering the presented common features as a socio- spatial framework, in designing, developing, and revitalizing of public squares, it is anticipated that social interaction and urban sustainability can be tremendously enhanced in Iranian cities.

\section{ACKNOWLEDGEMENTS}

The authors would like to express their thanks to Cultural Heritage, Handcrafts and Tourism Organization in Iran, and Tsinghua University of Beijing in China, for their support of the present research. 


\section{REFERENCES}

Abbasi-Shahvazi, M. J., McDonald, P. \& Hosseini-Chavoshi, M., 2009. The fertility Transition in Iran. Netherlands: Springer.

Arjmand, R., 2017. Public Urban Space, Gender and Segregation (Women-only parks in Iran). Florence: Routledge..

Ashrafi, N. \& Habib, F., 2013. Difference of Iranian mosques with other Islamic countries mosques. middle-East Journal of Scientific Research, Volume 17, pp. 260269.

Bahraini, S. H., 1998. Urban space analysis in related to user's behavior pattern: policies for urban design. Tehran: Tehran University Press (in Persian).

Blair, S. \& Bloom, J., 1995. The Art and Architecture of Islam. s.l.: Yale University Press.

Bolouki, B., 2008. The Rational Relationship between Vehicle and Human: Case Study in Iran. Master dissertation of Urban Design. Tehran: University of Tehran (in Persian).

Bramley, G. et al., 2009. Social Sustainability and urban form: evidence from five British cities. Environment and Planning, 41(9).

Colantino, A., 2010. Urban Social Sustainability Themes and Assessment Methods. Proceeding of the institution of civil engineers: Urban Design and planning, 163(2), pp. 79-88.

Colantino, A., 2010. Urban Social sustainability thems and assessment methods. Proceeding of the institution of civil engineers: Urban Design and planning, 163(2), pp. 79-88.

Fallahfar, S., 2010. The Dictionary of Iranian Traditional Architectural Terms. Tehran: Kamyab Publications (in Persian).

Habibi, M., 2013. From Shar to Shahr. Tehran: Tehran University Press.

Harun, N. Z., Zakariya, K., Mansor, M. \& Zakaria, K., 2014. Determining Attributes of Urban Plaza for Social Sustainability. s.I., AMER International Conference on Quality of Life.
Holden, M., 2012. Urban Policy Engagement with social sustainability in Metro Vancouver. Urban Studies, 49(3), pp. 527542.

Hosseini, Z. K., 2012. A Brief Survey on the Principles of Iranian Islamic Architecture. Nishinomiya, s.n.

L.H.Chiu, R., 2003. Sustainable Development: A New Perspective for Housing Development. Adelaide, South Australia, http://www.nhc. edu.au/past-conferences/adelaide2003/.

Laguna, J. M., 2014. Institutional Politics, power constellations, and urban social sustainability, Florida: Florida State University.

Liu, J. et al., 2015. Systems Integration for Global sustainability.. s.l.:Urban Planet | Science 347 .

Magis, K. \& Shinn, C., 2009. Emergent Themes of Social Sustainability, New York: Routledge.

McKenzie, S., 2004. Social Sustainability: Towards some definitions, Magill, South Australia: University of South Australia.

Mehan, A. \& Soflaei, F., 2017. Social Sustainability in Urban Context: Concepts, Definitions and Principles. Florida: CRC Press.

Pakzad, J., 2003. Guideline urban space design. Tehran: Housing and urban planning ministry of Iran publisher. (in Persian).

Polese, M. \& Stren, R., 2000. The social sustainability of cities: Diversity and the management of change. s.I.University of Toronto press.

Sanianiani, R., 2013. The Symbolic Expression of Power and Religion in the Public Buildings in Safavid Iran: A Conceptual Interpretation. Journal of Shi'a Islamic Studies, 6(2), pp. 199-218.

Shahabinejad, A., Abuei, R., Ghalehnoei, M. \& Emami, M., 2014. Formation and historic revolution of Isfahans Naghsh-e-Jahan Square. Bi - Annual Electronic Journal of Restoration Science \& Culture Heritage, 2(3), pp. 45-64. 
Soflaei, F., 2012. Public Squares and Social Sustainability in Iranian Cities(past,peresent,future). New Jersey, s.n.

Soflaei, F., 2014. A Study on Revitalization of Baharestan Square in Tehran, Iran: Redesigning with the goal of changing from an insufficient traffic node to a sufficient social place. s.l.:Scholars' Press.

Soflaei, F., 2017. Engaging lost Open Spaces in Urban identity: Mount Auburn Cemetery in Baltimore. Cleveland, s.n.

Soflaei, F. \& Aghajani, S., 2013. Manifestation of Socio-Cultural Identity in Iranian Public Squares: Case Study: Safavid Era. Spaces and Flows. Amesterdam, An International Journal of Urban and Extra Urban Studies.

Soflaei, F. \& Zhu, W., 2013. Manifestation of Socio-Cultural Identity in Iranian Public Squares: Case Study: Safavid Era. Amesterdam, s.n.

Soltanzade, H., 1991. Urban Spaces in the Historical Texture of Iran:Culture research in municipality of Tehran. tehran: Publications office of cultural studies.

Taylor, A., 1995. Book Arts of Isfahan: Diversity and Identity in Seventeenth-Century Persia. Oxford: Oxford University press.

Woodcraft, S., 2011. Social Sustainability and New Communities: Moving from Concept to Practice in the UK. Procedia - Social and Behavioral Sciences, pp. 29-42. 


\title{
PAPER \#2.14
}

\section{URBAN LANDSCAPE LIVING LAB. \\ BASE CAMP : VADOZNER HUUS (BC : VH), LIECHTENSTEIN}

\author{
Anne Brandla ${ }^{\mathrm{a}}$, Johannes Herburger ${ }^{\mathrm{a}}$, Luis Hilti ${ }^{ }$, Clarissa Rhomberg ${ }^{\mathrm{a}}$ \\ alnstitute of Architecture and Planning, University of Liechtenstein, Vaduz, Liechtenstein
}

\section{ABSTRACT}

Like many European regions, the Alpine Rhine Valley, at the intersection of Switzerland, Austria, and Liechtenstein, is characterised by a heterogeneous mix of settlement areas, transport infrastructure, settlement-related open spaces, agricultural areas, and open landscape structures. Planning science tries to describe this phenomenon of urbanization through different terms: agglomeration, urban landscape, urban area, in-between city, sprawl town, etc. The research parameter is an unremarkable but publicly accessible "inbetween" space within the urban landscape of Liechtenstein. The underlying hypothesis of this paper is that there is little aesthetic attention given to these in-between spaces in science, planning policy, and practice in the case of Liechtenstein. The research project investigates the question of how the perception-oriented perspective of everyday landscapes can be implemented into the institutionalised processes of conceptual landscapes on two levels: (1) Everyday landscapes: in-between spaces are examined from the perspective of perception in the case of Vaduz, Liechtenstein. (2) Conceptual landscapes: in-between spaces are viewed from the rational perspective of planning, systematisation, and control. In this paper, we specifically examine the potentials and challenges of Urban Living Labs (ULL) as an applied and participatory research method to integrate the perspectives of the everyday and conceptual landscapes through temporary revitalisation and activation of the "Parkhaus Marktplatz" in Vaduz. Hence, the focus is not on the impact on the built environment but rather on the learnings of this participatory process for future planning on three perspectives: (i) actors, (ii) process, and (iii) programme.

\section{KEYWORDS}

Town centre planning; landscape; perception; stakeholder analysis; involvement and participation; urban living labs.

\section{INTRODUCTION}

In spatial planning and science, it is becoming increasingly relevant to think of compact settlement development in relation to the landscape. The landscape is understood as a process - a dynamic system of humanmade spaces (Prominski 2004) - and as a quality of perception and experience (Burckhardt 2015). Landscape requires not only a rational-planning approach but a perception-oriented approach as well. There is need for research for planning of settlement development related to landscape and for a perception-oriented perspective, but above all, the linkage of both perspectives is crucial. This approach to landscape gained in significance in the last few years through various important publications like "Zwischenstadt" (Sieverts 2013) and its subsequent publications (Hauser and Kamleithner 2006; Sieverts et al. 2005). Furthermore, the German Academy for Spatial Research and Planning (ARL) published a research report on conceiving suburban spaces as cultural landscapes (Schenk 2012). 
We follow this argumentation and choose a multi- story parking garage "Parkhaus Marktplatz" in the centre of Vaduz, the capital of Liechtenstein, as the investigation perimeter of this paper. The parking garage, completed in 1974, is part of the suburban landscape of the Alpine Rhine Valley and illustrates numerous planning challenges

- in particular, car-dominated spaces in an increasingly anonymous urban context.

The parking garage is used on a daily basis by commuters, shoppers, and the local population of Vaduz and is perceived more or less as a transit place. This is the everyday landscape level that stands in contrast to the conceptual landscapes shaped by institutionalised spatial planning using plans or strategies. The usual way to get rid of a "planning problem" like the parking garage is to demolish it and build something new. This would involve a longer process, neglecting the inherent qualities of a typical suburban space. Hence, we use the temporary revitalisation and activation of the "Parkhaus Marktplatz" through the "Base Camp: Vadozner Huus" (BC : VH) project as a case study to answer the following research question: How can the perceptionoriented perspective of everyday landscapes be implemented into the institutionalised processes of conceptual landscapes in Liechtenstein? We will do this by focusing on three perspectives: (1) actors, (2) process, and (3) programme items. We follow the Urban Living Labs (ULL) approach as an applied research method through which the everyday landscapes of the population can be integrated into a standardised planning process. We conceive that ULLs can complement institutionalised processes and instruments of spatial planning (conceptual landscapes) with an experimental and collaborative approach to solve planning challenges such as the one we will describe in the following section

\section{CASE STUDY "PARKHAUS MARKTPLATZ" VADUZ}

Vaduz is the capital of the Principality of Liechtenstein with around 5,600 inhabitants (Amt für Statistik 2020) and is one of the central places in the polycentric region of the Alpine Rhine Valley. Liechtenstein is a centre of the finance industry, where this sector has developed very dynamically since the 1960s. In Vaduz in particular numerous banks and fiduciary offices have been established and with the public service sector also mainly situated in Vaduz, the number of employees is twice as high as the number of residents (Agglomeration WerdenbergLiechtenstein 2016). The numerous structural and economic changes in the centre of Vaduz have led the municipality to start a development process for the town centre in 2017 and in spring 2018 the Vaduz municipal council agreed on the strategy paper.

Two starting projects were defined to implement the strategy, which should provide new stimuli for Vaduz. On the one hand, the strategy identifies that there is a lack of lively meeting places for the community in the centre of Vaduz. The idea of a multifunctional building-the so-called "Vadozner Huus ( $\mathrm{VH})$ " - was established to function as a meeting point for various user groups in the future, but it is unclear what it is supposed to be. On the other hand, the originally multibut now mono-functional parking garage "Parkhaus Marktplatz" was defined as a new experimental development ground called Raum.Lab - to become the "hub of the centre development" (Gemeinde Vaduz 2018), since it connects the centre of Vaduz with the event hall and the elementary school. The municipality of Vaduz approached the University of Liechtenstein looking for a cooperation to establish a new and unconventional planning approach to integrate the two starting projects, the "Raum.Lab Parkhaus Marktplatz" and the 
"Vadzoner Huus", in one temporary project called "Basecamp : Vadozner Huus" (BC : $\mathrm{VH})$. With the "Basecamp (BC)", a mobile shipping container upcycled by students which is suitable as a temporary setting for an Urban Living Lab, the university provided the hardware for this cooperation. With the Basecamp as hardware, the multi-story parking garage was re-interpreted as a temporary meeting point for the population of Vaduz, through which ideas about the future future shape and functionalities of a "Vadozner Huus" could be gained.

The process of the $\mathrm{BC}$ : $\mathrm{VH}$ was designed as an "Urban Living Lab" by a transdisciplinary team (the project group) from the University of Liechtenstein and the municipality of Vaduz, together with the private spatial planning office "stadtland" and the startup platform "Ideenkanal". The cooperation began in spring 2019, and the BC: VH was installed from September 12 to 28, 2019, on the deck of the parking garage featuring 40 programme items, all of which were developed by the project group together with institutions and individuals situated in Vaduz. For answering the research question, the conceptual landscape is represented by the procedure of how the $\mathrm{BC}$ : $\mathrm{VH}$ was derived from the town centre development process, corresponding as it does to the usual planning logic of analysis-strategy-implementation of measures. The perspective of the everyday landscape is represented by the experimental and participatory process, which tests the requirements a future Vadozner Huus or a future development of the marketplace, should have to fulfil for the community. Before the results of the $\mathrm{BC}$ : $\mathrm{VH}$ are presented, the method of the Urban Living Labs is discussed.

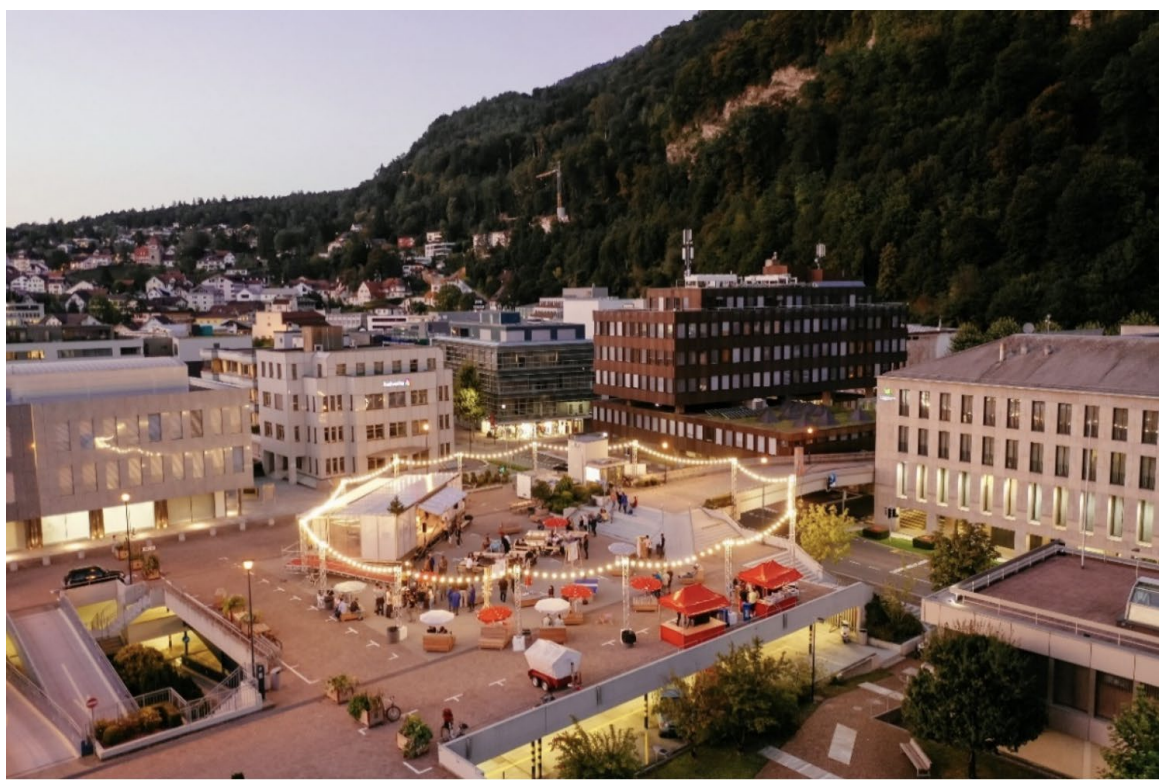

Figure 1. Basecamp : Vadozner Huus situated on the Parkhaus Marktplatz (Photocredit: Hanno Mackowitz) 


\section{URBAN LIVING LABS AS AN APPLIED RESEARCH METHODOLOGY}

Urban living labs (ULL) have emerged from the concept of living labs, which have been established primarily in the IT sector since the beginning of the 1990s (Leminen 2013). The focus of these early Living Labs was on how users experience products and services in their daily life context (Puerari et al. 2018, 3).

From this, living labs were ultimately developed by computer scientists to increasingly orient the design process of new products towards the user perspective instead of the product itself (Puerari et al. 2018). Other living labs, such as the University of Chicago Urban Labs or the Philips Homelab, as well as the Frauenhofer inHaus, have been dealing with questions of sustainability in urban spaces for several years with a technical focus (Franz 2015).

In the last few years, apart from the focus on ecological and economic sustainability challenges and technical solutions, ULLs have increasingly been pursuing questions of social sustainability (Buhr, Federley and Karlsson 2016). Hence, ULLs are complementing a paradigm shift in spatial and urban planning towards a more experimental, incremental, and communicative planning and governance approach (Bulkeley et al. 2016). Despite a general ULL euphoria (Franz 2015), Bulkeley et. al. are critical of their success: "Viewing ULL as part of the shifting governance landscape, a means through which interventions are increasingly pursued in order to realize urban objectives, does not mean that they are all equally successful in realising their aims" (Bulkeley et al. 2016, 15).

Another line of criticism occurs as to whether there is a clear ULL definition and the components of which a ULLS consists (Chronéer, Ståhlbröst and Habibipour 2019). Puerari et al. (2018) refer to sources who see ULLs not only as a methodology but also as an "organization, an environment, a system in itself". ULLs are also sometimes used synonymously with other terms such as "city laboratory", "field lab", or "testing ground" (Steen and van Bueren 2017). Due to this fact, it seems that more studies are dealing with the definition and the components of ULLS than with the results of the labs themselves (Chronéer, Ståhlbröst and Habibipour 2019; Steen and van Bueren 2017; Voytenko et al. 2016).

Despite these inconsistencies, we conceive of ULLs as a research methodology to work on socio-spatial issues, which gained considerable importance since the communicative turn in planning science and practice (Franz 2015).

Many urban living labs do not serve as company- driven technological research environments, but rather as a platform for citizens to participate in city planning (Buhr, Federley and Karlsson 2016).

Due to this change ULLs are increasingly used for participatory processes by cities to deal with urban policy challenges. In this sense, ULLs are defined as follows: "An urban living lab is a local place for innovative solutions that aims to solve urban challenges and contribute to long-term sustainability by actively and openly co-constructing solutions with citizens and other stakeholders" (Chronéer, Ståhlbröst and Habibipour 2019).

With respect to the actor-networks of an ULL, (Leminen, Westerlund and Nyström 2012) state that anyone designing, participating in, or intending to participate in a living lab will benefit from understanding the overall purpose of the living lab and which party drives the network; this understanding helps them to comprehend the characteristics of the living lab and adopt a feasible role within the network (Leminen, Westerlund and Nyström 2012).

For the implementation of ULLs, Leminen, Westerlund and Nyström (2012), Leminen (2013) and Nyström et al. (2014) propose a classification of four driving actors based on different actor-related starting points and motivations: (1) enabler-driven, (2) user-driven, (3) utilizer-driven and (4) provider-driven. Such a differentiation is particularly useful since actors from different societal domains and sectors 
still do not necessarily meet, understand each other, or corporate immediately (Puerari et al. 2018). With respect to this paper, and indeed many other spatial development topics, we see enabler and provider driven ULLs as the relevant ones for the research agenda.

According to Leminen et al. (2012) "enablers" are public actors such as municipalities or regional development organizations as well as NGOs. These actors pursue the goal of achieving social improvements within their field of action. Therefore, the enabler has the biggest interest in promoting the ULL. An enabler-driven ULL is usually dominated by local issues, topics, and challenges, which have been collected and selected by the municipality as part of a development process (Leminen 2013). Universities and other educational institutions as well as private actors can be part of an enabler-driven ULL network.

Provider-driven ULLs are primarily initiated by developer organizations such as universities (Leminen, Westerlund and Nyström 2012). However, it is often difficult for providers to find enablers who support them in implementing the ULL. The primary goal of the provider is to foster progress in research and theory and to identify specific solutions. Here, universities use ULLs to develop new research and teaching methods and generate useful knowledge for the wider network. Therefore, provider-driven ULLs can be built around a single project, while others "have succeeded in establishing themselves as longer-lived innovation platforms" (Leminen, Westerlund and Nyström 2012). Leminen et al. (2016) argue that provider-driven ULLs have the potential to create innovations as they can scale up the activities from an ULL for future strategies based on the defined goals (which go beyond the everyday life experience of users).

One of the foundational principles of ULLS is the concept of co-creation, meaning the collective action of different actors to solve spatial development challenges together with the population. Puerari et al. (2018) differentiate between three different groups that are formally or informally involved in cocreation processes: (1) the core group, which are mainly the initiators of an ULL as well as actors that have a contractual arrangement with the initiators, (2) the inner circle consists of people who are personally connected to someone from the core group and take part in an ULL in a semi-formalised form, (3) the outer circle is the broader public which is either entirely not or at least not directly involved in the ULL process. Even though they are the most relevant group for the success of an ULL, they are mostly challenging to reach (Buhr, Federley and Karlsson 2016).

\section{FINDINGS}

An Urban Living Lab (ULL) approach is used in this study because it provides a theoretical and methodological framework to operationalize the starting projects of the town centre development process of Vaduz and to analyse the findings of the $\mathrm{BC}: \mathrm{VH}$ project. The following results of the $\mathrm{BC}: \mathrm{VH}$ are based on observations and workshops during the project process, participant observations, conducted interviews, and informal conversations during the events in September 2019. They are organised as follows: (1) actors, (2) process, and (3) formats and program.

\subsection{Actors}

Figure 1 is based on the actor model of Steen and van Bueren (2017) with the differentiation of the municipality and its subcontractors as "public actors", the University of Liechtenstein as "knowledge institution", local companies and associations as "private actors", and "users". In the case of the $\mathrm{BC}: \mathrm{VH}$, the main drivers are the municipality of Vaduz-defined as a public actor-and the University of Liechtenstein as a knowledge institution. Therefore, the BC : $\mathrm{VH}$ is a mixture of an enabler and a providerdriven living lab. The other important actors in the core group of the project are the spatial 
planning consultancy bureau "stadtland" and the start-up platform "Ideenkanal" which are subcontractors of the municipality. These four institutions are regarded as the «core group» (following the definition by Puerari et. al. 2018) and «project group» of the $\mathrm{BC}: \mathrm{VH}$.

Figure 2 uses the colour scheme to illustrate which actors had which role. In general, the roles were defined as follows:

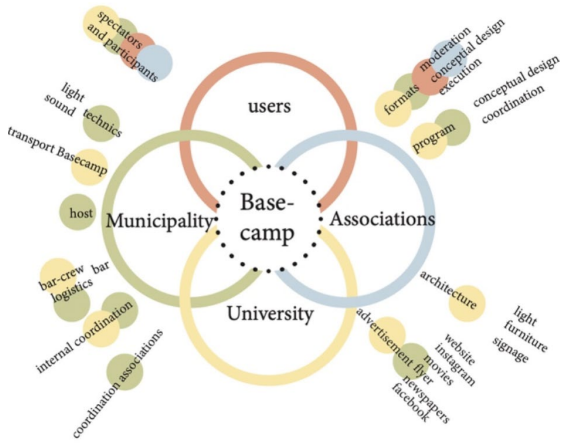

Figure 2. Actors of the Base Camp : Vadozner Huus. Source: (own illustration based on Steen and van Bueren 2017)

- Municipality of Vaduz: impulses and insights for the further planning of a "Vadozner Huus"; reach as many people from Vaduz as possible; - University of Liechtenstein: gaining insights for a research project; greater visibility of the university among the local population in Liechtenstein;

- Stadtland, spatial planning consultancy bureau: collect feedback from the participants in the form of idea cards and set up discussion events about the future center development Vaduz;

- Ideenkanal, entertainment \& host: reach as many visitors as possible.

Despite the seemingly clear division, there were occasional conflicts and disagreements within the project team during the implementation phase of the $\mathrm{BC}$ : $\mathrm{VH}$ due to the implicit and only partially directly expressed difference in interests and motivations. Buhr et al. (2016) and Leminen et al. (2013) defined challenges regarding communication and coordination as well as role definitions. It became obvious during the $\mathrm{BC}$ : $\mathrm{VH}$ project phase, which has shown that the actors who had a closer relation to the municipality identified more with the project.

\subsection{Process}

The aim of the process-oriented framework initiated by the project group was a collaborative and participatory implementation of the $\mathrm{BC}: \mathrm{VH}$ together with the associations and population of Vaduz. The project group structured the main programme, but it had to be flexible enough to integrate ideas and initiatives from the local population. The implicit aim was to incorporate them and change their role from consumers to participants and, in the best case, co-organisers during the event. In the definition of Puerari et al. (2018), the goal is to get the population from the outer circle (= target group) into the inner circle (= co-organisation of individual events), which is presented in Figure 3. Here, the core group and inner circle are combined within the "organisation" frame.

In the context of the Alpine Rhine region and in Vaduz in particular, ULL is an innovative approach. Hence, the BC : VH was initially viewed with scepticism by the local population. Only one feedback arrived

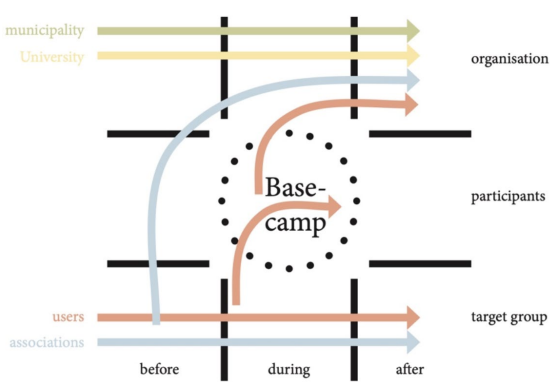

Figure 3. Role of different actors during the process. Source: (Author 2019) 
from the first reach-out to around 50 clubs and associations via e-mail with a request for participation in the $\mathrm{BC}$ : VH three months before the start. It required personal contacts and networks of project team members to mobilise individuals, associations and institutions to participate. Thanks to the contacts and existing networks, it was possible to get fourteen civil society actors to contribute to $\mathrm{BC}$ : $\mathrm{VH}$ beforehand, thereby turning them into co-organizers. The $\mathrm{BC}$ : $\mathrm{VH}$ thus confirmed the observation by Puerari et al. that the motivation to participate in a ULL depends primarily on personal, intangible goals and wishes (Puerari et al. 2018) and that the engagement of the target group cannot be assumed, even though it is about improving their everyday life (Buhr, Federley and Karlsson 2016). The sceptical view of the population was also represented by the fact that only one individual came up with an idea for a discussion during the three weeks in September, even though the project group would have wished for more of these spontaneous initiatives.

Feedback collected towards the end of the events and the completion of the project suggests that more communication and active participation is necessary, should there be a replication of the project. It took some time for the local community to understand the $\mathrm{BC}$ : $\mathrm{VH}$ concept, which eventually led to the reduction of mistrust and misinterpretation of the concept. This makes it evident that the success of an ULL like the $\mathrm{BC}$ : $\mathrm{VH}$ requires a long-term framework with a long-term commitment of the project team (Juujärvi and Pesso 2013). Due to the dependency of ULL projects on funding and political backing, long-term setups and thus the stability of ULLs are rarely achieved (Franz 2015; Voytenko et al. 2016). This insecurity can be observed in Vaduz as well, since the municipal council finally discussed the future of the $\mathrm{BC}: \mathrm{VH}$ in its December 2020 meeting.

\subsection{Programme items and participatory events}

The $\mathrm{BC}$ : VH took place during 17 days in September 2019 in Vaduz with more than 40 programme items. There was only one day without a programme item during these three weeks. The broad spectrum of events ranged from pure entertainment such as music gigs, frontal lectures and talks to discussions that questioned the spatial planning status quo in Vaduz and Liechtenstein. In total, there were 16 events that had a spatial planning or spatial development focus, whereas 24 events had an entertainment focus.

In the context of this research, the events are further distinguished between vertical, participative and horizontal events. Vertical events are characterised by a one-sided communication by one or two people with a largely passive audience. Participatory events were moderated but invited the visitors to participate and discuss.

Examples included meeting of the location marketing agency of Vaduz and the jam session by the local youth organization. Horizontal events were moderated but everyone at the event had the possibility to join in. The emphasis of the horizontal events was on celebrating and exchanging ideas. The kick-off and closing events were content-oriented ones (see Figure 4).

The fact that eight horizontal events had a content focus, meaning spatial development topics were on the agenda, represents the idea of the $\mathrm{BC}: \mathrm{VH}$, which allows to discuss the spatial development of Vaduz in a collaborative but also joyful manner. The six vertical content programme items were mostly lectures of the University of Liechtenstein, which took place in the BC : $\mathrm{VH}$ and were free for the public to join. Naturally, most of the entertainment events were vertically organised, such as concerts or readings. The number of people who visited the events ranged quite broadly. 


\section{vertical}

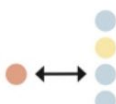

walking lecture reading

concert

theater

\author{
workshop \\ panel discussion \\ public municipality meeting \\ meeting of local marketing group
}

\section{participative}

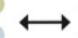

horizontal

opening ceremony

closing discussion

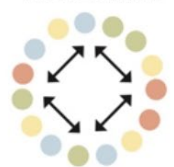

Jam-Session

powerpoint-karaoke

Figure 4. Description of the quality of the programme items. Source: (Author 2019)

One lecture was visited by no one, whereas the (free) concerts drew an audience of around 50 to 200 people. Even some of the spatial development programme items drew audiences of around 30 to 50 people, mainly depending on the weekday and how much the topic is in discussion in the municipality in general.

During the process, it became obvious that such a colourful mix of events was necessary. The strategy was to make the space more attractive to as broad of a section of the population as possible and involve them in other formats and contents. The combination of content and entertainment created a friendly and stimulating atmosphere, but at the same time, it was possible to discuss very complex planning related issues of Vaduz and Liechtenstein. Therefore, people who, according to their statements, do not typically get involved in such spatial development processes took part in the discussion on the future of the Vadozner Huus and Vaduz.

\begin{tabular}{l|rrrr} 
& VERTICAL & PARTICIPATIVE & HORIZONTAL & TOTAL \\
\hline CONTENT & 6 & 2 & 8 & 16 \\
ENTERTAINMENT & 14 & 3 & 7 & 24 \\
TOTAL & $\mathbf{2 0}$ & $\mathbf{5}$ & $\mathbf{1 5}$ & $\mathbf{4 0}$
\end{tabular}

Table 1. Amount and quality of the programme items. Source: (Author 2019) 


\section{LEARNINGS AND CONCLUSION}

To sum up, various insights were gained during the entire $\mathrm{BC}$ : $\mathrm{VH}$ process starting from the first meeting of the project group until the final discussion of the results in the municipal council. Since the planning and building laws in Liechtenstein do not oblige municipalities to include participatory processes during the development of their planning instruments, the inclusion of the everyday landscape of the population into the conceptual landscapes of institutionalized spatial planning depends mainly on the goodwill of the municipal councils. The experimental and collaborative approach of the Basecamp : Vadozner Huus is new in Liechtenstein since usually the measures that are defined in spatial planning strategies involve the building of new infrastructures or the demolition of obsolete structures. The integration of the everyday life perspective and use of the landscape by the local population into the conceptual landscapes is new in Liechtenstein.

Our goal therefore was to use the $\mathrm{BC}$ : $\mathrm{VH}$ as a case study and to analyse the three levels of (1) actors, (2) process, and (3) programme items. From this we were able to derive learnings for the future implementation of such experimental projects.

(1) Actors: The definition of clear roles with resources and duties is as fundamental as the participation of all actors in the meetings of the core group. Also we experienced the difficulty in explaining what the $\mathrm{BC}: \mathrm{VH}$ was supposed to be to various individuals. The target group therefore needs to be informed very early and very clearly. It is necessary to have a clear concept with a clear communication strategy. Clearly "just" the reinterpretation of an in-between space through an upcycled shipping container isn't sufficient to generate a response from the target group

Especially challenging for us as university was the double act of conduction research and helping with the organization and realization of the programme points. It is important not to lose focus of the research question as the results and lesson-learned of ULLs are often difficult to scale or institutionalize (Puerari et al. 2018).

(2) Process: In Liechtenstein it requires an increased commitment and political will to initiate these participatory development processes due to the more relaxed planning regulations. The results of $\mathrm{BC}: \mathrm{VH}$ has shown that transparent communication along the process and beyond is necessary. This is the only way to draw citizens' attention to the project and to commit citizens for long-term engagement. While architectural interventions such as the $\mathrm{BC}$ : VH are useful hardwares, it needs to be integrated into a long term strategy with specific funding and personal resources. This long term orientation is indispensable for a successful translation of ULLs from individual projects to long-term governance structures (Puerari et al. 2018; Voytenko et al. 2016).

(3) Programme items-wise, it can be emphasised that an appropriate programme mix is essential for the success of an ULL, and our differentiation between contententertainment and vertical-participatoryhorizontal can provide a framework for future ULLs. Ultimately, the exact programme definition always depends on the local stakeholders and their opportunities and interests. This requires architectural flexibility that could be certainly be obtained through the upcycled unprogrammed shipping container. About the long-term implementation of ULLs, it should be indicated that the effort and the actual result of co-creation processes with a broad public are often disproportionate to one another (Puerari et al. 2018, 10) Therefore, they are often linked with too high expectations, and this has to be taken into consideration for political actors (ibid. p.13).

To conclude, the results of the $\mathrm{BC}: \mathrm{VH}$ intend to represent scalable learnings that can be used and applied for further projects within the region. Besides, a reinterpretation of the unused space that is parking garage 
"Parkhaus Marktplatz" by activating it through the $\mathrm{BC}$ : VH showed the lack of a consumptionfree, discursive space with urban qualities in Vaduz. The intermediate use of the "Parkhaus Marktplatz" has created a sharp contrast to the centre of Vaduz, which is overloaded with design and commerce. We can therefore identify and conclude with Puerari et. al. (2018), who observe that spatially fixed ULLS can create a narrative about certain places that help reaching the target group. 


\section{REFERENCES}

Agglomeration Werdenberg-Liechtenstein. "Agglomerationsprogramm Siedlung Und Verkehr: Synthesebericht 3. Generation." Buchs, 2016.

Amt für Statistik. "Liechtenstein in Zahlen 2020." Vaduz, 2020.

Buhr, Katarina, Maija Federley, and Anja Karlsson. "Urban Living Labs for Sustainability in Suburbs in Need of Modernization and Social Uplift." Technology Innovation Management Review 6, no. 1 (2016): 27-34.

Bulkeley, Harriet, Lars Coenen, Niki Frantzeskaki, Christian Hartmann, Annica Kronsell, Lindsay Mai, Simon Marvin, Kes McCormick, Frank van Steenbergen, and Yuliya Voytenko Palgan. "Urban Living Labs: Governing Urban Sustainability Transitions." Current Opinion in Environmental Sustainability 22 (2016): 13-17. doi:10.1016/j. cosust.2017.02.003.

Burckhardt, Lucius. Warum Ist Landschaft Schön? Die Spaziergangswissenschaft. 4. Auflage. Edited by Martin Schmitz and Markus Ritter. Berlin: Martin Schmitz Verlag, 2015.

Chronéer, Diana, Anna Ståhlbröst, and Abdolrasoul Habibipour. "Urban Living Labs: Towards an Integrated Understanding of Their Key Components." Technology Innovation Management Review 9, no. 3 (2019): 50-62. doi:10.22215/timreview/1224.

Franz, Yvonne. "Designing Social Living Labs in Urban Research." info 17, no. 4 (2015): 53-66. doi:10.1108/info-01-2015-0008.

Gemeinde Vaduz. "Zentrumsentwicklung Vaduz: Strategie." Vaduz, 2018.

Hauser, Susanne, and Christa Kamleithner. Ästhetik der Agglomeration. Zwischenstadt 8. Wuppertal: Müller + Busmann, 2006.
Leminen, Seppo. "Coordination and Participation in Living Lab Networks." Technology Innovation Management Review, 2013, 5-14.

Leminen, Seppo, Anna-Greta Nyström, Mika Westerlund, and Mika J. Kortelainen. "The Effect of Network Structure on Radical Innovation in Living Labs." Journal of Business \& Industrial Marketing 31, no. 6 (2016): 743-57. doi:10.1108/JBIM-102012-0179.

Leminen, Seppo, Mika Westerlund, and Anna-Greta Nyström. "Living Labs as Open-Innovation Networks." Technology Innovation Management Review, 2012, 6-11.

Nyström, Anna-Greta, Seppo Leminen, Mika Westerlund, and Mika Kortelainen. "Actor Roles and Role Patterns Influencing Innovation in Living Labs." Industrial Marketing Management 43, no. 3 (2014): 483-95. doi:10.1016/j. indmarman.2013.12.016.

Prominski, Martin. Landschaft Entwerfen: Zur Theorie Aktueller Landschaftsarchitektur. Dietrich Reimer Verlag, 2004.

Puerari, Emma, Jotte de Koning, Timo von Wirth, Philip Karré, Ingrid Mulder, and Derk Loorbach. "Co-Creation Dynamics in Urban Living Labs." Sustainability 10, no. 6 (2018): 1893. doi:10.3390/su10061893. Schenk, Winfried, ed. Suburbane Räume Als Kulturlandschaften. Forschungsund Sitzungsberichte der ARL Bd. 236. Hannover: Akademie für Raumforschung und Landesplanung, 2012.

Sieverts, Thomas. Zwischenstadt: Zwischen Ort Und Welt, Raum Und Zeit, Stadt Und Land. 1997. 3., verb. und um ein Nachw. erg. Aufl., 4., unveränd. Nachdr. BauweltFundamente Stadtplanung/Urbanistik 118. Gütersloh, Basel: Bauverl; Birkhäuser, 2013.

Sieverts, Thomas, Bernhard Koch, Ursula Stein, and Michael Steinbusch. Zwischenstadt - Inzwischen Stadt? Entdecken, Begreifen, Verändern; Eine Collage Auf Der Basis Von Texten Aus Dem Forschungsprojekt 
"Mitten Am Rand - Zwischenstadt. Zur Qualifizierung Der Verstädterten Landschaft". Edited by Thomas Sieverts. Zwischenstadt Querschnittsband. Wuppertal: Müller + Busmann, 2005.

Steen, Kris, and Ellen van Bueren. "The Defining Characteristics of Urban Living Labs." Technology Innovation Management Review 7, no. 7 (2017): 21-33.

Steen, Kris, and Ellen van Bueren. "Urban Living Labs: A Living Lab Way of Working." Amsterdam, 2017.

Voytenko, Yuliya, Kes McCormick, James Evans, and Gabriele Schliwa. "Urban Living Labs for Sustainability and Low Carbon Cities in Europe: Towards a Research Agenda." Journal of Cleaner Production 123 (2016): 45-54. doi:10.1016/j. jclepro.2015.08.053. 


\title{
PAPER \#2.15
}

\section{SEVILLA 1910, THE MOTION OF CENSURE AGAINST THE ARCHITECTURAL STYLE ART NOVEAU. PERPETUATING AND CONTROLLING THE NARRATIVE OF THE SYMBOLIC CITY IN THE MODERN ERA}

\author{
Reyes Abad Flores ${ }^{a}$ \\ anniversidad de Sevilla, Sevilla, España
}

\section{ABSTRACT}

In the early years of the 20th century, Seville is still stuck in an economic, social and urban crisis. The idea of celebrating an international exhibition (EIA 1929) was then perceived as an impulse for a needed urban renovation. In despite of the real necessities (new infrastructures, architectural restoration, public sanitation system,...) the intellectual elite would raise the question of the identity and the rehabilitation of the memory, a motor for the city image transformation but also an effort to recapture the greatness of past eras.

In those days, the art nouveau was a reality in Seville and a few private buildings were built following the rules of this new style, the taste of European modernity. In 1910, a conservative municipal councilor, Francisco Javier de Lepe y Quesada, filed a no-confidence motion against the new architecture that could be considered a threat to the local identity. The approval of this motion can be considered the beginning of a permanent conflict between modernity and tradition in the urban landscape of Seville as well as a popular subject of discussion along the years.

\section{KEYWORDS}

Urban design; architecture; modern era; symbolic city; Sevilla; motion of censure.

\section{INTRODUCTION}

Kevin Lynch (1918-1984) spearheaded the approach of the different elements that comprise the city image, highlighting the perception of space as a result of the symbolic interaction between individuals from certain physical-structural features, a broadly developed concept in his work The Image of the City (Lynch 1966).

We draw on the premise that every city is the result of a first settlement and the collective and progressive need to formalise a project, these strident efforts, in the words of Edward Ludwing Glaeser make the city human beings' greatest achievements (Ludwing Glaeser 2011). The materialisation of this flattering habitat transcends the architectural and urban structure to develop a system of values, attitudes, relationships and behaviour, in short, a culture. Thereafter, our "major success" story shall take on different nuances.

Concurrently to the formal consolidation of every city, social, economic and cultural objectives begin to be designed and therefore, to draw a real yet similarly ideal image of what it aspires to be. This is expressed through architecture, art and other practices that shape and swell the collective imagination, namely identity. The creation, consolidation and destruction of the urban landscape is the result of this process of correspondence between an environment and social identification. The image of the city as aesthetic production is the result the entire scope, advances and desires that drive said urban project ${ }^{1}$. 
The symbol, such as urban brand, monument, clothing, building or urban party, fulfils that dual function of expressing (our desires) and representing (what we are). The aesthetic intent is simultaneous to the collective definition, colours the city as a human creation from certain semantic elements that remain over time and outlive its syntactic transformations (Aldo Rossi 2015).

It can be affirmed that marking symbolically is simultaneous to the act of occupying, an especially complex phenomenon in the case of the cities of Christian re-foundation, as is the case of Seville, from the thirteenth century onwards. Formal recycling is the basis of this model of symbolic urban development, the semanticsation of what has been bequeathed as a supply of identity, a period of abhorrence of that image and the new unit of power. The prevalence of symbols and meanings over the centuries embodies the need for memory and awareness beyond formal development and transformation. The motion of censure passed in 1910 against the modernist style is nothing other than the result of a construction of the image of Seville over time, of the importance of preserving / recovering certain foundational values and controlling the narrative in an attempt to forge an urban renaissance.

\section{HISTORICAL BACKGROUND}

\subsection{Construction of the symbolic city. From the Christian Reconquest to the Renaissance: enshrinement, utopia and power}

In 1248 , Isbiliya is a walled and inhospitable city with striking contrasts between the compactness of the monumental area, port and administrative centre in the face of large urban intramural and suburban voids. The two main aims following the process of the Christian Reconquest would be on the one hand, the distribution and occupation of that vast area and on the other, the enshrinement of a space marked by everyday life forms and the preceding religion through the suppression and superposition of labels and meanings.

The theophanisation or enshrinement of space would consist of the systematic mixing of the everyday and the extraordinary, a priority and synchronous act to the rebirth of the city. The great gaps would be the catalyst element of the convent city, extraordinary architectures that, together with other urban brands, embody strategies for qualification or symbolic control of space (López Lloret 2004, 83).

The innovation carried out in the design and narrative control of the city during the thirteenth to fifteenth centuries was effective and steadfast, though the definitive symbolic consolidation would arise in the sixteenth century thanks to the status acquired as the main port and institutional headquarters of Trade with the Indies. The enshrinement of space, based on a pedagogical iconography will be exported to America, a key strategy in the shaping of the Hispanic-Baroque identity. While Seville wins in terms of monumentality, milestones such as the body of bells of the Giralda, universal symbol of Seville, the House of Contracting (Casa de la Contratación) (1503), the Mint (la Casa de la Moneda), the Merchant's Market (1572) and Customs' Office (Aduana) (1587) are built in this period to create a capital, while the city lacked sound infrastructure, sewerage, water systems. Together with the monumentality, the development of the urban festivals will be a fundamental tool of semanticisation. Acting as social binders, symbolism and artificiality comprise a complex machinery that activates the urban scene.

\subsection{Consolidation of the city of virtue. Economic downturn, urban planning and spirit during the Baroque period}

After the heyday of the sixteenth century, in the seventeenth there is a decrease in traffic with the Indies, a commercial decline 
brought about by the corruption of a system that did not create sturdy economic pillars. The urban layout unveils few changes, but the city evolves significantly in aesthetic issues, with the development of a more narrative and ornamental architecture, the façades experience an innovation towards the embellishment that is consolidated in the Baroque. Precisely, the Baroque artifice finds its maximum expression with the urban festival. The ephemeral transmutation of public space equals total control over the city, a domain of its space and time. In this new established order of celebration, art and architecture, the city is an indispensable support of the symbolic. At the end of the 17th century, Seville is two cities in symbiosis, the real and the ideal. The shortfall of, or almost fleeing from, modernisation of infrastructure is compensated by the progress towards realism and plasticity. Architecture, decorative arts and festivities place the onus on the concept of city-objet d'art. Baroque masquerades constitute the culmination of the urban festivals, merging allegories, classical culture and baroque essence. Arranged and consumed by all groups and social groups the masquerade was a practice of total art: public space, ephemeral architecture, theatre, poetry, painting, spectators... Society representing itself, its weaknesses and ideals. The grandeur of a collective spirit through urbanism and architecture represents the evolution and permanence of its own natural order, an invention.

"It does not seem that he has wanted to reduce these kingdoms to a republic of enchanted men who live outside a natural order" (Bonet Correa, 1990, 14)

Finally, with the transfer of the Casa de la Contratación to Cadiz in 1717 and the Free Trade Agreement of 1765, Seville became bereft of its position and privilege. In spite of everything, the city maintained an aura, and an incomparable, decadent beauty. At that time, the city's grandeur was measured by its good order and operation above size or census, the ideal model was clearly the medium-sized city (Fortea Pérez, 2009, 115). The medium-sized city was easier to control and order politically, socially and aesthetically. This model was known in Europe as a city of virtue that symbolised moralising and exemplary values, urban planning measures whose rituals were continually updated.

Unable to combine tradition and modernity, Seville shifts within the European context and throws itself into its role as a city of virtue. The chosen destination of the nobility, selffulfilment would come with the brief transfer of the royal court of Felipe $V$ and Isabel de Farnesio to the city of Seville between 1729 and 1733. This perpetuation of the symbolic function of Seville repeated the same patterns of the process of urban enshrinement although with a semantic turn towards the courtly playfulness.

"Like all devotion, monarchical fervour is an acquired essence, the result of education and a carefully preserved tradition and transmitted generation after generation" (Aguilar Piñal 1989, 17)

\subsection{From the Enlightenment to Romanticism. Progress, functionality and idealisation}

Despite the consolidation of symbolic urbanism, Seville would not remain impervious to European influences and at the end of the 18th century a plan of interior reform was designed adapting the illustrated ideals of functionality, namely through Municipal Assistant Pablo de Olavide (1767-1778)2. At the same time, Seville adopts the municipal ordinances of Madrid that allowed for the academic world to participate in urban issues (Ollero Lobato 2005, 113-124). From 1780 
onwards, the Royal Academy of San Fernando assumes control over the professional organisation and imposes the classic taste against the backdrop of artisan baroque. In the façades the new principles of rationality, proportion and order are applied, equivalent to greater regularity and symmetry of the urban layout (Pérez Gálvez 2004, 20-23).

Within this context, the ideal of the common good arises, also applied to urban design. As a symbolic capital, it becomes a strategic aim of the Napoleonic army. In this very short period of occupation (1810-1812) the urban image breaks down considerably. Demolitions and selective usurpations of residential and religious buildings occur. The appropriation and transformation of these landmarks of the old political-religious order is that of those most significant symbols of society and its culture.

This process of modernisation through the desecration of symbolic spaces parallels the plundering of artworks. The contemporary perception of the past will hinge upon this desecration, the ransacking of the baroque landscape will leave an important void in the memory whose reaction will be displayed in the subsequent development of romantic picturesqueness and costumbrismo.

In the mid-nineteenth century, the modernisation of Seville continues in terms of sanitation, opening and communications system following the industrialising dream. "The fragmentation of the apple" in the words of Juan Luis Trillo de Leyva would lead to the reorganisation of the social space and the reconceptualisation of the urban image (Trillo de Leyva 1991). The aims: the demolition of doors and walls, interior refurbishments to improve the conditions of habitability and communications within the walls, as well as the implementation of the railway system. Under Isabel II (1833-1868), Seville once again positions itself within the national context and benefits from the historical link with the monarchy. In these years, and fleeing from the 1848 revolution in France, the Dukes of Monstpensier, Prince Antonio de Orleans and
María Luisa Fernanda de Borbón settle in Seville.

The disintegration of the symbolic city continues in this period, the purpose of a forceful physical transformation, aggressive and without clear planning. The need to protect memory leads to the Monuments Commission coming into being in 1844. On the other hand, in 1876 the Law of Expansion prevented growth outside the walls, thus prioritising internal problems and advocating internal enlargements, at the cost of further demolition. To compensate for this physical lack of memory, abstract references and picturesqueness are consolidated through new festivities and artistic displays. Seville becomes increasing comparable to the city Maurilia (Calvino 2007, 18), almost a fiction.

"The festivities recreate in the symbolic field the characteristics of a society, while bolstering them, given their emotional effects on the participants" (Núñez Roldán 2007, 237)

The integration of the new ideals of bourgeois urbanism is accompanied by the recovery of the symbols and landmarks of the past. The Dukes of Montpensier had enjoyed a significant impact on the image of nineteenthcentury Seville beyond the architectural and urban legacy. Faced with the modernisation under Isabel II, the patronage of the Montpensier involves recovery of traditions after a long period of secularisation, fostering the reconstruction of a city image based on clichés.

Seville, destination de rigueur for European romantic travellers, abuses that picturesque and idealised reduction of itself. The traumatic redevelopment strategies throughout the nineteenth century finally undermined the society that adopted the values of regional traditions, easily digestible, compatible with the collective spirit. Stereotyped reduction as post-traumatic therapy is strongly linked to the origin of this contemporary struggle between progress and tradition, architecture 
and urbanism, and therefore, to the image of the city.

\subsection{Regionalist thinking and the image of the city. Seville in the twentieth century, the Ibero- American Exhibition}

In this first third of the twentieth century, during the Bourbon Restoration the project and holding of the Ibero-American Exhibition of Seville in 1929 appears, the first major attempt at urban expansion and renewal of Seville's image. The Spanish socioeconomic map shows a polarisation between industrialised regions and those with an economy based on large farmsteads governed by the nobility and the new bourgeoisie. In a general sense, the south-southwest half predominates the old landowner aristocracy and the burgeoning wealthy middle-class.

In this polarised context, various ideological movements arise that find their aesthetic correspondence in the form of avant-garde, regionalism, customs, etc. The different struggles between traditionalist and regenerationist factions will accentuate political and ideological polarisation, fragmenting the identity issue. This identity debate will directly influence architecture and urban design. In Seville, the regionalist movement will prevail as an ideological current, as the official style of the future Ibero-American Exhibition (hereinafter, IAE) and urban renewal.

While the north is attracted to Europeanism, in the south, folklore roots that give rise to a particular region reign triumphant (Villar Movellán 2010, 20-21); a folklore that seeks to distance itself from picturesqueness. The regionalist movement promotes awareness of historical wealth to address the future. This injection of self-confidence will boost the project of the future IAE. It was about renewing the alliance between utopia and reality using architecture as a vehicle, through symbols that condense the Sevillian identity and its essence. The city of virtue journey is now the city of grace, primed for the great exhibition.
While the city suffers from poor political management, regionalist architecture emerges reminiscent of a glorious past, using a language of eclecticism; the architectural expressiveness boosts the imagination, the conscience and the reinforcement of the identity in the same way as the Baroque, in the semantic unity in the marvellous reality. The façades condense this symbolic enthusiasm; architecture and urban planning champion the challenge of recovering the collective spirit and therefore, greatness as a city.

Paragraphs immediately following their headings must be justified on both sides with no indents for first lines. The document should use single-line spacing throughout.

\section{THE 1910 CENSURE OF THE MODERNIST STYLE}

Seville had been preparing for the IAE from 1910 onwards when the Executive Committee announced the tender of projects for the site. If during the embryonic stage the local architects had experimented simultaneously with regionalism and other styles of European influence, as of July 1910 there is a fact that will limit the integration of elements outside the Sevillian spirit, considered as a threat, as a desecration of collective memory.

Following European trends, young graduates in Madrid and Barcelona would import the modernist style. In Spain, this trend prospered mainly in the industrialised areas, Levante and Catalonia, where it reached high levels of sophistication. In Seville, a group of architects such as Aníbal González, José Gómez Millán, Simón Barris and José Espiau and Muñoz integrated this current into housing devised for the upper bourgeoisie, in the case of the celebrated and well-preserved Juan de Haro's family house in Tomás de Ibarra St. (S. Barris,1904-1905), the house of Simón Barris y Bes in Luis Montoto St. (S. Barris 1906) or Laureano Montoto's family house in Alfonso XIII St. (A. González 1905-1906), as well as 
shops and entertainment venues of great popularity, in the case of the disappeared Café de Paris in La Campana (Villar Movellán 1973, 159). Despite the foregoing, the traditionalist ideological support of Regionalism would develop its control tools; the invention of this regionalist compact image clashed with modernism despite its similarities in formal experimentation and use of artisanal resources.

The proposal to reject modernism arises in the municipal administration itself, materializing and consolidating an political idelogy through architecture and art, a pillar of an urban identity and image policy. On July 22, 1910, at the Plenary Session of the City Council, the conservative councillor Francisco Javier de Lepe y Quesada submitted a motion of censorship on the modernist style. The following newspaper El Liberal echoed, stressing the "well-written" motion of the councillor urging the City Council to foster reforms and improvements of residential façades according to the beautification and arrangement of the peculiar and classic model $^{3}$. In his statement, De Lepe y Quesada proposes to agree on a series of measures:

First. To grant municipal rights to the different concepts covered by these reforms, to those who carry them out, by request accompanied by plans deemed admissible.

Second: Distribute cash prizes amongst those homeowners who have made these reforms, deserving special distinction.

For the distribution of these awards the Honourable City Council will issue a detailed Regulation, endorsing the conditions and appointing the examining Jury.

Third: In the offices of the Honourable City Hall a special department will be enabled to process and report the applications submitted for the abovementioned purpose.
Fourth: In said department, the owner who so wishes will be furnished with instructions regarding the nature of the reforms, drawings, models and background necessary to form a judgment of the style in which the decoration elements and façades which must be applied to the houses.

Fifth: The Honourable City Council will ensure that said department is intervened by people who have distinguished themselves in Seville for their artistic knowledge necessary for this purpose and for those architects who can guarantee the success of the endeavours.

Sixth: No application will be processed accompanied by plans that display modernist reforms.

Seventh: This exception regime shall conclude three months before the day the HispanicAmerican Exhibition is inaugurated, since the main aim sought is to ensure the general beautification of the population on the occasion of said Contest ${ }^{4}$

The city council hall was chaired by the Liberal Party. De Lepe followed the theories of Vicente Lampérez, placing the moralising values of architecture above the creative freedom of architects. The censure motion was passed without further debate. The proposed measures would take shape as the regulations of the Contest for the Construction and Refurbishment of a Sevillian Style Dwelling of February 23, 1912, marking the guidelines of the peculiar aesthetic renovation in full contemporaneity.

In this document, the stylistic question and the justification has been reiterated.

Article 4. "Façade" shall be understood for the purposes of this contest, alongside the exterior walls of each farm, the hallway, gate and patio, since these are wholly or partially visible from the street, all of this is what has to serve as a base for beautification and decoration of Sevillian houses from the outside. 
Article 5. The reconstruction, beautification or embellishment of the properties must obey the architectural or decorative orders sanctioned throughout history and in a highly singular manner those characteristic styles of our city during its different epochs.

Article 6. The so-called modernist style is excluded from the contest, and, therefore, applications whose plans and technical reports display such reforms or constructions would be automatically rejected ${ }^{5}$.

Artlcle 17. [...] Requests for reforms in the facades of shops, establishments or factories and $B$ ) requests that, even referring to reforms of a general nature in the facades of houses, are not considered admissible by the Jury or in view of the plans and reports presented.

This instrument of aesthetic control of facades based on a historicist and selfreferential architecture so that regionalism spreads throughout the city, triumphantly homogenizing the image of Seville

The impact of the censure motion highlights the enormous influence of the E.I.A. in the consolidation of the symbolic image of Seville beyond the exhibition project itself, that is, the aesthetic consequences and the urban traces left by this period of enormous expectation at the beginning of the contemporary era.

\subsection{Consequences of the censure motion of the modernist style in design and perception of contemporary architecture in Seville}

The events between 1910 and 1912 certified that the question of urban image transcended the strictly political. The rejection of the integration of new architectural formulas would become increasingly evident and legitimate, moving from urban planning to social and everyday conflict. Society would endorse the issue of the suitability of the contemporary in the public space of Seville, making it a recurring topic until today.

After the censorship of modernism, the rejection would also reach the architecture of the Modern Movement. A paradigmatic case of this future is the project presented in 1925 to erect an American-type skyscraper in the Prado de San Sebastián by the German company Saxen \& Jochem. In the report, the City Council requested a plot of public ownership for the construction of a monumental building (Figure 1) that would become the first skyscraper in Spain ${ }^{6}$. The company insists that the building solved a dual issue, on the one hand, the shortage of middle-class housing, and on the other hand, the lack of accommodation during the IAE. In summary, it offered a functional and adaptive architectural model in a nearby outside walls area to the exhibition grounds (Abad Flores 2017, 179-180).

The president of the Public Works' Commission dismisses the project but does not rule out a change of location. Then begins an administrative journey and a public debate that lasts three years on the suitability of integrating a skyscraper into the landscape. The press would play a decisive role in this debate, giving visibility and disclosure to a topic reveals numerous conflicts, reaffirms certain principles and leads to an examination of municipal conscience.

The design of the skyscraper Mira el Betis dabbled with modern architectural utopia. The Academy of Fine Arts publicly transmits its rejection considering it an affront to the Sevillian style, arguing that it dwarfed the Giralda, seemed vulgar and failed to adapt to local weather conditions. In turn, the newspaper La Unión was in favour and found no drawback to the integration between new city and old city, criticising the obsessive use of a decadent aesthetic, the continuous falsification of architectures and façades and defending renewal in accordance with the times.

\footnotetext{
${ }_{5}^{5}$ Diario El Liberal 27/02/1912, morning edition. Servicio de Hemeroteca, A.H.M.S.

${ }^{6}$ It must be borne in mind that the Telefónica Building designed by Ignacio de Cárdenas and considered the first Spanish skyscraper, it would not begin to be built in Madrid until September 1926
} 


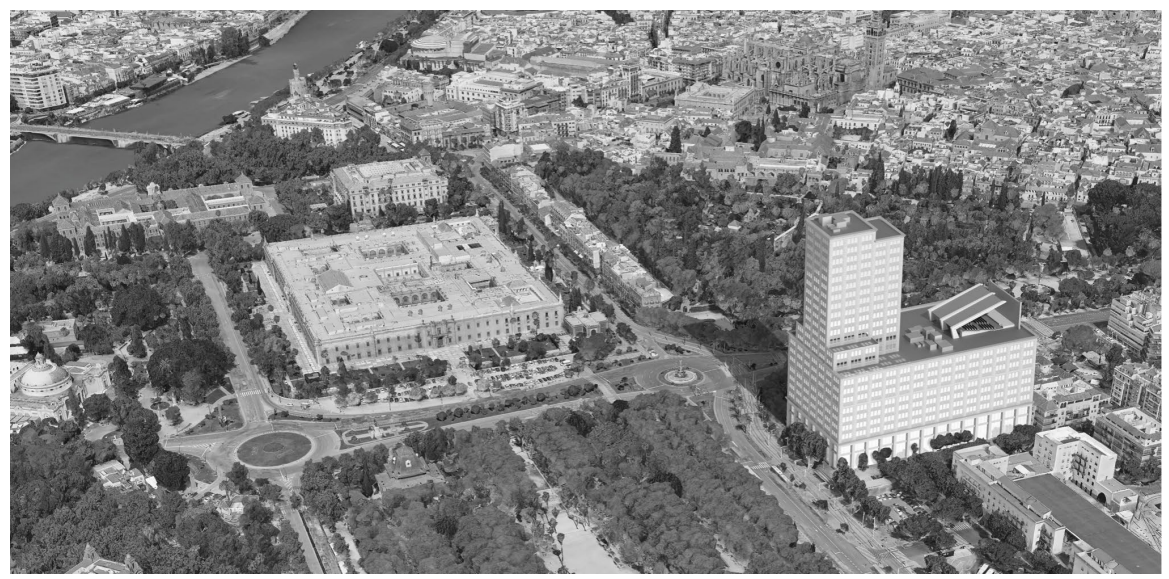

Figura 1. Architectural recreation of project Mira el Betis (Saxen \& Jochem,1925) Image by: Schlomo Goldberg

A skyscraper neighbourhood may be a heresy for the council meeting at the Academy of Fine Arts; but it would have the characteristic of a fool proof measure for the solution of the housing problem (Diario La Unión, 07/05/1925) 7 .

The imposition of regionalist aesthetics thus develops chronologically between the censorship of modernism and the denial of rationalism. Shortly after, having overcome the major social debate of the skyscraper, the City of Seville would appropriate the rationale of Saxen \& Jochem, publicly auctioning the land at the Prado de San Sebastián and developing the Housing Development Plan for the IAE that allowed for several convertible hotels to be built in households. The America Palace hotel stands on those requested grounds, once one of the tallest residential buildings in Seville, with a functional interior design and a regionalist style façade. For the rest of the hotels, freedom of style is granted, as the adaptability and familiarity of the tourist is deemed fundamental. Somehow, it was clear that the ideal city had to surrender in certain matters to the actual city and the present stateof-play.
Yet, in the evolution of cities the determining factors vary and although the rejection of certain architectural forms continues to occur, the chances of survival of regionalism are reduced due to high production and maintenance costs resulting from the ornamental profusion and the diversity of artisanal materials and resources. Its essence would remain as a reinvention symbol of a city at a time of great aspirations. The resounding failure of the IAE would drag, in later decades, dreams and much of the monumental footprint. At the same time, minor disputes arose around the integration of certain architectural designs, as happens in 1938 with the rationalist building Cabo Persianas by Gabriel Lupiáñez in the Plaza de la Magdalena, which the City Council accused of breaking the harmony of the environment, subsequently avoiding the construction of a similar building in the environs of the Archivo de Indias (Fernández Salinas 1992, 265-267). During the previous and contemporary years of Developmentalism, the aesthetic debate is blurred. The city, which continues to show a centripetal dynamic, succumbs to speculation, demolitions of historic buildings 
and the lifting of functional architectures. The adaptation of the General Urban Planning Plan of 1946 (hereinafter, PGOU) had as its direct reference the first General Urban Planning Plan of Madrid, written by Pedro Bidagor Lasarte (1939-1946), adapted by Alfonso Toro Buiza and Juan Delgado (ibídem 69), focused on urban reorganisation by areas of specialist use. The housing block is standardised, and Seville is compacted even further. The language of styles and the defence of an idealised image of the first half files of the 20th century disappears.

The advance of contemporaneity will not prevent the social debate from being reactivated from time to time as part of the necessary permanence of the rite, the values and uses of a city and its collective throughout the centuries. Already in the 21 st century, the raising the Seville Tower (Torre Sevilla) (20072015) by the architect César Pelli, hoists the conflict to hitherto unsuspected limits. The political opposition even requested that Unesco review the declaration of World Heritage should the project come into being. The Metropol Parasol by Jürgen Mayer (2005-2011) in the heart of the city also generates a sound political and social debate both in terms of dimensions and avant-garde design. However, the most conflicting case will be the Library of the University of Seville designed by Zaha Hadid in the Prado de San Sebastián park. Since its approval in 2006, the project receives criticism from a sector of the population and revives the debate about aesthetic appropriateness. With the works halted by judicial order, the building was definitively dismantled in 2012 following the ruling of the Superior Court of Justice of Andalusia for considering that the project went against what was established in the PGOU of 2006 that declared the Prado de San Sebastián a green zone, thus ascertaining the perfect argument.

\section{CONCLUSION}

The 1910 Censure Motion of the modernist style, the 1912 Casa Sevillanas Façade Contest and the Mira el Betis project in 1925 is an extraordinary case of control in the configuration of the city image and guarantees the continuity of the traditional symbolic function, the aesthetic will over any other urban issue. The level of sophistication in semanticisation strategies contrasts with the poor development of urban infrastructure and domestic architecture within the context of the city of virtue. The regionalist-modernist conflict is the product of an ideological construction that uses political instruments and the support of a determinant sector of society. The legitimisation of the traditionmodernity conflict and the rejection of the integration of architectural movements of international influence would not prevent regionalist architecture from behaving as an experimental and temporary movement. Solely in a symbolically representative city of identity values does the aesthetic issue acquire a social dimension, on the other hand, said reduction of the urban environment leads to deficiencies such as the innovation of constructive models, derived from architectural design issues adapted to new usage needs and the influence on social perception of architecture and contemporary urban planning. 


\section{REFERENCES}

Abad Flores, R.: Integración y desintegración del patrimonio contemporáneo en Sevilla. Tesis doctoral Universidad de Sevilla, 2017

Aguilar Piñal, F. 1989: Historia de Sevilla, siglo XVIII. Sevilla: Servicio de Publicaciones Universidad de Sevilla

Bonet Correa, J.M. 1990. Fiesta, poder y arquitectura. Madrid: Ed. Akal.

Calvino, I. 2007: Las ciudades invisibles. Madrid: Ed. Siruela.

Fernández Salinas, V., 1992, La reforma interior de Sevilla 1940-1959. Sevilla: Secretariado de Publicaciones de la Universidad de Sevilla.

Fortea Pérez, J.I.: La ciudad y el fenómeno urbano en el mundo moderno: España en su entorno europeo, Anuario IEHS 24 (2009), pp. 111-142.

López Lloret, J., 2004. La ciudad construida. Sevilla, Servicio de Archivo y Publicaciones de la Diputación de Sevilla.

Luswing Glaeser, E. 2011. El triunfo de las ciudades. Madrid: Ed. Taurus.

Lynch, K., 1966. La imagen de la ciudad. Buenos Aires, Ed. Infinito.

Núñez Roldán, F. 2007: Ocio y vida cotidiana en el mundo hispánico en la Edad Moderna. Sevilla: Ollero Lobato, F.: Arquitectura doméstica en Sevilla durante la segunda mitad del Siglo XVIII, Revista de Historia del Arte Atrio 10/11 (2005), pp. 113-124

Secretariado de Publicaciones de la Universidad de Sevilla.

Pérez Gálvez, F:: Las obras de fábrica en la arquitectura doméstica sevillana de los siglos XVIII y XIX. Características constructivas y parámetros resistentes. Tesis doctoral, Universidad de Sevilla, 2004.

Rossi, A., 2010. La arquitectura de la ciudad. Barcelona: Ed. Gustavo Gili.

Trillo de Leyva, J.L. 1991. Sevilla, la fragmentación de la manzana. Sevilla: Ed. Universidad de Sevilla.
Vicens Vives, J. 1972: Una aproximación a la historia de España. Madrid: Ed. Vicens Vives

Villar Movellán, A. 2010: La arquitectura del Regionalismo en Sevilla 1900-1935, 2a edición revisada. Sevilla: Diputación de Sevilla, Área de Cultura e Identidad. Servicio de Archivo y Publicaciones.

Villar Movellán, A. 1973: Arquitectura del Modernismo en Sevilla. Sevilla: Diputación de Sevilla. 
PAPER \#2.16

\section{URBAN LANDSCAPES IN BERLIN SHAPED THROUGH CULTURAL DIVERSITY}

Sigrun Prahla

aUniversity of Applied Science, Krefeld, Germany

\section{ABSTRACT}

Since decades immigrants from Arabic countries have come to Germany and they have changed the appearance, culture and urban experience in cities and neighbourhoods in a significant way. There are certain neighbourhoods like Kreuzberg, Wedding and Neukölln in Berlin that have gained a new identity through the mix and interchange of people with different backgrounds intermixed with the local population.

This is visible in the context of urban space. There are three main topics that will be analysed within this context: Small family businesses and their impact on their surrounding space; form and use of public space; and significant architecture types like mosques and their role for urban space.

Small scale family businesses shape many streets, they convey a certain array of goods and services within their neighbourhood. Arabic migrants have changed the face and the cultural characteristics of roads and places in the living environment; green areas and parks now experience a certain type of use. The public space also serves as a place for small and informal trade. Mosques as centres of the religious, cultural and social life have first been accommodated in backyards or cellars of the quarters with a high number of Muslim inhabitants. In recent years several mosques have been built along the streets, they are visible and they have a significant impact on the streets and on the surrounding neighbourhood. The local culture and the heritage of the immigrants, indications and traces found in the public area, their affiliation and memory shapes and changes urban space, public life and everyday culture in Berlin.

\section{KEYWORDS}

Berlin; informal use; local memory; public space; everyday culture.

\section{INTRODUCTION}

Islamic culture is present in everyday life in Germany, especially in its capital, Berlin. The Islamic everyday culture and how it shapes and changes urban space and public life in Berlin is the focal point of this paper. It is based on empiric data collection and critical observation in three distinct neighbourhoods, that have a big Islamic population: Kreuzberg, Neukölln and Wedding. Everyday culture ("Alltagskultur") presents a contemporary and highly respected viewpoint in nowadays German research. Our lives, chances, aspirations, our culture are at least as much influenced by our everyday lives as by our historic sites if not more.

This paper investigates the three main streets of three distinct neighbourhoods, shows how the Islamic culture shapes the street life, the small businesses, a new type of architecture in Germany, the mosque and its presence on the street. An additional focus is the life in the public parks and public spaces in the warmer seasons.

Therefore this topic of Islamic life and heritage in Berlin can show a very important contemporary aspect. This bottomup method also presents a new and contemporary approach to the research of Islamic culture and public space. 
1. ARCHITECTURAL APPEARANCE OF BERLIN AND ITS THREE "IMMIGRANT" NEIGHBOURHOODS

Berlin is the capital of Germany and at the same time one of the sixteen German states. Geographically it is embedded in the European glacier plains and influenced by a temperate seasonal climate. Generally speaking the city is recognised for its contemporary art, diverse architecture, scientific research and for a high quality of living due to a multicultural atmosphere and to moderate cost of living.

With a population of 3.4 million people, Berlin also is Germany's largest city located in the centre of the Berlin-Brandenburg metropolitan area, which is comprised of 5 million people. $13,9 \%$ are from over 190 nations. The largest group of foreign nationals are from Turkey $(111,285)$. Large numbers of Turks, but also Greeks and Italians originally came as "guest workers" in the 1960s. Today many citizens with foreign roots are second or third generation "migrants", a large number of them have adopted the German nationality or have double citizenship.

Most ethnic groups in Berlin live in the three neighbourhoods called Kreuzberg, Neukölln and Wedding, located in the former western part of Berlin. All three neighbourhoods basically have the same urban history. They date back to the Industrial Revolution, which transformed Berlin during the 19th century. The city's economy and population expanded dramatically during that time, and it became the economic centre of Germany. Additional suburbs soon developed and increased the area and population of Berlin. In 1861, outlying suburbs were incorporated into Berlin. In 1871, Berlin became the capital of the newly founded German Empire. Most of the three neighbourhoods investigated here were built during the industrial revolution. This period dates from the end of the German-French war in 1871 to the beginning of the second world war in 1914. During that time, numerous industrial plants and manufacturing businesses were founded in German cities. Berlin grew extensively during this time. Hundreds of thousands of factory workers came from all over the country and from neighbouring European countries to find work. They all had to find housing. New neighbourhoods relatively close to the centre were developed in a grid system during the second half of the 19th century based on an urban planning design from 1862 by James Hobrecht, the so-called Hobrecht Plan for Berlin.

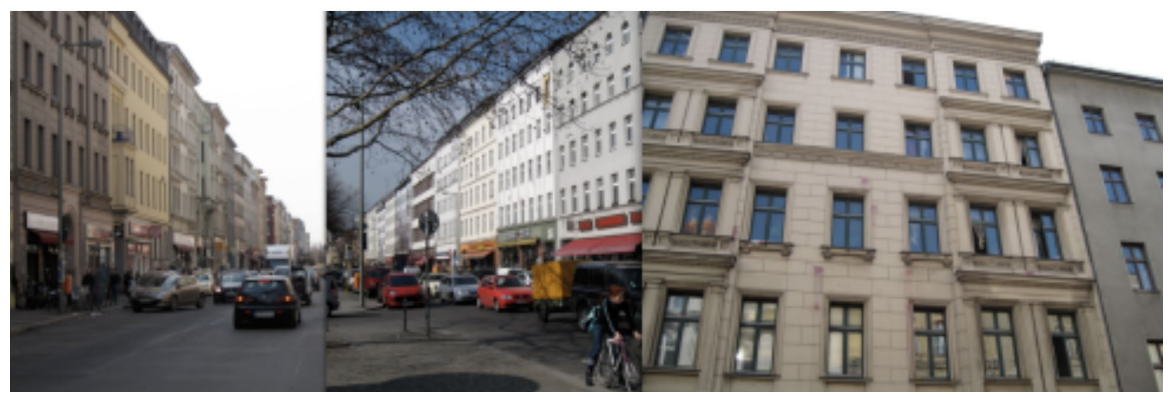

Figure 1. Typical street (Oranienstraße in Kreuzberg) 
With regard to urban planning, the districts form a relatively uniform picture. They are predominantly characterized by five-story, multiple dwelling units in closed blocks, the majority of which date from the turn of the century (1889 to 1905). Due to the long property lots, the blocks are very large and have backyards. Today, they form a nearly homogeneous historic building area. Envisioned as working-class districts, building blocks were composed of tenement houses ("Mietskasernen") with front houses containing larger apartments, and one or more rear buildings with small apartments or industrial lofts in the backyards. The streets were $22 \mathrm{~m}$ wide, the height of the buildings was $22 \mathrm{~m}$. These measurements were designed this way due to fire regulations. If a facade collapsed due to fire it would not destroy the building across the street.

The old buildings still give an impression of the days when the boroughs were part of so-called Steinernes Berlin (Rocky Berlin) as described by author Werner Hegemann in 1930.

\subsection{Kreuzberg}

Kreuzberg has emerged from its history as one of the poorest quarters in Berlin, located south of the centre of Berlin. The borough is known for its very large percentage of immigrants and second-generation immigrants, many of whom are of Turkish ancestry. As of 2006, 31.6\% of Kreuzberg's inhabitants did not have German citizenship. While Kreuzberg thrives on its diverse culture and is still an attractive area for migrants and students, the district is also characterized by high levels of unemployment and some of the lowest average incomes in Berlin.

Far into the 20th century, Kreuzberg was the most populous of Berlin's boroughs even in absolute numbers, with more than 400,000 people, although it was and still is geographically the smallest. As a result, with more than 60,000 people per square kilometre, Kreuzberg had the highest population density in Berlin.

In addition to housing, Kreuzberg was also one centre of Berlin's industry. The so-called export quarter along Ritter Street consisted of many small businesses, and the "press quarter" along Kochstraße was the home of most of Germany's large newspapers.

After World War II, Kreuzberg's housing rents were regulated by law which made investments unattractive. As a result, housing was of low quality, but cheap. Starting in the late 1960s, increasing numbers of students, artists, and immigrants began moving to Kreuzberg. In the eighties, the International Building Exhibition (IBA) was located in Kreuzberg, called "gentle urban renewal" ("Behutsame Stadterneuerung"). Many buildings were renovated and subsidized by the government, so that the rents remained affordable.

Since the fall of the Berlin Wall in 1989, Kreuzberg suddenly found itself in the middle of the city again. The initially cheap rents and many 19th century houses made some parts of the neighbourhood more attractive as a residential area for a richer variety of people. This lead to gentrification in parts of the neighbourhood. But immigrants and many students are still living there. Today, Kreuzberg has one of the youngest populations of all European city boroughs.

\subsubsection{Kreuzberg, Oranienstraße}

Oranienstraße is the main street of the neighbourhood Kreuzberg. Its one-kilometrestretch from Moritzplatz to Wiener Straße forms a mixed neighbourhood centre with many family businesses, clubs, restaurants and bars. Festivals and also demonstrations take place here on a regular basis.

\subsection{Neukölln}

Neukölln is an inner-city neighbourhood at the southern border of Kreuzberg. The district is 
densely settled with a population of 150,756 inhabitants (2008). It is characterized by a high percentage of immigrants, especially of Turkish and Arab descent.

In the past few years, northern Neukölln, frequently known as Kreuzkölln (Kreuzberg + Neukölln), has undergone a transformation and has seen a huge influx of students and artists as the area becomes increasingly popular. Gentrification has not really taken place here (yet), rents are still very affordable.

\subsubsection{Neukölln, Sonnenallee}

Sonnenallee is a long street starting a Hermannplatz, at the border of Kreuzberg and continuing into the eastern part of the city, the neighbourhood of Treptow. The most central part at a length of one kilometre from Hermannplatz to Elbestraße is a busy street with many Turkish and Arabian businesses like restaurants, bakeries, driving schools, shisha lounges. In recent years an originally African population found their new home here as well and opened a variety of shops.

\subsection{Wedding}

Wedding is located north-west of the inner city. In a way it is the northern counterpart to Kreuzberg and Neukölln. The constant migration of country-dwellers into the city at the end of the 19th century converted Wedding into a working-class district. The labourers lived in similar cramped tenement blocks as described above. Today, Wedding is one of the poorest areas of Berlin, with a high unemployment rate (almost 26\%). Almost $17 \%$ of the population live on social welfare; $27 \%$ live below the poverty line. Foreigners make up almost $30 \%$ of the population.

Wedding has so far not experienced the boom and gentrification of the 1990s that then happened in many parts in Berlin. Unlike many other 19th century working class districts like Kreuzberg and the northern part of Neukölln, the original character of Wedding and its population has been preserved, but there are currently artists and students moving there. Rents still remain cheap.

\subsubsection{Wedding, Badstraße}

Badstraße is one main shopping street of the district of Wedding. It starts at the transportation hub "Gesundbrunnen" where there also is a big shopping mall. On the one kilometre to Koloniestraße this street has numerous textile and fashion shops, mostly run by people of Turkish origin.

\section{SMALL FAMILY BUSINESSES}

Ethnic economies - and especially the Turkish economy - already have become and are predicted to become even more important for the German national economy in the near future. These family businesses have developed a successful structure in a foreign country that is highly accepted and used not only by their compatriots but also by German people. This implies that the entrepreneurs, who live and work in a culturally mixed context, have the necessary skills and cultural competencies to handle this complexity. The multicultural atmosphere is often visible in bilingual shop signs (predominantly German and Turkish or German and Arabic).

\subsection{Shops}

Shops for bridal wear, evening dresses, shoes, gift articles or furniture are geared towards the immigrant population. The fashion, culture and taste are too different to have customers from both populations.

Another important branch of the family businesses are the food shops, that sell fresh fruits, vegetables, bread, pastry, meat and other original food items. Like newsstands they are frequented by large numbers of all kinds of population. 


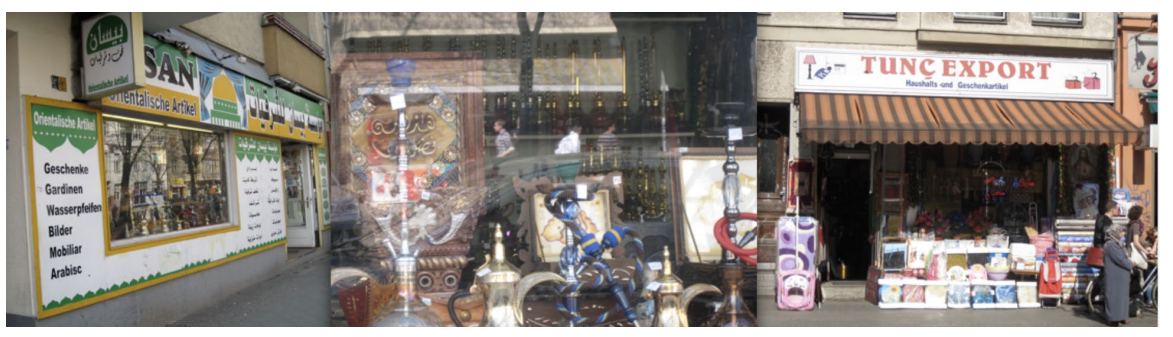

Figure 2. Gift shops

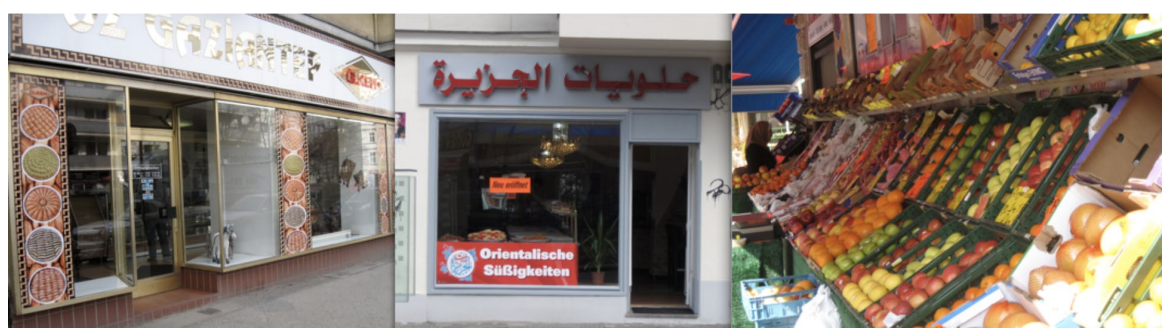

Figure 3. Food shops: bakery, pastry, fruit

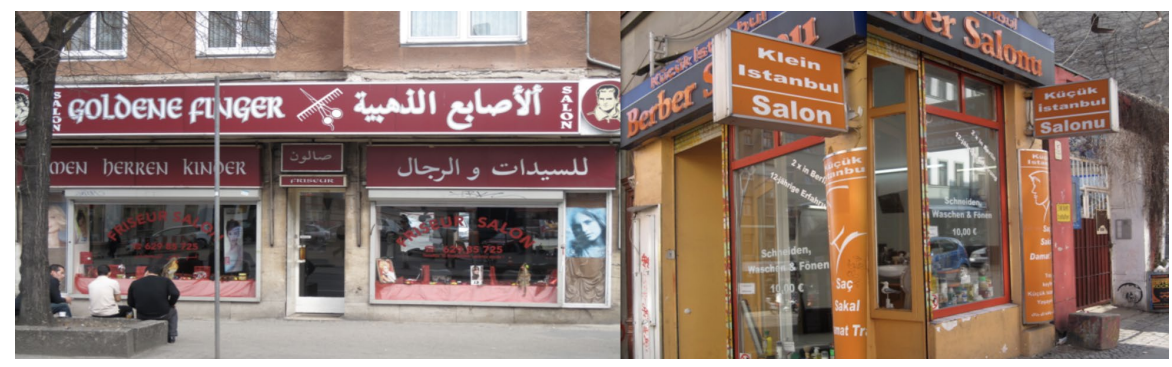

Figure 4. Barbers

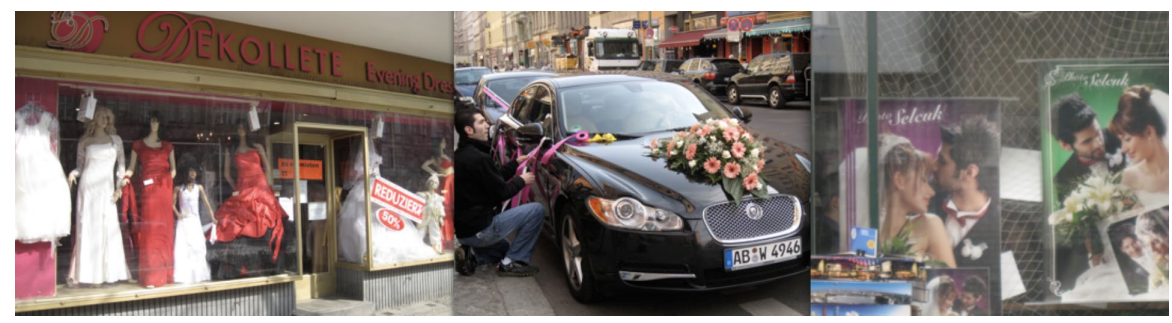

Figure 5. Wedding shop and services: bridal wear, wedding car, photo studio 


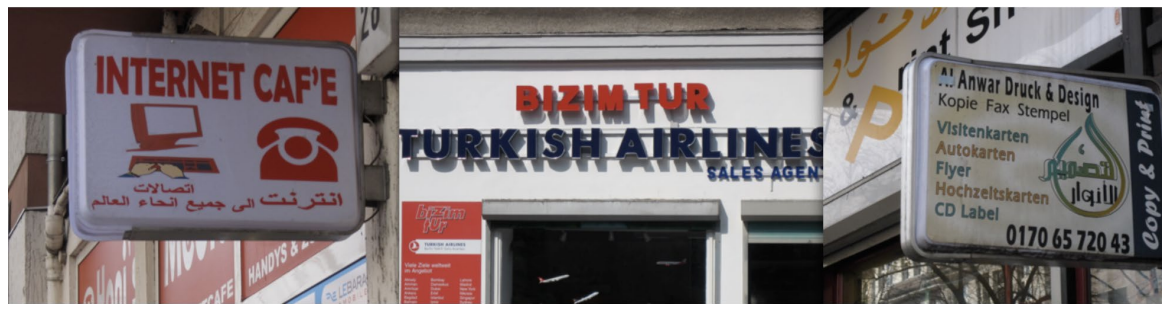

Figure 6. Internet café, travel agency, copy shop

\subsection{Services}

The services cater to the immigrant population as well. They are mainly comprised of phone shops, copy shops, photo studios, barbers, taxi and driving schools, religious schools and travel agencies.

\subsection{Food}

Berlin is a Döner/Falafel/Shawarma capital. It is not known who opened the first Döner Kebab snack bar in Germany. Legend says that it took place at the beginning of the 1970s in Berlin-Kreuzberg. First in Berlin, then all over Germany Döner became a popular lunch or evening snack or meal. There are more than 15.000 Döner/Sharwarma snack bars in Germany. 200 to 300 tons are being produced daily. The yearly turnover is around 1,5 Billion Euro. The Döner Kebab served in Germany is different from the one in the Arabic countries. It adds green salad, sliced tomatoes, cucumbers, cabbage and certain sauces. These snack bars are popular by Germans and immigrants. They are mostly integrated in the ground floor of the buildings. The German building code allows this mixed use in apartment buildings. There are some detached kiosk style snack bars as well, predominantly at street corners to attract more customers.

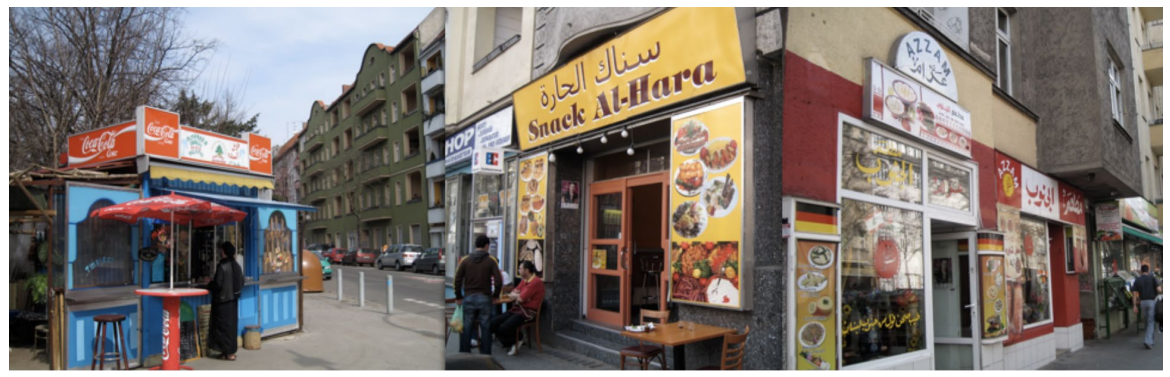

Figure 7. Snack bars: at street corner or in the ground floor of apartment building 


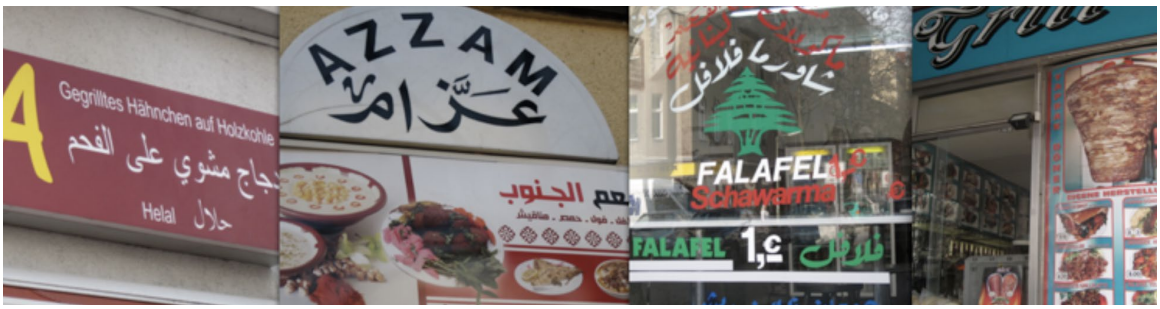

Figure 8. Snack bar advertisement in two languages

\subsection{Culture}

There are many oriental culture associations. Dance, wellness and music are among the creative industries that sprung up during the last twenty years. Kreuzberg-based Turkish/German rapper Killa Hakan mentions Kreuzberg in most of his songs, most notably in his 2007 single "Kreuzberg City". There is a very vibrant rap, hip hop and saz scene in Berlin. A Turkish film festival has been established in Berlin and took place five years in a row. TurkishGerman filmmaker Neco Celik who portrays the American influence over the youth culture in Kreuzberg in his first film "Alltag" (Daily Life) notes, "Kreuzberg is a kind of biotope where different nationalities live, but the environment determines their lives, not their nationalities."

\section{FORM AND USE OF PUBLIC SPACE}

While urban space is the most commonly experienced feature of the city, it possesses different meanings and serves various purposes for the individuals engaging with it. The urban landscape is thus a space changing all the time according to the habits of its inhabitants. As a dynamic space, it carries the narratives and symbolic meanings of the past, present, and future. The economic, social, and cultural uses of space showcase the everyday culture.

\subsection{Streets}

Shop owners display their goods in front of their shops. This changes the appearance of the

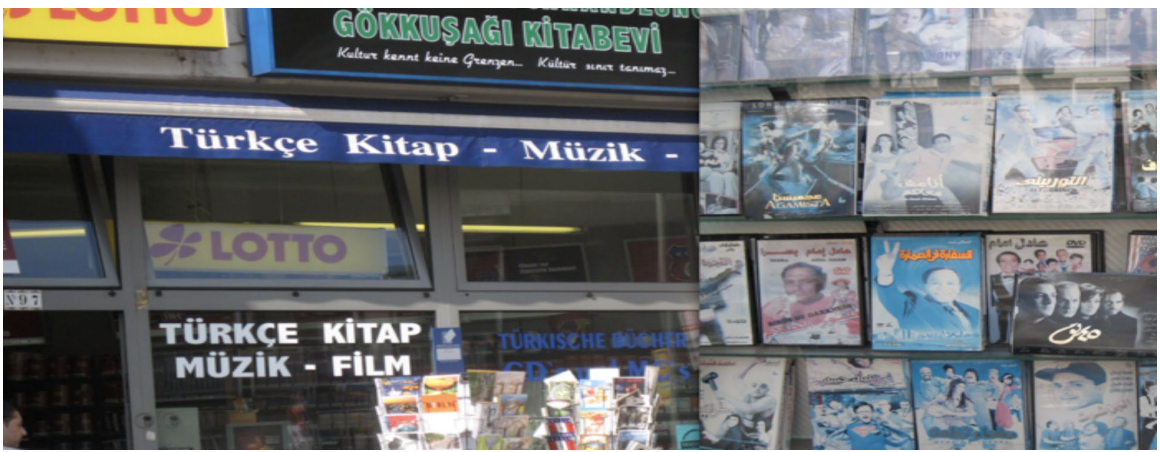

Figure 9. Music and DVD shops 


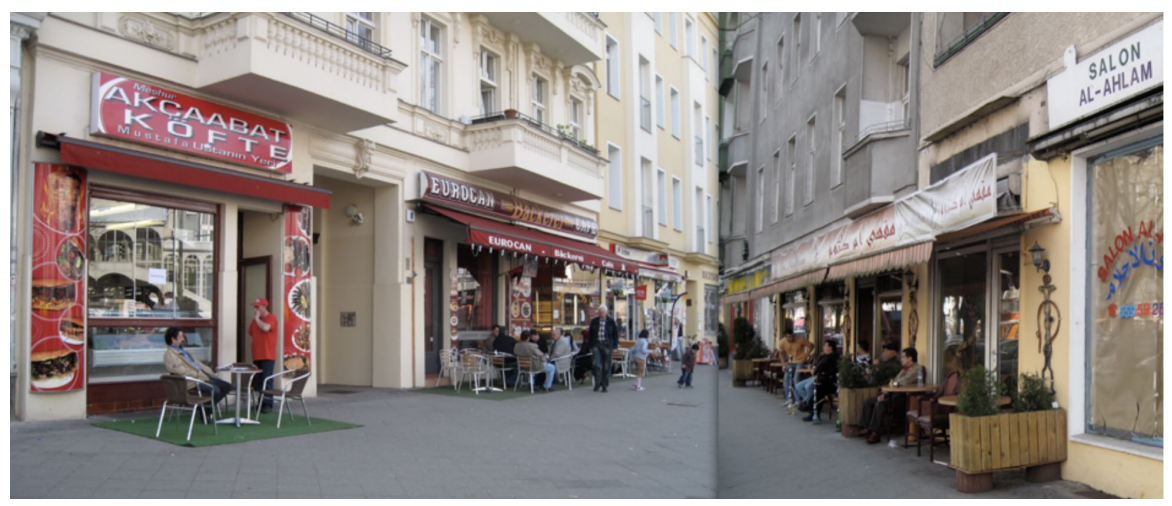

Figure 10. Use of sidewalk

sidewalk in a very animated and colourful way during the day and in warm summer nights. You can observe a similar effect in front of the snack bars and restaurants. Chairs and tables are put out in front, guests are invited to stay, and this animates the street life. The sidewalks in Berlin are wide enough to accommodate this additional use.

Many immigrants are also active business people on several markets, that take place once or twice a week in the neighbourhoods. In Neukölln at the border to Kreuzberg a socalled "Türkenmarkt" (Turkish market) has been established and successfully organized for decades. It is very popular by all kinds of shoppers and visitors, even by tourists because it is written up in several guide books. Streets and plazas are in some areas also being used for informal trade.

\subsection{Parks}

In the summer the central park of Berlin, the "Tiergarten" is known for being used for barbecues. Large Turkish and Arabian families gather here on weekends, they bring food like salad and meat to be barbecued, tea, chairs, tables, blankets and children's game and spend the day. The Berlin city council changed the regulation, since several years it is only allowed to put up a barbecue in certain areas of the park to prevent bush fires but also because some people complained about the fume all over the park.

Also the small neighbourhood parks (Görlitzer Park in Kreuzberg, Hasenheide in Neukölln and Humboldthain in Wedding) are being used for family picnics the minute the weather permits it.

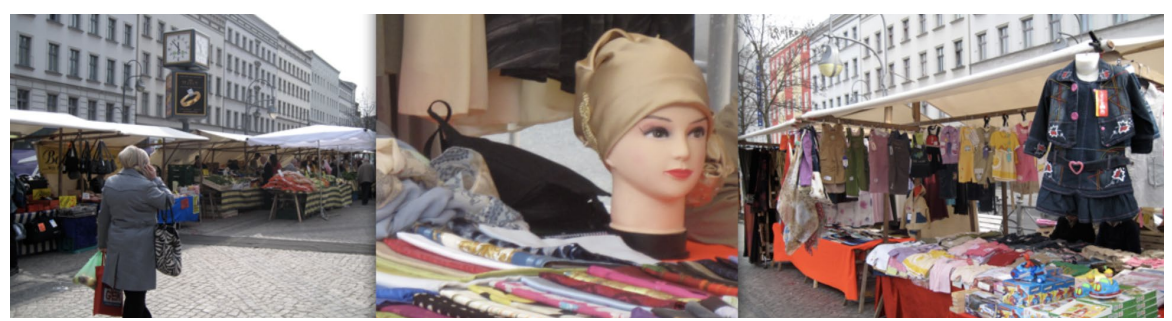

Figure 11. Market on Hermannplatz (border between Kreuzberg and Neukölln) 


\section{SIGNIFICANT ARCHITECTURE TYPES LIKE MOSQUES AND THEIR ROLE FOR URBAN SPACE}

Mosques as centres of the religious, cultural and social life have first been accommodated in backyards or cellars of the quarters with a high number of Muslim inhabitants. There are currently about 2,600 Islamic centres of worship in Germany along with 200 structures that can be classified as mosques. According to current plans, this last figure is now expected to double.

In recent years several mosques have been constructed in Berlin. This also represents the evolution of Islamic heritage from the private to the public sphere. It has become part of the cityscape. German building code allows the building of mosques and minarets, the buildings have to comply with the German regulations (e.g. height of buildings, fire regulations). Some resistance by the German population could be observed, conservative citizens did not want the presence on the street, and they were afraid that the mosques would attract too much street traffic.

Whereas some mosques are typically neighbourhood mosques where members live close by, other mosques attract Muslims from all over Berlin. Many mosques are combined with cultural centres. Mosques and businesses serve the particular needs of the Muslim community. They are examples of spaces in which minority groups feel accepted while not necessarily segregating themselves from the rest of the city. In this sense members can move between minority (city) and majority (mosque) communities. There are eighty mosques in Berlin, 56 of them Turkish. In Kreuzberg the big Umar Ibn Al-Khattab mosque has been completed in 2008, it can house 700 people. Located at a street corner, it forms part of the typical Berlin block of $22 \mathrm{~m}$ height, a necessity to get a building permit in this urban location. The mosque has four minarets. The Sehitliwwk mosque was constructed in 1983 in
Neukölln, it was expanded in 2005. It is located on a former Turkish cemetery, next to a Christian cemetery, it is a singular building, not part of an urban block structure. It has its own bus stop and traffic light regulated pedestrian crossing in front.

The visualisation of a religious minority through mosques is a cultural diversification of urban space.

\section{CONCLUSION: PRESENCE OF ISLAMIC HERITAGE IN THE EVERYDAY LIFE OF BERLIN}

The built environment provides perhaps the most immediate visual impression of a city. However, it is not only the physical structures, monuments, residential areas and public spaces which shape a city, but also its inhabitants. City residents imprint their own mark on urban spaces through everyday interaction with the environment in which they live.

Migration is changing the cityscape. Migrants bring with them own cultures, experiences and histories through which they shape the new environment in which they settle. This is how Islamic heritage is present in everyday life in Berlin every day, making it a more multicultural and diverse place to live. 


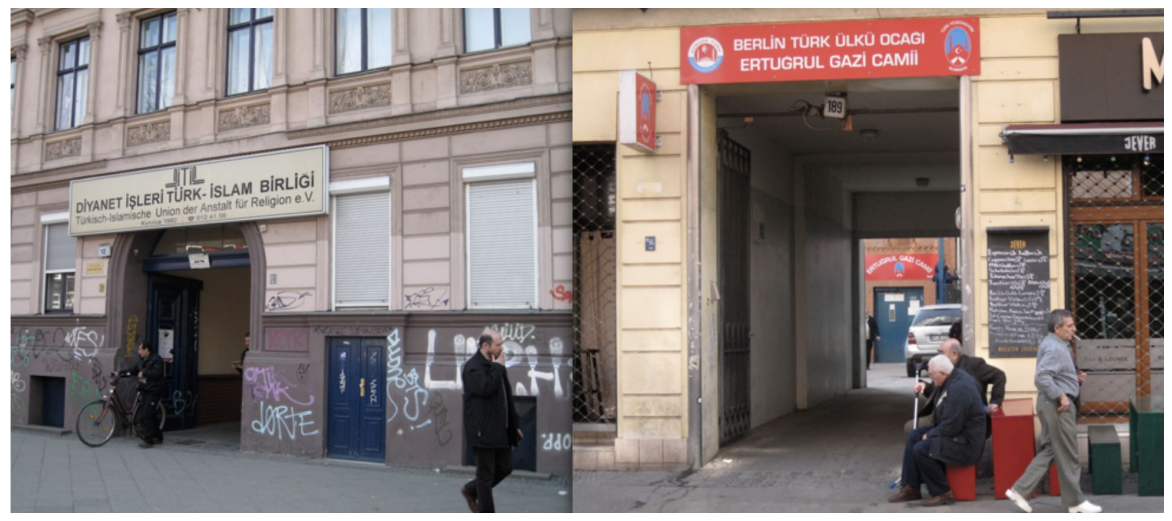

Figure 12. Religious centres in backyards in Kreuzberg

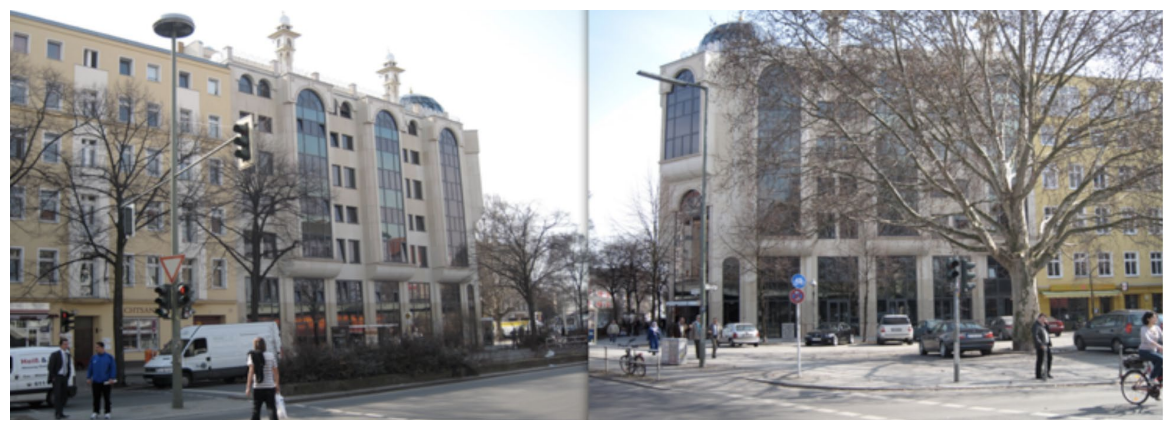

Figure 13. Umar Ibn Al-Khattab Mosque in Kreuzberg

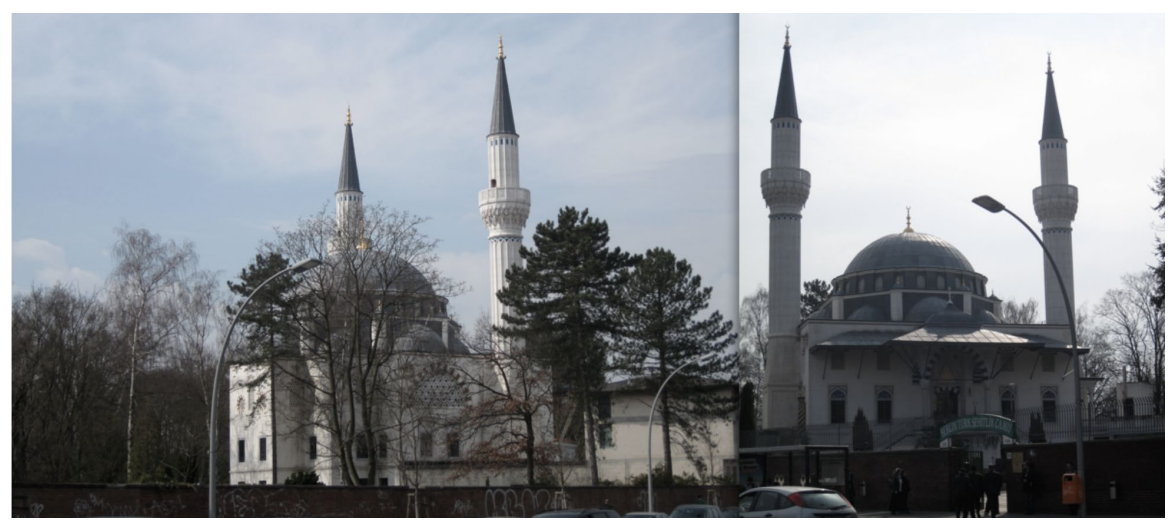

Figure 14. Sehitlik Mosque in Neukölln 


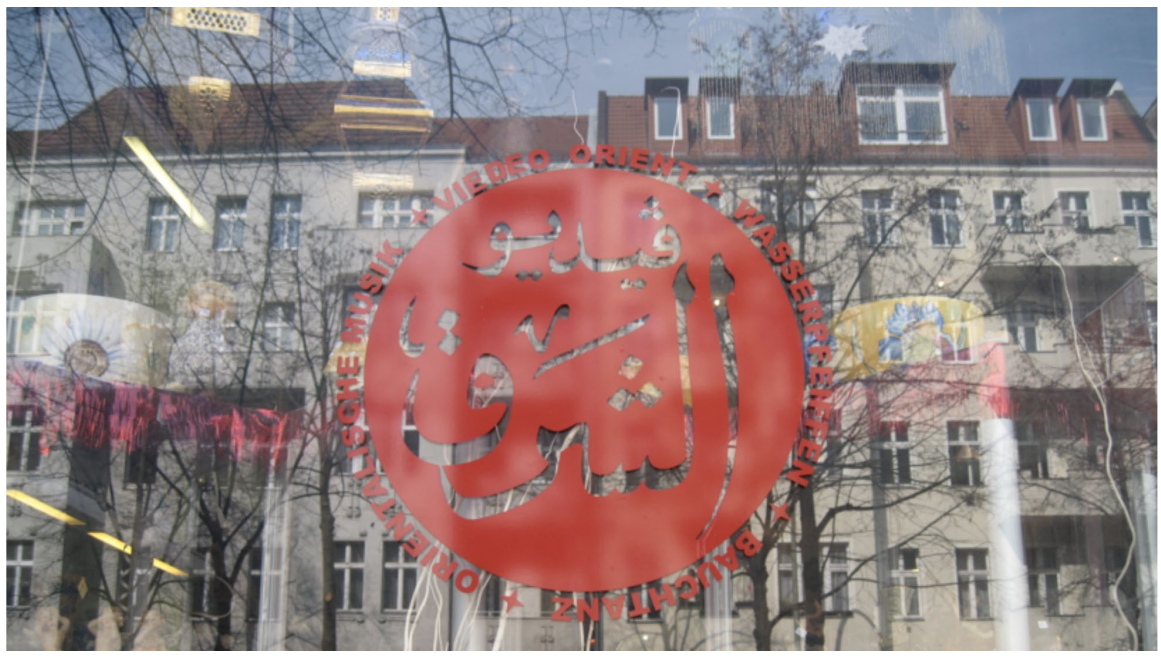

Figure 15. Imprint on urban fabric 


\section{REFERENCES}

Angeles, Vivienne; Bonifacio, Glenda Tibe (Ed.) (2009) Gender, Religion, and Migration: Pathways of Integration. New York: Lexington Books.

Beinhauer-Köhler, B.; Leggewie, C., 2009. Moscheen in Deutschland. Munich: Ch. Beck.

Bendixsen, S., 2009. Islam as a New Urban Identity? Young Female Muslims Creating a Religious Youth Culture in Berlin. New York, London, Budapest: Open Society Institute.

Geist, J., 1980. Das Berliner Mietshaus. Munich: Prestel.

Hegemann, W., 1930. Das steinerne Berlin. Geschichte der größten Mietkasernenstadt der Welt. Berlin: Birkhäuser

Jonker, Gerdian; Kapphahn, Andreas (Ed.) (1999) Moscheen und Islamisches Leben in Berlin. Erlangen: Zentrum für Islam und Recht.

Knöfel, Ulrike, 10/15/2008. Confrontational Architecture. Europe's Mosques Move from Back Alleys to Boulevards. Hamburg: Spiegel.

All pictures by Sigrun Prahl. 


\section{PAPER \#2.17}

\section{WAS LE CORBUSIER A UTOPIAN THINKER OR A REALISTIC VISIONARY? AN ANALYSIS OF TWO DIVERGING VIEWS}

\section{Cihan Yusufoglua ${ }^{a}$, Alexandra Staub ${ }^{b}$}

aPenn State University, University Park, Pennsylvania / Washington-Alexandria Architecture Center of Virginia Tech University, Alexandria, Virginia.

${ }^{b}$ Penn State University, University Park, Pennsylvania

\section{ABSTRACT}

Le Corbusier is considered a pioneer of modern architecture and urban planning. His projects are frequently cited as portraying a utopian vision of urbanity. Yet, scholars are divided on his utopian vision. On the one hand, scholars such as Stanislaus von Moos, urban historians such as Robert Fishman and neo-Marxist authors such as geographer David Harvey see Le Corbusier's urban work as an exercise in utopia. On the other hand, urban historians such as Kenneth Frampton or Peter Hall see Le Corbusier as a realistic visionary, rather than as a utopian. Although both of these viewpoints give Le Corbusier credit for the remarkable architectural and urban visions that he presented, the former view focuses on the insularity and homogeneity of his projects as evidence of his utopian vision, while the latter view gives weight to Le Corbusier's projects as a precedent for twentieth-century urban planning. Through the analysis of key texts on Le Corbusier's urban projects, this paper explores why two bodies of literature diverge so greatly in their evaluation of Le Corbusier's urban visions.

\section{KEYWORDS}

Le Corbusier; utopia; visionary; architecture; urban planning.

\section{INTRODUCTION}

$[U]$ rban planning and architecture appear not as concrete objectives but as crucial mediations that enabled the utopian message to gain momentum. Conversely, the very idea of calling any architecture "utopian" begins to be problematized when we reconsider the link between the legacy of nineteenth-century utopian thought and the projects of twentieth century modernist urbanism and architecture. In the case of Le Corbusier and others, where "visionary" might be a more appropriate qualifier, we may no longer be able to call any architecture "utopian" at all. (Picon 2017)

As one of the most influential representatives of architecture and urban planning in the twentieth century, Le Corbusier's architectural and urban designs as well as his theoretical writings have been widely studied by scholars. Although Le Corbusier's legacy as one of the most influential figures in modern architecture and urban planning is undisputed, scholars are divided on how his work should be defined. Two characterizations of his work and thinking stand out in the literature: Le Corbusier has been called both a utopian thinker and conversely, a visionary realist.

Although the dictionary definitions of "utopian" as "a person who imagines or proposes a utopia" or "an advocate of social reform" and "visionary" as "capable of receiving impressions, or obtaining knowledge, by means of visions" are similar (Oxford English Dictionary, n.d.), architectural 
scholars tend to draw a firm line between the two terms. In this context, two divergent views of Le Corbusier's work have appeared in the literature. One view describes Le Corbusier's work as propagating an illusory social reform; the other sees his work as that of a prescient realist.

The first school of thought, represented by scholars such as Lewis Mumford, Stanislaus von Moos, and Robert Fishman, pegs Le Corbusier as an unambiguous utopian. This line of reasoning argues that to fully understand Le Corbusier one must analyze his works within the utopian tradition and thus qualify him as a successor of early utopian thinkers:

...there has been a steady connection between the practical city of everyday life and the projection of utopias: from Alberti to Robert Owen, and from Owen to Howard and Le Corbusier, the ideal plans of one generation have become the practical realizations of the next. (Mumford 1970, 504)

Le Corbusier is not only accepted as a utopian thinker within the historical literature, he is often cited as such in neo-Marxist writings (Berman 1983; Harvey 2000):

All the great urban planners, engineers, and architects of the twentieth century set about their tasks by combining an intense imaginary of some alternative world (both physical and social) with a practical concern for engineering and re-engineering urban and regional spaces according to radically new designs. While some, such as Ebenezer Howard, Le Corbusier, and Frank Lloyd Wright set up the imaginative context, a host of practitioners set about realizing those dreams in bricks and concrete, highways and tower blocks, cities and suburbs, building versions of the Villes Radieuse or Broadacre City, whole new towns, intimate scale communities, urban villages, or whatever. Even when critics of the authoritarianism and blandness of these realized utopian dreams attacked them, they usually did so by contrasting their preferred version of spatial play with the spatial orderings that others had achieved. (Harvey 2000, 104)

Le Corbusier's ideas are thus widely described as "utopian" and his work compared with other utopian thinkers throughout history, more specifically those who appeared after the industrial revolution.

Yet not all historians frame Le Corbusier as a utopian thinker. Kenneth Frampton and Peter Hall, for example, abstain from using "utopia" or similar terms when referring to Le Corbusier or his works. Scholars arguing this line of thinking have focused on Le Corbusier's built projects and their proven feasibility. Regarding Le Corbusier's works as a whole, they emphasize that he was more productive in the architectural field than "utopian" thinkers, who are mostly known for one utopian design or "ideal city" in their lifetime (Hall 2014).

This paper examines the two divergent definitions of Le Corbusier's work in the literature and explores why Le Corbusier is in some cases considered "utopian" and in others a "visionary realist".

\section{LE CORBUSIER AS A UTOPIAN THINKER}

Scholars who associate Le Corbusier with utopianism largely regard his utopian adventure as having started with his didactic travels as a young man to locations throughout Europe (Serenyi 1967; Moos 1979; Rabaca 2016). A frequent claim is that Le Corbusier's utopian thoughts began with his drawings of housings when he visited the Charterhouse of Ema in Tuscany, Italy also known as "Ema Monastery", at the beginning of his "voyage d'Orient" (Journey to the East) in 1907. Serenyi interprets the monastery as an admirable example of cell and landscape that impressed the young Le Corbusier as an architectural ideal: 
It is revealing that his sermon on architecture begins a reference to monastic life and ends with a note on the home. It must be remembered that Le Corbusier likes to consider the home as a monastic cell, created, ideally at least, for the single individual; for the family, as a small, intricate social group, has no place in Le Corbusier's art or mind. (Serenyi 1967, 277-78)

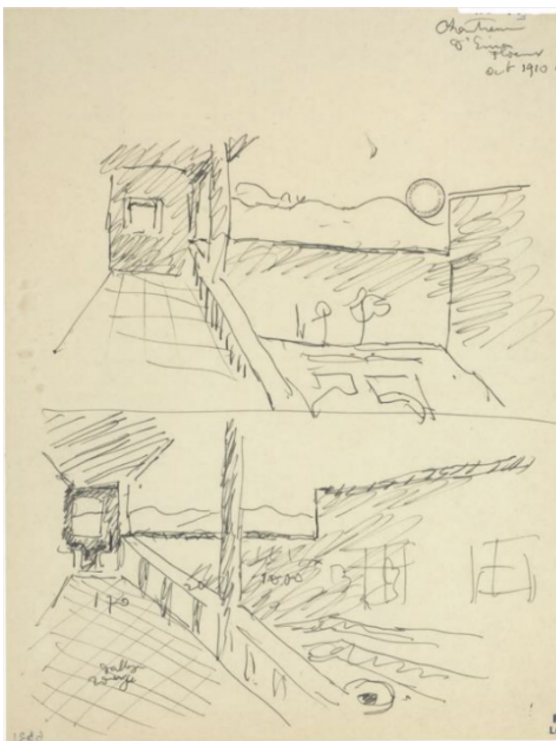

Figure 1. Charterhouse of Ema, Florence, 1911. Source: (c) FLC/ADAGP

Stanislaus von Moos also concentrates on Le Corbusier's gradual change through his early travels, outlining the utopian aspect of Le Corbusier's work in his book Le Corbusier: Elements of a Synthesis, in a chapter titled "Variations on a Utopian Theme" (Moos 1979). Moos's main argument is that Le Corbusier was progressively inspired by the real-life architecture he encountered on his voyages, and that inspiration eventually shaped his utopian vision. Moos argues that Le Corbusier's characteristic approach to housing models shows parallels to utopianism, which are not designed for the "man on the street", they are designed for the man of ideal societies:

The lifestyle suggested by this new urban form was that of the elegant apartment block or condominium where hardly anyone ever gets to know his neighbor: a nomadic way of life within the cosmopolitan anonymity of the metropolis. This is what separates Le Corbusier's reform model from most of the contemporary Anglo-Saxon and German attempts at a 'regeneration' of the city via a return to popular and pre-industrial forms of small town, or village, communities. In short, the "homme poli-vivant en ce temps-ci" [welleducated man who lives in our times], this classless Mr. X, envisaged by Le Corbusier as the standard inhabitant of his immeublesvilla, was not identical with the "man on the street". (Moos 1979, 148)

After bridging the gap between Le Corbusier and utopia in this manner, Moos places Le Corbusier within the utopian tradition and compares his work with that of other utopian thinkers such as Ebenezer Howard with his Garden City ideals, and Tony Garnier with his Cité Industrielle as well as architects such as Walter Gropius with his modular system for standardized housing. Moreover, Moos mentions the potential influence of the Russian avant-garde communal housing projects through Fourier's French utopianism on Le Corbusier's utopian thoughts. Even though Moos strongly believes that Le Corbusier was largely influenced by nineteenth- and early twentieth-century utopianism, most especially French and Soviet utopian traditions, he points out that Le Corbusier's work was different from that of nineteenth-century utopian thinkers (e.g. Charles Fourier's) since he based his work on "first-hand experience" with existing buildings (Moos 1979, 146).

Moos considers Le Corbusier's early housing attempts, in which he tried to illustrate his 
early collective utopian ideas, as prototypes for Le Corbusier's urban plans. For example, Le Corbusier's well known Unité d'Habitation housing project is described as a combination of many themes, such as Soviet avant-garde designs and, in particular, a Fourierist legacy, in order to "serve a reform of the modern city as a whole" (Moos 1979, 157). The Unité is not Le Corbusier's only housing project that reflects the legacy of utopianism. Le Corbusier's other two housing projects, designed for sites in Zurich, were inspired by Soviet avant-garde architects, namely the Vesnin brothers and Moisei Ginzburg: "So it was after all through Ginsburg [sic] and the Vesnin brothers that Le Corbusier came in contact with the reality of a Fourierist tradition of utopian socialism..." (Moos 1979, 154).

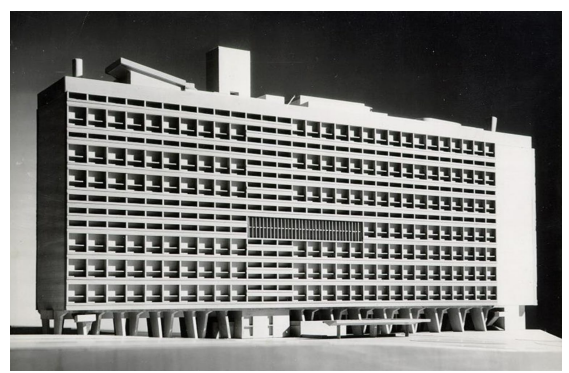

Figure 2. Unité d'Habitation, Meaux, France, 1957. Source: (c) FLC/ADAGP

Robert Fishman comes to similar conclusions as Moos in his analysis of Le Corbusier's work. Unlike Moos, who studied Le Corbusier within the context of a whole lifetime, Fishman focuses on Le Corbusier's utopianism in his book Urban Utopias in the Twentieth Century: Ebenezer Howard, Frank Lloyd Wright, Le Corbusier. Fishman purposely juxtaposes the three architects. He proposes that Le Corbusier has more in common with Ebenezer Howard and Frank Lloyd Wright than with nineteenth-century utopian thinkers such as Charles Fourier or
Robert Owen. Pointing out that Ebenezer Howard and Frank Lloyd Wright principally proposed nostalgic and pastoral utopias in contrast to Le Corbusier's "mechanized" techno utopias, Fishman (1982) states that the work of Howard, Wright, and Le Corbusier is nevertheless distinguished from that of other utopian thinkers since they acknowledged and allowed the industrial and technological advances of the twentieth century in their plans. Howard, for example, included factories and connected them to the Garden City with railway networks. Le Corbusier drew wide highways for automobile traffic, while Frank Lloyd Wright went a step further, illustrating flying, helicopter-like vehicles. Fishman clarifies why he separates Le Corbusier and others from nineteenthcentury socialist utopian thinkers:

They worked at the dawn of the twentiethcentury industrial era, but before the coming of twentieth-century disillusionment. Their imaginations were wholly modern; yet the coming era of cooperation was as real to them as it had been for Robert Owen. Their ideal cities thus stand at the intersection of nineteenth-century hopes and twentiethcentury technology. (Fishman 1982, 15)

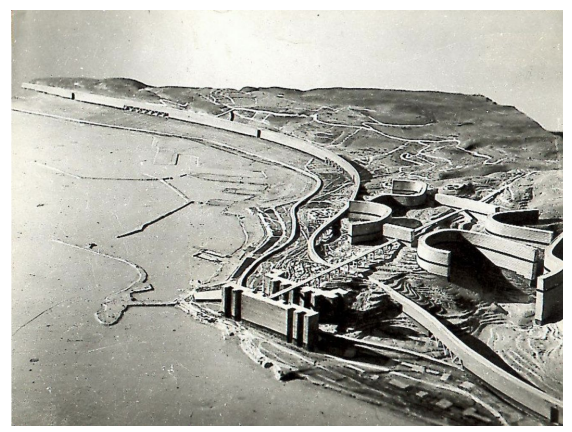

Figure 3. Plan Obus, Algiers, Algeria, 1930. Source: () FLC/ADAGP 
Moreover, Fishman separates out Le Corbusier from other twentieth-century architects and intellectuals. He states that Le Corbusier and others are isolated from "almost all the social movements and institutions of their time", and explains:

[The three ideal cities] separated them from the members of two groups who might have been their natural allies, the Marxian socialists and the professional planners. The three ideal cities were at once too technical for the Marxist and too revolutionary for the growing corps of professional planners. The latter was especially intent on discouraging any suggestion that urban planning might serve the cause of social change. These architectadministrators confined themselves to 'technical' problems, which meant, in practice, serving the needs of society-as society's rulers defined them. (Fishman 1982)

With this passage, Fishman also makes clear that he saw Le Corbusier not as a professional planner, but as the utopian architect of the twentieth century. Consequently, Fishman determines that Le Corbusier followed a unique path that defines a built environment by using utopian ideas as a key element.

\section{LE CORBUSIER AS A VISIONARY REALIST}

While one group of scholars has called Le Corbusier a utopian thinker, another group sees him as a visionary realist. This group emphasizes Le Corbusier's social and political views, that are rarely seen in the utopian tradition. In analyzing Le Corbusier's divergence from the road taken by most utopian theorists, they point out that during the course of his life, Le Corbusier's thinking took several turns. For instance, after a worldwide depression in the early 1930s tarnished the capitalist order's image, Le Corbusier sharply shifted his economic and political views from centralist capitalism to non-anarchist syndicalism: "...an ordered, hierarchical system, having some close affinities to the left-wing variety of Italian fascism" (Hall 2014, 244). As a result of this shift, Le Corbusier modified and reproduced his ideal city plans, tailoring them to his new point of view. The Plan Voisin for Paris, the Plan Obus for Algiers, and Chandigarh's Master Plan resulted from this era. Le Corbusier's flexible and adaptative architectural production gave cause for academics to describe Le Corbusier as being a prescient visionary rather than belonging to the utopian tradition, as other utopian thinkers, such as Charles Fourier, Robert Owen, and even twentieth-century architects such as Ebenezer Howard and Frank Lloyd Wright, stuck to their ideal city plans throughout their lifetimes.

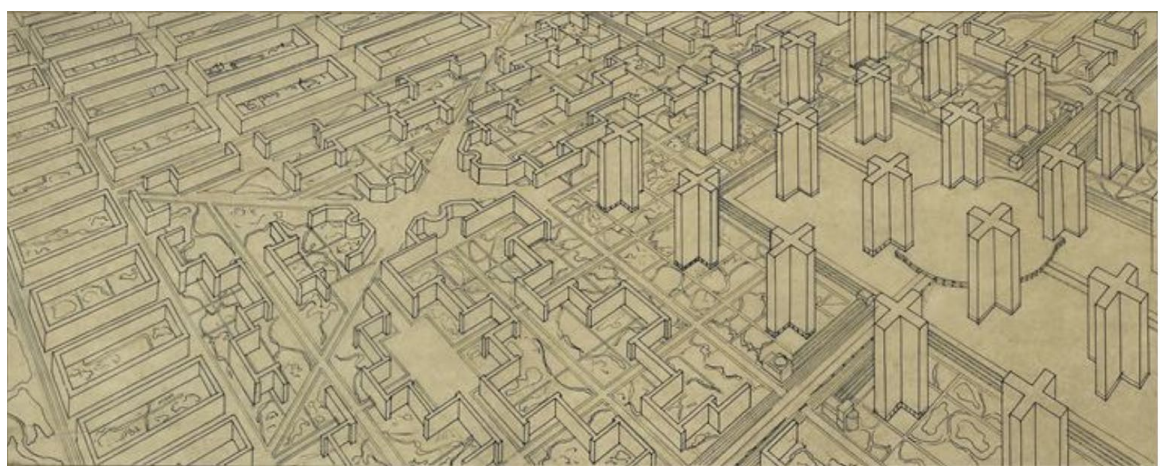

Figure 4. Ville Contemporaine, not located, 1922. Source: (C) FLC/ADAGP 


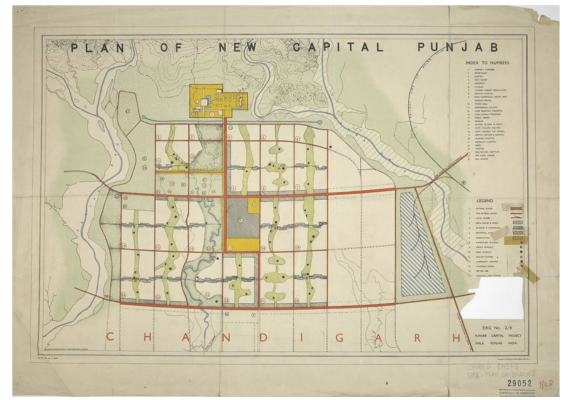

Figure 5. Chandigarh, India, 1950 - 1965. Source: (C) FLC/ADAGP

Even though some utopian schemes were occasionally constructed in an attempt to make their ideas come to life, utopias are by definition considered unattainable. The other main reason why this group of scholars considered Le Corbusier a visionary rather than a utopian thinker is his executed and well-grounded works, also rare within the realm of utopianism. Le Corbusier's extensive architectural production, considered together with his urban plans and their direct influence on the next generation of architects and planners, led this group of scholars to set Le Corbusier's work apart from that contained in the utopian literature, instead placing him in a category of "realistic" thinkers (Frampton 2001; Hall 2014).

As a prominent Le Corbusier biographer, Kenneth Frampton has examined the architect's life phase by phase, based on the substantial changes of direction that Le Corbusier experienced (Frampton 2001). The author portrays Le Corbusier as a visionary architect by evaluating his work, though also acknowledging that Le Corbusier was affiliated with utopianism and major figures of the movement for a short period of his life. Frampton makes the argument that Le Corbusier's works were more influenced by architects, urban planners, and engineers who are not known as utopian thinkers professionals such as Raymond Unwin, Baron
(Georges-Eugène) Haussmann, and HenryJules Borie - than by actual utopians, such as Charles Fourier and Henri de Saint-Simon. Ultimately, Frampton comes to the conclusion that when one looks at Le Corbusier's life as a whole, one regards the fluctuant life of a visionary.

Even though Frampton univocally presents Le Corbusier as a visionary architect, he does refer to Le Corbusier's relationship with utopian figures. In doing so, Frampton digresses from his main argument to mention Henri de SaintSimon, one of the most influential French philosophers of socialism in the nineteenth century, stating that "Le Corbusier remained a Saint-Simonian at heart" (Frampton 2001, 117). Along with Charles Fourier, Saint-Simon was a significant figure of utopian socialism, and he became a figure Le Corbusier admired greatly. Although Frampton argues that Le Corbusier was impressed by Henri Simon's revolutionary theories, he nevertheless does not consider Le Corbusier to be a utopian himself, as he proposed architectural solutions to problems rather than social or economic revolution. In this, Frampton sees Le Corbusier's focus as diverging from that of recognized utopian thinkers, who proposed utopia as a whole social revolution that incorporated architecture as well. As Le Corbusier succinctly framed it: "Architecture or Revolution. Revolution can be avoided" (Corbusier 1986, 289).

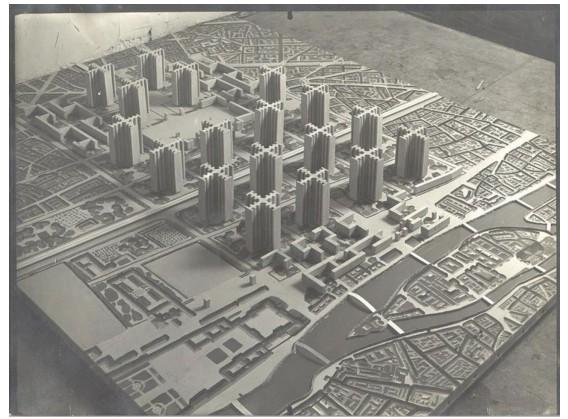

Figure 6. Plan Voisin, Paris, France, 1925. Source: (C) FLC/ADAGP 
Urban historian Peter Hall interprets Le Corbusier as a visionary architect as well and analyzes his work in the context of other significant planners of modern cities, including architects, utopian philosophers, and urban theorists. As does Frampton, Hall recognizes Le Corbusier's early affiliation with utopian thinking; nevertheless, the author claims that the utopian aspect was an integral part of Le Corbusier's visionary characteristic, not an ideal he used and abandoned:

The central argument can be succinctly summarized: most of them [architects under discussion, including Le Corbusier] were visionaries, but for many of them their visions long lay fallow, because the time was not ripe. The visions themselves were often utopian, even charismatic: they resembled nothing so much as secular versions of the seventeenthcentury Puritans' Celestial City set on Mount Zion, now brought down to earth and made ready for an age that demanded rewards there also. (Hall 2014, 2)

Despite this broadly painted view, Hall draws an exclusive framework around Le Corbusier's work, describing him as belonging to a set of "...authoritarian centralist [individuals] ... faithful servants of finance capitalism or totalitarian dictators" (Hall 2014, 3). To Hall, this set Le Corbusier apart from the members of anarchist planning movements:

The vision of these anarchist pioneers was not merely of an alternative built form, but of an alternative society, neither capitalistic nor bureaucratic-socialistic: a society based on voluntary cooperation among men and women, working and living in small selfgoverning commonwealths. Not merely in physical form, but also in spirit, they were thus secular versions of Winthrop's Puritan colony of Massachusetts: the city upon a hill [.... F] or me, however unrealistic or incoherent, the anarchist fathers had a magnificent vision of the possibilities of urban civilization, which deserves to be remembered and celebrated; Corbusier, the Rasputin of this tale, in contrast represents the countertradition of authoritarian planning, the evil consequences of which are ever with us. (Hall 2014, 3-5)

It is quite clear that Hall approaches Le Corbusier from a different standpoint from that of Moos or Fishman; namely, that Le Corbusier's ideology sets him apart from generally accepted utopian thinkers. According to Hall, Le Corbusier was not a socialist thinker, in contrast to eminent nineteenth-century utopian socialists. On the contrary, he had faith in royal figures, "grands seigneurs" such as Louis XIV and Napoleon (Fishman 1982, 210). In addition, the high density of ideal city plans that he designed differs from the decentralized plans of twentieth-century utopians, such as Ebenezer Howard with his "Garden City" and Frank Lloyd Wright with his "Broadacre City" plan. Hall reminds us that envisioning - and demanding $\neg$ - more density for cities of the future separates Le Corbusier from many of his contemporaries. Hall presents these aspects of Le Corbusier's work as reinforcing his assessment of Le Corbusier as a visionary realist, rather than as a utopian.

\section{CONCLUSION}

Le Corbusier was clearly more than just an influential architect. He was arguably a more complex figure than any former or contemporary associates. He entered into relations with a great variety of individuals and organizations, working within and espousing systems connected to centralist capitalism and hierarchical syndicalism. He worked with big companies (the name of the Plan Voisin comes from the "Voisin Aircraft Manufacturing Company" that demonstrates Le Corbusier's "capitalist" orientation) and governments that are at opposite ends of the political spectrum (for example the Vichy Government of France, 
a right-wing puppet regime of the Nazis, and the Soviet Union as a left-wing autocracy).

Despite their varying assessments of Le Corbusier's influence as a utopian thinker, scholars agree that he made an indelible impression on the architectural field through the versatility of his works. Even though some of these works had a resemblance to utopian thoughts and plans, his architectural production, taken as a whole, lies beyond utopianism. This fact is reflected in the literature and in the interpretations of his work. Taken together with the inherent ambiguity of the word "utopian", it is not surprising that scholars differ in their assessments of Le Corbusier as either as a utopian, or a visionary, or both. 


\section{REFERENCES}

Oxford English Dictionary [online resource]. https://www.oed.com. Accessed February 7, 2020.

Berman, Marshall. 1983. All That Is Solid Melts Into Air: The Experience of Modernity. [First Published in 1982]. New York: Verso.

Corbusier, Le. 1986. Towards a New Architecture. Translated by Frederick Etchells. [First Published in 1923]. New York: Dover Publications.

Fishman, Robert. 1982. Urban Utopias in the 20th Century: Ebenezer Howard, Frank Lloyd Wright, and Le Corbusier. [First Published in 1978]. Cambridge: The MIT press.

Frampton, Kenneth. 2001. Le Corbusier. New York: Thames \& Hudson.

Hall, Peter Geoffrey. 2014. Cities of Tomorrow: An Intellectual History of Urban Planning and Design in the Twentieth Century. 4th ed. [First Published in 1988]. Pondicherry: Wiley-Blackwell.

Harvey, David. 2000. Spaces of Hope. Edinburgh: Edinburgh University Press.

Moos, Stanislaus von. 1979. Le Corbusier: Elements of a Synthesis. Cambridge: The MIT press.

Mumford, Lewis. 1970. The Culture of Cities. [First Published in 1938]. New York: Harvest Books.

Picon, Antoine. 2017. "Notes on Utopia, the City, and Architecture." Grey Room 68: 94-105.

Rabaca, Armando. 2016. "Le Corbusier, the City, and the Modern Utopia of Dwelling." Journal of Architecture and Urbanism 40 (2): 110-20.

Serenyi, Peter. 1967. "Le Corbusier, Fourier, and the Monastery of Ema." The Art Bulletin 49 (4): 277-86. 



\title{
PAPER \#2.18
}

\section{UNIVERSITY IS CITY. THE INFRASTRUCTURE OF EDUCATION AND RESEARCH AS AN ENGINE OF URBAN REGENERATION}

\author{
Emilio Faroldia, Maria Pilar Vettoria \\ aPolitecnico di Milano, Milan, Italy
}

\section{ABSTRACT}

The aim of the work is to reaffirm the strategic correspondence between the university settlements and the city, in a logic of absolute complementarity. The University has always been the institution dedicated to education in its highest and most noble form: likewise, the relationship between universities and the urban context has characterized the debate on the management and development policies of the city. The first universities arose far from the cities according to a concept that saw advanced training and research as distinct from the progress and life of the urban context. The isolation of the university settlement from the vital center of a constantly growing city, while on the one hand guaranteed, with its physical autonomy, a more marked dedication to study and research, on the other decentralized the flows of students and staff university, in an attempt to limit integration with the urban context. Today the city and the university have profoundly changed: the progressive physical development of the anthropized contexts has gradually reached and definitively incorporated the most ancient university buildings originally built outside the urban boundaries. The city, in the new current phase of economic development, increasingly needs the University as the driving force for innovation and the revival of the economic-entrepreneurial fabric through culture. The universities, from structures specifically dedicated to the teaching and training of young people, have witnessed the constant growth of research and experimentation activities, by means of development models that find their effectiveness the closer the relationship with the system is. companies, institutions, other universities. The university institution represents one of the most important strategic nodes of the territory, through which the city can open and expand its borders to tend towards a global knowledge market. This paper intends to provide a contribution on the role of fundamental activator of relations that the University has had, provides and will be able to guarantee in the construction of the future city.

\section{KEYWORDS}

University; city; urban regeneration; architecture; future.

\section{THE UNIVERSITY BETWEEN MEANINGS AND CONTEXT}

The significance of the University and the places connected to it interprets, in the history of civilisations, a fundamental element of intellectual manifestation and representation, capable of conveying the importance that culture and education have acquired in defining the identity of peoples. History tells us that there was no era during which entire communities did not root their own growth in the transmission of knowledge and expertise, in the search for an identity of their own. Indeed, the university has always had a reputation as the institution dedicated to education and learning in its most lofty and elevated form: likewise, the 
relationship between a university and its urban context has often informed the debate on the city's management and development policies. The first universities in Italy were founded far from the cities, with a belief in a concept that involved advanced education and research as distinct functions, separable from the progress and life of the urban context. Whilst on the one hand, the isolation of the university campus from the vital centre of a city undergoing constant growth guaranteed, due to its physical autonomy, a greater degree of dedication to both study and research, on the other, it decentralised the flow of university students and staff in its attempt to limit the interactions and possible short circuits with the city-based setting and everyday life.

Nowadays, the city and the university have changed a great deal: the progressive physical development of the anthropised contexts has gradually reached and definitively incorporated even the oldest university sites, originally built outside the city limits.

The urban reality, in its new, current stage of economic development, has a growing need of the University as a driving force for innovation and the relaunch of the economic and entrepreneurial fabric: a push, an energy that are generated by the strength of culture. The Universities, as structures dedicated specifically to teaching and training young people, have witnessed the constant growth of research and experimentation activities, by way of development models whose effectiveness lies in their relationship with the system of companies, institutions, and other universities.

The role of the Universities within the city can be traced back to that of a crucially important urban actor, a nerve centre capable of generating and developing both urban and social regeneration and renewal strategies. Specularly, the university exhibits an osmotic dependence upon the city and the services that it can offer: the modern-day tendency for academic structures to open up to an ever-widening and international user base is reliant upon the full range of infrastructural, environmental, commercial, social, service and leisure facilities which the city is best equipped to provide.

The university institution represents, on this front, one of the most important strategic hubs for its local area, by way of which the city can open up and widen its boundaries to cater to a global knowledge market: it is the place formally dedicated to the production and circulation of knowledge and cultural and technical information; it is the catalyst of human capital; it is an active participant in technology transfer policies; it is a point of connection with the global research, innovation and development networks.

The University is an integral and fundamental part of the city, just as the city is a constituent part of the fabrics that take the form of university campuses: two realities which merge together and mutually integrate without a distinction of value between one and the other.

The relationship between the university sphere and the definition of the spaces dedicated to it - within the anthropised contexts - represents the barometer for the cultural expression and soul of a community. Spaces that are structured using the soul of the place as a starting point, interpreters of the memorial values of the communities they are a part of, capable of identifying these contexts as eloquent areas which are evocative of the anthropological experience: representations of material and identity culture which leave a symbolic footprint on the territory that they make their home.

The university can now, in its own right, be associated with the deeper concept of university infrastructure thanks to its ability to position itself as the interactive hub of an area, of which it becomes the driving force and dynamic expression. In this sense, the term "infrastructure", traditionally associated with the concept of the university, should be 
considered - in its material meaning - as an element which links urban functions with one another and its being an element capable of acting as a mouthpiece for the relationships established between them.

University infrastructures, through their spaces, represent one of the most effective social, functional and morphological adhesives of the many and complex relationships that are established in the urban organism, representing a dynamic system that is constantly evolving. As such, university infrastructure cannot be said to have a meaning which refers to an exclusive typology of buildings, but instead wholly to the role that these architectures have taken on in the evolutionary and structuring dynamics of the contemporary city, within which knowledge, information and education represent the qualitative hallmark of attractiveness of the physical and social fabric of a situation.

To consider buildings and architectures for education and research to be on a par with infrastructural networks in the traditional sense means positioning them within the complex articulation of the contemporary space which is the stage for our most noble activities. Indeed, this terminological scenario recalls the dynamic concept of "integrating" (or integrated), which, from the Latin, means to complete, to add something in order to make a system whole and functional.

When we pair the word infrastructure with the word university, from the semantic and operational point of view, we are attempting to define a new approach capable of including an overall rethinking of the role of educational facilities in society, the city, and the local area. In other word, it means integrating and connecting spaces and places which do not dialogue with one another, defining new settlement systems, rearranging scattered fragments of cities, creating new levels of experience.

University architecture identifies a model, a city system, which is also highly recognisable due to its high architectural quality: an overall vision in which design and process, form and function, construction and familiarity of places meld into a single structure marked by hierarchies and, consequently, by actions of organisation of the local area. These spaces are also intended to be occupied by a specific type of user/inhabitant, one who makes an effort to learn and to modify their behavioural approach in part according to the environment in which they spend their time: educational spaces as a stimulating opportunity for experimentation and integration between the articulated functional, morphological and technological components that has characterised the production of architecture and its urbanity in recent years.

It must be considered that the university, more than other functions, when engaging with a user base of a constantly fixed age range, changes with the changing requirements of the student population, bringing with it the feelings and concerns of a cultural renewal that involves instruments, forms and, therefore, also spaces. Architectures which simultaneously incorporate consolidated spatialities together with forms which evolve according to the educational models which stimulate and support them.

In recent architectural history, in line with the developments of university complexes and campuses within urban centres, the main tangible features draw their energy from the desire to constitute parts of the city that are integrated and in continuity with the places they belong to, becoming significant points of reference.

Research on these spaces blends their status as places with an international user base together with more local themes in relation to the productive sphere and the place they belong to, expressing their potential to "be part of the system" through large-scale networks and relationships in search of new centralities. The requirement for flexibility, connected to the rapid changeability of the 
logics which accompany the presence of a multicultural and international population, opens a view to the optimisation of the use of structures characterised by an increased size and, as such, potentially capable of addressing multiple needs, possibly planned, though also with the ability to accommodate one-off requirements which are often unplanned, including and especially of a public nature.

The architecture of the university and its nature as an urban place par excellence represents, for the discipline of urban planning and architecture, a real opportunity to engage with complex issues which are part of the tradition of the evolution of the city, with the aim of reclaiming the meaning of architecture and bringing it back to the centre of collective needs for transformation, shielding the architect from the danger of playing the role of "cultural organiser" rather than that of an intellectual dedicated to developing methods and tools within their discipline.

\section{MILAN AS A WORKSHOP WHERE "THE UNIVERSITY IS THE CITY"}

The paradigm of Milan authoritatively highlights these dynamics: the universities have gradually become one of the main figures within the strategies for the regeneration and innovation of the city, the central areas, the outskirts and the territorial sectors which have gone unaddressed for decades.

The city of higher education has slowly taken the place of the industrial city, replacing it including physically - in its historical sites: the Politecnico in the large abandoned industrial areas of Bovisa, the Università Bicocca on the sites once occupied by Pirelli, the IULM in Barona, and many more besides. In this scenario, the Universities have become major players in the urban transformation process.
To an even greater extent than in the past, teaching and research institutions have now established themselves as key urban protagonists: a condition which is able to stimulate processes for development and territorial, economic and social growth, capable of having an effect and taking actions of urban transformation in strategic locations by structuring new production and research centralities. Such phenomena are still undergoing change, not crystallising into a stable and concluded balance but rather remaining in constant evolution within an extremely dynamic framework which is receptive to new stimuli deriving from the onset of changing conditions of an economic, social, productive or relational nature.

As far as the recent history of the Politecnico di Milano is concerned, think of how its structures have evolved in the area known as Bovisa: from the second half of the 1990s onwards, the large factories which were abandoned at the time and the defunct warehouses used for the purposes of industrial production underwent a profound transformation aimed at a specific functional reutilisation of the buildings which gave them a new identity connected to higher education, culture and research. An operation of urban renewal, thought up and promoted by a cutting-edge university which was able to perceive the district's full potential, generating and triggering policies of social, economic and productive change for an entire portion of the city, promoting new synergies and relationships within the territory capable of reaching and involving the entire metropolitan area.

Referring specifically to the promotion of regeneration, enhancement and redesign that the Politecnico di Milano is currently implementing within its two campuses in Milan, it should be noted how this underpins its reasons for transformation with two profoundly different evolutionary histories and spirits. 


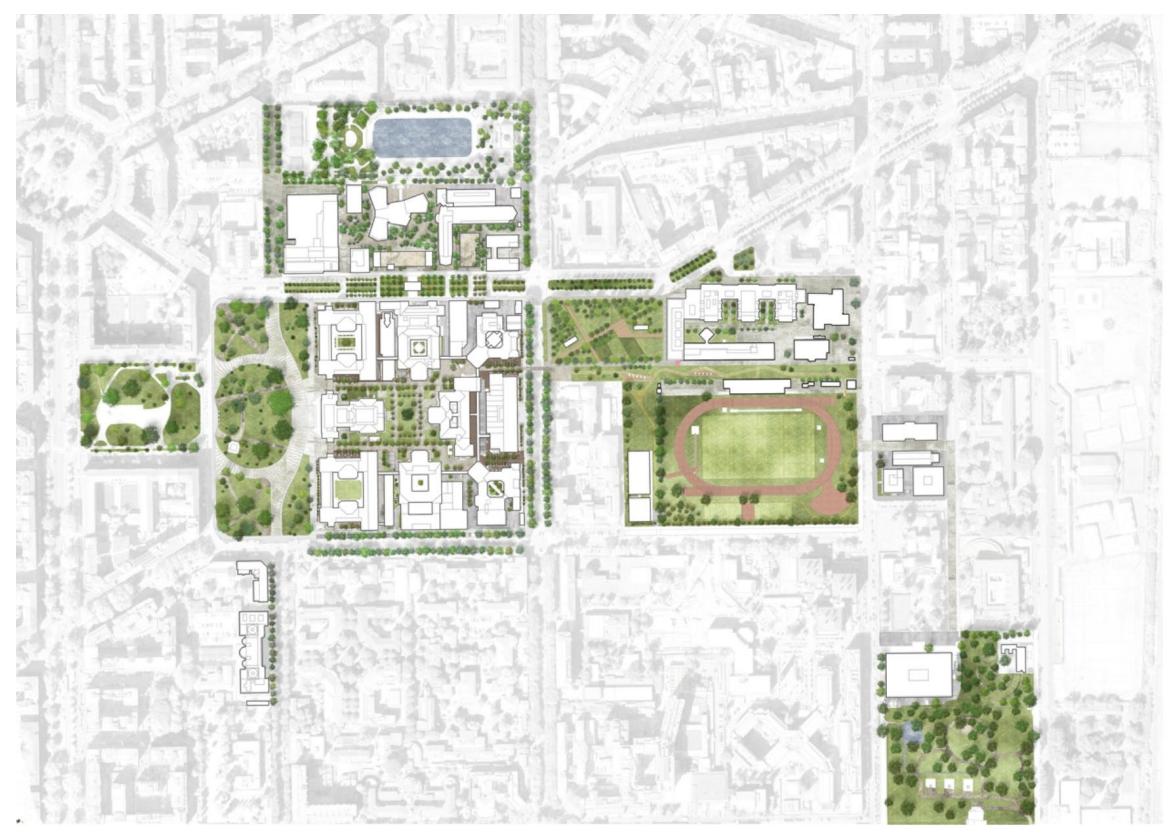

Figure 1. Masterplan for Campus Leonardo, Politecnico di Milano (VIVI.POLIMI, 2018)

The facility located in the Città Studi area, known as Campus Leonardo, is the historical Campus of the Politecnico di Milano, built in the early decades of last century and organised, distributively and morphologically speaking, after the model of hospital architecture with pavilions, from which it drew its inspiration. A strong setup with its own expressive quality, now fully integrated into the fabric of the city which, over the decades, has grown out of its origins as open countryside by way of additions that have enveloped and accommodated the university's spaces, raising them to the status of locations that are barycentric to the entire system of Città Studi.

With the development of the degree programmes and the increase in enrolments that followed World War II, the original nucleus expanded through the construction of new buildings in the surrounding areas, including the premises of the Architecture Faculty (established in 1934), whose current configuration is the result of a series of building operations: the original nucleus opened at the start of the 1950s under the presidency of Piero Portaluppi and work continued under the Plan for the Expansion of the Politecnico di Milano (1958-59), which involved, amongst others, Gio Ponti. Later on came the addition of a further extension, headed up by Vittoriano Viganò (1982-86). The logic of birth, evolution and settlement of the Campuses in the area known as Bovisa - namely Campus La Masa and Campus Durando - was quite the opposite. Bisected by the railway line that connects Milan with the north of Lombardy, the two campuses insisted on abandoned areas that the Politecnico, as of the 1980s, has managed to restore by settling there. 
At the end of the 1980s, with the start of the process that saw the university's extension into the wider area (with branches in Como, Lecco, Cremona, Mantua and Piacenza set up over the course of a decade) and the establishment of the Politecnico Rete, work began on the construction of buildings for teaching and research in the Bovisa area, a neighbourhood to the north of the city which was once one of the most important hubs in Milan's industrial history. The via Durando campus, intended for the Faculty of Civil Architecture and Design, was opened in 1994 and involved the restoration, alongside new building projects, of some historical buildings of industrial archaeology. A few years later, the La Masa area saw the start of a long process of converting the many warehouses in the area into facilities suitable for the laboratory and teaching activities involved in certain Engineering courses.
Starting in 2017, the Politecnico announced an investment policy with a view to bringing its buildings up to the international quality standards now necessary in order to be able to compete with the finest universities across Europe and beyond. In particular, 2020 will see the inauguration of the new Architecture Campus in the Leonardo area: a revitalisation project aimed at fixing up the existing structures belonging to a portion of the Campus which evolved mainly between the 1940s and the 1950s, along with making enhancements to the teaching buildings, with particular reference to model-making and innovative teaching.

The "Bonardi project", as it has been dubbed, focuses on creating the necessary infrastructure and connections for the most important architectural elements of the School of Architecture through a new system of green, public spaces as a replacement for

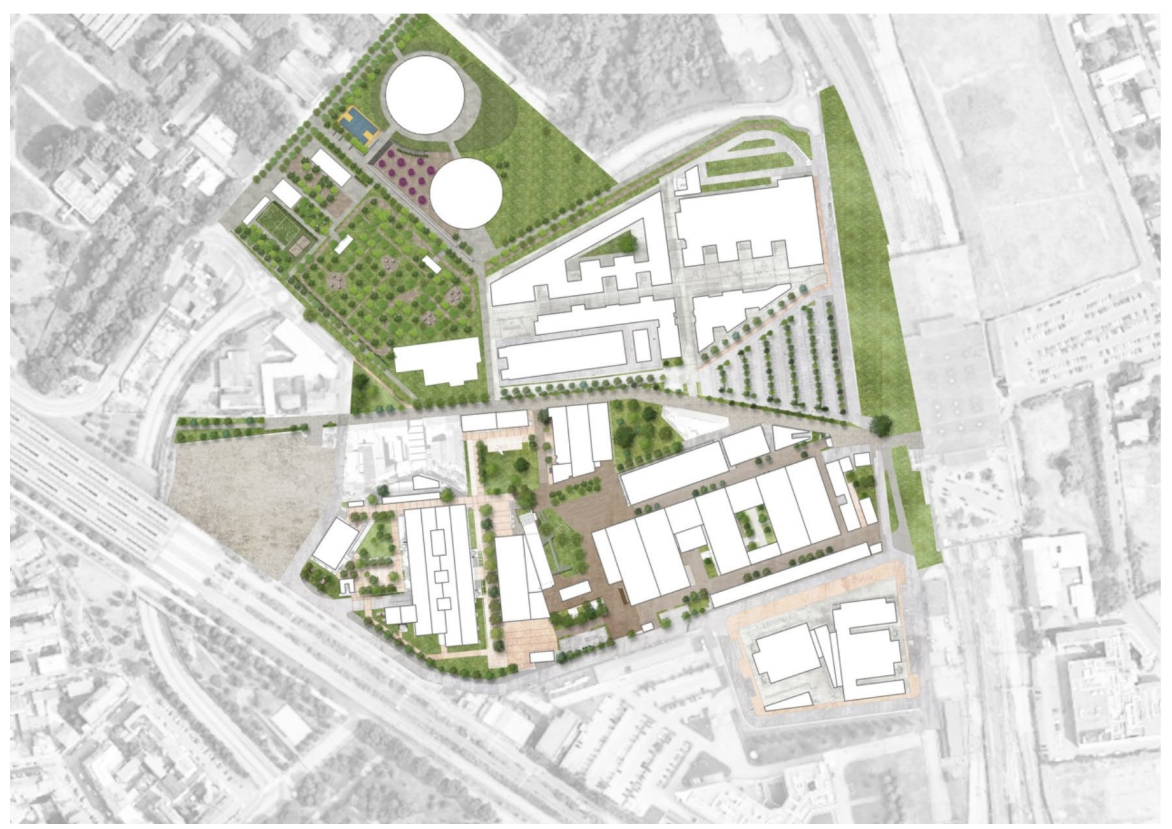

Figure 2. Masterplan for Campus La Masa, Politecnico di Milano (VIVI.POLIMI, 2019) 
the areas previously used as car parks, as well as constructing some new buildings and renovating other existing ones, including the Trifoglio and Nave buildings which are part of the scheme of works which took place in the 1950s under the auspices of Gio Ponti.

All the works are merely branches of a larger redevelopment plan, made possible by an idea from and with the collaboration of Renzo Piano, and drawn up by Ottavio di Blasi \& Partners, which tends to favour open space as the primary connective element of the entire system.

There are currently 15 active construction sites across the two Campuses, all related to works which will see the Politecnico equipped with new world-class structures for the purposes of research, teaching, sport, social inclusion and relationships of those within the University.

In the same vein, a complex and multidirectional strategic project entitled VIVI.POLIMI has been launched, involving the rectorate, teaching staff, research fellows and architects in the design of the Campuses of the future, with particular attention to the quality of the users' social lives, relationships and study in their everyday actions. A quality that involves confined spaces, open spaces, gardens, avenues, squares, meeting places and study places in a spatial continuum between full and empty spaces, different categories of user base, the positives and negatives of the urban fabric.

As such, it is a strategic project aimed at updating the quality of the spaces dedicated to work, research and teaching in the Politecnico di Milano with an international outlook that is increasingly open to a dialogue between the university and the city. Improving the quality of the spaces on the various Campuses means increasing the quality of life for the neighbourhood that has been home to the Politecnico for over 100 years. After years of one-off building works, the project aims to give a unified design to the Campuses, their history and their future.

\section{VIVI.POLIMI PROJECTS}

\subsection{The "Agorà degli studenti"}

One of the first construction jobs planned by the VIVIPOLIMI project - the creation of a space equipped especially for students (dubbed the 'Agorà degli studenti') on the first floor of the School of Architecture on the Campus Leonardo in Milan - involved the redevelopment and enhancement of the

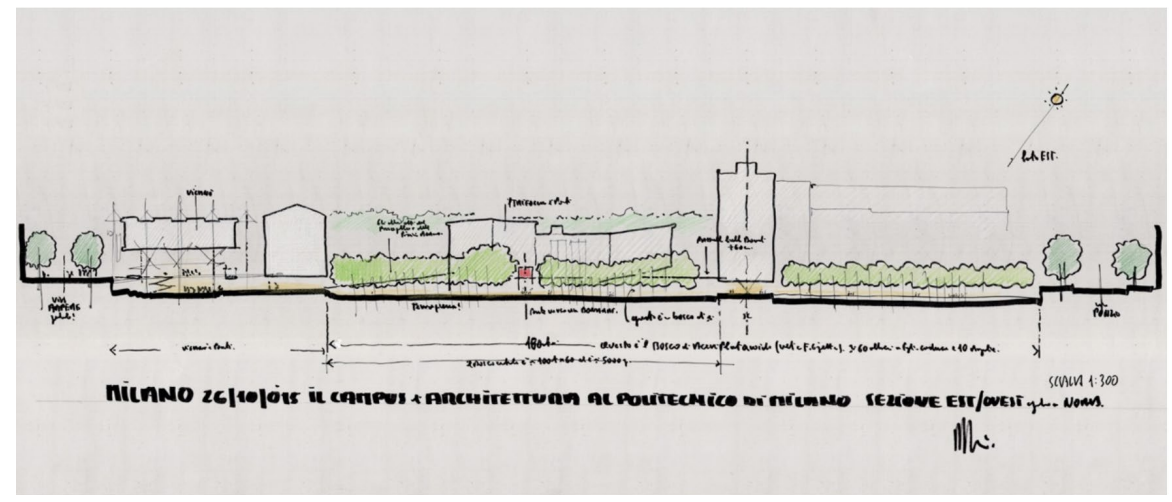

Figure 3. Idea for the new Campus of Architecture (Renzo Piano, 2015) 
interior spaces of the building, obtained by moving some of the secretarial offices to another location, thus creating a space for students capable of meeting the requirements for places to meet and study, which are currently in short supply in relation to the high number of students who attend the School, which is at the very top of global international rankings.

Two elements strongly characterised the intervention guiding the design choices, starting from those on the largest scale and working down to those regarding materials and detail: the historical and cultural importance of the architectural building and its positioning, which is barycentric and strategic with respect to its surrounding buildings.

The area being repurposed is located within a complex of buildings designed by architects/ masters who are universally acknowledged by critics and architectural history to be of considerable cultural importance. Built between 1953 and 1961 based on a design by Giordano Forti, Gio Ponti and Piero Portaluppi, the building was conceived as a "teaching building" within which a sort of sample collection of modern construction was installed, featuring all the existing types of structures, materials, finishes, doors, windows, furnishings and installations for students to get to grips with in a hands-on learning environment.
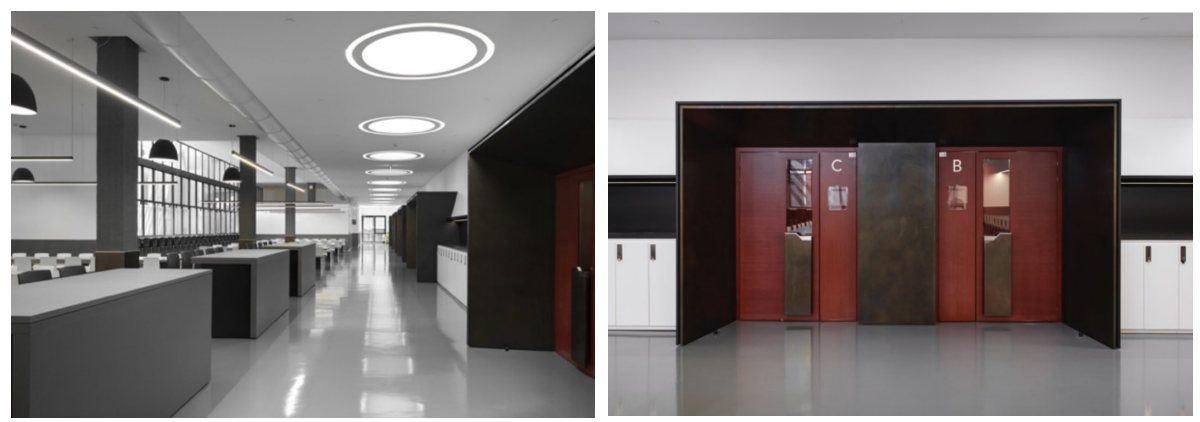

Only two wings of the initial design actually came to fruition, resulting in an L-shaped building and leaving the courtyard and via Ampère façade unfinished. The building was then later completed by a body, designed by Vittoriano Viganò and constructed between 1970 and 1983, which has since come to represent the School's truly iconic building.

The design of the new "Agorà degli studenti", whose execution was marked by the timings linked to the delivery of the lessons conducted within the classrooms which overlooked the construction area, involved demolition of the partitions that separated the Secretary offices, to create a large open space housing over 120 new wired study stations for working alone or in a group around a table, also using computerised tools. The demolition of the secretarial offices, with the consequent removal of the false ceilings, brought the original floorplan of the building to light, characterised by a single slanted roof with the upper extremity coinciding with the window-covered opening

The extreme uniqueness of the building and specific conditions surrounding it guided the selection of building materials, finishes and furnishings, all custom designed for this project: from the doors closing the apertures towards the classrooms, created to ensure adequate noise insulation during lectures, with handles geometrically reminiscent of towards the inner court. 
the shaped profile of a handle designed by Ponti for this same building, to the finishes on the ribbed base of the walls, similar to the parapet finish on the entrance staircase.

A new "student plaza" was immediately baptised "Agorà", symbolising the new meeting place for individual or collective studies, working around a table or on threedimensional models, equipped with new storage areas for personal items, as well as for exhibiting three-dimensional models or graphic projects. The Presidency of the AUIC School was transferred to this new space, reestablishing a historic precedent.

\subsection{Giardino di Leonardo}

As for the open spaces, in line with the strategy of the works as a whole, the priority was to commence the redevelopment of the spaces behind the historic building of the Rectorate: a new space, the "Giardino di Leonardo", bordering the historic and recently-renovated Piazza Leonardo da Vinci, now occupies the existing area through an effective pairing of contemporary flavour with early 20th century style.

The project focuses on restoring and enhancing the campus' historical heritage, creating formal order and enhancing architectural and environmental quality, specifically as regards the central natural green area adjacent to the Rectory and its tree-lined avenues.

In the original design of the Campus Leonardo, the "Giardino di Leonardo" was the heart of the Campus itself, overlooked by the main buildings in accordance with a symmetrical settlement code.

The primary objective is to guarantee the best use and maximum pedestrian viability in the space, making it easier to use by eliminating approximately 130 car parking spaces, which over time have invaded the area: in the scope of sustainability and regeneration, the project is designed to structure the open spaces on the campus to respond to how the space is actually used daily by the people who inhabit it.

The starting point for the design stemmed from the overall conditions of the open spaces on the Campus, which had significantly deteriorated over the decades. Intense use, new functional and technological needs, and the opening of the auto park altered both the spaces and paving materials. The elimination of the trafficable passage inside of the open spaces in the Campus, a source of noise, pollution and hazard, the true transformational element in the context, was the incipient idea driving the project.

The sustainability of the project was then interpreted by prioritising continuous natural green areas, expanding their size and rendering them useable both informally and in several detached equipped islands. These spaces are equipped with wired break tables and seats, with Santafiora stone bases and corten steel support frames. The two islands to the northeast and south of the Rectory are fitted with roofing for use during the sunniest seasons and rain; the equipped area in the garden without any roofing, is dedicated to use during the milder seasons. The project includes renovation of the tree-lined avenues in Luserna stone, creating a more harmonious environment in the historical context in respect to the previous cement pavement, in order to reach a complete pedestrian use, improving accessibility for cyclists, and marking out specific areas for bicycle parking. In terms of trees, the landscape remains largely unchanged, except for the replacement of the trees that had been compromised: the planting of new shrubbery with colourful blooms providing a diversified display over the course of the seasons, with the aim of enhancing the "Giardino di Leonardo" as a green space, is the extent of the garden's new endowment of plant life. 


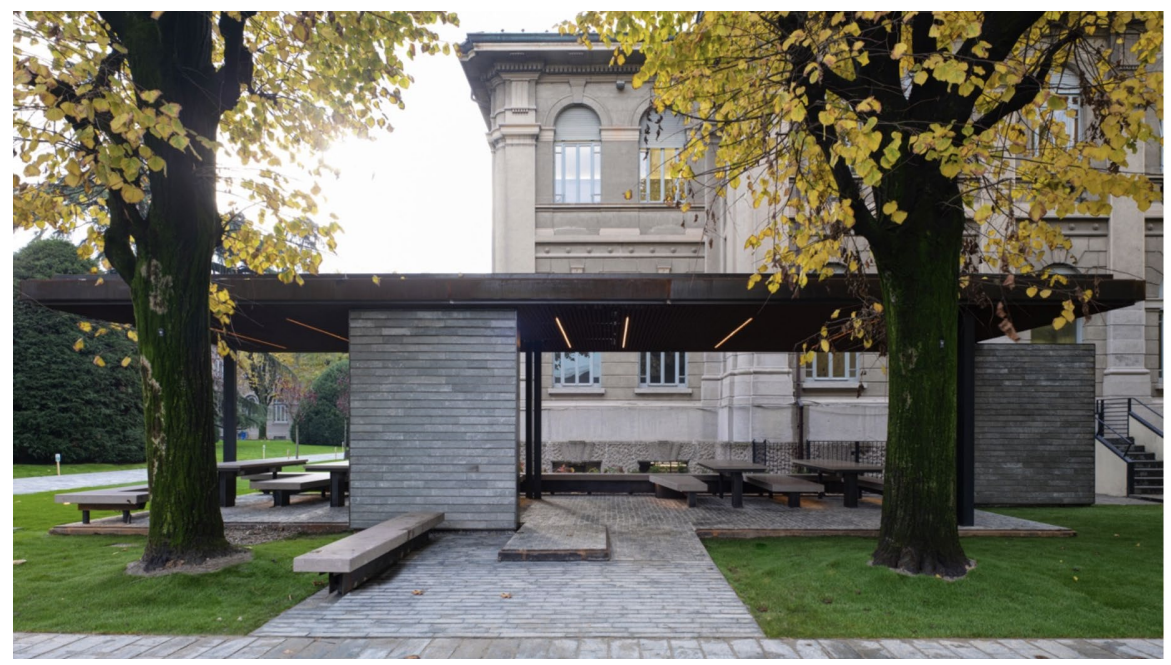

Figure 5. Giardino di Leonardo (VIVI.POLIMI, 2019)

\subsection{Continuity: the internal-external non-limit}

The underpinning idea of the project is to standardise, in terms of form and materials, the many and varied "Gates" dotted around the perimeter of the Campuses, both in Milan and in the university's centres across the region and beyond. Crossing the threshold of a university Campus is not just a physical step, but also a symbolic action. An architectural element made of concrete and corten steel marks the main entrance to the Campus La Masa, welcoming and greeting those who tread its ground day after day. A passageway with an iconic, institutional and monumental value: the Politecnico logo, carved into the material, is symbolic of the University's presence in Milan and the Bovisa neighbourhood.

\subsection{Lights at Polimi}

The recognisability of the Politecnico and its history is also sustained through the enhancement and restoration of its iconic buildings: the renovation and new lighting projects which involved the buildings of the
Rectorate, on the historic Campus Leonardo, were conceived in this vein, generating a domino effect of a progressive willingness to also restore the neighbouring ex-factory buildings.

\subsection{Collina degli studenti}

At the Campus La Masa, the absence of significant plant life and the poorly-identified connection space gave rise to the design of an renaturalised area, achieved through the insertion of a green hill, home to a building capable of holding over a hundred study workstations, on the mezzanine floor, and a faculty space dedicated to the social lives of the teaching staff. Located in a seldom-used area, this "Collina degli studenti" will give an injection of life into an anonymous space by transforming it into the beating heart of the entire Campus: In conclusion: the University represents a city of education and culture to which all advanced civilizations should strive in order to create a generation capable of facing the important challenges of the future. 
The projects listed here have been developed within the structures of the Politecnico di Milano and with the help of the figures related to it: contributions to their preparation of various kinds have been provided by professors, PhDs, research fellows and professionals, assisted by technicians from the Technical Construction Area of the Politecnico itself. In particular, contributions to the aforementioned projects in different roles and for different lengths of time have come from: Prof. Emilio Faroldi, Vice Rector and coordinator of the VIVIPOLIMI project; Prof. Stefano Capolongo, Prof. Francesco Infussi, Prof. Lorenzo Jurina, Prof. Camillo Magni, Prof. Laura Elisabetta Malighetti, Prof. Tomaso Monestiroli, Prof. Eugenio Morello, Prof. Filippo Orsini, Prof. Alessandro Perego, Prof. Gianfranco Petrot, Prof. Tiziana Poli, Prof. Maurizio Rossi, Prof. Michele Ugolini, Prof. Ilaria Valente, Prof. Maria Pilar Vettori; Eng. Arch. Andrea A. Bassoli, Eng. Fulvio Bernabei, Arch. Matteo Cervini, Ind. Eng. Alessandro Corti, Arch. Andrea Cremonesi, Arch. Andrea Gianni, Arch. Giuseppe Mondini, Arch. Giacomo Penco, Dr. Virgilio Piatti, Eng. Edoardo Poletì, Arch. Paolo Raffaglio, Eng. Bruno Sala, Arch. Alessia Sarno, Eng. Gianluigi Sevini, Arch. Manuela Strada, Eng. Michele Terreni. 



\title{
PAPER \#2.19
}

\section{THE MEDITERRANEAN PERI-URBAN HISTORICAL HUERTAS (MURCIA-ALICANTE- VALENCIA-ZARAGOZA). TRANSVERSAL RESEARCH}

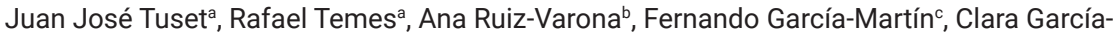 \\ Mayord, Marcos Ros-Sempere
}

\author{
aniversidad Politécnica de Valencia, Valencia, Spain \\ bUniversidad San Jorge, Zaragoza, Spain \\ 'Universidad Politécnica de Cartagena, Cartagena, Spain \\ dUniversidad de Alicante, Alicante, Spain
}

\section{ABSTRACT}

The Peri-urban Historical Huertas $(\mathrm{PHH})$ have been a keystone of the landscape, economy and culture identity of some Mediterranean cities. The change in the economic model, especially the agricultural and urban ones, has subjected these gardens to urban pressures that have induced significant spatial alterations. However, the understanding of these is not simple due to the scarcity of $\mathrm{PHH}$, the diversity of the changes and their variability over time, and the small scale at which the alterations operate over large territories. This paper includes the first steps in the consolidation of a research group focused on the better understanding of these changes, necessary to the conservation of their environmental, social and economic values. The text presents a classification of these alterations obtained through the transversal analysis of the orchards of Murcia, Alicante, Valencia and Zaragoza, distinguishing between those caused by replacement, dispersion, fragmentation and transformation. In addition, it collects observations on the study methodologies of each of these alterations adjusted to $\mathrm{PHH}$ characteristics.

\section{KEYWORDS}

Urban transformations; periurbanization; irrigated areas; methodologies.

\section{INTRODUCTION}

The Peri-urban Historical Huertas (PHH) are strategic in food production (Beltrán, 2012), provision of ecosystem services (Elmqvist, et al., 2015) and preservation of historical heritage, due to their complex traditional irrigation systems (Glick, 1970; Burriel, 1971; Courtot, 1986). In addition, its position in the edge of the urban areas makes this $\mathrm{PPH}$ especially vulnerable, undergoing processes of occupation and continuous transformations (Temes \& Moya, 2016; Ros \& García Martín, 2016; García-Mayor \& Canales, 2018a). As Romero (2016) comments, the (un)protection of the large $\mathrm{PHH}$ and the absence of coordination initiatives at the metropolitan level synthesize very well the risk of lacking effective coherent management and management mechanisms in the second decade of the 21st century. Mediterranean $\mathrm{PHH}$ represent a type of landscape of great singularity for its typological singularity in Europe, as recognized by the Dobris Report of the European Environment Agency (1998), which only identifies six of such landscapes in Europe. As defined by UNESCO, the cultural landscape, denomination in which the landscapes of the garden are inscribed, are a complex reality, composed of natural and cultural components, tangible and intangible, whose combination configures the character that identifies them. 
With the purpose of research about the changes and transformations that have been experiencing the $\mathrm{PHH}$ that still exist in Spain, we have set up a Researchers Network in the Mediterranean region committed to the analysis and study of these $\mathrm{PPH}$, focused specifically in the understanding of the changes this landscapes have undergone from the perspective of environmental and social sustainability.

The spatial alterations of these $\mathrm{PPH}$ have been analysed in recent years from local perspectives, developing methodologies adjusted to the particularities of the predominant changes in each of them. This paper includes a classification of the types of alterations based on the comparative analysis between the different $\mathrm{PHH}$ and a summary of the analysis methods used for each of them.

\section{SPATIAL TRANSFORMATIONS OF THE AGRICULTURAL LANDSCAPES}

\subsection{On the agricultural landscapes}

The morphology and dimension of the $\mathrm{PHH}$ that have been studied are very different, and this is also recognized in the nature and intensity of changes that have characterized each of them. Firstly, the area that constitutes Valencia's historical orchards includes 40 municipalities and covers about 23,000 hectares, half of them, 11,393 hectares, are irrigated orchards classified as undeveloped area by the urban planning. Secondly, Segura's historical orchards constitutes an agricultural continuum and it includes both Vega Media and Murcia's areas. If we focus on Murcia's, the area of huerta includes 13 municipalities and covers 21,169 hectares, which is similar to the Valencia's one. If we focus on the Vega Media's historical orchard, it reaches 21 municipalities that are included and it covers 710, 398 hectares, with traditional irrigated orchard land covering 21,000 hectares out of the total administrative area. Finally, Zaragoza's historical orchards includes 20 municipalities and the relation between irrigated orchard land with respect to total area is remarkably different that the others. Indeed, it covers 38,060 hectares and irrigated orchard land covers 24,850 hectares.

Once the abovementioned description and contextualization of the different orchard's, it is important to clarify what kind of spatial transformations have been identified in those areas. To be specific, we have identified four different types of spatial transformation as a result of having applied a specific methodology, that will be explained later.

- Firstly, the replacement of the historical agricultural fabric by the expansion of urban areas. Some of the references that evaluate and quantify these changes are found in the study of Valencia's PHH (Temes \& Moya, 2015; 2016), and their methodology reveals an example on how to describe these processes.

- Secondly, the dispersion of buildings over the initial agricultural plots involve a great intensity of transformation, especially in Segura's historical orchards. In this case of study Ros \& García Martín (2016a; 2016b; 2017) have defined a preliminary methodology to quantify, classify and supervise this transformation process.

- Thirdly, the transformation of land use into the initial agricultural fabric, from the traditional orchards to new activities. The "micro" scale of this kind of transformations, performed over small plots, reveals a difficulty to apply usual research techniques, with land cover databases, and it requires a methodological revision, as it is described below.

- Fourthly and finally, the fragmentation of the historical agricultural fabric by the definition and construction of new infrastructures highlights an important 
issue: the interaction between the urban development and the landscape conservation of these territories. The analysis of the invariant elements that define this agricultural landscape applied to Segura's historical orchards of Alicante (García-Mayor, 2017; García Mayor \& Canales Martínez, 2015, 2018-a; 2018-b) establishes some key points to study the impact and role of these infrastructures over the $\mathrm{PHH}$.

The following sections describe the main characteristics of the research methods of each of these spatial transformations. The analysis of the results is also explored.

\subsection{Replacement}

New urban development areas occupation processes over HHPM area correspond with urban growth analysis tools, at least initially. However, it reveals specific particularities. Indeed, urban growth is explained as a consequence of the extension of the urban built environment towards the orchard area. Its transformation has been represented as a vector dataset based on the 1:50,000 cartographies from the National Geographic Institute (NGI - IGN in Spanish), using urban blocks as minimal unit. This methodology and the data source guarantee a homogeneous coverage for all the HHPM area. Moreover, the analysis is complemented, for each period, with the raster information provided by the aerial photo coverage (Figure 1).

The analysis of this replacement is studied in detail in Valencia's orchard from 1957 to 2015. Results reveal a great transformation. Data information treatment shows an increase of more than three times of the urban growth area, from 3,414 to 9,730 hectares. This magnitude reaches a high importance if we compare it with regard to the population growth, which increased from 781,113 inhabitants in 1957 to $1,547,479$ in 2015, almost double.

The comparison of urban area in 1957 and 2015 (Figure 2) and its growths, reveal the change in the urban structure and the patterns of the agricultural lands replacement. In the first scenario, 1957, in addition to the historical core, it can be distinguished the first extensions of the city, the Grao and Poblados Marítimos areas next to the port and some linear growths along the main paths. The orchards area is occupied by several polarized settlements, linked to the agricultural economy.

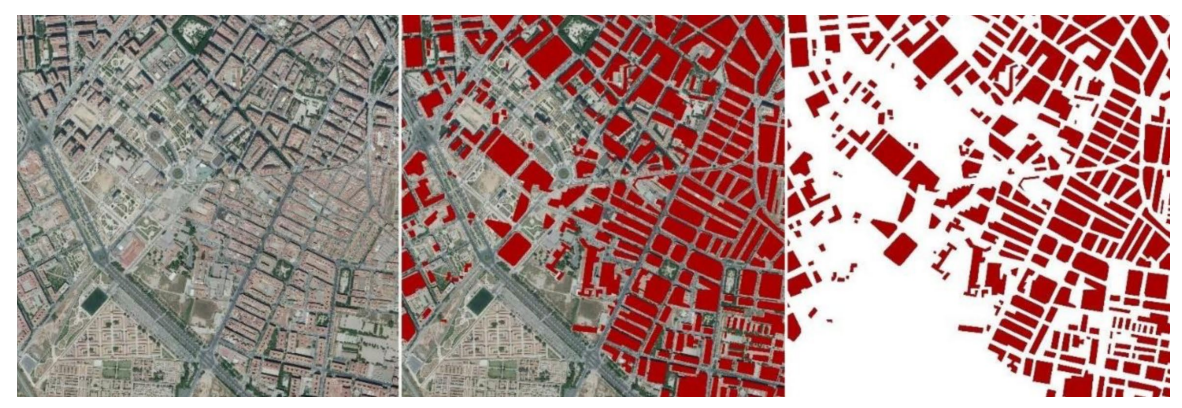

Figure 1. Aerial photography as a reference, vector dataset 1: 50,000 cartography superposition. Source: the authors 

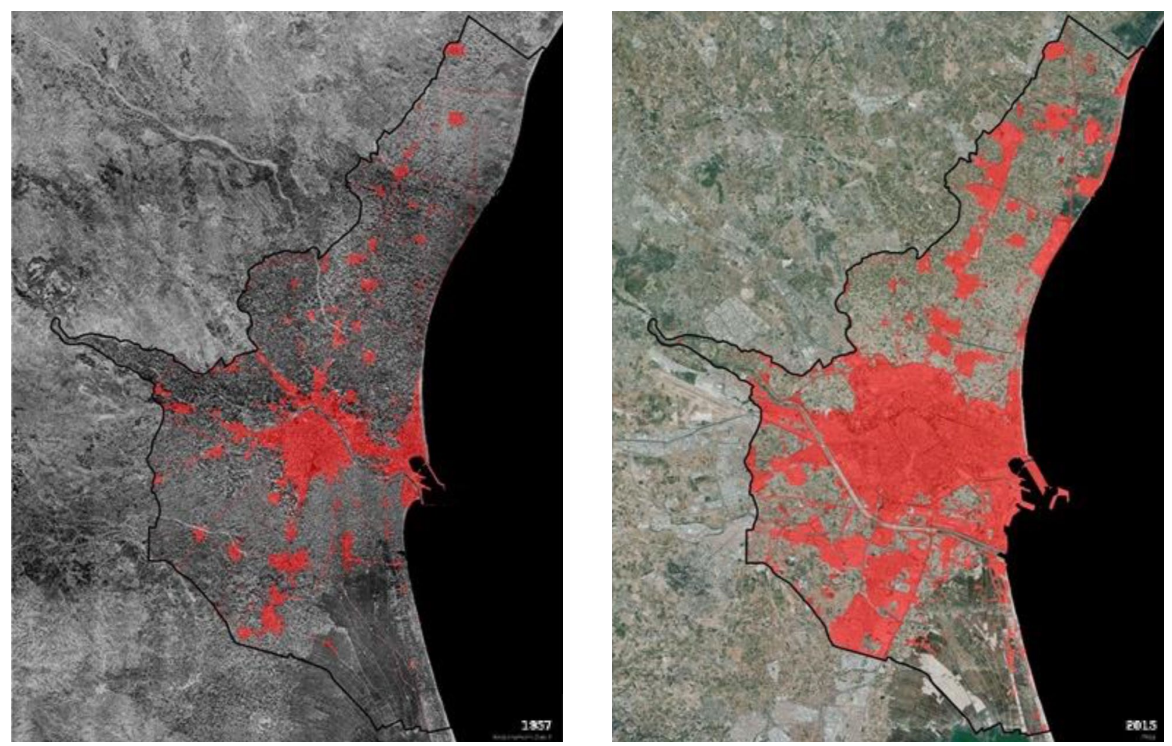

Figure 2. Comparison of the urban growth area transformation in Valencia. 1957-2015. Source: the authors.

In the second scenario, 2015, the shape has a completely different patter, which is clearly characterized by the absorption of all the coastal settlements and the predominance of the urban growth extension. Only two orchard's specific locations last to be replaced: Horta de Campanar, to the northwest area, and Horta de Rovella I Francs, Marjals I Extremals, to the southeast area. Moreover, this transformation reveals multiple urban morphologies that define a new edge between the built environment (the city) and the orchard. Other municipalities located in this area have also assessed some important transformations. Indeed, some conurbations are identified as a new urban patter, which has generated, therefore, not only the division and spatial discontinuity of the orchard, but also its functionality. As an example, a linear pattern of urban continuity can be identified in the north area of the orchard, linked to the roadway that connects Valencia to Barcelona. There is another important pattern of urban continuity in the south, covering Sedaví, Alfafar, Benetússer, Massanassa and Catarroja municipalities. This second area is also characterized by the high use of the land by the industrial sector. This comparison exposes a clear interruption of the continuity that previously defined the agricultural use of the land and the built and non-built environment. This balance has been shattered and it affects mainly the southern area of the orchard. While north area still reveals some continuity of these areas, remaining orchard in the south is currently characterized by residual minor areas.

\subsection{Dispersion}

The construction of dispersed buildings on the original agricultural fabric requires analysis techniques that are no longer based on the urban block but on the plot and its constructions, usually isolated houses. In the case of various orchards in the Region of Murcia, the main source has been cadastral cartography, which also guarantees coverage of all cases, as well as the series of aerial photographs available that allows identifying the period of appearance of existing buildings nowadays. 


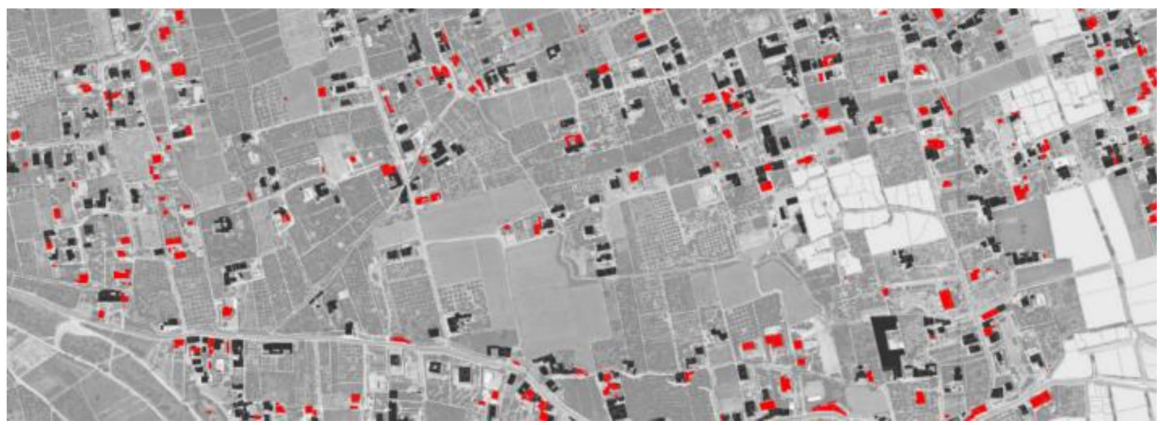

Figure 3. Differential study of the constructions in the West fragment of the Huerta de Murcia, due to the difference of orthophotos (2001-2015). Source: own elaboration by authors based on orthophotographies (SITMurcia) and cadastral cartography.

In the Huerta de Murcia, this method has allowed quantifying the growth of the total constructed area, which has gone from $929,207 \mathrm{~m} 2$ from 1956 to 4,665,395 m2, which is almost five times what was built in 1956. The rate of increase from one year to another, it suffered a gradual increase until 2007, when it fell sharply. The annual rate reached 1,231 houses per year during the period 2002-2007, decreasing to 69 units since 2007.

In addition, the identification of the period of appearance of the constructions has also allowed to identify the occupation patterns. In the period 1956-1981 the increase of houses into the $\mathrm{PHH}$ is very important, and it is mainly located in areas of homogeneous dispersion in the Huerta Oeste and Huerta Sur, as well as in a network of secondary roads, perpendicular to the main ones, in the Huerta Este. In the period 1981-2002 there are homes on the second line of main roads, on secondary roads and even on a third grade of paths. Wide areas of the Huerta Sur are also occupied by homogeneous dispersion. Finally, in the period 2002-2017 there is a very strong combination of all the patterns described above, in almost all of the Huerta sectors analysed.

The effects of the changes caused by this dispersion of housing have been evaluated in areas of smaller scale in the Vega Baja del Segura with two fundamental objectives: first, correlate the phenomena detected at territorial scale with the dynamics of local scale through of cartographic analysis; and secondly, to parameterize the changes in the territory from the application of a $400 \times 400$ m grid as an optimized measure of the habitat in the huertas. This methodological proposal is an adaptation with the same approaches that are used in the parameterization of indicators for urban contexts (AEU, 2008) (Rueda, 2008) since the generic model is based on the parameterization of the complexity of the physical reality of a surface (García-Mayor, 2017).

In the Vega Baja, the detailed analysis of these patterns reflects that the land occupation remains stable until the 80 s of the last century, having as main change the transformation of arable crops to arboreal up to $75 \%$ of the surface in some tiles studied. It will be during the last 30 years when there is a radical change of scenery: the traditional building, isolated and aligned only to one side of the path, is densified to form alignments on both sides of the road that represent a physical and visual barrier with the orchards adjacent. The typology of modest agricultural housing changes to a villa with urban standards, tripling the land occupation. Regarding the uses, the new constructions include, together with the residential, the activity of warehouses and commercial. To 
adapt the road network to the needs and intensity of traffic, the irrigation pipes are piped and the asphalted surface is increased, which increases the unproductive land due to abandonment of agricultural activity, in addition to the area destined to infrastructure corridors and esplanades Despite all these changes, it has been detected that the basic networks of water channels and roads together represent between $13 \%$ and $17.5 \%$ invariably over time in the metrics of the tiles under study.
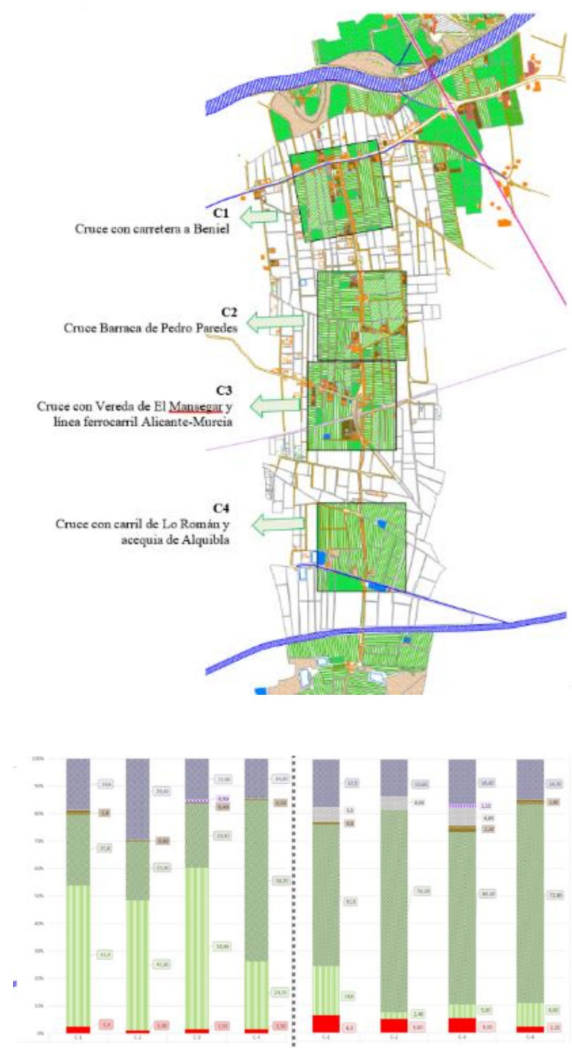

Figure 4. Study of the evolution of the components of the orchard pattern in relation to the growth of a traditional settlement from the analysis of the flights. Source: own elaboration by authors based on the images of Ruiz de Alda flight (1929) and PNOA orthophotographies.

\subsection{Transformation}

The main methodological challenge is related to changes driven in the use of land affecting the agricultural plots. In this regard, different techniques are considered in order to conduct a coherent analytical approach between all four case studies, following the same criteria as previous sections. For this propose, the analysis is based on both the agricultural allotment as a minimum unit and a specific cluster of several agricultural plots, considering that they are applicable to all the cases.

In order to deal with the measurement of changes in the use of land among the $\mathrm{PHH}$, the $\mathrm{NGI}$ provides a database on land occupation that has been the main source for identifying the land cover, namely the Spanish Information System on Land Occupation -SIOSE(Instituto Geográfico Nacional n.d.). Specifically, the database used is referred to three specific reference years: 2005, 2011 and 2014. Initially, the real usefulness of the information gathered through these databases has been contrasted by defining the map keys shown in Figure 5 : Map 1, level 1; Map 2, level 2 artificial and crops; Map 3: level 4 artificial unbundled data; and, Map 4: level 4 crops unbundled data.

These maps' analysis has permitted to detect the following issues and difficulties resulting from the use of the SIOSE data:

1. Considering all four $\mathrm{PHH}$ cases of study, it was detected that the representativeness of SIOSE database is not equally coherent mainly in relationship with "level 4 crops unbundled data; notwithstanding that in all the cases it is the same methodology applied for the identification of the use of land,

2. The land occupation by scattered houses produces distortions in the analysis results of the SIOSE among the cases of study. For instance, areas such as urban discontinuous or mix-urban lands with the greatest dispersion are identified as artificial land cover in some of the cases.

3. Moreover, it is highlighted that it doesn't exist a simple methodology for assessing changes in the land use using the ten-year temporal series of the SIOSE. 


\begin{tabular}{|c|c|c|c|c|c|c|}
\hline \multirow{2}{*}{$\begin{array}{l}\text { Leyenda mapa } 1 \\
\square \text { Delimitacion Huerta Vlc }\end{array}$} & \multicolumn{3}{|c|}{ Leyenda mapa 2} & \multicolumn{3}{|c|}{ Leyenda mapa 4} \\
\hline & \multicolumn{3}{|c|}{ Delimitacion Huerta Vlc } & \multicolumn{3}{|c|}{ Delimitacion_Huerta_Vlc } \\
\hline Coberturas artificiales & \multicolumn{3}{|c|}{ Cultivos herbáceos } & \multicolumn{3}{|c|}{ Otros Leñosos } \\
\hline Cultivos & \multicolumn{3}{|c|}{ Cultivos leñosos } & \multicolumn{3}{|c|}{ Cultivos herbáceos distintos de arroz } \\
\hline Arbolado forestal & \multicolumn{3}{|c|}{ Edificación } & \multicolumn{3}{|c|}{ Arroz } \\
\hline Matorral & \multicolumn{3}{|c|}{ Equipamiento, dotacional } & \multicolumn{3}{|c|}{ Citricos } \\
\hline Pastizal & \multicolumn{3}{|c|}{ Industrial } & \multicolumn{3}{|c|}{ Frutales no cítricos } \\
\hline Terrenos naturales sin vegetación & \multicolumn{3}{|c|}{ Infraestructuras } & \multicolumn{3}{|c|}{ Olivar } \\
\hline Coberturas de agua & \multicolumn{3}{|c|}{ Suelo urbanizable no edificado } & \multicolumn{3}{|c|}{ Viñedo } \\
\hline Coberturas húmedas & \multicolumn{3}{|c|}{ Suelo urbano mixto } & & & \\
\hline \multicolumn{7}{|l|}{ Leyenda mapa 3} \\
\hline Casco urbano histórico & \multicolumn{2}{|c|}{ Zona de extracción o vertido } & \multicolumn{2}{|l|}{ Energía eléctrica } & Educacional & Minero, extractivo \\
\hline Ensanche & \multicolumn{2}{|c|}{ Otras construcciones artificiales } & \multicolumn{2}{|l|}{ Energia hidroeléctrica } & Deportivo & Piscifactoría \\
\hline Urbano discontinuo & \multicolumn{2}{|c|}{ Red viaria } & \multicolumn{2}{|l|}{ Energia nuclear } & Parque urbano & Poligono industrial orden \\
\hline Edificación & \multicolumn{2}{|c|}{ Red ferroviaria } & \multicolumn{2}{|l|}{ Energía solar } & Penitenciario & Poligono industrial no ord \\
\hline Vial, aparcamiento o zona peatonal & \multicolumn{2}{|l|}{ Portuario } & \multicolumn{2}{|c|}{ Plantas de tratamiento de residuos } & Religioso & Industria aislada \\
\hline Zona verde artificial o arbolado urbano & \multicolumn{2}{|c|}{ Aeroportuario } & \multicolumn{2}{|c|}{ Administrativo o institucional } & Cementerio & Comercial u oficinas \\
\hline Suelo urbanizable no edificado & \multicolumn{2}{|c|}{ Conducciones y canales de agua } & \multicolumn{2}{|l|}{ Sanitario } & Campo de golf & Parque recreativo \\
\hline Lámina de agua artificial & \multirow{2}{*}{\multicolumn{2}{|c|}{ Depuradoras y potabilizadoras }} & Cultural & & Agrícola, ganadero & Complejo hotelero \\
\hline & & & & & & Camping \\
\hline
\end{tabular}

Figure 5. SIOSE 2011 - Key map levels used for the analysis of the Periurban Historical Huertas project.

In order to address the above difficulties, the following actions are proposed combining different databased that complement SIOSE information.

1. The development of a new classification which could be representative for the set of $\mathrm{PHH}$ taking advantage of use of land percentages from the SIOSE database.

2. Introducing complementary sources of information such as the Geographical Information System for Agricultural Plots -SIGPAC- (Ministerio de Agricultura 2015), which makes it possible to identify geographically the plots declared by farmers and stockbreeders under any aid scheme relating to the area cultivated or used by the livestock. In relation with SIGPAC database information, this system provides detailed information at the scale of the agricultural plot. Furthermore, intertwining SIGPAC and SIOSE provides accuracy and allows to make a double check of the land information.

\subsection{Fragmentation}

The landscape patterns and agricultural structures of the $\mathrm{PHH}$ are also affected by fragmentation, mainly due to the implementation of infrastructure routes: roads, trainlines, electricity grids, etc. The identification of these elements, which appear as clear cuts in the productive tissue, has been possible using the Spanish national-level topographic and cartographic bases (Instituto Geográfico Nacional 2015), combined with the graphic information from the aerial photography series which are accessible from the Spanish National Plan for Aerial Orthophotography -PNOA- (Instituto Geográfico Nacional 2016). It is important to highlight that the main methodological difficulty related to this issue has been to perform a correct interpretation of each element's role considering both, the effects on the landscape pattern tissue fragmentation, in contrast with the improvement of connectivity 
derive from each infrastructural element scale and connection with other landscape elements. For providing a more thorough insight to the territorial analysis, the historical series of structuring landscape elements of the $\mathrm{PHH}$ selected are being considered in order to better understand these territorial areas as follows:

1. The specific landform: using the terrain model with the contour lines map in combination with the territorial shadow model.

2. The irrigation network system that involves irrigation and drainage canals. These follow a hierarchical canal distribution, first carrying the water from the river to the agricultural plots (river - major canals minor canals), and the drainage of exceeding water (runoff waters and drainage canals). The water system has been fundamental to determine the final land organization and plot distribution, as well as the first stages of the scattered land occupation process.
3. The pathway network is also a hierarchical system which not only provides accessibility to the territory, but also permits the access to the water canal tracks for maintenance and for addressing the water distribution management.

4. The settlements original location in these territories followed a clearly searched for occupy slightly elevated topographical levels, trying to preserve as much fertile land as possible. Later, these settlement patterns resulted in the growth of villages and hamlets situated in relevant crossroads.

The accurate identification of all these elements is possible through the analysis of the Spanish National Geographic Institute documents MTN50 (Instituto Geográfico Nacional 2018), over the period from 1916 to 1950 in the case of the Huerta de Valencia. For the cases of the floodplains and Huertas del Segura there are aerial photographic materials available from 1927, which constitutes a fantastic graphic information for the study of the evolution of these territories.

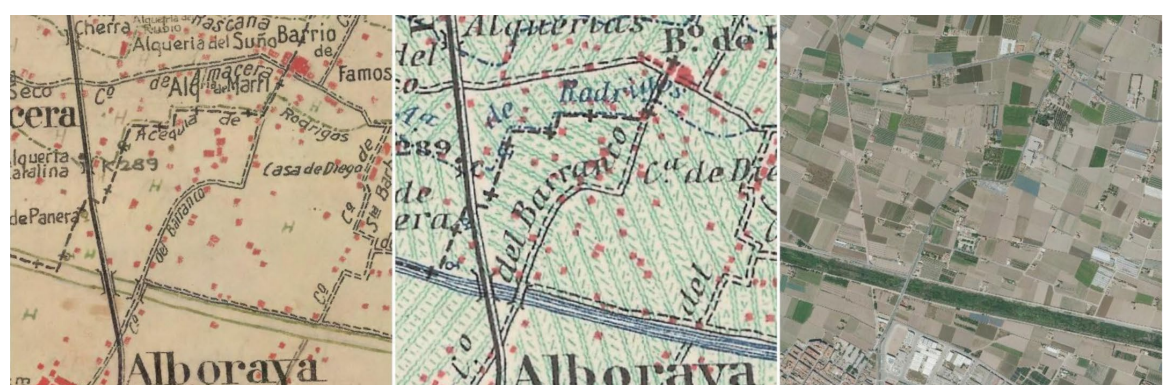

Figure 6. Representation of pathways, irrigation canals and riverbed over the historical cartographies 


\section{CONCLUSION}

The best understanding and parameterization of the characteristics and changes of agricultural tissues seeks to allow a better strategy of integration and safeguarding of these spaces. The cross-sectional analysis of the different $\mathrm{PHH}$ is allowing to complete the local analyses, incorporating phenomena of alterations from a wider context. One of the first results is the conceptualization of the alterations in four main types: substitution, dispersion, transformation and fragmentation. Each of them present in all cases, but with different intensity. The variety of alterations, and their scale and intensity, shows the flexibility to the changes of these tissues, because many are derived from 'micro' transformations, at the level of small agricultural plots. This permissiveness causes a constant phenomenon of transformation (Calvo, 1982), which paradoxically implies a greater resilience of the territory, modifying its structure and appearing new elements proper of the urban or suburban areas (Antrop, 2004). The necessary adaptation of the methods of analysis of the spatial transformations to this type of tissues, adapting the techniques and resources, has been another of the most outstanding results in this phase of the investigation. In this sense, the search for sources that have a homogeneous coverage in the four $\mathrm{PHH}$ analysed has been especially relevant, assessing their representativeness for each of them, and the determination of the scale of the minimum unit of study in each alteration phenomenon (plot, block or area). In this comparative approach, methods have been experimented to solve the disparities in the cartographic databases of land uses of the different spaces, showing the lack of efficient criteria for the classification of this type of peri-urban agricultural spaces. 


\section{REFERENCES}

Antrop, M. 2004. Landscape Change and the Urbanization Process in Europe. Landscape and Urban Planning 67 (1-4): 9-26.

Beltrán, J. P. 2012. El desafío global de la producción de alimentos y l'Horta de Valencia. En: J. Romero \& M. Francés (Eds) La Huerta de Valencia. Un Paisaje Cultural con Futuro Incierto, pp. 173-196 (Valencia: PUV).

Burriel, E. 1971. La Huerta de Valencia, Zona Sur. Estudio de Geografía Agraria.Valencia: Institución Alfonso el Magnánimo.

Calvo, F. 1982. Continuidad y cambio en la Huerta de Murcia. Murcia: Academia Alfonso X el Sabio.

Courtot, R. 1986. Agriculture irriguée et organisation ou l'espace dans les huertas de Valencia et de Castellon. Paris: Université Paris VII.

EEA, 1995. Europe's Environment: The Dobris Assessment, Copenhagen.

Elmqvist, T., Setälä, H., Handel, S., Van Der Ploeg, S., Aronson, J., Blignaut, J., GómezBaggethun, E., Nowak, D., Kronenberg, J. Y De Groot, R., 2015. Benefits of restoring ecosystem services in urban areas. Current Opinion in Environmental Sustainability, vol. 14, pp. 101-108.

García-Mayor, C. 2017. Invariants in the evolution and territorial identity of the traditional Huerta landscape of the Vega Baja of the Segura River: 1929-2010. Boletin de La Asociacion de Geografos Espanoles, 2017(73), 369-388. https:// doi.org/10.21138/bage.2422

García Mayor, C., \& Canales, G. 2015. La huerta de Orihuela en el Bajo Segura: elementos funcionales en la configuración del paisaje. (Universidad de Alicante, Ed.). Alicante: Universidad de Alicante. http:// rua.ua.es/dspace/handle/10045/52734
Garcia-Mayor, C., \& Canales, G. 2018a. Polynuclear urban system, landscape identity and economic development: The Vega Baja of the Segura River (Alicante) case study. In D. Urios, J. Colomer, \& A. Portalés (Eds.), 24th ISUF International Conference. City and territory in the Globalización (pp. 47-53). Valencia: Editorial Universitat Politècnica de València. https://rua.ua.es/ dspace/handle/10045/75990

García-Mayor, C., \& Canales, G. 2018b. La Vega Baja del Segura, una huerta sitiada: la transformación del territorio. Cátedra Arzobispo Loazes, Universidad de Alicante. https://rua.ua.es/dspace/ handle/10045/88415

Glick, T.F. 1970. Irrigation and Society in Medieval Valencia. Cambridge: Cambridge University Press.

Instituto Geográfico Nacional. n.d. Geoportal SIOSE. https://www.siose.es/.

2015. Base Topográfica Nacional de España. 2015. https://www.ign.es/web/cbg-areacartografia.

2016. Plan Nacional de Ortofotografía Aérea (PNOA). 2016. https://pnoa.ign.es/.

2018. Mapa Topográfico Nacional MTN50 (IGN) 2018. http://centrodedescargas. cnig.es/CentroDescargas/catalogo. do?Serie=Mapas.

Ministerio de Agricultura, Pesca y Alimentación. 2015. Aplicación SIGPAC | Fega.Es. 2015. https://www.fega.es/ es/PwfGcp/es/ayudas_dir_desa_rural/ aplicacion_sigpac/index.jsp.

Romero, J., \& Melo, C. 2016) La ordenación y gestión de las huertas mediterráneas españolas. El tiempo de la (s) política (s). En: Vera, J. Fernando; Olcina, Jorge; Hernández, María (eds.). Paisaje, cultura territorial y vivencia de la Geografía. Libro homenaje al profesor Alfredo Morales Gil. San Vicente del Raspeig: Publicaciones de la Universidad de Alicante, 2016. 
Ros, M. \& García Martín, F.M. 2016a. Cinco palmos 1929-2015. Transformación de usos del suelo en la Huerta de Murcia. Murcia: CRAl Biblioteca - Universidad Politécnica de Cartagena.

Ros, M. \& García Martín, F.M. 2016b. Patterns of non-planned occupation of the periurban territory of the Huerta de Murcia, 1929-2015. En: Centre De Política De Sòl I Valoracions (ed.), Back to the Sense of the City: International Monograph Book [en línea]. Krakow: s.n., pp. 826-837.

Ros, M. \& García Martín, F.M. 2017. Stages of territorial configuration in the non-planned occupation of the Huerta de Murcia, 19292015. 24th ISUF International Conference, City and territory in the globalization age. Conference proceedings [en línea]. Valencia: Universidad Politécnica de Valencia, pp. 97-106.

Rueda, S., Cormenzana, B. 2008. Plan Especial de Indicadores de Sostenibilidad Ambiental de la Actividad Urbanística de Sevilla.

Temes, R.R. \& Moya, A. 2015. Dynamics of change in the peri-urban landscape of Huerta de Valencia: the case of La Punta (Valencia). WIT Transactions on Ecology and the Environment. 192:123-131.

Temes, R.R. \& Moya, A. 2016. Typology of the Transformations Occurred in the Peri-Urban Space of Huerta de Valencia. Evidence from North Arch of Valencia (Spain). International Journal of Sustainable Development and Planning 11 (6): 996-1003. 



\title{
PAPER \#2.20
}

\section{EMPLOYING THE INDUSTRIAL LANDSCAPE. INSIGHTS ON THE USE OF COLLECTIVE SPACES OF INDUSTRIALIZATION IN ETHIOPIA}

\author{
Arnout De Schryvera \\ ${ }^{a}$ KU Leuven, Ghent, Belgium
}

\section{ABSTRACT}

After the end of the civil war in 1991 Ethiopia became a relatively solid country. Today it is going through what it looks like a turbulent coming of age. In the last two decades, the country has experienced a frantic and exponential wave of urban development, bolstered by the so-called "Ethiopian Renaissance", an optimistic narrative of economic, cultural and social blossoming. New housing ensembles, real estate investments, infrastructures and industrial villages are changing the urban structure of Ethiopia and its cities to an extent never reached before. This process is going with intriguing insights and constraints.

This contribution will look at the industrial landscapes emerged from this optimistic narrative of industrialization and globalization and uses three carefully selected case studies. These case studies are all financed and constructed by the local government through the IPDC "Industrial Parks Development Corporation" program and rented for competitive rates to global firms mostly in clothing industry such as H\&M, Calvin Klein, etc. . The development plan is an impressive display of faith in the ability of infrastructure and architecture to embody development.

However, its side effects - the creation of urban enclaves, extreme rationalization of space and clear social concerns - coupled with the constant threat that global firms can simply abandon those urban landscapes moving their production to cheaper environments are at the end undermining a sustainable development, the spatial and social structures of a city, a neighborhood or a community. At the same time, an answer to these shortcomings cannot simply pass through an uncritical celebration of resilient, inclusive industrialization processes, ignoring the economic and political realities of these processes. This contribution questions the use of collective spaces of those industrial landscapes to integrate into the social and spatial patterns of a city, neighborhood or community.

\section{KEYWORDS}

Ethiopia; industrialization; urbanization; infrastructure; collective spaces.

\section{INTRODUCTION}

Ethiopia's history reads as an intriguing voluminous book. Ethiopia in its political and structural form as we know now is relatively new but an undeniable result of its past experiences. A brief knowledge of these past experiences from ambitious modernization programs to civil wars and famine crisis's is necessary to understand the optimistic narrative of social, cultural, political and economic bloom we are witnessing now.

This introduction will briefly introduce you into Ethiopia's history to bring you later to the actual state of the research question and its rationale.

\section{A brief history}

A first age of modernization and preliminary kind of industrialization (export of coffee) in Ethiopia took place in the beginning of the $20^{\text {th }}$ century under emperor Menelik II and Haile Selassie. After the Italian occupation which 
took place from 1936 till 1941 Haile Selassie continued his ambitious programmes of modernization and centralization of policies. Right after WW II, Ethiopia became a charter member of the United Nations.

However, in this post-world war II period, the nobility, students and military officers began to see Haile Selassie more and more an "agent of US imperialism" ignoring the actual cultural strengths of the country. Peaceful protests where violently responded by the state. In 1974, after days of social unrests and protests in the capital city Addis Abeba, Haile Selassie was deposed. This unstable political and social period made the way for a communist regime, known as the Derg.

A civil war followed by droughts and a serious famine crisis which affected 8 million people and left 1 million dead hastened the collapse of the regime in 1991. This smoothened the path for another drastic change in the Ethiopian political system after a dark period of war and famine.

This political system, which we still know today, is an optimistic narrative that leans on the strengths of Ethiopia, being their national heterogeneity. This federal system (one of the few federal states of the African continent except for Nigeria, North and South Sudan and Somalia) wants to embrace the immense diversity of Ethiopia instead of one group suppressing the other. Since the collapse of the regime, Ethiopia is a relatively solid country experiencing an exponential wave of urban development, economic, social and cultural blossoming.

Recent endeavors to further decentralize the federal state puts new social and political pressure. The country is going through what it looks like a turbulent coming of age.

\section{Urbanization and industrialization}

With a current urbanization rate of $4.63 \%$, Ethiopia is the $7^{\text {th }}$ fastest urbanizing country of the world. With an urban population of only $20,8 \%$, Ethiopia has, on the contrary, one of the lowest urban populations (Central Intelligence Agency, World Factbook, 2018). Urban areas such as the capital of Ethiopia, Addis Abeba and secondary cities such as Bahir Dar and Dire Dawa are changing to an extend never reached before. An increase in urbanization of the population leads to growing challenges on how to sustainably accommodate this rapidly growing immigration into the larger metropolitan areas.

As a consequence, larger metropolitan areas are forced to produce easily accessible labor productive jobs beyond their own possible capacities. The local government's answer is to kick start industrialization by the construction of the so-called industrial villages. This development program is an incredible display of faith in infrastructure and architecture to embrace this extreme urbanization. This process goes with intriguing insights and constraints and is directly related to the mentioned population and immigration growth numbers and the multiple challenges they bring by for local sustainable development.

The construction of these industrial landscapes goes often with little of less spatial characteristics for human interaction and qualitative working spaces. They create urban enclaves with an extreme rationalization of space that brings clear social concerns with them. Simultaneously, the constant thread that global firms can simply abandon those industrial landscapes moving their production to cheaper environments are at the end undermining a sustainable and inclusive development for the spatial and social structures of a city, neighborhood or a community.

At the same time, an answer to these shortcomings cannot simply pass through an uncritical celebration of resilient, inclusive industrialization processes, ignoring the economic and political realities of these processes.

This research paper seeks to provide insights in the actual use and/or potentials 
of the collective spaces of those industrial landscapes to better understand how these spaces can integrate into the existing social and spatial patterns of a city, neighborhood or community. In a second phase (which will not be handled in this paper) those research findings will lead to insights on the transformation of the urban fabric through studying the role and impact of architectural and landscape interventions that operates at the intermediate scale (the scale between the architectural intervention and the urbanistic strategies). This paper is part of a long-term research engagement on how architectural interventions, open spaces, the property structure and its inherent accessibility and permeability models can configure collective spaces of social and productive encounter and how the local community can give meaning to them by engagement and appropriation.

This paper will first frame the research question by introducing conceptual notes on industrial landscapes and the collective space within them, followed by a specific reading of three carefully selected case studies of industrial villages in Ethiopia (Addis Abeba, Bahir Dar and Dire Dawa). These case studies have all one thing in common and are all financed and constructed by the local government through the IPDC "Industrial Parks Development Corporation" program and rented for competitive rates to global firms mostly in clothing industry such as $H \& M$, Calvin Klein, etc. . They are part of a larger program of 22 industrial villages giving a total size of approximately 17.735 hectares.

\section{NOTES ON THE INDUSTRIAL LANDSCAPE AND COLLECTIVE SPACES WITHIN THEM}

In literature on processes of industrialization in an African context, formalization of (collective) space and urbanization are mostly discussed together. As Doug Sanders mentions in his book Arrival Cities:

what will be remembered about the twentyfirst century more than anything else except perhaps the change of climate is the great, and final shift of human population out of rural agricultural life into cities, (Sanders 2011)

Sanders demonstrates the importance of a good understanding of processes of industrialization as a result of this worldwide urbanization trend. The subject is therefore widely discussed in the discipline of economy, anthropology, sociology, architecture, urban

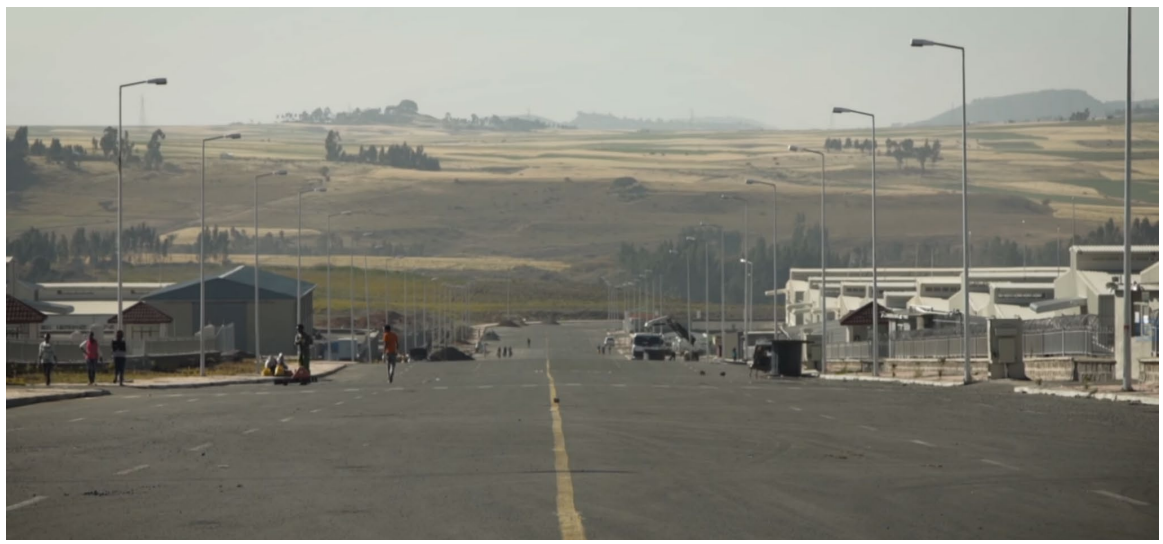

Figure 1. Image of the streetscape (Source; Own picture, 2018) 
planning and art. Can architecture alone solve the social challenges and concerns? No, nor can a journalist, economist, sociologist or anthropologist, but it can give concrete impulses and effective instruments or strategies; a different direction for these challenges and concerns to the ongoing discourse.

\subsection{Policy thinking}

In policy thinking there is a general consensus across different disciplines about the importance of sustainable and inclusive industrial landscapes and the important role of collective spaces within them.

Specifically in the field of Architecture Kastani, J., Polach, T., Sewnet, H., and Van Der Westhuizen, A., (Angélil and Hebel 2009) defined (based on various case studies in Ethiopia) the making of, what the authors call, social infrastructure based on public participation from different local actors one of the essential strategies for the making of sustainable and inclusive industrial landscapes.

These conclusions are in line with Jan Gehl's city planning and development strategy: "life, space, building", and to prioritize them in that order. One of Gehl's "toolbox" of planning principles is public participation.

Also equivalent to Gehl's planning and development conclusions is the current redevelopment of mostly Western postindustrial landscapes in which the people and the collective spaces within the industrial landscape are the protagonists. Postindustrial landscapes are emerging as a product of industrialization i.e. as a byproduct of the deindustrialization of a society (Cho, Shin, 2014; Garaca, et al., 2014; Jahic, et al., 2014). One of the common expressions used to describe this kinds of landscapes is "landscapes of nostalgia" (Halewood, Hannam, 2001; Xie, 2006).

Despite mostly all those industrial landscapes became "landscapes of nostalgia" and lost their initial function and by this are somewhat outside the scope of this research, most of those landscapes are intriguing examples of how the collective space can be or become the framework for the industrial landscape and by this more integrated in the existing social and spatial structures of their city. They are able to strengthen the local identity and to create new urban centres (Trettin, et al., 2011). The concept of restructuring the landscapes of nostalgia has shown significant potential. The positive experiences of Western countries can be used as a pattern for developing countries that have similar issues (e.g. Jahic, et al., 2014; Petrovic, 2013; Dukicin, et al., 2011, 2014).

Also in the discipline of economy there is a similar consensus. For example, the conclusions and policy recommendations in the ERA 2016 report of the United Nations Economic Commission for Africa (UNECA 2016) states that:
Africa's industrialization has the potential to create green jobs, ... , and exposing women to green skills and technologies on the way to achieving inclusive, equitable and sustainable green industrialization.

The ERA 2016 report in general is a celebration and encouragement for all African countries and cities to foster inclusive, sustainable and "green" industrialization processes in order to strengthen their role into the world economy which will then boost the local economy.

The role of collective spaces within the industrial landscapes are, in contrary with other disciplines, rather forgotten.

\subsection{Actual implementation}

Edgar Pieterse on the contrary witnesses a remarkable discrepancy of the earlier mentioned participatory and inclusive policy thinking and the actual implementation of 
industrial landscapes (Burdett, R., Rode, P. et al. 2018).

A first point which may explain this discrepancy is the political sphere in which most of these ambitious projects are happening. As Pieterse remarks "there is a gulf between the formal democratic prescripts and the everyday dynamics of governance and control in contexts of limited sources and various lines of social stratification". According the author, many local governments in African cities more likely opt for chauvinistic populist policies of clientelism and patronage which at the end undermines local participatory and inclusive development strategies.

This brings us to the second reason: the public administrations capacities and capabilities. The implementation of sustainable and inclusive industrial landscapes based on public participation might go beyond a local government's ability to handle the detail and complexity of a city's "small scale" development strategy. The implementation of inclusive industrial landscapes may work in small scale

cities, however, governments in smaller cities often lack the staff, and or in-house expertise to do so.

A third point that challenges the sustainable and inclusive implementation of industrial landscapes is the market. Land speculations, real estate investments and demand driven space developments have for ages increasingly characterized how cities look like. Project budgets, investment interests (beyond a building's role in a particular space) and client- service provider relationships may at the end result in buildings that do not contribute to a quality of urban (collective) space.

\subsection{Embrace the reality}

As briefly mentioned in the introduction, it is this discrepancy that is used as starting point for this research project without falling in an easy dichotomy of "the one is good and the other is bad". This research starts from the actual (large scale) implementation and looks for, sometimes invisible (small scale) collective spaces.

An example from the discipline of art in which this discrepancy is used as a starting point is the work of the Chinese artist Cao Fei. The artist starts from the actual (collective) space within the industrial landscape and is able to reflect this positive policy thinking about industrial landscapes (as earlier discussed) onto the rather negative reality (noted by Pieterse).

The film "Whose Utopia" for example (Cao Fei, 2006) explores the life of emigrant factory workers in which the factory workers share their aspirations and hopes for the future. The artist filmed them acting out their dreams within the factory space, interrupting the usual rhythms of factory life. The film is a rather optimistic approach in the discourse where the actual industrial landscape is more than a rationalization of space and pure economic production. The (collective) space within the factory is given a social dimension in which the industrial landscape acts as a framework for the integration of social patterns.

The selected case studies, subject of the research, indeed includes these discrepancies between policy thinking and actual implementation. This research aims to understand the actual use and/or potentials of

the collective spaces within the implemented industrial landscapes to give these existing collective spaces the same meaning as Cao Fei's insights and to include these insights in further development strategies.

The aim is to include the industrial landscapes more into the existing social and spatial patterns of the city, community of neighborhood. 


\section{CASE STUDIES}

The following selection of case studies have one thing in common and are all financed through the Ethiopian IPDC program from the local government and rented to global firms. In total, 22 similar industrial parks are planned or currently under construction, giving a total size of approximately 17735 ha. . The selection of the case studies is based on the following criteria and is a clear representation of the other 19 industrial parks in the IPDC program.

- The size: All the selected case studies have a considerable, non-neglectable size to the city they belong. As a consequence, all industrial villages do have a substantial impact on their city they belong to. Nonetheless there is a difference in scale between the different case studies. Bahir Dar is a rather smallscale industrial village compared to the others but is however in scale with the size of the Bahir Dar secondary city. Bole Lemi is a rather medium- sized industrial village compared to the scale of Addis Abeba. Dire Dawa on the other hand is the largest industrial city currently under construction and compared to the scale of Dire Dawa city the industrial village is absolutely out of scale. This range of different scales is representable for the whole development of industrial villages in Ethiopia. The financial entry: As mentioned before, most of the industrial villages are financed by the government through the IPDC program. In our selected case studies this is not different. - Industry type: In all industrial villages, the textile industry is largely present in which the ginned cotton is spun, meshed, coloured, sewn together as textiles, and packaged. The presence of this textile industry in the industrial villages is not by coincidence. Ethiopia has a rich tradition of cotton production and weaving

which is still widely exercised in rural households as a source of income. This textile production on an industrial scale slightly replaces the tradition and craftsmanship but, however uses the existing traditional skills of mostly rural women for their production. The industrial villages can be seen as arrival points for (mostly female) rural migrants using their tradition and skills to allow a fluid integration in the urban society.

- Urban/ rural link: All cases are located in the periphery of the city, strongly isolated from the city centre which makes the integration of the industrial city in the existing spatial and social urban network more difficult. In all cases there is a strong infrastructural link with the city they belong to. The scale of the city they belong differences in rages from approximately 5 mln. inhabitants (Addis Abeba) to 300000 inhabitants (Dire Dawa) which provides different social and spatial dynamics. Due to there location in the periphery all cases do have on the contrary also a very strong rural link. In all cases, rural inhabitants, villages and agricultural land needed to make space for the construction of the industrial village providing both tensions and opportunities for the former rural inhabitants.

- Infrastructure: In case study 1 and 3 (Bole Lemi and Dire Dawa) there is a strong infrastructural link with either Bole international airport in Addis Abeba or the Ethio-Djibouti railway in Dire Dawa. In Bahir Dar on the other hand we do witness a lack of an infrastructural link. Having both types of case studies will provide insights on the role and importance of having a strong infrastructural link or not.

- Conditions: All cases do not meet the minimum living and working conditions. All cases has been subject to a discourse on labour productivity, working conditions and minimum wages with various strikes in several factories as a result.

\subsection{Bole Lemi industrial village - Addis Abeba}

This first case study contains two industrial villages (Bole Lemi I and II) merged together into one of the largest industrial village located 
in the periphery of Addis Abeba, the capital city of Ethiopia and the African Union. Due to the presence of the capital city, the scale, social and spatial dynamics are different compared to other industrial villages located near secondary cities such as Bahir Dar or Dire Dawa. The planned size of the industrial village is approximately 342 ha. and aims to provide jobs to approximately 75000 citizens, mostly female workers in the textile and garment industry.

Every day, a certain type of formal bus system is bringing all the factory workers back and forth to their homes and/or neighbourhoods. Every morning and evening hundreds of busses, all coloured in blue so they are easy recognisable in the streets of Addis Abeba, are bringing or collecting thousands and thousands of people more or less at the same time.

This daily phenomenon is a fantastic display of collectivity in space and should be seen as an absolute strength for the collective spaces in the industrial villages. This massive displacement of people at the same time at the same place is giving meaning to the collective space in which this displacement is happening. Additionally, the recognisable blue colour of the commuting buses is another excellent example of how the presence of the industrial villages in the periphery of the city become part of the daily life and daily collective space even in the centre of Addis Abeba.

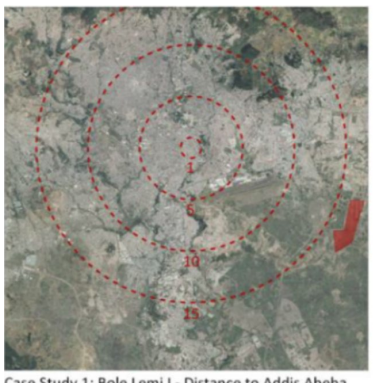

Case Study 1: Bole Lemi I - Distance to Addis Abeba city centre Google Earth Image: 28/09/2018

Figure 2. Plans and i inage Bol Lemi industrial village (Source: Own pitcture and plans 2018)

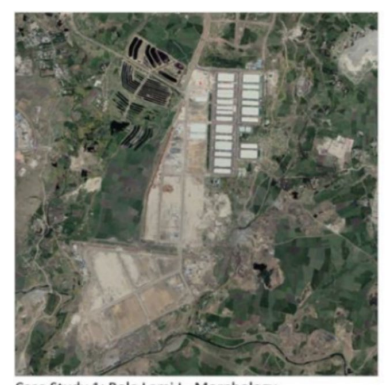

Case Study 1: Bole Lemi I - Morphology Case Study 1: Bole Lemi I- Morpho
Google Earth Image: 28/09/2018

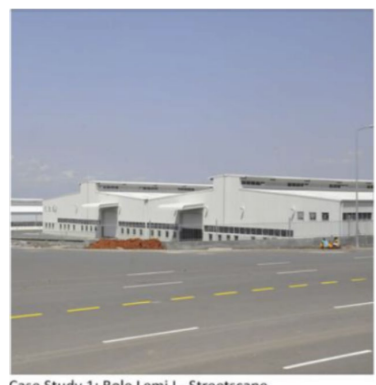

Case Study 1: Bole Lemi I- Streetscape
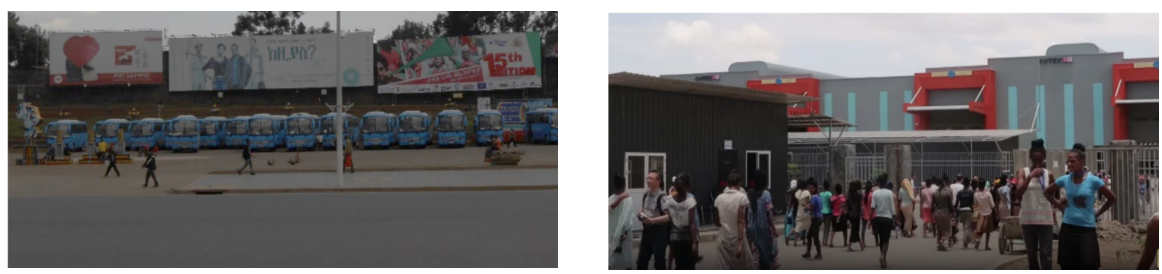

Figure 3. (right) Blue transport buses (Source: Own picture, 2016)

Figure 4. (left) Everyday arrival to the industrial village (Source: movie still CGTN, 2017) 


\subsection{Bahir Dar industrial village - Bahir Dar}

The "Bahir Dar industrial village" is located near the secondary city: Bahir Dar (approximately $580 \mathrm{~km}$ North of the capital, Addis Abeba). The planned size of this industrial village is 1000 ha. from which the first phase of 75 ha. is currently finished. The village aims to create labour productive job opportunities for 20000 people in the garment and textile industry. Global firms such as Calvin Klein and Tommy Hilfiger already subscribed their intention to partly move their production to this industrial village. The city of Bahir Dar is due to its location near Lake Tana and the source of the Blue Nile an assured overnight stop for all tourist tours in Ethiopia and by extend even tourist tours through The Horn of Africa.

In a global trend where tourism is largely directed by social media and a search for the most unique Instagram-worthy picture on unique settings (i.e. abandoned, out of scale spaces are always a big hit), this phenomenon could be used as one of the potential ingredients to give the collective spaces in the industrial village a different meaning. Tourism itself will not help to integrate those industrial villages into the existing social and spatial patterns of the city. The whole setting around it, mostly based on local entrepreneurship and local networks, and the fact the collective space gains a certain importance and meaning will indeed bolster the relation of those industrial landscapes with the city and may evolve towards an inclusive, sustainable landscape.

\subsection{Dire Dawa industrial village - Dire Dawa}

The last case study is the Dire Dawa industrial village near the city of Dire Dawa. Dire Dawa is a city of approximately 300000 inhabitants, East of Addis Abeba and close to the border of Djibouti. Unique is that this industrial village is located next to the Ethio-Djibouti railway. As Ethiopia is landlocked and the port of Djibouti, via the Ethio-Djibouti railway is currently the fastest over ground route to the sea, Dire Dawa is the first and thus fastest productive connection between Ethiopia and the sea (port of Djibouti). The industrial village with a planned size of 4000 ha. is to date the largest industrial village of Ethiopia. The first phase (150 ha.) is currently build and active. Phase two is under construction.

Dire Dawa industrial village is more than 15 $\mathrm{km}$ located outside the city centre and has compared to the others one of the strongest links with the rural setting.

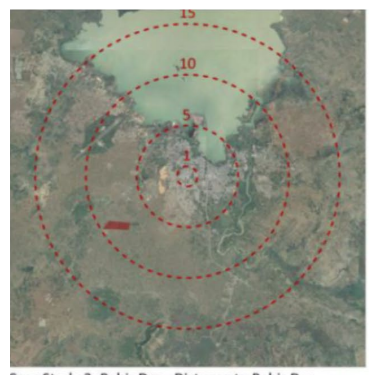

Case Study 2: Bahir Dar - Distance to Bahir Dar ity centre Google Earth Image: 12/11/2018

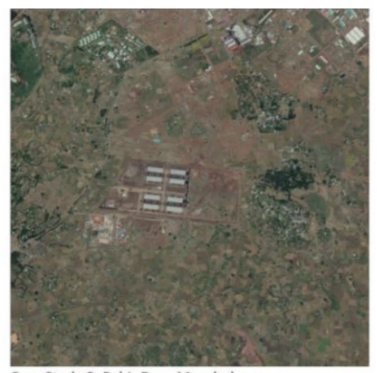

Case Study 2: Bahir Dar - Morphology Google Earth Image: 12/11/2018

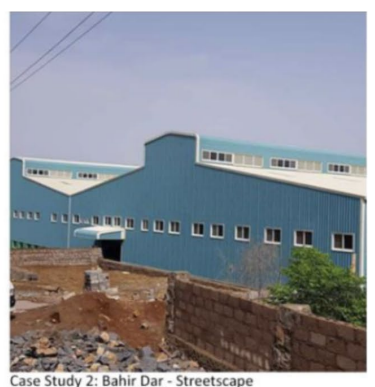

Case Study 2: Bahir Dar - Streetscape

Figure 5. Plans and image Bahir Dar industrial village (Source: Own picture and plans 2018) 


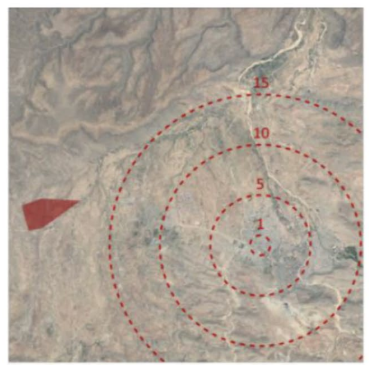

Case Study 3: Dire Dawa - Distance to Dire Dawa city centre Google Earth Image: 26/03/2018

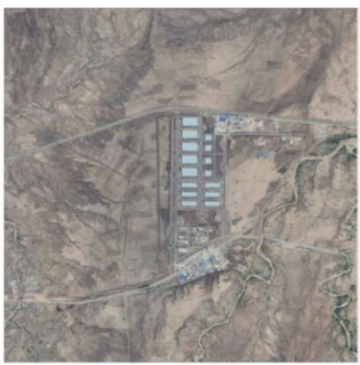

Case Study 3: Dire Dawa - Morphology Google Earth Image: 26/03/2018

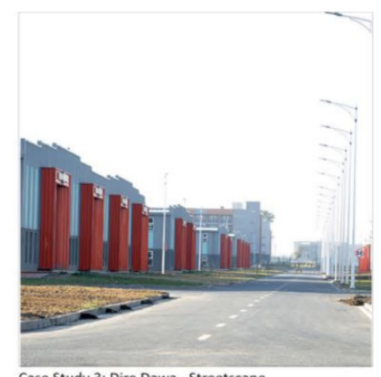

Case Study 3: Dire Dawa - Streetscape

Figure 6. Plans and image Dire Dawa industrial village (Source: Own picture and plans 2018)

Also here, the main activity within the industrial village is situated within the textile and garment industry. As earlier mentioned, Ethiopia has a strong rural tradition in the production of textiles in which raw cotton is weaved until textiles and further assembled in what the Ethiopians call now "traditional clothing". This traditional work is very often practiced by the girls and women of the family.

In today's reality where women empowerment is very often top priority of NGO's and local governments for development strategies and rural-urban migration, the factory spaces do have serious potencies. The collective space within the factory is more than only a rationalised space but does provide a space where skills developed by women in a rural setting can immediately be used in a globalised, urban setting. The collective spaces in the factory should be developed as a bridge between rural-urban traditions and by this be more integrated into the existing rural and urban social and spatial structures.

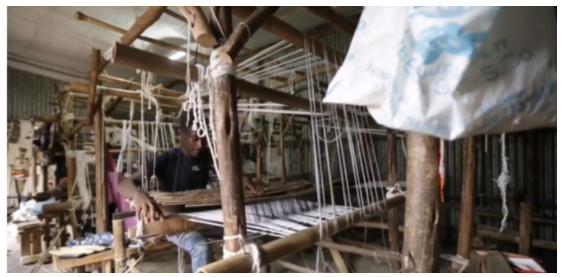

\section{CONCLUSION}

As mentioned in the introduction, this paper is part of a long-term research engagement between KU Leuven and several local partners such as the EiABC University in Addis Abeba and the Bahir Dar university. This paper should therefore be read as a teaser, a state of the art and first insights in the opportunities of the use of collective spaces in industrial landscapes in Ethiopia but is far from a finished product yet.

Giving meaning to those collective spaces in the industrial landscapes, transcending the purely economic rationalized space is one of the essential keys to let those spaces better integrate in the existing social and spatial structures of the city. We witness a general consensus among different disciplines that this process of industrialization should go in a sustainable and inclusive way. In policy thinking and purely urbanistic approaches

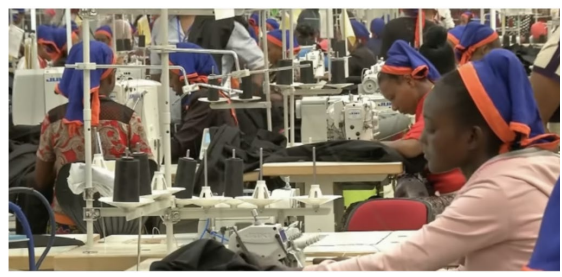

Figure 7. (left) Textiles in traditional context (Own picture, 2018)

Figure 8. (righ): Textiles in industrial context (Source: Movie still CGTN, 2017) 
the meaning of collective spaces within the industrial landscapes is on the other hand rather forgotten. Starting from multiple on-site observations at the level of the streetscape, more than strictly urbanistic or architectural approaches, this research proposal seeks to embrace a profound inclusive and sustainable implementation and development of the industrial landscapes (villages) in Ethiopia.

In a next phase, more fieldwork and on-site observations will be conducted to better understand the actual use of the collective spaces both inside and outside the factory space to further document the potencies of it. Later, strategies and small-scale interventions that will transcend the purely descriptive approach will be developed. 


\section{REFERENCES}

Angelil, M.; Hebel, D. (2010). Cities of change: Addis Ababa, Transformation strategies for urban territories in the 21st century. Basel: Birkhäuser.

Chang, Leslie T. Factory Girls: From Village to City in a Changing China. New York: Spiegel \& Grau, 2008.

Cao Fei - Whose Utopia, 2006. Consulted on february 8 2020. https://www.youtube. com/watch?v=OB0qJC2sp_0.

Cherenet, Z.; Sewnet, H. (2012). Building Ethiopia: Sustainability and innovation in architecture and design. Addis Abeba: Digital Impressions.

F. E. Ian Hamilton. Industrialization in Developing and Peripheral Regions. 1st edition. London: Routledge, 1986.https:// www.crcpress.com/Industrializationin-Developing-and-Peripheral-Regions/ Hamilton/p/book/9781138102354.

Fielding, A. J. (1994). Industrial Change and Regional Development in Western Europe. Urban Studies, 31(4-5), 679-704.

Gehl, J. (1994). Places for people. Melbourne: City of Melbourne.

Lip, Evelyn. Feng shui: environments of power: a study of Chinese architecture. London: Academy Editions, 1995.

Saunders, D. (2010). Arrival city: How the largest migration in history is reshaping our world. New York: Pantheon Books.

Wu, Fulong, Fangzhu Zhang, en Christopher J. Webster, red. Rural migrants in urban China: enclaves and transient urbanism. Routledge contemporary China series 104. London; New York: Routledge, 2014. Wang, Fang, en Martin Prominski, red. Urbanization and Locality: Strengthening Identity and Sustainability by Site-Specific Planning and Design. Heidelberg New York Dordrecht London: Springer, 2016. 



\title{
THE “SECOND LIFE” OF A BUILDING. HIDDEN FLEXIBILITY POSSIBILITIES ON APPROPRIATION OF ARCHITECTURAL SPACE
}

\author{
Caio R. Castroa , Amílcar Gil Piresa , João Mascarenhas Mateus ${ }^{a}$ \\ aLisbon School of Architecture, Lisbon, Portugal
}

\section{ABSTRACT}

An apartment building built in 1960 in a neighbourhood $5 \mathrm{~km}$ away from downtown Lisbon is the basis of this article. This, with a structural configuration composed of pillars located almost exclusively on the perimeter of the apartments, allowed some units to have spatial metamorphoses where once were spaces segmented by walls.

In this article, we analyze the modifications that interfered in the original spaces adjacent to the façade, therefore, the dining room, kitchen and bedroom, and also in small spaces located between them and the exterior, namely the balconies and the laundry room.

In this case, flexibility has the potential to be almost total, approaching the open-plan proposal. However, since this potential is surrounded by the original walls, these played a decisive role in interfering in some spaces, staying at the same place, but referring to a different spatial use. In others, on the contrary, their suppression was total, joining spaces once completely separated, and consequently suppressing some predetermined spaces.

A similar phenomenon, and in some completely attached to the spatial changes stated above, has also occurred in the skin of the building which serves as a membrane between the interior and exterior.

The original elements and configuration had in themselves a possibility of modification, and although not planned by the architect, it was glimpsed by the residents, when modifying elements such as hollow blocks and the possibility of merging the kitchen with the dinning room and also trasnforming the balcony into interior space. The intention with which each inhabitant realized this possibility generated the heterogeneity of solutions seen, where it is explicit a desire for personalization of their own home.

In this article, we sought to analyze the initial space as projected, and the resulting metamorphosis, in a confrontation between the morphological observation made by the author and the result of interviews with the residents who performed the "second life" of the building. Thus, obtaining conclusions that decipher the variety of solutions seen in both the modified interior space and the skin elements of the building.

\section{KEYWORDS}

Evolutive architecture; building metamorphosis; floorplan flexibility; vernacular architecture; architecture without architects.

\section{INTRODUCTION}

As time goes by, buildings are subjected to changes. These may be due to climatic and atmospheric actions, such as the effect of rain on the materials that make up the object's surface. Processes that we call patina when it refers to the relationship between metals and the environment, and calcification when it involves stone, ceramics or products derived from artificial cement. There is also the effect of the infiltration of water on the porous surfaces of the skin of a building, 
the appearance of cracks and chinks due to movements of the soil under the foundations, among other possible phenomena that may occur as a result of the action of the environment on the building.

However, there are other types of transformations, which are intrinsically linked to the basic nature of buildings and which differs from other constructions not inhabited by humans. These, in turn, create a relationship with their morphology and spatiality.

According to the concept of Claire and Michael Duplay $(1982,26)$, this relationship is divided into two. It is characterized as being passive, when the user is only influenced by the environment, and thus "the way the inhabitant uses and appropriates the domestic space is related to the housing available to him, constituting itself as an adaptation, as a circumstantial fact. " (Cruz 2006, 240, author's translation). In this relation, the space is highly imposing, since the creator decides for the user and projects how the future experience of the user will be in the space, aiming that this space, "(...) conceived from the program, will provide (from the architect's point of view) a more interesting and easier everyday life, and is built as an alternative to the current situation. " (Idem 2006, author's translation).

In the active relationship, the dynamics are different, of two vectors, because it allows the user to interfere in the built space that he enjoys and surrounds him. That is, the initial conformation foreseen by the design of the architect or engineer is a base that undergoes mutations. This necessarily involves a physical transformation of the building, which leads to a "second life", no longer dependent on the intentions of its creator, just as it does when a person reaches the capacity and maturity to be independent of their parents. As in human physiology, the change in physical space necessarily requires a chronological advance under the initial provision:
Change is as endemic to a city's ageing process as it is to that of human beings: in the case of the physiognomy of residential areas, that change can range in scale from complete redevelopment at one extreme to the addition of a room to an existing house or, at the micro scale, the replacement of a window frame. (Whitehand, J.W.R., and M. H. Carr, Christine 1999, 1661-1662)

\section{APPROPRIATION OF ARCHITECTURAL SPACE}

The motivation that leads to the process of user intervention in their space can have an endogenous root to the building, in situations where the spatial conformation and / or its formal elements are so incompatible with the desires of its users that it makes their enjoyment involved in friction. The main reason that leads to this situation is related to a mismatch between what the user expects to find in the space in which he interacts and what he finds out. In other words, for the average user, space is first of all an ideal construction, based on more or less similar examples found in other buildings in the city, or on typologies and elements that go through history and remain unchanged.

When user's find, in real space, configurations foreign to their stereotypical ideals of space, there is a desire to mold space to their measurements.

Some housing developments made during the Modernist period demonstrate this, from the larger scale, that of the neighborhood and the public space design, to the private scale, that of the house. With projectual premises that abandoned several concepts based on the history of what would be the user relationship with space and its elements, they ended up creating spatialities that caused strangeness in what is typically considered home. Thus, the only way this identification with the home occurs is 
through the spatial metamorphosis carried out by its inhabitants.

A paradigmatic example is what happened with the building complex of the Israeli settlement of Ramot Polin, designed by the architect Zvi Hecker, and located close to Jerusalem. In these, the membrane between interior and exterior is based on three-dimensional connections of several pentagons conjugated to form spaces. The transformations carried out by its inhabitants denied this geometry, and after their removal and construction of new geometries, forms with cubic bases, more traditional compared to the original ones, were used.

The Quartiers Modernes Frugès in the suburb of Bordeaux also demonstrates the strangeness of the inhabitants with unusual shapes and configurations. An example is visible in the horizontal windows, which in many cases were filled in half to form two common windows at each end, this being one among other changes made by the inhabitants of the houses:

Over the years they have transformed Pessac's abstracted imagery into a much more familiar domestic vernacular. The inhabitants, it seems, were especially concerned about the absence of two features characteristic of conventional houses in the region. Many felt they could not live in houses with front doors opening directly into the living rooms, which Le Corbusier had provided in order to make the most of the available space. Consequently a number of houses have had corridors carved out of the living rooms to accommodate the traditional pattern. The most persistent difficulty in understanding the houses was, however, the absence of a visible roof. The provision of roof gardens and terraces on top of the flat roof was seen by some to be a benefit, but for many it simply did not match their expectations of what a house should look like. (Moore, Gerald Allen and Lyndon 2000, 140)
On the other hand, the origin of the spatial change can be due to factors exogenous to the building itself, which occur when the user starts to have, from a certain moment in time, different requirements from those he previously had. In this case, if the construction responded adequately in the past, it no longer has the same efficiency, a situation that occurs, for example, when the number of households increases and there is an immediate demand for new room space. In a historical approach, this spatial inadequacy to certain demands of a certain moment after the initial construction of the building is also evident in the conversion of old Roman buildings after the fall of the empire. Due to the political change, structures such as the amphitheatres of Lucca and Arles were transformed from a venue place into housing, on the upper levels where the access corridors to the grandstands used to be, and in shops at street level.

Syracuse's cathedral is another notable example. The building was originally founded by the Greeks around 500BC as a pagan temple, fell into disuse during the period of Roman domination, and later, in the 7th century AD, was transformed into an orthodox church, an undertaking that resulted, among other changes, in the closure of the gaps between the Doric columns to create the internal nave. Over time, other changes took place, which transformed the building "in an architectural palimpsest". (Van Ooijen 2019, 5) Regardless of the origin of the motivation for the transformation of the building, this is primarily linked to the judgment of the user of the initial space that surrounds it, in order to understand it and propose changes, which leads to the "second life" of the building. This, unlike the monodimensional view that characterizes the phenomenon as mischaracterization, brings to the building greater vitality, by allowing the natural adaptation of its spatial forms to circumstances that arise over time: 
In fact, buildings are not static. If they were, their longevity would imply an immutability that would place them at risk of becoming obsolete. On the contrary, when buildings are allowed to stay 'in sync' with the changes in the world around them, their durability is reinforced, contributing to their resilience. In this view, resilience is an essential characteristic of individual buildings, and their capacity to adjust to changing circumstances is the key to achieving resilience. (Van Ooijen 2019, 4)

\section{METODOLOGY AND CASE STUDY}

After presenting the phenomenon of space appropriation, it is clear that there are two important mutual and complementary vectors that dominate architectural transformation. One relates to the expectations that a particular user has about the function and / or aesthetics of the building, and another, is directly related to the configuration of architectural materiality in its state before being modified.

The case study of this article allows these two vectors to be verified in practice. Thus, the first step was to carry out a historical study to find out what the building looked like in its initial state. The next step was to catalogue the changes and choose two that are predominant (the closing of the balcony and the removal of the concrete bricks), which were grouped in Results 1 and Results 2. The analysis made in these two topics considered the morphology of the modifications made, as well as the intentions of who made them. This latter was obtained using interviews with residents and, seen together with the contextualization of changes in the living habits of Portuguese families.

This methodology was applied in a building located in the parish of Alcântara in Lisbon and built in 1960, an example that represents a sample (both of spatial typology and façade elements) of the predominant multifamily residential architecture produced in Lisbon in the mid-20th century.

This building, located between two squares and raised on pilotis, has six floors and consists of two independent blocks, which we will call Alcântara 1 and Alcântara 2 (Fig. 1). Structurally, the pillars are concentrated in the core of stairs and elevators, and in the perimeter of each block, so that interference with the floorplan design of each unit is minimal.

Each block has two apartments per floor (Fig. 2), and each apartment, whose total floor area is about $72 \mathrm{~m}^{2}$, has three bedrooms, all with a balcony. The two largest rooms are grouped on one of the façades, and on the opposite (where the kitchen and dining room are also located) the smallest, originally the maid's room, which is directly connected to the kitchen. Between this and the exterior façade is the laundry room, which has the same width as the balconies, but was originally covered by a reinforced concrete membrane to serve as a grid (Fig. 3), which will be subject to intense modifications after the building's inauguration. 

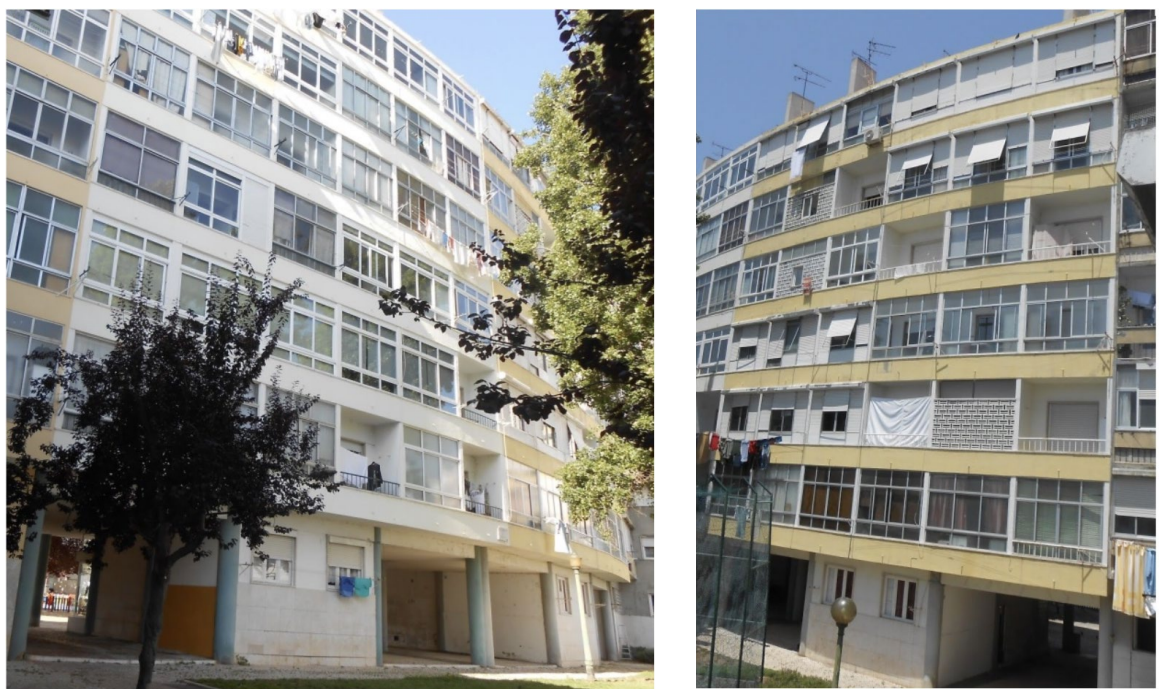

Figure 1. Alcântara 1 on the right and Alcântara 2 on the left, on its current state. Source: (Author 2019)

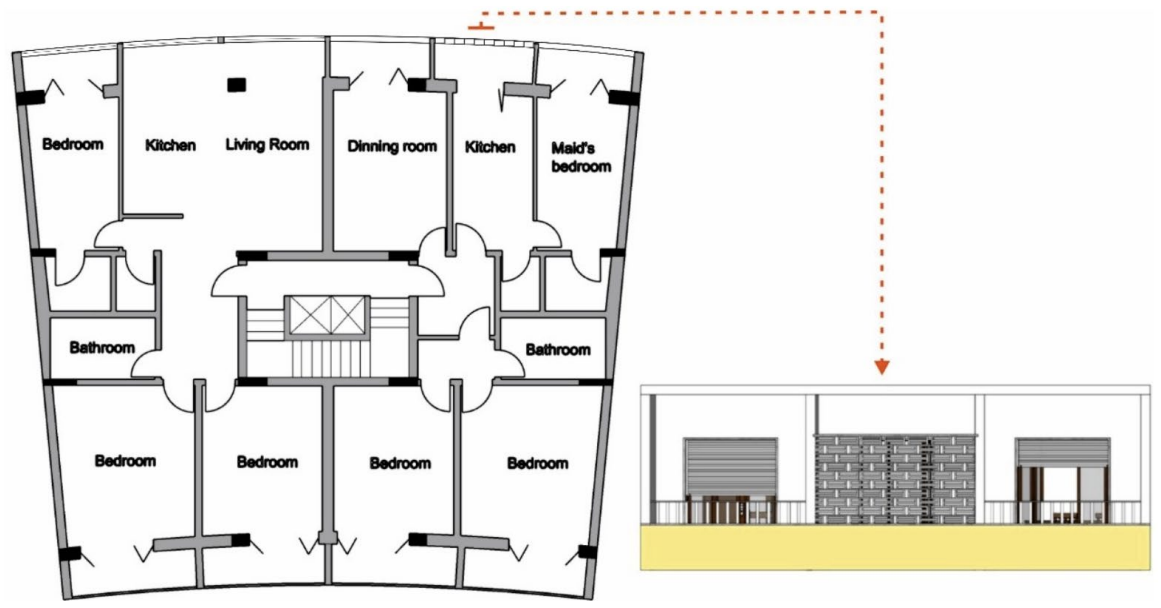

Figure 2. Typical floorplan,on the right,with arrow indicating part of the apartment's original elevation, and an example showing the modified layout on the left. Source: (Author 2019) 


\section{RESULTS 1}

The use of reinforced concrete grids in Portuguese architecture began in the 1950s when the Modern Movement took on a greater presence in Portugal in the face of the hitherto dominant traditional style called "Português Suave". The architects of that time, who were fascinated by the vitality of what was produced in Brazil, widely disseminated by the publication Brazil Builds, did not hesitate to use this membrane in their projects, among other elements they saw reproduced in that publication.

In the multifamily residential architecture made in Portugal, this grid is associated with the laundry room, where the garments were washed in the laundry tub and hang out to dry. The washing and drying machine was not common in Portuguese homes in the 1960s. The kitchen was directly connected to this area, generally occupying the same dimension as the facade, but located behind it. With this, the natural light into the kitchen was dependent on the treatment given to the laundry room. This typology is present in the Alcântara 1 and 2 building and is repeated by countless examples in Lisbon buildings constructed at the same time. The reinforced concrete grids, in this case, made of hollow bricks, had the function of hiding the unpredictable arrangement of the hanging clothes, an attempt very pertinent to the Modern Movement, that is, to endow the world with order, which would be broken with the addition of impurities to the formal composition of the facade. However, paradoxically to another dogma of Modern Architecture, they also hide the real function of the space where they fit.

The grid was not well accepted by the inhabitants of the Alcântara 1 and 2 building, basically for two reasons: climatic inadequacy and psychological factors related to the sensation of claustrophobia.

Developed for the tropical climate, where the winters are mild and of short duration and the summer with high temperatures and moist air, the grid adequately works to the function of ventilating in their country of origin. In Portugal, the act of washing clothes by hand with virtually no protection against the harsh winter climate dictated the need for measures to modify the membrane, in order to provide better thermal comfort.

That said, the least invasive solution to the preexistent shape that the inhabitants found was the placement of glass frames located immediately behind the grid, which allows it to be opened and closed through the lateral slide of two window panes, depending on the weather conditions.

Externally, this new skin overlaid on the original is only denounced by the small gap between the top end of the grid and the ceiling of the laundry room, which was previously empty, and no longer is, since it is filled by the window frames. In the two examples where this occurs in the Alcântara 1 building, on the fourth and fifth floors, this filling is independent of the frame behind the grid, that is, the closing part that fills the void fits into the perimeter composed by it, within the dimension corresponding to the thickness of the grid, and the rest of the frames are in a recessed vertical plane, behind the grid. This procedure demonstrates a process distant of a pragmatic solution of appropriation, which would be the total closure of both the span and the grid with a single frame. Instead, it's noticeable by the inhabitant's solution that they've had a comprehension of the two architectural elements as separate parts.

The morphology of grid modification described until now was present in a large number of apartments in the Alcântara 1 building, and correspond to the first moment of transformation of the grids, which begins to occur, according to residents' reports, at the end of the 1960s.

The aforementioned fourth and fifth floors are the only ones to still use the grid, except for a unit on the second floor, where it remains original. However, these two floors 
already have a second modification made on the first, which we described earlier. In order to solve the reported problem of claustrophobia, the inhabitants of these two floors tore part of the grid to place a window that would provide them with a relationship with the outside, not only visual, something that was blocked by the grid, but also enable the act of starring at the window, leaning at the sill while enjoying the view that allows for a landscape view up to the Tagus River. In addition, in a total subversion of the original function of the grid, they allow access to the clothesline located outside, hanging on a console supported on the facade, which is also a change made by the inhabitants.

Morphologically, the relationship between pre-existence and the new element is different on each floor. On the fifth floor, the window is located almost in the centre, while on the floor below it hangs to the left.

In both cases, the added window rests perfectly on the second layer of hollow bricks, and on the fourth floor, the top of the window is also inserted according to the modular design of the layers, different from the fifth floor, where the window cuts part of the bricks. However, on the sides of the windows on both floors there is no relation to the original layers, and the hollow bricks were all cut for the placement of the windows.

The placement of the fifth-floor window is recent, after 2015, and for the fourth floor, it was not possible to obtain a precise date with the interviewees, who, however, said that it was something done a long time ago. This information leads to another analysis of the two elements. The oldest modification has a marble finish on the edges, just as it exists in the original openings of the building, such as the access doors to the balconies. The most recent one does not have such a finish, and cement mass was used on the edges. It is possible to raise the hypothesis that the greatest care with the old intervention is because, overall, the modifications in the building at the time when it was made were few, and hence the concern of the builder to correlate the new window to the existing ones, aiming for aesthetic integration. In the most recent window, this no longer exists, since the heterogeneity of solutions on the facade is such that this concern is not justified.

The last type of transformation of the grid element is its total removal, to solve the aforementioned problem of claustrophobia, and also to provide more natural light to the kitchen environment. The search for more natural light was, indeed, the dominant factor in the interviewees who opted to remove the grid.

With the removal of the original membrane, the one that replaces it is composed of aluminum profiles (the oldest), or PVC (the most recent), and filled with glass.

The new skin is divided into three parts: the lower one, corresponds to the sill, just above the intermediate one is composed of movable parts that slide, and above this a transom.

It is important to mention the intention of the inhabitants to remove any remnants of the original grid, which explains the inexistence of cases where there could be use of the two layers of hollow bricks (properly filled to cover the holes) to serve as a parapet, with the new skin to be built above it. This eventual choice would consist of a more economical solution, since it would use less material by eliminating the need for the lower element of the new skin.

As for the existence of transom at the top of the new skin, there is no evidence of a compositional relationship between it and the previous shape of the void above the concrete grid. The use of the transom is present in countless other examples of modified buildings in Lisbon, and most of these have never presented the original grid. However, it cannot be excluded that the choice of the position of the base of the transom has some link with the position of the void. As it is visible from the outside, 
in fact, several examples of the new glass skin's transom of the laundry room have the dimension of the original void above the grid. This possibility was not answered through the interviews, and its confirmation is problematic because within the internal space of the laundry room, behind the grid, the door that allows access from this to the kitchen has its top exactly aligned to the top of the grid. That is, the void at the top of the grid is equal to the space between the top of the door and the ceiling. With this, it is concluded that if the similarity of shape between the transom and the void is not a coincidence, it may be the result of another geometry used as a reference.

As for the type of glass used in the new skin, the choice for textured ones prevails over transparent ones, which allow privacy without the use of curtains. It is noted that there is no concern with repeating types already used in neighboring apartments, which results in a huge diversity of light effects and reflections when the look from the outside turns to the facade. This diversity is not by chance, but the result of an attitude of personalization according to the resident's taste in the type of glass.

However, although not so common, textured glass is also used in balcony enclosing (the so-called "marquises" in Portuguese language), another type of modification, which although typologically is similar to the new skin of the laundry room, has a complexity and origin totally different from this, and it doesn't fit in this article.

\section{RESULTS 2}

The structure of pillars located on the perimeter walls of the apartments has allowed that the appropriation and new internal distribution of the layout could be done with great freedom, with little friction between the pillars and the new design of the floorplans as decided by the residents.
In the Alcântara 2 block, at least five apartments have made changes to the internal layout, always focusing on the redesign of the kitchen-living room connection. At the time Alcantara's building was erected, segmentation between the various areas that make up the layout of the residential building was a common practice in Lisbon's multi-family houses, intending to create autonomous routes between the intimate area of the rooms and the noble space of the living room, the place where the family interacted and also used to welcome guests.

The kitchen, in the case of this building, originally dedicated to the upper-middle class, has a direct link to the maid's room and respective bathroom, to isolate the functioning of this wing with the rest of the apartment:

The areas where the servants move are
preferably away from the eyes of the head
of the family and visitors of the house. Their
actions are intended to be spread throughout
the house in tidying and cleaning or preparing
meals, but the crossing of their movements
with the other lives that inhabit the house are
unnecessary. (Pedrosa 2010, 113, author's
translation)

A combination of new roles for family members, the relationship between cooking and leisure, and above all, new labour relations where the maid, being less and less requested, performs the tasks of cleaning particular houses per hours, dictated the obsolescence of the internal compartmentalized layout of the apartment's floorplan.

Consequently, the union between kitchen and living room in a single space, made possible by the removal of the wall that previously separated the two environments, allows gaining more visual amplitude and views to the outside, in addition to fostering new social interactions (Fig. 3). The space of the 
laundry room becomes useless with the use of the washing machine, combined with the help of the clothesline attached to the outer perimeter of the apartment, installed by the residents themselves, as already mentioned. The pragmatic attitude of increasing gross floor area also appears in the suppression of the balcony as an intermediary between exterior and interior - something already rehearsed as an attitude in the enclosing of these elements and their transformation into "marquises". However, the removal process is much more radical and involves the original door to access the balcony to be discarded, in addition to the destruction of one of the sidewalls. Also, the unevenness between the balcony floor and the living room is suppressed, and the membrane role is now played by the new glass panels and white PVC profiles installed on the facade perimeter.

If spatially the suppression of the pre-existent is total, without leaving traces of the previous layout, the same does not happen with the element corresponding to the facade. When installing this new panel, which occupies the modules where the balcony and the laundry room once stood, the residents chose to keep a remnant of the wall that served as a boundary between the two modules, which, visually speaking, translates into the permanence on the facade of the thickness of this wall.

The maintenance of such an element, which has no structural function, is mainly due to a decision linked to aesthetic factors in maintaining the external vertical modulation of the facade.

With the removal of the original façade and its consequent stripping from the pillar, this it is now exposed. In the apartment visited by the authors, located on the sixth floor, the design of the open kitchen furniture, made by the resident himself, has no direct relationship with this pillar, so that the support bench and cabinet, although close, does not touch the element.
The visit to this apartment allowed the authors to notice other changes to the original plan. While the union of the kitchen and the living room is common to the five modified apartments - information obtained through reports and confirmed by nighttime analyzes of the facade when the lights are on - other more discreet changes could be observed in this example.

In this example, the old maid's room no longer has that specific function, and the small size of the area is circumvented with the suppression of the balcony, which ends up adding more floor area. This suppression occurs in all but the second floor, where the original balcony was maintained.

Access to this room is no longer directly connected to the kitchen - now joined to the living room - instead, is linked to the entrance hall through the creation of a small corridor. The previously private bathroom now opens onto this corridor and is for collective use by the inhabitants. This change led to the removal of the old pantry, which was no longer needed as a large number of kitchen cabinets allowed for the storage of food and other utensils.

As for the hall, this one becomes wider with the demolition of the walls that isolated the formerly two main bedrooms and the main bathroom from the rest of the apartment, and there is now a spatial fluidity between the living room and kitchen integrated with the entrance hall.

The opposite façade, as well as the corresponding spaces where two rooms are located, has not undergone the same type of metamorphosis, maintaining itself intact since the construction of the building until today. Except for one unit, next to the one visited by the author on the sixth floor, where the two balconies were recently enclosed with the placement of "marquises", without, however, undergoing any change in the floorplan. 

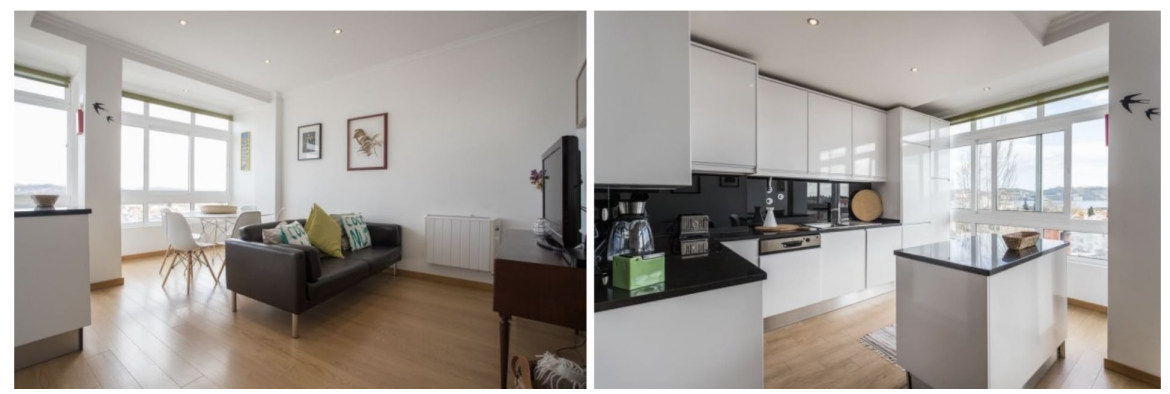

Figure 3. Views inside an apartment after the removal of the walls and creation the new skin, as seen on the floorplan on the floorplan at Fig. 1. Source: (Booking.com)

\section{CONCLUSION}

Through the analysis of the Alcântara building, it's noticeable that the organic metamorphosis of its architectural elements enabled its updating, from a project made for the 1960s to the demands of the residents as time went by.

The interaction of the inhabitants with the pre-existing elements, in the specifically case of the reinforced concrete grid, is reflected almost unanimously with its inadequacy and the need to change the element. This translates into its total removal and replacement by glass and metal panels, or, when maintained, in the perforation of the grid to insert a conventional opening. These two solutions, among others possible, but not verified in this building, demonstrate a certain repetition of procedures, where one resident ends up influencing the other with the form used for their intervention on the original. Still, the two solutions have variations, so that the design of the grid when torn to fit a window is not the same in the two examples. In the same way, the glass and metal panels vary from one another, including the color of the material, the type of glass used, the number of metallic profiles of the panel and the blinds placed in front of it, in cases where these exist.
When the reason for the modification arises from internal spatial demands, the balconies function as an expansion space, being suppressed. The reflection of this procedure on the outside, however, tries to keep a certain unity in relation to other apartments, as it occurs with the grid.

The perimeter location of the building's pillars works as a facilitator in the transformation of the apartment's plan, and has allowed it to undergo a change to be in accordance with the designs of the inhabitants in contemporary times. 


\section{REFERENCES}

Whitehand, J.W.R., and M. H. Carr, Christine. 1999. The Changing Fabrics of Ordinary Residential Areas, Urban Studies 36, no. 10, 1661-1667.

Cruz, M. 2006. Construir a casa: Elementos exploratórios para a compreensão dos conteúdos, do contexto e do processo de concepção arquitectónica da habitação unifamiliar, Revista da Faculdade de Letras: Sociologia 16, $231-250$.

Van Ooijen, J., 2019. Resilient Matters: The Cathedral of Syracuse as an Architectural Palimpsest. Architectural Histories, 7(1): 26, 1-12.

Duplay, C., Duplay, M. 1982. Méthode illustrée de création architecturale. Paris: Editions du Moniteur.

Moore, Charles W., Gerald Allen, and Donlyn Lyndon. 2000. The place of houses. Berkeley, Calif: University of California Press.

PEDROSA, Patrícia Santos. Habitar em Portugal nos anos 1960. (PhD thesis. Escola Tècnica Superior d'Arquitectura de Barcelona, 2010) 



\section{PAPER \#2.22}

\section{SHOPPING CENTER AND CONTEMPORARY CITY: DISCUSSION OF APPROPRIATION FORMS}

\section{Pedro Bento}

aCIAUD, Lisbon School of Architecture, Universidade de Lisboa, Lisboa, Portugal

\section{ABSTRACT}

One of the most controversial and outstanding pieces of the contemporary urban landscape is undoubtedly the shopping center. Loved by ones and hated by others, it has been one of the most polemic topics in the architectural and urban discussion throughout the last decades, whose role in the construction of the urban, did not yet find a sufficiently clear answer. On this occasion, when the importance of architecture in defining the city is under discussion, it seemed especially pertinent to approach this theme, thus, contributing to its clarification. Our purpose is to approach with particular detail, the forms of appropriation that take place in these collective spaces, assuming that the movements performed by users are not limited to consumption, but they encompass much broader and diverse experiences, from cultural, gastronomic or children's leisure, to the access to a wide range of services, by the way, similar to the forms of appropriation that occurred in the traditional public spaces of the canonical city. To carry out this research, an in-depth analysis of the distribution of uses and activities, found in six case studies, was carried out. Their choice (three in Lisbon and three in Barcelona) was based on two assumptions: the representativeness of the diversity of their physical characteristics (mainly, size and model); their position in the city (more central or more peripheral). To conclude, the identified uses correspond to the existing offer in the places that constitute the artifact, and the activities correspond to all those actions that may take place in the collective spaces. Through the reading and comparative interpretation of the building plans, the "in loco" observation and the photographic records, the current work analyzes in detail the forms of appropriation of each artifact and its collective spaces and ends with brief conclusions.

\section{KEYWORDS}

Forms of appropriation; shopping centre; collective spaces; public space; contemporary city.

\section{INTRODUCTION}

The discussion of the role played by shopping centres in the contemporary city is still a controversial topic. Criticized by some and appreciated by others, these spaces are today one of the most outstanding pieces of the contemporary urban landscape. With this study it's intended to demonstrate that the movements that can be carried out in shopping centres are not limited to consumerist actions, but that they cover much richer experiences, such as cultural, gastronomic, children's leisure, or access to a certain service, similarly, precisely, of what happened in traditional public spaces. The analysis of the distribution of uses and activities gives us the possibility of drawing concrete conclusions about the diversity of forms of appropriation offered by the collective spaces generated by shopping centres. In that sense, the uses correspond 
to those founded on the stores / commercial spaces that constitute the shopping centre and the activities correspond to all those actions / movements that can take place in the collective spaces of the mall. The uses are classified in - anchor tenants, restoration, services, retail and facilities - and activities in - gastronomic leisure (terraces), children's leisure (playgrounds), cultural leisure (multipurpose space), rest (rest spaces) and information. Through the reading and interpretation of the floor plans, the observation "in loco" and the photographic record, the present work analyses in detail the forms of appropriation of each artefact and its collective spaces and ends with a few brief conclusions.

\section{LITERATURE REVIEW}

It has been widely argued that shopping centers lead to a substitution, segregation and privatization of public space, generating uniformand ageographical spaces, monitored and controlled spaces, and thematic and simulated spaces, which eliminate diversity and freedom. Moreover, some authors such as Michael Sorkin, Mike Davis, Kenneth Jackson, Nan Ellin, William Whyte or Diane Ghirardo have accused shopping centers of weakening the public sphere and of inferring in the very notion of contemporary public space, considering them anti-democratic (Sorkin1992, 9-14), militarized (Davis1992, 178-179), artificialized (Jackson 1985, 260), panoptic (Ellin 1997, 73), who reject the activities of a true center (Whyte 1988, 208), and oriented exclusively to consumption (Ghirardo 1996, 66).

However, others, such as Rem Koolhaas, Sze Tsung Leong, Giandomenico Amendola, Witold Rybczynski, Margaret Crawford or Miguel S. Graça, find themselves at the opposite end of the cited positions. Some emphasize the inevitability of their hegemony in the actual "generic city" (Koolhaas 1997, 3-12), where consumption is the last stronghold of public activity (Leong 2001, 128-155), some say shopping centres offer new centralities and sociability (Améndola 1997, 259) safe urbanities (Rybczynski 1995, 210), constitute one of the most important architectural paradigms of the century. XXI in a world that is itself already a shopping centre (Crawford 1992, 15) and some explain that the shopping centres are today (...) one of the most visible manifestations of today's consumer society (Graça 2010, 12).

Nuno Portas (2011: 187), for instance, said that "the basis of the structure of the urbanized territory is its Collective Space System." He recalled precisely the teachings of Kevin Lynch (1981), Bollnow (1963) and Balmond (2003) on the importance of structure in the ordering of occupation and functioning of the territory, by promoting the creation of a mental map that allows understanding of the territory, its position with respect to it, as well as its appropriation. Then he explained that this system is the network that connects the various elements of the urban agglomeration and that it was constituted by the set of spaces that the subject travels and from which he reads and perceives the city. While in the canonical city, public spaces tend to concentrate a set of meanings - since they simultaneously respond to questions of form, function and symbolic value (sign) - in the vast urban area, the coincidence of these meanings is difficult to find. Thus, he adds that "shopping centers, for example, began to associate diversified uses related to leisure and culture, and this brought with them socialization practices. They have become meeting places, urban references and even poles generating new centralities (Wall, 2008: 22, 27), such as Norteshopping in Matosinhos or Arrábida Shopping in V.N. Gaia."

In short, loved by some and hated by others (Cautela and Ostidich 2009, 7) the shopping 
center is one of the most controversial and prominent pieces of the contemporary urban landscape and has been one of the most controversial issues in the architectural and urban discussion of recent decades. However, it still does not find a clear enough answer about its role in the construction of the urban.

\section{METHODOLOGY}

\subsection{Object of Study}

The object of the study is the urban shopping centers and other leisure and consumption collective artifacts that, since around two decades ago, were deployed in the compact cities of Lisbon and Barcelona. Once the object of study is defined, it is important to determine the case studies that are representative of all collective areas to be studied. Rather than analyzing an extensive list of case studies, in a more or less superficially way, I decided to focus on only six case studies, yet, in an incisive and profound way. To select the case studies, I relied on two criteria - the size and location. According to the typological criterion, the selected spaces should be representative of the different types of shopping and leisure centres that can be found in the city, mainly in relation to its size and format. The size can vary from a small or medium size, to a large and very large dimension. According to the standards fixed by the International Council of Shopping Centers (ICSC), the commercial centers of very large size, are those with more than $80,000 \mathrm{~m} 2$ of gross leasable area, the large-scale shopping centers rank between 80,000 and $40.000 \mathrm{~m} 2$ of gross leasable area, while medium or small size shopping centers are those of less than
$40.000 \mathrm{~m} 2$ of gross leasable area. As per their size, three case studies were selected in Lisbon and three in Barcelona. According to this criterion (very large, large, medium or small size), I chose, respectively, Colombo Shopping Centre, Vasco da Gama Shopping Centre and shopping and leisure complex of Campo Pequeno; In Barcelona, La Maquinista Shopping Centre, L'Illa Diagonal Shopping Centre and shopping and entertainment centre Maremagnum. Furthermore, these objects also correspond to different formats: La Maquinista corresponds to an opened shopping center, Maremágnum, to a closed shopping center and L'llla, to a simultaneously opened and closed shopping center. In Lisbon no opened shopping center was identified, therefore, we picked up two: Colombo and Campo Pequeno, closed shopping centers and Vasco da Gama, opened and closed. According to the location criteria, sites selected are representative of different areas in the city. Maremágnum and Vasco da Gama are located at fun and festive areas of the city, in both context, marked by the presence of water: in Lisbon, the Tagus River; in Barcelona, the sea. L'Illa and Campo Pequeno are located in consolidated areas of the compact city; La Maquinista or Colombo Shopping Center, in vacant or obsolete areas of the city, under renovation.

\subsection{Research Hypothesis}

The approach put forward in this research aims at demonstrating that some of the newer shopping and leisure centers, emerged in the inner city, are playing a very important role in the construction of the contemporary compact city - producing new collective spaces of gathering and stay, expanding the public sphere and generating new urbanities. 


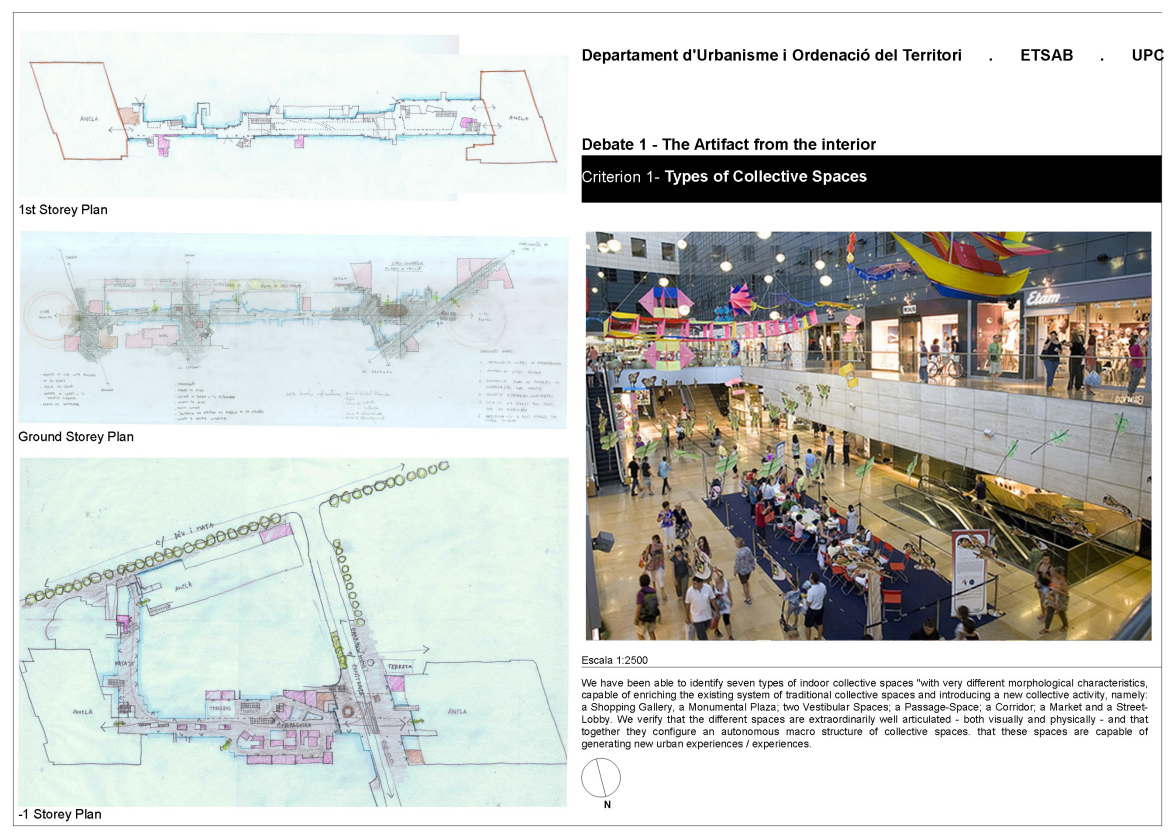

Figure 1. Case Study example. L'llla Diagonal, Barcelona. Source: (Author 2015)

\section{DISCUSSION}

The collective spaces generated by shopping centers constitute new urban spaces that have arisen in the compact city that complete the traditional public spaces, extending or expanding them. Thus, the work begins by analyzing in detail each of those artifacts (Fig.1) and ends up with an analysis of the forms of appropriation of them, discussing their mono or multi-functionality (Fig.2).

\subsection{La Maquinista}

In La Maquinista we identified ten units of collective spaces in a total of five types of spaces: les Naus Street, dels Trens Street, dels Ponts Street, a Passage, an Interior Corridor, the North Entrance Square with Potosí Street, the South Entrance Square with Sao Paulo
Street, the Clock Square, the Central Square and a large leisure and restaurant terrace on the second floor. Of the advertised spaces, only one is presented as an interior space the commercial corridor that functions as a transitional space between some of the most important collective spaces of the shopping centre and the hypermarket.

Les Naus Street, for example, is a street that connects the Ciutat d'Asunción street with the Dominican Republic street and in which the cinema and South entrance squares are developed just when they cross the streets dels Ponts and dels Trens respectively. It is of the three streets generated by the artifact the widest with about $21 \mathrm{~m}$ or $31 \mathrm{~m}$ if we consider the $5 \mathrm{~m}$ arcades on both sides. And it has a length of about $220 \mathrm{~m}$. It is flanked by high facades, three commercial floors, and equipped with urban furniture (medium-sized 
trees, lampposts, benches, wastebaskets, kiosks, etc.). This space can be accessed from the outside directly at street level from Ciutat d'Assunción street, and down stairs from the South entrance plaza or from the Dominican Republic street. It can also be accessed from the interior through dels Trens Street or dels Ponts Street. The Iongitudinal profile of this street is quite interesting to the extent that different sections of the same axis can be identified, with a singular spatiality. In the first section, we find the one that starts from Ciutat d'Asunción street until it meets the facility, it has a character like an announcement. That is to say, the user perceives the extension of an urban axis that starts from a public space towards a different collective space or the opposite that extends from the collective to the public space outside the facility. The second section would be the one in which the street becomes a corridor with a single floor height and where it communicates vertically with the other levels of the shopping centre, either through mechanical belts or through elevators. Immediately, a third section is generated, which is the one in which the cinema square emerges, a diaphanous space totally open for all kinds of events. And, later, a fourth section that would be the one that goes from the square to meet the Trens Street, which would be perhaps the highest point of this urban element, the street in all its splendour, flanked by triple-height commercial facades and imposing trees that are generating a movement of light and shadow and a feeling of freshness, only comparable to some of the most representative and traditional spaces in Barcelona such as the Rambla of Catalunya. And, the fifth and last section that would be the space that gives continuity to this axis and that through a vertical communication system in stairs communicates with the exterior street named Republica Dominican Street.
In La Maquinista shopping centre, the forms of appropriation change according to uses and activities existing in each space and depending on the time in which those spaces are used. In general, we would say that they are quite varied. The mix of uses is quite well projected, there are no mono-functional spaces or areas where we find exclusively retail. The uses founded are distributed as follows: tenant anchors are located on the periphery of the artefact, mainly occupying the ground floor and first floor of the building bodies that face the streets Ciutat d'Asunción and Sao Paulo; Cafes, bars and other catering services are distributed throughout the ground floor and first floor of the mall in a homogeneous manner, occupying key points of the building, such as the meeting areas between different urban elements, squares and passage areas; restaurants are concentrated in two zones, a food court on the first floor of the street of les Naus, which opens in the form of a balcony on the east entrance and a new gastronomic space on the second floor, known as the terraces of $\mathrm{La}$ Maquinista, where It's added a great variety of restaurants and bars. Similar to other cases, we will find more services and commodities on the ground and first floors, mainly due to the continuity that was established with the surrounding public spaces. Retail is concentrated in the first two floors (ground floor and first floor), there are no stores on the second floor. What should be noted about the stores is that the type of retail founded on the ground floor, such as videogame stores, perfumeries, bookstores, etc., differ a lot from that of the first floor most related to clothing and footwear. Facilities, such as cinemas or playgrounds are located exclusively on the second floor together with gastronomic areas, thus contributing to create a large day and night leisure zone. Also, in the case of La Maquinista, all kinds of activities were found, that in one way or another are generating different behaviors among its users. 


\subsection{L'Illa Diagonal}

In I'llla Diagonal shopping centre (Figs 1 y 2 ) we identified eight units of meeting and living spaces, in a total of seven types, with different morphological characteristics, namely: a Shopping Gallery; a Monumental Plaza; two Vestibular Spaces; a Space-Passage; a hallway; a Market and a Street-Lobby. The Shopping Gallery is one of the two most representative spaces in the shopping center. It is developed on two floors: on the ground floor it is interrupted by three vestibular spaces and on the upper floor it is continuous. The gallery is asymmetrical also relatively to its height. On the side facing the inner park of the block, it is two stories high and on the side facing Av. Diagonal it has three. The interior is uneven, complex, and lively, drawing visitors across it. The ground floor and the first floor are connected via escalators and elevators. The lighting is natural and artificial.

In I'llla Diagonal there is no monofunctional space. All activities and uses were distributed so as to ensure the multifunctionality of the building in its entirety. The forms of appropriation are diverse and vary from space to space. According to the analyses carried out, we have been able to identify all types of use and activity. The uses are distributed as follows: Anchor tenants are located at the ends of the building, functioning as magnetic poles, which take people from one end to another; interestingly, the restoration uses appear on the ground floor at the ends of the building, in the basement they appear mostly scattered in the market and on the top floor promptly in the middle of the gallery and square spaces; the services appear essentially located on the ground floor, next to the vestibular spaces and passage and, in some cases, inside the square and the gallery. The various shops of commerce appear distributed in all the spaces of the commercial centre. Finally, the activities that take place in the shopping centre are scattered throughout the artefact.

\subsection{Maremagnum}

In the Maremagnum we identified five types of collective spaces, in a total of eight units: a Plaza; a shopping gallery; a Main Hall; two Secondary Halls; some corridors; and a terrace. In the same way as in the previous case, La Plaza del Maremagnum is the most significant collective space of stay and encounter of the artifact. It is a large space that is developed on three floors and is covered by a large asymmetric skylight, with a height that varies between 13 and $25 \mathrm{~m}$. It is a space of horizontal and vertical crossings, which introduces an interesting dynamism of movements inside, but it is at the same time a resting space and a place equipped with a cafeteria, ice cream parlor and terraces where one can refresh and hydrate. Due to its extremely central and touristic position in the city, it ends up being one of the most visited leisure and consumption centers. Access can be made from all four sides of the facility, either through the main and secondary lobbies, through corridors or even from the underground parking, going up stairs or elevator located in a central position. The diversity of uses and activities found generates different forms of appropriation and increases the plurality of the public. The Maremagnum is one of the most interesting cases in the corpus of study due precisely to the forms of appropriation it generates, much more related to leisure experiences than to consumer activities. Although it is still a place where you can go shopping, it is increasingly aimed at being a place where you can go to eat with friends or where you can go to entertain yourself in one of its musical, artistic or other events, which usually take place in the central interior square or on the terraces on the second floor. Also, in summer and for several years now, a part of the car park has been converted into a cinema space and spectacular horror and suspense films are screened throughout the night. 
The mixture of uses is well designed and less segmented than in other cases. That is, restoration activities arise on all floors and not just one or two. The shops also work on all floors although with a higher incidence on the ground floor and first floor. However, with less weight than in other cases, there are also services on the ground floor and inside the building. On the first floor we can even find a maritime checkpoint of the Port of Barcelona. The only use that could not be found was a large anchor tenant that in this case can be justified due to the small size of the artefact. Regarding the existing activities, it is important to highlight the important role of the terraces that open both inside and outside the building and in each of the floors. As it has been pointed out, at least two multipurpose spaces that host all kinds of events are generated. The rest spaces are distributed throughout the building, through the insertion of own urban furniture, and increasing on the terraces of the second floor. The stairs function as informal places of rest and the terraces of the second floor as elevated viewpoints over the port and the city. The playgrounds or children spaces do not exist, probably, because all the outer space, where the Maremagnnum is located, is a great leisure area, and that right next to it is the BublePark, a dynamic outdoor amusement park for the little ones.

\subsection{Colombo}

As is evident, in large shopping centers such as Colombo, with about 475,000m2 of gross built area, numerous collective spaces can be found. We identified 33 spaces, which we could classify into six or seven types squares, corridors, lobbies, gallery, garden and amusement park - or 15 subtypes, taking into account the different existing squares, corridors and lobbies. But before detailing each of them we need to talk about the structure of collective spaces that hides behind this shopping center - a system composed of a virtual South North backbone of first level, two symmetrical curved axes of second level and other two cross shafts of third level. On the first, which is marked from the geometric center of the road junction generated by the 2nd Circular Road and Lusíada Av. infrastructures, the Fountain, Entry, Tropic of Cancer and the Continent or North Entry squares are drawn. The second element of this macro structure is a curved axis where the Commercial Gallery, the nominated Entrance squares of the Navigators and the New World, and the Eastern and Western entrance halls rest. Turning the aforementioned curved axis until it is inverted, the third element of the system is generated on which the corridors that connect the squares of the Navigators and the New World with the South entrance square are established. Finally, third degree axes are drawn that come out of the central circular Tropic of Cancer Square and extend to the aforementioned curved axes.

Colombo, due to the large size and the way it is organized, creates a multitude of forms of appropriation in its interior, condenses existing uses and activities and, in a similar way to previous cases, it hierarchizes them floor by floor. On the ground floor and -1 we find mainly services - such as bank branches, post offices, insurance companies, travel agencies, pharmacies, the Portuguese club car, etc. - general trade stores - such as music stores, bookstores, stationery stores, gourmet stores, etc. - leisure facilities such as a chiquipark and solar club, and even a worship facility. We highlight a small church, with daily service of masses, located in one of the entrances, on the -1 floor. On the 1 st floor, with the exception of a large anchor tenant specialized in culture and some bank branches, clothing and footwear stores are basically offered. On floor 2, two important restoration spaces and a significant leisure area are offered. A more informal dining space with fast-food restaurants supported by a large terrace-dining room and a more formal one where the user is invited to enter and eat inside the restaurant itself. The leisure 
offer is quite diversified and includes, among others, amusement park, bowling, outdoor terrace, gym with health club and cinemas. The hypermarket and large stores mainly occupy the periphery of the shopping center. Finally, the activities are organized according to the uses.

\subsection{Vasco da Gama}

In Vasco da Gama, five types of spaces have been found, totaling nine spatial units: Commercial gallery; entrance lobbies (east, west and Station, on floor -1); Corridors (curved, on Floor -1 and orthogonal, on Floor $0)$; Foodcourt and Terrace "Lounge". The commercial gallery, for example, is a space that establishes the connection between the Intermodal Transport Station designed by Santiago Calatrava and the recreational space of the Parque das Nações, the former site of Expo 98. It is a gallery that is developed on four floors, being that in the latter, there is hardly any collective space at the eastern end, a place where the Foodcourt restaurants on the lower floor extend. It is a large space, with a height of about $20 \mathrm{~m}$, it has a depth of about $112 \mathrm{~m}$ on the first floor and above and extends on the -1 floor through a $73 \mathrm{~m}$ long corridor. It has a pleasant width that increases plant by plant, starting with $8 \mathrm{~m}$ on -1 floor; $20 \mathrm{~m}$ on the ground floor and $28 \mathrm{~m}$ on the first and second floors. On the other hand, the roof and the glass entrance facades also extend the collective interior space to the outside. Entries in the Gallery can be made from different levels. At the level of floor -1 , it can be accessed through the corridor that connects with the station or, through the opposite façade, down a small staircase or ramp. At ground floor level, it can be accessed through the Occidental entrance hall (Station) at street level or by going up an escalator or other fixed stairs located in the eastern entrance hall (Río and Parque das Nações).

In Vasco da Gama the appropriation of space is intense and the forms of appropriation are diverse. The organizational logic of the previous artifacts is followed, with a particular way of separating uses and activities by floors. On the -1 floor, anchor tenants mainly occupy the extremities of the building, next to the center entrances. Small shops and services form the basis of the fabric of uses and promptly we find small cafes, ice cream parlors and kiosks. The ground floor has less diversity of uses and is formed by large areas on one side of the commercial gallery and small shops on the opposite side and in the other collective spaces of the building. On floor 1 you can find all the uses of this type of artifacts - two leisure facilities and two large anchor tenants on both sides of the gallery, small and medium-sized stores and an important restoration space at the eastern end of the shopping center. On the 2nd floor, the restoration uses are basically elevated, once the existing leisure facility and the anchor tenant do not have direct communication with the same floor. In Vasco da Gama, activities are more divided than in other cases. Fundamentally the terraces are produced at the eastern end of the artifact, both on the ground floor and in the food court of the upper floors, inside and outside the artifact. There is no specific playground for children, although an important part of the decoration of the building points to a children's imagination inspired by the oceans. In a way we could choose the curved corridor on the ground floor as the most specialized for children, with decorated carpets, walls lined with materials alluding to the oceans and ceilings animated by mobile decorative elements, such as fish, a diver, etc. Next to the eastern entrance of the shopping center there is an information kiosk for customer service, to make inquiries or request services, such as mobility, collection, etc.

\subsection{Campo Pequeno}

Because it is a small shopping centre, integrated into an existing facility (the Lisbon Bullring, where bullfights continue to be held 
today), the collective spaces that we can find in Campo Pequeno are not of big dimensions. However, we have found a set of five types of spaces, in a total of thirteen units, which we highlight: a shopping arcade; a Lobby Ramp; four helical lobbies, a Foodcourt or fast food hall and three types of hallways. The commercial gallery, except for the arena itself, forms the most important collective space of the present commercial and leisure artefact. It is an underground space that is developed by circular segments around the bullring. With the exception of the segment that touches the lobby ramp, which is $7.7 \mathrm{~m}$ wide, the other segments are only $6.2 \mathrm{~m}$ wide. The height is constant, about $4.5 \mathrm{~m}$ and the length, about $190 \mathrm{~m}$, which can be extended to $230 \mathrm{~m}$ if we extend through the lobby of the cinemas. The gallery does not get to complete a complete loop around the bullring, occupying practically half, since the other half is occupied by the main engines of the shopping centre - the supermarket and the cinemas. In short, we have a gallery that is limited by a major supermarket on one side and some cinemas on the other, a hall staircase in the middle that opens the gallery to the outside, and articulated helical lobbies with connecting corridors with the central Foodcourt that they intercept and illuminate. In the key points of the gallery, restoration and service activities are developed, generating spatial multifunctionality.

Although Campo Pequeno is a small artefact, you can identify exactly the same forms of appropriation that have been found in the shopping centres presented above. On floor -1 , all existing uses in this type of artefacts are present - an anchor tenant, small and medium-sized stores, services, restaurants and an eight-room cinema. On the ground floor an important set of restaurants and bars and the arena of the bullring - a multipurpose space that frequently becomes the stage for all kinds of musical, artistic, etc. shows. The activities vary between the indoor and outdoor terraces (located, respectively in the food court on the -1 floor and outside the bullring), between the playground areas (which are distributed through the gallery and hallways) and between some rest spaces (distributed through the corridors and the gallery of the mall). Of the five types of collective spaces founded in Campo Pequeno shopping centre - Commercial Gallery; Hall Ramp; Helicoidal Lobbies, Food court and Hallways - we would like to place special emphasis on the first one (the commercial gallery), among other things, for being the one that brings together most uses and activities. Indeed, this semicircular shopping arcade, flanked by small and medium-sized businesses, services of different types - banks, pharmacies, photography stores, stationery stores, etc. - punctuated by small cafes and other uses of restoration and at the ends crowned by a significant anchor tenant, favour other forms of appropriation than those of consumerism itself. The possibility of sitting observing and contemplating the present events for example enriches the appropriation of surrounding spaces. Also the connection with the food court and with the respective terrace space diversifies the environment and the type of movements in this new place. The escalators located next to the cinemas establish the connection between this space and the other collective spaces such as: the multipurpose arena, the circular corridor and the entire restaurant and terrace area, existing on the ground floor. 

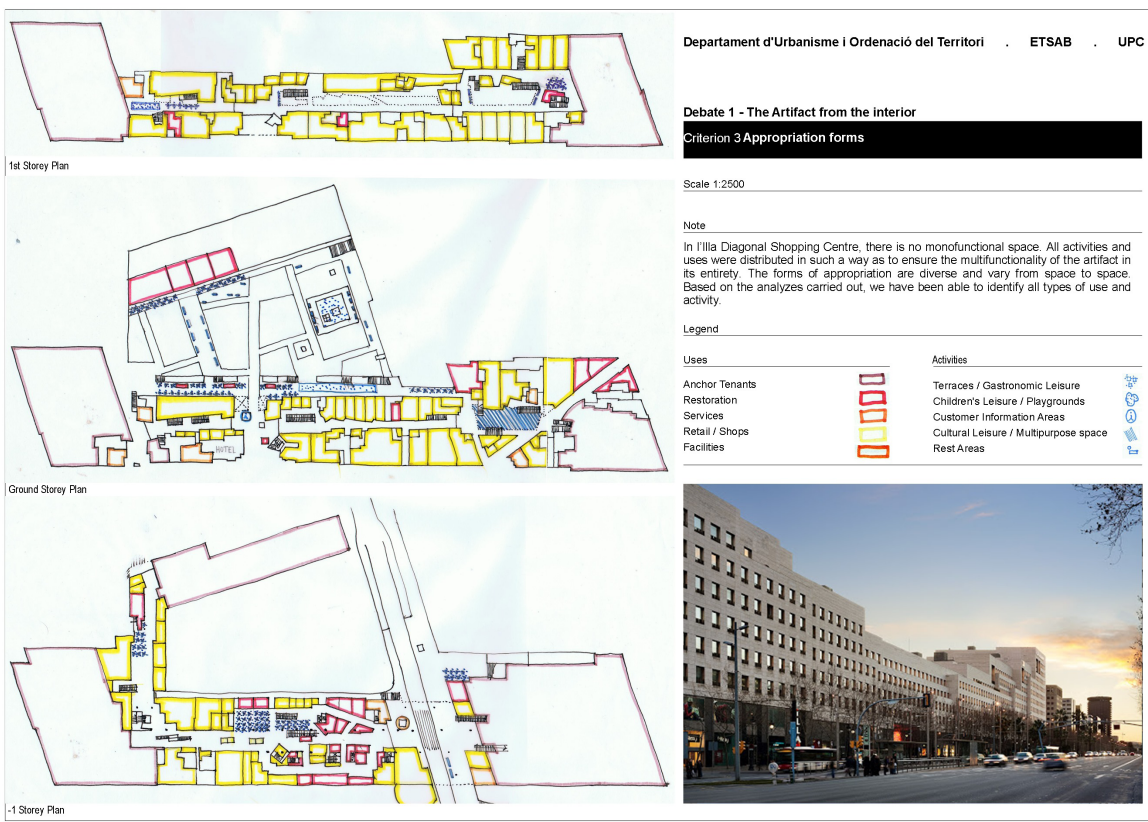

Figure 2. Analysis of the forms of appropriation of L'Illa Diagonal. Source: (Author 2015)

\section{CONCLUSION}

After a detailed analysis of the case studies, we can draw three findings that, on the one hand, question the rhetorical position of the first authors - those who attributed the origin of all urban ills to the shopping center - and which, on the other hand, bring us closer the positioning of the seconds - those who considered that these artefacts, if carefully designed, may come to play a very important role in the construction of the contemporary compact city, even generating synergies with public spaces in their surroundings. There is no doubt that in all case studies the forms of appropriation are multiple, thus confirming the initial suspicion that shopping centers and other leisure artifacts cannot be reduced to simple consumption spaces. The presence of different uses and activities in the same space generates multifunctional spaces where, apart from consuming, a set of other movements similar to those practiced in the public space can be made. After the analysis of the case studies it is quite evident that neither size, shape, or location (inside the compact city) seem to condition the forms of appropriation. In all cases, the forms of appropriation are multiple, because in all we can find a mixture of uses and activities. It is true that within each artifact there are spaces where the forms of appropriation are more diverse than others, but in general, all comply with the proposition of the multifunctionality of uses and activities. In some cases, these shopping and leisure centers diversify not 
only the forms of appropriation of collective spaces belonging to the artifact but also the forms of appropriation of adjoining outdoor public spaces. In the specific cases of Maremagnum and Campo Pequeno it can be clearly seen how the adjoining public space undergoes substantial modifications. With the new artifact, hallways appear, atracting people closer to the facility, so do the terraces inviting people passing by to stay and leisure, which, among other things, immediately enhances greater surveillance and social control of public space. In the case of I'llla Diagonal, this aspect is even more exploited. Not only lobbies and terraces are opened in a space where they did not exist before, but a park is generated, with numerous playgrounds for children and their respective families and rest spaces for older people, providing new experiences of public space and ultimately new forms of appropriation of it.

\section{ACKNOWLEDGEMENTS}

I would like to thank all the colleagues with whom I have been discussing this topic and in particular the teachers who have guided this work. So, to Professor Joaquin Sabaté (Universitat Politècnica de Catalunya) as supervisor and Professors Estanislao Roca (Universitat Politècnica de Catalunya) and Margarida Louro (University of Lisbon) as co-advisors, my greatest thanks. Finally, it is important to mention that this article is part of a research underway at the Center for Research in Architecture Urbanism and Design - CIAUD at the Faculty of Architecture of the University of Lisbon, and that it has been financed by the Fundação para a Ciência e a Tecnologia - MCTES. 


\section{REFERENCES}

Amendola, Giandomenico. 1997. La ciudad postmoderna: Magia y Miedo de la Metrópolis Contemporânea. Madrid: Celeste Ediciones. (trasl. La Città Postmoderna: magie e paure della metrópoli contemporánea, 1997)

Bollnow, O. Friedrich. 1963. Hombre y Espacio. Barcelona: Editorial Labor.

Cautela, Cabirio; Ostidich, Daniela (ed.). 2009. Hell Paradise Shopping: L'Inferno e il Paradiso degli acqusti e del consumo. Milan: FrancoAngeli.

Crawford, Margaret. 2004. "El mundo en un centro comercial”. In Sorkin, Michael (ed.). Variaciones sobre un parque temático: la nueva ciudad americana y el fin del espacio público. Barcelona: Gustavo Gili.p. 177-203. (trasl. of "The World in a Shopping Mall". In Sorkin, Michael (ed.). 1992. Variations on a Theme Park: The New American City and the End of Public Space).

Davis, Mike. 2004. "Fuerte Los Angeles: la militarización del espacio urbano". In Sorkin, Michael (ed.). Variaciones sobre un parque temático: la nueva ciudad americana y el fin del espacio público. Barcelona: Gustavo Gili.p. 177-203. (orig. 1992)

Ellin, Nan. 1997. Architecture of Fear. New York: Princeton Architectural Press.

Ghirardo, Diane. 1996. Architecture After Modernism. Singapore: Thames and Hudson.

Graça, Miguel S. 2010. SHOPPING \& CENTER: sobre o consumo, a cidade e os centros comerciais em Portugal e na Europa. (Tese de Doutoramento). Valladolid: Instituto Universitario de Urbanística - Universidad de Valladolid.

Jackson, Kenneth. 1985. Cabgrass Frontier: The Urbanization of the United States. New York: Oxford University Press.

Koolhaas, Rem. 1997. "La cittá generic = The generic city". Milan: Domus, nº 791.
Leong, Sze Tsung. 2001. "...And Then There Was Shopping”. In Chung, Chuihua Judy; Inaba, Jeffrey; Koolhaas, Rem; Leong, Sze Tsung (coord.) Project on the City 2: Harvard Design School Guide to Shopping. Köln-London-Madrid-New York-ParisTokyo: Taschen.

Lynch, Kevin. 1981. A Theory of Good City Form. Cambridge: MIT Press.

Portas, N., Domingues, A. e Cabral, J. (coord.). 2011. Políticas Urbanas II Transformações, Regulação e Projectos. Lisboa: Fundação Calouste Gulbenkian e CEFA da Universidade do Porto.

Sorkin, Michael. 2004. "Introducción: variaciones sobre un parque temático." In Sorkin, Michael (ed.). Variaciones sobre un parque temático: la nueva ciudad americana y el fin del espacio público. Barcelona: Gustavo Gili. p. 9-14. (orig.1992).

Ribczynski, Witold. 1995. City Life: Urban Expectations in a New World. New York: Scribner.

Wall, Alex. 2005. Victor Gruen. From Urban Shop to New City. Barcelona: Actar.

White, William. 1988. City: Rediscovering the Center. New York: Anchor Books. 
PAPER \#2.23

\section{INTERSECTIONS WITH THE GROUND IN THE CONTEMPORARY CITY}

\section{Luigi Savio Margagliottaa}

a"Sapienza" University of Rome, Rome, Italy

\section{ABSTRACT}

The economic growth and the technological advancement that have touched several countries for some time now, can be considered, in contemporary times, as the main engines that guide the transformation of the cities, which represent, today more than ever, the fruit of social, political and economic processes. Consequently the architectural design undergoes a weakening, since it no longer operates following its own intrinsic laws but finds itself complying with external speculative thrusts and the productivist criteria typical of our time; while the contemporary building is often self-referential and neutral to the context in which it is inserted.

In this scenario, the tall building takes on a leading role, as the emblem of the city's economic and technological progress. The tall building, moreover, in the search for verticality eludes every relationship with the ground, losing that link with the morphology of the places from which the urban artifact originates instead. Moving the point of view on the ground attachment of the building has the aim to turn the focus on the founding aspect of architecture and the need to reestablish a sense of belonging to the place, as well as re-signifying the space. Therefore, we intend to investigate the tension that is generated between the horizontality of the urban dimension and the verticality of the building through the study of its basement, understood as that symbolic-practical part of the construction, different in shape, function, matter or just for compositional treatment, which defines its mediation with the land.

Starting from the analysis of some emblematic examples, we finally identify different types through which the ground attachment is resolved, as a result of the relationship between form and construction that finds its concretization by the collision between the generalities of the type and the morphology of the places.

\section{KEYWORDS}

Architecture; contemporary city; tall building; basement; urban space.

\section{INTRODUCTION}

This essay fits transversally between the typological studies of the tall building and those concerning the urban dimension; and starting from them it intends to analyze the relationship, sometimes interrupted in the contemporaneity, between architecture and ground on which the former is based, starting from an analysis of the contemporary project and the building in the contemporary world, in its double but analogous configuration of architectural subject and urban object. Often neutral to the place, it rejects any relationship from and to the outside, aiming for selfreference and, consequently, fragmenting the urban space into disordered and undetermined facts. Our attention will then shift to the tall building, since, more than the others, as well as for mass and power, it constitutes the building emblem of the modern city.

Here, by tall building we will mean both the tower type and the skyscraper, as both, although differing in proportional and dimensional aspects (often in relation to the context of insertion), act with the same 
intentions and generally have similar urban characteristics and therefore the same problems of integration to the relative preexisting building fabric. Although one term is sometimes used rather than another (sometimes by convention, sometimes due to the specificity of the example), the aim will still be to identify the effects produced on the urban space starting from the qualitative study of the tall building and its ground attachment solutions, regardless of whether it is a tower or skyscraper.

This typology is usually examined in its static and structural aspects, due to its functional role and innovative character in the transformation of the modern city, in its vertical relationship with the sky. Moving the point of view to the foot of the skyscraper, studying its horizontality instead, represents a different but necessary perspective to conceive and interpret the urban role of the tall building, bringing attention back to the foundational aspect of the architecture, to its ability to investigate the ground as the first place of the design and, starting from it, to re-establish a sense of belonging to the place and re-meaning of space.

About the tall building we intend to analyze the often lost relationships that it establishes with the physical place and with the symbolic space of the city, investigating the tension that is generated between the verticality of the building and the horizontality of the urban dimension. Starting from the founding act that manifests itself in the first footprint of the building with the ground, we will therefore focus on the study of the ground attachment, in the belief that it is starting from it that relationships with the context are determined or not, with the surrounding, with the built, with man. The different basement solutions will be analyzed in detail, intended as the first expression of the relationship between form and construction that occurs in the soil of the city, from which in turn derive the physical and qualitative characteristics of the urban space.

\section{BETWEEN GROUND AND VOLUME}

Before getting into the heart of the argument, it is necessary to clarify some concepts. Although the theme of the basement in a broad sense, in this essay, is investigated with the second aim of studying the relationships of the building with the morphology of the places through the analysis of the ground attachment, we will proceed with a rapid clarification of terms to better explain the interpretation used.

With the term basement we will consider the lower part of the building that stands out for its formal or compositional treatment or that differs in function or material compared to the remaining volume in elevation. It can therefore assume the configuration of a portico, of an ashlar surface; it can correspond to one or more floors with different functional characterization; or simply be a low end that raises the entire building from the ground level or levels the support surface.

By ground attachment we can therefore mean both the basement just described, that is to say that part of the building near the ground, or an artificial element interposed between the ground and the building and clearly distinct from it that can take on the forms and functions of podium, platform, plinth, substructure, terracing, etc.; or even an organism other than the volume in elevation which is entrusted with the task of solving the attachment on the ground.

We could therefore say that by attachment to the ground, regardless of the formal typology, we mean that element or part of the building that is different in shape, function, material or composition that mediates its relationship with the ground, therefore with the place. It involves the set of relationships that bind an architecture to a place: it is both a founding act, a representation of the firmitas, a representation of the archetypal principle of settling; manifestation, by contrast, of the characteristics of a place, urban or natural. 
Ground attachment and basement are two terms that can therefore be equivalent in the event that the building rests on the ground without the interposition of an element that can be considered foreign to its volumetric configuration. However, it should be noted that the term basement will sometimes be used in a generic way, for simplification reasons and for a fact of a conceptual nature, even if in a rather improper way since the considerations expressed must be referred to the broader issue of ground attachment, of which the basement represents, in reality, only one of the cases, even if, perhaps, the most conceptually and conventionally recognizable.

\subsection{Some considerations about the basement}

From the thematic decomposition into three parts of the building in the basement, envelope and crowning, which corresponds to the composition of the classical order synthetically reproduced in the column's parts of the plinth, shaft and capital, we can read an elementary architectural form consisting of a support surface, a vertical support system, a vertical and a horizontal closure. This tripartite division, which represents one of the foundations of classicism, remains one of the permanent principles of architectural composition (Cao 1995, 128-130). In this reasoning, "basement and crowning are the places of confrontation of a building with its material growth and with the definitive structure of its construction, with its way of being born from the earth and rising to the sky. They are therefore the most obvious places where an architecture determines and gives meaning to its relationship with the preexisting landscape, be it city or countryside. [...] The foundation of a house on the ground must therefore not be considered only as a static fact, but also and above all, as a compositional fact" (Angeletti, Bordini, Terranova 1989, 260). In light of these considerations, the foundation is therefore not the starting point of building, "but the product of a process of will, of form, of a search for compatibility and dialogue; it is a form of questioning about the possibilities of an existing to welcome and support by changing" (Gregotti 1995, 2).

Protection, support, decorum (representativeness) and relationships are therefore "the reasons for the identity of a physical and figurative component of the architectural design which in history has been variously interpreted with different architectural solutions and adjectives, but always inevitably recognizable in the general composition" (Cao 1995, 130-131).

For a better understanding of the concepts dealt with, it is also useful to introduce another point of view, that of Gottfried Semper whose theory is always of extraordinary relevance. In 1851 Die vier Elemente der Baukunst (The four elements of architecture) was published, in which one of the main points was represented by the reflection on the Caribbean hut. This is the tectonic archetype consisting of a hearth, a basement, a framework/ roof, a space boundary membrane, which can be summarized as the four elements of architecture. Semper always attributed the supremacy of the framework subjected to tension and its filling, as opposed to the basement, stressed by compression, on which "[...] stereotomic and topographical mass literally found its foundation the most ephemeral form of the tectonic framework" (Frampton 1999, 107). Although he theorized an archetypal model based on the analogical connection of the elements of the structure, the German architect gives the basement a particular emphasis: it has the role of accentuating by contrast the hierarchical assembly that dominates it, and at the same time of fixing its shape and mediating it. the clash with the topos.

"The basement is configured according to the destination and shape of the superstructure, and, from this point of view, the general shape is independent of the structure; only the actual object, the one to be placed on the 
base, could and should have been influenced by the structural needs of the basement and modeled accordingly; even more directly, the same influence had to condition the form of the latter. The inorganic compositional principle, contained in the stone structure, alone led to regular elementary shapes, that is, composed according to crystalline and eurythmic criteria, the circle, the polygon and the rectangle" (Burelli, Cresti, Gravagnuolo, Tentori 1992, 279-280).

According to the German, the basement, since it refers to the stereometric category, can be made using a single material, stone, on whose superposition of the blocks the realization of this element depends. However, this is true if we refer to historical examples, from the most remote and archaic to the most recent, in which the construction technique was that of load-bearing masonry; in fact, the basement assumed very specific aesthetic standards, linked to the wall texture or in any case to the expressiveness of the stone material, from which, most likely, the subsequent and sometimes contemporary characteristics of solidity, massiveness and static sense derive. However, as clarified above, we know that different elements can participate in the basement typology in its practical configuration, such as parts of the building distinguished by shape, character or function and not necessarily by material.

Finally, we need to take a step back to understand and summarize the reasoning, returning to the architectural principle that anticipates the technique and the idea of space. "Before transforming a support into a column, a roof into a tympanum, before putting stone on stone one must put stone on the ground [...]" (Gregotti 1983, 8). In that way Gregotti brings us back to the idea of settlement, of which the basement represents the physical and conceptual foundation in architecture, able to investigate the site and then modify it; and although architecture represents an act of modification of reality, it concerns as much the technique as the site.

\section{THE CITY, THE TYPE AND THE PLACE}

The contemporary city seems to be the updated expression of what Ludwig Hilberseimer defined big city, an artificial entity that does not represent the largest-scale variation of the urban type that has become historical but the product of economic development (Hilberseimer 1981, 1). In fact, it differs from the city of the past not only in size but also in characteristics, ceasing to be an artifact that is generated by the interaction between the rational design of architecture and the values of the locus (Rossi 1995, 10); this is the reason why the forms of historical architecture cannot be separated from the context in which they were born (Hilberseimer 1981, 98). "Typicality and uniqueness, type and place, represent [in fact] the terms of a dialectical process through which architecture takes shape. [...] And it is precisely in that fixation of architecture, in its being rooted in a place, $[. .$.$] that Rossi finds the profound$ reason for what he calls the individuality of urban facts" (Martí Arís 1990, 88), in whose reiteration the construction of the city consists. The metropolis is instead governed by external factors, which accelerate its modification but disorientate its growth, with the consequent loss of that identity deriving from the uninterrupted relationship between architecture, form and place.

The economic progress and technological advancement are established today as the main engines of transformation of cities. Even the architectural project undergoes a weakening, since it no longer operates following its own intrinsic laws but finds itself following external speculative forces. Often neutral to the place, the contemporary building therefore appears self-referential, consequently fragmenting the urban space into disordered and undetermined facts. As Vittorio Gregotti says, in fact, in the oscillation between the expansion of the productive dimension of technology, conditioned by an increasingly driving technological innovation, 
and the aestheticizing of deconstruction processes (Gregotti 1999, 9), the architectural project has produced architectural objects that tend more to spectacularization than consolidation of an urban identity as a result of a formal research that has its roots in the nature of places.

In this scenario, the tall building takes on a first-rate role. The skyscraper, in addition to being a symbol of the big city, represents the "building type which, due to its constructive audacity, bears the germ of a new architecture" (Hilberseimer 1981, 62): it becomes, in fact, inextricably, the symbol also of the contemporary city, of which it interprets the shining sign of social and economic development. Its birth is actually closely linked to technological progress itself and to speculative factors, which are perhaps also the main reasons for its current and increasingly high typological diffusion.

However, there is a difficult relationship between the tall building and the city, as the criticisms of Wright and Lewis Mumford testify that the skyscraper is an anti-urban element. It often fails to integrate organically into the building fabric, remaining an isolated object, where among the causes there is certainly an excessive desire for individualism (Purini $2008,90)$. The tall building, moreover, in the search for verticality eludes any relationship with the ground, no longer understood as term of comparison between place and artifact, but as an abstract surface of an economic value or infrastructural function, abandoning that relationship with the morphology of places from which the urban fact originates.

In addition to the intrinsic quality of becoming a landmark itself, marking a place chosen to highlight its character or establish a polarity, the skyscraper establishes a powerful figurebackground relationship with the city, based on the image as it intervenes on the skyline, therefore on the urbanscape. But what are its formal relations with the urban space? How can it be organically integrated into the building fabric? How to found the tall building in the city soil?

\subsection{Birth and diffusion of the skyscraper}

The skyscraper was born in the 1880s in a small coastal district of Chicago. Given the ever stronger concentration in the center of the cities of the tertiary services, the mass of business acquired ever more impressive dimensions; in order not to give up the economic benefits deriving from such a concentration, in order to obviate the urgent need for space, the existing buildings were initially raised, then skyscrapers were built. The advantages of the new building type were immediately clear, so it was used even where, although there was no real lack of space, the technical and economic advantages were still decisive. Soon skyscrapers sprouted in large numbers in almost all major American cities and their physiognomy changed rapidly (Hilberseimer 1981, 62).

In a short time, the skyscraper became the symbol of the big city and was at the center of the development of some proposals concerning the ideation of the new modern city. This is the case of Le Corbusier and Hilberseimer, who set their theories on the possibilities opened up by the new typology. Le Corbusier designed a city for 3 million inhabitants in 1925, basing the planning on the principles of decongestion of the urban center and the contemporary increase in its population density, increase of transport and of green spaces; all advantages offered by the use of the skyscraper. In contrast, Hilberseimer conceives a city for 1 million inhabitants based on a greater concentration and aggregation. Thus, instead of organizing the city horizontally, he tries to give his metropolis a more vertical structure: it resulted in two overlapping cities, under the business city with vehicular traffic, above the residential one with pedestrian traffic; underground railway and underground lines (Hilberseimer 1981, 17). 
Beyond the characteristics of the two plans, which are more part of the theoretical ideas than in actual planning programs, the skyscraper is assumed as the possible key capable of countering the wild growth of the city and, therefore, the birth suburbs that would have erased the urban limits; to solve the problem of decongestion in the center, further favoring the creation of more useful space with less use of soil.

But after the impetus of the Modern Movement, some fundamental questions are brought to light, including the skyscraperurban space relationship and the typological reflection on the characters of the skyscraper. It is precisely the comparison with urban congestion that led to the identification of two ways of assuming the project: "the skyscraper as a simple volume that describes the building type, or the skyscraper that manifests, in the diversity of the parts, the complexity of the relationship with the urban space" (Maffioletti 1990, 41). Particular attention is therefore attributed to the ground attachment of the building: "from the decoration affixed to the basement in the Sullivan skyscrapers, to the public gallery open in the Flatiron between Broadway and Fifth Avenue, to the large lobbies of the deco skyscrapers, the ground floor of the tall American building is not only the link between the city and the building, but it is also the place where the urban space is returned to the public, thus made user" (Maffioletti 1990, 40).

However, in parallel, the American city and the European city take two different research ways: on the one hand the skyscraper represents a repeated typological unit, on the other an exceptional symbolic element, often used to accentuate the dynamics of a road or a square, a path or a destination.

\subsection{The tall building in America}

In America, the characterization of the irongrid inevitably makes the skyscraper the most suitable type for the characteristics of the city, being able to take advantage of the construction in height to obtain a greater built surface against the small portion of building land. However, in the constancy and regularity of the grid, every relationship with the urban space is often reduced to the positioning of the building within the lot, and the attachment on the ground only in the interpretation of the functional level. It is in this situation that American research enters, in which one of the most virtuous and wellknown cases is represented by the Seagram Building (New York, 1954-58). Mies van der Rohe, obtaining two adjacent lots for the construction of the skyscraper, withdraws the building on the side opposite the road. This generates a large square-podium which is returned to the city of New York; together space of architecture and space of the city and its inhabitants. The importance of this element lies not only in the spatial scope and in the mediation capacity of the building-city relationship: Mies redesigns the ground of the lot by inserting trees, flower beds, pools of water and seats, transfiguring the anonymous spatiality of the place. Furthermore, no less important, the stone slab flooring and the few steps, useful for reaching a slightly raised floor, differentiate the condition of being and, above all, elevate the character of the building placed on a crepidoma that clarifies its ground attachment.

An analogous example in urban intentions but different in actions is the unrealized Federal Reserve Building project (New York, 1969) by Kevin Roche. The architect pushes the limits of the building type by raising the entire volume on high pillars: in this way he moves the building away from urban congestion which finds a break in the apparently unedited free lot. The design expedient shows a stronger urban intentionality than the typological variation operation: the soil definitively returns to a collective place; its being empty, which in these cases coincides with public, is attributed by the presence of the tall building above it, which ensures its persistence and retains 
its character. The research conducted by Roche on urban space, although it expresses the complexity of the relationship between city and skyscraper, studies the potential of the building within the irongrid. In the Ford Foundation (New York, 1963-68), in fact, the architect transformed the lobby into a covered square, which became the heart of the city within the city. Here, unlike the Seagram or the Federal Reserve, it is the building that absorbs the urban functions, so the public space of the city is transformed into an internal collective space (Maffioletti 1990, 40).

\subsection{The tall building in Europe}

In Europe, however, or more properly in historic cities, the tall building is charged with many and complex meanings. It is configured as an exceptional and polarizing element, called to collaborate with the hierarchical principles of the built environment and its sedimented forms. The ground attachment therefore assumes different characteristics and functions: it represents the expression of the inseparable typos-topos relationship that characterizes urban morphology; that part of the building that most manifests the specificity of the place (urban, morphological and topographical), which return first as elements of the investigation and comparison which are then returned in the formal configuration of the building. The attachment on the ground ultimately represents the topographical substance of the skyscraper.

In the case of DaimlerChrysler Gebäude am Potsdamer Platz (Berlin, 2000), simply known as s Potsdamer Platz Tower by Hans Kollhoff, the ground attachment is solved in a granite basement corresponding to the first two levels of the skyscraper. In addition to tracing the pointed shape of the lot that lights up towards the square, it is made up of full parts and large colonnades, which indicate access and reinforce the urban character. The choice of material and the differentiation from that of the elevated volume underlines the foundational aspect, reaffirming the stereotomic and topographical character of the basement; its shape reverberates in the horizontality of the string courses which instead mark the tectonic structure. In addition, the entire configuration of the building highlights its growth starting from the ground and developing from this, exhibiting a stepped shape that tapers upwards and converts, rising, the horizontality into verticality. In this way it is the form itself that reveals the compositional process, which first investigates the relationship with the urban space and then, rising, the volumetric articulation; while the basement is able to reveal and, more importantly, respect the interrelation between built and urban form. (Fig. 1)

In the project for New Orleans (Rotterdam, 2007-10), a residential skyscraper built by Álvaro Siza, various factors enter the game. The nature of the space surrounding the building is different on all fronts and the architect solves the complexities of a place that is made up of the Nieuwe Maas river on one side and buildings, high and low, on the other side, through the insertion of an almost independent element, but able to dialogue equivalently in every direction. Thus the skyscraper expands its base, which extends longitudinally along the entire extension of the lot. Siza himself declares in an interview that the greatest difficulty, the initial one, was precisely to put together a tower and a low building (Siza 2010). The result is a typological combination in which, however, the low building becomes the key to the entire project: it becomes a representative front, low and urban, on the internal side, capable of dealing with the built, with the vehicles, with man; on the other, by stretching out, it follows the slow movement of water and boats.

The same procedure was used fifty years earlier by Arne Jacobsen for the Radisson SAS Royal Hotel in Copenhagen, who designed a low building on which he places the vertical volume. Despite its moderate height (the building does not exceed $70 \mathrm{~m}$ ), 
the juxtaposition of the low building allows Jacobsen to recover the road surface and mitigate the introduction of a vertical element within a rather low and measured context, just outside the historic center.

A third example is the Burgo Tower (Porto, 2017) by Souto de Moura. It is located inside a typologically heterogeneous fabric, just in the west of the city center. The project is configured as the set of two buildings side by side, one vertical and one horizontal, resting on a common platform. While the office tower has the task of establishing a new urban polarity, the basement that organizes the ground connection has a triple function: topographical-structural, to level the slightly sloping ground and support the artefacts; the urban one, to integrate the tower into the diluted surrounding spatiality and strengthen the overall planimetric layout through an extremely rational and orderly form. From the architectural point of view, however, it has a conformation of a sort of small acropolis designed ad hoc. In this sense, in addition to welcoming the artifacts, it has the task of putting them in dialogue with each other, isolating them on a neutral plane (which is why the architect chooses the incorruptible shape of the square) which is substantiated by the positioning of the buildings themselves, by the tension that it is generated between them and from the projection of their shadows that materialize their space. Also in this case, the absolute stereometry of the podium, in stark contrast to the accentuated tectonic structure of the metal profiles of the volumes above, expresses through its massiveness an aspiration to stability and a reference to that archetypal settlement principle.

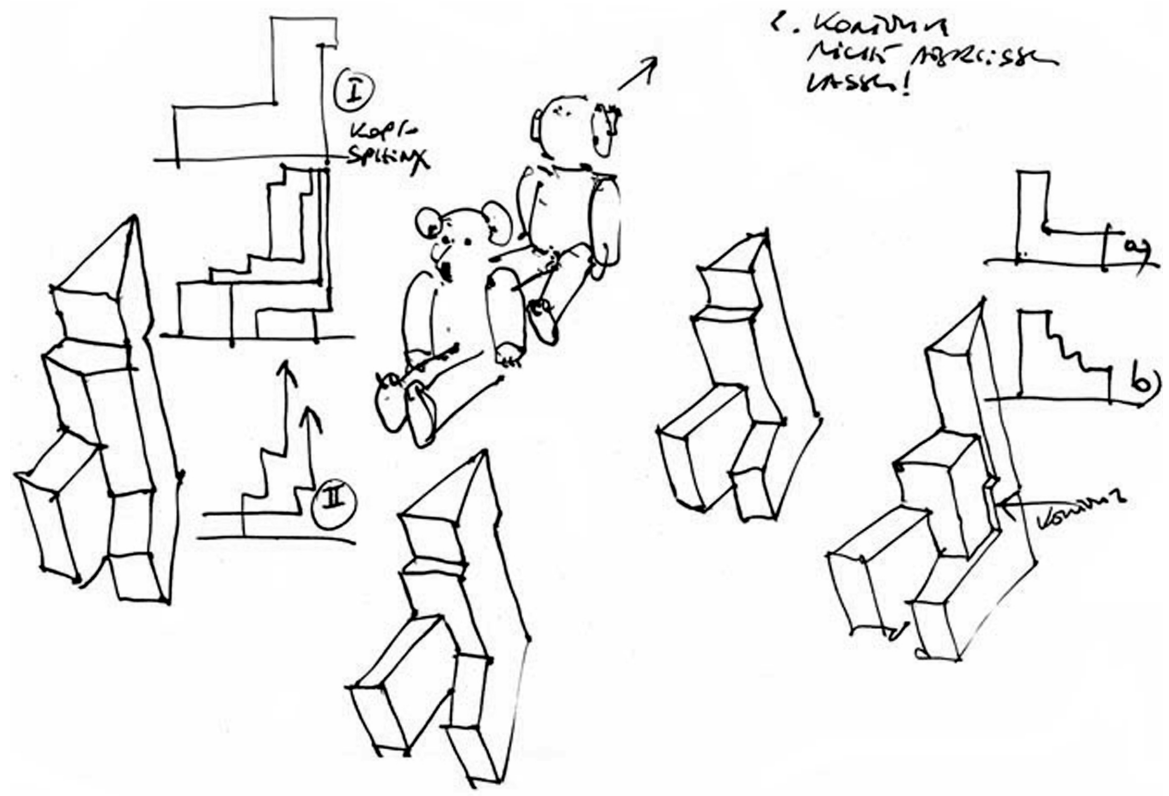

Figure 1. Sketch by Hans Kollhoff. DaimlerChrysler Gebäude am Potsdamer Platz. Source: http://www.kollhoff.de/en/index.html 


\subsection{The tall building in isolated contexts}

Finally, a further modus operandi, generalizable to any geographical-cultural context, but to urban situations, as we will see, not very compact or in which the natural component predominates over the artificial one, is that in which the skyscraper presents itself as the only architectural emergency or even as an isolated building. In these circumstances, the building is also entrusted with the task of defining the surrounding spatiality, providing itself with the few elements of dialogue present in the area; in these cases the place and the soil, the topographical and geomorphological aspects represent the main terms of reference. The complexity of operating within a well-defined urban context highlights the anti-urban tendency of the skyscraper, which tries in every way to disguise its belonging by exasperating its singularity. From this derives the difficulty in integrating into the building fabric, remaining, in most cases, contradictorily, an isolated object. In these conditions, however, in a place whose architectural presence is reduced, the complexities change: the challenge concerns first of all the primary relationship with the foundation soil and the ground line, however operating with a type that in itself leads to the limit the relationship between nature and artifice. However, the congenital aggressiveness of the skyscraper diminishes, missing the competition between neighbors in which each tower participates; on the other hand, his attitude to become a landscape reference to the city increases, a territorial pole that can expand its roots by creating a rich and articulated situation in its support on the ground (Purini 2008, 90).

In the Price Tower (Bartlesville, 1952-56), for example, Wright solves the contingencies of the place by performing two consecutive operations in the same project. The first one is the creation of a low organism, a real root system that expands by investigating the surrounding space; on it, then, rises the multifunctional tower that the architect himself renames the tree that escaped the crowded forest. The structure of the building is a real reference to that of a tree, with nineteen jutting planes that stretch like branches starting from a single central trunk that sinks into the ground like a pole well planted in the ground. Wright employs a ploy already tried in the Johnson Wax Building (Racine, Wisconsin, 1936-39). The sections of the two complexes in fact have the same solutions that immediately clarify the design intentions; however, what the architect accomplishes in Bartlesville in a single design act, he previously does in two temporally distinct phases: at first the low system is created; about ten years later the Johnson Wax Research Tower (1944-1950) was built, which sinks firmly into the deep ground and rises with its fourteen floors absolutely dependent on its base. The latter develops horizontally like a plastic organism and, welcoming the tower inside in a closed courtyard, it transforms into an urban mechanism with the function of grading the process towards the outside and creating a spatial continuity between the vertical volume and what happens outside. Thus in Wright the tall building is not an autonomous element of the city but an element that is part of an urban system that finds its verticality in it.

Leaving the urban context and returning to the old continent, this time we find ourselves in the midst of an entirely natural environment. This is the project presented by Jørn Utzon for the competition of a high school in Højstrup, Denmark. The project (1958, unrealized) is characterized by the composition of a housing tower that rises on a functional basement intended to host the center's activities. The whole school is developed above the platform that emerges from the woods and which opens in the center with a patio-garden, bringing the natural element inside. Inside the basement volume the service spaces, while above the various activities of the program. 
For the Danish architect, the platform is the archetype that best interprets the condition of inhabiting: it represents the clearing that makes the ground habitable, an element by definition planar that here acquires thickness and becomes inhabited; while planimetrically assumes the function of an elevated enclosure, in which all the artifacts are collected within the limits of the large basement. Everything is subordinated to the platform that organizes the space and houses the artifacts: on it the various environments are delimited by independently articulated walls that in turn circumscribe individual functional environments.

Utzon himself, in order to describe the project, uses a few useful words to just illustrate the gesture of the platform, which "stands on a slightly undulating landscape and underlines, thanks to its quadrangular and linear character, the gentle movements of the landscape" (Utzon 1962, 140). The entire project operation is resolved on the platform; becoming itself a topographical element to which the dormitory tower simply acts as a counterpoint, marking the place of the settlement. The tower becomes just one of the many and different artifacts that gathers the platform on it (Fig. 2). The latter represents for Utzon an element of constant formal experimentation and from which he draws repeatedly for his projects. The Mayan platforms that he visits in Mexico in 1949 become one of the most important architectural experiences of his life; so in 1962 he published an article in the magazine Zodiac in which he described the sensation that he produced passing from the dense vegetation of the jungle to the open horizon that is revealed by climbing on the platform, comparing this suggestion with what one feels in Scandinavia to see the sun come out after several interminable weeks of rain and darkness (Utzon 1962, 114).

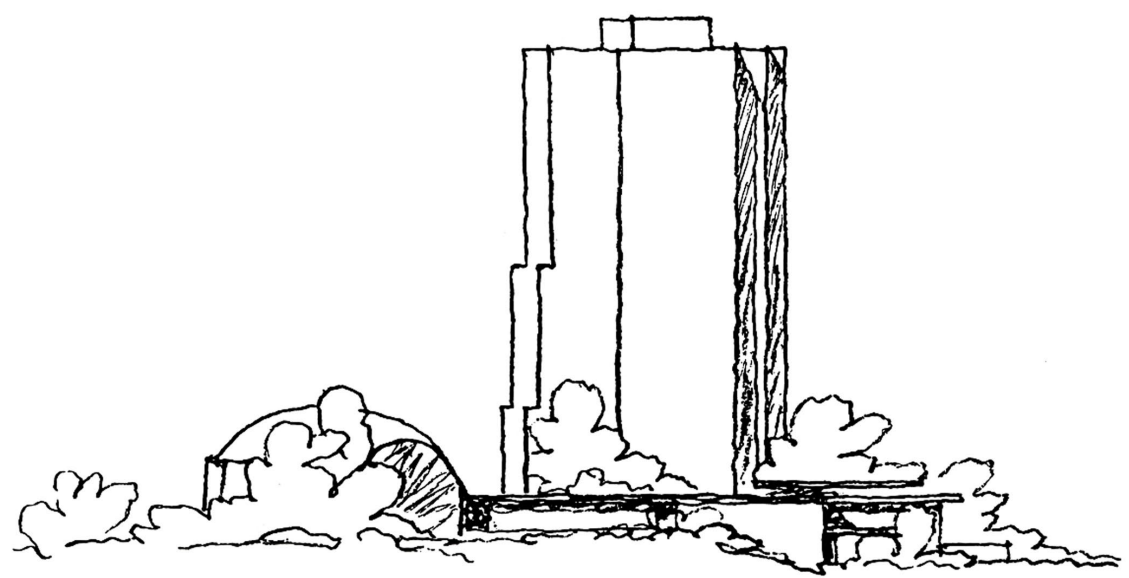

Figure 2. Sketch by Jørn Utzon. High school in Højstrup. 


\section{FROM THE FORM TO THE SPACE}

Through the analysis of some projects, we wanted to highlight the interaction between the tall building and urban space, or in detail the effects made by the interaction between the different forms of the constructed and the morphology of the places. The city is an artifact that has been built slowly and, in most cases, with its own but rational rules. The territorial homologation produced by the globalization is instead increasingly rapidly canceling its growth processes and the stratified identity of places.

The study of the ground attachment becomes today an opportunity to investigate together various aspects of the building, such as those more strictly technical and functional, as well as those of a compositional nature, and those concerning the founding aspect of architecture, full of urban intentions and sense of rooting in places (Fig. 3).

Reflecting also on the horizontality of the tall building therefore means searching in its intersection with the ground for renewed relationships, able to re-signify the urban space. It means to positioning oneself within a process of will, of reflection on the meaning of doing, of searching for a possible interpretative key for the architecture design, in an attempt to rediscover that relationship between topos and typos whose interaction, reciprocal and dialogical, since ever gives shape to the city.

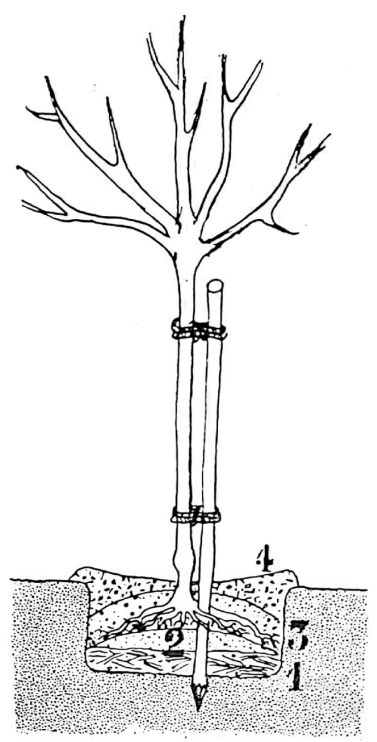

Pour bien planter un arbre : 1 . bonne terre et fumure de fond

2. dôme de terre fine

3. terre végétale très fine

4. terre du sous-sol et engrais.

Figure 3. To plant well a tree. Source: Le Corbusier 1933. La ville radieuse. Paris: Éditions Vincent, Fréal \& Cie. 


\section{REFERENCES}

Angeletti, P., Bordini, V. and Terranova, A. 1989. Fondamenti dicomposizione architettonica. Urbino: La Nuova Italia Scientifica.

Burelli, A.R., Cresti, C., Gravagnuolo B. and Tentori, F. (ed.) 1992. Lo stile nelle arti tecniche e tettoniche, o Estetica pratica: manuale per tecnici, artisti e amatori. Roma-Bari: Editori Laterza.

Cao, U. 1995. Elementi di progettazione architettonica. Roma-Bari: Università Laterza Architettura.

Frampton, K. 1999. Tettonica e Architettura, poetica della forma architettonica nel XIX e XX secolo. Milano: Skira.

Gregotti, V. 1983. "Address to the Architectural League", in Section A, n. 1, vol. 1.

Gregotti, V. 1995. "Fondazioni”, in Casabella, n. 628.

Gregotti, V. 1999. "Introduzione", in Frampton, K. Tettonica e Architettura. Poetica della forma architettonica nel XIX e XX secolo. Milano: Skira.

Hilberseimer, L. 1981. L'architettura della grande città, Napoli: Clean.

Maffioletti, S. 1990. La città verticale. II grattacielo: ruolo urbano e composizione. Trento: CLUVA.

Martí Arís, C. 1990. Le variazioni dell'identità. II tipo in architettura. Torino: CittàStudiEdizioni.

Purini, F. 2008. "Grattacieli italiani”, in Agnoletto, M. and Trentin, A. (eds.) Architettura 28. II progetto dell'edifico alto. Bologna: CLUEB.

Rossi, A. 1995. L'architettura della città. Milano: CittàStudiEdizioni.

Siza, A. 2010. "Interview Álvaro Siza New Orleans Rotterdam", interview by Huub Smeets, YouTube, March 11, https://www. youtube.com/watch?v=EvjNq7Fao6k.

Utzon, J. 1962. "Platforms and Plateaus. Ideas of a Danish Architect", in Zodiac, n. 10. 


\section{PAPER \#2.24}

\section{THE DOMESTIC CITY: EXPANSION OF THE DOMESTICITY IN THE CONTEMPORARY CITY}

Flavio Martella ${ }^{\mathrm{a}}$, Marco Enia ${ }^{\mathrm{b}}$

aUniversidad Politécnica de Madrid, Madrid, Spain

bUniversidad de las Américas Puebla, Puebla, Mexico

\section{ABSTRACT}

Ongoing social, cultural and economic changes in western societies are affecting the way people experience both urban and domestic environments. Contemporary technologies, the gender revolution and the evolution of habits are among the factors that are leading to the emergence of new forms of urban life, where the very ideas of home and city blur, and the dualities traditionally used to understand the cultural landscape are dissolving (man/woman, interior/exterior, public/private, work/leisure, sedentary/ nomadic, inside/outside). Domestic and urban life are slowly but inexorably merging. Home is increasingly understood, rather than as a fixed place enclosed within four walls, as a mental territory that extends into the broader context of the city. The domestic environment is opening up to the city, adapting many of its uses and spaces to new forms of nomadic, post-human and digital life; its identity is changing, evolving into a hybrid environment difficult to define. At the same time, the urban environment is being domesticated: many of the activities normally associated with domestic life, such as resting, eating, finding some intimacy, watching movies or talking to relatives, increasingly take place in the spaces of the city. This blurring of boundaries between home and city is radically changing the way of thinking and designing private and public spaces, to make them able to respond to emerging and future lifestyles. The paper aims at introducing the main facts about the contemporary blurring of the boundaries of domestic and urban space, explaining how this is currently affecting the architecture of both the house and the city.

\section{KEYWORDS}

Domesticity; nomadism; home; urban environment; domestic environment.

\section{INTRODUCTION}

Domestic and urban environments are apparently very different domains separated by spatial limits. House walls seem to draw a clear line of demarcation between them, unequivocally indicating where one realm begins and the other ends. However, this is true only when focusing on their physical boundaries: things get more complicated when attention is paid to their conceptual boundaries, that is, to those actions, events and situations that are usually associated with the urban or the domestic. Until the contemporary era, with its digital and gender revolution, the house was mostly perceived as a quite autonomous microcosm and the city as its receptacle, but today the distinction is not so sharp. Recent social, economic, political, technological and cultural changes have led to the emergence of new individuals (Echeverría, 2018) and of new forms of living, that are rapidly transforming both domestic and urban life. Nowadays, many activities commonly related to domestic spaces often take place outside. At the same time, houses increasingly accommodate typically urban functions, giving rise to hybrid situations that modify the very idea of city and home. Domesticity is more and more understood as a field, or as a mental territory that goes beyond the material, concrete, spatial and bodily limits of the house (Chávez Giraldo, 2010): it is a multidimensional domain, related to the intimate condition of human beings and their need for protection, care, rest, 
recovery and pleasure (Bachelard, 1957; see also Mallett, 2004). The identity of the space/ home is constantly being redefined; it expands and contracts, and increasingly depends not only on a specific physical interior, but also on a network of urban places.

The gender revolution started in the 60 s has significantly contributed to begin a radical change the concept of domesticity established mainly during the Modern Movement (and still ongoing). A concept that was based on the clear functional separation between home and context, between public and private, between man and woman, between work and leisure, between inside and outside (Sennett, 1977). A condition that created an idealization of the house that was easily recognizable, and therefore easily desirable, even if it was based on a much less recognizable spatial and functional isolation that hid an enormous effort to maintain it.

In fact, from the 1960s onwards, many voices have denounced the traditional domestic environment as a space that did not allow the emancipation of women; an environment in which a great deal of unpaid work was required to maintain the suitability for restoring the productive capacities of workers (usually men) (Federici 2009). The unmasking of this "reproductive" function of the house (in the sense that it reproduces, regenerates, productive capacities) allows the woman to emancipate herself from the role of housewife, making possible the emergence of new forms of urban life that differ from the traditional family model (Brubaker, 1993; Reigot and Spina, 1996; Beck-Gernsheim, 2003). In this radical transformation, the body acquires a new prominence. Freed from pre-constructed concepts, the body is identified as the starting point for constructing new social behaviours and a new meaning of domesticity, from new lifestyles based on a more heterogeneous and diversified structure (Madigan and Munro, 1990; Darke, 1994; Gilroy and Woods, 1994; Attfield and Kirkham, 1989; Heynen and Baydar, 2005; Taylor and Preston, 2006).
While the gender revolution highlighted some critical points and started a radical rethinking of the meaning of domesticity, the contemporary digital revolution is creating new kind of individuals that interact with the environment in a very different way (Castells, 1996), capable of superimposing an individualized virtual context on the material one. There is no epic image that symbolizes this change. It is a change without bank roars, without oil wars or physical deaths. It is a subliminal transformation, parallel to epic changes, inadvertent, such as the erosion of the clink of a drop on the stone (Zafra, 2016).

\section{DIGITAL REVOLUTION}

Contemporary digital media have already created new habits, which depend on patterns of life linked to speed of action, the possibilities of individual devices and the expanded urban relationships (Giaccardi \& Magatti, 2001). These habits are also changing the way we relate to ourselves. Individuals increasingly have an existence that goes beyond their physical body; they also exist as bits of information (Sheller and Urry, 2003). This paradigm shift is materialized through most of the contemporary urban daily routines: routines such as get in contact with people, socialize, get general and specific information, buy groceries and objects, study, see locations, but also work, leisure, play, have sex, etc. They create a digital self who experiments an augmented environment and that can exist and shape different realities. The perceived urban experience is now twisted through the mediation of devices, often digital ones, and their ability to project the person into a personal microcosm, where to comfort its daily needs. The superimposition of the digital layer over the material one creates new feelings of domesticity, of society, of production, of leisure and of commerce that influence the way of interaction with the urban material sphere. The diffusion of Internet, and with it of the new forms of instantaneous communication, 
has led to a kind of fragmentation of selves into different pieces scattered in virtual space. Nowadays, people can exist at the same time in the physical space, as moving bodies, and in the communicational space, wherever they left some of their information and identity: for example, in social networks, online gaming websites, or cross-platform messaging services (Echeverria \& Almendros, 2020). An important effect of this revolution is that the separation between house and the external world is becoming more and more thin. Today one can access the public world from his/her house, or communicate with people who live far way, or participate in real time of events happening in the farthest corners of the planet, or enabling the domestic environment from a public place.

The digital revolution not only transforms the individuals, but it relates them with a broader context that often extends to the urban scale. All these phenomena have given rise to a different use of spaces, both urban and domestic; people actively interact with the environment through a digital layer, and this results in a totally new form of relationship with the city (La Cecla, 1995). In fact, this new being lives in a different urban environment. No longer only rooted in materiality and in its form, this new environment enables new ways of living and understanding the city, that foster a radical change in the way of conceiving its architecture, the domestic environment and the workspace, i.e. the traditional pillars of the modern society.

As a consequence, homes are then potentially deterritorialized since they are losing their physical boundaries and facing a structural modification in one of their main values: the family (Roig, 2014). Nowadays, an individualistic and materialistic way of living is predominant over the familiar. Today there are many more lifestyles than in the recent past, such as co-living and solo living; however, even when living in a family context, the new urban digital inhabitants tend to individually enter the virtual world, to create trans-urban relationships that transcend the traditional ties, and that often are strong enough to be compared to the material ones.

This behavior, even though appears to happen only in the digital sphere, is radically affecting the architectural environment, by introducing a need for diversity instead of homogeneity, flexibility, the sense of occupation and the possibility of identification against the imposed abstractions.

It seems clear that today's western society, is the protagonist of a historical revolution in terms of both forms of socialization and individualization. This process corresponds to "a new way of organizing behaviors, characterized by the minimum of constraints and the maximum possible choices" (Amann, 2005), relying on individual possibilities of interacting with the (familiar, urban, global) community. The boundaries are lost and the internal/external, public/private, man/woman, work/leisure dualities become less clear (Bauman, 2000. Matsuda, 2010).

In contrast to the classical rationalist paradigm, the digital identity replaces the modernist ideals of harmony, purity, perfection and nature with those of network organization, decentralization, interchangeability and continuous transformation. Its architecture is then produced by networks of affinity groups; it is made of semi-autonomous components interconnected in networks similar to those of information and communications. From a political point of view, this architecture replaces the ideas of identity, hegemony, hierarchy and spectacle, with those of hybridization, plurality, horizontality and performance (De Lama, 2020).

\section{EXPANDED DOMESTICITY}

The sense of domesticity of individuals, once closed on itself, now opens the way for a new identity that lies in the overlap between the material and virtual world. Such domesticity no longer finds in the city its antagonist, but 
an ally. It is, in fact, where the spatial offer is potentially greater and where therefore it can allow a greater expression of individual personalities hovering between the public and the private sector. The digital revolution, among many other social, political, economic and cultural events that led to a progressive reduction of domestic spaces and a rediscovery of the semi-public context, helps to turn every room in the house into something different than before. The bedroom is thus converting into a new multimedia/office living room; the kitchen into an urban extension, because of home delivery services of all kinds; the living room in a space no longer uniquely defined, both public and privately; the bathroom in a place that rediscovers its own sensuality and relationship with the body, as well as a new extension of the office.

As has been noted, the bed and the sofa are slowly converging: in 2014 the bed overcame the sofa for the first time as the most used furniture in British homes (Bose, Self \& Williams, 2016). Bedroom culture (Livingstone, 2007) represents an increasingly generalized perception of the bed as a center of cinematic entertainment and an individualized leisure culture. For most of the new users the kitchen is losing its original use (Steegman, 2017) to become mostly a place to store small foods and to socialize. The entire city is now substituting the kitchen through the presence of daily menus, precooked food, street food activities, food offer apps such as The Fork, or the increase of the food delivery companies such as Deliveroo, Just Eat and Uber eats. This is completely reconfiguring the urban environment to satisfy the alimentary necessities of an increasing part of the population that prefers to live the city and uses the kitchen just for small tasks (Puigjaner, 2014).

The living room is now an integrated part of most of public and semi-public places, such as coffee shops, restaurants, pubs, offices, stations, airports and plazas. It is the place that most enables a physical domestic condition outside the house, and due to its deterritorialized condition, it is the symbolic place where to augment the individual environment (Martella, 2018). The change in the meaning of home is fundamental for the emergence of new forms of living, as the house has always been the pillar around which personal, everyday life was structured. Traditional routines are now broken; new ones are created which are completely dependent on new life patterns linked to the speed of action, to the possibilities of the individual devices and on the expanded urban relationships. All these phenomena have led to a different use of space, both in the city and domestic environments. Space can now change constantly, through the continuous passage of people who establish relationships that are always different with the surrounding environment (La Cecla, 1995).

The people actively and continuously interact with the others and the surrounding through the digital layer, enabling a new symbiosis of the people with the city through a technological omnipresence; a new "augmentation" of the physical environment, that goes beyond the material skin and that brings to a complete rediscovery of the urban as the scenery of daily life. A symbiosis like never before is then created between the inhabitant, the place, and personal devices that leads to a continuous re-modelling of the architectural program according to the needs of its users. Spaces that cannot be singular but plural, and can rely on many more factors than just themselves; they are part of an hyperconnected hybrid whole enabled by trans-urban devices; a condition that must be taken in consideration while designing and thinking the contemporary city. Every subject with a digital device can augment the material environment to redefine its main uses, changing the perception of the space.

This individual augmentation of the physical environment allows a new type of 'soft' occupation, in which the power to define program in a space is partially returned to 
the user. This 'soft' occupation of space empowers the electronomad (Mitchell, 2004) to individually impose program on to a space, leading to urban hybrid, mixed-use spaces. Coffee shops (like Starbucks and many others) for example, may simultaneously accommodate multiple programs by providing a flexible environment with seating, toilets, refreshments and network connectivity. They then enable new possible uses that moves from office works to streaming movies, from romantic dates to job interviews.

\section{TIME}

All of this would not have been possible without a change in the notion of time. Time, in contemporary era, is in fact increasingly perceived as something that compresses or even annihilates space (Rosa, 2015). Personal life is now continuously invaded by distant events, relationship and experiences: through their electronic devices, individuals are constantly confronted with symbolic and cultural worlds that are completely outside their range of action, and that relate them to other domains even when these are not physically present; a timeless time (Castells, 1996). This abstraction goes both in the direction of a dematerialization of experience, and of its delocalization (Tomlison, 1999), in the sense that the physical context of the subject is no longer a constraint and can be easily bypassed. With the advent of broader, multi-level global connections and of virtual communities, the external world enters and permeates the domestic sphere, questioning the bourgeois meaning of home as a purely private place.

The once so clear boundary between inside and outside is fading. According to a marketing research conducted by IKEA in 2016 , only $7 \%$ of respondents (250 families) identify a specific place as home. On the other hand, $37 \%$ believe that home extends outside the domestic walls; $38 \%$ identify it with the neighborhood, while $18 \%$ with the city itself (Ikea, 2016). These data are a good example of the contemporary tendency to displace in the urban many activities, habits and affections traditionally linked to the domestic space, merging it with the city. Also, according to the same research, most people of the new generations - Millennials, Generation Z - feel more comfortable outside their houses, even for activities such as watching TV, relaxing or sleeping. Home, in the era of globalization, can be interpreted as an open and porous place, an intersection of social relations and emotions; its contemporary identity should be built on communication, movement, and interactions, able to enrich the daily life of individuals, more than on separation (Blunt and Dowling, 2006).

Another important aspect in the current evolution of the idea of home is the mobility of many urban inhabitants. People now are constantly in motion, from home to work (and backward), from one house to another, from one city to another, often from one country to another. The 21st century individual increasingly resembles the "the Derridian parasite" (Derrida, 1988), the nomads of Deleuze and Guattari (1986), or Lyotard's hobo (Lyotard, 1993). The prototype of the contemporary individual is a mestizo with many identities and multiple belongings, who chooses certain life patterns according to his/her values and beliefs; he/she is flexible, and able to adapt to the changing circumstances. More and more people today live in the condition that Verschaffel (2012) has defined "a-topia", that is, as nomadic subject freed from the concept of belonging and in a state of perennial transit. With this new type of urban dweller, the perception of both domestic and urban space changes from permanent to temporary. Home, more than being associated to a stable and fixed place, may exist in many different locations and times, depending on where and when the body and the mind are in a specific moment (Chávez Giraldo, 2010). 
The concept of home is increasingly merging with domains that were previously regarded as clearly separate, such as the working sphere. The possibility of being continuously connected, and the dissolution of the physical frontiers between interior and exterior, facilitate immaterial labour (Aureli \& Giudici, 2018). Today, from any place it is possible to contribute to the production system; the domestic space is already one of its main cores. This is happening not only because new technologies make production ubiquitous, thus diminishing the importance of traditional workplaces (the office, for example); but also because immaterial production relies on aspects more typical of the domestic domain, such as sociability, affectivity, and care (Dogma, 2015). This releases at the same time the latent productivity of the domestic space and the domesticity of the traditional workplace. Home is now considered, for the first time in its recent history, a productive place, and the same goes for every place with an Internet connection: bars, trains, airplanes, banks, lawns, restaurants, cars, etc. (Mitchell, 2004). The separation between workplace and home is being erased, questioning the identity of the latter as a refuge from external worries and stress.

\section{CONCLUSION}

This evolution of contemporary domesticity goes hand in hand with the changing notion of interior. Today, the domestic interior is often no longer understood as a finished product, but as a process in continuous evolution, which depends from the relationship between the house and the physical and emotional wellbeing of its inhabitants. Such relationship is able to generate an incredible variety of ways to inhabit domestic space (Attiwill, 2012), and is supported and constantly remodeled on the basis of the flow of information produced by the current social system. Precisely because one of its main influences comes from the outside, the domestic interior extends beyond the limits of the house and expands into the urban. The house tends to the city, and the city turns into a home; they share rooms, spaces, times and atmospheres.

But changes in domesticity also arise from the evolution of the relationship between public and private domain, whose boundaries are increasingly mobile and fluid (Bauman, 2000). Throughout the 20th century, social sciences used to understand "public" and "private" as static and antithetical concepts: according to Sheller and Urry (2003) each "public" presuppose a certain contrasting "private". Nevertheless, nowadays the distinction does not seem to be so clear. In many respects, "public" and "private" have already become complementary rather than antithetical moments of contemporary social life, overlapping and hybridizing their conceptual and physical boundaries (Sheller and Urry, 2003; see also Kumar and Makarova, 2008). They now point to a multiplicity of different meanings, although often their semantic complexity is not fully recognized (Weintraub, 1997).

The blurring of traditional dualities (public/ private, man/woman, work/leisure, inside/ outside, digital/material, nomad/sedentary) is giving rise to a new concept of domesticity, replacing the idea of the home as a closed space with fixed uses and a static identity: a concept that allows multiple meanings and that exists in a context that transcends physical boundaries, spreading around the global urban environment. A concept that, as Braidotti (2006) suggested, requires a reconfiguration of our being in the world, in the framework of a global and nomadic conception of the subject, that exists in a networked environment. 


\section{REFERENCES}

Amann Alcocer, A., 2005. "El espacio doméstico: La mujer y la casa”. PhD diss., Universidad Politécnica de Madrid.

Attfield, J. \& Kirkham, P. (eds), 1989. A Wiew from the Interior: women and design. London: Women's Press.

Attiwill, S., 2012. "Interior, practices of interiorization, interior design". PhD diss., RMIT University

Aureli, P. V. \& Giudici, M. S., 2018. "The forum of otium: labour and leisure in ancient Greek and roman domestic space". In Work Body Leisure, edited by Verzier, M. O. \& Axel, N., 154-162. Rotterdam: Hatie Cantz.

Bachelard, G. 2014. Poetics of space (1957). Translated by Maria Jolas. New York: Penguin books

Bauman, Z., 2000. Liquid Modernity. Cambridge: Polity Press.

Beck-Gernsheim, E., 2003. La reinvención de la familia. En busca de nuevas formas de convivencia. Barcelona: Paidós

Bhabha, H. K. (2004). The Location of Culture. Abingdon: Routledge.

Blunt, A. \& Dowling, R., 2006. Home. Milton Park, UK and New York: Routledge.

Bose, S., Self, J., Williams, F., 2016. Home Economics: Five New Models for Domestic Life. London: The Spaces

Braidotti, R., 2006. Transpositions: On Nomadic Ethics. Cambridge: Polity Press

Brubaker, T. H. (ed), 1993. Family Relations: Challenges for the Future. Newbury Park, Cal.: Sage.

Castells, M., 1996. The information Age: Economy, Society and Culture. Volume 1: The Rise of the Network Society. Cambridge: Blackwell! Publishers Inc.

Chávez Giraldo, J. D. (2010). El espacio domestico tras el soporte arquitectónico: Claves para entender el sentido multidimensional de lo íntimo en el dominio del hogar. Dearq 07.
Darke, J., 1994. "Women and the Meaning of Home". In Housing Women, edited by Gilroy, R. \& Woods, R., 11-30. London: Routledge.

Deleuze, G. \& Guattari, F. (1986). Nomadology: The War Machine. Cambridge, MA: MIT Press.

Derrida, J. (1988). Limited Inc. Evanston, IL: Northwestern University Press.

Dogma, 2015. "Living and Working: How to Live Together". Retrieved from: https:// architecture.mit.edu/sites/architecture. mit.edu/files/attachments/lecture/ Tattara_living\%20and\%2 0working_intro. pdf (accessed April 17, 2019).

Echeverría, J. \& Almendros, L. S. (2020), Tecnopersonas: cómo nos cambian las tecnologías. Gijón: Trea.

Echeverria, J. (2018), "Philosophy of Technoworlds and Technopersons", in B. Laspra and J.A. López Cerezo (eds.) (2018). Spanish Philosophy of Technology - Contemporary Work from the Spanish Speaking Community. Berlin: Springer, pp. 153-164.

Federici, S., 2009. "The reproduction of Labour-Power in the Global Economy, Marxist Theory and the Unfinished Feminist Revolution". Paper presented at the Seminar on the Crisis of Social Reproduction and Feminist Struggle, Santa Cruz, UC.

Giaccardi, C \& Magatti, M. (2001) La globalizzazione non è un destino. Momenti strutturali ed esperienze soggettive nell'età contemporanea. Bari: Laterza.

Gilroy, R. \& Woods, R., 1994. eds. Housing Women. London: Routledge.

Heynen, H. \& Baydar, G., eds., 2005. Negotiating Domesticity: Spatial Productions of Gender in Modern Architecture. London: Routledge. 
IKEA, 2016. "Life at Home: What Makes a Home. Report 3". Retrieved from: https://ikeamuseum.com/media/ filer_public/9a/94/9a94647a-d3564a6b-9803- 3fc6a4ca0034/ikea_life_at_ home_report_3.pdf (accessed April 23, 2019)

Kumar, K., \& Ekaterina, M., 2008. The Portable Home: The Domestication of Public Space". Sociological Theory 26 (4): 324-343. doi: 10.1111/j.14679558.2008.00332.x

La Cecla, F., 1995. Mente locale. Per un'antropologia dell'abitare. Milano: Elèuthera

Livingstone, S., 2007. "From family television to bedroom culture: Young people's media at home." In Media Studies: Key Issues and Debates, edited by Devereux, E., 302-321. London: Sage Publications Ltd.

Lyotard, J. F. (1993). Libidinal Economy. Bloomington, IN: Indiana University press. Madigan, R., Munro, M. \& Smith, S. J., 1990. "Gender and the Meaning of the Home". International Journal of Urban and Regional Research, 14 (4): 625-647. doi: 10.1111/j.1468-2427.1990.tb00160.x 10.1111/j.1467-954X.2004.00442.x

Martella, F., 2018. "Hacia una nueva transformación de la sala de estar. Expansión del papel de la sala de estar a través de la sociedad contemporánea". Reia 13: 103-122.

Matsuda, K. (2010) Domesti/city. The dislocated home in the augmented space. Master's thesis, Bartlett School of Architecture, UCL.

Mitchell, W. J. (2004). Me+t; the cyborg self and the networked city. Cambridge, MA: MIT Press.

Pérez de Lama, J. (2020). Geografias de una multitud (conectada): entre la espacialidad de los flujos y la ciencia ficción. http:// hackitectura.net/osfavelados/txts/sci_fi_ geographies.html Puigjaner, A., 2014. "The kitchenless city". PhD diss. Universidad Politécnica de Catalunya
Reigot, B. P. \& Spina, R. K., 1996. Beyond the traditional family: voices of diversity. New york: Springer Verlag

Roig, E. (2014). El entorno aumentado: Imperativo informacional para una ecología digital de lo arquitectónico. UPM. PhD tesis.

Rosa, H. (2015). Accelerazione e alienazione. Per una teoria critica del tempo nella tarda modernità. Torino: Einaudi.

Sennett, R., 1977. The Fall of Public Man. New York: Alfred A. Knopf

Sheller, M. \& Urry, J., 2003. "Mobile transformations of "Public" and "Private" life." Theory Cultureand Society 20 (3): 107125. doi: 10.1177/02632764030203007

Steegmann, D., 2017. "Ciudad, Casa, Comida. Una aproximación poliédrica a los limites entro lo público y lo privado". PhD diss., Universidad Politécnica de Catalunya.

Taylor, M. and Preston, J. (eds), 2006. Intimus: Interior Design Theory Reader. New York: John Wiley Tomlinson, J., 1999. Globalization and culture. Cambridge: Polity Press

Verschaffel, B. (2012). "The Meaning of Domesticity", in Briganti, C. \& Mezei, K. (eds.), The Domestic Space Reader. Toronto: University of Toronto Press.

Weintraub, J., 1997. "The Theory and Politics of the Public/Private Distinction". In Public and Private in Thought and Practice: Perspectives on a Grand Dichotomy, edited by Weintraub J. \& Kumar, K., 1-42. Chicago, IL and London: University of Chicago Press.

Zafra, R. (2016). Los que miran. Madrid: Fórcola. 


\section{PAPER \#2.25}

\section{THE SUSTAINABLE HOUSE: PSYCHOLOGY VS TECHNOLOGY}

\section{Olivia Longo}

aUniversity of Brescia, Brescia, Italy

\section{ABSTRACT}

In this Digital Era (Industry 4.0) characterised by a great number of IT innovations, the questions are: which changes will there be in our future daily home life? Which kind of house will be appropriate to help us to find a balanced relationship between virtual spaces and physical ones? That is, between our mind (more and more supported by information technology) and our body (that ancestrally needs to feel well in contact with Nature)?

This contribution aims to underline the natural and human characteristics that can inspire architects during their composition processes of a sustainable house.

We are often used to thinking about a sustainable house only as a passive house. We care about the technological components and we rarely care about the psychological ones, that have to be connected with the context where the house will be built, so in a city we have to find the correct network of relationships between domestic spaces and urban ones.

Only a progressive transition from public spaces to private ones can offer the inhabitants a sense of urban well-being and identity. The concepts of "in-between" and "thresholds" have been abundantly studied in the past by famous authors of architectural theories but today those concepts are rarely used during the design process of a house in an urban context.

\section{KEYWORDS}

sustainability; house; threshold; psychology; uncanny.

\section{INTRODUCTION}

\begin{abstract}
"We are on the threshold of a revolution that is drastically changing the way we live... work and relate to others... Let's consider, for example, the almost limitless possibilities of connecting billions of people through mobile devices, generating unprecedented processing, storage and access to information..."1. (Schwab, 2016, 13)
\end{abstract}

Schwab underlines the incredible convergence of technological inventions such as artificial intelligence, robotics, the Internet of things, the manufacture of autonomous vehicles, 3D printing, nanotechnology, biotechnology, materials science, energy storage, quantum computing.

We think that all these phenomena will change our way to inhabit a house and that designers, architects and engineers will have to learn new methods to study and design the house of the future, a future 4.0.

Thinking about the Internet of things (IOT), Schwab affirms that "it is estimated that by 2020 more than 50 billion devices will be connected to the Internet"2 (Schwab, 2016, 169). IoT is a system of related computer devices, mechanical and digital machines, objects, animals or people with unique identifiers and the ability to transfer data over a network without requiring human-human or human-computer interaction.

The definition of the Internet of things has evolved thanks to the convergence of multiple technologies, real-time analysis, machine learning, raw material sensors and integrated systems, traditional fields of integrated 
systems, wireless sensor networks, control systems, automation (including home and building automation). ${ }^{3}$

At the same time, we know that an Artificial Intelligence is growing as a child does because, for example:

"ConceptNet4, a system based on artificial intelligence in languages, recently passed an IQ test with a higher score than a 4-year-old child... The next version should be able to achieve the same results as a 5 or 6-year-old child... in 2025 the central processing units could achieve the same reasoning capacity as the human brain"4. (Schwab, 2016, 181)

Another important technological innovation is Quantum Computing. A quantum computer is a machine that processes information and performs logical operations according to the laws of quantum mechanics. That is, it operates according to a quantum logic, profoundly different from the classical one according to which current calculators work... The principle of superimposition of quantum mechanics gives the quantum computer an enormous advantage, which consists in the possibility to process a considerable amount of data simultaneously... These properties make possible, in principle, an extraordinary computing power, not comparable with that of classical calculators. ${ }^{5}$

\section{ARCHITECTURE 4.0}

In the field of Architecture, a fundamental innovation has been the application of nanotechnologies. The first was in 1986 in the Almaden Research Center of San José in
California: Dan Eigler laid 36 xenon atoms on a nickel layer to form the IBM inscription. ${ }^{6}$

"One of the first definitions of "advanced materials" is given by Michael Bever in his Encyclopedia of Advanced Materials10, in which he defines "advanced materials" as those materials where the main characteristic is the ability to synthesize and control the structure of the material in order to obtain a precise set of tailor-made properties aimed at applications on demand." ${ }^{7}$ (Leone, 2010, 13)

We can observe many examples where architects used advanced technologies but, in this paper, we can analyze only three examples of architectures where we can find different materials and building methods. They are united by their reference to nature as a model, despite being equipped with very advanced materials and construction techniques. Both of them use their skin to communicate these concepts:

- the breath of man;

- the shadows of the leaves;

- $\quad$ the ground as protection.

The Herzog \& de Meuron's Allianz Arena, built in Monaco in 2005, consists of a dynamic and changeable wrapping created for the 2006 football world cup. Merging together the functional and well-being aspects with the communicative and representative charge of architecture, it takes full advantage of the potential offered by innovative technologies. ${ }^{8}$ (See Leone, 2010, 11). Its recyclable 2.816 cushions consist of two sheets of Tetra Fluor Ethylene that create an atmospheric building, made by 'air', deliberately detached from the ground with a slit of almost 4 metres that simulate the lightness of its titanic structure.

\footnotetext{
${ }^{3}$ See https://en.wikipedia.org/wiki/Internet_of_things 10/2/20.

${ }^{4}$ Schwab K., 2016. Cit. p. 181.

5 English translation of http://www.treccani.it/enciclopedia/computazione-quantistica_\%28Enciclopedia-della-Scienza-e-dellaTecnica\%29/12/02/2020.

${ }^{6}$ English translation: Leone M. F., 2010. Innovazione tecnologica e materiali avanzati alte prestazioni ed eco-efficienza: nanotecnologie per l'evoluzione dei materiali cementizi, Dottorato di ricerca in Tecnologia dell'Architettura, XXI ciclo, Università degli Studi di Napoli "Federico II", Scuola di Dottorato in Architettura, Dipartimento di Configurazione e Attuazione dell'Architettura, Dipartimento di Progettazione Urbana e di Urbanistica, Tutor: Mario Losasso, Coordinatore: Augusto Vitale, p. 36.

7 lbid., p. 13

${ }^{8}$ Ibid., p. 11.
} 
The concept of an atmospheric architecture reaches the apex when it works as a reactive apparatus creating a symbiosis between container, event and spectator, because it can change colours of his front during the soccer match, simulating the emotions of the audience. ${ }^{9}$ (See Cornaro, 2005)

Another type of architectural advanced skin is that of the Airspace Tokyo, Studio M, Thom Faulders Architecture, Proces2, built in Tokyo in 2007.

Composed of successive layers of perforated panels, the skin of the building is designed and created by the computer that has taken up, for each layer, cellular parametric geometries that were subsequently "flattened" on a plane to make the panels in rigid composite material made of aluminium and plastic materials. ${ }^{10}$ In this example, the design concept aims to create a new atmospheric space of protection simulating the demolished the layer of dense vegetation that wrapped the owner's family residence before the entire site was razed for the new development. ${ }^{11}$ (Faulders Studio, 2013)

Also, in this example, the artificial blends with Nature through an interstitial transitional space between public and private, where the view changes every time you move, and the rain does not reach the road by capillary action. ${ }^{12}$

The last example uses an advanced building system to create houses as they are shelters. I find this evident contrast the synthesis of our Era: futuristic hight building technology to get spaces that evoke ancient ancestral places. After the two architectural references to nature elements, like air and plants, we can find the ground as principal element that communicates the concept: get Architecture trough Nature. It is the TECLA house, designed by Mario Cucinella Architects and WASP, and built in Massa Lombarda (RA) in 2019.

As Mario Cucinella explains, Tecla is:

"an innovative 3D printed habitat prototype that responds to the increasingly urgent climate revolution and the needs of changes dictated by the needs of communities ... a combination of empathic architecture and the application of new technologies". ${ }^{13}$ (Cucinella, 2019)

"Mario Cucinella Architects and WASP have launched an innovative 3D printed habitat model. In a historical period of exponential increase in population and consequent lack of housing, TECLA was born from the idea of giving everyone the possibility of having a home and is a new circular model of housing entirely created with reusable and recyclable materials, collected from the construction site."14 (MC A \& WASP, 2019)

Initially, this technique was only used for small objects, today, 3D printers are able to extrude concrete and allow the construction of different structures of varying complexity, from houses to bridges to skyscrapers. ${ }^{15}$ (Selva, 2019)

\section{INHABITING TEMPORARINESS IN SMART CITIES: POSITIVE AND NEGATIVE CONSEQUENCES}

After the previous introduction on the relationship between innovative technologies and architectural design concepts coming from the Nature, in order to explore the actual world of the dwelling architecture, we can highlight about another phenomena that regards people's habits.

\footnotetext{
${ }^{9}$ English translation of Cornaro A., http://architettura.it/architetture/20050209/ 12/02/2020.

10 See Leone, 2010. Cit. p. 33.

${ }^{11}$ See Faulders Studio, https://faulders-studio.com/AIRSPACE-TOKYO 12/02/2020.

${ }^{12}$ English translation of https://www.archilovers.com/projects/5397/airspace-tokyo.html\#info 12/02/2020.

13 English translation of De Rosa L., 2019, https://www.greenme.it/abitare/bioedilizia-e-bioarchitettura/casa-argilla-stampata-3d/ $12 / 02 / 2020$.

${ }^{14}$ See English translation of MC A \& Wasp, 2019. TECLA un habitat eco-sostenibile stampato in 3D in terra, https://www.mcarchitects. it/wp-content/uploads/2019/10/Cartella-Stampa-191022.pdf 12/02/2020.

${ }_{15}$ English translation of Selva V., 2019, https://www.idealista.it/news/immobiliare/costruzioni/2019/10/23/137015-questa-casaprefabbricata-e-stata-costruita-con-una-stampante-3d 12/02/2020.
} 
Today, for work and study reasons, people change their homes very often and already a few decades ago, in America, families moved for work at most every 10 years. These movements have led to the habit of temporarily living in the house.

But what does it mean to "temporarily live in a house"?

The idea of "Temporary Home" seems to be in stark contrast with the theme of the Human Home, conceived as a system of domestic spaces. Starting from the consideration that the idea of home evokes that of a place of shelter, refuge and regeneration, inhabiting or observing it, people "do not always seek the repetition of an identical meaning, but always expect their home to contain an interpretation of the immutable essentials of their existence" (Rykwert, 1974). What happens when these immutable essentials become mutable due to profound transformations of habits and the way man lives in the home?16

Freud approached the definition of Unheimlich using his apparent opposite Heimlich and found that while Heimlich is associated with the intimate and "friendly, comfortable," it also alluded to things that are concealed, hidden from view, so that others cannot know them.

During his research, Freud discovered that Heimlich's meaning developed in the direction of ambivalence, to coincide with its opposite Unheimlich. The latter seems to emerge from the Heimlich and suddenly return when it seems to be dormant. "Unheimlich is the name of all things that should have remained secret and hidden, but which have come to light".

Charles Nodier in his Piranèse (1836) distinguished the general space of the sublime (height, depth, extension) from that of the uncanny (silence, solitude, inner reclusion). The passage from welcoming to unfamiliar, operating totally in the mind, reinforces the ambiguity between the real world and the dream, the real world and the spirit world.
A condition of modern anxiety, the uncanny also becomes public, overcoming domestic boundaries, turning into metropolitan uncanny, or metropolitan illness, from which all the inhabitants of the big cities suffered at the end of the 19th century: phobias associated with spatiality such as agoraphobia and claustrophobia were part of it.

As Freud demonstrated, in any case the uncanny emerged from the transformation of something that once seemed familiar and domestic into something different, from Heimlich to unhomely. In 1915 Europe, the cradle and seemingly safe home of Western civilization, "was going through a period of barbaric regression; a time when the territorial security that had promoted the notion of a unitary culture had been shattered". ${ }^{17}$

"In his reflection "Building Dwelling Thinking", Martin Heidegger reverses sign and directrix to the hierarchical sequence constructingdwelling that came about in the technical era. "Only if we are capable of dwelling, and here lies the reversal - only then can we build." These words probe those listening to them primarily because of the explosion, in our recent turbulent years, of the city suburbs where the issue at stake in the now viral, social contest is, indeed, the remaining within the protection, the search for what is similar and delivers us from evil. Whether it be the preserved memory of places or the possibility of dwelling in them as a home, of taming them or, conversely, of subtracting them from their non-animation and disguise as non-places, what feels at risk is one's ability to dwell. The loss of the sense of dwelling, in city centres and suburbs alike, is most powerful driver behind the explosion of political and social chaos: the city ceases to be a place of identification and becomes the space where 'All that is solid melts into air.... It is a deeper ontological collapse, the clouding over of the thought that grasps the essence of things. Dwelling - as Heidegger reminds us - is the stay of mortals on the earth: "But 'on

\footnotetext{
${ }^{16}$ See Longo O., 2004. Abitare la contemporaneità. Forma e identità nell'architettura, lla Palma, Palermo.

${ }^{17}$ See Vidler A., 1992. The Architectural Uncanny. Essays in the Modern Unhomely, MIT, Cambridge, London16 See Longo O., 2004.
} 
the earth' - the German philosopher clarifies - already means 'under the sky'. Both of these also mean 'remaining before the divinities' (die Göttlichen) and include a 'belonging to men's being with one another'." There is an original unity within which the Four - earth and sky, divinities and mortals - are just one thing. The mortals are in the Fourfold because they dwell. If the fundamental character of dwelling is looking after, it is a quadruple care that comprises saving the earth, receiving the sky, awaiting the divinities and escorting the mortals. It is a staying with things while letting them keep their essence. Dwelling is looking after your own space, being in a relation with space, filling the artificial gap between designing, constructing and eventually dwelling. 'However hard and bitter, however hampering and threatening the lack of houses remains - writes Heidegger - the real plight of dwelling does not lie merely in a lack of houses. The real plight of dwelling is indeed older than the world wars with their destruction, also older than the increase of the earth's population and the condition of the industrial workers. The real dwelling plight lies in this, that mortals ever search anew for the nature of dwelling, that they must ever learn to dwell.' Our distress today speaks of this which is, after all, the symptom and voice of our nostalgia. It will never find comfort in past contexts or regressive utopias but in a possible other present, in a thought capable of looking, listening and caring."18

In the 90s of the 20th century, Hertzberger defines the concept of threshold as the key of transition and connection between areas with different territorial vocations. Place in itself which essentially constitutes the spatial condition for the meeting and dialogue between areas of different order. The threshold par excellence is the entrance to the house. In it the street, on the one hand, and the private domain, on the other, meet and reconcile. For example, the child sitting on a step-in front of his house feels at home and at the same time part of the outside world. This duality exists thanks to the spatial quality of the threshold, a platform in its own right, a place where, instead of separating, two worlds overlap.

In the 1960s, Chermayeff and Alexander defined a number of differently characterized areas that articulated the hierarchy of spaces between public and private. In order from most accessible to least accessible:

- individual private

- family private: spaces common to a group of accommodations

- $\quad$ group private: meeting spaces between public space and private property

- urban semi-public, controlled by government bodies or other institutions, such as schools, offices, etc.

- urban public, totally public property.

The question of the public-private partnership could, however, become a distant memory if we think about the possibility, still remote but achievable, that in the XXV century a large part of the population could go around with bionic limbs implanted in the body, governed with a smartphone, in particular with Mems (Micro Electro-Mechanical-System), i.e. microsystems with an average size of a few microns.

The distance between an external world and a private environment could be cancelled by the invention of some researchers at the University of Tel Aviv who have devised a way to integrate Mems no longer on a silicon substrate but on a particular type of organic polymer, more suitable to be implanted in the human body. ${ }^{19}$ (See Rubei, 2013)

What does the house in the digital age look like? How does it interact with augmented (or computer-mediated) reality? The automated home gives the possibility to connect and manage all the systems of the house in a

\footnotetext{
18 See Freud S., 1991. II perturbante, in S. Freud, Saggi sull'arte, la letteratura e il linguaggio (trad.it. a cura di S. Daniele, Einaudi, Torino 1991).

${ }_{19}^{19}$ English translation of Rubei A., 2013, https://www.nextme.it/tecnologia/biotecnologie/6266-smartphone-cervello-sensori-mems
} 12/02/2020. 
centralized way through a single control element. The so-called intelligent house regulates the lighting, shading, climate, etc. according to the individual wishes of the inhabitant. Simple interfaces allow you to adapt processes and functions independently according to your needs.

For example, we can find on the market an "Augmented House" as a solution that puts people at the center of an unprecedented project: an ecosystem that integrates the best solutions in terms of comfort, safety and energy efficiency, to improve everyday life. It can be modular because the basic functionalities can be complemented by others according to the inhabitant's future needs. It can be integrated because it allows to remotely manage all internal and external devices, creating a unique and integrated ecosystem. It is flexible because it is customizable to meet all the needs of comfort, energy and safety.

As Schwab wrote, these possibilities create some consequences.

The positive ones are:

- $\quad$ "resource efficiency;

- comfort;

- detection of possible intruders;

- access control;

- $\quad$ ability to live independently (young people, elderly people, people with disabilities);

- increase in targeted forms of advertising;

- reduction of costs for the health care system (fewer admissions and medical visits, possibility to monitor the intake of medicines);

- real-time monitoring and video recording;

- $\quad$ remote management of your home."
The negative concern:

- "privacy;

- surveillance;

- $\quad$ cyber-attacks, crime, vulnerabilities;

- $\quad$ impact on the workforce;

- $\quad$ change of workplace;

- data ownership."20

\subsection{Sustainable House in the Anthropocene Liquid Era}

Expanding all these innovations to the scale of the city, Schwab writes that there are these

"unknown consequences:

- impact on the cultural dimension and lifestyle of the city;

- $\quad$ changes in citizens' individual habits."21

In 2016, at the Festival of generations in Florence, during his presentation: (PRE) VISIONS FOR THE FUTURE, Society and fears, Zygmunt Bauman affirms that in this era the phrase cogito ergo sum has been replaced by: "they see me on the screen and therefore I exist". Thinking about his words: "change is the only permanent thing and uncertainty is the only certainty, our fears move between forces we are unable to tame", is it possible to at least keep them at a distance? To deny them access to our homes and workplaces? So, if we think about what the previous industrial revolution (the third one) provoked, we can have an idea (albeit vague) of how much this last one, the 4.0 , will affect us.

Recently, many researchers are studying the connection between spaces and neuroscience trying to define a new kind of space where man can feel good.

In 2020 Ruzzon wrote that we don't know why in some places we feel good, right away

\footnotetext{
${ }^{20}$ Schwab K., 2016. Cit. pp. 170-171.

${ }^{21}$ Ibid., p. 174.

22 See English translation of Ruzzon D., 2020. "Immaginario e paesaggio incarnato", in AAVV, Boundary Landscapes, TAB Edizioni, Roma.
} 
in the blink of an eye. He asked if the mystery of this magnetism will remain impenetrable forever. He said that

"for some decades now, the humanities, anthropology and neuroscience have been investigating the chemistry of this link between the experience of places, the urban form, the landscape and the implicit emotional reactions of people... For more than twenty years now, it has been using the methods of neuroscience and environmental psychology to understand how the evolutionary perspective of man, and therefore his biological dimension, can influence the perception of the landscape and the urban context in which we are immersed every day". ${ }^{22}$ (Ruzzon, 2020)

Since 1993, the Heerwagen's and Gordon's studies told us that there is a widespread preference for a natural landscape composed of particular types of trees, with bushes arranged in a fairly precise order: the landscape of the East African Savannah. Through a long study in the different continents, they showed that this preference was well-founded, particularly among the younger generation. As it is now widely shared, the reasons for this reality were evidently to be found in the fact that mankind is the result of a diaspora that has its centre in that African area, which began about seventy thousand years ago, by a group of Sapiens perhaps composed of a few thousand individuals. (Idem)

This research demonstrates that there is some specific information inside the human precognitive dimension. In the field of the architectural design, these studies show how the shape of a space and the urban landscape that we design could speak to our body, at a level that precedes our cerebral reflection.

For this reason, I think that a house designed for man of this epoch, has to be sustainable also for these psychological aspects and not only on the front of energy saving and recycling of materials.

\section{CONCLUSION: A PSYCHOLOGICAL SUSTAINABILITY}

In both architectural and urban contexts, key concepts such as "threshold space", "in-between" and "uncanny" are therefore, still today, the indispensable traces for an investigation into the potential and role of experiential phenomena in the design process of an urban home.

Today many people live every day between the real world and the virtual world through the use of the internet and social networks. Perhaps the phenomenon of Freud's ambiguity is often felt by people who live online family experiences that turn into unexpected and unknown sensations.

Probably the relationship between our body and reality should be taken care of every day to find a new, more balanced connection with our urban places. So, thinking about the famous book The image of the city (1960), we could recreate our mental maps by adding new elements to Lynch's five (Paths, Edges, Districts, Nodes, Landmarks).

The design of our house could be conceived using thresholds and filters that from the bedroom connect private and public spaces, avoiding traumatic or too fast passages.

To realize this gradual passage, we can use every part of the city that can become a great patchwork of urban memories, thus creating a more comfortable city as if it were a 'house without limits'. 


\section{REFERENCES}

Freud S., 1991. II perturbante, in S. Freud, Saggi sull'arte, la letteratura e il linguaggio (trad.it. a cura di S. Daniele, Einaudi, Torino 1991).

Leone M. F., 2010. Innovazione tecnologica e materiali avanzati alte prestazioni ed ecoefficienza: nanotecnologie per l'evoluzione dei materiali cementizi, Dottorato di ricerca in Tecnologia dell'Architettura, XXI ciclo, Università degli Studi di Napoli "Federico II", Scuola di Dottorato in Architettura, Dipartimento di Configurazione e Attuazione dell'Architettura, Dipartimento di Progettazione Urbana e di Urbanistica, Tutor: Mario Losasso, Coordinatore: Augusto Vitale, p. 36.

Longo O., 2004. Abitare la contemporaneità. Forma e identità nell'architettura, Ila Palma, Palermo.

MC A \& Wasp, 2019. TECLA un habitat eco-sostenibile stampato in $3 D$ in terra,https://www.mcarchitects.it/wpcontent/uploads/2019/10/CartellaStampa-191022.pdf 12/02/2020.

Ruzzon D., 2020. "Immaginario e paesaggio incarnato", in AAVV, Boundary Landscapes, TAB Edizioni, Roma.

Schwab K., 2016. La quarta rivoluzione industriale. Milano: FrancoAngeli, p. 13.

Vidler A., 1992. The Architectural Uncanny. Essays in the Modern Unhomely, MIT, Cambridge, London. 


\section{How do parks} successfully

\section{provide comfort \\ to city dwellers?}

It is important to study urban parks and understand traits that make them successful because urban parks combat isolation, provide open area for healthy recreation, and encourage social sustainability. Research shows that cities are exponentially growing and $75 \%$ of the world population will be urban by 2050 . With the predicted popularity of city life there is a need to effectively design smart green spaces for growing urban populations.

This research summarizes a literature review conducted on the theory of nature, park typologies, and comfort in public urban spaces. Theoretical writings lead this research to conclude a park as a human-intervened space in a moment of time that brings peace of mind to visitors in an open-air community environment. Key thinkers have adopted the Pleasure Ground park, Reform Park, Recreation Facility, Open Space System, Sustainable Park, Pocket Park, and Spectacle Park as successful park typologies. Comfort is created through thoughtful design that brings visitors a sense of belonging, conviviality, and an attention to human dimension.

These concepts are are applied to the analysis of three case studies based upon direct

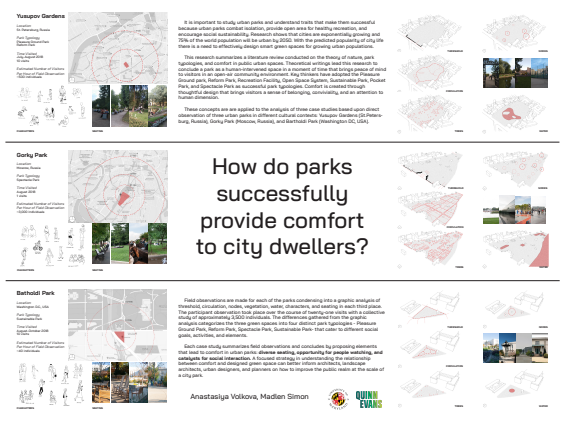

observation of three urban parks in different cultural contexts: Yusupov Gardens (St.Petersburg, Russia), Gorky Park (Moscow, Russia), and Bartholdi Park (Washington DC, USA).

Field observations are made for each of the parks condensing into a graphic analysis of threshold, circulation, nodes, vegetation, water, characters, and seating in each third place. The participant observation took place over the course of twenty-one visits with a collective study of approximately 3,500 individuals. The differences gathered from the graphic analysis categorizes the three green spaces into four distinct park typologies - Pleasure Ground Park, Reform Park, Spectacle Park, Sustainable Parkthat cater to different social goals, activities, and elements.

Each case study summarizes field observations and concludes by proposing elements that lead to comfort in urban parks: diverse seating, opportunity for people watching, and catalysts for social interaction. A focused strategy in understanding the relationship between comfort and designed green space can better inform architects, landscape architects, urban designers, and planners on how to improve the public realm at the scale of a city park. 


\section{Yusupov Gardens}

Location

St. Petersburg, Russia

Park Typology

Pleasure Ground Park

Reform Park

Time Visited

July-August 2018

10 visits

Estimated Number of Visitors Per Hour of Field Observation 500 individuals
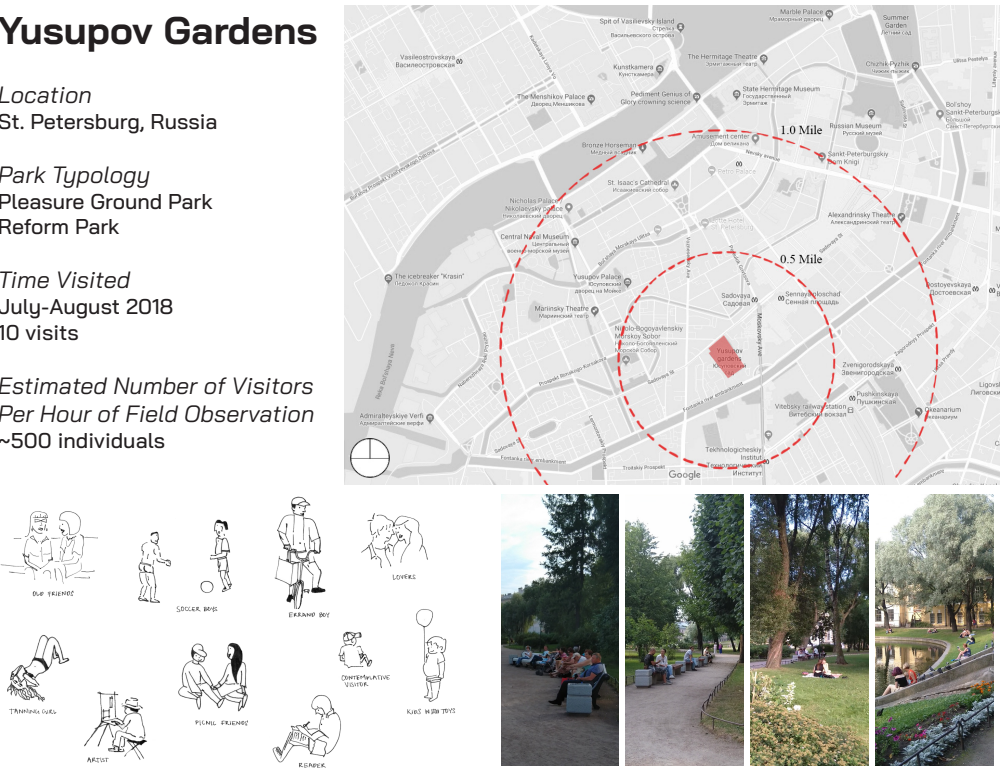

CHARACTERS

SEATING
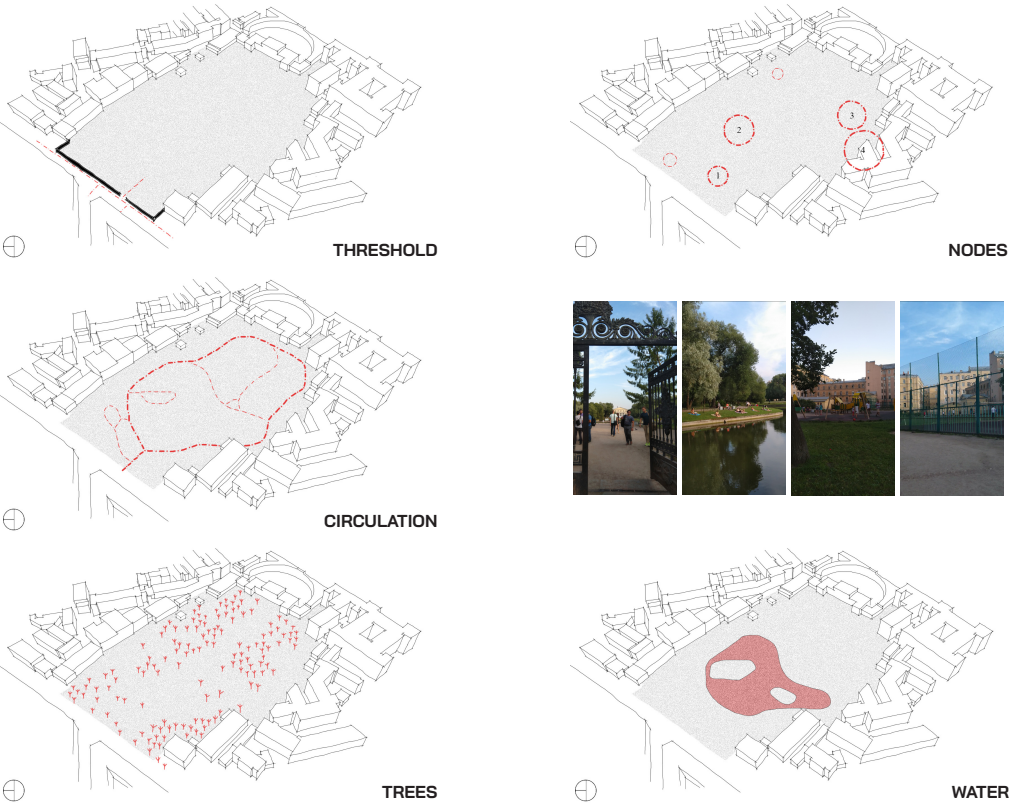


\section{Gorky Park}

Location

Moscow, Russia

Park Typology

Spectacle Park

Time Visited

August 2018

1 visits

Estimated Number of Visitors Per Hour of Field Observation $\sim 3,000$ individuals

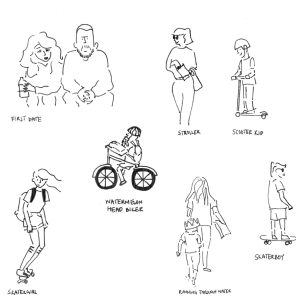

CHARACTERS
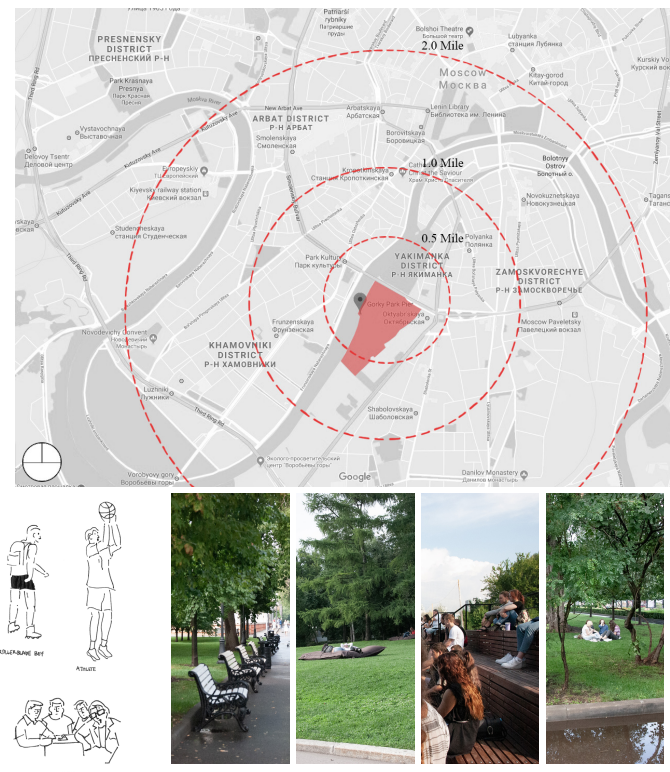

SEATING
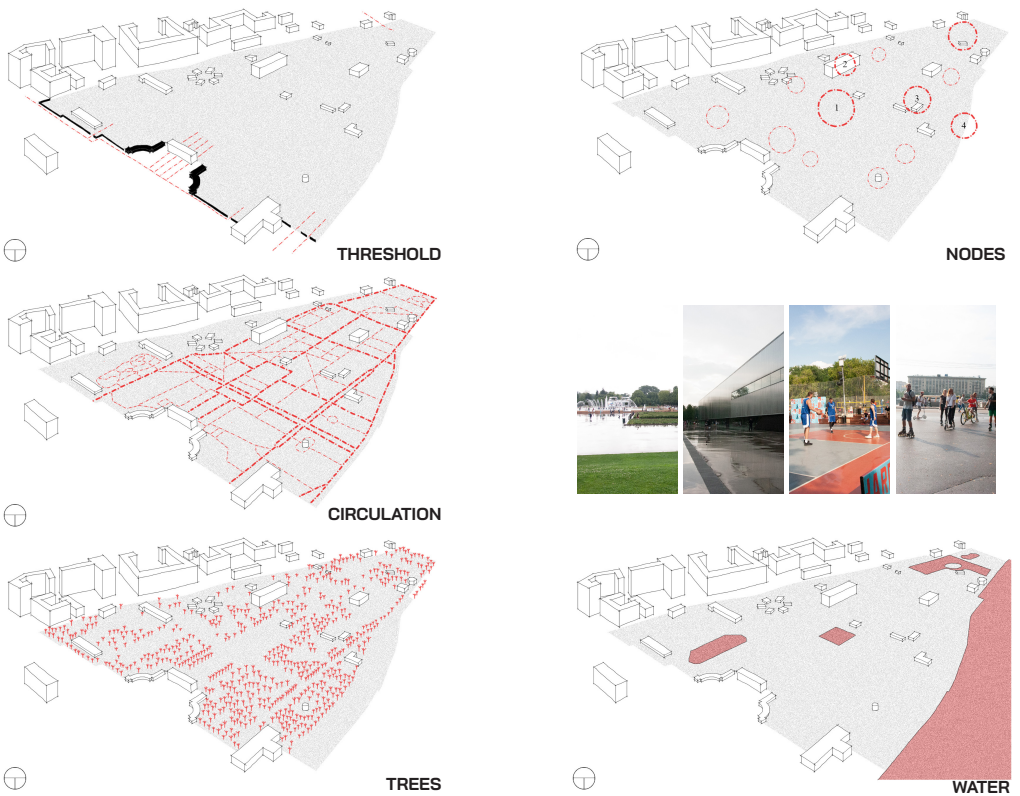


\section{Batholdi Park}

Location

Washington D.C., USA

Park Typology

Sustainable Park

Time Visited

August-October 2018

10 visits

Estimated Number of Visitors Per Hour of Field Observation $\sim 40$ individuals
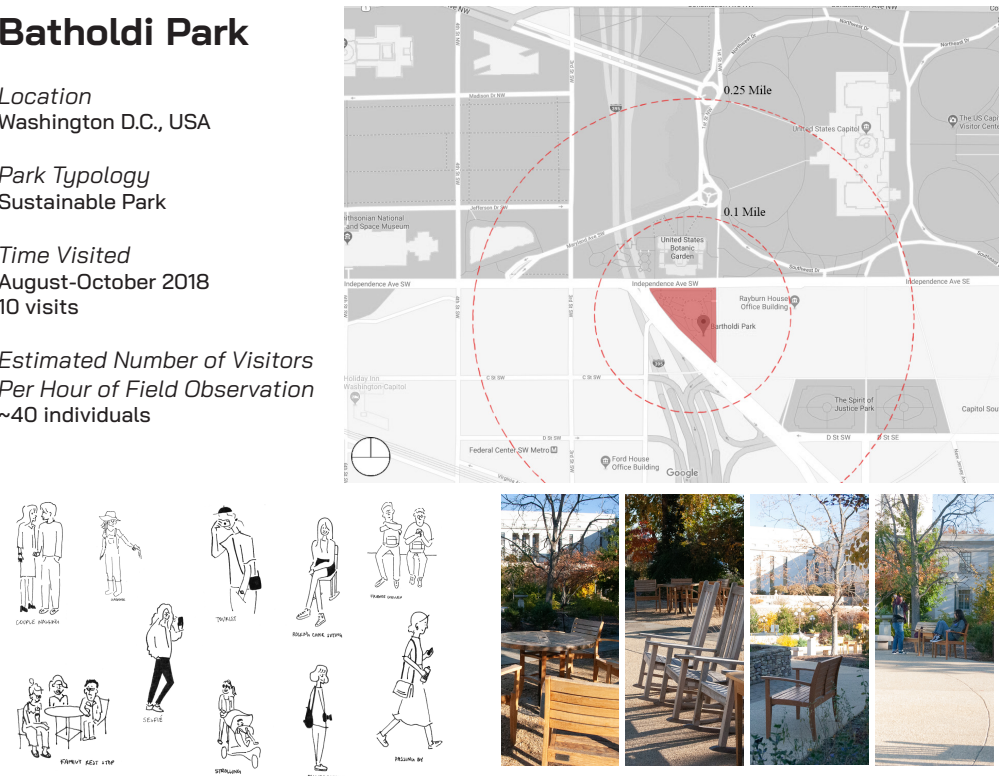

CHARACTERS
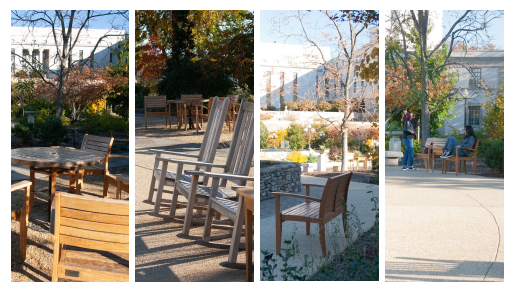

SEATING

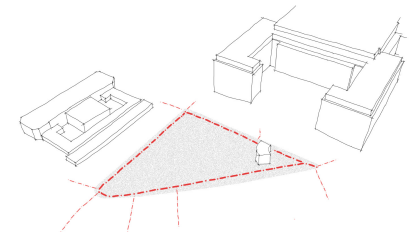

THRESHOLD

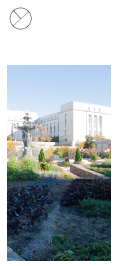

NODES

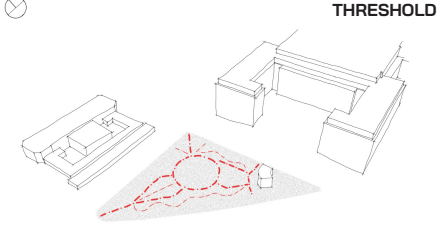

CIRCULATION
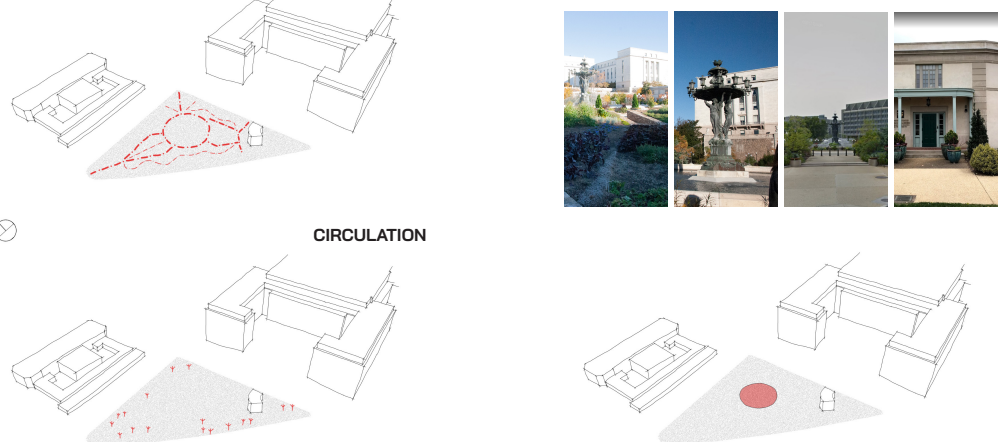

$\oslash$
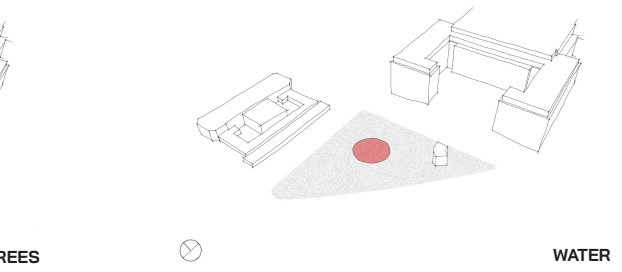



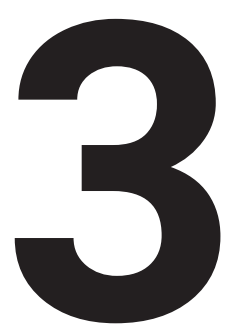

BLOCK 3: THE NEW FACES THE OLD 


\section{PAPER \#3.01}

\section{FROM DISMISSAL TO DEVELOPMENT: THE CHALLENGE OF ARCHITECTURE}

\author{
Roberta Ingaramo \\ a DAD, Politecnico di Torino, Turin, Italy
}

\section{ABSTRACT}

The re-use of dismissed buildings has been discussed on an international level. Model interventions, such as the successful redesign of the Tate Modern (which is housed in a former power station, Herzog \& de Meuron, 2016) or the ionic High Line (Diller Scofidio + Renfro \& James Corner Field Operations and planting designer Piet Oudolf, 2009, 2011, 2014, 2018), have revealed the approach of re-using abandoned buildings to the broader public. Starting from the state of the art, this paper will highlight the efficacy of the urban regeneration approach and its implications on a socio-economic level. What kind of projects can architects carry out, but more importantly, is it possible to classify the different projects based on the tangible results of the transformations? This paper will discuss the results of case studies based on research conducted in two post-industrial U.S. cities over the past few years. These case studies identify specific design strategies as tools for selecting and classifying project output. When it comes to the abandonment and decay of industrialized cities, Detroit is the poster city and it represents an exceptional site for experimentation and reflection, both in its present state, but also for imagining future transformation scenarios and identifying intermediate paths between conservation and demolition. Is adaptive reuse the only approach or are there different declinations of re-use which are influencing international research in architecture? The urban renewal project can be a resource for identifying new uses of different buildings or building complexes, even recent ones with uncertain or even non-existent restraint systems, in order to reinsert the buildings into today's urban metabolism, while preparing them for possible future transformations, which is to be kept in mind given how rapidly intended uses change in this day and age.

\section{KEYWORDS}

Dismissal; development; re-use; urban metabolism.

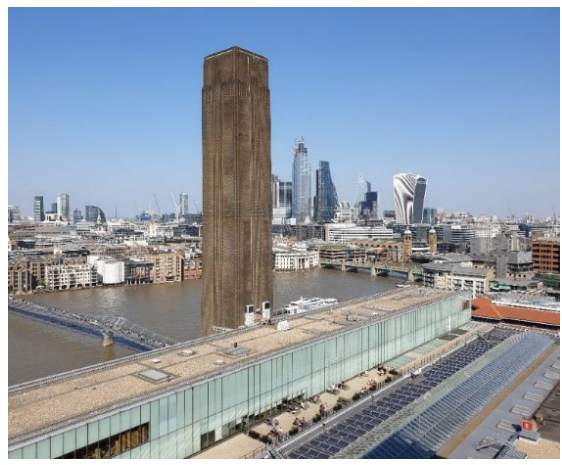

Figure 1. Urban image at the Tate Modern, Herzog \& de Meuron, 2016. Source: (Ingaramo R. 2019)

\section{INTRODUCTION}

Dismissal is a topic which is becoming more and more relevant considering the rate at which changes take place; it leads to transversal reflections and requires multiple disciplinary intersections. If the architect is responsible for the project, trying to make up for a progressive loss of what Françoise 
Choay once called compétence d'édifier ${ }^{1}$, then architectural research is responsible for identifying and clarifying approaches and processes supported by scientific value. Sometimes, construction is not the only possible effect/result of project research; the project can also result in the negation of formal action, considering the "ruins" as carriers of symbolic values. Is "dismissed" architecture something that can be reshaped and reinserted in the urban landscape or should it be "disposed of", like outdated residue? Significant research has been conducted on an international level in an attempt to give an answer to one of the most frequently-asked questions posed by those involved in these kinds of projects. The Roman arenas used as pits from which to gather construction materials remind us that the entity of renewal and transformation are intrinsically correlated to the size of the project. "To project" - i.e. project designing as defined in the Treccani dictionary means making the project design of something, that is to conceive something and study the possibilities and ways to perform it, or more in general to conceive something, to have the intention to do something. This term originates from the late Latin word proiectare, which mean to cast forward, and highlights the sense of foreshadowing that characterizes its use as a tool to construct scenarios of transformation. It is within the intrinsic etymological meaning of the word "project" that the architect positions himself, as he strives to cast forward towards a transformation which takes shape through the project, which in turn is the tool used to identify possible uses of the space available. However, some examples of infrastructure and building re-appropriation over the past few years, such as the Palais de Tokyo in Paris, site of contemporary creation as defined by the architects (Lacaton \&Vassal, 2014), have reignited the discussion on the role of the architect as a guide who can navigate through complex processes which have less to do with substantial structural modification and are increasingly affected by politics, society and economics.

\section{THE LEGACY OF INDUSTRIAL ASSETS}

\subsection{A Case Study of Two American Cities}

Detroit, known for its once bustling car industry, is the poster city for abandonment. It is universally recognized as an empty nest where more than $85 \%$ of the remaining inhabitants are Afro-American (Mcdonald 2014). Sprawl began to change the physical structure of the city in the mid50 s, leading to the displacement of a large, predominantly white, part of the population. The other city chosen for this research is Pittsburgh, the city of steel, which after a sharp decline, has begun to experience regrowth in the Eds and Meds industry, with the financial support of its native Foundations and the cooperation of private and public sectors. These two American cities have been selected as representatives of a larger phenomenon which also exists in far-away countries, and they present the opportunity for us to reflect on the "rebirth" of cities which have been heavily hit by abandonment and dismissal. The two cities share a common destiny: they are in a phase of partial post-industrialisation, or better, they are in a moment where the outdated industrial paradigm is shifting. This paradigm, however, transformed the actual layout of the cities, leaving behind significant industrial infrastructure in a state of disrepair; in the specific case of Detroit, its condition is comparable to that of post-war debris. Some of the so-called American "Rust Belt" cities (Thomas 2013), where abandoned buildings and brownfields bear witness to the recent past, are attempting to reignite interest and re-inject appeal into their cities. This has been partially achieved

${ }^{1}$ Choay, F. 2009. Le patrimoine en question: anthologie pour un combat. Paris: Édition Du Seuil. 
in Pittsburgh over the past few years, so much so that new innovative production lines have chosen to open their offices here (for example, Google, the East Coast film industry and Uber - the latter first tested selfdriven cars here in 2016), while in Detroit, the first steps towards recovery began in 2014. Overall, Detroit is still in a state of disrepair and the empty plots attest to the astronomical number of people who fled the city; however, there has been some positive change over the past few years. In 2014, Maurice Cox became Director of City Planning, bringing skills and knowledge also steeped in Italian urban design and architecture. In both Detroit and Pittsburgh, industrial infrastructure is a fundamental structural element of their industrial legacy. Compared to Detroit, Pittsburgh is lightyears ahead in its transformation process and its quest for and creation of a new identity, as Don Carter highlighted several times in his book published in $2016^{2}$. This is visible in the increasing demand for corporate spaces mainly light manufacturing - and new types of housing in the city, most of which is requested by young workers, mostly graduates and postgraduates. The market evolution and the demand for housing reflect the desire on behalf of the new American generations to re-appropriate this city: they wish to live near where they work and find leisure opportunities. This is a widespread countertrend in the U.S. which is leading to the need to differentiate the uses of the new properties being built, but also those of existing ones which can be converted, transformed, and renewed today, but also again in the future. In Detroit, significant new urban interventions, such as Brush Park, mark a break from the residential trend which was based on the widespread front garden-family house-back garden-car space suburban model. The model in Brush Park ${ }^{3}$ is the result of a long process negotiated between public administration, developers and local inhabitants. Its aim is to shift the focus from the individual to the shared, the singular to the plural, the isolated to the included, in the attempt to create a new city blueprint. This project, which saw the completion of 39 town homes and carriage houses south of Alfred Street in December 2019, foresees only one car space per house (slightly more space for larger houses), thus giving far more importance to public or semipublic spaces. Even the desire to distinguish the architectural models transforms this project into something new. This project also involved non-local architects; to an extent, it imported a successful European model - the German IBA - and updated it by adhering to the principles of the 20-minute neighbourhood and the new urbanism form based code. Thus, the city is renewed and focuses on re-using individual buildings, but also empty spaces such as Brush Park - an early 20th century Victorian upper-class neighbourhood - or real brownfields which attest to this city's heavy industrial legacy.

\subsection{Re-use as an Architectural Tool}

After an initial period where the attitude was mainly to demolish industrial sites and huge brownfields predominantly located on the riverside, a shift occurred in Pittsburgh, whereby the industrial legacy of the city was acknowledged as material value (Lubove 1996). Projects such as the Perkins Eastman's

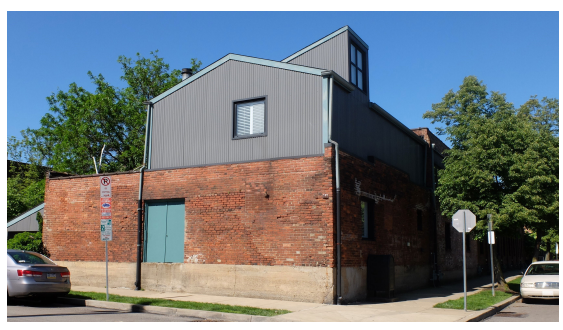

Figure 2. Foxway Commons, Pittsburgh. Town houses and apartments re-using an old warehouse. Source: (Ingaramo R. 2017)

\footnotetext{
${ }^{2}$ Carter, D.K., editor, 2016. Remaking Post-industrial cities. Lessons from North America and Europe. New York: Routledge. ${ }^{3}$ https://www.citymoderndetroit.com
} 
Foxway Commons in the city's South Side contributed to reversing the trend, offering housing solutions which re-used even anonymous-looking buildings such as local warehouses disseminated in many production neighbourhoods of the city, thus creating opportunities to intensify the connection with the industrial identity to which mainly negative connotations are normally attributed. The new integration uses recognisable materials, such as lacquered metallic sheets which perfectly match the solid brick walls of the warehouses. Re-use in many cases is a tool used to highlight the local identity of places and cities and is universally recognized as a sustainable action to save embodied energies; it is a response to the need "to reconstruct" a disjointed and strongly-diluted urbanized area - as evident in the case of Detroit and this becomes an opportunity to radically re-think abandoned buildings, brownfields and spaces awaiting transformation. Already in the 1970s, the practice of re-use in the U.S. was considered an operational tool for recycling a property estate (often post-industrial, abandoned, underused, $\mathrm{XL}$ or L) of significant impact in the urban or periurban structure. For example, Lee Harris Pomeroy won the Progressive Architecture Award in 1963 for the reconversion of a former can $\neg$ dy factory - Peaks Mason Mints - into apartments and studios for artists in Brook $l y n$ Heights (N.Y.). The term re-use takes on many different meanings which aren't fully synonymous. These include recuperation, modernization, transformation, conversion and rehabilitation 4 . Corboz used the term "recycling" which, in international literature finds little traction, given that the term is used to describe the re-use of materials rather than the re-use of buildings and spaces; however, it has been adopted to tag one of the most important research projects carried out by the Italian public university system in the last few years, through ministerial funding, called ReCycle Italy (Ciorra and Marini 2011). This research uses the term recycle as different from re-use, recovery, requalification and regeneration, extending the meaning to an action which is carried out through an architectural city and landscape project that takes on a decisive role in re-moulding the existing infrastructure so as to reinsert the buildings, spaces and urban fabrics into the city's ecosystem. In 2017, Robiglio offered a definition in line with the international literature, and specifically with the approach suggested in 2011 by Bullen and Love ${ }^{5}$, highlighting the complex system of implications which adaptive re-use carries and indicating a toolkit of actions and strategies to adopt in the process connected to the adaptive re-use of a space/building. The size of the problem on an urban scale, in the remake framework, is analysed in a book published by Routledge and edited by Don Carter, former Director of the Remaking Cities Institute at the Carnegie Mellon University di Pittsburgh (Carter D.K., editor, 2016), which compares the U.S. and Europe. The policies and actions undertaken to restore cities which have been strongly affected by industrialisation rather than push for a real post-industrialisation, as highlighted in the above-mentioned literature, offer scenarios of experimentation for architectural and urban projects whose restoration and re-insertion in renewed urban metabolisms, constitute an important field. But wich project are we talking about? Are there actually operational tools that can guide this transformation? What is clear is that projects that focus on ordinary heritage today - which do not correspond to industrial heritage - often are not subject to any restrictions (tutela in Italy) or do not belong to any local or state list, and need to take into account extreme variability

\footnotetext{
${ }^{4}$ As previously highlighted at the end of the 70s by André Corboz in the article Old Buildings and Modern Functions, published in Lotus on 13th December 1976

${ }^{5}$ Bullen, P.A., Love, P.E. 2011, Factors influencing the adaptive re-use of buildings, in: Journal of Engineering, Design and Technology, Vol. 9, n. 1, pp. 32-46.
} 
of uses over time; this includes a condition of temporariness which will unlikely adapt to the permanent nature of architecture. Moneo, in his famous piece on the durability of construction (Moneo 2004) in the collection La solitudine degli edifici e altri scritti, highlighted the importance of the duration of a construction in relation to the durability of the construction materials; the construction tends to outlive and break away from the architect; its durability today seems to be re-configured, especially in specific environments such as workspaces and service spaces which, more so than housing spaces, suffer the effects of the everchanging conditions of "uses and customs". Already back in 1988, Moneo opposes this (The Idea of Lasting, A Conversation with R. Moneo, Perspecta no.24 1988, then published in: La solitudine degli edifici e altri scritti), highlighting the importance of lasting, stable materiality in opposition to the trend which was already evident at the time, that is the dematerialisation of architecture, which tends to become "fleeting art", because it is everchanging ${ }^{6}$. Taking into account the fact that architecture needs to face different needs that are in continuous evolution, re-use presents itself as an operational tool which reconciles the need to not disperse the embodied energy and to attributed value in terms of durability, sustainability and adaptability to what is underused, dismissed or abandoned: a value - a legacy - becomes an opportunity for development and innovation, even with scarce financial resources. So, on the one hand, there's the idea of re-use and the durability of the construction materials; on the other, there is the acceptance of the fact that simple structures or disused areas have a life cycle that comes to an end; these reflections allows for the creation of new founding principles with design outcomes which will enable the identification of new forms and spatial features. From this perspective, the re-use of what already exists could become endemic. It could be the architect who may combine competences on new constructions, preservation and potentially restoration, without limiting his practice to specific realities but spreading the use even in countries undergoing significant development and ones which are constantly evolving, where new constructions become obsolete in shorter and shorter amounts of time. Catherine Slessor $^{7}$ made a provocative comment in relation to this: she said "the responsible architect might never build a new building" on the occasion of the AR New into Old Awards shortlist, which celebrates the most interesting adaptive re-use projects all over the world and where re-use is an "innovative topic", despite the fact that it has long been a construction technique. Today, re-use is identified as a highly sustainable intervention, a practice which can cross borders and obtain consensus. But the project which falls within this framework cannot be defined univocally; it is clear that we are lacking a classification system and a definition which can convey the variability of the approaches and founding principles.

\section{THE RESEARCH}

My research was carried out in different stages: the first stage was field research which lasted several months and took me to the cities of Pittsburgh and Detroit. There I conducted interviews, site visits, and photographic enquiries which allowed me to identify the cases to study. As a matter of fact, my research uses case studies as a research tool. 22 projects were selected in the two cities. These fell under three different design approaches: preservationist, additive, and brownfield remix. Each one applies a different definition of reuse and has specific and identifiable design features. As often occurs in field research, case studies tend

\footnotetext{
${ }^{6}$ Moneo, R. 1999. L'idea di Durata e i materiali della costruzione. In: Moneo, R. La solitudine degli edifici e altri scritti. Vol. I. Torino: Allemandi. p. 203.

${ }^{7}$ In: AR New into Old Awards 2019 shortlist revealed.

https://www.architectural-review.com/awards/new-into-old/ar-new-into-old-awards-2019-shortlist-revealed/10045244.article
} 
to generate highly relevant international literature, where the project and its analysis, decomposition and interpretation play a relevant role, offering a significant iconography which new generation research can also refer to. This was the case of the book City as a Loft by Baum and Christiaanse (2012), where the many examples selected and compared to one another provided access to real knowledge that must be highly relevant and significant simply because it exists in the world and was built. Case study as a research tool is not simply a theoretical construct; it is the result of a specific selection deemed important based on a series of parameters which represent the foundations of the research itself. A second stage of the research allowed me to collect the results in publications which constituted the scientific basis supporting the project experimentation carried out in a thesis seminar I tutored and which dozens of students took part in. These students conducted their specialist thesis (for a Masters' degree) on the topic of re-using buildings of ordinary industrial heritage, mainly warehouses. Further experiments on industrial buildings which are no longer used have been carried out by a group of professors of the Polytechnic Universities of Turin and Milan and interdisciplinary teams of students (Architecture, Engineering, Landscape Design, Urban Design, Planning, and Management Engineering). The projects selected in the first step of the research allowed to establish gradients of transformation which are distinguishable based on the intensity of the transformation of the given site/building. The context is always re-use, but the approaches to re-use differ; these approaches, which have different operational impacts, have been distinguished and analysed. Most of these case studies are usually defined as adaptive re-use interventions, extending the meaning of the term to

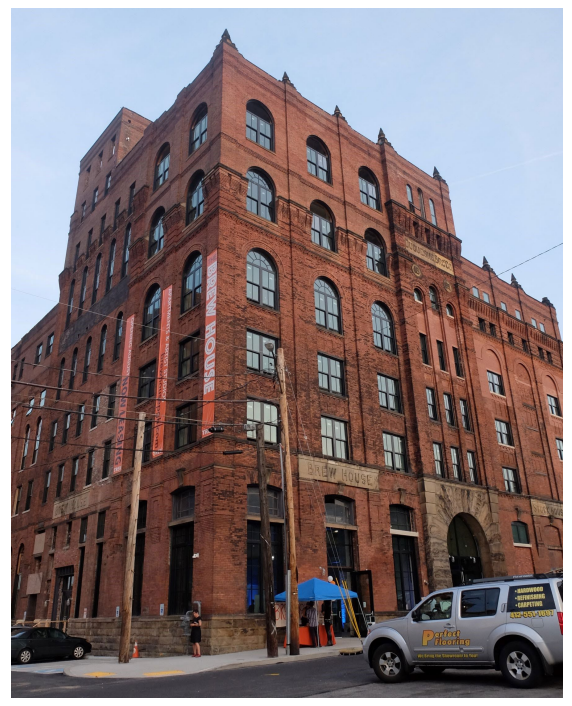

Figure 3. The Brew House. Pittsburgh. Source: (Ingaramo R. 2016)

cases of consistent transformation of original buildings. But the classification proposed in this research tries to base the distinction of the project outputs ${ }^{8}$. The Preservationist approach (Ingaramo 2017) is known as the antagonist to the conservative approach, which is based on the complete conservation of the building with only minimal reversible interventions. This approach could be applied to Listed buildings such as the Brew House in Pittsburgh, now an Art Gallery with artists' workshops and apartments, or the ongoing transformation of Michigan Station in Detroit, today a Ford Motors hub. Modifications are mostly made through blueprint changes, which do not drastically transform the original layout of the building. Volumes and façades are preserved and, for the most part, are only subject to ordinary maintenance. In some cases, the intervention is adaptive in the strictest sense: almost nothing is changed but the space is occupied for other uses with adaptations

${ }^{8}$ Ingaramo, R. 2017. Rust Remix. Siracusa: LetteraVentidue. 
and safety structures put in place. It is only in rare cases that the spaces are used for new purposes without appropriate adaptation to the regulations which, in a short time, leads to the building being abandoned once again; this was the case of the Russell Plant in Detroit. The building kept all its structural and spatial features, enhancing the original design by exploiting its potential, such as open spaces, modular articulations, great heights and big glass surfaces. The Additive approach (Ingaramo 2017) foresees significant changes through a process that creates stratifications, reinventing roles and forms to reinsert the building into the urban system. This approach manifests itself on different levels: from the simple addition of small functional parts (distribution systems, covering and insulation systems, openings...) which allow for new uses, to a significant formal redefinition which reinterprets the compositional roles of individual elements or portions of a building; a basement, the thickness of a wall, the wall texture, the size of the apertures. And this is how a simple warehouse becomes a reference model for extensive urban regeneration like in the abovementioned case of the Keystone residential block in Pittsburgh or the Ascend climbing gym, created in a section of a production warehouse devoid of any architectural value. On an urban scale, the Brownfield Remix approach (Ingaramo 2017) can be carried out both in permeable spaces such as parks, pedestrian walkways, bike trails or semipublic squares, such as Dequindre Cut in Detroit or in areas where obsolete buildings have been demolished and which can be rebuilt with buildings capable of reconstructing a new identity and amalgamating a past industrial legacy and modern vocations. After providing an analytical and interpretative grid, the case studies and the acknowledgement of the different gradients of intervention become an operational tool.

\section{DESIGN AS A TOOL TO TRANSFORM WHAT ALREADY EXISTS}

The cases of the two American cities highlight the intrinsic potential of spaces which have suffered severe abandonment. The deep crisis which affected Pittsburgh and which is still affecting Detroit in its urban fabric and local economy have led to structural synergies between not-for-profit organisations (e.g. the Mellon Foundation, the Kresge Foundation) and public and private administrations supported by the world of scientific research (in Pittsburgh, Carnegie Mellon University has created start-ups and has entered agreements with businesses to incentivise development). This synergy has allowed to carry out regeneration projects, which vary in size and relevance, with important repercussions on the perception of cities on behalf of the local inhabitants and the people who frequent them either for work or leisure.

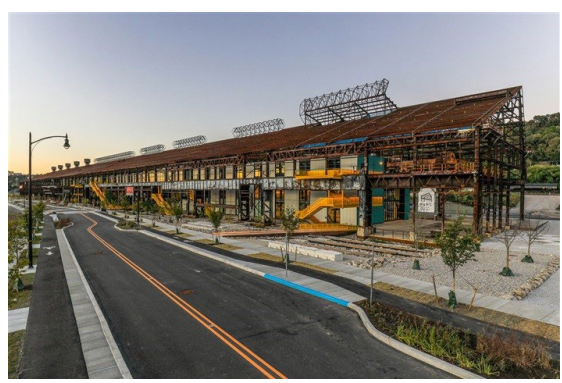

Figure 4. Hazelwood Green, Mill 19. Pittsburgh. Source: (Turner construction services. 2019)

In 2019, Pittsburgh was named one of the most liveable cities in the US (the 4th) and the 34th in the world according to an annual report published by the Economist Intelligence Unit. From the City of Steel to the City of Eds and Meds, Pittsburgh has undergone a transformation 
which is reflected in the city itself, specifically in the vitality of the Strip District and the new neighbourhoods being built on the banks of the Monongahela and on the brownfield of Mill 19, the only building of the imposing LTV Steel Company complex ${ }^{9}$ to have been preserved. It is not just the big projects of the Brownfield Remix such as Hazelwood Green (which includes the transformation of Mill 19) that are undergoing a transformation, but even small projects such as 7800 Susquehanna Street, where a small-sized abandoned factory today represents a beacon of opportunity for the Homewood neighbourhood with 24 tenants and over 100 people employees, offering business accelerator services which involve people from the neighbourhood. This building counted on scarce financial resources; the additive approach allowed for the introduction of vertical connecting elements which highlighted the fantastic lighting of the establishment.

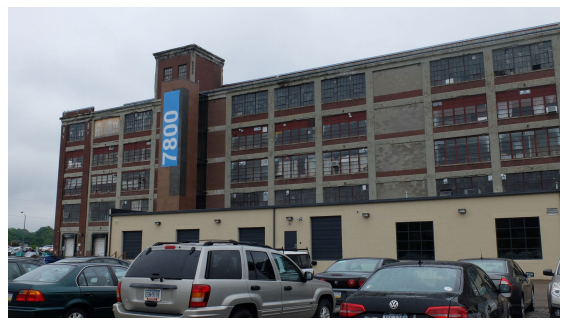

Figure 5. 7800 Susquehanna Street. Pittsburgh. Source: (Ingaramo R. 2018)
This project is a resource which aims to support the transformation of dismissed architecture and enable its insertion in the urban metabolism. In broader terms, architectural design aims to identify ways of remodelling space and buildings with different gradients of intervention on what already exists, while infilling what is new. This is the opportunity for detail-oriented architecture which gleans from innovative technology, interprets industrial legacy, guide transformation processes, and offers visions that can project us into a dimension of semi-permanent transformation, where architecture is the interpretative key of a variable reality, which seeks solid references capable of adapting to its uncertainty.

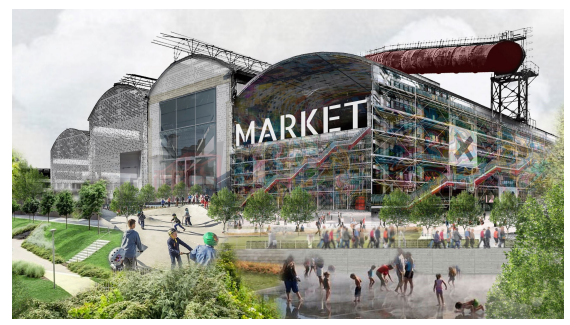

Figure 6. Industrial plant re-use. Vision. Source: (Negrello M. Ingaramo R. 2018)

${ }^{9}$ formerly J\&L, Jones and Laughlin Steel Company. 


\section{REFERENCES}

Baum, M., Christiaanse, K., editors, 2012. City as Loft: Adaptive Reuse as a Resource for Sustainable Urban Development. Zurich: gta Verlag.

Bullen, P.A., Love, P.E. 2011. Factors influencing the adaptive re-use of buildings, in: Journal of Engineering, Design and Technology, Vol. 9, n. 1, pp. 32-46.

Carter, D.K. editor. 2016. Remaking Postindustrial cities. Lessons from North America and Europe. New York: Routledge.

Ciorra, P., Marini, S., editors, 2011. Re-cycle: strategie per l'architettura, la città e il pianeta. Milano: Electa.

Corboz, A. 1985. II territorio come palinsesto. In: Casabella n. 516. Settembre 1985.

Ingaramo, R. 2017. Rust Remix. Siracusa: LetteraVentidue Editore.

Lubove, R. 1996. Twentieth Century Pittsburgh: The Post-Steel Era. vol. 2. Pittsburgh: University of Pittsburgh Press.

Mcdonald, J.F. 2014. What happened to and in Detroit? in: Urban Studies Journal, Vol. 51(16) 3309-3329.

Moneo, R. 1999. La solitudine degli edifici e altri scritti. Vol. I and II. Torino: Allemandi.

Thomas, J., editor, 2013. The City After Abandonment. Philadelphia: University of Pennsylvania Press. 



\title{
PAPER \#3.02
}

\section{THE HIDDEN DESIGNER: RETHINKING URBAN RULES IN CITY MAKING}

\author{
Caterina Barioglio ${ }^{a}$, Daniele Campobenedetto ${ }^{a}$, Marianna Nigraa ${ }^{\mathrm{a}}$, Lucia Baima ${ }^{\mathrm{a} 1}$ \\ apolitecnico di Torino, Torino, Italy
}

\section{ABSTRACT}

Urban rules have been used for centuries to control the interaction between actors involved in city-making and its translation into the built environment (Lehnerer, 2009). They are a stratified legacy that, especially from the Industrial Revolution, were overshadowed by the need for urban planning.

On the counter stream, we are witnessing new tendencies: in a time in which European cities have to deal with progressive modifications rather than massive expansions is arising the role of design tools meant to transform the existing city.

This paper builds on the analysis of the making of the ordinary urban fabric - the city intended as the combined result of spatial planning, market forces, swinging frames of reasoning, conformity to norms and individual expectations and aspirations. On this basis, this paper focuses on the role of urban codes in shaping the structure of our cities. Specifically, it aims at exploring the intertwined connection between urban codes and city morphology. Commonly urban codes are intended as a set of rules that regard singled out 'elemental types' (such as height, roofing, windows, and the like) and their relations within the built environment with no correspondence to a predetermined and unique location. In that, urban codes profoundly differ from plans, even if they both impact on the urban configuration.
Urban codes are usually associated with different scales, from building elements to street layouts intended to promote desired urban forms.

Rethinking urban codes, shifting from a post evaluation perspective to a design-oriented one, calls for the intervention of architects. This paper explores this approach through the case study of Turin, Italy, within the ongoing revision of the urban regulatory system promoted by their City Council.

\section{KEYWORDS}

Urban design; urban rules; urban codes; urban morphology.

\section{INTRODUCTION ${ }^{2}$}

The development of the set of rules that has determined the forms and uses of the European city, from the modern age to today, reflects the succession of priorities and paradigms: industrial expansion, reconstruction and urban growth, environmental protection and emergencies, functional and physical transformation of buildings. While the Italian debate has focused on planning tools and their effectiveness in responding to the socio-economic challenges of cities (Secchi, 2000; Mazza, 2002), accessory regulations seem of less importance. For example

\footnotetext{
${ }^{1}$ The autorship of this article is equally shared by Caterina Barioglio, Daniele Campobenedetto and Marianna Nigra. Lucia Baima collaborated to the analysis and proposals concerning the "roof" element.

2 This article is an aoutcome of the Re-coding Research project, developed as part of the collaboration agreement between the City of Turin and the Polytechnic of Turin for studies and research related to the preliminary investigation activities for the general revision of the PRG This document is the result of the research work of the Department of Architecture and Design (DAD) carried out at the Future Urban Legacy Lab (FULL) interdepartmental center. Principal Investigator: Matteo Robiglio. Coordination: Caterina Barioglio; Daniele Campobenedetto; Marianna Nigra. Research Group: Lucia Baima; Michele Barale; Caterina Barioglio; Daniele Campobenedetto; Francesca Frassoldati; Valerio Roberto Maria Lo Verso; Maddalena Martina; Guglielmina Mutani; Marianna Nigra; Anna Pellegrino; Matteo Robiglio; Riccardo Ronzani; Valeria Todeschi.
} 
building regulations which, according to a hierarchical order specific to zoning, often had the task of intervening after the definition of the use of land was set. This division of roles, understandable in a condition of urban expansion and city development guided and accompanied by public investment, has been gradually put into crisis by the transformation processes in the existing city.

This dimension is generically defined by the term coding, and is considered as a specific and complementary dimension to the intended use of land, mainly based on a system of laws and rules of conduct in a designated context, written by specialists but intended to be transmitted and communicated without interpretative doubts, with a sufficiently general and repeatable character. Without entering into the architectural choices, confronting the coding tools means confronting the set of rules concerning identified elements (height of the buildings, roofing, openings, relations between elements of the same or of different buildings and the like) and their relations with the built environment, but which do not refer to specific areas of the city.

Seaside's example shows how coding can operate as a set of complementary tools, not just under-ordered to planning. Taylor (1998) states that, in the course of spatial planning theory (in the conception of physical design of the city), a clear distinction has never been codified with respect to the architectural and urban design. It was only after the 1960s that this conception questioned. Coding for these reasons, which is articulated between plans and regulations (as often happens) or which is clearly identified by specific tools (as in the case of Seaside), is the preferred tool for the management of ordinary transformations, in practice and as potential field of elaboration and innovation.

It is Eran Ben-Joseph (2005) who emphasizes the role of coding urban rules, in particular through the definition of standards as a specific element that establishes the minimum characteristics of the built environment, both in terms of quantity and in terms of quality. Coding therefore constitutes a liminal field between ordinary transformation of the city and formation / redefinition of the urban layout (a necessarily extraordinary operation given the exceptional nature with which it presents itself with respect to the history of a city).

The codes are in this field because they allow the coexistence of different instances within the urban fabric and at the same time have effects on the shape of the city.

\section{CODING MATTERS}

In an era in which cities in Italy, as well as in the Western world, face progressive transformations rather than large expansions, the design tools aimed at transforming the existing city are becoming increasingly important. Over the past thirty years in Italy, some laws have been promulgated at national and regional level to encourage reuse practices in the city, in particular by facilitating changes of intended use, volumetric additions to existing buildings and use of unused spaces. $^{3}$

Over the past ten years, the value of urban codes has been highlighted as an important tool for controlling the shape and transformation processes of the urban fabric (Talen, 2012; Ben-joseph, 2005; Marshall, 2011).

A significant example is the renewed interest in form-based codes, which act on types, standards, elements of architecture and more generally on physical form - rather than the separation of uses - as an organizational principle of urban space. The form-based

\footnotetext{
${ }^{3}$ The law No. 106 of 12 July 2011 has as its objective the rationalization of this heritage - through incentives in volume and simplification of the procedures for changing the intended use - acting in fact directly on the settlements, independently from the Regulatory Plan. The regional law (Piedmont) n. 16 of 4 October 2018 establishes the morphological characteristics for the recovery of spaces for residential purposes, in particular of attic rooms, admitting functions already established in the PRG.
} 
codes are not guidelines but constitute real regulatory tools, which are integrated into the local regulatory system. In order to make the prescriptions, rules and standards of these codes accessible and communicable, they are presented both in textual language and in graphic form. A significant case is the code that The City of Cincinnati approved in 2013, awarded the title of Grand Prize for Best Planning Tool or Process at the thirteenth Congress for the New Urbanism in Buffalo in 2014. The code applied to the entire city attributes for each type of building fabric a series of specific morphological rules, with the aim of strengthening the character of a place and regulating the uses in relation to the shape of the built space. these codes are presented both in textual language and in graphic form.

Other initiatives are evidence of a growing attention towards coding which translates into experiences of various kinds. One of these concerns the drafting of illustrated manuals of urban rules, among which the New York case stands out. Since 1961 the city of New York has developed a practical manual that describes the rules contained in the pages of the zoning resolution. In the latest editions (2011-2018), the manual is also intended for a wide audience of non-experts and has the aim of spreading the understanding of urban rules. The simplified description of a part of the rules that act on the morphology of the built in New York allows citizens to become more aware of the regulatory system, promoting democratic debate around the transformation of the city and free initiative.

A second group of experiences concerns the development of new laws to encourage the reuse of existing spaces. The work from the cityLAB of the University College of Los Angeles, for example, led to drafting laws to encourage the construction of additional housing units (backyard homes, secondary units, garage apartments) within already partially occupied lots. To these experiences promoted by public subjects, systems are added that allow to automatically calculate the morphology made possible by the standard, while offering an automatic verification of compliance with the urban rules of preliminary projects ${ }^{4}$. These are mainly services developed by private entities and included in the market, especially in contexts characterized by an intense activity of transformation of buildings.

\section{TURIN AS A CASE STUDY}

Coding, applied to the Turin case, has some peculiarities that need to be retraced.

The first concern with the transformation models on which the Turin regulatory plan was conceived. Approved in 1995 and developed over the previous decade, the PRG was conceived in a period of profound change in the economy and geographies of the city (Bagnasco 1986, 1990).

The regulatory plan of Gregotti and Cagnardi is the result of an interpretation of this framework: it is a plan of reuse of the city, based on transformation rather than expansion, and which looks at the potential of the areas that were going to be disposed of, thus like the spaces occupied by the great infrastructures of the twentieth century.

By relying on the possibility of large public and private investments, still available despite the industrial crisis, the reuse of the city presupposes an intervention for large sectors of transformation.

However, some questions emerge from the study of the set of urban codes of the City of Turin.

Theregulationsarebornaboveallas aresponse to specific problems: even more than plans, they are built for successive stratifications of technical requests, successive additions, replacements and progressive integrations. 
Just as in the second half of the nineteenth century the health problems created by mass urbanization gave rise to hygiene regulations, so in the fifties of the twentieth century following the immigration from the regions of Southern Italy to Turin control tools were needed for the illegal sale of canned products; or again, with the spread of analog and then satellite television, it is necessary to check the installation of the antennas.

In recent decades in Turin, some international events and socio-economic changes (including the winter Olympic games, the rediscovery of the historic center, the temporary reuse of spaces) have contributed to the further - not always coherent stratification of the regulatory schedule.

The complexity of the regulatory system (Moroni 2015) thus structured makes it difficult to understand a priori its possible effects on the built space. This difficulty is not limited to reading the relationship between rules and cities, but is also an obstacle to the use of the regulatory system as a design tool. In parallel to these issues, the current form of the regulatory system is questioned with the emergence of some global emergent issues. The environmental emerging issues need to be addressed, not only through specific rules, for example regarding energy performance, but in an integrated way. Acoustics, water treatment, energy performance are increasingly considered by international urban regulations as interdependent aspects and intertwined with other urban standards, rather than as separate regulatory objects.

The change in housing demand, the expansion of e-commerce services and logistics platforms, the digital revolution, among others, have changed the ways of using the spaces of the city and the values - not only economic - that are attributed to these spaces .

The transformation of production systems and emerging forms of work contributes to a process, change tendencies compared to the recent past of reintegration and fragmentation of production activities within the urban fabric. Although these issues are subject to regional and national laws, they can no longer be addressed only through implementation in the plans that govern large sectors of transformation.

\section{A METHOD TO EXPLORE URBAN RULES: FROM BUILDING ELEMENTS TO REGULATIONS AND VICEVERSA}

Within this context, both on a European scale and on a local scale in Turin, the research project Re-coding, reconsiders the codes not only concerning their design, but above all as a way of rethinking the principles that have made the fortune of zoning: a city of incompatible industries and uses whose critical contiguities should be regulated, regulated by specific sectoral regulations aimed at listing in detail prescriptions and exclude undesirable occurrences. The unwanted results that derive from it, the sum of single uncoordinated objectives, entails new difficulties when it comes mainly to regulating the transformation of existing cities.

Such work is organized in two ways:

- from control tools (litigation, image, hygiene conditions) to project tools;

- from tools for city management to tools designed for the transformation of the city. If the paradigm shift of the 1960s went from a morphological conception of the city to the idea of ever-changing flows and activities (Taylor 1998: 159), the Re-coding project wants to reiterate the link between urban transformations and the codification of the morphological dimension of the city.

The Re-coding project therefore investigates the ordinary transformations of the urban fabric, the combined result of spatial planning, market forces, as well as the compliance with standards and individual expectations 
and aspirations. Re-Coding explores the role of urban codes in shaping the structure of cities, through the relationship between rules, morphology and uses of buildings, and aims to provide tools for restructuring the system of rules in support of a paradigm shift from "city of the new" to the "city of reuse".

The aim of the Re-coding project is to explore the concepts of simplicity, clarity and ease of use of the system of rules that regulate space (Moroni 2018), not only to facilitate accessibility and the democratic debate around the rules, but also to stimulate the activities of urban transformation and activating widespread projects. Furthermore, by analyzing the forms and by relying on data spatialization and dynamic visualization tools, the project aim is to foresee the spatial effects of the rules on the built environment.

By working on urban codes, the Re-coding project aims is to strengthen its potential as a design tool, and to read ordinary transformations in a systematic way on a city scale.

Specifically, the main objective of the project in relation to the regulatory system is to seek simplicity. The project aims is also to respond to the growing complexification of the city reuse of spaces, fragmentation of the use of resources - not through the complexification of the regulatory system, rather through its simplification. Such simplicity could be achieved as follow:

- Accessibility of the regulatory system by citizens, investors and professionals, even outside the national system, through legible and understandable rules. The intelligibility of regulatory tools makes the rules questionable by a wide range of social actors.

- Clarity of the regulatory system, i.e. promoting understanding of the effects of a rule in all cases where it can be applied.

To carry out this integration, the Re-coding project relies on three actions:

- Reorganization: the city of Turin uses different types of regulations, with different areas of application, different degrees of updating and overlapping. The Re-Coding project proposes the reorganization and rationalization of the regulations, starting from the rules that act on the urban space, and the graphic representation of the morphological rules.

- Disambiguation: in order to provide the city with a tool for managing ordinary transformations, the Re-Coding project proposes to collect and reorganize the morphological rules currently present in plans and regulations. In particular, it is proposed to eliminate ambiguities in fields where the morphological rules contained in plans and regulations overlap.

- Revision of the rules by "elements": The revision of the rules regarding identified elements of the city (height of the fronts, window, roof, envelope) aims to modify a control instrument into a project instrument, to unlock the potential of ordinary transformations .

The actions on the regulations thus described are carried out through a method that moves on a double track.

the first track instead starts from the containers of the rules (the regulations), to explore the environments in which they act and the objects they regulate.

The incremental growth of the city's regulatory systems (not only with regard to the management of the urban space) and the difficulty of continuously maintaining the regulatory system can generate overlaps and conflicts. This consequently not only results in a regulatory system that is difficult for citizens to use, but can also generate disputes in which the responsible public entity is called upon to respond in the legal seat.

To address such problem, this study proposes an investigation of the regulatory instruments according to four categories with the aim of eliminating ambiguities and reorganizing and the set of regulations:

1. The area of application of the regulation, which describes the spatial field in which the 
rule operates. The regulations can refer to an urban area or to a specific building, or concern the entire municipal area.

2. The relationship with the physical space of the city, which describes the action of the space regulation or its dependence on spatial parameters.

3. The functions regulated, in spatial, managerial, or procedural terms by the regulation.

4. The elements regulated by the individual regulations.

The second track consists of an analysis of identified "elements" and the rules that, regardless of the regulation in which they are contained, act on them. By "elements" we mean both the components of the building system - for example the roof or the openings of the enclosure - and the parameters that define the characteristics of the internal space - such as the size of the rooms, the minimum heights, the surface of the minimum real estate unit - and urban form - for example the land index, the coverage ratio, the settlement density (Talen, 2012; Alfasi, 2018; Marshall, 2011). For each element we have identified the rules that act on it, the level (municipal, regional, national) to which these rules refer and some internationally comparable case studies. In this study, the elements are divided into progressive scales (the city and the building, the building - internal spaces, construction systems, environmental control systems) and can be repeated at different scales. This ontology of the elements of the urban space has the aim of forming a tool for the public administration that can be useful to guide the analysis, the reorganization, the disambiguation and the revision of the urban rules, as well as the evaluation of the social, economic and of these possible actions. Furthermore, the division into elements constitutes a possible interface of the urban space regulation system to facilitate its consultation by the subjects involved in the transformation processes (citizens in the first place). A classification of rules built on the basis of elements can thus provide not only a structure for analysis, but also a tool that puts them in hierarchy and communicates them clearly to the actors of transformations.

\section{CODING RULES AS TOOLS TO FACE THE TRANSFORMATION OF THE EXISTING CITY}

As part of the revision of the City Masterplan of the city of Turin, three issues were addressed regarding the transformation of the built environment, for which urban rules and in particular the rules of Coding seem to be critical. Studies were carried out on topics identified as relevant and actions were proposed for each issue, according to the objectives described in paragraph 4, on the regulatory system of the City of Turin.

\subsection{The relation between Coding e Zoning}

Following the first of the methodological rails described in the previous paragraph, the first issue addressed is the relationship between Coding and Zoning, which, if not clearly identified in the city's regulatory system, can constitute an obstacle to the application and clarity of communication of the rules.

In this context, a first study was carried out regarding the organization of urban regulations. The city of Turin has 176 regulations. As a result of a regulatory stratification and subsequent revisions over time, these regulations are very different from each other in terms of scope, specificity, purposes and degree of updating. Despite this, due to their legal nature, they are presented by municipal communication systems in a nonhierarchical and non-themed way.

This analysis was subsequently translated into a proposal for the reorganization of the rules within the regulatory objects that contain them, in particular through the hierarchy of the 
regulations by merging them according to the functions or regulated elements.

A second particular study concerned the overlapping of the rules in the Coding and Zoning tools.

The Turin PRG assigns specific areas of the city of the quantities (in particular the land index) and the permitted interventions. Zones contain further subdivisions for admitted functions to which morphological rules are assigned: this involves a direct link between the admitted function and the morphology foreseen by the plan. With this structure, the PRG establishes a direct dependence of the morphological rules on the admitted functions. This entails an overabundance of different morphological rules in areas of the city where numerous functions are allowed, even if the typology of urban fabric is uniform and recognizable. In such situations the morphological rules are not consistent with the type of urban fabric.

From this study a disambiguation proposal was envisioned, which suggests the absorption of the regulations referring to a specific area of the city within the City Masterplan and the transfer of the morphological rules for the whole city within the building regulation, leaving the Plan the identification of particular rules for specific areas.

\subsection{The environmental issue}

The second issue addressed concerns the effects of the rules relating to the urban dimension of buildings (their public dimension, their envelope and their shape) and is explored through the analysis of the elements of the built environment.

The Energy Regulation Annex of the City of Turin regarding is being revised in order to update it and to include wider environmental aspects: the adaptation of the city to climate change, the mitigation of heat islands, the improvement of thermo-hygrometric wellbeing and air quality, the improvement of the usability of public spaces and the incentive for sustainable behaviors.

In this context, two particular studies were addressed that deal with the environmental issue through the analysis of the rules that act on two elements of the building envelope: the "window" and the "roof".

\subsection{The living space}

Lastly, the third issue addressed concerns with the effects of the rules relating to the interior spaces of buildings, which affect the ways in which spaces are inhabited.

The diffusion of new social and economic dynamics ways of living the urban space questions the usability of the residential heritage existing in contemporary cities, and call for reconsidering the relationship between emerging needs and built space.

Part of the current population living in Turin today expresses a demand for housing for social gatherings other than the traditional family (such as students or young workers, temporary or away workers, tourists). At the same time the Savoy city, like other European cities whose urban fabric is the result of a progressive stratification and densification hosts a real estate heritage produced by necessities, now outdated, expressed in past historical moments.

This translates into a poor response to the demand from the existing real estate, which results into a high number of vacant housing (over one in ten according to a 2018 study by the Observatory of the Housing Condition) which, however, could be adapted to respond to new needs.

To these are added unused or underutilized spaces that could be transformed for residential purposes. Attics, basements, garages, low buildings inside the courtyard, storage or work warehouses, solariums or other structures positioned on the roofs, illuminated stairways, caretakers' stations are some examples of "potential" living spaces. 
There are also other "accessory" spaces such as disused technical volumes, interstitial spaces or resulting areas - which, although they are not easily convertible into living spaces, can be rethought to increase the intensity of use of urban spaces; they can host, for example, temporary uses, domestic laboratories, vegetable gardens and gardens, activities for collective use indoors or outdoors.

To address these issues, an analysis of the rules is underway - in particular with regard to the minimum unit, the spaces that are rarely used and the accessory spaces - to stimulate the debate on the theme of living in institutional offices and to suggest tools both for returning to the market for stranded goods, both for the activation of the potential of spaces that are still little considered in the real estate market today.

\section{CONCLUSION}

European cities are the product of a stratification of norms and rules. As contemporary interventions have to deal with pre-existing buildings and urban layouts created for ceased purposes, they have to deal with pre-existing systems of rules too. Rethinking urban codes have been proved to be a key element for a strategic approach to the transformation of the contemporary European urban environment.

Within this frame, the role of the architect becomes as relevant as the one of urban planner in the conception of urban rules that can be a design tool for the city. Thus, urban rules can be considered as a "hidden designer" acting together with architects and planners. Through the reorganization of the regulations - which are very stratified and complex in the case of Turin - efforts are made to increase their accessibility and usability, as well as to allow a large number of actors to act on urban transformations.
In addition to the reorganization of the containers of the rules (i.e. the regulations), the disambiguation actions and the revision of the rules by elements also allow to act on the contents of the individual rules favoring their real time verification during the design process.

The inclusion of environmental issues within urban and non-segregated regulations in dedicated and thematic documents allows full integration with those urban rules that guide the design and transformation processes at the scale of the building and the city.

Moreover, the role of the architect in revising urban rules can also both stimulate the debate and encourage best practices for adaptive reuse (Robiglio, 2017) of urban space.

Consequentially, studies on contemporary living allow us to suggest tools both for the return to the market of "stranded" goods, and for the activation of the potential of underused spaces that are still under played in the real estate market today.

Finally, besides considering the transformative power of the regulation system, we can interpret the regulative potential of architectural projects, and thus of the role of the architectural designer. Designers agency can challenge and stress the regulatory system, eventually resulting in a change of rules. 


\section{REFERENCES}

Alfasi, N. 2018. The coding turn in urban planning: Could it remedy the essential drawbacks of planning?, in «Planning Theory», n. 17, pp. 375-395.

Bagnasco, A. 1986. Torino: un profilo sociologico, Torino: Einaudi.

Bagnasco, A. (Ed.), 1990. La città dopo Ford: il caso di Torino, Torino: Bollati Boringhieri.

Ben-Joseph, E. 2005. The Code of the City, Cambridge - London: MIT Press.

Lehnerer, A. 2009. Grand Urban Rules. Rotterdam: 010 Publishers.

Marshall, S. (Ed.) 2011. Urban Coding and Planning, London-New York: Routledge.

Mazza, L. 2002 Technical Knowledge and Planning Actions, in "Planning Theory», Vol. 1, pp. 11-26.

Moroni, S. 2015. Complexity and the inherent limits of explanation and prediction: Urban codes for self-organising cities, in «Planning Theory», n. 14, pp. 248-267.

Moroni, S., Buitelaar, E., Sorel, N., Cozzolino, S. 2018. Simple Planning Rules for Complex Urban Problems: Toward Legal Certainty for Spatial Flexibility, in "Journal of Planning Education and Research».

Robiglio, M. 2017. Old is the new new. Architecture and the adaptive reuse of industrial legacy, in Id. RE-USA. 20 american stories of adaptive reuse. Berlin: Jovis.

Secchi, B. 2000. Prima lezione di urbanistica, Roma, Bari: GLF Laterza.

Talen, E. 2012. City Rules: How Regulations Affect Urban Form. Washington - Covelo Londra: Island Press.

Taylor, N. 1998. Urban Planning Theory since 1945. Londra - Thousand Oaks - New Delhi: Sage.

New york zoning handbook https://www1.nyc.gov/site/planning/ zoning/zh-2016.page

(Last access 20/02/2020)
Accessory Dwelling Unit Guidebook https://citylab.ucla.edu/ab2299 (Last access 20/02/2020)

Plan Local d'Urbanisme http://pluenligne.paris.fr/plu/sites-plu/ site_statique_43/index_plu.html (Last access 20/02/2020)

Cincinnati Form Based Code

https://ww w.cincinnati-oh.gov/ planning/assets/File/CFBC\%20Full\%20 Document\%20Amended\%202-10-14.pdf (Last access 20/02/2020) 



\title{
PAPER \#3.03
}

\section{DESIGNED TO CHANGE: THE FUTURE OF ARCHITECTURE IS AGILE}

\author{
Salah Imamª, Brian R. Sinclair ${ }^{\mathrm{b}}$ \\ a School of Architecture, Planning and Landscape, University of Calgary + Entuitive Consulting Engineers, \\ Canada \\ ${ }^{\mathrm{b}}$ School of Architecture, Planning and Landscape, University of Calgary + sinclairstudio inc., Canada
}

\section{ABSTRACT}

We live in increasingly unpredictable and turbulent times. The physical form of cities is radically changing. Societies confront unprecedented and accelerating trends in urbanization, political instability, climate change and technological transformation. While we can identify aspects of existing structures that have enhanced aptitude to adapt, it is not guaranteed that mutable features will function effectively in the future. Predicting social, technological or climate change proves impossible. Designing for future cities cannot be about foreseeing tomorrow, rather it must be about creating capacity now given uncertainty later. The present research pursues strategies that are both responsive and holisticintegrating aspects of durability, flexibility and responsibility while introducing social, environmental and economic factors via a framework for dynamic design. Agile architecture demands a frame driven by an attitude that connects lessons from the past, necessities of the present and indeterminacies of the future.

The research first critically assesses the status quo, then pursues concepts of greater agility in contemporary building design-using case study and survey methods to illuminate best practices and identify potential. The work synthesizes an approach for Agility + sustainability that is relevant worldwide. The authors delineate a theoretical foundation needed to inform and inspire the frame. Seminal cases of Agile residential projects are strategically drawn from geographic regions with the highest current and projected floor area in the 21st century, aiming to illustrate progressive concepts within design, construction, legislative and/or financial ethos. Key deficiencies in the marketplace are illuminated as well as contextual barriers against formulating/implementing such an innovative approach. Advancing Gordon's 3L principle, Open Building (OB) and Sinclair's Holistic Framework for Design + Planning, the forthcoming integrative model aims at realizing potent Agile solutions-in essence migrating away from static modern architecture. When buildings are designed to readily cope with change, our cities can approach meaningful sustainability.

\section{KEYWORDS}

Agility; sustainability; future cities; climate change; integration; innovation; design.

\section{INTRODUCTION}

\begin{abstract}
"Architecture in the 21st Century, a period already understood through its dramatic movement and intense change, must be far more responsive, resonant and resilient than designs for days long past. Rather than requiring users to twist and surrender to fit into static environments, a new architecture reacts, adjusts and accommodates." (Sinclair, Mousazadeh and Safarzadeh, 2012, P. 42)
\end{abstract}

The physical form of our cities is radically changing. It is now commonplace to anticipate 
that a building will outlive the purpose for which it is built in a matter of a few years. Buildings must become flexible containers for use by a dynamic society. The challenge is to design buildings that can incessantly accommodate new technologies and allow for changes in the living patterns of occupants. Only when buildings are designed to meet both present and future challenges, will real estate decisions indeed characterize the holistic approach of worthwhile investments and transcend as sustainable communities. Our society confronts unprecedented and accelerating trends in urbanization, political instability, climate change and technological transformation. While it is possible to identify features of existing buildings that have enhanced their capacity to adapt, it is in no way guaranteed that such features will function similarly in the future. Thus, designing for Agility cannot be about predicting the future, it must be about how to create the capacity to allow change to happen.

As our communities continue to expand, relocate or merge, the need for Agility is growing. The globalized living and working patterns of our cities necessitate novel architectural concepts that can sustain such contemporary societies (Henket and Heynen, 2002; Kronenburg, 2007). Therefore, a holistic design approach that is transformable, movable, adaptable and Agile could more efficiently allow for multiple uses of space, could better sustain the economic factors and could more adequately manage the overuse of energy resources. There is evidence that the demand side of the built environment equation will be significantly changing (Kincaid, 2000, p. 160). Such changes in demand are clearly apparent in, for example, the increasing need for residential buildings in the developed world, leaving many nonresidential developments prone to functional obsolesce. In any event, by not examining and responding to the demand side of the equation today, we may be putting ourselves in the position tomorrow of mere spectators who see the output of the economic activity while having no real understanding of necessary inputs. This is indeed an inferior position from which to make policy and a nearimpossible position from which to identify the particulars of optimal physical and conceptual configurations of the built environment. Hence, the present research critically contemplates the condition of contemporary building design, examines emerging trends, explores the role of Agility in facilitating a realistic response to the sustainability agenda in order to propose an integrative framework for realizing a more responsive, responsible and fitting architecture.

\section{BACKGROUND}

"Flexible architecture is intended to respond to changing situations in buildings' use, operation or location. It adapts, rather than stagnates; transforms, rather than restricts; is motive, rather than static; interacts with its users, rather than inhibits." (Kronenburg, 2007)

\subsection{Flexibility, adaptability and agility}

Flexibility and adaptability have overlapping meanings and includes different approaches. Usually, researchers and architects use the term "flexible" for physical changes and "adaptable" for non-physical changes (Estaji, 2017, p. 37). According to Rabeneck, Sheppard and Town (1974), "flexibility is proposed against tight-fit functionalism." They argue that the inefficient design attempts at flexibility might lead to "a fallacy of freedom through control," while adaptability relates to units and spaces "that can be easily altered adjusting to changing circumstances." In 1991, Herman Herzberger claimed that "in a flexible design, no single solution is preferable to all others." He continues to criticize the flexibility approach uttering that the belief that neutral designs that make buildings 
adapt to changing situations results in a lack of identity. Consequently, he introduced a new concept, "polyvalence," which supports minimal flexibility so that the design could adapt to different uses without undergoing any changes. Steven Groak (1992) in his book 'The Idea of Building' referred to buildings as "unstable systems in dynamic environments." He defined a fine line between flexibility and adaptability, where flexible design is "capable of different physical arrangements," while the adaptable design is "capable of different social uses." Gerard Maccreanor (1998) viewed flexibility as a "design idea that leads to the collapse of traditional layout," while adaptability, in his words, is a "different way of interpreting flexibility and it refers to multifunctionality." Maccreanor further notes that "most adaptable buildings were those not originally planned for flexibility." Till and Schneider (2007) characterizes flexibility-in the context of housing-to be attained by "altering the physical fabric of the building," while adaptability is achieved "through designing units or spaces so that they can be used for various purposes."

While there are many ways one might define flexibility and adaptability with respect to building design, the present research pursues a measure which is more independent, responsive and holistic; a measure that integrates aspects of durability, flexibility and sustainability; a measure that unifies the scattered facets of contemporary sustainable designs; a measure that introduces all layers of physical, social, environmental and financial factors in the form of continuously evolving and dynamic framework; a measure better interlacing design phases to construction, operation, occupancy, disassembly and reuse; a measure that we define as "Agile". In 1972, Sir Alex Gordon-former president of the Royal Institute of British Architects (RIBA) -argued that "good architecture" should be designed for loose fit, long life and low energy (3L principle). The idea of integrating flexibility to accommodate future needs as well as minimizing energy footprint throughout the physical life of the building is undoubtedly the ultimate holistic objective for architecture in our modern society (Langston, 2014). Today, Gordon's objectives can be interpreted as flexible, durable and responsible. A thorough consideration of these parameters' objectives and how they have so far been addressed in the literature is essential to help clarify how future potentials could be achieved.

\subsection{The new faces the old}

Cities are living organisms in constant renovation. Yet, sustainable development means evading premature obsolesce of structures. For example, many buildings that were constructed since the 1920s-relying on the functionalist design approach-are now obsolete. These buildings were statically designed to meet the standards and functions of their time. Hence, they were not destined for occupants' evolving uses and require costly refurbishment due to their tight valueengineered specifications and incapability of being adjusted to meet shifting needs (Kendall, 1999). Similarly, a study in Minnesota, USA in 2004 identified that out of 227 demolished buildings, $30 \%$ of which were demolished due to the buildings' substantial physical condition, while $70 \%$ were demolished due to obsolescence as buildings could not shift to fit the functional needs at that time (Horst, 2004, p. 15). These findings suggest that the current way that we design communities-to perform to narrowly prescribed functions-is inadequate and is leaving our buildings prone to obsolescence, abandonment, and destruction. David Pearce (2005) contends that the construction industry "can be forgiven if it struggles to take sustainable development, or Agility, onboard since there is a shortage of sound guidance on what the concept meansfor construction-for the long-term and what the industry would have to do to achieve it." Within this context, Ursula Hartenberger (2008) argues that the knowledge and technologies 
needed to produce sustainable buildings are present in our modern communities. In addition, the economic benefits of sustainable design and construction are well-documented in the literature. However, what is standing in the way of progress is the misalignment of incentives between the stakeholders. This has become known as the "Circle of Blame" (Figure 1). The interplay between the different actors in the Architecture, Engineering and Construction (AEC) industry needs to be organized in such a way that knowledge of the benefits of sustainable and Agile buildings pervades all areas and is accounted for within the processes of design, construction, operation and reuse.

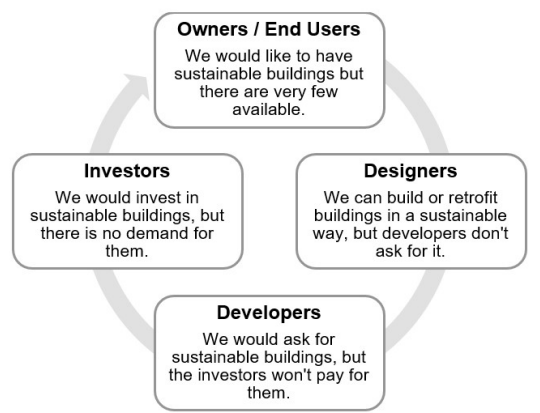

Figure 1. The AEC industry circle of blame (Hartenberger, 2008)

\subsection{Past limitations and future potential}

Beginning in the mid-twentieth century architects began to more seriously question narrow design approaches and in response explored more open, mutable and responsive ways of building. Visionary architects like Kisho Kurokawa and Cedric Price realized the urgency and need for more resilient and robust concepts for our future. They encouraged designing for greater user control over the built environment as a whole. Opposing traditional static designs where users had to adapt to the surrounding environmental restraints, Kurokawa and Price envisioned dynamic spaces that can adapt to user needs over the years (Sinclair et al., 2012). However, such progressive ideas were faced with significant limitations in available technologies, tools and design methods. In other words, such bold thinking ran ahead of technology's ability to keep pace. But today holds potential and promise-with cutting-edge technologies, more social awareness and the arguably aggressive push towards sustainability-we are now able to couple past and present visionary concepts with robust technological realities to develop a more Agile and sustainable architecture for the 21 st century.

Brian Sinclair (2009) had previously delineated a Holistic Integrated Framework for Agile Design + Planning. His theory considers the symbiotic interplay of Agility, Fitness, Diversity and Delight, understanding all hold equal value and significance. It considers energy and low carbon as components of a much greater system. The diverse action areas underlying these four core qualities are seen as having high flexibility, and subject to change and modification as conditions suggest and context dictates (Figure 2). This approach

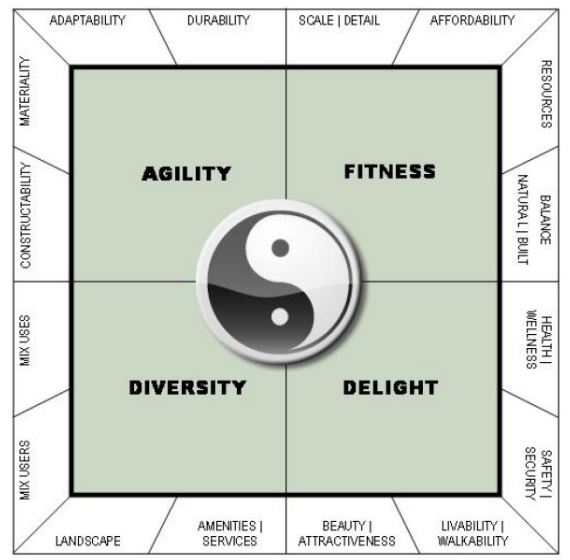

Figure 2. Sinclair's Holistic Integrated Framework for Design + Planning (Sinclair, 2009) 
complements Gordon's 3L principle in our present context. Looking at the suggested quadrant of agility, we can link into long life (recycling, design for disassembly and reassembly), loose fit (open building, usercontrolled design, skeleton infill) and low energy (reduced embodied energy, lowered life-cycle cost).

\section{SUSTAINABILITY: THE BIGGER PICTURE}

The current state of worldwide population growth, scarcity of resources and climate change explain the popularity and profile of the low carbon agenda in developed countries. Such circumstances led to a surge in research and development, making the technical and operational facets of low carbon buildings well understood (Loms, 2010). However, outlining Agility concepts as an agenda solely in the frame of the energy/ carbon reduction, results in an overly-narrow focus of the Agile agenda and prevents consideration of the broader benefits Agile design could present (e.g., the economic sustainability of continuously adaptable developments). Despite progress, energy efficiency improvements (e.g., envelope improvements, systems efficiency, etc.) have not been enough to offset strong growth in energy demand from rising population, floor area demand and pace of social change (IEA, 2017). Therefore, the pursuit of synergies between Agility and sustainability concepts demands us to look much more intensely at the big picture-looking from above through an integrative lens is a necessary precursor to more detailed evidence-based intervention. Evidently, the Agile agenda has interfaces with other pursuits beyond low carbon. In the view of the researchers, durability, flexibility and responsibility are interesting concepts for exploring Agility's collision with sustainability.
- Durability

Obsolescence can be defined as "the inability to satisfy increasing requirements or expectations" (Iselin and Lemer, 1993; Horst, 2004). This is an area that poses considerable stress due to varying social demands (Kintrea, 2007). Obsolescence does not mean poor performance. Most available resources on building durability are more applicable to building components and systems rather than entire buildings. Factors affecting component durability can be a) quality of components, b) execution level, c) indoor and outdoor environment, d) usage settings and e) maintenance level (Kincaid, 2000; Langston, 2014). While a building is a sum of its parts, such parts can be replaced and hence renewed, leaving the primary structure to determine overall life expectancy. Other literature on service life discusses the effect of external and internal actions on building durability and identifies location, usage and design as the main parameters.

\section{- Flexibility}

For an array of reasons, buildings can become functionally obsolete long before their physical life has come to an end. Developing long-standing structures may be inefficient if their useful-life ends prior to their physicallife. Future designs need to be flexible enough to support alternative functional uses. The development of an integrative holistic framework for agility enables building designers to understand the longterm impacts of their decisions early in the design stage. As a flexibility approach already embodies financial, social and environmental criteria, the framework would extend traditional operational considerations such as energy performance to include refurbishment, disassembly and reuse. 
- Responsability

Architecture has always played a major role in climate change. Many policies and actions are being implemented by governments with the aim of reducing greenhouse gas emissions. Buildings contribute to nearly 40\% of such emissions (Perez-Lombard, Ortiz and Pout), which is a huge part of the problem, but also the solution. Thus, architects and the industry as a whole need to assume responsibility for actions. Evidently, there are many comprehensive environmental rating systems for buildings worldwide (e.g., LEED, BREAM, Green Star, etc.), all of which are established for evaluating the environmental design and green attributes of projects. Most rating schemes are organized into a set of impact categories which usually cover issues of indoor environmental quality, energy, transport, water, materials, land use and emissions. Fundamentally carbon reduction can be framed as a problem of energy reduction, which is further decomposable into separate issues of operational and embodied (or process) energy reduction. The low carbon agenda indeed provides powerful leverage through the provision of ancillary benefits (beyond emissions reduction) such as reductions in energy bills and a reduced dependency on external energy sources. The resonance that flexibility has with ideas on the minimization of embodied energy (through a reduction in material wastage resulting from demolition and rebuilding) is also apparent (Gorgolewski, 2005). In the context of this research, responsibility refers to invoking ethical obligation to balance aspects of durability and flexibility-while introducing social, environmental and economic factors via a framework for dynamic design.

\section{AGILE IS THE NEW SUSTAINABLE}

Maladaptive buildings result in early obsolescence (Gorgolewski, 2005) and associated increases in resource utilization through the demolition and construction processes required to replace them. Fixed building services on otherwise useable buildings will increasingly drive obsolescence as energy performance regulations are tightened, and the costs of operation render them unsustainable. If we continue to choose to invest significant resources (and thus embodied carbon) in our built environment, it becomes imperative in a low carbon society that these resources are conserved through the provision for their continued utility. Evidently, the Agile agenda has interfaces with other factors beyond that of low carbon. Thus, a more profound knowledge of the intricacies and interactions between established agendas of low carbon goals and other industry/ society goals is critical to understand the consequential effect such interactions might have, and the desirability of these effects in a broader context. The position suggested here is that the agendas supporting both low carbon and Agile design form facets of the wider sustainability agenda, and that in order to achieve the goals of sustainability overall, it is crucial to evaluate the goals within each agenda and to explore potential alignments.

Nonetheless, the current state of environmental quantifications worldwide is characterized in what is promoted as comprehensive environmental rating systems. Although criticisms have been leveled concerning the use of such rating systems, for example, "point shopping" (designing for points or credits rather than for the good of the building), clearly, such rating schemes have achieved its goals of raising awareness and transforming the market. However, there has only been limited attention granted to the flexible design approach in such rating systems. In 2014, LEED-v4 was one of the first rating systems to recognize "design for flexibility" as an optional credit category. In this category, the designer is given a set of requirements-mostly related to physical flexibility (e.g., modular spaces and the use of 
demountable partitions) - which s/he needs to employ to be awarded the credit points (LEED-v4, 2014). Nonetheless, as per Croxton (2003), "If a building doesn't support change (in all its forms), you have only an illusion of sustainability." Therefore, the pursuit of Agility has to identify and consider all layers of social, environmental and economic factors in the form of a continuously evolving frame. Here, the question presents itself: should Agility have its own rating system?

Consequently, the present research aims to craft a new model that creatively and potently links agility and sustainability by exploring a spectrum of modern developments and emergent concepts. Figure 3 illustrates how Agility perspectives can manifest through a holistic design process to enable a cohesive transition of a building's behavior over time. Our knowledge, resources and constraints towards Agility come from a variety of sources and categories that can either hinder or accommodate change. These categories should not be perceived in isolation as they can ensue simultaneously depending on the uniqueness of the design and the voracity of the designer.

\section{CASE STUDIES}

The on-going research investigates the unifying principles of Agile architecture throughout both early (historic) and contemporary applications in an attempt to understand the unique factors required to develop much more sustainable environments. Case studies introduced in the present paper can be seen as pragmatic and strategic examples with which to explore modern Agile concepts. New construction projects present the best opportunities to achieve flexible, durable and sustainable buildings for future generations. At the same time, most existing buildings will still be in operation over the next few decades. For example, Canada Green Building Council (CaGBC) expects that over $80 \%$ of existing buildings will still be in operation by 2030 and $50 \%$ in 2050. Therefore, existing buildings must also be addressed (e.g., retrofit, rehabilitation, repurpose, etc.) in order to meet increasingly strict sustainability requirements (CaGBC, 2017). Case studies across a diversity of geographic regions were strategically selected in accordance with

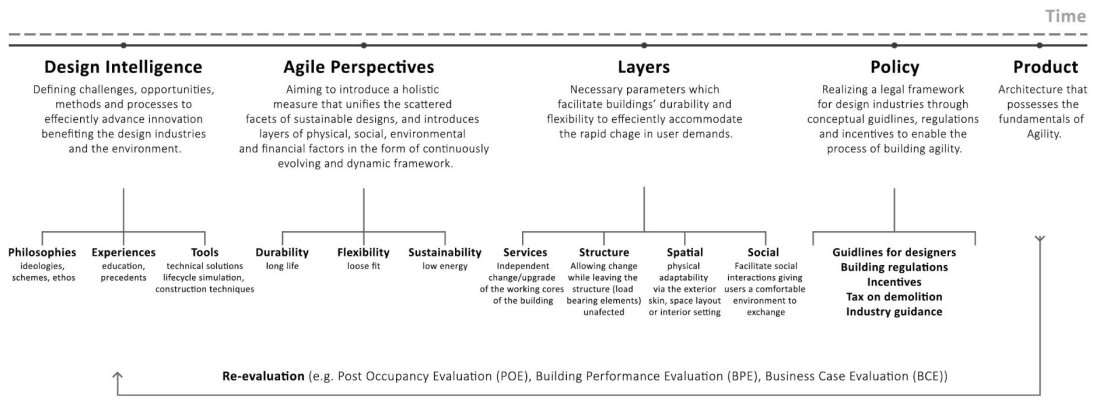

Figure 3. Design categories for which agility can manifest itself through. Categories are integrative and can vary depending on the uniqueness of each project 
data from the International Energy Agency (IEA) with respect to the highest current and projected floor areas in the 21st centurynamely, China, North America, Europe, Africa and India. Additionally, according to the IEA (2017), residential buildings account for two-thirds $(2 / 3)$ of the global energy consumption and $\mathrm{CO} 2$ emissions. Therefore, the present research focuses its efforts on studying Agility in residential buildings. We direct attention to eight contemporary designs drawn from the flexible/adaptable building movement (Figure 4). BlundellJones-in his book 'Modern Architecture Through Case Studies'-views the case studies approach as a unique dialogue and considers investigating the cultural and physical context of each case to be "a better way to disclose general set of principles and laws rather than bending the work to fit the rules" (Blundell-Jones, 2002, p. 5).

In order to draw generalizable theories and conclusions to the residential building design industry, the selected case studieswhich are vital components of this ongoing research-include different building scales and typologies while showcasing various responses to an array of contexts and conditions. Since a significant part of the industry is engaged with refurbishment, retrofitting and reuse, a total of three retrofit projects are studied in regions with the highest reported current floor area (China, USA and Europe). All cases were constructed or retrofitted during the 21 st century and had been recognized for national, state or regional architectural distinction. The present paper introduces these intriguing projects as subjects for the next-in-situ analysis-phase of the study. Our qualitative method evaluates each project objectively in the context of durability, flexibility and sustainability. Case studies data, in tandem with the strategic literature review, aim to highlight leading themes, ideas and practices of Agile architecture. The ongoing research connects the analysis of these contemporary projects with historical precedents deliberated in Imam and Sinclair (2018) and via a rigorous understanding of the literature. The next stage of the research synthesizes a framework that connects Agility and sustainability-equipping architects and builders with the theory, tools and techniques needed to develop and realize more mutable, adaptable, responsive and responsible buildings.

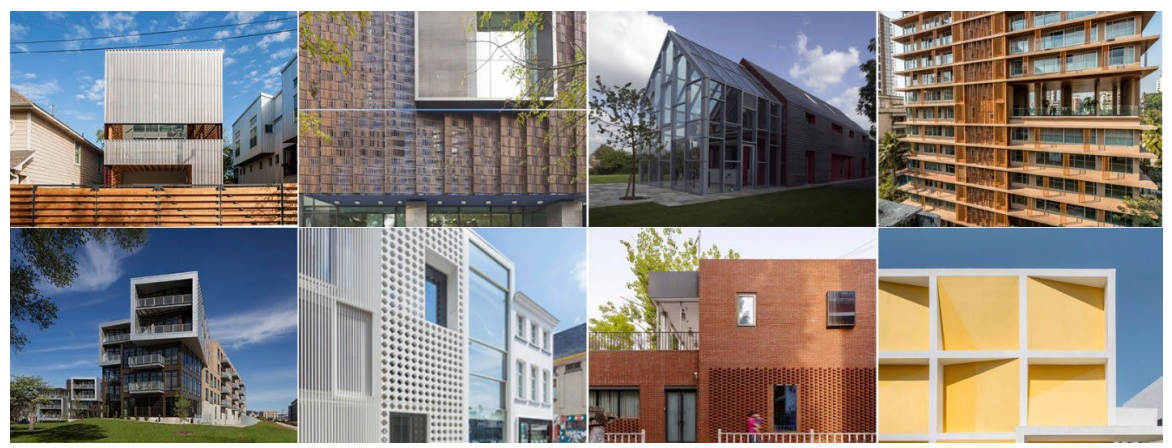

Figure 4. Selected contemporary case studies. Subject to change as the research progresses. From left (top) to the right (bottom): Shotgun Chameleon (USA), Yingijia Club Apartments (China), Sliding House (UK), Pali Palms (India), Seven 27 (USA), House of Lorraine (Belgium), Marina Residence (China), Yantai Chunhui (China) 


\section{CONCLUSION}

"Change must be the new constant." (Imam and Sinclair, 2018)

Architecture of the 21st century should possess the fundamentals of durability, flexibility and responsibility. Meaningful sustainability resides at the nexus of these three aspects. Such principles are not mutually exclusive, nor incompatible with values of delight and performance, but rather hold equal significance. A zero-carbon structure with no robust functional flexibility will still become obsolete long before its physical life has come to an end. While such design demonstrates technological advancement, it is merely a prototype for concepts that need integration into a more balanced and broader framework that should be more commonly practiced. However, a standard theoretical framework for setting such Agile concepts is not yet established, rather only generalized methods and guidelines are found in the existing literature. Hence, the long-term objectives of the present research are to: a) identify seminal layers, agents, facets and forces affecting the integrative design process, b) understand the failure and success of past attempts (technological, social, political, environmental and economic), and c) develop a novel framework and associated methods of analysis to provoke and provide the requisite levels of Agility. The authors understand that whether our designs are partially or entirely adaptable-or even somewhere in between-there can be no one-size-fits-all approach to pursuing Agility in our modern society. Complexity demands diversity and responsiveness. Appreciating that, -listening and truly responding to users' needs-is in the end, the optimal way to achieve strategic, successful and necessary outcomes.

The present paper delineates progress along a multifaceted journey that aspires to dramatically reconsider the way we design buildings. It critically explores prevailing thinking, observes emerging trends, and points to contemporary building designs (to be studied) in an effort to bring Agility into the spotlight. The ongoing research aims to synthesize a conceptual framework for heightened Agility and sustainability, thereby realizing more responsible architecture for the 21st Century. Advancing from the established foundation of Gordon's 3L principle, Open Building (OB) practices and drawing upon Sinclair's recent Holistic Framework for Design + Planning, the aspired integrative model aims to imagine and introduce continuously evolving and dynamic solutions that must be able to shift and morph as circumstances warrant-in essence migrating away from the static architectural practices and staid architectural outcomes that have defined modern architecture. The authors are pursuing clarity and applicability of factors, facets and concepts of Agility in contemporary building design-using case study methods to illuminate best practices and identify future potential. Given the growth of population, scarcity of resources and the emerging society expectations due to the modern world's technological advancements, our research pursuits into Agile Architecture is significant, timely and necessary. In our proposition for reconsidered and more appropriate architecture, people must reside centrally, and the dynamic, responsive and meaningful must eclipse the static, staid and stale. Ingenuity, creativity and imagination prove valuable and vital. 


\section{REFERENCES}

Blundell-Jones, P., 2002. Modern Architecture Through Case Studies. s.l.:Gulf Professional Publishing.

Canada Green Building Council (CaGBC), 2017. Zero Carbon Building Standard, s.I.: CaGBC.

Croxton, W., 2003. Disassembly and Deconstruction. s.l.:Architectural Record.

Estaji, H., 2017. A Review of Flexibility and Adaptability in Housing Design. International Journal of Contemporary Architecture "The New ARCH", 4(2), pp. 3749.

Gordon, A., 1972. Designing for survival: the President introduces his long life/loose fit/ low energy study. Royal Institute of British Architects Journal, 79(9), pp. 374-376.

Gorgolewski, M., 2005. Understanding how buildings evolve. Tokyo, Japan, s.n., pp. 2811-2818.

Groak, S., 1992. The Idea of Building: Thought and Action in the Design and Production of Buildings. London: Taylor \& Francis.

Hartenberger, U., 2008. Breaking the Vicious Circle of Blame - Making the Business Case for Sustainable Buildings. London, UK, The Royal Institution of Chartered Surveyors.

Henket, H.J. and Heynen, H., 2002. Back from Utopia: The challenge of the modern movement. Rotterdam: 010 publishers.

Hertzberger, H., 2005. Lessons for Students in Architecture. (First published in 1991, as an elaborated version of lectures given since 1973 at Delft University of Technology) ed. s.l.:010 Publishers.

Horst, S., 2004. Minnesota Demolition Survey: Phase Two Report, Prepared for: Forintek Canada Corp, Minnisota, USA: The Athena Institute.

Imam, S. and Sinclair, B., 2018. Dysfunctional Design + Construction: A Cohesive Frame To Advance Agility + Sustainability. Philadelphia, ARCC-EAAE International Conference, pp. 415-423.
Iselin, D. and Lemer, A., 1993. The fourth dimension in building: strategies for minimizing obsolescence, Committee on Facility Design to Minimize Premature Obsolescence. Washington DC: Building Research Board, Washington DC: National Academy Press.

Kendall, S., 1999. Open Building: An Approach to Sustainable Architecture. Journal of Urban Technology, 6(3), pp. 1-16.

Kincaid, D., 2000. Adaptability potentials for buildings and infrastructure in sustainable cities. Facilities, 18(3/4), pp. 155-161.

Kintrea, K., 2007. Housing aspirations and obsolescence: understanding the relationship. Journal of Housing and the Built Environment, 22(4), pp. 321-338.

Kronenburg, R., 2007. Flexible: Architecture that Responds to Change. 1st edition ed. London: Lawrence King Publishing.

Langston, C., 2014. Measuring Good Architecture: Long life, loose fit, low energy. European Journal of Sustainable Development, 3(4), pp. 163-174.

Langston, C., 2014. Measuring Good Architecture: Long life, loose fit, low energy. European Journal of Sustainable Development, 3(4), pp. 163-174.

LEED-v4, 2014. USGBC. [Online] Available at: https://www.usgbc.org/credits/ healthcare/v4-draft/mrcx-1[Accessed 12 April 2018].

Loms, K., 2010. Carbon reduction in existing buildings: a transdisciplinary approach. Building Research \& Information, 38(1), pp. 1-11.

Maccreanor, G., 1998. On nostalgia. Convention, OASE, Issue 49-50, p. 172-173.

Pearce, D., 2005. Do we understand sustainable development?. Building Research \& Information, 33(5), pp. 481-483.

Perez-Lombard, L., Ortiz, J. and Pout, P., 2008. A review on buildings energy consumptioninformation. Energy and Buildings, Volume 40, pp. 394 - 398. 
Rabeneck, A., Sheppard, D., and Town, P., 1974. Housing: Flexibility/Adaptability?. Architectural Design, Volume 44, pp. 76-90. Sinclair, B., Mousazadeh, S., and Safarzadeh, Gh., 2012. Agility, Adaptability + Appropriateness: Conceiving, Crafting \& Constructing an Architecture of the 21st Century. Enquiry - The ARCC Journal of Architectural Research, 9(1), pp. 35-43.

Sinclair, B., 2009. Culture, Context, and the Pursuit of Sustainability. Planning for Higher Education (PHE), Issue 38, pp. 6-22. Till, J. and Schneider, T., 2007. Flexible Housing. 1st edition ed. Burlington: Elsevier.

UN Environment and International Energy Agency (IEA), 2017. Towards a zeroemission, efficient, and resilient buildings and construction sector. Global Status Report, s.l.: s.n. 



\title{
PAPER \#3.04
}

\section{PERFORMANCE: THE FANTASTICAL DICHOTOMIES OF CITY-MAKING}

\author{
Shai Yeshayahua, Maria del C. Vera ${ }^{b}$ \\ aRyerson University, Toronto, Canada \\ bIndependent Researcher
}

\section{ABSTRACT}

Nearing its first centennial, the ideas of Ville Contemporaine, aiming to house three million people under lavish greenery (Le Corbusier 1994), are once again manifested through the purview of city legislators seeking to accommodate hundreds of thousands of humans in newly built cities. The spur of these fantastical proposals marketed as ecofriendly phantoms and designed by awardwinning firms deploy embellish storylines about better futures while the global scale of environmental damage increases (Sze 2009). Why? How did city planning get here? Are the culprits legislators, educators, or citizens?

In the absence of concrete truths, we examined city-making processes from the last one hundred years to identify city making ethos according to the reconditioning of their ecological scarcity or wealth. Two cities are outlined as case-studies, with a research emphasis on performance-based analysis. We describe their geodetic location, physical formations, and socio-economic outcomes in contrast to the age's urban parameters and strategies. Akin to referencing their urban successes and failures, our study indicates that the sum of environmental constraints and a human's quest for survival equates to a type of foundation, a resource if you will, underpinning community work and state-sponsored initiatives. Each approach highlights the current errors from Instagrammable eco-cities (City of Toronto 2018) that continue to offer visually appealing solutions that spotlight the aesthetics of cityplanning. Readymade cities are obsolete in an era when we are learning to mine and identify

future prerequisites for urban systems that seek to extend beyond the twentieth-century mindset.

\section{KEYWORDS}

Geodetic addresses; ready-made cities; instagrammable eco-cities.

\section{REALITIES AND VIGILANCE}

In the last one hundred years, bit by bit, earth's geological formation has rapidly eroded and morph into a human-made reality (Vera,Yeshayahu 2019). As Alphabet Inc., Facebook, Microsoft, Toyota, Amazon, and even Akon (rapper) spearhead toward the next mass production of breath-taking proposals, we decided to explore two one-hundred-yearold cities spurring from opposing modes of development. One of the rationales for this study stems from the realization that conglomerates, aforementioned, control most of the data used to develop artificial intelligence [Al]. Their rising power brought forth by surveillance is undeterred by the ecocity language they now apply to their emerging modes of gentrification. Planning proposals like Sidewalk, Woven City, Belmont, or O'Neill's echo the insurgence of technocratic cities. This new kind of urban sterilization is developing among incoming elite and developers, designers, and politicians willing to support their greed (Kitchen 2017). The second rationale of the paper is to ignite a brief account of city-building processes from the bottom up and to look at their extended 
outcomes from the lens of cities that sustain colonizing protocols.

In so doing, we argue that the future prerequisites for urban planners in the twentieth-first century will be to search, mine, and rank how cities continuously evolve. In an ideal Instageammable future, cities will be based on the scientific surveillance of biological behavior from micro-macro content. City building would occur in ways that the ecology of an urbanized planet becomes visible per Gottmann (geographer), Castells (sociologist), and Sze( Doctor of Interdisciplinary Studies) initial unfoldings. How cities affect ecologies, and human behavior is yet to become the sum of planners or city-planning work. Cities are not linked to the nature of urbanization in a scientific way like Galileo advocated in linking the universe's behavior to pursue scientific studies that connect to reality.

\subsection{In the Absence of Concrete Truths}

Heresy was Galileo's false-reality _the idea that what we see differs from what we believe. The simultaneous affirmation and disaffirmation of a heliocentric solar system was Galileo's dooming parallax. His quandary remains among us. Humans often experience these types of confusion. In the age of multiple intelligences, surveying technologies hope to become the instruments that observe everything from micro to macro details. In doing so, the output will seemingly identify reality.

City-planning challenges this assertion as the processes of fabricated realities plague the 21st century. Theoretically and empirically, millennial cities will correspond to a real-world environment defined by geological and environmental pressures. Conversely, like the recently live-streamed video from the Consumer Electronics Show (CES) in Las Vegas, the parallax of reality is an exact instrument of a false reality. Akio Toyoda, president and CEO of Toyota Motor
Corporation, and Bjarke Ingels, the Danish Architect from BIG, could barely contain their excitement while unveiling details of The Woven City by Toyota (Toyota 2020). In their speeches, there are no lessons learned from the extended journey humans undertook to avoid extinction. Instead, they retold the same kind of endless narrations about the realities and contingencies unfolding now that alter how, where, and why humans continue to survive. In contrast to the fauna and flora extinction, humans' fragile existence escaped the presenters' objective, embezzling their future city within established arrays of better air quality, greener streets, and prettier buildings.

In this kind of atmosphere, city-planning is one of the false-realities that CEOs promote. Lies dress as truth speaks of earth's crust without a black sticky liquid call asphalt that waterproofs life's resources and entombs the earth's fertility indiscriminately. Discovered in 3000BC (Bilkadi 1984), and spread across the planet, asphalt is the human's preferred material for survival. As master planners, builders, and government officials continue to speak of the urgency to build new ecosmart-sustainable cities; they are often talking about how additional tons of asphalt will be poured to make dams, roads, and homes. In 1824AD, when Champs Élysée became the first asphalted road in the modern world, no one imagined the next two hundred years' unfolding. From 1900 to 1999, the USA consumed 4,500 million tons of asphalt. Recently, in less than three years, from 2011 to 2013, China pour 6,500 million extra tons of asphalt into the planet's surface (Harvey 2016). The synchronization of human population growth and urban development parallels the consumption of asphalt. It mirrors an unrecognized reality emitting seventy percent of $\mathrm{CO} 2$ across earth's atmospheres that, according to Elizabeth Kolbert heralds, The Sixth Extinction (Kolbert 2014).

A hallmarked of eco-friendly- cities is often an Instagrammable blue-sky and a series of 
animations showing streetscapes full of trees, clean water, and dog-friendly parks like the Alphabet Projectsby Google (Lindzon 2019)). They stand in contrast to the display of realities supplied by satellites, robots, and sensors depicting refugee camps, shantytowns, acid ecologies, and all of the horizontal-vertical sprawls made with asphalt. Before satellite data, the story of how a city's territorial expansion occurred was first illustrated by geographer Jean Gottmann, who examined how the USA's northeastern cities strengthen their urban growth. In his 1960s depiction, Gottmann saw the northeast seaboard of the United States as an interdependent system of rivers, oceans, roads, farmland, and many interconnected metropolises that formed a vast geographic settlement called megalopolis (Gottmann 1957).

In the next forty years, as the use of satellites and computational tools expanded, Manuel Castells foresaw these kinds of geographic zones not as the sprawling effect of humankind, but as a series of megalopolises spreading across the globe. He identified these megalopolises as economic-machines made from social-cultural-political systems forging a new order of humanmadeinformational-networks (Castells 2013). Now, Julia Sze tells us that additional projects aiming to build more of these geographical formations will continue to distort the earth's ecological system. Her book Fantasy Islands discusses Dongtan Eco-City as the example of a collective misunderstanding brought forth by venture capitalist, starchitects, and politicians branding their master-plans as environmentally conscious platforms for new ways of living (Sze 2015). Although the completion of these cities is not yet within our grasp, the 16-mile bridge connecting Chongming Island to Shanghai stands as physical evidence of Dongtan's failed proposal. The invisible coexistence of fauna, flora, and local inhabitants has already been displaced or lost, and the eco-city has not materialized.
Like most proposals for eco-cities, Dongtan's bridge signals a type of false-reality fabricated at the start of the 20th century when master planning came into view. It is a kind of storytelling that remains a singular act under the redress of new perceptions; it is the modern phenomenon architects and planners know well -born from the efforts of educators who institutionalized master-planning, the false-realities to divide and conquer earth's geology remains(Erickson 2012).

\subsection{Eyes Beware}

In 1986 the New York Times published "Photos for Spying on Soviet Military:

\begin{abstract}
In the past, photos from civilian satellites were used mainly for crop forecasting, mineral exploration and forestry management. Such uses require a distant view of the earth's surface. But civilian satellite cameras, although still less powerful than military spy satellites, are being built to take closer looks at small objects. This enables city planners, for instance, to locate and evaluate sites for streets, buildings and parks (Broad 1997).
\end{abstract}

Surveillance evidences human behavior. But, sometimes, the lenses from which these behaviors are evidenced produces partial truths or false-realities. This phenomenon has been the subject of fiction, cinema, and courtrooms where crimes not committed become guilty pleas. It is also the way everyone else has learned to craft selfies and photoshop images to tell embellished stories of lives never lived.

Google Earth is one of these lenses leading to perceptual misunderstandings for urban planning. In the video production Timelapse: Las Vegas Nevada, a short visual narrative demonstrates how from 1980 to 2016, Lake Mead rapidly shrinks as Las Vegas housing sprawl grows (LandSat 2016). This time-lapse is a partial-truth because it fails to note the deformations and transformations inflicted 
on the Colorado River since the early 1900s and before urban sprawl became physical contexts extending beyond Las Vegas City. In the video, there is no articulation of how the built productions of the Hoover Dam or Lake Mead changed the Colorado River. It does not show when and how the rest of the Southwest suburbanized and sprawled. No mention of revisited water distribution agreements and management for Lake Mead per Colorado, California, Utah, Wyoming, Arizona, and Mexico negotiations. The latest of which was determined as follow:

1) $27 \%$ for the State of California

2) $24 \%$ for the State of Colorado

3) $17 \%$ for the State of Arizona

4) $10 \%$ for the State of Utah

5) $6 \%$ for the State of Wyoming

6) $9 \%$ for Mexico Central America

Beyond dams and sprawl acts like Parker Dam plus Lake Havasu add built-in islands that have nothing to do with support for electricity, agricultural, industrial, and residential developments and everything to do with future land use. Joseph Kerski, whose review of old maps and satellite images is featured in LANDSAT, tells that:

This modification is nothing new-it began as the earliest humans began burning of local grasslands to encourage new growth, tilling the soil for the first agricultural experiments, and building small dams to ensure a water source. Yet today's changes are more frequent and also larger in area, from the construction of cities, reservoirs, and tunnels, to widespread land use change through the conversion of the natural land cover to cropland, grazing pastures, mining sites, and other uses (LandSat 1911).

Vela produces visual narratives (Gonzales 2020). One of his visual stories starts two hundred years ago and shows how population growth will increase to ten million by 2050. In looking at his algorithmic account side by side with urban analyses published by NASA, it is clear how humans survived beyond the 1800s. Historical accounts of colonization and the shift from rural to urban life, verify the rapid and massive geographic changes occurring in Africa, Asia, Australia, and the Americas. By the 1900s USA takes the lead rapidly urbanizing and ranking in third place among thousands of urban developments as the world 's population growth (Simon 2002).

\section{ONE HUNDRED YEARS OF URBANITY}

During the last one hundred years and as a result of the machine age, cities propagated the planet becoming urban thesauruses that evidence an urbanize earth. By the mid1960s, satellite images, films, and scholarly work ignite new ways for designers to view this scale. Work like The Power of Ten from Charles and James Eames stars to deal with the proportion of perspective and the scale of things relative to the universe (Eames 1977) . Our mundane sight shifts according to the new magnitude for understanding reality from motion imagery and movies. Fictions like Alphaville 1965, Playtime 1967, and Brazil 1985 heralded the universalized city of anywhere and everywhere. In retrospect, our paper sees false-realities as the descriptions of most proposed and built environments. From this purview, we compare and contrast two cities from their:

1) Geodetic Location and Ecologic Wealth

2) Socio-Economic Interest and Outcomes

3) Physical Formations

\subsection{Nātūra Nātūrans}

\section{Geodetic Location and Ecologic Wealth} At $0^{\circ} 49^{\prime} 45.1^{\prime \prime S ~} 91^{\circ} 08^{\prime} 7.1^{\prime \prime W}$., from the depth of the ocean, around one hundred meters of profundity the Equatorial Undercurrent (EUC) collides with the Galapagos Islands. The clash causes an upwelling of nutrients that uniquely reconstructs and replenishes significant portions of the earth's biodiversity 
(Rodgers 2018 ). It is the act that inspired The Origins of the Species (Darwin 2012), a force unexplained for millennia where nature does what nature wants, always on the move, autonomously amending, adapting, and acclimating to the tinkering processes of life. Field studies from Dr. H. M. Saville of the American Museum of Natural History and writings by Kanz and Curtis, dating back to the late 1800s early 1900s, concluded that this coastal region might have been a resource that fortified the wealth of the Inca Empire (Wade 1999).

\section{Physical Formation}

By the shoreline, at $0.9677^{\circ} \mathrm{S}, 80.7089^{\circ} \mathrm{W}$, nature nurtured the inhabitants in the periphery. First passively identified by the simple communal ambitions of local fishers who selected to live off its bounty, the zone was under a spell of sunny days and breezy nights housing humans who lived in homes made from nature's caña gauda (structural bamboo). In oblivion of exploitation and expanding behaviors, indigenous people sought to live in symbiosis with their surroundings, nurturing their environmental wealth.

\section{Socio-Economic Outcomes}

By 1929, however, other kinds of settlers discovered the area, and the population grew. These new citizens needed a system of governance (Middleton 1988). La Ciudad de Manta and its municipality ensued from the industrialization of fishing. Gradually, additional immigrants from Germany, Spain, North America, and, most recently, Russia, and China colonized the oceanfront. The land is arbitrage and privatized (Bonilla 2013). The ocean currents were nationalized. In less than fifty decades, Manta became a shipyard fill with merchants, bankers, fishing crews, concrete buildings, asphalt, trucks, and private vehicles. Now a sea of sprawling homes dispersing like popcorn everywhere, decentralized human life. Populated by urban slums and countless gated communities, the automobile-dependent minority exacerbated the lack of adequate public transport, public parks, and open public spaces. Here, like in much of the Pacific Coast, Manta faces environmental challenges. Earthquakes, erosion, and lack of equity or opportunities for indigenous Mantencians plague the zone. The present unrest of Latin America is now inflicting a new type of migration in Manta. Migrants from Venezuela and Central America articulate a new and growing dystopia, forward by drugs and violence, with little knowledge or regard for its unique geographic milieu.

This story is old. Like countless of coastal towns where few humans once lived in solitude, without exposure to the modern world, Manta's habitat is no longer shaped by natural evolution. Explosive fabrications act as a counterforce to the Equatorial Undercurrent, endangering an environment in flux inundated by acts of exploitation. The narrative simulates MACONDO, Gabriel Garcia Marquez's fictional city, that starts as a paradise of environmental wealth and eventually gets swallowed by a gigantic but unforeseen windstorm in which readers are free to characterized as the speed of an urbanized inundation (de O. Martins 2016).

\subsection{Behind Us and Ahead of Us}

\section{Geodetic Location and Ecologic Wealth}

In contrast, at $32.0853^{\circ} \mathrm{N}, 34.7818^{\circ} \mathrm{E}$, nature did not always nurture humans. Throughout its history, dating back to ancient times and biblical recordings, different narrations tell different stories of a region oscillating from tales about water depletion to times of green bounty and periods of rainfall. Consider a wasteland by some, a battleground for many, and an opportunity of survival by a few Tel Aviv urbanized anew. From its inception, the area has experienced multiple beginnings (Chyutin 1979), yet, in the early 1900s, the city was marked by a gradual migration of 
scholars arriving from Germany, Austria, Italy, Britain, Bulgaria, and Yugoslavia. Over the years, and specifically, after WWII, near the 14th of May, 1948, migrants flocked the area with new arrivals of people from Poland, Romania, and Africa. Most recently, immigration from Spain, North and South America, Russia, and China continue to populate this city. It is a place marked by a socio-global awareness of its physical, biological, psychological, and social constraints. Human behavior is challenging.

\section{Physical Formation}

There, ideas are the means to observe, think, experiment, and validate life. There is a drive of perpetual surveillance where everyone is watching and watches the acts perpetrated in the city. Starting with an urban master plan proposed by biologist Patrick Geddes, Zionist collectively developed a community and a system of economic growth they called Kibbutz (Katz 1986). From the start, Israelis embarked on a soft socio-economic journey promoting social equity, educational rights, and health care for all. Urban growth was from the beginning, controlled by the Kibbutz planning system inspired by Bauhaus

Teachings (Welter 2009). Citizens undertook building tasks related to rest, cleansing, and nourishing. Together they form a society based on housing and shared governance. Public forums for idea creation, critical analysis, and education achievements became a type of production intertwined with comprehensive and reliable understandings of their environment. Agricultural research and novel techniques of irrigation spur, guaranteeing a steady and independent stream of food-supply. Collectively Israelis strategized a defense mechanism for survival, starting with their militarization system, medical research centers, and augmentation of scientific knowledge. Emerging water conservation programs and solar energy became the staple to promote self contain stability and security. Yet, in fifty years, by the late 1970s, the Kibbutzim system was reaching its peak, citizens steadily morphed their laws toward the privatization of economies forging a new era of labor and social revolution for Tel-Aviv.

\section{Socio-Economic Outcomes}

Growing away from their initial agro-socioeconomic model, Tel Aviv enacted a new type of urbanization called Irbutz (Philps 2000). This new modality focuses less on an economy of means and more on urban wellbeing, forging a re-fresh concept of neighborhood strata. This approach is an evolving exploration that remains focused on social behavior and cultural traditions. The goal is to share common causes and improve and expand on their environmental surroundings. Irbutzans often demand action from their municipality forging walkability, greenery, improve public services, carshare technologies, quality of food, and water, plus the participation of city officials engaged in social media forums.

In some particular way, weaning out of Kibbutzim culture is an indefinite journey leading the Municipality of Tel Aviv to become a shareholder with its citizens. Social unrest from Irbutz is creeping in. Citizens are identifying a robust participatory system based on the inclusion of citizenship, coupled with the Internet of Things [IoT] as an urban tool for citizens to seek a continuum of community engagement and improve living environments. Beyond humandata collection, their mobile applications are actively used to analyze information according to location, energy use, water needs, and food distribution. The municipality has dedicated workers delivering educational services, recreational activities, emergency alerts, health support, and other pertinent content to its citizens. 


\section{CONCLUSION}

Within one hundred years, earth has progressively urbanized, a move that exerts challenges to the coexistence between fauna and flora, as evidenced by shifting migrations and persistent planning errors caused by land arbitrage, ecological ignorance, and technological interference. This perspective matters because it is the basis to understand the earth's fabric further. It leads to an underlying and evolving paradigm about ecological and economic disruptions generated and detected through urban development. The eco-city language applied to Sidewalk, Woven City, Belmont, or O'Neill's is a century-old system that plays into false-realities. Even if the current state of technologies could materialize the promises of a new age center on advanced knowledge, city planning remains riffed with contradicting procedures that continue to tamper with the planet's motion. Thus, the socio-economic and environmental discussions driving humans to live, work, and co-habitat in urban settings requires readjustments at the educational and governmental level to lead humans away from existing praxis, which arbitrarily disenfranchises life.

From this perspective, we did not find new methods to build a lexicon for city planning, yet; we observed severe challenges to the ways we propagate across the planet. In the presence of warming environments, colonized by different types of urbanized spectrum, it is not enough to grasp the abuse of environmental wealth in the absence of planning ethos or imagine the aesthetics of urban planning and city-making through community engagement. Moving forward, how can we extract lessons from previous errors and look for ways to mine and identify the future prerequisites for urban systems seeking to extend beyond the twentieth-century mindset? From our study, we see these starting points:
- Pay attention to the earth's eco-system.

- Develop socio-economic strategies or systems of governance with scientific awareness.

- Aim to reconnected disenfranchise fauna and flora.

- Harness socio-economic labs based on a Galilean vision of the Universe.

- Ignore the asphalt centric movement of the 20th century.

- Escape the minds of city builders and leaders who engage in "smart" urban developments of recent years.

This list is not exhaustive, but it starts to render the challenges facing an urbanized world. It is also extending the perceptual scale of our existing stratum. Suppose we see Tel-Aviv as a city surviving under scarcity and directly benefiting from "a club-like" community; could we also envision community engagement at the scale of a planet facing scarcity? On the other hand, if we visualize Manta as a city imploding from its chaos, could that help humans reflect upon ensuing dangers at the scale of a depleting planet? Implicit within these two tales lies a meditative approach to infer additional or probable scenarios for survival under scarcity and depletion rather than uncheck city planning growth. 


\section{REFERENCES}

Bilkadi, Z. (1984). Bitumen: a history. Aramco. Bonilla, O. (2013). The Manta-Manaus project: nature, capital and plunder. In Ecological Economics from the Ground Up (pp. 111131). Routledge.

Broad, W. (1997, December). First Civilian Spy Satellite Soars Into Space, Launched in Russia by a U.S. Company. Retrived from https://www.nytimes.com/1997/12/25/ us/first-civilian-spy-satellite-soarsinto-space-launched-in-russia-by-a-uscompany.html.

Castells, M. (2013). Communication power. OUP Oxford.

Chyutin, M. (1979). Planning in a communal society: A comparison between physical planning in the kibbutz and in the city. Socio-Economic Planning Sciences, 13(6), 289-295.

City of Toronto. (2018). Public Space Public Life Study. Retrived from https://www. toronto.ca/ext/digital_comm/pdfs/cityplanning/2018-10-15-downtown-parkspublic-realm-plan-public-space-publiclife-study.pdf

Corbusier, L. (1994). Ville contemporaine de 3 millions d'habitants. Le Corbusier, Urbanisme, Paris, Champs Flammarion, 157-168.

Darwin, C. (2012). On the Origin of the Species and The Voyage of the Beagle. Graphic Arts Books.

de O. Martins, L. P., \& de Oliveira, P. J. V. (2016). Breaking the cycle of Macondo: design and decolonial futures. XRDS: Crossroads, The ACM Magazine for Students, 22(4), 28-32.

Eames, C., \& Eames, R. (1977). Powers of ten [Motion picture]. United States: IBM.

Erickson, A. (2012). A brief history of the birth of urban planning. The Atlantic Cities. Retrived from http:// www. theatlanticcities. com/jobsandeconomy/2012/08/brief-history-birthurban-planning/2365
Gonzales Vela, D. (2020). World Population Between 1800-2020 \& Projections 2050. Retrived from https://www.youtube.com/ watch? $\mathrm{v}=\mathrm{fmTj7SOLDmU}$

Gottmann, J. (1957). Megalopolis or the urbanization of the northeastern seaboard. Economic geography 33, no. 3 (1957): 189-200.

Harvey, D. (2016). Abstract from the Concrete. Sternberg Press.

Katz, Y. (1986). Ideology and urban development: Zionism and the origins of Tel-Aviv, 1906-1914. Journal of Historical Geography, 12(4), 402-424.

Kitchin, R., Coletta, C., Evans, L., Heaphy, L., \& Mac Donncha, D. (2017). Smart cities, urban technocrats, epistemic communities and advocacy coalitions: The Programmable City Working Paper 26.

Kolbert, E. (2014). The sixth extinction: An unnatural history. A\&C Black.

LANDSAT. (2016). Time Lapse Las Vegas, Nevada. Retrived from https://www. youtube.com/watch?v=OmNJAOM_6_A

LANDSAT. (2020). Creating an Oasis: Lake Havasu City, Arizona, 1911. Retrived from https://landsat.gsfc.nasa.gov/creatingan-oasis-in-the-desert-lake-havasu-cityarizona-1911/

Lindzon, J. (2019, September). How Toronto Locals Soured on Alphabet's Neighborhood of the Future. Retrived from https://www.fastcompany. com/90390377/alphabet-wants-to-turntoronto-into-a-digital-city-locals-arent-sosure

Middleton, D. R. (1988). Development and multiple use: conflict on an Ecuadorian beach. Urban Anthropology and Studies of Cultural Systems and World Economic Development, 351-364.

Philps, A. (2000). Cities Kibbutz' Helps Socialist Dream Live On. Retrived from https:// www.telegraph.co.uk/news/worldnews/ europe/1356509/City-kibbutz-helpssocialist-dream-live-on.html 
Rodgers, L. (2018). Climate change: The massive $\mathrm{CO} 2$ emitter you may not know about. BBC News.

Simon, C. J., \& Nardinelli, C. (2002). Human capital and the rise of American cities, 1900-1990. Regional Science and Urban Economics, 32(1), 59-96.

Sze, J., London, J., Shilling, F., Gambirazzio, G., Filan, T., \& Cadenasso, M. (2009). Defining and contesting environmental justice: Socio-natures and the politics of scale in the Delta. Antipode, 41(4), 807-843.

Sze, J. (2015). Fantasy islands: Chinese dreams and ecological fears in an age of climate crisis. University of California Press.

Toyota. (2020, January). Toyota to Build Prototype City of the Future. Retrived from https://global.toyota/en/newsroom/ corporate/31171023.html

Vera, M. D. C., \& Yeshayahu, S. (2019, May). Designing Eden. In ARCC Conference Repository.

Wade, N. (1999, May). Finch DNA Shows Darwin Was Right. Retrived from https:// www.nytimes.com/1999/05/11/science/ finch-dna-shows-darwin-was-right. $\mathrm{html}$ ? searchResultPosition $=5$

Welter, V. M. (2009). The 1925 Master Plan for Tel-Aviv by Patrick Geddes. Israel Studies, 94-119. 



\title{
PAPER \#3.05
}

\section{INFRASTRUCTURE FOR COLLECTIVITY: BUILT HERITAGE AND SERVICE PLANNING IN THE CITY}

\author{
Francesca Dapràa \\ aPolitecnico di Milano, Milan, Italy
}

\section{ABSTRACT}

The paper proposes a reflection on the potentialities of the existing ecclesiastical heritage in the urban context - with particular reference to the one related to the catholic "parish complexes" - The research introduces a reading of such particular heritage, with the aim of valorizing and innovating its system - widespread and diffused in the Italian cities - which is passing through a phase of reconsideration and regeneration, due to the changing of cultural and social needs of the multicultural citizen. The objectives of the research lie in the elaboration of tools and methods for the analysis and the re-signification of the parish heritage, this one conceived as a potential actor in the "collective services" supply chain of the "public" city.

The research uses the city of Milan as a privileged area of study, by virtue of the diffusion and capillarity of the heritage, the consolidated social and cultural tradition linked to it, as well as the degrees of innovation and experimentation in progress regarding the "subsidiary" planning of services.

The results of the research consist, initially, in a "systematization" of the contribution of different disciplines on the specific topic; secondly, they represent an analytic study about the context of Milan, supported by a multiple-case study analysis, framing some hints of innovation related to users, services, spaces and management of the parish heritage.

\section{KEYWORDS}

Infrastructure; ecclesiastical heritage; service planning; social innovation; urban planning.

\section{INTRODUCTION}

This contribution proposes a reflection on the role of built heritage within urban planning of services in the contemporary city, with particular reference to the ecclesiastical one. The considered field of study presents great chances to reinterpret new spatialities and to meet the material and immaterial needs of contemporary society, offering spaces and opportunities for experimentation and innovation. The object of the research refers to the so-called "parish complexes" 1 - specifically developed and spread in the Italian context - which include the Catholic worship building and all the structures attached or aggregated to it, devoted to social, entertainment and educational activities - such as Christian initiation, hospitality, sports and games, charity and assistance initiatives - and several other functions, recently being re-defined ${ }^{2}$. Together with the rest of the ecclesiastical heritage of other natures, it constitutes a huge part of

\footnotetext{
${ }^{1}$ By "parish complex" it is meant a complex building organism, which belongs to a specific "parish": a "community of faithful that is established permanently within a particular Church" and which includes the faithful of a specific territory (can. 515, can. 518, Codice di Diritto Canonico,1983).

2 The role of the parochial institution in the Italian society has been consolidated through centuries, flourishing under the inputs of priests and educators (San Filippo Neri in Rome in the XVI century, the great Lombardy bishops from Carlo Borromeo - XVI century - to Giovanni Battista Montini -XX century-, Don Bosco in Turim in the XIX century). After the Unity of Italy and especially during the XIX-XX century the parish consolidated as the social heart of the cities and districts, devoted to young people and their entertainment and education (Borzomati 1997, Tassani 1997).
} 
the entire built heritage of Italian cities, it is deeply rooted in the urban fabric of the main cities, as well as in rural territories, and it traditionally constitutes an identity symbol for cities, neighborhoods, countries, and villages. From a social point of view, these complexes are involved - like many others with a "collective" vocation - in a process of transformation and reconsideration of their vocation and identity due, among other factors, to the changes in religious, social, and cultural trends and needs of the multiethnic city. From a "physical" point of view, the real consistency of the heritage and its potential is greatly under-considered, often under-maintained, under-valued, and partially under-used; moreover, it has different spaces which are not adequate to the needs of the contemporary Christian community and civil society, and which are awaiting for a necessary updating. This observation is linked to the increasingly urgent need to enhance and re-use the built heritage of existing "containers", avoiding the consumption of soil. Moving from these considerations, the research focused on the definition of the "role" and the "potential" of this huge heritage in the contemporary city, with particular reference to the system of "collective services" and "welfare".

\section{METHODOLOGY AND OBJECTIVES OF THE RESEARCH}

The general objective of the research is to provide strategies, indications, and perspectives for the enhancement and optimization of this heritage, with the purpose of its integration in the "collective services" planning. The specific objectives of this reflection lie, firstly, in the analysis of the relationship between the system of parish complexes and the contemporary city, and of the consistency and quality of the heritage itself - which is barely examined today -; moreover they consist in the definition of some scenarios that suggest an innovative articulation of spaces, services and management methods for such complexes.

\subsection{Selection of a study area: the city of Milan}

Moving from the assumption that the parish heritage has a particular impact and relevance within the Italian panorama, a specific territorial area has been selected, to link the "physical" and architectural analysis of the structures with the urban development and the social impact of parish complexes in a specific context. The city of Milan has been selected, because of the significant number of structures present and the development of the parochial institution which differentiates the identity of the Ambrosian system from the others; moreover, for the wealth of researches and reflections on the topic from an urban, sociological, educational, and religious point of view.

\subsection{Phases, methods and tools of the research}

The research is articulated into three main phases.

PHASE I | theoretical: the goal lies in the reconstruction of the interactions between the ecclesiastical heritage and the contemporary city. The composition of the theoretical framework (State of the Art) is based on a bibliographical survey related to two main areas: the enhancement of the ecclesiastical heritage and the planning of urban collective services.

PHASE II | analytical: the second phase looks for the qualities and characteristics of these complexes and their relationship with the territory, analyzing their distribution and their "location" within the current "tools" of urban planning, and taking a "photograph" of their status in the Ambrosian city. It consists of a reflection on the territorial organization of 
the "public city" and the "ecclesiastical city", and of a multiple-case study analysis on 15 Milanese parishes. The research methods used range from bibliographic, cartographic, and archival one, direct analysis and statistics tools, supported by the use of geolocation and digital cartography tools, which act as a basis for the various reflections conducted.

PHASE III | strategic: the third phase synthetically elaborates some "profiles" of innovation for the "parishes of the future", based on the data collected in the previous part and a further bibliographic survey on some specific topics.

\section{REFERENCE FRAMEWORK: ECCLESIASTICAL HERITAGE AND "COLLECTIVE SERVICES"}

\subsection{Welfare, urban service planning, and subsidiarity in the contemporary city}

The relationship between welfare and urban structure is the subject of various innovations, conducted thorough research and design, and it is particularly lively in the Milan area (Pomilio 2009). The places and "containers" for "collective services" are slowly moving from a "standard" vision to a "horizontal subsidiarity" one; the "public city" is no longer defined by the application of abstract urban constraints, but by the definition of a daily and continuous project of the urban welfare system, in which social activation is possible, and alternative forms of services supply are implemented. Such a process involves not only the "public" actor but also other "subsidiary" entities, including private ones, volunteering, and the third sector (Vittadini 2007). In this sense, the concept of "public service" is extended to all which appears to be "of collective interest" and which responds to a general need: the actual "collective equipment" (Aymonino 2000, Valente 2009). Such principles are the basis of service planning in some recent Regulatory Plans - including the Milan one - where the municipality plays a supporting and coordinating role in soliciting the potential availability of the subjects active in urban transformations, and which are capable of directly generating services in the urban fabric (Vittadini 2007, Pomilio 2009, Comune di Milano 2019c). The subsidiary perspective, therefore, becomes a potential tool to respond to the multiple changing needs of contemporary living, due to a "cognitive advantage" of individuals and social realities that allows them to respond more appropriately to local needs, compared to public bodies (Garrone and Lauro 2012).

\subsection{Built and cultural ecclesiastical heritage: conservation, enhancement, and digitisation}

The ecclesiastical heritage - considered firstly as "cultural heritage" - represents a large part of the entire heritage of the territories and for this reason the reflections on it should be strictly connected to the panorama of researches and policies regarding conservation and enhancement of built heritage in Europe. Such frame passed from a concept of mere "conservation" of property to visions that include the development and enhancement of the "outstanding value" heritage of collective interest, involving socio-economic implications, values, and environmental factors (CHCfE 2015, Pontificium Consilium de Cultura 2018, Commissione Europea 2019). In this context, ecclesiastical and religious assets play a highly relevant role, since they represent a real "portion of culture" or "cultural identity" of a specific society and regions (Zetti 2010, 234, Cavana 2016, 46), elements of "cultural identification" and social aggregation (Pontifium Consilium de Cultura 2018 , 4). Nonetheless, religious heritage is often subject to a lack of systemic attention and, consequently, of strategic planning for its conservation and enhancement (Stovel et al 2005, CEI \& MIBACT 2014). In recent years, 
particular attention has been paid to the issue of digitisation and online accessibility of cultural heritage in Europe and Italy (European Commission 2011, Presidenza del Consiglio dei Ministri 2015, Commissione Europea 2019). Also on the ecclesiastical side, several efforts have been carried out in this direction, to "census" and "catalogue" the heritage (D’Agnelli and Gavazzi 2007, Bartolomei 2016): the first step towards a generation of "common good", proposing the vision of a widespread and integrated heritage and new relationships between the Church and the territories (Hesse and Ostrom 2007, Rizzo and Rizzo 2015, Bartolomei 2016). In this panorama, the Diocesi di Milano ${ }^{3}$ has recently undertaken the project of a management tool integrated with the geolocation of the parish buildings and their territorial boundaries (Fascicolo Tecnico del Fabbricato e Piano di Manutenzione Programmata della Diocesi di Milano). The geolocation process aims to anchor the management of the properties to the territorial specificities and local needs and it allows a "complete" and "territorial" reading of the properties, going towards a systemic and complementary conception of spaces, functions, and actions (Guzzetti et al. 2016).

\section{ECCLESIASTICAL HERITAGE AND CONTEMPORARY CITY: THE AMBROSIAN SYSTEM}

\subsection{Public/ecclesiastical city}

From an urban planning point of view, the heritage considered finds a precise "space" within the revision of the Piano di Governo del Territorio (Territory Government Plan) of 2012 "Milano 2030", approved in March 2019, within the Piano per le Attrezzature Religiose (Plan for Religious Equipment, hereinafter PAR), which maps the existing equipment and identifies the areas for those of new forecast. The PAR, created to respond to a legislative requirement $(L R / 2015)$ is part of a broader reflection on the urban service planning, where "religious equipment" is considered a real "service" for the multicultural citizen, to be included in the frame of "proximity services" (Comune di Milano 2019b, 19). Nowadays, the planning of the Milanese city and its services is closely linked to the definition of the 88 Nuclei di Identità Locale (hereinafter $\mathrm{NIL}$ ): territorial, non-administrative entities, which arose as modalities of "planning at the local scale"(Pomilio 2009). On the other hand, the "ecclesiastical city" system is organized into 170 "parishes" and 10 Pastoral Units4: an organization resulting from historic stratifications and urbanization trends, which led the religious planning to follow the urban one, conceiving churches and parishes as hearts of the new urban districts $^{5}$. The actual PAR shows that, in a certain sense, the development of the "ecclesiastical" city continues to follow urban planning, including the construction of new buildings for worship in the areas of future development. Nonetheless they follow different logics, recalling, on one side (the public), the identities of the NIL - which do not correspond, at a territorial level, to the historical division of the neighborhoods - and on the other side (the ecclesiastical) the unification of parishes - due to a lack of priests and resources -, which generates new territorial identities. An overlapped map of the two nets shows how much they are no longer coincident (Fig. 1, 2). The maps - processed through GIS tools - open up a reflection on the real meaning of the parochial borders and the NILs, and on the real "territorial incidence" of this secular institution - the

\footnotetext{
${ }^{3}$ The Diocesi di Milano represents the territorial extension of the Church of Milan and it includes the provinces of Milan, Varese and Lecco, Monza-Brianza, part of that of Como and some municipalities in the provinces of Bergamo and Pavia. It is composed of 1107 parishes, distributed in 73 deaneries, organized in 7 pastoral areas.

${ }^{4}$ By Pastoral Unit is meant a union of several previous parishes, with the creation of a new institutional figure, or a close coordination between parishes (Bressan 2007, 428).

${ }^{5}$ Outstanding, in this sense, are the XIX experiences of Bologna and Milan, where the Church worked in strict connection with the public administration to build modern parish complexes in the popular residential districts (Gresleri et al 2004, Lazzaroni 2014).
} 
parish - concerning the development and planning of the contemporary city.

This consideration is fundamental to analyze the potential of the parish heritage as a "container" of services - whose "territoriality" defines its use and users - and its inclusion within the "Piano dei Servizi". The mentioned reflections about the interaction parish services-neighborhood act a relevant role in the strengthening of the local identities and in the plan of a "systemic" offer of collectiveinterest services, as well as in the renewal and reorganization of the ecclesiastical fabric.

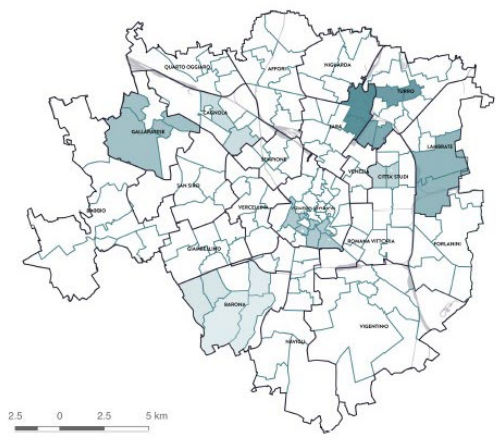

or laypeople), the collection of technical drawings and urban indications regarding each complex, and the data analysis. The choice of the sample used ${ }^{6}$ aimed at building a vision as articulated as possible, trying to intercept realities and experiences that could be representative of common trends.

The analysis focused, in particular, on the "spaces" and "services" offered by the parishes considered, to outline a comparative framework useful for subsequent analyses. A second objective lies in the will of studying the relationship between the parish and its neighborhood, to describe their

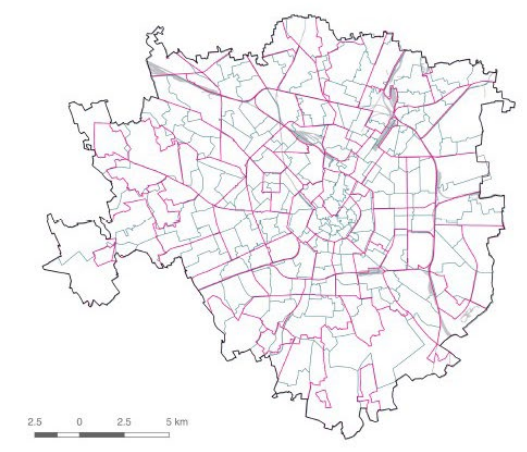

Figure 1, 2. From left: Map of the parishes and Pastoral Unities, City of Milan; Map of the overlapping of the parish network (green) and the NIL one (magenta), City of Milan. Edited by the author.

\subsection{The ambrosian parish complexes: a sample analysis}

The second part of the analytical phase aimed at taking a photograph of the current state of the analyzed system. A multiple-case study analysis has been conducted on 15 parish complexes, articulated into different phases: a direct observation - to collect qualitative and quantitative data - some interviews with parish interlocutors (priests interconnections at a territorial ("consistency" of the parish area compared to the one of the related NIL), functional (analysis of services related to those present in the neighborhood) and social level (analysis of users involved in parish activities concerning the demographic composition of the neighborhood).

The data collection about uses and users has revealed that - in most cases - the juvenile users are predominant - regardless of the location of the parish - and that, consequently,

\footnotetext{
${ }^{6}$ The choice of the structures followed four selection criteria: I. Afference to non-homogeneous territorial portions; II. Pastoral and social interest; III. Availability of existing data or their direct collection; VI. Historical and "typological" variety of the analyzed complexes. To give a systematic order to the collection, the city of Milan was therefore divided into three areas: "fascia centrale" (central belt), "fascia intermedia" (intermediate belt), and "fascia periferica" (peripheral belt), selecting five parishes for each area Here the list: San Simpliciano, San Lorenzo Maggiore, Santa Maria della Passione, Santa Maria al Paradiso, San Francesco d'Assisi al Fopponino (Fascia Centrale); Sant'lldefonso, San Pio X, San Vincenzo de' Paoli, San Nicola in Dergano, Sant'Agostino (Fascia Intermedia); Santa Maria Rossa in Crescenzago, Santa Maria Liberatrice, Pentecoste, San Carlo alla Ca' Granda, Beata Vergine Assunta in Bruzzano (Fascia Periferica).
} 
the services and activities addressed to young people are still predominant. Sports activity proves to be the main constant in the parish offer, following the activities of oratorio (traditional aggregative moments of play and free time entertainment) and Christian Initiation. The analyses also show that there is still a strong "celebratory" use of parishes as a "service" which, even today, is attended by several hundred people in each church. Further analyses showed the spatial and functional articulation of the complex, highlighting the differences between "historical" and "modern" heritage: the first, characterized by a spatial predominance of the church-building, which constitutes a strong artistic and cultural value; the second, defined by a balance of sacred and profane spaces. It has also been observed that the architectural and morph-typological attributes of the complexes act a relevant role in the definition of its uses and impact in the districts; this aspect deserves further investigations that have not been deeply conducted during the research.

The analyses deriving from the comparison between the parish and the local contexts revealed of particular interest. From a sociodemographic point of view it showed that considering the entire population living in the parish area, the participation in parish activities, in the majority of cases, involves no more than $20 \%$ of the inhabitants of the district; whereas the "incidence" of activities dedicated to young people is significantly higher: in most cases, parishes involve more than 30\% of young people in the neighborhoods, reaching peaks of $60-70 \%$. From a spatial point of view, the analysis showed a variety of different relations parish-NIL (i.e. parishes entirely covering the $\mathrm{NIL}$ area, and others whose area is not possible to relate with the NIL one).

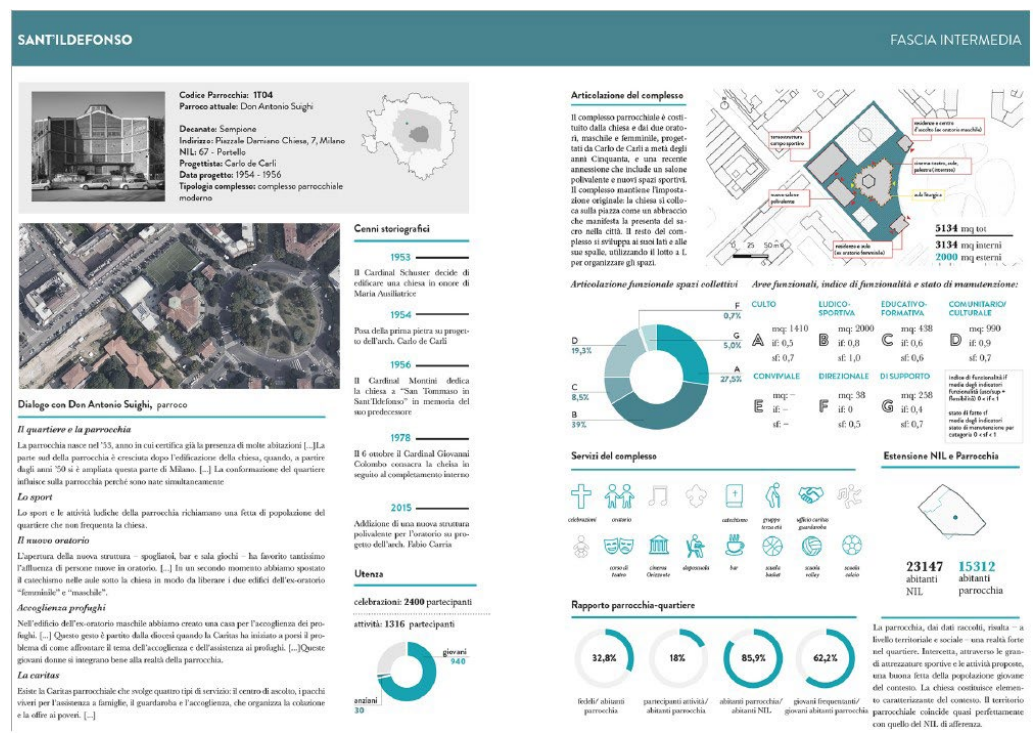

Figure 3. Example of the datasheet of one parish (Sant'lldefonso), organized in: main information about the complex: aerial view of the complex; excerpts of the dialogues with the parochial interlocutors; brief historiography of the parish; users; functional articulation; index of functionality and state of maintenance for each functional area, services of the complex; overlapped map of NIL extension and parish area; indicators of parish - neighborhood relationship. 
Those spatial relations could constitute a basis for a reflection regarding the parochial and public organization, to understand which are the most correct ways to foster a relationship between parishes and neighborhoods. For example, a brief reflection on the historic center situation could lead to the idea of stop concentrating on a resident-based and youth offer - because of its depopulation and inhabitants' ageing - and looking for new ways of "serving" the district and its users. In this sense, the constant social observation related to the NIL is a powerful tool to collect information about a specific area, moreover, participatory processes are recommended to involve the population in the possible transformations ${ }^{7}$.

In conclusion, the analyses carried out give an image of the Milanese parish reality which, in general, constitutes an active "presence" in the neighborhoods in virtue of the spaces, the services offered and the users - with particular reference to the youth bracket - . Nonetheless, it is not always able to respond to the social need of the contexts of its competence, as well as to adapt the traditional services and activities to the changing demands and citizens' needs (i.e. consider the sports trends). Moreover, it is equipped with spaces that diverge from the current demand of contemporary users, who increasingly need and prefer flexible places and spaces for meeting and aggregation.

\section{ECCLESIASTICAL HERITAGE, PUBLIC CITY, AND SOCIAL INNOVATION}

Throughout history, the parish has been able to respond to the needs of the society it knew and supported, varying over time its "offer" of services and activities, and facing the different pastoral and social pressures. Regarding these issues, when related and integrated with the offer of public and social services in the city, it represents a relevant player in the city's welfare network in response to social needs still unresolved or poorly resolved, establishing what can be expressed as "creative subsidiarity" (Cottino and Zeppetella 2009). Parish spaces, moreover, offer themselves as truly significant potential spaces, given their intrinsic openness to the territory and their use - in most cases, partial, or at least concentrated in certain time slots and days of the week -. In terms of innovation, this heritage reveals to have spaces available to fight the "individualizing trend" of society (Bauman 2002).

In this sense, its enhancement as an under-used resource, linked to its potential of new actors, networks, and relationships involvement and activation, makes the parish a field of action of great interest in the development of Social Innovation actions.

Concerning its users, the parish should act towards a multi-generational and supraterritorial perspective

- thus expanding its catchment area -, designing its spaces and services to meet the needs of the context and not only of the traditional parochial "sphere".

For what concerns the services offered, the analysis showed a particular incidence of the sports services held in the parish complexes. Given their widespread presence (more than two thousand structures on the Lombard territory), and their physical structure (which includes, within a single complex, indoor and outdoor spaces for sports - e.g. fields, gyms - and semi-public spaces for meeting with the city - e.g courtyards and parvis -) the parishes constitute a real opportunity to respond to the increased demand for spaces and services intended for physical and sports activities, with particular reference to the lack of "widespread services" for the practice of emerging urban sports, which require an adaptation of traditional sports venues (Vettori 2019, Ghiretti 2019).

\footnotetext{
${ }^{7}$ During the last years, the Italian Bishops' Conference (CEI) started interesting experimentations about the participatory processes in the design and renewal of parish complexes, intending to guarantee a recognized role to the communities - both religious and civil - in the design process, including the record of the needs and expectations of people in the Preliminary Document for the Design of new churches (DPP). (Cavallini, Daprà and De Lucia 2019).
} 
An example of such a transformation process could be given by the parish of San Pio $X$ in Città Studi: a parish complex in strict relation with the university users and life which started, during the last years, to open its spaces to study in the morning. A community-based survey, conducted in 2019, demonstrated how the parish and its spaces are mainly used by district-users to study, to meet, and to socialize, a totally different asset from the residentbased frequentation of the majority of the parishes. Such inputs led the parish to start a process of reconsideration of its role, aiming to restore both the church building and the sports structures in an innovative way (Daprà 2020). Finally, wide margins of innovation reside in the ways of providing services. The parochial services, when correctly inserted in the Piano dei Servizi (implementing, for example, an ad hoc voice to reflect the plurality and versatility of the types of services provided by these structures) and organized systemically - also through their digitisation - would constitute real "nodes" of a "subsidiary infrastructure" of services.

\section{CONCLUSION}

In conclusion, the research attempted to analyze the implications of the huge parish church heritage in the contemporary city. The analysis of the urban structure of the "public city" superimposed on the "ecclesiastical city" has shown how two "realities", which co-exist, could reveal the great potential for the territory and citizens if properly systematized. The systemic analysis of the physical consistency of the heritage, combined with that of its spaces and services concerning the neighborhoods of reference, constitutes an innovative vision of the topic, from which broad reflections on the role of the parish heritage as a "common good" to be revitalized can derive. As a matter of fact, some services provided by Christian communities have always been considered of public interest (such as amateur sports); whereas, today, it is necessary to reflect on the fact that the whole - by its widespread presence within the neighborhoods and its symbolic power (physical and cultural) in the urban landscape - represents a great potential as a "provider" of services to be enhanced and to be integrated into the public system.

The reflection on the parish's degrees of innovation in terms of users, services and methods, has shown that it is desirable an even greater interference and interpolation between the two institutions, to enhance and exploit both the physical heritage and the vocation of the parochial institution. The research led only a first small step towards considering the urban, social, and real estate potential of the heritage considered, waiting for further deepening on it.
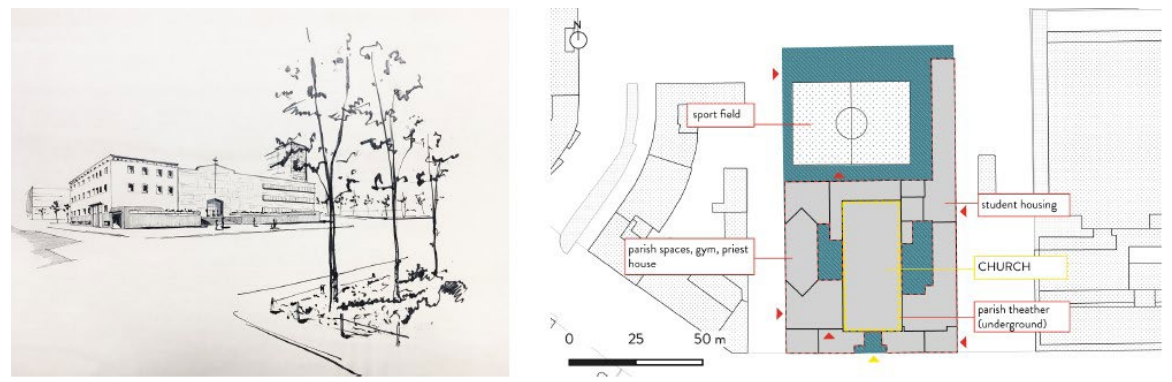

Figure 4, 5. The parish of San Pio X in Città Studi. From left: view from Piazza Leonardo da' Vinci, Giuseppe Chinigher architect, 1954. Source: Giuseppe Chinigher Archive, Politecnico di Milano; current planimetric configuration of the parish, edited by the author. 


\section{REFERENCES}

Aymonino, C. 2000. II significato delle città. Padua: Marsilio.

Bartolomei, L. 2016. "Le chiese abbandonate d'Italia. Cause, significato, prospettive di gestione". In_bo Ricerche e progetti per il territorio, la città e l'architettura, no.10: 6-26. Bologna: Università di Bologna. https://doi.org/10.6092/issn.2036$1602 / 7184$.

Bauman, Z. 2002. La società individualizzata. Come cambia la nostra esperienza. Bologna: II Mulino.

Borzomati, P. 1997. "La parrocchia". In I luoghi della memoria. Strutture ed eventi dell'Italia unita, edited by Isnenghi, M., 6791. Rome-Bari: Laterza.

Bressan, L. 2007. "Unità pastorali, parrocchie, e presenza della Chiesa nella società". La rivista del clero italiano, no.6: 426-439. Milan.

Cavana, P. 2016. "Chiese dismesse: una risorsa per il futuro". In_bo Ricerche e progetti per il territorio, la città e l'architettura, no.10: 44-56. Bologna: Università di Bologna. https://doi.org/10.6092/issn. 2036$1602 / 6488$.

CEI \& MiBact. 2014. Linee guida per la tutela dei beni culturali ecclesiastici. https://www.beniculturali.it/ mibac/ multimedia/MiBAC/documents/feed/ pdf/ Linee\%20Guida\%20Tutela\%20 Beni\%20Culturali\%20Ecclesiasticiimported-48392.pdf.

CHCfE Consortium. 2015. Cultural Heritage Counts for Europe, Krakow: International Cultural Centre. http://blogs.encatc.org/ culturalheritagecountsforeurope//wpcontent/uploads/2015/06/ CHCfE_FULLREPORT_v2.pdf.

Comune di Milano (ed). 2019a, Piano per le attrezzature religiose, Relazione generale e norme di attuazione, Milan. http:// allegati. comune. milano. it/ territorio/ PGT_ BURL/ 3_PAR/ 1_PAR_Relazione_Norme_ Attuazione.pdf.
Comune di Milano (ed). 2019b. Milano 2030 , visione, costruzione, strategie, progetto di città. Milano. http://allegati.comune. milano.it/territorio/PGT_BURL/1_DP/1_ DP_Relazione_generale.pdf.

Comune di Milano (ed). 2019c. Piano dei servizi, norme di attuazione. Milan. http:// allegati.comune.milano.it/territorio/PGT_ BURL/2_PS/1_PS_Norme_Attuazione_ Catalogo.pdf.

Cottino, P. and Zeppetella, P. 2009. Creatività, sfera pubblica e riuso sociale degli spazi. Forme di sussidiarietà orizzontale per la produzione di servizi non convenzionali. Paper no.4/2009. Rome: Cittalia.

Daprà, F., Cavallini, E. and De Lucia, G. 2019. "Design for and by community. Participatory processes for the construction of Italian parish complexes." Faith and Form, no. 52, 2.

Daprà, F. 2020. "Infrastruttura Sussidiaria. Strategie per la valorizzazione del patrimonio ecclesiastico: il sistema dei complessi parrocchiali ambrosiani", Final PhD Dissertation, Politecnico di Milano, Department of Architecture, Built Environment and Construction Engineering, Milan.

D’Agnelli, F.M., and Gavazzi, L. 2007. "Catalogazione, riordino, inventariazione e censimento: strumenti informatici e nuove tecnologie al servizio dei beni culturali". SICEInforma (march) 15-17.

European Commission. 2011. Commission recommendation of 27 October 2011 on the digitisation and online accessibility of cultural material and digital preservation (2011/711/EU). Luxembourg. https:// eur-lex.europa.eu/LexUriServ/LexUriServ. do?uri=OJ:L:2011:283:0039:0045:EN:PDF.

European Commission. 2019. European Framework for action on cultural heritage. Luxembourg: Publications Office of the European Union. https://doi. org/10.2766/622226. 
Garrone, P., and Lauro, C. (eds). 2012. Sussidiarietà e città abitabile, Rapporto sulla sussidiarietà 2011. Milan: Fondazione per la Sussidiarietà.

Ghiretti, R. 2019. "Il ruolo sociale nello sport. Evoluzione degli impianti sportivi tra marketing e comunicazione".In Architettura dello sport. Progettazione costruzione gestione delle infrastrutture sportive, edited by Faroldi, E. Santarcangelo di Romagna: Maggioli.

Gresleri, GI., Bettazzi, M.B., Gresleri, G. and Apa, M. 2004. Chiesa e Quartiere, storia di una rivista e di un movimento per l'architettura a Bologna, Bologna: Editrice Compositori.

Guzzetti, Invernici, Privitera and Ronconi. 2016, "Geolocalizzazione delle Parrocchie e dei loro beni immobili nella Diocesi di Milano", XX Conferenza Nazionale ASITA, 8 - 10 november 2016, Cagliari. atti.asita. it/ASITA2016/Pdf/044.pdf.

Hesse, C., and Ostrom, E. (eds). 2007. Understanding knowledge as a Commons, Cambridge: The MIT Press.

Lazzaroni, L. (ed). 2016. La diocesi di Milano e le nuove chiese 1954-2014. Milano: Centro ambrosiano. Pomilio, F. (ed). 2009. Welfare e territorio. Florence: Alinea Editrice.

Pontifium Consilium de Cultura. 2018. La dismissione e il riuso ecclesiale di chiese. Linee guida, Rome. www.cultura. va/content/dam/cultura/docs/pdf/ beniculturali/Lineeguidadismissione.pdf.

Presidenza Consiglio dei Ministri, 2015, Strategia per la crescita digitale 20142020, Roma. http:// www.governo.it/ sites/governo.it/files/strategia_crescita_ digitale.pdf.

Rizzo, R. G., and Rizzo, L. S. 2015. "Religious heritage in Italy: websites and geolocalization. A new appraisal". Bollettino della Associazione Italiana di Cartografia, no.154: 121-136. Trieste: Edizioni Università di Trieste. https://doi. org/10.13137/2282-472X/12493.
Stovel, H., Stanley-Price, N.,and Killick, R. (eds). 2005. Conservation of Living Religious Heritage, Papers form the ICCROM 2003 Forum on Living Religious Heritage: conserving the sacred. Rome: ICCROM. https://www.iccrom.org/it/publication/ conservation-living-religious-heritage.

Tassani, G. 1997. "L'oratorio”. In / luoghi della memoria. Strutture ed eventi dell'Italia unita, edited by Isnenghi, M., 136-172. Rome-Bari: Laterza.

Valente, I. 2009. "Servizi, attrezzature, infrastrutture: tre parole chiave per l'architettura degli spazi pubblici". In Welfare e territorio, edited by Pomilio, F., 111-115. Florence: Alinea Editrice.

Vettori, M.P. 2019. "Sport e spazio pubblico. II ruolo delle infrastrutture sportive nell'evoluzione della città'. In Architettura dello sport. Progettazione costruzione gestione delle infrastrutture sportive, edited by Faroldi, E. Santarcangelo di Romagna: Maggioli.

Vittadini, G. (ed). 2007. Che cosa è la sussidiarietà. Un altro nome della libertà, Milan: Guerini e Associati.

Zetti, I. 2010. "Built heritage, local communities and the production of territory. Citizen participation in heritage preservation and improvement". In Integrating aims - built heritage in social economic development, edited by Mälkki M. and Kaisa S., 231-250. Espoo: Centre for Urban and Regional Studies Publications. http://lib.tkk.fi/ Reports/2010/isbn9789526032849.pdf. 


\title{
PAPER \#3.06
}

\section{CIRCULAR ECONOMY AND REUSE OF ARCHITECTURAL HERITAGE IN FRAGILE TERRITORIES}

\author{
Marco Bovatia ${ }^{a}$ Alisia Tognon ${ }^{\mathrm{a}}$ \\ aPolitecnico di Milano, Milano, Italia
}

\section{ABSTRACT}

This paper aims to investigate how the architectural culture, and in particular the space design disciplines, can incorporate the paradigms of the Circular Economy in their principles and practices. The objective is to understand which theoretical postulates are valuable for defining disciplinary approaches applicable to abandoned historical contexts which need to be reactivated.

The object of the research is the Italian inland areas (SNAI - Strategia Nazionale Aree Interne - National Strategy of Inland Areas), which occupy about $60 \%$ of Italian territory.

These areas are characterised by the abandonment of architectural heritage and fragile cultural landscapes. However, these under-utilised places are an extraordinary resource and possess a historical-artistic heritage which offers various opportunities for territories and communities. Their significance is able to produce a cultural, economic, social and environmental impact which can be achieved through a sustainable development strategy. The political commitment is to create a common path for the enhancement of the local economy, but also to introduce innovations into public services such as schools, health and mobility. Among interdisciplinary theoretical speculations required for the creation of a strategic approach to sustainable architectural and urban regeneration projects, this ongoing research relies on the concept of Circular Economy as a theoretical reference (Ellen MacArthur Foundation), shaped into the notion of reuse defined in the cradle - to - cradle approach (McDonough, Braungart
2002) and extended to the model of the "3Rs" and "Design for Reuse".

The result of this work is to argue that in order to define new lifecycles, avoiding tactics of high energy cost recycling, down-cycle and linear economy, it is necessary to implement a "Design for Reuse" strategy. This is a design concept in which other possible uses for products, architectural artefacts and parts of the city can be planned. Therefore, the outcome is not to find conclusive answers but to open up questions and to hypothesise partial answers for the ongoing research.

\section{KEYWORDS}

Territorial fragilities; circular economy; reuse; cultural heritage.

It is well known that the construction of Venice took place literally by plundering (and then dismantling) the ancient Roman settlements and early Christian churches of the Venetian Lagoon.

It is also known that Filarete Hospital in Milan, over the centuries, has changed its use and is now the campus of Università Statale.

Referring to Aldo Rossi, he focused on the question of the reuse of architecture, something which depends more on the precise definition of its formal and identity characteristics than on a vague project of flexibility, only able to produce anonymous, ordinary and substantially unsuitable spaces for specific uses, precisely because they are without identity. 


\section{INTRODUCTION}

In recent times, the concept of Circular Economy and its application to the architectural field has seen the evolution of several investigations related to construction techniques and materials. These concepts seem to be coherent with the idea of circular economy, even if its development is complex and is the result of detailed research that also requires the involvement of different disciplines. Indeed, the theme of separation between natural and technical flows, launched by the book Cradle to Cradle: Remaking the Way We Make Things (McDonough, Braungart 2002) allows us to imagine innovative construction technologies and materials designed to guarantee the independence of the two fields. Moreover, the well-known 3Rs (Reduce-Reuse-Recycle) establish the pertinence to the technicalconstructive sphere of architecture, although it is not always easy to achieve. This approach is within the sphere of reducing the use of energy and materials, reusing the construction components and recycling waste and scrap.

Alongside this, the paper intends to take into consideration and propose a reflection on the relationship between the concept of Circular Economy - with its philosophical postulations - and the architectural field, which deals with compositional, typological and spatial issues of design. The translation into a more qualitative context opens to the challenge of determining building assessment systems capable of quantifying the efficiency and sustainability of the design processes. Setting up a theoretical background is a necessary prerequisite for creating a practical methodology for the reactivation of underused landscapes and will be developed in future steps of the research.

The scope of this reflection includes the architectural, urban and landscape heritage of fragile territories. It must be considered a theme of pressing interest; it tackles the design culture with the need to rethink principles, tools and practices in the light of new ethics and altered territorial conditions which now affect most of the world's geographical areas.

\section{THE RESEARCH ON TERRITORIAL FRAGILITIES}

The arguments studied in this paper are a fragment of broader ongoing research on territorial fragility ${ }^{1}$ and, as a case study, the inland territories of the Italian Alps and Apennines. These areas $\left(\mathrm{SNA}^{2}\right)$ constitute about three-fifths of the entire Italian territory and have extremely different characteristics. For the most part they are vast natural landscapes, away from large urban centre and services. For these reasons, these "neglected" rural regions become "fragile" and the conditions of marginalisation are further intensified by hydrogeological or seismic risks.

Nevertheless, they are places of great potential where development by combining innovation and tradition is possible. These are the places where communities have historically expressed themselves through a different relationship between urban dimension and territory, but today they are "hidden" spaces even if they hold a precious cultural heritage (Arcipelago Italia, Venice Biennale 2018). In these territories, it is possible to recognize numerous lines, natural or anthropic, which have determined in the past - and still today - the territorial morphology and development. In particular, the historical traces are a vibrant document able to recompose the complex framework of physical and cultural, commercial and artistic,

\footnotetext{
1 The Department of Architecture and Urban Studies (DAStU) at Politecnico of Milan has been awarded 'excellence department' by the Italian Ministry of University and Research for the period 2018-2022. In these five years, the department has been exploring the complex and multiple phenomena that engendered processes of fragilisation of the relationship between space and society in the Italian inland territory. 16 post-doctoral fellows, 12 PhD students, groups of professors and scholars of international research centres, Italian administrative representatives are at work on the 'Territorial Fragility' project. The goal is to build methods and skills as a reference milestone on the fragility of inland areas in Italy and abroad.

https://www.agenziacoesione.gov.it/strategia-nazionale-aree-interne/; https://www.miur.gov.it/documents/20182/890263/ strategia_nazionale_aree_interne.pdf/d10fc111-65c0-4acd-b253-63efae626b19
} 
political and economic connections of the places. Reading their historical watermark means understanding their material and immaterial physiognomy deposited in the territory with visible signs (Cucinella 2018). These marginal areas link environmental and productive territory with smaller urban centres. Inside, new dynamics have taken over, which have stratified and produced irreversible transformations. However, the acceleration and breakdown of the coevolution nexus between man and environment has in recent years increased profoundly the environmental crisis, exacerbated by a more marked abandonment of entire portions of the territory. On the one hand, the anthropic crises lead gradually to the creation of dense congested territories where the development centres are concentrated. On the other hand, increasingly empty territories are produced, where the negative effects of abandonment are concentrated (Teti 2017). Hence there is an irreconcilable double speed; man (and capitalism) consumes nature faster and faster resulting in a slower pace of regeneration. Capitalism, therefore, undermines the foundations of its own development (O'Connor 1991; Severino 2003).

Climate change, loss of biodiversity, hydrogeological instability, abandonment of territories and depopulation, become the protagonists of the Italian inner areas. To these, a population decrease and increasing consumption of soil in the marginal suburban area must be paradoxically added (Pileri 2017).

Considering the inevitable profound changes related to the modification of environmental, economic, socio-cultural and migratory flows for several decades, the issue of territorial fragility has taken on relevance within the academic debate. We underline that the size of the phenomenon is expanding within the European territory (the internal areas of Italy, or regions of Greece, Portugal or Spain), but also to "remote" territories such as India or Bangladesh, although characterised by a different scale of the place and other historical-cultural dynamics.

Commonly, all of these territories are the less strategic places, far from the most extensive urban agglomerations in which most of the world population is today concentrated, the polycentric areas of the provinces and the marginal lots of the urban peripheries where social contradictions are more radical.

Since the economic crisis of 2008, the urban agglomerations have been the main object of studies, analyses and proposals to get out of the critical conditions. The opposite point of view, instead, aims at focusing on those places which have such underlying dynamics within them and are able to activate new propulsive courses of development. In light of the current dependence between environment, economy and society, the marginal areas determine unique actions of resilience which can inspire new transformations (Tognon 2016). They are the privileged places of experimental freedom, where innovation leads to emancipation (Carrosio 2019). Even though the aspects of marginal territories have been investigated, in regard to their characteristics of transformative energy, since the 80s (Osti 1985, Gubert 1983), the inevitable interest in seeking new fertile land is now shifting from a concept of wealth based on income to one based on quality of life, where innovative fervours establish a new model of society.

In the words of Bell Hooks (1991) in order to stop the perception of the margin as a residual area, the intrinsic geometric dynamics must be overturned and considered as a sphere in which the maximum design potential is deployed. Metaphorically, it is necessary to activate an overturning process between scenery and core, to configure itself in hybrid implications.

Working on marginal territories becomes strategic also for those central places where acceleration is pervasive. This practice implies identifying new models of sustainable development. The reactivation of these places involves a rewriting of the urban and territorial 
text where deletions and insertions of new writings have been made over time.

In a constantly changing reality, between concrete experience and collective vision, these places can activate virtuous processes of adaptation. In the following we will try to investigate how these processes can be increased by an overall rethinking of strategies in the light of Circular Economy principles.

\section{CIRCULAR ECONOMY: MEANING AND ORIGINS}

In the past decade, the concept of Circular Economy has become central in the future dynamics of new sustainable models for the economy. According to Ellen MacArthur Foundation, the Circular Economy is a restorative and regenerative model, relying on system-wide innovation. It aims to redefine products and services in order to design out waste and pollution and minimise negative impacts. The circular model builds economic, natural and social capital, keeping products and materials in use, and regenerating natural systems (Ellen MacArthur Foundation 2015). The concept of Circular Economy came up when the professors David W. Pearce and R. Kerry Turner - pioneers of the environmental economics - asserted that the traditional economy was not opened to recycling and the world economy considered the environment as a waste reservoir (Pearce and Turner 1990).

In the light of these paradigms, the Circular Economy model answers as "restructuring the industrial systems to support ecosystems through the adoption of methods to maximise the efficient use of resources by recycling and minimising emissions and waste" (Preston 2012).

The industrial environment becomes conceptually regenerative and reproduces nature, actively improving and optimising the systems through which it operates (Rizos et al. 2015). The ambition of the model is to break with the current "linear" economic rationale of taking, making and arranging, which is creating business value only for its participants (Lacy and Rutqvist 2015). On the contrary, the creation of the 'circular' idea of economy is a radical and brilliant concept. As Hobson (2016) reports, the Circular Economy disjoints a schedule of consolidated systematic relationships that have produced the "unsustainability" that characterises the linear and contemporary forms of global capitalism.

According to the literature (Ellen MacArthur Foundation 2015; Rizos et al. 2015), four main principles related to Circular Economy can be summarised: to decrease waste by considering reuse from the design step, using renewable materials and energy, analysing feedback step by step to optimise the whole circuit of the production system, sharing the products among more users and prolonging their life through regular reuse, maintenance and repair.

Circularity has in fact been the master principle of nature since the beginning (Stahel 2019), when molecules have been used, dismantled and reused in several cycles. This capability permitted the environment to change the internal conditions by growing biodiversity and to develop new states. This idea has shaped the "cradle-to-cradle" design methodology (McDonough and Braungart 2002). In the book "Cradle to Cradle (...)" the authors claim that in the circular model, recycling is seen as downcycling, involving energy processes that still leads to a "slow death". Moreover, the new products made of recycled materials are smaller in volume and lower in terms of quality than the original ones. The paradigms of $\mathrm{C} 2 \mathrm{C}$ create fundamental principles for industrial design. Firstly "waste equals food" means that in nature, one organism's waste provides nutrients for other organisms. The second principle classifies several sources of natural energy (sun, wind, waves,) as renewable energy which can be genuinely refilled, as opposed 
to "slowly" degraded sources or biomass commonly used for biofuel. In contrast, these sources of energy do not require the burning of biomass (Braungart 2013). The third principle involves understanding of natural biodiversity, addressing the knowledge of a healthy ecosystem. Drawing inspiration from ecological diversity, C2C underlines the importance of using local materials to create products congruent with the surrounding environment. Nature's diversity has become a model for increasing the positive effects on the local ecosystem (www.c2ccertified.org).

Consequently, the Circular Economy aims to create waste-free technical loops that resemble biological loops and make waste disappear at the same time as being restorative and regenerative by design. In these directions, the strategy adaptable by the UE to support the idea of sustainability is to improve the concept of repairability, durability and recyclability through product specifications. In this way, it is possible to control the potential planned obsolescence throughout the specific schedule, even created before the first existence of the object.

\section{RECYCLE VS REUSE}

In architectural and urban regeneration projects, multiple methodologies are required for the construction of strategic approaches. Defining new lifecycles, avoiding the tactic of recycling, down-cycle and linear economy, where the logic of programmatic obsolescence is fixed (Latouche 2012), means eliminating the "waste" - as a concept and physical element - during the design steps.

The concepts of "Circular", "Recycle", "Cycle of Life" are linked by common denominators. On one hand, the idea of circularity - the geometric circle - is assumed both as a process and a characteristic of what is - precisely - circular. On the other hand, the concept of cyclic nature is the character of what returns, that has no beginning and no end, escaping the idea of linearity and tending to the geometric circle. However, these terms present significant differences when their use, in economic disciplines and social practices, takes shape and assumes the role of a paradigm capable of defining a sphere of actions animated by specific principles and purposes. In particular, between the "circular", proper to the economy, and the "recycling", proper to effective practices, it may perhaps be said that the two terms are, in substance, opposed. (Bovati, Cozza 2014)

As we already mentioned, the concept of Circular Economy is inspired by the observation of nature, which is based on closed cycles and can reintegrate waste into new processes, without using additional energy and eliminating junk production. Two seminal books set the theme: "The Closing Circle: Nature, Man, and Technology" (Barry Commoner 1971) defined the postulations, and the already mentioned "Cradle to Cradle: Remaking the Way We Make Things" (McDonough and Braungart 2002) figured out its application to the design field. These were followed - in addition to the definition of the principle - by a series of essays showing its possible applications to different fields of human action.

Conversely, "recycling" is a practice - even virtuous - which is based on the transformation of waste to reuse it for purposes even very different from the original. Recycling implies two aspects: the existence of waste - as a base material for the transformation action - and the wasting of significant amounts of energy to be used in transformation processes. Also, the result is the creation of objects planned for a fairly short life cycle, until their consequential return to the sphere of garbage (unless significant efforts of energy are invested for further recycling). This is considered a linear type of process, even though the "cycle" concept is contained in the word. 
For this reason, we quote Circular Economy and Recycling as opposites and antithetic. The first is aimed at eliminating the precise idea of waste and, contrariwise, the second needs waste to build an admittedly linear process, rather consistent with the mechanism of planned obsolescence (Latouche 2012). Paradoxically, the more virtuous recycling is, the more it belongs to the economy of uncontrolled consumption, offering partial solutions to the waste problem.

Therefore, reuse is preferable to recycling, in other words it is the idea of being able to give new meaning and new use to objects, preserving them as much as possible in their original form, without great transformative efforts, if not minimal maintenance. In this context, the importance of design appears evident, a crucial moment to define their form and therefore, the actual possibility of reuse.

\section{CIRCULAR ECONOMY, ARCHITECTURAL DESIGN AND URBAN REGENERATION}

In the debate between the urban regeneration process and the principles of Circular Economy - as synergies for promoting resilience, creativity and sustainability - we move the concept from a sectoral approach (waste management, etc.) to the whole organisation of the city. Accordingly, the circular process invests the economy, social system and governance to improve the whole urban productivity (Fusco Girard 2013).

As specified in the "New Urban Agenda" (United Nations 2016), the Circular Economy model appears as a radical approach to control the existing resources such as land, water, energy, materials and food, and the key to solving the problems connected with greenhouse gases emission and air pollution. In the architectural field, it is crucial to evaluate the environmental impact and sustainability of new architectures, and the common aims are the evolution to a Circular Economy facilitating ecosystem conservation, restoration, regeneration and resilience in the face of new challenges emerging. In particular, the Circular Economy paradigm can play a virtuous role according to urban heritage conservation principles (Ellen MacArthur Foundation. Cities in the Circular Economy: An Initial Exploration. 2017). Opening the circular model to the urban context, the paradigms of leasing, reusing, repairing and recycling, are switched from a precise heritage vision to an overall historic urban landscape evaluation (Bandarin, Pereira 2019). The Historic Urban Landscape (HUL) approach promoted by UNESCO (Unesco. Recommendation on the Historic Urban Landscape, including a Glossary of Definitions, 2011), emphasises the systemic interrelation between the economic, human natural and cultural capitals and the inherent complexity of any intervention aimed at transforming the urban setting.

In the light of the discussion about fragile territories, the historical layering of cultural and natural values, beyond the notion of an urban centre to include the broader context and natural surroundings, becomes crucial. Looking at the Italian territory, since the 70's, some examples of regeneration projects can represent a new approach of reactivation for villages and their surrounding territories. A set of (re)enhancement actions carried out in contexts characterised by processes of territorial fragility (e.g. depopulation, hydrogeological risk, seismic, etc.), and by heritage landmarks - even minor - are taken as a reference framework. The context scale goes from the group of buildings to the largest settlement, not focusing on the single building but working on a medium scale, which allows rethinking the design of the built and open space in symbiosis.

From these starting conditions, some specific cases seem significant enough to be mentioned along with this paper, even if they are not considered best practice tout court, or may be implemented.

Some practical interventions for the spatial, economic, settlement recovery, requalification 
and re-launching of minor towns in the Italian inland are significant examples to quote. An essential factor to be underlined is the upgrading modality for relaunching, which involved individual villages or landmarks ("points action"), creation of paths, which relaunch a territory ("lines action") and physical or thematic reticular relationships ("grid action") (Bonfantini 2016).

Following this classification, among the specific interventions, we can cite some of the several cases that since the 70s have seen tourism as a possible strategy to reactivate the territory, in particular abandoned historical centres known for their architectural beauty.

Through the practice called "Albergo Diffuso" villages such as Montegridolfo, Civita di Bagnoregio, Santo Stefano di Sessanio, have been involved in restoration and conservation project for hospitality purposes. This prototype has led to the dissemination of this practice in ever more numerous contexts.

The same example was followed by the "ecovillages", the artists' villages, which were created following the enthusiasm for new "communities of practice" and new lifestyles. This is the case of Craco (Calabria), which has been revitalised for cultural and creative purposes. The regeneration of the abandoned town of Colletta di Castelbianco (Liguria), started in the 90 s by Giancarlo De Carlo, becomes even more emblematic for the creation of a community of remote workers thanks to the creation of an IT network. This case should be emphasised as a precursor for possible solutions for the health crisis.

There are also examples that have focused on economic and social aspects, such as Riace, which has seen an interesting relaunch through a significant process of social integration of foreign ethnic minorities, a problem of particular importance for the Italian territory.
A similar approach follows the linear regeneration strategies, which are based on the construction/recognition of cultural values through routes and itineraries, where the path is related to specific elements (e.g. the vineries' roads, the abandoned railways, ...) It must be assumed that the issue of the abandonment of villages - till the final stage as a ghost town - and territories is the result of economic, social, and cultural reasons of a region in its complexity and is linked to largescale political problems.

However, the above paradigmatic typologies represent a starting point from which to build new regenerative strategies, while not fully responding to the idea of intervention consistent with the CE paradigm.

\section{OVERTURE: REUSE OF ABANDONMENT SITES}

The fundamental difference between the examples of reuse observed above and the cases cited from the past is that the latter are not the result of an intentional reuse project, but an intrinsic and spontaneous practice. The challenge for the present and the future is to understand how to design a circular process of reuse today for tomorrow.

Therefore, in the scenario described up to this point, the theme of "Design for Reuse" seems to play a central role; the design phase should lay the grounds for possible reuse and for extending the life of the building. This idea is not close to the concept of generic flexibility, but should tend to come closer to an idea of resilience ${ }^{3}$ and adaptivity $^{4}$ of the architectural form. Indeed, if designed with attention to the specific qualities of the very space that gives an identity to it, architecture makes it easier to reuse, and uses it better, even after having fulfilled what it was created for.

\footnotetext{
${ }^{3}$ Adaptive: capable of adaptation, which is able to adapt.

${ }^{4}$ In psychology, resilience is a concept that indicates the ability to cope positively with traumatic events, to reorganise one's life positively in the face of difficulties, to rebuild oneself by remaining sensitive to the positive opportunities that life offers, without alienating one's identity. (Cit. Wikipedia) In architecture, the translated sense of resilience could be understood as the ability of an architectural organism to be reorganised in the face of a sudden change of purpose and function, without alienating its own identity.
} 
As already mentioned, recycling derives from the necessity to invest a great deal of energy to ensure a new lifecycle as a result of complex transformations. Reuse, on the other hand, is understood as the ability of things to satisfy different purposes, allowing for multiple uses during their life, without entailing high costs that would nullify the overall ecological balance of the process.

This justifies giving priority to the concept of reuse because it takes root in the principles of Circular Economy, which maximise the intensive use in the life of things. Moreover, it is suitable with two of the "3R" (ReduceReuse), and with the need for separation between biological and technical flows. A first practical indication should go to the proposal of creativity through scarcity or "Bounded design", in analogy with the concept of "Bounded rationality" (Simon 1957). Moreover, technological efficiency, building architectures and spaces characterised to identity, quality and a good capacity to settle in the collective consciousness has to be guaranteed. In this way, they can become an active part in the composition of the urban landscape, and be equally adaptive at the same time (i.e. able to lend themselves to different uses without massive transformation or refurbishment costs).

Faced with the objectives implied by the theme formulated, further development of research is represented by the idea that the principles of the Circular Economy can become an integral part of the design process, also and above all, in contexts characterised by phenomena of territorial fragility and architectural heritage, for which reuse processes will begin hopefully. In the end, the question of materials, construction techniques and restoration methods returns, but this is part of a larger scenario in the regeneration processes.

\section{WAY FORWARD}

Declination of the abovementioned principle in the architectural field, and in particular of the design approaches on heritage, must necessarily deal with the degree of transformability of the existing artefact, with its scope of reuse, with the conditions of the buildings, and with the level of obsolescence and the degrees of constraint.

The design of new buildings, as well as redevelopment of existing ones, should be grounded in a thinking form capable of forecasting successive life cycles. This can be achieved, considering the requirement of finding the technical and waste management responses side by side. Furthermore, it is required to translate the paradigms of the Circular Economy both technologically (from performance quantity to spatial quality) and on a scalar level (from the architectural artefact to the set of buildings).

Along with this thought, there is a significant theme linked to the typological and spatial redevelopment of buildings and open spaces. The ambition of this thesis is that the reuse tactics can preserve the heritage elements on which design strategies are being applied.

However, at the same time, it is necessary to establish transformative practices and design processes which define future scenarios at different scales of fragile contexts, opening the theme of sustainability to the paradigms of circularity.

First, a poor definition of spatial qualities and cultural identity creates low architectural value in the artifact as a consequence, and a weak capacity to take root in the community, resulting in its death as the first life cycle ends. Otherwise, a valuable architecture, designed with great observation to spatial qualities, can easily be "inhabited" for a long time, with uses similar or not to the original. Indeed, we are conscious that it will not be adaptable to all functions, but we must ask ourselves whether 
generality, or even neutrality, is the necessary condition for a long-term architecture. Historical experience shows us something different. A house, well designed, can easily be converted to similar uses and for a very long time, adapting - as many architectures of the past - to the social and spatial changes that affect the theme of the residence, office space, the institution building and so on. The same could be considered for a public building, a museum, a school, a barracks or a hospital.

Secondly, materials and construction technologies can have expensive maintenance processes. The typologicalspatial qualities, the value of the work and its role in the relationship with the city, will determine its conditions of survival. A low valuable building commonly imposes a maintenance process much more expensive than a simple demolition and reconstruction. On the other hand, a valuable architecture, designed for being reused, will incorporate the circular principles into the project solutions.

Therefore, we want to stress that we are not talking about material cycles, with their degradation, partial or integral substitutability, but we are underlining the functional cycles. This interpretation on conceiving a new life for abandoned places puts within the scope of Circular Economy the spatial, formal, and functional aspects of architecture, as part of a strategy that embraces the topics of temporality and durability of the building. Durability, linked to the architectural value and role, is the key that sets specific conditions for sustainability: lasting over time is a consequence of building quality, as well as the cost of its maintenance. The characteristics of typological and spatial design - linked to the value and urban role of a building - and technological and structure - conditions of costs and durability - are inextricably linked. They combine a scenario in which architecture is merged with the principles of circular economy, according to a complex system of factors. 


\section{REFERENCES}

AAVV. 2017. Aree Interne. Per una rinascita dei territori rurali e montani. Soveria Mannelli: Rubbettino.

Bandarin, F., Pereira, A. 2019. Reshaping Urban Conservation. The Historic Urban Landscape Approach in Action. Berlin: Springer.

Bateson, G. 1972. Steps to an Ecology of Mind, New York: Chandler

Bonfantini, B. 2016. Attivare risorse latenti. Metodi sperimentali per l'analisi, la mappatura e la gestione informativa integrata delle trasformazioni di territori e manufatti del patrimonio culturale diffuso. Roma-Milano: Planum Publisher.

Borghi, E. 2017. Piccole Italie. Le aree interne e la questione territoriale. Roma: Donzelli Editore.

Bovati, M., Cozza, C. 2014, "Cycle vs Re-cycle”, in: Marini, S., Rosselli, S. C., Op-position 1, Quaderni Re-cycle 6, Roma: Aracne Editrice.

Braungart, M. 2013. Waste to energy. https:// www.catalystreview.net/2010/02/cradleto-cradle-transitioning-from-wasteincineration-to-beneficial-materials/ [accessed on 09.02.2020]

Carrosio, G. 2019, I margini al centro. L'ttalia delle aree interne tra fragilità e innovazione, Roma: Donzelli Editore.

Cucinella, M. 2018. Arcipelago Italia. Macerata: Quodlibet.

Ellen MacArthur Foundation (2015), Growth within: a circular economy vision for a competitive Europe, www. ellenmacarthurfoundation.org [accessed on 17.02.2020]

Ellen MacArthur Foundation. Cities in the Circular Economy: An Initial Exploration. 2017. Available online: https://www. ellenmacarthurfoundation.org/ publications/cities-in-the-circulareconomy-an-initial-exploration [accessed on 28.02.2020

Ferracuti, A. 2016. Addio. il romanzo della fine del lavoro. Milano: Chiarelettere.

Fusco Girard, L. 2010. "Sustainability, creativity, resilience: toward new development strategies of port areas through evaluation processes". International Journal of Sustainable Development, vol. 13, n. 1-2, pp. 161-184.

Fusco Girard, L. 2013. "Toward a smart sustainable development of port cities/ areas: The role of the "Historic Urban Landscape approach". Sustainability, vol. 5, n. 10, pp. 4329- 4348.

Gubert, R. 1983. Ruralità e marginalità. Tre aree alpine a confronto. Milano: Franco Angeli.

Hobson, K. 2016. "Closing the loop or squaring the circle? Locating generative spaces for the circular economy". Progress in Human Geography 40 (1): 88-104.

Hooks, B. 1991. Elogio del margine. Milano: Feltrinelli (1998).

ICOMOS 2011. Guidance on Heritage Impact Assessments for Cultural World Heritage Properties

Lacy, P. and Rutqvist, J. 2015. Waste to wealth: The circular economy advantage. Basingstoke: Palgrave Macmillan.

Latouche, S. 2012. Bon pour la casse: Les déraisons de l'obsolescence programmée. Paris: Les liens qui libèrent.

McDonough, W. and Braungart, M. 2002. Cradle to Cradle: Remaking the Way We Make Things, New York: North Point Press.

Meloni, B. (Edited by). 2016. Aree interne e progetti d'area. Torino: Rosenberg \& Sellier.

O'Connor, J. 1991. "On the two Contradictions of Capitalism", in Capitalism Nature Socialism, II, 3, pp. 107-9.

Osti, G. 1985. "L'imprenditorialità marginale in un'area agricola alpina". in Sociologia urbana e rurale. 16. pp. 131-46 
Pearce, D., Turner, R. K. 1990. Economics of natural resources and the environment. Baltimora: Johns Hopkins University Press.

Pearce, D.W., Turner, R. K. 1991, Economics of natural resources and the environment. American Journal of Agricultural Economics 73(1).

Pileri, P. 2017. “Persistente ed inefficiente: così è il consumo di suolo nel Paese". in Ispra. Consumo di suolo, dinamiche territoriali e servizi ecosistemici. Edizione 2017. Roma: Ispra. pp. 160-1.

Preston, F. 2012. "A Global Redesign? Shaping the Circular Economy". Chatam House Briefing paper, n. 2, pp. 1-20.

Rizos, V., Behrens, A., Kafyeke, T., HirschnitzGarbers M. and Ioannou A. 2015. "The Circular Economy: Barriers and Opportunities for SMEs". CEPS Working Document, n. 412, pp. 1-22. Rockström, J., Klum M. 2015. Big World, Small Planet. New Haven: Yale University Press.

Severino, E. 2003. Tecnica e architettura. Milano: Raffaello Cortina Editore.

Simon, H. 1957. "A Behavioral Model of Rational Choice", in: Simon, H. Models of Man, Social and Rational: Mathematical Essays on Rational Human Behavior in a Social Setting. New York: Wiley.

Stahel, W. I. 2019. The Circular Economy: A User's Guide. Abingdon: Routledge. Talamo, C., Migliore, M. 2017. L'utilità dell'inutile. Santarcangelo di Romagna: Maggioli.

Teti, V. 2017. Quel che resta, Litalia dei paesi, tra abbandoni e ritorni. Roma: Donzelli Editore.

Tognon, A. 2016. Architetture attraverso il tempo. Progetto, memoria, trasformazione. Phd Thesis in Architecture and Urban Design, XXVII cycle, Politecnico di Milano. Unesco. Recommendation on the Historic Urban Landscape, Including a Glossary of Definitions, 2011. 



\title{
PAPER \#3.07
}

\section{BINCKHORST: A PALIMPSEST OF ARCHITECTURAL LIVES}

\author{
Angeliki Siolia, Willemijn Wilms Floet ${ }^{a}$, Pierre Jennen ${ }^{a}$ \\ aDelft University of Technology, Delft, Netherlands
}

\section{ABSTRACT}

Engaging the example of the course "Binckhorst: A Palimpsest of Architectural Lives"-a master level design studio-this paper addresses issues of cohabitation and coexistence between past and current actors, activities and programs in Binckhorst, The Hague. It discusses explorative methodologies of analysis and design, that aim to create innovative and anchored urban interventions for the transformation of post-industrial landscapes. Binckhorst is an exemplary case-study to this regard. Home to a 14th century Castle, a 1920s cemetery, 1950s-60s heavy industry buildings and empty offices, postmodern housing projects and contemporary refugee settlements, it currently witnesses an accelerated change. Small-scale creative industries, event venues and apartment buildings transform and redefine its architectural identity. Moreover, Binckhorst's strategic location next to the city's center and a major train station, has attracted the interest of local and international architects, planners and developers.

The course "Binckhorst: A Palimpsest of Architectural Lives" engages the students with this rich context and guides them to develop design methods where the old and the new can be actively part of the area's new blooming. Through innovative site analysis assignments, personal interactions with the area's actual actors, careful and in-depth study of the Binckhorst's heritage, a precise selection of The Hague housing typologies, and the employment of bottom-up design methodologies, the studio advocates for a pedagogical approach in which the knowledge acquired from the analysis informs every step in the design process. The studio follows a structured sequence of three phases: "Description," "Transcription," "Prescription" (Havik, 2014) ensuring the constant interweaving between analysis and design. It culminates in a big-scale housing project that needs to incorporate the area's past and present layers and suggest architectural propositions that envision a future for the co-existence between the old and the new.

A thorough presentation of the studio's theoretical context, the methodological framework, the topics and parameters of investigation along with selected student's examples, will unpack in detail the pedagogical topics addressed by this studio and suggest possible courses of action for architectural education.

\section{KEYWORDS}

Post-industrial landscape; typology; lived space; urban analysis; urban literacy.

\section{INTRODUCTION}

Scope of this paper is to discuss and analyze a pedagogical methodology for design in post-industrial urban areas. As an educational approach it partakes from the philosophical and architectural discourse that values place, the lived experience of this place, and the place's local characteristics both at the scale of the site and the city. It advocates that, although the globalization and digitalization of everyday life has led to 
less place-bound architectural practices or human interactions, "getting back into place"1 is a crucial position for a meaningful and longterm revitalization of urban landscapes. As a pedagogy it guides students to investigate the richness embedded in a given topos (place) and include in their work its actors, users, prevalent culture and underlying history in order to ensure that old and new spatial conditions can interact creatively and prosperously. This pedagogical methodology is implemented and examined in the case study of a studio course-taught during the fall semester of 2019-that challenged students to imagine the revitalization of Binckhorst. Binckhorst is a post-industrial and rapidly transforming area in the city of The Hague, Netherlands, where historical, cultural and social elements have impressed a strong mark on space. The studio consisted of twenty (20) international master level students, and was taught simultaneously by two architectural instructors and one building-technology instructor. We, as instructors, met the students for in-person education a whole day (eight hours) once a week, during the course of twenty (20) weeks. In these weekly meetings selective guests ran short workshops (on topics like narrative techniques, circular economy, comfort and discomfort in architecture) and offered constructive feedback as the students were developing their work. In between the weekly meetings the students were instructed to follow specific lectures in relation to the topics under examination, offered by the Faculty's Lecture Series, while also conduct site and bibliographical research. Through the specific case-study we wish to discuss explorative approaches of analysis and design, that aim to create site-specific and experience-anchored urban interventions for housing programs. Instead of advocating for the replacement of the industrial business- as often happens under the pressure of the housing market-we asked the students to develop projects that ensure the co-existence of new and existing programs in the place. Aligned with the conference's thematic, "The new faces the old," the studio led to design proposals where "the different physical and cultural layers that have built our cities can live together in harmony." In short, "Binckhorst: A palimpsest of architectural lives," invested in a close and multilayered reading of place, proceeded with imaginative and unconventional interpretations of this reading, and culminated in a housing design project that negotiated the creative interweaving between existing and new spatial relationships.

\section{THE CASE STUDY}

\subsection{The intellectual context}

In developing the studio, we took the freedom to explore and combine two main positions in relation to place: a typological (formal, artifact centered) and a phenomenological (linguistic, human centered) one. Both positions question the notion of place and place-making in developing meaningful, site specific projects, although starting from what appear to be two opposite ends. Following the Italian historian Giulio Argan, we believe that an exploratory and analytical study on typologies-designed and built according to a determined architectural position-could be an important step in the development of new types in relation to the characteristics of a given place. The emphasis is not on copying the past, but rather on finding ways to carefully maneuver between the richness of architectural historical knowledge and contemporary spatial questions (Argan 2007, 157). Based on a similar approach, architectural 
theoretician Antonio Monestiroli argues that a design project should combine communal and continuous general characteristics, with the specificities related to given site conditions (Monestiroli 2005, 32). Including in the analysis the notion of typology, offers the opportunity to organically anchor a new project in an existing city, which is another way to address the project's sustainability and longevity. Engaging further the discourse on place, our studio followed a phenomenological and experiential connection to place; an emphasis on how space is actually lived by its users and experienced by its inhabitants. Henry Lefebvre and his notion of "lived space," as unpacked in his seminal work The Production of Space, urges us to focus on the dimensions of space that can be heard, touched, seen and even smelled: to study spaces as they are lived. In other words, to question what role spaces play in the lives of their users and inhabitants, how space features in their thoughts, minds and memories (Lefebvre 1974, 84). Juhani Pallasmaa has expanded this philosophical thinking into architecture, through his homonymous essay "Lived Space: Embodied Experience and Sensory Thought." Pallasmaa discusses the importance of sensorial perception of place, the role of the body in space, and of course the fact that "lived space is structured on the basis of meanings and values reflected on it by the individual or groups" that inhabit it (Pallasmaa 2005, 129). Theoretician Alberto Pérez-Gómez, following this phenomenological tradition, furthermore warns us that architecture nowadays cannot be blindfolded by technological or engineering demands, without a careful connection of these demands to lived place. In his most recent work Attunement: Architectural Meaning After the Crisis of Modern Science he specifically argues that:

Ecologically responsible buildings and sustainable cities do not in themselves connect us to a meaningful life; (...) The issue is cultural sustainability, our ever-sought ambition to peacefully co-exist with others on a shared living planet (Pérez-Gómez 2016, 232-233).

This observation is of particular value to our educational approach, as our architectural studio had a pedagogical particularity. It was taught simultaneously by both architectural and building technology professors, bringing into the conversation questions of construction, structure, environmental issues and environmental impact from the very beginning. The interest in sustainability and circularity, a big conversation in architecture nowadays, was an important element of the studio, but it was discussed within the theoretical context unpacked above and in which the studio was based.

\subsection{The physical context}

Binckhorst is a rough and non-curated palimpsest of distinctively different architectural buildings and identities. Its historic 14th Century Castle-the very first building of the area-functions currently as a plastic surgery clinic. A 19th Century gas factory, which heavily polluted the soil during its operation, is now transformed into a workshops-lab. Modern structures of glass and metal have been added to accommodate the growing needs of a 1920s cemetery. The 1950s-60s heavy industry buildings and offices are re-appropriated by small scale creative industries, often run by people with a special commitment to the area and its community. Postmodern office buildings converted in housing projects are adjusted (many times by the owners themselves) to accommodate a 21st Century lifestyle. The former landmark aircraft-production school is transformed into a social-events venue, without changes to its exterior façade. Printing industries and former government services have left the site and the buildings they used to occupy remain empty. Automobile businesses, with a long presence in the place, continue functioning, along with many building-construction firms. A garbage 
collection center covering the needs of the city of the Hague-and emitting a strongly unpleasant smell around it-along with several recycling firms are fully functioning on a daily basis. Refugee settlements are added in between all the above programs, while at the same time many big vacant plots attract the interest of local and international architects, planners and developers. The area's strategic location close to the city's center and the country's national agenda for the addition of 1.000 .000 homes until 2040, are the main reasons behind the strong renewed interest in the Binckhorst. This rich, almost surreal, conglomeration of architectural and cultural identities, is surrounded by water canals, as water in the area (and the country in general) is still used both for industrial and recreational purposes.

\subsection{The educational context}

Framed within the theoretical context already presented above, the aim of our studio was to develop new housing-typologies with interconnected social programs, so as to transform the post-industrial Binckhorst into a sustainable, high-density, mixed workingliving environment. To this end, the studio asked the students to address four main questions:

1. What kind of housing typologies and which public programs are needed for the future of Binckhorst?

2. How could existing industrial buildings get incorporated into new design interventions?

3. How can the new Binckhorst transform into a sustainable (circular) and inclusive society, becoming also an integral part of the city of The Hague?

4. What would the new identity of the area be?

The intention of our studio was to work towards a culturally and environmentally sustainable future urban Binckhorst, through an educational frame that urged students to take a clear position in a pressing contemporary problem, encountered in many urban environments around the world.

\section{METHODOLOGY}

Given the focus on the local character of place, the interest in a phenomenological approach to architectural design and the urban nature of the area of study, we valued relevant to experiment with the pedagogical methodology proposed by architect and educator Klaske Havik in her book Urban Literacy: Reading and Writing Architecture (2014). Havik's work synthesizes creatively many of the theoretical positions that have formed the core of our pedagogical philosophy. Her ideas emerge from the notion of Lefebvre's "lived space," touch on phenomenology and prioritize place and local particularities, like typology, atmosphere and narratives. The book suggests a methodology based on three consecutive modes of action: "Description," "Transcription," and "Prescription". These were the modes we followed in structuring our studio.

\subsection{Description}

Emerging from the definition of the very verb describe (...), Havik reinforces the conviction that "to be able to describe, be it in text or in drawing (...), one has to be able to observe, and to perceive an object in all its complexity" (Havik 2014, 38). To understand spaces and places, "and to understand how we 'live' them, one should start by closely observing them, by identifying their spatial characteristics, as well as their atmosphere and the activities and trajectories of their inhabitants" (Havik 2014, 38). Our Binckhorst studio emerged indeed from a systematic and meticulous study of place. ${ }^{2}$ Through dedicated weekly assignments the students explored the history of the area's

\footnotetext{
${ }^{2}$ The area was specifically chosen because it could be easily accessible by the students any time during the semester.
} 
development, the history of its architecture, the place's physical elements and materiality, the immaterial characteristics and the prevalent atmospheres. The assignments were designed to cultivate the students' observational as well as creative skills. Observations and analysis about Binckhorst had to be synthesized in imaginative and creative ways to be communicated in class. Engaging the place's history for example and examining old habits and customs that influenced space and its appropriation, the students experimented with drawings that like palimpsests incorporated aspects from different time periods. Elements and activities from the past appeared in different and complementary directions on the same surface, literally layering on the same drawing many different temporalities (Fig. 1).

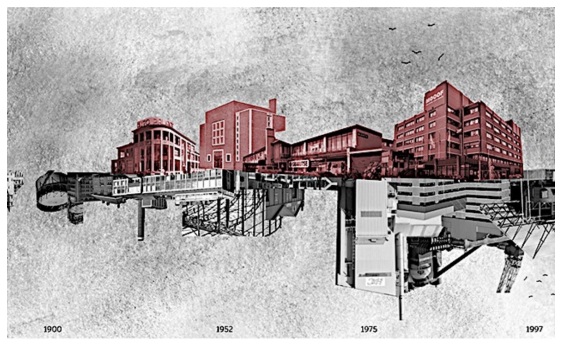

Figure 1. The different temporalities of Binckhorst. Source: (Aga Kús 2019)

Mapping activities captured physical and immaterial elements of Binckhorst, as they appear interwoven in the real experience of lived space. The students proceeded with hard and soft mapping pairings in order to communicate the atmospheres that some of the physical spatial elements impress on the area. How do specific programs create vibrant environments around them for example? How do social networks (that is a non-architectural element) appear and transform space? Examples on urban and architectural mapping and readings on the topic deepened students' comprehension on the nature of these assignments. Precedent studies both through drawings and in-situ visits led to a deep knowledge of apartment typologies with a long history in the city of The Hague. Conversations with the current inhabitants and recordings of their activities and social interactions further enabled a close reading of the Binckhorst. Building-technology exercises on circularity and sustainability pointed out the current difficulties of the area and the possibilities for improvement and change. Each week the findings of the different explorations on "Description" were discussed extensively in class and shared among all the course participants. At the end of the "Description" stage the group compiled a collective Binckhorst Atlas, to be used as a formative guide throughout the following stages.

\subsection{Transcription}

Following the mode of "Description," Urban Literacy focuses on the use and social parameters of a place. It introduces the mode of "Transcription". This methodological stage "departs from the observation that architecture is influenced by social practices, and that even so, architecture, by giving space to people's environment, has its influence on social behavior" (Havik 2014, 93). Based on" the commonly used meaning of transcription as 'to write a version of something,' or 'to write in different medium; transliterate,' (Havik 2014, 94) Urban Literacy discusses the necessity of literary strategies for architectural design. How can narratives for example help us feel what it means to be in the place. The importance of narratives for architecture has in recent decades been argued for by many architectural educators. ${ }^{3}$ Professor Anca Matyiku in her article "Architecture Drawn Out of Bruno Schulz's Poetic Prose" for example, starts from the observation that architectural design is an act of fiction (exploring fictive possibilities that eventually condense into built environments)

${ }^{3}$ For more see: Sioli, A., Jung, Y., 2018. "Introduction," in Reading Architecture: Literary Imagination and Spatial Experience. New York; London: Routledge 
and proves with her work how fiction, narrative, literary and poetic constructs can be valuable tools in the creative process that leads to architecture (Matyiku 2018, 114-115).

With these theoretical underpinnings guiding the stage of "Transcription," we proceeded with a three-week assignment titled "The Many Narratives of Binckhorst." We experimented with literary techniques to imagine people's interactions and inhabitants' activities in the area. We asked the students to write narratives that explore how it feels to inhabit one of the buildings in the area. We asked them to "inhabit" their precedent studies and produce architectural drawings that emphasize the elements they captured with their narratives. We encouraged them to work with graphic novels and story boards that investigated daily rituals and habits in space.

Concluding this stage, we asked the students to imagine and work with fictional characters. In groups of four, the students had to conceive of three characters at the figurative scales of $1: 20,1: 200$ and 1:2000. The first character (scale 1:20) had to be someone with limited social interactions in the area, an inhabitant knowing approximately twenty (20) neighbors. The second character (scale 1:200) had to interact with approximately two hundred (200) people in Binckhorst (being the owner of a small bar or a small industry for example), while the third character had to be someone who interacts with approximately two thousand (2000) people in the area (like a city counselor that works on the current transformation of Binckhorst or an artist with an active Instagram account for workshops and performances in Binckhorst for example). Departing from these characters and their individual storieswhich the students imagined, wrote, revised and shared with their peers - the assignment culminated with the creation of a device that propagated random and unforeseen interactions among these characters-as is usually the case in real life. The example of "Binckhorst's Wundercamera" was one of these devices. The group of students, inspired by the idea of a wundercamera, a box of wonders, created a box with slides. The slides included information based on four categories: stories and habits of the characters, slides with historical moments of the area, slides capturing characteristic landmarks of Binckhorst, and slides with atmospheric aspects. Random and spontaneous arrangements of the various slides could lead to new interconnections and activities in place. The "Binckhorst Wundercamera" was an open-ended device, as the students' intention was to add new slides in the future (following the rapid transformation of Binckhorst) or remove existing slides if they were not capturing the identity of the place any more (Fig. 2). With the stage of "Transcription" completed, the studio moved to the third and last mode, that of "Prescription".

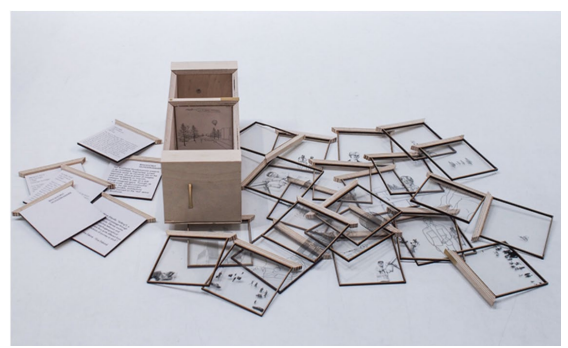

Figure 2. Binckhorst's Wundercamera. Source: (Rachel Mein, Chloë Oosterwoud, Sofia Pavlova, William Shaw 2019)

\subsection{Prescription}

"Prescription" was meant to lead to a design with a critical position for the future of Binckhorst. As Havik points out, "prescription can be translated as 'to write before', thus to outline the contours of a not yet existing spatial reality-this is, to imagine a future reality" (Havik 2004, 149). Though, an important point needs to be clarified here. "Prescription," as she says should "by no means be understood as a recipe of which the effect is already known-on the contrary, precisely the unknown character of a future 
world is at stake here" (...) grounded on the delicate balance between reality and imagination, and the possibility of taking a critical position (Havik 2014, 149-150). Indeed, the studio asked for a critical position towards a project incorporating housing and social programs in the area. No more requirements were added, apart from the constant reminder to learn from and build on the knowledge acquired during the analysis stages. Students were required to combine living with programs and activities they thought appropriate for the place, necessary for its future, and related with its current condition and its inhabitants. They had to design apartments for life-styles connected to the revitalization of the area, while also inspired by the existing architectural housing typologies. The students had to select the location of their project in Binckhorst as no plot was specified by us, they had to decide on the number of apartments and houses they thought appropriate to add with their project, they had to advocate for the necessity of additional programs in the area, and they had to demonstrate how and why their proposal is appropriate for the existing character of the place and can lead to a sustainable future. The final proposals varied from apartment buildings with urban farms, educational programs, libraries, community centers and commercial activities.

\section{OUTCOMES}

\subsection{Sitopia: A slow food commune}

Student Sofia Pavlova studied in detail the distribution of food in Binckhorst during the mode of "Description." She discovered that many social and impromptu interactions happen during lunch time, in ways that influence the development of the area. Many urban furniture appears in Binckhorst to facilitate eating together (from benches to urban picnic tables) and many small and bigger restaurants start occupying former industrial buildings. The area's existing buildings also prioritize eating, and many new firms incorporate big open kitchens in their offices. During the "Description" mode, she also studied the communal living in the famous hofjes (courtyards surrounded by small private residences usually for older women) of the Hague. Moving to the "Transcription" mode she studied the movements of "Slow Eating" and the many emerging urban farms, around cities of the world. She created imaginative narratives anchored around the social aspect of eating. As she proceeded with the "Transcription" she advocated for the necessity to "gather more around the table, as a community, as neighbors, as citizens." She worked towards the creation of a sitopia, a word inspired by the Greek words oitos (sitos), which means crop, and тónоs (topos), which means place. Her project touched on the many communal activities witnessed in the area, and the emergence of a group of young professionals who prioritize a healthy life style, value access to fresh ingredients and are committed to understand how food is produced and consumed. Her final design project, which emerged from the re-appropriation of an old industrial building, consisted of an apartment complex by the water front, combined with a program for fish farming, vegetable cultivation and poultry growing (Fig. 3). Her building was designed to provide fresh food for the immediate dwellers but also bring together the broader community of the Binckhorst and the Hague through seminars on food education and hands-on workshops on cooking. The emphasis on the social aspect of food, guided also the design of the apartments. The dwelling units were designed so that movable divisions could open up-according to the inhabitants will-the individual kitchens to the building's communal areas, allowing for neighbors to literally cook together while they inhabit their apartment. Moreover, two main atria-where the main vertical circulation takes place-were 
designed to allow the sharing of food and "coming around the table" opportunities for the community of the building. Thus, the project suggested a new future for the area, based on the lively social network of the neighborhood it was located, the possibility for low energy fulfillment of many of our daily needs, the care for circularity and the interest in a lifestyle much more communal and social.

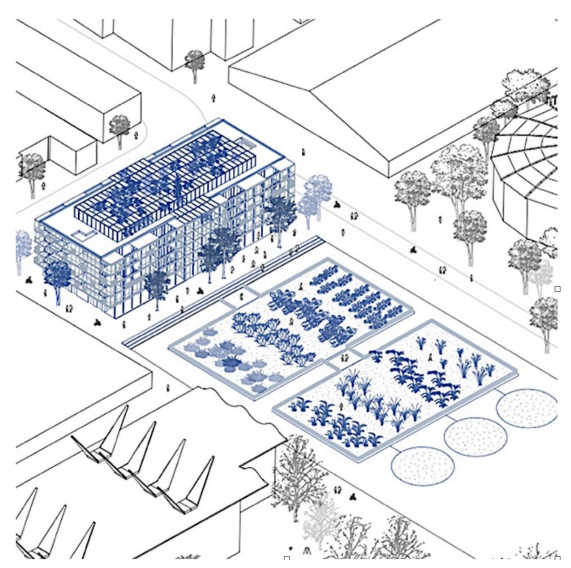

Figure 3. Sitopia in Binckhorst. Source: (Sofia Pavlova 2020)

\subsection{Making the Living: Hybrid high-rise}

Maarten van Blokland developed an unconventional proposal emerging from a critical and radical position on Binckhorst's current transitional phase. As he observed during the stage of "Description," the existing small and medium scale entrepreneurs and industries-which produce goods and offer services for the wider area of The Haguerun the risk to disappear from the area. Developers and investment companies seem to aim for high-rise apartment buildings for the future of the Binckhorst, as a way to cover the high demand for housing. While working on the "Transcription" phase, Maarten created characters based on interviews with many professionals in the area. That led him to suggest a radical co-habitation of living and working environments. His design proposal advocated for the absolute extinction of commute time and space, by creating highrises that bring apartments and workshops next to each other (Fig. 4). He selected the three most prominent professions to be found in the area-heavy industry, delicate production, creative businessesand designed for those a symbiotic living and working that eliminates the threshold between the two activities, interconnecting them in a dense and productive fashion that promotes the sharing of facilities. It was not a coincidence that during the typological studies, Maarten had explored in depth one of the first apartment buildings of the Hague with shared facilities rooms (laundry, garbage collection, etc.). Proceeding with his design, Maatren looked thoroughly into the functional needs of each selected profession and the social norms of the professionals involved. He created spatial conditions tailored to them specifically. His high-rise proposal was meant to invigorate the local character of the area and allow services and industries to better serve the whole city, thus becoming a vital part of the Hague.

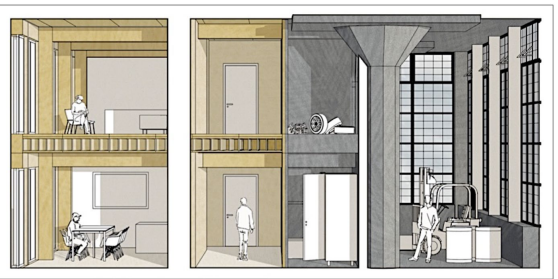

Figure 4. Symbiotic working and living (detail). Source: (Maarten van Blokland 2020) 


\subsection{Street of Slow Embrace: The surreal in the everyday}

The Street of Slow Embrace was another critical proposal for the development of post-industrial areas. During the stage of "Description" student William Shaw identified historical moments of slow speed in the area (streets designed to slow down cars prioritizing pedestrian movement). He noticed surreal collages of unexpected coexistences: free running chickens next to fast running trains; art installations in the middle of impossible to reach junctures, public playgrounds in between small factories. He also studied a communal living apartment building, where the inhabitants lived much of their daily activities in a public setting. His observations lead to the creation of the "Binckhorst Wundercamera"-during the "transcription" stage-which multiplied further the surreal, unexpected and magical interactions in space. He thus proceeded with the design of a housing complex and public spaces where the speed and haste of everyday urban living was questioned. Possibilities for surreal and magical moments in the everyday living became the driving force of his design: washing the dishes while becoming part of the public space and a spectacle in the city (Fig. 5), sleeping while looking at the stars and hearing the animals that inhabit the apartment's external walls. The materiality of his apartment building enhanced the slow embrace of the project. The walls, covered in fur-like thatching drawn from local resources, would grow over time as the inhabitants would water them. William advocated that the public space should be infiltrated by elements of private life, a possibility inspired by the Dutch culture itselfin order to get sustainably revitalized. He refused to design additional programs, making the public space his main emphasis in the project and showing how such an approach can connect the Binckhorst with the rest of the city.

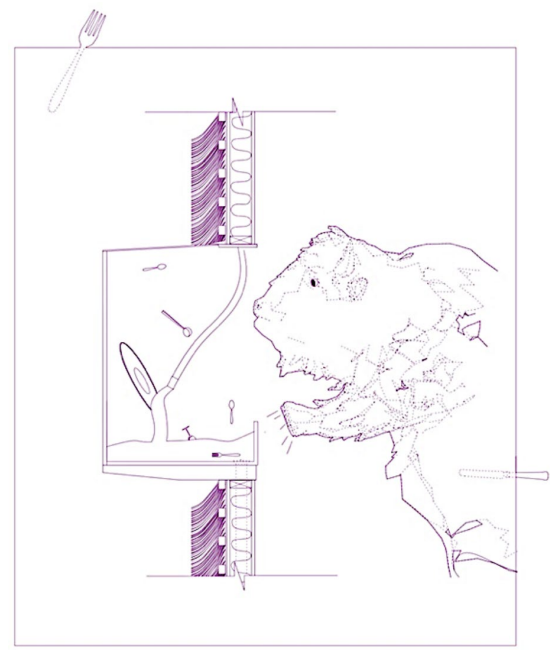

Figure 5. Surreal moments of everyday life. Source: (William Shaw 2020)

\section{CONCLUSION}

The studio "Binckhorst: A palimpsest of Architectural Lives" concluded with an exhibition of the students' proposals in the Binckhorst itself. The city of The Hague has recently re-appropriated an old building, transforming it into an information center for the future development of the neighborhood. It is in this building that the students' exhibition took place. Inhabitants of the immediate area and the city, municipal officers, and people from close-by cities like Delft came together to see the proposals and discuss with the young architects-to-be their visions for the transformation of the postindustrial area. The site-specific approach of our pedagogy, the interweaving of knowledge from the Hague building typologies with the lived space and its experiential richness, were communicated strongly to the audience, who engaged in asking questions and contributed to the general dialogue for 
the area. The audience moreover cared to understand the proposals in depth and tried to imagine, along with the students, what the design interventions could offer to their life. Anchoring the projects in existing and tested typological precedents, molding the findings from these typological investigations to incorporate the changing needs of the area's younger population, and spending time in the area understanding the people's needs and aspirations, was what made the proposals convincing for the exhibition visitors. It is also what made the proposals exemplary paradigms of an educational approach towards design, that values place with its history and lived experience. Theoretician Pérez-Gómez reminds us that historically it was the architect's job to make "inhabitants feel at home in the city, to intensify their sense of purpose and belonging in public, through the institutions that framed daily life" (PerezGomez 2016, 3). The students with their work, felt that they could provide precisely such a sense of belonging to the future inhabitants of the fast shifting post-industrial and multi-cultural area of the Binckhorst. 


\section{REFERENCES}

Argan, G. C. 2007. "Het concept van architectonische typologie," in H.J. Engel. F. Claessens, Wat is Architectuur?. ( $p$. 151-161), Amsterdam: SUN Publishers.

Casey, E.S. 1999. Getting Back Into Place: Towards a Renewed Understanding of the Place-World. Bloomington: Indiana University Press.

Deplazes, A. 2005. Constructing Architecture: Materials, Processes, Structures. A Handbook. Basel: Birkhäuser,

Frampton, K.1995. Studies in Tectonic Culture: The Poetics of Construction in Nineteenth and Twentieth Century Architecture. Cambridge: the MIT Press.

Havik, K. 2014. Urban Literacy: Reading and Writing Architecture. Rotterdam: naiOI0 publishers.

Lefebvre, H. 1992. The Production of Space. New Jersey: Wiley-Blackwell Press

Monestiroli, A. 2005. The metope and the Triglyph: Nine Lectures in Architecture. Amsterdam: SUN Publishers.

Matiyku, A. 2018. "Architecture Drawn Out of Bruno Schulz's Poetic Prose," in Reading Architecture: Literary Imagination and Architectural Experience. London; New York: Routledge.

Pallasmaa, J. 2005. Encounters. Helsinki: Rakennustieto Publishing

Pérez-Gómez, A. 2016. Attunement: Architectural Meaning After the Crisis of Modern Science. Cambridge: MIT Press.

Wilms Floet, W, Havik, K., Mejija, J., Avermaete T. 2018. "Tools of the Architect," in: Spool: Open Access Jopurnal for Design in Architecture and the Built Environment. https://journals.open.tudelft.nl/index. php/spool/article/view/2093/2445, last accessed Februayr 2020. 



\title{
PAPER \#3.08
}

\section{PURSUING POTENTIAL ARISING FROM COLLISION: THE ISLAMIC CITY CONSIDERING WESTERN HEGEMONY}

\author{
Sabeen bin Zayyad ${ }^{\mathrm{a}}$, Brian Robert Sinclair ${ }^{\mathrm{a}}$ \\ aUniversity of Calgary, Calgary, Alberta
}

\section{ABSTRACT}

City building is intensely complex - rich with identity, culture and place-making; it is uniquely manifest given context and culture. The industrial revolution, most notably over the last century, witnessed Western models of city life having demonstrable influences on built environments of the Islamic world. A clash between Islam's traditional formal structures and the West's modern perspectives has led to on-going discourse on development --notably its meaning, interpretation and implications. Western notions that technology defines economic and social progress have been viewed as misaligned with Islamic beliefs that "...the divine order was a commonly accepted reality and accordingly, the given system of daily rituals was capable of infusing meaning and consistency to every single human activity". This undeniably extends to the built environment. Dichotomies between old and new are evident in approaches to architectural and urban developments in Gulf countries. Islam's influence on the formation and fabric of cities and their inhabitants is not a unique phenomenon. The authors used an "Islamic" approach in understanding the challenges of building cities in the Gulf Region, providing insight into a more authentic approach to the built environment. Authentic in charting sensible paths around branding, consumerism, Starchitecture, globalization, etc. while introducing layers of historical complexity, contextual sensitivity and cultural richness that are not in contrast with Islam. Known as Little Sparta for its aggressiveness, rapid growth and significant transformation, the Emirate of Abu Dhabi has been transforming into an exemplar of modernity. What does this

mean in an era where history and traditions should be considered to balance past and future? The authors posit a new framework -- one that's diverse yet inclusive, distinct yet connected, traditional yet innovative, and dramatic yet relevant.

\section{KEYWORDS}

Urbanism; islamic; design; planning; modernity; pluralism

\section{INTRODUCTION}

As globalisation unfolds, the Islamic world will be there in myriad ways. Multitudinous encounters are inevitable. The Muslim world, once a remarkable bastion of scientific and humanistic knowledge, a rich and self-confident cradle of culture and art, has never forgotten its past. The abyss between this memory and the towering problems of tomorrow would cause disorientation even to the most secure societies. (His Highness the Aga Khan 1996)

In 1978, the Arab-American philosopher Edward Said wrote a seminal titled Orientalism. In it he stated that the Orient helped shape the West's perspective in how it viewed itself as a "...contrasting image, idea, personality, experience" (2) to the East. This gulf between the East and the West is nowhere better reflected than in the built environment, specifically the building of cities. Four decades later, the Islamic world in particular the Gulf region, faces an overwhelming range of questions confronting its cities' architectural and urban developments - how can these developments 
embrace and wholly incorporate the values of cultural continuity; how can inherited traditions be honoured while simultaneously engaging with technological innovations and how can social challenges such as changing identities be addressed while meeting the needs of rapidly evolving societies in these nations? Rather than treating these questions frivolously, they must be addressed with compassion, understanding and commitment in an encompassing way that aligns with the Islamic tenets of honouring the diversity of people and cultures.

\section{ISLAM AND THE CITY}

In contemporary times, "Muslim cities have, to a large extent, become utter failures" (Kotkin 2003, 1). At a time of globalization and growing resurgence in Islamic beliefs, the question of the Islamic city has once again come to the fore. Urban planners across the world are rediscovering Islam's achievements in the realm of the built environment and are looking for "...ways to reproduce in today's cities some of the patterns of city building that have been identified as Islamic" (Abu-Lughod 1987, 1). According to Rabbat (n.d.), the idea of the Islamic city (al-Medina) and its various interpretations has been a contentious one in the study of Islamic history. While Islam did not have a 'prefabricated' model of what a city should look like, its impact on the social and economic relationships of its followers shaped the urban fabric of communities in which they lived. Over time, this historical fabric adapted in response to changing social, economic and political conditions. Since the early twentieth century there have been numerous approaches and interpretations of the variables used in defining an Islamic city. To gain a better understanding of these approaches and city transformations in the Islamic world, a brief review of some of the literature is important.
In her seminal article The Islamic city - historic myth, Islamic essence and contemporary relevance (1987), Janet Abu-Lughod examined the history of scholarship on the Islamic city. Using the concept of isnad or "provenance", Abu-Lughod begins with William Marcais' 1928 article, L'Islamisme et la vie urbaine in which he states that Islam was an urban faith given that the Prophet Muhammad was a city resident, and thus the early converts were also city dwellers. Abu-Lughod then discusses George Marcais's work in 1940, that gave a specific form to the Islamic city by incorporating residential places and the physical organization of the markets. This was followed by an examination of Robert Brunschvig's (1947) article Urbanisme médiéval et droit musulman from which she concludes that the interpretation of the Islamic laws by different schools of thought had an impact on how cities (in particular North Africa) were spatially and physically structured. In her second provenance (isnad), Abu-Lughod discusses Jean Sauvaget's (1934, 1941) work on the Islamic cities of Aleppo and Damascus. Abu-Lughod then describes the work of Ira Lapidus (1969) as being very hesitant in his descriptions of the social structures of mainly Aleppo and Damascus, rendering them very abstract. Studies over what constitutes or defines an Islamic city, continue to this day. Many scholars have proposed different definitions using different perspectives. According to Abu-Lughod, Dale Eickelman's (1974) article Is there an Islamic city? tentatively answers the question by critiquing various approaches such as that of William Marcais. Eickelman also found that Muslim writers tended to 'gloss over' the issue rather than attempting to resolve it. In 1965, Albert Hourani and Samuel Stern organized a colloquium on the subject of Islamic cities and Hourani concluded that a definition of an Islamic city could not be reached because past work had focused mainly on cities in North Africa (Abu-Lughod, 1987), thus 
ignoring a greater diaspora of cities within the Islamic world. Similar in approach like AbuLughod, Andre Raymond (1994) stated that the definitions of an Islam city by previous scholars were based entirely on the faith of Islam without taking into consideration the political, economic, or social contexts of those periods.

The turning point in how the Islamic city was viewed and perhaps defined was by the historian Marshall Hodgson (1974) in his three-volume magnum opus, The venture of Islam: Conscience and history in a world civilization. His work on Islamic history emphasized the difference between the religious and secular aspects of Islamic civilizations (Tamari, 2015). His insistence on studying Islamic history as a result of the diverse political and socio-economic cultures that Islam came into contact with during its expansion and not solely as being centered on its Arab origins, challenged how Islamic cities were also viewed (Mukhopadhyay, 2015). This insistence by Hodgson on a pluralistic approach to the way Islam was viewed also changed the way(s) in which scholars studied Islamic cities (Mukhopadhyay, 2015; Tamari, 2015).However, this does not mean that "Islamic" approaches to the study of the
Islamic city do not exist. For example, Besim Hakim (1986), outlines some of his reasons as to why he chose to title his book, ArabicIslamic cities as opposed to simply Islamic cities. First, Islam was founded in the Arabian Peninsula and many Arab traditions were incorporated into the design and development of cities and initially carried over to other parts of the world. Second, the main language for communicating and disseminating knowledge in the Islamic world was Arabic. As a result, "prime sources in various disciplines are in Arabic" (12). Bianca (2000) uses a slightly different approach to his study of the Islamic city by crediting Islam with having a huge influence on the form and function of cities in the Arab world. His "...strong interest in the traditional Muslim philosophy of life" (8) and how this philosophy influenced the structures that shaped the Islamic city environment, stemmed from living and working in the Arab world for over 35 years.

A new aspect has now been added to the discourse beyond the numerous approaches of Abu-Lughod and others in answering what is an Islamic city. How are architects applying selective elements of the 'Islamic city' to their designs?

\begin{tabular}{cc}
\hline Perspectives / Approaches & Proponents \\
\hline \multirow{2}{*}{ Orientalist } & William Marcais (1928) \\
& George Marcais (1940) \\
& Robert Brunschvig (1947) \\
\hline \multirow{2}{*}{ Historical } & Jean Sauvaget $(1934,1941)$ \\
& Ira M. Lapidus (1969) \\
& Albert Hourani (1970) \\
Critical & Samuel Stern (1970) \\
& Dale Eickelman (1974) \\
& Janet Abu-Lughod (1987) \\
& Andre Raymond (1994) \\
\hline \multirow{2}{*}{ Islamic } & Besim Hakim (1986) \\
& Stefano Bianca (2000)
\end{tabular}

Table 1. An overview of the perspectives / approaches to the study of the 'Islamic City'. 


\section{FROM ISLAMIC CITIES TO MEGA-BLING CITIES - THE NEW GULF URBAN}

In studying urbanization in newly or rapidly developing countries, it is important to divest oneself of the Western image of urbanization. This process is absolutely mandatory, though difficult. (Breese 1966, 4)

Wirth (1938) stated that modernity in Western civilization has been marked by the development of huge cities. These cities attract and influence the social fabric of its residents and evolve to become the centre of political, economic and social activities (Wirth, 1938). These activities further fuel the growth of the city and begin to take on a character of its own, one that attempts to but is not necessarily aligned with meeting the needs of its residents and those who come to seek new opportunities. With the growth of cities, new sets of socio-cultural values, symbols and attitudes develop that are sometimes in contradiction with what already exists.

[This] rapid and profound transformations characterizing man's social condition in the world today are emergent of urban processes. (Meadows and Mizruchi 1976, 1).

The Western world has had a very strong influence on the cities of the Islamic world. The idea of progress echoed in terms such as secularization, capitalism, globalization, and technological innovation all reflect an ethos alien to the foundational creed of Islam. In order to better understand the effects the Western hemisphere has had on the architectural and urban developments of cities in the Islamic world, it is necessary to delve into the processes behind this influence.

According to Bianca (2000) the process of Westernization began with the Renaissance period, the Enlightenment period and the Industrial Revolution. This marked a new beginning for Europe in its revival of the arts, sciences and commerce. Search for new raw materials, led to the colonization of lands in Africa, Asia and the Middle East regions. As Europe began to emerge from the Dark Ages in the 14th century, the Ottoman Empire (also known for their achievements in the arts, science and medicine) began its gradual decline. This was due to economic and social unrest caused by various factors such as corruption, decline in state revenues and the ceding of lands to European military coalitions. It was also around this time that the Moorish civilization in Spain began to weaken in the face of the Christian reconquest of Andalusia by King Ferdinand $V$ and Queen Isabella I. By the 17th century, not only were the Muslims expelled from Spain, but the Ottomans also began losing their economic dominance and several key areas of their empire. The expulsion and loss was due to secularization - separation of the Church and State. Bianca further elaborates that this division between the material and the spiritual accommodated the notion of progress and created a moral and ethical dilemma. The separation from the Church meant that confirming what was good and true and what was not, was lost.

This explains the aggressive expansion of modern Western civilisation during this period, as well as the absence of shared higher standards and principles, which became manifest in the repeated social and political upheavals of modern Europe (162).

The sudden realization that man was able to determine what was good for him without the constraints imposed on him by the Church, was reinforced by the political processes also taking place simultaneously, notably the French Revolution in 1789. The absolution from both Church and the aristocracy, set the platform for major political, economic, social, scientific and technological changes in the 18th and the 19th centuries, leading to the birth of modern Western civilization. This "new" civilization was transmitted through colonization of the 
rest of the world by Europe. However, the end of colonialism in its orthodox form did not stop the continuing transfer of political, economic and technological influences to the newly independent countries. These factors led to uncontrolled developments and an increase in the speculation of properties. To better understand the variables involved in these unplanned and often spontaneous developments, the following schematic illustrates how development is approached from both Western and Islamic perspectives. It is important to note that these approaches should not be viewed as direct opposites of each other but rather as differing in the manner in which developments are considered from a socio-cultural perspective.

'Iconic' structures (e.g. Burj Khalifa in Dubai) are cropping up in the Gulf Region as the Islamic world attempts to balance the modern and traditional. These urban forms and structures are considered soulless imitations that do not reflect the rich historical era and past traditions of the Islamic world but lead to an unbalanced built environment. Regardless of the rapid pace of growth "...the mental map of the Gulf city is still rooted in the Islamic imagery" (Katodrytis 2015, 122). How can a balance be reached in such cities where local and historical contexts are overwhelmingly rooted in the Islamic faith while the built environment in selectively trivializing historic architectural elements runs the risk of destroying that heritage?

\section{LITTLE SPARTA}

In command of nearly 8 percent of global oil reserves...over $\$ 1$ trillion in sovereign wealth funds... with innovative new economic sectors being established according to a thoughtful masterplan, Abu Dhabi...will soon yield enormous influence across both developing and developed worlds [and] will soon be poised to eclipse even Dubai - its ubiquitous UAE partner - as a household name. (Davidson 2009, 1)

In a letter to his mother in 1948, the British explorer Wilfred Thesiger (1910-2003) said that Abu Dhabi was a small but as yet unspoilt port, but he feared that once oil would be discovered, the natural beauty that was Abu Dhabi would be gone (Soussi 2019). His prediction of modernity having an influence on the development of Abu Dhabi would prove correct, for the oil revenues pouring in the country, had transformed the region forever, from a series of tiny settlements into the capital of the United Arab Emirates (UAE). Known as Little Sparta due to its rapid growth as a global city since 2004, Abu Dhabi has been ruled by the al-Nahyan family since the 19th century. The fast-paced transformation is attributed to its revenues derived from oil and "...by other factors, especially shifts in governance and planning paradigms" (Alawadi \& Benkraouda 2017, 4). Literary sources differ in the delineation of phases that have marked Abu Dhabi's architectural and urban developments. Khalaf (2006) posits Abu Dhabi's urban

\begin{tabular}{cc}
\hline Western Perspective & Islamic Perspective \\
\hline Rational & Culturally sensitive \\
\hline Contemporary & Historical \\
\hline Independent & Interdependent \\
\hline Secular & Spiritual \\
\hline Purposeful & Reflective \\
\hline Abstract & Shared
\end{tabular}

Table 2. Paradigms of Architectural and Urban Development 
development on the search and discovery of oil, terming them the traditional, initial, rapid urbanization and final gradual phases. Similar to Khalaf (2006), Salama (2014) frames Abu Dhabi's architectural evolution on the pre-oil era, impact of the discovery of oil and the forecasted decline in oil reserves. Elsheshtawy (2008) considers the divide of Abu Dhabi's urban development along these phases as "superficial". Using the Abu Dhabi Municipality 2003 report as a basis upon which to mark Abu Dhabi's development, Elsheshtawy states that Abu Dhabi has five phases of urban development and is grouped between two to approximately twenty-year periods. First, the historical period (19621965); second, the creation of a city (19661968); third, the establishment of a city (1969-1988); fourth, the development of the Emirate's Masterplan (1988-2004); and fifth and current phase (2004- present), its appearance on the world stage. However, the developments taking place in Abu Dhabi during the first four phases were still rooted in a conservative structure as state intervention was strong in ensuring a balance between modernity and tradition (Elsheshtawy 2008). Abu Dhabi remained cautious in its urban development, beginning with the goal of improving the living conditions of its people following the discovery and export of oil in the early-60s. By the late-1980s, the Emirate saw a huge surge in construction activity, most of which was focused on creating housing for its citizens, and other needed infrastructure such as schools, and hospitals.

Construction continued until the death in 2004 of Sheikh Zayed bin Sultan alNahyan, the ruler of Abu Dhabi and the driving force behind the facilitation of this balance. Post-2004, changing political climate and oil income allowed Abu Dhabi to diversify its economy into finance, logistics, manufacturing, tourism, cultural and realestate development. This also influenced Abu Dhabi's architectural and urban developments, believing itself on par with other global cities such as London, Paris and New York. Incorporated as part of its initial Masterplan (1990-2010), the Abu Dhabi Town Planning department recommended the development of several islands surrounding the Emirate. Sa'adiyat Island is one such example. Located approximately 500 metres from the coastline of Abu Dhabi and encompassing an area of 27 square kilometres, the island has been described as

undergoing a remarkable transformation into a world class leisure, residential, business and cultural hub of global proportions, housing the world's largest single concentration of premier cultural assets. These will include the Zayed National Museum, Louvre Abu Dhabi and Guggenheim Abu Dhabi - all designed by Pritzker prize winners (Department of Culture and Tourism 2020).

One of the most visible structures on the island is the Louvre Abu Dhabi designed by one of the Pritzker Prize winners, Jean Nouvel. Inspired by the idea of the Islamic medina, Nouvel built a double dome of 180 metres in diameter. Believing the dome to be a major symbol of Arab architecture, he described it as an "...evident shift from tradition..." and "...a modern proposal" (Nouvel 2017). Nouvel wanted a design that reflected the history of the UAE, "...by providing a direct echo in Arab architecture, but one that equally addresses universality." (Suri 2017). Following a trip to the Louvre Abu Dhabi in 2018, Rasem Badran a Palestinian-Jordanian architect and 2019 winner of the prestigious Tamayouz Lifetime Achievement Award for Architecture, stated that the Louvre Abu Dhabi did not reflect a traditional Arab city. In a Facebook post (December 22, 2017), he wrote

[It is] an attractive outside space in midday [with the] projection of sun rays, while the interior is a boring failure and does not reflect Arabic streets. It is a typical misreading [by] the west [of] oriental civilisation. Even the 
exterior space does not reflect the dynamism of the open spaces in the traditional architectural texture of Arab cities. [it is] a contemporary space that has lost its soul (Alsammarae 2018)

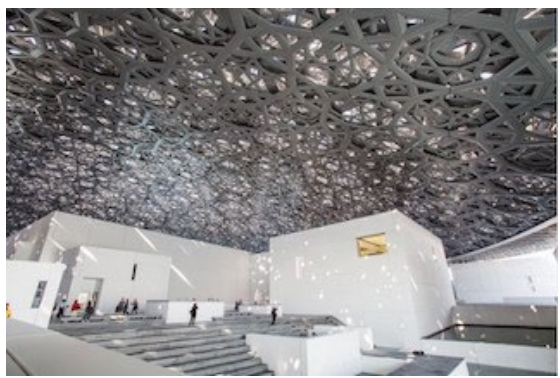

Figure 1. Dome of the Abu Dhabi Louvre during the day. (Sean-Paul Doran 2018)

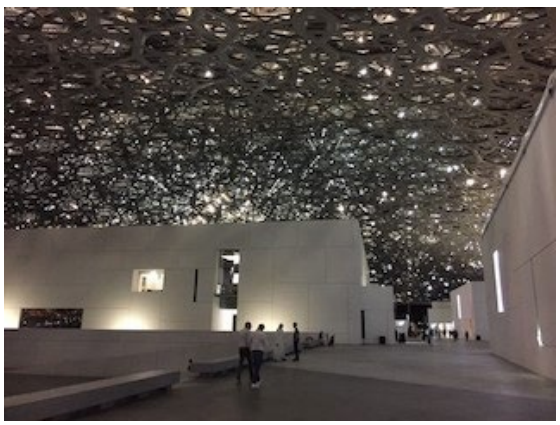

Figure 2. Dome of the Abu Dhabi Louvre at night. (Sabeen bin Zayyad 2018)

Ironically, this "misreading by the west of eastern civilizations" has also been reflected in the direction that the open foyer of the museum faces. The French military base located in Port Zayed is visible across the water from the foyer of the museum. According to Nouvel (2009), he

designed the museum in a way that would allow the visitor disoriented by the glare of the relentless sun and the strong white colours of the desert sands to look toward the French naval base and to rest his eyes on the calm gray colours of the French warships! (Rabbat 2018)

Apart from the development of the land surrounding Abu Dhabi, the Emirate has also seen the construction of "neoIslamic" structures in projects such as the Emirates Palace Hotel, located along the Emirate's Corniche, and noticeable by its "...assortment of domes and lavish 'Islamic' decorative patterns." (Elsheshtawy 2009, 273). Many view this as Abu Dhabi's attempt to distinguish itself from Dubai "... by constructing monuments that reflect some sort of Islamic renaissance." (273). The authors however believe that this is no different than many of the developments in Dubai that pay homage to such neo-Islamic designs like the Atlantis hotel located on Palm Jumeirah, an offshore palm-tree shaped island built from reclaimed sand. When asked to describe the hotel's building style, US-based architect Larry Ziebarth whose clients include Disney, Universal Studios and Sea World described it as being

deeply rooted and borrows from regional Islamic traditions, but with a strong dash of fantasy - which will become synonymous with the entire project (as cited in Elsheshtawy 2004, 189).

A final example of the juxtaposition of developments taking place in Abu Dhabi is the Central Souq (marketplace). Built in the early-70s and situated in the midst of numerous skyscrapers, it housed more than 700 shops that sold everything from spices, household and consumer goods. In 2002, Abu Dhabi authorities decided to demolish the old souq and build a new one "... reflecting traditional Arab and Islamic design..." (Gulf News 2002). Although official sources at Abu Dhabi Municipality's architecture department stated that the souq was not expected 
to last for much longer, assuming that it was structurally unsound, Elsheshtawy (2008) states that the old structure was not compatible with the new and modern image that Abu Dhabi was projecting. The initial architects tasked with designing the new souq confirmed that the old structure was part of Abu Dhabi's history and that every attempt would be made to recreate its history rather than working towards revitalizing and preserving the structure. In addition, the design of the new souq was to be similar to the old bazaars of Cairo and Damascus as they had "...Islamic and Arabian structural designs..." (281).

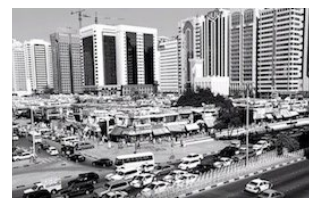

Figure 3. A shopkeeper's memories of Abu Dhabi's old central souq before its demolition. (The National 2013)
Although Abu Dhabi's attempts to be viewed as a global city should be lauded (by way of some of the aforementioned developments taking place), it does not negate the fact that it is using 'modern' models of development and 'paying lip service' to its cultural and religious contexts. It is with keeping this in mind, that the authors posit an alternative approach to how Abu Dhabi charts its development path.
In 2011, the souq (now known as Aldar Central Market, Abu Dhabi) was completed. Rebuilt over a space of 600,000 square meters, it sits amidst a number of tall buildings containing apartments, offices, and a luxury hotel all built on the same site. The outside of the building itself is covered by lattice panelling also known as a mashrabiy'ya. According to Norman Foster (2007), the souq is a "... reinterpretation of the traditional marketplace and a new civic heart for Abu Dhabi" and is an alternative to the ubiquitous shopping mall as it "offers a distinctive modern interpretation of the regional vernacular." Gone was the community feeling, the sense of belonging, familiarity, continuity of traditions and culture that came with a space built on meeting the needs of its residents.

\section{PLURALISM - AN ALTERNATIVE APPROACH}

At a time of rapid change in the Middle East, the enforcement of Western models of development has eroded traditional Islamic values...the Islamic idea of development cannot be reduced to any of the models prevailing in the West, which are based on concepts of progress and evolution alien to the Islamic worldview. (Said 1989, 619)

Roberto Unger (1991) a socio-political theorist stated in his published essay that architects had to change their ways of thinking in order to address the changes that society was undergoing. The changes that were taking place in the political, economic 
and technological realms had to be reflected not just in the structures being created but that the architects themselves had to "uphold the commitment to express in physical vessels a shared vision of collective life." (1). In 1995, Unger further elaborated on the above idea and stated that "latter-day urban icons would work all the more if they became more pluralistic." (1). According to Begde (2000), the culture of economics and consumerism are taking over the ethics and values that guide society. This is reflected in the urban landscape of cities around the world such as unaffordable housing, increasing poverty and a dismantling of the social fabric.

There are many theories and perspectives on pluralism and Eck's (2001) view gives the broadest perspective, that it is not a political, economic or social ideology. It is a process where humans engage with each other through their most profound differences, on a continuous basis, building relationships that become the platforms for moving forward on issues affecting all mankind. Humans are not born with this outlook but are taught to understand and accept the existence of the different types of diversity, be it cultural, religious, gender or creed. Karen Armstrong (1988) notes that the faith of Islam incorporates the notion and practice of plurality in its teachings, traditions and approaches to living in the material world (duniya). This has been demonstrated in the various geographic regions of the world that Islam came into contact with during its expansion into Andalusia, Central Asia, India and China. The recognition of different cultures that contributed to the flourishing of these regions is testament to the fact that Islam is not just a religion but it also provides a set of ethics and values that guide the daily lives of its followers wherever they may be, exemplifying the connection between the divine and temporal worlds. Islam is not a passive faith. It does not believe that the spiritual (din) be isolated from the material (duniya).
Inextricably linked to each other and strongly guided within the Islamic tariqah (path), this lack of separation also provides an accommodating environment (uncommon to other monotheistic faiths) to embrace foreign concepts that allow for spiritual interpretation as well as meaning and progress of not just Muslims but all of humanity in an arguably more ethical manner (bin Zayyad and Sinclair 2017, 227).

The authors believe that a balanced integration of the modern and traditional into expanding urban landscapes, is essential in the face of accelerating forces of social change in a globalized world. This pluralistic approach is important because it brings together diverse and competing interests and then redistributes them in a balanced manner, as the framework below demonstrates. What is even more relevant is that this approach reconciles what is unique in individual traditions with a deep awareness of what connects one to past, present and future of mankind. Our approach is critical in addressing the disconnect in disparate cities as it provides the foundation upon which to build connections and understanding across economic and social differences. In doing so, the objective of this approach is to engage, inspire, reappraise and share the challenges and successes of responsible urban development amongst different stakeholders. It is intended that over time, the processes forming this pluralistic approach become iterative where cities evolve into more balanced manifestations of rich traditions and contemporary narratives.

\section{SINCLAIR + BIN ZAYYAD MULTIPLICITY MODEL}

The goal of construction has commonly outpaced the ability of design to find arguably appropriate expression in many parts of the world. Often the need for space 
and form eclipses the demand for humancentric, culturally suitable and place-specific solutions. The authors note that design professions tend to have limited research depth, translating into risks around making decisions based on instinct, feelings and trends. Often, this lack of evidence-based decision-making renders caricatures as viable inspiration for and influencers of design. Such stereotypes arise in part due to the duality of opposites where it is easier to fall on polarities than to dig deep to grasp authenticity. This over-simplification can translate into historicism and nostalgia rather than pursuing a more profound understanding - for example, how should Islam be most suitably expressed in today's buildings and cities?

The Sinclair + bin Zayyad Multiplicity Model for Islamic City Design is intended as a provocation - a way to challenge our comfort and convention when exploring Islamic architecture and urbanism. It intentionally sets up a polarity and opposition, such as secular versus spiritual or simple versus complex, with a goal to catalyze critical thinking within the design process. The model identifies 'pulls', modern and Islamic, which over-simplify the character of design, but which prompt us to question the validity, value and strategy of said duality. For example, Western design today is frequently fueled by bottom-line thinking - valueengineering and the mantra 'if you can't count it, it doesn't count'. On the opposite extreme is culture, which in most cases transcends the assignment of price tags. Under the proposed model, future developments should be aggressively examined and scrutinized along each of the dualities with arguably a suitable posture lying in a more moderate range between the pairs of poles (the arrows illustrate such tolerance for and embrace of opposing forces). The model accepts over-simplification as a means to precipitate much needed dialogue. For example, Islam has historically been grounded in science as much as it has advanced artistic endeavour. That said, the uninitiated and ill-informed may intuitively claim Islam as more concerned with abstract and ethereal qualities. The model is not definite but a beginning. It is not conclusive as much as it is probative. In a world where comfort is found in exaggerated difference and solace sought in quick answers, the model aims to apply some checks and open a conversation around Islamic design in ways that honours the past, celebrates the present and anticipates the future.

The question of the 'best' way forward is, as the authors have delineated, open to debate. The point of the model is to ensure that debate transpires and that a path of robustness, resilience and responsibility is sought before hasty and mindless reactions to the design and construction of Islamic buildings, blocks and cities continue to populate the urban landscape.

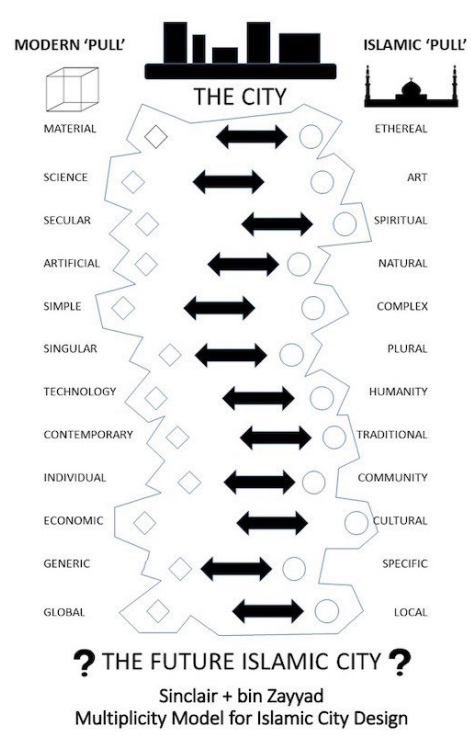

Figure 6. Sinclair + bin Zayyad Multiplicity Model for Islamic City Design 


\section{CONCLUSION}

Modern does not always translate into progress. Progress does not necessarily mean building iconic structures but structures that encapsulate the characteristics and the spirit of the locale, its inhabitants, its traditions, culture and socioeconomic ethos. It is apparent that Islamic cities in the current century are short of the sublime. They illustrate recurring Western influences in their architectural designs and urban structures, and lack convergence of the spirit of the local cultures and traditions. Islamic cities in the past centuries have been built in accordance to the Islamic traditions. These traditions have had far reaching influences throughout Europe particularly during the Andalusian and Ottoman periods. There are no concrete reasons as to why these traditions cannot be upheld as the authors' model has illustrated, except for the lack of will - of the governing stakeholders, of the architects to carry out research and submerge into the local contexts while upholding the traditions. Modern and tradition can engage and intertwine but traditions need to supersede so that the inhabitants are able to find comfort in their own culture, beliefs, ethics and values. After all cities are built to engage the inhabitants and surround them within contexts unique to themselves. 


\section{REFERENCES}

Abu-Lughod, Janet. 1987."The Islamic City - Historic Myth, Islamic Essence and Contemporary Relevance." International Journal of Middle East Studies 19: 155-176.

Ahmad, B. 1995. "Urbanization and urban development in the Muslim World: From the Islamic City Model to megacities." GeoJournal 37 (1): 113-123. https://doi. org/10.1007/BF00814892.

Alsammarae, Rima. 2018. "The Louvre Abu Dhabi does not reflect a traditional Arab city, writes Palestinian architect Rasem Badran." Middle East Architect, January 2, 2018. https://www.middleeastarchitect. com/thoughts/the-louvre-abu-dhabi-doesnot-reflect-a-traditional-arab-city-writespalestinian-architect-rasem-badran.

Begde, P. 2000. "Architecture of pluralism." Architecture Plus Design 17 (6): 43-45. ProQuest Ebrary.

Bianca, Stefano. 2000. Urban Form in the Arab World. New York: Thames and Hudson.

bin Zayyad, S. \& Sinclair, Brian R. 2017. "Culture, Context + Environmental Design: Reconsidering Vernacular in Modern Islamic Urbanism." In Architectural Research Addressing Societal Challenges, edited by da Costa, M.C., Roseta, F. et al., 223-229. London, UK: Taylor and Francis Group.

Breese, Gerald. 1966. Urbanization in Newly Developing Countries. Englewood Cliffs, $\mathrm{NJ}$ : Prentice-Hall.

Davidson, C.M. 2009. Abu Dhabi: Oil and Beyond. London, UK: Hurst and Company.

Eck, Diana. 2001. A New Religious America: how a "Christian country" has now become the world's most religiously diverse nation. San Francisco, CA: Harper San Francisco.

Elsheshtawy, Yasser. 2008. "Cities of Sand and Fog: Abu Dhabi's Global Ambitions." In The Evolving Arab City: Tradition, Modernity and Urban Development, edited by Yasser Elsheshtawy, 258-303. New York, US: Routledge.
Hakim, Besim. 1986. Arabic-Islamic Cities: Building and Planning Principles. London: $\mathrm{KPI}$.

Katodrytis, George. 2015. "Performative Urbanism: An Emerging Model of the Gulf." Architectural Design 85 (1): 120-127. Khalaf, Sulayman. 2006. "The Evolution of the Gulf City Type, Oil, and Globalization." In Globalization and the Gulf, edited by Fox, Mourtada-Sabbah and al-Mutawa, 244287. Oxon, UK: Routledge.

Kotkin, Joel. 2003. "Islamic Cities - The Past as a Key to the Future: Could a revival of Islam's urban legacy transform modern Muslim society?" Globalist Perspective, June 1, 2003. https://www.theglobalist. com/islamic-cities-the-past-as-a-key-tothe-future/.

Meadows, Paul and Mizruchi, Ephraim H. 1976. Urbanism, Urbanization, and Change: Comparative Perspectives. Philippines: Addison-Wesley Publishing Company. Citations refer to the second edition.

Mukhopadhyay, Urvi. 2015. "Defining 'Islamic' Urbanity Through a Trans-Regional Frame." Asian Review of World Histories 3(1): 113-135.

Nouvel, Jean. Retrieved from http://www. jeannouvel.com/en/projects/louvreabou-dhabi-3/.

Rabbat, Nasser. 2018. "France's Oriental Dream: The Louvre Abu Dhabi." Artforum, January 19, 2018. https://www.artforum. com/architecture/nasser-rabbat-on-thelouvre-abu-dhabi-73429.

Said, Edward. 1979. Orientalism. New York: Pantheon Books.

Salama, A.M. 2014. "A Century of Architecture in the Arabian Peninsula: Evolving Isms and Multiple Architectural Identities in a Growing Region." In Architecture from the Arab world (1914-2014): A Selection: Bahrain Catalogue in Biennale Venice, edited by G.G. Arbid, 137-143. Manama, Bahrain: Bahrain Ministry of Culture. 
Soussi, Alasdair. 2019. "A line in the sand: The European explorers who battled to claim the Empty Quarter." The National, June 27, 2019. https://www.thenational.ae/ arts-culture/books/a-line-in-the-sand-theeuropean-explorers-who-battled-to-claimthe-empty-quarter-1.879881.

Staff Reporter. 2002. "Designs underway to build new market in Abu Dhabi." Gulf News, December 29, 2002. https:// gulfnews.com/uae/designs-underway-tobuild-new-market-in-abu-dhabi-1.406734.

Suri, Chari. 2017. "Jean Nouvel Reveals His Singular Vision Behind the Louvre Abu Dhabi." Architectural Digest, November 7, 2017. https://www.architecturaldigest. com/story/jean-nouvel-louvre-abu-dhabi.

Tamari, Steve. 2015. "The Venture of Marshall Hodgson: Visionary Historian of Islam and the World." New Global Studies 9 (1): 73-87.

Unger, Roberto M. 1991. "The Better Futures of Architectures." The Work of Roberto Mangibeira Unger. California, Los Angeles: Harvard University.

Unger, Roberto M. 1995. "The Present of Architecture and Future of Democracy. Harvard Law School. Harvard University.

Wirth, Louis. 1938. "Urbanism as a Way of Life." American Journal of Sociology 44, no. 1 (July): 1-24. 



\title{
PAPER \#3.09
}

\section{NEW VS OLD: UNDERSTANDING ARCHITECTURAL TENSIONS IN THE DESIGN OF PUBLIC SPACES}

\author{
Giulia Settia \\ aDAStU Department, Politecnico di Milano, Milan, Italy
}

\section{ABSTRACT}

The essay aims to reflect on the role of the design of public space in contemporary cities, starting from the emblematic case of Milan, to build a broader debate on the need of public spaces that European cities are increasingly showing and on the role that architectural design must assume in this instable scenario. In Milan, architectural tensions between new and fashion interventions and the background of the traditional city are alive, fertile and sometimes conflicting: it opens-up a space for design. The heart of the powerful urban transformations in Milan are public spaces, or rather their redefinition; observing Milan today means to put at the center of the debate the role of public spaces and a latent, but crucial, conflict between new and old.

Cities and architectures are changing faster, so the relationship between new and old is taking a central role in the architectural debate; what does it means to design the new and how this could necessarily integrate with what already exists, in a delicate and precious balance?

In this sense, Milan represents an open-air laboratory: it is a city that has strongly changed from its past. However, the change raises important questions about the relationship between new and old.

The essay proposes a reflection on architectural tensions that new interventions of Porta Nuova, City Life and Feltrinelli Foundation have generated in the city. The architectural design has redefined entire portions of the city, modifying strongly its identity; if, on one hand, the new has given back to Milan architectures and public spaces, on the other the integration between new and old appears to be an open issue.

\section{KEYWORDS}

Architectural tensions; public spaces; Milan; identity.

\section{INTRODUCTION}

The making of cities - today like yesterday passes through the design of its public space, of a collective and shared (play)ground that becomes the background of architectures and phenomena. Cities and architectures are changing faster, so the relationship between new and old is taking a central role in the architectural debate; what does it means to design the new and how this could necessarily integrate with what already exists, in a delicate and precious balance?

Especially in contemporary context, the integration with the existing represents a complex and delicate design issue, because it highlights tensions that the juxtaposition between new buildings with the traditional city forms produces. A latent tension, which in some cases, could bring out difficult balances, necessary, however, to transform and to improve contemporary cities.

The essay reflects on the relationship between new and old by observing its effects on a city, like Milan, which has been radically transformed in the last ten years, highlighting a fervent capacity of modification, no longer related to the great urban design plans developed during the 1980s (Bianchetti 2016). It is a radical revolution that has revealed several significant issues that will be the subject of this text; starting from the role of public space in new projects to urban and architectural tensions related to its use and property to arrive to 
understand how, and if, the new interventions have changed the perception of the traditional city and its identity.

In this sense, Milan represents an open-air laboratory: it is a city that has strongly changed from its past. However, the change raises important questions about the relationship between new and old.

The essay proposes a critical debate on architectural tensions that new interventions of Porta Nuova, City Life and Feltrinelli Foundation have generated in the city. The case study will be explored through a critical comparison of architectural elements applied in each project, highlighting similarities and differences, observing the shape of buildings and open spaces. A methodology that aims to describe both the contrast, often not solved, within the context, and to underline the different design choices made. The architectural design has redefined entire portions of the city, modifying strongly its identity; if, on one hand, the new has given back to Milan architectures and public spaces, on the other the integration between new and old appears to be an open issue (Colomina 1994; Gaventa 2006).

\section{BETWEEN NEW AND OLD: A CRITICAL PREMISE}

Architectural design has always reflected on the relationship with the existing, both with the aim of safeguarding memories and traces of the past, both to understand what could be removed or demolished downstream of processes of contraction or abandonment.

In this sense, the Italian context is paradigmatic: a stratified architectural and urban tradition has clashed with sudden events, economic crises and, also, the most recent climate changes that have highlighted the precariousness of an urban system that seemed unalterable. On the contrary, the city is, and remains, a laboratory of "urban facts" as Aldo Rossi claimed (Rossi 1981); it is the engine of continuous and deep transformations, in which the effects will be given in a longer time and not within few months. These changes are often slow, complex and difficult for urban contexts because changing parts of cities necessarily means to modify inherited and long-lasting balances.

In this perspective, the powerful transformation that has affected Milan brings out contradictions, conflicts and tensions in redesigning portions of the city; the new advances in the iconic buildings that dot Milan, in the definition of different architectural languages imported by international firms. Recent projects completed in Milan tell of a complex, and unresolved, relationship with the past, or rather with the tradition. Projects that are showing latent tensions between the actors involved in the design of the contemporary public space and its uses.

The pilot projects, carried out in Milan in the recent years, have given rise to powerful transformation processes. Private entities invest capital and resources to build a new image of themselves: they are large banks, prestigious qualified companies that have found possible opportunities to rebirth in the empty and abandoned areas of Milan.

In this sense, the essay aims to reflect on the role of the design of public space in contemporary cities, starting from the emblematic case of Milan, to build a broader debate on the need of public spaces that European cities are increasingly showing and on the role that architectural design must assume in this instable scenario.

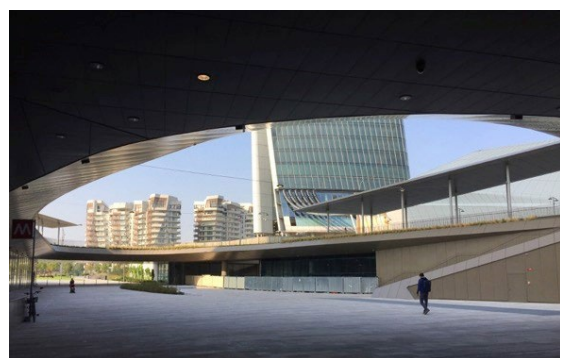

Figure 1. The project of City Life (Milan) and its system of public spaces. (Giulia Setti 2017) 
In Milan, architectural tensions between new and fashion interventions and the background of the traditional city are alive, fertile and sometimes conflicting: it opens-up a space for design. The heart of the powerful urban transformations in Milan are public spaces, or rather their redefinition; observing Milan today means to put at the center of the debate the role of public spaces and a latent, but crucial, conflict between new and old. A conflict that has distant roots: in the critical reconstruction of Berlin, after the Second World War, carried out, among others, by Josef Paul Kleihues emerges the need to re-establish a link with existing architectural shapes, establishing precise languages and parameters. A complex story that questioned again the relationship between history and project, between new and old indeed.

The essay will describe some major projects completed, or under construction, including the area of Porta Nuova and Piazza Gae Aulenti, Feltrinelli Foundation and the complex intervention of City Life, but not only, we will try to reflect on what it is still in process, in particular in the area of Porta Nuova and City Life which have become contemporary laboratory for the city. It will be a journey to (re)discover the contemporary soul of Milan, but above all, it will be a story about the rediscovery of a new role for public space in these new interventions and the architectural image they have produced in the city.

If the role of architecture is radically changing, it is also changing the nature of public space in these contexts; no longer just an expression of a past monumentality, crystallized in the fixity of the plaza, but a (public) space discussed, stratified and complex in its definition. A public space that is uncertain and necessary for the construction and image of this new Milan.

The essay questions these urban transformations and tries to read them critically by investigating the different architectural tensions that the new projects have activated in the city. A city, Milan, with a strong industrial past, which has been able to rise after numerous economic crises, the last one started in 2008. These projects tell about how architecture represented an incentive and a tool of action, albeit partial, to recover portions of cities previously in a state of decay. In particular, each project has been described through its history, its design genesis and architectural peculiarities, identifying the essential key aspects, such as the design of the ground floor, the definition of systems of open spaces and of a new urban and architectural verticality. The inquiry works through a detailed investigation of drawings, architectures and images that have been generated by these interventions; it is a story seen through the eyes and the critical gaze of an architect, who tries to grasp the latent design issues raised by contemporary projects in Milan.

\section{THE TIME OF CONTEMPORARY PUBLIC SPACES}

The design of public space has always crossed the development of cities and, in particular, the (public) void remains and it is shaped by the buildings' design that surrounds it. In the recent interventions, previously mentioned in Milan, the design of the contemporary public space is the result of daring but clear formal and architectural choices.

Buildings that we observe walking through Porta Nuova or City Life (Fig. 1) are iconic artifacts, powerful landmarks, which once again mark the city shape; the design of its public spaces could only be influenced by these choices but strongly highlights the necessity of public open spaces that citizens have showed. Interventions and projects described here mark an important moment for the city, also in relation to the world economic crisis that began in 2008 and, in fact, not yet concluded. It is thus a series of impressive urban and architectural transformations 
that began before the advent of the crisis, therefore they had to redefine their ambitions and actual construction times.

The story, developed in this essay, also tries to understand the contradictions between the use and ownership of contemporary public spaces, result of complex negotiation and, in fact, financed by private investors. Observing Milan today means to discuss on architectural and urban tensions that led to a radical transformation of Milan.

\section{PORTA NUOVA PROJECT: REDESIGN AN URBAN VOID}

The image that emerges from this journey in a Milan that has changed, and is still changing, is that of a city tormented between past and future; a future that raises questions around the life of new projects, as well as on the architectural quality of spaces that has been determined. Piazza Gae Aulenti is an expression of this, walking in the large central void defined by Unicredit skyscraper and by a series of fragmented and disrupted architectural objects one captures an unexpected life (Molinari, Catella 2015).

The square, and the public space, appears as a residual component, surrounded by a dense border of massive buildings: it quickly assumed a key role in the public life of citizens. Raised up by the arterial roads that innervate the background of Porta Garibaldi railway station, it is a protected enclave and, therefore, perceived as a safe place by citizens.

Public and private strongly face each other: the square, built thanks to the funding of banks and private actors who have thus been able to move their offices in the heart of Milan, has become the stage of public life: it lives at different times and seasons, it is quickly crossed by those who go to workplaces, lived by young people, children and elderly people who could enjoy the slow time of contemporary life.

The transformation of Porta Nuova area, close to Porta Garibaldi railway station, began in 2005', it represented one of the major urban projects carried out in Milan in the last twenty years ${ }^{2}$, compensating a large void, full of meanings, that it could not find a completed definition. Porta Nuova intervention denounces, on one hand, the need to intervene and, therefore, the desire of re-appropriation of abandoned places by citizens, at the same time it marks a complicated balance between glossy architectural objects, brought into this context, and the sensitivity of the place, as well as the relationship with its historical roots.

At the end of the works, the plaza has been able to accommodate different possible uses, becoming a social place, protected by the city and defined by new urban edges. No longer the nineteenth-century monumentality of Piazza Duomo, but a lively contrast of architectural styles and languages resulting from a non-unitary planning. Piazza Gae Aulenti's public spaces have been able to regenerate it, becoming a meeting place for young people and children who have transformed the anonymous square into a vital place. Therefore, piazza Gae Aulenti brings together various forces; it determines connections and unites self-referential and autonomous objects unwilling to open up, but on the contrary inclined to individuality. The tension is generated by the evident contrast between the productive and iconic ambition of Porta Nuova project and the need for public spaces, and it is also fueled by the various informal uses that citizens make of the square (Fig. 2).

\footnotetext{
1 The redevelopment of Porta Nuova area has involved several architects both to realize the masterplan (Pelli Clarke Architects, Kohn Pederson Foz Associated, Stefano Boeri Architetti), and to design the buildings, including Cino Zucchi Architetti, Antonio Citterio and Partners, Piuarch, Michele de Lucchi e Mario Cuccinella: http://www.porta-nuova.com/.

2 The construction sites of Porta Nuova Project were the largest in Europe in 2012-2013, see also:

http://milano.repubblica.it/cronaca/2012/02/01/news/foresta_di_giorno_deserto_di_notte_ecco_il_rischio_della_milano_ verticale-29109861/. The urban tradition of Milan is marked by major urban interventions, referring to the Vittorio Gregotti's project for Bicocca created during 1980s which has characterized an urban season that has now ended.
} 
The new urban intervention has become a public material, populated in different ways; you could sit, dance, and enjoy the protection offered by an artificial ground, people felt inside a new part of Milan. Different actors inhabit the plaza: next to traditional urban users, there are also those who cross the square to go to work or to reach the railway station.

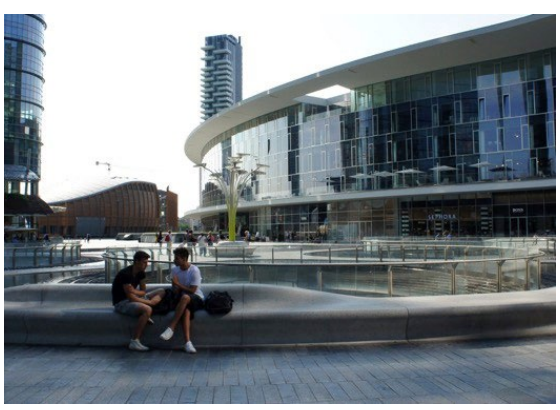

Figure 2. The pseudo-public space of piazza Gae Aulenti, Milan. (Ivan Ashkinadze 2017)

The development on different levels of Piazza Gae Aulenti and its sprawling and minute connections with the surrounding spaces show how different speeds and uses coinhabit; the plaza hosts those who stop for a short time, those who use it for a longer time and, at the same time, welcome the dynamism of work, of the rapid and necessary movements. It is a place of discussion between the requests that made it possible, but at the same time, it is a harmonious claim for what could be considered public in the city; the tension does not show itself in a clear or disruptive conflict, but determines a dynamic balance between different actors involved.

Piazza Gae Aulenti, and its immediate surroundings, could be defined as a pseudo- public space, in which we have the perception of a public place, however regulated by private instances. Taking photographs in Piazza Gae Aulenti with a tripod is, for example, prohibited 3 : a common action in the squares such as stopping to take some images, it is not practicable in a place that shows itself as public but which, in fact, is not. Therefore, it is a pseudo-public space because it is a space that declares itself as public, in which the use of it is conditioned by private property, which nevertheless allows an impeccable care $^{4}$ (Kayden J. S. 2000; Cicalò E. 2009).

While there is the fear that forces to check, even more so when it is a central place for economic and productive activities; however, there is at the same time the necessity to show the sharing and sociability that also arises from informal practices. The special observatory of Piazza Gae Aulenti is a mirror of tensions and conflicts of our time, where being monitored is possible, more than ever necessary, after the intensification of terrorist acts in large public spaces ${ }^{5}$ : control imposes a restriction of freedoms. If we observe the life of Piazza Gae Aulenti, we will be able to notice how it is an effective urban and architectural condenser, able to hold social classes and different uses together, adapting its spaces to an informal life.

\section{PORTA VOLTA AND FELTRINELLI FOUNDATION: THE REDISCOVER OF AN URBAN VOID}

The project for Porta Volta was born from the investment of Feltrinelli Group, which decided to entrust the construction of a building, intended to host its Foundation, to the architects Herzog\&de Meuron. Completed in 2016, the building located along the axis

\footnotetext{
${ }^{3}$ During a workshop conducted with some students of Politecnico di Milano in June 2017, a student was invited to disassemble his tripod by a security guard, who invited him to ask for a permit to be able to take pictures of the plaza and its activities during the day. ${ }_{4}^{4}$ Milan, like London and New York, faces and discusses the issue of pseudo public spaces (POSP: Privately Owned Public Space), places at the center of tensions, precisely, between ownership, uses and management:

https://www.theguardian.com/cities/2017/sep/26/its-really-shocking-uk-cities-refusing-to-reveal-extent-of-pseudo-public-space

${ }^{5}$ Referring to the recent terrorist attacks in Barcelona (2017), Nice and Berlin (2016), which questioned the use, sharing and security of public spaces.
} 
of via Pasubio, in correspondence with the former tollhouse of Porta Volta, represents an interesting real estate transaction carried out in Milan; the building of a private nature assumes a complex public role, in relation to its location in the consolidated city fabric. The large void that surrounds the Feltrinelli Foundation on the side of Via Pasubio was born as a public space, a place of aggregation and sharing; the proximity to both Corso Como axis and the development of Chinatown in via Paolo Sarpi gives centrality to this intervention which becomes an urban device able to aggregate people and activities.

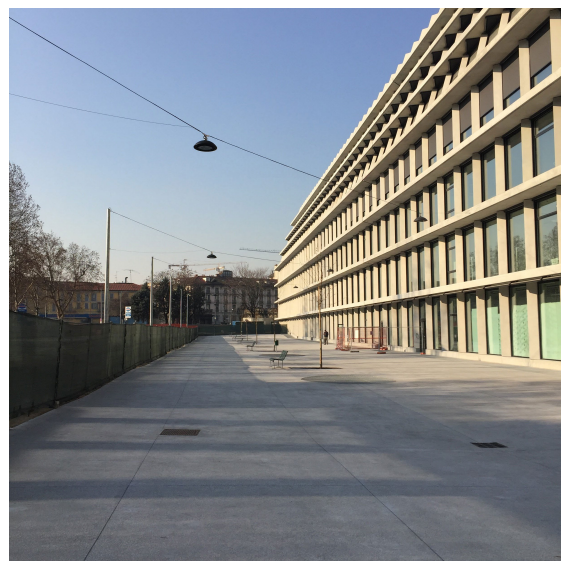

Figure 3. Feltrinelli Foundation (Milan): a forgotten and to be completed public space. (Giulia Setti 2017)

If Piazza Gae Aulenti lives on mix between public and private activities, the Feltrinelli Foundation denounces a latent, and less resolved, tension between informal uses and urban practices; the building, design by Herzog\&de Meuron, concentrates offices and private activities inside, while only a limited portion opens to the city with the presence of a library and a café, thus the surrounding space does not seem to have the strength to constitute itself as public space. It is an uncertain and transitional space between the monolithic and monumental interior of the Foundation and the austerity of the external ground floor: here tensions between actors and uses appear much more radical and less balanced.

Public space is determined beyond design negations; it finds the strength to become a lived-in urban space, not just a residual void. If it is true that we are witnessing to a revival of public space, to recapture and enhance the idea of sharing, a reflection should be opened on the characteristics that define these spaces. Piazza Gae Aulenti perhaps supported the growing need of squares and meeting places that rise around the Porta Nuova transformation and the lack of protected places to meet. At the same time, Feltrinelli Foundation denies the public space, leaving it on the borders, but witnessing a growing interest that leads to think of a future enhancement of what today appears to be an empty, albeit frequented, surface (Fig. 3).

The uncertainties that the public space project, close to Feltrinelli Foundation, opens up concern the role and power of the architecture itself, designed as an urban catalyst, able of fulfilling all these needs. The pure and measured beauty, monumental and massive at the same time, of the building designed by Herzog\&de Meuron strikes and fascinates to the point to forget what does not happen around. Or the surrounding silence emphasizes the rigor of the project; the design of public space, around the Feltrinelli Foundation, appears too silent, too hidden and covered by the strength of the architectural intervention. However, it is the life surrounding the architecture that seems able, in certain circumstances, to cover this lack.

\section{CITY LIFE: THE ICONIC ARCHITECTURE}

As mentioned before, the economic crisis, which began in 2008, has eradicated and changed values and uses of public space, as well as diverting attention to the redesign of void; a void, however, which is the terrain of continuous struggles and claims, tensions and appropriations. 
Based on this discussion, the description of the transformation and recovery of the former trade fair, now called City Life, take place. The City Life project strengthens some of the key questions raised before: an operation managed by private actors (Generali Assicurazioni, Allianz in particular) was born with the idea of giving back to the city an important portion of its urban fabric, densifying and concentrating the built up interventions into three skyscrapers, The Straight One, The Twisted One and The Curved One, as the expression of as many designer firms: Arata Isozaki, Zaha Hadid, Daniel Libeskind (Fig. 4).

An ambitious project that shows the integration of spaces for offices, tertiary and residential activities with a generous open space for public uses; the architectural objects should
City Life is (and perhaps will remain) a void in the city, a space not practiced because it is thought in an extra urban scale, according to the logic of homologation of many European cities. The tensions between public and private sectors will probably explode, giving to the city a space that will never be public, in the traditional sense of the term, but it could define a new paradigm of contemporary public surfaces. City Life denounces a tension between the unique forms and uses of the historical city compared to the homologation promoted and produced by the global market, where to grow seems to be a synonymous of good architecture.

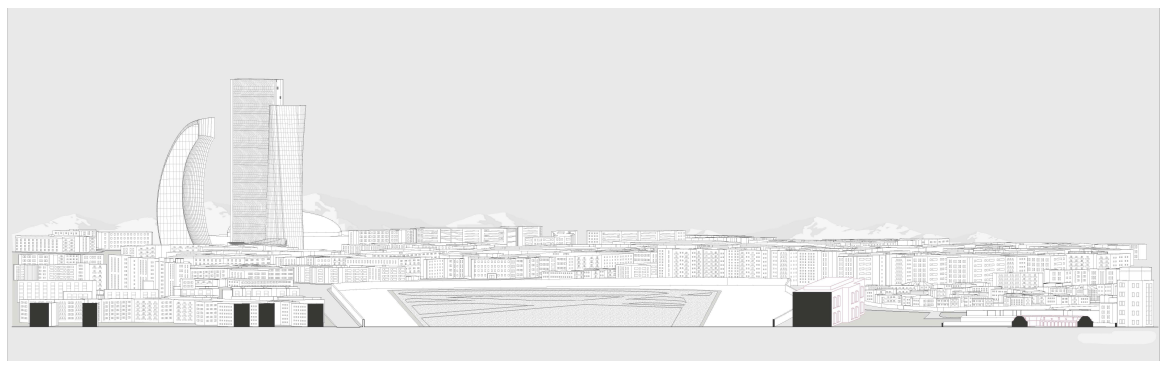

Figure 4. City Life project, the design of a new verticality (Mara Fraticelli 2019)

have been kept together by public space and by a partially covered square. The project has undergone numerous delays and slowdowns due to the economic and real estate crisis, as well as to uncertain fate of the three towers, launched in 2004, started in 2007, it has not yet been completed, the last tower by Daniel Libeskind is now under construction. In this context, the disconnection between the iconic and self-referential force of the three skyscrapers and the uncertainty of the open space is evident; the open space is not unable to unify the ground floor because it is not thought as an attractor or as a dense urban space

\section{ARCHITECTURAL TENSIONS: THE FUTURE OF CONTEMPORARY PUBLIC SPACES}

To read and to observe tensions between private property and public use of space leads to reflect on the meaning of the term public space today, as well as on the processes and methods with which it is possible to think and design contemporary spaces (de Solà-Morales 2009)

The cases shown, and the example of Milan, indicate the will and the need to regain possession of sharing places; it is possible to see these phenomena starting from the rediscovery generated by the interventions of 
Porta Nuova and Porta Volta. At the same time, it implies a redefinition of the concept of public associated with the term space.

Architectural and urban tensions challenge traditional definitions and place us facing hybrid places: conceived as public spaces, lived as such, but financed, built and regulated by private entities. Milan, as well as London and other European cities, presents similar cases, characterized by the presence of pseudo-public spaces; spaces poised between public wills and private instances, where tensions emerge in the use and appropriation of these places.

It is a tension that denounces a transition and a misunderstanding of uses and properties; generating spaces designed to compensate private real estate investments, the only ones able to have the necessary capital for these interventions. What will be the duration of these places and how they will age, is a question to which it is not possible to give answers now; however, a rapid aging of public pseudo-spaces could be imagined.

Places that could pass, like a current fashion language, therefore, undergo and quickly show the signs of the past. A fast time, the one of productivity and economy, that of the power of banks that made its life possible, a time that could escape and change. How much public space costs could be another topic able to show the implications of what has been described before. Within a changing scenario, such as the one of Milan, architectural and urban design must find strength and tools to become part of the building process of new parts of the city. Attention is increasingly focused on buildings, icon of modernity, therefore fragmented episodes that intensify the tensions between public and private. The project of public space needs integration and enhancement within the ongoing interventions. The recovery of large portions of city could not be separated from a calibrated and measured relationship between built-up space and open area.

Tension arises where this balance is lacking and where conflicting forces face each other in the use and appropriation of space. The cases described in this short journey in Milan tell about an evolving public space, result of mediation between private instances and public needs, where, however, an idea of how to design open spaces seems to be missed.

In the case of Porta Nuova, the new plaza invites because it is protected by the built edge and it is elevated above the roads, therefore able to consolidate and strengthen the idea of a new public space. In the case of Porta Volta, architecture is the catalyst of the entire intervention, leaving the role of emphasizing its power to the void.

The space surrounding the Feltrinelli Foundation has not yet had enough time to settle down and become part of everyday life and, perhaps, only time will help this integration. The context of City Life, on the other hand, leaves many doubts about the possible life of public space, financed by the Insurance Companies that will move here; it is a space out of scale, not public, still bare and unable to strengthen relations between different elements of the design.

Tensions observed in these places allows a redefinition of the concept of public space, a place of representation of the city's economic power (of banks, insurance companies, etc.), a showcase of recent transformations and a place to show urban and architectural contemporaneity.

The projects presented here described an articulated debate on the relationship between new and old, in a continuous process of design experimentation: new buildings are juxtaposed to the existing one redefining a new architectural language for Milan. In these years, Milan has represented a laboratory of constant mutation that shows forms and ways with which the architectural design and the design of public space could be defined. It is an open debate, still evolving, which however describes important changes in the construction, definition and use of contemporary public spaces. 


\section{REFERENCES}

AA.VV. 2013. Fight-Specific Isola. Art, Architecture, Activism and the Future of the City. Berlin: Archive books.

Aymonino, A. and Mosco, V. P. 2006. Contemporary public space: un-volumetric architecture. Milano: Skira, 2006.

Bianchetti, C. 2016. Spazi che contano. II progetto urbanistico in epoca neoliberale. Roma: Donzelli.

Carmona, M. et al. 2010. Public places, urban spaces: the dimensions of urban design. Oxford: Architectural Press.

Cerruti But, M., Kërçuku, A., Setti, G. and Vassallo, I. 2017. Tensioni Urbane. Ricerche sulla città che cambia. Siracusa: LetteraVentidue.

Cicalò, E. 2009. Spazi pubblici. Progettare la dimensione pubblica della città contemporanea. Milano: Franco Angeli.

Colomina, B. 1994. Privacy and publicity: modern architecture as mass media. Cambridge (MA): The MIT Press.

de Solà-Morales, M. 2009. Public Spaces, Collective Spaces. in AA.VV, Architectural Positions. On Architecture, Modernity and Public Sphere. Amsterdam: Sun.

Gaventa, S. 2006. New public spaces. London: Mitchell Beazley.

Gehl, J. and Gemzoe, L. 1996. Public spaces, public life. Copenagen: Danish Architectural press. The Royal Danish Academy of fine arts school of architecture publishers.

Kayden, J. S. 2000. Privately owned public space: the New York city experience. New York: The Municipality Art Society of New York.

Lotus. Meteo Milano, n. 161, 2017.

Lotus, The New, Again, n. 169, 2020.

Lynch, K. 1972. What time is this place? London:The MIT press.

Madanipour, A. 2003. Public and private spaces of the city. London-New York: Routledge.
Molinari, L. and Catella, K.R. 2015. Milano Porta Nuova. L'Italia si alza, Italy rise. Milano: Skira.

Rossi, A. 1981. A scientific autobiography. London: MIT Press. 

PAPER \#3.10

(SUB)URBAN; MERGING SUBURBAN HOME QUALITIES WITH URBAN HOUSING

Craig S. Griffen ${ }^{\mathrm{a}}$

aThomas Jefferson University, Philadelphia, PA, USA

\section{ABSTRACT}

For decades, the growth pattern for housing around American cities has been a continual, wasteful expansion outward onto greenfield land, leaving behind numerous vacant, urban blocks and brownfield sites. Recent rebuilding efforts on these vast lots by developers and government agencies has resulted in blocks of suburban-style homes where once stood row houses and factories. While suburban homes have certain desirable qualities missing in the city, the blocks of kitschy houses being built greatly conflict with the scale and patterns of the historic urban context. But these large, vacant tracts of lower-priced land outside the urban core present an opportunity to rethink how we can better rebuild housing in the city. Instead of just recreating the dark, cramped 16-foot-wide worker's row house of the past, can we appropriate the best aspects of suburban housing, as well as incorporating energy-efficient design? Can we design brighter, more spacious, sustainable homes with additional outdoor space, but do it in a culturally sensitive manner that is more respectful of the existing urban context than is currently being done? This project investigated ways to create hybrid (sub)Urban housing typologies that: 1. Utilize passive energy strategies to improve comfort, energy efficiency and minimize carbon load; 2 . Reduce density to provide additional exterior and interior space while respecting and reinforcing existing urban patterns; and 3. Increase home affordability by using economy of scale prefabrication techniques. Proposals, from both my personal explorations and student work developed in a 5th-year design studio, demonstrate how concepts imported from suburban housing could coexist with, and if done thoughtfully, improve dwelling in the city.

\section{KEYWORDS}

Suburban development; urban housing; sustainable construction.

\section{INTRODUCTION}

"Global urbanization is heading towards infinite suburbia. Around the world, the vast majority of people are moving to cities not to inhabit their centers, but to suburbanize their peripheries". Infinite Suburbia ${ }^{1}$

In the second half of the 20th century, the United States had a disgraceful record for abandoning its cities in favor of the new suburbs beyond, with Detroit being the bestknown example. The post-war exodus from cities to the suburbs left extensive amounts of abandoned houses and factories that became deserted lots and blocks. By the end of the century, a 2001 study of 70 US cities found an average of $15 \%$ of urban land was vacant. ${ }^{2}$ At the same time, the suburbs kept exploding outward, eating up virgin greenfield land (valuable for carbon sequestration) and stretching farther and farther from the urban core. But continued expansion outward beyond the Exurbs is not a sustainable planning strategy. Because of the typical, radial expansion from an urban center, roads, utilities and public services are spread 
farther apart, stretching the infrastructure and reinforcing the reliance on the automobile for transportation. But abandoned urban land left over in the outer fringes of the city (and increasingly in older inner-ring suburbs) comes with an existing infrastructure of utilities, streets, and public services already in place, thereby providing prime opportunity for housing redevelopment. Thankfully, many US cities have seen a reversal in the movement of people outward, to a surplus of people moving back in. But this sector is mainly populating the urban core because of its cultural amenities, ease of transportation and relatively safer neighborhoods. In many cities, like my case study city of Philadelphia, there is a zone outside the city center but inside the inner-ring suburbs that is not experiencing this same degree of urban rebirth. This zone contains many former working-class neighborhoods with small row houses surrounding the factory where the residents worked. (e.g. Fig. 1) When industry left the city, many residents left with it, abandoning some neighborhoods to slowly degenerate over time. Vacant houses became vacant blocks as the homes were bulldozed and the lots sat empty for years. But the cheap land associated with these neighborhoods in less desirable parts of the city presented an opportunity for government agencies to build subsidized public housing. The welldocumented failure of public housing towers has been replaced by another approach which, while more conscious of neighborhood scale, has had questionable outcomes. The recent trend for subsidized housing by agencies like the Philadelphia Housing Authority (PHA) is to construct multi-block neighborhoods of pseudo-suburban twin (duplex) houses that are nothing like the row homes they replaced. ${ }^{3}$ Instead of multi-unit rows of attached row houses, the double homes are set back from the street and incorporate suburban elements like gable roofs, driveways, lawns and other suburban elements that feel out of place in the city fabric. (e.g. Fig. 2) In some cases, even the stereotypical white picket fence has appeared. While architects and planners may rightly criticize the manner in which suburban style homes are dropped into an urban pattern without much thought, the houses are all occupied, well-liked by the residents and have a multi-year waiting list. It appears the American Dream of the suburban house image is as powerful in the city as outside it.

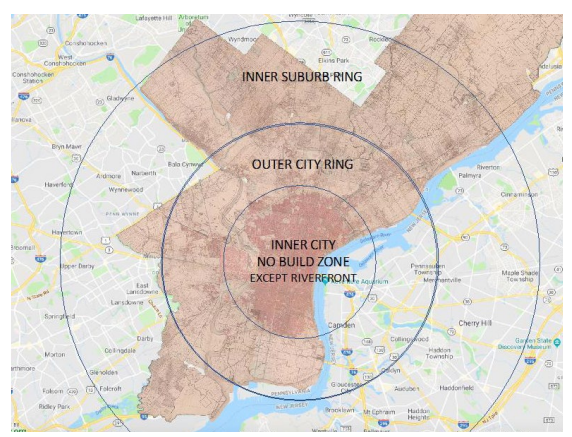

Figure 1. Philadelphia's Outer Ring. Source: Author

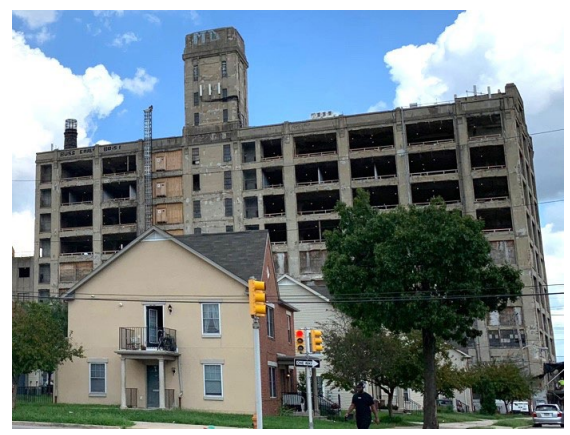

Figure 2. Suburban Style Houses in the City. Source: Author 


\section{SUBURBS IN THE CITY}

\subsection{Smart Rebuilding}

Often, a first response from architects and planners when confronted with an empty lot or block in a city is to restore the density and scale of the previous buildings, thereby reestablishing the urban room of the street. Yet as we rebuild our cities, we have an opportunity to reevaluate this strategy to seek ways to create healthier, happier and more sustainable ways of urban dwelling. The typical row houses surrounding the former factories were built to be cheap, basic, no-frills housing for blue-collar workers. Sixteen-footwide houses built right on the street with low ceilings, small windows on narrow front and back facades and tiny back "yards", created dark, cramped spaces with little access to air, light and space. In addition, most workers relied on public transportation trolleys and could not afford a car, so space for parking was never considered in the original planning and therefore is a problem today in these older neighborhoods. While we don't want to swing the pendulum to the opposite end by directly transplanting suburban housing models into the city, there is an opportunity to create a hybrid model that incorporates some of these suburban amenities while still preserving the best qualities of city living.

Since we are considering new types of housing, it is also ethically imperative to address the issues of climate change through passive energy-efficient house design that is also affordable to the middle-income buyer. There are a growing number of buyers who are concerned with the sustainability of our environment and would prefer an energyefficient house, but they are often younger firsttime buyers who cannot afford the price for their first purchase. However, the increasingly palpable effects of climate change are causing a corresponding increase in the public's acceptance of it as a tangible looming crisis. Sixty-two percent of the public now understands that global warming is caused mostly by human activities, an increase of 10 points since $2015 .{ }^{4}$ As climate change worsens and affects more people, we may see an increasing demand for more efficient homes as well. Because the locations of these vacant sites are outside the city center, the price of land is lower. Therefore, houses do not necessarily need to be constructed to maximize every available square foot of space and so can be built at a lower density to allow in more sunlight and provide more interior and exterior space. Taking this all into consideration, can we incorporate ideas from suburban and sustainable design to create brighter, more open, sustainable and affordable urban homes with additional exterior space, but in a culturally sensitive manner than is being done now? This paper documents personal research that was tested as the subject of a 5th year studio project. The main objectives of the project were to investigate ways to create hybrid (sub)Urban housing typologies in the city's outer rings that:

1. Utilized passive energy means like the sun for daylight, heat and power and the wind for natural ventilation to improve energy efficiency and reduce carbon load.

2. Reduced density to provide space for larger, brighter living spaces, off-street parking and personal green space while respecting and reinforcing urban patterns.

3. Increased home affordability in the more expensive urban market by using the economies of scale of prefabrication techniques like highly-insulated, panelized skins and modular construction.

\subsection{Passive Energy Efficient Homes}

Many belive any new form of housing has an ethical responsibility to address the crisis of 
climate change to minimize energy use and carbon load. When looking at the the potential of solar energy in the city, orientation to the sun versus the orientation of the city grid are vital concerns. Suburban development houses face the street, regardless of the cardinal direction. But a typical passive solar house extends in the east-west direction with abundant glazing facing to the south. The grid form of urban streets can be favorable geometry for transferring passive solar strategies if oriented close to south. If a city's grid is oriented within $20^{\circ}$ of south, (it is $11^{\circ}$ in Philadelphia) it can serve as a prime planning layout for fitting passive solar houses into the urban fabric. In a previous research project looking at the potential for passive solar in suburban developer housing, I discovered the Charleston house typology worked well as a precedent to provide both sun access and privacy. Since this house type is itself an urban form that fronts on the street, the type has long ago proven itself viable in an urban setting, and Renee Chow has already demonstrated how the urban fabric pattern of the Charleston typology can be a sustainable solution for increasing density and reducing suburban sprawl. ${ }^{5}$ This typology also works well when passive energy strategies are added. By placing a gallery and side yard to the south of the thin house, there is enough clearance for the sun to clear the roof and penetrate the neighboring house to the south. (e.g. Fig. 3) Since the glazed wall on the south looks across the lawn to the mostly opaque north wall next door, privacy is maintained. And when arranged in a checkerboard pattern on an urban block, each home gains personal off-street parking and a private green side yard. In this way, these hybrid homes incorporate qualities of suburban housing while maintaining the urban wall and the fabric of the previous neighborhood, just more loosely woven.

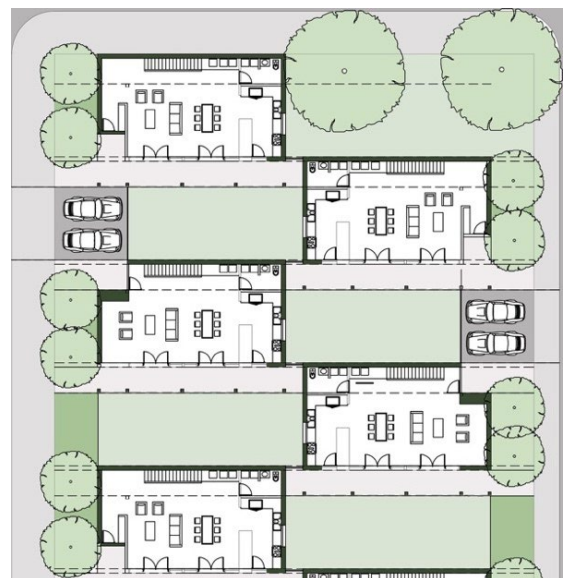

Figure 3. Passive Urban House Model. Souce: Author

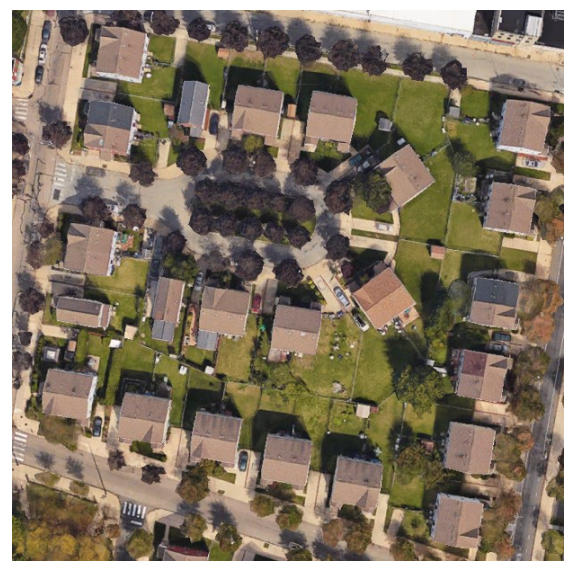

Figure 4. "Suburban" Urban Homes. Source: Google Maps 


\subsection{Reduced Density}

Another myth of city living is that housing sales and rent prices are more expensive than in the suburbs. But in certain markets it is the opposite, and Philadelphia is one example. It is nearly twice as expensive to live in the suburbs of Philadelphia as the average rent takes up $18.7 \%$ of the area's median income versus $9.8 \%$ in the urban market and mortgage payments take up an average of $30.5 \%$ of the median income compared to $20.9 \%$ in the city. ${ }^{6}$ As mentioned before, the prime sites for this type of investigation are located on land outside the expensive urban core but inside the first-ring suburbs, in the outer city ring. The land prices are lower in these areas for a very good reason; they are typically less desirable lower-income neighborhoods, so redevelopment of these sites would need to be incremental and grow out from more established neighborhoods. However, these areas provide the necessary amount of affordable open and affordable land for developing blocks of lower scale housing on the larger urban scale. The recently constructed PHA suburban-style twin homes on multiple blocks in the Poplar neighborhood of North Philadelphia, replaced a failed earlier attempt of public housing named the Richard Allen Homes. ${ }^{7}$ The new homes have (small) front porches, off-street parking and surprisingly large back yards for the city. Even the cul-de-sac, typically exclusive to suburban planning, is used just blocks from the urban core. (e.g. Fig. 4) While this layout does provide more open green space, it is not well utilized and the spacing and setbacks of units conflicts greatly with the established rhythm and sense of enclosure of the surrounding older neighborhoods. But we can use the density of these developments to establish a baseline ratio for a reasonable number of units per acre in this part of the city. The proposed checkerboard model above would create an even higher density level while still providing room for substantial, secure side yards and personal off-street parking. And bringing the houses closer to the street would establish an urban wall more in tune with the surrounding neighborhoods than the current homes on the site. This concept is also scalable to accommodate a range of house sizes on different width blocks.

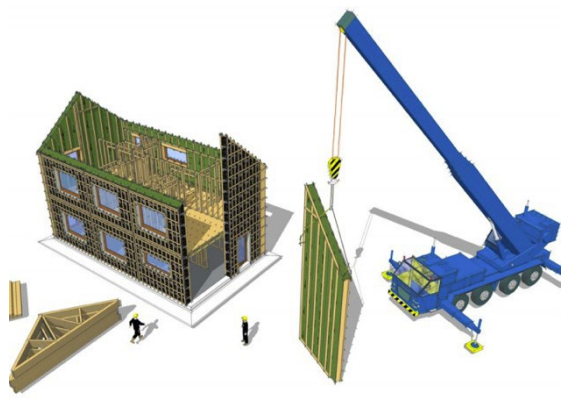

Figure 5. Panelized Wall Assembly. Source: Ecocor

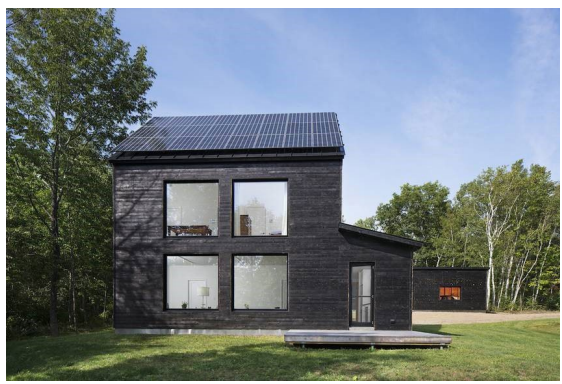

Figure 6. Passive Prefab. Go Home. Source: Go Logic

\subsection{Affordable Construction}

All new homes should strive to achieve Passive House level energy-efficient envelopes, but the additional materials needed to create these high-performing wall and roof assemblies also drives up their initial cost. The developer housing industry has created successful methods for pre-packaging building elements

\footnotetext{
${ }^{6}$ Heather Senison, The Suburban Burden: Living In The City Is Less Expensive In These Areas, (Forbes Magazine, October 17, 2018) ${ }^{7}$ Kromer
} 
to reduce labor and material costs. Because of the volume of houses produced using prefabricated assemblies, developers like Toll Brothers have surprisingly been able to keep their construction cost below $\$ 100$ per square foot. This economy-of-scale strategy could be extended to urban passive houses when built at the volume of an entire block. To be economically feasible, these houses cannot be site-built, but should utilize modular or prefabricated construction techniques. One possible solution is the use of prefabricated panelized wall and roof panels such as those manufactured in the US by the Ecocor company, that are shipped to the site and erected by cranes to shorten construction time and save labor costs. ${ }^{8}$ (e.g. Fig. 5) The long, thin design of the homes, intended initially to capture south light, is also a good proportion for modular units that could fit on the back of a flatbed truck. The firm Go Logic has been producing several models of prefabricated, passive Go Homes that are constructed in units and assembled on site. ${ }^{9}$ (e.g. Fig. 6) The construction site assembly time cost-savings would help to balance out the additional material costs of the wellinsulated envelope panels and increase home affordability.

\subsection{Studio Results}

These ideas were tested in a fifth-year architecture design studio that asked students to incorporate suburban style housing amenities into new housing prototypes at the periphery of the city. The semester was divided into 3 major phases consisting of 1 . Research \& analysis, 2. Site selection and programming and 3. Masterplan/house design. The charge was to reevaluate the potential of detached, semi-detached and attached low-rise housing incorporating suburban style amenities in both semi-urban and inner-ring suburban conditions. The proposed design solutions needed to address the realities of today's market and legal constraints but also present a forward-looking idea of what could be developed in the future.

In the first phase, students leaned about the history of several experimental suburbs, ${ }^{10}$ and visited sites of less successful examples of suburban/urban style housing, including the PHA houing above. They conducted extensive research in small groups to investigate issues of Philadelphia suburban housing including history and precedents, land and zoning codes, affordable/sustainable home construction, and socio/economic demographics. In Phase 2, students evaluated and selected an underutilized site outside the urban core of Philadelphia and wrote a program that identified the target audience and proposed the percentage of detached, semi-detached and attached housing they felt was best suited for their chosen site. In the third and largest phase, groups refined their program and designed a detailed masterplan with building/ lot sizes, street/sidewalk layouts, and green/ open spaces. (e.g. Figs. 7-8) From this plan each student created a model home design that fit into their framework. One example of each different house typology used, detached, semi-detached or attached, was developed per group. As the house designs developed, adjustments were made to the masterplan in a non-linear design process. Collaboration among the team members was essential to ensure a cohesive collection of house types that maintained neighborhood identity. Students were given freedom with their chosen site to suggest a variety of housing typologies and many veered towards traditional urban infill housing as part of their group's masterplan. However, the two examples shown in this paper demonstrate projects that best integrated suburban home qualities into their part of the masterplan and home design.

\footnotetext{
${ }^{8}$ Hallie Busta, More PreFab Passive House Options for North America, (Architect Magazine Website, June 14, 2016)

${ }^{9} \mathrm{GO}$ Logic Website, http://www.gologic.us/

${ }^{10}$ Amanda Kolson Hurley, Radical Suburbs: Experimental Living on the Fringes of the American City, (Belt Publishing, 2019)
} 


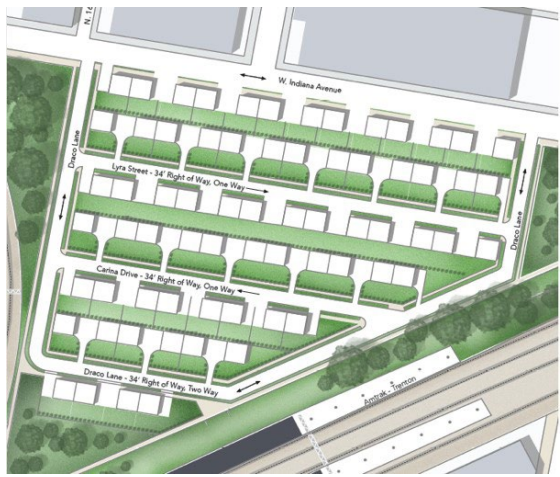

Figure 7. Example 1 Site Plan; Turchi, Messner, Juliano

In Example 1, the group selected a site with many vacant buildings and lots at the intersection of several train, subway and bus lines where they proposed a new transitoriented development (TOD). While other team members proposed double-lot infill housing and a Single Room Occupancy hotel, Alexandra Turchi focused on designing a neighborhood of low-income passive solar homes on an underused parking lot next to the train station. (e.g. Figs. 7, 9-11) Her goal

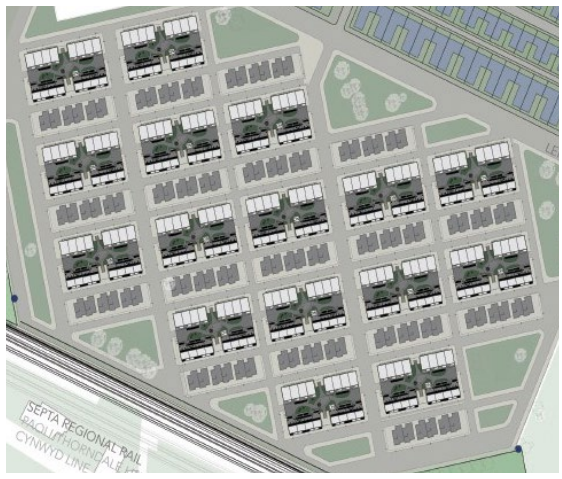

Figure 8. Example 2 Site Plan; Pratty, Etienne, Hughes

was to discourage over-gentrification by creating small affordable homes that existing residents of the surrounding depressed neighborhood would be able to afford. The twin (double) homes have an abundance of windows and shading balconies on the south side, minimum fenestration on the north for privacy, and are arranged in a checkerboard pattern to maximize sun access. Each unit also provides a private parking spot and a green space to the south.

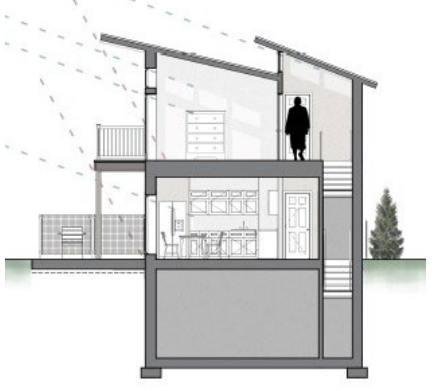

Figure 9. Example 1 Section: Turchi

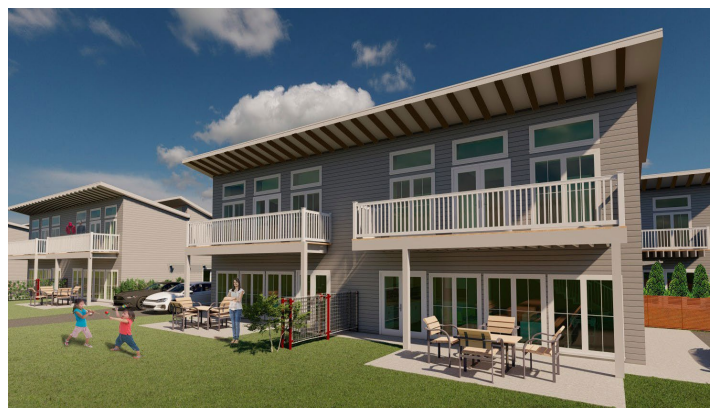

Figure 10. Example 1 Housing, South Perspective: Turchi 


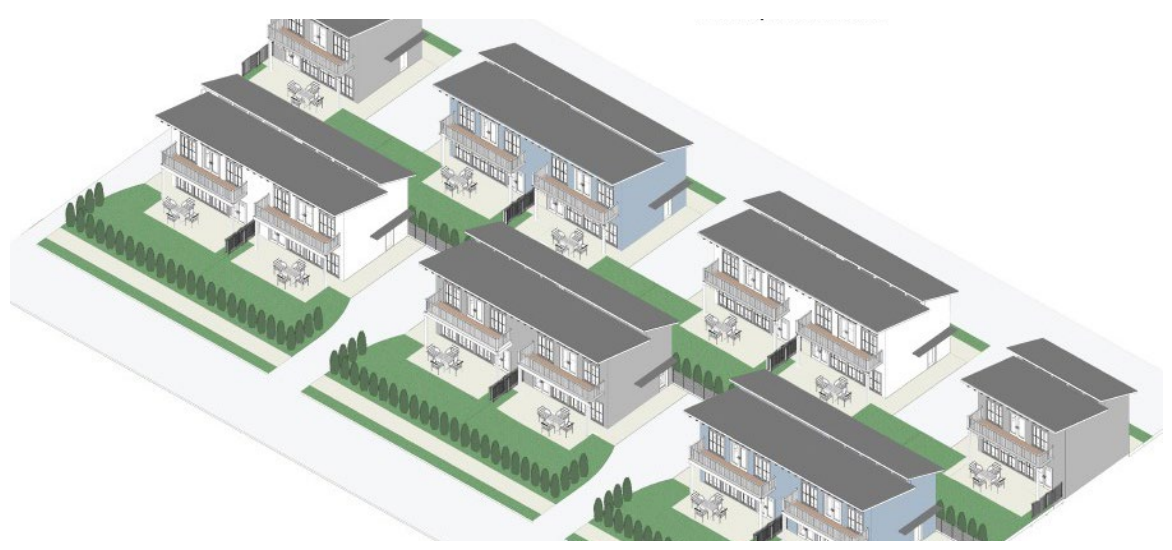

Figure 11. Example 1 Isometric; Turchi

For Example 2, the group selected the site of a long-abandoned rail yard just a block away from beautiful Fairmount Park, one of the largest urban parks in the US. A new street grid was oriented towards the south to maximize solar exposure and two different types of passive attached housing were proposed on alternating blocks. Lauren Pratty's design (e.g. Figs. 8, 12-13) proposed two rows of 3-story rowhomes separated by an elevated common green space with a parking garage below. The elevated terrace provides a safe, enclosed place for kids to play while sheltering the cars below to reduce hard-paved surfaces and eliminate garage doors on the street. The plaza width is sized, and the southern rowhouses are massed, to ensure enough south sun reaches both the green space and the homes on the north side.

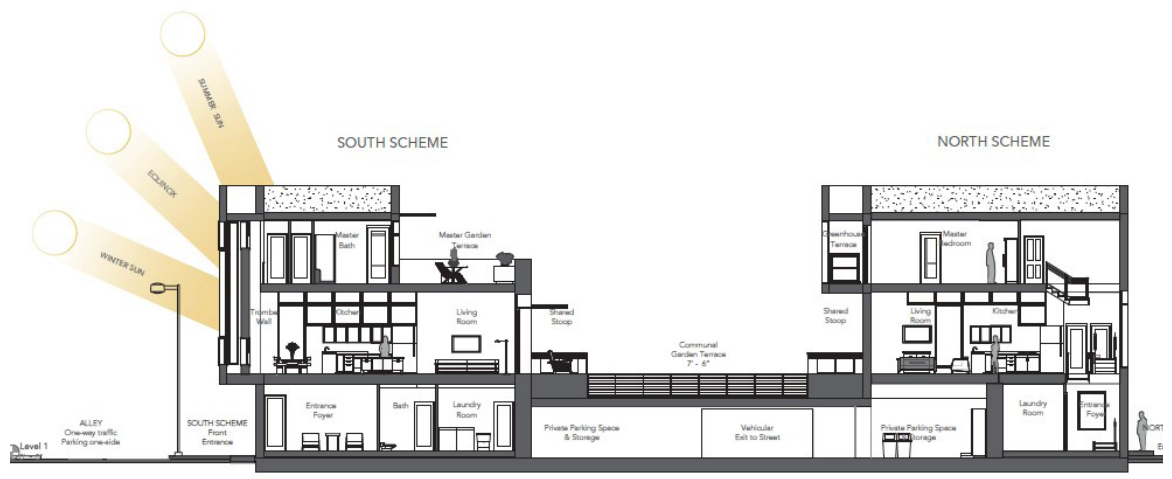

(2) SECTION - A

Figure 12. Example 2 Cross Section; Pratty 


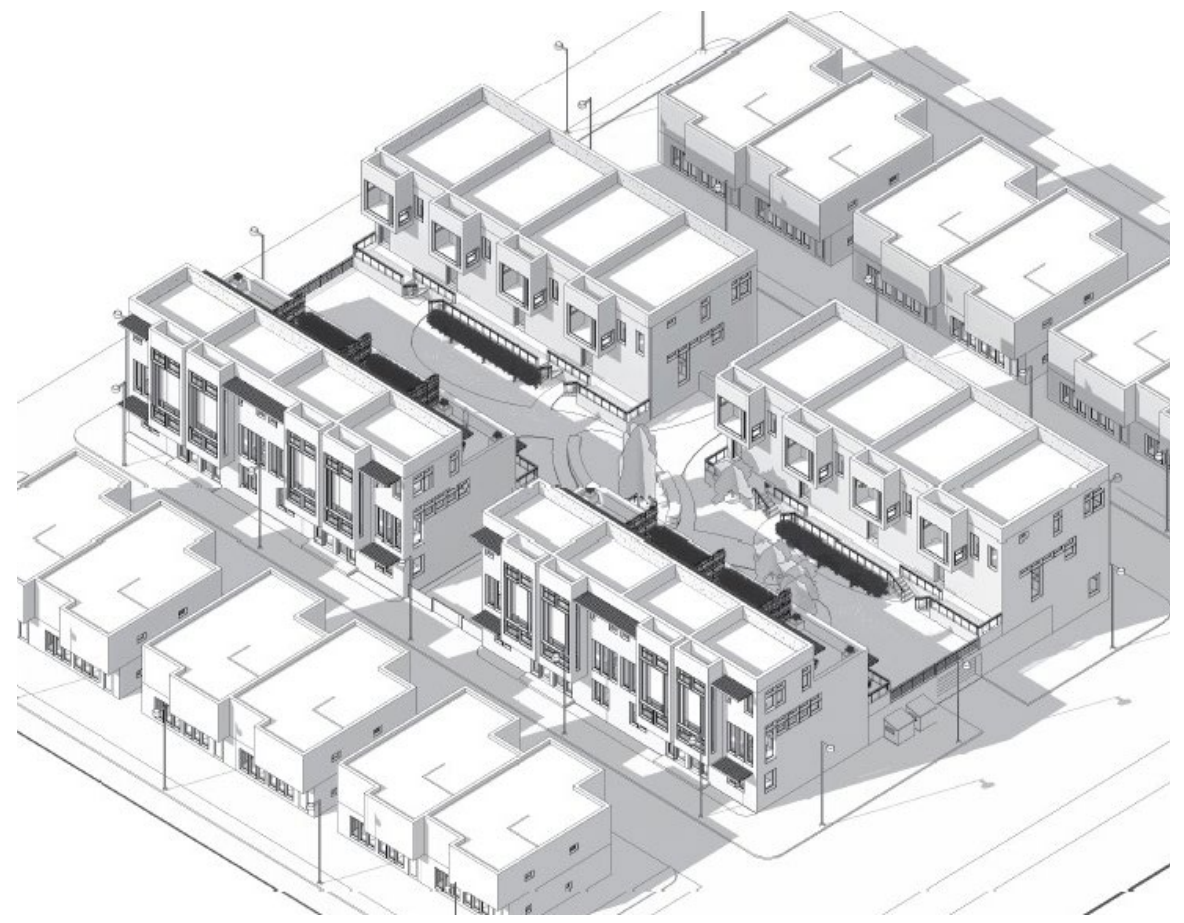

Figure 13. Example 2 Isometric; Pratty 


\section{CONCLUSION}

"...the general idea was that the suburbs offered comfort and personal space, private backyards and a bedroom for each kid. City living was more exciting and offered culture and a more diverse mix of everything, but required some sacrifice. Apartments were smaller, parking a headache and a backyard unimaginable."11

Both of the examples above were able to create hybrid (sub)Urban housing typologies that provided dedicated off-street parking, more green space, direct sunlight for heat and light, and are forms that are good candidates for prefabrication. They add these suburban qualities while simultaneously respecting and maintaining the urban scale and patterns of the existing neighborhood to take advantage of the underused land outside our city centers. Urban dwelling has shown to be a very sustainable way to live because of the shared walls, services, transportation, etc. created by its density of buildings. To attract hesitant home buyers away from the suburbs and into the city, we may need to entice them with certain qualities of suburban living, along with greater energy efficient homes, that buyers are starting to request. ${ }^{12}$ Some builders are already offering suburban amenities like rooftop lawns with hammocks, easy parking and house-like apartments in their new urban developments claiming "the suburban life in the city is what we're going for."13 The open lands at the peripheries of our cities could provide the place to blend the best of both worlds. If the perceived (and real) negative aspects of city living such as small, dark homes with scarce parking and tiny yards can be minimized though (sub)Urban hybrid house models, more people may be willing to move back inward to fill the holes left at the city's fringes by decades of continual, outward expansion.

\footnotetext{
${ }^{11}$ Candace Jackson, The Suburbs Are Coming to a City Near You, (New York Times, May18, 2019)

12 Gabriel Popkin, Can expensive, ultra-green homes sell in a gritty suburban Maryland town?, (Washington Post Magazine, May 18, 2017)

13 Jackson
} 


\section{REFERENCES}

Alan Berge, Joel Kotkin, Celina Balderas Guzman, Infinite Suburbia, (Princeton Architectural Press, New York, 2017)

Brookings Institute, Vacant Land in Cities: An Urban Resource, (2001)

John Kromer, Fixing Broken Cities: The Implementation of Urban Development Strategies, (Routledge, 2010)

Yale Program on Climate Change Communication and the George Mason University Center for Climate Change Communication, Climate Change in the American Mind, (2018)

Renee y. Chow, Suburban Space: The Fabric of Dwelling, (University of California Press, 2002)

Heather Senison, The Suburban Burden: Living In The City Is Less Expensive In These Areas, (Forbes Magazine, October 17, 2018)

Hallie Busta, More PreFab Passive House Options for North America, (Architect Magazine Website, June 14, 2016)

GO Logic Website, http://www.gologic.us/

Amanda Kolson Hurley, Radical Suburbs: Experimental Living on the Fringes of the American City, (Belt Publishing, 2019)

Candace Jackson, The Suburbs Are Coming to a City Near You, (New York Times, May18, 2019)

Gabriel Popkin, Can expensive, ultra-green homes sell in a gritty suburban Maryland town?, (Washington Post Magazine, May 18, 2017) 

PAPER \#3.11

CHANGING THE CURRENCY OF MANUFACTURED LAKES IN THE GREAT PLAINS

David Karle

aUniversity of Nebraska, Lincoln, Nebraska

\section{ABSTRACT}

This paper tackles the principle research question of how the coexistence of old material extraction pits and new residential development has brought the process of urbanism into manufactured sites. This paper will discuss the importance of balancing urban expansion within decommissioned material extraction sites in the Great Plains, and specifically in the city of Grand Island, Nebraska, for the purpose of framing new design opportunities for post-industrial sites.

\section{KEYWORDS}

Urbanism; architecture; planning; reclaimed landscapes.

\section{INTRODUCTION}

Radical transformations of land use, infrastructure, and ecology that take place beyond urban city limits have been described by Neil Brenner as operational landscapes of planetary urbanization, all of which have made urban density possible (2018). Examples of these transformations include the resource extraction, waste management, food production, water use, energy harvesting, improved transportation networks, and creation of infrastructure that sustains urban society. These transformations have played a significant role in supporting urban growth throughout history, one example being the clear-cut logging operations in the midwestern United States and central Canada between 1890-1920 that provided lumber to build the modern commercial centers of Boston, New
York, and Philadelphia (Belanger, 2010, 9). Even today, this and other transformations continue to create significant social, spatial, economic, and environmental change.

Prior to industrialization, city and landscape existed not in a state of conflict, but a state of support. It was only with the coming of the industrial era that cities, countries, and landscapes became isolated zones of occupation and practice. What is often left in the wake of these operations is a decommissioned site with minimal foresight or opportunity for future use. These decommissioned or out-of-use sites index the histories and eras of urban and rural landscapes, and include railroads, sandpits, train stations, single-room schoolhouses, and post offices. Over time these abandoned sites scar the built environment and often service an urban- or infrastructural-scale agenda. As Lucy Lippard describes, "urban culture is unaware of its origins and rural birthplaces" (Lippard, 2014, 11).

Today, urban and rural America are littered with evidence showing the country's former industrial prowess over the last two centuries, and many of these old places, now abandoned, hold new latent value for their transformation and reuse. The Midwest rustbelt and the Mountain West (Berger, 2002) regions have arguably been the most impacted by rapid industrial development. These areas frame the more seldom-discussed Great Plains, whose industrial-scale sites of natural resources (particularly water and sand) have serviced large metropolitan regions around the globe for over a century. This essay addresses the principle research question of how the coexistence of old material extraction processes and new residential development have brought the process of urbanism into 
manufactured sites. Specifically, it focuses on the importance of balancing urban expansion within decommissioned material extraction sites in the Great Plains for the purpose of framing new design opportunities for postindustrial sites.

The Great Plains has continually reclaimed old industrial sites by seeking new solutions via innovative programming. This can be seen in examples ranging from sites of agricultural products and production to sites of material extraction. Unlike historic landscape-scale sites such as urban brickyards and cement plants that pose enormous difficulties for brownfield redevelopment, Nebraska's rural sandpits are post-industrial sites with valuechanging capacity for emerging recreationaland architectural-scale interventions altering the currency of water by creating new, untapped spatial and environmental configurations that balance systems of urban growth, material extraction, and ecology. These configurations take the form of parks as well as planned and unplanned residential developments ranging from suburban developments and single-family estates. Alan Berger suggests these reclaimed manufactured landscapes "reflect cultural values and shape new models of consuming and occupying the land" (Berger, 7-9). Cultural values change the built environment quickly and often with unforeseen impacts to the space, environment, and quality of life. To understand this impact on the built environment we must recall the value of extracted materials in the Great Plains.

\section{EXTRACTION IN THE GREAT PLAINS}

\subsection{History of Water in the Great Plains}

Thomas Jefferson's label of the Great Plains as a garden (1803) was central to his concept of agrarianism, initiating the first misunderstanding of water in the Great Plains. Decades later in 1820 this reading was corrected by explorer Stephen H. Long's label of "great desert," which serves as a more accurate reading of the historical and current condition of the land. The late 1800s saw a rise in attempts both locally and nationally to fabricate water in barren arid climates. This movement was led by Frank Melbourne, who traveled the country alluring communities with his claims to fabricate water from the sky. The idea of fabricating water was revisited by farmers and ranchers in Colorado and western Nebraska through the use of pivot irrigation. A few decades later, however, the role of water was barely considered by the U.S. government in its 1936 New Deal Planning Report for the drought-stricken region, as discussed in Gilbert White's 1986 essay "The Future of the Great Plains ReVisited." White posits that the implementation of groundwater pumping in the early 1940s and resultant drought-resistant crops "altered their [productivity] capacity" for decades to come (White, 1986, 93). Fabricating water through groundwater pumping and access water through the root systems of droughttolerant crops has attempted to mediate the harsh climate above the earth by using access water below the surface.

Through resource extraction technology such as the ubiquitous fields of water-pumping wells for cattle and agriculture, the value of pumping water in the Great Plains has never been more clearly visible. Today, nearly one third of irrigation to the region's crops is supplied by the High Plains Aquifer. The semiarid region of the Great Plains has had a long and often troubled relationship between water and sand, as documented most notably during the Dust Bowl of the 1930s. Today, water and sand are connected through the process of aquifer recharge, although the recharge rate does not equal the rate of extraction. Throughout the region, sand serves as a building block for ecosystems, agriculture, and the built environment. 


\subsection{History of Sand in the Great Plains}

James Swinehart, emeritus research geologist, notes that "the Central and Southern Great Plains contains the greatest concentration of windblown sand in North America" (Swinehart), which includes the Nebraska Sandhills, a national natural landmark and region of mixedgrass prairie on grass-stabilized sand dunes in north-central Nebraska that covers just over one quarter of the state. The Sandhills are the largest and most intricate wetland ecosystem in the United States, and contain a large array of plant and animal life. In addition to being an ecological building block, Nebraska's sand has been considered a commodity since the settlement of urban areas in the 1800s and continuing with the expansion of continental infrastructure systems such as the interstate highway network. The population of Omaha quadrupled from 30,000 to 120,000 in the late 1800s, and the city's first asphalt pavement was laid in 1882, sparking an ambitious street improvement project. This endeavor would last for the next forty years and expand the city's transportation network while providing a huge market for the sand used in making asphalt. At the time, sandpit mines were mostly located along railroad tracks, allowing the use of steam-powered drag-line as well as making it easy to transport material across the state.

Between 1900 and 1993 Nebraska hosted 3,228 separate sand and gravel pits covering nearly 40,000 acres. In 1986 alone over 9,600 short tons of sand and gravel with a value of nearly \$24 million were sold or used by producers in Nebraska. In 1999, the annual production value of Nebraska sand and gravel was valued at approximately $\$ 40$ million. Following the reduction in construction activity that began with the 2008-2009 recession and continued through 2011, the construction industry again began expanding in 2014 with increased production and consumption of cement, construction sand and gravel, crushed stone, and gypsum, mineral commodities that are used almost exclusively in construction.
Sand and water in the Great Plains continue to negotiate space and function similar to the way they did a century ago. More recently, the economy built on sand and water has expanded the value of both by considering old commodity sites based on sand and gravel extraction pits into new amenity-based sites through recreational and residential developments. The old sites consist of decommissioned out-ofuse sand and gravel extraction locations, which are then reclaimed with new amenity-based programs allowing the site to evolve with the new needs and values of the local community.

\section{SAND AND WATER}

\subsection{Sand for Lakes}

The majority of sand and gravel extraction mines in Nebraska are located directly above the state's aquifers. Unlike other national mining locations, the water table along the Platte River extends only 5-10 feet below the surface, causing the sandpits to quickly fill $w$ ith water. $S$ andpit $m$ ines transformed into freshwater lakes dot the landscape and mask the extraction process in the state. The visibility of these lakes in the semi-arid climate has shifted regional assumptions about water from a mere commodity to a valuable amenity capable of generating an emergent city growth pattern and constructed ecologies that mask the material extraction process.

Nebraska is a landlocked state without any significant $b$ odies o f water, $m$ aking former sand and gravel sites reclaimed as recreational and residential lakes the prevailing lake type in the state. These sandpit lakes are not new to Nebraska and were the result of the state's infrastructure expansion during the 1950s. The cohabitation of old post-industrial sand and gravel extraction sites with new amenity-based programs reconsiders spatial programing in the form of recreational lakes, nesting grounds for endangered birds, and residential development. 


\subsection{Sand for Infrastructure}

In 1956 the Federal Aid Highway Act signed by President Dwight D. Eisenhower authorized construction of the National System of Interstate and Defense Highways. This was a grand plan that required both vision and material resources to produce the necessary 41,000 miles of highway surface. In Nebraska the decision was made to align the interstate highway with the state-spanning Platte River over a distance of 150 miles in the middle of the state. This alignment proved to be beneficial since there was a tremendous amount of raw sand and gravel material available for the extraction and mixing of concrete. However, balancing the river's potential with the needs of the highway would become a point of contention and debate.

During the construction of the interstate's overpasses and on-off-ramps, extraction pits quickly filled with water due to the high water table of the nearby Platte River. At the time, Mel Steen, head of the Fisheries Division of the Nebraska Game and Parks Commission, was aware of the high water table's effect and sought to challenge assumptions related to water and extraction pits in the Platte River valley by advocating for a chain of lakes. Steen determined specifications and "strongly

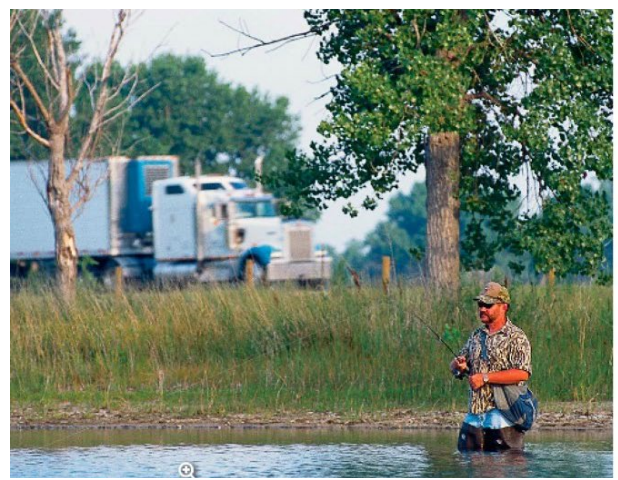

recommended the contractor be required to take fill dirt from a series of small, concentrated surface areas to a depth of approximately 15 feet" (Thomas). The sand, gravel, and fill from these sandpits were needed to construct the roadbeds and overpass approaches, and mining these materials off the right-of-way was an easy way to complete the task. At the time, Steen knew these excavations could create unique fishing opportunities for anglers, and engineers and fishery biologists lobbied hard to keep them within the public right-of-way of the interstate. Their efforts were eventually successful: currently the 150-mile section of I-80 from Grand Island to North Platte has more than 116 excavated lakes, 46 of which are publicly owned, making up 720 surface acres of water available for public fishing. These sites are collectively referred to as the 1-80 lakes (Thomas), and the first of these pits near Grand Island generated a 39-acre lake easily accessible from the interstate. These artificially constructed freshwater lakes are an example of a constructed ecology and are a spatial type overlooked by the design disciplines; they hold immense potential for balancing global extraction processes with local ecological systems and create new value for these areas through wildlife habitat (see Figure 1).

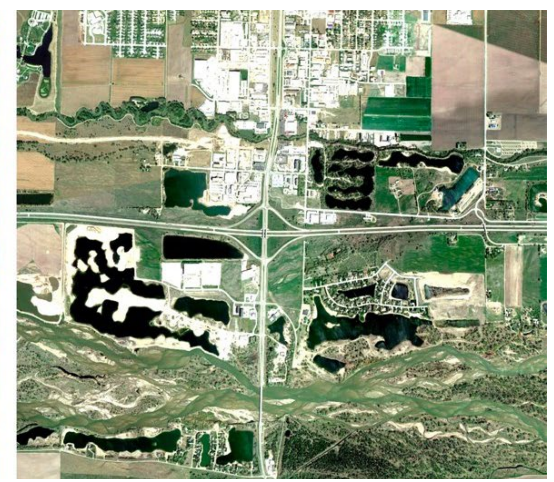

Figure 1. The 1-80 lakes range in size from 1 to 42 acres and are visible from the highway, offering habitats that attract new wildlife both above and below the water. (Left photo (c) Nebraskaland Magazine/Nebraska Game and Parks Commission, right image from Google Earth.) 


\subsection{Sand for Survival}

In Nebraska, sand is more than just a raw material for infrastructure: it is considered an essential habitat. The previously mentioned Nebraska Sandhills are only one example of large areas of sand providing an ecosystem for the state. Throughout Nebraska endangered birds are dependent on the byproducts of heavy industry, including old sandpit lakes, for survival. Active and abandoned sandpit lakes across the state currently sustain two populations of endangered and threatened birds: the interior least tern and the piping plover. These habitats are an example of a constructed ecology-or what David Fletcher describes as the unavoidable result of the interaction of infrastructural and natural systems (Fletcher, 2009, 34-51). In this constructed ecology sand provides an adequate place to nest and the lakes provide opportunities for feeding.

Historically, the state and federally endangered interior least tern and the threatened piping plover have flourishedo nt he sparsely vegetated midstream sandbars of local rivers, but recently much of this natural habitat has been lost due to broad-scale alternations of natural river systems. These habitats are inadvertently created by sand and gravel mining, dredging, and other construction operations. As a result, these birds frequently nest in human-created habitats outside of the river channel: in 2018 there were 47 off-river nesting sites, including 21 at lakeshore housing developments and 26 at sand and gravel mines. These off-river sites are aided by the significant efforts of I ocal a ctivists, university partnerships, and mining and construction companies who incorporate bird nesting into the industrial process (Brown). The humancreated habitats represent the coexisting of old sites and new function in an urban context. They are examples of proactive environmental thinking and complex spatial research by the Tern Plover Conservation Partnership (Tern and Plover Conservation Partnership), who annually meets with production crews, property managers, real estate developers, and homeowners' associations to establish sitespecific management and monitoring plans.

\section{EXTRACTING THE BUILT ENVIRONMENT OF GRAND ISLAND}

\subsection{Spatializing Extraction}

Centered around the idea that an infinite supply of gravel exists in central Nebraska, sandpit extraction is helping to facilitate growth in Grand Island, the state's second fastestgrowing city. Grand Island has a population of about 50,000 people and is the third-largest city in Nebraska behind Lincoln and Omaha. Located in close proximity to the Platte River, Grand Island is also located six miles north of Interstate 80 . The city's sand and gravel demand figures to b e a bout 388,450 tons per year based on population estimates from the Regional Planning Department, with the majority being used for streets, highways, and buildings (Overstreet).

As of 2020, seventy-plus post-industrial sandpit lakes are helping to facilitate population growth in Grand Island. The city has embraced both the sand and gravel extraction process and a newfound appreciation for the value of water, with most of the development happening near the seventy industrial-scale sandpit extraction sites within and surrounding the city. These sites are typically mined for as little as a single season or as long as multiple decades, with the majority currently out of production. Lucy Lippard, writer, activist, and curator, posits that "most landscapes are actually designed by culture at the hand of anonymous amateurs who work by trial and error and privileged function over form" (Lippard, 7). Likewise, the shapes and forms of these sandpits are often irregular and based around machine mining until they are no longer economically viable. Several of the seventy-plus extraction pits in Grand Island have been decommissioned, but by adding new social programs to these 

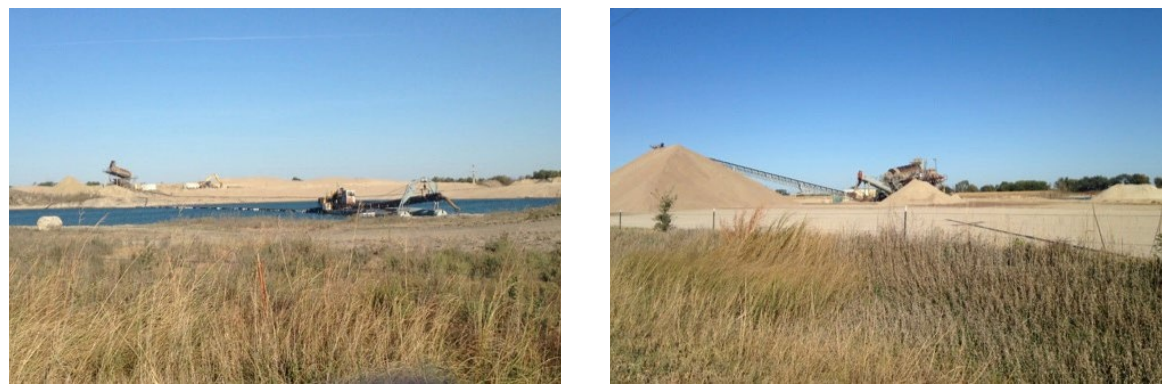

Figure 2. Grand Island active sandpit extraction, size separation, and aggregate separation. The high water table of the Ogallala Aquifer supplies freshwater lakes. Photos by A. O'Neill.

lakes they can be viewed through the lens of what Alan Berger describes as a "reclaimed landscape." According to Berger, "reclaiming landscape is the creation of a new condition in which land is rescraped in accordance with a new program (subdivisions, grazing fields, ponds, etc.) (Berger, 151). The resultant form occupies the land through the co-existence of the previously abandoned old sites and the new amenity-based programs. The reclaimed ground or space for programming among the almost seventy-plus extraction pits is changing the process of city expansion in Grand Island.

The industrial- and ecological-scale networks are forming new development patterns that no longer rely either on the dominant Jeffersonian grid or on architecture's historic role as the basic building block for organizing space, but instead rely on the operating procedures of material extraction and the resultant lakes. These sites are an example of what Nina Marie Lister describes as "complex and dynamic cultural-natural systems [resulting in] a multi-scaled and multi-layered urbanism involving cultural, social, political, economic, infrastructural, and ecological conditions that are layered, tangled, and mutually dependent" (Lister, 525-526). In Nebraska, this multilayered urbanism consists of vertically layered groundwater where ecologies and architectural environments concealed below ground are revealed to the surface. Multi-layered urbanism exists in Grand Island where the city continues to benefit from material extraction while balancing city expansion. From as early as the 1930s the city's groundwater was made visible in the form of sandpit lakes, and these lakes challenge our assumptions about water usage while drastically altering the city's built environment. While the majority of old extraction pits surrounding the city have not been reclaimed, several have been redeveloped with new amenity-based programs consisting of residential housing, and a smaller number have been reclaimed as public parks.

\subsection{Programming Extraction}

Over the years the functional and social value of the seventy mining sites in Grand Island has changed, and as of 2017 the existing function of the old extraction pits consisted of 28 residential, 14 undeveloped, 9 ag/business, 8 public parks, and 9 currently active. Some pits are located in the urban center while most are located near the agrarian edge. The overall size of the pits ranges from several hundred feet to a half mile in length. The resultant lakes generally have steep banks and dramatic changes in depth (Nebraska Game and Parks), and some smaller lakes have microtopography ranging from 15-30 feet deep with larger lakes reaching depths of 70-plus feet (Pekraek). Currently the sandpit lakes are owned by homeowners' 
associations, engineering companies, private owners, and sand and gravel extraction companies. In an attempt to understand this evolution of pit size and program type, a series of visualizations were assembled to index the changing landscape by documenting the limits of water and sand over the last twenty years.

\subsection{Indexing Extraction}

Changes to the built environment of a city are often difficult to visualize or spatialize due to their overall size and increment. In the case of Grand Island, the processes of digging down for material extraction and building up for residential development have significantly impacted the annexation of the city. The defining s patial characteristics organizing old urban order for Grand Island include the orthogonal Jeffersonian Grid and the irregular railroad lines that cut diagonally across the city. Today the city is challenging the historical topdown national planning order and no longer relying of the superimposed continental grid to dictate space, with the old urban orders quickly being replaced by new spatial practices based on natural features that include soil type and water table level. This bottom-up practice organizes space around natural features instead of arbitrary ordering systems. The results provide a variety of unique spatial types rather than predictable and repetitive ordering systems, with one example occurring when the former sandpits are reclaimed as public parks and residential developments.

The impacts of these processes can best be seen by analyzing freeze-frame aerial photographic sequences of Grand Island, with the photos cataloguing discrete moments that represent the city as both an object within a field o fagriculture a nd a n urban condition undergoing changes over time. The visualizations provide a lens allowing us to understand the correlation between the old material extraction sites and the new residential developments.
The process of indexing and analyzing freezeframe aerial photographic sequences utilized historic imagery from Google Earth Pro's time slider feature to document the evolution of the extraction pits over the years 1993, 1999, 2002, 2003, 2005, 2006, 2009, 2010, 2011, 2013, and 2016. Aerial photography from the state and county historical societies extended the timeline beyond Google Earth to include 1938 and 1975. The indexing and analysis process provided a new perspective for viewing the city based on the growth and development of material extraction sites. Google Earth Pro technology allows users to track the irregular boundary profile of each lake and compare its evolution over time. This technology also serves as an effective tool for determining the location of each lake relative to Grand Island's city limits, allowing further analysis and consideration of future city annexations. A comparative assessment of each lake relative to its geographical location indicated several trends among each lake type: for example, most residential lakes lie outside the city limits, undeveloped lakes are equally split between city and non-city, all current extraction pits are outside the city limits, most business/ag lakes are outside the city limits, and most park lakes are inside the city limits.

The history of these sites is diverse, ranging from landowners creating their own lakes by allowing extraction companies to mine their land to families purchasing property at the edge of an existing lake on which to build a house. Throughout the city of Grand Island 28 lake areas reminiscent of typical suburban subdivisions were intentionally designed, excavated, and converted into desirable high-end housing. The majority of both planned and unplanned residential lakes remain outside of Grand Island's city limits, suggesting an appeal for suburban dwelling. Using a method of evaluation based on the shifting profile boundary of each lake and the uniformity of the surrounding development, it was determined that only about 20 percent of residential lakes were originally planned for 
domestic development. The lakes originally planned for residential habitation share two common characteristics: relatively unchanged lake profiles and an organized array of housing. The planned developments often replicate traditional suburban models with front and back yards, forming continuous yards of grass in the front and back of each house and a strip of sand following the perimeter of the lake. Each home sits perpendicular to the water offering a 180-degree view across the lake to neighboring residents with an attached garage in front and front doors facing the street. Most planned residential lakes operate as homeowners' associations and could have considered public open space or additional community amenities, including
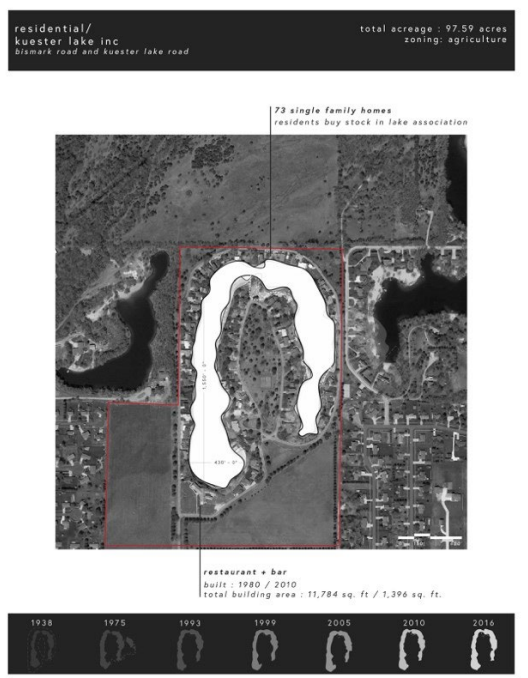

Figure 3. Visualization worksheets indexing changes in sandpit extraction sites and resultant lake changes from 1993, 1999, 1995, 2010, and 2016. Kuester Lake (left), McMahon property (middle), Hooker Bros. Sand \& Gravel (right). Of the 29 total residential lakes, 9 are within the city limits and 20 are outside. Visualizations by author. parks, playgrounds, or sports fields for use by residents. A good example of these amenities can be seen in the horseshoe-shaped Kuester Lake, which contains a restaurant/bar at one end of the lake and a large park with tennis courts on the peninsula (see Figure 3). The planned residential lakes have about half the average and median property acreage compared to other unplanned lake types. By operating outside the city limits, both planned and unplanned lakes are most easily implemented as new residential areas, likely due to their high desirability and the lack of density and city regulations. The reclaimed landscapes of these sandpits serve a new programing and urban order for the city by bringing urbanism into manufactured sites.
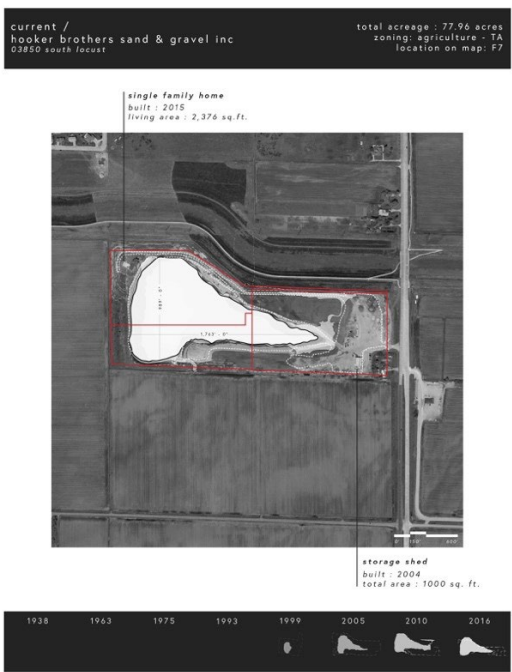


\subsection{Occupying Extraction}

There are several ways to occupy the planned and unplanned extraction sites in Grand Island. The city has constructed a range of programs and types of development in Grand Island. The multi-unit planned residential development Kuester Lake is outside the city limits and one of the oldest sandpits in Grand Island, having been mined from 1919 to 1937 by an Omaha sand and gravel company to support asphalt pavement in Omaha. While an active mining site, rail cars would move sand and gravel to building projects, though after operations ceased in 1937 the mine's two ponds were dredged to create the lake's distinct horseshoe shape. Resource extraction and mining operation in this part of the city was replicated over the years, creating new pits, lakes, and residential developments. Another planned site, the residential development of Ponderosa Lake Estates, is within the city limits and ranks as one of the most prestigious sandpit residential sites in Grand Island. The sandpit was developed, mined, and pumped by Missouri Valley Construction in the 1960s and 1970s. The lake is surrounded by 88 homes with an average square footage of 3,311 , with the largest covering 10,582 square feet. Currently, some of the houses are undergoing issues with settling because most of them were built on sand that had not yet completely settled after the dynamite mining.

Alternately, an example of an unplanned residential development is one partially owned by Hooker Bros. Sand \& Gravel, which was mined from 1994 to 2014. The property has four land parcels, two of which are owned by the gravel company and two of which are owned by individuals. In 2015 a 2,376 square foot house was built on the northwest corner of the site by the co-owner of the Hooker Bros. company. These instances illustrate how both planned and unplanned residential sandpit lakes are maximizing the land value of these decommissioned post-industrial spaces. They have successfully negotiated the process of bringing urbanism into manufactured sites and offer a precedent for similar spatial conditions around the world. In addition to these developed residential sites, the city has repurposed ten former extraction sites into city parks.

Out of Grand Island's seventy mining sites, ten have been converted into public parks in or near the urban center. These lakes have an interesting history: several were hand-dug, and as early as 1910, prior to refrigeration, they were harvested for ice that was sold to residents in the era of iceboxes. In the 1930s, three sites became public parks when they were filled in with topsoil from other pits. Augustine Park (a.k.a. Sunken Garden), which is depressed by about five feet, was used as a borrow pit for an elementary school. These public spaces formerly aided in the development of the urban center by supplying sand and gravel during the 1920s and 1930s for making concrete for building purposes. These old sites leave a mark on the city in the form of physical objects (e.g., buildings or roads), with the resultant park or exposed lake remaining as negative space. The negative space has been programmed with public amenities, including public parks and schools, that physically show the city's history. These urban sites represent an era of development and expansion that has resulted in concentration and density. How will the sandpits at the edge of the city that are being developed by homeowner's associations or as single-family residences contribute to the daily experience for all Grand Island citizens in a manner similar to that of the urban parks? Or is it too late for the edge-city sandpits to engage in public experience, since so many of them have been privatized? As industrial extraction processes have increased, new concerns have surfaced related to the quality of water, habitat, and architecture of sandpit lakes. 


\subsection{Excessive Extraction}

While waterfront residential subdivisions are in high demand throughout Nebraska, they often mask the undiscussed negative impacts of their development: challenges include issues with settling house foundations, lack of awareness, and disagreements among residents regarding best water management practices, temperature and thermal stratification, and chemistry and chemical stratification. Such issues may partly stem from the reclamation of these lakes, since, as Katie Pekarek, Extension Educator on Water Quality, states, "sandpits and stormwater ponds are marketed to homeowners as an amenity, but are not developed with the primary intention of being an amenity and are therefore not designed to serve the purposes that they are sold for" (Pekarek). Consequently, over time these land-use transformations are likely to trigger small-scale environmental changes leading to the displacement of native wildlife, the introduction of new species, and vegetation change, among other ecological consequences. Moving forward, if active mining sites are designed in a responsible way by considering factors from machine mining to architectural buildings, future lakes could provide better amenities for people, animals, and the regional ecological network.

\section{FUTURE SCENARIOS}

Post-industrial site development has seen landscape and ecology become primary vectors in contemporary urbanism (Lister, 525). This can most prominently be seen throughout the countryside, where these systems are inherent to water usage, land use, and settlement patterns. Mohsen Mostafavi lays the groundwork for challenging the development status quo when he states that "we must be aware of the dynamic relationships, both visible and invisible, that exist among the various domains of a larger terrain of urban as well as rural ecologies" (Mostafavi, 29). Building upon Mostafavi's ecological urbanism theory, these hybrid cultural-natural sites have great value for balancing the demands of global resource extraction with the needs of local planning efforts. In Grand Island alone, eight active and fourteen inactive and undeveloped extraction sites exist, all of which have the potential for a new sensibility that balances the value of water as a developer-driven amenity. Considering the relationship between global resource extraction and urban development further suggests the types of design innovations that can emerge from architecture, landscape architecture, urban design/planning, and ecological thinking as a result of this relationship between postindustrial sites and cultural-natural systems (see Figure 4).

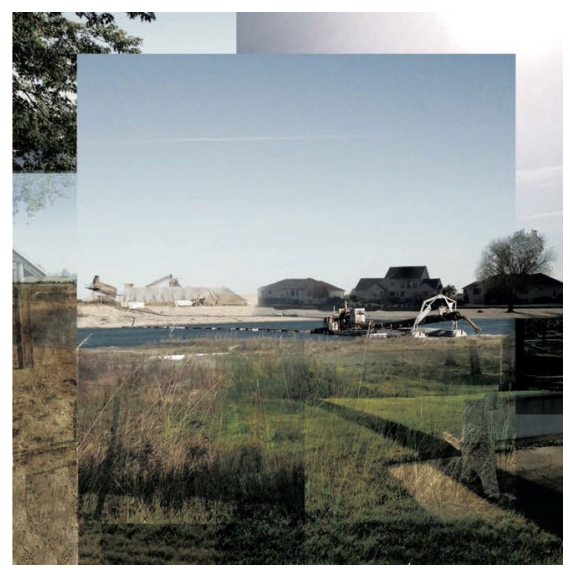

Figure 4. Photographic collage depicting a hybrid scenario balance ecology in the foreground, material extraction in the middleground, and residential development in the background. Representation by $A$. O'Neill. 
As central Nebraska continues to confront changing assumptions about water and sand, manmade lakes serve as a critical culturalnatural nexus. Reclaimed sandpit lakes reflect cultural values by forming a pattern of development and creating new freshwater ecologies across the state. The performance of these lakes, however, can be made more productive prior to and during the mining process by considering factors related to post-industrial development (see Figure 4). Responsible design solutions must be forged through architecture, landscape architecture, urban design/planning, and ecological thinking as a result of this relationship between postindustrial sites and cultural-natural systems. Those seeking future possibilities for sandpit lakes as both operational landscapes and amenities should acknowledge the foresight of Mel Steen as well as the development potential of the lakes themselves to simultaneously provide social, economic, and ecological benefits.

\section{ACKNOWLEDGEMENTS}

The author would like to thank the research assistants who aided in the development of this paper and funding from the Undergraduate Creative Activities and Research Experience (UCARE) program at UNL. 


\section{REFERENCES}

Berger, A. 2002. Reclaiming the American West. Princetone, NJ: Princeton Architectural Press.

Brown, M.B., Dinan, L.R., Jorgensen, J.G. 2015. Interior Least Tern and Piping Plover Monitoring, Research, Management, and Outreach Report for the Lower Platte River, Nebraska. University of Nebraska. http://ternandplover.unl.edu/download/ annualreport/2015_TPCP_annual_report. pdf

Fletcher, D. 2009. Los Angeles River Watershed: Flood Control Freakology. The Infrastructural City: Networked Ecologies in Los Angeles. Barcelona: Atrar Pres.

Lippard, L. 2014. Undermining: A Wild Ride Through Land Art, Politics, and Art in the Changing West. New York \& London: The New Press.

Lister, N. 2010. Insurgent Ecologies: (Re) Claiming Ground in Landscape and Urbanisnm. Ecological Urbanism. Lars Muller.

Mostafavi, M. 2010. Why Ecological Urbanism? Why Now. Ecological Urbanism. Lars Muller.

Nebraska Game and Parks. 2013. Managing Sandpits for Better Fishing. outdoornebraska.gov/wp-content/ uploads/2016/12/SANDPITMANAGEMENT-for-Better-Fishing-2013. pdf.

Overstreet, T. 2005. Sand and Gravel permit controversy back in front of city. The Grand Island Independent. http://www. theindependent.com/news/sand-andgravel-permit-controversy-back-in-frontof-city/article_a2fe89fa-cf19-50fc-832e557eaba3f216.html.

Pekarek, K. 2019. University of Nebraska, Institute of Agriculture and Natural Resources, UNL Water Extension Educator. Swinehart J. Sandhills. University of NebraskaLincoln. http://plainshumanities.unl.edu/ encyclopedia/doc/egp.pe.053.
Tern and Plover Conservation Partnership. University of Nebraska, School of Natural Resources. http://ternandplover.unl.edu/

Thomas, B. 1970. Super Highway Lakes. Feild \& Stream.

White, G. 1986. The Future of The Great Plains Re-Visited. Great Plains Quarterly 973. 


\section{PAPER \#3.12}

\section{SCARPA IN LIGHT OF CROCE: THE POST-LYRICAL CITY}

\section{Frank Harrison Weinera}

aVirginia Polytechnic Institute and State University, Blacksburg, Virginia, USA

\section{ABSTRACT}

Analogies across the disciplines of philosophy and architecture are always difficult to construct and often result in 'specious analogies' to borrow a phrase from the philosopher Susanne Langer. Despite the risks accompanying such endeavors this paper attempts to forge meaningful connections between the philosopher Benedetto Croce's idea of lyrical expression and the virtuoso architectural work of Carlo Scarpa at the Museo Civico di Castelvecchio in Verona, Italy. Through a reading of Castelvecchio in light of Croce's aesthetic thought the formulation of a post-lyrical city will be posited.

\section{KEYWORDS}

Scarpa; croce; expression; lyrical; lyre.

\section{INTRODUCTION: NORTH AND SOUTH}

In bringing together the philosopher Benedetto Croce (b. 1866 - d.1952) and the architect Carlo Scarpa (b.1906 d.1978) one is reminded about the historic divide existing between the North and South of Italy. As to the significance of this division one may recall the book by the Italian poet Carlo Levi exiled to the South under the regime of Mussolini in his memoir, Christ Stopped at Eboli. At one time to cross south of Eboli was tantamount to leaving the influence of Rome and the Church. Croce was born in Naples the seat from which Vico established a most beautiful Neapolitan humanistic philosophy uniquely Italian in spirit. Scarpa born in Venice also saw himself a child of ancient Greece and Byzantium. Scarpa worked rather locally but his reputation spread widely among architectural cognoscenti worldwide. Croce's influence spread to the North and well beyond Europe by virtue of the quality of his ideas and the tenacious industry of his substantial publishing efforts. His extensive publication activity was an efficient method to broadly disseminate his ideas to a wide audience in and outside of Italy. Croce and Scarpa both had a love and passion for books. Scarpa's library included nine volumes of Croce's works. To what extent Scarpa explicitly adopted Croce dictums regarding aesthetic expression is certainly a matter for speculation. There are however indications that there was in fact a significant influence from Croce on Scarpa regarding the importance of expression and this may shed new light upon Scarpa's work. In what seems to be a proper proportion Scarpa had over 4,000 books in his library and Croce about 70,000. Let us count these books among their many friends.

Scarpa's substantial personal library was open to many of his friends both within his architectural circle and others such as the noted Venetian musical composer Luigi Nono (b.1920 - d.1990). Nono's wife Nuria Schoenburg Nono spoke of their wonderful experiences as a frequent guest at Scarpa's Venetian home. She learned from the visits Scarpa was deeply erudite and exceptionally well-read across many fields of culture. This of course is true to an even larger extent for Croce. Reading provided Scarpa with a deeper legibility to his work if one takes the time to read his buildings. Perhaps in fact the weakness of Croce was his incredible erudition in which the breadth and depth of his 
knowledge were simply too powerful for his own good. He had a tendency to compulsively edit or correct the thoughts and work of others with the mentality of a critic. However, his moments of lucidity particular in relation to aesthetics, literature and history remain largely undetected and are relatively untapped repositories for thinking about architecture. To paraphrase Adolf Loos, only a small part of architecture belongs to art and it is this small artful part that gains large importance when thinking about the work of Scarpa in relation to Croce's idea of expression. Croce's somewhat anachronistic use of the term 'expression' appears to hover between the relative and the absolute and is a novel turn in the history of an idea. ${ }^{1}$

\section{A BRIEF GUIDE TO CROCE AND HIS IDEA OF EXPRESSION}

Croce burst onto the philosophical scene with the publication of his Aesthetic as the Language of Expression and the General Linguistic (first published in English in 1909). It could be said this work unexpectedly propelled him far too quickly into a fame he may have never sought. Throughout the rest of his remarkably productive scholarly life, he amended his initial thoughts about aesthetics that were of part of his broader systematic attempt to layout a fuller philosophy of the human spirit. However, through all his scholarly life the core of his aesthetic ideas remained the same - art was expression identical with intuition. Later he would say that art is a form of lyrical expression and even cosmic expression. It is perhaps this lyrical turn that is most amenable to the work of Scarpa. The simplicity of Croce's statements about expression belies a deep hidden complexity and understanding of the history of aesthetics. Since the time before and after the many attempts at articulating the basis of modern aesthetics by Vico, Baumgarten, Kant, Hegel and Croce no one has been able to conclusively and without equivocation crack the riddle of those things that stir our thoughts and emotions towards a sense of the beautiful. One could ironically call all these attempts beautiful in themselves. This difficulty resides in the ancient agonistic relationship between poetry and philosophy that miraculously stand apart together.

Since Benedetto Croce's death and well before his passing there was a precipitous drop among other philosophers regard for Croce's thought. Some claimed his work to be unintelligible and self-isolated. Others were turned off by what they assumed to be his latent Hegelianism and their own aversion to the Absolute. They also rejected his dependence on Germanic thought. Croce once said that he did not make a system but only attempted to make a system. He is however indeed part of a great tradition of systemic thinking following philosophers such as Spinoza, Leibniz and Hegel. Even Heidegger an opponent of system making devoted a large part of his book on Schelling's idea of freedom to explicate the idea of system.

The reasons for the downgrading of Croce's reputation are many as this was a period that led up to and through two bitterly fought world wars. One has to always keep in mind that as high as one can rise one can fall. Croce lived during a long period of political volatility and upheaval within and without Italy. Many

\footnotetext{
${ }^{1}$ Croce was decidely anti-metaphysical and anti-aesthetical in his use of the term 'expression' and lies outside the mainstream of philosophical thought. For the metaphysical understanding of the idea of expression, see, Deluze, Gilles, Expressionism in Philosophy: Spinoza, trans. Martin Jooghin (New York, 1997). See also George Eliot's translation of Spinoza's Ethics in which the idea of expression, although not explicity stated is a crucial hinge to the related realms of natura naturans (naturing Nature) and natura naturata (nutured Nature). It should be noted writing about 'expression' is a notorioulsy difficult as expression has often been understood in the realm of speech but does not seem particulaly amenable to forms of writing. There is also the dillema of the irreducibility of visual traditions to speech. A recourse to save the idea of expression is through the ancient idea of exphrasis (poetry about poetry). For Croce's somewhat inconsistent use of the term 'expression', see, R.B. Patankar, "What Does Croce Mean By 'Expression?", The British Journal of Aesthetics, Vol. 2, Issue 2, (April 1962):112-125. One should also bear in mind the word 'expression' in Italian (espressione) may carry different meanings than the English word 'expression'. In Italian the word takes on an operatic meaning.
} 
prominent individuals including Croce often changed political sides and positions for the purposes of protecting their own interests. While serving as an editor of the influential literary and philosophical journal La Critica from 1903-1945 he made many enemies with his often rather brusque and blunt criticism of almost everyone except himself. The philosopher cum senator became a target in some ways due to the fame he achieved during his lifetime. Resentment about his positions both philosophically and politically still remains to this day. Lastly the idea of expression seen as a remnant of romantic thought was repudiated by the turn towards modernity and the search for a 'degree zero' and 'colourless' expression in Roland Barthes sense of these ideas.

In some ways Croce was an even more brilliant literary critic than philosopher. As a literary critic following in the footsteps of Franceso de Sanctis ( b.1818 - d.1883) he was fervently searching for the form and soul of a national and even trans-national literary criticism. Perhaps it was this nationalism along with his on again and off again dalliance with Marxism that drew the wrath of his critics. However, his own hyper-critical bent should not take away from the significance of his philosophical thought. That he was a difficult person is not disputed however if one can ever separate a person from their ideas this may be necessary in this case to save the importance of his aesthetic thought and to construct a potentially new frame of reference for understanding Scarpa's work.

Clearly, Croce wanted to demystify the work of the artist. In this own autobiography, he summed up his theory in this way;

\footnotetext{
...true thought is simply thought, beautiful expression is simply expression...false thought and ugly expression are non-thought and non-expression. ${ }^{2}$
}

In Croce's systematic quest for an absolute spirituality, the primacy of aesthetics is posited as a unifying basis for ethical, practical and economic considerations. One of the main ideas in his aesthetic is the identity of expression and intuition. Croce was interested in debunking to some extent all prior theories of art predicated upon the concepts of imitation, representation and beauty per se. Art, taken in the broadest sense subsuming architecture is understood to be an expression of an impression - an expression spiritually imbued by intuition and a sense of the lyrical. He would add art proper has no content but expression alone in the "serenity to form". ${ }^{3}$ For Croce expression makes the poet and one might add the architect. ${ }^{4} \mathrm{He}$ has little patience for mediocre expression as if he were the single arbiter of what constitutes a beautiful expression or ugly non-expression! If something was ugly in his eye it simply could not and did not exist.

\section{CROCE'S AESTHETICS}

Croce is best known for this book Aesthetic as a Science of Expression and the general linguistic. The book written in a highly critical spirit systematically demolished many prior and widely held aesthetic theories while at the same time positing yet another theory. His thoughts on aesthetics are enigmatic in character. The full translation of the Aesthetic runs approximately five hundred pages half of which is a history of aesthetics. Croce's brusque criticisms turned away many who may have been sympathetic to the virtue of his ideas. One can speculate Scarpa was willing to accept the bluntness of Croce for the perennial importance of his ideas, especially his expansion of the idea of expression well beyond the limits of expression as a verbal phenomenon. The single prior aesthetic theory

\footnotetext{
${ }^{2}$ Benedetto Croce, Benedetto Croce: An Autobiography, trans. R. G. Collingwood (Oxford: Claredon Press, 1927$), 94$.

${ }^{3}$ Benedetto Croce, Aesthetic, trans. Douglas Ainslie (New York: Farrar, Straus and Giroux,1972), 21. Regarding the importance of form in Italian literature and poetry Croce was highly influenced by the writings of the Italian literary critic Francesco De Sanctis.

${ }^{4}$ Croce, Aesthetic, 25.
} 
Croce accepts (with some qualifications) is that of G. B. Vico.

In Croce's quest for an absolute spirituality, the primacy of aesthetics is posited as a unifying basis for ethical, practical and economic considerations. One of the main ideas in his Aesthetic is the identity of expression and intuition. By virute of this identity he may in fact be confusing intuition as an a-priori category in a Kantian sense and expression as something a-posteriori. At times it is difficult to distinguish in his thought the ideas of expression, intuition and beauty. Art, taken in the broadest sense subsuming architecture and including language is understood to be an expression of an impression - an expression spiritually imbued by intuition and a sense of the lyrical. He would add art proper has no content but expression alone in the "serenity to form". ${ }^{5 .}$ For Croce expression makes the poet and one might add the architect. ${ }^{6}$

In the Aesthetic, he posits two kinds of knowledge, either intuitive or logical. Logical knowledge deals with universals and intuitive knowledge with particulars. Logical knowledge is obtained through the intellect and intuitive knowledge through imagination and images. Croce's appeal to the importance of intuitive knowledge and the assertion this is indeed legitimate knowledge in its own right is a critique of the ancient philosophical defamation of imagination. The mistrust towards imagination 'expressed' in Plato's famous description of the divided line in the Republic held sway in philosophy well into the early decades of the 1900's. It suggested the realm of the human spirit regarding imagination could only be vaguely understood since it lacked the demonstrative and syllogistic basis of logical knowledge. For Croce it was not enough to have a thought in one's mind unless one made the effort and had the capacity to express it well. The act of expression demanded one cross what he called the "Pons Asinorum of expression".? As he points out, this is the point where most learners fail. He posed the challenge regarding expression in this way, "...here is a pencil, draw, express yourself." ${ }^{\text {" }}$ Croce knew full well that it was indeed not that simple. He even had the audacity to dismiss Vitruvius when he writes, "...learn the art and have done with it.".

\section{SCARPA'S EXPRESSIVITY VIA CROCE}

In a lecture "Can Architecture be Poetry" Scarpa stated succinctly;

"The value of a work lies in its expression when a thing is well expressed its value is high."10

This appears to be a clear demonstration of the importance Scarpa placed on the idea of expression perhaps finding its origin in Croce's aesthetic theory. One gains a glimpse into the contents of the extensive personal library of Carlo Scarpa in a brief article written by Raffaella Vendramin. ${ }^{11}$ One comes away after reading this short description with the realization that Scarpa was a highly cultivated auto-didact and his relationship to books was important to his bearing as an architect. His library was open to his wide circle of friends drawn to the power of books. Among the over 4,000 items mentioned are nine volumes by Benedetto Croce. The extent to which Scarpa studied these works is a matter for speculation An architect's personal library always remains an implicit source for inspiration and influence. It is upon accepting such possible

\footnotetext{
${ }^{5}$ Croce, Aesthetic, 21. Croce was highly influenced by the writings of Italian literary critic Francesco De Sanctis. Croce's idea of expression attempts to make the idea of form more precise.

${ }^{6}$ Croce, Aesthetic, 25.

${ }^{7}$ Croce, Aesthetic, 11

${ }^{8}$ Croce, Aesthetic, 11 .

${ }^{9}$ Croce, Aesthetic, 113.

${ }^{10}$ Carlo Scarpa, "Can Architecture be Poetry?", Paper delivered at the Academy of Fine Arts, Vienna, November 16, 1976. Franceso

Dal Co and Giuseppe Mazzariol, Carlo Scarpa: The complete works, trans. Richard Sadleir (New York: Rizzoli, 1985$), 283$.

${ }_{11}$ Raffaella Vendramin, "Carlo Scarp's Library," Carlo Scarpa: the complete works, p. 307
} 
linkages between Scarpa's work and Croce's thought new ways of understanding Scarpa may emerge. Was Scarpa 'expressing' Croce's idea of expression in his expressions?

There is a profound empathy for the idea of expression in both Scarpa and Louis Kahn. Perhaps it is based upon their shared innate understanding of how expression emerges from the broader institutions of humankind such as the musem and the city. This kinship has to do in one sense on their reliance and faith in the idea of expression. In a lecture Louis Kahn gave at the ETH in Zurich in 1969 the word 'express' and its' related forms 'expression', 'self-expression' and 'expressiveness' are invoked no less than twenty-five times, as well as in diagrams he drew on the chalkboard. ${ }^{12}$ In Kahn's lecture, it was desire and the desire to be that grounds acts of expression. Desire becomes the inspiration for expression. Mario Botta studied architecture under Scarpa when he served as Co-Director at what was then called the Istituto Universitario di Architettura di Venezia (IUAV). Botta perceptively stated in an interview;

As for Scarpa, what is important was his capability and sensitivity in giving expression to materials; his ability to read into the very structure of the material in order to draw the greatest possible expression from it. Then there's also the great pleasure, the joy he derived merely from something well made..$^{13}$

There is a remarkable photograph of Scapa taken while he viewed one of the sculpture installations at Castelvecchio. ${ }^{14}$ This highly expressive photograph of Scarpa tells us much about the architect. ${ }^{15} \mathrm{He}$ has the stance of both architect and curator unifying two professions often at odds. Something of the spirit of the sculpture he was viewing penetrated his very countenance vivifying the brute material existence of the sculpture itself. The photograph shows the back of a robed sculptural figure in the foreground while Scarpa is in the background looking towards the unseen front of the figure while apparently glancing towards a colleague standing just outside of the frame of the picture. Scarpa is pointing downwards to the floor as if to confirm the correctness of the installation with a colleague that stands outside of the frame of the photograph. It is as if the sculpture and Scarpa were confirming each other's existence. Scarpa wore a long robelike overcoat mirroring the garment on the sculpture. It is as if two 'expressions' were speaking to each other across the space of time. The sculpture raised off the surface of the floor on a simple plinth is spiritually and lyrically animated and awakened from its long night of material slumber.

\section{MUSEO CASTELVECCHIO}

It may be timely, especially in lieu of the primary topic of this conference - The Architect and The City - to reconsider one of Scarpa's most universally admired works - the Museo Civico di Castelvecchio developed across three periods spanning three decades (1957-64, 1966-1967 and 1973-1975). Scarpa's work at Castelvecchio stands as a high water mark of architecture as a form of expression. The project challenges the modern obsession for the condition of tabula rasa out which architecture miraculously appears seemingly out of nothing. The initial stages of Scarpa's interventions began in 1957 under the direction of the museum director Licisco Magagnato (b.1921 - d.1987) and continued until 1975. Most recently in 2017, the East wing rooms were renovated by the Veronese

\footnotetext{
${ }^{12}$ Alessandro Vassela, editor, Louis I. Kahn:Silence and light (Zurich: Park Books, 2013).

${ }^{13}$ Dennis Doordan, "Changing Aggendas: Architecture and Politics in Contemporary Italy," Assemblage No. 8 (February 1989 ): 71.

${ }^{14}$ For a reproduction of this photograph see, Carlo Scarpa: The complete works, p.15.

${ }^{15}$ Since a photograph can be considered a kind of frozen slice of reality the question can be raised as to whether this form of technological reproduction can in fact capture the living and vital sense of expression in Croce's sense of the term. The question can be asked - Can Croce's idea of expression extend to photography?
} 
architectural firm Bricolo Falsarella assocati. The brutality across much of Castelvecchio's history underscores the eloquence of Scarpa's interventions. Base expressions are side by side with rarified expressions. ${ }^{16}$ Scarpa's unique expression at Castelvecchio broadly resides somewhere between Byzantine iconicity and Grecian lyricism.

In considering Scarpa's work at Castelvecchio it is important to realize that it was in settings of intense, rough and even brutal existing conditions that some of Scarpa's best work was produced. It is expression embedded in-situ or what could be termed a situated expression. Expression, like poetry, is not a problem to be solved but rather the unspoken conatus of the architect and the architecture. ${ }^{17}$ When Scarpa had more free and open circumstances for expression he could at times become overwhelmed by the force of his own maniera and become Scarpesque..$^{18}$ However, within the gaps and fissures amidst the limitations of what he found present at Castelvecchio he was able to care for the place like a doctor. It was an extraordinary act of what could be termed expressive curation. The architect does not only curate as in safeguarding with great care all the contents of a museum but as architect cum curator innately expresses the curation across an entire project from the scale of hardware and individual installations to the mise en scène of building in the city.

Scarpa's successive work at Castelvecchio can be described as the restoration and renovation of an open wound in need of surgical care and reconstruction. This medicinal and ministerial act of restoration required an architect with the capacity to care for the buildings in great detail by taking on the role of a curatorial doctor not only for the Castelvecchio complex of buildings but the city of Verona. In a sense Castelvecchio is Verona. The castle and the city remain inseparable as if there is no real difference between 'architecture and the city'. Scarpa acts as the curator of the city, the castle and the river. For Scarpa architecture is a renovation of expressions past, present and future. Something must be already there in the form of architecture as a concrete expression. His best work innately intuits the existing conditions of expression in terms of what is found and what will be founded. The condition of tabula rasa is neither possible nor desired. In the beginning was the fragment and out of this, new layers of fragmentation heighten the feeling of an intensified expressionistic palimpsest.

Aldo Rossi's The Architecture of the City offered architects a way back into the city through the idea of affective memory rather than history per se. One could say the work of Scarpa is about memory as well but more precisely a form of remembrance of Verona. Rossi relied on a form of typological monumentality to bring the existence of the city to light and shadow. Scapa telescoped the city into his work through elaborately localized expressive and highly lyrical embellishments dispersed as fragments throughout the project. The word embellishment is selected as distinct from ornament to free the work to new readings and to offer it an aspiration towards musicality in Pater's sense that all art aspires to a condition of music. With Rossi one sees things best from a distance with Scapa the enjoyment heightens when one closes the distance only to be magnetically and magically drawn into its remarkable sway of expressive intensities. The unity of

\footnotetext{
${ }^{16}$ A colleague has perceptively remarked the significant damage inflicted on Castelvecchio during Allied bombing raids in WWII ironically gave Scarpa the opportunity to work on its rennovation. Prof. Steven Thomspon, personal communtiation (undated). On September 25, 1991 the Gold Medal for Miltary Valor was conferred upon Verona by the Republic of Italy in remembrance of the heroism occuring in Verona during WWII.

17 There appears to be an unspoken and deeper ancient conatus (effort, endeavor, inclination, impulse) in Croce's thought about expression. The reader is referred to the entry on "conatus" in, Stuart Brown and N.J. Fox, Historical Dictionary of Leibniz's Philosophy (Oxford, 2006), p. 53. Conatus may be considered a presupposition of expression and expression as the externalization of an inner conatus.

18 In this regard Scarpa's work amidst the intense existing conditions at Castelvecchio and the Fondazione Querini Stampalia in Venice are exemplary. However, in settings such at the Casa Ottolenghi in Bardolino it appears the expression has less limits to overcome creating its own stylistic universe much in the manner of F. L. Wright.
} 
the place is caused by the capacity of these fragments to leap across space joining one to the other in a connective tissue. The spacing of the expressive conditions, more than mere details, allows them breathing room.

\section{THE CANGRANDE EQUESTRIAN STATUE AS AN EXPRESSION OF VERONA}

Of all the remarkable installations at Museo Castelvecchio Scarpa devised perhaps the most exceptional is the re-location and placement of the statue representing the Cangrande della Scala the child lord of Verona. Scarpa choreographed the museum and in particular the staging of the Cangrande sculpture as the quintessential symbol of Verona's past. The Cangrande was a member of the Scaligeri family ruling over Verona during the 13th and 14th centuries. Richard Murphy commenting on this installation writes, "...it is the most extravagant architectural setting in which to display a single work of art that has ever been created."19 It is a kind of raised burial mausoleum suspended in the air like a hanging concrete garden.

The sculpture, sitting under an overhanging roof, is mounted on a high platform placed in a semi-enclosed exterior court at the end of a remarkable enfilade of five exhibition rooms. The statue and its setting is a complex crescendo to these series of rooms known as the 'sculpture corridor' and stands in a commanding position over the entire castle complex. The Cangrande statue, with its curious odd smile, lords over the Museo Castelvecchio as he did during his short but consequential reign from 1311-1329. The statue is significant because of the unique place of Cangrande in the history of Verona. The Cangrande hosted exiles from other cities and it is said he treated them with generosity and uncommon respect. The story of the young Cangrande imbues the sculpture with an importance it might not otherwise have if one only considers the sculpture itself.

It was this same statue, at that time in another location, John Ruskin made a series of exquisite drawings of during his excursions to Verona. The poet Dante Alighieri had visited the actual Cangrande during his stay in Verona and extoled his virtues in The Divine Comedy. He wrote of "the great Lombard who bears the holy bird upon the ladder..." This is a reference to the family crest of the Scaligeri family. Displayed on the ground in the courtyard where the Cangrande sculpture is located resides a cast bell with this same symbol. Verona is a city of scalas or ladders where the stairs are more like ladders. Scarpa by the nature of this installation curated the history of Verona by expressing that history in the ladder-like monument to the Cangrande. Museo Castevecchio is a place of ladders and a distllation of the city of Verona itself. The sheer numbers of exceptional stairs cum ladders carefully placed throughout the museum are experientially staggering.

\section{CONCLUSION: THE POST- LYRICAL CITY}

It may be too late for the lyric tradition to have an efficacy in the architecture of the city hence the notion of the post-lyrical city. There is a need to save the lyrical from its total extinction and the road to its continuation is through lyrical expression. Is it proper to consider Scarp's work at Castelvecchio as post-lyrical? The literary critic Marjorie Perloff has written the lyric tendency in poetry had reached an impasse and saw in the later work of Ezra Pound and those that followed the beginning of a turn away from the lyrical towards a kind of intellectual poetry rather than an expressive poetry. ${ }^{21}$ The expressive and emotive aspect of poetry was purposely held in abeyance.

\footnotetext{
${ }^{19}$ Richard Murphy, Carlo Scarpa and Castelvecchio Revisited. (Edinburgh: Breakfast Mission Publishing, 2017), 174

${ }^{20}$ Dante, The Divine Comedy of Dante Alighieri. Vol. 21, Great Books of the Western World, trans. Charles Eliot (Chicago: Encyclopedia Britannica, Inc., 1952), 132.

${ }_{21}$ Marjorie Perloff, The Dance of the Intellect: Studies in the Poetry of the Pound Tradition, Ch. 8, "Postmodernism and the Impasse of the Lyric", (Evanston: Northwestern University Press, 1985), 172 - 200.
} 
Perloff refers to Eliot's essay, "Tradition and Individual Talent", where Eliot states;

Poetry is not a turning loose of emotion, but an escape from emotion: it is not the expression of personality, but an escape from personality. But, of course only those that have personality and emotions know what it means to escape these things. ${ }^{22}$

Despite Eliot's rather subtle admonition, it is clear Scarpa understood the limits of an unfettered highly personalized notion of expression. To paraphrase John Cage an artist seeks the expression of self rather than self-expression. The remote origins of the lyric reside in ancient Greek myths associated with the figures of Hermes and Orpheus. ${ }^{23}$ We are told as part of the oral tradition of the Homeric Hymns Hermes invented the lyre and Orpheus was the first Greek poet and a virtuoso of the lyre. ${ }^{24}$ We may recall for Scarpa the sway of ancient Greece was strong. Orpheus's music asserted its charm to the extent flowing streams would pause in the presence of such sonority. It is important to note in the myth Hermes meets the tortoise (soon to be lyre) at the entrance to his cave. There is a violent darkness associated with the orphic tendency that is particularly amenable to Scarpa's poetics at Castelvecchio best viewed under the cover of shade rather than under a full sun. A post-lyrical architecture suggests an architecture exiting from the threshold of the lyric, closer to the dionysian than the appollonian. As Hermann Broch has written in The Death of Virgil ; "...no song becomes lost that has ever plucked the strings of a lyre..."25
Could one view the city as a place of postlyrical expression and the architect as the individual most responsible for actualizing this expression? Might the city itself fall under the umbrella of Crocian expression? This may provide new life for the idea of a city expressed as a work of art. To this end, the architect's responsibility is firstly aesthetic and secondly ethical. In his Noble Laureate lecture of 1987, Joseph Brodsky spoke of aesthetics as the foundation of ethics. In his words, "...aesthetics is the mother of ethics. ${ }^{26}$ $\mathrm{He}$ adds we are aesthetic creatures before we are ethical ones. For Brodsky our moral compass is made possible and shaped by our fundamental aesthetic intuitions. He writes, "The more substantial an individual's aesthetic experience is, the sounder his taste,... the sharper his moral focus, the freer - though

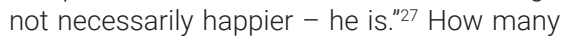
of us are willing to trade our happiness for our sense of beauty? In Brodsky's sense beauty and the expression that presses it into being offers a challenge to our happiness.

Brodsky raises important considerations for the architect working in the city. In positing his thesis Brodsky touched upon one of the most crucial dilemmas of our time - the tension between aesthetics and ethics. The city is the place where this debate is played out most significantly. The architect who does not cultivate and curate his or her aesthetic expression with precision and rigor leaves the city weaker aesthetically. This in turn leads to a weakening of the ethical dimension of a city. As Eliane Scarry reminds us "...beauty leads us to justice." ${ }^{28}$ How do we as architects give expression to the justice beauty can lead us to? The city as aesthetic expression allows

\footnotetext{
${ }^{22}$ T. S. Eliot, Frank Kermode editor, Selected Prose of T. S. Eliot, "Tradition and Individual Talent" (New York: Harcourt Brace Jovanovich 1975). 37-44.

${ }_{23}$ Personal communication, Prof. Steven Thompson (August, 2020). See, Mark Cartwright, "Orpheus", Ancient History of Encyclopedia, Last modified March 19, 2020. <www.ancient.eu/Orpheus/>

${ }^{24}$ Regarding the mythical invention of the lyre, see, Romani Mistretta Marco, "Hermes the Craftsman: The Invention of the Lyre" in, Gaia: revue interdiscplinaire sur la Grece Archaique, numero 20, (2017): 5-22. For the the importance of the mythic origins of the lyre I am indebted to Prof. Steven Thompson for pointing this out.

${ }_{25}$ Hermann Broch, The Death of Virgil, trans. Jean Starr Untermeyer (New York: Vintage Books, 1995), 39.

${ }^{26}$ Joseph Brodsky, Nobel Lecture, <www.nobleprize.org/prizes/literature/1987/Brodsky/lecture/>.

${ }_{27}$ Brodsky, Nobel Lecture, <www.nobleprize.org/prizes/literature/1987/Brodsky/lecture/>

${ }^{28}$ Elaine Scarry, On Beauty and Being Just (Princeton: Princeton University Press, 1999), 93.
} 
the just and the fair to symmetrically extend in all directions like a perfect cube. ${ }^{29}$ What is the just city we as architects desire to lyrically express? The fate of the city known as Verona la Degna (Verona the Worthy) rests upon on the worthy expression of the architect. ${ }^{30}$ Appropriately Scarpa was interred like the roots of a flower in a vertical standing position under a discretely placed horizontal grave marker at Brion-Vega in the city of his own death of which there can be no visitor among the living. This installation is an homage to the curatorial prowess and highly selective architectural virtuosity of Scapa. One is reminded of a single line from a poem by Charles Baudelaire, a poet Scarpa very much admired - "(For the deep grave is ever the poets friend)". ${ }^{31}$

\section{ACKNOWLEDGMENTS}

I want to acknowledge Emeritus Professor Sal Choudhury, a long time colleague of mine at Virginia Tech for his construcive and enlightened criticism. I also express my gratitute to Prof. Steven Thompson for his sympathetic and objective readings of later drafts of the paper.

29 Scarry, On Beauty and Being Just, p. 93.

30 Alethea Wiel, The Story of Verona (London: J. M. Dent \& Co., 1904), preface, viii. The reader is also referred to the poignant fable "The Land Where One Never Dies" in, Italo Calvino, Italian Folktales: Selected and Retold by Italo Calvino, trans. George Martin (New York: Houghton Mifflin Harcourt, Inc., 1980), 77 - 79

31 Charles Baudelaire, The Flowers of Evil, A selection edited by Marthiel and Jackson Mathews (New York: New Directions Publishing Corporation, 1955), 37. The quotation is from the poem is entitled "Remorse of the Dead". See also the first stanza in the poem entitled, "The Glady Dead". 


\section{REFERENCES}

Baudelaire, Charles. 1955. The Flowers of Evil. Edited by Marthiel and Jackson Mathews. New York: New Directions Publishing Company.

Chiavarini, Moira. Editor. 2018. Carlo Scarpa: The Shapes of Light. Exhibition Catalogue. Repetto Gallery, London 26-September - 26 October 2018. Arezzo: Magonza Editore.

Croce, Benedetto.1972. Aesthetic as Science of Expression and General Linguistic. Translated by Douglas Ainslie. New York: Noonday Press.

Croce, Benedetto.1995. Benedetto. Guide To Aesthetics: (Breviario di esetica). Translated by Patrick Romanell. Indianapolis: Hackett Publishing Company, Inc.

Dal Co, Francesco and Mazzariol. 1985. Carlo Scarpa: The complete works. Translated by Richard Sadleir. New York: Rizzoli International Publications.

D’Amico,Jack, Trafton,Dain, Verdicchio,Massico. Editors. 2019. The Legacy of Benedetto Croce: Contemporary Critical Views. Toronto: University of Toronto Press.

Dante. 1952. The Divine Comedy of Dante Alighieri. Translated by Charles Eliot Norton. Chicago: Encyclopedia Britannica, Inc.

Kosuth, Joseph. 2019. To Invent Relations (for Carlo Scarpa). Edited by Chiara Bertola and Fiona Biggiero. Venice: Trolley Ltd.

Nakamura, Yoshio. Editor. 1985. Carlo Scarpa. Tokyo: A + U Publishing Co., Ltd.

Moss, M. E. 1987. Benedetto Croce Reconsidered. Hanover N. H.: University Press of New England.

Murphy, Richard. 2017. Carlo Scarpa and Castelvecchio Revisited. Revised edition. Edinburgh: Breakfast Mission Publishing. Ruskin, John. 1894. Verona and Other Lectures. New York: Macmillan and Co.
Scarry, Elaine. 1999. On Beauty and Being Just. Princeton: Princeton University Press.

Vassella, Alessandro. 2013. Louis Kahn: Silence and Light. Zurich: Park Books.

Weil, Alethea. 1907. The Story of Verona. London: J. M. Dent \& Co. 


\title{
PAPER \#3.13
}

\section{WHAT DOES A SINGLE BUILDING TELL ABOUT A CITY?}

\author{
Burcin Basyazicia, Birsen Sterler ${ }^{a}$, Safak Cudi Ince ${ }^{a}$ \\ aYeditepe University, Istanbul, Atasehir
}

\section{ABSTRACT}

Ataturk Cultural Center (AKM) which was built in between 1946-1969, is considered one of the unique architectural examples of Turkish modernization period and stands out as one of the most controversial buildings in Turkey. Since it stands in Taksim Square, which is also considered as the main public square of Istanbul, the building has witnessed many to historical public events -including Gezi Protests- and has served as a showcase of the city by its meticulously designed façade.

However, the building was demolished in 2018. After a series of sterile discussions and protests, the government declared that AKM will be re-built again by the son of the architect who designed the original one. The new architect who is also a well-known architect of Turkey, declared that the façade of the building which has borne witness to an age, will be kept. This paper proposes to expose the architectural and urban history of AKM by confronting the concepts of the new and the old through the same building. AKM will be taken as a case to discuss the impact of a single building to the history of a city by focusing on the following questions; (i) what makes a building historical and iconic for a city? (ii) Can a new building represent the same meaning with the old even if the two have same function and façade? (iii) What are the effects of politicians and architects to urban memory? Even though the new building is under construction now, previous versions of the building will be presented through archival files and shared documents of the related architecture firms. The old and new press clippings will also help to understand not only historical and architectural but also sociological effects of the building on the urban memory.

\section{KEYWORDS}

AKM; Istanbul; taksim; urban memory; new-old; relation in architecture.

\section{INTRODUCTION}

The new faces the old is a promising and creative phrase by all its means, including architecture. Those kind of contention areas that faces two so-called incompatible ontological terms, have always a creative potential to ask new questions. If the case is architecture, the new can face the old in several research areas including restorations projects, urban planning, extension projects and etc. However, this paper does not concern these type of encounters and proposes to confront the new with the old through the same building, that is, Atatürk Cultural Center which has been renewed, re-imagined, reconsidered, and rebuilt many times in its short history. Ataturk Cultural Center (AKM) has a potential to help us to re-question what is new and what is old in architecture and to ask further questions on the power of a building in historiography of a city, as well. Therefore, it would be crucial to ask first; what AKM can teach us by focusing on the following questions; (i) what makes a building historical and iconic for a city? (ii) Can a new building represent the same meaning with the old even if the two have same function and façade? (iii) What are the effects of politicians and architects on urban memory? AKM is the most polemical building of Istanbul and Turkey. It is a unique example to understand how a building becomes historical for a city and interiorized and defended by professionals and civilians. This paper aims to question and understand the effect of a single building 
in a city in terms of architectural, historical and political concerns. Since the building was demolished and is being re-built again, can we still call it a historical building or has it ever been this? What have changed during never ending debates it caused and what have those debates taught us as professionals? The historical development of AKM has been quite visible. It is often written in academic articles, newspapers and magazines. This study doesn't aim to re-write it's as-known steps again but to help readers to understand its unusual and unique position in Istanbul, the uncompleted history of AKM has been briefly mentioned in following section.

\section{UNCOMPLETED HISTORY OF AKM}

The history of the building dates back to 1930's and has still not concluded due to the everlasting design and construction processes. Its history began with a decision to build a contemporary Opera Hall in Istanbul to represent the contemporary lifestyle of young Turkish Republic back then. After this first decision of the Government, the first design agreement was made with a group of German designers in 1930 (Cumhuriyet 1930).

However, it has been suspended due to WWII. When it had been put on the agenda again in 1946, the first proposal was designed by architects Feridun Kip and Rüknettin Güney by name Istanbul Opera. Due to budgetary savings of the government, construction was stopped and assigned to The Ministry of Public Works in 1953. Finally, in 1956 the Ministry have assigned architect Hayati Tabanlıoğlu who was a public servant in the same Ministry, to build a new project in Taksim (Can 2015). The building has been built in 1969 after twenty-three years long construction by name Istanbul Culture Palace and celebrated as an example of Turkish Modernization period. In 1970, the building nearly demolished due to a conflagration, and in 1977, it was reopened with the name Atatürk Cultural Center, which is still the name of the building today (Tabanlıoğlu 2010). AKM had done the honors of many national and international prestigious art events in-between 1977-2005. The building has also witnessed to the milestone protests in history of Turkey and the façade of the building had been used to hang protests' banners and posters. In 1999, AKM was registered as A-Class Cultural Asset by the second Preservation Board of Istanbul (Istanbul Atatürk Cultural Center Directorate Briefing File 2005). However, the Minister of Culture and Tourism declared the demolition of AKM in 2005 based on the idea that the building has concluded its lifespan (Hürriyet 2005). After a series of protests against this declaration, the building was not demolished however was closed. In 2008, the Government decided to restore the building instead of demolishing it. The Ministry of Culture and Tourism signed a contract with Murat Tabanlıoglu who is the son of Hayati Tabanlıoğlu for a new restoration project (Cumhuriyet 2012). However, the restoration process has been stopped by order of 9th Administrative Court. In-between 20052018, AKM has been left as dilapidated and no one announced anything about the building despite the calls of Chamber of Architects and professional associations. During the process, AKM had witnessed the Gezi protest in 2013. During Gezi protest, today's president and the then prime minister of Turkey declared that AKM will be demolished and a new Baroque Opera Hall will be built in place of it. After a series of discussions and protests again, the President declared the new AKM project which is designed by Murat Tabanlıoğlu in 2017 and the building was finally demolished in 2018. Although it is declared that the new AKM will be completed in 2019, it is still under construction today in January 2020.

\section{METHODOLOGY}

To analyze AKM within the scope and the main arguments of the study, the building has been evaluated in terms of the crucial 
breaking point of its history. Five periods were determined according to following features; (i) The 1st period in-between 19301956 correspond to the period starting from the first decision in 1930 by name Istanbul Opera to the Hayati Tabanlıoglu's design of Istanbul Culture Palace, including the unbuilt proposals of the other architects who had been involved the process, (ii) The 2 nd period in-between 1956-1977 corresponds to the period starting from the construction of AKM to the second opening of the building including the conflagration and restoration process, (iii) The 3rd period in-between 19772005 corresponds to the period when the building had served for its purpose and been used for many prestigious events, (iv) The 4th period in-between 2005-2009 corresponds to the period when the building had been closed and left as dilapidated, (v) The 5th period from 2009 till today corresponds to the period when the final decisions have been taken in a wide range of proposals including restoration, demolition and re-build. The building has also been left as dilapidated till its demolition in 2018 and still under construction for the new project today.

All five periods have been evaluated separately in following sections according to the main questions of the study with the help of captions in newspapers. The paper clippings helped to understand the whole process as it is officially announced in related years. For the first three periods, the original paper clippings and official gazettes have been used for main data to follow up the leading decisions and discussion on AKM. For the fourth and the fifth period, the articles which has been written by architects and/or columnists has been also used in addition to original paper clippings. Data have been firstly collected from Tabanlıoğlu Family Archives which has been donated to a research institute in Istanbul by name SALT. That archive has helped to collect photos and paper clippings in .jpeg format. The archive of Cumhuriyet Newspaper which is the oldest newspaper of Turkish Republic also helped to collect the old press clippings not available in SALT Research Online Archive. Articles and captions in other national newspapers also used for cross-check. To achieve the data; AKM, Istanbul Culture Palace, Istanbul Opera and Taksim Theatre and Opera keywords had been scanned through the archives inbetween the years of $1930-2020$.

\section{WHAT HAD BEEN DISCUSSED IN 90 YEARS: AKM WITH PRESS CLIPPINGS}

\subsection{The 1 st period in-between 1930-1956}

1930 refers to the early period of Turkish Republic and the political approach of those years embraced the occidental lifestyle and improvements to carry the new Republic to future. It was also a break of from monarchical state structure of Ottoman Empire to construct the new democratic structure of Turkey. Ankara was -and stillthe capital but Istanbul has always been in spotlight. Therefore, it was not surprising that the Government aimed to build a Theatre and Opera Hall in Istanbul instead of Ankara. Taksim Square has always been considered as the main square of Istanbul, and the Government organized an international competition for its masterplan. In 1937, the French architect and urban planner Henry Prost had been invited to Istanbul by Ataturk himself to design the masterplan of the city including Taksim Square and Gezi Park (Bilsel and Pinon 2010). At those years there was a mansion belongs to the Power Administration in the place where AKM has been built later (e.g. Fig. 1). The aim of the new Theatre and Opera Hall was to represent the new contemporary face of Turkey. That's why AKM has always been considered one of the most important concrete declaration of the changed system of government and therefore it has always carried a political approach. By referring to the article that 
was published in Cumhuriyet Newspaper in 1930 (e.g. Fig. 1), the Government had an agreement with a group of German designers and it was expected to meet with them in Istanbul in the summer of 1930 for the new project. However, the project had been suspended due to the economic conditions of Turkey after WWI. In 1946, it has been put on the agenda again. Although the Government took the suggestions of French architect Auguste Perret for design, Feridun Kip and Rüknettin Güney who had designed many projects for the Government so far, designed the first project by name Istanbul Opera. Unfortunately, project had been halted till 1956 due to the budgetary savings of the Government. On the other hand, according to Murat Tabanlıoğlu, the last building, which was designed by his father in 1969, was still representing the traces of Kip and Güney's design (Mimarlara Bülten 2013).

In 1953, the project assigned to The Ministry of Public Works, and the Ministry asked German architect Paul Bonatz who was working as an instructor at Istanbul Technical University in those years, to proceed the design of Kip and Güney. Bonatz worked on some sketches for the building nevertheless none of those proposals had been built (e.g. Fig. 2).
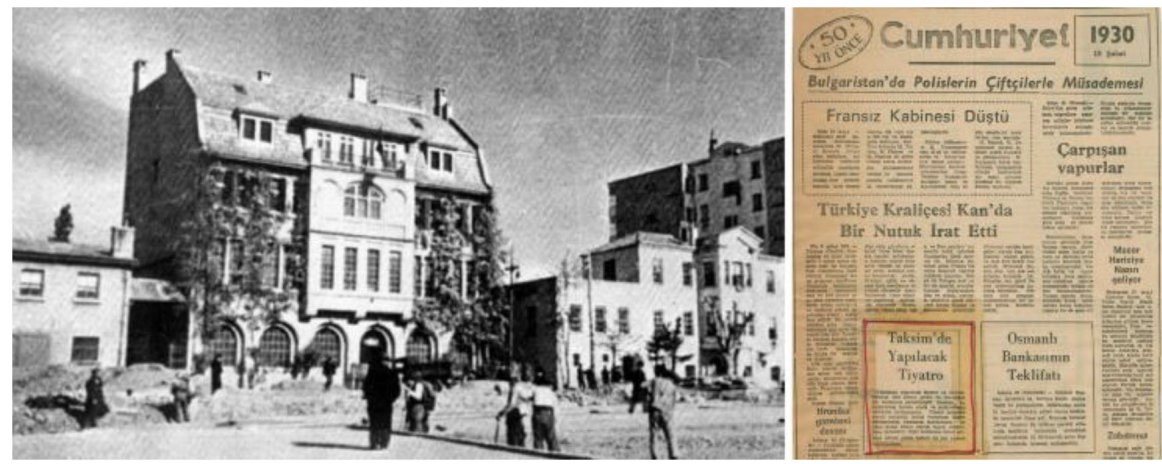

Figure 1. The Mansion in Taksim where AKM has been built later and the first paper clipping declares the new Theatre and Opera Hall in 1930. Source: (Salt Online Archive 2020)
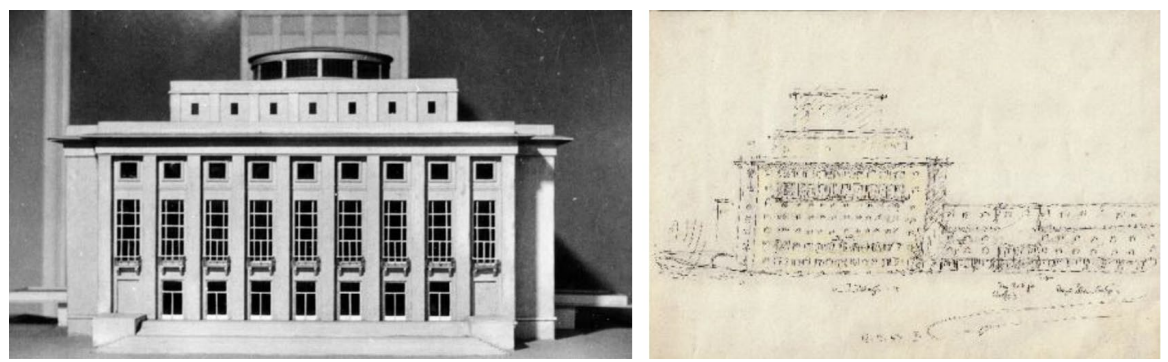

Figure 2. Model of the Istanbul Opera by Kip and Güney and Bonatz's sketches in 1953. Source: (Salt Online Archive 2020) 
Finally, in 1956 The Ministry assigned Hayati Tabanlığlu to conclude the project but, he designed a new project that conserves the basic structure of Kip and Güney's design. For the 1st period in-between 1930-1956, very few press clippings are available for Istanbul Opera except the announcements of the process. This period had also witnessed an important political change in Turkey. In 1950, Democrat Party (DP) which is considered as one of the first conservative political party -although its name is democrat- had won the elections and Republican People's Party (CHP) -democrat although its name is republican- which is founded by $\mathrm{M}$. Kemal Atatürk, had positioned as the opposition party. Even the major political approach of the county had changed, DP also embraced the Istanbul Opera as the monument of Turkish Modernization project.

\subsection{The 2nd period in-between 1956-1977}

When it was announced that Hayati Tabanlıoğlu was assigned to the project, the building was expected to be completed in the following years. As a matter of fact, Cumhuriyet Newspaper had announced two times, once in 1960 and second in 1961, that the building will be opened in these years (Cumhuriyet 1959, 1960). Those press clippings show that the society of Istanbul was looking forward to experience Istanbul Opera. One of the columnists in the newspaper even mentioned that every highbrowed human being in Istanbul may emulate to experience such operas in Europe and therefore Istanbul Opera is so crucial to allow them such kind of experiences in their hometown (Felek 1965). On the other hand, the building was concluded in 1969, after 9 years from the expected date. The press clippings which were collected from archive of Cumhuriyet Newspaper also help us to understand the construction process of the building took twenty-three years. It is clearly seen that; it was the budget saving to avoid the conclusion. A press clipping dated January 1958 shows that the legislator of CHP had accused DP to postpone the opening by saving insufficient budget for the construction for the proudly presented building (Cumhuriyet 1958). In 1969, finally the building opened by name Istanbul Cultural Palace with a grand opening ceremony. Since the program of the building was expanded for all branches of art not only opera, the name of the building has also changed. This alteration also caused a debate. According to Muhsin Ertuğrul who was the director of Istanbul Municipal Theatre, the building has been constructed for twenty-three years but naming took less than twenty-three days. He also said that palace is not an appropriate name for a contemporary Opera Hall and, also a contemporary country (Ertuğrul, 1969). Newspapers announced that opening as "the long-awaited Cultural Palace has finally been opened" (Cumhuriyet 1969a). Besides Hayati Tabanlıoğlu and the directors of art institutions -also artists and architects- the then President Prime Minister and even the Chief of General Staff of Turkey was attended the opening ceremony (e.g. Fig. 3). This can be interpreted as a declaration that what AKM means for Turkish Governors and politicians. Besides the supporters, there were also some critics about the building. Some important columnists of those years considered the building as a luxury consumption. While Barlas was pointing out that Turkey has bigger problems than having an international cultural palace (Barlas, 1969) and many other journalists was criticizing the elite events and their budgets (Cumhuriyet 1969b). The underlying approach of those critics was; the palace was built for just a few highbrowed people in Turkey and -because in that cultural era- opera, ballet and theatre is not a tradition for low-income society. Ironically, paper clippings in those years shows that the servants of surrounding Universities also protest the daytime schedules of the shows because they could not attend (Cumhuriyet 1969c). 

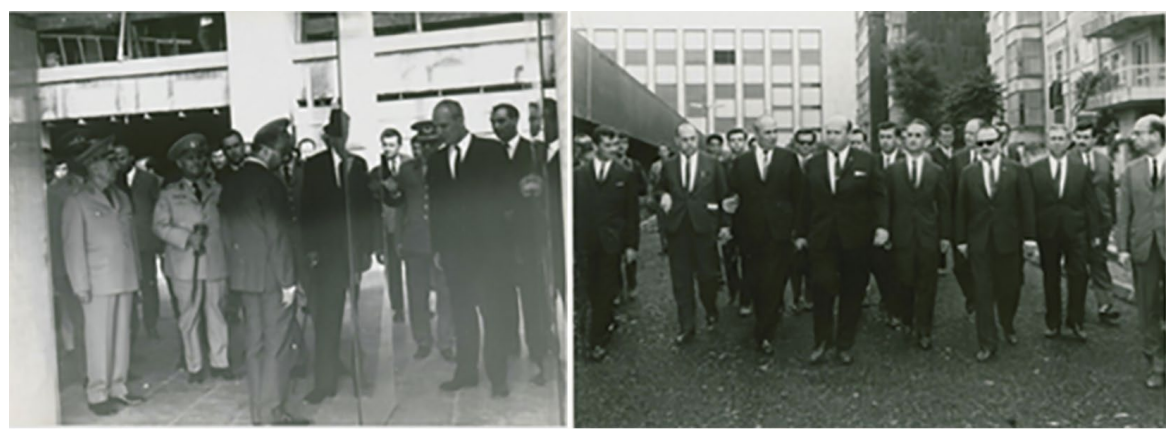

Figure 3. The visit of Hayati Tabanlıoglu, the then Prime Minister and senior staff of Turkey. Source: (Salt Online Archive 2020)

The building at the Pafos Gate consists of two main sections that are connected through a corridor over the street leading to the old city (Fig. 5). The north section hosts the entrance of the complex and a glassed exhibition space. The first floor hosts the private and semi-public research spaces accessible by the visitors. The façade panel openings adjust to the functional requirements of the corresponding spaces.

The building units at Sarayonu are positioned at the moat level of the city walls (Fig. 6). The main building section is situated below the street level, and extends on one side of the moat. Deployable units adjust through their size, structure and envelope elements to the functional disposition of the program. In this case the building primarily conveys open and closed spaces within the landscape at the moat level.

The façade of the building was another debate. It is still considered as an important example of contemporary Turkish architecture for architects and scholars. The façade had been designed by a well-known architect Aydın Boysan in corporation with Arçelik which was and still one of the pioneer international technology firm in Turkey. That's why their contribution to construction means a lot for architects to improve new construction techniques. The most important breaking point in the 2 nd period is the conflagration in 1970 (e.g. Fig. 4). There had been many speculations on what caused that catastrophic fire, even some left-orientated organizations had been accused to sabotage the building. Some people who has worked for these organizations decreed by death sentence (Son Havadis 1973) and this also shows how AKM had been politicized during its history. However, it turned out that it was the electrical system caused the fire. The large part of the building was heavily damaged after the conflagration and the building was decided to be closed due to the need of restoration. It should be also mentioned that Turkish Armed Force staged a coup in 1971 and overthrew the Government. The outcomes of this politic event also blocked the restoration process. It had taken eight years to restore the building. A newspaper captioned that the restoration is going on at a snail's pace because it needs 25.000.000 TL while the budged of the Government is 15.000.000 TL (Gün 1973). In 1974, a columnist in Cumhuriyet Newspaper published an article titled File: Culture Palace to elucidate the ongoing process of the restoration. He declared that no one is taking the responsibility of the fire because everyone is so busy to share the tenancy of the Cultural Palace (Ketenci 1974). That everyone includes 
the Government, the Municipality of Istanbul, the organization of State Opera and Ballet and Istanbul Municipal Theatre.

Another press clipping in 1976 shows that the construction workers also protested the Government for their unpaid salaries, and they declared strike for a month (Cumhuriyet 1976) and this also postponed the re-opening date. It is clear that the low budget was the first reason for delayed re-opening. In 1977, the citizens, reporters, organizations and professionals were at the end of theirs rope. A newspaper captioned that citizens have waited twenty-three years to build plus seven years to restore and now they are waiting for re-opening (Hürriyet 1977). In 1977, the building witnessed one of the most heartbreaking event of Turkey which is called the bloody 1st of May. Under the leadership of Confederation of Progressive Trade Unions of Turkey, 500.000 people gathered in Taksim for the celebration of the worker's day. The Union also covered the façade of AKM with banners. But unfortunately, 34 people were killed by a group of unidentified murderers by an open fire. The image of the building with that banner still represents 1st of May, 1977 and also still used as a reminder to emphasize the power of the working-class in Turkey. In September 1977, the building has been finally re-opened. However, the name of it had been changed again as Atatürk Cultural Center and this new name of the building could manage to survive till today.

\subsection{The 3rd period in-between 1977-2005}

The importance of the 3rd period is the only period that AKM had served as its purpose. It means that one of the most iconic building of Istanbul which has 90 years of history could be used only for twenty-nine years but still is the most important building of Turkey. During those years the building has also witnessed several government changes and also public events. The period in-between 19772004, there wasn't much thing to discuss about AKM within the scope of this paper. Only a columnist in Cumhuriyet Newspaper critiqued the abbreviation of Atatürk Cultural Center as AKM and he claimed that it is a political discourse of the conservatives, they do not want to pronounce the name of Atatürk on purpose (Arpad 1979). Another press clipping mentioned that AKM still has not an insurance for fire in 1980 (Cumhuriyet 1980). Apart from these, newspaper generally mentioned about the exhibitions and art events, not about the building. However, in 2005 the Government announced an unexpected declaration about AKM. The Minister of Culture and Tourism declared that AKM should be demolished because the building is not earthquake-resistant. The first reaction came from Istanbul Chamber of Architects. They declared that this proposal is baseless and illegal. Because AKM has
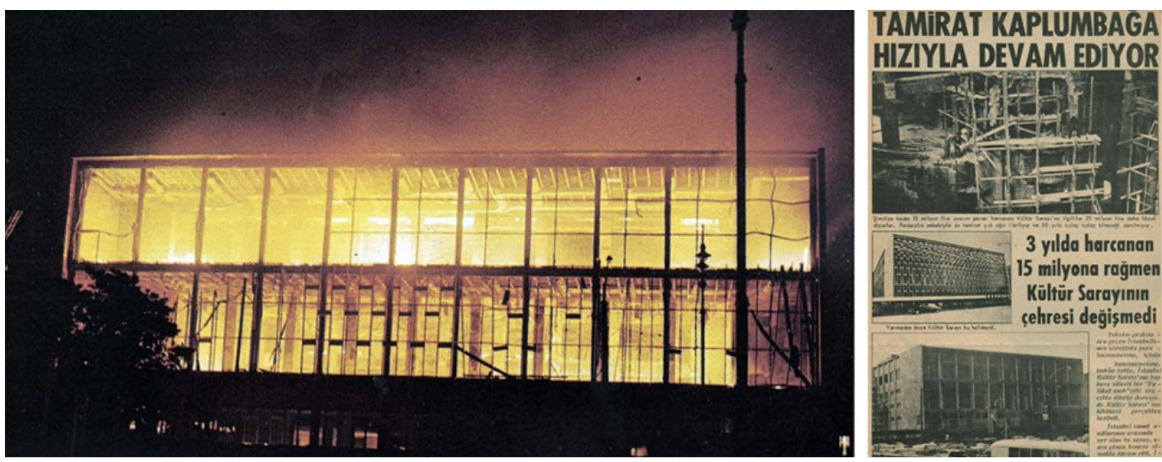

Figure 4. A photograph of fire and the paper clipping after then. Source: (Salt Online Archive 2020) 
already been registered as A-Class Cultural Asset by the second Preservation Board of Istanbul. However, AKM was closed again without any other declared reason but then it has been understood on following years that the Government has another agenda for Taksim Square. Many people blamed Justice and Development Party (AKP) for this declaration. Architects, artists, students, columnists, professional organizations and some politicians also supported Istanbul Chamber of Architects and the newspapers had started to caption about AKM again. Murat Tabanlıoğlu was also one of them who was against the demolition decision. He gave an interview to Radikal Newspaper together with his four colleagues titled as "Demolishing AKM? Don't even think about it!" (Aktuğ 2005). He also published an article in Radikal Newspaper in 2007 and said that "AKM is not just a building, it is an icon" (Tabanlıoğ/u 2007). However, he gave up his critical position in later years and has been announced as the new architect of the new AKM in 2017.

\subsection{The 4th period in-between $2005-2009$}

This period corresponds to the second period of AKM that had been kept close. During these four years it was not clear if AKM will be demolished or restored again. In 2007 Cumhuriyet Newspaper caption that AKM should be restored instead of demolition and added that it is a God-given right of art lovers in Istanbul to interpose the demolition. At the same page the newspaper also features the declaration of Istanbul Chamber of Architects titled as AKM shouldn't be demolished, it is one of the most unique example of Turkish Republic architecture and also the symbol of Taksim Square (Cumhuriyet 2007). Within these four years many protests had been organized by artists and architects. The Government was in the cross hairs of all these protests. A columnist in Radikal newspaper published an article about AKM titled as "AKM and Memory Removers". He emphasized that it is not important if you like or don't like the architecture of AKM but still to demolish it means to remove one of the most important heritage of 20th century history of Istanbul and the modernization period of Turkey. He also added that who is Istanbulian, has also a memory about AKM. If you demolish it, you will also demolish those memories and none of the buildings can replace those memories even if it will be the most beautiful building of the world (Şahin 2007). In 2009, the Government declared that AKM will be restored and the restoration project has been assigned to Tabanlıoğlu Architects which means Murat Tabanlıoğlu. It was not surprising to think that Murat Tabanlıoğlu wants to restore the building which is designed by his father to keep it out from demolition. The restoration project has been accepted by the Preservation Board in 2009, however in the same year the Union of Culture and Art indicted the Ministry of Culture and Tourism by justifying the verdict of A-Class Cultural Asset (Tabanlıoğlu 2013). Although Istanbul 2010 European Capital of Culture Agency Executive Board tried to arbitrate, the Union didn't withdraw the case and the 9th Administrative Court decided to halt the decision of restoration.

\subsection{The 5th period in-between 2009 till today}

From 2009 to 2017 there have been no official news about the future of AKM, will it be demolished or restored. In 2009 the Government allowed the 1st of May ceremonies to be held in Taksim Square again and in 2011 the Confederation of Progressive Trade Unions of Turkey hold the same banner on the façade of the AKM after 34 years to remind the bloody 1 st of May in 1977 (Cumhuriyet 2017). 2013 is also another important year throughout the history of the building. Thousands of people in Istanbul had protested the decision of demolition of Gezi 
Park in Taksim Square. The protest held in in Taksim Square again even it was not allowed by the Government. The Government tried to disperse the demonstrators by police force however it took nearly one month to end the protest. National and international press announced this as "Gezi Protests in Taksim". Throughout the protest, AKM has taken to the stage again. Although the building was closed on that date, protesters used the façade of the building again as a screen and representation of the event (e.g. Fig. 5).

During the protest the president of Turkey announce that not only Gezi Park but also AKM will be demolished. He also proposed to build a baroque style opera hall in place of Taksim. This proposal was also caused a debate among citizens and professionals. Istanbul Chamber of Architects published a release to the public and claimed that the demolition of AKM will be illegal and it is not understandable to demolish one of first Modern project of Turkey to build a baroque style building instead of it. In 2015, another debate occurred related to the façade of the AKM. The Ministry of Culture and Tourism covered Turkish Modernism' iconic façade with a movie poster that, the Movie about Ottoman Empire. It was the first time that one of the most important public square of Turkey had been represented by a movie poster and it was also the first time AKM had been used as an advertising board. In 2016, World Architecture News 2015 Awards announced a project which is designed by Adrian Smith \& Gordon Gill Architecture awarded as Future Project Civic Building. It was a surprising disclose for Turkish citizens because the building was designed in place of AKM. The newspapers announced this news as "the mysterious project" (Cumhuriyet 2016). It is still a mystery for all that who ordered the building and in which purpose. However, this project has also never been built (e.g. Fig. 6).
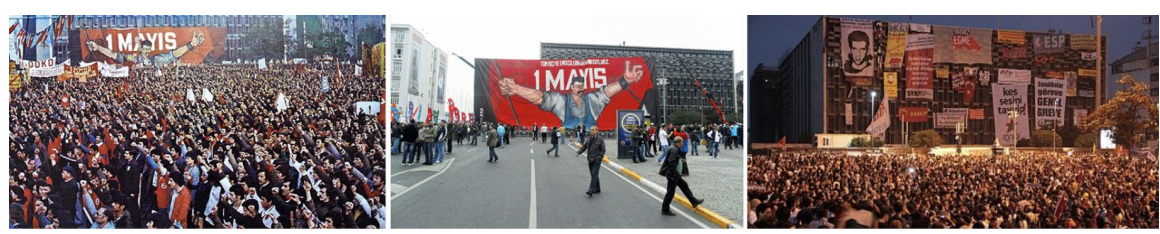

Figure 5. The façade of AKM in the bloody 1st of May 1977, same banner in 1st of May 2011 and Gezi Protests in 2013. Source: (Cumhuriyet 1977, 2017; Sözcü 2013).
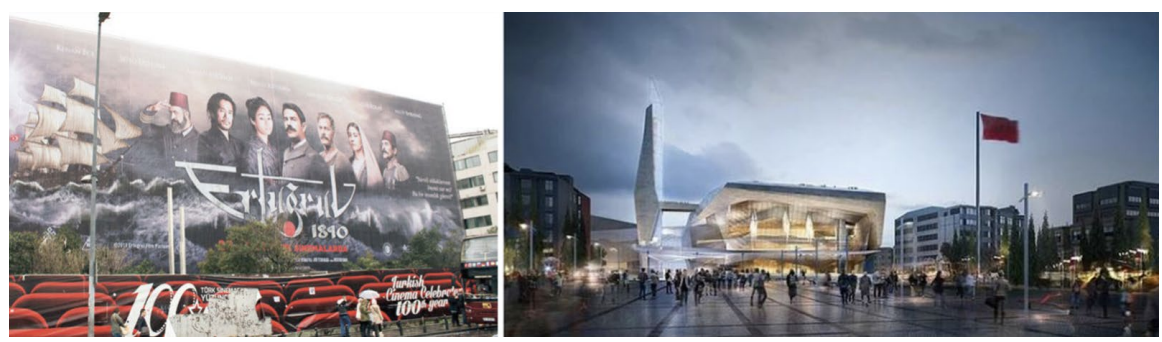

Figure 6. The façade of AKM as advertising board in 2015 and the "mysterious project" in 2016. Source: (Cumhuriyet 2015, 2016) 
Finally, in 2017, the Government announced the new AKM project with the participation of the Ministry of Culture and Tourism, the governor and mayors of Istanbul and Tabanlıoğlu Architects. The project was introduced via a video including 3D renders of the new design. The new AKM is completely designed by Tabanlıoğlu Architects under the leadership of Murat Tabanlıoğlu. as far as it is understood, the old and famous façade of the building has been kept and it is the only thing that has matched with the original AKM. Now besides all the memories, the new AKM will also face the old with its façade physically. In the opening speech of the ceremony, the President of Turkey declared AKM as an unfortunate building. According to him, there is an institutionalized lobby in Turkey which is also supported by foreign agents. That lobby has been trying to sabotage every urban decision in Turkey just because political reasons. To him, they used AKM as a tool to protest the Government and the only reason that the building has been kept as a ruin for 10 years was the acts of this lobby (Hürriyet 2017). The President also considered this lobby in the same equation with advocates of the terror in Turkey and he also declared this again in the groundbreaking ceremony of the new AKM in 2019 (CNNTürk 2019). The design of the new AKM and Murat Tabanlıoğlu is still a very controversial subject in current days. Since Murat Tabanlıoğlu was one of those who strongly opposed the decision of demolition in 2005 , those critiques were not unexpected. Hereupon, Murat Tabanlıoğlu answered those critiques via an interview he gave to Financial Times in 2019. He said that "normally, I would never collaborate with the Government however AKM is a family inheritance for me". Nonetheless, he added that he was so upset the day the building had been demolished and could not even watch or see it (Financial Times 2019). In the groundbreaking ceremony, the President declared the building will be opened in 2019 however today in August 2020, the current situation as in figure 7 .

\section{CONCLUSION}

AKM with its unique history has been representing the role and the debates of architecture in a contemporary society in many perspectives. Within the scope and the questions of this paper, it contains all answers as a cumulative case. What makes a building historical and iconic for a city? The answer would be the architectural design as it is in this case. AKM was one of the first examples of the Turkish Modernization in architecture, it would be also the historical events that the building had witness and AKM has always carried this responsibility throughout its history. The answer also would be the landmark features of the building; AKM
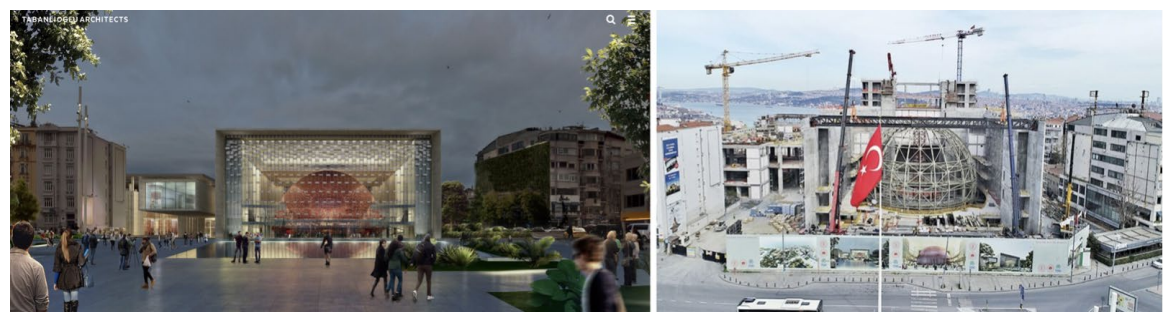

Figure 7. The new AKM project and the current project site. Source: (Tabanlıoğlu Architects 2020) 
is placed in the most important public square of Istanbul. However, beyond those answers AKM is historical and iconic because it has always been a battlefield of ideological struggle between modernist revolution and the conservative counter-revolution. This directly leads us to the 3rd question: What are the effects of politicians and architects to urban memory? Even the citizens of Turkey who had never visited Istanbul know many things about AKM. It has created a kind of cumulative urban memory for all Turkish citizens. While some of them strongly against its demolition the others celebrated the new building. When it is considered that it is just a cultural center, this separation becomes much more interesting for architecture. Besides the politicians who has participated the process as decision makers, when current Turkish President claimed people who protested the demolition as terrorist, AKM also became a terror weapon that causes public indignation and this is the answer what are the effects of politicians on urban memory. It is understandable that architect Murat Tabanlığlu has wanted to design the new building to adopt his father's legacy. He is neither politician nor decision maker. However, he has also been accused of betraying the urban memory, and this is the role and the effect of the architect in urban decisions. He was expected to conserve an architectural legacy and the urban memory, so the architect became a political figure and/or a savior instead of a professional. AKM also shows that if a building becomes an urban legend no matter if it is new or old. Possibly, the new AKM will be more functional and well-designed according to the original one however It is not the design that causes the debate in here, it is the memory that a city needs. Thus, when the new AKM will face the old, it will also represent the demolition of the original one, but still will be historical and iconic again. The 2nd question of the paper is still open to discussions. Since the building has not been completed yet, it is not appropriate to answers this question. Future discussions will show us can a new building represents the same meaning with the old even if the two have same function and façade? 


\section{REFERENCES}

Aktuğ, Erkan. 2005. "Mimarlar: AKM'yi yıkmak mı? Aklından bile geçirme!" Radikal. Accessed December 2, 2019. https://archives.saltresearch.org/ handle/123456789/89687.

Arpad, Burhan. 1979. "Niçin AKM." Cumhuriyet. Accessed December 10, 2019. https://www.cumhuriyetarsivi. com/cumweb/html/.

Barlas, Mehmet. 1969. "Benzersiz durum." Cumhuriyet. Accessed January 5, 2020. https://www.cumhuriyetarsivi.com/ cumweb/html/.

Bilsel, Cana and Pierre, Pinon. 2010. Henri Prost's planning works in Istanbul (1936-1951): Transforming the structure of a city through master plans and urban operations. Istanbul: Istanbul Araştırmaları Enstitüsü.

Can, Aslı. 2015. "Atatürk Cultural Center as a part of Hayati Tabanlığlu archive." European Union Prize for Cultural Heritage / Europa Nostra Awards 2015, Special Mention. Accessed December 21, 2019. https://www.europanostra.org/2015eu-prize-cultural-heritageeuropa-nostraawards-special-mentions/.

CNNTurk. 2019. "Yeni AKM'nin temeli atıldı, Cumhurbaşkanı tarihi törende konuştu." Accessed February 10, 2020. https:// www.cnnturk.com/turkiye/son-dakikayeni-akmnin-temeli-atiliyor-binaliyildirim-torende-konusuyor.

Cumhuriyet. 1930. "Taksim'de yapılacak tiyatro." Accessed December 10, 2019. https://www.cumhuriyetarsivi.com/ cumweb/html/.

Cumhuriyet. 1958. "Opera binası meselsi bütçe komisyonunda görüşüldü." Accessed December 10, 2019. https:// www.cumhuriyetarsivi.com/cumweb/ $\mathrm{html} /$.
Cumhuriyet. 1959. "Istanbul Opera Binası 1961 yılında bitiyor." Accessed December 10, 2019. https://www. cumhuriyetarsivi.com/cumweb/html/.

Cumhuriyet. 1960. "Istanbul'un ilk opera binası 19 Mart'ta perdesini açıyor." Accessed December 10, 2019. https:// www.cumhuriyetarsivi.com/cumweb/ html/.

Cumhuriyet. 1969a. "Istanbul Kültür Sarayı dün açıldı." Accessed January 2, 2020. https://www.cumhuriyetarsivi.com/ cumweb/html/.

Cumhuriyet. 1969b. "Opera, gecekondu, övüntü." Accessed January 2, 2020. https://www.cumhuriyetarsivi.com/ cumweb/html/.

Cumhuriyet. 1969c. "Operaya gitmek bizim de hakkımı" Accessed January 2, 2020. https://www.cumhuriyetarsivi. com/cumweb/html/.

Cumhuriyet. 1976. "Günde 750 lira fark için kültür sarayı onarımı durdu." Accessed January 2, 2020. https://www. cumhuriyetarsivi.com/cumweb/html/.

Cumhuriyet. 1980. "AKM'nin ne sigortası var ne de iskan izni." Salt Online Archive. Accessed January 6, 2020. https://archives.saltresearch.org/ handle/123456789/89685.

Cumhuriyet. 2007. "Yıkmak değil onarmak gerek." Accessed December 15, 2019. https://archives.saltresearch.org/ handle/123456789/73710.

Cumhuriyet. 2012. "AKM de restore edilecek." Accessed December 14, 2019. http://www.cumhuriyet.com.tr/ haber/diger/317616/AKM_de_restore_ edilecek.html.

Cumhuriyet. 2016. "Yeni AKM'nin fotoğrafları internette yayınlandı... Müşteri bölümü gizli." Accessed February 4, 2020. http://www.cumhuriyet.com.tr/ haber/turkiye/491184/yeni-akmninfotograflari-internette-yayinlandimusteri-bolumu-gizli.html. 
Cumhuriyet. 2017. "Işte DISK'in arşivlerinden çıkan 1 Mayıs fotoğraf ve afişleri." Accessed February 4, 2020. http:// www.cumhuriyet.com.tr/foto/ foto_galeri/730411/1/iste_DiSK_in_ arsivlerinden_cikan_tarihi _ 1_Mayis_ fotograf_ve_afisleri.html/15.

Cumhuriyet. 2019. "Yıkmak değil onarmak gerek." Accessed December 15, 2019. https://archives.saltresearch.org/ handle/123456789/73710.

Ertuğrul, Muhsin. 1969. "Taksim'deki bina." Cumhuriyet. Accessed January 2, 2020. https://www.cumhuriyetarsivi.com/ cumweb/html/.

Felek, Burhan. 1965. "Personel Kanunu." Cumhuriyet. Accessed December 10, 2019. https://www.cumhuriyetarsivi. com/cumweb/html/.

Financial Times. 2019. "Architect's son performs second act for Istanbul opera house." Accessed February 10, 2020. https://www.ft.com/content/123bd2e6c9a8-11e9-a1f4-3669401ba76f.

Gün. 1973. "Tamirat kaplumbağa hızıyla devam ediyor." Salt Online Archive. Accessed January 5, 2020. https://archives.saltresearch.org/ handle/123456789/91681.

Haluk, Şahin. 2007. "AKM ve Bellek Silicileri." Cumhuriyet. December 15, 2019. https://archives.saltresearch.org/ handle/123456789/85831.

Hürriyet. 1977. "23 yıl yapılışını, 7 yıl tamirini bekledik, şimdi de açılışını bekliyoruz." Salt Online Archive. Accessed January 6, 2020. https://archives.saltresearch.org/ handle/123456789/90647.

Hürriyet. 2005. "Koç: AKM'yi yıkacağız." Accessed December 14, 2019. https:// www.hurriyet.com.tr/gundem/kocakmyi-yikacagiz-3128860.

Hürriyet. 2017. "Yeni AKM projesi tanıtıldı." Accessed Februay 10, 2020. https:// www.hurriyet.com.tr/gundem/iste-yeniakm-40635485.
Istanbul Atatürk Cultural Center Directorate Briefing File. 2005. "Binanın idari ve hukuki durumu." Salt Online Archive. Accessed November 17, 2019. https://archives. saltresearch.org/handle/123456789/70030.

Ketenci, Şüfran. 1974. "Kültür sarayı dosyası." Cumhuriyet. Accessed January 2. 2020. https://www.cumhuriyetarsivi.com/ cumweb/html/.

Mimarlara Bülten. 2013. "Modern Mimarlık ve AKM'nin Dönüşüm Rüreci." Accessed December 27, 2019. http:// mimarlarabulten.com/yazilar/modernmimarlik-ve-akmnin-donusum-sureci

Salt Online Archive official website. Accessed January 5, 2020. http://saltresearch. org/primo_library/libweb/action/ searchalt\&dscnt $=0 \& d s t m p=158185960$ 5805\&backFromPreferences=true

Son Havadis. 1973. "Sabotajcıların idamı istendi." Salt Online Archive. Accessed January 5, 2020. https://archives.saltresearch.org/ handle/123456789/83728

Tabanlıoğlu, Murat. 2007. "AKM salt bir bina değil, bir simge yapıdır." Radikal, December 2, 2007. Accessed January 2, 2020. https://archives.saltresearch.org/ handle/123456789/76871

Tabanlıoğlu, Murat. 2010. "Istanbul AKM yenilenirken." Mimarlık 352, no. 2. Accessed December 11, 2019. http:// www. mimarlikdergisi.com/index. cfm?sayfa= mimarlik\&DergiSayi=366\&ReclD $=2319$

Tabanlıoğlu, Murat. 2013. "Atatürk Kültür Merkezi: Yirminci Yüzyıl Yapısını Yirmi Birinci Yüzyıla Taşımak, part 1." Mimarlık 371, no. 3. Accessed December 11, 2019. http://www. mimarlikdergisi.com/ index.cfm?sayf $=$ mimarlik\&DergiSayi=385\&ReclD=3149

Tabanlıoğlu Architects offıcial website. Accessed June 5, 2020. http://www. tabanlioglu.com/. 



\section{PAPER \#3.14}

\section{THE URBAN CHURCH: REPURPOSING A COMMUNITY DETAIL}

\section{William O'Neil Bourke}

aTemple University, Philadelphia, Pennsylvania, USA

\section{ABSTRACT}

What is the status of urban churches today? Changes in congregations and notions of community are causing the abandonment of urban religious structures. As cities change, so do their architecture and communities. This results in urban churches becoming a popular focus for redesign.

The common trend for church redesign-Christ Reformed Church (Philadelphia) and First Baptist Church (Dayton, Oregon)--shows approaches for housing and restaurant space, respectively. Though they seem to be reasonable solutions, they lack the connection to traditions of community embedded in these structures.

This paper looks at the challenging design for hyper-specialized architecture. Through historical research, detail, and respect, the paper proposes how church architecture adaptive reuse should respond to the originality of these sacred spaces. Design should take into consideration adaptive reuse trends of contrast (new vs. old) to architecturally create new buildings with revitalized community purposes.
The design case study it analyzes is the Church of Assumption BVM at 12th and Spring Garden in Philadelphia, PA. Being a Gothic Revival cathedral, the design focuses on not just the space, but also, the sublime experience of the church itself. The design calls to reinvent the way the public interacts with these buildings by changing the procession of space. Since Gothic art was considered an act of devotion, the project, Art as an Act of Devotion, adapts and reprograms the space as an artist collective where community members can come to create and experience art in a neighborhood lacking public space.

By introducing site connections that form new geometries (contrast), changing notions of entrance (transparency), and creating new experience through moments of reflection (prayer) and movement, adaptive reuse of churches can begin to respect, reinvent, and revitalize buildings and their communities within the city.

\section{KEYWORDS}

Adaptive reuse; new meets old; contrast; urban churches; gothic architecture.
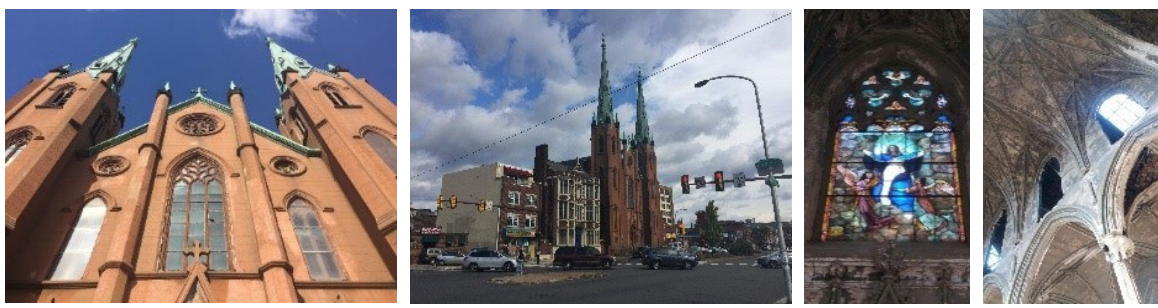

Figure 1. The Church of the Assumption BVM. Philadelphia, PA. Source: (Bourke 2019) 


\section{INTRODUCTION}

"The True Church can never fail. For it is based upon a rock" (Elliot 1917, 27-8).

Throughout history, churches have been gathering places for communities. These structures stood as symbolic representations of spirituality, community, and tradition. They are used for big congregations, pilgrimage destinations, and daily prayer. Yet, in today's changing urban dynamics, they are beginning to lose the purpose of their original design.

Research has shown that churches are primarily affected by changes in their congregations.

"Far from being fixtures in the urban landscape, the population of congregations is a constantly shifting array--some coming, some going, others moving and still others reinventing themselves" (Simons, 2017 12).

This makes congregations "drivers of change of sacred places" because the changes like "births of new congregations, deaths of existing congregations, contractions and expansions of existing congregations" affect the groups and function of churches themselves (Simons 2017, 12). As communities grow and change, the groups shift and move to different buildings, consolidate from multiple to one, and leave others as a result. The dynamic changes cause the abandonedment of urban churches while their communities develop new needs. The result leaves urban churches with no congregation to serve and creates an infrastructure with no purpose.

The question then becomes why save these buildings? Aside from being beacons for community, they are examples of sublime detail and beauty worth saving. John Milton wrote:

"But let my due feet never fail/To walk the studios cloister's pale,/And love the high embowed roof/With antique pillars massy
proof,/And storied windows richly dight/ Casting a dim religious light" (Milton 2012).

As houses of god, these churches were designed with care and high craft. The spaces they create have an air of spirituality. Architect Steven Holl often talks of the feeling of a place. Holl states,

"A five-year-old can walk into a building and not really understand the concept, but still get that feeling" (Phaidon (Holl), 2019).

It is the indescribable effect of walking into a space and being struck by an unconscious feeling of awe and beauty that makes one remember a building. Most urban churches do not have to strive to become special spaces because they already embody both the tradition of craft and service that we unconsciously appreciate through our nostalgia towards history and memory (Zumthor 1998, 7). This paper broadly looks at the dilemma of urban church architecture and then focuses more specifically on the Gothic and Gothic Revival building type to propose an interdisciplinary solution to the design problem of respecting these buildings but revitalizing them with new purpose.

The adaptive reuse process will be explained through a design case study that focuses on the Gothic cathedral type and the experiences its architecture creates. Their ornament, their play with light and shadow, and the connection to the spiritual, create an example of awe and stunning architecture that new construction fails to achieve. Church sublimity combined with a community function prove that churches have valuable and unique characteristics. Even though they have lost their institutional purpose, that does not mean the building must lose the qualities that make it special. 
1. COMMON USES, REOCCURING ISSUES: HOUSING, RESTAURANTS, AND PERFORMANCE VENUES

With their current uses for abandoned ecclesiastical architecture, designer's approaches fail to preserve the beauty of these spaces. Designs include bars, housing, restaurants, and performance spaces. Cities have many adaptive reuse projects of churches, like Christ Reformed Church-Chapel Lofts (Philadelphia) and the Sheba Apartments, Fishtown (Philadelphia) and First Baptist Church-Block House Cafe (Dayton, Oregon), to name a few. Though these are profitable solutions, they fail to create a connection to the tradition and service-oriented function that churches were designed for. All current reuses devalue the sacred, degrade the institution, and restrict the accessibility of these urban churches.

Housing design devalues the sacred nature of a church. Instead of being a holy "house of God", these buildings lose the sublime by becoming an "apartment for rent." The designs lose the dichotomy of big lofty spaces of the nave, and narrow aisles that shape the spatial integrity of a church (Fig. 2 left). This special and unique spatial organization becomes segmented and fractured to fit in as many rooms as possible and in doing so, destroys the interior dynamics of these churches. By doing this, churches lose their ability to be used for reverence and reflection. Their aspect of awe and emptiness is missing. Located in Fishtown, Philadelphia, Sheba Apartments, was repurposed as apartments, and looking through the front door, it already becomes apparent that there is a change in spatial organization (Fig. 2 right).

Other attempts, like restaurant reuse, degrades the character of the institution of the Church. Rather than being a building for public service the building becomes a business or "profitable" enterprise. Capitalizing on the big open spaces, the approach crams as many tables into a large space with disregard to the original programmatic intent. The nave

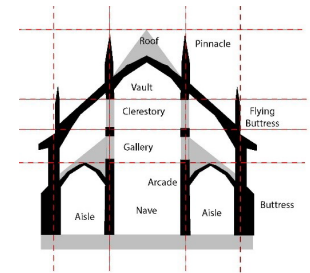

The Cathedral Structure

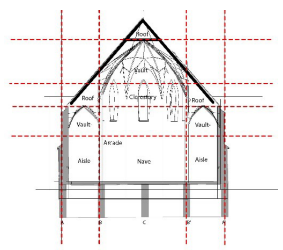

Church of the Assumption

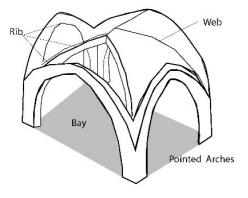

The Rib Vault

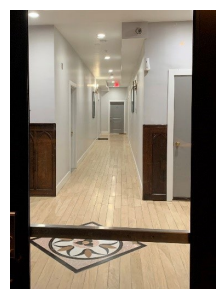

Figure 2. Gothic Church Spatial Diagrams (left), Front Door, Sheba Apartments (right) Source: (Bourke 2019)

becomes cluttered with tables and chairs and the institution shifts away from its service-based focus (Fig. 3). The reuse does little to change the space and approaches the "redesign" as a chance to fit in whatever furniture they can based on a square footage count.

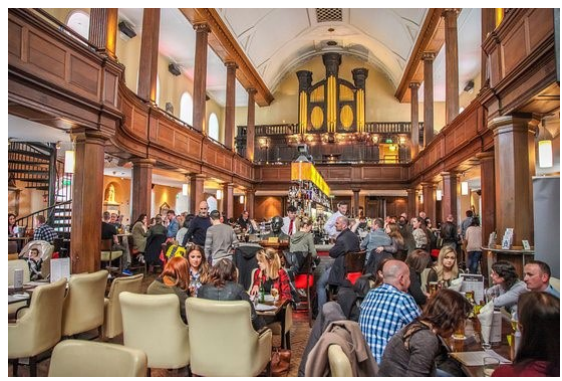

Figure 3. The Church, Dublin, Ireland. Source: (The Church (Management) 2017) 
The performance venue approach, like The Old Church (Portland), appears at first to be a more viable use but has its shortcomings as well (The Old Church (Management), 2019). This effort restricts accessibility and becomes an issue of "day and night." The design questions the fundamental nature of church-goers needing access to building throughout the day. The adaption becomes a venue operated only at night and no longer offers solace for daily prayer losing its communal purpose. They revitalize the building with new function similar to prayerperformance-which appears to speak to the fact the churches were meant to be big, beautiful, and acoustic spaces, with a large area for gathering. However, this approach narrowly responds to the church architecture and removes the interaction and connection to the building and its details. Performance reuse successfully creates an experience where the participant can interact with the performance (like mass service) but fails to connect the architecture as an active facilitator in its function. Venue plans remove accessibility and the building becomes a shell in which a performance occurs rather than an active contributor to a spiritual experience.

All three types are options, but can church adaptive reuse become something more? New design should reflect the originality of these buildings. Current uses fail to respect the social responsibility that these buildings were created for. By using a method like historical analysis of church design, we can learn to find more appropriate ways to redesign these buildings.

\section{METHODOLOGY: RECONNECT AND RESPECT THROUGH HISTORY AND TRADITION}

To better grasp design solutions for the urban church, one must understand the history and development of the design of ecclesiastical architecture, and more specifically, Gothic architecture. History can give lessons on how to create more meaningful connections within architectural design by connecting these existing buildings to their roots. Gothic cathedrals were designed with two community-based functions in mind: pilgrimage and the daily purpose of prayer. The fundamental basis of a church design was its programmatic intent to serve the community (Monrose 2012). The architecture was a public space representing a religious institution but meant to be open to all. The program was defined by civic duty, and its beauty was a representation of craft and a call to something greater-a sense of spirituality. To understand these buildings, we must understand their history, as well.

History gives clues to the origins of cathedral architecture. In the Gothic era, art [and architecture] was seen as an act of devotion (Homan 2016, 50). In response to what some saw as the degradation of society, Gothic Art was a mode for uplifting and improving the state of the community and society in general (Homan 2016). Gothic architecture embodied this message, and the relics and the buildings were designed with the intent to create moments of deeper connection for personal prayer and reflection.

The architectural design of these churches was carefully laid out to serve its function. Tracing the history of a church, from a Roman basilica to the Gothic Revival cathedral, shows how its service-oriented function formed its architecture (Fig .4). As mentioned, the Gothic cathedrals were designed as pilgrimage churches with the architecture of the nave, apses, and ambulatory simultaneously facilitating prayer (Stalley 2007). Religious service or mass also shaped the architecture, as the two functions could occur together. The functions led to the development of the church to have a conflicting dynamic of movement and meditation that created the unique spaces found in cathedral design. 
These spaces allowed for people to move freely and find their own personal moments for reflection even during mass. This gave churches a purpose as a space of devotion, reflection, and beauty for the community (Homan 2016). The uniquely orchestrated procession of spaces creates a sublime architectural experience of active and static moments centered around prayer and reflection.

\subsection{Methodology: Themes of Contrast (New vs. Old)}

The adaptive reuse projects call upon one important concept of transformation from new to old, which is contrast. Liliane Wong mentions that "Adaptive reuse, in contrast to demolition and preservation, perpetuates a continuum of growth and change" (Wong $2017,35)$. Adaptive reuse is founded upon the

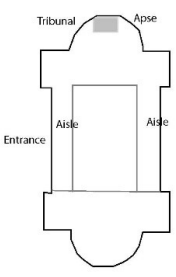

Basilliaca

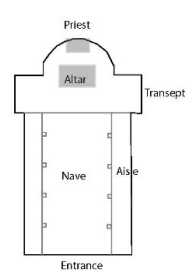

Early Christian

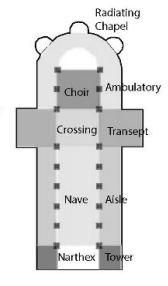

The Spaces

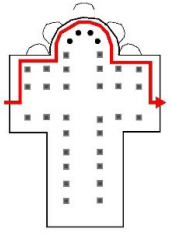

The Purpose

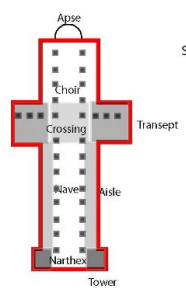

The Form

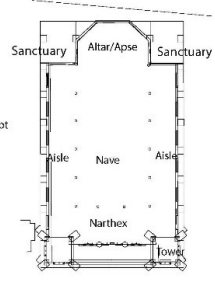

Church of the Assumption

Figure 4. The Historical Development of Church Architecture. Source: (Bourke 2019)

To respect and redesign a sacred space calls on a sensitivity to the original intent, tradition, and beauty found in religious architecture. When designing these spaces, thereare special difficulties that arise because the architecture is so specific. How does one design a new adaptive function for a building so focused on its programmatic intent for religious service? The other question is how to create a dynamic change while respecting the originality, spatial organization, and beauty of the church? The solution comes with three foci: community (program), contrast (tectonics), and sublime experience (design approach). To respect the original design, the reuse must maintain its community function. In addition, the reuse will focus on recalibrating the sublime experience, which is the aspect of the design reliant upon the original notion of movement and reflection or procession of spaces. Lastly, the design will call for the contrast of new and old to architecturally state the changing function. notion of change. Architecture must respond to the changing notions within a community and adapt to fit new needs. As mentioned, churches are facing a period in which they are losing their original function for prayer, so they need to adapt or find a new purpose. The tectonic architectural response to create new functions is through the process of contrast. Charles Blozies states that adaptive reuse projects require an element of contrast. With adaptive reuse, there should be a response within the architecture that enhances "our appreciation of both new and old" (Blozies 2011, 139). He further breaks down the notion of contrast into three categories: extreme, reserved, and referential. With extreme projects, like Daniel Libeskind's Contemporary Jewish Museum, Blozies shows how new alien-like structures can completely redefine old spaces through the introduction of new geometries (Blozies 2011, 94-5, Fig. 5). With reserved contrast, found by Renzo Piano's 
Morgan Library, Blozies illustrates how architectural interventions can be simple and austere. The design unites three buildings from three different eras of design history with a simple connective tissue forming a new complex (Blozies 2011, 98-9, Fig. 6). With referential contrast, like Forte Di Fortezze, Blozies shows how collective architecture can use contrasting materials to create connections that artfully respond to the historic complex and create new passages and routes through the existing building (Blozies 2011, 80-1, Fig. 7). Through all three modes of contrast, adaptive reuse can create new spaces through a varying dialogue between new and old elements to reinvent and revitalize existing architecture.

Disregarding the degrees of extremity, all three projects hold one thing in common, the element of contrast. Whether it's glass and
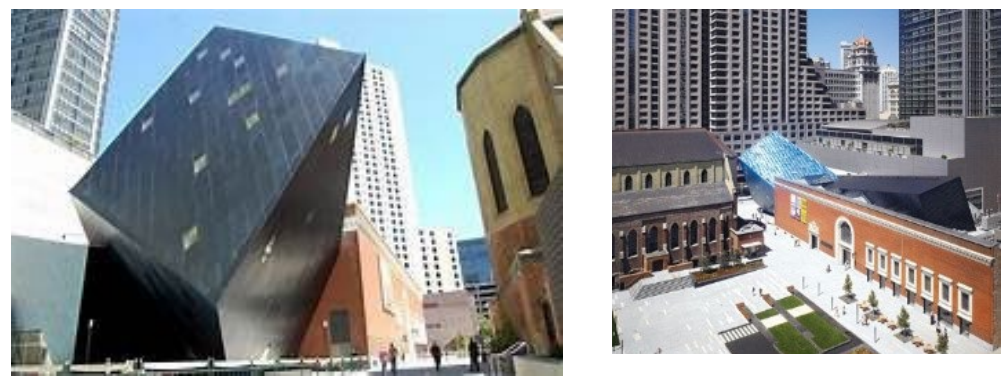

Figure 5. Contemporary Jewish Museum_Studio Daniel Libeskind_San Francisco, CA 2008. Source: (Basulto 2008)
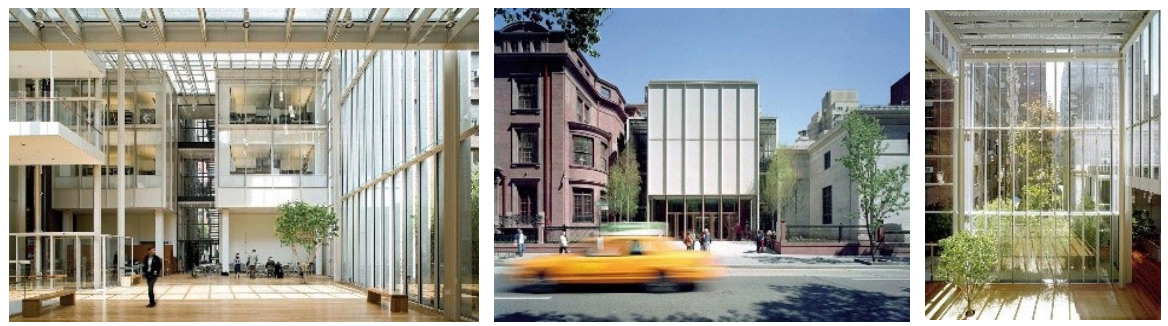

Figure 6. Morgan Library_Renzo Piano Building Workshop_New York, NY 2008. Source: (Denance 2020)
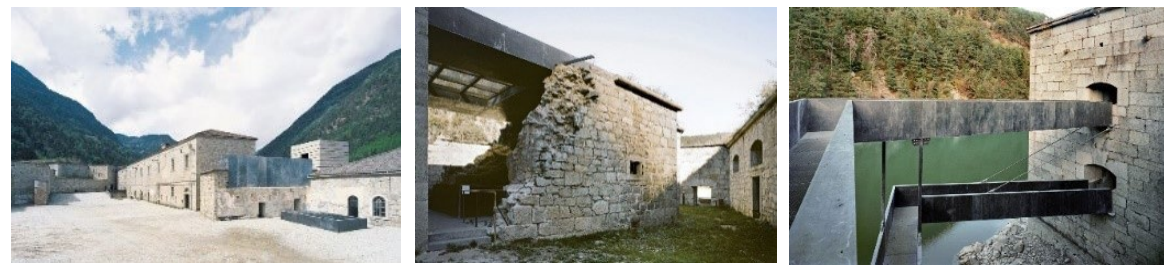

Figure 7. Forte Di Fortezze_Markus Scherer and Walter Dietl. Fortezza, Italy. 2007. Source: (Jett 2011) 
steel against stone, or metallic panels against brick, or steel infiltrating granite, contrast can be used to call attention or notify that there is something new and different within the old architecture. With architects like ViolletLe-Duc and Louis Kahn, contrast becomes an element that contributes and improves the existing architecture. The connections to "the nature and tradition of a space....and the ideal..human aspiration"(design) show how architecture can respond to what exists rather than ignore it (Bressani (Le Duc) 1989, 327350). The design case study's approach at the Church of Assumption B.V.M. in Philadelphia, learns from all modes of contrast and looks to create a new architecture that redefines the existing site while paying attention to "the nature of a space..and the will to exist a certain way" (Wong 2017, 35). The proposal shows how interventions can respond to and respect the building and not destroy the integrity and tradition steeped within the beauty and experience of its space.

\section{CONTEXT: SPRING GARDEN COMMUNITY}

The design case study for the adaptive reuse of an urban church focuses on Church of the Assumption BVM. The church is a Gothic revival building located in the heart of a changing area of Philadelphia, Pennsylvania. Philadelphia has become a hot bed for the dilemma of abandoned church infrastructure. As a city, Philadelphia is built on the foundations of religious freedom, and as one of the largest cities in the United States, the population has been affected by the flux of congregation demographics.

The Church of the Assumption B.V.M. is in the Spring Garden District of Philadelphia. Recently, the area has been rebranded as the Spring Arts District. It lies in an old industrial part of the city, and has an architectural variety ranging from warehouses, to row homes, to abandoned railways. As a major component of adaptive reuse, the Reading Viaduct, an abandoned railway, has been planned to be repurposed as public greenspace, and as a result, it has sparked incentive for redevelopment of the area (Saffron 2018). With a promising architectural landscape, the area's adaptive resue face the problem of serving a new complex demographic

Many projects only offer an activation of the area at night in the neighborhood. With large populations of homeless people, and the call for redesign of forgotten industrial infrastructure, the area has become popular for adaptively reused buildings like performance venues and breweries (Flynn 2017). Through the process of redevelopment, the creative class is drawn to the area because of its affordable options for artist spaces, which creates an incoming demographic of young creative professionals. The tension between the new incoming population and existing area offers an opportunity for a new community space that can be focused on the arts, performance, and outreach.

Looking at the urban demographics and development, the Art as an Act of Devotion project looks at redesign within the context of its emerging community. With new artists and existing outreach, the adaptive reuse design case study looks to serve the community through a new artist collective where the community can come to make, teach, and connect communities through art. A building created through devotion and art, can be repurposed to serve and revitalize a community through that same devotion.

\section{CASE STUDY: THE CHURCH OF THE ASSUMPTION B.V.M. (PHILADELPHIA, PENNSYLVANIA)}

The case study, Art as an Act of Devotion, looks at the site bordering 12th and Spring Garden. The Church of the Assumption BVM adaptive reuse looks at redesign through elements of contrast, community, and the sublime. The site 
includes three religious buildings: the rectory, the convent, and the church (Fig. 8, 11). The buildings are situated neighboring each other and packed tightly together creating spaces that recall the narrow streets and towering masonry buildings of a Medieval city (Fig. 11). The focus of the redesign connects the support buildings and the church to create new spaces for outreach, residences, and studios. By introducing connections between all three buildings, the design calls for an activation of the whole site rather than one building. The artist collective becomes a dialogue for community by creating a complex for public service.
The adaptive reuse proposal focuses on two key elements: creating new viable connections, and fostering the growth of a new community. The connective tissue called the "cloister" encloses bridges between the three buildings making the complex. The bridges then connect the inside by creating new routes on the second floor or "gallery" level. These links are formed by joining the existing and adjacent masonry openings-like windows and doors-of the buildings. The design reinvents, redirects, and reorients the buildings with new routes through the three buildings that offer new interior geometries in the church (Fig. 9). Newly formed connections
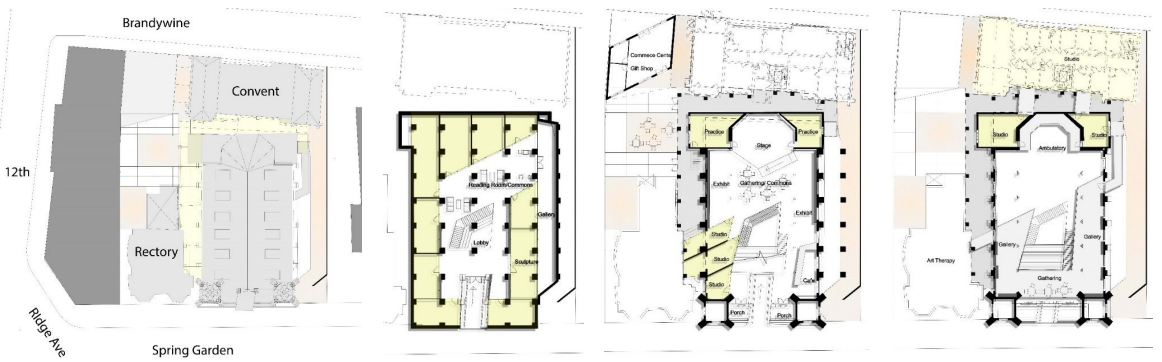

Figure 8. (From left to right) Site Plan, Basement, First Floor, and Gallery Level. Reference. Source: (Bourke 2019)
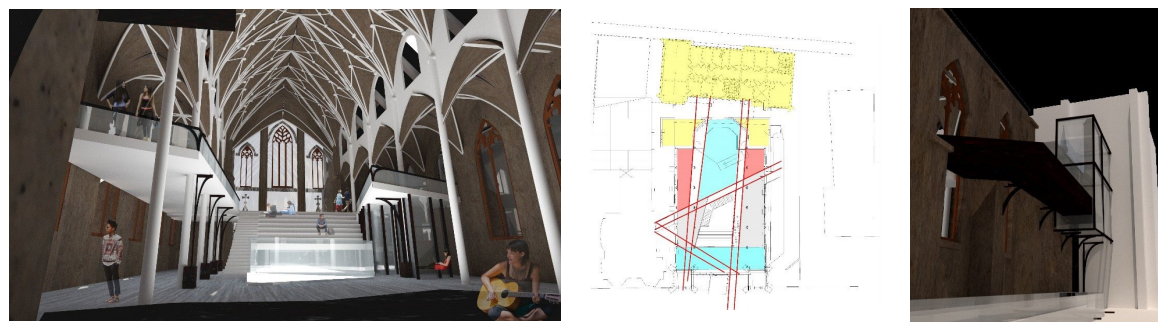

Figure 9. Church Interior (left) Regulating Site Lines and Openings (center) Cloister (right). Source: (Bourke 2019) 
begin the dialogue of contrast of the new and the old.

The adaptive reuse implements all contrast types proposed by Charles Blozies. Like Forte di Fortezze, the bridges themselves are referential as they respond to the "raw form and structure" of the existing buildings. They solve the "practical problem" of how to connect these three closely knit buildings. In addition to form and structure, the bridges also refer to the industrial past of the area with the material choice of galvanized steel (Blozies, 80). These bridges then actively introduce new extreme geometries. Like Daniel Libeskind's Museum, these geometries are "unsettling and vertiginous" and they notify the shift from old to new by forming new interior spaces (Blozies, 94). Lastly, the cloister connects three startlingly different buildings with a simple reserved response tectonically (Fig. 9). Made of steel and glass, it is constructed with a mesmerizing "rhythm of new and old" in an "understated" manner like Renzo Piano's Library (Blozies, 99). The design does so with regard to material and scale. The glass enclosure allows light into the interstitial space that is wedged between the three buildings. The cloister itself does not reach higher than any of the three structures and allows the church to remain as the focal point of the complex. The proposal creates a complex that calls to serve a new function and design through the technique of contrast.
The design decisions call to breakdown the hierarchy of tradition encompassed in these structures through a focus on concepts of transparency and entrance. The front façade gets modified from stone to glass, which makes the interior always visible to the public (Fig. 10, 11). The design creates street view that establishes the church as a lantern for its community activating it with different programmed areas like classrooms, exhibits, studios, and practice spaces. The new program for the building begins to bring activity to the Spring Garden corridor throughout the day. By doing so, the building breaks down the barriers--institutionally and physically--that seem to be arising between the community, the church, and its architecture.

After inviting the public into the newly repurposed collective, the next step was to change the procession of space (sublime experience) by recessing the entrance into the building and submerging it below grade. This shifts the entrance from going up to going down, and it reactivates the unused basement of the church for new studio spaces and a lobby. The new entrance into the church from the basement allows for a dramatized entrance into the nave of the church (Fig 10). By opening the basement to the nave, the design amplifies the height of the nave space, and reorients the experience of the space by drawing the viewer to look up at the decorative rib vaulting when entering the church. This begins to touch on
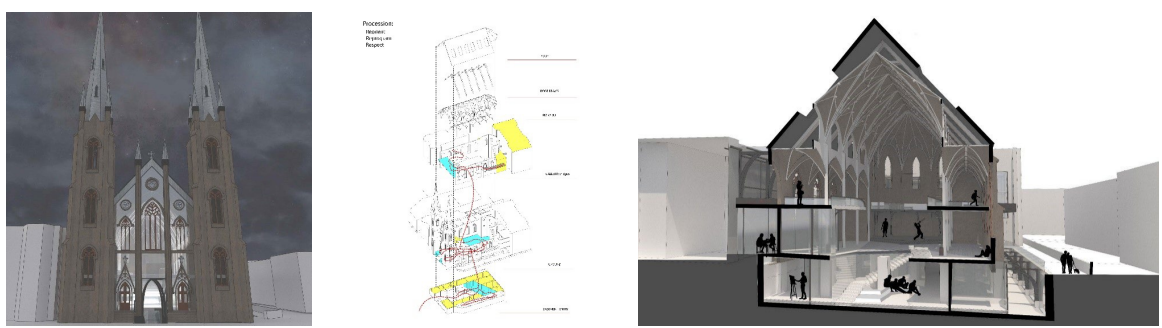

Figure 10. Community Lantern (left), Sublime Procession (center), Section (right). Source: (Bourke 2019) 
the importance of redesigning the spatial sequence that becomes the driving force for design (Fig. 10).

The design approach calls for one to design with respect to the integrity of the space and the institution of the church. What gets redesigned in this approach is not quite the building itself but rather the interaction with and procession through the spaces. Elements of contrast, connection, transparency, and entrance, work to respect, reorient, and reprogram the church. By introducing bridges and changing the entrance, the design changes the movement through the building. With new program and geometries, the building becomes activated with a new function and architecture. (Fig. 10) From a building built upon prayer, mass, and movement, it gets reactivated regarding that original function. The Art as an Act of Devotion adaptive reuse calls for the community to reexperience the church through a newly activated spiritual framework for the religious structure. As people come to create, learn, and experience art, the church naturally provides spaces and places where they can participate, reflect, and grow through a community artsbased program. The design proposes to respect religious tradition yet offers a space and opportunity to serve new community needs that its original design no longer can.

\section{CONCLUSION. RECREATING MEANING BY LEARNING FROM TRADITION}

Looking at the history of the institution of the church and the original design intent, we can learn how to respect and celebrate church architecture. Looking at Gothic Revival churches and their history, designers can use approaches like sublime experience and meaningful public purpose as a guide to adaptive reuse solutions. By doing so, architects can repurpose these buildings in a manner that does not ignore the beauty, integrity, and spirituality of the space. Church architecture is steeped in tradition and conflict as a house for a religious institution. That does not mean that redesign solutions should ignore tradition, but instead, it should embrace it. When redesigning, architects will run into issues because these buildings are connected and revered by the communities due to the fact, they were created to serve them. It is the tradition and community service that should remain as an integral part of design for these structures. The problems arise when community structures are demolished or redesigned, and the original function ignored.

Can we respond to what is there rather than destroy what exists? The hyper-specialized spaces are designed with spatial relations and feelings that must be preserved. Rather than looking at fracturing these buildings or packing them with furniture, we can celebrate them and their history. Urban Churches not only serve as an interesting topic for redesign, but also offer lessons to design in general. They offer opportunities to work with architecture
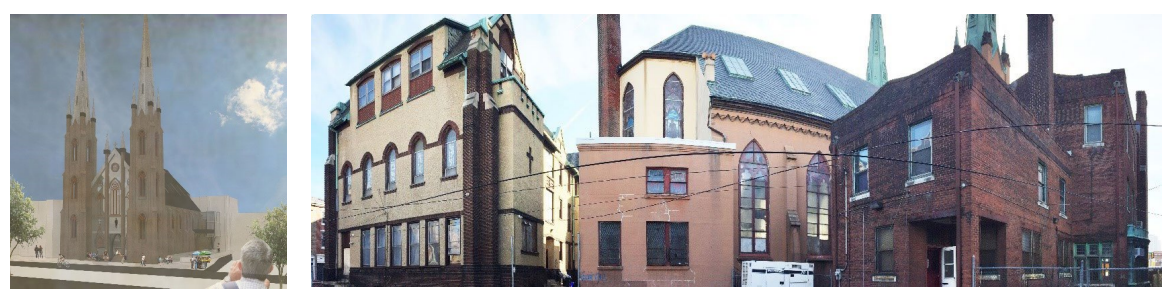

Figure 11. Art as an Act of Devotion (left), Site of Church of the Assumption BVM (Left to Right: Convent, Church, Rectory). Source: (Bourke 2019) 
already steeped with meaning and tradition. There is a need today for designers to create architecture that has a deeper meaning and significance. Architecture that was created with fundamentals in history, tradition, the sublime, and public service is an architecture worth saving.

\section{ACKNOWLEDGEMENTS}

I would like to dedicate this paper to my Grandad, who passed due to COVID-19. An engineer and artist, whose talent and work ethic inspired me to become an architect, Rest In Peace with Gram 08-23-20. 


\section{REFERENCES}

Basulto, David. "Jewish Contemporary Museum San Francisco / Studio Libeskind." ArchDaily, ArchDaily, 10 June 2008, www.archdaily.com/2113/jewishcontemporary-museum-san-francisco-bydaniel-libeskind-opening/.

Blozies, Charles. 2011. Old Buildings, New Designs. Princeton Architectural Press.

Bourke, William. 2019. Art as an Act of Devotion. (Temple University). Architectural Thesis.

Bressani, Notes on Viollet Le Duc's Philosophy of History, 1989. Journal of the Society of Architectural Historians, 48,327-325.

T. S. Eliot, 1920. Poems. New York: Alfred A. Knopf, 27-28.

Homan, Roger. 2016. The Art of the Sublime: Principles of Christian Art and Architecture. London: Routledge.

Jett, Megan. 15 Sept. 2011. "Fortress of Fortezza / Markus Scherer with Walter Dietl." ArchDaily, ArchDaily. www.archdaily. com/168769/fortress-of-fortezza-markusscherer-with-walter-dietl.

Milton, John. 2012. /I Penseroso. Hardpress Publishing.

Monrose, Pastor Gilford T. 19 Nov. 2012. "The Role and Importance of the Church in the Community." The Huffington Post, TheHuffingtonPost.com. www. huffingtonpost.com/pastor-gilford-tmonrose/role-of-the-church_b_1896969. html.

PHAIDON (Holl). 2012. "Steven Holl 'Architecture Brings Art into Our Lives' । Architecture | Ageda." Phaidon. https:// www.phaidon.com/agenda/architecture/ articles/2015/october/07/steven-hollarchitecture-brings-art-into-our-lives/
Flynn, Katherine, and Preservation. 19 July 2017. "Fertile Ground for Adaptive Reuse In Philadelphia's Former Industrial Buildings: National Trust for Historic Preservation." Fertile Ground for Adaptive Reuse In Philadelphia's Former Industrial Buildings I National Trust for Historic Preservation. savingplaces.org/stories/fertile-groundfor-adaptive-reuse-in-philadelphiasformer-industrial-buildings\#.Xht6ZchKiUk.

Saffron, Inga. October 18, 2018. "Philadelphia Expected the Rail Park to Generate New Development. Instead, We Might Get a Self-storage Facility. I Inga Saffron." The Philadelpia Inquirer.Accessed December 05, 2018. http://www2.philly.com/philly/ columnists/inga_saffron/philadelphia-selfstorage-density-zoning-board-michaelgrasso-planning-commission-20181018. html.

Simons, R., DeWine, G., Ledebur, L., Wertheimer, L. 2017. Retired, rehabbed, reborn: The adaptive reuse of America's derelict religious buildings and schools (Sacred landmarks monograph series). Kent, Ohio: The Kent State University Press, 12.

Stalley, Roger Andrew. 2007. Early Medieval Architecture. Oxford University Press.

The Church, (Management). 2019. "The Church, Dublin - Menu, Prices \& Restaurant Reviews." TripAdvisor, www.tripadvisor. com/Restaurant_Review-g186605d792839-Reviews-The_Church-Dublin_ County_Dublin.html.

The Old Church, (Management). 2019. "About Us." The Old Church, www.theoldchurch. org/about/.

Wong, Liliane (Kahn). 2017. Adaptive Reuse: Extending the Lives of Buildings. Basel: Birkhäuser, 35.

Unknown. 2017. "Church Brew Works Pittsburgh Brewery \& Restaurant in an Historic Church." Church Brew Works, churchbrew.com/.

Zumthor, Peter. 1998. Thinking Architecture. Baden: Lars Muller. 


\section{PAPER \#3.15}

\section{NEW OLD CITIES. \\ THE REBIRTH OF GERMAN HISTORICAL CENTERS}

\section{Michele Giovanni Caja ${ }^{a}$}

aPolitecnico di Milano, Milan, Italy

\section{ABSTRACT}

The rebirth of historical centers in some important German cities represents a unique phenomenon, due to the programmatic nature of the designers' intentions and the variety of proposed solutions. Accompanied by a controversial debate, the cases here considered share the same principle of critical reconstruction. A principle which aims to correct the errors often carried out in a state of emergency in the post-war period and mostly based on alternative ideas of city. If this reaction - introduced by the revision of the principles of the Modern Movement since the 50s - arises from a slow awareness of the value of the historical heritage, it is with the first critical reconstruction of historical centres of the 80s that the will to recall concretely their identity is manifested.

The projects here presented are to be considered a mature phase of this reflection on urban history and the possibility to reactivate it nowadays. In the search of a new identity of their old characters, emerges a dialectic relationship between historical continuity, critical reconstruction and urban design, with recurring themes like: the memory of the layouts of streets and squares, the small-scaled parcels of the blocks, the reuse of historical typologies, the individuality of each house, the representativeness of the façade, the use of traditional forms and materials. According to a growing attention to the veracity of the original urban image, these projects are intended not as a mere mise en scène, but as a real implementation of the historical city with respect to current needs.

\section{KEYWORDS}

Germany; historical centers; critical reconstruction; urban image; identity.

\section{INTRODUCTION}

The ongoing rebirth of historical centers in some of the most significant German cities - Berlin, Dresden Frankfurt, Lübeck and Potsdam - represents a unique phenomenon, not only in Europe, due to the programmatic nature of its designers' intentions, the richness of the actors involved, the variety of proposed solutions. Accompanied by a lively and controversial debate, the cases here considered share the same principle of critical reconstruction (Caja 2018). Such a critical approach dates back to the revision of the urban principles advocated by the Modern Movement in the 20s of last century, which have built the theoretical basis for almost all the projects for the reconstruction of European cities, especially German cities, destroyed by the Second World War. This critical reflection on the fundaments of the historical city arose from the rediscovery of its temporal dimension, understood as a complex and stratified phenomenon built up over time. A phenomenon based on the overlapping of distinct historical layers, of different ideas of cities, surviving only in fragments and parts, for the analysis of which techniques similar to those of archaeological stratigraphy have been developed. 


\section{THEORETICAL BACKGROUND}

The origin of this awareness dates back to the 1950s when, for the first time, the loss of the center and the need to restore a heart to the city became a main topic in the architectural debate (Rogers et al. 1952). The merit of this questioning was to highlight how the functionalist city, so attentive to the question of zoning and the optimization of living spaces, had completely forgotten not only the question of historical centers, but also that of newly founded nuclei. The question of the heart of the city was raised as a social, political and economic center as the issue of the new center for many of the devastated cities after the Second World War emerged. This concern for the regeneration of life in the city raised a great range of strategies on how to deal with it. However, many of these actions incorporated decontextualized parts attributable to the model of the open city, which caused the loss of historical identity of the urban space.

The urban analysis developed in Italy during the 1960s (Muratori 1960; Aymonino et al. 1970) became an operational tool to investigate the morphological structure and typological features of historical cities. If the merit of this intense analytical decade was that of classifying historical types and forms in a taxonomic way, its limit was that it didn't have a direct influence on the design phase, which was still understood as an autonomous moment in a tight continuity with the idea of open city based on abstract principles. The reflection of these studies on an international scale in the following decade rediscovered the value, the individuality and uniqueness of historical centers in their spatial and urban dimension. A rediscovery capable of activating a renewed attention towards them, no longer intended only as an object of study and analysis, but as real design references.

This gave rise later to an awareness of the need not only to revitalize these centers but, where necessary, to rebuild them according to the specific settlement principles of the
European city (Delevoy 1978). From Léon Krier's first ideal projects for the reconstruction of German cities such as Bremen (Krier 1984) to the Internationale Bauausstellung Berlin (IBA 1984/87), the reconstructive principle took on a formal definition and critical emphasis, poised between revisionism and experimentation. The interventions carried out in Berlin in the two decades following the reunification of the city (1990), under the guidance of Hans Stimmann and a group of "architects of the city", constitute an updated example of this re-constructivist line, pursued today even in smaller historical centers, such as those analyzed here.

The projects here presented are to be considered as a mature phase of a reflection on urban history and the possibility to reactivate it nowadays. Aimed at reconstructing the identity of the historical features of the here considered German cities, they establish a dialectic relationship between historical continuity, reconstruction and urban design.

Within the history of reconstruction (Nerdinger 2010), these interventions prove to be paradigmatic for the questions they raise, but also for the concrete architectural solutions they offer, in their dialogic connection between copy and reinterpretation, which makes them true witnesses of the contemporary condition in which we live (Eco 2016). On the other hand, despite their obvious character of "constructed historical images" (Pehnt 2011), they are to be explained in opposition to the often exasperated desire to be current and new in much contemporary architecture.

In this sense, they constitute a new chapter in the reconstruction of historical centers, different from previous efforts, based on stylistic, typological or technical aspects, as it is shown in the well-known cases of post-war period such as Warsaw, Münster or Colmar; the Bolognese blocks (Cervellati et al. 1977); the Nikolaiviertel in Berlin with its use of prefabrication.

On the other hand, they are also different from the exported urban cities inside extraEuropean contexts, especially China (Bosker, 
2013), for their different intentions and for the expectations they arise: no images to be evoked or suggested, but real pieces of the historical city to be reconstructed where they were before. There is no displacement, as in the idea of Satellite cities often proposed by the Modern Movement - see Das Neue Frankfurt by Ernst May - to be built outside the city center, but also in some Italian cases of urban reconstruction after natural disasters as in Gibellina, Teora or Monteruscello. But there is also no analogy, the typical compositional instrument introduced by Aldo Rossi in the 60s and then echoed in the European and American debate by authors like Colin Rowe, Miroslav Šik, Hans Kollhoff and others to recreate imaginary cities as collages of well-known architectures of the past. What these cases present is a new way of critical reconstruction on site, where the margins of interpretation emerge from the architectural solutions, more than from the historical morphological structure, which follows directly the original one, with its compact structure, the recognizability of its typologies, the representative character of its urban image.

\section{DIFFERENT WAYS OF URBAN CORRECTIONS}

These cases do not arise from an emergency condition or from the need to provide an immediate response, as in the above- mentioned experiences or more recent ones linked to natural disasters. The here presented projects are in fact cases of transformation and replacement of previous reconstructions and, as such, are rather to be considered as interventions of urban correction on earlier parts, realized after World War II, considered today, for various reasons, inadequate for scale, morphological characters and architectural language - to the pre-existing structure of historical city. They are projects, therefore, that arise from the conception of the urban form as a palimpsest of different layers and historical traces, modifiable in themselves, and from the desire to restore, as far as possible, the image erased and lost over time.

\subsection{Destruction vs. Reconstruction: Hildesheim as paradigm}

A first paradigmatic case in this sense is represented by Hildesheim in Lower Saxony, where for the first time a post-war building was demolished to allow the reconstruction of the ancient historical ensemble of the medieval Marktplatz(Häger 2011). For the reconstruction of the most representative historical building on the square - the butchers' guild house (Knocherhaueramtshaus), built according to the typical wooden frame structure common to many other buildings of the historical ensemble -, a Hotel from the 1960s, in the typical forms of the post-war International Style, was demolished. (Fig. 1)
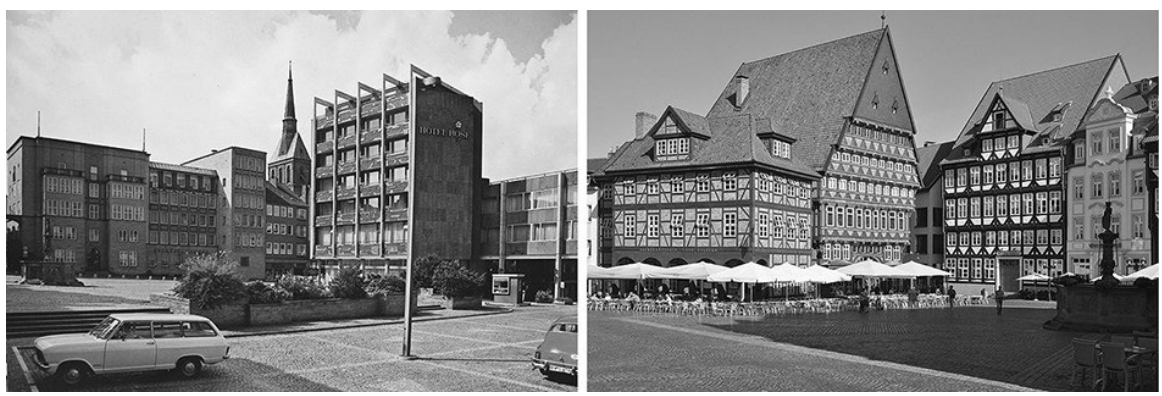

Figure 1. Hildesheim: Hotel Rose; Knochenhaueramtshaus, rebuilt (from: «Arch+», n. 204) 
Likewise, in the other cases treated here, there have been similar cases of punctual replacement. At the Neumarkt in Dresden, it was necessary to remove an oversized moloch dating back to the 1980s, the extension of the Police Garrison, to allow the reintegration of the original perimeter of one of the eight historic blocks. At the Friedrichswerder in Berlin, the Foreign Ministry (Aussenministerium, 196467), built on Schinkelplatz site during the GDR regime, partly occupying the Bauakademie area and overlooking the Friedrichswerdersche Kirche both designed by Karl Friedrich Schinkel, was demolished. In Frankfurt, the Technisches Rathaus (1974), a brutalist building, was destroyed in 2010 to free the Dom-Römer Areal area, while in Potsdam the large complex of the Teachers' Training Institute on FriedrichEbert Strasse was recently removed to make room for the new blocks in the process of being built around the Castle. These out-ofscale functionalist buildings, dating back to the socialist or technocratic era, produced, for their volume and architecture, an alienating effect within the original historical fabric, without being able to regenerate a real urban life. (Fig. 2)

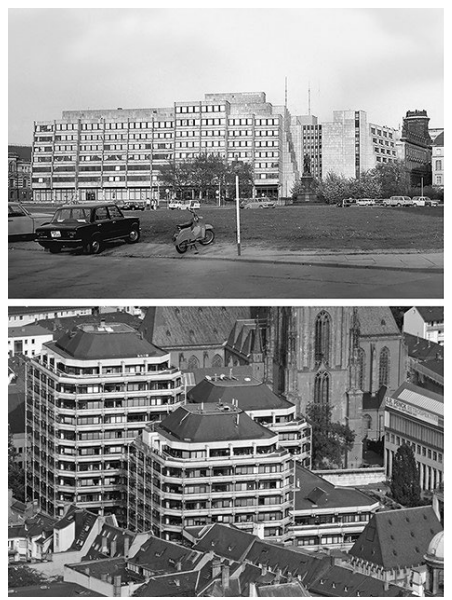

2.2. The mixed Model: Leitbauten and Neubauten

Compared to Hildesheim, a true reconstruction in style (at least for the façades) of the original historical substance, the model adopted in the cases analyzed here is different and more articulated, as it includes both reconstructions as they were where they were and contemporary reinterpretations of the destroyed houses. The mixed model is based on the coexistence of Leitbauten and Neubauten - buildings reconstructed in the same way as the original ones and new buildings inspired by the existing ones.

This model was firstly adopted at the beginning of the new millennium in the reconstruction of the urban blocks around Dresden's Neumarkt, in conjunction with the completion of the reconstructed Frauenkirche.

Similarly, the Dom Römer Areal in Frankfurt consists of an ensemble of houses: about a third are copies of the originals and the rest are entrusted to a wide range of local and non-local architects. In contrast to the general plan for the reconstruction of the Altstadt, only a few blocks will be built in Berlin by
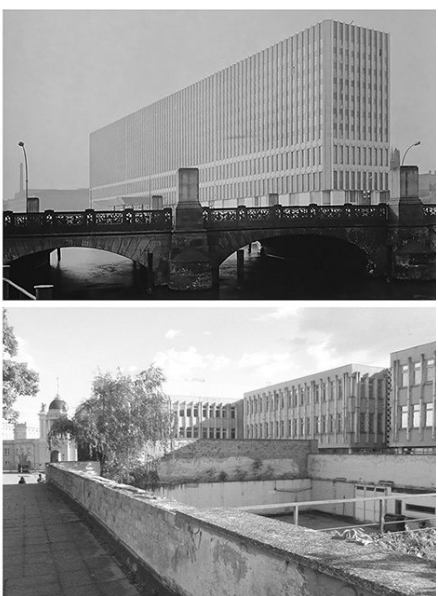

Figure 2. Demolished Buildings: Extension of the Police Garrison, Dresden; Foreign Ministry, Berlin; Technisches Rathaus, Frankfurt; Teachers' Training Institute, Potsdam. 
a team of not only national studios, with a compact construction similar to the original, but without the stylistic restoration of the old houses.

The validity of the mixed model seems to be reconfirmed in the other two cases. The blocks around the Alter Markt in Potsdam are based on a general plan (Leitbautenkonzept), according to which different types of intervention are identified: from the faithful reconstruction of the original façades of 18th century buildings to new houses which follow the original volumetric and compositional guidelines.

Also in the case of the narrow and elongated blocks of the Gründungsviertel in Lübeck, a similar approach was followed under the guide of UNESCO: reconstructed pilot project buildings and current reinterpretations of the Gothic-merchant houses typical of Hanseatic cities.

In some cases, like Frankfurt, the dialectics between old and new is defined by the permanence of historical traces and spolias, considered as building stones to be reintegrated into the new houses. Their presence has the intent to make the reproduction of the original state - still alive in the collective memory of the actively involved community - more plausible.

\subsection{Figurative reconstruction of Baroque city: Neumarkt, Dresden}

As one of the most important squares in Dresden's historical center, the Neumarkt was built in the 16th century on the space of the pre-existing city walls in continuity with the market square (Jüdenhof). After the War destructions in 1945, its boundaries disappeared, leaving a large open space around the ruins of the Frauenkirche. During the clearing of their rubble, the complexes of the Johanneum and other historical buildings - still partially standing and available to reconstruction - were also removed.
The actual reconstruction of the urban blocks around the Frauenkirche - planned since the German reunification -, has profoundly transformed the place, according to the original baroque layout (SAK 2008) and its famous views painted by the Italian painter, Bernardo Bellotto. (Fig. 3)

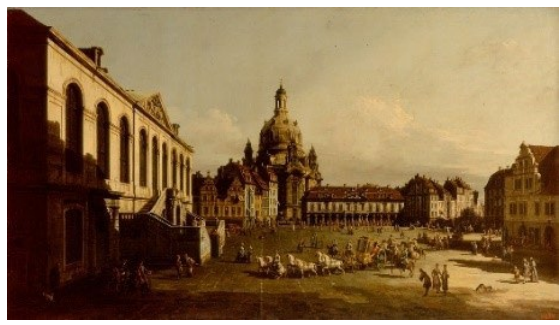

Figure 3. Bernardo Bellotto, Neumarkt in Dresden, 1747 (Hermitage Collection)

The plan was based on the rebuilding of eight parceled blocks, including a series of historic pilot project buildings, under the coordination of the Gesellschaft Historischer Neumarkt Dresden (GHND). The reference points for the reconstruction were: the relationship with the perspective views of the paintings, the compactness of the building, the preservation of the original features, such as the road sections, the continuity of the façades, the eaves heights, the shape of the roofs, the layout of the plots, the type of court house. (Fig. 4)

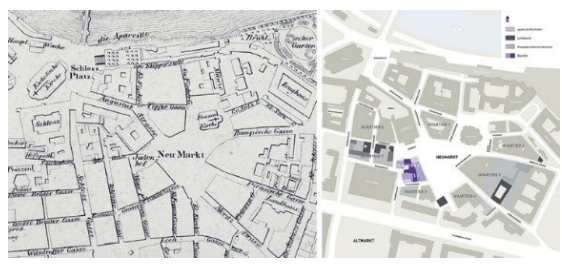

Figure 4. Von Heinrich Lesch, Stadtplan Dresden, 1828 (extract); Neumarkt, 8 Quartiere, Plan 

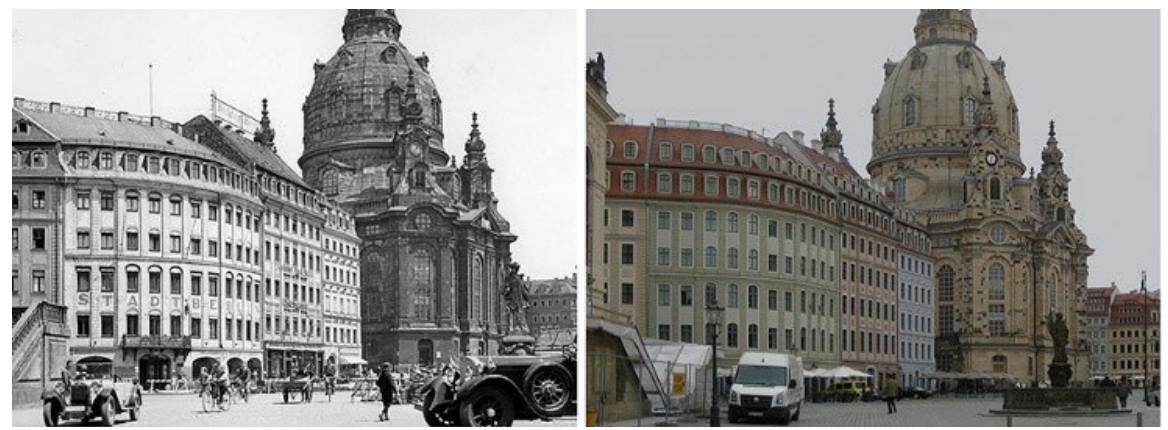

Figure 5. Neumarkt in Dresden, Quartier 1 and Frauenkirche, historical view and actual situation

The City Council, together with investors, has debated and supported these guidelines with the collective participation of the population, through referendums and public demonstrations. The guidelines set out in the Charter of Guidelines defined to rebuild more than 60 plots according to the principle of pilot project buildings and façades, while for the other plots, new houses with simplified façades were planned to fit harmoniously into the complex. The reconstruction of the historical blocks at the Neumarkt won the National Prize for Integrated Urban Development and Architectural Culture awarded by the Federal Ministry of Transport in 2009. (Fig. 5)

\subsection{The reinvention of Renaissance city: Dom Römer Areal, Frankfurt}

Accompanied by a broad and controversial critical debate, the recent inauguration of the new old town center, the Dom-Römer Areal, poses substantial questions about the future of European cities in the era of globalized standardization (Sturm et al. 2018). The project, which received the international MIPIM Award 2019 for the best urban regeneration plan, aims to give back an identity and a heart to the centre of Frankfurt, erased by the war and rebuilt in successive phases, without a precise idea of city. This intervention has filled the gap left by the demolition of the Technical Town Hall, a brutalist building from the 1970s. The old medieval parcellarium, the housing typologies with small courtyards and rich façades, dating back from Mediaeval to Renaissance time, were reused to restore the existing historical structure of urban spaces made of small squares and narrow streets. (Fig. 6)
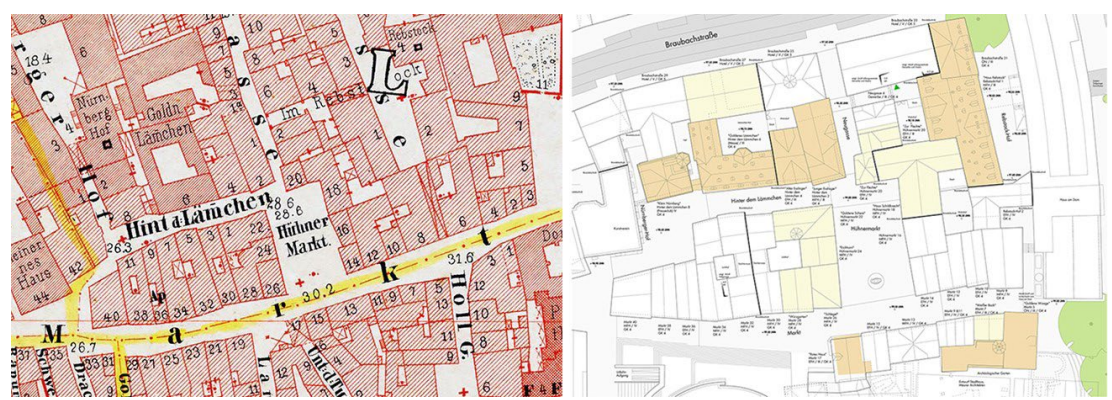

Figure 6. Frankfurt am Main, Ravenstein Plan, 1861 (extract); Dom Römer Areal, Plan. 

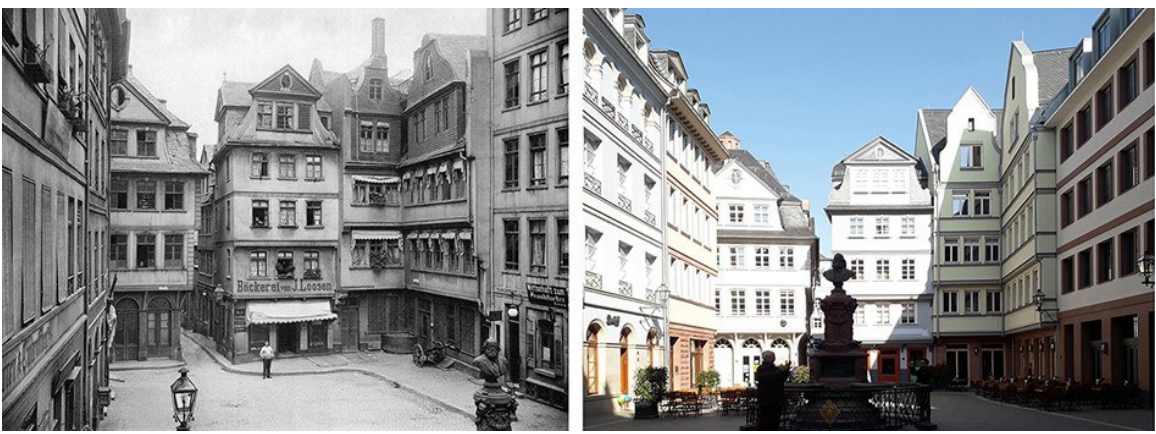

Figure 7. Dom Römer Areal, Hühnermarkt, historical (1904) and actual view.

The competition, promoted by the city, was carried out under the coordination of an architectural quality control committee chaired by local architect Christoph Mäckler. The plan, coordinated by DomRömer $\mathrm{GmbH}$, which was set up specifically for the executive coordination and financing of the project, was based on the urban layout of the original medieval town center, restored while preserving the underground car park of the demolished building. Realized with the close participation of the citizens, the project saw the involvement of several local and some international architectural firms (56 in total), which, following a complex selective phase (5 to 8 different proposals were made for each plot), resulted in a very rich and multifaceted intervention, consisting of 35 houses.

The fundamental principle was based also here on two different degrees of reconstruction: on the one hand, the reconstruction as it was and where it was of the most significant historical buildings (Leitbauten) - initially eight, but which then became more - thanks also to the extensive documentation available, assumed as pilot project buildings. On the other hand, the construction of new houses, inspired by the old ones but not identical to them (Neubauten). (Fig. 7)
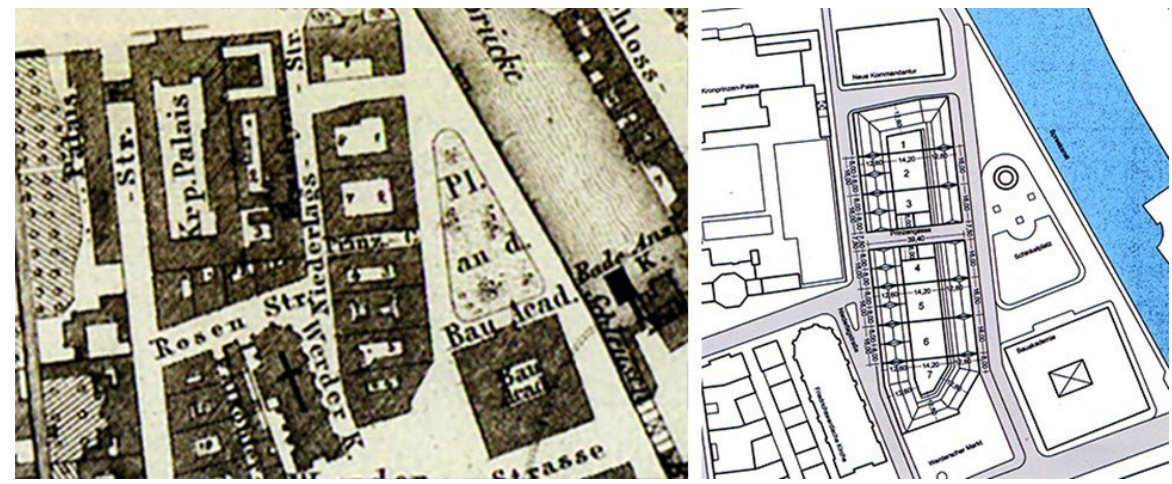

Figure 8. Friedrichswerder: W. Liebenow, Plan 1867 (extract); K. Th. Brenner, Plan 2005 (from: Stimmann 2014). 
2.5. The difficult comparison with K.F. Schinkel: Friedrichswerder, Berlin

The area around the former Bauakademie, the Friedrichswerder church and the reborn Schinkelplatz (Fig. 8) - obtained after the destruction of the new Foreign Ministry of the GDR period - is part of the Plan for the city center (Planwerk Innenstadt) elaborated under the direction of former Senate Building Director Hans Stimmann (Stimmann 2014). The actual design of this new prestigious residential area follows the layout of the original blocks, on which the former house typology was to be reinterpreted according to its compact character and its high building density.

The difficulty of this intervention is revealed in the delicate relationship with the two adjacent brick masterpieces by Karl Friedrich Schinkel, the author of Berlin's classical rebirth at the beginning of XIX century, the church of Friedrichswerder and the Bauakademie, the first school of architecture which has been waiting to be rebuilt for more than ten years.

The block known as Kronprinzengärten on the west side of Friedrichswerdersche Kirche (plan: nps tchoban voss, 2014) appears as a simplified version of a first proposal, in which the individuality of each house was called into question by the presence of a common underground car park below the entire block.
The unity of the intervention, guaranteed by the constant eaves height and the continuity of the street line, is however compromised by the heterogeneity of the façades, often characterized by strong historicist accents.

The block between the church and the Bauakademie is the result of the re-elaboration of a first plan designed by Klaus Theo Brenner in 2005, divided into two parts, with a total of seven independent plots, two of which are places at corners and five are extended from one side to the other of the block. During the realization this original parceled structure war replaced by a more compact one, with a smaller number of houses. (Fig. 9)

\subsection{Reconstructing copies of copies: Alter Markt, Potsdam}

The ongoing reconstruction of the urban blocks in the centre of Potsdam, around the Alter Markt, bordered by the Castle, the Nikolaikirche (both rebuilt in different periods) and the buildings along the river Havel, aims to restore the original settlement layout erased by historical events. And this, through the re-proposal of buildings that oscillate between stylistic reproduction and creative reinterpretation of formal principles taken from the past.
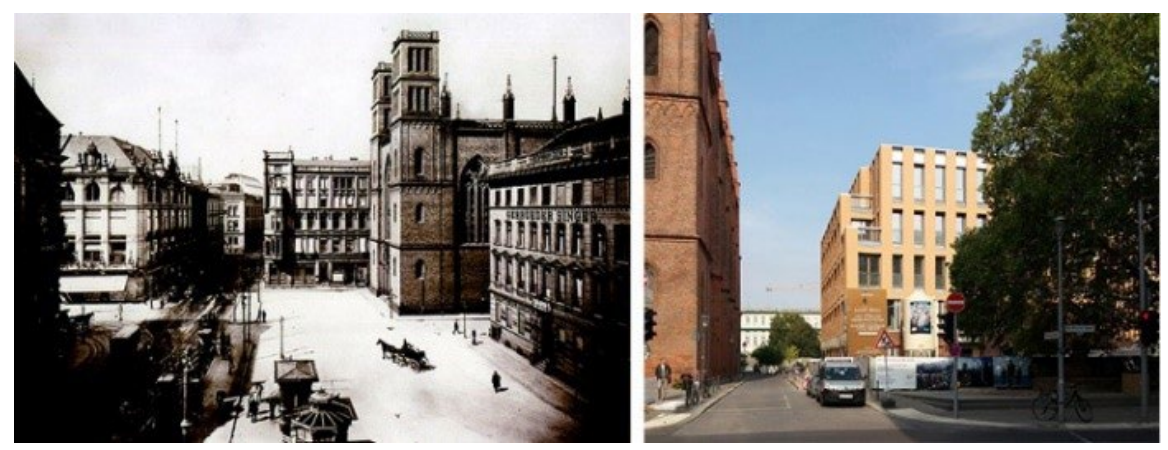

Figure 9. Werderscher Markt: Historical view (1904) and actual situation (House on the right by R. Moneo). 
Although the first proposals date back to the last century, it was in 2004 that a competition was launched to redefine the area around the Alter Markt. The winning project introduced the idea of rebuilding the urban blocks around the Nikolaikirche and the Castle which was recently rebuilt almost as it was and where it was by architect Peter Kulka. This also gave rise to the idea of reconstructing the sequence of the old buildings on the waterfront, once called Alte Fahrt (STP 2012).

The plan of the pilot project buildings elaborated in 2012 (Integrierter Leitbautenkonzept Potsdam) proposed to rebuild the old blocks and, inside them, to reconstruct the houses according to the façades of the ancient models. On an urban scale, the Leitbautenkonzept also modified the wide street lane of the late 60 s, diverting it and reducing its section, in order to make it possible to rebuild the Castle (even if shortened in length). The blocks under construction, following the demolition of the large building that contained the Fachhochschule Potsdam (FHP), were defined on the basis of a functional mixite principle, capable of conferring new urban complexity and vitality on this central area of the city. (Fig. 10)

In the general plan of the blocks facing the Castle, the Nikolaikirche and the Alter Markt, a precise layout of the plots was outlined, such as to ensure the small scale of the individual houses adjacent to each other. The corner houses, often with façades referring to historical examples, were intended to hold together those arranged along the newly designed streets. Here, too, the levels of reconstruction range from reproducing how it was and where it was, in the case of buildings referred to pre-existing models, to a rebuilding subject to common urban and architectural constraints.

The first reconstructed buildings are those on the riverside (Alte Fahrt) in front of the castle: here the three adjacent palaces, Barberini, Chiericati and Pompeii, have already been completed, re-proposing the original façades. (Fig. 11)

\subsection{The grammar of medieval blocks: Gründungsviertel, Lübeck}

The Gründungsviertel (Founders' Quarter) in Lübeck is one of the oldest areas in the western part of the city. Despite some historical references, it underwent several transformations in the post-war period - the modification of some historical traces, the creation of a parking lot, the construction of two isolated professional schools - which led to a shift from the compact structure of the historical blocks towards a more thinned out one (https://www.luebeck.de).

Since the 1990s there had been plans for a restoration of the Gründungsviertel. With the support of the UNESCO World Programme
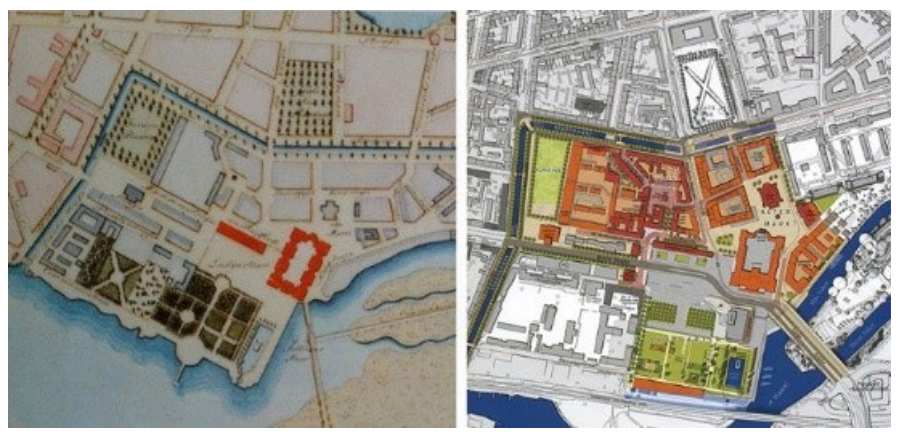

Figure 10. Potsdam: C.L. Oesfeld, Plan 1778 (extract, in red: the Castle); General Plan, 2012 (from: STP 2012). 

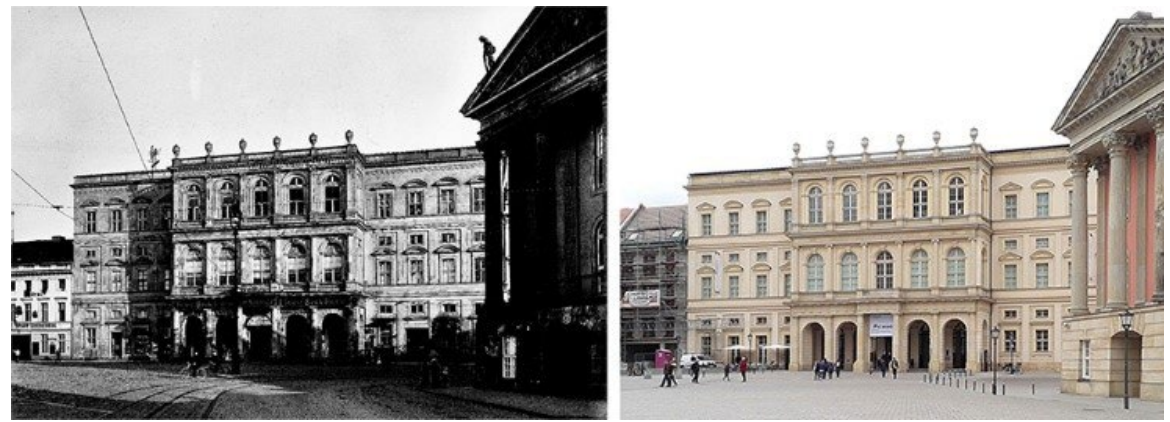

Figure 11. Palazzo Barberini, Potsdam: 1907 (Photo: E. Eichgruen), 2019.

Lübecker Altstadt, the schools were demolished in 2009. Archaeological excavations and documentary analyses of the site were carried out on the cleared land.

The expected rebirth of the Gründungsviertel on the structure of the original parcels was thought of in the sense of a critical reconstruction of the historical layout of the city. The historical parceling of the land made available plots of different widths, thanks to which the richness and variety of the urban image of the past was recreated. In the project under realization, different typologies of houses can accommodate different destinations within a compact building line, which fits well into the minute scale of the medieval center of Lübeck.
Based on the "Rahmenplan Gründungsviertel", the conditions for urban reorganization and development of the district as a residential area within the city were defined in 2015. This plan forms the basis for a reorganization of the "founding district" according to historical street alignments, differentiation of the building type, variation of roof ridges and eave heights. (Fig. 12)

The reconstruction of the Gründungsviertel as an area of contemporary living is one of the most important and challenging projects in the Hanseatic city of Lübeck. The new district is based on the historical precedents, with its compactness of the blocks, the density of the plots, the building alignments, the pitched roof houses. In total, 170 units, including apartments, shops and offices on the ground floor, are foreseen.

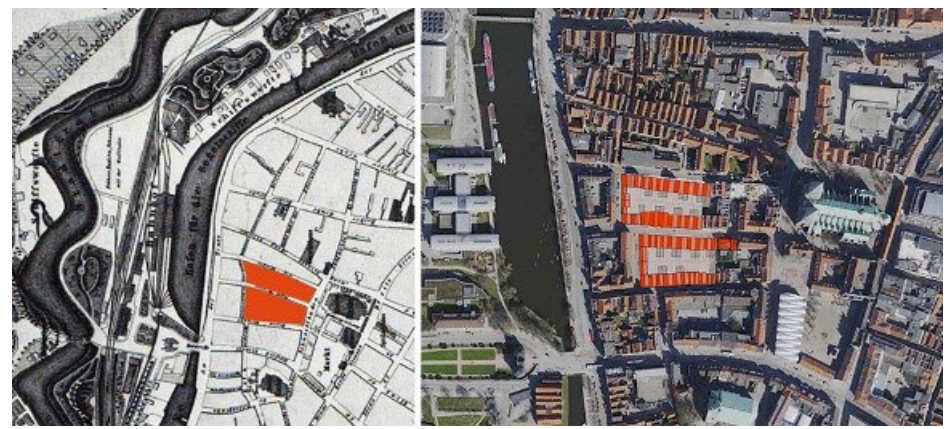

Figure 12. Lübeck, Gründungsviertel: historical situation (1872) and actual plan. 


\section{CONCLUSION}

For the extent of the here analyzed interventions, recent critics have spoken of reconstructionism as a response to deconstructivism born in the late 1980s (Fischer 2011). With respect to the desire to dissect the historical city analytically - as if it was a patient on an operating table, attempting to dismember its individual pieces and subject them to conceptual processes of abstraction - the attempt here is rather to reintegrate the surviving fragments and traces still present within a unified image. The aim is to propose an updated version of the historical image that has been lost, following wrong - or today no longer suitable - choices. Choices mostly born from a desire to erase the historical and compact structure of the inherited city, often still legible in its foundations and building layout, and in any case received through the historical iconography, albeit in fragmentary form, in favor of new ideas of the city, which today have mostly proved to be inadequate.

Therefore, these cases are not to be understood as nostalgic attempts to reproduce the city as it was, nor as simple urban regeneration projects, but as advanced and mature examples of "critical reconstruction", according to the meaning introduced in the European debate since the 1970s. Projects that are also attentive to current issues related to sustainability and the return to a human scale of city living. In contrast to the futuristic ideologies advocated by the avant-gardes, mostly based on the myth of technological progress, these interventions start from the human scale as a measure to re-found the city and its architecture, in respect to actual needs of pedestrians, cyclists and new ecological means of transport.

In fact, these examples have already been taken as a reference by other nonEuropean nations in search of their identity - following the too rapid processes of urban transformation in recent decades - through processes of reinvention of their history and tradition (Engel 2018). Abandoning the taboo of authenticity and historicity of the original, they reinvent traditional forms as if they were authentic. These "invented traditions" attempt "to establish continuity with a suitable historic past" (Hobsbawm 1983, p. 1).

Beyond the many doubts and criticisms that such interventions are raising, what is clear is that these are real projects of contemporary architecture, in which the historical city acts not only as an image, but as a concrete reference. It is still too early to assess whether their actual role within the city stops at the pure image, or becomes structural to the real life of those who live there. That is, if these reconstructed centers do not actually remain a simple tourist attraction, but become real places to live in, capable of truly reactivating the sense of community lost over time. 


\section{REFERENCES}

Aymonino, C., Brusatin, M., Fabbri, G., Lena, M., Lovero, P., Lucianetti, S. and Rossi, A. 1970. La città di Padova. Saggio di analisi urbana. Roma: Officina.

Bosker, B. 2013. Original Copies. Architectural Mimicry in Contemporary China. Hawai: University of Hawai'l Press.

Caja, M. 2018. Principi di ricostruzione urbana. «Aión», n. 21, p. 24-33.

Cervellati, P.L., Scannavini, R. and De Angelis, C. 1977. La nuova cultura delle città. La salvaguardia dei centri storici, la riappropriazione sociale degli organismi urbani e l'analisi dello sviluppo territoriale nell'esperienza di Bologna. Milano: Edizioni scientifiche e tecniche Mondadori.

Delevoy, R. (ed.) 1978. Rational Architecture. The reconstruction of the European City. Brussels: A.A.M.

Eco, U. 2016. Nel cuore dellimpero: viaggio nelliperrealtà (1973-76). In: Eco, U. Dalla periferia dellimpero. Cronache da un nuovo medioevo. Milano: La nave di Teseo.

Engel, B. (ed.) 2018. Historical versus Modern. Identity through Imitation? Berlin: Jovis.

Fischer, J. 2011. Rekonstruktivismus als soziale Bewegung. Eine architektursoziologische Aufklärung. «Arch+», n. 204, p. 76-79.

Häger, B. 2011. Der Marktplatz zu Hildesheim und das Knochenhaueramtshaus. «Arch+», n. 204, p. 70-75.

Hobsbawm, E.J. and Ranger T. (ed.) 1983. The Invention of Tradition. Cambridge: Cambridge Univ. Press.

Krier, L. 1984. Heimat und Wiederaufbau oder der Wiederaufbau der deutschen Stadt. In: Hämer, H.-W. and Kleihues J. P. (ed.) 1984. Idee Prozess Ergebnis. Die Reparatur und Rekonstruktion der Stadt. Berlin: I.B.A. 1987/ Fröhlich \& Kaufmann.

Muratori, S. 1960. Studi per una operante storia urbana di Venezia. Roma: Istituto Poligrafico dello Stato.
Nerdinger, W. 2010. Zur Einführung Konstruktion und Rekonstruktion historischer Kontinuität. In: Nerdinger W. (ed.), with Eisen, M. and Strobl, $\mathrm{H}$. 2010. Geschichte der Rekonstruktion. Rekonstruktion der Geschichte, München: Prestel Verlag, p. 10-14.

Pehnt, W. 2011. Eine Kopie ist nur die halbe Wahrheit. Kampf dem Attrappenkult: Die Debatte um die Rekonstruktion verlorener Bauwerke bleibt heftig. "Süddeutsche Zeitung», n. 96.

Rogers, E.N., Sert, J.L. and Tyrwhitt, J. (ed.) 1952. The Heart of the City. Towards the humanization of Urban life. New York: Pellegrini and Cudahy.

SAK (Sächsische Akademie der Künste) und Stadtplanungsamt der Landeshauptstadt Dresden (ed.) 2008. Historisch contra modern? Erfindung oder Rekonstruktion der historischen Stadt am Beispiel des Dresdner Neumarkts. Dresden: Akademie der Künste u. Stadtplanungsamt.

Stimmann, H. 2014. Berliner Altstadt. Neue Orte und Plätze rund um das Schloss. Berlin: Dom Publisher.

STP (Sanierungsträger Potsdam GmbH) (ed.) 2012. Potsdam. Der Weg zur neuen Mitte. Berlin: Nicolai.

Sturm, P. and Cachola Sturm, P. (ed.) 2018. Die immer Neue Altstadt. Bauen zwischen Dom und Römer seit 1900. Frankfurt a.M./ Berlin: Jovis. 
PAPER \#3.16

\title{
ADAPTIVE REUSE \& REGENERATION AS POTENTIAL FOR INDUSTRIAL SITES IN THE METROPOLITAN CITIES OF PAKISTAN
}

\author{
Naveed Iqbala, Koenraad Van Cleempoel ${ }^{\mathrm{a}}$ \\ aFaculty of Architecture and Arts, Hasselt University, Hasselt, Belgium
}

\section{ABSTRACT}

Karachi and Lahore are Pakistan's most important cities and they are also among the world's most densely populated cities. After the partition of the Indian subcontinent in 1947, there was a strong emphasis on textile, mechanical, and steel industries such as Pakistan steel mill in Karachi and PECO industry in Lahore. Like many other sites, there are still visible traces of its industrial heritage. Industries such as these were the reason for internal migration towards the cities providing jobs and life to the cities.

Currently, the urban infrastructure \& public amenities of these cities are inadequate and insufficient. But more construction will lead to demolition generating a loss of important layers of recent history. The urban paradox, however, may create opportunities for the city to consider reusing its abandoned industrial sites. Such processes occur in Europe and are now also followed by China where the reuse of former industrial sites became levers for city development and regeneration. Chinese cities like Beijing and Shanghai have several recent examples of adaptive reuse of abandoned industrial sites.

The paper presents the analysis of Karachi's \& Lahore's industrial legacy, its adaptive reuse potential, and aims for its regeneration through a local, socio-economic, and cultural revival. This project fits within a broader Ph.D. research on the industrial heritage of Pakistan; its identification and potentialities. Unlike Europe, Pakistan does not recognize industrial sites as heritage. Political instruments to offer new programs for these areas are limited and they are currently not on the radar as potential places for future city development. However, due to unprecedented demographic and geographic challenges, it may well become valuable to reconsider its potentials.

\section{KEYWORDS}

Industrial heritage; adaptive reuse; regeneration; revival; Pakistan.

\section{INTRODUCTION}

Pakistan's industrialization began during the British rule but continued after the Partition of British India in 1947. Shortly after the partition in the 1950s, it was the time of an apparent stagnation and mounting economic problems due to disruption of the separation. This was predicted by TIME magazine calling Pakistan an economic wreck (Zaidi 2005). By the mid 1960s, however, economic growth was strong and Pakistan was considered a model developing country (Papanek 2019). There were different policies in different regimes in the history of Pakistan which had a direct influence on the industrialization and deindustrialization of Pakistan (Table 1).

1947-58 was the first phase in which the foundation was laid for the coming years. The second phase was from 1958-68 with the continuation of the previous policies, at least in general direction and principles. During the second phase, the industries grew rapidly, and they were mainly developed by private entrepreneurs. S.Akbar Zaidi called it The decade of development in his book "Issues in Pakistan's economy(2015)". The third significant phase was 1972-1977 and it was bad luck or bad management years in 


\begin{tabular}{ll}
\hline TIME PERIOD & DEVELOPMENT / DOWNFALL \\
\hline 1947 & Division of subcontinent industries after \\
& Partition \\
$1947-1958$ & $\begin{array}{l}\text { The first phase after partition, Civil } \\
\text { bureaucracy, and industrialization }\end{array}$ \\
$1958-1971$ & Civil and military-bureaucratic capitalism \\
$1973-1977$ & Nationalization in Bhutto regime \\
$1977-1988$ & Structural adjustment; the Zia regime \\
$1988-2019$ & Crises and abandonment of Industries \\
Source: Based on S. Akbar Zaidi's book Issues in Pakistan economy
\end{tabular}

Table 1. Pakistan Industrial development timeline.

Pakistan's industrial history. During this time the nationalization program was introduced in which some of the key private industries were taken over by the government and converted into state-owned industries like Batala engineering company BECO in Lahore was converted to Pakistan engineering company PECO. Most of the industries went into loss after nationalization and were shut down eventually (Zaidi 2005). Some of the abandoned industries are now engulfed by buildings around it due to the rapid urbanization of the cities.

The recent tide of industrial 'heritage' sites (Douet 2013; Wang and Nan 2007; 'The Nizhny Tagil Charter for the Industrial Heritage' 2003; Chen, Judd, and Hawken 2016; Xie 2015; Florentina-Cristina et al. 2014; Cizler, Pizzera, and Fischer 2015) and reuse is unique for south Asian countries. But it seems like an established and recognized strategy in city planning elsewhere. Many western cities preserved its industrial heritage and added values to it by inserting new programs with societal values. Pittsburgh, Chicago, and Detroit the major post-industrial cities in the United States have put life in the industrial spaces to becoming new community assets. Other examples of giving soul to abandoned industrial spaces include the navy yard in Philadelphia, or the High Line in New York (Robiglio 2017). There are also a variety of examples of activating industrial spaces in Europe like the LX factory in Lisbon Portugal,
C-mine (former mining sites) in Genk Belgium, tobacco company converted into residential use Wills buildings Liverpool, Richmond station in north Yorkshire converted into restaurant cinema and many more ('Re-Using Industrial Sites | Historic England' n.d.; 'Lx Factory' n.d.).

When it comes to the Pakistani context, little to no research and practices have been done related to industrial heritage identification and reuse. Pakistan Industries constructed after the partition are not old enough to be considered as heritage according to the Pakistan antiquity act 1975 (last modification in 1992) ('Antiquities Act1975' 1992). Besides numerous industrial sites like abandoned tobacco factories, food factories, steel mills, textile mills, warehouses, salt mines, and railway buildings, industrial heritage, and its potential is little recognized in Pakistan. There are no policies and guidelines at hand related to industrial heritage conservation, regeneration, and reuse. The argument of this paper, therefore, is that the industrial heritage sites of Karachi \& Lahore have the potential for adaptation and can be initiated by regional-level factors. We want to identify 19th and 20th-century industrial buildings and the involvement of cultural capital (i.e. local artist community, cultural organizations, educational institutes; and the introduction of industrial heritage in regional cultural and heritage policy). 
Since the topic of industrial heritage is a new concept for the Pakistan Heritage field, so the first part of the paper is case selection. The case selection area is done broadly by selecting the two largest cities of Pakistan briefly explaining its history and its potential in the field of industrial heritage and its adaptive reuse. The second part is an analytical framework discussing physical type of industrial heritage in Pakistan, possibility in its regeneration, and interventions for activating such sites. The last part discusses international case studies of industrial heritage and its reuse, selected in a way which are relatable to the industrial sites in Pakistan and its potential in the locality in terms of issues and possibilities.

\section{CASE SELECTION}

The cities of Karachi and Lahore are selected as a starting point for the study and identification of industrial heritage in Pakistan. Both cities have metropolitan characteristics. Karachi is the capital of Sindh province (also the first capital of Pakistan) and at the same time economic capital of Pakistan. It is also the largest city of Pakistan in terms of population (Table 2). The commercial functions of the city are strengthened by international investment, due to its maritime business (Khuhro and Mooraj 1997). Similarly, Lahore is the capital of Punjab province and the cultural capital of Pakistan. Lahore is the second-largest city in terms of population in Pakistan with a history dating back to 1000BC (Kabir, Abbas, and Hayat 2017) (Table 2)(Fig 1). Both cities have large stocks of industrial heritage but from different activities like steel, engineering, textile, and food industries. Unfortunately, most of the practices related to the industrial buildings after closure is neglect or demolition. Unlike the situation in Europe or the USA, such sites are not considered as heritage, witnessing from a particular kind of urban memory. They are measured with the same parameters and rules with which cultural and religious heritage are measured. Although according to Nizhny Tagil charter ('The Nizhny Tagil Charter for the Industrial Heritage' 2003)industrial heritage is defined differently;

Industrial heritage consists of the remains of industrial culture which are of historical, technological, social, architectural or scientific value. These remains consist of buildings and machinery, workshops, mills and factories, mines and sites for processing and refining, warehouses and stores, places where energy is generated, transmitted and used, transport and all its infrastructure, as well as places used for social activities related to industry such as housing, religious worship or education. The historical period of principal interest extends forward from the beginning of the Industrial Revolution in the second half of the eighteenth century up to and including the present day, while also examining its earlier pre-industrial and proto-industrial roots ('The Nizhny Tagil Charter for the Industrial Heritage' 2003).

\begin{tabular}{|c|c|c|c|c|}
\hline City name & City orientation & Population & Area & Types of industries \\
\hline Karachi & $\begin{array}{l}\text { Economic capital, } \\
\text { beta global city, } \\
\text { cosmopolitan, trading } \\
\text { port since } 1852\end{array}$ & $\begin{array}{c}14.2 \\
\text { million }\end{array}$ & 3780 sq.km & $\begin{array}{l}\text { Textile, state-led heavy Industries: Steel } \\
\text { Industries, transportation, footwears }\end{array}$ \\
\hline Lahore & $\begin{array}{l}\text { Cultural capital, } \\
\text { Historically rich, } \\
\text { Educational institutes }\end{array}$ & $\begin{array}{l}11.2 \\
\text { million }\end{array}$ & 1305 sq.km & $\begin{array}{l}\text { State-led heavy industries: } \\
\text { Agriculture machinery, } \quad \text { Electrical } \\
\text { equipment, small Industries }\end{array}$ \\
\hline
\end{tabular}

Table 2. Statistics and types of industries in Karachi and Lahore. 


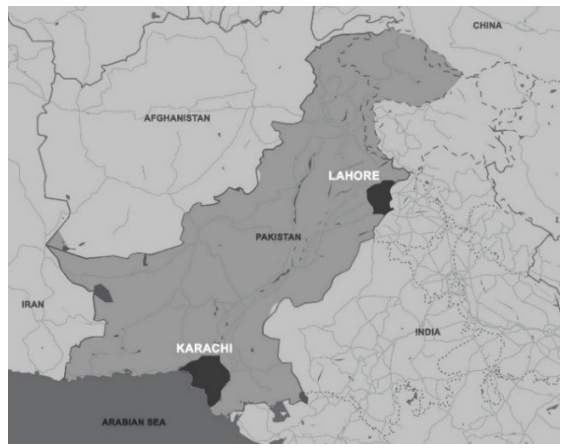

Figure 1. Source: Google Maps, www.google.be/maps edited by author

Instead of demolition the urban paradox mentioned earlier could be the reuse of these sites for a new purpose. Adaptive reuse the addition of new programs to an existing historical building (Plevoets and Cleempoel 2011) - is the richer option compared to demolition. Rebuilding also enhances the long term usefulness of a building (Bullen 2007). Conversion of architectural sites is not a new phenomenon in the history of the discipline (Wilkinson et al. 2014). Chen, Judd, and Hawken (2016) refer to Grodach and Loukaitou (2007) to develop three cultural development strategies: "progressive strategies", "creative class strategies" and "entrepreneurial strategies" and used it to investigate the adaptive reuse of industrial heritage for cultural purpose in Beijing, Shanghai and Chongqing (Table 3)

Pakistan's industrial development timeline is almost the same as in China. Modern industrial development in China after the 1840 Opium war with Britain was continued after founding of the People Republic of China (PRC) in 1949. In the 1970s due to the high level of urbanization and pollution in the city centers the industries were shifted and the old industrial sites were regenerated and adaptively reused as cultural precincts (Chen, Judd, and Hawken 2016). Most often, adaptive reuse is considered as the only option for regeneration of an industrial building or area. This roots of adaptive reuse in the United States can be found in the 1960s in economically buoyant cities like San Francisco and Boston. Architects Wurster Bernadi and Emmons conversion of Ghirardelli chocolate factory to offices, shops, galleries, and restaurants in the 1964 \& 1968 set a style that has followed and evolved worldwide (Douet 2013). The trend of waterfront rehabilitation based on recycled historic buildings have turned industrial waterfronts into desirable properties like St Kathrine Docks, London; Albert Dock,

\begin{tabular}{|c|c|c|c|}
\hline Strategy type & Goals & $\begin{array}{l}\text { Types of cultural projects and } \\
\text { programs }\end{array}$ & Target audiences \\
\hline Progressive & $\begin{array}{l}\text { Community development } \\
\text { Arts education and access }\end{array}$ & $\begin{array}{l}\text { Public arts centers } \\
\text { Art education and } \\
\text { Programmes }\end{array}$ & $\begin{array}{l}\text { Underserved } \\
\text { residential } \\
\text { population }\end{array}$ \\
\hline $\begin{array}{l}\text { Creative } \\
\text { class }\end{array}$ & $\begin{array}{l}\text { Economic growth through } \\
\text { quality of life amenities } \\
\text { Promotion of "creative } \\
\text { economy" }\end{array}$ & $\begin{array}{l}\text { Arts and entertainment } \\
\text { districts } \\
\text { Collaboration between arts } \\
\text { and private sector }\end{array}$ & $\begin{array}{l}\text { Prospective } \\
\text { residents } \\
\text { "Knowledge- } \\
\text { based" } \\
\text { workers }\end{array}$ \\
\hline $\begin{array}{l}\text { Entrepreneur } \\
\text { ial }\end{array}$ & $\begin{array}{l}\text { Economic growth through } \\
\text { tourism and city image } \\
\text { Private sector investments }\end{array}$ & $\begin{array}{l}\text { Cultural landmarks } \\
\text { Cultural festivals } \\
\text { Promotional activities }\end{array}$ & $\begin{array}{l}\text { Tourists } \\
\text { Affluent residents }\end{array}$ \\
\hline \multicolumn{4}{|c|}{$\begin{array}{l}\text { Source: Based on (Grodach and Loukaitou-Sideris 2007) table by (Chen, Judd, and Hawken } \\
\text { 2016) }\end{array}$} \\
\hline
\end{tabular}

Table 3. Types of cultural development strategies. 
Liverpool; Darling Harbor, Sydney and Granville island, Vancouver. The conversion of the great textile mill complex of Lowell, Massachusetts, into a National historic park is also an equally influential project. (Douet 2013).

The mentioned cities in Pakistan are famous for their historical importance, art, and architecture. National Academy of Performing Arts (NAPA) is one of the famous schools of performing arts in Karachi. National College of Arts (NCA) Lahore is one of the top architecture and art schools in Pakistan. The abandoned industrial sites can be used by these artists communities if assisted by the government and can be a starting point for its regeneration. The second important issue in these cities is the shortage of public and green spaces. According to a report in Dawn newspaper, green areas in Karachi decreased by 4 percent from 2005 to 2017 . Many residential neighborhood have almost no green areas,(Ahmed 2020). According to the united Nations health standards, the availability of green space is at least 9 sqm per person while most areas in Lahore city fall short than the UN standards (Shirazi, Zia, and Minallah 2014). The industrial sites have also the potential to be reused as public green spaces and community centers. The examples of industrial sites in Pakistan are discussed below in section four.

\section{POTENTIAL INTERVENING FACTORS; AN ANALYTICAL FRAMEWORK}

This section characterizes the local intervening factors which can be a lever to developing and reusing industrial heritage or sites. Most of the industrial heritage of Pakistan can be identified from 1958-1971 during the civil and military bureaucratic capitalism and then from 1977-1988 after structural adjustment policies by Zia Regime.

\subsection{Physical type of industrial heritage}

After the partition, larger parts of the industries of Indian subcontinent came in the territory of India, most of the industrial development in Pakistan started in the mid20th century (Jaleel 2012). Current industrial types in Pakistan were brought up in two periods, first phase after the partition in the 1950s civil bureaucracy and industrialization and in the 1970s civil and military bureaucratic capitalism. The third period after the 1970 s stopped most of the industries due to various reasons one of which was the Nationalization policy.

\subsection{Possible role of the community in regeneration}

In various examples in the UK, USA, Europe, and now also in China, we see that bottomup initiatives from the cultural community started using the abandoned industrial sites due to laxer controls and lower rates and converted them into art districts (Evans 2009). In the informal cultural district formation, the local artist community plays a leading role. The organic development of creative clusters and cultural quarters emerged in the USA and Europe in the 1970s and 1980s (Zielke and Waibel 2014).

\subsection{Policy intervention influence on activating such sites}

The main stakeholders and the different development modes for the governance of developing creative spaces in china are summarized by Zielke and Waibel (2013). The main stakeholders in the development of cultural precincts from redundant industrial sites include the local state, artist community, privates developers, and the actual owners (Chen, Judd, and Hawken 2016). Four types of development methods are put forwarded for the development of creative spaces. BottomUp method; the method in which industrial 
areas are organically occupied by artists and then through official policy promoted by the local government. Top-Down; the method in which the local government plays different roles to arrange a common ground for investors owners and developers. PublicPrivate Partnership PPP; In this method the private investor and local government team up to establish a public-private company to coordinate interest between them. Private Development; In the private development method the government acts as a supervisor or supporter while the private developer finances most of the investment and in return gain the value addition of the property. In all the development modes local government is involved in one or another way.

\section{THE INDUSTRIAL HERITAGE REUSE IN INTERNATIONAL CITIES AND POTENTIAL IN THE STUDY CITIES: A CASE COMPARISON}

Besides a handful of immediate reuse potential industrial heritage sites in the cities of Lahore and Karachi (Table 4), they are still standing abandoned and are on the verge of decay, in some cases demolition. First, the urgency is to consider such sites a valuable heritage asset as mentioned by James Douet.
The industrial landscape is a misunderstood heritage, at worst urban rustbelt, dangerous, a toxic wilderness; at best, an outstanding historical resource to be re-used, regenerating communities, offering real richness and opportunity, reinforcing cultural identity and creating new commercial prospects. But it can also be a vivid reminder of how today's world came to be the way it is, when industry employed whole communities and provided the heartbeat for many towns and cities. In this respect these historic industrial landscapes deserve our closest attention (Douet 2013).

The antiquities' acts and policies related to the heritage of Pakistan (M.R Mughal 1995) is focused on the archeological artifacts, cultural and religious heritage. Industrial buildings in general are not considered as heritage and neither the reuse potential is exploited. Comparing Industrial heritage reuse trend in the city of Beijing summarized by Chen, Judd \& Hawke in three ways; In the 1990s it was spontaneously reused by the artist community; in the 2000s was established by private developers through PPP and was driven by the local government in 2010. An example worth mentioning is the conversion of a formal electronics factory

\begin{tabular}{|c|c|c|}
\hline City name & Redundant industrial buildings & City rundown \\
\hline Karachi & $\begin{array}{l}\text { Textile industries, } \\
\text { Industries, transportation, railway } \\
\text { infrastructure, seaport related } \\
\text { infrastructure }\end{array}$ & $\begin{array}{l}\text { Economic capital, artist community, } \\
\text { Educational institutes, } \\
\text { Entrepreneurs, } \\
\text { Small businesses, } \\
\text { Fashion capital }\end{array}$ \\
\hline Lahore & $\begin{array}{l}\text { Mechanical industries, leather } \\
\text { industries, textile industries, flour } \\
\text { mills }\end{array}$ & $\begin{array}{l}\text { Artist community, Cultural capital, } \\
\text { Historically rich, } \\
\text { Educational institutes }\end{array}$ \\
\hline
\end{tabular}

Table 4. Abandoned industries and potential reuse users. 
from the 1950s to "798 Art Zone" in the 1990s. Promoted by the Beijing government it was converted into a "mature creative cluster" from an "underground space of art" (Zielke and Waibel 2014)(Fig 2-3). Chunming Slub Mill a defunct cotton factory in Shanghai is similarly converted into an art district, it was first reused by local artists in the 1990s and then expanded by the Shanghai CIC policy in 2004 (Chen, Judd, and Hawken 2016)(Fig 4).

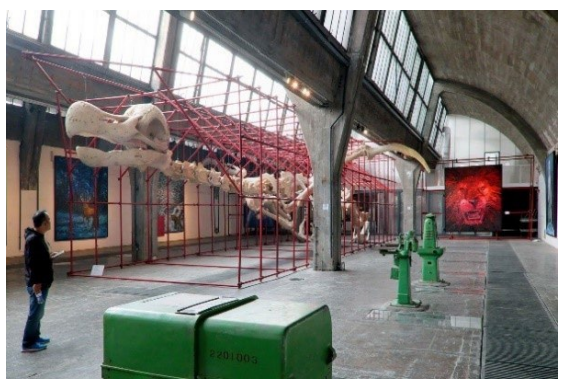

out of the total 955 in the Indian subcontinent. Most of them were small size industries and were based on raw materials like small sugar mills, cotton ginning factories, flour mills, etc. The first investment in the industries was by the private investors from 1947-1950. In 1952 Pakistan Industrial Corporation PIDC was established by the government of Pakistan to invest in heavy industries like cement, fertilizer, jute mills SUI Karachi gas pipeline

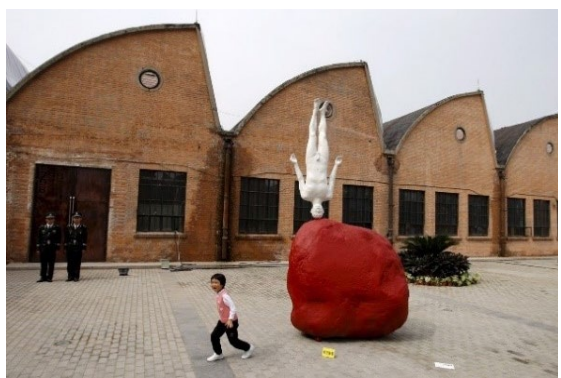

Figure 2-3. 798 cultural district Beijing. Source: (Martin Thomas Photography-Michael Reynolds)

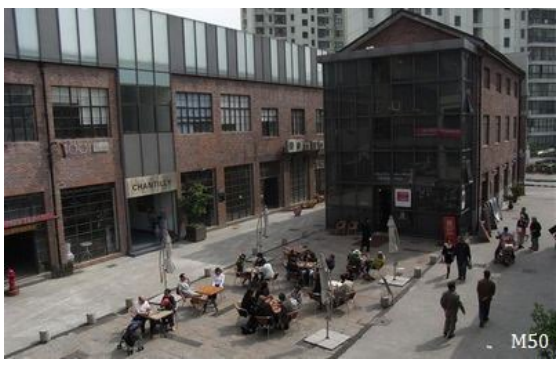

Figure 4. M50 Shanghai China. Source: (Chinatravelpage.com)

\subsection{Industrial development history of Pakistan}

The industrial legacy of Pakistan can be traced back to the mid-19th century during the British rule in the subcontinent. But after the partition in 1947 Pakistan got 34 industries and by 1971 completed 59 industries and created a solid industrial sector base for Pakistan. The GDP share of the industrial sector rose from $9.7 \%$ in $1954-55$ to $11.9 \%$ in 1959-60. After the 1960s Pakistan started investment in heavy industries shifting from consumer goods industries such as mechanical, Petro-chemical, iron, and steel. From 1971-77 the industrial growth and export were disappointing due to various reasons like; separation of East Pakistan, the Indo-Pak war in 1971, suspension of foreign aid, loss of local market of east Pakistan, fall in export, nationalization of industries, and unfavorable investment climate (Jaleel 2012). Due to the above-mentioned reason, there were a lot of industrial buildings abandoned which can be reused for different functions by suitable interventions. 
3.2. Cultural capital artist community, cultural organization and Industrial heritage in the study cities

If you take a comparable example of a city to Lahore in terms of industrial development and its reuse will be Beijing. The industrial heritage reuse was driven by the critical mass of artists as Beijing is rich in history due to serving as a capital for five dynasties. Beijing has long been a political and cultural center (Chen, Judd, and Hawken 2016). Similar is the case with Lahore, it is the cultural capital of Pakistan and its importance can be seen in the history of different Rules like Hindu raj, Afghans, Mughals, Sikhs, Britishers, and many more (Baqir 1985). Due to its geographic location, Lahore once called the Paris of the east is still the center of attraction for many in recent years (Kabir, Abbas, and Hayat 2017).
Lahore has many universities, art schools, theater, and libraries with a huge density of artist community as compared to other cities of Pakistan (Table 5). Some of the leading art schools in the country are in Lahore. Considering the presence of such a potential artist community there is an opportunity in the industrial sites like PECO industry in Lahore to be reused as cultural precincts like M50 in Shanghai and 798 Art Zone in Beijing. Pakistan Engineering Company PECO which was once Batala Engineering Company BECO established in 1932 by Chaudry Muhammad Latif Batala was one of the leading and Key industries of Pakistan before the nationalization policy (Khan 2008). After the nationalization policy, it went under loss and was eventually closed, currently, it is lying abandoned in the center of Lahore within a densely populated area (Fig 5-6)

\begin{tabular}{llll}
\hline City name & Listed universities & Art schools & $\begin{array}{l}\text { Museums, Libraries, } \\
\text { cinemas \& theaters }\end{array}$ \\
\hline Karachi & 26 & 18 & 68 \\
Lahore & 34 & 16 & 52 \\
\hline
\end{tabular}

Table 5. Educational institutes and cultural resources in the study cities.
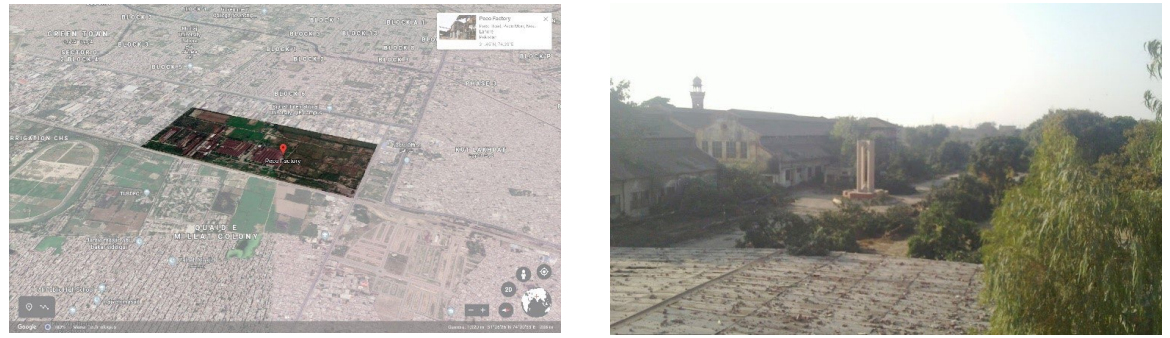

Figure 5-6. PECO industry Lahore Pakistan: (Google earth) edited by the first author 
The PECO industry lies almost in the center of densely populated Lahore with universities and sports areas in the immediate vicinity. These points add in the value and promising reuse of such a potential site in the center of the city if opened and assisted by the local government as it is walled and guarded in the current situation.

Similarly, if we talk about the city of Karachi a comparable example is Shanghai. During the trading port period, Shanghai was developed under the influence of semi-colonial and semifeudal system and the modern culture known as sea culture has a hybrid nature and fusion of western and eastern culture (Wu 2004). Its culture is more market-driven and is based on design industries like media, fashion, and advertising (Ren and Sun 2012). Similarly, the case with Karachi as it is the fashion capital of Pakistan with an active seaport and its architecture is mainly influenced by British colonial architecture. Karachi has also a vast market of small industries and handicrafts. Karachi also has many universities, art schools, libraries, and museums with one of the active artist community of Pakistan. There are several examples of abandoned seaport sheds, railway infrastructure textile industries which can be reused for a new function in the densely populated city of Karachi. The most important example is the recently abandoned Pakistan steel mill PSM with an area of almost 76 square kilometers constructed in the 1960-70s with the help of the USSR. 20 different plants including a thermal power station, forklifts, warehouses, conveyor belts, railway tracks, stockyards, and dozens of other industries standing still (Hasnain 2016) (Fig 7-8). Although political figures of Pakistan always discuss about reviving the PSM but it is already consider as sick industry by some of the economist as it is under the debt of almost 130 million USD.

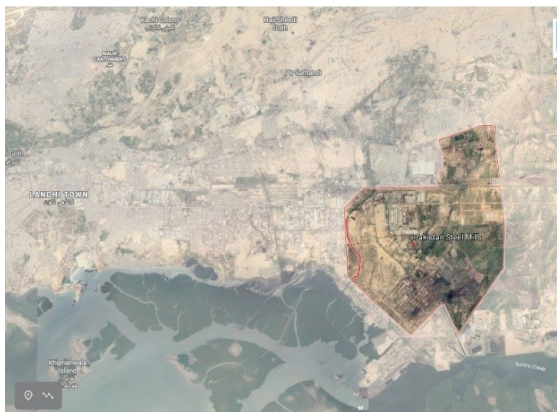

Figure 7. Pakistan Steel Mill Karachi: (Google maps) edited by first author

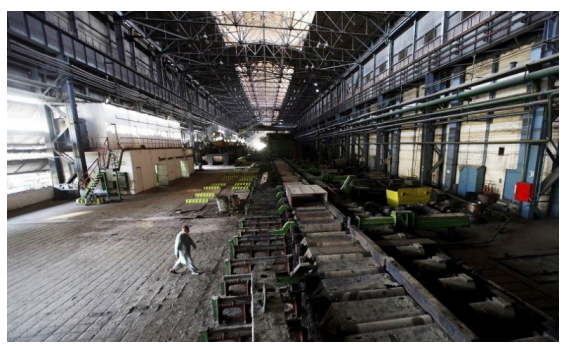

Figure 8. Pakistan Steel Mill Karachi:

(pakistantoady.com)

\subsection{Policy intervention}

Whether it be a top-down, bottom-up, public-private partnership PPP or private development the local government involvement in reusing such kind of industrial sites cannot be ignored. More specifically the strategies for the promotion and development of creative industries on such abandoned industrial sites like providing funding, sponsoring cultural spaces, and providing a resident card for prominent professionals (Chou 2012). Such initiatives have been given in the abandoned industrial sites of Beijing which acted as a catalyzer for creating a fullfledged cultural district. Capital steel industrial Park in Beijing is an example of such statesponsored cultural projects. 


\section{DISCUSSION AND CONCLUSION}

Industrial development history has left Karachi and Lahore with a substantial amount of industrial heritage. But they are not considered as heritage, which, sadly, seems to hinder their development. We observe the same industrial development timeline in the cities of Beijing and Shanghai, but also in other European or American cities. The first step towards the preservation of industrial heritage in Pakistan is the identification of its potential. Besides looking at it from a Heritage perspective it also creates the possibility for reuse and can be a key area in the city regeneration. For example, the PECO industry in Lahore can be a vital organ for the city's cultural and art activities. Similarly, the Pakistan steel mill can be a center for shifting the urban nucleus of the city as it is already saturated. The heritage reuse policy requires greater consideration of the regional context. Both the cities face a shortage of green urban spaces and parks and these abandoned sites have the potential to be reused as green public and community spaces.

The findings of the paper are; the major intervening factors in starting for a chain reaction of industrial heritage reuse in Pakistan can be government policy and cultural capital. Government policies can start from; sponsored events flagships, incentive policy on a local cultural program, funding on cultural festivals in such kind of abandoned sites. Investigating the regional context and involving the local cultural capital like public cultural organization, public or private cultural enterprises, educational resources; schools, universities, colleges, artist community, and professionals involved in cultural industry. Involving the mentioned resources of the city and providing incentives can be the start of developing and regenerating such abandoned industrial sites which is a sustainable way of preserving such sites both in a material and environmental point of view. 


\section{REFERENCES}

Ahmed, Amin. 2020. 'Green Areas in Karachi Decreased by 4pc from 2005 to 2017, Says WB Report'. DAWN.COM. 14 February 2020. https://www.dawn.com/ news/1534272.

'Antiquities Act1975'. 1992. Google Docs. 1992. https://drive.google.com/file/d/1_ 9d1YKRIJEytnJkI77DtzGXVKFp4EX6c/ preview? usp=embed_facebook.

Baqir, Muhammad. 1985. Lahore, Past and Present: Being an Account of Lahore Compiled from Original Sources. B.R. Publishing Corporation.

Bullen, Peter A. 2007. 'Adaptive Reuse and Sustainability of Commercial Buildings'. Facilities 25 (1/2): 20-31. https://doi. org/10.1108/02632770710716911.

Chen, Jie, Bruce Judd, and Scott Hawken. 2016. 'Adaptive Reuse of Industrial Heritage for Cultural Purposes in Beijing, Shanghai and Chongqing'. Structural Survey 34 (4/5): 331-50. https://doi. org/10.1108/SS-11-2015-0052.

Chou, Tsu-Lung. 2012. 'Creative Space, Cultural Industry Clusters, and Participation of the State in Beijing'. Eurasian Geography and Economics 53 (2): 197-215. https://doi. org/10.2747/1539-7216.53.2.197.

Cizler, Jasna, Judith Pizzera, and Wolfgang Fischer. 2015. 'Industrial Heritage as a Potential for Redevelopment of Post-Industrial Areas in Austria'. АГГ+ 1 (2). https://doi.org/10.7251/ AGGPLUS1402052C.

Douet, James. 2013. Industrial Heritage ReTooled: The TICCIH Guide to Industrial Heritage Conservation. Walnut Creek, UNITED STATES: Routledge. http:// ebookcentral.proquest.com/lib/ ubhasselt/detail.action?doclD=1977967.

Evans, Graeme. 2009. 'Creative Cities, Creative Spaces and Urban Policy': Urban Studies, May. https://doi. org/10.1177/0042098009103853.
Florentina-Cristina, Merciu, Merciu GeorgeLaurenţiu, Cercleux Andreea-Loreta, and Drăghici Cristian Constantin. 2014. 'Conversion of Industrial Heritage as a Vector of Cultural Regeneration'. Procedia - Social and Behavioral Sciences 122 (March): 162-66. https://doi. org/10.1016/j.sbspro.2014.01.1320.

Grodach, Carl, and Anastasia LoukaitouSideris. 2007. 'Cultural Development Strategies and Urban Revitalization'. International Journal of Cultural Policy 13 (4): 349-70. https://doi. org/10.1080/10286630701683235.

Hasnain, Subuk. 2016. 'The Demise of Pakistan Steel Mills'. Herald Magazine. 30 October 2016. http://herald.dawn.com/ news/1153574.

Jaleel, Sadaf. 2012. 'PAKISTAN INDUSTRIAL GROWTH', 27.

Kabir, Najma, Ghulam Abbas, and Khizar Hayat. 2017. 'A Historic Journey of the Lahore City, to Attain Its Identity through Architecture'. European Journal of Interdisciplinary Studies 8 (1): 87. https:// doi.org/10.26417/ejis.v8i1.p87-97.

Khan, Anika. 2008. 'Impact Of Nationalization On BECO And Pakistan Economic Development'. Ramblings of a Pakistani Woman. (blog). 22 August 2008. https:// anikakhan.wordpress.com/2008/08/22/ impact-of-nationalization-on-beco-andpakistan-economic-development/.

Khuhro, Hamida, and Anwer Mooraj. 1997. Karachi, Megacity of Our Times. Oxford University Press.

'Lx Factory'. n.d. Lx Factory (blog). Accessed 14 February 2020. https://Ixfactory.com/ en/lx-factory/.

M.R Mughal. 1995. 'Legislation for the Protection and Management of Archaeological Heritage of Pakistan'. Kifayat Academy Educational publishers Karachi. https://en.unesco. org/sites/default/files/pakistan_ legislation_07_1995_engl_orof.pdf. 
Papanek, Gustav F. 2019. Pakistan's Development: Social Goals and Private Incentives. Harvard University Press.

Plevoets, Bie, and Koenraad van Cleempoel. 2011. 'Adaptive Reuse as a Strategy towards Conservation of Cultural Heritage: A Literature Review'. In . https:// doi.org/10.2495/STR110131.

'PROVISIONAL SUMMARY RESULTS OF 6TH POPULATION AND HOUSING CENSUS-2017 | Pakistan Bureau of Statistics'. n.d. Accessed 13 January 2020. http://www.pbs.gov.pk/content/ provisional-summary-results-6thpopulation-and-housing-census-20170?fbclid=IwAR1E5v641 afiqk-oZRD2Zek K_3j3bdiW9tCLQtzy7sZZpnUwG100M 2 c678.

Ren, Xuefei, and Meng Sun. 2012. 'Artistic Urbanization: Creative Industries and Creative Control in Beijing'. International Journal of Urban and Regional Research 36 (3): 504-21. https://doi.org/10.1111/ j.1468-2427.2011.01078.x.

'Re-Using Industrial Sites | Historic England'. n.d. Accessed 14 February 2020. http:// historicengland.org.uk/advice/heritageat-risk/industrial-heritage/our-industrialheritage/re-using-industrial-sites/.

Robiglio, Matteo. 2017. RE-USA: 20 American Stories of Adaptive Reuse, a Toolkit for Post-Industrial Cities. Jovis Verlag GmbH.

Shirazi, Safdar Ali, Syed Zia, and Muhammad Minallah. 2014. 'SPATIAL DISTRIBUTION OF URBAN GREEN SPACES IN LAHORE, PAKISTAN: A CASE STUDY OF GULBERG TOWN'. Pakistan Journal of Science 66 (September): 277-81.

'The Nizhny Tagil Charter for the Industrial Heritage'. 2003, July, 4.

Wang, Jianguo, and Jiang Nan. 2007. 'Conservation and Adaptive-Reuse of Historical Industrial Building in China in the Post-Industrial Era'. Frontiers of Architecture and Civil Engineering in China 1 (4): 474-80. https://doi.org/10.1007/ s11709-007-0064-5.
Wilkinson, Sara J., Craig Langston, Hilde Remøy, and Hilde Remøy. 2014. Sustainable Building Adaptation: Innovations in Decision-Making. Somerset, UNITED KINGDOM: John Wiley \& Sons, Incorporated. http://ebookcentral. proquest.com/lib/ubhasselt/detail. action?docID=1597997.

Wu, Weiping M. 2004. 'Cultural Strategies in Shanghai: Regenerating Cosmopolitanism in an Era of Globalization'. In . https://doi. org/10.1016/j.progress.2003.10.002.

Xie, Philip Feifan. 2015. 'A Life Cycle Model of Industrial Heritage Development'. Annals of Tourism Research 55 (November): 141-54. $\quad$ https://doi.org/10.1016/j. annals.2015.09.012.

Zaidi, S. Akbar. 2005. Issues in Pakistan's Economy. 2nd ed. rev. and expanded. Karachi: Oxford University Press.

Zielke, Philipp, and Michael Waibel. 2014. 'Comparative Urban Governance of Developing Creative Spaces in China'. Habitat International 41 (January): 99-107. https://doi.org/10.1016/j. habitatint.2013.06.007. 


\title{
PAPER \#3.17
}

\section{METAMORPHOSES IN PARIS: THE FATE OF SAMARITAINE AMONG PRESERVATION AND INNOVATION}

\author{
Antonella Versacia ${ }^{a}$ Alessio Cardacib \\ aUniversity of Enna 'Kore', Faculty of Engineering and Architecture, Enna, Italy \\ bUniversity of Bergamo, Dept. of Engineering and Applied Sciences, Bergamo, Italy
}

\section{ABSTRACT}

In our times, cities regenerate by not only welcoming new and unprecedented activities but also reorganizing themselves from the morphological and social points of view. For a long time, the historic centre has wrongfully been considered as a space crystallized over time - implemented through integral conservation - that has transformed the urban fabric into an enormous museum that is not coherent and no longer meets the needs of the contemporaneity. Today, finding a dialogue, however difficult, between tradition and innovation is essential to implement renewal actions that inevitably must and must increasingly involve the built heritage. A complex palimpsest in which traces of the history and life of man are imprinted and deserve to be read and respected within inescapable mutative processes. However, these processes should be implemented without violence or cancellation, in a planning vision, not limited to the achievement of economic well-being but also to the reinforcement of the cultural dimension of development. Focusing on the transformations that involve the very heart of Paris and, in particular, an iconic place of commerce such as La Samaritaine, this essay aims to analyze the complexity of planning strategies in which specific actions of restoration, renewal and reuse involve the entire city to reconfigure new images and urban spaces.

\section{KEYWORDS}

Urban transformation; commerce; cultural heritage; architectural design; Paris.

\section{INTRODUCTION}

The concept of 'innovative' city refers to an archetype of technologically advanced and particularly characterized urban space. However, towns to regenerate need not only to welcome innovative activities but also to reorganize themselves from a morphological and social point of view.

For a long time, the idea of the historic centre has wrongly given back an image of space crystallized over time - implemented through integral conservation - which has transformed the urban area into a huge museum that no longer fits the demands of the contemporaneity. Today, having overcome this concept, to find a dialogue, however difficult, between tradition and innovation is indispensable given the implementation of renewal activities that inevitably will increasingly involve the built (Purini 2008). A complex palimpsest where the traces of human history and life are imprinted, which deserves to be read and respected within inevitable changes. Metamorphoses that should, however, be implemented without violence or cancellation, following a strategic vision, not limited to the achievement of economic well-being but also aimed at strengthening the cultural dimension of development.

In this sense, emblematic is the city of Paris. Its evolution is, in fact, the result of a continuous 
process of adaptation and transformation - obviously not free from contradictions regulated by debates, challenges, negotiations and crossed by a contextual and progressive change in the conceptions and forms of planning. The latter was first understood as a general instrument and then as a strategic tool, based on long-term choices and applied through timely interventions.

If a radical urban reorganization commissioned by Napoleon III and the prefect Georges Eugène Haussmann was carried out between 1852 and 1870, it was from the second half of the 20th century that the greatest and most traumatic changes occurred (Fumagalli 2008). In the thirty years that followed the end of the Second World War - the so-called Trente Glorieuses - French territories were affected by countless operations centred on the merciless operating practice of the rénovation urbaine. A concept with a vague and unclear meaning that was essentially translated into modernization - or demolition/ replacement - operations. Especially in Paris, it was materialized in a series of exemplary initiatives aimed at 'revisiting' the city. Although already in 1962, the Malraux law introduced provisions concerning the safeguarding of historic centres, the first decade of application of this instrument innovative and courageous but extremely rigid and problematic - was still essentially based on the praxis of renewal (Versaci, 2012). This led to the erection of towers, slats and other rationalist buildings in the core of the cities (Nigrelli 1999).

However, new concerns regarding the conservation and recovery of the existing urban and building heritage gradually emerge. By showing all its limitations and contradictions, the practice of renewal, therefore, opens the door to the formulation of new urban theories more attentive to the quality of the city and the life of its inhabitants. With the election to the presidency of the Republic of Valéry Giscard
d'Estaing, the thinking of the institutions on the urban transformations hitherto accomplished changes. The excesses of a certain 'quantitative urbanism' are criticized, also thanks to some vehement debates conducted by intellectuals and to a population more sensitive to the fate of their towns (Pinon 2011).

In 1977, the appointment of Jacques Chirac as the mayor of Paris, initiates a substantial review of the ongoing renovation operations, thus helping to define the guidelines of a new French urban planning more prone to the requalification of built heritage and conceived to both respond to the deep aspirations of the community and foster social relations. In 1978, the Paris Projet magazine focuses on the description of the objectives of this new policy. This latter proposes a return to volumes coherent with the peculiarities of the context, greater respect for the urban fabric, the protection and improvement of some elements of the existing habitat, the maintenance of traditional craft and industrial activities, the development of gardens and public spaces. In these years, France thus discovers the 'urban form', long denied by a technical approach to development.

An attempt will, thus, be made to achieve the 'active' preservation of the architectural and urban heritage of Paris - carried out through new constructions in the historic centre and its main sites (APUR 1985) - however not free from demolition activities and as many disputes.

Architectural heritage protection that in Paris takes on the forms of the urban project and which is expressed as a series of important operations, such as the remake of the old central food market Les Halles that opens in 1979, while devoted to other commercial function. A 'serious' mistake that Paris will never forget without ever stopping 'reinventing' itself, often at the expense of the Paris skyline':

\footnotetext{
1 The offence deriving from the suppression of the Baltard pavilions, a now universally recognized masterpiece of industrial archaeology, or the quality of the architectural organisms then made in replacement, globally devoid of character, banal, often ugly, will never be forgiven. at least according to contemporary perception. Above all, architecture is a clear expression of an ephemeral and technologically constantly evolving world, which has inevitably collided without ever reconcile with the values of permanence and immutability of the historical context.
} 
Paris is a fragile beauty. No city has captivated the imagination or inspired like Paris. It is a beauty different from any other city in the world. And the skyline is integral to that beauty. Like a subtle membrane containing the city in its most delicate aspects, this skyline defines the city. Destroy this, and you destroy Paris. The city will go on standing, and people will come, of course, but the city will be diminished (Pitt 2016, 119).

Today's Paris presents a succession of modern additions that help to define its image of charm, well-known and appreciated all over the world. Works of architecture, which nevertheless at the time of their creation created doubts and malaise: from Beaubourg (1977) to the Grande Arche in the La Défense district (1989) via the Arab World Institute (1987) and the Pei's Pyramid at the Louvre (1988).

Still, in the last decade, numerous experiences of transformation of the urban space have been planned in the French metropolis. Many of them are summarized in iconic projects - often huge skyscrapers - unfortunately inevitably associated with the negative image of a liberal and globalized economy that seems to contradict sustainable and lasting choices regarding plans, materials and construction techniques used (Mercuriali 2018). From the project for the new Forum des Halles (2018) to the various modernization and conversion programs of the Gare du Nord and the MaineMontparnasse district currently underway, up to the project concerning the Samaritaine, numerous are the demolition/reconstruction actions and extensive changes that affect the commercial sector. They call for some reflections on the scope and quality of these interventions.

In particular, the case of the La Samaritaine - a historical department store among the most representative of early 20th-century architecture and dear to Parisians because it conveys to them, in a contemporary context, the spirit of the Belle Époque - is of great interest. The complex has for some years been affected by a vast campaign of works aimed at its renovation. A bold operation that has sparked numerous controversies and that deserves further study, especially for an overall evaluation of the activities that include new grafts in the existing fabric.

\section{THE SAMARITAINE AS THE ARCHETYPE OF TRANSFORMATION}

The witness of a historical period marked by significant changes impressed, first of all, by the industrial revolution, the department stores appear in the Parisian landscape, along the course of the second half of the 19th century. The great success of Universal exhibitions ${ }^{2}$, the new policies of centralization of the railway sector and, within the cities of Paris, the spread of horse-drawn omnibuses that transport a large clientele in the centre, favour an ever-greater development. The introduction of new sales methods (free admission, fixed prices, a wide range of goods) and, at the same time, the possibility of growing - also in a colossal way on the internal courtyards, where it is possible, thanks to the use of the iron and glass, providing lighting through the establishment of zenithal windows - are elements that will facilitate their quick expansion.

In the new Parisian districts resulting from Baron Haussmann's Grands travaux and, in particular, in the transit and high-traffic areas, firms are confronted to find strategic planting opportunities. New imposing buildings replace old ones - picturesque but unhealthy - that persist in the heart of the city: the department store is a "modern, solid and light cathedral of commerce, created for a people of customers" - as Émile Zola claimed (Zola 
1883, 282) - intended to revolutionize retail and city lifestyles (Leveau 2006).

Five department stores overlook the Parisian market during this period, transforming its landscape: Le Petit Saint-Thomas and Au Bon Marché ${ }^{3}$, the oldest grand magasin created in 1852 in rue de Sèvres (7th arrondissement), Les Grands Magasins du Louvre ${ }^{4}$, in rue de Rivoli, built in 1855 and definitively closed in 1974, the Bazar de l'Hôtel de Ville (known as $\mathrm{BHV})^{5}$ opened to the public in 1856 at No. 52 of the rue de Rivoli right in front of the town hall, the Printemps Haussmann built in 1865 in the Opéra district, at No. 64 of boulevard Haussmann, La Samaritaine founded in 1869 facing the Seine, near Pont Neuf and, finally, Les Galeries Lafayette opened in 1894 in the Opéra district, at No. 40 of boulevard Haussmann (Fig. 1).

For these private companies, the role played by architectural design in the conquest of customers is very important (Vayron 2015). The architects in charge of their realization define a style that becomes specific to the department stores, characterized by spectacular codes inherited from the great noble palaces: a classic style chosen to impress passers-by and elevate buildings to contemporary monuments. Extremely attractive features distinguish the façades, the layout and ornamentation of the roofs, the height of the buildings often established in derogation of municipal regulations (Cantelli, 1991). They also concern the interiors, which are sumptuous, true and own triumphs of frescoes, iron's florilegia and stained-glass windows, to adequately serve the flourishing bourgeoisie of both the Second Empire and the Third Republic. In the context of this Parisian transfiguration, the case of the Samaritaine is representative, also for the more recent evolutions that make it one of the most interesting cases of contemporary transformation.

\subsection{La Samaritaine, a monument of Modernism}

The history of the department store is linked to the lives of Ernest Cognacq - a self-
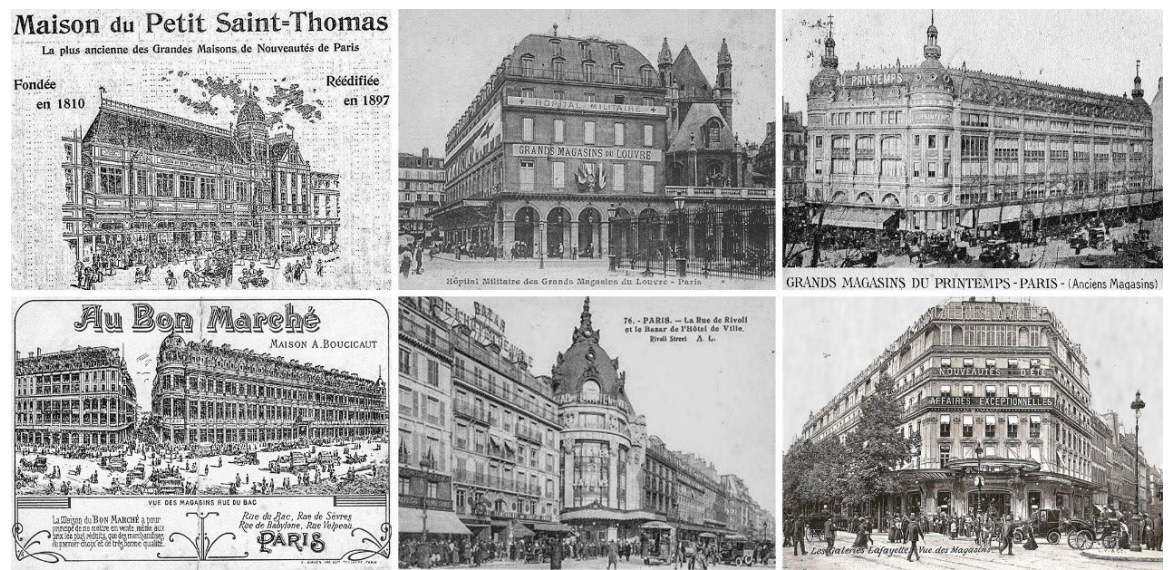

GRANDS MAGASINS DU PRINTEMPS - PARIS - (Anciens Meqasins)

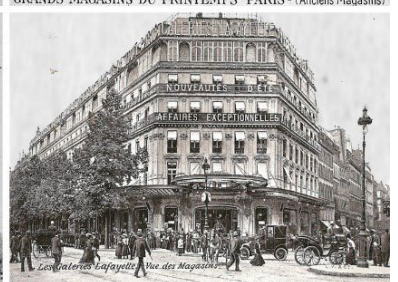

Figure 1. Construction phases of La Samaritaine. Source: (La Samaritaine, 2015)

\footnotetext{
${ }^{3}$ In 1989, the name changed to the current Le Bon Marché.

${ }^{4}$ Today on the same site is the Louvre des Antiquaires.

${ }^{5}$ Since 2013 , renamed Le BHV Marais.
} 
made man - and his wife Marie-Louise Jay, a first salesperson at Bon Marché). This extraordinary entrepreneurial activity started, in 1870, in a commercial space of just 48 square meters located on the corner of rue du Pont Neuf and rue de la Monnaie, in the Parisian 1 st arrondissement. Their small boutique was called La Samaritaine after the old 17th basrelief representing Jesus with the Samaritan woman placed on the nearby Seine water pumping station. The shop, thanks to the low price policy and the choice of goods suitable for multiple customer groups - but above all because it allowed small producers to have a space to sell their items directly - soon began to grow by acquiring the nearby shops, remodelling at the same time the whole district. The success of this epic commercial adventure is due to the visionary and utopian spirit of its owners and at the same time "to the conscious effort of some French architects towards new forms and towards adapting architecture to the needs of modern life" (Cognat 1930, 1). First of all, the Belgian Frantz Jourdain, a proponent of Viollet-le-Duc structural rationalism, a trenchant critic of the École des Beaux-Arts, and ardent supporter of Modernism. He was hired in 1883, later helped, and gradually replaced by the pupil Henri Sauvage, a renowned protagonist of Art nouveau and later of Art déco. Jourdain and Sauvage together will dare systematise the use of iron and glass to build quickly without ever stopping the sale:

Tempting facades, dizzying halls, exuberant and offbeat advertisements ... sometimes at the risk of shocking good taste, nothing is daring enough to seduce a clientele that attracts the decor, the profusion of goods and affordable prices (Cabestan 2015, 5).

From the first nucleus, Magasin No. 1 extends along the whole lot. To establish a constant relationship between artistic production and daily life is the goal that governs Jourdain's activity for the Samaritaine. Following the thought of the philosopher Hippolyte Taine, he believes that works of art are the reflection of the social moment and civilization (BarréDespond 1988). He is sure that the artist has a leading role in modern life - "talent has always adorned with magnificence or grace the flattest, brutal requirements of existence" (Jourdain 1909) - and then entrusts in 1891 to the painter and decorator Charles Toché, the realization of a fresco on the façade on what will become the Magasin No. 2. Jourdain is then called to unify the neighbouring buildings acquired over time through a series of important internal structural modifications and some specific modifications on the external fronts.

Works of the Magasin No. 2 in rue de la Monnaie, in front of the first shop, essentially take place in two phases (1904-1910 and 19271929) and are marked by internal and external transformation, expansion campaigns, and later by bold reconstructions. A metal and glass architecture - technologically performing and long-lasting - gradually replaces the traditional construction, characterizing the identity of the department stores.

La Samaritaine - the Samar as it was named by the public - will, therefore, acquire a new 'trendy' look, so becoming one of the most sought-after stores in Paris. Two particularly 'exuberant' polychrome domes will close the building scandalizing and creating many moods in the town.

Soon, Ernest Cognacq imagines the extension of the second store enriching it with a new façade on the Seine. This involves the closure of the rue Prêtres-Saint Germain-I'Auxerrois, as well as the purchase and destruction of the buildings located between the road and the riverbank. The Paris municipality expresses a favourable opinion on this important transformation as long as the domes of Jourdain are demolished and the new façade is planted backwards from the road alignment, to widen the intersection at the Pont-Neuf. In 1922, Frantz Jourdain defines a first project that is radically rejected; it is then joined in 1925 by Henri Sauvage, to whom the task of definitive is finally assigned. However, the second project 
is also rejected due to the presence of an exposed metal frame, the polychromy of the facades, the effect - deemed unpleasant - of two bow-windows on the main front and a top lantern' ${ }^{6}$. In May 1926, a third project is drafted by Sauvage which envisages a self-supporting counter-façade characterized by the presence of large stone blocks, the replacement of the lantern with a terrace accessible to all and the downsizing of the decoration. The new Samaritaine thus become a reference for Art Deco architecture:

emblematic, unitary and of immediate readability, the Senna side facade of the Magasin No. 2 thus conceals the backbone of a very complex reality (Cabestan 2013, 51)

The department store is again extended in the 1930s along the rue de Rivoli. At the request of Gabriel Cognacq, grandson of the founder, the Magasin No. 3, is built in the block placed between the Rivoli, Pont-Neuf and Boucher streets. The building permit is issued on 31 December 1929 and the construction site starts on 2 February 1930. The edifice, a masterpiece in terms of prefabrication and assembly, is carried out by the company Lange,
Escande et Cie which concludes the works in just eight months, without ever stopping retail. Designed once again by Henri Sauvage, the façades draw clear inspiration from those just built on the Seine but, free from the constraints imposed there, are characterized by lightness and elegance. They inaugurate an urban aesthetic that is no longer the Haussmannian one (Fig. 2). A colossal rewriting that marks the start of an urban sequence of imposing and authoritarian facades that would have been followed by the Magasin No. 4.

After Sauvage's death, the extensive building harmonization program continues. Jourdain starts the construction of the last tranche which foresees the rebuilding of the front built on the rue de Rivoli. After his death, his collaborators Louis d'Escrivan and LouisMarie Charpentier conceive the project for the conversion of the complex consisting of a group of buildings of the 19th century. Alas, the onset of the economic crisis will put a brake on these intentions. The already advanced project of reconstruction of the façades is not realized and the Magasin No. 4 remains a succession of four pre-Haussmannien immeubles de rapport of a certain aesthetic interest, but certainly not a rarity in the capital.
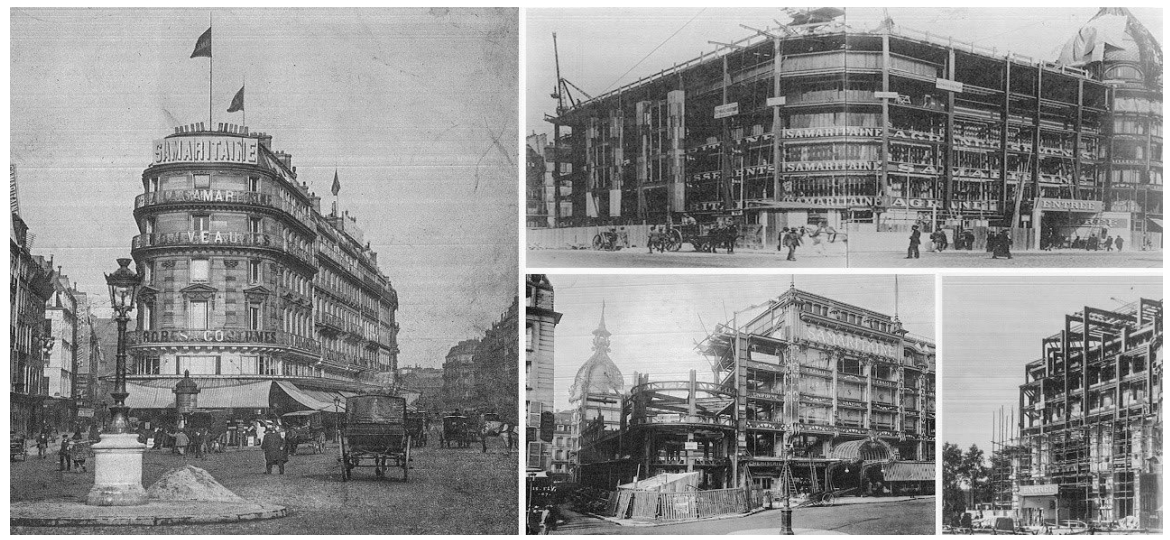

Figure 2. Construction phases of La Samaritaine. Source: (La Samaritaine, 2015)

${ }^{6}$ The municipal authorities were concerned about the impact of this new building on the skyline of the right bank of the Seine and co-visibility with the Louvre. 
If in 1990 buildings Nos. 1, 2 and 3 are listed in the inventaire supplémentaire des monuments historiques, the intrinsic value of the edifices belonging to the Magasin No. 4 did not justify a priori any opposition in terms of new projects, moreover planned but interrupted since the crisis of 1929.

The continuous transformation that governed both the architectural life of the Samaritaine and the entire area, abruptly stopped for incidental causes, could no longer be delayed, especially because of an economic revitalization of the department store, long affected by a process of 'ageing' and decay.

\section{RECENT METAMORPHOSIS AND NEW GRAFTS IN HISTORIC LANDSCAPE}

In the 1990s, despite several attempts at renovation, the image of the department store is lowering and some financial difficulties arise. In the decade 1990-1999, the Samaritaine suffers a $6 \%$ decrease in its turnover while the four other Parisian department stores are up 9\%. In 2001, the luxury group LVMH (Louis Vuitton Moët Hennessy) already the owner of Bon Marché, purchases the Samaritaine and inaugurates a new stage in the history of the Parisian department store. Notwithstanding the decision to keep the commercial vocation unchanged, the retail business is shortly after suspended and stopped on 15 June 2005 following studies, which highlight the lack of security of buildings in the face of the risk of fire. At the time, La Samaritaine occupies $75,000 \mathrm{~m} 2$ in the heart of Paris, employs 1,400 people and is visited by 10,000 to 20,000 customers per day.

Its sudden closure is a trauma, first for the employees but also for the surrounding neighbourhood, which loses much of its vitality (APUR, 2007). The objective of LVMH is then to renew the activities and change the image of the Samaritaine to attract the young and active clientele.
The department store's grip is further reduced. In 2002, the Magasin No. 1 (16,000 m2), long unoccupied, is rented to the Kenzo and Sephora brands (two subsidiaries of LVMH), the Zara group and to offices. The Samaritaine then focuses on its main stores: the Magasins No. 2 and No. 4, (75,000 m2 in total).

A bold and innovative project is therefore conceived by the architects Kazuyo Sejima and Ryue Nishizawa of the Japanese studio SANAA, winners of the Pritzker Architecture Prize in 2010. The program aims to increase and relaunch the image of Paris as the capital of luxury. The redevelopment of the facades and interior spaces, inspired by the original idea of the architects Jourdain and Sauvage, involves the modernization of the commercial spaces and the construction of offices, a luxury hotel (80 rooms), a restaurant with terrace, a nursery for 60 children $7,000 \mathrm{~m} 2$ of social housing: (96 homes). A project based on the diversity of function, architectural forms and construction methods.

A conservative approach is followed for the historic façades of Magasin No. 2, the multicoloured glazed tiles of the interiors, the glass roof, the monumental staircase and the furnishings; while a contemporary project is conceived for the façades and buildings of Quai du Louvre and Rue de Rivoli, marked by the use of new materials and design elements. The SANAA project has sparked a series of controversies especially from various associations - in particular, the Société pour la protection des paysages et de l'esthétique de la France (SPPEF) and SOS Paris, who have appealed against the project. The latter was considered in contrast to the plan local d'urbanisme (PLU) which requires that each new construction would be integrated into the existing urban fabric, taking due account of the morphological and typological peculiarities of the neighbourhood, as well as that of the existing façades and roofs. 
Can we destroy an almost whole block, in the heart of Paris, to build a private commercial building? (Gady 2014);

For LVMH, as for many industrialists and local authorities who are now playing the same game, starchitecture is a pretext as much as a tenure if not all-risk insurance. It thus relegates architecture to the rank of a consumer product (Chemetov 2014)

are just some of the criticisms brought to the project.

Indeed, the transformation of this important symbol of Paris had already foreseen numerous exchanges among the parties involved. Several meetings, conferences, studies were taken, to guarantee a broad debate on the changes that would take place. Also, in June 2011, two feasibility studies focusing on the compatibility of Sanaa's project with the requirements of urban architectural protection were carried out under the direction of eminent personalities. The one directed by Jean François Cabestan confirmed the validity of the design proposal, recognizing a particularly high historical and patrimonial awareness in support of the analysis of "what must be maintained, what could evolve and what must change" (Cabestan 2011, 121). The logic of the conversion of the Samaritaine and the idea that its rebirth could be based on a contemporary contribution to the image of the old department store in the Parisian public space appeared more than legitimate. It was also added that the transformations were an integral part of the history of this building, as well as the 'transparent' solutions, already widely adopted in the recent architectural history of Paris, even in the historic centre.

Otherwise, the second report drawn up by Pierre Pinon and François Loyer, considered the proposal unacceptable, since it disregarded the characteristics of the urban fabric. Old edifices would be replaced by a new one characterized by a very long and high facade, so destroying the rhythm established by the parcel breaks (Pinon \& Loyer 2015). The dimensions of the new building - $75 \mathrm{~m}$ in width and $25 \mathrm{~m}$ in height - differed substantially from those of an ordinary edifice - on average $15 \mathrm{~m}$ wide and about $17 \mathrm{~m}$ high - even though its function will be (offices, housing, shops, etc.).

The large undulating glass façade with serigraphies that stands today as a scenographic urban backdrop on the rue de Rivoli was at the core of the criticisms (Fig. 3).
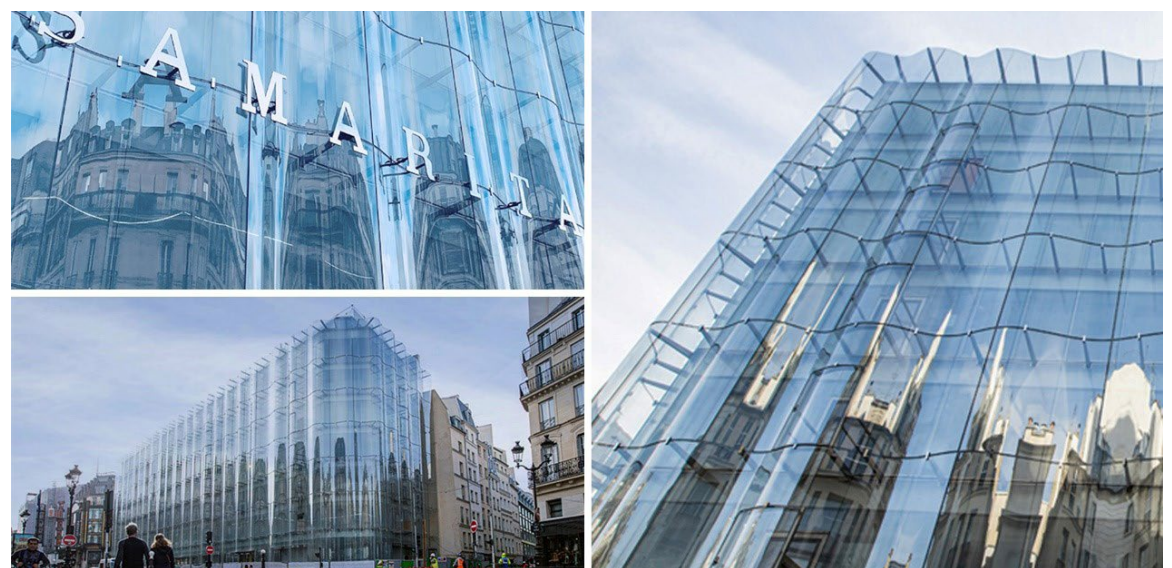

Figure 3. The new Saana's project for Magasin No. 4. Source: (Author 2020) 
The so-called 'shower curtain' was the cause of a long procedural battle. As a consequence, in May 2014, the building permit for this project was annulled. However, while legalities proceeded, the work continued and the original four buildings were torn down. The annulment went then to appeal, and in June 2015 LVMH won.

Ultimately, whatever was the purpose of these procedures, they raised many questions regarding the place of architecture contemporary in old centres. They brought out new blames around the forms of expression of contemporary architecture.

\section{AS A 'TEMPORARY' CONCLUSION: CRITICISMS AND MISUNDERSTANDINGS ABOUT CONTEMPORARY ARCHITECTURE IN HISTORIC CENTRES}

The case of La Samaritaine perfectly falls within the longstanding, rough and always open debate over the reconciliation of heritage conservation and development. A debate related to the quality and the character of the architectural insertions in historic areas, which especially in the last years - in parallel with the enlargement of heritage conservation significance, from the mere protection of the legacy of the past to the idea of sustainable management of urban growth - has become a timely research topic. However, the notion of quality of the architectural act is not easy to define, but certainly includes some essential requirements such those related to the prior analysis of evocative, cultural and formal values of the place, the concept of durability, objective aesthetic rules, as well as its relevance (i.e. cultural, economic) to be evaluated and assessed based on the most effective community-based decision-making. The definition of specific guidelines for a successful 'combination' of new constructions with the existing urban fabric, is unfortunately very problematic. Many authors agree that criteria can be used as points of reference or as a reminder list for applicants and evaluators, but they cannot ensure good - or avoid bad design. In general, the approaches followed in the insertion of the new in the old are varied and constantly evolving: about architecture, they can refer, according to Giovanni Carbonara, to the principles of autonomy/ dissonance, assimilation/consonance or be based on the establishment of a dialectical relationship/reintegration of the images (Carbonara, 2011). All categories in which different worthy examples of design, showing a good equilibrium between the exigencies of modernity and that of the historicity, can be found. Besides, there are also special experiences, often aimed at the construction of an image useful to highlight the novelty of the place, turning it into a catalyst for people and activities to exploit in a commercial and marketing perspective.

Located in the centre of Paris - indeed in its hyper-centre, the rue de Rivoli - the Samaritaine, "last avatar of a brilliant, cheerful, somewhat carefree era [...] unquestionably the ancestor of today's functionalist constructions" (BarréDespond 1988, 194) seems to embody all the concerns of a social milieu - even culturally high - wary of contemporary architecture. To the latter is attributed the danger of the loss of identity of a historic centre increasingly attacked by homologation processes and 'sold' to mass tourism and to commercial gentrification.

The lack of sympathy for contemporary architecture becomes dislike when the contemporary project 'affects' the historical heritage, a legacy that belongs to the community (local, firstly); that heritage "whose loss constitutes a sacrifice and whose conservation presupposes sacrifices" (Chastel 2008, 62). It turns into a real rejection when the architect is a star architect and the design seems to be so subordinated to technology, so much as to lose any reference to the past. When the architecture is so light and almost immaterial as to seem to have 
no connection with the context and poor durability. When, in comparing it to historical architecture, it is judged superficial and without underlying codes.

In reality, the Magasin No. 4 project - although it has made tabula rasa of the past, perhaps not pushing research enough towards a rewriting of the existing, yet possible - is unquestionably extremely refined and elegant. Today, having removed every yard fence, it appears in the definitive version respectful of the alignments and elevations of the close buildings, without clashing with their materiality made up of stone facings. Its aesthetics may not appeal to everyone, but the final judgment will be that of those who will enjoy it every day or maybe a few minutes. In any case, the much-contested façade seems to fit perfectly in the continuity of that will of the invention that was inherent in both its creators and the first owners of the Samaritaine. A vision that allowed to enrich the neighbourhood, characterizing it with an originality that is today perpetuated. 


\section{REFERENCES}

Atelier Parisien d'Urbanisme. 1985. Paris Projet, No. 25-26.

Atelier Parisien d'Urbanisme. 2007. La fermeture de La Samaritaine et son impact sur le quartier environnant. Paris: APUR.

Babelon, Jean-Pierre, Chastel, André. 2008. La notion de patrimoine. Paris: Éditions Liana Levi.

Barré-Despond, Arlette. 1988. Jourdain. Frantz, 1847-1935, Francis, 1876-1958, Frantz-Philippe, 1906. Paris: Editions du Regard.

Cabestan, Jean-François (ed.), Le Corrolier, Laurent, Lempereur Hubert, Léna Étienne. 2011. La Samaritaine Magasin 2: Étude d'intérêt patrimonial, Grenoble: Attrapa Atelier de transformation des patrimoines. Cabestan, Jean-François. "La transformation de la Samaritaine ou l'actualité des processus de reconversion à Paris, au travers des dessins de Jourdain, de Sauvage et de Sanaa (1904-2011)". In Città storiche città contemporanee. Strategie di intervento per la rigenerazione della città in Europa, edited by Riccardo Florio, 45-62. Napoli: Clean, 2012.

Cabestan, Jean-François. 2015. La Samaritaine. Paris: Picard.

Carbonara, Giovanni. 2011. Architettura d'oggi e restauro. Un confronto antico-nuovo. Torino: Utet.

Cantelli, Marilù, Guillerme, Jacques. 1991. Lillusion monumentale: Paris, 1872-1936. Liège: Mardaga.

Chemetov, Paul, "Le projet de la Samaritaine se résume à de l'empaquetage", Le Monde, 11 juin 2014.

Cognat, Raymond, «La Samaritaine par MM. Jourdain et Sauvage", L'Architecture, No. 1 (1930): 1-10.

Fumagalli, Mario. 2008. Inarrestabile città: note di geografia urbana. Milano: Maggioli Editore.
Gady, Alexandre, "La bonne Samaritaine?", Le Monde, 21 May 2014.

Jourdain, Frantz, "Le rôle de l'artiste", Le Rationaliste, June 1909.

Leveau, Jean-Damien. "La Samaritaine". In Les cathédrales du commerce parisien, edited by Béatrice de Andia, 73-80. Paris: Action artistique de la Ville de Paris, 2006.

Mercuriali, Mathieu. 2018. Concevoir à grande echelle. Paris: Éditions B42.

Nigrelli, Fausto Carmelo. 1999. Percorsi del progetto urbano in Francia e in Italia (19601997). Roma: Edizioni Officina.

Pinon, Pierre. 2001. Paris détruit: du vandalisme architectural aux grandes opérations d'urbanisme. Paris: Eds. Parigramme.

Pitt, Leonard. 2016. My Brain on Fire: Paris and Other Obsessions. Berkeley: Soft Skull Press.

Purini, Franco. "La necessita del nuovo. Le città innovative net quadro della competizione globale: il caso italiano". In La città come testo critico, edited by Nicolò Privileggio, 39-49. Milano: Franco Angeli, 2008.

Vayron, Olivier, "Dômes et signes spectaculaires dans les couronnements des grands magasins parisiens: Dufayel, Grand-Bazar de la rue de Rennes, Printemps, Samaritaine", Livraisons de I'histoire de l'architecture [online], No. 29 (2015) http://journals.openedition.org/ Iha/478;DOI:10.4000/lha.478.

Versaci, Antonella. 2012. L'origine des secteurs sauvegardés. Intentions et difficultés sans la mise en place des premières operations. Lille: ANRT.

Zola, Émile. 1883. Au bonheur des dames. Paris: G. Charpentier Éditeur. 



\title{
PAPER \#3.18
}

\section{BUILDING A MODERN ASUNCION: CONTRIBUTIONS OF THE HOTEL GUARANI IN THE CONFIGURATION OF A NEW URBAN SPACE}

\author{
Julio Diarte ${ }^{\mathrm{a}, \mathrm{b}}$, Elena Vazquez ${ }^{\mathrm{a}}$ \\ aPenn State University, University Park, PA, USA \\ bUniversidad Nacional de Asuncion, San Lorenzo, Paraguay
}

\section{ABSTRACT}

The relative geographical isolation of Paraguay has always been an essential attribute of its cultural production, including its architecture. This condition has also made Paraguay a late and eclectic adopter of the principles of the Modern Movement in architecture. While Oscar Niemeyer's pavilion for the 1939 world's fair represented a hallmark in the definition of a Latin American Modern Architecture, some of the first examples of this type of architecture in Paraguay appear just in the 1950s. Overlooked for decades, recent investigations developed in the last years have studied the architectural production in Asuncion during the mid-twentieth century through the lens of historical, sociopolitical, and aesthetic considerations. There are two modern buildings in Asuncion, the capital, which can be considered of utmost importance for their scale and their meaning as cultural artifacts: the Colegio Experimental Paraguay-Brasil designed in 1952 by Affonso E. Reidy- and the Hotel Guarani -designed in 1956 by the Brazilian architects Adolpho Rubio Morales, Rubens Carneiro Vianna, and Ricardo Sievers. While several studies have investigated the first, the Hotel Guarani has received much less attention despite its strategic location in downtown Asuncion and introducing novel architectural strategies in terms of urban space configuration. In this paper, through digital reconstruction and formal analysis of this emblematic case study, we analyze the architecture of the building with a focus on the design strategies that defined new urban spatial relationships between the building and the city of Asuncion. Through a formal reconstruction of the project, we identified several architectural concepts such as permeable street-level floorplan, semi-public corridors, and large overhangs. We argue that these design strategies contributed to the new architectural language of the incipient Paraguayan modern architecture.

\section{KEYWORDS}

Modern architecture; Paraguay architecture; urban space.

\section{INTRODUCTION}

The relative geographic isolation of Paraguay has always been a trait represented on its cultural and architectural production. This condition can also be reflected in its late and eclectic adoption of the principles of the modern movement in its architecture. Scholarship in Latin American modern architecture, for instance, usually frames the story of modernism in the continent from Le Corbusier's 1929 visit to South America to the 1960's completion of Brasilia (Fraser 2001). However, some of the first examples of what could be characterized by modern principles in Paraguayan Architecture do not appear until the 1950s. Overlooked for decades, recent studies have sought to investigate the impact of modern architecture in Paraguay. A recent publication has presented an extensive catalog of buildings dated from 1948 to 1985 (X et al. 2018), providing a panoramic view of the architecture in Paraguay with a focus on buildings that followed design principles of 
modern architecture or presented a modern trait. However, there has been little discussion on the contributions that some of these buildings had in the development of a new architectural language with modern principles and its impact on the configuration of new urban spatial relations in Paraguayan cities.

There are two modern buildings in Asuncion, the capital, which can be considered of utmost importance for their scale and their meaning as cultural artifacts that represent the sociopolitical context in which they were built: the Colegio Experimental ParaguayBrasil and the Hotel Guarani (Figure 1). The first, a school designed by notorious Brazilian architect Affonso E. Reidy, has been extensively analyzed both in its formal traits and its contribution to modern Paraguayan architecture (Diarte 2009; I. Rivero and Delpino 2009). The second, the Hotel Guarani, has received much less attention despite its strategic location in downtown Asuncion and introducing novel architectural strategies in terms of urban space definition (Diarte 2015). The Hotel Guarani was designed by Brazilian architects Adolpho Rubio Morales, Rubens Carneiro Vianna, and Ricardo Sievers, who won the international competition for its design, the first of its kind in Paraguay in 1956 (Morra 2010) $)^{1}$. This paper presents a formal analysis of the Hotel Guarani, identifying its prominent architectural features that help define a new modern urban form and space in Asuncion. Furthermore, we illustrate the surrounding area of the Hotel Guarani and deliberate how its design strategies could have influenced subsequent buildings. The main argument of this paper is that this emblematic building with distinct modern design principles gave shape to innovative design approaches, especially in the transformation of the urban space. This paper contributes to the growing body of research on Latin American architecture by discussing a well-known symbol of modern design and the new ideas it brought to the language of Paraguayan architecture.

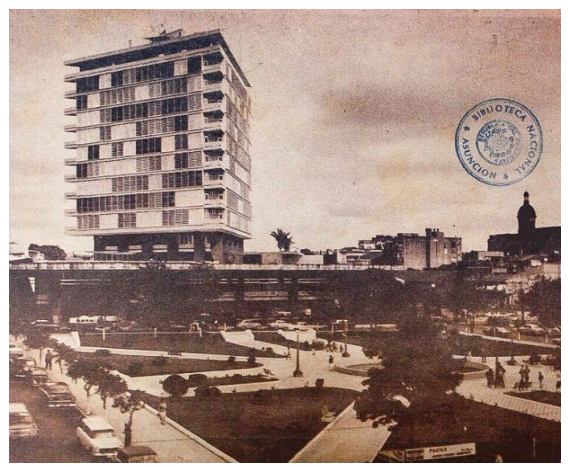

Figure 1. View of the Hotel Guarani from the Plazas in the late 1960s. Source: (ABC Color 1967)

\section{BACKGROUND OF THE PROJECT}

The development of modern architecture in Paraguay is closely linked to the country's regional relationships (C. I. Rivero 2016); thus, to understand its origins, one must look at the sociopolitical conditions of the region. Paraguay is surrounded by three countries, Argentina, Brazil, and Bolivia, the first two being prominent players in exerting cultural influence throughout the region-Buenos Aires as the unchallenged cultural capital before World War II and Brazil emerging as a strong contester in cultural supremacy during the Cold War (García 2014). The 1950s then represents, in Paraguay, a shift in regional relations from Argentina to Brazil. However, modernist principles were introduced into Paraguay's architectural production through other vital players in the region. Rivero (2016)

\footnotetext{
${ }^{1}$ Morales, Vianna, and Sievers received an award of $\$ 4,000$ and the contract for the design development of the project and the supervision of the construction. The 2 nd place $(\$ 2,000)$ was awarded to the architect Jaime Larrain Valdez and his collaborators, Julian Larrain Echeverria, Hernan Martinez, and Federico Lorca, all of them from Santiago de Chile. The 3rd place (\$1,000) was awarded to the architect Jose de Souza Reis from Rio de Janeiro, and the 4th place $(\$ 700)$ was awarded to the architect Ruben Dufan from Montevideo (La Tribuna 1957). All of them, except for the 4th place of which we have not found information until the submission of this article, were highly renowned architects in their countries. This situation evidences the importance of the contest in the region.
} 
discusses the influence that Brazil, Argentina, and Uruguay had in the development of modern architecture, describing how modern ideas were exchanged among these southern countries.

According to local researchers, there were two critical moments in the construction of a Paraguayan Modern Architecture. First, the return of Paraguayans instructed in the architecture school of Montevideo (FADU$(U D E L A R)^{2}$ in the 40s and 50s; and second, the arrival of renowned Brazilian architects to Paraguay such as Affonso E. Reidy. The return of Paraguayans graduated from the FADUUDELAR helped form the first architecture school in Paraguay in 1957 (at the Universidad Nacional de Asuncion). Nevertheless, two of the most iconic buildings of modern architecture in Paraguay have been influenced by the presence of Affonso E. Reidy in Paraguay, either as the designer himself the Colegio Experimental Paraguay-Brasil- or as part of the jury that selected the winning design -the Hotel Guarani.

As mentioned before, the Hotel Guarani resulted from an international architecture competition organized by the Instituto de Prevision Social (IPS). The IPS is a government institution that played an essential role in the construction of public buildings with modern traits. Arturo Herreros, for example, the first architect that graduated from the architecture school in Paraguay in 1963 (Diarte et al. 2019), led the architectural design of important buildings such as the (Diarte et al. 2019)Hotel Acaray in Ciudad del Este in 1965 and the Hotel Casino San Bernardino in 1974. The contest for the Hotel Guarani, first of its kind, called for a design that would become a "symbol of modernity" and attracted 28 entries from different countries. Tomas Romero Pereira-also an architect and former president of Paraguay with strong political connections-chaired the jury, which also had famous Brazilian architect Affonso
E. Reidy. Reidy played a key role in the dissemination of Brazilian modernism within his role as architect-in-chief of the Engineering Department of the Distrito Federal city council of Rio de Janeiro (Rovira Llobera and Herrera Milek 2018). The building's inauguration was on September 11, 1961, on the founding anniversary of the dictator's party. The 15,000 m2 competition brief ended up being a 23,753 $\mathrm{m} 2$ of built surface, and the building became an icon for the dictatorial regime that governed the country from 1954-1989 being included even in one of the local currency bills ${ }^{3}$.

Up to now, the paper described the broader context and meaning that the Hotel Guarani has as a cultural and social artifact. What follows now is an analysis of the architecture of the building with a formal methodological approach centered in its aesthetic, geometric, and constructive nature. The proposed research approach relies on means of graphic representation, such as photographs and drawings-means that architects use to design-to uncover meaning and intentions (Gastón 2010). Data for this study was collected through archival work, photographs, and digital reconstruction of architectural blueprints of the original design. For this study, the architectural project becomes the center for extracting design strategies. In this way, we intend to unveil and discuss design intentions and ideas observed in the architectural project, particularly those concerned with the definition of the urban space.

\section{A NEW RELATIONSHIP BETWEEN BUILDING AND THE URBAN SPACE}

The Hotel Guarani is strategically located in downtown Asuncion: in front of a group of four Plazas in which the neoclassic Panteon de los Heroes (1863) is located, and near the Banco Nacional de Fomento (ca. 1940 and formerly

\footnotetext{
${ }^{2}$ The full name is Facultad de Arquitectura, Diseno y Urbanismo de la Universidad de la Republica Oriental del Uruguay, Campus Montevideo

${ }^{3}$ The total cost of the venture cost around US\$4 million representing almost US\$35 million of today's value
} 
known as Banco del Paraguay), another neoclassic institutional building (Figure 2). The design of the hotel follows the modern typology of a tower over a horizontal base, that can be seen in other iconic buildings such as the Lever House in New York City by Gordon Bunshaft in 1948. The horizontal base contains public programs such as stores, an 800-seats theater, a restaurant, and a terrace with a playground and a pool. The tower on top of the horizontal base is a prism with a triangular base, which also carries over to other design elements such as the columns and terrace design. The tower houses all the 170 hotel rooms and a restaurant at the top with views over the city and the Paraguay river. The program has not changed from its original function as a hotel, although the building has suffered periods of abandonment until the last recent renovation in the decade of 2000 that executed substantial interventions in its architecture.

Jose G. Rodriguez de Francia-the dictator who ruled Paraguay after its independence in 1811 until 1840- established the orthogonallike geometry of the urban fabric of downtown Asuncion in the decade of the 1820s intending to reorganize the organic development of the city (Gutierrez 1983). The site for the hotel occupied a whole block of this fabric in the hearth of a city characterized by lowrise buildings-mostly private houses-of continuous and modest facades. The largest public building in the perimeter of the four Plazas was the Banco National de Fomento, built in the 1940s and designed by the renowned Argentinian architecture office of Sanchez, Lagos y de la Torre 4 . The relation between the surrounding buildings and the streets around the Plazas was very restricted for three reasons: (a) their design principles-a combination of colonial and neoclassical types of architecture mostly closed to the exterior and turned to inner courtyards to counteract the crude hot and humid local climate; (b) the construction system with which the buildings were erected-load-bearing masonry walls with limited openings in the exterior facades; and (c) the material resources available at that timethe use of glass, steel, and concrete was very limited in Paraguay during the mid-twentieth century, thus, the openings were very limited. In this context, the Brazilian architects who won the international contest for the design of the Hotel Guarani, proposed a completely opposite approach that relied on the technological advancements in construction materials and techniques available in Brazil at that time ${ }^{5}$.

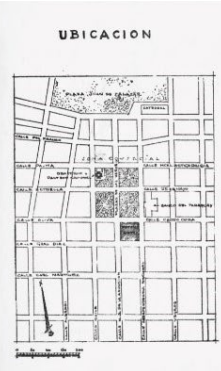

(a)

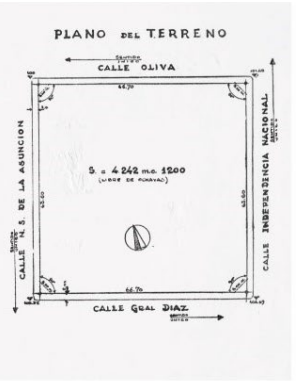

(b)

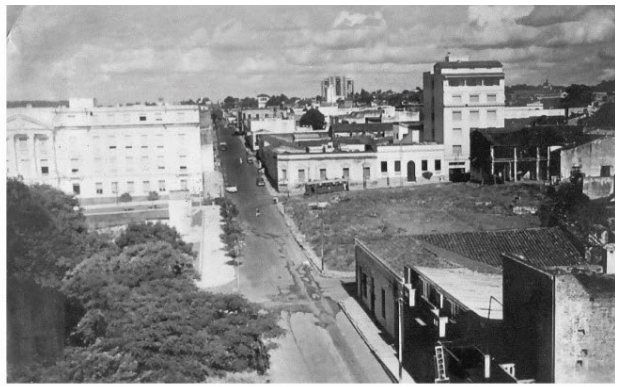

Figure 2. (a) Site plan and (b) aerial view of the site in the early 1950s. Source: (a: (Instituto de Prevision Social 1956); b: Javier Rodriguez Archive)

\footnotetext{
${ }^{4}$ Sanchez, Lagos y de la Torre designed the Cavanagh Building in Buenos Aires in 19

5 Paraguay did not produce cement until 1969 when the government inaugurated the Industria Nacional del Cemento and did not produce steel products for construction until 1970 when the Aceros del Paraguay was inaugurated. Before that, most of the cement and rebars were imported from Argentina.
} 


\section{UNVEILING THE ARCHITECTURE OF THE HOTEL GUARANI BUILDING}

The following section describes and considers the architectural features of the horizontal base and the tower in relation to the urban space. To illustrate the architecture of the building, Figure 3 shows the graphic reconstruction of the basement, street level, and +2 level floorplans of the horizontal base, and +4 to +12 levels floorplans of the tower. The reconstruction of all these drawings followed the original design of the building ${ }^{6}$.

The organization of the street level floorplan was composed by three main areas occupying the whole block and separated by internal corridors-shaded in light gray in Figure 3-b: (a) the primary access, lobby, and restaurant on the northwest; (b) a small block of stores on the east; and (c) a second block of stores and service areas in the south. The configuration of the internal corridors going through the building from east to west and north to the south allowed anyone who was walking through three of the four surrounding streets to enter the building. This permeability of the building was a completely new urban phenomenon for Paraguay; however, other architects in Sao Paulo, previously adopted this strategy with great success in mix-use buildings $^{7}$. In Figure 3-b, we emphasize the contrast between the openness of the hotel's street-level floorplan in comparison to the surrounding buildings.

Following this idea of permeable street-level floorplan ${ }^{8}$, and to reinforce the autonomy of use of the different parts of the program, the architects separated the main entrance of the hotel-that includes a small parking area for the guests-and the entrance to the 800-seats theater (Figure 2-a). The main entrance faces the Plazas, and the entrance to the theater is in the northeast corner of the block in direct connection to the street. The lobby of the hotel is a two-levels inner courtyard accentuated by six monumental triangular-based concrete columns and a straight stair on the side that connects the lobby to the level +1 of the horizontal base-the conference rooms are in this level. Overall, the street level floorplan of the horizontal base is key in articulating the different components of this multifunctional building-hotel, theater, restaurant, conference rooms, and shops-their requirements, and hierarchy in the program list. Next, we will stress the main features of the following levels of the building.

Figure 3-c shows the floorplan of the +2 level, which is the roof of the horizontal base. Similar to the Lever House Building in New York City, the roof of the horizontal base occupies the whole block and works as a terrace and leisure area of the hotel that is restricted only to their guests. Triangular shapes dominate three of the four main elements in the terrace. The first triangle is the off-centered tower of the hotel rooms; the second, an exterior lounge covered with a flat roof and a small enclosed space; the third, a triangular void in the horizontal base roof that gives room to a courtyard in the conference rooms level; and lastly, an irregular-shaped pool facing the Plazas and exposed to the sun all year-long.

It is somewhat surprising how the architects changed the criteria between the design of the floorplans of the horizontal base and the design of the terrace. The first follows an orthogonal geometry, and the second has a less structured composition of triangularshaped elements. The triangular shape of the tower, for example, is almost imperceptible in the geometrical disposition of the columns in

\footnotetext{
${ }^{6}$ The current Street level floorplan of the hotel looks different from the original due to changes in the program implemented by successive tenants.

${ }^{7}$ The Conjunto Nacional building in Sao Paulo, Brazil, designed by David Libeskind in 1952

8 The architects took a similar approach in subsequent design projects. In this sense, two of the most interesting are the contest in 1957 for the City Hall building of the city of Campinas, Brazil, designed by Viana and Sievers (Instituto de Arquitetos do Brasil Nucleo Regional Campinas 2015) and the contest for the Legislative Assembly of the Sao Paulo State in 1962 designed by Morales, Viana, and Sievers (Machado Marquez Gabriel 2013) The architects received the 1st place in both contests and the buildings exist until today. The Campina's City Hall building, for example, shares many formal and structural elements with the project for the Hotel Guarani.
} 
the lobby area of the street level floorplan. A possible explanation for this might be that the architects wanted to interrupt the regularity of the orthogonal structure of the urban space by placing triangular-based elements that would be unique in the context, especially for the hotel tower. Another possible explanation for the triangular-based shape of the hotel tower is that this shape allows more rooms to have a better view of the city and the river (Figure 3-d). This combination of different forms in a less structured pattern is a trend in the work of modern Brazilian architects, especially in the works of Oscar Niemeyer, who usually combine regular-shaped buildings with irregular-shaped connectors. The Ibirapuera Park, designed by Niemeyer in 1954, is an excellent example of this design strategy.

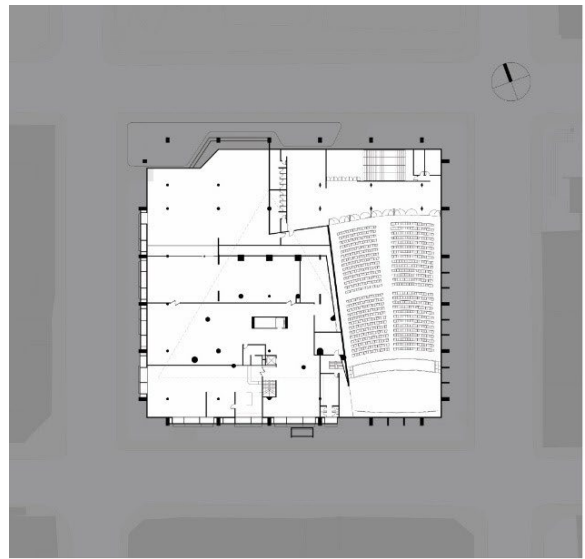

(a) Basement -1
1

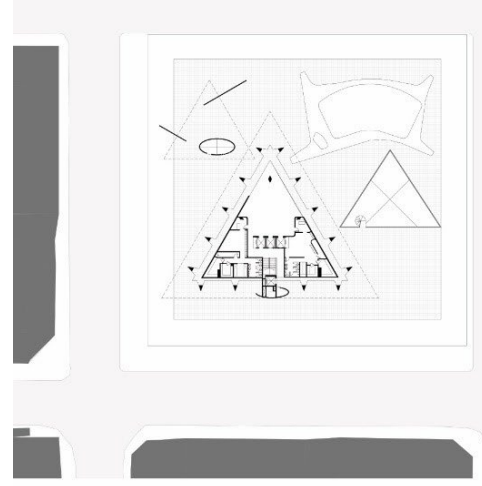

(c) +2 Level Floorplan

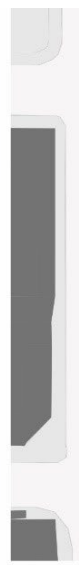

口

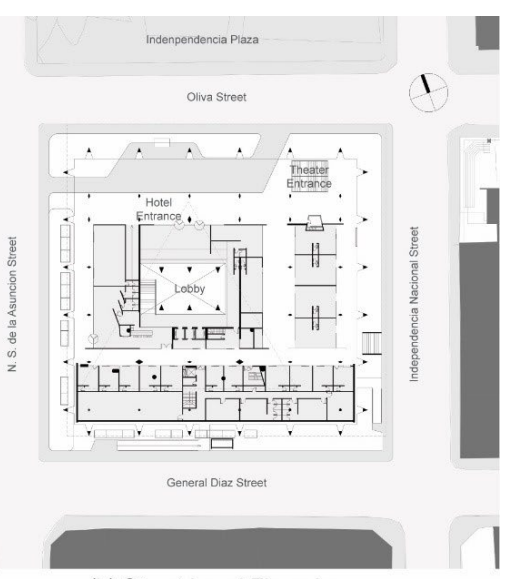

(b) Street Level Floorplan

1

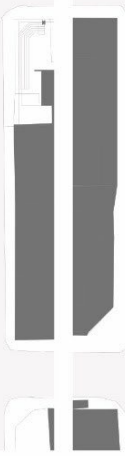

(d) +4 to +12 th Levels Typical Floorplan

Figure 3. (a) Basement; (b) Street Level, (c) +2 Level; and (d) +4 to +12th Levels Floorplans 


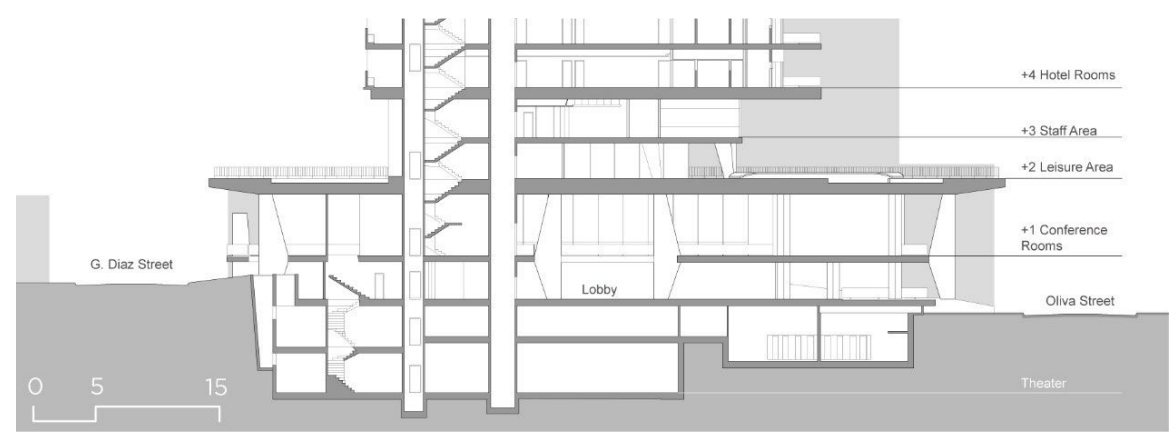

Figure 4. North-south section of the building base.

Turning now to another view of the horizontal base, Figure 4 shows a longitudinal crosssection of this component of the project. As discussed above, the horizontal base is a critical element of the project and controls the transition between the exterior and public urban space and the interior space of the hotel. The horizontal base roof is also a structural element that redistributes loads of some of the columns of the triangular-based tower to the lower levels. The base also compensates for the height difference between the G. Diaz and Oliva streets, as shown in the section. Another feature that stands out from the section is the significant length of the overhang on the four sides of the square-shaped horizontal base. This overhang creates a type of intermediate space between the street and the façade of the building, and although it is not entirely walkable, it resembles the traditional "Recova" or semi-open gallery of the colonial-times buildings in downtown Asuncion. While it is unlikely that the designers took inspiration from the colonial-style galleries, it would be safe to assume that the introduction of the overhangs as an intermediate space shows sensitivity towards the local climate ${ }^{9}$. The section also shows the use of double-height columns in the lobby, similar to those used in the perimeter. The following section will focus on other aspects of the building in relation to the surrounding Plazas.

\section{POTENTIAL REPERCUSSIONS ON SURROUNDING BUILDINGS AND THE PUBLIC SPACE}

The information in Figure 5 shows that there has been a steep rise in the number of modernist-style buildings around the Plazas since the inauguration of the Hotel Guarani in 1961. The axonometric reconstruction offers some information about $40 \%$ of the total buildings around the Plazas. Foreign architects designed most of these buildings ${ }^{10}$ and some of them-especially the Banco de la Nacion Argentina and Banco Sudameris-share some architectural features with the Hotel Guarani regarding, for example, the openness of the street level floorplan of the building in relation to the exterior urban space. Nevertheless, it is not clear if the Hotel Guarani was the actual reason these newer buildings were designed with a more open configuration in the street level, or it was instead a general trend in the

\footnotetext{
${ }^{9}$ Asuncion's climate, according to the Köppen-Geiger classification system is hot and humid.

10 Although there are buildings designed by Paraguayan architects that can be considered within the principles of modern architecture in downtown Asuncion, all of them were built after the 1970s. The first group of Paraguayan architects who graduated from the School of Architecture at the National University of Asuncion was in 1963. After this, their participation in the construction of buildings in Asuncion increased significantly.
} 
design of institutional buildings that followed the principles of the "International Style" at that time. The question remains, nevertheless, what was the actual benefit of the application of this concept to the urban space in downtown Asuncion in the late 1950s?

A possible answer to this question can be found in work done by researchers who have analyzed the significative concessions of "private space" towards urban "public space" in examples of modern architecture. The dissertation of Andrea Parga (2017), for example, investigated the work of Gordon Bunshaft at the Skidmore, Owens, and Merrill's architecture office in New York City. Parga suggest these concessions did not only have an economic reason-the buildings could be taller if they granted private space to the public space, thus more space to rentbut also an architectural intention that makes these buildings much better articulated to their surroundings and therefore "producing" a new type of-privately owned-urban space. Although we cannot draw a direct comparison between the Hotel Guarani and Bunshaft's buildings in Manhattan, we believe the Brazilian architects did not ignore the benefits of this strategy to the urban quality of their buildings and even the benefits related to climate conditioning. Later projects in Brazil by the same architects demonstrate this was a recurring strategy, especially the City Hall building in Campinas (1957) and the Legislative Assembly of the Sao Paulo State (1962).

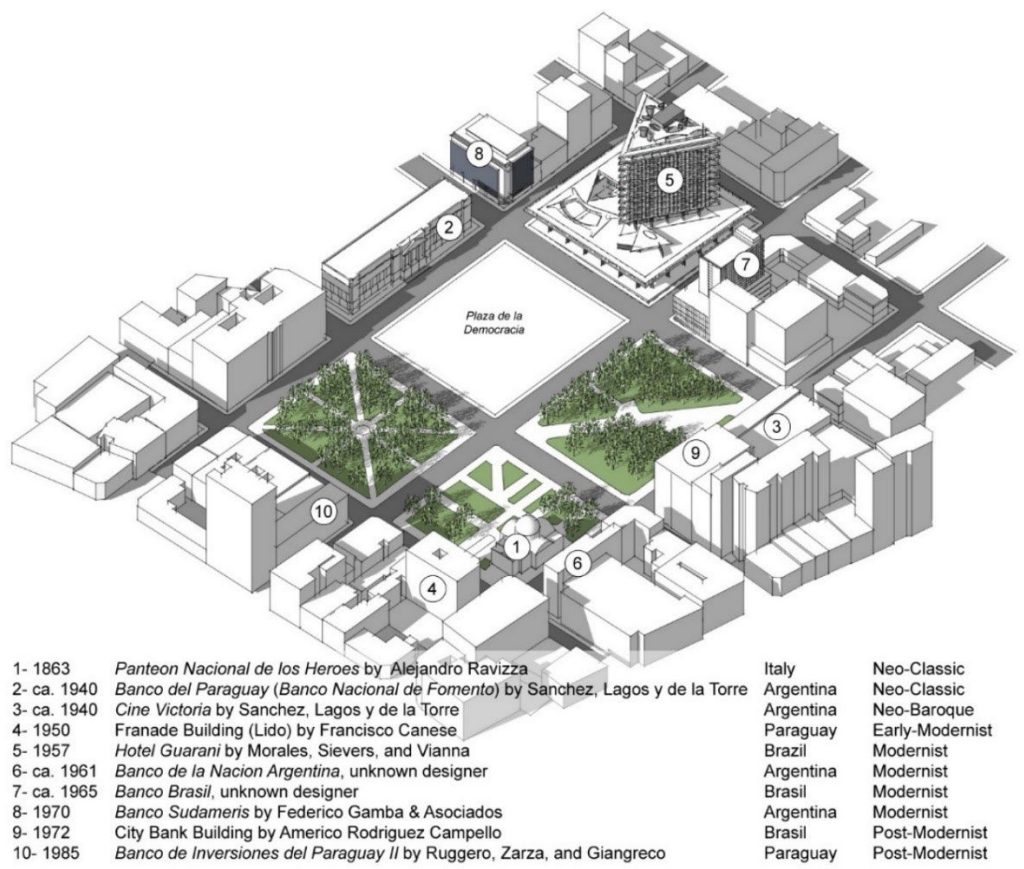

Figure 5. Axonometric view of the area of the four Plazas with the Hotel Guarani 


\section{CONCLUSION}

The present research aimed to analyze the architecture of the Hotel Guarani, with a focus on novel design strategies that defined new urban spatial relationships between the building and the city of Asuncion. Through a formal reconstruction of the project, we identified several architectural concepts such as permeable street-level floorplan, semi-public corridors, and large overhangs, that contributed to the new architectural language for the existing Paraguayan architecture. With this paper, we aim to contribute to the literature on Latin American Modern architecture, in general, and to the construction of a history of Paraguayan architecture-in particular. Furthermore, this paper presents one of the first accounts of the Hotel Guarani's architecture and the first comprehensive assessment of the Hotel Guarani's architectural features with a focus on its relationship to the urban space.

A limitation of this study is that we relied exclusively on the documents and architectural floorplans found in the archives of the Instituto de Prevision Social, and on local publications. It is hard to account for original architectural intentions and ideas behind the design of the building without having, for instance, access to documents from the competition. Furthermore, there is limited information on modern buildings built after the Hotel Guarani, to asses the impact it had in design language adopted by the subsequent generations of Paraguayan architects. However, further studies could do a formal analysis of buildings with modern traits build after the Hotel Guarani, comparing architectural features and design principles used.

A somewhat secondary but significant impact the Hotel Guarani had was the technological transfer that supposed the introduction of new materials and technologies into Paraguay's construction industry. The materials imported for the construction of the Hotel Guarani permitted the successful continuation of the works at Reidy's Colegio Experimental Paraguay-Brasil (Barrail, personal communication, December 15, 2015). In a way, the know-how of concrete construction technologies helped introduce a new set of possibilities in terms of architectural language: open floorplans, large overhangs, monumental structures, high-rise buildings, among others. Open floorplans, then, allowed designers to introduce permeability into public buildings with layers between public and private spaces. 


\section{REFERENCES}

ABC Color. 1967. "Asuncion. Piedra y Cielo." ABC Color, 1967.

Diarte, Julio. 2009. Reconstruccion Del Proyecto: Affonso Eduardo Reidy, Colegio Experimental Paraguay-Brasil (1952-65). Edited by Facultad de Arquitectura Diseno y Arte. 1st ed. San Lorenzo: FADA UNA.

---. 2015. "Confluencias Arquitectonicas Paraguay-Brasil." In Relaciones Bilaterales Paraguay-Brasil: Sociedad, Economia y Cultura, edited by Ariel Orue, 95-132. Ciudad del Este: Editorial Escuela de Postgrado - Universidad Nacional del Este.

Diarte, Julio, Claudia Fleitas, Carla Herrera, Irina Rivero, Teresa Rovira, and Carlos Sosa. 2018. ARQ MOD PY: An Exploration of the Paraguayan Architecture Between 1948 to 1985 with a Focus on Modern Architecture. Edited by Julio Diarte and Claudia Fleitas. 1st ed. San Lorenzo: CIDiFADA-UNA.

Diarte, Julio, Elena Vázquez, Claudia Fleitas, and Juan Carlos Cristaldo. 2019. "ARTURO HERREROS." AIA 49 (2): 21937. http://www.iaa.fadu.uba.ar/ojs/index. php/anales/article/view/321.

Fraser, Valerie. 2001. Building the New World: Studies in the Modern Architecture of Latin America, 1930-1960. New York: Verso.

García, María Amalia. 2014. "Hegemonies and Models of Cultural Modernization in South America: The Paraguay-Brazil Case." ArtMargins 3 (1): 28-54. https:// doi.org/10.1162/ARTM.

Gastón, Cristina. 2010. El Proyecto Moderno. Pautas de Investigación. Vol. 8. Barcelona: Universitat Politecnica de Catalunya.

Gutierrez, Ramon. 1983. Evolucion Urbanistica y Arquitectonica Del Paraguay, 1537-1911. Edited by Departamento de Historia de la Arquitectura Universidad Nacional del Nordeste. Asuncion: Ediciones Comuneros.
Insituto de Prevision Social. 1956. "Bases Hotel Guarani.Pdf." Asuncion: Instituto de Prevision Social.

Instituto de Arquitetos do Brasil - Nucleo Regional Campinas. 2015. "Prefeitura Municipal de Campinas." Inventario Patrimonial Do Bem Arquitetonico. Campinas: Instituto de Arquitetos do Brasil - Nucleo Regional Campinas. https://iabcampinas.org.br/identidadearquitetonica/prefeitura-municipal-decampinas/.

La Tribuna. 1957. "Perpectiva Del Hotel a Costruirse En Nuestra Capital Por Prevision Social," 1957.

Machado Marquez Gabriel, Raquel. 2013. "TRÊS PODERES: A ARQUITETURA CÍVICA PAULISTA, 1950-1970." In X Seminario DOCOMOMO Brasil. Curitiba: DOCOMOMO Brasil.

Morra, Cesar. 2010. "Hotel Guarani: La Marca Del Lugar." Vitruvius 33 (5).

Parga V., Andrea M. 2017. "Edificios Que Hacen Ciudad. La Arquitectura de Gordon Bunshaft Para La Gran Manzana. 1947-1967." Universidad Politecnica de Cataluña. https://doi.org/10.1017/ CBO9781107415324.004.

Rivero, Clara Irina. 2016. "Triple Alliance in Reverse." The University of Texas at Austin.

Rivero, Irina., and Rossana. Delpino. 2009. Colegio Experimental Paraguay-Brasil: Obra de Affonso Eduardo Reidy. 1st ed.

Rovira Llobera, Teresa, and Carla Herrera Milek. 2018. "Arquitectura Moderna En Latinoamerica." In ARQ MOD PY Una Exploracion de La Arquitectura de Paraguay Entre 1948 y 1985 Con Enfasis En Arquitectura Moderna, edited by Julio Diarte and Claudia Fleitas, 152-63. San Lorenzo: Facultad de Arquitectura, Diseño y Arte. 
PAPER \#3.19

\title{
THE ARCHITECTURAL SPANISH IMPRINT IN CHINA. WHY AN “ALHAMBRA-STYLE” MANSION IN SHANGHAI?
}

\author{
Álvaro Leonardo Pérez ${ }^{\mathrm{a}}$ \\ aUniversidad de Alcalá de Henares, Madrid, Spain
}

\section{ABSTRACT}

The history of an old mansion with neo-Arab Spanish style elements in the vibrant, everchanging city of Shanghai is intertwined with the lives of the two remarkable men: the sole Spanish architect in the city of his day, Abelardo Lafuente García-Rojo (Madrid 1871-Shanghai 1931) and that of Antonio Ramos, the Spanish tycoon who introduced motion pictures in China and was then known as "the king of cinema". A longforgotten story, its recent discovery reveals the interests and desires of the cultural mix that was the multinational community of what was the most open city of the continent. After launching his career in Manila, the Philippines, in 1898, Lafuente worked almost uninterruptedly in China from 1913 to 1931. Either on his own or collaborating with partners, in these almost two decades in Shanghai, Lafuente expressed himself in a variety of architectural styles. His wideranging list of clients included Jewish businessmen, bankers, Spanish tycoons, and also the most important Spanish religious missions in Asia. For ten years, Lafuente was commissioned work in several cities in China from the most renowned hotel chain in Asia, "The Hong Kong and Shanghai Hotels Limited". Furthermore, he single-handedly managed to introduce the Spanish neo-Arab style in several buildings which today are still standing in the city, although he is currently not identified as the architect. His littleknown professional career in China is a case study of the cultural melting pot of the city of Shanghai. This article aims to showcase the four buildings commissioned in Shanghai by
Antonio Ramos: two cinemas, an apartment building and last, but foremost, his Alhambrainspired summer family mansion for which he imported tiles from Spain.

\section{KEYWORDS}

Abelardo Lafuente; spanish architects in China; Shanghai; neo-Arab style; spanish tiles.

\section{INTRODUCTION}

Present day Shanghai is undoubtedly a modern, cosmopolitan and fast-paced city, one of the largest metropolises in Asia and the world with 25 million inhabitants, with urban modernizations and architectural renovations in the last decade that have progressed at a speed that Europe can't even imagine. One expects to find streets full of billboards, state-of-the-art buildings intermingled with Chinese temples, and probably maddening traffic resulting from the high population density and the various means of transport used in the country that so differ from our continent. Neither outlandish nor false, the truth is that this same description was applied to the city a hundred years ago -in 1920- in the surprising and dynamic history in the peak of the Golden Age of this metropolis, between 1907 and 1927, the two decades around which this article is centered. This urban history started seventy-eight years earlier with China's defeat in the First Opium War at the hands of the British which resulted in the 
signing of the Treaty of Nanjing in 1842. This treaty opened the city to the English, along with four other coastal cities (French 2010). Unfortunately, few are aware of the British and foreign influence on the country's most multicultural city, as a result of the British, American and French domination between 1860 (after the Second Opium War) and 1949 (with the coming to power of the Communist Party). But absolutely no one could imagine that strolling through the Hongkou neighborhood, known as the Jewish ghetto during World War II and very little exposed to foreign tourism, you may perchance come upon what could be considered the jewel of Spanish neo-classicist architecture in China, and until 2010, a forgotten part of the history of both countries. The building there located is the only still standing example of neoArabic Spanish style of the twentieth century, miraculously preserved without having been listed among the Cultural Heritage sites despite its paradigmatic uniqueness, nor having undergone any conservation works to help mitigate the passage of time. The mansion was built between 1923 and 1924 by the only Spanish architect established professionally in the city, Abelardo Lafuente García-Rojo (Madrid 1871-Shanghai 1931) for Antonio Ramos Espejo (Alhama de Granada 1878-Madrid 1944), a Spanish businessman also based in Shanghai known for laying the groundwork of the film industry in China. These Spanish adventurers and entrepreneurs made use of this fruitful professional relationship to advance on the other side of the world and to succeed in their respective disciplines as no one had ever done in China. All this happened at the dawn of a vibrant multicultural society, when, together with a small but select group of fellow Spaniards formed by members of the clergy, lawyers, businessmen, artists, writers, journalists or "pelotaris", under very adverse conditions, they managed to flourish during decades.
This article will attempt to reveal for the first time the fascinating history that intertwined the lives and careers of two of the three most influential Spaniards in Shanghai in the first half of the twentieth century. Their names are almost forgotten by history, save for a brief mention in a posthumous work of Vicente Blasco Ibáñez, volume II of "The Trip around the World of a Novelist" (Blasco 1924). In the chapter dedicated to Shanghai, Blasco refers to the two men, an architect from Madrid and a businessman from Granada who introduced cinema in China, as the cornerstones of the small Spanish population living in Shanghai. Lafuente built not only cinemas for Ramos, but also commercial properties, and his personal mansion on the outskirts of the city. In each of those buildings, Lafuente employed a style that was personal and unique for the city, with a guiding theme reminiscent of an architecture that Spain at that time exported to the world, an architecture that represented the Iberian culture in stark contrast to other European cultures of remarkable world influence. This article traces the connections between the Spanish cinema tycoon, owner of the "Ramos Amusement Company" a successful business in Shanghai, and the professional trajectory of Abelardo Lafuente. In the 1920s and 1930s, Lafuente designed many of the most sophisticated and influential sites in Asia's most cosmopolitan city, including spectacular hotels ballrooms, social clubs, banks or mansions.

Lafuente was a self-taught architect, and to date, there is no documentary proof of his university studies in either Madrid or Manila. His extensive non-formal training and experience in construction was tied to his father's career as Manila's interim municipal architect and continued until his father's death in 1900. Subsequently, he worked in the construction field in Manila for 13 years. There is no clear evidence that Lafuente was influenced by the European Beaux-Art tradition. Rather, his unique architectural designs are 
reminiscent of the eclectic and historicist style of nineteenth-century Spain. The question of how he succeeded in capturing the attention of the heterodox Jewish community, which was the wealthiest class in Shanghai, as well as the city's sparse Spanish community with his unorthodox style is an intriguing one. The answer to this question would yield insights regarding an exceptional architect with a unique career. Lafuente is particularly remarkable given his origins in Spain, a nation that was evidently retreating from the global stage at the beginning of the twentieth century. (Leonardo Pérez, 2019b)

Antonio Ramos, who would later be known in the city as the "King of the cinemas", arrived in the city in 1903 with nothing but a projector, knowing, after his stay in the Philippines, that exhibiting films in China would be an absolutely novelty. It took him several years to establish himself, but from the 1910s he controlled the entire emerging Chinese film industry with a heavy hand (Toro, 2012b). He started out projecting films, then went on to convert rented rooms into screening rooms, and eventually built the theatres. By the time he had started a chain of seven cinemas in different parts of the city with his partner -with the same last name as him-, he was even producing his own films with both foreign and Chinese actors. Together with a third Spanish partner named Goldenberg, Ramos, who was by then one of the main players in the film industry, showed some of the first American films in Shanghai. They would buy these American movies, like Charlie Chaplin's, from the black market. This was enormously profitable but also angered the American exhibitors who had wait to legally purchase the films to screen them in their theaters. Tensions in the film industry reached a fever pitch when in 1922 his partner was murdered in one of his theatres, the Olympic Theatre-Cinema. The murder was never solved. With his family now in danger, Ramos hastily left the city. These events, coupled with the social and economic unrest the city started experiencing in 1926, had Ramos decide to sell or lease all of his properties and companies in China and return to Spain as a millionaire. With the fortune made in China, Ramos settled in Madrid with his family, bought a plot on the Gran Vía and built the Rialto Theater (1930, Gran Vía, 54 Madrid). Until his death in 1944, Ramos continued working in Spain in what he knew best: the world of cinema.

The first two works we shall cover in this article were the last ones designed for Ramos in China. They were built during the five-year period in which Lafuente developed his solo professional career in the city (1919-1924) under the architectural firm called "Abelardo Lafuente G Rojo" located at 6, Kiukiang Road and then at 13, Ezra Road (Leonardo Pérez 2019a). Both the mansion and the apartment building that still bears his name were designed and built at the same time. Both were part of the only large plot that Ramos initially bought in this northern area of the city. He decided to divide the acquired plot into two parts: the part that was larger and more exposed to the main street would be for his real estate investments, and the smaller more secluded plot with a chamfered corner, would be for his family's summer residence, since the Ramos family lived in the center of the city the rest of the year.

\section{SUMMER MANSION FOR ANTONIO RAMOS (1923-1924)}

Given its relevance and formal significance in its surroundings to the north of the modern and exuberant city of Shanghai, this large mansion stands out, as it is on a street where all the affluent people of the city moved to. Far from the centre of town, on the road leading to the northern railway station, as well as to the Rifle Range, Antonio Ramos bought a large corner plot on North Szechuan Road and Darroch Road, where he intended to build a 
summer house with a remarkable peculiarity: it was to be a small replica of the Alhambra of Granada in Shanghai, as he wanted to remember his birthplace in this part of the world so far removed from his origins.

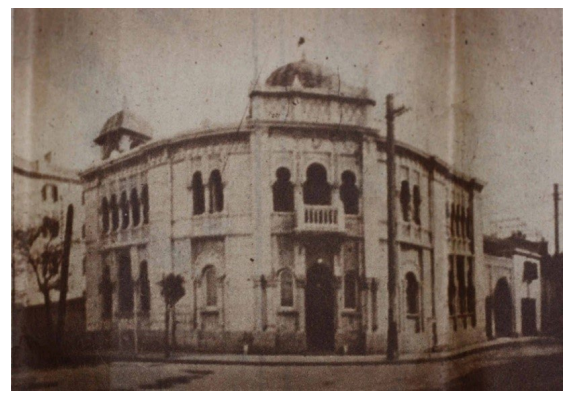

Figure 1. Ramos Summer Mansion (front view) circa 1930. Source: (Leonardo Pérez 2019 a)

Work on the mansion began in 1923. On the chamfered corner, the architect placed the main entrance giving it a unique significance on Darroch Road. The main façade was divided compositionally into three areas: in the centre, the door was flanked by two Nasrid-style columns, replicas of the Court of the Lions of the Alhambra, with remarkable ceramic spandrels (albanegas) composed of very colourful ceramic tiles of eclectic Spanish neo-Arab style. The central element of the composition was an overhanging balcony and three horseshoe arch windows. Originally, the most noteworthy element of the central body was the main dome of the house located on the stairwell that accessed the roof floor.

The second area of the main façade had a horseshoe arch on the ground floor with a simple scalloped arch, with a polylobed lintel and a polychrome ceramic tiled spandrel. On the first floor, were two windows with multifoil arches, its upper spandrels ornamented with Arabic geometric motifs of plaster.

The third area of the façade was composed on the ground floor by three narrow multifoil windows with spandrels decorated with
Arabic plaster latticework. On the first floor, there was a series of five small windows in the same style. Due to the exterior composition, we can presume that the main room was located in the center of the façade and the other rooms were behind those smaller windows.

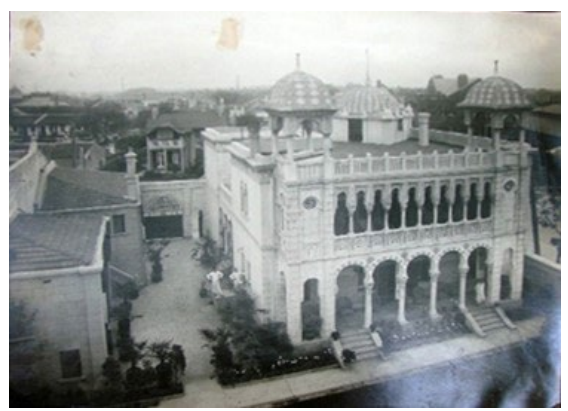

Figure 2. Ramos Summer Mansion (back viewveranda) circa 1930. Source: (Leonardo Pérez 2019 a)

The wrought iron gate where the cars or carriages entered through is located on the side of the street; to this day, 1924, the year of its inauguration, is still carved on this gate.

On the rest of the grounds, there was a private remarkably well-kept garden (according to the original photos), which served as a buffer between the mansion and the apartment building. The house was connected to the garden by five central horseshoe arches flanked by two stilted arches that served as the base of a large covered terrace on the first floor which opened to at least two of the upstairs rooms. It was framed by ten stilted arches.

The whole volume of the house was arranged around the large square Andalusian courtyard, which was closed off by a wrought iron gate and with Nasrid capitals crowning the columns such as those mentioned above. The patio was facing the side of the house opening to the entrance of the cars. Its appearance 
and use in summer can be seen in the only photograph found of its owner with his son.

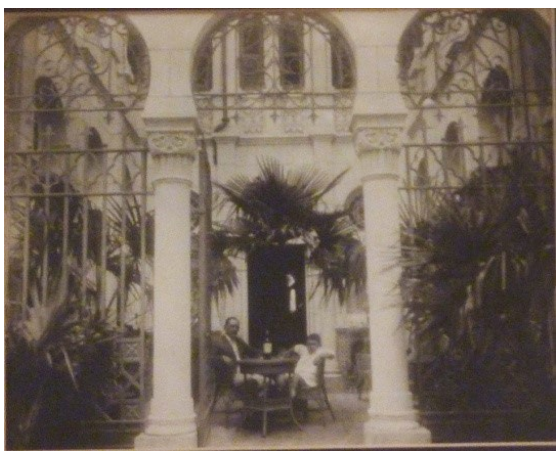

Figure 3. Ramos' Summer Mansion (back viewandalusian courtyard) circa 1930. Source: (Toro Escudero 2012 b)

As of today, the mansion is not accessible since it is inhabited by several Chinese families who moved there when the Communist Party came to power. I have been able to observe it in situ, and I can confirm that it is composed of a ground floor with a main drawing room which is now used as the common area for the families that live on both floors. I was also able to see that on the ground floor there are at least three rooms inhabited by three families. The upper floor is accessed by a marble staircase which still has its original wooden handrail carved with Moorish motifs. It ends in a corridor that has been closed off to give privacy to the families who use the four rooms on the top floor. All but one of the above rooms and bedrooms open to the Andalusian courtyard. The original mansion had a flat roof that is now in disuse. Its original domes have been lost and only the four pillars sustaining each former dome now remain as bizarre remembrance of the original shape which stood above them at the time.

In 2013 there was a disappointing attempt to restore its exterior façade by a private company which was supported by the
Hongkou district government, but all the external elements that were supposed to be recovered were instead forever damaged. Recently there have been efforts to protect heritage in China, but sadly the building has never been listed in any conservation inventory. The truth is that buildings hailing from the times of foreign domination are just now beginning to be reviewed, whereas buildings in the Bund and surrounding areas that are attractive for international tourists and offer a high economic interest, have been first on the list for proper conservation and rehabilitation.

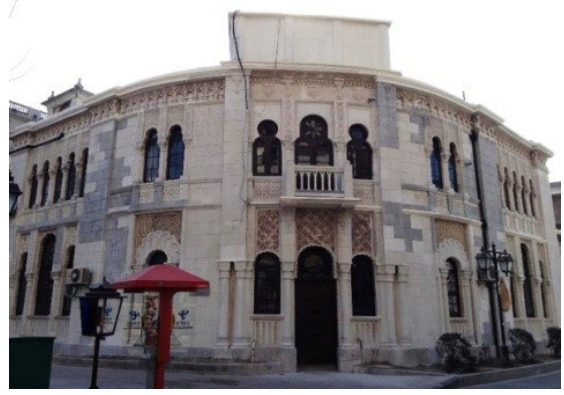

Figure 4. Ramos Summer Mansion (front view) in 2013. Source: (Leonardo Pérez 2019 a).

The study of this façade, in my opinion, should focus not only on the heterodox composition but also on the materials employed, as most of ceramic tile was certainly imported from Spain. Letters have been found that the architect sent to Francisco Valldecabres' company in Manises, Spain (addressed to Calle Pellicers 7 in Valencia).

The following is a detailed list of each area of the building in order to study the ceramic tiles used in the project. Four different decorative typologies were used in the elements of the walls, and only two in the tiling used as floorings. All of them are replicas of vegetal and decorative motifs similar to those made in the Alhambra of Granada. All of them are shown below. 
- Tile type 01: (20x20 cm)

Places where it is used: entrance hall between the two front doors. Keystones of the horseshoe arches on the eastern façade. Covered porch on the ground floor of the eastern façade.

\section{- Tile type 02: (20x20 cm)}

Places where it is used: in the three main door spandrels, on the spandrels of the horseshoe arch window with simple scalloped arch with polychrome ceramic tiled spandrel. In the decorative rhombuses between the arches of the eastern façade on the ground floor.

\section{- Tile type 03: (20x20 cm)}

Places where it is used: this tile is only used on the exterior pavement of the main courtyard of the house.
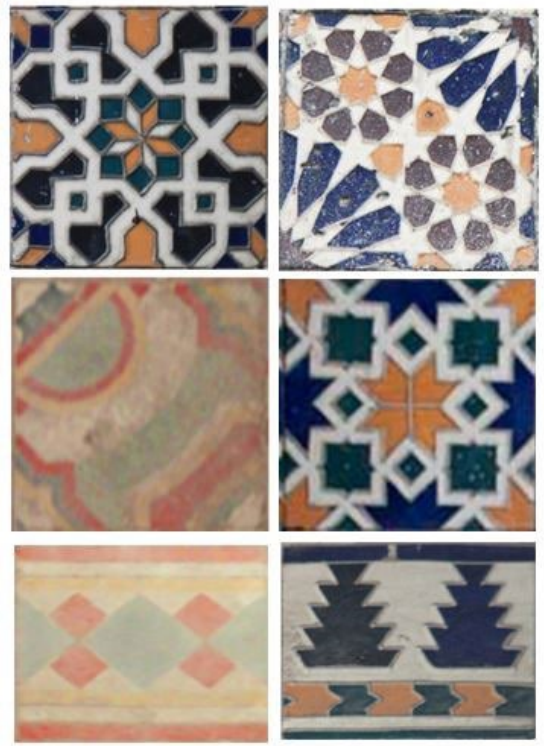

Figure 5. Spanish-made tiling currently in place at Ramos' Summer Mansion. Source: (Leonardo Pérez 2019a).
- Tile type 04: (20x20 cm)

Places where it is used: Main drawing room, exterior walls of the main courtyard.

- Tile type 05: (border 15x20 cm)

Places where it is used: this tile is only used on the exterior pavement of the main courtyard of the house and is used on the perimeter of the area of tile 03 .

- Tile type 06: (border: 15x20 cm)

Places where it is used: this tile is always associated with the place where Type 04 tile is used. Main drawing room, exterior walls of the main courtyard. It is also used together with type 01 tile on the covered porch on the ground floor of the eastern façade.

The whole ensemble of the mansion has a very striking visual effect on the visitor especially due to its surroundings: on the opposite corner there is a communist-era tower of little formal interest, and its adjacent buildings are all very similar and repetitive. This part of the Hongkou district has been intentionally left less modernized as all the mansions on Duoluon Road have been conserved and gradually rehabilitated in order to give local tourism a taste of the city's history. Despite this, there is unfortunately no plaque adequately honouring the neighbourhood's history. A plaque marking the residence of the Minister of the Kuonmitang $\mathrm{H}$. $\mathrm{H}$. Kong has been removed in order to update the information.

\section{2. "RAMOS" APARTMENT BUILDING (1923- 1924)}

This project was carried out at the same time as Ramos' summer mansion also located on the North Sichuan Road Street. It was originally an apartment building with ground floor commercial space used mainly for social clubs and shops. The building was originally divided into four stairwells, with two 
apartments per floor each. The fourth stairwell furthest to the right of the picture, next to the grounds of the mansion, is a half-floor and consequently has only one apartment per floor, although in the original plans it had two apartments like the others. There were therefore 32 apartments according to the plan, but then only 28 were built. Each apartment had a living room opening to the main façade, two rooms opening to an inner patio (very rare in Shanghai in the twenties), a dining room, a kitchen with a room for domestic service, and a single complete bathroom with bathtub, toilet and sink. They have a secondary entrance through the kitchen, which is accessed by the emergency stairway for the residents. Both the living room and the dining room have chimneys. The ground floor apartments do not have a front living room as this space is ceded to the shops. The most notable feature of this building is the introduction of the inner patio in the distribution of its storeys, an element so common in Spanish architecture but virtually unknown in China and which therefore makes it stand out on an architectural and constructive level. In China, the room shapes of high-rise residential buildings are usually designed with many corners which are reflected in stepped façades so that all rooms receive natural lighting, according to Feng shui guidelines, though inner patios which would provide lighting and airflow to the interior of the dwellings are not common. According to the building's recovered plans, it was built entirely with reinforced concrete, using isolated footing with four small piles at the bottom to enhance the grip on the terrain. The plan shows the distribution of pillars and beams, as well as the unidirectional elements of the formwork. They are all made out of a wooden platform on the in situ concrete slabs being formed by bidirectional configuration.

The composition of the elevations is classical, consisting of a base part formed by the ground floor shops openings and the original shapes generated by the still original hallway entrance

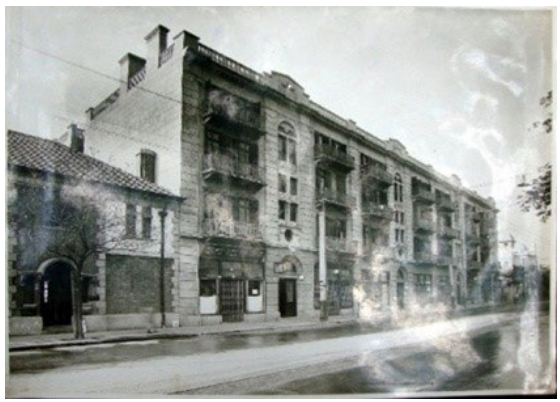

Figure 6. Ramos Apartment Building (front view) circa 1930. Source: (Leonardo Pérez 2019 a).

to the apartments, the shaft of the façade would be the wide-span lintels, with individual rectangular lintels which stand out over the rest of the decor outside of the drawing room on all the storeys. In this middle part of the façade composition, the most decorated areas are the stairwells: each window of the staircase for each floor displays a different style. The first of the windows is circular and is decorated with a large moulding.

The windows of the next floor are all square, as are those of the third floor though the latter are crowned by a glass semicircle, on the outside, both are in joint composition joined by another larger blinded semicircle. Finally, in the composition of the façade, there is a large stone balustrade and a series of gables crowning the stairwells, under which is a Greek-inspired ledge that linearly crowns that main façade. This sort of crowning was common in his neoclassical works, and therefore through their study we might be able to better determine the authorship of other works in the city that remain anonymous.

The apartment block that is preserved to this day at 2081-2093 North Sichuan Road is called "Ramos Apartments" and was composed of a ground floor plus four stories, with a later added last floor on the top of the building consequently having the premise as of today of 35 apartments. All the original elements of the top were eliminated when 
the floor was added to the building. The current maintenance of the façade and the stairwell is the minimum to preserve the main elements of the shaft of the façade. The state of the original carved wood railing of the main staircase is remarkable, as is as the the woodwork of the exterior windows of the stairwells. Many of the windows of the apartments are also original, as are the steel railings of all the outside balconies.

Unlike the previous work, its relationship with its neighbourhood is more of mimicry, as its height and volume do not greatly differ from other buildings of this part of the city. Most buildings around it are of similar dimensions, and since the section of the street is wide, it does not seem enclosed by the adjacent buildings nor drowned by its neighbours, unlike what occurs to old buildings in other parts of this city.

\section{OLYMPIC CINEMA NAMED EMBASSY)}

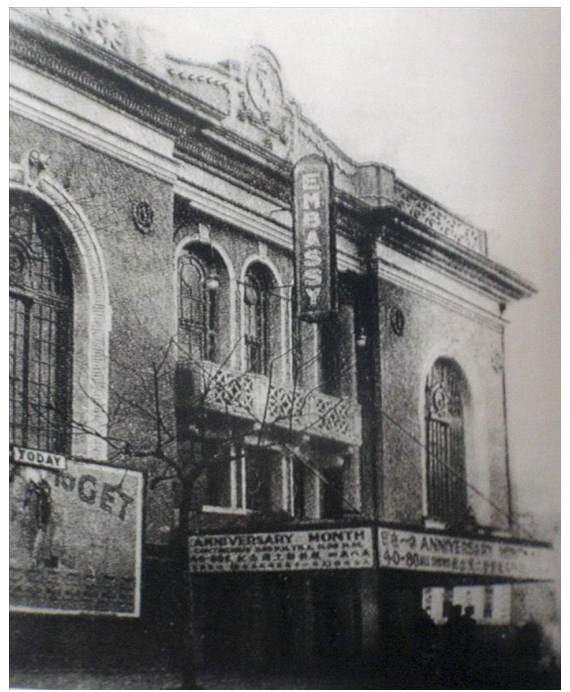

Figure 7. Olympic Cinema (front view) circa 1930. Source: (ACE 2020).
Antonio Ramos' second movie theatre in the city but first new build project, was located on one of the most important streets of the "International Settlement", specifically on 127 Bubbling Well Road -now West Nanjing Road. It was the most successful of all theatres of the "Ramos Amusement Co." not only because of the quality of the films projected there, but also because the audience was made up of the foreign upper class of the city. The "Olympic" was inaugurated in June 1914 and later in the thirties it was renamed "Embassy". There are many references to it, but I wish to draw attention to the article written regarding its construction in La Vanguardia Española (1949, p.4) under the amusing title "Un Rinconcito Español" (A little Corner of Spain), of May 6, of which an extract is reproduced below.

[...] Ramos and three of his collaborators entered the enclosure: the architect Abelardo Lafuente, who designed the plans and directed the construction of the Olympic and the Victoria, and the Martís, father and son, great artists who decorated the buildings [...] An architect of great value and who knows his worth, after proving himself in the Philippines, Lafuente moved to Shanghai to make his mark, in a place where everything was unfavourable, where there were already architects from many countries, most of them English, who counted on the strong support of their government and their fellow countrymen. [...].

In the various historical photos found we observe how the façade shows some influence of the works of Juan de Villanueva in Spain, as well as the first theatre that was built in Spain in 1820, the Vitoria Theatre.

As Silvestre Pérez did in the Vitoria Theatre, Lafuente's "Olympic" is monumentalized thanks to its block structure and the flatness of its façade, accentuated in the center with two Corinthian columns placed in-antis above 
the glass canopy, supporting a powerful and cushioned entablature, although it is not entirely visible. The intercolumnium houses on the lower part of the canopy three indented apertures in the central body and smooth parament on the sides to place the film posters at street level. That central body at the top has three small windows decorated with steel fences above the canopy, forming the compositive precedent of the large balcony finished by three thermal windows. This central piece, similarly, to Juan Villanueva's most representative works, eliminates the front as a finish, replacing it with a shield with garlands, and a great set of mouldings. The two lateral bodies are made up of a single thermal window of a much larger scale than those three of the central body described before. In what would be the spandrels of the side windows, the architect places clypes with an indistinguishable decoration. Finally, both bodies at the top have a balustrade finish.

The building plans were solved in a more organic and free manner than on the façade, employing curves both in the shape of the amphitheatre and the side boxes, something that had been already advanced by Benito Bails in his treatises in Spain. According to several press articles, both this and many other venues were at the time all made of wood, and so after several destructive fires, smoking was quickly banned inside all the city's cinemas.

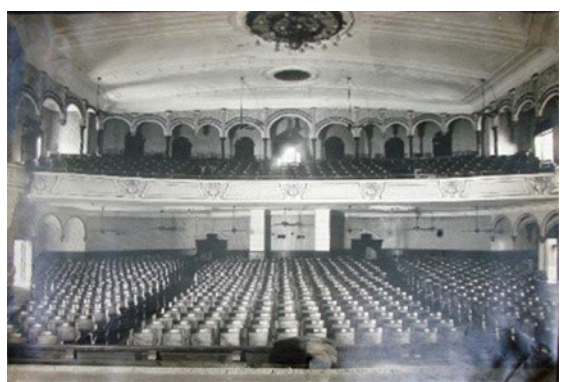

Figure 8. Olympic Cinema (interior view) circa 1930. Source: (Leonardo Pérez 2019 a)
The only existing image of the interior has been found in the original personal portfolio of the architect, and shows us a profusely decorated auditorium with half-point arches with decorative motifs that brings to mind a neo Arabic style, and the pillars' shafts painted in a dark tone with the arches in white. A large wrought-iron lamp presided over the entire space, another material that he would repeatedly use throughout his work.

In his outstanding professional career, Lafuente had a very close relationship with the city's entertainment business. In addition to working on the aforementioned venues, he designed most of the dance halls for the most important hotel company in Asia, "The Hong Kong and Shanghai Hotels Limited". Ballrooms such as the one in the "Astor House Hotel" and the largest and most imposing of all in the "Majestic Hotel" brought him such fame and recognition that even Hollywood called at his door, reason why he opened a professional studio in Los Angeles in 1927. $\mathrm{He}$ also worked on the interior renovations of more of the company's hotels, such as the "Palace Hotel" or the "Kalee Hotel" both in Shanghai. Lafuente oversaw the renovations at the "Repulse Bay Hotel" and the "Peninsula Hotel" in Hong Kong, as well as at the "Victoria Hotel" in Canton (Shameen).

Unfortunately, the "Olympic" was demolished in the late eighties to make way for yet another high-rise office tower. The only noteworthy element within the city plan is the new building's concave form, evoking the theatre that once occupied the plot. Therefore this example of a type of architecture more in accordance with what was being produced in Spain in the 19th century has been forever lost because of its economically strategic location, in a part of the city where few historical buildings were not protected in time from real estate speculation, a fate which the sites on the Bund escaped. This foreign architectural ensemble is now confronted with the spectacular, modern and iconic image of Shanghai's most representative skyline which 
originated from the urban development of the Pudong financial district in the nineties to the present day, also responsible for transforming the city of Shanghai into a global financial hub. Therefore, through this review of the three works made by Lafuente for his countryman and patron on the other side of the world, we can see the three most common ways that the old meets the new in the city of Shanghai and in China. Also, it should be noted that although from a Spanish point of view, it may seem that this developmentalism destroys all trace of the past, Shanghai is actually the city in China with the greatest number of preserved historical foreign buildings. There is an increasing awareness on behalf of the authorities who slowly begin to realize the importance of knowing about the past and conserving works that are truly worthy of such conservation and rehabilitation.

We could therefore conclude that in the rapidly evolving urbanism that China is experimenting, the chances of the old to survive are very slim, as proven by the third of the works analysed. The odds improve if the sites are not in affluent districts or ones attractive to real estate speculation as might be the case of Jingan, Huangpu, Luwan or Zhabei. By contrast, in other districts which are more committed to their history such as Xuhui or Hongkou and follow a more conservationist attitude in their architecture, survival can occur thanks to one of two different strategies: "mimicry" with the environment or "singularity" in the environment. It seems as though buildings that survive in Shanghai thanks to the second strategy are rather small-scale, and those that fit into the first strategy are usually residential and were therefore quickly inhabited by Chinese families, with no option to demolish them because it was necessary to shelter a very large population. Nevertheless the lack of training in Chinese architectural professionals in the conservation of cultural heritage in China is striking, as well as the absence of appropriate techniques for them to carry out the type of work meriting the relevant heritage that is still standing in China and Shanghai. Aesthetic and historical training on this type of construction has been almost non-existing until recently, and therefore the ways in which these buildings are "conserved" and "rehabilitated" remain in most cases "dramatic", as they have suffered almost irreparable damage, although there is room for hope in a near future, and it is therefore very necessary to let it be known. Hope should always remain, if not all these forgotten imprints from hundred years ago would never been uncovered by one person only having a first feeling in Shanghai. To become something bigger as it is nowadays it has to be supported by all the unpublished original photos, letters and newspapers luckily kept by the architect's family hope in Madrid. Note that only one of these six photos come from a public archive while the rest are from a private one.

For this reason I would like to thank the Lafuente family for their never ending support to this researcher to be able to uncover the trully remarkable story of their grandfather in China. 


\section{REFERENCES}

ACE- Archivo China-España de la Universitat Oberta de Catalunya (UOC).

"Embassy cinema," China-Spain Archive, 1800-1950, consulted on January 2020, http://ace.uoc.edu/items/show/1139

Argente, B 1949 "Un rinconcito español". Barcelona: La Vanguardia Española Newspaper, May 6 Page 4.

Blasco Ibáñez, V. 1924 "La vuelta al mundo de un novelista" Valencia: Prometeo Editorial.

French, P 2010, "The Old Shanghai. A-Z", Hong Kong: Hong Kong University Press.

Leonardo Pérez, A 2019 a "Abelardo Lafuente García-Rojo (1871-1931), un arquitecto español en China" (Madrid: Universidad Alcalá de Henares, unpublished PhD thesis)

Leonardo Pérez, A. 2019 b "Overnight at the Crossroads: Abelardo Lafuente's Architectural Legacy for 'The Hong Kong and Shanghai Hotels Ltd.' in Shanghai'. Shanghai: Built Heritage Magazine Special Issue No. 3 Volume 3.

Toro Escudero, I 2012a, "España y los españoles en el Shanghái de entreguerras" unpublished PhD thesis. Universitat Oberta Catalunya.

Toro Escudero, I 2012b, "La participación Española en los inicios del cine chino en Shanghái (1896-1937): Antonio Ramos Espejo (1878-1944)" Master's thesis. Universidad Rey Juan Carlos, Madrid. 

PAPER \#3.20

\title{
TRANSFORMATION OF A HISTORICAL AREA IN ELCHE THROUGH AN APPARENTLY INVISIBLE ARCHITECTURE
}

\author{
Antonio Maciá Mateu ${ }^{\mathrm{a}}$, Ana Mora Vitoriab \\ aUniversity of Alicante, Alicante, Spain \\ ${ }^{b}$ WOHArchitects, Elche, Spain
}

\section{ABSTRACT}

The place where the project is located has extraordinary urban conditions due to relevance of the buildings allocated in its surroundings: the Basilica of Santa María (s. $X V I I I)$, a tower which once was part of the Arabian city wall and the Park of the City of Elche (World Heritage).

When we started to work on the proposal, we asked ourselves some questions: how to act in an environment with such historical background? Should our intervention be expressed in contemporary, mimetic terms...? Do we choose, then, an architecture with or without tectonic presence?

Our main goal was, from the very beginning, to regenerate this residual area located in such an emblematic spot of the city. In order to so, we decided to design an invisible architecture that wouldn't compete with its old neighbors, and also to focus on the new vertical garden as the main architectural item of our intervention. Therefore, we built a quasi-vertical garden which hides, in its thicknes, the construction of the cafeteria, the restrooms and a storage room, leaving empty the rest of the square, ready for the terrace to appear.

The garden is a tile of $105 \mathrm{~m}^{2}$ made up of over 3000 different Mediterranean plants, some of them endemic and singular: Mirto, Hipérico, Lavanda, Carex, Tubalgha, Pennisetum or Lampranto are few of them. Thanks to its hydroponic irrigation system and the mentioned selection of plants, the use of pesticides is not required for its maintenance, what fosters natural pollination. It should be pointed out that this green wall is able to create oxygen for over 100 people, it can catch 70 tons of gases, more than 26 kilos of heavy metals and almost 14 kilos of dust in a year.

\section{KEYWORDS}

Historical environment; green city; green architecture; sustainability.

\section{INTRODUCTION}

This project starts from the need to make a vertical garden coexist with a cafeteria building in a complex urban space, since it is defined by two of the historic buildings in the city of Elche: the Basilica of Santa María and the architectural complex of "La Calahorra", all this, in the area of the Santa Isabel square. The proposal aims to merge the two needs into a single action. A vertical garden is projected and built that acquires volume to be able to house the cafeteria building inside and, therefore, acquiring the status of "invisible building". In actions of this type, it seems important to bear in mind two aspects from the beginning, on the one hand, the impact that a new construction causes in the historical surroundings of the cities, and on the other, the condition of the use of vegetation as part of the project and the positive consequences it means for the air in these environments. The use of prefabrication processes complete the developed proposal. 


\section{STARTING DATA, BACKGROUND AND HISTORICAL ENVIRONMENT}

In 2013, the Elche City Council published a list of 35 urban spaces in the city that could be transformed through the construction of kiosks or cafeterias, calling a competition for each of them. Space number 25, square of Santa Isabel, turned out to be one of the most interesting. It is an urban space, 140 $\mathrm{m}^{2}$, finished on sand and delimited by a party wall belonging to a $19^{\text {th }}$ century house. This square enjoys a privileged location, because in its immediate surroundings we find great samples of the city's heritage: the Basilica of Santa María (18th century), a tower-entrance belonging to the Arab wall of the city $\left(12^{\text {th }}\right.$ century), the Altamira Palace (original from the $15^{\text {th }}$ century), the municipal park of Elche (World Heritage) and the remains of the old $12^{\text {th }}$ century Arab palace known as "the governor's house".

For this space, the competition asked for the design of a $20 \mathrm{~m}^{2}$ built cafeteria, a terrace that covered the earth floor and a vertical garden on the party wall.

At the beginning of the proposal we asked ourselves the following questions: how to act in an environment with such historical baggage?

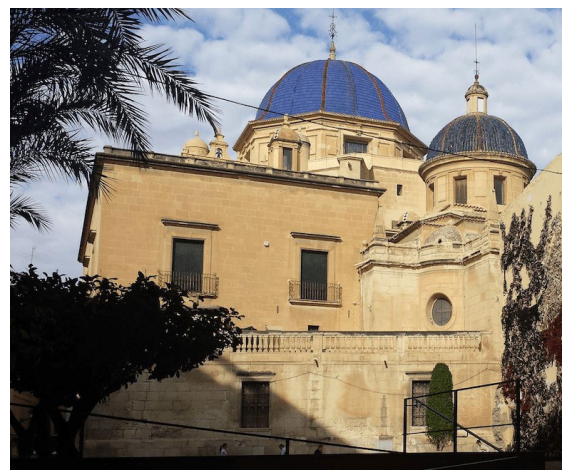

Figure 1. Basílica of Santa María (WOHArchitecure 2014)
Should our intervention be expressed in contemporary, mimetic terms ...? (Mikhaïl 1992) So, do we opt for an architecture with or without a tectonic presence? (Castrillo, 2011). The proposal opts for an invisible construction that does not compete with its neighbors of past centuries and that puts the vertical garden in the foreground of the intervention. Thus, the project ends up becoming an almost vertical garden, a garden with volume that houses the dry construction of the cafeteria, the toilets, a warehouse and the rest is terrace.

\subsection{Basílica of Santa María. sXVIII}

The first of the buildings that define the performance environment is the Minor Basilica of Santa María. It is located in the historic center of Elche, within the old walled area from the Arab period and in front of the tower that marked the entrance to the city from the northeast towards Alicante. The basilica is located on top of a previous church that, in turn, was built over a mosque and is one of the first baroque buildings in the diocese of Orihuela. "The church is the scene of the representation of the "Festa or Misteri d'Elx" every August 14 and 15, uninterruptedly since the 15th century. For many authors, this

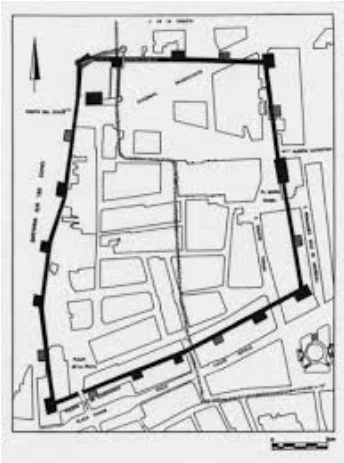

Figure 2. Medieval wall (López Seguí 2004) 
purpose is what influenced their spatial and stylistic conception. " (Guía de arquitectura de la provincia de Alicante 1999)

The basilica has a "Latin cross" plan, with four chapels on the sides of the nave, transept and ambulatory behind the presbytery. The arms of the cross are covered with semicircular vaults and the transept with a grandiose dome that every year makes a heaven (a baroque sky) for the "Misteri", hiding the aerial section. The exterior is forceful, with large smooth cloths that contrast with the reliefs on the covers. Both the dome and the large, bare and forceful cloths, that define the ambulatory are visible from the project's area of operation and make up part of the Santa Isabel square.

\subsection{Arab wall (s.XII) and the interventions of centuries XV and XIX}

The second of the buildings, which marks the environment of the performance and condition is the main tower of the medieval wall. "After numerous reforms, today there are only the remains of what was the main tower of the town's medieval wall. It is a prismatic tower with a rectangular ground plan, with the base walls stunted; the factory is made of masonry covered with mortar, with stone ashlars at the base and at the corners. The neo-Arab windows with the arches in the line of the change of plane and the semi-open vertical booklet blinds. Both these elements and the castellated brick finish are from the $19^{\text {th }}$ century. The semi-detached manor house outside the walls must have taken advantage of the villa's starch. It consists of a basement and two floors and the windows and the portal are a good example of the noble architecture of the XV-XVI s ". (Guía de arquitectura de la provincia de Alicante 1999). On the wall, houses were built that have disappeared over time to the point where there is only one from the s. XIX. Next to this house, another residential building was erected, which was demolished at the end of the $20^{\text {th }}$ century. The party wall of the house attached to the tower and the site left by the demolished house form the basis of the action, since the cafeteria and vertical garden were built on the party wall and the terrace was placed on the site as an extension of the Santa Isabel square.

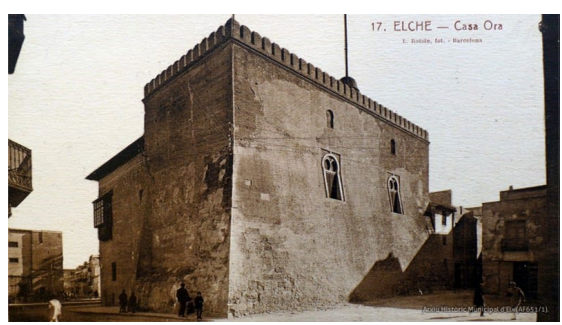

Figure 3. Tower of Calahorra (Municipal Archive of Elche 2016)

\subsection{The urban environment in the centuries $X X$ and $X X I$. Santa Isabel square}

The Plaza de Santa Isabel is the annex to the performance area and is delimited by the Basilica of Santa María, "La Calahorra" and buildings from the $20^{\text {th }}$ century. In 2004 and as a consequence of the pedestrianization of the area, a series of archaeological excavations were carried out. As a consequence of these excavations, the discovery of the remains of a $12^{\text {th }}$ century Mozarabic palace that was called the Governor's House occurred. (Amorós Fructuoso 2005). In the Amorós and Fructuoso project, the floor of the old palace was built using travertine marble blocks. The square connects with three of the most representative areas of the city of Elche: the Eucharistic Congress square, the Glorieta square and the Municipal Park 


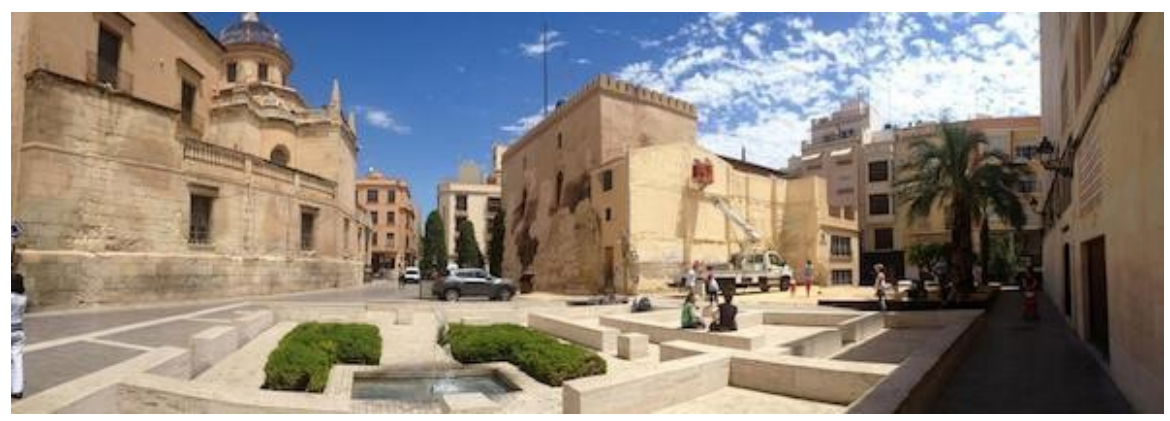

Figure 4. Santa Isabel square (WOHArchitecure 2014)

\section{PROPOSAL FOR INTERVENTION IN THE HISTORICAL CENTRE}

As explained in point 1.0, once the scope of the action has been chosen and bearing in mind the urban and historical environment where the proposal is developed, the question arises whether it should be an intervention that clearly shows a contemporary construction or not. (Heath 1996). In any case, how to intervene? With an exposed piece? Through architectural mimesis? or acting with an invisible architecture or which one of the most significant materials prevails in this beginning of the XXI century: vegetation. (Abel 2010) Initially, several intervention proposals were made, but only two were developed and one of them was built. The first one was made up of three elements: a constructed piece of $20 \mathrm{~m}^{2}$, a 100\% vertical garden (Xin xin 2011) and a terrace for tables. The second of them continue the same three pieces but developed differently. The $20 \mathrm{~m}^{2}$ building is hidden under the garden, which becomes an almost vertical garden. The terrace occupies almost the entire performance area.

\subsection{Exempt Building}

The first of the proposals consisted of designing an architectural piece of $20 \mathrm{~m}^{2}$ of extreme lightness that allowed showing the power of structural actions typical of the s. $X X I$. For this proposal, the projects of the Japanese architect Junya Ishigami were studied together with Jun Sato's laboratory for the 2008 Venice Biennale and the KAIT workshop building for the University of Tokyo. (Ishigami 2018)

The architectural piece was solved through the use of two parallel ring-shaped porticos $8 \mathrm{~m}$ long by $2.60 \mathrm{~m}$ high and separated by $2.30 \mathrm{~m}$. These porticos were designed as preflected structures in the same way as those proposed by J. Ishigami and J. Sato (Sato 2020). In the design of the porticos, a $56 \mathrm{~mm}$ counter-arrow in the central part was considered. This structure was tensioned with a $12 \mathrm{~mm}$ diameter steel bar until it recovered $80 \%$ of the counter-arrow. The structure proposed, thus, is extremely light since it resolved an $8 \mathrm{~m}$ light with only a structural tube of 100.60.8. In the thickness of $100 \mathrm{~mm}$ all the facades and roof were resolved. The proposed materials, in addition to structural steel, were aluminum and glass.

The piece houses the part of the program related to the cafeteria and was placed in the square formed by the site of the old residential building of the $\mathrm{s}$. XX that existed next to the old wall. The cafeteria was separated $3 \mathrm{~m}$ from the party wall of the s. XIX built next to the "Calahorra". In this party wall, the construction of a $100 \%$ vertical garden was 
proposed (Pérez-Urrestarazu 2015). The rest of the plaza was intended to house the outside terrace of the cafeteria occupied by tables.

This first proposal presented the alternative of showing a small building that represented contemporary technologies and materiality. The concern to contribute to the improvement of the air conditions of the immediate environment of the area of action was also shown. Therefore, it showed two of the contemporary concerns of architecture: technology and the relationship between human beings and nature. only show the new architecture through the vegetation. Try to show the relationship between contemporary architecture and concern for the environment and, therefore, show how architecture can contribute to it. In this new proposal only an almost vertical garden is shown that, which houses the construction of the cafeteria inside and that leaves, almost $100 \%$ free, the performance plot that is intended for the expansion of the Santa Isabel square and that houses the tables that form the terrace of the cafeteria. It is important to highlight how an almost invisible performance allows

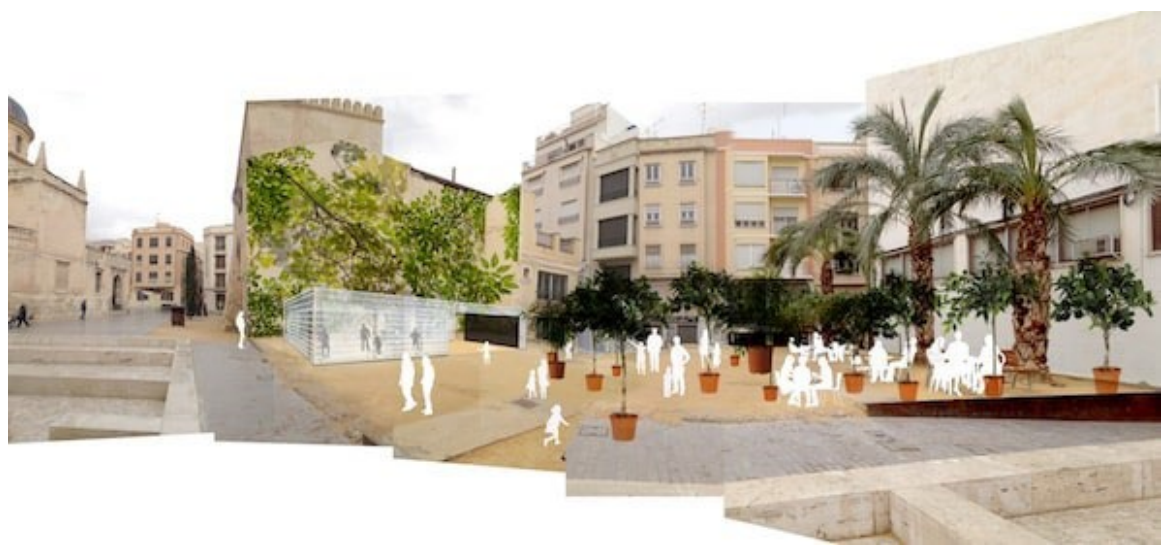

Figure 5. Proposal1. Exempt building (WOHArchitecure 2014)

\subsection{Integrated building}

The second of the proposals studied maintains the essential concerns and premises of the first one, but applied with another approach. In the first, it was shown how the proposed construction "competed" with the historical constructions of the environment. Perhaps, this first alternative was too pretentious and its modification allowed to develop the second alternative. In this new proposal, the built architecture is hidden behind a green cloak. The decision is clear: to value historical architecture and transforming an urban area. The initial site showed a somewhat abandoned area with an unmarked party wall and which, over the years, had become a "pipican". The result was not in accordance with the historical and architectural importance of the environment. The union of the intervention area with the Santa Isabel square allows a clearly recognizable urban link to be established that highlights the historical constructions that define it, in addition to serving as a connection to the important urban points of the city: Eucharistic Congress square, the Municipal Park and the Glorieta square. 


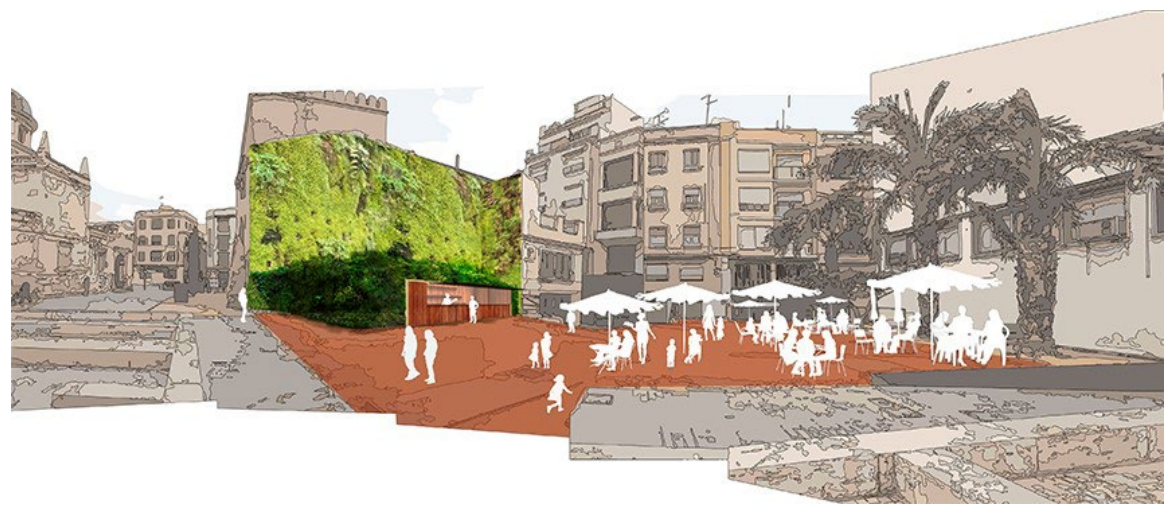

Figure 6. Proposal 2. Integrated building (WOHArchitecure 2014)

3. THE IMPORTANCE OF VEGETATION IN THE PROJECT AND ITS IMPACT ON THE NEAR URBAN ENVIRONMENT

The vegetation and the architecture have always been in contact but with more intensity today due to their quality to interact and purify the air in the environment where it is placed and to be able to create microclimates. (Ochoa de la Torre 2012)

Vegetation is also important for the role it plays in shaping and environmental quality of open spaces. It is useful as a humidifier and purifier of the environment. A tree-lined street is four times less dusty than a non-wooded one, and $150 \mathrm{~m}^{2}$ of leaves or $15 \mathrm{~m}^{2}$ of grass produce enough oxygen for ten people. " (Díaz 2005)

The data presented above gives an idea of the importance of the use of vegetation in the air quality of cities. Fortunately, the city of Elche is the fifth city in Spain in the ratio of $\mathrm{m}^{2}$ of vegetation per inhabitant.

\subsection{Effect on the city environment}

The almost vertical garden has a surface of $105 \mathrm{~m}^{2}$ and composes a vertical mosaic consisting of more than 3.000 Mediterranean plants, some endemic and unique, of high botanical value. Among all of them, it is worth mentioning the Myrtle, Hypericum, Lavender, Carex, Tulbalghia, Pennisetum or Lampranto. Thanks to its hydroponic system and said selection of species, the use of plant protection products is not necessary for its maintenance, which favors the natural action of pollinators.

The garden was completed in 2014 and after six months and after measurements made, this garden allows the following annual parameters to be achieved:

- generates the necessary oxygen for more than 100 people.

- obsorbs 70 tons of gases,

- removes $26 \mathrm{~kg}$ of heavy metals and traps 14 kilos of dust. (Solano 2014)

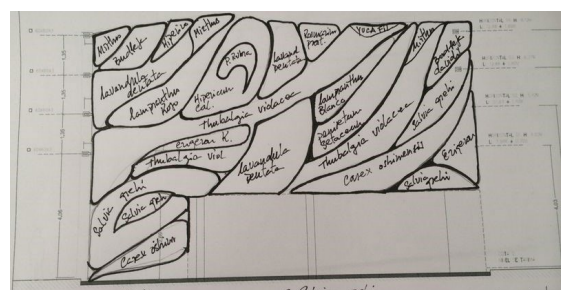

Figure 7. Plant species map (Solano 2014) 


\section{TECHNICAL DEVELOPMENT OF THE PROPOSAL}

The technical development proposal of the intervention is divided into three parts: the base structure that forms the garden, the construction of the cafeteria container and the platform that forms the terrace.

\subsection{The almost vertical garden structure}

For the construction of the garden, a triangulated structure was designed, attached to the partition consisting of square steel profiles. This structure is vertically attached to the masonry party wall and is supported on the foundation in order to define an interior space to house the prefabricated construction of the cafeteria and the rest of the garden facilities. The garden base is made up of two layers, one of $10 \mathrm{~mm}$ PVC bolted to the metal frame and the other made of a double layer of felt. Between the two layers of felt is placed the irrigation system formed by a 1 " PVC tube that soaks the felts (Solano 2014). The outer felt layer is trimmed and stapled to the PVC to form a container to place the plants.

The structural and cladding package described allows giving enough volume to the garden to be able to house the construction of the cafeteria, the toilets, the warehouse and the facilities.

\subsection{Floor plan and structural volumetry}

The container that houses the cafeteria program is intended as a prefabricated construction. Within the volume defined by the structure and envelope, described in the previous point, all the facilities that the garden needs are introduced: nutrient dispensers, filters, control of the $\mathrm{PH}$ of the irrigation water, water tanks and the cafeteria container. This piece is presented, at a constructive level, as if it was just another deposit for the garden installation and is made of fiberglass and resin. The construction of this container was carried out in a carpentry workshop and is made up of a $5 \times 5 \mathrm{~cm}$ pine wood skeleton and $19 \mathrm{~mm}$ high-density MDF boards. All this structure is covered with fiberglass and resin in the same way that they build the water tanks that the installation of the garden requires (Keller 2008). The piece was built in three parts to facilitate its transportation and assembly on site and was placed on a reinforced concrete foundation base.

The built piece, thus, contains the storage, facilities and service areas of the cafeteria, as well, as the bathrooms.
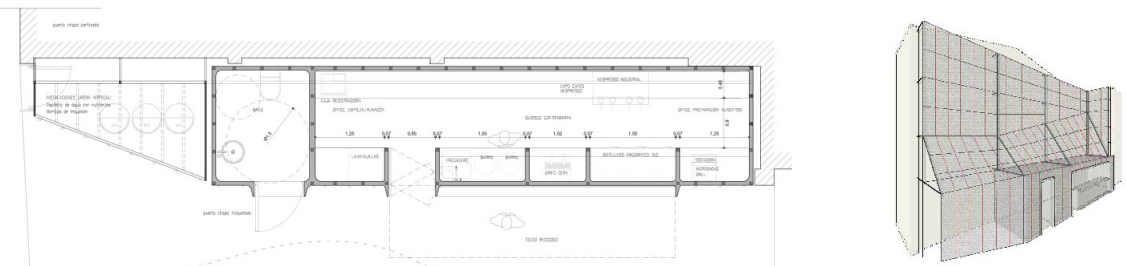

Figure 8. Floor plan and structural volumetry (WOHArchitecure 2014) 


\subsection{The terrace platform}

The platform that forms the terrace is defined by an $8 \times 8 \mathrm{~cm}$ pine wood substructure on which a series of $12 \times 2 \mathrm{~cm}$ green lacquered pine wood boards are placed. This platform contributes to the expansion of the Plaza de Santa Isabel in a staggered way due to the unevenness between the sides of the terrace.

\section{CONCLUSION}

The situation raised in this intervention and its development, allow us to draw three conclusions clearly and concretely:

1. The best way to intervene in an urban environment defined by a historical architecture is not always to display or show a construction that competes with the existing ones. It seems sensible on this occasion to be able to act and solve a program by hiding the construction and not altering the built historical environment. (Loew 1998)

2. The importance of the use of vegetation in architecture and in cities as a means, on the one hand, of showing the intentions and commitments of contemporary architecture with the environment and, on the other hand, of showing the commitment to people's health that we live in cities.

3. The importance of the constructions that plan the processes of manufacture and industrialization of architecture. For more than a century that incorporated this approach and proceed in the field of Architecture. This approach has, today, much more power given the rapid advance of the technology that we live. 


\section{REFERENCES}

Abel, 2010 "The vertical garden city: towards a new urban topology" CTBUH journal issue ॥

Amorós, Fructuoso, 2005 "Pedestrianisation of Plaza de Santa Isable, Replaceta de la Fregassa, Calle Bisbe Tormo, Calle Sant Jaume and Calle Sant Pere. Elx" ARA 05 Alicante Recent Architecture

Castrillo Romón, Jiménez Jiménez. 2011 “La práctica de la arquitectura contemporánea en las ciudades históricas españolas: notas para una aproximación históricourbanística". E-spacio.uned

Díaz, 2005 "Vegetación y calidad Ambiental de las ciudades" Arquitectura y Urbanismo Volume XXVI n:. 1

Heath, Oc, Tiesdell, 1996 "Revitalising historic Urban quarters" Routledge. Taylos and Francis Group

Ishigami, 2014. How small?, Haw vast?, How architecture growns. Hatje Cantz

Ishigami, 2017 "Another scale of Architecture" Seigensha Art Publishing

Ishigami, 2018. Freeing architecture. Ed. Fundation Cartier

Jaén, Martínez, Oliver, Sempere, Calduch, 1999. Guía de Arquitectura de la provincia de Alicante. Institute of culture Juan Gil-Albert y CTAA

Jaén, 1989. Guía de la Arquitectura y el Urbanismo en la ciudad de Elche. COACV

Jun Sato laboratory + Jun Sato engineers, official website. Accessed January 25, 2020. http://junsato.k.u-tokyo.ac.jp

Keller, Hass, Vallée, 2008 "Structural concept, design and experimental verification os a glass fiber-reinforced polimer sandwich roof" Journal of composites for contruction volume 12 issue 4

Loew. 1998 "Modern Architecture in historic cities". Routledge. Taylos and Francis Group

Mikhaill. 1992 "Original ou copie? les dilemmes de la restauration." Monuments historiques, $n^{\circ} .179$
Municipal Archive of Elche, official website. Accessed febraury 25, 2020. http://www. elche.es/archivo/

Ochoa de la Torre, 2012 "La vegetación como instrumento para el control microclimático" Politecnic University of Cataluña

Pérez-Urrestarazu, Fernández-Cañero, 2015 "Vertical greening systems and sustainable cities" Journal of urban tecnologies, volume 22 , issue 4

Solano, 2016. Definitive Guide of the Vertical Garden. Ignacio Solano Cabello

Xin-xin, 2011 "From nature to cities: Patrick Blanc's Vertical Garden" Landscape Architecture

WOHA, World Of Holistic Architecture, official website. Accessed January 25, 2020. http://antoniomacia.com/projects/ cafeteria-en-el-interior-de-un-jardinvertical/ 

PAPER \#3.21

\title{
RECUPERATION OF THE STAIRCASE SPACE OF ARMA CHRISTI SAN JERÓNIMO OF COTALBA
}

\author{
José Manuel Barrera Puigdollers ${ }^{a}$ \\ aUniversitat Politècnica de València, Valencia, Spain
}

\section{ABSTRACT}

In the structural consolidation works of the body of the Arma Christi staircase of the Monument of San Jerónimo of Cotalba, authorized by the regional Ministry, previous works are carried out on debris, removal of partitions and test pits that allow for the locating of various elements and substructures that were not previously identified. These consist of a relevant heritage and historical value in recognizing the evolution of the monument. Given the relevance of what was found, the intervention is conditioned: the most significant element to introduce, the recovery of the internal staircase to access the Renaissance doorway, the Arma Christi attributed to those who followed on from Pere Compte which was initially proposed as a mere element of use, must now adjust to the relevance of what was found and with this, adapt the intervention criteria to the narrative of the space and its discovered values. Therefore, moving from the action of mere wall and structural recovery over an era, to the recovery of a space with historical heterogeneity, requiring as a response the introduction of a staircase that dialogues with this sequence, at the same time that the historical succession itself is displayed. Moving therefore from a functional to temporary element. This allows diverse time-memory and time-semiotic devices to be used, which activate meaning and even the emergence of the interpreting invention.

\section{KEYWORDS}

Intervention; heritage; temporary devices; structure; semiotic.

\section{INTRODUCTION}

In the works followed by "Structural reinforcement of the Arma Christi staircase", significant heritage elements have been uncovered $^{1}$. Given the relevance of what was found, the intervention is conditioned: the most significant element to introduce, the recovery of the interior staircase of this disappeared space must adjust to the relevance of what was found. Its objective: the design should adapt its original material-formal criteria of the planned intervention, taking on a more diverse role displaying all of the present spacetime; turning into an element of temporary activation or temporary device instead of assigning its design to a unique or neutral abstract temporary-space representation. Additionally, this area has undergone various alterations over time and present serious pathologies, making the north and east façades to progressively detach, dragging the structure of the monastery (Alonso 1988). Therefore, the design works of the new stairwell, are treated as a temporary device, are conditioned simultaneously to the structural.

\footnotetext{
${ }^{1}$ Through resolution published in the DOGV no. 8361 of August 14th, 2018, aid is granted by Conselleria, Dirección General de Cultura y Patrimonio, to intervene in the stairwell space of the northeast corner of the BIC-Monument, San Jerónimo de Cotalba. By Decree of the Mayor's Office of the City Council of Alfauir, no. 223/2018 of October 11 th, the intervention is authorized.
} 

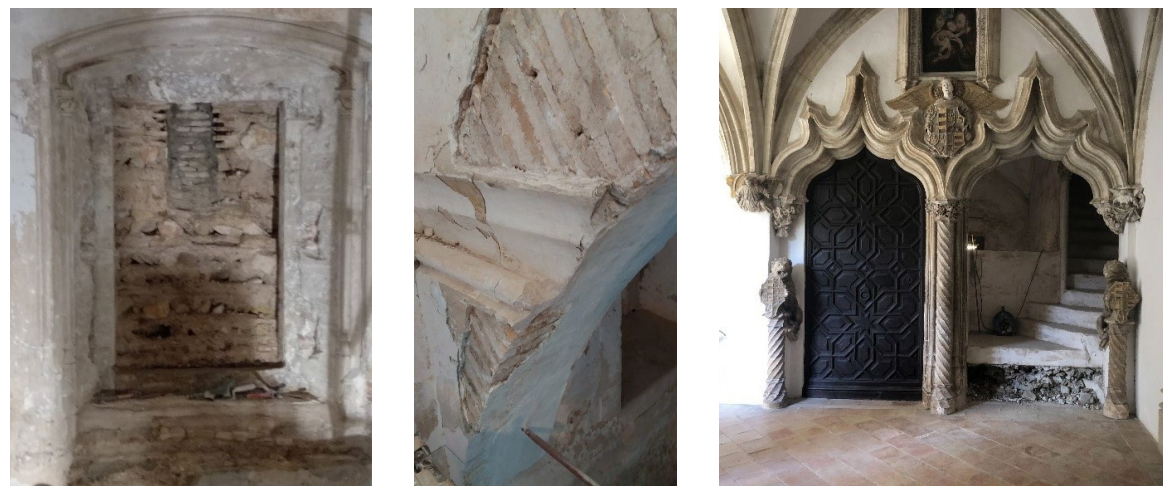

Figure 1. Partitioned façade hole after removing the painting. Springs and carved railings on walls and facade after removing the door, where the overlapped staircase can be appreciated which was later removed to reveal the lower original one. Behind it, the partition on the flamboyant railing. Source: photographs by the author.

\section{HERITAGE FINDINGS IN THE PREVIOUS ARCHAEOLOGICAL WORKS}

The appearance of the unknown original heritage elements alters the initial estimate on the value and character of this space (Arciniega 1999), requiring it to be part of the guided visits. These elements that change the marks of the intervention and design of the staircase are the following:

Behind the off-center frame facing the wall of the north façade, concealed an original Gothic opening with superior rosettes in perfect condition, small pillars that defined some tambours that have partially arrived and are carved in stone. The opening had been walled up in a previous period, with a smaller niche in the middle, perhaps to prepare for an image. Due to its offset from the axis, its size and finish, it would correspond to a definition that considered an upper reading, since it is centered with this section that reaches the first floor (Barrera 2015).
Discovered on the ground floor, at the spring of the staircase was a stone embedded in the ground, of stone tap or limestone equivalent, similar to those originally used as a carving stone, smaller than the existing hole. This makes us think that the original 1388 staircase was carved in this stone at least at its spring, and was narrower than the current opening without completely occupying it, and due to its size, very likely simpler than the renovated one next to the 1 st floor door and cloister promoted by María Enriquez. It was this intervention of 1505 that altered its longest-running configuration, taking advantage of the entire perimeter of the current stairwell, leaving marks of the carved handrail on the perimeter wall. From this, we only found three steps of the landing built into the width of the $120 \mathrm{~cm}$ wall.

The uncovered gap of the main façade, due to its typology of lowered segmental arch, corresponds to the Gothic base, built before 1485, when it was acquired by the Borja family. The carving motifs are floral, grape leaves, verifying this period. 
We uncovered two overlapping staircases ascending from the floor level to the upper floors of the cells, attached to the side wall to the east, that is partially emptied in order for it to be built-in. It was developed in only one flight with a compensating curved spring. The lower staircase is the original one. It is fairly simple in design with a clay tread and riser. Once the overlap has been eliminated, leaving the side of the wall where it supported the identifying marks for its explanation, we found the original ascending one in perfect condition and we understand the problems that led to the two overlaps. When reaching the landing at the end, there is a lower altar and two entrances: to the right through three steps you access the corridor elevated in 1630, originally Cambras. The left it is accessed through three steps, now only two since one is missing that would invade the landing (the reason for its new layout), the access step to the landing of the laundry rooms (under the current roofs of the northern cloister wing). Following its layout, ascending two more overlapping but unequal sections, up to the upper floor of cells, 4th level raised in the 18th century. This floor was raised between 1739 and 1759; some works were delayed until 1828 where there are still small finishing actions, after a brief period of secularization and abandonment of the convent. At the same time, in 1739, the decision to raise this 4 th floor to $70 \mathrm{~cm}$, is recorded, perhaps to make it flush with the height of the church. We say that the sections are not identical. While the first one adheres to the smaller stairwell over half of the east vault of the space of the staircase which no longer existents, the upper stairwell that accesses the 4th floor is made bigger occupying the space between the north walls and its inner parallel. The reason for this duality is to leave a corridor behind the first section of the staircase for another direct access from the 3rd cell corridor to the clotheslines and laundry rooms, the space under the northern roof. Dual access solution to the same space that was solved by dividing the direct accesses from the staircase that were was found later, leaving only the access through the rear hallway.

We discovered that the support systems and stabilization of the overlap of the ascending stairwell to the upper floors were not as we expected. Through the drawings made and the previous data collection, the graphic results give us a glimpse of the possibility that the staircase with two overlapping sections that saves the height of the 3rd to 4th floor, was supported by a relieving arch that arranged north-south supporting this and will transfer its weight to the two parallel walls, $120 \mathrm{~cm}$ thick. However, disassembling this overlapping flight of stairs and verifying the existence of another original below blur this reasonable hypothesis. The reality is that the described northern landing, which has two entrances, a cell corridor next to the north façade and laundry rooms next to its north façade, rests directly on the lower vault, in its northeast quarter. The rest of the sections and the perimeter staircase are supported on sand, pieces of rubble and straw which provide a filling on the lower vault, the southeast quarter, since only half of the right vault is conditioned by this load. This defines a very risky layout and gives rise to the relevant identifiable cracks. It also accounts for vertical cracks due to offsetting, torsion and loss of verticality of the guide wall for the stairs.

We uncovered a handrail -a lookout over the staircase opening, with quality flamboyant latticework, dated around the same time as the flamboyant staircase of the old refectory, today the Virgen de la Salud Chapel, as the closing of the Arma Christi portal over the stairwell space. It is accompanied by a circular pillar with a capital similar to the one on the portal, from the same era and authorship with a tambour base perfectly synchronized with original ascending steps of the Arma 
Christi portal. This indicates its simultaneous execution, around 1505-1510. This balcony is designed inside the stairwell on the outside, $40 \mathrm{~cm}$ of overhang on the design of the 120 $\mathrm{cm}$ lower wall. But we observe that this capitel did not originally reach the ribs of the current vault, but a composition that was added later. Originally it was a mullion of the bent entrance of an equivalent rail lengthways that would give access to the priory cell. The surfaces found under the side staircase and the remains of the edge vault under landing confirm it.

Design of the ascending staircase: the entire ascending staircase is arranged around an "espina" that between the ground floor and 1 st floor forms the right support of the vault and its stairwell envelope, its thickness being only $15 \mathrm{~cm}$. It is arranged roughly on the axis of the right arcade of the portal. To arrange the ascending section, it is necessary to gain space in the lateral wall, which is the inner wall of the cloister, east ambulatory, which continues north. To make this happen, it must be emptied, reducing from $120 \mathrm{~cm}$ in the cloister to $50 \mathrm{~cm}$; that is, taking away $70 \mathrm{~cm}$, to arrange the only ascending section. This reduced stonework is the one that separates from the old priory cell arranged on the old ante refectory kitchen in the extreme northeast. Today, this wall coincides with a lower diaphragm arch in PB over the silos, of the same thickness. But it can be seen shaped by the emptying of an older thicker wall, by certain signs: on the north wall and in the uncovered underground corridor. Thus the ascending section from 2 nd to 3 rd level is encased in a $15 \mathrm{~cm}$ guide wall and a $50 \mathrm{~cm}$ wall. In the section from 3rd to 4th level, the $50 \mathrm{~cm}$ wall is made up of two $10 \mathrm{~cm}$ hollow sheets filled with rubble, where the ascending staircase vault supports on the inside and is built into the outside, gaining thickness in its upper flight. This effect is worsened on the 4th floor where this wall becomes $15 \mathrm{~cm}$ again, when the interior facade-closing wall is $60 \mathrm{~cm}$. That is, reducing its width considerably and losing bearing capacity. As a result, it is necessary to replace and strap it so it can work correctly in its elevation. On the other hand, the left guide wall of that one-flight staircase, continues vertically, incorporating a staircase eye partitioned to the left, in the form of a cantilever, which forces the collapse in its width due to the lack of rigidity and excess weight in that direction. Both circumstances justify the level of breakage, torsion and collapse of this staircase, which requires strapping and bending to give it mechanical capacity.

The ascending staircase is poor in material nature and is resolved with ordinary partitioned vaults, which are in line with a time when these professions were certainly daring. Its layout was most likely redone in the 18th century, when the decision was made to raise the floor and thus giving an adequate route, from 1759 .
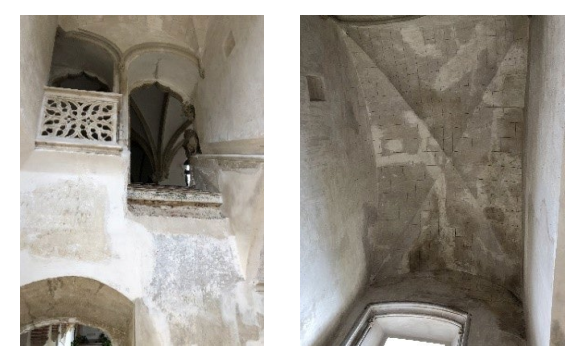
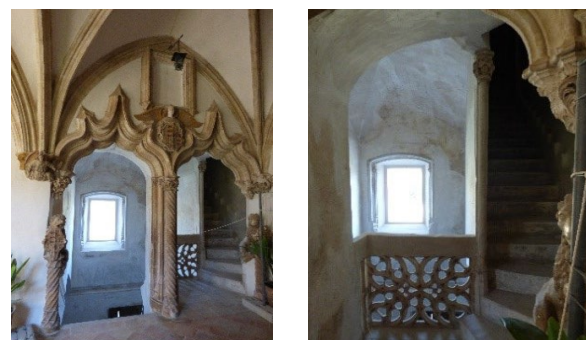

Figure 2. Images of the heritage elements found and cleaned. Source: photographs by the author. 
The lack of resources at that time would justify its finishes: It has a partitioned exterior space on the upper floor, with a semicircular upper arch, but without lateral finishes. The general partitioning of the opening of the convent is in line with the period of secularization, to avoid intrusions. The upper opening must never have been opened, since in its center there is an original battlement that has been left as a test pit, wider than the closure of the rest of the opening with which it is integrated. It must have had this lightweight configuration to reduce weight and emerge in a simple way as a staircase above the northern ambulatory roof.

The guide wall that we describe is not vertically aligned on the design of the left diaphragm arch of the stairwell, but projects into the gap, $40 \mathrm{~cm}$, like the flamboyant square viewpoint. Given its vertical development and the weight it supports, has facilitated its breakage. This effect is carried out on the support plane of the flat slab on the lower vault by sticking out brick by brick, about $3 \mathrm{~cm}$, which are then refined making a curved cup or cantilever. This is divided in a third of the north interior façade, with a displacement of $4 \mathrm{~cm}$ towards the staircase. Which requires urgent repair.

\section{CONCEPTUAL CRITERIA APPROACHES TO THE STAIRCASE}

Initially, a vaulted staircase was anticipated that recovered the original construction system, which allowed the internal and external parallel walls of this body to be braced. The state of the interior substance and the localized remains were less relevant and we did not know if their state would be finally recognized. For this reason, the staircase was functional and not relevant from a heritage perspective; that is, it did not have an impact on the authentic values. However, the previously outlined description and the findings give this space a much greater importance due to the accumulation of the remains of different space-time, whose appreciation will allow to tell its own evolution. Given this relevance and following the consolidated patrimonial discourse in these types of actions, any trace of a phase or style of construction accumulated in the extensive history of the monastery should be highlighted in its value and made known. Fortunately, there are no dualities that require declarations on one phase or another, except for the 1759 staircase that was overlapped onto the previous one from 1630, on a lookout with a railing dating 1505 . Proven that the second is
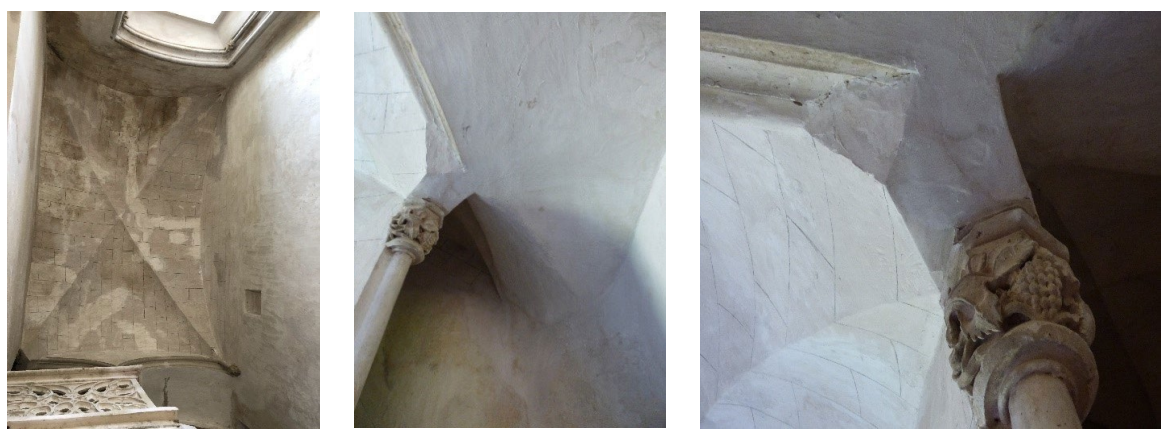

Figure 3. In the first image we see the problem in the outline the upper vault of the stair space whose edges do not coincide at the vertices. The second and third images show problems of joints and geometry posed by the incorporated mullion, originally the top or square post of the flamboyant L-shaped railing, which is strangely extended to form the start of the added ascending staircase. Source: photographs by the author. 
improper, modifying the encounter with the floor plan where the Arma Christi portal is arranged and verifying that an intervention took place to make this route more comfortable, it was dismantled leaving a mark on its side to describe its existence and its reasons. Thus, the whole body is recovered and returned to its original heritage value. But the staircase to be introduced is a current element that constitutes one more page in its history, that of 2018. From a semiotic perspective, must solve a stairs that contains the following features:

It begins a dialogue with the existing: this dialogue is as equals, without complexes, but without debt. Enough elements have been found to build such a dialogue: the first three steps to arrive at the 1st floor exist, so their tread to riser relationship is established. The height and modality of the railing is engraved on the surrounding walls, and therefore its details, geometries and characteristics are set, but interrupted. The opening of diaphragm arches, where originally there would have been walls reaching its support plane, are cut and interrupt it, with the railing appearing sectioned. There are so many lines that it is irrelevant to continue it, so as not to create conflict, but it is possible to recover its 'significant' elements in the central flight, with its staircase eye following the Gothic tradition of marking the side of the step on the thread of the vault.

The dialogue must be respectful in both directions: this will force its autonomy: different materials, different configurations, not to be touched, not even brush up against it and yet both are necessary. The surround staircase is necessary because it tells the story of its initial layout and demolition. Its changes over time speak of a noble and relevant access, and end to famine, economic needs and the return of the monastery to an agricultural production unit, typical of the 18th century. This is its part of the speech. The recovery with a current response speaks of the return of the routes, of its absence of an agricultural unit in the present day, its cataloging and its consideration as a Monument. It speaks about putting the building in value in its current conditions, regardless of the urgency and needs of another time under the opinion of the friars. It speaks about today, looking back in search of a future.

The meeting of the present and history should be a structure of limits: get close, but do not touch; they are needed, but are avoided; speeches are distributed, like a magnetic interaction. The new staircase will be light in its lateral view, of only the thickness of the step, showing constructive and technical capacity, as represented at the time by advances in stonework and production in 1505. It will have lighting around the perimeter to highlight the historical surround staircase without being able to touch it; at the $5-6 \mathrm{~cm}$ joint perimeter is left. But without being seen, hidden and indirect. Climbing the staircase leaves gaps with the diaphragm arches executed a posteriori, by enabling the trullos. These gaps do not have a railing so as not to affect the existing remains of the perimeter but they must have protection against collapsing. This protection will be made with sections of double, tempered glass held like the curtain walls by means of linear support on platen at its base and upper clamp anchored in the diaphragm intrados about two or three $\mathrm{cm}$ from its edge. This means approximately 8-9 cm of projection from the edge of the step; projecting the support steel plate marking a light perimeter void. Knowing that the staircase will have $155 \mathrm{~cm}$ of step on each side and being projected from the box of the central structure in the form of a cantilever its execution must be by means of sheet metal measuring $1.5 \mathrm{~cm}$ and $12 \times 31$ with a platen in the middle $3 \mathrm{~cm}$ for intermediate support of surface finish stone. This requires a hidden support at the outer end. For this 
reason, the seal strip in the shape of steps will be made of $1.5 \mathrm{~cm}$ and 500 steel. Being exempt, it needs a centered support: in the corridor between trullos there will be a support of $\mathrm{H}$ 100 , with bracket and fastened bracket, where it supports the cantilever that forms the central railing of the two sections. Actually supported by the two centered beam sections that extend into the plateau. Those beams will be UPN 180, arranged broken, resembling the tread and riser will leave the dark on the intrados of the staircase, with side view when ascending, so that this game of breakage recalls the usual Valencian Gothic layout, in reality resolved, on the contrary, by means of a lateral projection. Such tiered beams will receive a cantilever box projected on both sides, doubling the cantilever effect from the trampoline. The staircase is fastened on the existing brick masonry at two points: under the third step found in a high flight, carved in a wall $120 \mathrm{~cm}$ thick, carved for the support of the original vault, and at its spring on the ground floor, where it was previously attached. In this case removing the original stone from its minor spring, to show it. The trampoline beams described are not self-supporting: they need superior latticework, which must be hidden with the thickness of $12 \mathrm{~cm}$ of the original rail. As the upper handrail is visible on site, it is reproduced in metal with a diameter of 9.5 $\mathrm{cm}$ like the existing one, from where lateral collaborating plates will be welded with the same original cutting, to cover the latticework.
The prominent limitation is then evident: the central parapet on the trampoline supports the corbelled steps. A technical display equivalent to the constructive achievements of the time. It is a tribute to its risky progress, to the skills of Pere Compte and his officer, Genovés, to his contributions to complex balances. This reference is accompanied by the internal emptying that the UPN 180 profile will leave as a shadow on the intermediate ascending parapet, which in turn will be lined with a steel sheet lacquered on the outside to recover its original $12 \mathrm{~cm}$ thickness. To intensify this Gothic reference a little more, the meeting of the vertical plate with the UPN profile will be resolved with a $4 \times 6 \mathrm{~cm}$ structural tube with a thickness of $4 \mathrm{~mm}$, which will resolve the meeting and will leave an additional $2 \mathrm{~cm}$ projection, thus conforming the typical but abstract and conceptual pattern of conventional Gothic formalization.

\section{THE STAIRCASE AS A TEMPORARY DEVICE}

A temporary device is a skein or multi-linear unit made up of lines of different nature that evoke temporary dimensions. These can be shown through adhesions of social, material, phenomenological, aesthetic, psychological, environmental and hermeneutic or memory information (Deleuze 2012; Foucault 1998). Kubler refers to them as condensers of
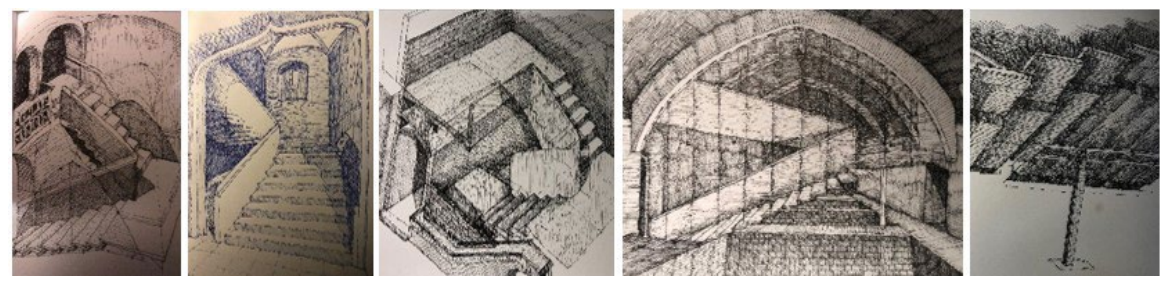

Figure 4. Evolution of the design, the drawing being the support for understanding the scope of the staircase and its implications in allowing to see the time. All temporary devices are derived and graphically tested. Source: drawings by the author. 
satisfactory and potentially active states; Buchanan, active agents of longer duration; Calvino, machines for multiplying narratives; and Derrida calls the work that integrates various devices, the producing machine. The representation of time with the intervention takes on a demanding nature, for several reasons: the narration present in the heritage values belong to historical events in time, superimposed; because all time has been relevant in the evolution of the monastery and its appropriation as we now know it; it is linked to a changing social history and because it presents an evolution of the cultural matrix; it is a melting pot of ethnography and history that is part of us. Therefore, expressing their time, in time, through time and generating time is a necessity, without forgetting that from the dialogue between the performance and design, a time yet to come can appear. The floating staircase acts like Denkbilder, "images that think" (Benjamin 2012; Kracauer 2008; Benjamin 2006); like in Erewhon by Samuel Butler, this fantasy arises from the negative view of the Darwinian theory, that allows the building of an anti-ethical world, where the concepts are treated as objects of an encounter, endlessly rise up in the successive here and now. Two characters must stand out for this; semiotic time and its display devices and memory time with their own.

\subsection{Time and semiotics}

- The metonymy part: "the sculpture staircase" for "recuperating the staircase has a structural autonomy". What is shown here is that a mark represents the seed to which it belongs. The "sculpture" mark associated with "structural autonomy" has a certain consistency and veracity. In this way we carry out a displacement of the structural through the sculptural, making a lateral shift of meaning, although metonymy maintains a certain resistance, because a new meaning is not produced. It is metonymical because a meaning always refers to another meaning or in different way, the meaning does not lie in a single signifier, but in the game between signifiers in the chain, and consequently resulting in this unstable operation. "The staircase floats", for "the staircase is inserted into its opening without affecting the test pits and carved remains on the walls from which they nourish to finally understand itself geometrically". Here a seed represents one of the marks. This set is specially forced on its glazed outer perimeter against the Gothic arches, where the lightness that forces the gaze on the central parapet is evident. "Floating sculpture" refers to the weightlessness of certain advances in designs and drawing of high Gothic arches, at the start of the Valencian Renaissance period. It refers to new materials, bold claims, operations of structural risk and assembly that we know. The temporary dimension of this device deals with the recovery of a past by 'its law', not by its form, and its open dialogue with its past characteristics. - Metaphor: 'Recovery of the lateral enclosures of pointed glass'; 'Recovery of the staircase eye as a bearing wall within the same original cut'; 'Recovery of the size of the staircase in mimetic geometry, but in metallic material discreet in its finish'; 'Recovery of the Gothic geometric lateral cut'; 'Recovery of the extrados of the broken stringer as if it were a Piranesian staircase'. All these elements seek condensation, consisting in substituting one meaning for another, creating a new meaning that replaces that one by adopting the meaning of the first. The condensations with the topic are not the same as those achieved with words since it does not break from a common language and therefore, it is always wider and more open. - Itineraries of the event: the visual route of the staircase, observing the trullos on the right, the exhibition hall, the old winery, on the left, along with the other trullos, is in itself a poetic journey that takes you to a transformed origin. The rescued facade window and the recovered flamboyant railing, take us back to the intended nobility of the predecessor of the Arma Christi portal, María Enríquez, consecutive wife of the 
two eldest sons of Pope Borgia. Memories and the passing of time are displayed, as in Ingmar Bergman's cinema, which converge and diverge in a precise place (idyllic garden, junction, corner, here the noble staircase that ascended to original priory cells) to explain the condition of the subject. This condition shows its intimate and psychological interior with the enunciating exteriority (narratives present in the peripheral material recovery). From the symbolism of the exterior, an internal introspection of the subject is carried out. "Retrospective journeys" that reconstruct memory, relating space and time, in both directions. In this, the relationship between the architectural landscape shown and time is crucial (De Lacour 2013, 59). Also presented are some "cinematographic devices" such as: - Façade window as an object device, which marks the atmospheric hours and relates to the surrounding landscape, weather, times, etc. The phenomenological resources allow giving a concept of time in the act of understanding. But they also transfer the time of its existence, in this multiple case; the recovery was necessary to dismantle three overlapping holes with different openings, until the main one with its capital sculptures is extracted. - Flamboyant railing on the upper plateau; added in 1505-1510, forming a viewpoint with two sides, of which only one remains, is also as an object device. At that time there was no access to the upper porch from this point, which was introduced in the elevation of cells over the priory in 1630, with partial ruin in 1702-1704, with placement of an octagonal prop on that date. A body that was raised again in 1734. The long side of the original flamboyant parapet served as a corner access balcony to the priory cell over the old kitchen. The intervention of the 1630 (the first elevation of cells) eliminates the long balcony and introduces a staircase, partitioning the recessed side into the hole, but without modifying the upper vault. It is 1734 , with the second expansion of cells when this staircase modifies the vault on the staircase, and on this an additional two flights are designed reaching the high cells on the 4th floor. The certainty of this route comes from having found the inner lateral capital of the right portal, buried among the remains of the missing staircase, and therefore in the latest reconstruction actions from 1759 to 1824 . Since they were partitioned, they have remained intact. This dialogue between the added staircase (whose lateral marks were kept) and the visible must reveal this temporary sequence. Its understanding is clear, if we have the capital suspended on the wall in its place of origin. - Other lighting devices: the perimeter light of the staircase arranged in the gap against walls highlights the expressionism of the footprints left by time and the reconstructive transformations of the monks successively: prints, marks, scratches, mortar patches, crevices, cleaned cracks, etc., are expressions of the roughness of the envelope. We show intentions since artificiality contrasts the natural lighting of the front hole. - Evocation devices: materials and added elements, show different times. The same color of the staircase, primed with zinc oxide, leaves a degraded whitish texture like the perimeter, but different: we understand Deleuze (2012) when he describes it as an expressionist gesture of "making a hole". As André Breton does with regard to Chirico's paintings, Mystery and melancholy in a street, 1912, "what he does is express feelings that help recognize images in the subconscious, evoking hidden ideas". Here, are the ghosts and fantasies of the interpreting subject that connect with the images recognized in the action of the route and in some visitors it will link with their pareidolia or apophenia. The devices, by forcing situations, radicalize the differences, preventing impossible repetition and highlighting the imaginary illusion. - Factography: the contribution to the constructivist epic theater contributions by B. Brecht, E. Fuchs and S. Tretiakov, bring different concepts together with Benjamin, within "the dialectic of the state of detention"; the 

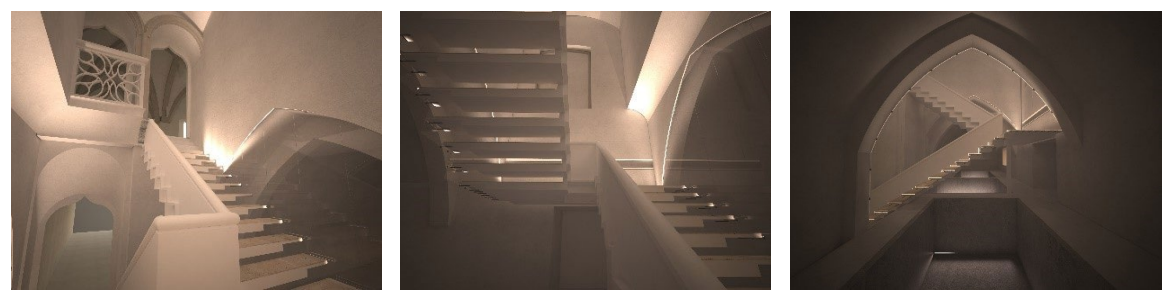

Figure 5. Digital tests of the staircase, its spaces and relationships, develop it as a temporary device. Source: drawings by author.

aesthetic fusion, the re-functionalization, the active and influential participation that coincide in a sequence of strategies: estrangement, factography, use of attractors, affirmation of authenticity. All within the following process: interruption principle, staging as ideogram, subconscious relationships, discovery of the state of affairs, exhibited value, merchandise, heterotopia or organization of the discursive mass. In this case, the following dualities: the existing and recovered old steps and the new ones; the perimeter railing embedded in the wall and cut; the lateral window facing nothing; the ascending route observing on both sides other agricultural structures forcibly introduced in times of starvation, facing an image of a closed box typical of these structures; lateral transparency when they used to be staircases between walls; the duality between visible vault and the design of the original through the recovered rosette; the supported structure facing the exempt, massive against light, stone against metal, open and transparent against closed and dark; internal plasticity carved on the mass against the external plasticity from the added.

\subsection{Time and memory}

The project is approached as an archaeological excursion, which crystallizes a symbolictheological thought, but also the political and social power of the Borgia family and the Duchy of Gandía. When it is finished it will act as an axis world, axis, or visual landmark of the cloister, that is, a symbolized part of the general object that channels the temporary reading and the opening of time-memory. There is some death evoked, figurative, and inferred in intervention, through impossible ruin; the previous one rescued, or the ruin of not seeing a clear and different time, but complex overlapping times. The design will link art and heritage. The remnants left will show the law, or what remains of it in some cases. The remains bear witness to other times, other structures that do not remain except in the imagination of the viewer who recomposes space-time. Through figurative mosaics, or irreplaceable elements that show different temporary natures, which at the same time configure aporias of their own cultural and ritual aspects, of access, travel, understanding, dialogue with the past, etc. This creates a theatrical effect that separates and distinguishes the times, those actors and the spectators, some spectators from others. But also the theatricality derived from what is produced in space and the typical acts that make up a representation of scenes proper or inappropriate for the anthropomorphic function of space, now paradoxically faced with a floating sculpture as a staircase and its dialogues. That, taken to the limit, it even constitutes a certain progressive Museumization, as the building became a container for cultural activities, when, in its history, culture derived from matter, art incorporated into stone, not from its exteriority. Especially, when culture was a set of creative displays and today culture is understood as 
"showing the way of life of contemporary society" or culture of the masses. The paradox of these encounters provides images or dialectical sequences that open the appearance of memory, and with it, the querying present, past and future. This questioning activates the circularity of time, and impels us to position ourselves interpretively in the role of the monastery in our constitution as a society. These dialogues are complemented by the ceremonial aporia or, also, functional incongruity, derived from separating its teleological and theological objective from the body, from the trampoline staircase introduced, distancing the reasons that illuminated it, its liturgy and ritual, by a modernized reading of the same, which reveals other additional questions: transparency, multiplicity, versatility, lightness, etc. The new staircase will mark a new liturgy of routes, the sequence of spaces, of additional historical readings, which will provide the viewer with more information about its character. And with it you will have a greater dimension of the memory of it. Things you never thought of before will be clarified and with it, you will understand your limitation. You need to know to understand.

\section{CONCLUSION}

The patrimonial value of what was found needs to be shown. However, alterations over time do not give credit to how it was and how it evolved. In order to explain all this from its remains, it is necessary to work with the remnants in the way that the added body of the staircase helps make what is not seen to be seen. Always together with the viewer; who must weave the apparent information, the forced, the expressive, the erased, the subtle and the imaginary reconstruction. The objective is to remove the multiple temporary elements present in the workspace, turning the staircase into a agitator of nuances, or into a complex temporary device. That at the same time clarifies; articulate the activation of time without aim. Time that, a priori, is trapped between its immobilized past and an eternal present, in the case of having designed a functional neutral element without a stylistic character, as the law prevents. The activation of time, the reflection on possible sequences, even the opening of a possible future, challenges the present technical predominance and the utilitarian logics placed in society. Thus allowing another scope or understanding of other criteria, as well as the re-functionalization of history. The definition of the device followed is equivalent to the process of symbolizing language, here rehearsed its entire unfolding through the drawing, avoiding contradictions against fact. This reflection of language supports a certain semiotics of time. 


\section{REFERENCES}

Alonso López, J.E. 1988. Sant Jeroni de Cotalba: desintegració feudal i vida monàstica (segles XVIII-XIX). Gandía: C.E.I.C. Alfons el Vell.

Arciniega García, L. 1999. «Santa María de la Murta (Alzira): artífices, comitentes y la damnatio memoriae de Don Diego Vich». In La Orden de San Jerónimo y sus monasterios. Actas del Simposio, 1-5, IX, 1999: 269-292. San Lorenzo del Escorial.

Barrera Puigdollers, J. M. 2015. Plan Especial de Protección del Monasterio de San Jerónimo de Cotalba. Valencia: unpublished.

Barrera Puigdollers, J. M. 2018. «S. Jerónimo de Cotalba. Strategies for the preservation of the monastic complex». In Vernacular and Earthen Architecture: Conservation and Sustainability. London: CRC Press/ Balkema.

Benjamin, W. 2006. Obras I/1. Madrid: Abada editores.

Benjamin, W. 2012. Denkbilder: Imágenes que piensan. Madrid: Abada editores.

Campos y Fernández de Sevilla, F. J. 2008. «Los reyes de España y la Orden de San Jerónimo en los siglos XV-XV|». In Carlos $\checkmark$ en Yuste. Muerte y gloria eterna, 113143. Madrid: Patrimonio Nacional.

Castillo, Franscisco. 1757. Historia General de Nuestro Real Monasterio de San Gerónimo de Gandía. Gandía: Inédito.

De Lacour, R. 2013. «Smultronstället, el paisaje de la memoria». In Arquitectura y el tiempo. Madrid: Abada editores.

Deleuze, G. 2002. Diferencia y repetición. Buenos Aires: Amorrotu.

Deleuze, G. and Tiqqun. 2012. Contribución a la guerra en curso. Madrid: Errata Naturae.

Delicado Martínez, F.J. and Ballester Hermán, C. 2000. «El monasterio de Cotalba (Gandía), una fundación jerónima del siglo XIV». In Ars longa: cuadernos de arte, no. 9-10, 73-86. Valencia: Universitat de València.
Foucault, M. 1998. Las palabras y las cosas. Madrid: Siglo XXI Editores.

Kracauer, S. 2008. El ornamento de la masa. Barcelona: Gedisa.

López Martínez, F. J. 1999. «Tapias y tapiales». In Loggia, Arquitectura \& Restauración, no. 8, 74-89. Valencia: Universidad Politécnica de Valencia.

López-Yarto Elizalde, A., Mateo Gómez, A. and Ruiz Hernando, J. 1995. «El monasterio jerónimo de Santa María de la Murta (Valencia)». In Ars longa, no. 6, 17-23. Valencia: Universitat de València.

Mut Oltra, F. and Palmer Terrades, V. 1999. Real Monasterio de San Jerónimo de Cotalba. Gandía: F. Mut.

Osset Merle, J. 1927. «Lo rei Felip II visita el monestir de San Jeroni de Gandía». In Cultura Valenciana, no. 2, 59-63.

Perles Martí, F.G. 1988. El Monasterio de San Jerónimo de Cotalba de Gandía. Gandía: Revista Vall de Bairén.

Ruiz Hernando, J.A. 1997. Los monasterios jerónimos españoles. Segovia: Caja Segovia, Obra Social y Cultural.

Sigüenza, J. 1600. Historia de la Orden de San Gerónimo. Madrid: Imprenta Real.

Sucias Aparicio, P. 1907. Los monasterios del Reino de Valencia. Estudios de las fundaciones de los monasterios del antiguo reino, desde sus primeros tiempos hasta la exclaustración. 


\title{
PAPER \#3.22
}

\section{WORKSPACES EVOLUTION, TOWARDS THE NEW COWORKING SPACES}

\author{
Alicia Llorca Ponce ${ }^{a}$, Franca Cracogna ${ }^{a}$ \\ aUniversitat Politècnica de Valencia, Spain
}

\section{ABSTRACT}

Several criteria have led the design of administrative spaces throughout time; this paper explores these rules from the origin of offices down to the recent appearance of coworking spaces. Our intention is to make progress in the knowledge of the aspects that should be kept in mind when designing the office of the future. Workspaces are created from the needs derived from productive activities and from the different tasks required. By the analysis of the literature over the history, we conclude that, in the course of time, offices have undergone a constant change guided by the search of productivity and have also been persuaded by the promotion of the corporate image and its firm. Among the factors that have influenced the office design, without a doubt, the technological advances that have sped up since the end of the twentieth century with the incorporation of the information and communication technologies have been key both in workspaces design and daily life activities. The creation of thoughtful and different spaces that consider teamwork, user comfort, exchange, community life and freedom of movement that develop meetings and facilitates creativity and synergies is required. The change in the way of working and, especially, in the characteristics of the tasks to be carried out, have conditioned the unstoppable evolution of workspaces and it could be said that it is difficult to find a list of criteria to follow to ensure the success of a type of offices because each company and activity requires different conditions.

\section{KEYWORDS}

Real estate market; office space; office design; co-working.

\section{INTRODUCTION}

Workspaces have been transformed throughout history. The changes in the way of working and also in the needs and lifestyles of the workers have been the driving forces of these transformations in office spaces (Harris, 2015). These things, in turn, have witnessed several changes that have been sped up during the last decades, but it is true that there are also a lot of workspaces that are still heirs of the past. To be able to understand and adapt to the current affairs and the future of administrative spaces it is interesting to analyse the evolution of workspaces in the last century and the events that have conditioned its transformations. This article begins by describing the evolution of offices from its origins to the latest developments and proposals opening the way to tackle other interesting and relevant aspects of actual and future office design.

\section{CHANGE FACTORS. EVOLUTION OF WORKSPACES}

First historical evidences of spaces where administrative tasks were carried refers us to the Sumerians and Ancient Egypt. Already in the fifteenth century Francesco di Giorgio established the bases of what could 
be considered a prototype of the modern office in his treatise "Casa degli Officiali" ${ }^{1}$. He pointed out that all the rooms of this office prototype must flow around an open atrium with a single entrance. In 1560 the Uffizi Gallery was built, which is considered the first office building of the modern age and an archetype of many others. Two centuries later with the start of the industrial revolution on Great Britain, a radical transformation of the production methods took place, an increment of specialization and division of tasks and a significant increase in administrative. Centuries later, the development of the information and communication technologies, will mean new radical changes on the way of work. The industrial revolution makes possible the appearance of new studies that focus on the optimization of process as Taylor's research reaching its highest point with the publication in 1911 of the Principles of Scientific Management. Taylorism looked for a productivity increase by proposing a hierarchical organization of work where the business management takes the strategical decisions and divides the tasks between the workers. Leffingwell was a Taylor disciple who centred his investigation on the administrative work and publishes in 1917 his book Scientific Office Management and then, in 1925 a manual called Office Management. The objective of this manual is to rationalise the movement of office work and applied, it entailed a constant control over the workers and their job. Years later, during the Great Depression the approaches of the human relations movement began to gain strength, which culminates with Elton Mayo's work, The Human Problems of an Industrial Civilization, where he questions Taylor's vision. In the 1960s, the work of Douglas Mcgregor is published with a theory called " $Y$ Theory" that is positioned against Taylorism that is associated with "X Theory". Y Theory defends that the management should be opened to the individual recognition and to the stimulation of workers to reach their goals instead of supervising them. Then, from the $80 \mathrm{~s}$, the development of computers entails a new transformation that will free the workers from many tasks and also allow them to focus on creative tasks, with this emerges a new class of workers, the knowledge workers, those who will be the most important resource of the companies. At the same time appears a new theory, the "Z Theory" by Ouchi, (Saval 2014). it was inspired by the Japanese models and proposes horizontal and flexible organizations with capacity to adapt to changes.

In addition to the organization types, technological advances allow and inspire new office designs. By the 50s and the 60s the General Office or Bull Pen appears, based on the cellular office which consist on an open floor where the workers are in the center and the executives in the perimeter. Years later the Open Plan Office rises, another open floor design that allows workers communication. In Europe, after decades without new proposals, appears in Germany in the year 1958 the Bürolandschaft translated as the Office Landscape, a more organic and natural design which offers more flexibility and adaptation but also noise and more distractions. Continuing with the office layouts, in 1964 is presented the Action Office by Herman Miller and Robert Prost, a furniture design where the worker is the main object. Its creators, ahead of their time, claim that the role of the worker will change and that the repetitive work was being replaced by the "knowledge work", they think that the office is a thinking place. Modularity and flexibility should help adapt the spaces and anticipate to new changes. Action Office was well received by theorists, but it wasn't delivered because of its high price (Saval 2014). They created later the Action Office /I which was related with System Furniture, adopted by the Open Plan Office and defended by the Modern Movement.

After the second half of the 80s the United States and Europe started to follow different paths. In Europe, the oil crisis shows that open concepts were no longer profitable; workers 
wanted more privacy, and, in this period, a pathology known as Sick Building Syndrome (SBS) appears. Office landscape wasn't valid anymore, so new designs that give answer to the objective of having open offices but maintaining the workers privacy appears. On the other hand, on the United States the Open Plan evolved to the Cube Farm. From the latest 80s, personal computers and digital technology development give rise to new ways of working and needs because of that many workspaces design became obsolete.

\section{CHALLENGES OF WORKSPACES. DESIGN AND PRODUCTIVITY}

The most important challenge of the companies of the 21st century is the need of continuous innovation to maintain it activity. Being competitive requires the creation of new products and adapting to a continuously changing market. More flexible spaces with higher connection are required (Harris, 2015). It is imperative to provide spaces for workgroups rather than hierarchy especially in sectors related to digital and knowledge
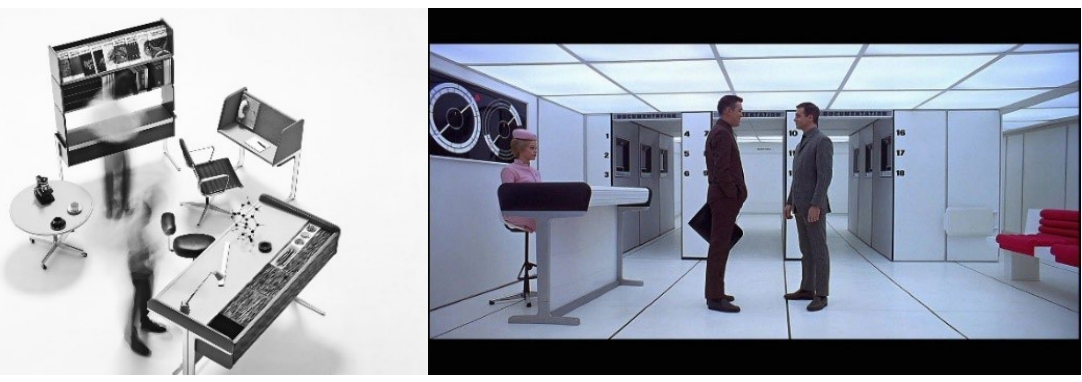

Figure 1. Action Office by Robert Prost and Action Office desk in the film 2001 a Space Odyssey. Concept by Robert Prost and Design by George Nelson. Source:Fist Image recovered from https://www.wired.com/2014/04/ how-offices-accidentally-became-hellish-cubicle-farms/. Second Image recovered from: https://www.decorsed. com/2001-a-space-odyssey/
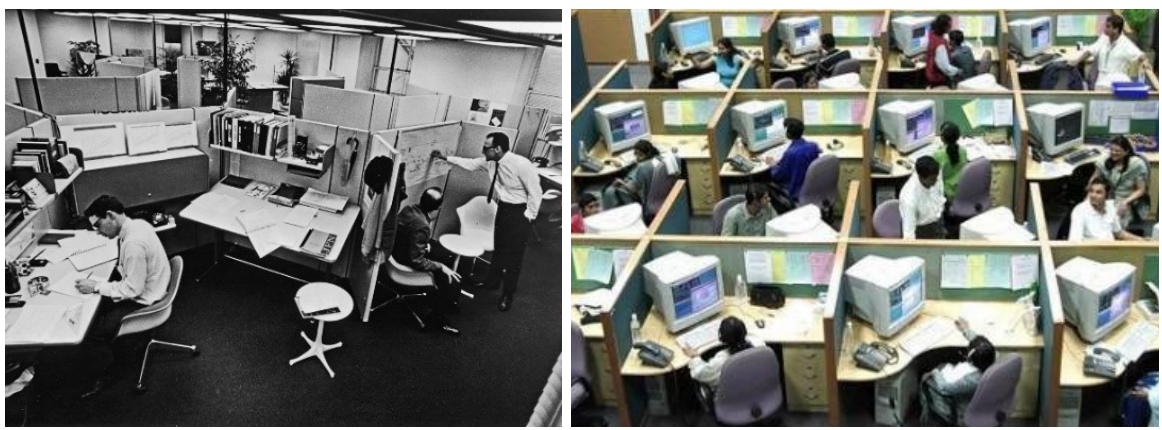

Figure 2. Action Office II and the evolution of Action Office II, the cubicle. Source Firs Image recovered from: https://www.dezeen.com/2015/02/01/office-cubicle-50th-birthday- herman-miller-robert-propst/. Second Image recovered from: http://www.mikanet.com/museum/item.php?item=2010 
economy; office is a place for workers to collaborate developing ideas, strategies and solutions. In offices designed for today and the future the workspace is considered as a hub, it is a network where workers share knowledge and collaboration (Harris, 2015). Nowadays the new context of work allows more flexibility and autonomy to the workers. With that appears the Agile Working which says that work is a task, so it is not tied to a place. This philosophy allows a cost reduction in companies and has a positive effect over sustainability reducing trips and energy waste. There are also some disadvantages, recent studies demonstrate that higher levels of innovation are produced when there is interaction between team members, so it is not a surprise that in some cases remote working leads to less incomes and productivity. Face to face is the most valuable way of communication, (Pentland, 2012; Waber, 2014), ${ }^{2}$ casual meetings between workers improve the results. And while ideas can emerge in social places, it is really in workplaces where they are shaped and become real.

Related to Agile Working, a new concept of colocation appears, to refer to those workers that do not always occupy the same workplace. If part of the employees or part of the time is worked remotely, the space per worker is reduced and if workers occupy different places each day there will be more communication, making knowledge flow to favor innovation. In the past, private offices and cubicles were the most common type of room in workspaces, but nowadays collaborative spaces where knowledge and ideas can flow are needed.

Collaboration, creativity and communication are needed as well as concentration, privacy, contemplation or relax in actual office designs. It means, diversity of spaces is required. (Harris, 2015).

Beyond organizational issues and the tasks to carry out, workspaces should attract and keep the staff. In companies where talent is the fundamental source of productivity this idea is primordial. Today's workers consider that work is only a part of their life, so having different spaces to practice sport, eat healthy or take a break to have a balanced life is valued, especially in non-traditional sectors. Silicon Valley companies were the first adopting this vision in their designs. With that, Active Design concept emerged, outlining that offices should offer more active and collaborative spaces as well as other quieter or different as well as bicycle parking or changing rooms (World Green Building Council, 2014).

From here on, we are going to analyze how performance and productivity are conditioned by design. There are two key points, on one hand, the ergonomics and, on the other hand, the flow of the workers (Riaz, Shoaib \& Sarfraz, 2017). Productivity is influenced by design because it affects your concentration capacity, efficiency, creativity or idea generation. Design should contemplate environmental sustainability, workers health and productivity, which is also affected by workplace comfort. Following the 2014 World Green Building Council these last two elements are specially influenced by indoor air quality, thermal and visual comfort (daylighting and lighting), noise and office layout.

\section{Indoor air quality}

Air quality is based on ventilation indices, pollutants and $\mathrm{CO} 2$ concentration. Studies affirm that productivity could be increased between 8 and 11 per cent with air quality improvements, (Loftness, Hartkopf \& Gurtekin, 2013). On the contrary, studies state that poor air quality and elevated temperatures diminish efficiency, (Anderson 2006). Good ventilation helps to reduce malaises; therefore, sick leave diminishes too, and it is beneficial for workers health and companies' productivity (Milton, Glencross \& Walters, 2000). High CO2 emissions cause fatigue and affect to decision making. Covid-19 is an actual 
proof of the importance and impact of good ventilation over health and companies' sustainability. As Daisey (2013) indicates, increasing the ventilation ratio and reducing polluted air concentration -computer systems and building occupants being the principal sources- are needed to improve air quality. A good natural ventilation system in office spaces will be a benefit for workers health and for companies because it entails an increase in efficiency and in savings from reduction in energy consumption (Borgeson \& Brager, 2011)

\section{Thermal comfort}

Thermal comfort has a positive effect over workers satisfaction and productivity, and it is influenced by six factors. Four of this factors are related to work environment, such as air temperature, mean radiant temperature, air relative humidity and air velocity; the other two are related to personal factors, they are human metabolic rates and insulation through clothing (Katafygiotou \& Serghides, 2014). All these factors and local weather must be considered in building design to create satisfactory office spaces.

\section{Visual comfort}

As previously mentioned, well-being, productivity and efficiency are benefited by visual comfort among other parameters, furniture and lighting being the most important elements that affect both workers' performance and health, (Riaz, Shoaib \&Sarfraz, 2017). ${ }^{3}$ Visual comfort depends on some design parameters such as lighting conditions and views. The access to natural light and the artificial lighting quality to avoid blinding is also significant. As Al horr (2016) notes quoting Mac Nicholl and Lewis (2014) work, "geometry of windows, photometry of surfaces, amount of glazing, etc., all have an impact on the illumination levels in a work area". Regarding exterior views, proximity to windows and green spaces have positive effects over productivity too, (Newsham, 2008). Prioritising natural lighting is making a bet where both occupants and company wins; workers have higher satisfaction levels and the company could save costs.

\section{Noise}

Large number of research papers and studies consider that employees' productivity and efficiency is negatively influenced by noise because they could cause frustration, high stress levels or bad concentration (Leather et al. 2003; Seddigh et al. 2014; Witterseh et al., 2004). Some studies reveal that there are beneficial noises too, such as background sounds or lower intensity noises (Danielsson, 2015).

\section{Office layout}

According to actual researches workers have different points of view about the factors that could affect comfort or productivity depending on their office layout. On one hand, the enclosed private offices occupants consider that this type has positive impact on productivity because it avoids distractions. But, on the other hand, Open Plans occupants think that this kind of layout has negative effects because there are more interruptions or distractions, (Al horr, 2016), but they also recognize that there is an increase of productivity bounded to the access to informal meeting points and connections between employees. Special mention on this point to the importance of spaces that invite to healthy life as Active Design, mentioned previously, suggests.

Privacy versus interaction and communication People need concentration to carry out certain activities, so they need spaces with no distractions. In contrast, activities related to innovation have better results on spaces that encourage teamwork, where communication and discussions are fundamental. In 
this regard, refreshment spaces play an important role, but sometimes they could be considered as a distraction (Haynes, 2017). Placing refreshment spaces where they cannot interrupt or distract other workers is something to consider during the design period. Another important factor is the use of printers, photocopiers or kitchens could be used to foment interaction on workspaces (Haynes et al 2007; Gladwell, 2000; Dobson \& Suckley, 2015).

\section{THE FUTURE OFFICE}

According to Myerson and Ross (2003) proposal, the $21^{\text {st }}$ century office has evolved into four key themes: Narrative, Nodal, Neighborly and Nomadic office. Narrative office expresses the firm personality and principles, giving visual incentives to the workers. Nodal office works as a knowledge exchange platform, betting on flexibility and promoting multidisciplinary projects. Neighborly office intends to put an end to hierarchical organization bringing workers closer and creating a cooperation and engaging environment. This type of workspace counts on different types of engaging spaces such as cafeterias, open areas and meeting points. Nomadic office describes workspaces located on buildings or places that are not designed specifically for working but have amenities too, such as airports or coworking. All these types of offices converge on the disassociation of office and workers empowered by digital technology to be connected all the time and everywhere.

Telecommuting has been greatly intensified recently with Covid-19 pandemic; this is possible thanks to the new technologies. Reduction of commuting time and cost or the possibility to balance work and other activities are some of the advantages of teleworking. By contrast, workers isolation and the loss of control over employees are negative factors of this type. Public buildings such as cafés or libraries could function as workspaces, this is the Flex Office, which is defined by Van Meel (2015) as an intermediate typology between the Nomadic and Nodal office of Myerson and Ross joining the Nonterritorial Office of Chiat. Coworking, a typology that fits well on the nomadic office of Myerson and Ross (2003), is a place where entrepreneurs, freelancers, SMEs and start-ups share spaces, creating synergies. It is born as an alternative for telecommuting or Home Office (Klauck, 2005), avoiding the isolation of working from home and offering amenities like an office. These spaces emerge to answer the needs derived from the new working methods, the new creative economy and the new information technologies. The creation of collaboration and community between users obtaining synergies is the main idea of coworking spaces.

The development of coworking spaces is accelerated by the economic difficulties from the 2007 crisis. Due to staff reduction in companies, many workers had to start their own business finding in coworking spaces great amenities as internet connection, IT services and flexible spaces. Serendipity and synergies occur thanks to coworking (Messina, 2007), professionals could find partners, clients and new ideas to make their business rise, productivity boost and their business network expansion. To ensure user's continuity, coworking owners try to facilitate their work and concentration and they also offer several services such as legal and economic consulting, training, workshops or mail service. 


\section{CONCLUSION}

Workspaces have changed and evolved due to social progress and production activities changes influenced by technological advances. Office spaces had to adapt to new processes and technology. At present, the worker is considered an intellect strength, but there has been an important shift from manufacturing and repetitive tasks to creative and ideation activities to get to this. Many professions have been replaced by automation done by computers while more spaces are needed today to crate and innovate. Workers are the most important asset for companies, they are not just machines repeating tasks; for this reason, the workers' comfort and flexibility are nowadays fundamental for a firm to success.

Relationship between design, workers wellbeing and productivity has been a transcendent factor too. Noise, thermal control, lighting and layout design are pointed out as the most important factors that relate productivity, workers efficiency and design. Noise has a negative effect reducing worker's ability to concentrate, by contrast, thermal control, good light, natural if possible, and outside views increase productivity. There are many different interior layouts and all of them have advantages and disadvantages. For example, while noise causes distraction on the Open Plan, interaction and communication have the opposite effect, increasing productivity and innovation possibilities; on the other hand, cubicle office problems and advantages are completely different. In addition, refreshment and sportive spaces should be provided in today offices.

Nowadays workspaces should be prepared for a constantly changing productive environment, for this purpose, flexibility, adaptation capacity and communication, ideas exchange and teamwork fomentation are key points but offering concentration and quieter spaces too. Beyond efficiency and productivity requirements, interior layout plays an important role attracting new talents. Workers from the creative and knowledge economy value pleasant environments with personality and amenities to maintain a balanced and healthy life.

Distancing between work and workspaces is enabled by the transformations derived from computers development, the Internet and digital technology. Remote work separates workers and fixed offices reducing workstations and promoting new interaction between workers because they are not grounded to workplaces. Today what we understand as a workspace has extended to the public space too, work happens in many places. In this context, due to its lower costs, well-cared environment and the ability to connect with other professional and to achieve greater business opportunities, co-working adapts to the autonomous professional, entrepreneurs, freelancers, SMEs, start-ups and today's market. 


\section{REFERENCES}

Al horr , Y., Arif, M., Katafygiotou, M., Mazroei , A., Kaushik, A., \& Elsarrag, E. (2016). Impact of indoor environmental quality on occupant well-being and comfort: A review of the literature. International Journal of Sustainable Built Environment, 5, 1-11. doi:http://dx.doi.org/10.1016/j. ijsbe.2016.03.006

Andersson, J., Boerstra , A., Clements-Croome, D., Fitzner , K., \& Hanssen , S. (2006). Guidebook: Indoor Climate and Productivity In Offices. (P. Wargorcki, \& O. Seppänen, Edits.) REHVA.

Bakó-Biro, Z., Clements-Croome, D., Kochhar N. Awbi, H., \& Williams, M. (2011). Ventilation rates in schools and pupils' performance. Building and Environment, 48, 1-9. doi:http:// dx.doi.org/10.1016/j.buildenv.2011.08.018

Borgeson, S., \& Brager, G. (2011). Comfort standards and variations inexceedance for mixed-mode buildings. Building Research \& Information, 39(2), 118-133. doi:10.1080 /09613218.2011.556345

Chang, C.-Y., \& Chen, P.-K. (2005). Human Response to Window Views and Indoor Plants in the Workplace. HortScience, 40(5), 1354.1359. doi:https://doi.org/10.21273/ HORTSCI.40.5.1354

Danielsson, C., Bodin, L., Wulff, C., \& Theorell, T. (2015). The relation between office type and workplace conflict: A gender and noise perspective. Journal of Environmental Psychology, 42, 161-171. doi:https://doi. org/10.1016/j.jenvp.2015.04.004

Frontczak, M., \& wargocki, P. (2011). Literature survey on how different factors influence human comfort in indoor environments. Buiilding and Environment, 46(4), 922$937 . \quad$ doi:https://doi.org/10.1016/j. buildenv.2010.10.021

Gladwell, M. (2000). The tipping Point: How little things can make a big difference. London: Abacus.
Harris, R. (2015). The changing nature of the workplace and the future of office space. Journal of Property Investment \& Finance, 33(5), 424-435. doi:https://doi. org/10.1108/JPIF-05-2015-0029

Haynes, B., Suckley, L., \& Nunnington, N. (2017). Workplace productivity and office type. An evaluation of office occupier differences based on age and gender. Journal of Corporate Real Estate, 19(2), 111-138. doi:DOI 10.1108/JCRE-11-2016-0037

Hongisto, V. (2005). A model predicting the effect of speech of varying intelligibility on work performance. Indoor Air, 15, 458468. doi:https://doi.org/10.1111/j.16000668.2005.00391.x

Kaarlela-Tuomaala, A., Keskinen, E., \& Hongisto, V. (2009). Effects of acoustic environment on work in private office rooms and open-plan offices - Iongitudinal study during relocation. Ergonomics, 52(11), 1423-1444. doi:https://doi. org/10.1080/00140130903154579

Katafygiotou, M., \& Serghides, D. (2014). Bioclimatic chart analysis in three climate zones in Cyprus. Indoor and Build Environment, 25. doi:https://doi. org/10.1177\%2F1420326X14526909

Leather, P. J., Beale, D., \& Sullivan, L. (2003). Noise, psychosocial stress and their interaction in the workplace. Journal of Environmental Psychology, 23(2), 213222. doi:https://doi.org/10.1016/S02724944(02)00082-8

Leffingwell, W. H. (1917). Scientific Office Management. Chicago, New York: A.W. Shaw Company.

Leffingwell, W. H. (1925). Office Management. Chicago and New York: A. W. Shaw Company. doi:https://doi. org/10.1177/000271622512200139 
Loftness, V., Hartkopf, V., \& Gurtekin, B. (2003). Linking Energy to Health and Productivity in the Built Environment: Evaluating the CostBenefits of High Performance Building and Community Design for Sustainability, Health and Productivity. USGBC Green Build Conference,. Obtenido de http:cbpd. arc.cmu.edu/ebids Last accessed 5 August 2014

Mak, C., \& Lui, Y. (2012). The effect of sound on office productivity. Building Services Engineering Research and Technology , 33(3), 339-345. doi:https://doi. org/10.1177\%2F0143624411412253

Mayo, E. (1933). The Human Problems of an Industrial Civilization. New York: The Macmillan Company.

McGregor, D. (1960). The human side of enterprise. New York: McGraw-Hill.

Milton, D., Glencross , P., \& Walters, M. (2000). Risk of Sick Leave Associated with Outdoor Air Supply Rate, Humidification, and Occupant Complaints. Indoor Air(10), 212212. Obtenido de ttp://www.e-co.uk.com/ Recirc-Milton2000.pdf Last accessed 5 August 2014

Moriset, B. (2013). Building new places of the creative economy. The rise of coworking spaces. Territoire en Mouvement. doi: 10.4000/tem.3868

Myerson, J., \& Ross, P. (2003). La oficina del siglo XXI. Madrid: H.Kliczkowski.

Newsham, G., Aries, M., Mancini, S., \& Faye, G. (2008). Individual Control of Electric Lighting in a Daylit Space. Lighting Research and Technology, 40, 25.41.

Ouchi, W. G. (1981). Theory Z: How American Business Can Meet the Japanese Challenge. Reading, Mass. : Addison-Wesley.

Pentland, A. (2012). The New Science of Building Great Teams. Harvard Business Review. Obtenido de https://hbr.org/2012/04/thenew-science-of-building-great-teams

Riaz, A., Shoaib, U., \& Sarfraz, M. S. (2017).
Workplace Design and Employee's Performance and Health in Software Industry of Pakistan. International Journal of Advanced Computer Science and Applications, 8(5), 543-548.

Saval, N. (2014). Cubed: A Secret History of the Workplace. New York: Random House.

Seddigh, , A., Berntson, E., Bodin Danielsson, C., \& Westerlund, H. (2014). Concentration requirements modify the effect of office type on indicators of health and performance. Journal of Environmental Psychology, 38, 167-174. doi:https://doi. org/10.1016/j.jenvp.2014.01.009

Serghides, D., Chatzinikola, C., \& Katafygiotou, M. (2015). Comparative studies of the occupants' behaviour in a university building during winter and summer time. International Journal of Sustainable Energy, 34(8), 528-551. doi:https://doi.org/10.1080 /14786451.2014.905578

Taylor, F. W. (1911). Principles of Scientfic Management. New York, NY, USA and London,: UK: Harper \& Brothers,. Obtenido de http://www.gutenberg.org/ ebooks/6435

Van Meel, J. (2015). Workplaces Today. Icop.

Veitch, J. A. (2001). Psychological Processes Influencing Lighting Quality. Journal of the Illuminanting Engeenering Society, 30(1), 124-140. doi:https://doi.org/10.1080/0099 4480.2001.10748341

Waber, B., Magnolfi, J., \& Lindsay, G. (2014). Workspaces That Move People. Harvard Business Review. Obtenido de https:// hbr.org/2014/10/workspaces-that-movepeople

Witterseh, T., Wyon,, D., \& Clausen, G. (2004). The effects of moderate heat stress and open-plan office noise distraction on SBS symptoms and on the performance of office work. Indoor Air, 38, 167-174. doi:https://doi.org/10.1111/j.16000668.2004.00305.x 
World Green Building Council. (2014). Health, Wellbeing \& Productivity in Offices. The next chapter for green building. doi:https:// www.worldgbc.org/news-media/healthwellbeing-and-productivity-offices-nextchapter-green-building

Yun, G. Y., Kong, H.j.., Kim, H., \& Kim, J. (2012). A field survey of visual comfort and lighting energy consumption in open plan offices. Energy and Buildings, 46, 146-151. doi:https://doi.org/10.1016/j. enbuild.2011.10.035 



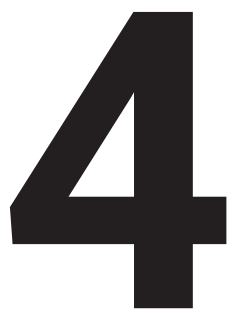

BLOCK 4: SMART CITIES VS. TECH CITIES 


\title{
PAPER \#4.01
}

\section{IS DUBAI A NEW PARADIGM FOR SMART CITIES?}

\author{
Sabeen bin Zayyada, Thomas Patrick Keenan ${ }^{\mathrm{a}}$
}

aUniversity of Calgary, Calgary, Alberta, Canada

\section{ABSTRACT}

As one of the fastest growing urbanized cities in the world, Dubai is aiming to become the smartest city on the planet by 2021. At the launch of Dubai's Smart City strategy in 2018, the ruler of Dubai tweeted, "Our goal is for the entire city's services and facilities to be available on smartphones". McKinsey Global Institute states that cities are becoming more habitable and accessible as they get smarter. Technology is becoming part and parcel of citizens' lives by virtue of having access to all types of information in an instant. In addition to keeping pace with innovations in technology, cities also face the challenges of social and economic exclusion. Current literature defines smart cities as ranging from those that use technology as tools to make better decisions and improve the quality of life, to using data to increase efficient delivery of government services to its citizens, to making cities more effective in their operations. Current literature also posits that smart cities do not necessarily mean intelligent communities - making cities better and inclusive. In other words, inclusive means that all citizens should be able to have access to essential services including technology to improve the quality of their lives. This paper will begin by tracing Dubai's journey to become a smart city. The second part will examine the social and economic challenges it currently faces in providing access to the Internet and government services for the majority of its residents. The paper will conclude by proposing that Dubai's approach to becoming not only a smart but also an intelligent city should begin by reevaluating the alignment of the application of various types of technology with the needs of its residents rather than focusing on the

economic return of investment that this implementation brings forth.

\section{KEYWORDS}

Smart city; intelligent community; technology innovation; community development; Dubai.

\section{INTRODUCTION}

The 19th century was a century of empires, the 20th century, a century of nation states. The 21st century will be a century of cities (HuffPost 2017).

The World Bank (2018) and United Nations (2014) state that, over 55 per cent of the world's population live in urban areas and that number is expected to increase to 66 per cent by 2050 . More and more people are moving to cities in search of job opportunities, better wages and access to basic services such as affordable housing, health care and education. Unfortunately, this does not always translate to a better quality of life. The pressure on cities to meet these minimum needs is very high. The development of diverse lifestyles, declining infrastructure, climate change, ageing population, and more recently the influx and integration of refugees are some of the 'newer' challenges that cities currently face. In their attempts to manage existing economic, social and environmental resources, city officials are increasingly turning to the notion of a smart city to not only improve the quality of the lives of their citizens but to also increase the efficiency of how cities operate and reduce costs. 
So, what is a smart city and how is that different from an intelligent community? How does the idea of a smart city align with sustainable development?

\section{SMART CITIES, INTELLIGENT COMMUNITIES}

According to the Intelligent Community Forum (2015), a smart city approach makes cities work better by using innovations in technology to cut down on costs, increase efficiency and provide better services to its citizens. Gassmann, Böhm, and Palmié (2019) define a smart city as one that

systematically applies digital technologies to reduce resource input, improve its people's quality of life, and increase the competitiveness of the regional economy in a sustainable manner (26).

Other definitions such as Manville's (2014) describes the smart city as one where a collective partnership is formed between government and non-government stakeholders to address the challenges of urbanization by providing solutions based on information and communication technologies. Pelton and Singh's (2018) characterization of a smart city is one that is not defined by its technology and application but, instead is a process that combines seven elements that are key to building a smart city:

- Meeting the needs of citizens - providing basic services of housing, education, health care, transportation and access to the Internet - Sustainability / circular economy - tackling the challenges of climate change, pollution, urbanization, and growth in population while minimizing the wastage of resources

- Jobs and competitiveness - stimulating economic competition and growth by creating jobs and retention through retraining programs
- Smart planning and citizen support involving all demographics of the population including youth to find answers to key questions around delivery of vital services, infrastructure, etc.

- Infrastructure and resources - effective and efficient delivery of key services to both citizens and businesses

- Technology and Al - meeting the needs of the community through the smart use of technology

- Security - ensuring protection against cyber-attacks, key infrastructure, natural and humanitarian disasters

Although the definitions of a smart city are many, it is important to note the difference between the concept of a smart city and that of an intelligent community. Defined as civic groups that strive to make urban and rural areas better places to live in, intelligent communities ensure that citizens are able to prosper in a broadband economy. Technology is not necessarily the primary focus of these communities. Instead, they aim to create an environment where citizens are engaged by providing access to technology to develop a highly skilled workforce, thus ensuring better employment opportunities resulting in an improved quality of life (Intelligent Community Forum 2015). The concept of and processes behind the creation of a smart city does not only require cooperation across different disciplines ranging from politics to economics, from social sciences to the law (Celino and Kotoulas, 2013) but is gaining increasing importance for governments who are looking for manageable and sustainable solutions to the rising urbanization of their cities. Given the interdisciplinary nature of a smart city, how do smart cities and intelligent communities translate into 'smart urbanism' where information and communication technologies are incorporated in an efficient and integrative manner to meet the challenges of a city's urban development? Although research into the area of smart urbanism is 
very limited (Luque-Ayala and Marvin, 2015), it is becoming a more adaptable response to the challenges of urban growth in which the questions of who the smart cites are geared toward, the governing processes behind it and how this can be socially inclusive, begin to emerge in different urban contexts.

Proponents of smart cities remain divided on the development and implementation of ideas, potential solutions and possible outcomes. On the one side, there are those that want to develop smart city technologies that meet the immediate needs of city administrations and are sustainable, economical and effective. This group consists of mainly scientists and engineers who work in academia, private corporations and the government. On the other side, are civic organizations, policy makers and not-for-profit groups who find that technology-based solutions are extremely narrow in their application and do not take into consideration the addressing of political, economic and social challenges that exist within the urban milieu (Coletta et al, 2018). This dichotomy between a technologyoriented approach and a civic development approach highlights and emphasizes the disconnect between what municipalities think its citizens want versus what its citizens actually need. The approach of the former is top-down and functional determined by what it thinks is best for the citizens, whereas the latter involves the engagement and participation of the citizens to determine their needs and how best they can be met. Coletta et.al. (2018) state that the reasons behind this divide stems from providing short-term solutions rather than addressing the underlying causes of urban issues. They further state that regulations and the lack of partnerships between the public and private sectors highlight the inefficiencies and the inability of governments to deliver critical amenities to its citizens (Kitchin et al 2017). Instead, governments should draw upon the competencies held within industry and academia [to] help deliver better solutions through public-private partnership, leasing, deregulation and market competition, or outright privatization (Coletta et al 2018,4)

Coletta et.al. also believe that governments are already outsourcing the creation of smart city technologies to the private sector. For example, consider the proposed development of a 12-acre parcel of land along Toronto's waterfront by Sidewalk Labs, an urban innovation lab and subsidiary of Alphabet Inc., the corporate parent of Google. After a competitive bid process, Sidewalk Labs was chosen as the "...successful Innovation and Funding Partner to help think through tough urban challenges..." (Waterfront Toronto, 2017). This partnership between Waterfront Toronto (a government agency) and Sidewalk Labs, has been described as a 'smart city' makeover of Toronto's waterfront area (Bozikovic, 2017, October 17). On their frequently asked questions tab of their website, Sidewalk Labs states that it

...proposes to focus on core areas it is uniquely suited to achieve and that the market or government are not able to pursue on their own, including limited deployment of core technologies necessary to achieve qualityof-life objectives that are not available in the market today.

This project has not been without its share of controversies. Many fear this supposedly limited use of "core technologies" will infringe on the liberties of citizens, thus bringing into perspective the role of digital governance in protecting these rights.

It is also important to note that a smart city does not necessarily translate to a better quality of life or a more secure one. It could be if the technology used was carefully planned and thoughtfully implemented (Pelton and Singh (2018). Celino and Kotoulas (2013) state that the adoption of Internet-based technologies in urbanized cities around the 
world is evidence enough that Internet-based solutions are effective in providing tangible services and solutions to its citizens. Yet, they make no mention of maintaining the quality of citizens' lives or their security vis a vis their rights as mandated by their governments. Keeping these two perspectives in mind, we now trace Dubai's journey to becoming a smart city.

\section{DUBAI'S JOURNEY AS A SMART CITY}

We are building a new reality for our people, a new future for our children, and a new model of development (Sheikh Mohammed bin Rashid al-Maktoum, 2018)

A city of superlatives, ambitious, glamorous, and expensive are some of the adjectives used to describe the Emirate of Dubai. From its origins as a tiny fishing and pearling port in the early-20th century, Dubai today has established itself as a 'city of opportunity' according to PricewaterhouseCoopers sixth edition of its 'Cities of Opportunity' report on in 2014. In addition, Dubai was ranked 12th in the intellectual capital and innovation sector and 13th in terms of technology readiness. Its ranking overall was sixteen out of a total of thirty cities. However, Dubai's ranking dropped a notch in PricewaterhouseCoopers report of 2016. In terms of readiness in technology it stayed the same - 13th but dropped to 13th place in intellectual capital and innovation. It is important to note that it was the only city from the Middle East and North African region to be included in both these reports. With the diversification of its economy away from oil, Dubai has constantly reinvented itself to

\begin{tabular}{|c|c|c|}
\hline Year & Initiatives & Purpose \\
\hline 1999 & ICT strategy & - no information available as to its purpose \\
\hline 2000 & Dubai Internet City & $\begin{array}{ll}- & \text { tech hub to nurture talent and creativity } \\
\text { - } & \text { www.dic.ae }\end{array}$ \\
\hline 2001 & Dubai e-government & $\begin{array}{ll}- & \text { all government services are made available } \\
\text { - } & \text { redline } \\
\text { - } & \text { more accessible } \\
\text { - } & \text { ease the lives of its residents } \\
\text { - } & \text { previous website - www.dubai.ae } \\
\end{array}$ \\
\hline 2013 & Dubai Smart Government & $\begin{array}{l}\text { - } \quad \text { formerly known as Dubai e-government } \\
\text { - } \quad \text { www.smartdubai.ae }\end{array}$ \\
\hline 2014 & Smart Dubai & $\begin{array}{l}\text { government office in charge of facilitating } \\
\text { Dubai's transformation into a smart city and } \\
\text { promote the city into an efficient and seamless } \\
\text { experience for its residents and tourists } \\
\text { some key initiatives include Dubai Blockchain } \\
\text { Strategy, the Happiness Agenda and the Dubai } \\
\text { Paperless Strategy } \\
\text { www.smartdubai.ae }\end{array}$ \\
\hline 2017 & Smart Dubai 2021 & $\begin{array}{l}\text { - a strategy designed by the Smart Dubai Office } \\
\text { to respond to the changes that are shaping } \\
\text { Dubai by preparing Dubai to become a world- } \\
\text { leading city by } 2021 \\
\text { is a 'revolutionary new vision' for a smart city by } \\
\text { making Dubai the 'happiest' city in the world } \\
\text { to promote advances in technology that benefit } \\
\text { its economy, resources and its residents } \\
\text { www.2021.smartdubai.ae }\end{array}$ \\
\hline
\end{tabular}

Table 1. Timeline of Dubai's transformation into a smart city. 
face the urban challenges that are similar to that of other growing cities in the world. The unusual demographics, rapid urbanization, form(s) of governance, and globalization are some of the challenges that require Dubai to continually adapt the way it provides and delivers the services needed to sustain a growing population. A city of approximately 3.2 million people where ninety-two percent are expatriates (Dubai Statistics Center 2018), Dubai's journey to becoming a smart city began in 1999 with the initiation of its ICT Strategy. Table 1 below illustrates when these initiatives were launched and the purpose behind them.

After conducting a thorough review of the Dubai Smart government, Smart Dubai and Smart Dubai 2021 websites, the authors found that there were common key terms used to describe each of these three initiatives. Some of the common terms used across both the websites were:

a) to be the happiest city in the world

b) to use innovations in technology such as blockchain, Internet of Things (IOT) systems, and $\mathrm{Al}$ applications so as to become the smartest city in the world

c) make city experiences seamless, efficient, safe, personalized, deliver enhanced quality of life and ensure sustainability

This begs the question as to how do each of these initiatives differ from each other in Dubai's bid to join the ranks of other smart cities in the world? At first glance, the initiatives are iterative. The themes are revisited over and over again without any tangible incorporation of new ideas. However, rather than being critical about this, the authors believe that the initiatives should viewed as incremental phases towards achieving Dubai's goal amongst others, to become the smartest city in the world. In addition, Dubai can and should be viewed as a pioneer in its attempt to become the first smart city in the Middle East and North Africa region (Virtudes, Abbara and Sá, 2017).

\section{SOCIAL AND ECONOMIC CHALLENGES POSED}

We are making Dubai the happiest city on earth by embracing technology innovation making Dubai a more seamless, safe, efficient and personalised city experience for all residents and visitors (Smart Dubai 2021 n.d.)

Using Dubai's Transformation Agenda model below (Figure 2), the authors have chosen two of the six 'strategic themes' as a guide to illustrate the social and economic challenges that Dubai's faces in embracing the notion of a smart city. The 'city experience' and 'emerging technologies' were chosen because they offer an insight into two important elements that are crucial to building a smart city affordability and liberty.

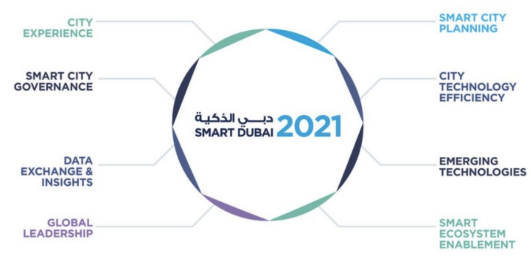

Figure 1. Dubai City's Transformation Agenda. (Smart Dubai 2021 n.d.)

\subsection{Affordability of the city experience}

Human capital is the bedrock of a nation's development. Given Dubai's highly unusual demographic where expatriates outnumber the citizens, this can pose a challenge where terms like happiness, resilience, wellconnected, well-planned do not necessarily translate into what Smart Dubai 2021 deems or identifies or states on its website as "... an unmatched urban experience." Being able to 'connect' with the rest of the world is important in this era of globalization. According to the World Bank (2016), only 15\% 
of the world's population can afford access to the Internet with $60 \%$ having no access at all. In addition, despite cell phones being the main device with which to connect to the Internet, approximately 2 billion people do not own one (World Bank, 2016).

In 2013, the Dubai government launched an initiative whereby all government services would be made accessible on mobile devices by 2015 . Although only "...96\% of public services in the government's 337 most significant departments had successfully gone digital" (Smart City Press 2018), the ruler of Dubai set a new target. It wanted at the very minimum $80 \%$ of its residents to actually access government services using their mobile devices. Therein lay the challenge of how both residents and visitors alike could have a seamless experience whilst in Dubai. What is even more daunting is the fact that despite "...active mobile penetration skyrocketing above 260 percent..." (Salem 2016), the financial costs of being able to afford access to the Internet remain unaddressed to date. According to Hassan (2018), of the 9.3 million residents in the UAE in 2015, 89\% were migrant workers with most of them being semi-skilled or unskilled. It should be noted that the statistics on what percentage of Dubai's labour force constitute unskilled workers is not available. Although the list is not comprehensive, this demographic includes construction workers, housemaids, drivers, security guards, and building caretakers to name a few. With an average income of US \$362 per month (Hassan 2018), most of their income is remitted back to their home countries to support their

\begin{tabular}{|c|c|c|}
\hline & Smartphone plan (talk, text \& data) & Basic phone plan (talk \& text) \\
\hline Etisalat & $\begin{array}{l}\text { Waselgo Extra Large } \\
\text { US } \$ 88.48 \text { per month }+5 \% \text { tax } \\
3.5 \mathrm{~GB} \text { data } \\
175 \text { flexi minutes } \\
3 \text { favourite local numbers }\end{array}$ & $\begin{array}{l}\text { At time of writing, the Etisalat website } \\
\text { was undergoing a scheduled system } \\
\text { maintenance despite the authors' } \\
\text { numerous attempts to explore other } \\
\text { plans }\end{array}$ \\
\hline du & $\begin{array}{l}\text { US } \$ 40.84 \text { per month }+5 \% \text { tax } \\
\text { Includes } 3 G B \text { of data }+3 G B \text { 'free' } \\
\text { full data (available plan at time of } \\
\text { writing) } \\
150 \text { flexi minutes }\end{array}$ & $\begin{array}{l}\text { At time of writing, du requested the } \\
\text { authors' contact details as they were } \\
\text { 'currently working on improving our } \\
\text { eShop experience' }\end{array}$ \\
\hline Rogers & $\begin{array}{l}\text { US } \$ 56.56 \text { per month }+5 \% \text { tax } \\
\text { Unlimited in country-wide calling, } \\
\text { text, picture and video messaging } \\
\text { including voicemail, call display, call } \\
\text { waiting \& conference calling } \\
\text { Includes } 10 \mathrm{~GB} \text { of data }\end{array}$ & $\begin{array}{l}\text { US } \$ 26.40 \text { per month }+5 \% \text { tax } \\
\text { Unlimited in country-wide calling, } \\
\text { messaging, call display, call waiting \& } \\
\text { conference calling }\end{array}$ \\
\hline Bell & $\begin{array}{l}\text { US } \$ 56.56 \text { per month }+5 \% \text { tax } \\
\text { Unlimited in country-wide calling, } \\
\text { text, picture and video messaging } \\
\text { including voicemail, call display, call } \\
\text { waiting \& conference calling } \\
\text { Includes } 10 \mathrm{~GB} \text { of data }\end{array}$ & $\begin{array}{l}\text { US } \$ 30.17 \text { per month }+5 \% \text { tax } \\
\text { Unlimited in country-wide calling, } \\
\text { messaging, call display, call waiting \& } \\
\text { conference calling }\end{array}$ \\
\hline
\end{tabular}


families there. One of the ways in which they are able to keep in touch with their families and the world is by using their own mobile devices or borrowing one from friends and colleagues. Despite Dubai's desire to ensure that access to the Internet is available to all, the telecommunications market in the UAE is dominated by two providers - Etisalat and the Emirates Integrated Telecommunications Company (EITC), represented as the brand "du" (ITU 2017). The former is mostly owned by the UAE government with the rest of the shares being publicly traded (Etisalat 2019). Du has a similar ownership structure with different entities of the UAE government owning most of the company and the rest by public shareholders (du 2020). What this means is that competition is limited, thus making the plans unaffordable for many. The table below illustrates the price point of similar plans from the websites of the two providers in the UAE and how it compares to similar plans from the websites of two providers in North America, using pre-paid plans.

Given the average monthly income of these semi-skilled and unskilled workers is only US \$362, this makes it very costly for them to connect with their families back home. Allocating between approximately 12-26 percent of their income towards staying in touch with their family and the world does not seem feasible or sustainable in the long-term. The city experience for them begins to lose the connection to simplified living. It begs the question whether this particular demographic who form a large segment of the expatriate labour force has been taken into account in the planning of Smart Dubai? In an Access and Use of Information and Communications Technology survey carried out by the UAE Telecommunications Regulatory Authority (2008) and conducted over a period of 6 months, $65 \%$ of the respondents surveyed in 1350 households "...noticed reductions in prices of telecommunication services in the past year or two..." (8). It should be noted that the portion of households surveyed represented only $0.2 \%$ of the total number of households in the UAE in 2008. The survey also concluded that $66 \%$ of these households had access to the internet. A total of 2 people per household were surveyed and "96\% of respondents...had access to a mobile phone which may be owned by the respondent or another party." (12). Although statistics on the number of users that have access to the Internet in the UAE vary from $90.6 \%$ to $94.3 \%$ (CIA 2016, ITU 2017), the type of demographics surveyed is not clearly stated. This makes is very difficult for the authors to understand the perceived impacts of the various initiatives launched by the Dubai government. What also needs to be taken into consideration is, whether any of the initiatives that Dubai has launched will eventually lead into its transition to an intelligent city where inclusivity becomes a defining factor in the quality of their lives. The advent of smartphone applications such as WhatsApp allow users to communicate with their family and friends at no charge (by accessing free WIFI connectivity), is fast gaining a huge following. The smartphone applications provided by Etisalat and du such as BOTIM, are not free as users are required to pay when downloading the application. With the incremental costs of living, applications that provide communication services at very little to no cost is a boon to many who struggle with being able to afford access to talk and text plans. However, this also comes at an intangible price for many as the next challenge will outline.

\subsection{Liberty meter with emerging technologies}

"The challenge moving forward is choosing the right technologies to incorporate" according to Danish Farhan of Xische and company in a recent article written for Gulf News. The context within which it was written was a nod to how the transformation of Dubai's government will be based on innovation. This innovation means the deployment of the best 
technologies such as blockchain, the Internet of Things (IOT) and artificial intelligence. What is equally disruptive in the embracing of new technologies is the government's reluctance to allow technologies that enable free voice and video calls using the Internet. Commonly used across the world, these Voice over Internet Protocol (VoIP) applications such as Skype, FaceTime, Viber and WhatsApp, are banned not only in Dubai but in the entire UAE. Although the text features of these services are allowed, voice and video calling are not permitted. In Dubai's efforts to become the happiest and smartest city in the world, this does seem in direct contrast to its Smart Dubai initiative launched in 2014. Many residents in Dubai have called for the ban to be lifted stating that it was affecting the development process in Dubai (Habib alMulla 2018). In a 2019 Twitter post, prominent Dubai businessman Khalaf al-Habtoor stated that these free VoIP services

...improved the lives of residents and investors...that must be provided as we strive to be a smart city. Stop the monopoly mentality of telecommunications companies.

Many residents have resorted to using virtual private networks (VPNs) to work around these restrictions. In 2019, the UAE's Telecommunications Regulatory Authority issued a statement saying that there were no laws preventing the use of VPNs as long as it was being used for legitimate purposes such as "...to gain access to internal networks via the Internet." The interpretation behind what would be legal and illegal is broad. In an article on their website, a well-known law firm in Dubai, Al Tamimi and Company state that unless 'nefarious' content was going to be accessed, the authorities were less inclined to stop a user from accessing the latest episode of a television series not yet available in Dubai.

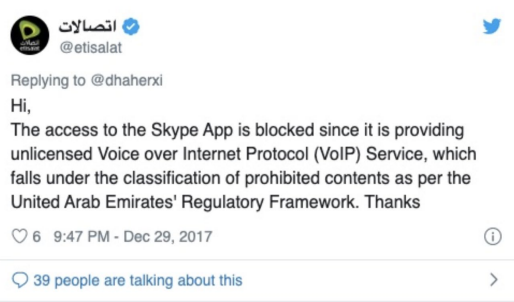

Figure 2. Etisalat response to a customer regarding access to Skype. (Gulf News 2018)

Both the telecommunication providers Etisalat and du have fee-based VPN packages that allow users to make calls via the Internet using applications supported by the providers, such as BOTIM, C'ME, HiU Messenger and Voico UAE. Given the geopolitical tensions that are constantly present in the Gulf region, it is understandable when certain applications are not made completely available to residents in Dubai and the UAE. Citing encryption and the UAE's 'regulatory framework' as reasons for the ban (Taylor CNBC 2019), Dubai's approach to the use of telecommunications technologies is understandably cautious vis a vis their national security. One could argue that this is not much different than the precautions taken by other countries in the world. The executive director of the UAE's National Electronic Security Authority, Mohamed al-Kuwaiti (2019) acknowledged that the enabling of increased connectivity in the country meant that the government needed to reassess how national security could be balanced with access to technology. At the time of writing, Microsoft, Facebook and Apple were in discussions with the UAE government on lifting the ban on their VolP applications. Regardless of the outcome, a fundamental question remains - if Dubai is to become the happiest and smartest city in the world, how does restricting the freedom to select what technologies its residents embrace, enhance its development? While 
leading democracies like the USA, Canada, Britain, France and Germany monitor their citizens' use of the Internet, Dubai restricts and monitors its residents' use of the Internet. Although, more control may be gained by cities in restricting available technologies and tracking their usage by their citizens, it is not sustainable in the long-term (Kar, et al 2019). Cities need to facilitate their citizens' interactions with different technologies in order to better processes, resulting in effective outcomes. In the planning of its initiatives, Dubai needs to enable and integrate a broad range of technologies that will allow for human progress. Granted that the security of cities and their nations is vital to a viable future, embracing new technologies while restricting access to them does not mitigate the challenges associated with urbanization.

\section{CONCLUSION}

Smart cities make cities run better by creating efficiencies through technology, whereas intelligent communities focus on making cities better by providing access to technology and developing a highly-skilled workforce. Both intend on increasing the quality of life for its citizens. Both are necessary for urbanization to prosper. However, Dubai's path geared towards developing a smart city requires consideration of the social context rather than the focus on economic return of investment that technologies bring. What this means is that the inclusion of "...citizens, urban dynamics, and citizen participation in public life and decision-making" (Celino and Kotoulas 2013,9) is important to deliver tangible solutions to a city's inhabitants.

The authors propose three recommendations they believe are crucial to building upon the existing platform of Dubai's current initiatives to becoming a smart city:

- Digital connectivity - just having high-speed Internet is not enough. Providing access to all its residents is important, especially in areas with weak cellular coverage and access to publicly available WIFI is desired but not available. This would require Internet service providers Etisalat and du to streamline processes to improve services. It would also require them to review industry standards, assess current levels of connectivity available, and foster greater competition in the telecommunications industry with a goal of reducing the financial burden that is associated with accessing the Internet.

- Erudite workforce - as new technologies emerge, it is important that all sectors of the labor force are trained and prepared to use information and technology effectively. Greater collaboration needs to take place between Dubai's educational institutions and employers where opportunities such as workstudy programs, internships, lunch n' learns are encouraged and created.

- Stakeholder advocacy - with Dubai positioning itself as a smart city, the government should engage in broader collaborations with its residents in building a better future by involving them in open forums, government-resident task forces and resident surveys, to understand how communities work with different technologies. It needs to analyze the dynamics between the public sphere, private sector and communities, and explore best practices to engage the stakeholders in opportunities for them to explore new ways of doing things that are more efficient and cost-effective.

As new technologies develop, Dubai needs to ask itself if its initiatives can be adapted to the changing economic, social and demographic variables? What implications does this have in the delivery of services to its residents? Are their initiatives integrated enough to provide alternative solutions to fulfill, support and sustain the needs of their residents? These and many more important questions deserve further research so as to achieve better collaboration between the government and its residents. Rather than simply focusing on the economic return on investment that the 
application of various types of technology will bring, Dubai needs to apply technology to meeting the needs of its residents, improving the quality of life and strengthening the economic and social fabric of its communities if it is to achieve its goal of being the happiest city in the world. 


\section{REFERENCES}

Du. 2020. "Ownership structure." Accessed February 20, 2020. https://www.du.ae/ about-us/investor-relations/shareholders

Acuto, Michele. 2010. "High-rise Dubai urban entrepreneurialism and the technology of symbolic power." Cities 27: 272-284.

Alketbi, Hamad. 2018. "An Evaluation of E-government Effectiveness in Dubai Smart Government Departments." PhD diss., Southampton Solent University.

Bozikovic, Alex. 2017. "Google's Sidewalk Labs signs deal for 'smart city' makeover of Toronto's waterfront." Globe and Mail, October 17, 2017. https://www. theglobeandmail.com/news/toronto/ google-sidewalk-toronto-waterfront/ article36612387/\#: : :text=0n\%20 Tuesday $\% 2$ C $\% 20$ sidewalk $\% 20$ Labs $\% 2$ C $\% 20$ a,pursue $\% 20$ a $\% 20$ much\%20larger\%20area.

Celino, Irene and Kotoulas, Spyros. 2013. Smart Cities. IEEE Internet Computing 17 (6): 8-11. https://ieeexplore-ieee-org.ezproxy. lib.ucalgary.ca/document/6682980

Central Intelligence Agency. 2020. Accessed August 10, 2020. https://www.cia.gov/ library/publications/the-world-factbook/ geos/ae.html

Coletta, C., Evans, L., Heaphy, L., \& Kitchin, R., eds. 2018. Creating smart cities. ProQuest Ebrary.

Dubai Statistics Center. 2018. "Yearly Population Estimates." Accessed February 15, 2020. https://www.dsc.gov. ae/Report/DSC_SYB_2018_01\%20_\%20 03.pdf

Eger, John M. 2017. "This Is The Decade of Cities." HuffPost, December 6, 2017. https://www.huffpost.com/entry/this-isthe-decade-of-cit_b_9596524

Etisalat. 2019. "Ownership structure." Accessed February 20, 2020. https:// www.etisalat.com/en/ir/corporateinfo/ ownership-structure.jsp
Farhan, Danish. 2020. "Dubai Council will be catalyst for change." Gulf News, February 20, 2020. https://gulfnews.com/ business/analysis/dubai-council-will-becatalyst-for-change- 1.69826448

Fawcett, Andrew and Saleem, Sana. 2019. "Is Using a VPN in the UAE illegal?" November 2019. https://www.tamimi. com/law-update-articles/is-using-a-vpnin-the-uae-illegal/

Hassan, Riaz. 2018. "The UAE's Unsustainable Nation Building." YaleGlobal Online, April 24, 2018. https://yaleglobal.yale.edu/ content/uaes-unsustainable-nationbuilding

Intelligent Community Forum. 2015. "What is an Intelligent Community". https://www. intelligentcommunity.org/what_is_an_ intelligent_community

International Telecommunication Union. 2017. "Big Data for Measuring The Information Society: Country Report - United Arab Emirates. Accessed August 10, 2020. https://www.itu.int/en/ITU-D/Statistics/ Documents/bigdata/United\%20Arab\%20 Emirates.pdf

Khan, Sajid M., Woo, Mina, Nam, Kichan and Chathoth, Prakash, K. 2017. "Smart City and Smart Tourism: A Case of Dubai." Sustainability 9 (12): 2279.

Khatoun, Rida and Zeadally, Sherali. 2016. "Smart cities: concepts, architectures, research opportunities." Communications of the ACM 59 (8): 46-57. ProQuest Ebrary. Kitchin, R., Coletta, C., Evans, L., Heaphy, L. and MacDonncha, D. 2017. "Smart cities, urban technocrats, epistemic communities, advocacy coalitions and the 'last mile' problem." it - Information Technology 59 (6): 275-284.

Luque-Ayala, A., \& Marvin, S. 2015. "Developing a critical understanding of smart urbanism?" Urban Studies 52 (12): 2105-2116. https://doi. org/10.1177/0042098015577319 
Maceda, Cleofe. 2018. "Individuals can access VPNs in the UAE, with caution." Gulf News, January 3, 2018. https://gulfnews.com/ technology/individuals-can-access-vpnsin-the-uae-with-caution-1.1872304

Manville, C., Cochrane, G., Cave, J., Millard, J., Pederson, J.K., Thaarup, R.K. and Kotterink, B. 2014. "Mapping smart cities in the EU." Accessed February 18, 2020. http://www.europarl.europa.eu/studies.

Pelton, J. N., \& Singh, I. B. 2018. Smart cities of today and tomorrow: Better technology, infrastructure and security. ProQuest Ebrary.

PricewaterhouseCoopers. 2014. "Cities of Opportunity 6." Accessed February 18, 2020. https://www.pwchk.com/en/citiesof-opportunity/cities-of-opportunity-6.pdf

PricewaterhouseCoopers. 2014. "Cities of Opportunity 7." Accessed February 18, 2020. https://www.pwc.com/us/en/ cities-of-opportunity/2016/cities-ofopportunity-7-report.pdf

Salem, F. 2016. "A Smart City for Public Value: Digital Transformation through Agile Governance - The Case of "Smart Dubai". Dubai: Governance and Innovation Program, Mohammed Bin Rashid School of Government. World Government Summit.

Sheikh Mohammed bin Rashid. 2018. "Mohammed bin Rashid: Reigniting Our Civilisation a Resolution, Not a Slogan". https://sheikhmohammed.ae/en-us/ news $/$ details?nid $=25191 \&$ cid $=$

Smart City Press. 2018. "How Dubai Wants to Scale Up The Happiness Meter With Easily Accessible Public Services?" Smart City Press, February 9, 2018. https://www. smartcity.press/smart-accessible-publicservices-dubai/

Smart Dubai. n.d. https://2021.smartdubai. ae/.

Smart Dubai. 2020. https://www.smartdubai. ae/about-us
Taylor, Chloe. 2019. "UAE may lift ban on WhatsApp call, head of country's cybersecurity authority says." CNBC, November 6, 2019. https://www.cnbc. com/2019/11/06/uae-may-lift-ban-onwhatsapp-calls-head-of-cybersecurityauthority.html

UAE Telecommunications Regulatory Authority. 2008. "UAE ICT Survey: Access and Use of Information and Communications Technology in the UAE." United Nations Population Division. World Urbanization Prospects: 2018 Revision.

Woetzel, Jonathan, et al. 2018. "Smart cities: Digital solutions for a more livable future". McKinsey Global Institute. June 2018. https://www.mckinsey.com/industries/ capital-projects-and-infrastructure/ourinsights/smart-cities-digital-solutions-fora-more-livable-future

World Bank, 2016. "World Development Report 2016: Digital Dividends." Accessed February 19, 2020. https://www. worldbank.org/en/publication/wdr2016

Virtudes, A., Abbara, A. and Sá, J. 2017. "Dubai: A Pioneer Smart City in the Arabian Territory." IOP Conference Series: Materials Science and Engineering 245 (5). https:// iopscience.iop.org/article/10.1088/1757899X/245/5/052071/pdf

World's Urbanization Prospects. 2014. "World's population increasingly urban with more than half living in urban areas." United Nations, July 10, 2014. https:// www.un.org/en/development/desa/ news/population/world-urbanizationprospects-2014.html

WAM. "Dubai e-Government renamed Dubai Smart-Government". Gulf News, June 20, 2013. https://gulfnews.com/business/ dubai-e-government-renamed-dubaismart-government-1.1199985 


\title{
PAPER \#4.02
}

\section{PERFORMING AND MEASURING SMARTNESS GIVING GROUND TO URBAN INTELLIGENCE BY AN ALTERNATIVE METRIC}

\author{
Julien Lafontaine Carbonia, Dario Negueruela del Castillo ${ }^{b}$ \\ aALICE, Swiss Federal Institute of Technology (EPFL), Lausanne, Switzerland \\ buniversity of Zürich, Switzerland
}

\section{ABSTRACT}

Since the emergence of cybernetics and the growing prominence of the use of IT as tools and instruments to develop and manage urban spaces, the discourses on smart city and their agency reached a central role in the outlining of new markets of urban management and transformation. Numerous scholars attempted to disclose the mechanisms of Smart Cities (SC) as a corporate discourse and a tool for disciplinary control. In this contribution, we propose to unveil the processes of future's normalisation enacted by the current SC program and metrics. We argue that this discourse is acting as an extraction of sovereignty through normalised and neoliberal representations, constraining the way we sense, act and think on and with cities. Grounded on actual alternatives proposed and analysed by the emerging field of SC critique, we will try to outline the frame of a new metric of smartness, based on political and spatial imagination that emphasizes on the coupling between a measure and its worth. Then, we will explore a path opened up by the distributed cognition theory (Hutchins 1995; 2000) and the scaffolded mind theory (Sterelny 2010) put in perspective with the understanding of spatiality as performative (Butler 1993;Gregson and Rose 2000; R.Glass and Rose-Redwood 2014). From these theories giving ground to a new definition of intelligence, we will propose a complementary set of dimensions for an alternative metric, opening up new roles and possibilities for renewed spatial imagination and practices.

\section{KEYWORDS}

Smart city alternatives; metrics; sociospatial imagination; spatial intelligence; performativity.

\section{INTRODUCTION}

Smart cities, intelligent cities, creative territories... The amount of labelling and publications on the topic of urban intelligence is flourishing. Since the emergence of cybernetics and the growing prominence of the use of IT as tools to develop and manage urban spaces, the discourses on SC and their agency reached a central role in the outlining of new markets. Based on an almost unconcealed collusion between the public sector and a military-industrial complex, numerous scholars attempted to disclose the mechanisms of SC as a corporate discourse and a tool for disciplinary control. Under the banner of efficiency and rationality toward a sustainable and resilient future, most of the SC programs are narrowing decision-making processes, enhancing the decline of the political in urban context and disempowering public policies and local populations of their capacity to imagine alternatives.

In this contribution, we intend to unveil how the current metrics and program of SC impose a normalization, standardization even, of the future. We argue that this discourse is acting as an extraction of sovereignty through neoliberal representations, constraining the way we act and think on and with cities. We thus claim the urgency of finding new ways of theorising and measuring urban intelligence. 
Grounded on some alternatives proposed by the emerging field of SC critique, we will try to outline the frame of a new metric of smartness, based on political and spatial imagination that emphasizes on the coupling between a measure and its worth. Then, we will explore a path opened up by the distributed cognition theory (Hutchins 1995) and the scaffolded mind theory (Sterelny 2010) put in perspective with the understanding of spatiality as performative (Butler 1990; Gregson and Rose 2000). From these theories giving ground to a new definition of intelligence, we will propose a complementary set of dimensions for an alternative metric, opening up new roles and possibilities for renewed spatial imagination and practices.

\section{RE-EVALUATING THE SMARTNESS. PASTS AND PRESENTS OF THE SMART CITY}

\subsection{Recent evolutions and metrics of the Smart City}

Most of the scientific articles on SC notice the lack of clear definitions. This lack originates in a largely self-congratulatory use of the label (Holland 2007), both shaped by a corporate storytelling and the economic need of cities to develop a competitive image (Söderström and Klauser 2004). If it was firstly used by the public sector, after the reorientation of IBM, the term was appropriated by companies in order to gain a 'dominant position in a huge market'.

Smart city developed at the same moment than the Rise of the Creative Class (Florida 2002). Interrogating the coincidence, Holland questions the sustainability of smart entrepreneurialism with its associated economic growth and gentrification, as the city is becoming through IT more economically and socially divided; he considers that smartness is exclusive, attracting a certain part of the population and ignoring the welfare of other citizens. To counter this critique that grew in civil society, the corporate discourse mutated in 2010's to drastically include citizens; 'To build a smart city, we need citizens capable of inventing a new world.' (Vanolo 2014, citing, www.barismartcity.it). With this strategy, the SC enrols citizens by force in its fabrication, and imposes them to be 'smart'. Participating in the construction of the SC becomes a moral obligation. In this process of forced democratization, a new form of moral and ethics of control are enacted by the participation. Enclosing the field of the political and the means of imagination into a standardized participatory contribution, the SC entered a third phase, exhausting political and spatial imagination.

The metrics of the SC suffer from the same problem of high heterogeneity. According to the purpose of the labelling or ranking, the dimensions and the ontologies of the data vary consequently. As noted by Picon, they all nevertheless share common means and objectives: ecology, sustainability, efficiency and optimization through the use of IT, providing competitive environments. Two techniques are mainly used to measure the degree of smartness: Benchmarking and Modeling (Komninos 2007). We will focus on benchmarking practices as they constitute the main core.

Benchmarking consists in the comparison of cities between each other to learn from the best practices. It permits to understand the weaknesses or strengths of a particular environment, and to work to overcome or rely on them. The role of these rankings is of a huge importance for territories in order to situate themselves in the international competition and to foster economic growth (Giffinger 2010). Territorial Benchmarking is defined as such:

In all cases the process starts with a definition of benchmarking topics, and goes on to select 
the indicators per topic, followed by data collection, selection of the comparison group, calculation of benchmarks, and interpretation of the results. The scope of the methodology is always the same. We attempt to define the range of variation of performance in any field of activity, the minimum, average, and maximum scores of performance, the distance from the best, and the practices that sustain performances. (Komninos 2007,131)

Even if there is no consensus on metrics, we can note some more influential insights. One of the most representative research is the Smart-Cities Ranking of mediumsized city. The aim of the benchmarking is clear, it is to help medium-sized cities to become competitive at international scale in terms of resources, critical mass and organizing capacity. Were selected cities of more than 100.000 inhabitants, with at least one university, already cited in other ranking or with headquarters of a major company. These criteria added with the data availability permitted to rank 70 cities in Europe. According to the literature' review the scientists made, six domains of smartness were identified -smart economy, smart people, smart governance, smart mobility, smart environment, and smart living. Upon these domains, they proposed 74 indicators, themselves regrouped in 31 factors. There is a lot that could be commented on the factors and indicators of Smartness, but we will focus on the Smart people factors, as it is representative of the new radically inclusive strategy.

The diverse dimensions used point at one type of population. Well trained, adaptable to the labour market, flexible and creative, cosmopolite and open-minded, while always voting; the factors clearly indicate which behaviour is right to be smart. Benchmarking practices and dimensions' finding 'are full of values, judgements and deliberate strategies of occlusion' (Kitchin 2016, 52).

Despite lack of evidence of its impact on the population, the authors insist on how this ranking has oriented numerous politics, particularly in the cities included in the ranking. Coupled with the forced enrolment of citizens in the fabrication when implementing corporate SC initiatives, the performativity of such metrics is extended with the use of environmental technologies that 'mobilise urban citizens as operatives within the processing of urban environmental data [...]. Citizens [...] have a set of citizen-like actions at their disposal, enabled by environmental technologies that allow them to be participants within the smart city.' (Gabrys 2014, 41). These metrics and technologies introduce a self-enforced means of regulating the way we act, move, think and perceive in the SC, without the need to directly govern individual practices; the new environment outlines and makes the right behavior emerge by compliance and convergence. In this motion, the rights of the citizen are replaced by choices to be made (Cowley, Joss, and Dayot 2018), and we observe a transformation from inhabitant to consumer and data-producer

\begin{tabular}{|c|c|}
\hline 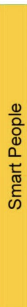 & $\begin{array}{l}\text { Level of qualification } \\
\text { Level of qualification } \\
\text { Level of qualification } \\
\text { Affinity to life long learning } \\
\text { Affinity to life long learning } \\
\text { Affinity to life long learning } \\
\text { Social and ethnic plurality } \\
\text { Social and ethnic plurality } \\
\text { Flexibility } \\
\text { Creativity } \\
\text { Cosmopolitanism/Open-mindedness } \\
\text { Cosmopolitanism/Open-mindedness } \\
\text { Cosmopolitanism/Open-mindedness } \\
\text { Participation in public life } \\
\text { Participation in public life }\end{array}$ \\
\hline
\end{tabular}

Figure 1. Dimensions, factor and indicator corresponding to the calculation of Smart People. Giffinger et al. 2007)

$\begin{array}{llc}\text { Importance as knowledge centre } & 2006 & \text { regional } \\ \text { Population qualified at levels 5-6 ISCED } & 2001 & \text { local } \\ \text { Language skills } & 2005 & \text { national } \\ \text { Book loans per resident } & 2001 & \text { local } \\ \text { Participation in life-long-learning in \% } & 2005 & \text { regional } \\ \text { Participation in language courses } & 2005 & \text { national } \\ \text { Share of foreigners } & 2001 & \text { local } \\ \text { Share of nationals born abroad } & 2001 & \text { local } \\ \text { Perception of getting a new job } & 2006 & \text { national } \\ \text { People working in creative industries } & 2002 & \text { national } \\ \text { Voters turnout at European elections } & 2001 & \text { local } \\ \text { Immigration-friendly environment } & 2006 & \text { national } \\ \text { Knowledge about the EU } & 2006 & \text { national } \\ \text { Voters turnout at city elections } & 2001 & \text { local } \\ \text { Participation in voluntary work } & 2004 & \text { national }\end{array}$


in the way people are considered by policymaking (Cardullo and Kitchin 2019).

The metric of SC does not function as a mirror that reflects reality. The dimensions, indicators and factors that permit to rank cities and policies is creating a form of ethic based on algorithm (Söderström 2014; Vanolo 2014), strongly de-politicising the planning decision, indicating what is the good behaviour to adopt. This 'objective reality' based on the city as a set of measurable facts, apparently transparent and nonpolitical deeply modifies the way cities are produced. They are strongly normative as they are shaping governance while influencing decision-making, institutional spending and workers forms of labour (Kitchin et al. 2015). In this perspective we intend to outline that, through SC' programs, our spatial and political individuation (Simondon 2005) are short-circuited, hindering our capacity to think the articulation of contingent sociospatial alternatives, from the level of the body (what is a good and smart citizen) to the level of the institution (what is a good and smart university) and policy-maker (what is a good and smart decision). This reality formulated by those metrics and programs presents itself as natural, and thus should be considered as hazardous (Zupancic 2011; Fisher 2009), extending a scientific realism to constitute a capitalist realism. Capturing our future (and its markets) by a colonisation of its imaginaries, it is then urgent to find new narratives and alternative figurations of the way IT could be implemented in our environments, and of what could be a SC.

\subsection{Alternatives}

Nevertheless, some perspectives arise in the need of new ways of theorizing, cases to examine and methodologies for comparative research (Luque and Marvin 2015). Soderstrom and McFarlane (2017) proposed a new framework to define smart urbanism. To do so, they depart from several assumptions for the most shared amongst critical scholars: urban intelligence or SC program should not be primarily associated with new technologies. Secondly, territories and cities of the Global South should also be studied and hypothesized as potential fields for smart urbanism, for the notion not to be north centric and normative. Then, if technology is not the (main) core of Smart Urbanism, knowledge, in all its forms, is the main means of such an approach.

According to the authors, the return of modernist and technocratic approaches of planning in smart urbanism necessitates the use of theories of usable knowledge (Lindblom and Cohen 1979). As such scientific knowledge is inefficient without the encounter with ordinary knowledge, which combination is at the core of an usable one. It demands scientists or companies to first identify the knowledge and use out of the traditional scope of the 'techno-fetichism of smart urbanism discourse' $(2017,16)$, and defined by grounded co-productions, and simultaneously understanding the knowledge forms of the residents. Knowledge and learning are then becoming the critical point of smart urbanism, as the technology implemented should follow the lines of identification and not the inverse. Based on empirical research, this renewed approach of urban intelligence and SC is grounded on the 'place-based, experiential, and largely neglected urban knowledges of residents in precarious contexts' $(2017,30)$, permitting to foresee an inclusive and contributive dimension in the smart urbanism. Also, Barcelona is developing a remarkable counter-model based on digital sovereignty and it has been largely noticed by scholars. Even if some scholars now proposing some alternative visions' state of the art (see Morozov et Bria 2018), no scholars have yet attempted to provide a frame for an alternative metric. We argue that if we develop a demanding and situated metric, the act of measuring could be seen as an occasion to foster inclusion, knowledge in all its forms 
and socio-spatial alternatives to the dominant models of SC.

\section{GIVING GROUND TO (URBAN) INTELLIGENCE. IN BETWEEN COGNITIVE SCIENCES AND ARCHITECTURE}

\subsection{Focusing on the value of the metric. Political and Spatial Imagination}

One of the key aspects to consider when assessing the adequacy of any given metric regards the relationship between two distinct yet inextricably linked elements of measurement: worth and value. In explaining the main of Tractatus de mensuris, by Von Freiberg, Brighenti (2017) argues that establishing 'measures' is a double task: on the one hand, a measure ought to provide a ratio of magnitude [molis ], on the other, it ought to provide a ratio of worth [virtus]. Brighenti unsurprisingly argues that the asymmetrical development of magnitude corresponds to the development of modern science. In this process, we seem not only to have lost sight of the crucial link between measure and worth, but also to have fallen into the argument that magnitude is devoid of any inherent valuing apparatus. Such step conceals that measures constitute a directed focus of attention that frames any given phenomenon within a chosen reference (the metric), and value therefore lies at the core of measure, yet not simply as a product of measurement.

That a magnitude has its meaning dependant on the broader context that explains the consequences of such a score is evident. However, with the development of synthetic indicators as in the area of SC assessment, the moral-political face of measures might not be explicitly rendered. Any magnitude's use is endowed with such dimension because it was devised as a technical tool to capture an essentially axiological value and requires, as Brighenti (2017) puts it, to be cast into light - including for instance issues of justice, fairness, competition and reward.
Our objective in this paper invites us to tackle Brighenti's question anew: How could a nonformalised notion of value be envisaged in connection to measure?

One of the the key elements that any metric devoted to capture the intelligence of cities cannot circumvent are the main core values of urban settlements: urbanity. Cities have arguably proven in the course of history to be spatial and social devices for the articulation of social diversity, facilitating the birth of societies that respond to completely different logics than those in rural areas (Tonnies, Durkheim 1912). In fact, cities have facilitated the emergence of greater heterogeneity as if they were devices for overcoming determinism and entropy. A particularly interesting and fecund notion that captures the inherent pregnancy of value within the measures of salient forms (here borrowing from Thom 1988), is urbanity, conceived in terms of unbounded or unrestricted communication (Heidegger and Habermas 1984). In this respect, urban living is closely associated with an orientation towards the other through uncertain and undirected means and uncodified forms. Such orientation is best captured in Levinas' notion of "hospitality", as a sensual contact mediated by closeness and physical proximity (Levinas, 1969,172-174). In Jacques Derrida's (1995) work we find an expansion of this ethics towards an "unconditional hospitality": the idea of welcoming differences rather than simply tolerating them.

This view captures the value of urbanity as essentially alien to current metrics of city's smartness. In fact, this necessary ingredient of contingent indeterminacy brings us to one of the key elements and capacities through which an urban society can effectively dissipate entropy: imagination, understood as the virtual manufacturing (in lack of a better term) of virtual horizons of possibilities.

Now, how can such ideal elements of urbanity be materialized or even programmatically rendered into measurable elements? Analysing 
this notion of welcoming diversity through a material spatial perspective, it is in the theories and methods of space syntax (Hillier and Hanson 1989; Hillier 1996) where we find a sophisticated method of quantifying how urban morphology contributes to engendering social heterogeneity. Approached from a spatially syntactical perspective (1996), their methods quantify urban centrality through network measures, allowing us to verify to what degree a given tissue favours types of interaction between locals and passers-by that are arguably behind dynamics of societal richness. We bring this as an example of particular instances of molis (measure) where a complex yet specific virtus (value) is evoked, which seems to us more relevant and programmatically useful than most current indicators of smartness.

\subsection{Spatiality as a support for thinking. Intelligence, coupling and performativity}

Evelyn Tribble's Cognition in the Globe (2011) begins with an enigma: 'Early modern adult playing companies coped with enormous mnemonic loads, apparently performing up to six different plays a week, with relatively infrequent repetition, all the while learning and mounting a new play more than once a month' $(2011,1)$. The traditional explanations of such performances were hypothesized the actor's enormous internal cognitive capacities. Nevertheless, it seems that even for extremely trained actors, to learn so rapidly and with no or little rehearsal is almost impossible. Against all odds, she applied the model of distributed cognition's research that takes into account for a full range of factors that could foster, enhance and distribute certain cognitive processes. She led an analysis of the material conditions, of the social structure of the company, of the gestures in the performances, and of the nature of the text, amongst others, within the hypothesis that "no one of these elements, taken alone, has sufficient explanatory power" $(2011,7)$. What
Tribble proved in her book is that the space of the theater and the embodied and collective use of the stage played a tremendous role in the capacity of the actors to memorize and play the piece. Space and its myriad of objects actively participate to a form of collective intelligence.

Going out of the theater, we could argue that urban spaces are supporting cognitive processes. In some, we put memories -cognitive offloading-, and thus, they support processes of remembrance; in other, we may be supported by the environment to learn, discuss, make politics, imagine, invent as much as space help us in navigating or feeding. In this perspective, thinking, without being situated would be an utterly demanding cognitive burden.

This idea is highly supported by recent cognitive science's theories that go further than the distributed cognition hypothesis. The scaffolded mind theory (Sterelny 2010) proposes that 'human cognitive capacities both depend on and have been transformed by environmental resources' (Sterelny 2010, 472). Going from the analysis of Otto's notebook (2010, and others) to emotions and affect (Colombetti 2017), these theories have been used to outline how human cognition can be better understood if we think the mind in its place and in its body (Varela, Thompson, and Rosch 1991; Conein et Jacopin 1994). Nevertheless, 'there is an absence of a serious consideration of spatial dimension of such resources beyond their object like dimension' (Negueruela del Castillo 2017, 163).

Recent theories on performativity have suggested that 'performances do not take place in already existing locations [...] These "stages" do not pre-exist their performances, waiting in some sense to be mapped out by performances; rather, specific performances bring these spaces into being.' (Gregson and Rose 2000, 441). A performance is a 'situated convergence of human and nonhuman elements and force relations through which people, places and things emerge or 
become' (Kaiser and Nikiforova 2008, 123), reenactment of sociospatial norms through citational practices (Butler 1990).

Thus, returning to the Globe Theater, we could argue that the spatial intelligence demonstrated by the actors is due to a performative reenactment of the Elizabethan theater; through their practices, the actors, the spectators and all the nonhuman agents are performing a spatiality that supports the actors individual cognitive capacities in the process of remembrance. In this perspective, it seems really important to insist on the fact that the spatiality that support cognitive processes is brought into being by an individual and collective practice; it underlines that there is no form of spatial or urban intelligence that could exist per se, demanding a relational understanding between objects, bodies and virtualities.

\subsection{Measuring. Trust reliability and commons}

If there is still a lot to investigate on the way urban spaces can support cognitive processes, and consequently, on how we could (if possible) design space that performatively becomes resources for thoughts and actions, we can frame a metric for urban intelligence based on dimensions that permit to measure to which extent a resource is scaffolding a cognitive process. In his essay, Sterelny, without pretending to be exhaustive, proposed Trust, Interchangeability / Individualisation / Entrenchment and Individual / Collective.

o Trust is characterised by the internal assessment of the reliability of the access to the resources, as much as the reliability in the resources in itself. The more the agent has trust in the resources, the less he/she needs to assess insurances against forms of failure - Interchangeability, Individualisation and Entrenchment are dimensions of the relationships manufactured by skills in time. In order to illustrate the individualisation dimension, Sterelny introduces the example of the professional cooker's knife. His/her knife is necessarily highly individualised; the weight, the sharpness and the balance of the knife are transformed and modified, fitting perfectly in the routine of the cooker. In the same motion, the routine of the cooker, his/her movements are adapted to the balance, the weight and the sharpness of the knife; his/her knife is highly individualised but also highly entrenched in his/her cognitive processes. The gradient is then from interchangeable and standardised resources to individualised and entrenched.

o The Individual and the Collective are gradients integrating the notion of collective as an environmental resources. In this sense, a lot of cognitive processes occurs through collective interaction and not through individual to external resources' interactions. The collective resources are under the scope of intergenerational dynamics, responding to the niche evolution theory (Odling-Smee, Laland, et Feldman 2003), shaped by collective buildings, generational transmissions and modifications.

While trying to apply this model to urban spaces, several elements can be reported. In first place, dimensions of trust and reliability does testimony for a radical ecology; any damaging or spoiling of a resource -urban space- would have for consequences a biais for cognitive processes, addressing in this prospect the growing prominence of the value of care and of the urban as a common good (Harvey 2008; Lefebvre 1974). As already underlined Clark and Chalmers in 1998, 'It may be, for example, that in some cases interfering with someone's environment will have the same moral significance as interfering with their person. And if the view is taken seriously, certain forms of social activity might be reconceived as less akin to communication and action, and as more akin to thought' $(1998,10)$.

Equally, it emphasizes on the accessibility of urban space as one of the main dimensions of urban intelligence; if a space can not host, he can not support individual and collective intelligence. In continuation, the urban in its 
capacity to welcome and host the alterity (Derrida 1995 elaborating on Levinas 1969), to be radically inclusive in unbounded (Habermas 1984) and potentially uncodified ways, captures the essence of a radical and pregnant (Thom 1988) value, or intensity (Brighenti 2019), which ought to be resituated in relation to any extensive measure or metric.

The dimensions of interchangeability, Individualisation and entrenchment unveil two other major issues of urban intelligence; hyper-locality and appropriation. Thus, the westernisation' process of cities are phenomenon that does harm the tissues' ability to support certain kinds of cognition, notably highly specialized and situated cognition. This dimension could be measured through the diversity of uses of the spaces and their degree of specialisation. In continuity, appropriation testimonies of an entrenchment of space into uses, and emphasise the role of care and common. The Individual-collective dimension are directly echoing with the accessibility and sovereignty, as means of imagination. Even if we can not postulate an urban intelligence and its metrics per se, these dimensions indicate the crucial role of spatialities that support cognitive capacities and ways to frame situated research in the future.

\subsection{Chimerical visions for the smart city. Imaginations, figurations and performativity}

Proposing this definition of smartness and urban intelligence implies a major shift in current policy-making and SC initiatives. It formulates urban intelligence as a relation between a capacity of the urban to support cognitive processes and an individual and collective process of imagination and entrenchment. As introduced, corporate discourses on SC and IT's implementation are strongly normalizing the future's imaginaries. Spatial imagination is influenced and enacted by representations outlined by powers and the performative re-enactment of social norms and relationships to space (Gregson and Rose 2000). Thus, scholars from geography argue that new technologies are not leading to a re-invention of these practices, but to their reinforcement. Their implementation in cities is reproducing class and genderrelations, racialized urban landscapes, urban inequalities, while serving the interests of corporations and governments (for a resume, see Rose 2017). Sharing this critical stance, Rose underlined that the urban media manifold is however producing new posthuman agencies; posthumans 'can reiterate, modulate, and translate those differences, as well as create new forms of differentiation' (2017, 787); namely this same horizon could make emerge alternatives and subversions from the very material seams of its entangled apparatuses.

Re-appropriations of sovereignty and future through imagination are a key hinge toward an integrative and embodied smart urbanism. As such, we contend that the implementation of new technologies into urban planning can be the occasion to create new situated worldviews based on new posthuman agencies and their associated differentiations' forms. Literature on anticipatory techniques have been flourishing in these last decades (Kinsley 2010). Techniques and technologies play a fundamental role in the merging of new figurations. Through the outlining of new figurations of the SC, at the encounter of embodied practices, individual/collective imagination and anticipation, can emerge new performative spatialities (Gillian and Rose 2000) for cognitive processes to be supported by. Along the proposed dimensions for the new metric based on cognitive sciences theories, these chimerical visions, in between bodies, technologies, virtualities and other vibrant matters (Bennett 2010), give ground to a situated, politicized and embodied urban intelligence. 


\section{CONCLUSION}

In this article, we try to outline in which ways the SC program and its metrics are acting from policy making to bodily scale. We emphasize the diverse forms of rationalism that lie under the implementation of new technologies in urban planning. This reveals how the realitymaking process they are based on is fostering an extraction of sovereignty. A review of one of the most influential metrics showed us how SC programs were addressed to a certain kind of population -well-trained, flexible, creative... Coupled with the forced enrollment of citizens in SC programs and the environmental technologies that permit citizens to monitor their own practices, these metrics are giving ground to a new form of ethics whose compliant associated behaviors are emerging from diffuse and indirect strategies of control. From that point, we bring in the point of view of different scholars and projects on possible or realized alternatives to this SC paradigm. They attest to a dynamic and coherent field of critique challenging the corporate perspective. Nevertheless, no alternative metrics have yet been developed. We argue, in regard to former paradigms, that this could be an instrument for democratization and citizen's sovereignty enhancement by establishing and discussing the worth of a ratio in relation to its magnitude. Grounded on insights from cognitive sciences and performativity theory, we propose another definition of spatial, and thus urban, intelligence. Spatiality has been sketched out as a support for cognitive processes, while being itself brought into being by citational practices, opening the path for a relational, situated and embodied definition. From there, we discuss the dimensions assessing to what extent a resource is scaffolding (supporting) a cognitive process in the context of urban intelligence, defining six non-exhaustive dimensions: trust, reliability, accessibility, sovereignty, hyper-locality, appropriation.
Then we emphasize the importance of new forms of posthuman agencies in the outlining of urban intelligence, as themselves being able to renew and reinvent spatialities of SC. As such, spatial -and political- imagination, as an embodied and collective practice, had been argued as the main mechanism of creating socio-spatial alternatives to the corporate and normalized SC.

It is thus evident that this metric is highly theoretical and has been manufactured in between the secured and comfortable walls of a (Swiss) university. We nevertheless contend that it is from this same locus that should emerge new SC programs and initiatives focused on knowledge-intensive and inclusive territories despite all the scientific crises that universities are going through. It has been for long outlined that the power-knowledge relationships in cities are the core of the re-enactment of inequalities and corporatism (Foucault 1969, 1975), and universities are the center of this distribution. While recognizing the importance of usable and situated knowledge, against systemic and unadapted solutions, institutions should reinvent their role in their own territories and start taking care of their environment. Institutional imagination (Barnett 2013), as an extension of the chimerical imagination we discussed, is one of the major hinges toward an embodied, politicized and inclusive urban intelligence. 


\section{REFERENCES}

Barnett, Ronald. Imagining the university. Routledge, 2013.

Batty, Michael. "Big Data, Smart Cities and City Planning ». Dialogues in Human Geography 3, no 3 (november 2013): 274-79.

Brighenti, A.M « Umwelt-measures. On extensive and intensive measures: Introduction to the special issue 'Theorising measures, rankings and metrics'» In Social Science Information 1-14. 2019

Bennett, Jane. Vibrant Matter: A Political Ecology of Things. Durham: Duke University Press, 2010.

Butler, Judith. " Gender trouble, feminist theory, and psychoanalytic discourse ». Feminism/postmodernism 327 (1990): x.

Cardullo, Paolo, and Rob Kitchin. "Smart Urbanism and Smart Citizenship: The Neoliberal Logic of 'Citizen-Focused' Smart Cities in Europe ». Environment and Planning C: Politics and Space 37, no 5 (august 2019): 813-30.

Clark, A., and D. Chalmers. "The Extended Mind ». Analysis 58, no 1 (1 january 1998): 7-19.

Colombetti, Giovanna. "Enactive Affectivity, Extended ». Topoi 36, no 3 (septembre 2017): 445-55.

Conein, Bernard, and Éric Jacopin. "Action située et cognition. Le savoir en place». Sociologie du travail 36, no 4 (1994): 475-500

Cowley, Robert, Simon Joss, and Youri Dayot. "The smart city and its publics: insights from across six UK cities ». Urban Research \& Practice 11, no 1 (2018): 53-77.

Derrida J, Points: Interviews 1974-1994 Stanford: Stanford University Press, 1995

Durkheim, Emile. Les formes élémentaires de la vie religieuse: le système totémique en Australie, Quadrige, 5. éd, [original 1912] (Paris: Puf, 2005).
Florida, Richard L. The Rise of the Creative Class: And How It's Transforming Work, Leisure, Community and Everyday Life. Nachdr. New York, NY: Basic Books, 2006.

Foucault, Michel. Surveiller et punir. Naissance de la prison. Editions Gallimard, 1975.

Foucault, Michel, et Angèle Kremer-Marietti. L'archéologie du savoir. Vol. 1. Gallimard Paris, 1969.

Fisher, Mark. Capitalist Realism: Is There No Alternative? Zero Books. Winchester: 0 Books, 2009.

Gabrys, Jennifer. « Programming environments: environmentality and citizen sensing in the smart city ». Environment and Planning D: Society and Space 32, no 1 (2014): 30-48.

Giffinger, Rudolf, Christian Fertner, Hans Kramar, and Evert Meijers. « City-ranking of European medium-sized cities ». Cent. Reg. Sci. Vienna UT, 2007, 1-12.

---.« Smart Cities Ranking: An Effective Instrument for the Positioning of the Cities?» ACE: Architecture, City and Environment, february 2010.

Gregson, Nicky, et Gillian Rose. «Taking Butler Elsewhere: Performativities, Spatialities and Subjectivities ». Environment and Planning D: Society and Space 18, no 4 (août 2000): 433-52.

Habermas J, The Theory of Communicative Action. Vol.1 Cambridge:Polity Press, 1984

Harvey, David. «The right to the city ». The City Reader 6, no 1 (2008): 23-40.

Hillier, Bill. Space Is the Machine: A Configurational Theory of Architecture. Cambridge: Cambridge University Press 1996

Hillier, Bill, and Julienne Hanson. The Social Logic of Space. Reprint edition. Cambridge: Cambridge University Press 1989

Hollands, Robert G. «Will the Real Smart City Please Stand up?: Intelligent, Progressive or Entrepreneurial? » City 12, no 3 (december 2008): 303-20. 
Hutchins, Edwin. Cognition in the Wild. MIT Press, 1995.

Kaiser, Robert, and Elena Nikiforova. "The Performativity of Scale: The Social Construction of Scale Effects in Narva, Estonia ». Environment and Planning D: Society and Space 26, no 3 (2008): 537-62. Kinsley, Samuel. "Representing 'Things to Come': Feeling the Visions of Future Technologies ». Environment and Planning A: Economy and Space 42, no 11 (novembre 2010): 2771-90.

Kitchin, Rob, Tracey P. Lauriault, et Gavin McArdle. "Knowing and Governing Cities through Urban Indicators, City Benchmarking and Real-Time Dashboards». Regional Studies, Regional Science 2, no 1 (janvier 2015): 6-28.

Komninos, Nicos. Intelligent Cities and Globalisation of Innovation Networks. 1re éd. Routledge, 2008.

Laland, Kevin N., John Odling-Smee, and Marcus W. Feldman. "Niche Construction, Biological Evolution, and Cultural Change». Behavioral and Brain Sciences 23, no 1 (february 2000): 131-46. Lefebvre, Henri. «La production de l'espace». L'Homme et la société 31, no 1 (1974): 15-32.

Levinas E, Totality and Infinity: An Essay on Exteriority Pittsburgh: Duquesne University Press, 1961

Lindblom, Charles Edward, et David K Cohen. Usable knowledge: Social science and social problem solving. Vol. 21. Yale University Press, 1979.

Luque-Ayala, Andrés, anbd Simon Marvin. «Developing a Critical Understanding of Smart Urbanism? » Urban Studies 52, no 12 (september 2015): 2105-16.

McFarlane, Colin, et Ola Söderström. « On Alternative Smart Cities: From a Technology-Intensive to a KnowledgeIntensive Smart Urbanism ». City 21, no 3-4 (4 july 2017): 312-28.
Montello, Daniel R. 1998. 'A New Framework for Understanding the Acquisition of Spatial Knowledge in Large-Scale Environments'. In Spatial and Temporal Reasoning in Geographic Information Systems, edited by Max J. Egenhofer and Reginald G. Golledge, 143-154. Spatial Information Systems. New York: Oxford University Press.

Morozov, Evgeny, and Francesca Bria. "Rethinking the smart city ». New York: Rosa Luxemburg Stiftung, 2018.

Negueruela Del Castillo, Darío. "The City of Extended Emotions ». Thesis, Ecole Polytechnique Fédérale de Lausanne, $2017 . \quad$ https://infoscience.epfl.ch/ record/231145.

Picon, Antoine. Smart cities: théorie et critique d'un idéal auto-réalisateur. Paris: Éditions B2, 2013.

Simondon, Gilbert. L'individuation à la lumière des notions de forme et d'information. Krisis. Grenoble: Millon, 2005.

Rose, Gillian. "Posthuman Agency in the Digitally Mediated City: Exteriorization, Individuation, Reinvention ». Annals of the American Association of Geographers 107, no 4 (4 juillet 2017): 779-93.

Söderström, Ola, Till Paasche, and Francisco Klauser. "Smart Cities as Corporate Storytelling ». City 18, no 3 (4 may 2014): 307-20.

Sterelny, Kim. " Minds: Extended or Scaffolded?» Phenomenology and the Cognitive Sciences 9, no 4 (december 2010): 465-81.

Thom R 1988 Esquisse d'une sémiophysique. Paris: InterEditions.

Vanolo, Alberto. "Is There Anybody out There? The Place and Role of Citizens in Tomorrow's Smart Cities ». Futures82 (septembre 2016): 26-36.

--- . "Smartmentality: The Smart City as Disciplinary Strategy ». Urban Studies 51, no 5 (april 2014): 883-98. 
Tribble, Evelyn B. Cognition in the Globe: Attention and Memory in Shakespeare's Theatre. 1st ed. Cognitive Studies in Literature and Performance. New York: Palgrave Macmillan, 2011.

---. « Distributing Cognition in the Globe ». Shakespeare Quarterly 56, no 2 (2005): 135-55.

Varela, Francisco J., Evan Thompson, et Eleanor Rosch. The embodied mind: cognitive science and human experience. Cambridge, Mass: MIT Press, 1991.

Zupancic, Alenka. Ethics of the real: Kant and Lacan. Verso Trade, 2011. 


\title{
SMART DESIGN FOR BICYCLE PARKING STATIONS. A PROPOSAL FOR THE HISTORICAL CENTER OF AREQUIPA, PERU
}

\author{
Gabriela Manchego a ${ }^{a}$ Cinthya Butrón Revilla ${ }^{a}$ \\ aUniversidad Nacional de San Agustin de Arequipa, Arequipa, Peru
}

\section{ABSTRACT}

The sustainable development of cities implies a comprehensive urban approach, coupled with this mobility and environmentally friendly modal alternatives, have taken an important focus on citizenship. This research addresses the problem of urban mobility in historic centers recognized as cultural heritage of humanity, where the urban layout has similar characteristics, such as the square grid and orthogonal streets. In addition, in recent years, the increase in the number of motor vehicles and the centrality of activities have generated vehicle pressure and congestion in this urban area. The present study proposes to improve the urban mobility of the historic center of Arequipa - Peru, implementing and promoting the use of bicycles, as a modal alternative and part of a sustainable and intelligent urban mobility policy. This current study proposes a quantitative methodology that combines the use of mobile applications with traditional urban design to intelligently and efficiently plan the location of bicycle parking stations. For the purposes of this proposal, two sources of data were used; the first corresponds to the analysis of geo-positioned data of a group of urban cyclists, who agreed to use a mobile application that identifies itineraries and their potential daily routes, while the second corresponds to the visualization of the proposal of the location of the two-party systems generated through the diagnosis of the case study, based on traditional urban design criteria. This information was contrasted, to finally show as a result the criteria for the efficient location of bike parking using technology, thus concluding, in an efficient proposal for locating and typifying bike parking stations for the historic center of Arequipa.

\section{KEYWORDS}

Bicycle parking; sustainable urban mobility; smart mobility; historical center.

\section{INTRODUCTION}

Modern societies demand high and varied mobility, and this demand has been gradually overcome by the creation of a transport system that guarantees the safe, flexible and efficient movement of people and goods, something which is framed in the new logic of the paradigm of sustainability. From this standpoint, the sustainable development of cities implies an integral urban approach, where the design of a flexible, safe and efficient transport system contributes to intelligent and sustainable mobility patterns. These patterns are currently relevant due to environmental pressures, the effects of on technology social and economic factors, as well as the correlation between them. Therefore, the exponential growth that this sector has experienced and its foreseeable increase makes the challenge of sustainable urban mobility a strategic priority on a wide-ranging scale.

Sustainable urban mobility and environmentally friendly modal alternatives, such as the modal alternative of the urban bicycle, have taken on greater importance for local residents. In this sense, in recent decades, local governments have increasingly encouraged the use of this modal alternative through various initiatives, such as investments in bicycle infrastructure. In addition to this, the amount of research on this 
topic has grown exponentially. Latest studies focus on the infrastructure necessary for the circulation of bicycles, but studies related to the infrastructure for bicycle parking have received limited attention, although the bicycles are parked most of the time. For example, studies in Germany and the United States show a probable underestimation of bicycle parking, although bikes are often parked for up to 23 hours a day. This estimate assumes that cyclists who own parked bicycles do not use bicycles as a modal alternative.

In general, in developing cities, where the use of the bicycle as a modal alternative has increased markedly and the construction of infrastructure to boost it has been increasing its value, various studies have shown that bicycles are mostly parked at the place of residence of the users, in a second position at work and in a third position near public transport stations. On the other hand, in developing cities, where bicycle use has also increased, despite the low investment in infrastructure, said increase has been more notable in the historical centers, where the greater concentration of activity generates pressure and vehicular congestion in its urban layout, which has motivated the use of the bicycle as a modal alternative

Arequipa is an intermediate city, whose foundational grid was declared by UNESCO as Cultural Heritage of Humanity in 2000. There are several Latin American cities, which have historical centers with a reticular pattern, narrow streets, religious facilities, entities public, specialized trade and work centers. The local government has implemented measures for the restriction and regulation of motorized mobility, however, there are few actions to promote non-motorized mobility. This work shows the requirement for innovative methodologies that allow prioritizing actions in favor of infrastructure such as bike parking that increase conservation and urban equity in the heritage management of historic centers.

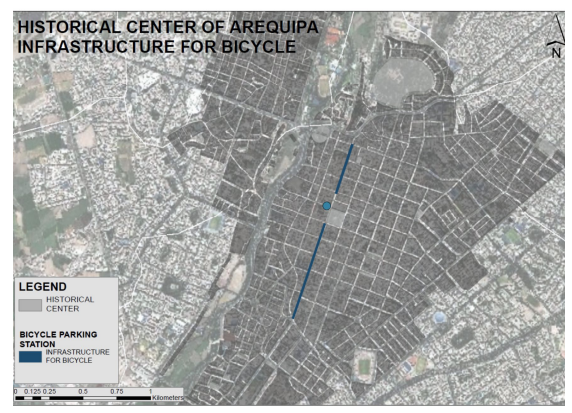

Figure 1. Infrastructure for Bicycle in Historical Center of Arequipa (Manchego 2020)

\section{SUSTAINABLE URBAN MOBILITY}

Cities feed, change and reproduce in accordance with the mobility of their inhabitants (Joye, Kaufmann, y Bergman 2004). Mobility refers to a series of variables that, unlike transport, which only considers available displacements. Mobility includes the social, political, economic and cultural conditions of those who mobilize. Sustainable urban mobility must be defined based on the existence of a system and transport patterns capable of providing the means and opportunities to cover economic, environmental and social needs efficiently and equitably (Mollinedo 2006). Therefore, the actions to be taken to achieve solutions within the framework of sustainable mobility must consider three factors: First, the social aspect, which must allow the accessibility and generating social equity in the transport systems; second, the ecological aspect, because any such system must protect the environment, reducing the greenhouse gas emissions generated by motorized transport; and third, the economic factor, which must satisfy the economy by promoting development and competitiveness, reducing and regulating the needs of various economic sectors (Muñoz Sotomayor, Betancourt, and Jaramillo Sangurima 2016). 
The International Public Transport Union considers that sustainable urban mobility must be based on three "pillars": A land use that incorporates all types of mobility needs, the restriction of the use of private vehicles and the promotion of a system of effective public transport (UITP, 2003). Therefore, adding to the concept of "mobility" the qualification of "sustainable" aims at urban planning that restores the balance between all means of movement (automobile, public transport, walking, cycling), protects the environment and that is articulated to urban development planning and territorial planning (Poole-Fuller 2017). The new concept focuses on the improvement of the mobility and accessibility conditions aiming at a better quality of life for urban citizens, and hence on the pursuit of what is currently called sustainable urban mobility (Costa 2008). In this context, for urban mobility policies to be effective, they must adopt a more integrated approach and make use of technological innovation, promote clean, safe and intelligent transport, economic incentives and changes in legislation. Also, Mobility management consists of soft measures such as awareness, information, communication and marketing campaigns.

The concept of sustainable urban mobility must therefore be understood to be the result of a set of transport and circulation policies that seek to provide broad and democratic access to urban space through the prioritization of non-motorized and collective modes of transport, of effective, socially inclusive and ecologic ${ }^{\circ} a l l y$ sustainable factors, based on people and not on vehicles (Boareto, 2003, p. 49). As a result, sustainable mobility policies must be integrated from the planning stage, promoting the use of means of clean, safe modes of transport and intelligent, communication awareness and generating changes in legislation as well as the promotion of non-motorized means of transport.

\subsection{Smart Mobility}

The analysis of urban mobility can be used to understand the behavior of citizens and improve the services, transport and use of urban areas (Ahlers et al. 2016). By adding to the concept of "urban mobility", the qualifier of "sustainable" aspires to an urban planning that restores the balance among all means of displacement (Poole-Fuller 2017) such as cars, public transport, walking and the bicycle. On the other hand, by adding the qualification of "smart", the aim is to articulate these means of displacement transversely (Fu et al. 2016), using technological innovations.

In general, displacement research that contributes with results for studies of sustainable urban mobility has focused on the analysis of the trajectories generated through a smartphone. Paths that are generated by a mobile phone and represented as geographical points on a map are called Smartphone Tracking or Mobile Tracking (Fu et al. 2016). Data obtained from citizens' mobile devices can be used as a basis for urban planning tools. This type of data can facilitate analysis tasks, such as the extraction of human mobility patterns (Wang et al. 2018), or the determination of the urban dynamics of cities. In addition, the data obtained from different users can be visualized simultaneously in a single view, making it possible to identify trajectories or groupings of displacement. In addition, we can analyze the similarity between trajectories, similarity between points within the same grouping, and find anomalous displacements (Senaratne et al. 2018).

Additionally, urban monitoring can be expanded in real time, not only from buses and taxis, but throughout a larger urban area, via an anonymous monitoring platform (Wang et al. 2018). Some studies (Calabrese et al. 2011) have analyzed mobile tracking in order to identify travel or traffic modes in real time, as well as the choice of routes or distribution of products, which has allowed improved urban mobility in terms of vehicular 
congestion, especially in spaces where there are conglomeration of activities, such as historical centers or metropolitan areas of large cities. In addition to this, one of the most efficient responses to the problem of vehicular congestion lies in the intensive use of computer systems and telecommunications applied to traffic management. Indeed, the so-called Intelligent Transportation Systems (SIT) have proved to be an efficient support for citizens and for public institutions in the attempt to alleviate the problems of congestion of urban and interurban transport (Seguí Pons and Martinez Reynés 2004), not only helping to improve its mobility but making it more sustainable.

\subsection{Mobility in Metropolitan Areas (Historical Centers)}

Historical centers, or in the foundational metropolitan centers of cities, especially those that have already grown, have the need to respond to changes in use, customs and a rapidly expanding demography, and in turn need to satisfy commercial, administrative or governmental needs, observing how some colonial mansions or structures have acquired various uses and have become the daily scenario of vehicular and pedestrian, daytime and labor chaos. It is these same centers of the city, subjects of higher density, which brings with its disintegration and greater environmental, visual and auditory pollution, making the deterioration of the city and the lack of attention to important aspects such as protection of history, security and mobility even more evident.

Furthermore, the main problems of mobility and accessibility in the centers of historical cities are the central position, special characteristics of the roads, the concentration in the historical centers of tertiary activities, particularly administrative and commercial, and the presence in these centers of the main historic and heritage buildings. Fig 2. While the main problems generated by road traffic in the historic centers are air pollution, noise pollution, negative visual impacts, the effects on pedestrian movements, streets and squares as places of passage, as well as other effects. (Gutiérrez Puebla and García Palomares 2016). When these conflicts become visible, it is possible that the deterioration of the city center is already advanced, becoming a thorough study of the theory and history of the city's conformation.

Then, to review other cases, models of improvement that facilitate making a diagnosis

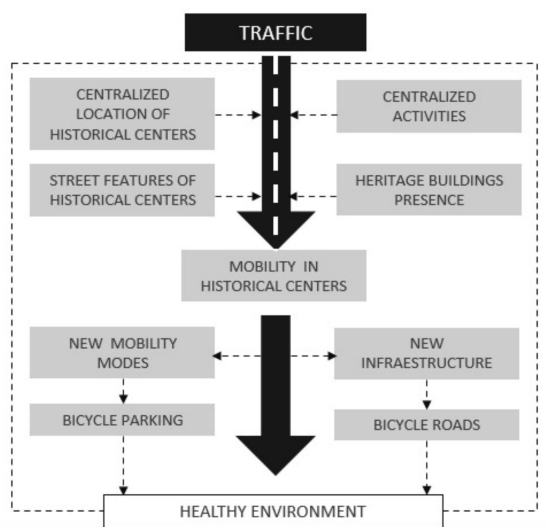

Figure 2. Mobility in Metropolitan Areas (Butrón 2020) based on (Gutiérrez Puebla and García Palomares 2016)

and an appropriation of the problem in order to generate a specific theoretical position of its own (Gutiérrez Puebla and García Palomares 2016). So, if government solutions which take into account the importance of mobility in historical centers are not initially established, the question arises of how to implement tentative strategies to improve not only mobility but also the quality of life of people living in and using this sector. From the point of view of the incorporation of friendly mobility modes, it is the implementation of infrastructure that encourages the use of the bicycle, which would contribute as a tentative strategy to create a healthier environment. 


\subsection{Biclycle Parking}

The location of bicycle parking stations in cities is a challenge from a mobility and urban planning perspective. The development and application of bicycle infrastructure is essential to increased bicycle use. Bicycle parking can protect bicycles from theft, damage and weather. The presence of bicycle parking stations, the comfort and security of the location, its quality and the potential cost facilitates or hinders cycling. Easy-to-access, safe and economical bicycle parking can increase the likelihood of cycling. On the contrary, the absence of an easily accessible, safe and economical bicycle parking stations may deter cycling (Heinen y Buehler 2019). For example, in schools, the availability of parking spaces or stations was found to have a positive effect on cycling to school, but the evidence is mixed, even though the lack of bicycle parking is often mentioned as a reason for not cycling to school (Mackie 2010).

Transportation professionals and urban planners have limited guidance on where parking is best located, how many parking stations are needed and what features this parking should have in terms of quality, proximity and price. The desirable characteristics of bicycle parking facilities may depend on the characteristics of the parking behavior itself (for example, duration and frequency of parking), characteristics of the trip (for example, purpose and distance), the bicycle (value and/or type), location (at home, work, public transport stop) and the user. In addition, these factors can be interrelated. For example, long-distance
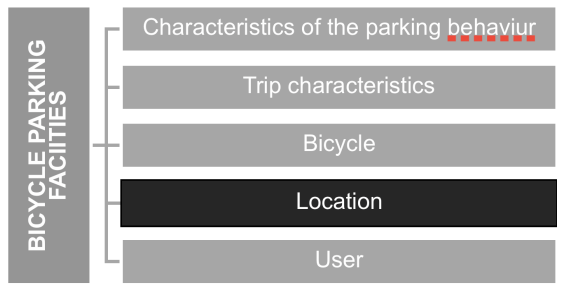

Figure 3. Bicycle Parking Facilities (Manchego 2020) based on (Heinen and Buehler 2019)

trips may require higher quality and more expensive bicycles with greater financial damage in case of theft. Alternatively, people can ride cheaper and lower quality bicycles if the possibility of theft is high (Heinenand and Buehler 2019).

\section{MATERIALS AND METHODS}

The case study of this research is the historical center of the city of Arequipa, Peru, which is a concentrated urban area of square blocks with narrow, perpendicular streets, stone pavements, and both with both civilian and religious historical buildings. In addition, the city center concentrates important activities and the cycling groups demand more cycling infrastructure. Fig. 1 shows the infrastructure for the existing bicycle, counting only one kilometer of segregated bikeway and one bicycle parking near the main square. It is urgent to prioritize the investment of infrastructure based on evidence that encourages the use of non-motorized modes of travel.

The research presents 2 stages of analysis (Figure 4): Phase 1, a traditional urban analysis and Phase 2 an intelligent analysis of routes
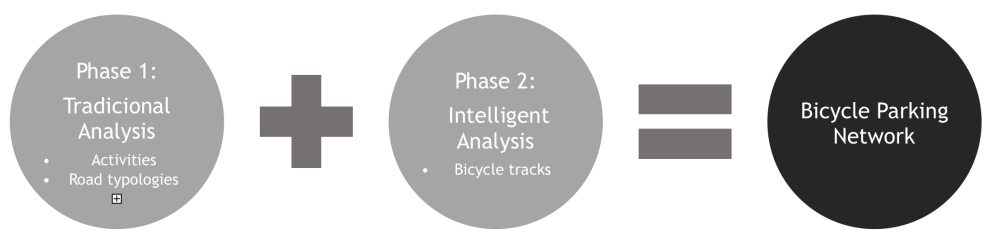

Figure 4. Bicycle Parking Network Stages (Manchego 2020) 
of cycling users through the use of a mobile application for the location of a two-station network for the case of study, the historical center of Arequipa ( $\mathrm{CHA}$ ).

The first stage was carried out in the subject Urbanism 1 of the academic period 2018 B, in the School of Architecture at the National University of San Agustin of Arequipa. The students carried out the formative research work entitled "Bike Parking Proposals for the Historical Center of Arequipa", for which they formed work teams to perform an analysis of the components of the urban structure of the historical center of the city of Arequipa, such as activities (land uses), typologies of roads and squares, parks and green areas. In their Tradicional Analysis of the Historical Center of the city of Arequipa, they recognized numerous equipment from administrative, educational, also attracts attention the number of religious equipment. Likewise. Arequipa presents a variety of Parks and places, among the most representative, the Main Square and the San Francisco Place, both spaces around religious equipment. In addition, the Plazoleta San Camilo and the Duamel Park, represent attractive spaces for the location of bicycle parking for the commercial activities they offer in their immediate surroundings. And for another park, in the north zone is the park Selva Alegre, open space for active and passive recreation on weekends. In this Phase the students proposed the location of 15 biparking based on traditional urban design.

In the second stage, on the initiative of the local government and the Metropolitan Institute of Planning IMPLA, and supported by the Faculty of Architecture and Urbanism; volunteer urban cycles were called to use a mobile free application data. The cyclists use the application to generated data during a week. Ten urban cyclists were summoned to register their routes through a mobile free application data, to identify potential daily itineraries and routes showing the following. Ten urban cyclists, among women and men, managed to report at least 3 itineraries in the week of experience.

\section{RESULTS}

The results are visualized on three levels: a macro-level with the general routes of urban cycling at a metropolitan scale (Fig.5); a mesolevel where cycling routes in the historic center are displayed (Fig.6); and a micro-level where the public spaces of the historic center and cycle routes are showed (Fig.5). As a result, the contrast between urban cycling routes and cycle parking points are displayed. Those are proposed by a traditional urban design that analyzes: activities and services diagnosis, road directions and open spaces (squares and parks) of Arequipa's Historic Center to find its strategic location.

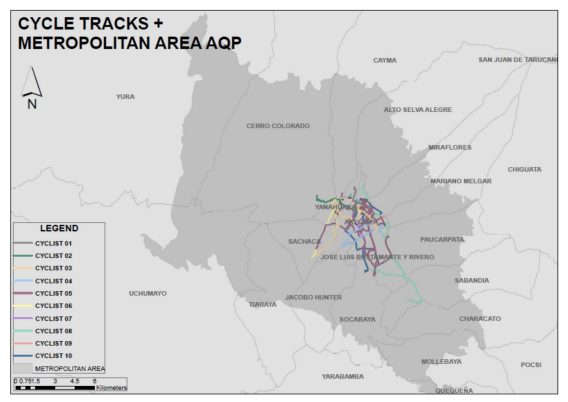

Figure 5. Macro scale. Cycle tracks and metropolitan area of Arequipa (Manchego and Butrón 2020)

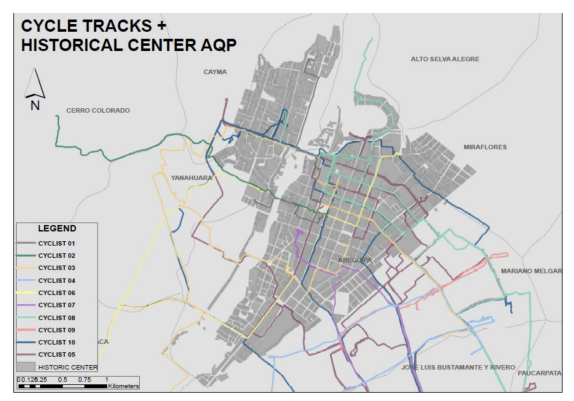

Figure 6. Meso scale. Cycle tracks and historical center of Arequipa (Manchego and Butrón 2020) 


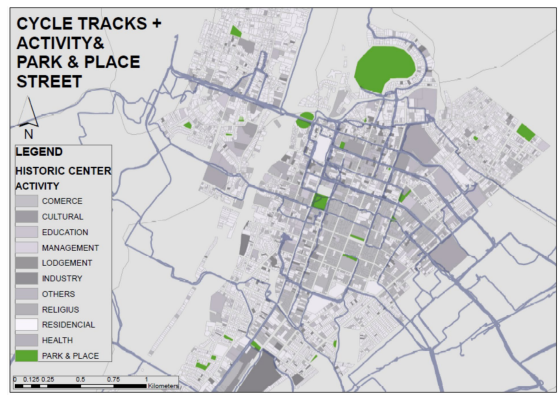

Figure 7. Micro Scale: Cycle tracks and activities of historical center of Arequipa (Manchego and Butrón 2020)

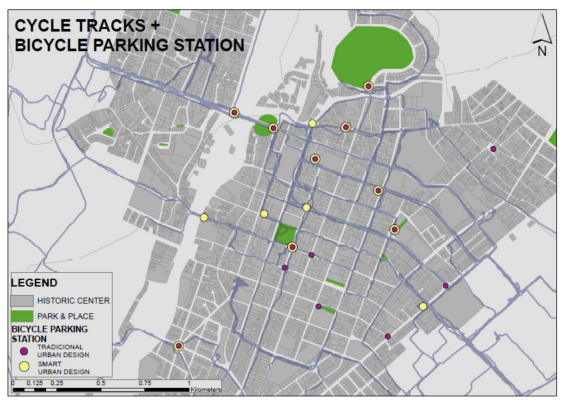

Figure 8. Proposal of Bicycle Parking Station (Manchego and Butrón 2020)

The intelligent analysis shows the real demand of urban cyclists, on the macro scale (Fig. 5) it indicates that the trips are made in the metropolitan area and that in no case do they exceed $5 \mathrm{~km}$ in distance. Also, all trips have origin, destination or passage through the historic area. On the micro scale (Fig. 7 ), it is shown that the routes that cyclists choose to travel through the historical center, is the north zone and displacements in the east-west direction. It can be inferred, the preference of urban cyclists for streets with mixed uses.

\subsection{Advantages of smart analysis}

As a result, the contrast between urban cycling routes and cycle parking points are displayed. Those are proposed by a traditional urban design that analyzes: activities and services diagnosis, road directions and open spaces (squares and parks) of Arequipa's historical center to find its strategic location. This work shows the need for cycling infrastructure based on real demand, necessary to enhance this mode of travel.

The combination of the two data sources, the geo-positioned routes of urban cyclists and the preliminary

proposal for the location of the whereabouts are showed at Figure 8. The traditional proposal of location of the bike parking stations have 15 locations and the smart analysis proposal raises 14 . There are 9 locations that correspond to both analyzes, however, it is observed that 6 stations proposed in the initial phase do not correspond to the demand of the urban cyclist tracks. In addition, due to the registered tracks, 5 new locations are proposed, completing the proposed bike parking for the historical center of Arequipa.

\section{CONCLUSION}

The actions to be taken to achieve solutions within the framework of sustainable urban mobility, are specified in three factors, the social, economic and ecological factors, which in their analysis work must have the technological component in an integral way. Also, of the three factors plus literature also proposes three pillars, which from a traditional urban design, are implemented daily in the different urban plans and manage, however it has not been proposed that these three pillars, which are, the use of land, the promotion of public transport and the decrease in the use of the car, link the modal capacity of the city in a transversal way, taking into account more 
options of modes of transport the citizen has greater freedom to mobilize.

This research evidences the importance of the data obtained from the mobile devices of citizens and its relevance as a tool for urban planning and design. From the perspective of the use, analysis and management of citizen displacement data, the literature is corroborated, stating that the use of these can facilitate analysis tasks and decision making in planning, as well as in the extraction of patterns of human mobility or the determination of urban dynamics of cities. In addition, the data obtained from different users allow us to identify trajectories or groupings of displacements that not only link us to determine displacement patterns, but also grouping of anomalous displacements.

The analysis of results allows to detect that urban mobility can be used to understand the behavior of citizens and improve the services, transport and use of urban areas, as is the case of the proposal of the location of the bicycle parking stations. It may have concluded in a traditional urban design, but when using technology, the smart urban design proposal is made, which finally allows us to safely discard some stations where cyclists do not travel frequently. Also, the result, shows the importance of real-time urban monitoring not only motorized vehicles such as public transport, but of friendly transport modes, which allow to implement or improve urban infrastructure in this case, cyclist infrastructure like bicycle parking station, especially in spaces with particular urban structures of historical value.

\section{ACKNOWLEDGEMENTS}

We want to thank to the Faculty of Architecture and Urbanism of the National University of San Agustin of Arequipa. 


\section{REFERENCES}

Ahlers, Dirk, Patrick Driscoll, Erica Löfström, John Krogstie, and Annemie Wyckmans. 2016. "Understanding Smart Cities as Social Machines», 759-64. https://doi. org/10.1145/2872518.2890594.

Calabrese, F., C. Ratti, M. Colonna, P. Lovisolo, and D. Parata. 2011. «Rome. Real-Time Urban Monitoring Using Cell Phones: A Case Study». IEEE Transactions on Intelligent Transportation Systems 12 (1): 141-51.

Costa, Silva. 2008. "Multiple views of sustainable urban mobility: The case of Brazil ^nio Ne» 15: 350-60. https://doi. org/10.1016/j.tranpol.2008.12.003.

Fu, Zhongliang, Zongshun Tian, Yanqing Xu and Changjian Qiao. 2016. "A twostep clustering approach to extract locations from individual GPS trajectory data». ISPRS International Journal of Geo-Information 5 (10). https://doi. org/10.3390/ijgi5100166.

Gutiérrez Puebla, Javier, and Juan Carlos García Palomares. 2016. «Modelos de optimización de la localización de bases de bicicletas públicas: un enfoque basado en Sistemas de Información Geográfica». En . http://bike-sharing.blogspot.com.

Heinen, Eva, and Ralph Buehler. 2019. «Bicycle parking: a systematic review of scientific literature on parking behaviour, parking preferences, and their influence on cycling and travel behaviour». Transport Reviews 39 (5): 630-56. https://doi.org/10.1080/01 441647.2019.1590477.

Joye, Dominique, Vincent Kaufmann, and Manfred Max Bergman. 2004. "Motility: Mobility as Capital». International Journal of Urban and Regional Research 28 (4): 745-56. https://onlinelibrary. wiley.com/doi/pdf/10.1111/j.03091317.2004.00549.x.
Mackie, Hamish. 2010. «Overcoming barriers to cycling to school: a key to improving transport system performance.» 151 (4): 1-46. https://doi.org/10.1016/j. cell.2009.01.043.

Mollinedo, Carmen Lizárraga. 2006. «Movilidad urbana sostenible: un reto para las ciudades del siglo XXI» VI. https:// doi.org/http://dx.doi.org/10.22136/ est002006260.

Muñoz Sotomayor, Verónica Alexandra, David Betancourt, and Wilson Jaramillo Sangurima. 2016. «Diseño de Ciclovías para Ciudades Intermedias, una propuesta para Loja». INNOVA Research Journal 1 (12): 11-22. https://doi.org/10.33890/ innova.v1.n12.2016.77.

Poole-Fuller, Esteban. 2017. «¿Hacia una movilidad sustentable? Desafíos de las políticas de reordenamiento del transporte público en Latinoamérica. El caso de Lima». Letras Verdes. Revista Latinoamericana de Estudios Socioambientales, n.o 21: 4. https://doi. org/10.17141/letrasverdes.21.2017.2445.

Seguí Pons, Joana María, and María Rosa Martinez Reynés. 2004. «Los sistemas inteligentes de transporte y sus efectos enla movilidad urbana e interurbana». Revista electronica de geografia $y$ ciencias socialesnica de geografia $y$ ciencias sociales VIII: 170-60. https://doi. org/10.1017/CB09781107415324.004.

Senaratne, Hansi, Manuel Mueller, Michael Behrisch, Felipe Lalanne, Javier BustosJimenez, Jorn Schneidewind, Daniel Keim, and Tobias Schreck. 2018. «Urban Mobility Analysis with Mobile Network Data: A Visual Analytics Approach». IEEE Transactions on Intelligent Transportation Systems 19 (5): 1537-46. https://doi. org/10.1109/TITS.2017.2727281. 
Wang, Yulong, Kun Qin, Yixiang Chen, and Pengxiang Zhao. 2018. «Detecting anomalous trajectories and behavior patterns using hierarchical clustering from Taxi GPS Data». ISPRS International Journal of Geo-Information 7 (1). https:// doi.org/10.3390/ijgi7010025. 


\title{
PAPER \#4.04
}

\section{A BIOMIMETIC RESEARCH ON HOW CITIES CAN MIMIC FORESTS TO BECOME SUSTAINABLE AND SMART}

\author{
Aliye Rahşan Karabetça ${ }^{a}$ \\ aistanbul Kültür University, İstanbul, Turkey
}

\section{ABSTRACT}

In nature, everything is functional to each other. Every single organism supports the other either with a symbiotic relationship or in terms of form and function. For instance, some trees shed their leaves to the ground to prepare themselves for harsh winter conditions and also to create nutrition for microorganisms and fungus under the surface. This kind of interaction with nature could lead architects to develop better solutions to create better built environments; this is the main objective of this paper. The paper aims to clarify and prove that nature is the greatest mentor and can teach humanity many solutions about designing smart cities. There is a new and powerful way of seeking solutions in nature; biomimicry. In this context, using biomimicry as a design strategy is the methodology of this study. Biomimicry is used as a design approach to reach examples in nature by filtering them with biology. These examples are considered to be scientific fields for researching and understanding the structural strength, bioclimatic properties, functional morphology and other features of forests. They are explained to identify forests and provide resilient solutions for developing smart cities. Outcomes of this paper aim to scientifically state that forests are naturally sustainable environments which are the greatest examples for smart cities. When they unite, they can create the most suitable living environments for all living organisms. Several conceptual ideas and methods are suggested based on the biomimetic design approach to make the argument clear and more understandable.

\section{KEYWORDS}

Resiliency; biomimicry; smart cities; forests; architecture.

\section{INTRODUCTION}

Since the Industrial Revolution, cities were created without considering nature, such as surrounding environments, weather conditions, oceans, natural resources, forests, etc. This led humans to become incautiously independent, unaware of the natural world, and put themselves at the top of the life cycle. Thus, today's cities have become incapable of supporting massive population growth (URL1). Considering that environmental pollution, carbon emission, energy consumption, damage to nonrenewable resources are increasing very rapidly. Sets of precise and sustainable solutions should be developed to stop this catastrophe. How can this problem be reversed? What can be done? There are some ways and approaches designers consulted to look for better ideas in the past but very few looked at nature. As Einstein once said, looking into nature helps humans to understand everything better. What one should do to create sustainable cities is to look at nature for solutions. Otherwise, building cities with similar methods and expecting different results is just a hopeless effort. Humanity needs to build environments that function like forests; resilient, generous, recycling, energyefficient, aesthetic, etc.

This paper aims to emphasize the importance of using biomimicry and biology to reveal functions and solutions a forest can offer 
for a sustainable city design. Designing built environments that function like these ecosystems can be possible with the biomimetic design approach. It is a scientific field that works with different disciplines, mainly biology. Thus, multidisciplinary collaboration is a must. Biomimicry is a new field of science that deals with transferring nature's genius into human-made designs. It leads and guides designers to use principles and strategies of functions in nature to solve human challenges. It is a broad and powerful field and offers nature's endless solutions for every part of the built environment.

Forests live as large groups of trees. They can be counted as the biggest built environments of nature. They are the largest ecosystems which differ from each other according to their species, locations and regions containing thousands of microecosystems within them. Every single member of this ecosystem; mainly trees, when they come together, they create the most sustainable, suitable and resilient living environments for other organisms. For example, a dead tree trunk can manage water consumption for living trees even by standing still that provides a useful service (Wohlleben, 2016). This is how trees embrace and give life to thousands of different life forms; fungi, woodpeckers, beetles, leaf cutters, ants, butterflies, giant trees, etc. The safety and lives of these organisms depend on the strength and durability of each tree in the forest. Therefore, they are well designed, structurally strong, durable, resilient and aesthetic.

Forests are part of a biome that is part of a sustaining biosphere (Benyus, 2014). Their contributions to humans' lives cannot be ignored or be underestimated. Humans cannot exist without forests, but forests can. They are natural air filters. They breathe in the carbon dioxide we produce and breathe it out as oxygen for us to survive which is called photosynthesis. So, why not buildings photosynthesize like trees to eliminate the carbon footprint?
The following must be considered: if a city functions as a forest, then local and nonrenewable resources will be conserved. The main requirement for cities to be sustainable and smart is to understand how forests work and incorporate them into humans' lives.

\section{NATURE CAN PROVIDE SOLUTIONS VIA BIOMIMICRY}

Constructing sustainable buildings with technology is solely possible if the technology considers nature as the design mentor. To follow nature's pathway of designing means searching nature's sustainable design ideas to develop innovative technologies and applying these ideas into humans' lives in the most suitable and appropriate ways. Hereby, design challenges such as pollution in cities, energy loss, climate and structural equipment, etc. which have a large impact on the increment of carbon footprint, would be improved and would make the greatest contribution to the development of smart cities. The fundamental principle of these studies is to accept the biomimetic design approach as the major design guide. During this stage, biology is the first discipline to be considered as a fundamental supporter. Besides, it is highly possible to derive healthy and accurate data by applying biomimicry as a design criterion into the design stage to create a prototype that would be tested in pilot regions.

There are some concrete examples of this process proving that biomimicry can change the design and its results. One of them is the East Gate Building in Harare, Zimbabwe (Fig.1). This building is one of the original biomimetic designs. The inspirational organisms are termites and their mound. Cities created with these kinds of designs could decrease and perhaps eliminate the negative impacts of urbanization. According to research, the world is urbanizing rapidly, and cities will be tripled in size by 2030 (URL 2). The research also states that the need for smart and sustainable cities 

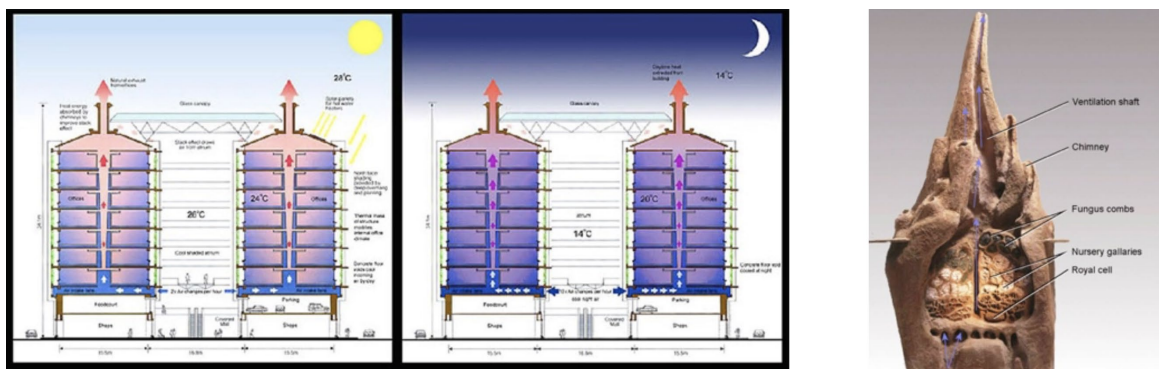

Figure 1. (a) East Gate building designed by Mick Pearce and (b) termite mound. Sources: (URL 3).

is overriding. This is why the design of cities should be based on principles that nature has developed and tested.

There is another example that is not designed with the biomimetic design approach but still a promising building example for designing a sustainable city, Bosco Verticale in Milan. It is considered as pilot project of a new generation of sustainable buildings (URL 4). These buildings were designed in collaboration with ethologists and botanists to develop the botanical components. Two towers have some benefits for the city. For instance, plant-based shields on facades do not reflect sun rays that decrease solar radiation that helps to reduce the use of mechanical ventilation systems (URL4). As a result, forestation on facades can indirectly decrease their carbon footprint.

However, such buildings are considered green buildings where the biophilic design approach is involved more than biomimicry, still very much needed for sustainable cities (Fig. 2). Using biomimicry in architecture not only as a source of form but also as a design strategy comprises more sustainable designs; for example, shapes of nature may provide solutions to architects and engineers for designing resilient structures. On the other hand, many different organisms may offer solutions for energy efficiency, anti-reflective surfaces, self-cleaning paints, or water collecting facades (Karabetça, A.R.,2015). Buildings designed with these ideas would have different consequences.

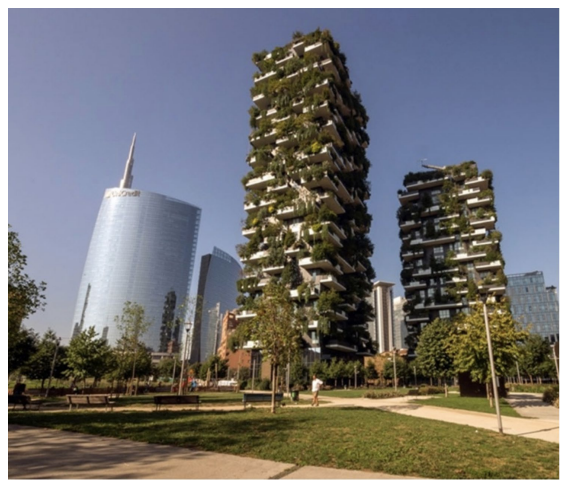

Figure 2. Bosco Verticale (Vertical Forest) in Milan, Italy (URL 4).

\subsection{How do forests work?}

It is critical to consider nature while designing. Nature allows nothing to go to waste; it recycles water, soil, carbon, and air to sustain all habitats. A responsible and sustainable architecture lies underneath this logic. Nowadays, the relation between architecture and nature is at its peak point due to the environmental crisis. Because of this peak point, seeking a responsible architecture became vital. Consequently, several kinds of researches on how to establish built environments mimicking 
forests have been made throughout the last decades.

Forests are incredibly sustainable and smart environments. They are capable of many things. They have many functions to survive the worst. They can absorb water from clouds, and they can help retain water onsite by interacting with other species. Fallen trees can stabilize and enrich the soil; they inhabit thousands of species working and living in collaboration. There are thousands of valuable functions that forests provide for themselves and for the other living organisms within. Trees in forests such as firs, spruce, beeches or oaks, support each other due to tough/beneficial conditions. They help their young to grow with full nutrients mainly sugar provided from fungus under the soil through their roots. Roots are the most important parts of forests, they are considered as the brain of forests; they provide a very powerful intercommunication with other species (Wohlleben, 2016). On the other hand, every forest survives according to the living conditions of that region. Redwood forests in California have different habits but spruce forests in Europe are quite different then redwoods. For example, Alders can survive in wetlands/marsh areas, but beech cannot. It's because beeches cannot grow in wetlands due to their physical conditions. The forest ecosystem has a sensitive balance. Each member of the forest has functions that contribute to others' lives (Wohlleben, 2016). However, conditions in the forest are not very easy. Each species tries to survive and takes what it needs from others. All of them are brutal and there is only one reason why the system does not collapse; there are protective methods against those who ask for more than their needs (Wohlleben, 2016). It is one of the important reasons why humans face too many problems; we take more than we need, and there is not a protective method against this behavior. The consequences of this greed are underwhelming.
Forests recycle everything cities do not, forests do not produce waste, cities do, and it is mostly not recyclable. Although there are some fights within everything, forests work in harmony where others get benefit from it. Forests are restorative, regenerative, sustainable, and life-giving. Nature uses a minimum amount of energy to complete the process when producing, there are no leftovers. It makes everything as it requires to be when it needs to be (Harman, 2013).

\section{SUSTAINABLE SMART CITIES THAT MIMIC FORESTS}

A city can be smart but not sustainable that today's most cities are alike. Cities, in general, are growing upwards and outwards like forests. However, they are not the same. One grows upwards due to photosynthesis, which is vital for the sustainability of the forest, and other grows for people to gain benefits of clustered urban life that outweigh the liabilities of living in a densely populated place called economy and business (URL 5). These two targets are essential. But people do not have to live in a city where there are too many adverse effects for sustaining their lives; traffic, air and environmental pollution, energy loss, large carbon footprints, buildings that spread radiation, and carcinogen, etc. Cities are not only growing vertically but also growing horizontally, and doing them at the same time at recorded levels creates deliberate consequences for land use, environment, and planet earth (URL 2). When cities filled with green, does it mean they are sustainable and/or smart? In many cases, they are not. Because turning the city into green helps to reduce radiation of sunlight that also helps to reduce energy consumption. If cities could be designed with ideas emulated from nature, they would not only reduce energy consumption but would reduce water consumption, collect water, store water, create better circulation 


\begin{tabular}{|l||l|l||l||}
\hline \hline No & Name of the city & Location & Design features \\
\hline \hline 1. & $\begin{array}{l}\text { Smart Forest City Cancun by } \\
\text { Stefano Boeri Architects }\end{array}$ & Cancun, Mexico & $\begin{array}{l}\text { To inhabit 130.000 people with } \\
7.500 .000 \text { plants } \\
\text { Completely food and energy self- } \\
\text { sufficient. (URL7) }\end{array}$ \\
\hline \hline 2. & Liuzhou Forest City & Liuzhou, China & $\begin{array}{l}\text { absorb 116.000 tons of carbon dioxide, } \\
\text { solar panels, self-sufficient energy, } \\
\text { green roofs and facades }\end{array}$ \\
\hline \hline 3. & Vincent Callebaut Smart City & Paris, France & $\begin{array}{l}\text { bio-air condition the urban heat island } \\
\text { phenomenon, } \\
\text { thermodynamic green towers, etc. }\end{array}$ \\
\hline \hline
\end{tabular}

Table 1. Examples of Forest Like Cities (Table created by the Author).

systems, habitable indoors and outdoors, etc.

William Mcdonough known as green architect stated as follows "...buildings conceived as mass-produced machines impoverish cultural diversity and leave their inhabitants cut-off from the wonders and delights of nature (URL 6). Based on this statement, it can be said that forests that create considerable parts of nature are fundamental for the sake of the whole world. Several cities that attempted to be designed following some principles of forests (Table 1). However, these promising ideas are still immature, designed with conventional construction systems, and nearly all of them focused on energy saving.

\section{Smart Forest City Cancun, Mexico:}

Boeri designed a city that can inhabit millions of plants and 130000 people in an area of 557 hectares (Fig. 3).

The city is designed mainly with green plantation and landscaping. Also, there is going to be internal electric and semiautomatic mobility that aims to reduce the carbon footprint of the city. City plans to absorb 116.000 tons of carbon dioxide. The amount of green and the number of buildings is almost equal to each other which provides a significant balance. There are solar panels for self-sufficient energy, green roofs, and facades for reducing solar radiation enabling less energy use. Agricultural fields for food are other important features of the design (URL 7).

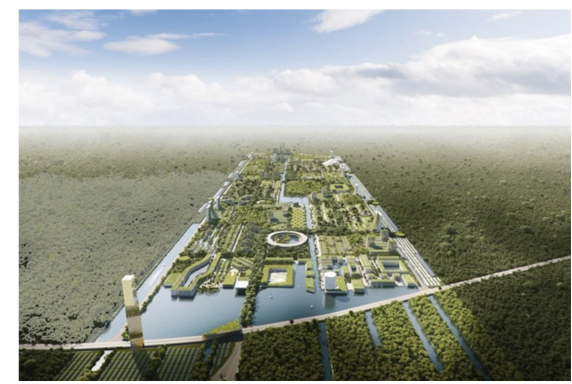

Figure 3. Smart Forest City Cancun, Mexico. Source: (URL 7).

However, there aren't any biomimetic design approaches in this design which are based on emulating/transferring functions of a forest rather than integrating trees and plants into a city.

\section{Liuzhou Forest City, China:}

Liuzhou Forest City (Fig. 4) is also designed by the same architect as the previous example. There will be 40.000 trees and more than a million plants which will allow the reduction of carbon dioxideemissions in the city. All buildings will be covered with plants accommodating more than 30.000 inhabitants. All buildings designed in this city are much alike Bosco Verticale in Milan which was also designed by Boeri. The city has similar characteristics to 
the previous example explained above. Solar panels on roofs, green roofs and facades, zero impact, an autonomous urban agglomeration, geothermal energy for heating interiors, electric train railway. According to the designer, the environmental benefits of such design are highly obvious. Vegetation for better air quality which aims to absorb 57 tons of carbon dioxide and produce 900 tones of oxygen per year. Other benefits are avoiding the use of cement, blocking the city to cluster outside by keeping buildings within the forest, safeguarding forests, and conserving biodiversity (URL8).

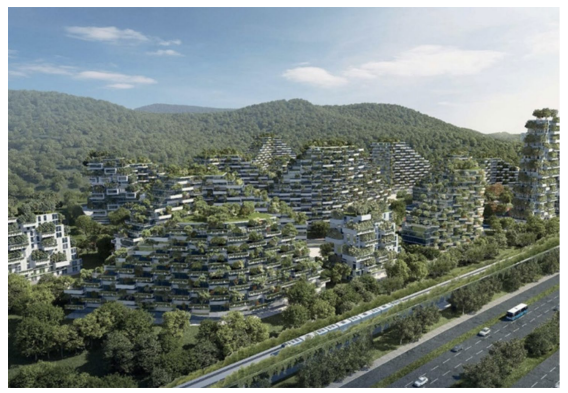

Figure 4. Liuzhou Forest City, China designed by Stefano Boeri is expected to be constructed in 2020. Source: (URL 8)

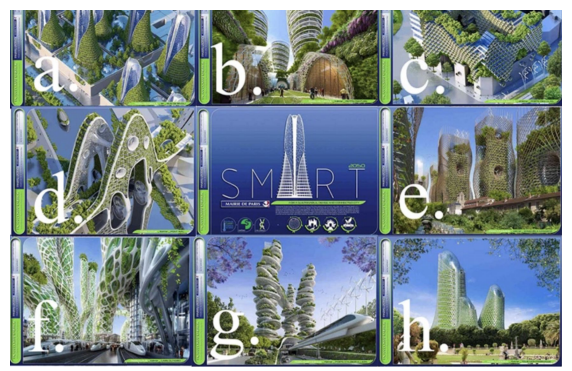

Figure 5. Eight prototypes of energy plus towers for Paris 2050 designed by Vincent Callebaut. Source: www. vincentcallebaut.org (URL 9)
Vincent Callebaut Smart City Paris 2050, France:

Vincent Callebaut is another green architect who has concerns about nature. He created many city designs that contain many plantations for some other countries. But for Paris, he has eight prototypes of energy-plus towers eco-conceived to fight against climate change (Fig. 5) (URL 9).

These are a. mountain towers that are green, solar, and hydrodynamic towers which bioair condition the urban heat island effect, b. antismog towers that create an ecologic corridor in the center of Paris, c. honeycomb towers that are housing buildings that develop energy solidarity corporation, d. bridge towers that inhabit amphibian bridging across the Seine river, e. bamboo nest towers that are thermodynamic green towers wrapped by a bamboo wired mesh of vertical gardens, $f$. farmscrapers towers is a vertical urban farm returning the countryside to the city, g.mangrove towers that are photosensitive and rooted on piezo-electrical station platforms and $h$. photosynthesis towers that have algae powered bio-facades (URL 9).

Although these designs do not include any function emulated from nature, they are still considered as smart cities. The main idea is to conserve and save energy, decrease pollution, decrease deforestation, and decarbonization which is caused by planting too many plants and trees on tall buildings. However, unexpected consequences of this type of design may result in negative ways, such as ventilation problems of materials of buildings, durability against roots and infestation, weather changes in the cities due to much planting and forestation, high risk of fire, etc. Building such cities in small scales in pilot lands to record expected and unexpected results can be suggested as an option. Meanwhile, biomimetic designs and prototypes can be developed for further achievements. As can be understood from the study, collaborative laboratory studies 
must be generated to provide accurate and usable systems.

Not all city forms can do the work the same. They may provide different consequences concerning different countries, locations, weather conditions, topography, and human culture, etc.

2.1. What can be achieved in terms of energy, structure and recycling (zero waste) behaviors of forests?

Biomimetics is a field of science that defines itself consistently with the technical implementation and application of structural systems, emulations, and biological design systems. Although emulating systems is a way of the design approach, there are some points to consider; designers must be cautious during the translation of living systems into artificial human life where everything is mechanic and should not expect the impossible. The other one is to do analog research, such as the ventilation system of Eastgate building based on termites is an analogous system (Pohl and Nachtingall 2015).

Forests have many design features that can be analogous. In this paper, energy and water efficiency, structural behavior, and recycling are studied briefly to reveal some proposals. Here are some examples based on three fundamental features of forests that can inspire innovation in designing and planning a sustainable city (see Table. 2).

Energy and water efficiency (considering that energy consumption is the primary cause of global warming and pollution)

Energy efficiency is one of the primary functions of forests. Forests save energy when they grow, shed their leaves during harsh weather conditions to eliminate energy and water use. Water is vital for the survival of forests. They have specific behavior that saves water for all inhabitants. For example, pine needles divide raindrops into smaller droplets to create a pastoral forest fog that becomes a water source for many organisms
(URL11). The density of branches and leaves of different species in the forest creates calm air that prevents water from evaporating for saving water (Wohlleben, 2016). This can inspire façade designers to develop a new generation of façades that could collect water and save energy. Buildings' roofs can be

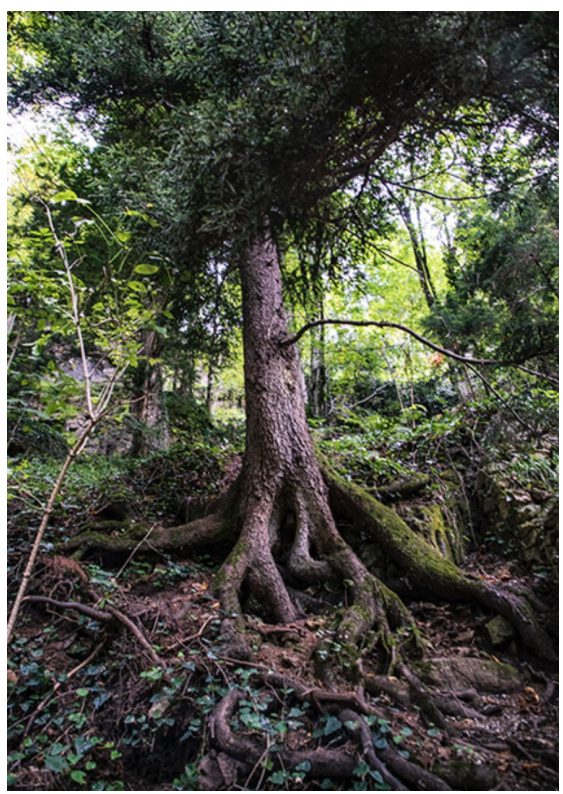

Figure 6. Roots of a tree from an old-growth forest in Trabzon holding the ground very strongly. Source: (Photo archive of the Author)

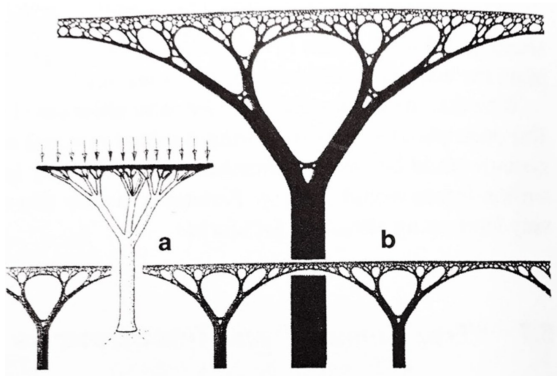

Figure 7. Lightweight tree columns for spanning structures. Source: (Pohl and Nachtingall 2015) 


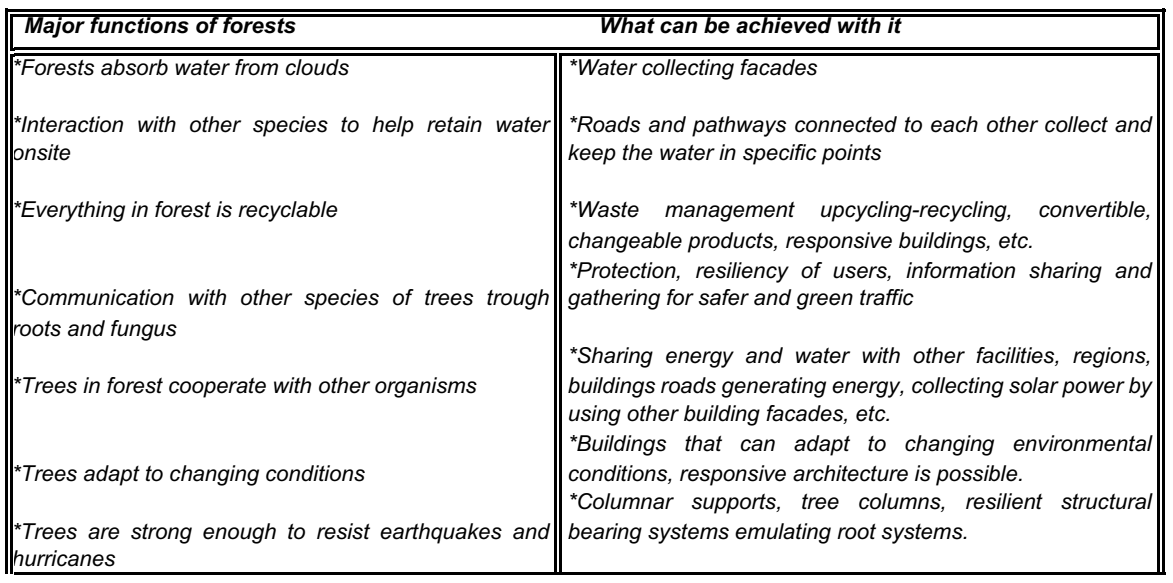

Table 2. Some major functions and design ideas that could be achieved and developed Source: www.asknature.org (URL 10) (Proposals by the Author)

designed connected like tree crowns to collect rainwater and to avoid evaporation (Fig.6).

Structural behavior

Structures such as the adhesion of a tree to the ground (Fig.6), the body of a tree, and its resistance against strong winds can be an essential structural solution method precisely for the cities on the earthquake lines. Trees grow according to the distribution of total constant stress and thus avoid peaks of tension at roots and forks. During this growth, trees add material specifically in tensioned parts, such as branches and roots (Gruber, 2011). This makes brunches and roots durable and resilient against unexpected storms and wind loads. So, it is possible to design structures functioning like tree trunks, roots, and branches. There are some examples of such systems: lightweight tree columns, root systems for resilient building design specifically located on earthquake lines (Fig. 7). The roots of trees can inspire designers to create foundations for buildings. In rain forests where the soil is shallow and cannot provide the same resistance as others in temperate climates, trees have evolved buttresses that can show greater resistance to larger loads (Pawlyn, 2011). These kinds of structural designs would help to resist against devastating earthquakes.

Recycling

Nature produces what it needs and recycles everything. There is no waste; one's trash is other's nutrients; one's carbon dioxide is another's sugar; dead tree trunk is a nutrient provider for young trees. Life in nature depends on this cycle. As the number of live and dead trees in the forest increases, the humus layer on the ground becomes very thick, as a result, more water is stored in the total forest mass (Wohlleben, 2016). It means even the dead trees have a very high and privilege benefit for all living organisms in the forest. The question is "How can this system be transferred into city planning?" or "Is it possible to design a zerowaste city?". The answer is not discovered yet. However, a prototype pilot region can be designed and built to record results for future generations. A smart and sustainable city, which has waste management similar to forest, convertible or changeable materials, responsible systems that work with recyclable materials, is possible. 
There are many organisms in the forests that can inspire designers. Table 2 shows some other examples that could be achieved. These proposals are only representing possible solutions that could inspire designers. Laboratory studies should be achieved to record and prove the results.

\section{CONCLUSION}

As a result, forests work very much different from built environments. Their main duty is to survive with the least amount of materials, effort, and energy to achieve the required job, to survive and recreate itself without giving any harm to its foundational ecosystem. After 3.8 billion years of experience, nature has found out effective ways of surviving challenges after many errors, attempts, and experimentations. Now it is designers' time to look at nature's endless library for elegant and efficient methodologies free of charge for those who are on the right path of research (Harman, 2013).

By 2025 , biomimicry is expected to impact a considerable percentage of manufacturing, waste management, architecture, and other services such as technology and robotics that are related to remediation and innovation. Technology and nature are two facts that form parts of a continuous process. Biomimicry guides designers to develop a continuous process. Sustainable and smart cities are possible yet difficult to achieve, but not impossible. Biomimicry has the potential ways of using nature's genius to develop ideas and solutions. Studying nature provides opportunities. However, turning these opportunities into rewarding solutions depends on profound laboratory work and collaboration with other disciplines. A special research center is required for such works to be supported and completed. Can a city be both sustainable and smart? What would it take for a city to function as elegantly as a forest? The answers to such questions could be given if serious researches would done. Nature is always ready to share its endless secrets with humans to achieve sustainability in architecture. It consistently uses energy more effectively and efficiently; its production system and materials are much more innocent and harmless than the materials produced by the human that significantly increases environmental pollution and energy loss. 


\section{REFERENCES}

Benus, J., 2014. Cities that Function Like Forests: Biomimicry Maps a Sustainable Future. Keynote Speaker at Geodesign Summit, California, USA.

Gruber, P., 2011. Biomimetics in Architecture. Architecture of Live and Buildings. Springer Wien, New York, USA.

Harman, J., 2013. The Shark's Paintbrush. Biomimicry and How Nature is Inspiring Innovation. Nicholas Brealey Publishing, Boston, USA.

Kellert, S.R, Heerwagen, J.H, Mador, M.L., 2008. Biophilic Design. The Theory, Science and Practice of Bringing buildings to Life. John Wiley and Sons. New Jersey, USA.

Karabetça, A.R., 2015. Nature Inspired Architectural Designs: Using Biomimicry as a Design Strategy. International Conference on New Trends in Architecture and Interior Architecture. Proceeding Book p. 143-179. Dubai, United Arab Emirates.

Mazzoleni, I., 2013. Architecturel Follows Nature. Biomimetic Principles for Innpvative Design. CRC Press, New York, USA.

Wohlleben, P., 2016. Ağaçların Gizli Yaşamı, Translated by Ali Sinan Çulhaoğlu, A.S. Publisher Kitap Kurdu, İstanbul. Turkey.

Pawlyn, M., 2011. Biomimicry in Architecture. Riba Publishing, London, UK.

Pohl, G., and Nachingall, W., 2015. Biomimetics for Architecture and Design. Nature-Analogies-Technology. Springer, Germany.

URL1:

http://themodernape. com/2015/06/02/building-cities-likeforests-when-biomimicry-meets-urbandesign/

URL $\quad 2$ : $\quad$ https://www.curbed. com/2019/2/1/18205869/city-growthurbanization-sprawl

URL 3: https://www.mickpearce.com/ Eastgate.html
URL 4: https://www.stefanoboeriarchitetti. net/en/project/vertical-forest/

URL 5: https://www.e-education.psu.edu/ emsc 100 tsb/node/144

URL 6: https://mcdonough.com/writings/ buildings-like-trees-cities-like-forests/

URL 7: https://www.designboom.com/ architecture/stefano-boeri-smart-forestcity-cancun-mexico-10-30-2019/

URL 8: https://www.lifegate.com/people/ lifestyle/liuzhou-forest-city

URL 9: http://vincent.callebaut.org/ object/150105_parissmartcity2050/ parissmartcity2050/projects

URL 10: www.asknature.org

URL 11: https://www.ozy.com/fast-forward/ cities-that-function-like-forests-are-onthe-horizon/71976/ 


\title{
PAPER \#4.05
}

\section{AGGREGATED DATA MANAGEMENT AND BUSINESS MODEL IN DESIGNING POSITIVE ENERGY DISTRICTS}

\author{
Paolo Civiero ${ }^{a}$, Jaume Saloma , Jordi Pascuala \\ aIREC Catalonia Institute for Energy Research, Sant Adrià de Besòs, Barcelona, Spain
}

\section{ABSTRACT}

The paper aims to describe the results of the on-going EU founded research titled "PEDRERA Positive energy districts renovation model" which scope is to design a tool able to support smart district renovation programmes. The key goal of the model is to facilitate the multiple stakeholders' engagement in largescale renovation actions according a Positive Energy District (PED) vision, and to predict the sustainability and positive outcomes of distinct renovation scenarios. One of the main barriers to reach this goal is the lack of integration of disaggregated information coming from heterogeneous data sources. The PEDRERA model means to build trust in the business opportunities by allowing better support to decision-making and impact assessment in order to understand and manage both the complexity of financing renewal processes at district scale and the interests of each stakeholder.

The paper addresses these challenges and will examine how data sources from different domains could be adopted in PED design once the information is aggregated, systematized and addressed to specific key performance indicators. Furthermore, the customized model will run data through a special wizard able to filter input data which are displayed and shared on a GIS platform.

According to this approach, the novel tool will be able to (1) guide and support the entire retrofit process according different issues, (2) meet the most relevant requirements from each stakeholder by prioritizing and designing energy efficient measures based on a reliable business model, and (3) help on willing sustainable energy communities to come.

\section{KEYWORDS}

Positive energy districts; smart city; sustainable energy communities; data aggregation; interoperability.

\section{INTRODUCTION}

In 2050, the built environment should be nearly carbon neutral but it's still not fully clear how to achieve a sustainability scalable model coherently with the SDGs (Sustainable Development Goals) of $\mathrm{UN}^{1}$. Considering that the building stock constitutes the largest single energy consumer in the EU, and that the value of the European mortgage market is equal to $53 \%$ of EU's GDP, there is huge potential to bridge financial innovation and the energy efficiency (EE) world and to unlock the benefits of mortgage financing to support EE to the benefit of all².

The revised Directive 2018/844/EU introduces targeted amendments aimed at mobilizing of investments toward decarbonized cities and accelerating the cost-effective renovation at the neighborhood and district scale ${ }^{3}$ which means a transition to an intelligent system based on: (a) Cluster of geo-referenced Energy-efficient Interactive Buildings (EelB) [Arbizzani et al. 2014]; (b) Interoperability and integration of data; (c) Feasibility of

\footnotetext{
${ }^{1} 2050$ Energy Strategy, European Commission https://ec.europa.eu/energy/en/topics/energy-strategy-and-energy-union/2050energy-strategy.

${ }^{2}$ Source: Energy efficient Mortgages Action Plan. https://cordis.europa.eu/project/id/746205.

${ }^{3}$ Source: ZEBRA 2020 www.zebra-monitoring.enerdata.eu/
} 
technical and economic scenarios enabled by economies of scale.

In this contribution, we present the approach of the PEDRERA (Positive Energy District Renovation Model) project whose main goal is to design an innovative energy largescale renovation model able to accelerate the urban transition towards Positive Energy Districts (PEDs) by collecting and gathering available data from multiple domains and demonstrating the feasibility and opportunities of renovation projects at large scale. The design of energy efficient retrofitting projects, in this case at district scale, is a challenging problem that requires a spatial model, a multiscale and multidomain evaluation, a constant interaction among stakeholders, and other not-directly related to energy information that will be useful to formulate predictive and feasible business model adherent to the purpose. Retrofits of this scale will require the ongoing management of a well-financed, datadriven, and strategically-targeted program.

\section{LITERATURE REVIEW}

Recent developments in the fields of Internet of Things (IOT), Artificial Intelligence (IA) and new city modeling, are driving and supporting the development of smart sustainable cities where Positive Energy Blocks (PEBs) and Positive Energy Districts (PEDs) represent crucial nodes of such cities, due to their capability in achieving a positive average annual energy balance ${ }^{4}$. When the positive energy balance assessment moves from a single building to a group of buildings at district level, new considerations are needed in terms of integrating urban and energy planning and evaluating the overall energy performance (according to different choice of assessment methods defined in the modular and overarching framework of the ISO 52000). Thus, in that case of district scale, the assessment boundaries are strictly related to the attributes of the assessed cluster of buildings, as also the mutual interactions between each other, regarding to the common technical building systems and the delivered energies carriers.

Even if an accurate concept of PED is still under discussion, PEDs are widely considered as mixed-use energy-efficient districts that have net zero carbon dioxide (CO2) emissions and actively manage an annual local surplus production of renewable energy (RES). They require interaction and integration between buildings, the users and the regional energy, mobility and ICT system, while ensuring social, economic and environmental sustainability for current and future generations.

An extensive range of different approaches and actions are currently focused on the PEDs definition and the implementation of PEDs strategy for energy transition and the climate mitigation in the urban context, among which: - PED concept integration in the SET Plan Action 3.2 implementation plan ${ }^{5}$;

- Consultations with city representatives and other urban stakeholders in various countries, in particular collecting input under the PED Programme;

- European Energy Research Alliance (EERA) Joint Programme on Smart Cities (JPSC) and the Smart Cities Information System (SCIS) ${ }^{7}$ support for the PED definition and a pathway towards PED in Europe.

\footnotetext{
${ }^{4}$ The concept of PEB is now fully recognised by the European Commission even if PEB is defined by the EU as a group of at least three connected neighbouring buildings (new, retro-fitted or a combination of both) producing on a yearly basis more primary energy than what they use. The ISO 52000-1:2017 establishes a systematic, comprehensive and modular structure for assessing the energy performance of new and existing buildings (EPB) in a holistic way.

${ }^{5}$ The Strategic Energy Technology (SET) Plan Implementation Working Group 3.2 Programme "Positive Energy Districts and Neighbourhoods for Sustainable Urban Development".

${ }^{6}$ Among other, JPI Urban Europe AGORA is focused on JPI Urban Europe's Stakeholder Involvement Platform which aims at creating the space to meet and exchange for urban actors.

${ }^{7}$ The EERA JPSC aims to accelerate new energy technology development by cooperation on pan-European programmes and is directly involved in the SET PLAN TWG 3.2. The SCIS is a platform that brings together different type of stakeholders from across Europe to exchange data, experience and know-how and to collaborate on the creation of smart cities and an energy-efficient urban environment.
} 
- National initiatives supporting $R+D+I$ on PEDs as the Spanish Technological Platform for Energy Efficiency (PTEee) ${ }^{8}$.

The draft definition of PED developed by the EERA JPSC working group, is the result of reviewing and considering definitions from current projects and programmes and bringing in particular R\&l perspective - such as the "Booklet of Positive Energy Districts in Europe $^{\prime 9}$, the PED Programme Cities Workshop, H2020 Lighthouse projects - and consultations of stakeholders on national and European levels.

Smart districts modeling methods

In this transition process toward efficient and sustainable cities, it is well known that data collection will drive planning investment policies on urban domain. Availability of widely monitored and shared data is one of the key aspects of smart cities, and would represents a barrier to sustainable urban development in the next future. The chance to access information and to manage data depends mainly by the availability of open data according specific departments at regional or local level, but also refers by the ability to aggregate data and exploit this information according user' scope. Furthermore, in order to achieve long term urban renovation processes, innovative monitoring and managing smart decision-support tools are needed to gain economies of scale through a demand-aggregation approach.

In many case the workflows can be developed for whole cities and neighborhoods to generate urban massive models from available datasets such as GIS and CityGML [Ascione et al., 2011]. Furthermore many district tools support the calculation of the yearly energy balance according different categories depending on the scope, scale and purpose of the work at hand ${ }^{10}$. Such information includes usage and conditioning profiles, the number of occupants, schedules, equipment power density, lighting and passive and active systems and their control strategies. The development of Urban-Scale Energy Modelling (USEM) at district or city level is today the goal of many research groups due to the increased interest in applications such as new strategies for city energy supply/ demand, urban development planning, or distribution networks stability. USEM faces a complex set of multi-domain problems e.g. related to multiscale heat and mass transfer phenomena (climatology, building physics, infrastructure requirements, etc.) as well as land use, transportation, urban morphology, local availability of energy resources, or user behaviour [Sola et al. 2019, Letellier-Duchesne et al. 2018].

The first step, which consist in the collection of information for creating spatial models needs, is one of the most time-consuming and costly tasks. There are many different sources of geographic spatial data and many ways to collect them. In practice, there are two main methods of data collection: (1) direct (direct data collection on the object e.g. LIDAR or its raw image); (2) indirect (based on data available in processed form (e.g. cadaster, maps, statistics, etc.) [Yanwen et al. 2017]. In both cases, a high degree of coherence is required for the application of specific data that are associated with the different objects image-into an effective model [Madrazo 2019]. This also could involve creating scenarios for future urban growth. The number of cities in the world that have their own maps model $(3 D / 2 D)$ is constantly growing. Cities like New York, London, Amsterdam, Helsinki have created their own 3D model based on open CityGML data. This type of service can be used to access geographic information or datasets of several departments, moving from many basic maps to other information on energy

\footnotetext{
${ }^{8}$ The PTEee promotes the Spanish Priority Technology Initiatives (Iniciativas Tecnológicas Prioritarias -ITPS) among which one of the goal for 2020 is to encourage $R+D+i$ collaborations between the public, scientific and business sectors on energy efficiency with a specific focus on PEDs. https://static.pte-ee.org/media/files/documentacion/itp-01-2019-distritos-deenergia-positiva-peds-tZU.pdf

${ }^{9}$ https://jpi-urbaneurope.eu/app/uploads/2019/04/Booklet-of-PEDs_JPI-UE_v6_NO-ADD.pdf.

${ }^{10} \mathrm{Among}$ others, the Building Energy Software Tools. (www.buildingenergysoftwaretools.com)
} 
and water consumption or may include the calculation of the solar potential of all roof and building surfaces. The data content in these city information model can be enriched without limit, and geometrical information are very useful, even more in the cases of a large number of buildings, enabling to calculate slope, aspect or roof surface, and to support a large number of analysis (e.g. solar radiation analysis and the design of Renewable energy sources (RES) and photovoltaic (PV) energy production in that case of self-consumption and energy communities) ${ }^{11}$.

The need for innovative financing schemes

The Energy Efficiency Financial Institutions Group reported in 2015 [EEFIG, 2017] that investments of the order of €60-100 billion are required to improve the energy performance of buildings in Europe, while the International Energy Agency (IEA) in its $2^{\circ} \mathrm{C}$ (450ppm) scenario estimates a requirement of US\$1.3 trillion in the period 2014-2035 globally [BPIE 2019]. These financial needs mean that they cannot be met by public funds alone and that also public-private partnership (PPP) must promote the energy performance improvement of buildings. The market has fully recognises that this is a low-risk activity, and that the lack of credible information on results prevents, in most cases, investments in retrofitting. [OptEEmAL 2019].

Adequate financial instruments to overcome market failures and sustain higher renovation rates are highly promoted by the $\mathrm{EC}^{12}$ and ongoing studies ${ }^{13}$ are seeking to validate three main assumptions: (1) improving energy performance has a positive impact on property value, thereby reducing a bank's asset risk; (2) borrowers have a lower probability of default as a result of more disposable income due to lower energy bills, with positive effect on bank's credit risk [source:EeMAP]; (3) implementing sustainable urban models provides notable health impacts on inhabitants, reduce harmful environmental exposures and mitigate effects of climate change, thereby improving economic savings for the healthcare system [Ortiz et al. 2019, Muller et al. 2019]. The availability of a large-scale pipeline of bankable projects to feed investment platforms and financial instruments is the key to upscaling and replicating successful projects, thereby reducing overall renovation process costs. It has been largely demonstrated [Salom et al., 2018] that the scale economy would ease the achievement of the building renovation ratios goals, by lowering the unitary required investments and optimizing the operative processes, from the technical to the administrative one's. Furthermore, this approach is wired by most recent initiatives and regulations (e.g. RD244/2019) that encourage the private sector relationships from an energy and business point of view, by introducing new concepts and legal frames as the so-called energy communities. Due to the complexity and the large number of administrative issues to be solved in such processes, the implementation of new financial schemes and partnerships with local actors (e.g. SMEs, financial institutions, energy agencies or private investors) is crucial for success [Salom et al., 2018]. Cities and regions in cooperation with local financing institutions and investors help to overcome these shortcomings by developing financial products, financial model

\footnotetext{
${ }^{11}$ Among others, the commercial suite of the software Aurora includes design and financial analysis tools custom built for C\&l projects.

${ }_{12}^{12}$ The STUNNING (SusTainable bUsiNess models for the deep reNovation of bulldiNGs) Renovation Hub is a web-based knowledge sharing platform addressing technology and business models for building renovation whose aim is benchmarking innovative and adaptable refurbishment packages and sharing and promoting successful business models for their large scale deployment and replication.

${ }^{13}$ On this matter, the MED Efficient Buildings Community, established by interreg MEDNICE Project, gives an overview of available existing barriers and financing schemes to implement Energy Efficiency projects in Public Buildings. (https://efficient-buildings. interreg-med.eu). Other relevant initiatives funded via the EC' Horizon 2020 Programme are the Energy efficient Mortgages Action Plan (EeMAP) that aims to create a standardised "energy efficient mortgage", according to which building owners are incentivised to improve the energy efficiency of their buildings or acquire an already energy efficient property by way of preferential financing conditions linked to the mortgage, or the Energy efficiency Data Protocol and Portal (EeDaPP) project to design and deliver a marketled-protocol to enable the recording of data relating to energy efficient mortgage assets and which will be made accessible via the design of a common data portal.
} 
(e.g. PPP or cornerstone management model) and innovative methods (e.g. one-stop shops) combining affordable financing with peoplecentric technical assistance (e.g. EuroPACE Platform). The above mentioned solutions make investment in energy efficiency and active measures more attractive and easier for different types of homeowners (e.g. medium income households) and for specific types of buildings (e.g. condominiums) [BPIE, 2019].

\section{METHODOLOGY}

The following key aspects will briefly describe the potential and main features of the PEDRERA model approach whose aim is to widely support and implement the largescale renovation projects towards sustainable districts by:

- Defining of fields (issues) and indicators that allow to evaluate, guide and support the best retrofitting strategy, according an holistic outlook from multiple domains and sources;

- Integrating and aggregating of data at building and district scale in order to assess the potential for renovation according specific areas of interest (categories) and scopes.

- Ranking and prioritizing values in an integrated and multidimensional model framework which facilitates - according different stakeholders' profiles - to explore potential cluster of buildings to be renovated, propose rehabilitation measures and refurbishing scenarios, and evaluate the economies of scale.

- Designing a reliable business model able to validate the whole renovation process, and to build trust in the business opportunity for investors and users.

According a wide PEDRERA vision beyond a reliable business tool, the model - still in processing - is meant to offer additional services, empowered by its implementation into a platform environment enabling: (1) to explore urban areas and automatically evaluate their renovation potential based on specific indicators; (2) to create and assess retrofitting plans supported a the reliable business plan; (3) to follow up the impact and the co-benefits of the energy renovation. Indeed, the model refers to a wider "district performance" concept, based on an holistic approach of a few indicators that really can strengthen both the stakeholders recruitment, the design and the fulfillment of the results attended. Thus, many input and indicators considered in the model may appear far from the energy efficiency goals of the renovation process itself, but the reason is stated in the remark of both the real interests of the stakeholders when financing and tackling the process, and the scope of the process.

\section{PEDRERA MODEL}

Building renovation programmes need to adopt a broader approach to increase awareness and emphasize the co-benefits of the renovation plans such as the appreciation in housing value, increase of building lifespan and improved health benefits for both the household occupants and the healthcare system. Aligned with this vision, the business model is powered by the integration of processed input that can be assumed to assess more than one indicator. Input data are supposed to be automatically retrieved from a large number of external data sources (e.g. weather, demographic/aging condition, income/energy poverty or socio-economic rating, energy demand and consume data, etc.) while other input are measured, calculated or simulated. Each indicator is arranged in specific issue and category, and its value and prioritization rank will modify the business model result [Civiero, 2017].

The model is designed according to a step by step approach where a different deepening of input - output data belongs to each phase of the renovation process (Figure 1). Seven main phases are identified where different activities and action are required: (0) the 


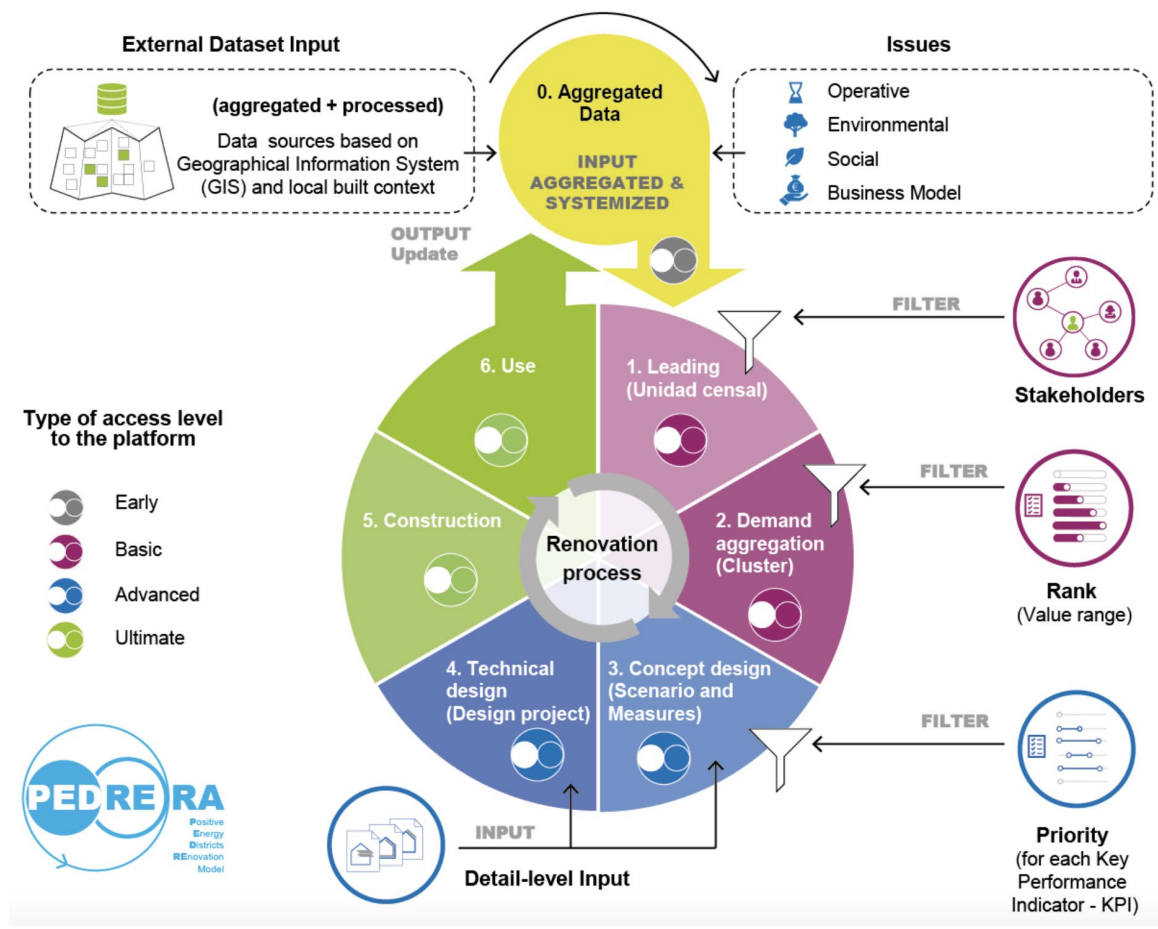

Figure 1. Renovation process: phases and interactivity of the model with data. Source: authors.

"data aggregated" - early aggregation of information, (1) the "leading"- boundaries definition of the energy community at district level (e.g. unidad censal), (2) the "demand aggregation" - clustering, (3) the "concept design" - measures to adopt according a package of solutions, strategies and potential scenario, (4) the "technical design" - economic evaluation (PEC) and business model validation, (5) the "construction phase", (6) "use".

Each phase provides a deeper and different type of information elaborated in the model. The early aggregation of input data in four main fields of performance of the district (Operative, Social, Environmental, Business Model) represents the baseline of the renovation process. In the "leading phase" an evaluation tool of the model manages all input, and returns the "district performance" dataset meant for each issue. Learnt lesson from past experience and literature review, demonstrates that in the first stage of the renovation process, investors need just a very clear and simple information able to show them the potentialities and risks of an investment. Thus, a few number of indicators are strictly linked with the definition of a weighting scheme, namely applying some values that represent the importance a certain indicator has over others.

Once input are collected, systemized and filtered, the first phase is overtaken, and a second level of information is required to 


\begin{tabular}{ll}
\hline & Grant, and EE revolving funds size \\
& PEC (including Economies of scale) \\
& Public Subsidies for low income \\
& Annualized Return on Investment (ROI) \\
& Cash Fow (according works schedule/phase) \\
& End user type of loan $(50 / 50,60,120, \ldots)$ \\
& Housing implementation price value \\
& Housing prices (value/sqm) \\
& Loan Rate (Monthly payments max value/dwelling) \\
& Loan Years \\
& New job opportunities \\
& Operational costs (each stakeholder) \\
& Property (public/private ownership) \\
& Property ratio (Owners/tenants) \\
& VAT (each activity/stakeholder)
\end{tabular}

$\begin{array}{ll}\text { A } & \text { Financial Appraisal/Renovation Measures } \\ \text { A } & \text { Financial Appraisal/Renovation Measures } \\ \text { A } & \text { Financial Appraisal/Renovation Measures } \\ \text { A } & \text { Financial Appraisal } \\ \text { A } & \text { Financial Appraisal/Renovation Measures } \\ \text { A } & \text { Financial Appraisal } \\ \text { U } & \text { Financial Appraisal/Marketing } \\ \text { A } & \text { Financial Appraisal } \\ \text { A } & \text { Financial Appraisal } \\ \text { A } & \text { Financial Appraisal } \\ \text { U } & \text { Financial Appraisal/Welfare \& Security/Marketing } \\ \text { A } & \text { Financial Appraisal/Renovation Measures } \\ \text { E } & \text { Financial Appraisal/Renovation Measures/Energy model } \\ \text { A } & \text { Financial Appraisal } \\ \text { A } & \text { Financial Appraisal }\end{array}$

\begin{tabular}{|c|c|c|}
\hline \multirow{16}{*}{ 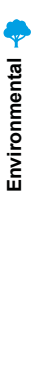 } & Energy community & Energy flexibility (between buildings) (Prosumer index) \\
\hline & & Montly/annual energy bill reduction \\
\hline & & Number of buildings affected \\
\hline & & Number of dwellings affected \\
\hline & & Self-consumption Energy community (ScEC) reference \\
\hline & & Radius Max distance $(<500 \mathrm{~m})$ inside the same ScEC \\
\hline & & Solar irradiance (horizontal surface) \\
\hline & & Solar irradiance (vertical surfaces) \\
\hline & Energy consumption & Electric consumes (after works) \\
\hline & & Electric consumes reduction (\%) \\
\hline & & EPC (comparison before and after r.w.) \\
\hline & & EPC implementation (upgrade) \\
\hline & Environmental potential & Electric consumes (before renovation works) \\
\hline & & EPC (before renovation works) \\
\hline & & GhG emissions reduction (\%) \\
\hline & & Primary energy consumption reduction (\%) \\
\hline
\end{tabular}

\begin{tabular}{lll}
\hline Building Function & Property type ratio (residential/other) \\
Building Size & Floors (other function) sqms \\
& Floors (Residential) sqms \\
& Number of levels (ground + floors) \\
& Building cluster type according Age \\
& Building cluster type according Technologies \\
& Envelope extension \\
& Roperational potential & Rextension (general + accurate) \\
& Renovation Measuress (Package of measures) \\
& Renovation Strategy (permanence in the place) \\
& Renovation target no.A (Deep Renovation) \\
& Renovation target no.B (Accessibility) \\
& Renovation target no.C (RES individual/community) \\
& Renovation works scheduling (duration of works) \\
& Accessibility (guarantee: yes/no) \\
& ITE (certificate: yes/no) \\
&
\end{tabular}

\begin{tabular}{llll}
\hline \multirow{2}{*}{ Risk solvency } & \% of population in age range & E & Financial Appraisal/Energy model/Welfare \& Security \\
Gross disposable households incomes & E & Financial Appraisal/Renovation Measures/Energy model \\
H. & Households composition (no. of adults/children) & B & Financial Appraisal/Energy model \\
& Life expectancy (ref. to health/age/pollution) & E & Financial Appraisal/Energy model/Welfare \& Security \\
& People at risk of energy poverty (income decile) & B & Financial Appraisal/Renovation Measures \\
& Unemployment & A & Financial Appraisal/Energy model
\end{tabular}

Notes

E - Early Access, B - Basic Access, A - Advanced Access, U - Ultimate Access

Energy model/RES production/Marketing

Financial Appraisal/Marketing

Financial Appraisal/RES production

Financial Appraisal

Financial Appraisal/RES production

Financial Appraisal/RES production

Renovation Measures/Energy model/RES production

Renovation Measures/Energy model/RES production

Financial Appraisal/Marketing

Financial Appraisal/Marketing

Environmental impact/Marketing

Environmental impact/Marketing

Renovation Measures/Energy model

Renovation Measures/Energy model

Environmental impact/Marketing

Environmental impact/Marketing

Financial Appraisal/Energy model/RES production

Renovation Measures/Energy model

Renovation Measures/Energy model

Renovation Measures/Energy model

Renovation Measures/Energy model

Renovation Measures/Energy model

Renovation Measures/Energy model

Renovation Measures/RES production

Financial Appraisal/Energy model

Renovation Measures

Financial Appraisal/Renovation Measures/Energy model

Financial Appraisal/Renovation Measures/Welfare \& Security

Financial Appraisal/Renovation Measures/RES production

Financial Appraisal/Renovation Measures

Renovation Measures/Welfare \& Security

Renovation Measures/Welfare \& Security

Figure 2. Input and output that will be implemented in the PEDRERA model and managed by the multi-step form wizard of the platform. Source: authors. 
guide the design and find out the strategy that best fits with the goal. In the second phase, the boundaries and the preferences of the stakeholders involved in the retrofitting project will be applied through pairwise comparison of indicators. The model provides as outcome the calculation of composite performance indexes (categories), as well as the information on compliance with the targets and boundaries established by the user.

In the third phase a cost-benefit customized function will evaluate retrofitting alternatives, taking into account both (a) the available data and information, (b) the database of renovation measure and (c) the system of filters and prioritization applied by the user on the indicators.

Additional more detailed input can be introduced into the model to better perform the Concept and the Technical design in the third and fourth phases. This information will help to refine the knowledge about the building and user' profile, as well as the loans strategy, the costs and the renovation works/cash flow schedule. After the Construction phase is concluded, during the sixth phase of Use, updated information can be uploaded to the on-cloud database, where data can be used for monitoring activities/continuous evaluation (e.g. monitoring of the energy consumes or analysis of the building performance, which can be used for the promotion of new business/intervention actions).

The PEDRERA model is designed to run on web platform with different suited access levels (Early, Basic, Advanced, Ultimate). The PEDRERA model will be implemented into the operating URBANZEB platform provided by CICLICA, main partner of the research project (https://ciclica.eu/en/urbanzeb_en/). Authorized stakeholders will monitor and analyse the whole system sustainability status online. Once stated the priorities and performance required, the users launch a set of simulations by the wizard panel and the data inserted and processed will generate scenarios. In this way a great deal of subjectivity can be introduced to the process finding a relationship between the goals established by the user and relating them to the evaluation criteria (indicators) of the model. Otherwise, users can set up the goal and the algorithms will calculate the best business model scenarios required. The performance of each indicator (e.g. costs, revenue, $\mathrm{ROI}$, regulation compliance, etc.) is the result of distinct algorithms running in the model where the information - mandatory and optional - will be automatically collected and calculated according specific scopes (Figure 2).

\section{CONCLUSION}

Research and development in energy transitions should necessarily face both technological and socio-economic problems. Viable business cases remain the weakness point of many renovation plans, while novel methods to integrate co-benefits of smart city solutions in business models are still in their early stages. Therefore, in a sustainable long term vision, the goal of this innovative model is to promote solutions able to create the trust and commitment from civil society to embrace and foster the overall development of the smart cities to come as a whole.

The data which is necessary to calculate sustainability indicators in building renovation areas are distributed in multiple sources, each one managed by a different organization, even from apparently far domains, and of different types. Additionally, one of the main challenge of the future is not only the data availability - which still represents a gap in some European urban areas - but how to integrate heterogeneous data in order to get a comprehensive understanding of district scale renovation complexity thus 
enabling better decision support and impact assessment. In spite of a large amount of data about cities are increasingly available and processed according multiple domains and formats, nonetheless there is still a lack of tools/services oriented to the relevant key stakeholders of the building retrofitting processes: building developers, financial institutions, public administrations, building owners and tenants. In order to take informed decisions in their respective realms, these stakeholders need to have access to information which suits their knowledge and capacities. Furthermore, the possibilities of using city model maps are inherently unlimited and can be addressed to current and future city issues that may arise.

The technological-economical feasibility assessment, the proper identification of the types of intervention and their combination in potential scenarios must be investigated and estimated at a multi-buildings large scale, with an effective and interdisciplinary design approach integrating in a whole system the socio-technical aspects into the feasibility study of economical, social, environmental and technical issues. Conventional energy planning and technological learning models are not sufficient because of their inability to deal with issues such as the behaviour of consumers, prosumers of energy or selfconsumption community and investors. The role of models in the energy field is cross-sectorial and the use of common principles and techniques are stimulating a rapid development of multi-disciplinary researches (e.g. multi-domain models, GIS cities modeling, open data, etc.), which is an essential part of innovation.

\section{ACKNOWLEDGEMENTS}

The research project was funded by EU Horizon 2020 research and innovation programme under the Marie SkłodowskaCurie grant agreement No 712949 (TECNIOspring PLUS) and by the Agency for Business Competitiveness of the Government of Catalonia, ACCIÓ. 


\section{REFERENCES}

Ascione, F., R. F. De Masi, F. de'Rossi, R. Fistola, and G. P. Vanoli. 2011. "Energy Assessment in Town Planning: Urban Energy Maps." WIT Transactions on Ecology and the Environment 155: 205-216. doi:10.2495/ SC120181.

Buildings Performance Institute Europe (BPIE). 2019. Future-proof buildings for all Europeans. A guide to implement the Energy Performance of Buildings Directive (2018/844). BPIE.

Civiero, P. 2017. Tecnologie per la riqualificazione. Soluzioni e strategie per la trasformazione intelligente del comparto abitativo esistente. Santarcangelo di Romagna (RN): Maggioli Editore.

Energy Efficiency Financial Institutions Group (EEFIG). 2017. EEFIG underwriting toolkit Value and risk appraisal for energy efficiency financing. no. June.

Fonseca i Casas A., Ortiz J., Garrido N., Fonseca P. \& Salom J. 2018. Simulation model to find the best comfort, energy and cost scenarios for building refurbishment. Journal of Building Performance Simulation, 11:2, 205-222, https://doi.org/ 10.1080/19401493.2017.1323011.

Garcia Casals, X., Sanmartí, M., Salom, J. 2019. Smart energy communities: Insights into its structure and latent business models. Institut Català d'Energia.

Madrazo, L. 2019. The Social Construction of a Neighbourhood Identity. Open House International, Special issue "Urban Performance between the Imagined, the Measured, and the Experienced", vol.44/1.

Mueller, N. 2020. Changing the urban design of cities for health: The superblock model. Environment International 134 (2020). 105-132. https://doi.org/10.1016/j. envint.2019.105132.

OECD. 2008. Handbook on constructing composite indicators: methodology and user guide. ISBN 978-92-64-04345-9. (available on line: http://www.oecd.org/ sdd/42495745.pdf ).
OptEEmAL. 2019. The solution for designing your energy efficient district retrofitting project. OptEEmAL Final Booklet. SteinbeisEuropa-Zentrum der: Germany. (https:// www.opteemal-project.eu/press-corner/ publications/further-downloads.html).

Ortiz, J., Casquero-Modrego,N., Salom,J. 2019. Health and related economic effects of residential energy retrofitting in Spain. Energy Policy, 375-388, https://doi. org/10.1016/j.enpol.2019.04.013.

Prieto, I., Izkara J.L., Béjar, R. 2018. A continuous deployment based approach for the collaborative creation, maintenance, testing and deployment of CityGML models. International Journal of Geographical Information Science, 32:2, 282-301, https://doi.org/10.1080/13658816.2017.1 393543.

Salom, J., Pascual, J. 2018. Residential Retrofits at district scale. Business Models under Public Private Partnerships. ÍnnoEnergy; ISBN 978-84-09-07914-8. (available on line: https://www.buildup.eu).

Letellier-Duchesne, S., Nagpal, S., Kummert, M., Reinhart, C. 2018.Balancing demand and supply: Linking neighborhood-level building load calculations with detailed district energy network analysis models. Energy (150/2018). 913-925. https://doi. org/10.1016/j.energy.2018.02.138.

Yanwen, L., Jiang, H., Yuting, H. 2017. A rulebased city modeling method for supporting district protective planning, Sustainable Cities and Society (28-2017).277-286. https://doi.org/10.1016/j.scs.2016.10.003.

Scognamiglio, A., Adinolfi, G., Graditi, G., Saretta, E.2014. Photovoltaics in Net Zero Energy Buildings and Clusters: enabling the smart city operation. Energy Procedia 61: Elsevier.1171 - 1174.

Sola, A., Corchero, C., Salom, J., Sanmarti, M. 2019. Multi-domain urban-scale energy modelling tools: A review. Sustainable Cities and Society. 2019 101872. https:// doi.org/10.1016/j.scs.2019.101872. 


\section{PAPER \#4.06}

\section{PURPOSEFUL PLAY: BRIDGING THE ENERGY-EFFICIENCY GAP IN CITIES}

\section{Malini Srivastava}

a University of Minnesota, Minneapolis, MN, USA

\section{ABSTRACT}

In the United States, buildings use almost $40 \%$ of energy produced and are responsible for $38 \%$ of greenhouse gas emissions. Urban areas account for a majority of global energy use and carbon emissions. Compared to usual current practices, energy-efficiency focused urbanization has the potential to reduce energy use by more than $25 \%$. Energy-efficiency measures thus provide an opportunity for substantively impacting global carbon emissions from and energy use at the City scale. While energy efficiency is the cheapest method to reduce energy use, owners and occupants often fail to adopt energy-efficiency measures, a phenomenon known as the energy efficiency gap.

The work described here shows that serious pervasive energy games (SPEGs) have the potential to simultaneously engage individual community members' particular needs while informing city-scale interventions that could impact climate change at larger scales. This approach was tested in our team's winning entry to the nationwide Georgetown University Energy Prize (GUEP) competition, opened in 2014 to American cities with populations between 5,000 and 250,000 people. Over a period of two years, our team effort successfully reduced citywide municipal and residential energy use by $6.85 \%$, normalized for population growth, weather effects and energy source, by the competition organizers. Through iterative research, design and implementation of serious pervasive energy games (SPEGs), we connected the city's built environment and its energy use to the community occupants.
This paper discusses one of the game designs that included individual action, neighborhood cooperative action, nested public-municipal interaction and other engagement activities that empowered community members to make city-wide impacts through personal action by forming active communities in the efargo game.

\section{KEYWORDS}

Serious energy games; pervasive games; energy efficiency gap; nested scales; energy efficiency; energy savings.

\section{INTRODUCTION}

Long-term temperature observations are consistent and widespread evidence of a warming planet (United States Global Change Research Program, 2018). With high confidence, the likely range of the human contribution to the global mean temperature increase over the period 1951-2010 is 1.10 $F$ to $1.40 \mathrm{~F}$. As of 2018 , an estimated $55 \%$ of the world's population lives in urban areas, a proportion expected to increase to $68 \%$ by 2050 (United Nations 2018). Seto et al (2014) project that urban areas are responsible for $67 \%-76 \%$ of global energy use and $75 \%$ of carbon emissions. In the United States, buildings consume almost $40 \%$ of all energy produced (U. S. Energy Information Administration 2019 (2)), over 70\% of all electricity produced ("Buildings Share of $U$. S. Electricity Consumption (Percent)" 2012), and are responsible for producing $40 \%$ of CO 2 emissions ("Carbon dioxide emissions for 
U. S. buildings, by year" 2012). As such urban built environments lend themselves as a location for large-scale interventions.

Despite the fact that energy-saving measures have cost-saving potential, several studies identify barriers preventing owners and occupants from pursuing them. Hirst and Brown (1990), in coining the term "energy efficiency gap," note the failure of households, businesses, manufacturers and government agencies to take full advantage of costeffective energy-conserving opportunities. Moreover, occupant behavior can have a significant impact on the energy use and causes uncertainty in the predictions of building energy use even for the same properties in similar climate conditions. Hong and Lin (2013) report that austere workstyles in offices consume up to $50 \%$ less energy while wasteful workstyles consume up to $90 \%$ more energy compared to standard workstyle. There is growing evidence that,

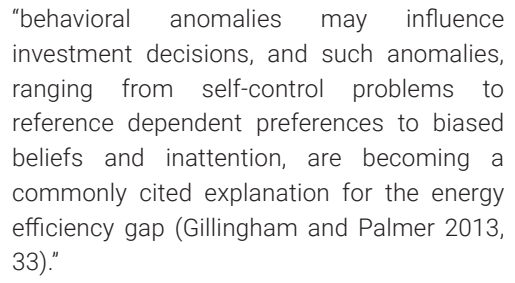

Different issues are relevant to different consumer groups making one-size-fits-all efforts effective only to a limited audience and less effective to other audiences. Heterogeneity presents researchers with both an opportunity and a challenge (Gillingham and Palmer 2013) in energy efficiency programs.

This research contends that Serious Pervasive Energy Games (SPEGs) may successfully address the heterogeneous needs of the community, by accommodating the diverse realities, goals, needs and modes of play of various community members. This paper discusses the design, implementation and results of a SPEG called efargo game in the City of Fargo, North Dakota. The efargo game was released publicly and open to voluntary participation in order to study the potential of incentivizing owners and building occupants through games, to make changes in energy use behavior, leading to energy savings.

\section{SERIOUS GAMES WITH ENERGY GOALS}

Serious Game research is an established and expanding field. Serious Games are fun, but they have goals beyond entertainment. Serious Energy Games (SEGs) focus on energy as their primary subject matter. This research has identified 127 Serious Energy Games created worldwide since the 1970s, both reflecting and reacting to contemporary energy issues. Based on this research,

\subsection{Serious Pervasive Energy Games}

Pervasive Games create social, temporal and spatial expansions of game life into ordinary life (Montola, Stenros, and Waern 2009). According to Gustafsson, Bang, and Svahn (2009) traditional learning games may have difficulty achieving a transfer of actions between game play and actual life but pervasive games can include reality in the game play, creating an opportunity for "a situated learning experience." Transferring learning from within a game's "magic circle" to the real world is a challenge (Gustafsson, Katseff, and Bang 2009), but Pervasive Games, by expanding the magic circle into ordinary life's social, temporal, and spatial constructs may enable transfer to occur simultaneously. Serious Pervasive Energy games (SPEGs) are games aimed at impacting energy use outcomes by incorporating actual life energy use, energy users, and energy use infrastructures and structures within the game. The documented history of 
SPEGs begins in 2007 with the Power Agent game, implemented by Anton Gustafsson and Magnus Bang, designed to encourage Swedish teenagers and their families to reduce energy consumption. Of the 127 SEGs, there are a total of 14 SPEGs of which 11 have reported results. The 11 that have reported results have achieved substantive results in short periods of time. Energy savings range from $8 \%-38 \%$ of those games reporting energy results. Behavior tests report changed habits, improved attitudes, involvement in energy savings and people formulating new energy saving strategies. Of the SPEGs reporting results, only 3 have been designed and implemented in the United States in small targeted implementations and only 2 have reported results (Energy Chickens (Orland et al. 2014); Dropoly; and Makahiki). In the Energy Chickens game $69 \%$ of game participants indicated that the game helped them be more energy conscious and participants reduced their plug load by $13 \%$ from baseline (table 2.6). 95\% of the participants rated the Makahiki game as educational.

\subsection{The Georgetown Prize}

The opportunity to further design, implement and test SPEGs as a way of bridging the energy efficiency gap presented itself in the nationwide competition conducted by Georgetown University called the Georgetown University Energy Prize (GUEP). The GUEP goal was to reduce the energy use of cities with populations ranging from 5,000-250,000 people. The competition duration of the semifinals was January 2015 to December 2016. Normalized data collection of energy use in 2015 and 2016 was compared against a baseline energy use during years 2013 and 2014. In the energy use data collected and published by the GUEP, efargo's work resulted in Fargo being ranked as the fourth highest energy saver and overall winner of the Georgetown Prize. Long (1958), based on a year of field study in the Boston metro area, proposes that "the local community can be usefully conceptualized as an ecology of games." He noted that games provide goals to gamers, sense of structure, the sense of being on a team, and determine roles and strategies and tactics to achieve those goals. Imagining the locality of Fargo as an ecology of games with several interconnected games and gamers as actors of note, a partnership called efargo (led by this author) was established between North Dakota State University, the City of Fargo, ND, and local utilities in 2014. The University (through the efargo research group) provided design, scholarship, research, production and implementation. The utilities provided information and connection to their customer bases. The City provided permissions, resources and connected the team to various for-profit and nonprofit organizations and governmental agencies such as schools, parks, fire stations etc.

\subsection{Game locations and types}

While this paper primarily focuses on the scaled structures and narratives within the efargo game, there were other games designed, implemented and tested in the community. The first SPEG titled, efargo game, targeted residential energy use, rental and ownership. This game was launched in late February 2016, and ended with a community Earth Day celebration in April 2016. Another SPEG called $\mathrm{K}$-12 Energy Challenge targeted the municipal sector of the Georgetown University Energy Prize, was focused on reducing energy use in $\mathrm{K}-12$ schools while also educating students about energy waste, energy use reduction and energy efficiency (Srivastava 2019). Lastly, several energy games were designed and played at community events where the efargo research team was invited to provide outreach related to energy education and awareness. The community space included the local 
farmers market, street fair, winter festival, local shopping malls, downtown community partnership etc. The games at these events included the light bulb game (Figure 1), the energy wheel of fortune, the weights game, the earth piano and others.

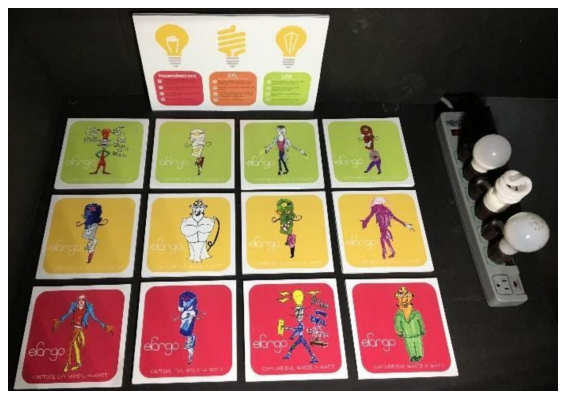

Figure 1. Community Games. Source: (efargo, Troy Raisanen, Greta Berens, Dylan Neururer, Alex Jansen, Sam Goodman, Author 2020)shared photographs.

\subsection{The scaled narratives within the efargo game}

For the efargo game, gamers had to complete energy-saving actions primarily in their homes in order to earn game points. Within the game website, each token (blue circle or coin) indicating a theme such as lighting, heating, community action etc., had to be selected and then moved by a gamer to climb challenge levels represented by blocks. Each level (made up of seven blocks) was associated with a level of difficulty (Level 10-70). For each token, Level 10 (the first level) presented information and quizzes for the gamer to complete for which short tutorials were provided within the game.

"Level 20 included an easy action item associated with that token that is typically a low-cost or no-cost energy-saving effort such as changing 5 light bulbs in the home from incandescent or fluorescent to LED. Level 30 asked people to share their participation in that week's token through social media or traditional media (phone, email, conversation),
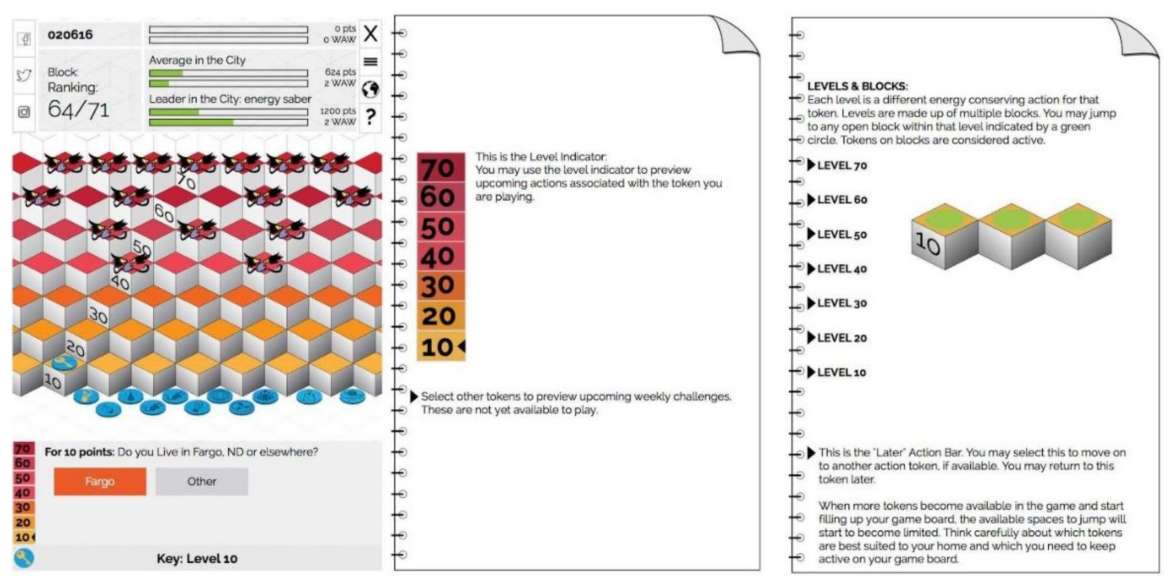

Figure 2. The efargo game board, dashboard, communications box, tokens, challenge block levels and mapping. Source: (efargo, Peter Atwood, lan Schimke, Troy Raisanen, Nick Braaksma, Greta Berens, Author 2020) 


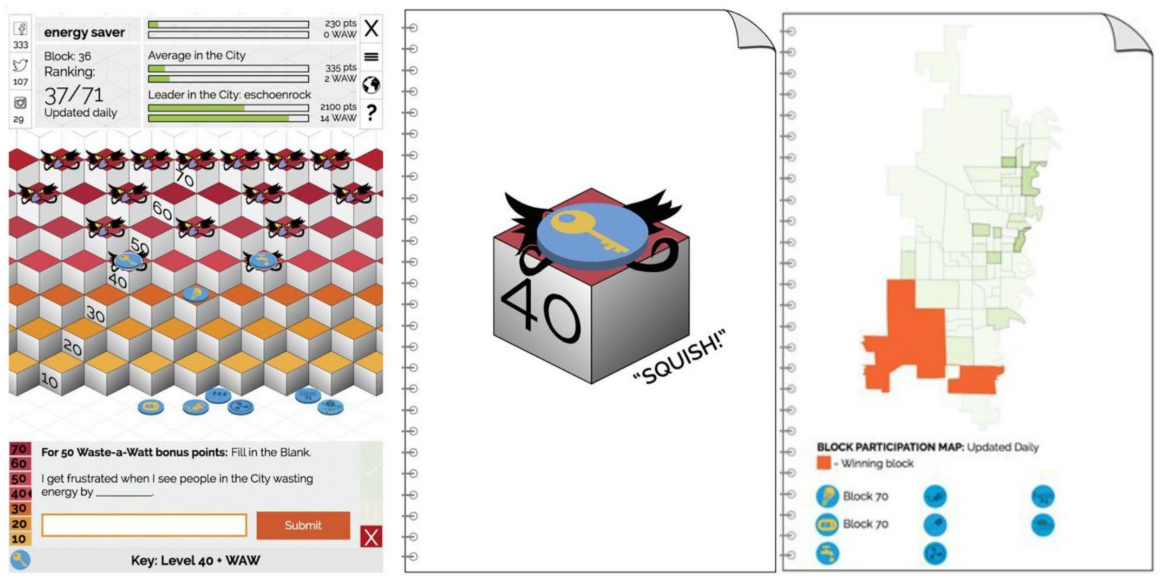

Figure 3. efargo game map based on census blocks. Source: (efargo, Peter Atwood, lan Schimke, Troy Raisanen, Nick Braaksma, Greta Berens, Author 2020)

inviting friends, family, and neighbors to participate. Levels 40-70 asked gamers to complete energy-conserving action items with increasing levels of difficulty, requiring more time, effort, cost or preparation (Srivastava 2016)."

As they played the game, information about energy waste and energy efficiency was provided to the gamers. Gamers implemented energy-saving actions in their homes and shared information through social and other media about their actions. Gamers earned points for their activities and could see their scores in comparison to other gamers in the dashboard (upper left corner) (Figure 2), how much they had advanced in the game, and the ranking of their block that allowed them to see how their block was faring in the game in comparison to other blocks in the city. The game board also included a map showing the performance of the city as a whole, based on census blocks (Figure 3). The game scores of all gamers in a census block were aggregated to create the block participation score. The census block with the highest block participation score for the week was declared the block winner. The game included a weekly reward (a \$50 gift certificate) given to a randomly selected gamer, the weekly champion from the winning block (Figure 4).

Since the game incentivized the aggregate block performance, activities that involved connecting with neighbors in order to achieve broader participation from the block were as important as achieving energy reductions in

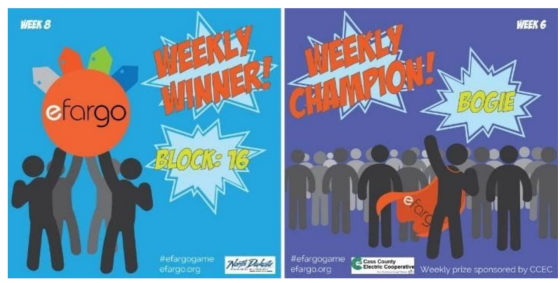

Figure 4. efargo weekly winners and champions. Source: (efargo, Greta Berens, lan Schimke, Author 2020) (Srivastava 2016) 
Table 1: Sample of community responses to one of the Waste-a-Watt question (total 700 responses)

\begin{tabular}{llll}
\hline $\begin{array}{l}\text { I wish the City would } \\
\text { energy. }\end{array}$ & to save & $\begin{array}{l}\text { Municipality actions/ } \\
\text { policies for the City } \\
\text { infrastructure }\end{array}$ & $\begin{array}{l}\text { Municipality } \\
\text { incentives for the } \\
\text { community }\end{array}$ \\
\hline Renewables & $\begin{array}{l}\text { Use more solar resources } \\
\text { Use more solar panels on city buildings }\end{array}$ & $\begin{array}{l}\text { x } \\
\text { Put in solar panels }\end{array}$ & $\mathrm{x}$ \\
Implement more sustainable practices, like & & \\
solar panels & $\mathrm{x}$ & \\
Invest in renewable sources & $\mathrm{x}$ & \\
Use nuclear power & $\mathrm{x}$ & \\
Use sustainable energy sources (preferably & & \\
wind--vertical tube designs don't take up much & & $\mathrm{x}$ \\
room--or solar) & $\mathrm{x}$ & $\mathrm{x}$ \\
Require a renewable portfolio & & \\
Actively support tax credits for green or & & \\
alternative energies or other sustainable & & \\
energy initiatives. & $\mathrm{x}$ & \\
Utilize wind & $\mathrm{x}$ & \\
Utilize wind energy & $\mathrm{x}$ & \\
Do more solar power & $\mathrm{x}$ & \\
Use more solar energy & & \\
\hline
\end{tabular}

Table 1. Sample of community responses to one of the Waste-a-Watt question (total 700 responses)Goodman, Author 2020)shared photographs.

individual homes. Nested within the game were bonus points awarded for landing on and answering a "Waste-a-Watt question". The gamers had to land on specific locations in the game board indicated with a Waste-aWatt icon (Figure 2). These icons were located in the higher levels of the game (Level 4070). As a result, the fundamental actions on Levels 10-30 had to be completed to access the bonus points associated with questions accessed by clicking the Waste-a-Watt icon.

Gamers' responses to these questions were posted on the game website (Table 1 contains a small sample from 700 responses), creating a dialog within the gaming community. Gamers earned bonus points by responding to Waste-a-Watt questions, incentivizing community participation. Additionally, the last two tokens were focused on creating community-municipality dialogue and a celebratory community event, expanding the game beyond the home to a larger scale. The gamers were connected to an app called Sidewalk, commissioned by the city for citycommunity dialogue, through the efago game. In this app the gamers could ask questions pertaining to policies, incentives, goals, action items that they believed the city could be involved in or promote. For the community event, on Earth Day weekend in 2016, the efargo group organized a space in downtown Fargo. Several experts from organizations and corporations working on energy issues were invited to the event. Gamers could earn points in the game by learning about all the energy-related work that was happening in the community. 


\section{RESULTS OF GAMEPLAY}

Energy-use data related to household energy use was collected before, during, and after the game. Of the 322 people who joined the efargo game, 55 people completed a pre- and post-game survey. Of these 55 people, 26 people gave permission to access the energy use data. Of these, 18 people were identified as customers with active accounts (13 with Xcel Energy and 5 with CCEC). 13 of the 18 gamers had complete electricity-use records covering the 2013- 2016 period (provided by the utilities)

Data for these thirteen gamers was analyzed using ETracker, a software application developed by Kelly Kissock at the University of Dayton (Ohio), with support from the United States EPA for the Energy Star Buildings Program. ETracker "uses ambienttemperature regression models to reduce the influence of changing weather so that retrofit savings can be more accurately measured" (Kissock 2003). Two study periods were considered for analysis: during game play and after game play. The first study period (during game play) was defined as March 2016 - April 2016. The second study period (after game play) was defined as May 2016 December 2016. The ETracker prediction was made on the basis of utility bills collected for a four-year period (2013, 2014, 2015 and 2016).

\section{first study period: during game}

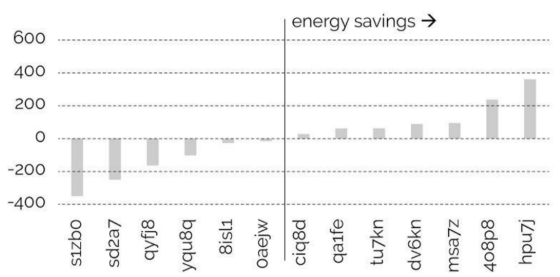

Energy use prior to March 2016 was used to create energy-use data files for each of the individual gamers. Over each study period, each gamer's actual energy use (in kWh) was reported from utility records. Individual gamers' predicted energy use from ETracker was then compared to their actual energy use data from the utilities, and the difference was calculated for each gamer. During the first study period, some individual improvements in energy use were observed: of the 13 individual gamers, 7 showed energy-use reductions. A monthly total drop of $27 \mathrm{kWh}$, or $0.23 \%$, and a marginal drop in mean difference between actual and predicted energy use (-2 kWh) were observed. Post-game analysis was conducted on the remaining months of energy use data available, from May 2016 to December 2016. A monthly total drop of $1,273 \mathrm{kWh}$, or $11.65 \%$, and an appreciable drop in mean difference between actual and predicted energy use (-98 kWh) were observed. Figure 5 summarizes the individual gamers' energy use in the two study periods. An increased number of gamers experienced energy savings in the second study period. Thus, with respect to the comparison of (a) predicted energy use with (b) actual energy use, both before and during the efargo game, findings are positive and consistent with SPEG efargo game reducing energy use, but the findings are not statistically significant $(p=0.25(>0.05)$, likely due to small sample size.

\section{second study period: after game}

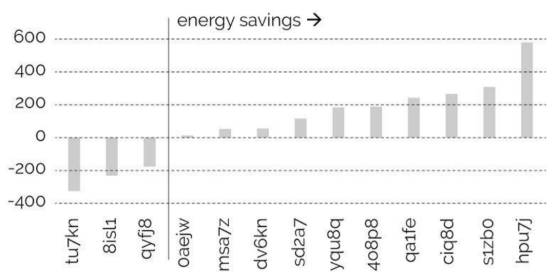

Figure 5. Individual gamers' energy use (Author, Peter Atwood, Mike Christenson). 
While the Georgetown University Energy Prize established the core goal of reducing community-wide residential and municipal electricity and natural gas consumption, the structure left it up to each individual community how best to accomplish this goal. The final evaluation of the Prize accounted for energy-use reduction, but also considered whether innovative, sustainable, replicable, and scalable approaches were developed that had potential for wider application. Energy use data submitted by the cities was normalized by the GUEP team according to the protocols outlined in the GUEP

(Srivastava, Nelson 2017). The normalized data constituted the overall results for the City of Fargo for competition years 2015 and 2016 compared to baseline years 2013 and 2014. In two years, Fargo reduced overall energy consumption by over 172,361,882,500 BTUs. Estimated CO2e saved was 49,719 metric tons, and the overall energy consumption reduced on average per-household was over $8,165,800$ BTUs. Although it cannot be conclusively stated that the playing of games led to the substantive energy use reductions shown in the GUEP results, it is nevertheless noteworthy that three of the ten cities with the greatest energy savings were gaming cities in addition to other activities (Figure 6). At the end of the competition, the winner (Fargo) and two of four honorable mentions (Fort Collins, CO and Walla Walla, WA) were gaming cities (Srivastava, Nelson 2017).

\section{CONCLUSIONS \& LIMITATIONS}

In making the local community analogous to a game, Long (1958) contends that games are not trivial but quite the opposite. He contends that,

\section{"... (hu)man is a game-playing and a game- creating animal ... and that it is through games or activities analogous to game- playing that $(\mathrm{s} /$ )he achieves a satisfactory sense of significance and a meaningful role (Long 1958, 252)."}

Long posited that politics, banking, contracting, journalism, civic organizations, and ecclesiastics as interconnected, albeit different, games sharing a common locality where each game has well-established goals, known and understood ways to behave and a set of strategies and tactics for gamers. In

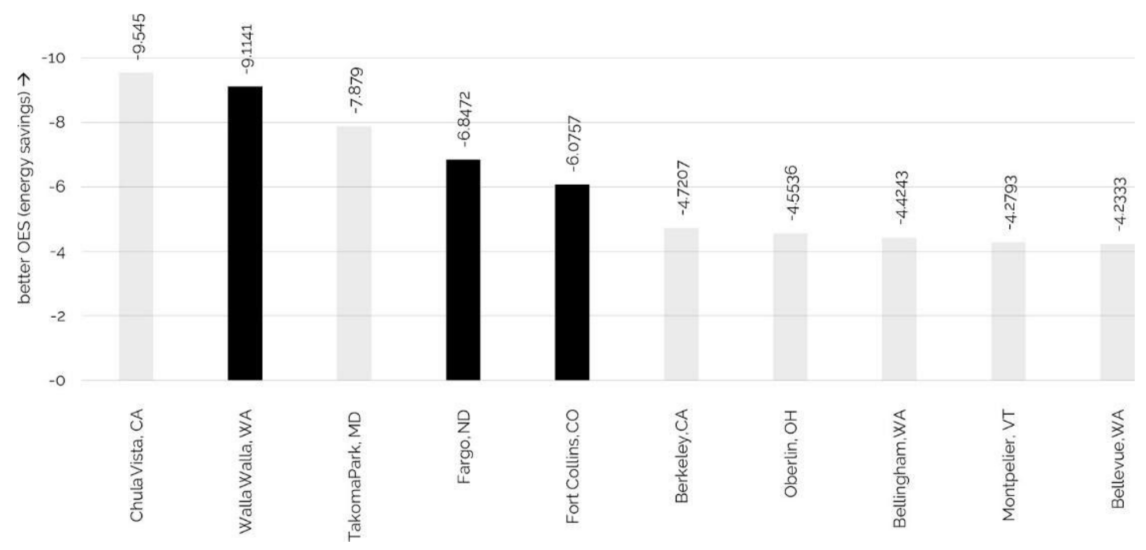

Figure 6. Individual gamers' energy use (Author, Peter Atwood, Mike Christenson). 
the efargo game, the most meaningful social expansions not only increased the numbers of people involved but ensured that various constituencies (home owners, renters, community experts, businesses, municipal government, schools and other organizations) were involved, actively participating towards shared goals. This meant that while the game needed temporal flexibility, so people and entities could participate when they were able to, an overall synchronous structure was also needed for meaningful competitive play to occur and shared goals to be realized. Thus the game design had to balance flexible play and a synchronous structure with a defined play duration. Structures game elements such as the Waste-a-Watt questions revealed that frequent opportunities to create a meaningful sense of community within the game elicited the greatest dialogue from gamers (700 responses). Other dialogue structures between the gamers and designers (Key tokens), between gamers and the City (City Token, Sidewalk app) and between multiple organizations, corporations and the gamers (Community Token, Earth Day event) also garnered considerable responses. While dialogue and data collection within the game structure were successful in getting gamer responses, the final attempts to collect post-game surveys and energy use data collection after the gameplay period, were not as successful and had a much smaller response rate. Lack of gamer engagement in the post-game traditional survey format, severe database limitations on the Utility end, such as needing exact format and spelling duplication of gamer addresses made it difficult to locate the gamer utility invoices even for those gamers who had signed the release to access their data. Embedding surveys and energy use data collection within the game, where gamers are asked to submit their own energy use invoices rather than trying to acquire them from the Utility after the game play, needs to be tested in the future.

\section{ACKNOWLEDGEMENTS}

The work included in this paper would not have been possible without several members of the efargo team including but not limited to Peter Atwood, Troy Raisanen, Mike Christenson, Nate Wallestad, Ian Schimke, Greta Berens and Nick Braaksma. This research was funded by grants from the City of Fargo and the North Dakota Department of Commerce. 


\section{REFERENCES}

Buildings Share of U. S. Electricity Consumption, Buildings Energy Data Book, retrieved from https://web.archive. org/web/20170122013356/http:// buildingsdatabook.eren.doe.gov/docs/ xIs_pdf/1.1.9.pdf

Carbon dioxide emissions for U. S. buildings, by year, in Buildings Energy Data Book, retrieved from https://web.archive. org/web/20170122013421/http:// buildingsdatabook.eren.doe.gov/docs/ xls_pdf/1.4.1. pdf

Gillingham, K., and Palmer, K. 2014. Bridging the energy efficiency gap: Policy insights from economic theory and empirical evidence. Review of Environmental Economics and Policy 8, no. 1 (2014): 18-38.

Gustafsson, A., Katzeff, C., and Bang, M. 2009. Evaluation of a Pervasive Game for Domestic Energy Engagement Among Teenagers. Computers in Entertainment 7, no. 4: 54:1-54:19.

Gustafsson, A., Bang, M., and Svahn, M. 2009. Power Explorer: A Casual Game Style For Encouraging Long Term Behavior Change Among Teenagers. In Proceedings of the International Conference on Advances in Computer Entertainment Technology. n. p. Association for Computing Machinery.

Hirst, E. and M. Brown. 1990. Closing the efficiency gap: barriers to the efficient use of energy. Resources, Conservation and Recycling 3(4): 267-281.

Hong, T., \& Lin, H. W. 2013. Occupant behavior: impact on energy use of private offices (No. LBNL-6128E). Lawrence Berkeley National Lab.(LBNL), Berkeley, CA (United States).

Kissock, K. 2003. ETracker User's Manual (Version: 7-26-2003).

Long, Norton E. 1958. The Local Community as an Ecology of Games. American Journal of Sociology 64:3, 251-261.

Montola, M., Stenros, J., \& Waern, A. 200). Pervasive games: Theory and design. Burlington, MA: Morgan Kaufmann Publishers.
Orland, B., Ram, N., Lang, D., Houser, K., Kling, N., Coccia, M., 2014. Saving energy in an office environment: A serious game intervention. Energy and Buildings 74: 43-52.

Seto K., Dhakal, S., Bigio, A., Blanco, H., Delgado, G., Dewar, D., Huang, L., Inaba, A., Kansal, A., Lwasa, S., McMahon, J., Müller, D., Murakami, J., Nagendra, H., \& Ramaswami, A. 2014. Human settlements, infrastructure and spatial planning. In O. Edenhofer, R. Pichs-Madruga, Y. Sokona, E. Farahani, S. Kadner, K. Seyboth, A. Adler, I. Baum, S. Brunner, P. Eickemeier, B. Kriemann, J. Savolainen, S. Schlömer, C. von Stechow, T. Zwickel \& J. Minx (Eds.), Climate change 2014: Mitigation of climate change ( $p$. 923-1000). Cambridge (UK): Cambridge University Press.

Srivastava, M. 2016. The efargo Game: A playful way to achieve city-wide energy use reductions. In ACEEE Summer Study on Energy Efficiency in Buildings (pp. 8.1-8.12)

Srivastava, M., \& Nelson, C. 2017. The Energy Efficiency Prize: Simple Design to Overcome Complex Barriers. In the ARCC 2017 Conference-Architecture of Complexity (pp. 354-351).

Srivastava, M. 2019. Architecture as a Gaming Board in Pervasive Energy Games. The Routledge Companion to Games in Architecture and Urban Planning: Tools for Design, Teaching, and Research. United Nations. 2018. World urbanization prospects. Accessed February 7, 2019.

U. S. Energy Information Administration. 2019 (2). How much energy is consumed in U.S. residential and commercial buildings? Accessed February 7, 2019. https://www. eia.gov/tools/faqs/faq.php?id=86\&t=1

United States Global Change Research Program. 2018. Fourth National Climate Assessment - Volume II: Impacts, Risks, and Adaptation in the United States. Accessed December 31, 2018. https:// nca2018.globalchange.gov/ 


\title{
PAPER \#4.07
}

\section{OPTIMAL OPERATION STRATEGIES OF THREE DIFFERENT HVAC SYSTEMS INSTALLED IN A BUILDING}

\author{
Yeo Beom Yoon ${ }^{a}$, Byeongmo Seo ${ }^{a}$, Suwon Song ${ }^{b}$, Soolyeon Cho ${ }^{a}$ \\ aNorth Carolina State University, NC, USA

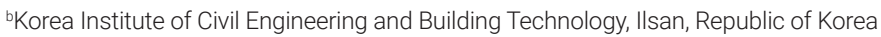

\section{ABSTRACT}

A public service building in Korea is undergoing a retrofit process, adding heat pump systems, especially variable refrigerant flow (VRF) systems. The building currently has both central and zonal HVAC systems installed. Absorption chillers provide chilled water to both air handling units and fan coil units. Some rooms also have air source VRF heat pump (HP) systems installed, which have been added after the construction to provide additional energy. Unfortunately, these HVAC systems still do not meet the heating and cooling loads of the building. Simulation modeling processes were conducted to identify the building's thermal performance, verify the peak heating and cooling loads, and propose optimal additional VRF-HP systems to be installed. Optimal operation strategies were proposed for three different HVAC systems (i.e., AHUs, FCUs, and VRF-HPs) after adding additional VRF-HP systems to the building. Results show that operating the VRFHP system as a main system, while central HVAC system as a secondary system, can reduce the building energy consumption. It is also required a low capacity of the additional VRF-HP system.

\section{KEYWORDS}

Air handling unit; VRF system; fan coil unit; system operation; energyPlus.

\section{INTRODUCTION}

Some existing buildings do not meet heating and cooling loads. This happens due to usage changes in spaces and addition of new equipment over time. Global warming is also a likely contributor to the additional cooling demand. These factors increase or decrease internal heat gains for which more heating and cooling energy is required. To overcome this issue, studies have been conducted on the retrofitting of buildings.

Luddeni et al. (2018) conducted research to reduce the building energy consumption of an office building in Italy by improving insulation performance, replacing windows, using highefficiency equipment, and improving boiler efficiency. Somasundaram et al. (2020) applied low-emissivity windows to reduce the building energy consumption, while Biswas et al. (2019) conducted research to reduce building energy consumption by enhancing insulation performance. Previous studies have mostly applied energy efficiency measures or strengthened thermal insulation to reduce building energy consumption. Some studies attempted to reduce the energy consumption of buildings where heating, ventilation, and airconditioning (HVAC) systems with sufficient capacity are already installed.

The target building of this study is a public service building where the capacity of the HVAC system installed is insufficient. An additional stand-alone air conditioner and a variable refrigerant flow heat pump (VRF-HP) system were installed to the target building to overcome indoor thermal discomfort, yet 
doing so did not solve the problem of thermal comfort.

The purpose of this study, therefore, is to identify the capacity of additional HVAC systems and to propose HVAC system operation strategies, including the existing central HVAC system and fan coil unit (FCU) to improve indoor thermal comfort and reduce the building's energy consumption.

\section{SIMULATING MODELING}

\subsection{Simulation software}

This study used the EnergyPlus program version 9.0 developed by the U.S. Department of Energy (U.S.DOE). The OpenStudio program was used to implement the simulation model. The OpenStudio program is based on the EnergyPlus Engine and is one of the plug-ins of the SketchUp program.

EnergyPlus combines the advantages of the building loads and system thermodynamics (BLAST) in the building load analysis part and the merits of the DOE-2 program, which has the strength of a system-level analysis. In addition, EnergyPlus uses the heat balance calculation, which is recommended by the American Society of Heating, Refrigerating and Air-Conditioning Engineers (ASHRAE). It has the advantage of dynamic analysis, such as conduction, convective, and radiative heat transfer [U.S.DOE, 2018a].

\subsection{Simulation model}

The target building of this study is a public service building located in Ilsan, Republic of Korea. It is a six-story building with one basement floor and consists of multifunctional spaces, including office spaces, seminar rooms, and public service centers.

As previously mentioned, the actual target building does not have enough HVAC systems installed to meet the heating and cooling loads. The indoor air temperature could not meet the heating or cooling setpoint temperature due to the insufficient capacity of the HVAC system. Due to this problem, even in one space, temperature may vary, depending on the location.

To solve this issue, additional HVAC systems were installed in the target building, but these still do not have enough capacity. This study, therefore, aims to identify the additional capacity of the HVAC system that building needs through simulation analysis and to suggest the optimal operation strategies of the HVAC system to ensure energy consumption efficiency.

Figure 1 presents the simulation modeling of the target building. The simulation model is implemented based on the actual building drawings. The window-to-wall ratio of the target building is $35.57 \%$ on the east side, $22.17 \%$ on the west side, $37.19 \%$ on the south side, and $27.48 \%$ on the north side.

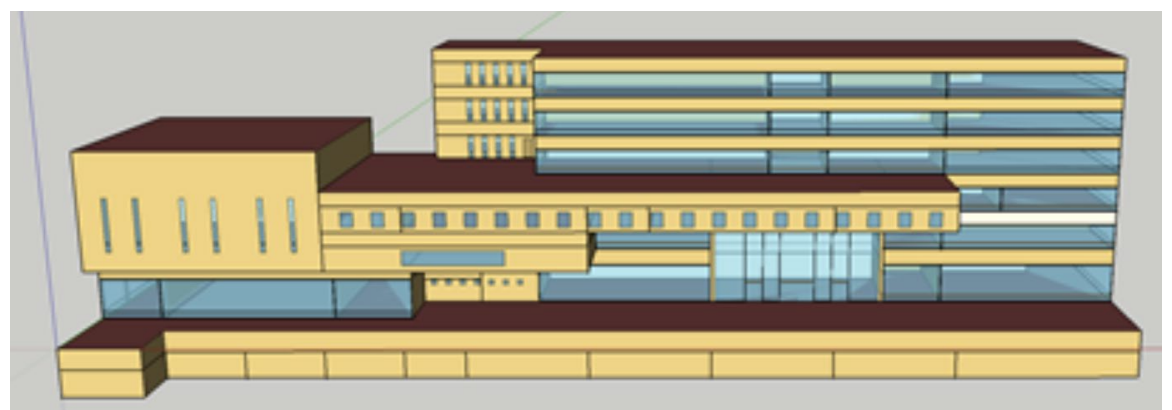

Figure 1. Simulation modeling 
Tables 1 and 2 outline the properties of the building materials and the construction sets of the simulation model. The construction set is based on the drawings of the target building. The drawings of the target building do not have information about the building material properties, so we used the actual properties of the building materials that the EnergyPlus simulation program provided [U.S.DOE, 2018b].

The thickness of the air inside the interior wall and floor is not shown in Table 2. The EnergyPlus simulation program requires only thermal resistance values for air, which is one of the building materials. This is why there is no value for air thickness. The thermal resistance of the air layer is $0.15 \mathrm{~m} 2 \cdot \mathrm{K} / \mathrm{W}$ for the interior wall and $0.18 \mathrm{~m} 2 \cdot \mathrm{K} / \mathrm{W}$ for the ceiling. The U-value of windows is $3.35 \mathrm{~W} /$ $\mathrm{m} 2 \cdot \mathrm{K}$, with the solar heat gain coefficient (SHGC) of 0.36 and visible transmittance (VT) of 0.27 .

Table 3 presents the internal heat gain and infiltration values. Lighting power density is based on the drawing of the target building. Other values, equipment, and people are based on the DOE reference building (19802004) because the drawing does not include these values. The infiltration values are based on the infiltration modeling guidelines published by the Pacific Northwest National Laboratory [PNNL, 2009].

The heating and cooling setpoint temperatures in the simulation model are the actual setpoint temperatures used by the target building. The heating setpoint temperature is $20^{\circ} \mathrm{C}$, and the cooling setpoint temperature is $26^{\circ} \mathrm{C}$.

\begin{tabular}{cccc}
\hline Material & Conductivity $(\mathrm{W} / \mathrm{m} \cdot \mathrm{K})$ & Density $\left(\mathrm{kg} / \mathrm{m}^{3}\right)$ & Specific heat $(\mathrm{J} / \mathrm{kg} \cdot \mathrm{K})$ \\
\hline Stucco & 0.692 & 1,858 & 837 \\
Concrete & 0.530 & 1,280 & 840 \\
Gypsum board & 0.160 & 785 & 830 \\
Roof membrane & 0.160 & 1,121 & 1,460 \\
Insulation & 0.049 & 265 & 837 \\
Metal Decking & 45 & 7,480 & 418 \\
Acoustic tile & 0.060 & 368 & 590 \\
\hline
\end{tabular}

Table 1: Building material properties

\begin{tabular}{|c|c|c|c|}
\hline Construction & \multicolumn{3}{|c|}{ Outer layer to inner layer (thickness; mm) } \\
\hline Exterior wall & Stucco $(25)$ & Concrete (300) & Insulation (50) $\quad$ Gypsum board (12) \\
\hline Interior wall & Gypsum board (19) & Air & Gypsum board (19) \\
\hline Roof & Roof membrane (9.5) & Insulation (135) & Metal decking (1.5) \\
\hline $\begin{array}{l}\text { Ceiling and } \\
\text { floor }\end{array}$ & Acoustic tile (19) & Air & Concrete (100) \\
\hline
\end{tabular}

Table 2: Construction set

\begin{tabular}{cc}
\hline & Values \\
\hline Lighting & $13.83 \mathrm{~W} / \mathrm{m}^{2}$ \\
Equipment & $23 \mathrm{~W} / \mathrm{m}^{2}$ \\
People & 0.054 people $/ \mathrm{m}^{2}$ \\
Infiltration & Perimeter: 0.3 Air change per hour and Core 0.15 Air change per hour \\
\hline
\end{tabular}

Table 3. Internal heat gain and infiltration 


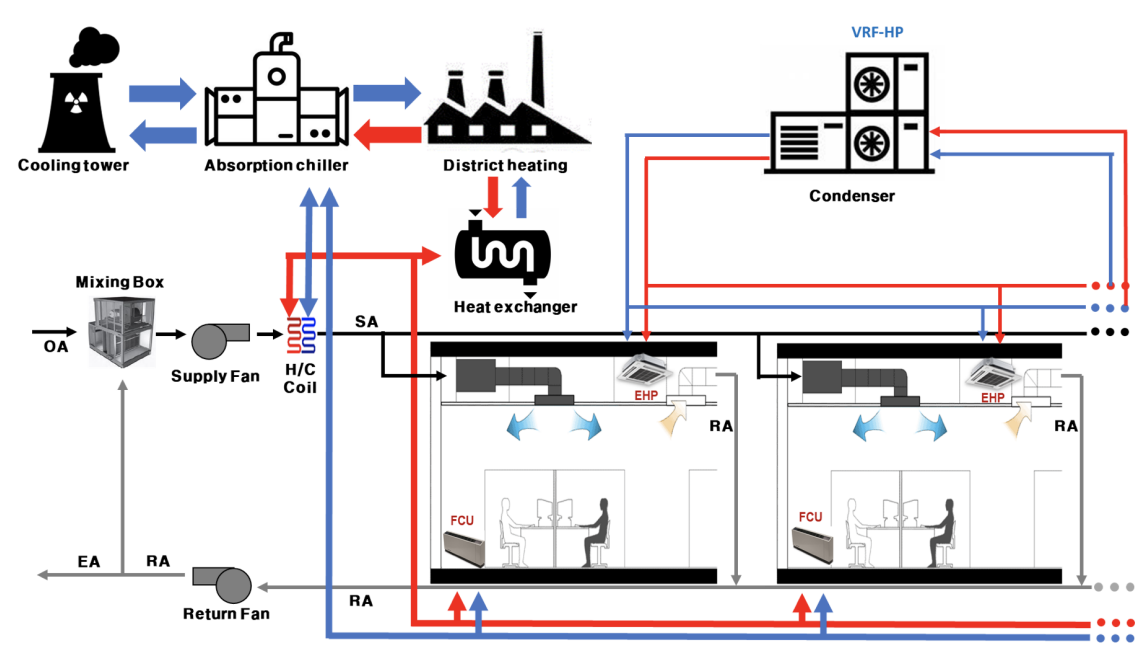

Figure 2. Diagram of the HVAC system in the target building

Figure 2 displays the conceptual diagram of the HVAC system installed in the target building. The FCU systems are installed in the perimeter zones, while the central HVAC systems are installed in the core zones. The existing HVAC system does not have a VRFHP system in the upper right side of Figure 2 and is currently installing an additional VRF-HP system to improve indoor thermal comfort.

Information on the FCU system in the simulation model is the same as that of the FCU system installed in the target building.

For the absorption chiller and cooling tower, only the number is known, so the actual number of installations is entered, and the rest of the information is autocalculated by the simulation program.

\subsection{Calibration}

The simulation model was calibrated with the actual monthly electrical energy consumption. The cooling period is from June to September, while the heating period covers December, January, and February.

To calibrate the simulation model, we used the coefficient of variation of the root mean square error (CV(RMSE)) and Normalized Mean Bias Error (NMBE). ASHRAE Guideline 14-2014 provides the tolerance ranges of the calibrated simulation models, and the ranges differ, depending on the data frequency. The hourly data is $30 \%$, whereas monthly data is $15 \%$ for CV(RMSE). For NMBE, hourly data is $\pm 10 \%$ and monthly data is $\pm 5 \%$ [ASHRAE, 2014]. The CV(RMSE) value is $14.4 \%$ which is in the tolerance range of the calibration model and NMBE value is $7.1 \%$ which is out of the tolerance range. NMBE value is for data value, and CV(RMSE) is for data pattern. Actual data are not enough to compare with simulation results currently. In the future, the simulation model will be updated with more detailed actual building data. Figure 3 compares the actual monthly electric energy consumption and the simulation results. 
Equations for CV(RMSE) and NMBE are as follows:

$R M S E_{\text {period }}=\frac{\sqrt{\sum(S-M)^{2}{ }_{\text {interval }}}}{N_{\text {interval }}}$

$A_{\text {period }}=\frac{\sum_{\text {period }} M_{\text {interval }}}{N_{\text {interval }}}$

$\operatorname{Cv}\left(R M S E_{\text {period }}\right)(\%)=\frac{R M S E_{\text {period }}}{A_{\text {period }}} \times 100$

$\operatorname{NMBE}(\%)=\frac{\sum(S-M)_{\text {interval }}}{\sum M_{\text {interval }}} \times 100$

4)

where,

$\mathrm{y}=$ monthly (or hourly) data

$\mathrm{N}=$ number of data

$\mathrm{S}=$ Simulation results

$M=$ Measured data

Ninterval=number of data

Aperiod=Average of data

\section{RESULT AND ANALYSIS}

\subsection{Analysis of the indoor temperature}

Figure 4 shows the indoor air temperature patterns for the winter and the summer representative days. The winter representative day is February 6, while the summer representative day is August 4-both reflect the typical outdoor air temperature pattern in the winter and the summer seasons.

Since the temperature patterns of all rooms in the building cannot be expressed, we selected the office space on the fifth floor. The core shown in Figure 4 is the core of the office space, while perimeter refers to the perimeter zone of the office space. The black line represents the heating and cooling setpoint temperatures, whereas the green line represents the outside air temperature. Although the temperature in the core zone, which is not exposed to the external environment, is higher than that of the temperature in the perimeter zone, the temperatures in both spaces do not reach the set temperature in both the summer and the winter representative days. The installation of additional HVAC systems is, thus, necessary.

Figure 5 presents the indoor air temperature pattern after the installation of the VRF-HP

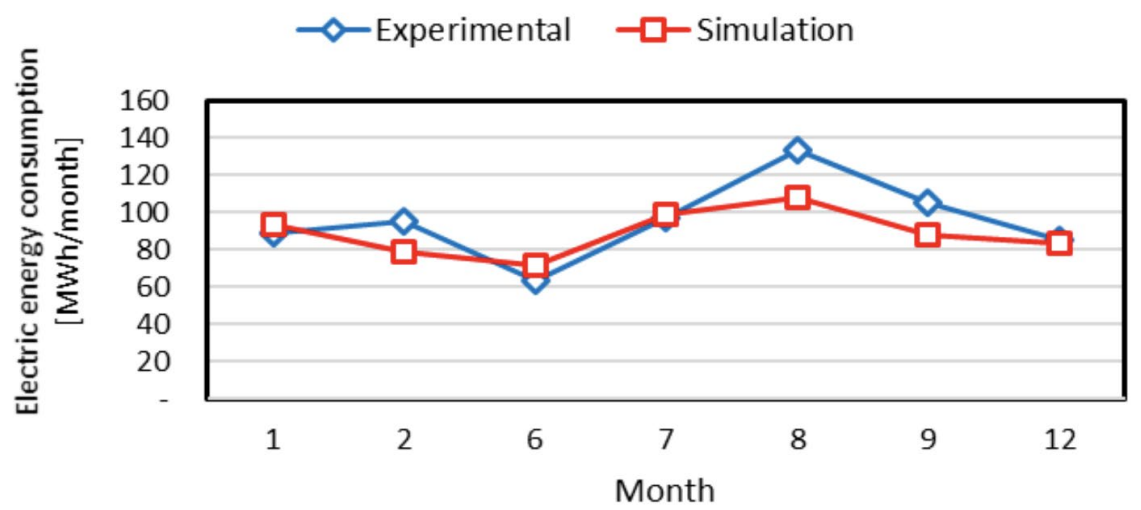

Figure 3. Comparison of the actual monthly electric energy consumption and the simulation results 
system. Because of the additional VRF-HP system installed, indoor air temperature reached the heating and cooling setpoint temperature for both the winter and the summer representative days.

\subsection{Strategies for optimal operation of three different HVAC systems}

This section compares and analyzes the energy consumption of four different cases to suggest strategies for the optimal operation of three different HVAC systems. The four cases are as follows:

- Case-1: Central HVAC system only (current HVAC system);

- Case-2: Central HVAC as main system and VRF-HP as secondary system (sequential);

- Case-3: VRF-HP as main system and central HVAC secondary system (sequential); and
- Case-4: VRF-HP system and central HVAC system work simultaneously (uniform).

The sequential method (Case- 2 and Case- 3 ) is the main system handles all the loads. When the main system cannot handle all the loads, it means that the load is larger than its capacity. The secondary HVAC system handles the remaining heating or cooling loads.

The Uniform method (Case-4) is that when heating or cooling loads occur, all the HVAC systems operate at the same time, regardless of the amount of the loads.

Before analyzing the electric energy consumption and the district heating consumption, we describe the energy resources that the central HVAC system and VRF-HP system used. District heating is currently used for both heating and cooling in the target building. Hot water is sent directly to the heating coil in the FCU and air handling

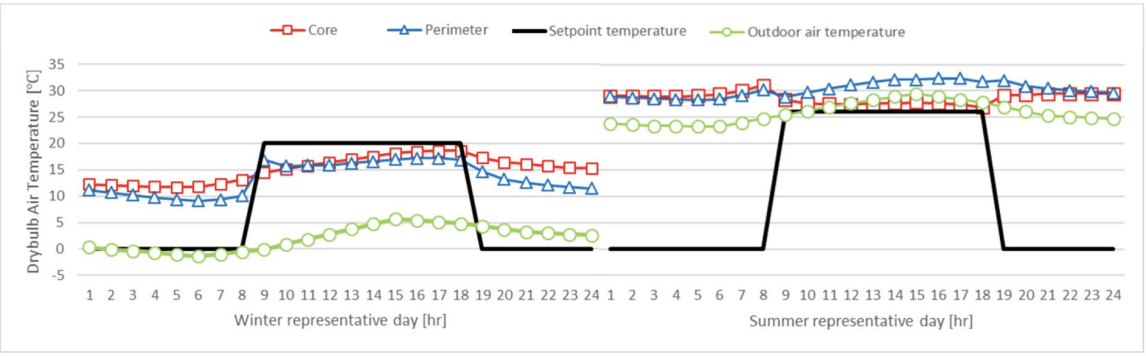

Figure 4. Comparison of indoor air temperaturas for the winter and the summer representative days

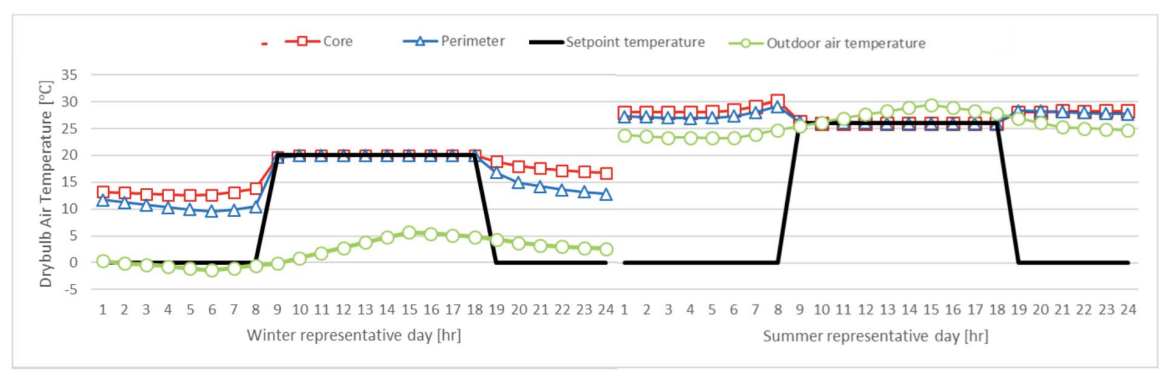

Figure 5. Comparison of indoor air temperature for the winter and the summer representative days after VRF-HP system has been installed 
unit (AHU) to provide hot air in the building. For cooling, hot water is sent to the absorption chiller to be cooled through evaporative cooling. Because of these mechanisms, the target building uses district heating not only during the heating season but also during the cooling season. As regards electric energy, the VRF-HP system consumes electric energy to provide hot air and cold air to the zone. The central HVAC system also consumes electric energy for the fans, pumps, chillers, and FCUs. The operating hours of each system varies, depending on the load distribution method. It is essential to maintain a high part-load ratio (PLR) by ensuring the efficiency of the system so that less district heating or electric energy is consumed. Depending on the system's operation hours, it affects district heating, and electric energy consumption.

Central HVAC system information was entered in the other three cases based on the actual data and values calculated in Case- 1 . Figures 6 and 7 show the monthly electric energy consumption and district heating according to the load distribution method.

Central Only in the figure refers to Case1 , where only the central HVAC system is operated. CEN-VRF refers to Case-2, where the central HVAC system is the main system, while the VRF-HP system is the secondary system. VRF-CEN refers to Case-3, where the VRF-HP system is the main system, while the central HVAC system is the secondary system. Uniform refers to Case-4, where the central HVAC system and VRF-HP system are operated simultaneously. Case-1, which operates only one system, is represented by lines, whereas Case-2, Case-3, and Case-4, which operate two systems, are represented by boxes.

The analysis confirms that the indoor air temperature of all the cases, except Case1 , reached the cooling and heating setpoint temperature (see Section 3.1). This finding indicates that the VRF-HP system handles cooling and heating loads that the existing system (i.e., central HVAC system) cannot handle. Although Case-2 handled more cooling and heating loads than Case- 1 , the annual electrical energy consumption of Case-2 is lower than that of Case- 1 . This is due to the characteristics of the HVAC system of the target building, which circulates indoor air without introducing outdoor air.

Before the VRF-HP system is installed in Case-1, indoor air temperature does not reach the heating and cooling set temperatures. Higher air temperature than cooling setpoint temperature is, thus, introduced into the HVAC system during the cooling season, and lower air temperature than heating setpoint temperature is introduced back into the HVAC system during the heating season. In Case-2, where the VRF-HP system is installed, indoor air temperature reaches the cooling and heating setpoint temperatures. Compared with Case-1, lower air temperature is introduced back into the HVAC system during the cooling season, and higher indoor air temperature is introduced back into the HVAC system during the heating season. Case-2, therefore, consumes less electric energy than Case- 1 due to the difference in return air temperature. This also affects the district heating consumption because of the same reasons: The temperature differences between return air temperature and supply air temperature in Case-2 are smaller than that of Case- -1 . This explains why Case- 2 consumes less district heating than Case- 1 .

We also compared Case-2 with Case-3, where indoor air temperature reaches the cooling and heating setpoint temperatures, and only the system sequence is different. In Case-2, where the VRF-HP system is the secondary HVAC system, the central HVAC system covers loads as much as the central HVAC system can handle, and the VRF-HP system only operates when the loads remain. This explains why the electric energy consumption in Case-2 is less than that of Case-3, where the VRF-HP system is the main system. 
In other words, when the load is low, the main system takes care of all the loads. For Case-2, the main system is the central HVAC system, while for Case-3, it is the VRF-HP system. As such, while the VRF-HP systems installed in Case- 2 and Case- 3 have the same capacity, the operation hours of VRF-HP in Case-3 are more than that in Case-2. Case-3, therefore, consumes more electric energy than Case2. On the contrary, the operation hours of the central HVAC system in Case-2 are more than that in Case-3 since operation hours of the VRF-HP system in Case-3 are more than in Case-2. As such, Case-2 consumes more district heating than Case-3.

In Case-4, the VRF-HP system and the central HVAC system operate simultaneously when a load occurs, which means that both systems operate at low PLR, which lowers the efficiency of the system. The electric energy consumption in Case-4 is, therefore, higher than in Case-2 and Case-3. Notably, in Case4 , the VRF-HP system is responsible for $50 \%$ of the load, which requires more capacity than that installed in Case-2 and Case-3.

Considering both district heating consumption and electric energy consumption, Case2, where the central HVAC system operates primarily, has less electric energy consumption than Case-3, where the VRF-HP system is the main system. However, because the central HVAC system is the main system, Case-2 uses more district heating energy than Case-3.

As regards all energy consumption, Case- 3 consumes less energy than Case-2.

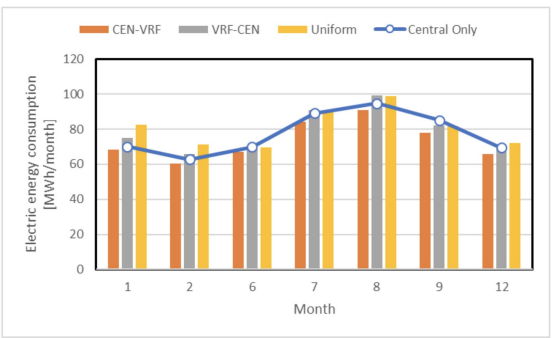

Figure 6. Comparison of monthly electric energy consumption in each caseHP system has been installed

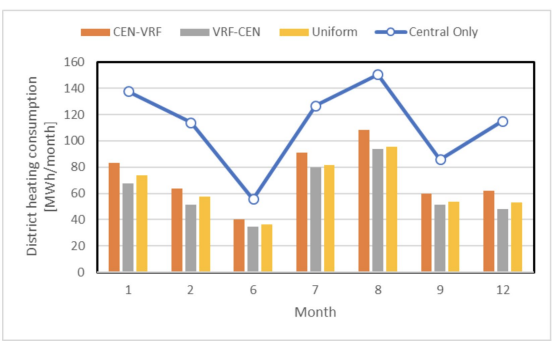

Figure 7. Comparison of monthly district heating consumption in each case 


\section{CONCLUSION}

The purpose of this study is to identify the capacity of additional HVAC systems, ensure indoor thermal comfort, and propose an energy-efficient HVAC operation strategy for buildings with HVAC systems that do not have sufficient capacity.

The proposed load distribution method in this study is to operate the VRF-HP system as the main system and the central HVAC system as a secondary system (Case-3). In this case, the required installation capacity of the VRF-HP system is smaller than in the uniform method (Case-4), and the energy consumption is less than that of both the existing HVAC system (Case-1) and Case-2, which has a different strategy.

In the future, we will consider factors other than the HVAC systems, such as windows and shading systems, to reduce building loads, and we will suggest the optimal HVAC system installation capacity and control method for the minimized building loads.

\section{ACKNOWLEDGEMENTS}

This study was supported by the R\&D Project (No. 20180576-001) of the Korea Institute of Civil Engineering and Building Technology. 


\section{REFERENCES}

The American Society of Heating, Refrigerating and Air-Conditioning Engineers (ASHRAE). 2014. ASHRAE Guideline 14-2014. Section 5.3.3.3. 10 .

Luddeni. G., Kararti. M., Pernigotto. G., and Gasparella. A. 2018. An analysis methodology for large-scale deep energy retrofits of existing building stocks: Case study of the Italian office building. Sustainable Cities and Society.

Biswas. K., Patel. T., Shrestha. S., Smith. D., and Desjarlais. A. 2019. Whole building retrofit using vacuum insulation panels and energy performance analysis. Energy and Buildings.

Somasundaram. S., Chong. A., Wei. Z., and Thangavelu. S. R. 2020. Energy saving potential of low-e coating based retrofit double glazing for tropical climate. Energy and Buildings.

The U.S. Department of Energy (U.S.DOE). 2018a. Getting Started version 9.0.1. The U.S. DOE: Washington, DC, USA.

The U.S. Department of Energy (U.S.DOE). 2018b. ASHRAE 2005 HOF Materials.idf.

Pacific Northwest National Laboratory (PNNL). 2009. Infiltration Modeling Guidelines for Commercial Building Energy Analysis. 
